\title{
Las murallas en las Comunidades de Villa y Tierra de la Diócesis de Segovia en los siglos XI a XIII \\ Técnica y sistemas constructivos de la arquitectura defensiva medieval
}

Alicia Sainz Esteban

Tesis doctoral

Universidad de Valladolid

Director: Félix Jové Sandoval

Codirector: Pascual Martínez Sopena


Las murallas en las Comunidades de Villa y Tierra de la Diócesis de Segovia en los siglos XI a XIII.

Técnica y sistemas constructivos de la arquitectura defensiva medieval.

Tesis Doctoral

Presentada por Alicia Sainz Esteban para optar al grado de Doctora por la Universidad de Valladolid.

Programa de Doctorado en Arquitectura.

2017

Dirigida por:

Félix Jové Sandoval

Codirigida por:

Pascual Martínez Sopena 

A mi padre, que me ha transmitido su interés y sensibilidad por el patrimonio arquitectónico.

A mi madre, que me ha hecho creer que puedo conseguir aquello que me proponga. 



\section{Agradecimientos}

Me gustaría expresar mi gratitud a las personas que han colaborado en el desarrollo de esta tesis, tanto desde un punto de vista profesional como en el ámbito personal.

A Félix Jové Sandoval, por haber aceptado la dirección de esta investigación y por guiarme en su desarrollo.

A Pascual Martínez Sopena, por la gran ayuda prestada en la elaboración del contexto histórico y por su entusiasmo constante en su labor como codirector.

A la Fundación Juanelo Turriano, sin cuya financiación esta tesis no habría podido salir adelante.

A Fernando Cobos, por hablarme de las Comunidades de Villa y Tierra y de las murallas de Fuentidueña y Sepúlveda, punto de partida de este trabajo.

A Ignacio Javier Gil Crespo, por el interés que ha mostrado en esta investigación y la ayuda que me ha prestado en su comienzo.

Al equipo TRACES de la Universidad de Toulouse, en particular a Nelly Pousthomis-Dalle, Jean-Loup Abbé, Noémie Luault, Bastien Lefebvre et Christian Darles por acogerme en la Maison de la Recherche y permitirme conocer la visión del arqueólogo sobre el patrimonio arquitectónico.

A los arquitectos Fernando Nieto Criado y Jesús Nieto Criado, que me han facilitado el acceso a los datos, dibujos y fotografías que poseen de la muralla de Cuéllar y de su proyecto de restauración.

Al estudio de arquitectos Álvaro Planchuelo, en particular a Susana Sánchez-Izquierdo, por facilitarme el acceso al Plan Director de Restauración de la Muralla de Maderuelo.

Al profesor Luis Ángel García Escudero, que ha atendido y resuelto mis dudas en Estadística, lo que me ha simplificado la interpretación de las gráficas de esta investigación. 
A mi amiga Noemí García Lepetit, por sus sugerencias y correcciones de la versión francesa de este documento.

A mi hermana Aurora Sainz y a Miguel Martín, por la revisión que han realizado de este documento, que se suma al interés que han mostrado por esta tesis desde el principio.

A mis compañeros y amigos Sara González, Sara Uzquiano, Melisa Duque, Mónica del Río, Luis García, David Marcos, Manuel Salviejo y Teresa Polo, por los buenos momentos que hemos disfrutado juntos y que han hecho más llevadero el desarrollo de esta tesis.

A mis padres, $M^{a}$ del Rosario y José Luis, y a mi abuela Rosario, que me han apoyado en todo momento, animándome en los días más difíciles.

A Jaime Carretero, por su apoyo incondicional, su paciencia y su disponibilidad. 


\section{Índice simplificado}

\begin{tabular}{|lr|}
\hline Resumen & xiii \\
Résumé & xv \\
\hline
\end{tabular}

1 Introducción 1

2 Estado de la cuestión: el estudio de la muralla a través de las fuentes y la investigación.

$3 \quad$ Las Comunidades de Villa y Tierra

$4 \quad$ Método y herramientas de trabajo

5 Casos de estudio

5.1 Coca

5.2 Cuéllar

5.3 Fuentidueña

5.4 Maderuelo

5.5 Pedraza

5.6 Sepúlveda

6 Análisis y discusión de resultados

7 Conclusiones

Conclusions

Bibliografía

Anexos 

Índice completo

Resumen

Résumé

1 Introducción 1

1.1 Origen y motivación de la investigación 1

1.2 Interés y oportunidad de la investigación 5

1.2.1 Patrimonio abundante de gran interés 5

1.2.2 Estado de conservación de las murallas en Castilla y León 9

$\begin{array}{ll}\text { 1.2.3 Restauración de las murallas } & 11\end{array}$

1.2.4 Gestión del patrimonio defensivo en España a través de su legislación

1.3 Planteamiento de la investigación $\quad 15$

$\begin{array}{ll}\text { 1.3.1 Marco histórico y geográfico de la investigación } & 15\end{array}$

1.3.2 Enfoque de la tesis doctoral 18

$\begin{array}{ll}\text { 1.3.3 Hipótesis de la investigación } & 19\end{array}$

$\begin{array}{ll}\text { 1.3.4 Objetivos de la investigación } & 20\end{array}$

$\begin{array}{ll}\text { 1.3.5 Estructura de la investigación } & 21\end{array}$

1.3.6 Limitación y precisión de la investigación 23

2 Estado de la cuestión: el estudio de la muralla a través de las fuentes y la investigación.

2.1 La muralla en fuentes clásicas y tratados históricos 25

2.1.1 La muralla en las obras clásicas 25

2.1.2 La muralla en las fuentes medievales 30

2.1.3 El estudio de la muralla durante el siglo XIX 32

$\begin{array}{ll}\text { 2.1.4 Tratados de arquitectura y construcción } & 34\end{array}$

2.2 La arquitectura defensiva medieval en España a partir del siglo XX 35

2.3 Estudios de murallas medievales en España 38

2.3.1 El estudio historiográfico de la muralla 38

2.3.2 El estudio de la muralla con enfoque arquitectónico. 39

2.3.2.1 La dimensión urbana de la muralla 39

2.3.2.2 La ciudad hispanomusulmana 40

2.3.2.3 Estudios constructivos y tipológicos de la muralla $\quad 41$

2.3.3 El estudio arqueológico de la muralla $\quad 42$

2.3.4 Otros enfoques 43 
2.3.6 Congresos y jornadas de divulgación científica vinculados con murallas en España

2.4 Estudios históricos que tratan la época de construcción de las murallas objeto de estudio

2.5 Resumen de las publicaciones más relevantes para esta investigación

2.6 La investigación acerca de murallas en la actualidad

3 Las Comunidades de Villa y Tierra

3.1 Antecedentes: suma de factores que dan lugar al surgimiento de las Comunidades de Villa y Tierra

3.2 Estructura territorial 53

$\begin{array}{ll}3.3 \text { Organización política } & 57\end{array}$

3.4 Estructura jurídica 58

3.5 Estructura social $\quad 59$

3.6 El papel de la iglesia católica $\quad 62$



$\begin{array}{ll}3.8 \text { La oligarquización del sistema de concejos } & 68\end{array}$

4 Método y herramientas de trabajo

4.1 Recogida de datos

4.1.1 Trabajo de campo $\quad 72$

$\begin{array}{ll}\text { 4.1.2 Fuentes históricas } & 74\end{array}$

4.1.3 Bibliografía y proyectos de investigación $\quad 76$

$\begin{array}{ll}\text { 4.2 Tratamiento de datos } & 77\end{array}$

4.2.1 Selección de casos de estudio $\quad 77$

4.2.2 Creación de Sistema de Información Geográfica (SIG) para la creación de planos y como método de trabajo $\quad 77$

4.2.3 Fotografía digital a través del software Agisoft PhotoScan $\quad 79$

4.2.4 Dibujo en AutoCAD sobre fotografía rectificada 81

4.2.5 Dibujo sobre fotografía sin rectificar 82

$\begin{array}{lll}4.3 & \text { Análisis de datos } & 82\end{array}$

4.3.1 Análisis general de casos: localización, topografía y
parcelario

4.3.2 Análisis del recinto amurallado y sus elementos 83

4.3.3 Análisis constructivo $\quad 83$

4.3.3.1 Identificación de elementos $\quad 84$

$\begin{array}{ll}\text { 4.3.3.2 Tipología constructiva } & 84\end{array}$ 
4.3.4 Aproximación al análisis estadístico de datos: utilización del programa $\mathrm{R}$

4.4 Material y herramientas utilizados $\quad 90$

$\begin{array}{lll}\text { 4.5 Formación investigadora } & 91\end{array}$

4.5.1 Conocimiento de otros métodos de investigación: Estancia en la universidad extranjera de Toulouse Jean Jaurès, Francia.

4.5.2 Puesta en común de los avances de la investigación publicaciones en congresos y jornadas. 93

$\begin{array}{ll}\text { 4.5.3 Cursos realizados } & 94\end{array}$

$\begin{array}{ll}\text { 5.1.1 Localización } & 97\end{array}$

5.1.2 Estudios en la villa $\quad 98$

5.1.3 Datos históricos destacados del núcleo 100

$\begin{array}{ll}\text { 5.1.4 Tejido urbano } & 101\end{array}$

5.1.4.1 Planeamiento y figuras de protección 105

5.1.5 Descripción general de la arquitectura defensiva 105

5.1.6 Tramos y elementos de la muralla medieval 110

5.1.6.1 Características de los principales elementos
descritos

$\begin{array}{ll}\text { 5.1.7 Análisis constructivo } & 118\end{array}$

5.1.7.1 Soluciones constructivas presentes en la muralla 118

5.1.7.2 Análisis del tramo T1-T2 desde el interior del recinto 123

5.2.7.2.1. Estudio dimensional y características de la tapia del tramo T1-T2

5.2.7.2.2. Tipología de la tapia en T1-T2 138

5.1.7.3 Torres del tramo L1 139

5.1.8 Resumen de resultados para el caso de Coca 145

$\begin{array}{ll}5.2 \text { Cuéllar } & 149\end{array}$

5.2.1 Localización 149

$\begin{array}{ll}\text { 5.2.2 Estudios en la villa } & 151\end{array}$ 
5.2.3 Datos históricos destacados del núcleo 153

5.2.4 Tejido urbano 154

5.2.4.1 Planeamiento y figuras de protección $\quad 156$

5.2.5 Descripción general de la arquitectura defensiva 156

5.2.6 Tramos y elementos de la muralla medieval 159

5.2.6.1 Características de los principales elementos
descritos

5.2.7 Análisis constructivo 182

5.2.7.1 Soluciones constructivas presentes en la muralla $\quad 182$

5.2.7.2 Lienzo interior del tramo C-PN1, recinto 1

5.2.7.2.1. Estudio de dimensiones y características
de la tapia en el tramo C-PN1

5.2.7.2.2. Tipología de la tapia en tramo C-PN1 195

5.2.7.3 Lienzo interior P6-TM1, recinto $1 \quad 196$

5.2.7.4 Lienzo P6-T9, vista interior y exterior, recinto 1

5.2.7.5 Lienzo P9-P10, calle de la Muralla, recinto 2

5.2.8 Resumen de resultados para el caso de Cuéllar 203

$\begin{array}{ll}5.3 \text { Fuentidueña } & 205\end{array}$

5.3.1 Localización 205

5.3.2 Estudios en la villa 206

5.3.3 Datos históricos destacados del núcleo 207

5.3.4 Tejido urbano 209

5.3.4.1 Planeamiento y figuras de protección 212

5.3.5 Descripción general de la arquitectura defensiva 213

5.3.6 Tramos y elementos de la muralla medieval 215

5.3.6.1 Zona noroeste del recinto 215

5.3.6.2 Zona suroeste del recinto 221

5.3.6.3 Zona sur del recinto 226

5.3.6.4 Zona este del recinto 232

5.3.6.5 Zona noreste del recinto 233

5.3.6.6 Características principales de los elementos
descritos

5.3.7 Análisis constructivo $\quad 237$

5.3.7.1 Soluciones constructivas presentes en la muralla 237

5.3.7.2 Lienzo exterior T5-T6 240

5.3.7.2.1. Estudio de dimensiones y características
de la tapia en el tramo T5-T6 (D1) 
5.3.7.2.2. Estudio de dimensiones y características de la tapia en el tramo T5-T6 (D2)

5.3.7.3 Lienzo P3-T10, vista interior y exterior

5.3.7.3.1. Estudio de dimensiones y características de la tapia en el tramo P3-T10

5.3.7.4 Tipología de las tapias en tramos T5-T6 y P3-T10

5.4.2 Estudios en la villa 268

5.4.3 Datos históricos destacados del núcleo 269

5.4.4 Tejido urbano 269

5.4.4.1 Planeamiento y figuras de protección 271

5.4.5 Descripción general de la arquitectura defensiva existente $\quad 271$

5.4.6 Tramos y elementos de la muralla medieval 273

5.4.6.1 Características principales de los elementos
descritos

$\begin{array}{ll}\text { 5.4.7 Análisis constructivo } & 287\end{array}$

5.4.7.1 Soluciones constructivas presentes en la muralla $\quad 287$

5.4.7.2 Lienzo exterior T1-P1 290

5.4.7.3 Lienzo exterior T2-suroeste 293

5.4.7.4 Tipología de las tapias de los lienzos T1-P1 y T2-
suroeste

5.4.8 Resumen de resultados para el caso de Maderuelo 296

$\begin{array}{ll}\text { 5.5 Pedraza de la Sierra } & 299\end{array}$

5.5.1 Localización 299

5.5.2 Estudios en la villa $\quad 300$

5.5.3 Datos históricos destacados del núcleo 301

$\begin{array}{ll}\text { 5.5.4 Tejido urbano } & 301\end{array}$

5.5.4.1 Planeamiento y figuras de protección 303 
5.5.5 Descripción general de la arquitectura defensiva 303

5.5.6 Tramos y elementos de la muralla medieval 305

5.5.6.1 Puerta de la Villa 305

$\begin{array}{ll}\text { 5.5.6.2 Frente sur del recinto } & 306\end{array}$

5.5.6.3 Zona de Hontanillas 308

5.5.6.4 Zona suroeste del recinto 310

5.5.6.5 Características principales de los elementos
descritos

5.5.7 Análisis constructivo $\quad 315$

5.5.7.1 Soluciones constructivas presentes en la muralla 315

5.5.7.2 Postigo de Hontanillas 317

5.5.7.3 Tipología de las tapias en el postigo de Hontanillas (P2)

5.5.7.4 Lienzo exterior L8, fondo de parcelas calle Matadero $n^{\circ} 7$

5.5.7.5 Lienzo exterior L2

5.5.8 Resumen de resultados para el caso de Pedraza

5.6.1 Localización $\quad 327$

5.6.2 Estudios en la villa $\quad 328$

5.6.3 Datos históricos destacados del núcleo 329

$\begin{array}{ll}\text { 5.6.4 Tejido urbano } & 331\end{array}$

5.6.4.1 Planeamiento y figuras de protección 333

5.6.5 Descripción general de la arquitectura defensiva existente 333

5.6.6 Tramos y elementos de la muralla medieval 336

5.6.6.1 Tramo Puerta del Río a Castillo Fernán González
(P1-T13) 336

5.6.6.2 Castillo de Fernán González 337

5.6.6.3 Tramo Castillo Fernán González a Puerta del Azogue (P3) 339

5.6.6.4 Zona del Postiguillo $\quad 340$

5.6.6.5 Zona del postigo del Vado 341

5.6.6.6 Tramo desde la puerta de Duruelo (P11) hacia el
oeste

5.6.6.7 Tramo desde la puerta de Castro (P10) hacia el
oeste

5.6.6.8 Zona de la puerta de la Fuerza (P8) 346

5.6.6.9 Características principales de los elementos
descritos 
5.6.7 Análisis constructivo 351

5.6.7.1 Soluciones constructivas presentes en la muralla 351

5.6.7.2 Lienzo exterior P11-Oeste 200, visto desde el
exterior del recinto amurallado

5.6.7.3 Puerta de la Fuerza (P8) 360

5.6.7.4 Puerta de Duruelo (P11) 363

5.6.7.5 Tipología de las tapias del lienzo P11-Oeste200 364

5.6.8 Resumen de resultados para el caso de Sepúlveda 367

6 Análisis y discusión de resultados 369

6.1 Las villas en el territorio 369

$\begin{array}{ll}\text { 6.2 La muralla en la villa } & 371\end{array}$

6.3 Dimensiones generales de las murallas $\quad 374$

$\begin{array}{ll}6.4 \text { Elementos de las murallas } & 376\end{array}$

$\begin{array}{lll}\text { 6.4.1 Puertas } & 376\end{array}$

$\begin{array}{ll}\text { 6.4.2 Torres } & 380\end{array}$

$\begin{array}{lll}\text { 6.4.3 Almenado } & 388\end{array}$

6.4.4 Base de las murallas 390

6.4.5 Imagen proyectada de la construcción defensiva 394

6.5 Soluciones constructivas en las murallas $\quad 394$

6.5.1 Tapia de mampostería 400

6.5.1.1 Dimensiones: altura y anchura de la tapia 400

6.5.1.2 El tapial: configuración del encofrado 402

6.5.1.3 Aparejo de mampuestos en el tapial $\quad 404$

6.5.1.4 Tramos constructivos 408

6.5.1.5 Mechinales y agujas $\quad 412$

6.5.1.6 Tipología de la tapia $\quad 415$

6.5.1.7 Comparativa de las tapias utilizando la Estadística $\quad 418$

6.6 Ambigüedad en la terminología del tapial 421

6.6.1 Tapia de cal y canto, tapia de mampostería, mampostería
encofrada

6.6.2 Tapia de tierra 422

6.7 Tiempos de construcción de la tapia de mampostería 422

6.7.1 Obtención de materiales: piedra, tierra, cal y madera 423

6.7.2 Construcción de la tapia 425

6.8 ¿Quién construye las murallas de tapia de mampostería? 426

$\begin{array}{ll}\text { 6.9 Cronología de las murallas estudiadas } & 427\end{array}$

6.10 Restauración de las murallas 431 
7.1 Conclusiones relativas a la metodología

7.2 Conclusiones en el conjunto del recinto amurallado

7.3 Conclusiones en el ámbito constructivo

7.1 Conclusions relatives à la méthodologie

7.3 Conclusions dans le cadre constructif

1 Coca (Diócesis de Segovia)

2 Cuéllar (Diócesis de Segovia)

3 Fuentidueña (Diócesis de Segovia)

4 Fresno de Cantespino (Diócesis de Segovia)

5 Íscar (Diócesis de Segovia)

6 Maderuelo (Diócesis de Segovia)

7 Montejo de la Vega de la Serrezuela (Diócesis de Segovia)

8 Pedraza (Diócesis de Segovia)

9 Sepúlveda (Diócesis de Segovia)

10 Segovia (Diócesis de Segovia)

11 Turégano (Diócesis de Segovia)

12 Ayllón (Colinda con Diócesis de Segovia)

13 Haza (Colinda con Diócesis de Segovia)

14 Olmedo (Colinda con Diócesis de Segovia) 
15 Peñafiel (Colinda con Diócesis de Segovia)

16 Portillo (Colinda con Diócesis de Segovia)

Anexo 2 Líneas de comando empleadas en el programa R para la realización de gráficas.

Anexo 3 Fichas de características de las herramientas empleadas 



\section{Resumen}

Palabras clave: muralla medieval, arquitectura defensiva, mampostería encofrada, tapia de cal y canto, tapia de mampostería, Comunidades de Villa y Tierra, Coca, Cuéllar, Fuentidueña, Maderuelo, Pedraza, Sepúlveda, siglo XII, reino de Castilla.

A finales del siglo XI, se inició al sur del río Duero un fenómeno muy singular de repoblación y creación de nuevas villas que llegó hasta el río Tajo. Fue impulsado por la monarquía castellana para hacer frente al empuje musulmán y para ello se dividió el territorio en comunidades. Cada una de el las tenía una villa cabecera y un territorio subordinado donde existían pequeñas aldeas. En este contexto, se creó una sociedad medieval particular a escala europea, donde los habitantes gozaban de libertad y podían participar en las decisiones políticas de su ciudad a través de asambleas. Una de las características de es tas villas cabeceras era la muralla que las protegía. En muchos casos, esta muralla abarcaba un área muy extensa de terreno. Esta investigación analiza los recintos amurallados de una parte de estas villas, concretamente seis de las que se encontraban en la Diócesis de Segovia, que son Coca, Cuéllar, Fuentidueña, Maderuelo, Pedraza y Sepúlveda. Muchas de estas villas conservan restos de arquitectura defensiva en distintos estados de conservación: en algunos casos se encuentran arruinados; en otros se han restaurado o reconstruido. El enfoque de es ta investigación es el análisis constructivo de es tas murallas, con el objeto de determinar qué técnicas se empleaban para su construcción y compararlas entre sí.

El sistema constructivo de la tapia de mampostería o mampostería encofrada es una técnica muy presente en los casos analizados. Este sistema utiliza un molde de madera, el tapial, que se llena de una m ezcla de mampuestos, tierra y cal. Con el fraguado, la mezcla se solidifica formando un bloque rectangular, la tapia, que tiene un tamaño que puede variar aproximadamente de $260 \mathrm{~cm}$ a $290 \mathrm{~cm}$ de anchura, de $105 \mathrm{~cm}$ a $130 \mathrm{~cm}$ de alto y un fondo que se corresponde con el espesor de la muralla, que se aproxima a I os $200 \mathrm{~cm}$. En la actualidad, estas tapias son todavía visibles en I as murallas, los lienzos tienen divisiones verticales y horizontales que delimitan estos grandes bloques. Las agujas del tapial se abandonan habitualmente en el interior del muro dejando rítmicos huecos visibles en la superficie. A través de un estudio con mediciones, fotografías, fotogrametría digital, dibujos y análisis estadísticos se ha extraído una tapia representativa de cada caso para comparar sus características y averiguar en qué aspectos coinciden.

Una de las conclusiones directas de esta investigación es el protagonismo de esta técnica constructiva, la tapia de mampostería, en la construcción de e stas murallas cristianas. De forma más específica, la comparación de c ada tapia ha puesto en 
Las murallas en las Comunidades de Villa y Tierra de la Diócesis de Segovia en los siglos XI a XIII. Técnica y sistemas constructivos de la arquitectura defensiva medieval.

evidencia semejanzas dimensionales en casi todos los casos. La c onfiguración del sistema de sujeción del tapial o la forma de colocar las piedras en s u interior ha permitido relacionar y diferenciar algunas de estas murallas.

Finalmente, la divulgación de las técnicas constructivas de es tas murallas es un aspecto clave para su conservación. Con esta investigación se busca contribuir al entendimiento de estas construcciones para que tengan el reconocimiento que merecen y también para fomentar su correcta restauración. 


\section{Résumé}

Mots clé : muraille médiévale, maçonnerie coffrée, XII ${ }^{\text {ème }}$ siècle, royaume de Castille.

Le patrimoine historique présent dans les villes aujourd'hui représente un témoignage matériel d'une société passée. La muraille est un des nombreux exemples de ce patrimoine, ce n'est pas une construction isolée mais un système qui se trouve immergé dans le tissu des villes et dont ses caractéristiques restent imprimées dans le fonctionnement urbain. L'étude des murailles peut aider à la compréhension de la formation des villes, des caractéristiques d'une société ou des systèmes de construction de cette période historique. La muraille, comme un document matériel d'une certaine époque, permet d'observer quel est son parcours ainsi que les techniques constructives employées dans sa construction. Dans l'actualité, il existe encore des restes de murailles dans plusieurs noyaux urbains. Dans quelques villes, les murailles se conservent ou ont été restaurées, dans d'autres villes, elles ont disparu ou il n'y a que quelques restes qui se conservent. Dans peu de cas, elles sont reconnues et appréciées par la société et les institutions. Dans de nombreux cas, même en existant des restes considérables, il n'y a pas un accord d'importance sur les murailles, elles se trouvent négligées.

Le cadre historique de cette recherche se situe entre le $\mathrm{XI}^{\text {ème }}$ et le XIII ${ }^{\text {ème }}$ siècle. Durant cette période, le panorama politique dans la péninsule ibérique est variable et instable. Des changements se produisent dans le contrôle du territoire, puis une ampliation très importante du territoire contrôlé par le royaume de Castille se matérialise. Entre 1085 et 1212, chrétiens et musulmans luttent pour le contrôle d'un territoire déterminant pour la domination de la péninsule ibérique, celui qui s'étend entre les fleuves Douro et Tage. Avec la prise de Tolède en 1085 par les chrétiens, une grande surface est restée dans l'arrière-garde. Un repeuplement a été mis en pratique pour consolider cette conquête au sud du fleuve Douro, frontière géographique des royaumes chrétiens au $X^{\text {ème }}$ siècle. Le roi Alfonse $\mathrm{VI}$ impulse la création d'un réseau de nouvelles villes et de villes repeuplées dans l'Estrémadure de $C$ astille. Le résultat de cette stratégie a é té une singulière organisation territoriale et politique, les «Comunidades de V illa y Tierra ». Ce phénomène était organisé en communes, territoires d'une étendue considérable qui possédaient une ville principale, la "Villa », qui était fortifiée, puis un territoire subordonné, la "Tierra», où il y avait des petits villages, d'importance inférieure à la ville. Le territoire entre les fleuves Douro et Tage a été organisé avec ces communes qui, même si elles dépendaient du roi, constituaient des conseils qui profitaient d'une autonomie de gouvernement exceptionnelle. En effet, ses habitants se bénéficiaient d'une liberté inhabituelle et pouvaient participer dans les décisions politiques du conseil, ou tour au moins dans une première étape de ce phénomène. 
Les murailles dans les "Comunidades de Villa y Tierra" dans la Diocèse de Ségovie du XI ${ }^{\mathrm{eme}}$ au XIII siècle. Technique et systèmes constructifs de l'architecture défensive médiévale.

Vu que l'étendue de ce territoire est très grande, pour cette recherche la surface à étudier a été réduite. Les limites des provinces et des municipalités dans l'actualité ne se correspondent pas avec celles qui existaient à I'époque, et utiliser les limites politiques actuelles ne serait donc pas utile dans cette recherche. En conséquence, le domaine de recherche a été choisi en fonction des limites de la Diocèse de Ségovie à l'époque. Les communes sous l'influence de la diocèse sont les suivantes: Coca, Cuéllar, Fresno de Cantespino, Fuentidueña, Íscar, Maderuelo, Montejo de la Vega de la Serrezuela, Pedraza, Segovia et Sepúlveda. Après avoir réalisé une analyse de ces villes puis de quelques villes adjacentes comme Olmedo, Ayllón, Haza, Peñafiel et Portillo, une nouvelle sélection a été faite, en accordant de l'importance aux villes ayant des restes importants de muraille, ainsi qu'à l'absence d'autres chercheurs sur ces villes avec une approche architectonique. Finalement, six villes ont été sélectionnées pour une analyse en profondeur: Coca, Cuéllar, Fuentidueña, Maderuelo, Pedraza et Sepúlveda.

L'approche utilisée dans cette recherche a été d'analyser d'une façon exhaustive le système constructif employé dans la construction des murailles. Pour chaque cas, les restes de murailles ont été analysés pour extraire quels matériaux étaient employés et quelles techniques suivaient pour édifier les murs. D'une part, et d'une façon plus générale, les différentes techniques de construction employées ont été identifiées ainsi que leur localisation dans la muraille. D'autre part, dans les tronçons o les parties des murailles sélectionnées, un relevé a été réalisé pour localiser les éléments constructifs visibles dans le mur. Ceci a permis de détailler la configuration, la composition et la position, tout comme les dimensions des éléments constructifs, pour comprendre le fonctionnement et l'ordre des techniques employées puis pour réaliser des comparaisons entre les différents cas.

Les hypothèses posées dans cette recherche signalent que les restes d'architecture défensive peuvent apporter de l'information sur la façon dont ils se construisaient. Les matériaux, les techniques, l'ordre et la planification sont des critères constructifs qui peuvent aider à avancer dans le savoir de l'architecture défensive de ce territoire. Ce réseau de villes relié d'un point de vue historique, peut aussi être rapproché en base à une façon similaire de construire ses murailles. L'étude des techniques constructives peut aussi contribuer à la détermination des dates de construction de ces murailles. De plus, l'analyse de ces techniques et matériaux peut apporter de l'information au sujet des personnes qui participaient à la construction, si elles étaient nécessairement des experts ou si n'importe quel habitant collaborait dans la construction.

Les objectifs poursuivis dans cette recherche quêtent, d'une façon générale, mettre en valeur l'architecture défensive dans le domaine constructif. Aussi, ils cherchent à renforcer la muraille face à d'autres architecture fortifiées comme les châteaux ou les forteresses, puis face au panorama touristique de Castilla y León pour exploiter son potentiel historique et urbain. D'une façon plus spécifique, un objectif de c ette recherche est de décrire et documenter d'une manière détaillée une partie des murailles qui existent au sud du fleuve Douro, puis identifier les systèmes constructifs 
présents dans chaque cas pour pouvoir réaliser des comparaisons et localiser des patrons ou modèles constructifs.

La source principale de cette recherche a été les restes architectoniques des murailles existantes dans les villes citées ci-dessus. La muraille est elle-même un document architectonique duquel il est possible d'extraire beaucoup d'information. La m éthode employée a ét é d'une part l'analyse visuelle des restes, complétée avec des photographies, dessins et prise de mesures. Cette récolte d'information a été aussi réalisée dans le domaine historique avec la consultation de sources historiques reliées à ces villes. La consultation de bibliographie sur les villes de cette recherche a été aussi réalisée pour compléter la récolte de données.

Les données réunies ont simplifié la sélection des six murailles parmi le total de murailles visitées de la Diocèse de Ségovie et ses alentours. Pour chaque ville, un Sistème d'Information Géographique (SIG) de travail a été crée pour faciliter l'analyse du territoire et pour la création des plans de situation qui décrivent la configuration du territoire proche à la ville fortifiée. Le programme informatique ArcGIS ArcMap 10 a été utilisé pour réaliser ces plans, puis un partie très importante des données a ét é téléchargée des portails de I'Institut Géographique National (IGN), de I'Infrastructure des données Spatiales de Castilla y León (IDECyL) et du Cadastre.

Les relevés des pans de muraille ont été réalisés avec photogrammétrie digitale. Le programme Agisoft PhotoScan permet de pr oduire des modèles 3D à partir des photographies et des données introduites par l'utilisateur. Sur les relevés photogrammétriques obtenus, l'identification et le dessin à échelle des éléments constructifs a été réalisée avec AutoCAD.

L'analyse constructive accomplie dans les visites puis sur les relevés, a identifié l'utilisation d'une technique similaire au pisé, qui construit les murs en utilisant des banches qui se remplissent avec de la terre, des pierres et de la chaux. Le pisé se remplit seulement avec de la terre, ajoutée en couches qui sont comprimées avec un pisoir. Dans ce cas, les matériaux de la banche ne se compriment pas, des pierres sont placées dans les côtés extérieurs, collées aux planchers de la banche, pour former une face plus régulière, puis un mélange de pierres, terre et chaux est versé à l'intérieur de la banche qui fait durcir l'ensemble comme le béton et forme un grand bloc solide. La technique ici utilisée est une sorte de " maçonnerie coffrée ». Dans les relevés obtenus, des traces de cette technique on été identifiées, ce qui a permis de dessiner les éléments suivants: les limites verticales et horizontales des blocs, la position et configuration des boulins dans les pans, les hypothèses des blocs d'accord avec les boulins retrouvés, les éléments singuliers construits avec de la pierre de taille ou de la brique et les limites verticales dans les pans qui permettent d'identifier les portions de muraille visibles. L'analyse de ces éléments a permis d'extraire un groupe de caractéristiques, une typologie représentative de bloc pour chaque pan. Les typologies extraites ont été comparées avec celles développées par les chercheurs Amparo Graciani y Miguel A. Tabales Tabales $(2008,139)$ dans la région de Séville, 
Les murailles dans les "Comunidades de Villa y Tierra" dans la Diocèse de Ségovie du XI ${ }^{\mathrm{eme}}$ au XIII siècle. Technique et systèmes constructifs de l'architecture défensive médiévale.

puis par le chercheur Ignacio J. Gil Crespo $(2013,554-557)$ dans la région de Soria. Des paramètres propres ont été utilisés, ajoutées à ceux des chercheurs cités.

L'analyse des mesures des blocs ou de la séparation entre les boulins a é té gérée avec des outils statistiques simples pour aider à représenter les donnés d'une façon plus claire. Les diagrammes en boîte ont été utilisés pour représenter les mesures obtenues des blocs puis pour extraire la marge dimensionnelle plus utilisée dans la hauteur, largeur ou la distance entre les boulins. Pour comparer les typologies identifiées pour chaque pan, des graphiques en composantes principales ont été élaborées, pour complémenter la comparaison visuelle des typologies.

\section{Cas d'étude}

La muraille de Coca se conserve bien dans la zone sud de la ville, où les restes sont suffisants pour analyser le système constructif employé, la maçonnerie coffrée. Les dimensions générales sont d'une épaisseur proche aux 2,00m et une hauteur entre $7,50 \mathrm{~m}$ et $8,60 \mathrm{~m}$. L'analyse constructive a permis de détecter des éléments préexistants dans quelques parties de la muraille, faciles à identifier car ils se situent dans les bases puis montrent des solutions constructives différentes aux employées dans les zones supérieures. La pierre employée dans les blocs est singulière, quartzite rouge, qui évoque l'ardoise, avec une forme allongée. Les blocs ont été réalisés avec une banche individuelle. Dans la construction de la banche, la technique du petit mur de pierre a été utilisée pour fermer un des côtés courts de la banche. Dans quelques blocs, il est possible d'identifier les traces des planchers employés dans la banche. Les tours et la porte qui se conservent se construisent aussi avec le même système. Les bases des pans n'ont pas de fondations évidentes, une différentiation des matériaux pour former un soubassement n'est pas visible dans les parties inférieures des murs. Les ressources défensives del a muraille sont d'une part les tours flanquantes séparées d'une distance de $20-25 \mathrm{~m}$, puis les créneaux simples dans quelques pans et dans les tours.

L'abondance de restes de muraille conservés à Cuéllar est remarquable. La continuité de ses pans est importante dans la première enceinte où sont visibles des grandes longueurs de pans. La deuxième enceinte possède des restes intermittents et moins accessibles. Les caractéristiques générales de la muraille, d'après l'étude des tronçons choisis, montrent une hauteur de presque $12 \mathrm{~m}$, puis une épaisseur qui dépasse les $2 \mathrm{~m}$. D'un point de vue constructif, il est significatif l'emploi de maçonnerie coffrée dans toute la muraille. Les pans qui se conservent utilisent cette technique, à l'exception de tu tronçons T6-T7 où la technique n'a pas été clairement identifiée. D'autres solutions constructives apparaissent principalement dans les portes et les tours. Dans l'emploi de maçonnerie coffrée il a des différences dans la configuration des boulins entre des tronçons de muraille différents, mais aussi dans les mêmes tronçons, avec des positions très proches. La présence de fondations dans les pans n'est pas visible. Les murs partent directement du rocher, sans différences dans les matériaux ou l es solutions employées. Les systèmes défensifs visibles ne sont pas abondants. Les tours 
flanquantes ne sont pas nombreuses par rapport à la longueur des pans. Deux types de créneaux se conservent, le plus employé a une forme allongée avec une proportion de 5 à 1 ent re la largeur du créneau et l'espace entre créneaux. Des archères avec une forme en croix sont visibles dans les créneaux. Ce sont les seuls motifs décoratifs de cette muraille. Dans les portes et les tours il a des combinaisons de matériaux qui ont peut-être une intention esthétique, mais ceci n'est pas visible sur les pans.

La muraille de Fuent idueña est un ex emple extraordinaire de murailles construites avec de la maçonnerie coffrée. Des importantes longueurs de pans sont témoins de l'emploi de c ette technique. Les restes qui se conservent sont abondants, et permettent de déduire le parcours de la muraille. Les caractéristiques générales montrent une épaisseur très petite qui descend jusqu'aux $90 \mathrm{~cm}$ dans quelques points. Cette minceur ne semble pas affecter à sa solidité, même si les pans dépassent la hauteur de 7-8m. Les tours présentent des formes semi-circulaires puis rectangulaires, en ressortant les semi-circulaires par son immense diamètre. D'un point de v ue constructif, une utilisation majoritaire de maçonnerie coffrée a été remarquée, avec des différences dans la configuration des boulins. L'utilisation des banches continues est évidente dans le tronçon T5-T6. Dans d'autres tronçons cette utilisation est probable en raison de l'équidistance entre les boulins ou du partage des clefs des banches entre deux blocs. Les clefs employées présentent des différences, leur section peut être circulaire, plate ou avec des couples de bâtons. La singularité du tronçon T5-T6 est étonnante, une rencontre entre deux pans semble se produire dans ce pan, qui doit se résoudre dans un terrain avec une importante dénivellation. Un grand désordre est visible dans la construction des blocs, et il y a une variété importante de types de clefs. Quant aux fondations, II n'y a pas une base différente dans la partie inférieure des pans. Les blocs se construisent directement su le rocher. Les portes montrent des différences constructives, l'emploi de pierre de taille et de brique est visible. Du point de vue défensif, les ressources utilisées ne sont pas nombreuses. Les créneaux se remarquent tout aulong des pans conservés. Les tours sont nombreuses puis semblent avoir possédé des créneaux. Les distances entre elles ne sont pas constantes, avec quelques unes très proches $(15 \mathrm{~m})$ puis d'autres très éloignées $(60 \mathrm{~m})$.

La ville de Maderuelo étonne car sa localisation est singulière, elle est située dans une sorte d'appendice du terrain qui rentre dans le barrage qui l'entoure. La muraille se construit dans ses bords, en s'adaptant au relief. Dans ce cas, il n'est pas facile de retrouver des parties de muraille qui ne soient pas modifiées ou al térées pour de nouvelles édifications ou réparations. Les dimensions générales de la muraille, mesurées sur un des tronçons conservés sont les suivantes : la hauteur est de $9-10 \mathrm{~m}$, bien que les pans ne son pas complets puisque les créneaux ne sont pas visibles. L'épaisseur est proche à $1,50 \mathrm{~m}$ mais peut varier dans le reste de l'enceinte. II y a deux tours facilement identifiables dans la muraille, qui se conservent au sud-ouest puis au nord de l'enceinte. Ce ne sont pas des tours massives, elles ont un espace à l'intérieur. Les tours flanquantes de la porte, aujourd'hui disparues, ont laissé des traces qui montrent qu'elles auraient aussi un es pace à l'intérieur. Dans d'autres points de la muraille sont présentes des possibles bases de tours massives, qui ont dans un des cas, un talus dans la base. L'analyse constructive a montré l'emploi de maçonnerie 
Les murailles dans les "Comunidades de Villa y Tierra" dans la Diocèse de Ségovie du XI ${ }^{\mathrm{eme}}$ au XIII siècle. Technique et systèmes constructifs de l'architecture défensive médiévale.

coffrée dans plusieurs tronçons qui se conservent. Le tronçon au sud utilise aussi cette technique, bien qu'il y a d'autres solutions comme l'appareil de pierre de taille. Dans les bases des pans, il n'y a pas des fondations visibles ou des changements de matériaux, à l'exception des pans prochains à la tour T1 où des pierres de taille sont utilisées. Quant aux ressources défensives, il n'y a pas de créneaux visibles sur les murs, seulement dans la porte « de la Villa ». II n'y a presque pas de tours dans le parcours de la muraille.

La ville de Pedraza se trouve dans une localisation très protégée pour le relief. Elle est seulement accessible du côté sud-est et montre des importantes dénivellations dans les autres orientations. La muraille se construit sur le bord du terrain en profitant des défenses naturelles. Les restes de muraille qui se conservent ne sont pas nombreux et sont intermittents. Ils se trouvent altérés par les édifications ou bien conservent seulement les bases des murs. Les tronçons analysés montrent une hauteur de $10 \mathrm{~m}$, puis une épaisseur proche aux $2 \mathrm{~m}$. Les tours qui se conservent se situent au sud de l'enceinte et ne sont pas homogènes. La tour " de Hontanilla " est hexagonale face aux autres tours qui ont un plan rectangulaire. La porte " de la Villa » est flanquée dans son côté nord avec une tour différente, qui a une fonction d'édifice et des dimensions beaucoup plus grandes. Du point de vue constructif, l'emploi de maçonnerie coffrée est observé dans une grande partie des pans analysés. D'autres techniques sont visibles dans les portes puis dans la tour " de Hontanilla », la pierre de taille est utilisée pour l'exécution de l'arc d'une des portes ou dans l'appareil des murs de la tour. La brique est utilisée aussi dans l'exécution de l'arc de la porte et la partie supérieure de la porte " de la Villa ». Quant aux fondations, aucun soubassement a été identifié, le système employé est le même dans les bases des murs que dans le reste des pans. Du point de vue défensif, les ressources employées ne sont pas nombreuses. C'est probable l'existence de créneaux, mais ils ne sont pas visibles dans l'actualité. La tour "de Hontanilla " possède une c onfiguration défensive plus sophistiquée. Sa position semble se détacher de la ligne des pans, puis son plan polygonal paraît profiter des avantages de la géométrie. Elle incorpore des techniques défensives plus avancées que celles des tours flanquantes, ce qui soutient l'hypothèse qu'elle a été construite après les murailles.

La muraille de Sepúlveda englobe une surface très importante, très supérieure aux cas étudiés, comparable à l'étendue de la muraille de la ville de Ségovie. Cette grande surface fait penser à l'existence de plusieurs enceintes, mais les restes qui se conservent ne permettent pas de poser des hypothèses sur des enceintes plus petites. Dans une partie majoritaire des pans, des préexistences sont visibles dans les bases de murs. Des appareils variés sont visibles dans la muraille, des grandes pierres de taille, de la maçonnerie, de la maçonnerie coffrée ou de la maçonnerie singulière. Le tronçon analysé a une haut eur e $6-7 \mathrm{~m}$. Les portes étudiées ont des hauteurs différentes, de $6,50 \mathrm{~m}$ de la porte de "la Fuerza " face aux plus de $10 \mathrm{~m}$ de la porte " de Duruelo ». Les tours ont des sections rectangulaires principalement. L'épaisseur des pans est proche aux $2 \mathrm{~m}$ dans le tronçon analysé. Les techniques constructives visibles dans les bases de pans sont des appareils de pierre de taille de moyenne et grande dimension dont les arêtes et sommets sont érodés, ce qui montre la 
réutilisation de ces éléments. Sur ces bases, des murs ont été reconstruits avec la technique de la maçonnerie coffrée. Les ressources défensives de la muraille sont modestes. II n'y a pas de restes de créneaux qui permettent d'analyser leur configuration. Dans le tronçon analysé, un chemin de ronde est identifiable en haut des courtines puis peut-être des restes de créneaux, insuffisants pour mener une analyse. Les tours flanquantes ne sont pas nombreuses et sont reliées aux bases préexistantes. Dans le tronçon analysé, il n'y a pas de tours, même si sa longueur est importante, proche aux 400m.

L'analyse de r ésultats a comparé chacun des cas étudiés, en approfondissant principalement l'étude constructive des pans. Même si cette recherche a eu une approche constructive, d'autres aspects qui concernent la construction et la configuration de la muraille ont été aussi comparés. Premièrement, la position des villes dans le territoire est mentionnée, puis l'extension des leurs enceintes ou la distance qui sépare chacune des villes est comparée. L'existence de pl usieurs enceintes, ou le pourcentage d'occupation de la surface clôturée sont d'autres facteurs de comparaison. Après, les différentes configurations des murailles étudiées sont confrontées entre elles, en se basant sur divers aspects : les dimensions générales, le nombre des tours ou des portes et la configuration des créneaux, en identifiant les caractéristiques communes puis les différences. Finalement, les techniques constructives utilisées sont comparées. La technique de la maçonnerie coffrée est examinée dans chaque cas en comparant les dimensions des blocs, la configuration des clefs, puis d'autres traces des banches utilisées. Les typologies des blocs extraites dans chaque tronçon sont comparées pour déterminer le degré d'affinité qui existe entre elles. Chacune de ces comparaisons a permis d'extraire les conclusions qui sont exposées à la fin du document. 



\section{1}

\section{Introducción}

El patrimonio histórico existente en la actualidad en las ciudades y pueblos representa un testimonio material de una sociedad pasada. La muralla es uno de los muchos ejemplos de este patrimonio; no es un edificio aislado sino que es un sistema en sí mismo que se encuentra inmerso en el tejido de la ciudad y cuyas características quedan impresas en el funcionamiento urbano. Su estudio puede ayudar al entendimiento de la formación de las ciudades, de las características de una sociedad, o de los sistemas de construcción de este periodo histórico. La muralla, como documento material de una época, permite observar cuál es su trazado y qué técnicas constructivas se han e mpleado en s u construcción. En la actualidad, todavía se conservan restos de estas murallas en muchos núcleos urbanos. En algunos lugares, las murallas se han conservado y restaurado $y$ en otros, las murallas han desaparecido o quedan escasos restos. En pocos casos, las murallas cuentan con reconocimiento por parte de la sociedad y las instituciones actuales. En numerosos casos, aun existiendo restos considerables, las murallas no son valoradas y se encuentran desatendidas. Estas son algunas de las razones por la que se ha iniciado esta investigación.

\subsection{Origen y motivación de la investigación}

Durante la realización de la carrera de arquitectura tuve ocasión de participar en varios trabajos que significaron una pr imera toma de c ontacto con el patrimonio arquitectónico. Estos proyectos, realizados en el seno de la Universidad de Valladolid, en los departamentos de $\mathrm{E}$ xpresión Gráfica y Urbanismo y Construcciones Arquitectónicas de la Escuela Superior de Arquitectura, consistieron en gran medida en tareas de inventariado y documentación de elementos patrimoniales. Uno de ellos es el proyecto BIPE, de inventariado de Bienes Inmuebles de Patrimonio Etnográfico, coordinado por el Dr. arquitecto José Luis Sainz Guerra, y encargado por la Dirección General de Patrimonio Cultural de la Junta de Castilla y León en el año 2006. Este proyecto consistió en u na exhaustiva documentación de estos bienes en todo el territorio de la comunidad de Castilla y León que se completó a lo largo de dos años. Implicó un acercamiento a la naturaleza del patrimonio etnográfico en esta comunidad, a su estado de conservación, a la identidad de cada elemento y a su significado en la sociedad actual. Desde un punto de vista más práctico, supuso un aprendizaje del trabajo de campo necesario en investigaciones relacionadas con el patrimonio arquitectónico: documentación previa de un bien, localización en el territorio, extracción de datos del mismo, toma de fotografías, realización de análisis y redacción 
Las murallas en las Comunidades de Villa y Tierra de la Diócesis de Segovia en los siglos XI a XIII. Técnica y sistemas constructivos de la arquitectura defensiva medieval.

de resultados y conclusiones. Igualmente, supuso conocer la naturaleza de un inventario, primera herramienta en la formación de un investigador en este campo, que permite, a posteriori, delimitar un marco sobre el que iniciar un trabajo de investigación. El manejo de una base de datos es un aspecto muy importante en la elaboración de un i nventario, pues es sobre estos datos sobre los cuales se podrá realizar comparaciones, extraer semejanzas, diferencias y otros resultados. Posteriormente, participé en otros trabajos de inventariado de bienes arquitectónicos, esta vez de patrimonio industrial: los proyectos IPIVA (Inventario de Patrimonio Industrial de la Provincia de Valladolid) e IPISA (Inventario de Patrimonio Industrial de la Provincia de Salamanca), coordinados por el Dr. arquitecto Jesús San José y llevados a cabo desde el Laboratorio de Fotogrametría Arquitectónica de la ETS de Arquitectura de Valladolid.

Más adelante, en el programa de doctorado para la obtención del Diploma de Estudios Avanzados, llevado a cabo en el año 2010, participé como colaboradora en el desarrollo de la tesis doctoral del Dr. arquitecto Gamaliel López Rodríguez, bajo la dirección del Catedrático de Construcción Arquitectónica Alfonso Basterra, en el Departamento de $\mathrm{C}$ onstrucciones Arquitectónicas de la ETS de Arquitectura de Valladolid. Esta tesis trata de las múltiples aplicaciones de la Termografía Infrarroja para la evaluación no destructiva de las estructura de madera, con el objeto de detectar lesiones en este material. El apartado en el que colaboré trataba una de estas aplicaciones, que plantea que es posible evaluar el contenido de humedad presente en el material con el empleo de esta técnica. A lo largo de esta colaboración tuve un primer contacto con la estructura de una tesis doctoral como documento escrito, desde una perspectiva de la construcción arquitectónica.

Cursar el Máster de Restauración Arquitectónica de la Universidad de Valladolid en los años 2010 y 2011 contribuyó a as entar mi interés por el patrimonio en general y la forma de intervenir en el mismo. Es muy habitual iniciar investigaciones sobre un bien arquitectónico a partir de restauraciones que se llevan a cabo sobre el mismo. Resultados de un a restauración o descubrimientos producidos durante una intervención de este tipo se publican con frecuencia en revistas especializadas y en congresos relativos a la construcción arquitectónica.

En el año 2011, se inició la investigación realizada por el equipo dirigido por el Dr. Arquitecto José Luis Sáinz Guerra, y formado por los Catedráticos de Historia Medieval Pascual Martínez Sopena y Carlos Reglero y por el Dr. Arquitecto Félix Jové Sandoval, titulada: "Villas Nuevas Medievales de Castilla y León (fase I: Valladolid y Palencia). Patrimonio, protección y potenciación de recursos", Beca I + D + I de Ia Junta de Castilla y León. Esta investigación se centra principalmente en las villas del norte del río Duero, más concretamente Vertavillo (Palencia), Peñaflor de Hornija (Valladolid), Herrera de Pisuerga (Palencia), Tordehumos (Valladolid). En este contexto, se comenzó a forjar el tema de investigación de esta tesis doctoral. Mi interés por la disciplina de la Construcción, del análisis de los materiales físicamente, me condujo a la búsqueda de un aspecto constructivo dentro del estudio de las Villas Nuevas Medievales. Desde este punto de vista, la muralla todavía posee materia que estudiar, en muchos casos los materiales empleados se encuentran todavía 
físicamente. En otros casos, como la arquitectura popular o u rbana en v illas medievales, no siempre es factible encontrar un ejemplar a estudiar que se conserve todavía y donde se pueda afirmar sin duda que sus materiales son originales.

A esta participación en trabajos sobre el patrimonio arquitectónico y en la Edad Media como contexto histórico, se suma el interés personal en la arquitectura fortificada. $Y$ muy concretamente, el interés por la muralla. La muralla de una c iudad es un concepto, en un principio, muy sencillo. Es un muro continuo, masivo, de gran altura, que recorre habitualmente una di stancia considerable y que cerca un conjunto de edificaciones o simplemente una superficie ${ }^{1}$. Es un elemento que rodea la ciudad, que la contiene. Tiene una relación muy directa con la ciudad y con la actividad urbana. La ubicación de sus puertas condiciona los accesos a la ciudad y por tanto también la movilidad dentro de la misma. Es un el emento que forma parte de la ciudad y cuya existencia queda marcada en su desarrollo urbano; su recorrido es visible frecuentemente en el trazado actual de las calles y en la forma de las parcelas actuales.

La muralla tiene un carácter público, social, una dimensión civil, es un elemento común que pertenece a los habitantes de una ciudad y los protege. Esta función protectora de la muralla fomenta simpatía. No es un castillo o una fortaleza que protege a un acaudalado señor o tenente, es una construcción que ampara a los habitantes de una ciudad. No obstante, es también un elemento que separa el interior del exterior de una población, está pensado para ser infranqueable, a excepción de las puertas, donde el control de paso es estricto y sujeto al pago de impuestos. Necesariamente, esta naturaleza diferencia a los ciudadanos que viven en la ciudad frente a aquellos que no, concediendo mayor posición social a aquellos protegidos tras sus puertas.


Fig. 1.1. Matriz del sello concejil de Cuéllar donde se observa la imagen de la villa fortificada como símbolo del concejo. Fuente:

http://www.cervantesvirtual.com/obra/la-matriz-delsello-concejil-de-cuellar/ [Consultado el 22/7/2016]



Fig. 1.2. Anverso de una reproducción del sello del concejo de Benavente, en Zamora, donde se emplea la ciudad fortificada como imagen de representación. Fuente: Portada y contraportada de (Martínez Sopena et al. 1996)

\footnotetext{
1 "La cerca que non quiere decir sinon cosa que ciñe alrededor". Partida II, título XXIII, ley XXIII.
} 




Fig. 1.3. Imagen que muestra a un grupo de personas en plena celebración frente a la puerta de la muralla de Coca. Fuente:

http://www.descubrecoca.com/ [Consultado el 03/02/2015]



Fig. 1.4. Aspecto de la página web de Coca en la actualidad, donde también se utiliza la imagen de la muralla como elemento de representación. http://www.coca.es/el-ayuntamiento [Consultado el 03/02/2015]

De acuerdo con Julio Valdeón $(1991,85)$ las murallas medievales tenían además de la función defensiva una función de representación. En la villa se llevaban a c abo celebraciones que se realizaban junto a la muralla; se organizaban fuera del recinto y se vinculaban a la puerta más importante. La posesión de muralla era síntoma de fortaleza económica y de poder político. La i magen de ciudades amuralladas que aparece en los sellos de varios concejos refuerza esta hipótesis (Fig. 1.1, Fig. 1.2). La muralla significó entonces un elemento del que enorgullecerse que se empleaba como símbolo con el que se identificaba la villa y su concejo.

Desde hace siglos, la muralla ha perdido su carácter defensivo en nues tro territorio. Con todo, no ha perdido esa función de representación que le atribuye Julio Valdeón. Se conservan fotografías que muestran cómo todavía en el siglo pasado se utilizaba la muralla como elemento representativo de un a villa y sus habitantes (Fig. 1.3). La celebración de festividades se realiza en la puerta de la muralla, donde se reúnen los habitantes. La muralla adquiere un significado en la ciudad, los habitantes se identifican con ella, de manera que se convierte en un s ímbolo, para finalmente utilizarse como elemento de representación. Contemplada en la actualidad, la muralla es un elemento que todavía engloba varias funciones. Alberga un significado histórico, urbano, constructivo, de identidad ciudadana, comunitario, social. En muchas ocasiones también se conserva físicamente y es en estos casos donde se hace posible un estudio constructivo. Hoy, la muralla sigue siendo un elemento de representación, la página web del ayuntamiento de Coca (Fig. 1.4) emplea la imagen de la muralla como símbolo de la villa.

Los trabajos y proyectos llevados a cabo por el arquitecto Fernando Cobos han sido igualmente una fuente de inspiración. El estudio constructivo de los castros y recintos de la frontera de León en los siglos XII y XIII (Cobos 2012) recoge ejemplos de conjuntos amurallados y fortificaciones construidas con tapia de cal y canto o c on mampostería encofrada en León, Mansilla de I as Mulas (León), Ciudad-Rodrigo (Salamanca), Belver de los Montes (Zamora), Medina del Campo (Valladolid), San Pedro de Lat arce (Valladolid) y muchos otros. A través del análisis del sistema constructivo, consigue relacionar un grupo de fortificaciones en un territorio de frontera 
entre los reinos de León y de $\mathrm{C}$ astilla. En una conversación mantenida con el arquitecto Fernando Cobos acerca del panorama de la investigación en arquitectura fortificada de la región de Castilla y León, me habló de las Comunidades de Villa y Tierra, donde se crearon villas amuralladas de nueva fundación o se repoblaron villas existentes y evolucionaron en el territorio entre los ríos Duero y Tajo. Fuentidueña (Segovia) es un ejemplo magnífico y es representativo de este fenómeno. Su análisis supone un punto de partida de esta investigación y ha funcionado desde el principio como estructura de esta tesis doctoral.

El conocimiento de técnicas constructivas tradicionales, a raíz de mi colaboración intensa desde el año 2004 con el Grupo Tierra de la Universidad de Valladolid, dirigido por los arquitectos José Luis Sainz Guerra y Félix Jové Sandoval, también fue decisivo para completar el interés sobre estos conjuntos amurallados, puesto que en gran parte de ellos se emplea la técnica del tapial. Por otro lado, también en este grupo he tenido la oportunidad de aprender a valorar el patrimonio arquitectónico y tener la voluntad de trabajar en investigaciones que tengan por objetivo ponerlo en valor y garantizar su conservación.

A través de jornadas de arquitectura defensiva, organizadas por el arquitecto José Ignacio Gil Crespo en la Universidad Politécnica de Madrid, Ilegaron a mi conocimiento otras investigaciones en curso acerca de la arquitectura fortificada en zonas cercanas a las que estaba estudiando y que sirvieron de referencia en el proceso investigador (Martín Blanco 2014, Herrero 2014, Escobar 2014, Gil Crespo 2013).

La concesión de la beca bianual de investigación por parte de la Fundación Juanelo Turriano en julio de 2014 fue clave para la impulsión de este trabajo. El interés de esta fundación por el estudio histórico de la Técnica y de la Ciencia en sus diversas vertientes, con especial énfasis en la Historia de la Ingeniería, hizo que el estudio de la técnica constructiva en las murallas medievales atrajera su atención y se decidiera destinar parte de su capacidad económica para financiar esta tesis doctoral.

\subsection{Interés y oportunidad de la investigación}

\subsubsection{Patrimonio arquitectónico defensivo}

Actualmente se conservan en la península ibérica muchos ejemplos de arquitectura defensiva de gran variedad y riqueza formal. Existe gran número de castillos, ciudades amuralladas o torres defensivas aisladas que datan de distintas épocas, todos ellos con formas, estilos y orígenes muy diversos. Los recintos amurallados son muy frecuentes en toda la península ibérica. Solo en la Comunidad de Castilla y León hay ejemplos muy numerosos. En las provincias de León, Salamanca, Valladolid y Zamora, el catálogo elaborado por Fernando Cobos (2011) recoge una cantidad ingente de ejemplos de arquitectura defensiva. 
Las murallas en las Comunidades de Villa y Tierra de la Diócesis de Segovia en los siglos XI a XIII. Técnica y sistemas constructivos de la arquitectura defensiva medieval.



Fig. 1.5. Tramo de muralla en la zona cercana al castillo de la Mota en Medina del Campo, Valladolid. [A.S.E. 05/11/2014]



Fig. 1.7. Muralla de Ávila vista desde el oeste [A.S.E. 21/02/2015]



Fig. 1.9. Puerta de la muralla de Portillo, Valladolid. [A.S.E. 23/10/2014]



Fig. 1.6. Cerca que rodea las torres de León [A.S.E. 22/02/2014]



Fig. 1.8. Parte de la muralla de Segovia. [A.S.E. 30/12/2014]



Fig. 1.10. Puerta de la muralla de Arévalo [A.S.E. 11/12/2014] 
Los estudios que se han realizado acerca de murallas han sido, de forma general, estudios planteados desde un punto de vista aislado, estudio formal, análisis del tipo arquitectónico, estudio histórico o constructivo de un solo castillo, de la muralla de una ciudad; también se han realizado inventarios o catalogaciones de fortificaciones 0 construcciones fortificadas, habitualmente de una manera individualizada o a modo de inventario y sin tratar de relacionarlos entre sí. Por fin, Fernando Cobos (2012) publica un trabajo que establece relación entre los recintos amurallados de la frontera de los reinos de León y Castilla durante el siglo XII. Se puede ver una pequeña muestra de recintos amurallados en las imágenes Fig. 1.5 a Fig. 1.10.

Algunos autores (Gil Crespo 2013,4) coinciden en que la arquitectura defensiva no ha sido estudiada de la misma manera que ocurre con edificios de carácter religioso, donde existen estilos claramente diferenciados y datados. La arquitectura defensiva se construye con una función muy específica; su aspecto cerrado y la escasa ornamentación que presenta ha hec ho siempre muy complejo su entendimiento, dificultando su identificación, clasificación, datación y también su lugar en un marco histórico y geográfico. Por esta razón, se trata de un patrimonio un tanto apartado de los estilos arquitectónicos establecidos, olvidado tal vez en algunas disciplinas. A pesar de ello, son construcciones que atesoran gran cantidad de información en su configuración y en su forma de construirse. Las técnicas empleadas para su edificación pueden ofrecer pistas valiosas acerca de su naturaleza.

Hay algunos casos donde se observa gran reconocimiento social del valor cultural e histórico de una muralla, como ocurre en Ávila (Fig. 1.7), ciudad muy conocida y visitada, considerada Patrimonio de la Humanidad por la UNESCO desde $1985^{2}$ y donde las murallas tienen mucha importancia cultural. Pero esta no es la situación más corriente, por ejemplo en Segovia, las murallas no tienen ese grado de protagonismo, quedando a la sombra de otros monumentos de la ciudad como el Acueducto o el Alcázar. Esto se puede apreciar de forma indirecta en este ejemplo: cuando se produce una agresión vandálica sobre el acueducto de Segovia, se condena en la prensa y la policía busca al culpable para multarlo (Fig. 1.11); en comparación, no es noticia que haya ocurrido lo mismo en varios de los lienzos de la muralla medieval (Fig. 1.12). Incluso leyendo estas líneas, alguien podría pensar que no es comparable el valor histórico y cultural de una obra de ingeniería como el acueducto de Segovia con la muralla de Segovia; sin embargo, la muralla tiene un gran valor histórico, cultural y urbano que también hay que apreciar y explotar.

La arquitectura defensiva, y más concretamente las murallas, necesitan de un impulso para ganar interés, entendimiento y deseo de conservación por parte de la sociedad. En muchos casos, la población sigue considerándolas como un elemento obsoleto que hay que eliminar, o simplemente no suscitan su interés. Este escaso apego se traduce en una menor demanda a las administraciones para que emprendan acciones que preserven la integridad de estas construcciones. Es habitual encontrar panfletos

\footnotetext{
2 Se encuentra inscrita "la ciudad vieja de Ávila e iglesias extramuros" en la Lista de Patrimonio Mundial de la UNESCO con el número de referencia 348 bis. http://whc.unesco.org/en/list/348/
} 
Las murallas en las Comunidades de Villa y Tierra de la Diócesis de Segovia en los siglos XI a XIII.

Técnica y sistemas constructivos de la arquitectura defensiva medieval.

turísticos de una $v$ illa amurallada, o con restos de $m$ uralla, que no recogen su existencia o no proponen un recorrido para conocer el trazado de la muralla (Fig. 1.13). Es fácil visitar la villa de Sepúlveda y marcharse sin conocer la gran extensión de superficie amurallada que albergaba la muralla medieval, que es semejante a la de la muralla de Segovia y que todavía se conserva en varios puntos.



Fig. 1.11. Artículo en el periódico Norte de Castilla con fecha 23 de diciembre de 2014. http://www.elnortedecastilla.es/segovia/201412/23/pol icia-investiga-pintadas-vandalicas20141223192409.html [Consultado el 23/12/2014]



Fig. 1.13. Fragmento de un folleto turístico de Sepúlveda que no recoge el recorrido de la muralla (mayo 2016). Fuente:

http://segoviaturismo.es/files/pdf/20131219205507 90bfbdaf97a4790e884d6d28087e16e8.pdf [Consultado el 29/11/2016]



Fig. 1.12. Grafiti en la muralla de Segovia. [A.S.E. 30/12/2014]



Fig. 1.14. Extensión amurallada de la villa de Sepúlveda, que actualmente se encuentra vacía en su mayor parte. Fuente: Elaboración propia con la ortofoto del PNOA como base. 


\subsubsection{Estado de conservación de las murallas en Castilla y León}

El estado de conservación de estos ejemplos es variado. Se dan casos de castillos que han sido restaurados como por ejemplo el Castillo de Peñafiel (Valladolid), convertido en un museo, o el Castillo de la Mota también restaurado y visitable. Es habitual que edificaciones que ahora se encuentran restauradas y son visitables, como es el caso de la Alhambra de Granada, hayan estado abandonadas durante el siglo XX y expuestas al deterioro, al expolio, o destinadas a usos no adecuados para la conservación del patrimonio.



Fig. 1.15. Castro de Torrejón de la Nava, en Nava del Rey, Valladolid. [A.S.E. 20/02/2015]



Fig. 1.17. Tramo de muralla en la calle Rondas de Peñafiel, Valladolid. [A.S.E. 29/10/2014]



Fig. 1.16. Ruinas en Ayllón, Segovia. [A.S.E. 03/09/2014]



Fig. 1.18. Detalle de la muralla en la calle de la iglesia de Haza, Burgos. Las nuevas construcciones se aproximan demasiado a la muralla. [A.S.E. 29/10/2014]

Es habitual que los ejemplos más monumentales o i mponentes, como grandes castillos con colosales sistemas de ataque y defensa, con fosos y torres abaluartadas provistas de saeteras, sean estudiados e investigados más en profundidad. Por el contrario, otras construcciones más modestas, pero no menos interesantes, quedan relegadas a un segundo plano. La muralla, por su dimensión urbana, es en muchos casos fagocitada por la ciudad y en otros casos demolida. La muralla se convierte en un obstáculo para el crecimiento y funcionamiento de la ciudad moderna y es 
destruida. Torres Balbás (1922, 77-79) explica cómo los municipios derriban las murallas por ser viejas, inservibles y molestas, e indica que la cantidad de murallas y puertas destruidas durante el primer tercio del siglo XIX es incontable. En muchos pueblos amurallados de castilla se habla de cuantas puertas había en origen, ahora desaparecidas. En Olmedo se conservan imágenes de un a de s us puertas, hoy inexistente (Fig. 1.19).



Fig. 1.19. Antigua puerta de San Pedro en Olmedo, Valladolid. Fuente: Cromo de la Fundación Joaquín Díaz

[http://www.funjdiaz.net/basefotos3.php?id=2489]



Fig. 1.20. Restos de las tapias de la muralla de Olmedo en estado de abandono. [A.S.E. 01/09/2014].

En su estudio de la ciudad de Zamora, José Luis Gago $(1988,127-128)$ rescata un poema de Víctor Blanco Román que habla del derribo de las murallas de esta ciudad en 1905. Con este poema, el autor se despide de la muralla ensalzando su valor histórico, simbólico, estético y evocador. Describe el desprecio de las gentes que al grito de "¡Abajo! (...) ¡Fuera el estorbo!" reclaman el derribo, y transmite un sentimiento de pesar por la pérdida de la muralla, consciente de que sus quejas son vanas. En sus estrofas centrales, dice:

\section{(...)}

¡Por miserias del hombre te edificaron! ¡Por miserias del hombre hoy te deshacen! y entre bloques de piedra diseminadas que en informes montones doquiera esparcen, todos tus elementos desaparecen hasta que ni resquicios de ti se hallen. (...) 
Todavía hoy se produce la demolición de murallas o partes de ella. El arqueólogo José Avelino Gutiérrez habla del ejemplo de la cerca de Valencia de Don Juan en León (Sainz Esteban 2014a, 238), donde existieron durante años los restos de parte de la muralla, construida con tapia de tierra, que contaba con más de 5 metros de anchura, y que ha sido destruida recientemente. El desconocimiento de la configuración de estas construcciones y de su sistema constructivo ha hecho que en muchos casos se hayan destruido murallas o partes de ellas, por no identificarlas como tal, también por no saber cómo preservarlas y en oc asiones, por no tener interés alguno en su conservación. La idealización del castillo o la muralla como un elemento pétreo, de aparejos ordenados y rectos, hace difícil la comprensión de que la muralla en la Edad Media podía estar simplemente construida con tierra. También se da el caso de partes de murallas que se conservan, pero se encuentran en estado de abandono aún dentro de un conjunto amurallado que ha sido restaurado. Las murallas de Olmedo han sido restauradas, pero olvidando algunas partes que han quedado arruinadas (Fig. 1.20).

\subsubsection{Restauración de las murallas}

La labor de r estauración de las murallas es muy importante para preservar estos ejemplos de arquitectura defensiva. La restauración arquitectónica es una disciplina en permanente cambio y evolución, que a lo largo del tiempo ha tratado distintas posturas a la hora de intervenir en una construcción a restaurar.

En el campo de la arquitectura defensiva, concretamente de las murallas, se repite un requisito que parece indispensable a la hora de restaurar una muralla, y es que sea transitable su adarve y se pueda pasear en la zona del almenado. Este aspecto tiene, al parecer, gran atractivo turístico y, sin embargo, no permite la contemplación de la muralla, sino que se contempla el paisaje o la ciudad. La legislación actual en cuanto a accesibilidad, seguridad de utilización, seguridad estructural, que es muy extensa y está más bien orientada a I a obra nueva, implica que nuevas dimensiones y requerimientos se apliquen a las murallas para que estas sean transitables, modificando su morfología original.

La muralla, tal vez por encontrarse inmersa en la ciudad, está más habitualmente sujeta a añadidos o modificaciones. El factor de la reconstrucción, es decir, construir desde cero tramos de muralla desaparecidos con el tiempo, o que se han derribado en los últimos siglos, es una de las soluciones que se aplican en algunos casos. La reconstrucción implica la invención de una ar quitectura y la imposición de una interpretación para todos.

En muchos casos, la restauración llevada a c abo en m urallas, ha di storsionado la realidad de I as mismas, modificando su forma, ocultando sus características y confundiendo a la sociedad en general y a los investigadores en particular en su interpretación. 
Las murallas en las Comunidades de Villa y Tierra de la Diócesis de Segovia en los siglos XI a XIII. Técnica y sistemas constructivos de la arquitectura defensiva medieval.

La consolidación de los restos existentes de una muralla es una solución de interés. También la diferenciación de añadidos a través de materiales claramente distinguibles permite que se produzca una comprensión de cuáles son las modificaciones y qué parte es original.

\subsubsection{Gestión del patrimonio defensivo en España a través de su legislación}

En España, existen desde el siglo XIX normas para la protección de bienes inmuebles, inicialmente sujetas a la noción de monumento arquitectónico de acuerdo con sus valores históricos y artísticos, y que ya entonces responsabilizaban al os ayuntamientos de su conservación y protección. A principios del siglo $\mathrm{XX}$, aparece la ley sobre Excavaciones Arqueológicas de 1911, donde se establecen normas para excavaciones arqueológicas; y la ley de Monumentos Arquitectónicos en 1915, que desarrollará el concepto de la declaración formal de los monumentos a proteger, figura que ha llegado a nuestros días (Becerra 1999, 9-12).

En el Real Decreto-Ley de 9 de agosto de 1926 sobre Protección, Conservación y Acrecentamiento de la Riqueza Artística, se habla de bi enes muebles e inmuebles dignos de ser conservados por razones de Arte y cultura, y se establece que quedan bajo la tutela y la protección del Estado (Art.1). También establece que será de utilidad pública la conservación, protección y custodia de I os monumentos arquitectónicos (Art.7). Según Becerra $(1999,13)$, el concepto de cultura que se emplea en este real decreto amplía el tipo de inmuebles que se protegen, incluyendo edificaciones o conjuntos de ellas que contribuyan a mantener el aspecto característico de España, superando el concepto de monumento como elemento aislado. Se incorporan dos nuevos tipos de inmueble, de Sitios Históricos y Conjuntos Históricos.

La Constitución Española de $1931^{3}$ incluye en su articulado (Art. 45) una referencia muy amplia de los bienes a proteger por el Estado, pues indica que "toda riqueza artística e histórica del país" deberá ser protegida por el Estado.

La Ley 13 de mayo de $1933^{4}$, sobre Defensa, Conservación y Acrecentamiento del Patrimonio Histórico-Artístico es el primer documento de estas características que incluye la arquitectura defensiva en el patrimonio español a pr oteger, con una referencia expresa a las murallas y fortalezas como conjunto donde son aplicables las mismas prescripciones que a los monumentos histórico-artísticos (Art. 33).

Más adelante, se promulga el Decreto de Protección de los Castillos Españoles del 22 de abril de $1949^{5}$, que supone un paso importante pues hace referencia

\footnotetext{
${ }^{3}$ http://www.congreso.es/docu/constituciones/1931/1931_cd.pdf [Consultado el 23/11/2015]

${ }^{4}$ http://nueva.iaph.es/html/portal/com/bin/portal/Tematicas/InformacionPH/Presentacion/Espana/sigloXX/in dex/1139822454442_ley_1933.pdf [Consultado el 23/11/2015]

${ }^{5}$ http://www.patrimoniocultural.jcyl.es/web/jcyl/PatrimonioCultural/es/Plantilla100DetalleFeed/12841802554 60/Normativa/1284220172433/Redaccion [Consultado el 23/11/2015]
} 
exclusivamente a las edificaciones militares. Con un preámbulo que ensalza la belleza y el carácter evocador de los castillos, establece que todos los castillos de España, cualquiera que sea su estado de conservación, quedan bajo protección del Estado y éste impedirá cualquier intervención que altere su carácter o pueda provocar su derrumbamiento. Atribuye a los Ayuntamientos en cuyo ámbito municipal se encuentre el edificio cualquier daño que se produzca en el mismo. Indica que se deberá asignar un arquitecto conservador responsable para atender su vigilancia e incluso establece que la Dirección General de Bellas Artes deberá proceder a redactar un inventario documental y gráfico de los castillos de España.

La Ley de Patrimonio Histórico Español del 25 de junio de 1985, sustituye a su predecesora de 1933, y en cuanto al patrimonio defensivo, remite a la ley de 1949 para considerar de interés cultural todos los bienes sometidos bajo tal decreto.

En 1998, se aprueba el Plan Nacional de Castillos, con un inventario de fortificaciones a cargo de la Asociación Española de Amigos de los Castillos, actualizando de esta manera el Inventario de Protección del Patrimonio Cultural Europeo (IPCE) de 1968 (Schnell 2014, 81).

La ley de Patrimonio Cultural de Castilla y León, Ley 12/2002 de 11 de julio plantea en el artículo 8, la definición y clasificación de los Bienes de Interés Cultural, dentro de la cual se define en pr imer lugar la clase "monumento" como construcción u obra producto de actividad humana, de relevante interés histórico, arquitectónico, arqueológico, artístico, etnológico, científico o técnico, con inclusión de los muebles, instalaciones o accesorios que expresamente se señalen como parte integrante de él, y que por sí solos constituyan una unidad singular. Esta definición permite referirse a una muralla como monumento, término empleado habitualmente por la sociedad para referirse a otro tipo de construcciones arquitectónicas.

La Carta de Baños de la Encina para la Conservación de la Arquitectura Defensiva en España, se redacta los días 30 y 31 de octubre de $2006^{6}$ en Potes, Cantabria, de común acuerdo entre los participantes de las Jornadas Técnicas sobre Castillos y Arquitectura Defensiva Histórica Española, que tuvo lugar en Baños de la Encina, Jaén, 27 a 29 de septiembre de 2006. La redacción de este documento fue coordinada por el Instituto del Patrimonio Histórico Español del Ministerio de Cultura y la Dirección General de Bienes Culturales de la Consejería de Cultura de la Junta de Andalucía. Este documento resalta la importante relación de la arquitectura defensiva con la historia de España, indicando que está indisolublemente ligada a acontecimientos trascendentes y a personas y colectividades que han representado papeles relevantes a lo largo de la historia. Pone de manifiesto la pérdida de la función original de estas edificaciones que ha d ado lugar a un desuso generalizado, y por lo tanto a u $\mathrm{n}$ paulatino y constante deterioro. Finalmente expresa que la arquitectura defensiva merece una atención particularizada por tratarse de un patrimonio complejo y extenso. Como propuesta para la conservación de la arquitectura defensiva en España recoge ocho recomendaciones que son: el conocimiento, el paisaje cultural, la memoria

\footnotetext{
${ }^{6}$ http://www.iaph.es/revistaph/index.php/revistaph/article/viewFile/2292/2292 [Consultado el 8/5/2015]
} 
Las murallas en las Comunidades de Villa y Tierra de la Diócesis de Segovia en los siglos XI a XIII. Técnica y sistemas constructivos de la arquitectura defensiva medieval.

histórica, la arquitectura defensiva y el poblamiento, la función y el uso, difusión, aplicación y desarrollo, y define una metodología de estudio e intervención en la arquitectura defensiva. ${ }^{7}$

En el año $2006^{8}$ se puso en marcha el Plan Nacional Arquitectura Defensiva, gestionado por la Dirección General de Bellas Artes y Bienes Culturales, a través del Instituto del Patrimonio Cultural de $\mathrm{E}$ spaña ${ }^{9}$. Los objetivos que plantea este instrumento son en primer lugar crear un sistema común como marco de referencia para la conservación del patrimonio defensivo. En segundo lugar, llevar a cabo un análisis general del estado de conservación de esta arquitectura. También es un objetivo definir criterios y métodos unificados para la adecuada conservación de este patrimonio y para ello es necesario coordinar al as administraciones y entidades implicadas. Finalmente, se recuerda que es importante contemplar en las intervenciones el valor histórico de estas construcciones, y la necesidad de motivar a la sociedad para que participe en la conservación de esta arquitectura.

En Castilla y León, el interés de la administración autonómica se ha traducido en los años 2011 y 2012 en el patrocinio de proyectos que han dado lugar a varias publicaciones en formato digital que estudian la arquitectura defensiva de la región. Dos de estos proyectos se han realizado por el arquitecto Fernando Cobos y su equipo de trabajo; el primero de ellos, realizado en el año 2011, aborda un compendio de criterios para valorar e intervenir en la arquitectura defensiva, con una metodología que identifica Sistemas Territoriales de $\mathrm{P}$ atrimonio. Incluye un i nventario de construcciones defensivas de las provincias de León, Salamanca, Valladolid y Zamora (Cobos 2011). Más adelante en 2012, este equipo trabaja en los castros y recintos de la frontera de León en I os siglos XII y XIII, donde pone en r elación varios ejemplos de arquitectura defensiva basándose en su sistema constructivo (Cobos 2012). Arturo Balado y Consuelo Escribano (2012) llevan a cabo una publicación donde se estudian los castillos de Castilla y León, y se agrupan en función de las fronteras que han defendido a lo largo del tiempo.

En el contexto económico y político actual, España continúa inmersa en una crisis económica de gran magnitud, y particularmente intensa en el campo de la arquitectura. De forma general, esta circunstancia no es favorable para el patrimonio histórico, por lo que no es esperable que en los próximos años haya nuevos proyectos a nivel nacional o autonómico para impulsar la conservación y puesta en valor del patrimonio defensivo.

\footnotetext{
${ }^{7}$ Noticias PH. La Carta de Baños de la Encina actualiza la protección legal del patrimonio arquitectónico defensivo. Boletín del Instituto Andaluz del Patrimonio Histórico. n61. Febrero de 2007.

${ }^{8}$ http://ipce.mcu.es/pdfs/PNArquitecturaDefensiva.pdf [Consultado el 24/11/2015]

${ }^{9}$ Plan Nacional de Arquitectura Defensiva http://ipce.mcu.es/conservacion/planesnacionales/defensiva.html [Consultado el 25/01/2016]
} 


\subsection{Planteamiento de la investigación}

\subsection{Marco histórico y geográfico de la investigación}

Durante los siglos XI a XIII, el panorama político en la península ibérica es cambiante e inestable. Se producen cambios significativos en el control del territorio, y se lleva a cabo una expansión muy importante del territorio controlado por el reino de Castilla. Entre 1085 y 1212, cristianos y musulmanes pujan por el control de un territorio determinante para el dominio de la península ibérica, el que se extiende entre los ríos Duero y Tajo. Ermelindo Portela $(1985,91)$ resalta la importancia estratégica de este territorio y recuerda, citando a Ramón Menéndez Pidal, que es entre 1045 y 1250 cuando se produce la etapa de la Reconquista. La victoria castellana en la batalla de las Navas de Tolosa en 1212 supuso el control definitivo de este espacio por parte del reino de Castilla (94).

Con la toma de T oledo en 1085, una superficie muy importante quedó en la retaguardia castellana y se hizo necesario llevar a cabo una repoblación para afianzar esa conquista (Martínez Díez 1983, 20). A través de una estrategia de repoblación, iniciada por el rey Alfonso VI, se creó una red de villas nuevas y repobladas en Ia Extremadura Castellana, al sur del Duero, frontera geográfica de los reinos cristianos en el siglo $X$. El resultado fue una singular organización territorial y política, las denominadas Comunidades de Villa y Tierra. Se denominaron originalmente concejos de villa y tierra y fue en el siglo XIX cuando se consolidó el nombre de Comunidad de Villa y Tierra en los textos jurídicos (Muñoz Gómez 2012, 10). Esta estructura territorial estaba formada por concejos, comunidades de extensión considerable que poseían una villa principal, la "Villa" y un t erritorio subordinado, la "Tierra", donde había pequeñas aldeas, de menor entidad. El territorio entre los ríos Duero y Tajo se organizó mediante concejos que, aunque dependían directamente del rey, gozaban de una autonomía de gobierno excepcional y donde sus habitantes disfrutaban de una libertad inusitada y participaban de las decisiones políticas del concejo, al menos en la primera etapa de este fenómeno. Además de esta breve introducción sobre el marco histórico, en el capítulo 3 se analiza de forma más intensa este contexto políticoeconómico.

Las villas cabecera de los concejos poseían una muralla que rodeaba la ciudad y la protegía. Las aldeas, por el contrario, no se encontraban fortificadas (Martínez Díez 1983, 20). Los restos de lienzos, torres y puertas de muralla que se conservan en la actualidad hacen posible un estudio físico de los mismos. Esta investigación pretende identificar los sistemas constructivos visibles en los restos de muralla y analizar cuáles son los más usados y bajo qué configuraciones.

El contexto histórico en el que se produce la construcción o la reconstrucción de las murallas objeto de es te estudio, permite delimitar un marco geográfico de forma bastante precisa. El territorio donde tiene lugar el fenómeno de las Comunidades de Villa y Tierra queda limitado al norte por el río Duero, a excepción de la zona de Soria de algún concejo como Zamora, que se extiende al norte del río Duero. Al sur encuentra límite en la línea del río Tajo. Se cierra al este por el Sistema Ibérico, y al 
oeste por la frontera con el reino de Portugal. La superficie del espacio descrito supera los $80.000 \mathrm{~km}^{2}$. Este territorio se encuentra dividido de este a oeste por el Sistema Central, una cordillera montañosa de aproximadamente $600 \mathrm{~km}$ de longitud definida como un "soberbio espinazo" por Franco Aliaga $(1997,50)$ y que divide la Meseta Central en dos partes, en sentido este-oeste. La Cordillera Central se compone de numerosas sierras que están separadas entre sí por valles o por puertos de montaña, donde es posible la comunicación norte-sur. Las sierras más conocidas son la Sierra de Gredos (donde se sitúa el pico Almanzor, el más elevado con $2.591 \mathrm{~m}$ sobre el nivel del $\operatorname{mar}^{10}$ ), la de Guadarrama y la de Ayllón. Los principales puertos que permiten la comunicación son los siguientes: Béjar, entre la Peña de Francia y Gredos, la Paramera de Ávila, entre Gredos y Guadarrama, y Somosierra, entre Guadarrama y la Sierra de Ayllón. A ambos lados de la cordillera, se abren los valles de los ríos Duero Tajo.

En el valle del Duero, los afluentes más importantes son los siguientes: Águeda, Tormes, Adaja, Eresma, Cega, Duratón y Riaza. En el valle del Tajo, descendiendo por los valles de la Cordillera Central, se abren paso los ríos Alagón, Tiétar, Alberche y Jarama. Estas dos partes diferenciadas geográficamente también se diferencian políticamente; al norte en el valle del Duero, se configura la Extremadura y en el valle del Tajo se estructura la Transierra. La repoblación de la Extremadura y Transierra es diferente; es más conocida y cercana la Extremadura pues se ha tratado de repoblar con anterioridad. Portela $(1985,105)$ diferencia estos dos territorios desde un punto de vista agropecuario, indicando que el valle del Duero se dedica más al cultivo por ser un área más fértil, frente a la dedicación ganadera de las zonas serranas del sur de la cordillera.



Fig. 1.21. Plano de relieve del territorio situado entre los ríos Duero y Tajo, que ilustra la descripción del marco geográfico de la investigación. Fuente: Elaboración propia a partir de mapas del Instituto Geográfico Nacional.

\footnotetext{
${ }^{10}$ De acuerdo con los datos del Instituto Geográfico Nacional].
} 
Dada la enorme extensión de este territorio y la cantidad de concejos que abarca, más de cincuenta, se hace necesaria una acotación más reducida. Los límites de las provincias y municipios hoy en día no se corresponden exactamente con el panorama de este fenómeno en la época, y utilizar los límites políticos actuales puede no ser de utilidad en esta investigación. Por esta razón, se ha buscado otros factores presentes en la época, que sean de utilidad para delimitar un área de interés. Se ha mencionado que esta región se encontraba dividida en c oncejos, comarcas que abarcaban superficies variadas, desde los $148 \mathrm{~km}^{2}$ del concejo de Fresno de Cantespino, hasta los más de $8.000 \mathrm{~km}^{2}$ del concejo de Ávila. Además de esta división en jurisdicciones, realizada a partir de una nueva forma de gobierno de este territorio, sigue existiendo la influencia de la iglesia, que extiende su poder a través de las Diócesis. El campo de estudio de esta investigación se encuentra dentro de los límites del territorio de la Diócesis de Segovia (Fig. 1.22). A la hora de determinar cuál es el límite de la Diócesis de Segovia, se ha tomado como referencia el descrito por Villar García $(1986,296)$ y datado en torno al año 1250. Los concejos que se encuentran en esta Diócesis son los siguientes: Coca, Cuéllar, Fresno de C antespino, Fuentidueña, Íscar, Maderuelo, Montejo de la Vega de la Serrezuela, Pedraza, Segovia y Sepúlveda. Se han encontrado otras delimitaciones de es ta Diócesis, por ejemplo González Herrero $(1998,34)$ incluye los concejos de Ayllón y de Haza. De acuerdo con Martínez Díez $(1983,414)$, la Diócesis de Segovia se creó en torno a 1120, la bula del papa Calixto II confirma su existencia en 1123.



Fig. 1.22. Plano de la diócesis de Segovia, se observan los 10 concejos que forman parte de esta diócesis. Fuente: Elaboración propia de acuerdo con planos de Luis Miguel Villar García (1986, 296-298). 
Las murallas en las Comunidades de Villa y Tierra de la Diócesis de Segovia en los siglos XI a XIII. Técnica y sistemas constructivos de la arquitectura defensiva medieval.

La Extremadura castellana estaba dividida en varias diócesis, la de Zam ora, la de Salamanca, que abarcaba desde Ciudad-Rodrigo hasta Medina del Campo, la Diócesis de Ávila que incluía Ávila, Arévalo y Olmedo. Más allá de Segovia se sitúa la Diócesis de O sma, que incluía Ayllón y otros concejos. Al norte del río Duero se situaba la diócesis de Burgos, que albergaba los concejos de Haza y Peñafiel. Portillo se situaría ya en la diócesis de Palencia (Villar García 1986, 183). En esta investigación se ha tenido en cuenta las villas amuralladas limítrofes con la Diócesis de Segovia. Olmedo, Haza, Ayllón y Medina del Campo ofrecen ejemplos de murallas de interés que tiene puntos en común con las murallas de las villas de Segovia.

El territorio de la Diócesis de Segovia tiene una superficie de $10.000 \mathrm{~km}^{2}$ aproximadamente, de acuerdo con la medición de este estudio. Los datos recogidos por Villar García $(1986,288)$ hablan de una s uperficie menor, de $7.450 \mathrm{~km}^{2}$. Este territorio abarca parte del valle del Duero en su zona norte, bañado por los ríos Cega, Eresma, Duratón y Riaza. En la zona sur se sitúa la sierra de Guadarrama. La diócesis de Segovia supera la Cordillera Central y se extiende al sur de Madrid. De acuerdo con Ermelindo Portela $(1985,111)$ esto se explica por la actitud expansionista que adoptaron algunos concejos como el caso de Segovia, que bajo la protección del rey Alfonso VIII, extiende su término al otro lado de la sierra, en detrimento de Aljamín, Canales y sobre todo Madrid.

\subsection{Enfoque de la tesis doctoral}

Las distintas disciplinas que abordan el estudio de estas construcciones, plantean enfoques distintos. El enfoque arqueológico analiza el patrimonio de forma activa, es decir, a través de la retirada de estratos interviniendo directamente sobre los restos y analizando lo que es visible en los suelos y paramentos. El resto arqueológico se analiza con técnicas que evalúan el orden de las modificaciones, permitiendo realizar dataciones relativas entre los distintos elementos. El enfoque histórico da un sentido a los restos de murallas existentes. A través del estudio de documentación histórica que menciona las murallas de una villa, es posible situar a un monarca a las puertas de una ciudad o conocer las cuestiones fiscales en la construcción o el mantenimiento de la muralla. Se puede conseguir entender qué contexto rodeaba la construcción de las murallas de una ciudad. No obstante, es muy difícil encontrar datos concretos de cómo se construían las murallas en doc umentos históricos. Es posible que se tratara de profesiones cuyas técnicas se transmitirían de forma oral, siendo hoy en día muy difícil encontrar documentación que las describa.

Dentro del enfoque arquitectónico, se sitúa el análisis con un carácter urbanístico, donde se analizan las relaciones entre el trazado de la muralla y el trazado urbano, la forma de las calles, el recorrido, las características del parcelario de la villa, o la ubicación de los accesos en función de la estructura urbana. El estudio de la tipología arquitectónica también forma parte del enfoque arquitectónico, se analizan las formas, dimensiones y el orden de los elementos que configuran el recinto. Las puertas son un elemento donde se plasma a lo largo de los años la influencia y el poder de la villa, a través de decoración, escudos y geometrías imponentes. Por esta misma razón, es 
también uno de los elementos que más varía a lo largo del tiempo, modificado por cada grupo representante de pode r. La variedad de soluciones es extraordinaria y también es compleja la evolución de es tas construcciones, con modificaciones, añadidos o desapariciones que hacen muy difícil la lectura e interpretación de estos recintos en la actualidad.

El enfoque de esta tesis doctoral es analizar de forma exhaustiva el sistema constructivo que se utilizaba en la construcción de las murallas. En cada uno de los casos se han analizado restos de muralla para extraer qué materiales se empleaban y qué técnicas se utilizaban para edificar los muros. Por una parte, y de forma más general, se han identificado las distintas técnicas empleadas a lo largo de todo el recinto amurallado, localizando después en qué zonas se han aplicado. En los tramos de muralla seleccionados de c ada caso, se ha realizado un I evantamiento para localizar los elementos constructivos visibles en el muro. El objetivo final ha sido el de detallar la configuración, la composición, la posición y las dimensiones del os elementos constructivos para entender el funcionamiento y el orden de las técnicas empleadas y compararlas en los distintos casos.

Por otra parte, se ha tratado de incidir en el planteamiento de que la muralla es un elemento patrimonial de gran importancia. Es un elemento de gran interés en la arquitectura defensiva y se ha de gestionar su conservación y las intervenciones en la misma de forma responsable, como ocurre en otros ejemplos de arquitectura monumental.

\subsection{Hipótesis de la investigación}

A continuación, se plantean las hipótesis de este trabajo. Algunas de ellas se han formulado como preguntas, como incógnitas a las que se ha tratado de dar respuesta en esta investigación.

- El análisis constructivo de los restos de la arquitectura fortificada puede aportar información acerca de cómo se construían las murallas, acerca de quién construía las murallas y acerca de cuándo se construyeron. Estos aspectos podrían comprenderse a través del estudio constructivo de esta arquitectura: el orden y la planificación, los materiales de construcción y las técnicas empleadas. La combinación de criterios constructivos con criterios históricos y geográficos puede servir para avanzar en el conocimiento de la arquitectura defensiva de este territorio.

- Desde un pun to de vista histórico, parece aceptado que existe una planificación en la construcción de villas nuevas y repoblación de asentamientos existentes con nuevos recintos amurallados en la Extremadura Castellana. ¿Puede el análisis de los sistemas de construcción de los restos de estas murallas aportar datos que refuercen esta hipótesis? 
Las murallas en las Comunidades de Villa y Tierra de la Diócesis de Segovia en los siglos XI a XIII. Técnica y sistemas constructivos de la arquitectura defensiva medieval.

- ¿Es posible, apoyándose en el estudio de los sistemas constructivos de las murallas existentes de esta investigación, afirmar que se construyeron bajo unas mismas premisas o siguiendo un mismo sistema constructivo?

- ¿Puede el análisis constructivo aportar datos acerca de la fecha de construcción de las murallas?

- Finalmente, la forma de ejecución de los lienzos de muralla, la configuración del trazado o las características de los elementos que la integran puede arrojar luz acerca de la naturaleza de los constructores.

\subsection{Objetivos}

De forma complementaria a I as hipótesis planteadas en el anterior apartado, se enumeran a continuación los objetivos que se persiguen en esta investigación. Los primeros tres objetivos listados tienen un carácter general y tienen un enfoque patrimonial. Los objetivos siguientes son más específicos y de carácter constructivo.

- Profundizar en el estudio y el análisis de la arquitectura defensiva, concretamente en el campo constructivo. Hasta ahora el estudio de este tipo de arquitectura ha sido minoritario. Se ha producido mayoritariamente en disciplinas como la historia o arqueología. En el campo de la arquitectura, ha sido más habitual el análisis urbano de los recintos amurallados frente al constructivo.

- Buscar la revalorización de la muralla frente a otras arquitecturas fortificadas. Es habitual que la muralla quede relegada a segunda posición cuando existen fortalezas o ejemplos monumentales. La arquitectura de fortaleza monumental y ornamentada se entiende con mayor facilidad por su mayor proyección en el imaginario colectivo y consigue mayor atractivo turístico. Se ha planteado para ilustrar esa cuestión el ejemplo de la ciudad de Segovia, donde existe una muralla muy bien conservada que, sin embargo, es menos conocida y publicitada, en comparación con otros monumentos de la ciudad.

- Poner en valor las murallas existentes en el territorio estudiado como atractivo turístico dentro de la comunidad de Castilla y León. Por otro parte, la muralla se puede explotar no solo desde un punto de vista turístico. En algunos casos, es factible el empleo de la muralla como recurso urbano, aprovechando su trazado para crear un recorrido a los pies de la muralla, un eje de comunicación verde con uso peatonal o c iclista, destinado a la comunicación, al paseo o al esparcimiento.

- Describir y documentar pormenorizadamente una parte de las murallas existentes en el sur del Duero, para complementar los estudios ya realizados en Castilla y León. Identificar todos los elementos de un recinto amurallado, en ocasiones sólo los más famosos o mejor conservados están identificados 
oficialmente como tales y otros restos no $\mathrm{s}$ consideran integrantes del recinto.

- Identificar los sistemas constructivos empleados en cada recinto amurallado. Analizar detalladamente las características de los sistemas constructivos más empleados o los de mayor relevancia.

- Relacionar los recintos amurallados estudiados a través de los sistemas constructivos identificados en cada caso. Aportar mediante el análisis constructivo datos que puedan ay udar a i dentificar similitudes entre los distintos recintos.

- De acuerdo con los sistemas constructivos identificados y su uso en diferentes recintos, identificar los posibles patrones o modelos constructivos en el territorio y época estudiados. En este sentido, algunos autores (Cobos 2011, 189) son muy críticos con la idea de utilizar criterios históricos, geográficos $\mathrm{o}$ de otro tipo empleados aisladamente para establecer similitudes en un grupo de construcciones. En este caso, se ha tratado de incluir más de un criterio para llevar a cabo comparaciones. Se han empleado criterios históricos y geográficos para establecer un marco en la investigación. Aun así, se es consciente del a existencia de $r$ estos arquitectónicos pertenecientes a otras épocas en estos recintos.

- Contribuir a través del análisis constructivo de estas murallas a la identificación cronológica de su construcción. Extraer datos que permitan relacionar unas construcciones con otras de acuerdo con las características constructivas.

- Favorecer la difusión del conocimiento de la forma de construir murallas en este territorio, muy estancada con la idealización de l as fortalezas como edificios de grandes sillares.

\subsection{Estructura de la investigación}

Esta investigación se estructura en siete capítulos. El primer capítulo corresponde con esta introducción donde se tratan aspectos iniciales de la investigación: el origen de la misma o cuáles fueron los puntos de partida, dónde radica el punto de interés en esta investigación y si existe oportunidad en la elección de este tema. Se toca el estado de conservación de la arquitectura defensiva en general, se habla de cómo se encuentra el panorama legislativo en cuanto a arquitectura defensiva se refiere. Se hace una referencia breve a las restauraciones llevadas a cabo en arquitectura defensiva. En ese apartado introductorio se sitúa el marco geográfico de la investigación, detallando los límites de la misma en el territorio. También se hace referencia al marco histórico, indicando cual es la horquilla de siglos en los que se construye la arquitectura estudiada. Más adelante se dedica un apartado más exhaustivo de descripción del contexto histórico de la investigación (Capítulo 3). En este apartado introductorio se 
Las murallas en las Comunidades de Villa y Tierra de la Diócesis de Segovia en los siglos XI a XIII. Técnica y sistemas constructivos de la arquitectura defensiva medieval.

plantean también las hipótesis de la investigación. Se enumeran a c ontinuación los objetivos planteados en este estudio; en primer lugar se indican los objetivos generales y posteriormente los objetivos más específicos. Por último se explica cuáles han sido las limitaciones de esta investigación.

El segundo capítulo trata el estado de la cuestión. Se realiza un análisis de los estudios realizados hasta la fecha en este campo de investigación, detallando qué autores han trabajado en el campo de la arquitectura defensiva y bajo qué ópticas. También se han buscado menciones y referencias a la muralla como recurso defensivo en $\mathrm{f}$ uentes clásicas, con la intención de $\mathrm{r}$ esaltar la importancia de su construcción en las ciudades y su uso recurrente por parte de diferentes civilizaciones.

El tercer capítulo tiene como objeto explicar el contexto histórico de esta investigación de forma pormenorizada. La situación política, económica y social de la península ibérica en la época es un factor de importancia dentro de este estudio, porque va a permitir entender el contexto en el que estas murallas se construyeron y cómo es la sociedad que participó en su construcción y en su mantenimiento. En este sentido, la situación de frontera de este territorio, la repoblación iniciada por monarcas de forma estratégica en un contexto de guerra, la estructura social o el papel de la iglesia son realidades del marco histórico que es necesario contemplar y tener en cuenta a la hora de plantear conclusiones. Por otro lado, es una realidad que el estudio del patrimonio conecta varias disciplinas académicas y profesionales entre sí, y se hace necesario conocer los estudios de investigadores de otros campos.

El cuarto capítulo explica cuál ha sido la metodología empleada en la investigación, detalla qué herramientas se han manejado en el análisis de las murallas, qué dispositivos o programas informáticos se han empleado. También se trata el análisis de fuentes históricas, fuentes bibliográficas, se detalla la participación en c ursos, congresos o jornadas de investigación y la colaboración con centros de investigación extranjeros a través de estancias en universidades extranjeras.

El quinto capítulo reúne los casos de estudio elegidos, seis ejemplos de murallas seleccionadas dentro del territorio de la Diócesis de Segovia. Cada caso incluye una descripción general del recinto amurallado, en relación con la topografía y con la ciudad. Se realiza a continuación un análisis de los distintos elementos de la muralla como torres, puertas y lienzos, destacando los elementos singulares. En cada caso se ha procedido a un análisis de las soluciones constructivas empleadas en el recinto amurallado, con levantamientos de algunos tramos para identificar y caracterizar los elementos constructivos.

En el sexto capítulo se realiza un análisis de los resultados obtenidos en cada uno de los casos estudiados, llevando a cabo comparaciones entre sí y tratando de evaluar las relaciones que existen entre ellos.

El séptimo capítulo enumera las conclusiones que se extraen de la investigación. Se añade al final un apartado que menciona posibles líneas futuras de investigación que profundizarían o complementarían los análisis de esta. 
Tras las conclusiones se recogen las referencias bibliográficas de la investigación, que se encuentran listadas por orden alfabético. Finalmente, se adjuntan tres anexos. En el primero se incluyen las fichas realizadas de los recintos amurallados dentro de la Diócesis de S egovia y de algunas comunidades colindantes, que han servido para llevar a cabo la selección de los casos de estudio. En el anexo segundo se incluyen los datos relativos al programa informático $\mathrm{R}$ con el que se han realizado las gráficas de esta investigación. En el tercer anexo, se adjuntan igualmente datos de las características técnicas de las herramientas utilizadas.

\subsection{Limitación y precisión de la investigación}

Esta investigación tiene una serie de limitaciones que condicionan su desarrollo. Por un lado, se ha de ceñir exclusivamente a la existencia de restos de muralla en Ia actualidad. En aquellas arquitecturas que se citen en documentación histórica, pero que no existan hoy en día, será imposible realizar un anál isis constructivo. Por otro lado, el acceso a algunas edificaciones es difícil por estar valladas y encontrarse en propiedad privada, o con acceso supeditado al paso a través de propiedades privadas.

Por otro lado, el limitado apoyo económico hace imposible llevar a cabo análisis de laboratorio costosos que permitirían, por ejemplo, una datación de las muestras tomadas. En estos casos el conocido análisis de Carbono 14 no resultaría de utilidad ya que los resultados que arrojan son demasiado amplios cronológicamente; por contra, en análisis por dendrocronología, que se realiza en muestras de madera, permite conocer la fecha en la que se cortó la madera. El inconveniente de este ensayo es la dificultad de conocer si la madera empleada ha sido reutilizada o se ha cortado para la ocasión. Asimismo, hace imposible la intervención en las murallas con un sondeo arqueológico, que podría aportar información muy valiosa. Las herramientas que se han empleado para elaborar esta investigación ha sido exclusivamente la del análisis visual de la arquitectura y la interpretación del mismo a partir de dibujo analítico, fotografía, fotogrametría digital y toma de medidas.

Por otro lado, el análisis de los restos de una edificación construida hace siglos es complicado. Muchos factores intervienen y cada caso presenta particularidades que hacen compleja su relación y comparación con otros ejemplos. 



\section{2}

\section{Estado de la cuestión}

La muralla es una c onstrucción que has ido estudiada desde puntos de $v$ ista diferentes. Tiene un papel importante en el funcionamiento de las ciudades, por lo que los enfoques urbanos son habituales. La muralla y la ciudad son dos conceptos que de forma recurrente aparecen juntos, debido a la relación tan estrecha que se produce entre ellos, hasta el punto de que la presencia de la muralla condiciona la formación y el desarrollo de la ciudad. A su vez, en el campo de la arquitectura defensiva, la muralla configura una tipología arquitectónica concreta, junto con castillos y torres. Los estudios en el campo de la historia de l a construcción también afectan a estas construcciones, allí donde los restos conservados permiten analizar las técnicas constructivas empleadas. Se ha analizado la muralla desde distintas disciplinas, como la historia medieval, la arqueología, la arquitectura en su enfoque urbano, tipológico y constructivo. El factor cronológico y la civilización constructora generan otro punto de vista que se utiliza para caracterizar estas construcciones.

En este capítulo, se describe en primer lugar la visión de la muralla visible a través de las obras clásicas. En la Antigüedad se redactan textos que hablan de es tas construcciones, indicando cómo se han de construir o cuáles son las tácticas para defender la cuidad desde las murallas. También en la Edad Media se escriben obras que tratan la defensa de las ciudades o que describen una sociedad y su forma de construir. La investigación acerca de las murallas es visible en el siglo XIX a través de análisis de arquitectos, ingenieros y otros polímatas que analizan la historia de la arquitectura, y se interesan por la génesis de castillos y ciudades fortificadas. Ya en el siglo XX, los estudios acerca de la muralla en España están principalmente vinculados a la ciudad, o se analizan en un formato de inventario, agrupando varios ejemplos de esta arquitectura. El análisis constructivo de los restos de recintos amurallados se ha intensificado en I os últimos años de I a mano de es tudios de ar queología de la arquitectura, con un enfoque arqueológico y arquitectónico.

\subsection{La muralla en fuentes clásicas y tratados históricos}

\subsubsection{La muralla en las obras clásicas}

Ya en las obras clásicas se trata la arquitectura militar como una disciplina necesaria y se estudia para garantizar y mejorar la defensa de las ciudades. Leonardo Villena (1965) estudió las fuentes clásicas en busca de temas como la poliorcética y fortificación. Se remonta a la protohistoria para comentar el origen de las primeras 
Las murallas en las Comunidades de Villa y Tierra de la Diócesis de Segovia en los siglos XI a XIII. Técnica y sistemas constructivos de la arquitectura defensiva medieval.

murallas y considera las primeras torres de e stas como el arquetipo de c astillo. Atribuye a las civilizaciones mesopotámicas notables progresos en la calidad de las defensas, con constantes perfeccionamientos como torres, taludes, fosos y adarve 0 refuerzo en torno al as puertas. Indica que el adobe, con juntas de betún, es el material empleado para la construcción, aunque más tarde se usará la piedra. Habla de las ciudades griegas como hitos en el desarrollo dela fortificación y describe máquinas de guerra como el escorpión, que se emplea para arrancar las almenas de las murallas y hacer agujeros. Comenta algunos textos romanos que tratan la poliorcética y también se refiere a textos bizantinos y árabes, así como a la técnica medieval europea y los manuscritos de la época bajomedieval. Habla de la expansión de la artillería y delos cambios que esta técnica produjo en las construcciones defensivas. Finalmente menciona los textos modernos que desarrollaron esta arquitectura.

Se han c onsultado algunas de las fuentes que menciona este autor, para extraer ciertas menciones que se hacen de la muralla. Eneas el Táctico, en el siglo IV a.C, escribió un tratado en el que explica cómo defender una ciudad amurallada desde un punto de vista militar. Habla de cómo han de defenderse las puertas y de qué guardas han de apostarse en el las. También define la forma de realizar rondas al pie de la muralla. Dedica un capítulo a la defensa de las puertas en caso de ataque, indicando que todas las puertas han de cerrarse excepto una, que deberá tener un postigo que permita entrar y salir a los hombres de uno en uno. Hace referencia a las máquinas que sirven para repeler asaltos y a las maneras de protegerse del lanzamiento de objetos por encima de las murallas. Plantea soluciones cuando la muralla es perforada o destruida, como hacer fosos o grandes fuegos. Los traductores de esta obra hacen referencias a ot ros autores de la época como Herodoto o T ucídides que también hablan de la defensa de las ciudades amuralladas. Estos textos demuestran por un lado la antigüedad de la muralla como recurso defensivo y por otro su eficacia, ya que se sigue empleando durante siglos.

Leonardo Villena $(1965,157)$ también menciona los diez libros de la arquitectura de Vitrubio, el tratadista romano del siglo I a.C. que recoge, ya en el Libro Primero, en el Capítulo $\mathrm{V}^{11}$, cómo han de construirse las murallas y torres para que tengan gran resistencia. Se habla de la búsqueda de suelo firme y de una anchura superior de la cimentación frente a la de la muralla. Se habla de que las torres "volarán hacia fuera de los muros (...) para que el enemigo pueda ser ofendido por las troneras de las torres". Indica igualmente que las ciudades "no deben ser cuadradas (...) sino a la redonda". Define la anchura del muro como suficiente para el paso de dos hombres armados. Detalla que en la construcción de las murallas deberán meterse "espesos leños o trozos de olivo tostados" que sirvan de atado de las dos caras de los muros. Define también la distancia entre torres, no mayor que el alcance de un tiro de flecha, o la adición de terraplenes a las torres para que resistan cualquier ataque de ariete 0 minas. Se plantea como algo necesario la construcción de un foso ancho y profundo.

\footnotetext{
${ }^{11}$ Se ha consultado el ejemplar Los diez libros de arquitectura de M. Vitruvio Polion traducidos del latín, y comentados por don Joseph Ortíz y Sanz, del año 1787, editado en Madrid por la Imprenta Real. Fuente: Biblioteca Digital Hispánica de la Biblioteca Nacional de E spaña http://bdhrd.bne.es/viewer.vm?id=0000012956\&page $=54$ [Consultado el 18/2/2016]
} 
No determina un material concreto para la construcción, entendiendo que dependerá de cada caso.

En la obra Historia natural de Plinio el Viejo, del siglo I, también se hacen referencias a la construcción de murallas. En los libros de Mineralogía, se habla del uso de la tierra en la construcción y también de la arquitectura. En la traducción al francés de Émile Littré $(1870,490)$ se puede leer la referencia a la utilización de la tierra como sistema de construcción de murallas en África y España. Se indica que es un sistema muy resistente, que dura siglos, y que es inmune a las inclemencias del tiempo. Para la construcción, indica que se ha de echar tierra entre dos paredes de madera que funcionan como molde. No se hace referencia expresa a los bloques de tapia tal y como se conocen hoy en día, construidos uno tras otro en fábrica trabada. Se habla de la existencia de torres construidas con tierra visibles en lo alto de las montañas del paisaje español. Habla también de los taludes que se construyen para fortificar los campamentos y de los diques que se edifican en los ríos e indica que se construyen con este sistema. Al final de este apartado menciona paredes de madera revestidas de arcilla y de muros construidos con ladrillos crudos.

\begin{abstract}
“Hé quoi! n'y a-t-il pas en Afrique et en Espagne des murailles de terre, dites murailles de forme, parce qu'on les jette en moule entre deux parois, plutôt qu'on ne les construit? Elles durent pendant des siècles, inattaquables à la pluie, au vent, au feu, et plus solide que tous les ciments. L'Espagne voit encore les guérites d'Annibal et les tours de terre placées sur le sommet des montagnes. Les glacis qu'on emploie pour fortifier les camps et les digues qu'on oppose à l'impétuosité des fleuves sont aussi de cette manière. Qui ne sait que des parois en bois sont crépies en argile, et que des murs sont construits en brique crue?" [Libro XXXV, Apartado XLVIIII ${ }^{12}$
\end{abstract}

Más adelante, en el apartado XLIX del mismo libro, se menciona el uso del ladrillo; no se hace referencia alguna a la cocción, por lo que se interpreta que se refiere al ladrillo de tierra cruda, el adobe. El autor indica qué tipo de tierra ha de emplearse para su fabricación, expresando su rechazo por tierras pedregosas o arenosas, y recomendando el uso de tierra de gr eda, más arcillosa. También refiere que la primavera es la mejor estación para darles forma, ya que en verano se agrietan. Indica que se emplean en la construcción de edificios después de pasados dos años. Habla de tres tipos de ladrillo en función de sus dimensiones, el primero es el que utilizan los romanos, con un pie y medio de longitud, y un pie de ancho. Los dos siguientes son los utilizados por los griegos, de cuatro y cinco palmos tanto de longitud como de anchura. El de cinco palmos se emplea en las construcciones públicas y palacios, revestidos $u$ ocultos posteriormente con piedra. Menciona que en Roma no se construye así ya que un muro de espesor de un pie y medio no soportaría el peso de

\footnotetext{
${ }^{12}$ Traducción al castellano (A. Sainz): ¡Eh! ¿Qué pasa? ¿Acaso no hay en África y en España murallas de tierra, llamadas murallas de forma, porque se las echa en un molde entre dos paredes, en lugar de construirlas? Duran siglos, resistentes a la lluvia, al viento, al fuego, y son más sólidas que cualquier cemento. En España se ven todavía garitas de Aníbal y las torres de tierra situadas en la cima de las montañas. El talud que se emplea para fortificar los campamentos y las presas que se oponen a la impetuosidad de los ríos se hacen también de esta manera. ¿Quién no sabe que las paredes de madera se revisten con arcilla y que los muros se construyen con ladrillo crudo?
} 
más de una planta; explica que no se puede superar ese grosor y se refiere a unas reglas de muros medianeros que limitan el espesor de los mismos. Establece que las murallas de ladrillo duran eternamente.



Fig. 2.1 Las murallas según la descripción de Vitrubio, por José Ortiz y J. Joaquín Fabregat. Fuente: Biblioteca Nacional de España. http://bdh-

rd.bne.es/viewer.vm?id=0000012956\&page $=32$ 1 [Consultado el 18/2/2016]



Fig. 2.2 Portada de la obra Historia Natural de Plinio el viejo, traducida por Émile Littré en 1870. Fuente: Biblioteca Nacional de Francia.

http://gallica.bnf.fr/ark:/12148/bpt6k282082c/f 4 [Consultado el 24/2/2016]

De re militari de Vegecio, del siglo IV d.C, tiene una aproximación a la cuestión desde el punto de vista de la batalla, del ataque a una ciudad con un ejército y de la defensa de la ciudad cuando es asediada. En la traducción al castellano de Antonio Duarte, Jorge Mambrilla y Alfonso Rodríguez (2004) se pueden ver varias referencias a la muralla, desde la construcción de un rudimentario atrincheramiento para el campamento de un ejército, hasta la forma de derruirlas con minas. En el libro IV, y Capítulo I, habla de la importancia de conjugar las ventajas naturales con las de rodearse de torres y muralla para conseguir la mejor defensa. Al igual que Vitrubio, defiende las ventajas de una muralla con ángulos y torres en lugar de en línea (Libro IV, Capítulo II). Indica que la tierra extraída para la construcción del foso ha de emplearse en la construcción de la muralla, a modo de relleno compactado entre dos muros construidos en paralelo. Establece que estos muros han de $s$ er de diferente altura, más bajo el muro interno, para permitir construir una pendi ente suave que permita acceder desde el interior a las defensas (Libro IV, Capítulo III). Indica que las puertas han de estar provistas de matacanes para poder lanzar agua en caso de que se incendien (Libro IV, Capítulo IV). También apunta que las murallas deben estar dotadas de garitas para permitir una vigilancia continuada y no verse sorprendidos por el enemigo (Libro IV, Capítulo XXVI). 
En el capítulo "Estado de la Cuestión" de la tesis doctoral de Ignacio J. Gil Crespo $(2013,49)$, se hace referencia al historiador bizantino Procopio, del siglo VI, y a su obra Los edificios; se menciona la importancia que tiene para el conocimiento de la construcción bizantina. En la traducción de la obra por parte de Miguel Periago (2003), la reconstrucción de murallas en diversas ciudades aparece mencionada a lo largo de esta crónica, que ensalza la calidad y resistencia de las construcciones reparadas y reforzadas por el emperador Justiniano. Se describe en det alle las mejoras y reparaciones que acomete (50), como en la muralla de la ciudad de Dara, donde "ideó la adición de un realce de unos treinta pies al recinto defensivo, sin levantarlo sobre todo el grosor del muro, para que no resultara algún perjuicio insoportable a la obra, al estar sobrecargados los cimientos por el exceso de peso que se les echaba encima, sino que recubriendo el espacio que allí quedaba con un aporte externo de piedras, construyó un pórtico que daba la vuelta a todo el recinto, añadiéndole defensas al pórtico, de modo que el muro tenía, en su totalidad, una cubierta doble, y en las torres había también tres pisos destinados a los que defendían el recinto y rechazaban los ataques"



Fig. 2.3 Imagen de un ejemplar de De re militari de Vegecio, edición del siglo XV. Fuente: Biblioteca Nacional de España. http://bdh.bne.es/bnesearch/detalle/bdh00000 96078 [Consultado el 18/2/2016]


Fig. 2.4 Fragmento de la obra De Aedificiis de Procopio, transcrita por Claude Maltret en 1662. Fuente: Biblioteca Nacional de Francia. http://gallica.bnf.fr/ark:/12148/bpt6k5774214k/f 72.item [Consultado el 18/2/2016]

Muchas otras menciones se encuentran en esta obra, que detallan soluciones constructivas aplicadas en la reparación de murallas existentes, o en la construcción de nuevas fortificaciones. Se detallan, por ejemplo, la reparación de torres empleando la piedra de las muelas de molino o el aprovechamiento del río Éufrates como defensa natural (57). Se habla de murallas en ciudades cuyas fábricas eran deficientes por estar construidas sólo con adobe (62) y que son reforzadas. Para la ciudad de 
Martirópolis (70), se define la construcción de un segundo muro, separado cuatro pies del primero y con un grosor similar, con el objeto de rellenar con piedras y mortero y obtener un muro de 12 pies de grosor. Para la ciudad de Capadocia (101), detalla la construcción de una muralla que abarcó una gran extensión de terreno, con el objeto de incluir unas colinas que suponían un peligro para la seguridad de la ciudad. En ese recinto cercó campos, huertos, roquedales y pastizales para los ganados. Explica que este recinto quedó vacío e inseguro al ser tan extenso y hubo que reducirlo.

El texto de P rocopio transmite la gran importancia de I as murallas en la época, atribuyéndole a la solidez de las mismas la prosperidad de las ciudades. También se trasluce una cultura estética que requiere de la muralla como ingrediente necesario para la belleza de la ciudad. La propaganda que recibe el emperador Justiniano se hace asignándole la capacidad de as egurar las ciudades a través de una muralla sólida y resistente.

\subsubsection{La muralla en las fuentes medievales}

Durante la Edad Media, se escribieron obras que trataban la cuestión de la guerra y la defensa. Se conservan algunas de estas obras, pero muchas de ellas se han perdido. En las crónicas de algunos reyes o las partidas que algunos de ellos redactaron, se incluyen también recomendaciones y normas para mejorar la defensa de una ciudad, o para construir edificios defensivos. Ignacio J. Gil Crespo $(2013,49-50)$ hace referencia a algunas fuentes medievales del siglo $\mathrm{x}$, como el tratado militar De veliatione, del emperador Nicéforo Phocas, traducido al francés por Dagron como Traité sur la guérilla, y menciona otros textos que hablan de la construcción de fortificaciones o de las técnicas de guerra, escritos por personajes religiosos, eruditos o monarcas. En el siglo XIII, Villard de Honnecourt escribe un manuscrito del que se conservan varios dibujos que representan máquinas de guerra, caballeros o construcciones fortificadas.



Fig. 2.5 Representación de una puerta en un recinto o edificio amurallado. Manuscrito de Villard de Honnecourt del siglo XIII, lámina 38. Fuente: Biblioteca Nacional de Francia. http://gallica.bnf.fr/ark:/12148/btv1b10509412z/f38 [Consultado el 23/2/2016]



Fig. 2.6 Detalle que muestra una ciudad fortificada. Manuscrito de Villard de Honnecourt del siglo XIII, lámina 9 Fuente: Biblioteca Nacional de Francia.

http://gallica.bnf.fr/ark:/12148/btv1b10509412z/f9 [Consultado el 23/2/2016] 
Algunas fuentes árabes que se conservan ofrecen una visión de la construcción de la época. Los Muqaddima de Ibn Jaldún, escritos en 1377, se dividen en 6 capítulos que tratan temas como la civilización humana en general, los pueblos sedentarios y nómadas, la política, las ciudades y los países, la economía, las artes y las distintas ciencias. En el capítulo $\mathrm{V}$, apartado $24^{13}$, habla del arte de la arquitectura y de la forma de construir casas para refugiarse. Hace referencia a la necesidad de construir una muralla que rodee un asentamiento, para protegerse de ataques y peligros. Ese conjunto lo denomina ciudad e indica que está custodiada por un grupo de autoridad. Explica que este grupo construye castillos y fortalezas para protegerse desde los que dictan normas. Habla de las diferentes formas de construir en cada ciudad, cambiantes en función del clima y de las condiciones de los habitantes. Describe del uso de castillo como vivienda, construido en piedra, amueblado y decorado al máximo, con sótanos para almacenar alimento y establos; y como extremo opuesto describe la vivienda modesta. Explica que la arquitectura es necesaria para la construcción de monumentos y señala que las personas poderosas se esfuerzan en c onstruir buscando la perfección.

Describe varias técnicas de construcción, donde se emplean materiales como la piedra o el ladrillo, firmemente unidos a través de arcilla y cal viva. Describe la tierra como material de construcción en sí mismo y explica la técnica de la tapia o tabiyah. Indica que se usan dos tableros de madera de di mensión variable de ac uerdo con la costumbre local, y plantea cuatro por dos codos como una di mensión media. Se colocan sobre una cimentación y la distancia entre ellos depende del espesor que el constructor haya considerado apropiado para la cimentación. Se unen entre sí con piezas de madera sujetas con cuerdas. Los dos lados restantes entre los tableros se cierran con otros tableros pequeños. Después se rellena el molde con tierra y cal viva, y se golpea la mezcla con herramientas especiales hasta conseguir la mezcla completa. Se añade tierra una segunda y tercera vez hasta que se llena el molde. La mezcla de tierra y la cal viva han formado una sola materia. Explica que este proceso se repite hasta conseguir el muro completo.

Otra técnica que describe es la aplicación de cal en muros, indicando que se diluye la cal en ag ua y se deja reposar una o dos semanas, dependiendo del resultado deseado, y se comienza a aplicar en el muro por la parte superior, frotándolo hasta que adquiera una textura pegajosa. Describe la realización de cubiertas de madera, en la que se colocan vigas de madera apoyadas sobre dos muros, sobre las que se colocan tableros de madera que se unen con clavos. Sobre esta base se vierte tierra y cal viva, y se mezcla. Se cubre con cal viva, de la misma manera que los muros. Describe la ornamentación como una técnica de construcción, en la que se mezcla yeso con agua para formar figuras simétricas. También habla del empleo de mármol, ladrillo arcilla, conchas o azabache para decorar los muros.

A lo largo de la obra se menciona la muralla como construcción en varias ocasiones, describiendo la protección que brinda al as poblaciones sedentarias (Capítulo II, apartado 5), que pueden evitar ser atacadas por sorpresa (Capítulo II, apartado 7). Habla de que las murallas se amplían para abarcar el crecimiento de las ciudades.

\footnotetext{
${ }^{13}$ Se ha consultado la traducción de Franz Rosenthal (1967).
} 
Las murallas en las Comunidades de Villa y Tierra de la Diócesis de Segovia en los siglos XI a XIII.

Técnica y sistemas constructivos de la arquitectura defensiva medieval.

Cuando habla de la planificación de las ciudades, indica que se ha de situar la ciudad en un lugar inaccesible, sobre una accidentada colina o junto a un río, donde sea necesario acceder a través de un puente; indica que las casas han de estar protegidas por la muralla (Capítulo IV, apartado 5).

Otros contenidos encontrados en las fuentes clásicas son las formas de construir las distintas edificaciones. Rafael Cómez (2009) recopila en Los constructores de la España medieval, diversas técnicas presentes en la península ibérica, describiendo los alarifes de al-Ándalus y los maestros constructores de la España cristiana. Se apoya en fuentes históricas y tratados de construcción para ilustrar las técnicas empleadas.

La aparición de la artillería produjo un cambio en las técnicas de defensa y en la forma de las construcciones defensivas. Al parecer, durante los siglos XII y XIII existe algún indicio de uso de artillería, aunque con seguridad se usó en el siglo XIV (Villena 1965, 174). Fernando Cobos $(2007,234)$ puntualiza que la artillería de pólvora comenzó a ser superior a las defensas a partir de mediados del siglo XV. En algunos tratados del siglo XV se explican soluciones constructivas frente a la artillería. En la publicación Tratado de arquitectura y urbanismo militar de Alberto Durero, editada por Juan L. González García (2004), se hace referencia a las lecciones de este autor sobre la fortificación de ciudades en 1572. Se habla de la construcción de bastiones para la defensa de grandes ciudades, de cómo fortificar una ciudad de antigua fundación o cual es el diseño y montaje idóneo del os cañones defensivos. El tratado de fortificación de Cristóbal Rojas (1598) responde a premisas similares y describe cómo fortificar a través del empleo de la geometría. También son conocidas las propuestas de fortificación del mariscal Vauban durante el siglo XVII que desarrolló varios sistemas de defensa, aunando los aciertos de sus precursores y creando nuevas soluciones, como el diseño de las dos murallas concéntricas. Esta solución permite controlar la acción bélica más lejana con la muralla externa y, a la vez, atacar al enemigo desde la muralla interna mientras trata de superar la externa (Gutiérrez 1991, 6-8).

\subsubsection{El estudio de la muralla durante el siglo XIX}

Los autores franceses analizaron, durante el siglo XIX, los castillos medievales en Francia. Viollet-le-Duc escribe en $1854 \mathrm{~s}$ u obra Essai sur l'architecture militaire au Moyen-Âge donde aparecen numerosas menciones al a muralla como elemento defensivo. Se hace referencia a distintas técnicas para mejorar la resistencia de las torres y lienzos de muralla, y se reflexiona acerca de cómo se producían los asaltos y asedios a las ciudades amuralladas.

Auguste Choisy, en su obra de Histoire de l'Architecture de 1899 no contempla un capítulo concreto de ar quitectura defensiva para cada una de I as civilizaciones que analiza, aunque se hacen menciones aisladas respecto a la forma de construir lienzos de acuerdo con los romanos, a modo de ejemplo. 




Fig. 2.7 Representación de una torre de la muralla de Carcassonne, Francia (Viollet-le-Duc 1888, 3). Fuente: Biblioteca Nacional de Francia. http://gallica.bnf.fr/ark:/12148/bpt6k204053b/f6 [Consultado el 22/2/2016]



Fig. 2.8 Representación de la batalla frente a las murallas (Viollet-le-Duc 1854, 187). Fuente: Biblioteca Nacional de Francia.

http://gallica.bnf.fr/ark:/12148/bpt6k165547k/f19

1 [Consultado el 22/2/2016]

Además de los documentos escritos, la muralla ha quedado reflejada en los planos de las ciudades, donde se representaba la ciudad por razones políticas o económicas. En la ciudad francesa de Cahors (Fig. 2.9), se puede ver una gran extensión de territorio amurallado. En la zona derecha del plano se ven las murallas que cierran por el norte el meandro que forma el río Lot. El plano data de 1840 y puede dar una idea de lo que sería una ciudad amurallada que incluye grandes espacios para el cultivo, grandes áreas sin edificar. Las ciudades de este estudio no tienen una extensión tan importante ni una relación directa con Cahors, sin embargo, dada la ausencia de planos o dibujos históricos de villas como las que se estudian en esta investigación, puede servir de ejemplo para conocer el aspecto de una ciudad cuyas murallas incluyen territorios de cultivo. 




Fig. 2.9 Plano de Cahors que ilustra la situación de la ciudad en 1840, se observan campos de cultivo dentro del recinto amurallado. Las murallas que cierra en la zona este del plano, les remparts de la Barre, todavía se conservan en la actualidad. Fuente: Biblioteca Nacional de Francia.

http://gallica.bnf.fr/ark:/12148/btv1b8440116c/ [Consultado el 5/10/2015]

\subsubsection{Tratados de arquitectura y construcción}

A lo largo del siglo XIX, desde un punto de vista constructivo, se elaboraron varios tratados de arquitectura y construcción ${ }^{14}$. Describen técnicas constructivas tradicionales que buscan transmitir la forma de construir correctamente. Algunas de estas técnicas se han empleado en la época medieval y conocer su descripción en el siglo XIX puede servir de ayuda para identificarlas en murallas medievales. En Arte de albañilería de Juan de Villanueva (1827) se quiere enseñar al joven albañil las técnicas de construcción más útiles y la forma de ejecutarlas correctamente. Se explica cuáles son las herramientas del albañil, cómo se ejecuta la tapia de tierra, se habla del uso de la piedra, de la cal y arena, del ladrillo, de la construcción de ar cos, cornisas, particiones interiores, tejados y cubiertas, acabados constructivos, y se describe la construcción de andamios y el uso de máquinas. Para justificar el uso de la tierra como material de construcción, se hace referencia a la antigüedad de las murallas que se veían en España (Capítulo II), que emplean este sistema de construcción. El Manual del Ingeniero, de Nicolás Valdés (1859), tiene un perfil más técnico, tratando en sus primeros capítulos cuestiones matemáticas y mecánicas. El capítulo VI se dedica a las

\footnotetext{
${ }^{14}$ La página web de la Sociedad Española de Historia de la Construcción reúne varias decenas de tratados de esta índole, que datan del siglo XV al XX.

http://www.sedhc.es/biblioteca/tratados.php [Consultado el 16/03/2016]
} 
construcciones, donde describe los materiales y su resistencia. En el apartado de mampostería (685-688) describe las técnicas constructivas para realizar muros, entre ellas, la tapia. Florencio Ger y Lobez $(1898,196-197)$ hace referencia a las murallas en la península ibérica al hablar del a tapia, sistema constructivo que des cribe detalladamente y al que atribuye gran resistencia.

Poco antes de la entrada del siglo XIX, tiene especial interés el manual École d'architecture rurale, de Cointeraux (1793) que se compone de cuatro cuadernos. El primero, habla de cómo construir sólidamente una casa de varias plantas, empleando la técnica del tapial. El segundo cuaderno trata de la calidad de l a tierra para la construcción, de la mano de obra y de lo que denomina el autor como nouveau pisé. El cuarto cuaderno, habla del nouveau pisé y de las ventajas de su empleo como material de construcción.

\subsection{La arquitectura defensiva medieval en España a partir del siglo XX}

A lo largo del siglo $\mathrm{XX}$, el estudio centrado en castillos medievales predomina sobre cualquier otra construcción defensiva, como las torres aisladas o la muralla, estudiada habitualmente en contextos urbanos. Durante la primera mitad de este siglo, se realizaron estudios acerca de los castillos de la geografía española. Federico C. Sainz de Robles (1952 [1932]) publica Castillos en España donde realiza una descripción histórica de en torno a 90 castillos, y adjunta láminas con dibujos y fotografías de muchos de ellos. Castillos de España (1982 [1932]), de Carlos Sarthou Carreres es otro ejemplo de estudio de castillos en esta época, con levantamientos en planta de muchos de el los. La bibliografía de es ta época se centra más intensamente en la figura del castillo, con una voluntad de documentar los castillos existentes y, a la vez, con la intención de denunciar su estado de abandono.

La arquitectura defensiva también aparece citada en las obras que analizan la arquitectura civil o la historia de la arquitectura en general. La obra Arquitectura Civil Española de los siglos I a XVIII de Vicente Lampérez y Romea, publicada en 1922, habla de castillos, palacios, puentes y analiza las puertas de murallas representativas, analizando algunos casos más en detalle y mencionando otros a modo de recopilatorio de ejemplos. Chueca Goitia (2001 [1964]) dedica en su obra de Historia de la arquitectura un capítulo a la "arquitectura mudéjar civil y militar" (513), donde recoge ejemplos de $\mathrm{m}$ urallas de varias ciudades. También incluye un capítulo de l a "arquitectura militar de la época gótica" (641) donde describe y documenta una serie de castillos. En la publicación de B ernard Bevan (2012, 201-220) Historia de la arquitectura española: del Imperio Romano a la llustración, el estudio de la muralla se engloba dentro del capítulo XIII "Castillos", donde se mencionan las murallas de Berlanga, Ávila o Daroca, entre otras.

En la segunda mitad del siglo $X X$, se publican numerosos estudios que hablan del castillo medieval bajo distintas perspectivas. Se estudian en función de su tipología, su cronología, el lugar donde se asientan o también se analizan de forma aislada, como monumento donde existen partes primigenias, añadidos posteriores, remodelaciones y restauraciones. En Castilla y León se publica, en la década de los 50, Castillos en 
Las murallas en las Comunidades de Villa y Tierra de la Diócesis de Segovia en los siglos XI a XIII. Técnica y sistemas constructivos de la arquitectura defensiva medieval.

Castilla: estampas comentadas, que reunió el Conde de Gamazo (1958), donde se realizan varios recorridos que incluyen grupos de castillos, que se documentan con una descripción y fotografías. En el caso de Coca, se observa en las fotografías la imagen de la muralla de Coca (Lámina XXXVI) y en el caso de O Imedo se muestra una fotografía de par te de I as murallas (Lámina XXXIII). Otro ejemplo de es tos estudios es el que realiza Edward Cooper (1981) acerca de los castillos señoriales del reino de Castilla, durante los siglos XV y XVI, donde identifica cada uno de ellos y lo documenta con fotografías y levantamientos. En la zona andaluza, Antonio Malpica Cuello $(1996,1998)$ recoge en Poblamiento y castillos en Granada los castillos de alÁndalus e incluye un catálogo donde documenta algunas de estas construcciones. En Los castillos en al-Ándalus y la organización del territorio, se realiza un recorrido por los castillos andalusíes, de acuerdo con los distintos periodos históricos.

En la provincia de B urgos, Gonzalo Miguel Ojeda (1960) realiza un inventario en Torres y castillos burgaleses de donde se hace un listado de cada uno de los casos con una br eve descripción. La publicación de Juan Espinosa (1974) Corpus de castillos medievales de Castilla también reúne la descripción y fotografías de castillos medievales, denunciando su mal estado de conservación. En Castillos y murallas de Valladolid, de Feder ico Carrascal (1976), se tratan 22 castillos de la provincia, con descripciones y fotografías. En Castilla-La Mancha, Antonio Herrera (1989) realiza una descripción de los castillos y fortalezas existentes en cada una de las provincias de la región. El libro de Carlos de la Casa (1990) Castillos de Soria hace un recopilatorio de los castillos de la provincia de Soria. Otro ejemplo de estas características es Castillos de Castilla: Valladolid, donde Ángel Blasco (1996) reúne los castillos de la provincia, con fotos y descripciones y propone una ruta para su visita, con un afán de difusión y de reconocimiento de su valor patrimonial. Carlos Martín Jiménez (2003) elabora una guía con rutas para conocer los castillos de la región. La Guía de la ruta de las fortificaciones de frontera: Salamanca, de J avier de C astro (2001) junto con otros autores, recorre la frontera con Portugal poniendo en valor las fortificaciones de Ciudad Rodrigo, San Felices de los Gallegos, Aldea de Obispo y Yecla de Yeltes.

Tomás Mañanes y Felipe Valbuena realizan, en 1977, un estudio acerca de torres y fortalezas de la zona sur del Duero, en la provincia de Valladolid, donde recogen un catálogo de estas construcciones, acompañadas de una descripción de cada una de ellas y documentación fotográfica. Estos autores junto con José L. Alonso Ponga reúnen en la publicación $L a$ arquitectura militar de la frontera del reino de León con el de Castilla, en lo siglos XII y XIII, del año 1980, los recintos amurallados o castillos existentes en di stintas localidades de las provincias de Salamanca, Valladolid y Zamora, que tuvieron un papel en la frontera de estos reinos.

Fernando Cobos realiza varias publicaciones relacionadas con la arquitectura fortificada en Castilla y León. La publicación Castillos y Fortalezas en 1998 recoge las fortalezas de I a comunidad mejor conservadas, agrupadas en $\mathrm{C}$ astillos-Palacio, clasificadas por señoríos o por pertenecer al estilo conocido como "Escuela de Valladolid". Describe la importancia de la artillería en el diseño de las fortificaciones y acompaña las descripciones con levantamientos arquitectónicos y documentación fotográfica. La publicación Metodología, valoración y criterios de intervención en la 
arquitectura fortificada de Castilla y León, en el año 2011, propone un sistema de identificación este tipo de arquitectura y adjunta un catálogo de las provincias de León, Salamanca, Valladolid y Zamora. Resulta de gran interés la publicación Castros y recintos de la frontera de León en los siglos XII y XIII, del año 2012, donde se analizan las fortificaciones construidas con tapia de cal y canto o con mampostería encofrada en esta región de frontera entre reinos. A través de este estudio se ponen en relación varios núcleos fortificados que se construyen de una forma similar. Se hace hincapié en la necesidad de estudiar esta arquitectura con precaución, sin sacar conclusiones precipitadas en función de un solo aspecto, sea histórico o de otra índole. La frontera de Portugal también ha sido estudiada por Fernando Cobos y João Campos (2013), describiendo paralelamente las ciudades de Almeida y Ciudad Rodrigo.

Se han r ealizado publicaciones a modo de inventario de arquitectura defensiva en zonas geográficas concretas. En la tesis de Ignacio J. Gil Crespo (2013), se estudian las construcciones defensivas de la provincia de Soria. El periodo histórico abarcado es desde el siglo XII al XV, durante el enfrentamiento entre el reino de Castilla y la Corona de A ragón en ese territorio. Se localizan y documentan las fortalezas y construcciones militares que se construyeron durante la lucha fronteriza entre los dos reinos, que suman una treintena de ejemplos. Se han realizado comparaciones de estos ejemplos, teniendo en cuenta factores arquitectónicos, de la poliorcética y las técnicas constructivas empleadas, dentro del ámbito temporal de c ada uno de los casos. Se ha extraído un total de tres casos de estudio, sobre los que se ha realizado un análisis constructivo más exhaustivo.

Las torres aisladas son otro ejemplo de arquitectura defensiva que se ha investigado en menor medida, y que en la última década ha sido objeto de varios estudios. La tesis de Elena Merino (2011), realizada en I a Universidad de V alladolid, trata las torres medievales existentes en la zona de la baja Moraña, en Ávila, con el estudio de siete casos. Para cada uno de ellos realiza un análisis constructivo de las fachadas, con un levantamiento detallado; también se estudia la configuración interior y se detallan los materiales y técnicas constructivas empleadas. Finalmente pone en relación los rasgos comunes de todas las torres, y aunque refiere muchas similitudes, destaca la disparidad de tamaños. En esta misma línea, se han hecho estudios acerca de torres de tierra en Castilla y León (Fernández, San José, Sánchez Rivera 2014), donde se analiza el recubrimiento de la torre de tierra original con material cerámico. En la zona valenciana, destaca la tesis de Pablo Rodríguez Navarro (2008), acerca de la torre árabe. El estudio se realiza sobre una veintena de torres que rodean la ciudad de Valencia y contempla aspectos formales, de tipología arquitectónica, de acuerdo con la técnica constructiva empleada y teniendo en cuenta la implantación de las torres en el territorio. En el año 2015 se han realizado estudios sobre una torre valenciana de Benifaio en los que participa este autor. Santiago Quesada y José García-Pulido (2013), de I a Universidad de G ranada, realizan un es tudio sobre torres aisladas construidas con tierra en el valle del Segura, que incluye un levantamiento fotogramétrico de las mismas. En un contexto más urbano se sitúan los análisis de Ana Escobar (2014) de las casas torre en la ciudad de Segovia. 
Las murallas en las Comunidades de Villa y Tierra de la Diócesis de Segovia en los siglos XI a XIII.

Técnica y sistemas constructivos de la arquitectura defensiva medieval.

En los últimos años, el castillo continúa siendo objeto de anál isis; entre las últimas publicaciones, se encuentran Castillos de las fronteras, edición digital coordinada por Consuelo Escribano (2012), que describe los castillos que se construyeron en Ias fronteras entre reinos dentro de la comunidad de Castilla y León. Roberto de Pablo (2014) estudia el castillo de Berlanga de Duero, en Soria, así como la muralla que lo rodea. Edward Cooper (2014) ha realizado una publicación recientemente acerca de La fortificación de España en los siglos XIII y XIV; en la introducción, ha recuperado un fragmento escrito por Torres Balbás en los años 50, en el que denuncia la escasa atención que se ha prestado a castillos y restos de cercas.

\subsection{Estudios de las murallas medievales en España}

En este apartado se ha tratado de clasificar los estudios realizados en función de la disciplina de los investigadores, que suele tener un enfoque similar. Esta clasificación no es sencilla, puesto que aunque se estudie con ópticas diferentes, se están estudiando en muchos casos los mismos aspectos, obteniéndose resultados que son complementarios. Por otra parte cada característica de la muralla sea formal, estructural, constructiva, urbana, social o hi stórica es susceptible de ser estudiada desde diferentes ópticas, de forma que algunas de las investigaciones mencionadas aquí podrían pertenecer a distintos apartados.

\subsubsection{El estudio historiográfico de la muralla}

En el campo de la arquitectura fortificada o militar, la muralla no ha estado habitualmente en una pos ición principal; estos términos parecen y suelen hacer referencia al castillo y sus defensas. En el año $2006 \mathrm{~s}$ e consolida la expresión "arquitectura defensiva" para designar toda esta arquitectura. Hasta esta fecha, se empleaban habitualmente otros términos, como arquitectura fortificada o castellología, que se refieren más directamente al castillo o al fuerte. En esta línea, no es tan habitual encontrar publicaciones monográficas acerca de $\mathrm{m}$ urallas, como se han enumerado anteriormente acerca de castillos. Murallas de España, de Jorge Jiménez (1993) es una de las escasas publicaciones de este tipo, cuyo objetivo es sensibilizar y mostrar su valor patrimonial, a través de la difusión de imágenes de una selección de recintos amurallados españoles. Este libro se compone de 45 ej emplos de ciudades amuralladas de la geografía española, entre las que se encuentra Fuentidueña, en Segovia. Cada una de ellas está documentada con fotografías, planos y una descripción general.

La muralla de Ávila también se analiza en varias publicaciones de José L. Gutiérrez Robledo $(2007,2009)$ a través de artículos en congresos o por medio de publicaciones como Las murallas de Ávila: arquitectura e historia que aborda su estudio con un análisis histórico y arquitectónico, representando la muralla a través de levantamientos y análisis formales. Esta muralla ha sido estudiada con un punto de vista historiográfico, con un interés por su construcción (González de la Granja 2010). 
El derribo de las murallas de Cádiz, de Juan M. Suárez (1999), es otra forma de aproximarse a l a muralla en l a ciudad, en un a crónica que narra el proceso de destrucción de la muralla de una ciudad, el uso de los nuevos espacios vacíos y los problemas que surgieron por la gestión de escombros y por la propiedad de las zonas antiguamente ocupadas por la muralla.

En el campo de la Historia del Arte, Castillos, fortificaciones y recintos amurallados de la comunidad de Madrid, realizado por Alicia Cámara y Javier Gutiérrez (1993) es una publicación que describe las fortificaciones y también los recintos amurallados de esta región geográfica. Arquitectura fortificada de la provincia de Burgos (Cadiñanos 1987), presenta su portada con el plano del recinto amurallado de Aranda de Duero de 1503, y describe esta arquitectura detallando sus tipologías y su función. En Las murallas de Zamora, de Guadalupe Ramos (1978), se describe el trazado de I a muralla, los materiales empleados, y se explica de forma especial las características de cada una de sus puertas.

Luis Cervera Vera $(1980,1989,1993)$ ha llevado a cabo varios estudios que tratan las murallas de Urueña (Valladolid), Madrigal de las Altas Torres (Ávila) o las de Lerma (Burgos) con descripciones históricas y formales de los conjuntos amurallados.

\subsubsection{El estudio de la muralla con enfoque arquitectónico}

\subsubsection{La dimensión urbana de la muralla}

La muralla ha sido analizada durante el siglo XX de forma muy vinculada a la ciudad, centrándose sobre todo en el análisis de su trazado, la evolución de las calles y el parcelario en función de la preexistencia de una muralla. También se han analizado los accesos a través de sus puertas que condicionan la formación y la configuración de la ciudad. El análisis parcial de la muralla, destacando el estudio de puertas y torres, se ha producido también.

La muralla ha sido estudiada como elemento indisociable de la ciudad medieval. En los estudios acerca de la ciudad medieval, la muralla es un elemento que forma parte de la formación, de la configuración y del funcionamiento de la ciudad medieval. En urbanística medieval (Guipúzcoa) de Beatriz Arizaga (1990, 107-112) se menciona la muralla como un elemento muy importante en la ciudad medieval, necesario para la defensa de la misma. Le atribuye también un significado simbólico, un elemento diferenciador entre lo de fuera y lo de dentro. Habla de la naturaleza construida de las murallas, indicando que en muchos casos se construían cercas modestas y compara la escala de éstas con la de la vivienda medieval (127). También hace referencia a las puertas de la muralla que define como el "lugar de encuentro entre dos mundos" (131) y los caminos como vías de comunicación de la ciudad con el exterior.

En la Génesis de la plaza en la Edad Media (Sainz Guerra 1990,65), se indica que la muralla es un elemento imprescindible en la ciudad medieval, hasta el punto de que basta con su presencia para adquirir carácter urbano un c onjunto de casas, por humildes que sean. Describe varias localidades donde es posible identificar los recintos defensivos en el trazado urbano como Simancas, Villabrágima o Villafrechós 
Las murallas en las Comunidades de Villa y Tierra de la Diócesis de Segovia en los siglos XI a XIII. Técnica y sistemas constructivos de la arquitectura defensiva medieval.

(Valladolid) y explica la evolución de los recintos amurallados en función del cambio en las condiciones de inseguridad del territorio, que pasa del castillo inexpugnable encaramado en un alto a un recinto amurallado situado en el llano, cercano al antiguo castillo, pero ya en las zonas más fértiles (67). Se señala la función de la muralla en la actividad de mercado (207), justificada por la capacidad de control del aprovisionamiento que se podía realizar en la puerta de la muralla. El comercio se organiza a ambos lados de la puerta y a través del ejemplo de Poza de la Sal (Burgos) se explica la importancia de la puerta de la muralla en el desarrollo del mercado, que originalmente depende de la iglesia y posteriormente se va independizando de esta.

En la ciudad y sus murallas, editado por Cesare de Seta y Jacques Le Goff (1991), se ofrecen visiones de varios autores acerca de la muralla, dentro de un contexto urbano e histórico. Jacques Le Goff habla de la construcción frente a la demolición de las murallas, Julio Valdeón describe las murallas de Castilla, se tratan temas como la iconografía y el simbolismo de la muralla y se describen casos concretos de ciudades amuralladas italianas y francesas. Se habla de la utilidad de las murallas y de la expansión de la ciudad frente a la conservación de la muralla. En la publicación La formación de la ciudad medieval, Félix Benito $(2000,133)$ dedica un a partado para hablar de la muralla con un en foque urbano, analizando su trazado y cuál es su incidencia en la formación de la ciudad. Hace referencia a la iconografía para justificar que la ciudad está definida por su muralla, también se refiere a fuentes históricas que describen la ciudad como un recinto amurallado.

El estudio de las Villas Nuevas Medievales que se lleva a cabo en la Universidad de Valladolid, con la colaboración de investigadores del Departamento de Urbanismo y el Departamento de Historia Medieval ha producido varias publicaciones donde se trata la ciudad medieval. Como resultado del proyecto Villas Nuevas Medievales del Suroeste Europeo, fruto de la colaboración entre las Universidades de Valladolid, Coimbra, Toulouse III, y las entidades Arkeolan, AEGUSA, Centre d'études de Bastides de Villefranche-de-Rouerge y Colegio de Arquitectos de Cantabria, se publicó en 2006 Las Villas Nuevas Medievales del Suroeste Europeo (Martínez Sopena, Mertxe Urteaga 2006) que reúne los estudios de estas villas en España, Portugal y el suroeste de Francia, con un enfoque urbano e histórico. Las Villas Nuevas Medievales de Castilla y León, editada por José Luis Sáinz Guerra en el año 2014, incluye estudios de $\mathrm{v}$ illas como Peñaflor de $\mathrm{H}$ ornija o $\mathrm{T}$ ordehumos, que estuvieron amuralladas.

\subsubsection{La ciudad hispanomusulmana}

El estudio de I a ciudad musulmana también incluye el análisis de I as defensas urbanas. Leopoldo Torres Balbás (1985 [1944]) aborda muy directamente las murallas de la ciudad musulmana en su obra Ciudades hispanomusulmanas, dedicada en el tomo II a las defensas urbanas. Habla de que prácticamente todas las ciudades hispanomusulmanas estaban muradas, lo que justifica por la gran eficiencia defensiva de estas construcciones. También hace referencia a la conservación y la destrucción de las murallas una vez perdida su función defensiva y narra varios casos de puertas 
de muralla derribadas por considerarse inútiles. El trazado de la muralla es estudiado como uno de los aspectos más característicos de la muralla medieval, por adaptarse al relieve del terreno de forma constante, aprovechándose las condiciones geográficas favorables (458). Analiza la disposición de I as cercas, en án gulos entrantes, en cremallera, la existencia de torres y las dimensiones de los recintos, indicando que no se ajustaban a una norma sino que había diferencias en cada ciudad (466). Dedica un capítulo a la cronología y la disposición de las cercas, detallando las épocas de construcción de las murallas atribuyendo la construcción a los almohades en el caso de Cáceres y Badajoz o a los nazaríes en el caso de Granada. Habla de la importancia de anteriores civilizaciones que pudieron influir en I a construcción de las cercas hispanomusulmanas, como la construcción bizantina (503). Los materiales de construcción empleados son también tratados por este autor, detallando las técnicas de sillería, tapial, mampostería o el empleo del ladrillo (551). Dedica un capítulo (567) a las torres de la muralla, tratando la morfología en planta, la separación entre sí, la ausencia de torres, la forma de construcción así como la decoración. Las torres albarranas son estudiadas también, detallando su morfología y los ejemplos más representativos. Es un capítulo especialmente amplio el dedicado a las puertas y postigos de las murallas, y en él se detallan las características de es te elemento, cuantas puertas había en la ciudad, la forma del acceso y las distintas soluciones en planta, entre otros.

Basilio Pavón Maldonado muestra el gran interés de la cultura de la España musulmana, analizando muchos elementos arquitectónicos propios de la ciudad. En su Tratado de arquitectura hispanomusulmana (1999), dedica un t omo completo al estudio de ciudades y fortalezas. En este tomo, el capítulo IV (233) habla de I as murallas y de las torres. Describe las murallas, tratando los grosores y dimensiones habituales, con especial interés en sus torres, qué tipos existen, la forma que adoptan, sus dimensiones o la distancia que las separa.

\subsubsection{Estudios constructivos y tipológicos de la muralla}

Miguel Ángel Martín Blanco $(2013,2014)$ ha publicado varios estudios acerca de la muralla de Segovia, describiendo las características de sus torres, su trazado y sus distintas fases constructivas. Estefanía Herrero $(2014,2015)$ ha r ealizado también estudios constructivos sobre la muralla de Segovia. Murallas y puertas de Burgos, de Javier Yzquierdo (2009) analiza las defensas de la ciudad de Burgos. En el año 2016 se ha publicado una tesis en la Universidad de Valladolid que trata el recinto amurallado de Zam ora desde un punto de vista urbano (López Bragado 2016). La muralla de Segovia de David Domingo y Begoña Sevillano (2012) se realiza a modo de guía para el visitante de la ciudad.

Otro de los enfoques arquitectónicos en el estudio de la muralla es el que se produce a raíz de una restauración o en la labor de conservación. La publicación La ciudad y sus murallas: conservación y restauración de Francisco J. Gallego Roca (1996) es el resultado de un curso de restauración arquitectónica orientado a la conservación, uso y restauración de las murallas. Con la aportación de distintos investigadores, se trata la figura de la muralla en la historia, su importancia en el paisaje y la estructura 
Las murallas en las Comunidades de Villa y Tierra de la Diócesis de Segovia en los siglos XI a XIII. Técnica y sistemas constructivos de la arquitectura defensiva medieval.

urbana, su uso y su conservación. Se aborda cómo está regulada su gestión desde el planeamiento urbanístico y se narran experiencias de restauración de murallas de distintas ciudades.

\subsubsection{El estudio arqueológico de la muralla}

En las últimas décadas del siglo XX, se publicaron investigaciones acerca de murallas de algunas ciudades o pueblos, generalmente planteadas como estudios aislados de un solo caso. Aunque de origen romano, un ejemplo es La muralla de Tarragona de José Sánchez Real (1986) donde analiza los restos con un enfoque arqueológico. Ya de época medieval, otro estudio de las murallas de una ciudad es el de Pablo Rossier (1990) con Origen y evolución de las murallas de Alicante donde analiza la transformación de la muralla con el paso del tiempo a través de fuentes históricas. La publicación Las murallas medievales de Murcia de José García Antón (1993) analiza la muralla a través de los restos que quedan en la ciudad detallando cada una de las partes a través de fotografías de ex cavaciones arqueológicas, con descripciones y análisis de fuentes históricas. Muy útil para los casos de estudio de esta investigación, es la publicación que realiza María D. Martín Aymerich (1990) junto con otros autores, que recoge un estudio arqueológico de las pervivencias arquitectónicas de la muralla de Sepúlveda. En la villa de Coca, el arqueólogo Juan F. Blanco (1991) analiza el circuito amurallado describiendo su recorrido apoyándose en fuentes históricas.

El arqueólogo Avelino Gutiérrez $(1995,1998)$ realizó estudios acerca de las fortificaciones del reino de León, durante los siglos IX a XIII. En 2014 ha trabajado junto con Magdalena Valor en la publicación The archeology of medieval Spain, un texto que reúne los estudios de varios investigadores. Antonio Malalana (2009) estudia en "La evolución de los recintos urbanos amurallados castellano-leoneses a lo largo del siglo XII", la formación y configuración de estos recintos y describe el empleo de la muralla en las distintas fases del avance del reino cristiano sobre el musulmán. También analiza estos recintos amurallados en el proyecto Hacedores de Fronteras dirigido por Manuel A. Rodríguez (2009), donde se estudian también los castillos fronterizos del reino de Toledo (Palacios Ontalva 2009) y la organización territorial en la comarca de Valencia, durante el siglo XIII (Cardells Martí 2009).

Las murallas de Madrid, han sido estudiadas por Antonio Fernández Ugalde (1998) con un enfoque arqueológico, Las murallas de Madrid: Arqueología medieval urbana, propone recorridos para conocer los dos recintos de las murallas de Madrid. Describe la ciudad en la Edad Media a través de sus pobladores.

También se han realizado publicaciones que describen los resultados de es tudios arqueológicos en $\mathrm{m}$ urallas concretas. El caso de Las murallas de Miranda del Castañar (Salamanca), realizado por Esther Villafruela (2005) y otros autores, explica el estudio arqueológico ejecutado en la fábrica y en una de I as puertas. Asimismo, analiza el contexto histórico y estudia los materiales constructivos empleados. Consuelo Escribano y Mónica Hernansanz (2001) tratan las fortificaciones medievales de Íscar, identificando mediante técnicas arqueológicas las murallas más antiguas del castillo. 
El análisis estratigráfico o la arqueología de la arquitectura es otro recurso empleado para el análisis de las murallas, como en el estudio que realiza Emilio Campomanes (2001) en la muralla de León. Tania Bellido (2008) emplea este método en el análisis de la muralla medieval de Marchena. El equipo de Camila Mileto y Fernando Vegas (2010) también estudia los beneficios de este sistema para el análisis de paramentos históricos. Luis Caballero (1995a) ha analizado en profundidad este método de análisis del documento construido.

Samuel Márquez Bueno y Pedro Gurriarán $(2003,2008)$ estudian la muralla de Cáceres, definiendo la muralla tipológica y morfológicamente, describiendo sus accesos y caracterizando cada uno de s us lienzos y torres. Estudian los aspectos constructivos del as fábricas, detallando la forma de encofrados y los restos de revestimientos.

\subsubsection{Otros enfoques}

En el campo del análisis de materiales, se sitúa la tesis de Miguel Fraile Delgado (2005) que analiza los materiales de construcción de los castillos de Castilla y León a través de análisis de muestras tomadas de cada caso y detallando, con un enfoque geológico, la composición de los materiales. En este mismo campo trabaja Esther Ontiveros (2008) que analiza los materiales de construcción de las murallas del Albaycín de Granada.

La muralla se ha estudiado también con un en foque antropológico (Cátedra Tomás 2007) a través del análisis de la muralla de Ávila. También en esta dimensión social, Isabel Gea (2008) habla de los orígenes de los distintos pobladores de la ciudad de Madrid y describe las murallas a partir de crónicas de otros autores, de fuentes históricas y de los resultados de excavaciones arqueológicas.

\subsubsection{La investigación en construcción medieval}

Por otra parte, existen investigaciones que tratan la construcción medieval de forma general, donde se detallan las técnicas empleadas en regiones geográficas o en construcciones concretas, independientemente de si se tratan o no de construcciones defensivas. Rafael Azuar (1995, 2005) estudia las técnicas constructivas medievales en al-Ándalus, describiendo el origen y el uso del tapial en la España musulmana. André Bazzana $(1993,1998,2003)$ también estudia estas técnicas medievales en las regiones que rodean el mediterráneo y concretamente se interesa por el uso de la tapia de tierra. Juan Eslava (1984) escribe acerca de los materiales y las técnicas constructivos en l a fortificación bajomedieval, explicando la técnica del tapial, las construcciones con piedra o con madera. El estudio de los sistemas constructivos medievales y también tradicionales es abordado por Luis Maldonado, Francisco J. Castilla y Fernando Vela (1997) con el estudio de la técnica del tapial en la comunidad autónoma de Madrid y la aplicación de nuevos materiales para su consolidación. Luis Maldonado y Fernando Vela (2003) realizan el Diccionario de la construcción 
Las murallas en las Comunidades de Villa y Tierra de la Diócesis de Segovia en los siglos XI a XIII. Técnica y sistemas constructivos de la arquitectura defensiva medieval.

tradicional, donde recogen la nomenclatura de las técnicas tradicionales, existentes también en la construcción medieval. Amparo Graciani (2008) junto con Miguel A. Tabales analizan el uso tapial en la zona sevillana. En la misma área, Jacinto Canivell (2011) estudia en su tesis doctoral la metodología de diagnóstico y caracterización de fábricas históricas de tapia y analiza el caso de la muralla de Sevilla, construida con tapia de tierra.

Amparo Graciani (2002) también dirige la publicación La técnica de la arquitectura medieval donde se agrupan los estudios de varios investigadores que tratan la cuestión desde distintas ópticas. Miguel Tabales (2002) realiza un estudio que explica como la arqueología medieval es muy útil para el análisis de las técnicas constructivas. Mercedes Borrero (2002) estudia cuáles son medios humanos que se emplean en la construcción medieval. Amparo Graciani (2002) analiza los medios auxiliares en Ia obra medieval. En este sentido, Ignacio J. Gil Crespo $(2013,64)$ menciona la importancia de las últimas investigaciones que interpretan las huellas que dejan los medios auxiliares para el estudio de los procesos constructivos. Habla del francés P. Bernardi, que junto con otros autores ha publicado textos sobre los medios auxiliares en la construcción medieval. Valentina Cristini y José R. Ruiz Checa (2011) estudian la caracterización constructiva de fábricas medievales en el ámbito del fuero de Cuenca, durante los siglos XII y XIII, en arquitecturas de varios tipos, como torres y puentes medievales, iglesias o chozos.

\subsubsection{Congresos y jornadas de divulgación científica vinculados con las murallas}

Desde los años 90, se han producido varios congresos o jornadas que estudian la arquitectura defensiva, de forma directa o través de la historia de la construcción o de la ciudad. Las actas de los congresos de Historia de la Construcción se publican en cada edición bianual y prácticamente todas las ellas incluyen estudios relacionados con la arquitectura defensiva. Los congresos se organizan desde la Sociedad Española de Historia de la Construcción y dieron comienzo en el año 1996. En sus distintas ediciones, se encuentran estudios que tratan casos individuales como la muralla de Oviedo (Adán Álvarez 1996), o la fortaleza de Castrotorafe (Ferreras 1996), presentes en la primera edición del congreso. En la segunda edición del congreso, se encuentran también publicaciones acerca de la muralla de Illice (Alía Alía 1998), de Talavera de la Reina (López Vázquez et al. 1998), el castillo de Chinchón (Villanueva 1998), o se abordan la estructura de es tas construcciones (Anselmo 1998). En la primera edición internacional de este congreso, se observan estudios de las torres gallegas a través de un ejemplo concreto (Freire Tellado 2003) y el estudio de las murallas de tapia en Sevilla (Graciani García et al. 2003). En la cuarta edición, se estudia la muralla de Jerez (Romero Bejerano 2005) y de Moya (Villanueva, Mora, Sanz 2005). En el sexto congreso, se tratan las fortificaciones medievales en Almería (Martín y Martín 2009). El séptimo congreso aparecen estudios de las fortificaciones de la provincia de Soria con un enfoque constructivo (Gil Crespo 2011), se analizan las torres y murallas de Cullera (Climent Simón et al. 2011) y se estudian casos individuales como el castillo de Cubelles (Genís y Planelles 2011) o el torreón de las Guzmanes de Caleruega (Gonçalves y Miranda 2011). El estudio torres en Segovia 
analiza los modelos constructivos de dos torres de la ciudad (Escobar González 2013). También se encuentra estudios que tratan un grupo de ejemplos que comparten características como las fortificaciones nazaríes (López Ramón 1996) ol os paramentos de fortificaciones en S egovia (Zamora, Vela 2005). Los arquitectos Estefanía Herrero y Miguel A. Martín Blanco (2015) estudian la muralla de Segovia a través de su sistema constructivo. Parte de esta tesis doctoral se ha compartido en la novena edición del congreso, en el año 20 15, describiendo las características constructivas de algunos casos, como el de Coca, Cuéllar o Montejo, en Segovia.

También se encuentran varios estudios que analizan la forma de construir en la Edad Media empleando los tratados, ordenanzas y otras fuentes históricas que aportan valiosa información. Se analizan textos que tratan la construcción de murallas de acuerdo con los tratados de arquitectura militar (Galindo 1996), o que abordan la construcción en la Edad Media a través de las ordenanzas municipales (Curiel Esparza 1998). En la tercera edición de es te congreso, del año 2000 , no ex isten publicaciones directamente relacionadas con la arquitectura defensiva, pero sí se producen estudios acerca de la construcción medieval, por medio del análisis de ordenanzas municipales (Albardonedo Freire 2000). El mismo autor analiza en otro artículo el régimen jurídico de la construcción de acuerdo con Alfonso X (Albardonedo Freire y Betancourt 2005).

Otro enfoque para estudiar arquitectura defensiva, presente en varias ediciones de este congreso, es el estudio de una técnica constructiva presente en es tas construcciones. En el primer congreso se encuentran algunas publicaciones que hablan de la técnica del tapial, aunque en contextos geográficos concretos (Galarza Tortajada 1996), desde un punto de vista de la técnica tradicional (Cuchí i Burgos 1996) o haciendo hincapié en el escaso conocimiento de la técnica en la actualidad (Algorri García et al. 1996). También se realizan estudios de la técnica del tapial con enfoques históricos (Martín García 2005) o s e describen los medios auxiliares de construcción medieval (Ignacio Vicens 2000). En el quinto congreso, del año 2007, se realiza una publicación acerca de la construcción con mampostería en la Edad Media, concretamente en la zona de Segovia (Hernández, Moreno 2007). Más adelante, se estudia la técnica del tapial en las fortificaciones de Sharq Al-Andalus (Soler Estrela 2009). El estudio de la tapia como técnica constructiva en la arquitectura defensiva española es otro caso de anál isis (García Soriano, Mileto, Vegas 2013). La restauración de arquitectura fortificada ofrece otro punto de vista en estos congresos, Carlos Quevedo Rojas (2015) narra la intervención restauradora en el castillo medieval de Matrera, en Villamartín (Cádiz), intervención que ha sido fuertemente cuestionada por la imagen final que ofrece.

Las actas del Congreso Internacional Ciudades Amuralladas de Pamplona del año 2005 recogen varios estudios sobre las murallas de varias ciudades y agrupan visiones desde distintas disciplinas y épocas. El simposio Internacional Arquitectura Fortificada: conservación, restauración y uso de los castillos, celebrado en el año 2004 en Segovia, recoge en sus actas estudios acerca de la restauración de c astillos españoles y extranjeros. Indica que la restauración de los mismos es un proceso que tiene fines culturales. También incluye el estudio de una muralla, la cerca vieja de San 
Las murallas en las Comunidades de Villa y Tierra de la Diócesis de Segovia en los siglos XI a XIII. Técnica y sistemas constructivos de la arquitectura defensiva medieval.

Felices de los Gallegos. En el año 2014, se organizó el Congreso Internacional sobre Patrimonio Fortificado: gestión y desarrollo sostenible (Pamplona, 15 - 17 de Octubre de 2014) que tiene un enfoque patrimonial, y como objetivo la preservación y la integración de construcciones defensivas en las ciudades. En el año 2015, se celebró el Congreso Internacional Fortmed sobre Fortificaciones de la Edad Moderna en Ia costa oeste del Mediterráneo, que se centra en las fortificaciones del Mediterráneo occidental durante los siglos XV a XVIII.

El grupo Tierra de la Universidad de Valladolid realiza congresos anuales que recogen, a través del uso de la técnica de la tapia de tierra, el estudio de arquitectura defensiva. Víctor Gamero, Pablo Rodríguez y Teresa Gil (2014) estudian las murallas de Mascarell, en Castellón, con un enfoque constructivo, detallando el uso de la tapia en su fabricación. Luis García Pulido y Manuel M. Alonso (2013) estudian restos de fábricas de tierra que asocian, por sus características constructivas, a la amuralla de Arcos de la Frontera, en Cádiz. Paulo Quitério (2010) estudia la muralla del castillo de Paderne, narrando la intervención restauradora llevada a cabo. El arquitecto Félix Jové (2011) junto con otros autores ha realizado estudios de caracterización de suelos para la restauración de las murallas de tapia de la alcazaba de Badajoz. Parte del análisis de la muralla de Fuentidueña de esta tesis doctoral se ha compartido en la edición del año 2014 (Sainz Esteban 2014).

Desde el punto de vista de las publicaciones periódicas, la Asociación de Amigos de los Castillos publicaba desde 1956 el Boletín Amigos de los Castillos, que pasó a denominarse revista Castillos de España a partir de 1967. Aunque el nombre parece incluir solo a castillos en la geografía española, algunas publicaciones son de interés desde el punto de vista del conjunto amurallado medieval, Félix Escudero $(2003,2004)$ estudia las murallas de Daroca y Madrigal de las Altas Torres y Aitor González (2006) realiza una investigación acerca de oficios concejiles con la muralla en las villas vascas. La muralla medieval de Tarifa se estudia en el contexto de la guerra de la Independencia (Núñez Roldán 2009).

En el año 2012, se publicó la primera edición de la revista Cuadernos de arquitectura y fortificación donde se recogen publicaciones que hablan de recintos amurallados y fortificaciones de diferentes enclaves y épocas. El siguiente número, de los años 20132014, reúne estudios de la muralla de Tejada la Vieja, la muralla de Segovia o la muralla omeya de Madīnat Išbīlia, entre otros estudios.

Las actas de actas del Congreso Internacional de Lugo, en 2005, tratan de murallas de ciudades romanas en el occidente del Imperio. Incluye los estudios de $v$ arios investigadores acerca de murallas romanas, que se dividen en c uatro grupos: las murallas la zona de Galicia, Asturias y León, la zona de la España oriental, la zona de Portugal y un cuarto grupo que incluye recintos de diversas partes del imperio romano. Es de interés conocer ejemplos de murallas romanas, con el objeto de establecer comparaciones y de identificar de forma más precisa la construcción medieval. 


\subsection{Estudios del periodo histórico donde se produce la construcción de las murallas de esta investigación}

Para la comprensión del contexto histórico en el que se construyeron estas murallas, se ha consultado bibliografía que analiza esta etapa. Se han examinado las hipótesis de Sánchez Albornoz (1966) acerca de la desertización de la zona al sur del Duero y las aportaciones de Ángel Barrios $(1983,1987)$ que analizan la situación demográfica en esta zona. Los planos de S alvador de M oxó (1979) se han i ncorporado a I os realizados en esta investigación para entender los distintos avances en la repoblación de la zona que afecta a este estudio. Se ha estudiado el texto de Julio González $(1951,1975)$ acerca de la repoblación de Castilla y de la Extremadura Castellana así como la visión de Reyna Pastor (1975) acerca de la situación política en la península ibérica. El enfoque de Ermelindo Portela (1985) cuando describe el territorio del Duero al Tajo ha permitido incorporar varias de sus reflexiones acerca del funcionamiento político de los concejos.

De cara a la estructura de las Comunidades de Villa y Tierra, la publicación de Gonzalo Martínez Díez (1983) acerca de su configuración se ha utilizado para extraer datos históricos que aclaran o al menos ayudan a entender su aparición de forma individual. Los planos de este autor se han utilizado como base para la delimitación de las comunidades en esta investigación. Los planos de José María Monsalvo (2010) han permitido completar los anteriores para obtener un resultado más actualizado. Este mismo autor (2003) ofrece una visión de la formación de estas villas y de su funcionamiento político y social que han sido muy importantes para contextualizar esta investigación desde un punto de vista histórico. La es tructura social que plantea M. Trinidad Gacto (1977) se ha analizado aquí para tratar de localizar quienes eran los encargados de construir y mantener las murallas. La importancia de las colaciones como punto de partida de la organización de las villas que establece María Asenjo (2006) ha permitido prestar atención a estas agrupaciones en el estudio de la villa amurallada.

\subsection{Resumen de las publicaciones más relevantes para esta investigación}

Una vez planteados los estudios realizados sobre murallas en España, es necesario destacar cuáles de estos estudios han sido de especial relevancia para esta investigación, de los que se ha extraído ideas o se han aplicado métodos de trabajo. En el campo de la arquitectura, se han tomado como referencia la publicación Castros y recintos de la frontera de León en los siglos XII y XIII. Fortificaciones de tapial de cal y canto o mampostería encofrada, de Fernando Cobos y otros autores (2012) de la que se han tomado métodos de representación o características a señalar de los lienzos de muralla. La tesis doctoral de Ignacio Javier Gil Crespo (2013) ha resultado de gran ayuda para entender el panorama investigador español en la arquitectura fortificada. Por otra parte, el sistema de clasificación de tapias que propone se ha utilizado para la comparación de las tapias estudiadas en esta investigación. En este sentido, se ha utilizado también el sistema de clasificación de tapias propuesto por Amparo Graciani (2008) aplicando los parámetros de comparación que establece. El estudio de la muralla de Segovia por Miguel Ángel Martín Blanco $(2013,2014)$ a través de varias 
Las murallas en las Comunidades de Villa y Tierra de la Diócesis de Segovia en los siglos XI a XIII.

Técnica y sistemas constructivos de la arquitectura defensiva medieval.

publicaciones ha aportado muchas ideas y métodos en la realización de esta tesis doctoral, donde se hace referencia a varios planteamientos de este autor.

Los estudios que existen de los casos estudiados aquí son escasos, pero han resultado de gran utilidad, en gran parte debido a su enfoque arqueológico. J. Francisco Blanco $(1991,2011,2014)$ aporta mucha información acerca de la muralla de Coca que se ha empleado para el desarrollo de ese caso de estudio. En el caso de Sepúlveda, M. Dolores Aymerich y otros autores (1990) realizan un estudio en profundidad de I a muralla que se ha ut ilizado y citado profusamente en el caso estudiado aquí.

\subsection{La investigación acerca de murallas en la actualidad}

En la actualidad, no se observa una tendencia particularmente ascendente en el estudio de la arquitectura fortificada. En el campo de la arquitectura no se aprecia una dedicación especialmente intensa al estudio de murallas y castillos y todavía en menor medida acerca de murallas. Por el contrario, es tal vez más significativa la dedicación de los arqueólogos a estas construcciones; ha sido habitual encontrar investigaciones de esta disciplina en relación con las murallas estudiadas aquí.

La investigación sobre arquitectura defensiva medieval en el contexto histórico de esta investigación es muy escasa. Al consultar las actas o los programas de congresos de construcción arquitectónica, al os que acuden gran número de investigadores, las ponencias sobre arquitectura defensiva no suelen alcanzar la decena. Los congresos o jornadas que tratan exclusivamente de ar quitectura defensiva son igualmente poco frecuentes y las aportaciones relacionadas con la construcción medieval de murallas es todavía más reducida.

Por otra parte, esta investigación analiza las murallas de villas de escasa población, que no tienen gran impacto en el panorama nacional. Los restos de las murallas en sí no son especialmente conocidos. Aun así, esta investigación quiere contribuir a impulsar el estudio de este tipo de construcciones en este ámbito de estudio. 


\section{3}

\section{Las Comunidades de Villa y Tierra}

\subsection{Antecedentes: Suma de factores que dan lugar al surgimiento de I as Comunidades de Villa y Tierra.}

Como se ha adelantado en la introducción, este estudio se enmarca en un territorio de importancia en el proceso de repoblación del reino de $\mathrm{C}$ astilla. El territorio entre los ríos Duero y Tajo es el escenario de un asentamiento singular, estructurado y organizado en concejos, que se inició a finales del siglo XI y evolucionó más allá del siglo XIII.

Al principio de este período, en torno al año 1031, la frontera entre el reino musulmán y el cristiano se situaba en l a línea del río Duero. En la Fig. 3.1, se muestra el panorama político de la península ibérica a principios del siglo XI. Los territorios cristianos Castilla se encontraban confinados al norte del río Duero, que se consolidó como frontera geográfica. Sólo en algunos puntos, el reino castellano traspasaba la línea del río, como en el caso de la villa de Sepúlveda. De acuerdo con Monsalvo (2003, 50), estos lugares no serían probablemente centros territoriales de l a monarquía, sino plazas fuertes cristianas aisladas. Al otro lado de la frontera, se organizan los reinos de taifas, con una situación política dividida tras la ruptura del califato de Córdoba. Hasta 1090 se mantuvo esta situación de división. Más adelante se sucederían dos imperios, el almorávide y el almohade (Pastor 1975, 53).

Desde el río Duero hasta el Sistema central, se encontraba un territorio de frontera muy extenso que habitualmente se define como despoblado, una zona de frontera entre los reinos enfrentados, un área inestable donde se producen periódicamente incursiones de los distintos bandos con el objeto de mejorar o mantener posiciones y de conquistar territorio. Es una zona sujeta a ofensivas y ataques por parte del Califato de Córdoba, de la mano de Abd er-Rahman III y posteriormente de Almanzor, que arrasa ciudades enteras. A principios del siglo $X$, es conocida la repoblación cristiana en 912 por parte de Gonzalo Fernández de Burgos, conde de Castilla, de las villas como Maderuelo, Ayllón y Montejo (Segovia), Roa y Haza (Burgos) o San Esteban y Osma, en Soria (Martínez 1983, 295, 301, 312). La ofensiva de Abd er-Rahman III contra Simancas en 939 afectó a numerosas villas al sur del Duero que quedaron arrasadas y destruidas. Es el caso de Ayllón, Haza y Montejo. Los habitantes de estas 
Las murallas en las Comunidades de Villa y Tierra de la Diócesis de Segovia en los siglos XI a XIII. Técnica y sistemas constructivos de la arquitectura defensiva medieval.

villas huyeron incluso antes de la llegada del enemigo, como en Coca o en Íscar (Martínez 1983, 438).

El califa fue derrotado en Simancas, lo que permitió iniciar numerosas empresas repobladoras a través de nuevas villas o ampliando asentamientos existentes. Desde 939 y durante cuarenta años, Castilla impulsa reiteradamente repoblaciones y fortificaciones de la mano de condes; es el caso de Sepúlveda, repoblada en 940 por el conde Fernán González, Peñafiel en 943 y también Cuéllar en 977, ambas repobladas por Asur Fernández (Martínez 1983, 407). En torno al año 941, el rey Ramiro de León y el conde Vermudo Núñez de Cea pueblan Salamanca y Ledesma. Sin embargo, no era segura la protección de las villas y el control del territorio no estaba garantizado. De nuevo en 983 es atacada Simancas por Almanzor, en una razzia que arrastra consigo la destrucción de Coca, Sepúlveda y otras poblaciones. Esta situación de continuas incursiones y ofensivas por parte del Califato de Córdoba, generan un territorio de frontera muy extenso, en general con escasa población que ha de desplazarse en caso de ataque; un territorio con villas arrasadas periódicamente. Según Monsalvo $(2003,51)$, hasta ahora los modos de repoblación empleados eran altomedievales, no se estaban aplicando métodos nuevos. Por el contrario, se estaba continuando con el modelo empleado al norte del Duero, donde fundamentalmente predominó el sistema de torres y castillos ordenados en dirección norte-sur para defender territorios desarticulados. En 1011, algunas villas como Haza o Montejo fueron repobladas por el Conde Sancho Garcés. Los tímidos intentos de repoblación cristiana fueron llevados a cabo a través de villas aisladas por manos privadas, nobiliarias or eligiosas, utilizando estrategias conocidas, con tenencias-fortaleza a cargo de señores del rey.

La despoblación de las zonas fronterizas de los reinos cristianos ha sido objeto de debate y desacuerdo entre los investigadores. El primer autor que describe como despoblado el valle del Duero es Sánchez Albornoz $(1966,215)$ y hace referencia a varios testimonios cristianos y musulmanes para acreditar su hipótesis. Salvador de Moxó (1974, 42-43) matiza que en la zona sur del Duero la despoblación no sería tan radical como la descrita al norte y que se da la posibilidad de que perviviesen grupos de población goda e incluso contingentes beréberes. Tal y como indica Ermelindo Portela $(1985,96)$, no hay una i dea definitiva acerca de la despoblación de estas áreas. Este autor hace referencia a las opiniones de varios investigadores, e indica que incluso los más claros defensores de la teoría de la despoblación aceptan que existen indicios de al gún tipo de poblamiento. Apunta que no se produjo un despoblamiento completo, sino que descendió de forma importante la densidad de pobladores. Por otro lado plantea que no se originó una interrupción en el tiempo de los asentamientos, sino que se redujo la cantidad de pobladores. Se trata entonces de un área con poca población, asentada de forma aislada y poco articulada, desprovista de organización política. En escritos más recientes, José A. Linage Conde $(2011,17)$ se refiere a la repoblación de la villa de Sepúlveda como hecho innegable, e indica que admitir que existió repoblación implica reconocer que esta sería escasa en un principio. No obstante, matiza que la palabra desierto implica una densidad de población muy baja y no la inexistencia total de pobladores. 




Fig. 3.1 Plano que ilustra la situación política a comienzos de siglo XI, en torno al año 1031. Fuente: Elaboración propia a partir de planos de José. L. Martín Rodríguez (1993, 192-193), José M. Monsalvo (2010, 99-101) y Salvador de Moxó (1979, 32).

José M Monsalvo $(2003,49)$ denomina esta franja "frontera elástica", una zona sometida a las presiones musulmanas donde no cuajan los intentos de repoblación. El modelo de avance empleado al norte del Duero no estaba funcionando en este nuevo territorio por lo que se hacía necesario un enfoque distinto en el modelo de repoblación. Según este autor (51), esta situación intermitente de avances y retrocesos en la línea del río Duero, con repoblaciones fallidas mediante estrategias conocidas, generó unas condiciones particulares de frontera que fueron clave para el desarrollo de una nueva estrategia de repoblación.

La decadencia del mundo musulmán a pr incipios del siglo $\mathrm{XI}$, dividido en $\mathrm{t}$ aifas enfrentadas, facilita la conquista de Toledo en 1085 por el rey Alfonso VI. El reino de León y Castilla se encuentra con una gran extensión de territorio conquistado que es necesario repoblar para poder afianzar y mantener la conquista. La conquista de Toledo no significó un dominio militar de la zona de retaguardia, pero facilitó su colonización. Según Portela (Portela 1985, 94), la ciudad de Toledo fue un "glacis defensivo" que amparó las tierras situadas al norte de los montes. Éstas a su vez, participaron activamente en la defensa de la Transierra. José M. Monsalvo $(2003,53)$ apunta que esta repoblación ya se estaba gestando con anterioridad y que se inició en torno al año 1072, cuando se produjo un giro en la política regia. El rey decide modificar sus políticas con el objeto de impulsar un nuevo modelo de colonización de la frontera. Se sustituyó el sistema de "paz y parias", que consistía en recibir tributos de los musulmanes para que conservaran sus territorios por el sistema de "conquista y repoblación", que implicaba obtener beneficios si se participaba en el proceso de 
Las murallas en las Comunidades de Villa y Tierra de la Diócesis de Segovia en los siglos XI a XIII. Técnica y sistemas constructivos de la arquitectura defensiva medieval.

repoblación. Alfonso VI impulsó mediante este cambio el avance fronterizo, y posiblemente comenzó a presionar para la repoblación de Cuellar, Medina del Campo, Olmedo e Íscar.

En la Fig. 3.2, se observa la situación del avance de los reinos cristianos sobre el territorio musulmán. En el panorama político es visible la aparición de Portugal, la extensión de los reinos de León y de Castilla, la aparición del reino de Aragón y de Cataluña. En la frontera, se ha tomado Toledo y el territorio de los concejos de Villa y Tierra se sitúa en la retaguardia. El rayado azul muestra el área de repoblación que se atribuye a Alfonso VI, comprendida entre los años 1072 y 1109. Según Salvador de Moxó $(1979,202-203)$, se repoblaron poco a poco las villas que se encontraban en la línea central del río Duero, estas son Olmedo, Medina del Campo, Coca, Íscar o Cuéllar. Estas repoblaciones eran posibles por la anterior función de las fortalezas de Peñafiel o Portillo. Íscar se repobló en 1086 por orden de Alfonso VI, y se encargó a Alvar Fáñez. En la repoblación de la villa de Cuéllar tuvo notable protagonismo el conde Pedro Ansúrez. La villa conoce gran prosperidad en el siglo XII, reuniendo siete colaciones o parroquias y casas de buena construcción. En el alfoz se contaban más de una veintena de al deas. La repoblación de Coca es menos importante y reúne menos aldeas y colaciones que los anteriores casos. Olmedo es otra villa que adquirió un tamaño importante con 14 colaciones, que dobla las pertenecientes a la villa de Arévalo (González 1974, 29-32). En la zona soriana, denominada Extremadura de arriba frente a la Extremadura de abajo segoviana, la repoblación se atribuye a Alfonso I durante los años 1104 a 1134. En cuanto a las ciudades más cercanas a la sierra, como Ávila, Segovia, Sepúlveda y Candespina, Julio González $(1974,34)$ hace referencia a las palabras del rey Alfonso VI cuando describe una desolación absoluta de estos territorios a su llegada. La villa de Sepúlveda, ya repoblada con anterioridad en una avanzada de Fernán González (Salvador de Moxó 1979, 32), aunque con un poblamiento débil, recibe el apoyo del rey a través de la concesión del fuero de la villa.

En este contexto, se produjo el surgimiento de soberanías locales, originadas por las estimulantes corrientes jurídicas y políticas de Occidente y favorecidas por las nuevas políticas regias de repoblación (Monsalvo 2003,53). En el plano musulmán, los almorávides iniciaron una nueva etapa de resistencia a los empujes castellanos con intentos de recuperar los amplios territorios perdidos y amenazando las zonas conquistadas, tornándolas inseguras (Monsalvo 2010, 111-112).

En definitiva, son varios los factores coincidentes en el tiempo que fomentaron el surgimiento del nuevo modelo de repoblación en la Extremadura castellana. El primer factor es la existencia de este amplio territorio de frontera casi virgen donde existe un vacío político, donde no hay dominantes claros. La aparición de soberanías locales es el segundo factor que marcó la característica autonomía política de los concejos. Y finalmente, es significativo el nuevo enfoque repoblador de Alfonso VI con una política que beneficia a los nuevos pobladores y a los asentamientos musulmanes existentes, y su agresivo empuje que desplaza la frontera hasta Toledo. 




Fig. 3.2 Plano de la península ibérica en 1110. Fuente: Elaboración propia de acuerdo con J.L. Martín (1993, 192-193) y Salvador de Moxó (1979, 224bis).

\subsection{La estructura territorial}

Las Comunidades de Villa y Tierra, también llamadas universidades o asocios (Muñoz Gómez 2012, 10), se configuraron mediante un entramado de villas y aldeas. Todo el territorio entre los ríos Duero y Tajo se dividió en concejos, en jurisdicciones encabezadas por una villa cabecera que funciona como centro neurálgico (Portela $1985,113)$. Los concejos tienen superficies considerables pero también variables; en la zona más cercana al río Duero, las superficies son más reducidas, con valores en torno a los $150 \mathrm{~km}^{2}$. Más cerca de la sierra, los concejos de Salamanca, Segovia o Ávila tenían superficies que superaban los $8.000 \mathrm{~km}^{2}$. Los concejos eran de realengo mayoritariamente; no obstante, algunas zonas aisladas como Granadilla, Alcántara, Alcalá o S igüenza formaban parte de s eñoríos de or den militar o ec lesiásticos (Monsalvo 2010, 152). En la Fig. 3.3, se muestra la distribución de los concejos con la intención de ilustrar el panorama territorial en estos siglos. Se ha sombreado en gris la zona correspondiente a los límites de la Diócesis de Segovia en la época. Los concejos parecen limitados al norte y al sur por los dos principales ríos, pero con excepciones: en la zona de Soria, los concejos superan la barrera del Duero y se extienden por el norte; lo mismo ocurre con los concejos de Zamora y Toro al oeste; al sur, los concejos sobrepasan el río Tajo. Gonzalo Martínez (1983, 10-15) planteó la hipotética distribución de concejos en los que se apoya la Fig. 3.3. José M. Monsalvo $(2003,86)$ apunta que estas delimitaciones fueron cambiantes a lo largo de los siglos y no estáticas, por lo que resulta difícil conocer con exactitud cuáles fueron los límites, 0 como evolucionaron a lo largo de la existencia de las Comunidades de Villa y Tierra. 
Esta forma de colonización es el resultado de la evolución de I os procesos de repoblación que se produjeron en la zona norte del Duero, adaptándolos a las condiciones del nuevo territorio. No es producto de la casualidad sino que es el resultado de la adaptación a las condiciones del momento, por un lado la debilidad de la monarquía ante la gran extensión del territorio que pretendía dominar, por otro, la necesidad de dar fórmulas jurídicas que regulasen la adquisición de derechos sobre el suelo en el contexto de la repoblación (García de Cortázar 1985, 18). La creación del sistema político concejil de Villa y Tierra es un recurso novedoso en la época, debido la autonomía de gobierno de estas Villas y a la libertad de la que gozaban sus ciudadanos. Al parecer, en ninguna otra monarquía europea se llegó tan pronto y de forma tan intensa y extensa a la autonomía y a los territorios municipales. El modelo social alcanzado en las Comunidades de Villa y Tierra durante 200 años fue una de las formas de poder más avanzadas, sobresalientes y singulares de la Europa medieval (Monsalvo 2003, 121).



Fig. 3.3 Esquema de la distribución de las Comunidades de Villa y Tierra, entre los ríos Duero y Tajo. La zona sombreada corresponde con el territorio bajo la influencia de la Diócesis de Segovia. Fuente: Elaboración propia, de acuerdo con Martínez (1983, 10-15) y Monsalvo $(2010,152)$.

Con este nuevo modelo de asentamientos, se estaba produciendo un cambio importante en las formas de control territorial, se sustituyó el sistema empleado al norte del Duero con fortalezas que estaban gobernadas por señores al servicio del rey, por el de ciudades fortaleza concejiles, con tenente, alcalde, villa con su cerca, que sirvió como baluarte defensivo en caso de peligro, y que abarcó incluso a los habitantes del alfoz. El modelo al norte del Duero, con castillos y torres diseminados 
en lo que ahora era alfoz concejil, aunque hubiese sido funcional en luchas fronterizas, perdía ahora su sentido en el escenario concejil. La delegación de poderes en los concejos, llevada a cabo por los monarcas castellanoleoneses lleva a la aparición de nuevas relaciones sociales, es decir, "un conjunto de derechos que permite definir a los concejos como señoríos colectivos" (Portela 1985, 113). Máximo Diago $(2012,86)$ matiza que, aunque en muchos aspectos las relaciones entre villas y aldeas eran similares a las de señores y vasallos, en el caso de las comunidades de Villa y Tierra los aldeanos consideraban que las aldeas y las villas formaban parte de una misma "república" donde se repartían beneficios y cargas.

La fórmula de defensa empleada estaba determinada por la importancia del factor militar, entendida desde dos puntos de vista, por un lado la defensa del territorio y en última instancia del núcleo urbano, la villa; por otro lado el ataque, la capacidad ofensiva contra los musulmanes, en una tarea constante de acoso por medio de incursiones continuas en el territorio musulmán, por medio de grupos de caballeros que se dedicaban al pillaje. Esas correrías debilitaban de manera extraordinaria al poder musulmán. En este área se implanta una sociedad más jerarquizada, que viene a sustituir el modelo repoblador a base de aldeas homólogas, que se había llevado a cabo al norte del Duero, por un modelo que se apoya en la creación de centros urbanos potentes, bien fortificados, rodeados por aldeas subordinadas, que dependen de él desde los puntos de vista económico, militar y jurídico (García de Cortázar 1985, 18).

Las villas cabecera de estos concejos tenían una función centralizadora, administrativa y militar. Estaban fuertemente protegidas a través de una muralla que rodeaba la ciudad (Benito 2000, 78). La muralla de las villas era habitualmente de gran extensión, albergaba una superficie importante que cercaba no sólo las construcciones urbanas, sino también áreas vacías destinadas al cultivo o al pasto. Las murallas que se conservan en la actualidad pueden atestiguarlo, es el caso de Sepúlveda con $70 \mathrm{Ha}$ de superficie amurallada. La muralla es igualmente una de las manifestaciones más claras de la estrategia de la monarquía de León y Castilla para consolidar su poder en el sur del Duero. Dota a la villa de un poder territorial y económico y la diferencia de otros asentamientos. Las villas eran las piezas que articulaban el territorio, a través de una relación de dominio sobre el campo (García de Cortázar 1988, 201). De forma general, el esquema de todos los núcleos fortificados entre el Duero y el Tajo es similar: un castillo ubicado en la zona más alta o más inaccesible, que ofrece mejores condiciones defensivas, entendido como el último reducto y asentamiento original (Sainz Guerra 1990, 62) y la ciudad amurallada alrededor del castillo, en Ias zonas más bajas, pero todavía en territorio elevado. Frecuentemente, el castillo aprovechaba la existencia de as entamientos defensivos anteriores. La función militar es lo que caracteriza a es tos núcleos, y la muralla es uno de los elementos principales. El dominio del territorio cercano a la villa se materializa en los caminos que tienen forma radial (Portela 1985, 104) y que conducen a los campos desde las puertas de la muralla.

La elección del emplazamiento de la villa era importante. Se elegía para estos núcleos lugares elevados y de difícil acceso, con vistas sobre el territorio para asegurar una 
Las murallas en las Comunidades de Villa y Tierra de la Diócesis de Segovia en los siglos XI a XIII. Técnica y sistemas constructivos de la arquitectura defensiva medieval.

vigilancia efectiva de los entornos. Es el caso de Sepúlveda, que se sitúa en las hoces del río Duratón y utiliza los grandes desniveles del terreno para adquirir la condición de inexpugnable. Fuentidueña posee, asimismo, una posición privilegiada desde donde domina el territorio circundante.

Dentro de la villa se produce una organización por colaciones o barrios. En función de su origen, los nuevos pobladores se agrupan en torno a un edificio religioso, una parroquia. Según María Asenjo (2006, 257), las colaciones constituyeron la base sobre la que se asentó la organización política y administrativa del concejo. Los representantes de las colaciones constituirían las asambleas vecinales desde donde se toman las decisiones de gobierno de la villa. Varios autores (Monsalvo 2003, 69; Martínez Sopena 2015, 204) han comentado la descripción de Al Idrisi acerca de las ciudades de Segovia o Salamanca, que las retrataba como una acumulación de aldeas cercanas entre sí, pobladas de jinetes vigorosos. Este aspecto que ofrecían las ciudades podría ser el resultado de esta agrupación de parroquias. En algún momento se construiría la muralla que rodearía todas estas agrupaciones.

En el alfoz, existían pequeñas aldeas a través de las cuales se gestionaban los recursos del territorio. Las aldeas eran pequeños núcleos con escasa edificación, que al contrario de las villas, no poseían muralla, pero sus gentes podían resguardarse del peligro en la villa, incluso con su ganado. En las partidas de Alfonso X, que datan de la segunda mitad del siglo XIII, se insta a los hombres del pueblo a correr a refugiarse a los castillos con la llegada de Ios enemigos (Partida II, Título XVIII, Ley XVII). La actividad ganadera, más fácilmente protegible en zonas de conflicto, era realizada por los caballeros, que aprovechaban que era complementaria con la vocación militar (Benito 2000, 78).

La relación entre poder territorial y núcleo urbano amurallado se extiende a lo largo de toda la Edad Media en Castilla y va evolucionando a través del desarrollo de la tarea de la repoblación. En este caso, es visible la evolución de esta relación y la modulación que se estableció entre el poder real, las necesidades de la villa y las condiciones defensivas y ofensivas contra el poder musulmán. La muralla adquiere gran importancia en este escenario concejil. Ya no se trata de sólo de asentamientos aislados en forma de fortaleza construidos en un al to inexpugnable, sino que el asentamiento ha crecido, está conectado directamente con el campo y otras aldeas. Máximo Diago $(2012,85)$ refiere otro modelo similar al descrito aquí para la mitad meridional del reino de Aragón, donde se empleó un sistema en el que se dividió el territorio en porciones con aldeas cuyo control lo detentaba un núcleo urbano. Indica que este modelo se fue difuminando al perder las villas su control sobre las aldeas.

En definitiva, José M. Monsalvo $(2003,46)$ diferencia tres etapas en la evolución de las Comunidades de Villa y Tierra. La primera etapa se inicia desde finales del siglo XI hasta mediados del XII. En este periodo de tiempo irrumpe de forma espontánea la estructura de concejos, la nueva forma de poder en este territorio. La segunda etapa, que abarca la segunda mitad del siglo XII hasta los años centrales del siglo XIII, se describe como el periodo en el que se produce una quiebra progresiva de la estructura de concejos. La tercera etapa se desarrolla en I os años centrales del siglo XIII, y representa el triunfo de las élites. 


\subsection{Organización política}

Desde un punto de vista político, aunque cada una de las villas dependía directamente del rey, el gobierno del concejo tenía gran autonomía y un carácter participativo por parte de la población. Según González Herrero $(1998,29)$ la Comunidad es un estado en sí misma, ya que posee todos los atributos de poder, es decir, una población importante, un territorio extenso, un fuero y una jurisdicción propias, un gobierno autónomo y un ejército propio. Este autor (17) hace referencia a Julio González para afirmar que varios diplomas medievales hablan de la Extremadura castellana como reino que cuenta con su propia organización e instituciones diferenciadas.

Se cree que, al menos en las primeras etapas de formación del sistema concejil, se permitía que los habitantes de las villas y aldeas participaran en la toma de decisiones de gobierno del concejo, a través de asambleas de vecinos abiertas y participativas. Se hereda el funcionamiento de aldeas donde se encontraban habitualmente hombres libres y el sistema era el de toma de decisiones colectivas en reuniones de, al menos, los cabezas de familia (Monsalvo 2003, 68). En estas reuniones, las asambleas concejiles, se reunían los vecinos de la villa, incluyendo caballeros y aquellos que cumplían los requisitos de v ecindad de la villa. Se tomaban decisiones sobre el gobierno de la comunidad, los recursos económicos, y sobre los cargos del concejo. Estos cargos se renovaban anualmente y debían ser aclamados en la asamblea, de acuerdo con el fuero de Cuenca (Monsalvo 2003, 109).

Los cargos concejiles incluían juez, alcalde, hombres buenos, jurados, escribanos, sayones y otros funcionarios. El juez actuaba de intermediario entre el concejo y el rey, tenía una función judicial relativa al poder del rey y de recaudación de impuestos debidos al rey (Gacto 1977, 124). Los alcaldes eran los representantes del concejo y eran varios dentro del mismo concejo. Administraban justicia en el concejo de manera individual o junto a otros alcaldes. El concejo tenía también funciones judiciales, de forma que tenían autoridad sobre la actuación de los alcaldes. Cuando un particular no quedaba satisfecho con el juicio podía apelar al concejo y al rey (130). La autoridad política del concejo queda reafirmada por el fuero de Viguera, que aunque mucho más al norte, indica lo siguiente: "Todo alcalde deve ser puesto por concejo. Todo juez que fuere deve ser puesto por mano de concejo, é si al concejo non ploguiere pueden lo toyllir é potier otro. Esso mesmo sea del sayon. Et podestat deve dar al juez XII ss. é los vecinos den al sayon é á los peones medio almut de avena ó medio de ordio. El sayon non deve ser al, sino dar posadas et el mandado del juez."

Otro aspecto importante de la villa es la colación, la primera base administrativa de la villa, que como se ha mencionado antes, tiene también una función política. Era un ámbito operativo en lo relacionado con pleitos de avenencias, justicia y paz, o persecución de del itos. El habitante del a colación tenía una f unción política importante, con un papel en la designación de cargos concejiles, alcaldes o jueces. También existía el concejo de la aldea, que gestionaba los comunes de la aldea, vigilaba los términos del concejo y resolvía litigios civiles de poca cuantía.

En este contexto, el papel de la monarquía frente a los núcleos de población ha cambiado. Se ha producido una transformación en las relaciones dentro de la jerarquía 
Las murallas en las Comunidades de Villa y Tierra de la Diócesis de Segovia en los siglos XI a XIII. Técnica y sistemas constructivos de la arquitectura defensiva medieval.

política. Los representantes del rey, tenentes o señores, que antes eran los encargados de gobernar a través de un sistema feudal, ven reducido su poder frente a la creciente autoridad del concejo. El ejercicio del poder lo detenta ahora la organización concejil. El rey se reservaba de forma simbólica el dominio directo de algunos espacios en torno a ciudades: sernas, alcaceres, huertas, que daban fe de la procedencia de la soberanía originaria. El resto del dominio se transfería al concejo. El rey sigue controlando, si bien mutan las relaciones con sus vasallos con el objeto de favorecer la acción repobladora y darles más libertad. En este sentido, la actuación de la monarquía fue clave ya que se produjo una transferencia de funciones políticas desde el realengo al concejo (Monsalvo 2003, 62).

\subsection{Estructura jurídica}

La presencia de instrumentos jurídicos en los concejos se traslada de los modelos aplicados anteriormente por la monarquía en otros territorios. El fuero es un recurso conocido y aplicado con anterioridad, y se utiliza como norma en los concejos. En este nuevo escenario, se cree que cada comunidad tenía un fuero aprobado por el rey, una compilación de normas que se aplicaban a ese territorio, que recogía los privilegios y las exenciones de los individuos que allí moraban. La novedad reside en el contenido de los fueros, que eran muy ventajosos y se habían redactado con el objetivo de atraer población a un territorio despoblado e inseguro (Benito 2000, 68). El nuevo poblador de estas villas se ve muy favorecido desde un punto de vista jurídico. En el fuero de 1076 de Sepúlveda el rey concede a los vecinos unas ventajas exorbitantes, justificadas por la circunstancia de que se trata de un área fronteriza. Reúne normas muy beneficiosas para los habitantes de Sepúlveda, donde no se pagaban impuestos de mercado y donde robar o asesinar podía realizarse impunemente. Estas ventajas atrajeron a población de orígenes muy diversos que se agrupaban espontáneamente por procedencia en barrios o colaciones, organizados por parroquias.

El reconocimiento jurídico de privilegios a través de los fueros pone de manifiesto la apuesta regia por un modelo político que ofrecía transferencias políticas y libertades a los habitantes de I os concejos. Por una parte, el monarca se limitó a confirmar el derecho consuetudinario que existía ya en determinados asentamiento o territorios, como se había hecho en otros lugares. Además, otorgaba un papel especial al concilium, que se convierte en el verdadero gobierno de la ciudad (Gautier 1979, 199). Es verosímil atribuir a la acción de A Ifonso $\mathrm{VI}$ un papel importante en la creación formal del sistema concejil de frontera. Según María Asenjo (2006, 256), la intervención de la monarquía no fue una operación organizada sino que consistió en la introducción de ventajas y facilidades acompañadas de una labor de reconocimiento que alentaba a los pobladores.

El fuero de Sepúlveda fue uno de los primeros redactados y se fue otorgando a otras villas como Uclés o Cuenca. Los fueros de las villas que se conservan en la actualidad datan de fechas más recientes. No obstante, se cree que estos fueros, aunque reescritos más tarde, conservan una parte de los preceptos de la época y contienen su espíritu original. De acuerdo con José M. Monsalvo (2003, 94), en el reino leonés hay 
varias familias de fueros, relacionados con los reinados de Fernando II y Alfonso IX, los fueros de Salamanca, Ledesma y Alba de Tormes. Son fueros bastante similares y no parecen corresponderse con fueros anteriores, aunque los fueros de Alba y Salamanca puedan ser el más antiguo sustrato jurídico. El Fuero Extenso de Ciudad Rodrigo, de finales del siglo XII, se corresponde con otra familia de fueros. Es un texto que se ha perdido y es conocido por su extensión a varios concejos portugueses, tal vez a Cáceres, aunque tiene su propio fuero latino. Debieron existir en el reino de Castilla otros fueros que se han perdido. El fuero de Olmedo no se conoce, pero se sabe de su existencia por un documento de 1205 que se extiende a la villa de Peñaflor, traspasando hacia el norte la línea el Duero.



Fig. 3.4 Imagen de un ejemplar del fuero de Sepúlveda. Fuente: Biblioteca Nacional de España. http://bdh.bne.es/bnesearch/detalle/bdh00001166866 [Consultado el 18/2/2016]

\subsection{Estructura social}

Las condiciones políticas y jurídicas que se dieron en los concejos produjeron, al menos en un principio, una sociedad muy singular, donde se gozaba de una gran libertad y autonomía, impropia de la época medieval (Monsalvo 2003, 83). La llamada de la monarquía a nuevos ciudadanos para poblar la Extremadura castellana tiene el efecto de atraer a pobladores de orígenes muy diversos. En villas y aldeas se produce una mezcla de poblaciones cuya agrupación se realizaba por procedencia, hecho que justifica la estructura de la villa en colaciones. Por otro lado, en la toma de ciudades 
Las murallas en las Comunidades de Villa y Tierra de la Diócesis de Segovia en los siglos XI a XIII. Técnica y sistemas constructivos de la arquitectura defensiva medieval.

islámicas la población existente se rendía en lugar de resistirse por miedo a las represalias si eran vencidos, lo que favorecía esta mezcla de orígenes. Portela (1985, 112) hace referencia a lo que significó la incorporación de estas ciudades con su población. En el caso de Toledo, la existencia de actividades artesanales y comerciales concentradas en el núcleo urbano significó un aporte económico positivo para el reino cristiano. En el caso de Salamanca, la situación de los distintos grupos pobladores variaba dentro de la villa. Los francos, serranos y caballeros ocuparían la villa. Los mozárabes o poblaciones residuales ocupaban zona cerca del río. Los grupos norteños se asentaban en las áreas nuevas fuera de la villa, que antes de la construcción de la nueva muralla, serían arrabales (Monsalvo 2003, 70).

En un inicio, se produjo una traslación de cuadros sociales propios del norte de la Meseta (Monsalvo 2003, 51). Más adelante, se implantarán los grupos y la jerarquía propia de la sociedad de la Extremadura, originada por las nuevas condiciones presentes en este territorio.

Gacto Fernández (1977) establece una c lasificación de los grupos de vecinos que existían en es tas villas, a partir de las menciones relativas a ellos en los fueros de Salamanca, Ledesma, Alba de Tormes y Zamora. En primer lugar indica que los vecinos se diferencian entre sí por varios factores. Su lugar de residencia es uno de ellos, siendo los arrabales lugar de personas de la más baja extracción social (37), las aldeas en s iguiente posición y el habitante de l as villas contaría con un es tatus superior (41). La antigüedad de residencia es un valor añadido a la calidad de vecino, requiriéndose en el fuero de Ledesma la residencia de dos años para aspirar a cargos del concejo (42). La propiedad de la casa es otro factor de gran importancia que demostraba que el vecino estaba arraigado en el lugar (43). La profesión tenía un papel significativo en esta escala, el caballero sobresale del resto de la población y la posesión de caballo de guerra será un elemento de diferenciación. Los tenderos y artesanos tienen una condición inferior por considerarse vil el trabajo realizado para los demás (48). Una condición necesaria para ser vecino era ser libre, es decir no depender de ningún señor, sino ser directamente vasallo del rey. Por otra parte esto implicaba el pago de un impuesto, la pecha, que justifica que se disfrute de los bienes del concejo (49). En este sentido, aparecen nuevos factores de diferenciación ya que algunos grupos quedaban eximidos del pago, por ser caballero o funcionario, por ser un recién llegado o por otras razones. Se menciona además la contribución fiscal dentro de los concejos que, de forma simplificada, se debía al rey y se realizaba a través del concejo, y que aparece asociada a servicios-tributo de tipo militar y municipal. Un ejemplo de esos servicios es por ejemplo la prestación para construcción y reparación de caminos, la prestación militar de carácter ofensivo, la marcha rápida sobre campos enemigos para ocasionar daño y obtener botín y prisioneros, participar en actividades de defensa o hacer un servicio de vigilancia a caballo (55-58). La capacidad de prestar estos servicios era también un elemento de diferenciación. Aunque no aparece directamente mencionado por la autora, trabajar en las murallas de la villa, en su construcción o en su mantenimiento podría considerarse un servicio-tributo. 
La religión diferencia a los vecinos y los separa por grupos en los asentamientos. Los moros y judíos debían pagar al rey un impuesto anual. La edad es otro elemento que define la participación de un vecino en la sociedad concejil, en función de la edad se pagaban impuestos o no y se era considerado responsable. En cuanto al sexo, era necesario ser varón para ser vecino (68).

Apoyándose en los factores citados que diferencian a los vecinos, la autora diferencia varios grupos de vecinos, los contribuyentes o posteros son aquellos que están arraigados y tributan en el concejo (69). Los no posteros son aquellos que se encuentran exentos de cargas del concejo, y en consecuencia excluidos de participar en el gobierno: por ejemplo los nuevos pobladores (93). Los hombres buenos se describen como personajes representativos del concejo, que forman parte del concejo como institución (85). Los aldeanos se contemplan como grupo de vecinos distintos ya que cuentan con un fuero diferente que los villanos (93), con diferencias también en la situación fiscal. De acuerdo con la profesión se crean otros grupos, los agricultores y ganaderos tienen especial importancia por la relación directa que establecen con el dominio de la tierra, que en el contexto de la repoblación obtienen directamente en propiedad, por la mera ocupación inicial o por concesión real (98). Los menestrales y tenderos son otro grupo profesional que no se considera merecedor de cargos de gobierno. Los familiares de vecino son un último grupo que se describe como dependiente del vecino cabeza de familia; se componía de menores de edad y mujeres.

Se detallan vecinos relacionados con el clero regular, vinculados a monasterios, a órdenes militares y con el clero secular. La figura de constructor o albañil aparece recogida en el grupo de "vecino de obra" en relación con la obra de la catedral de Salamanca, el apoyo del rey Alfonso VII permitió que en 1152 que los obreros que trabajasen en ella quedasen eximidos del pago de tributo, un privilegio que mantuvieron los monarcas posteriores, Fernando II y Alfonso IX. La autora indica que estos operarios tal vez constituyeran cuadrillas procedentes de fuera del concejo, que no contaban con estatuto propio, y que a través de su vinculación con una ob ra, adquieren la condición de vecino, pagando su tributo a la iglesia en lugar de al rey o al concejo. Tal situación de vecino sólo tenía vigencia en la duración de la obra (175). Según algunas menciones que se hacen acerca de la reparación y conservación de la muralla, los habitantes de la villa y de la aldea se encargaban de estas labores (Valdeón 1991, 81), pero no se especifica si se designaban a una clase de vecino particular. Félix Benito $(2000,121)$ se refiere al fuero de León de 1017 para expresar la obligatoriedad de todos los vecinos de contribuir en las obras de conservación y reparación de la muralla. Hace referencia a los fueros de las zonas de la Extremadura y la Transierra para indicar que incluso en estas zonas, donde era habitual eximir de tributos a los vecinos, no se les eximía de la labor de conservación de la muralla.

Destaca de forma particular la figura del vecino postero que posee un caballo de guerra o a rmas. Es el denominado caballero villano. Su posición depende de la posesión de es tos elementos e incluso está obligado a ad quirirlos a partir de la tenencia de un mínimo de bienes. Es habitual que tras los más destacados puestos de 
Las murallas en las Comunidades de Villa y Tierra de la Diócesis de Segovia en los siglos XI a XIII. Técnica y sistemas constructivos de la arquitectura defensiva medieval.

gobierno de I os concejos, jueces, alcaldes, jurados, se sitúe un caballero villano (Gacto 1977, 111).

José M. Monsalvo $(2003,106)$ plantea que la sociedad cristiana y laica de los concejos estaba dividida en una primera categoría de vecinos privilegiados, los caballeros, que junto a los clérigos gozaban del mejor estatuto; una segunda categoría de vecinos posteros que tienen pleno derecho, tributan al concejo y tienen bienes; una tercera categoría de moradores, recién llegados y sin derechos; una cuarta categoría de aldeanos, una quinta categoría de excusados de vecino, que eran sirvientes y criados dependientes del concejo; una sexta categoría de habitantes de señorío dentro del alfoz y una última de habitantes de señorío fuera del alfoz. De acuerdo con este autor (82), en un primer momento existió una democratización y distribución de poder entre los grupos sociales. No hay prueba de que solo los caballeros ocuparan los cargos municipales. El acceso a la caballería era socialmente abierto entonces, aldeanos podían llegar a ser caballeros y muchos de ellos eran habitantes de las aldeas. Hay testimonios sobre lo accesible que sería ser caballero en el fuero de $S$ antarem otorgado por Alfonso VI, en Portugal. Más adelante, se va produciendo una brecha que dará lugar a divisiones clasistas y relaciones de explotación, pero al inicio se trataba de diferencias funcionales. En contraposición al despunte de los caballeros concejiles, se definieron los peones concejiles que englobaban todos aquellos que no eran caballeros. Esta oposición fue tal que los demás sectores sociales tendieron a desaparecer y todo el sistema social empezó a estructurarse en torno a estos dos grupos.

Además de la estructura territorial descrita anteriormente, que tiene un objetivo de defensa del territorio, también se busca conquistar territorio y para ello es necesario también formar milicias guerreras, para así poder combatir a los musulmanes (Monsalvo 2003, 45). Los caballeros serían entonces el recurso creado para engordar estas milicias y su labor en el objetivo principal de es ta estrategia poblacional les dotaría de gran importancia dentro de esta sociedad. Según Ermelindo Portela (1985, 110 ), todos los años las milicias concejiles hacían incursiones profundas en el territorio enemigo, para saquear y obtener botines que incluían cautivos, cabezas de ganado, dinero y otras riquezas que eran repartidas y de las que se entregaba una parte al rey. Las milicias concejiles también se ven reflejas en los fueros, donde se habla de que la población concejil asumía la defensa militar del territorio.

\subsection{El papel de la iglesia católica}

A mediados del siglo XII, la iglesia no tenía tanto poder y dominio en la Extremadura; aun así, se implantó progresivamente a través de cada una de las parroquias que se construyeron en cada aldea y colación, introduciéndose de acuerdo con los modelos de funcionamiento del norte del Duero. La iglesia era un elemento que apoyaba la existencia de jerarquías sociales y funcionaba mejor en un sistema feudal. Moxó $(1979,203)$ indica que en las localidades que se repoblaban, se construían iglesias parroquiales que buscaban expresar la fe de los habitantes que se instalaban. En las villas, la parroquia es el foco en torno al cual se agrupan los nuevos pobladores. 
Además de la estructura territorial de villas y aldeas, términos aldeanos completos fueron segregados de los concejos iniciales para dotar a las instituciones eclesiásticas de la Extremadura. Iglesias, monasterios y órdenes militarse obtuvieron la jurisdicción de lugares que inicialmente habían sido concejo y que quedaron fuera de la jurisdicción concejil. Villar García $(1986,324)$ señala que los concejos reaccionaron de forma violenta a estas cesiones y habla de las protestas de Peñafiel y Fuentidueña en 1175 e incluso de la redacción de una legislación que buscaba frenar la disponibilidad de tierras para quienes la ocupaban.

Como consecuencia de esta forma de as entarse, el patrimonio eclesiástico se caracterizaba por estar disperso y por ser heterogéneo. La dispersión se traducía en la localización del patrimonio de una sola catedral alejado entre sí, que en el caso de Segovia se encontraba en territorios cercanos al Duero y en áreas más allá de la Cordillera Central. La heterogeneidad hace referencia a la variedad de patrimonio: grandes espacios, heredades o bienes de naturaleza urbana e incluso villas o aldeas completas, como Vitigudino, donada a la catedral de Salamanca por Fernando II (Villar García 1986, 325).

A pesar de tener poca presencia en un principio, con el tiempo los señoríos episcopales llegarían a ser importantes y dispondrían de campesinado dependiente (Monsalvo 2003, 79). A través de la influencia de las sedes religiosas, el territorio de la Extremadura se reparte en diócesis, que van ganando poder sobre los concejos.

\subsection{La seguridad en la villa: la muralla}

En la época medieval que se está describiendo, la sola mención de ciudad implica necesariamente que esté amurallada y así se indica en las Partidas de Alfonso $X$, donde se dice que "dondequiera que sea hallado este nombre: ciudad, que se entienda todo aquel lugar que es cercado por los muros, con los arrabales y los edificios que se tienen con ellos" (Partida VII, Título XXXIII, Ley VI). La muralla de la ciudad representa un papel importante en la ciudad medieval y este hecho es visible por las menciones que se encuentran en varios fueros de estas villas. La muralla funciona como frontera social, marcando grandes diferencias entre los moradores intramuros y los extramuros. También se trasluce que su mantenimiento es costoso: parte de los impuestos se destinan a su conservación y también se establecen penas de labor de mantenimiento en las murallas.

En el fuero de Salamanca, se hace referencia al "muro" en lo relativo a la recaudación de impuestos, se dice que todo hombre que al morir tuviera una fortuna de 20 maravedís, ha de pagar uno destinado a la muralla. También se ha de tributar con destino a la muralla cuando una viuda contrae matrimonio antes del año de la muerte de su anterior esposo, en este caso dos maravedís.

"Todo orne que morier, é ovier valia de veinte marauedís, dé uno por su alma al muro" [CLXXXIII. Del mortuorio quanto den al castiell] 
Las murallas en las Comunidades de Villa y Tierra de la Diócesis de Segovia en los siglos XI a XIII. Técnica y sistemas constructivos de la arquitectura defensiva medieval.

"La vilda que anta del anuo pressier marido, peche dos marauedís, é metanlos en lauor del muro, é pierda la manda quel' fecier su marido".

[CCXXVIII. Bilda que se casa antes del anno]

Se encuentran menciones donde la muralla se utiliza como diferenciador de derechos, privilegiando a los que viven en el interior del recinto amurallado frente a los que no. En este sentido, la muralla se cita en un privilegio de Enrique II a la ciudad de Salamanca en 1369 y hace referencia a aquellos moradores que viven dentro del recinto amurallado, a los que exime de pagar tributo alguno.

"Tenernos por bien que todos los vezinos é moradores que moraren dentro en la dicha ciudad de Salamanca, de los muros adentro, legos, clerigos, que sean quitos, y escusados de todo pecho..."

También se utiliza para limitar las actividades aceptadas dentro de las murallas, que de nuevo es un el emento diferenciador de carácter social, que preserva a I os habitantes dentro de las murallas de soportar las desventajas de determinadas actividades. En las ordenanzas de 1619 de esta ciudad, se dice "ninguna persona tenga, ni crie ganado de cerda dentro de los muros delta ciudad, ni lo traya por ella de dia ni de noche, pena de mil marauedis por cada vez. ... Y que qualquiera persona que los hallare en esta ciudad los pueda tomar y matar sin pena alguna, y del dicho ganado se pague la dicha pena, y no de los bienes del dueño."

En las ordenanzas de la Villa de P edraza, Franco Silva $(1991,109)$ extrae varias referencias a impuestos o multas que se destinarían en parte a la conservación de la muralla. También en el fuero de Molina se hace referencia al pago de tributo para la muralla, en este caso como castigo a quien mienta o dé falso testimonio (Cap. 28 del fuero). Se menciona que el vecino con casa en Molina queda eximido de tributos a excepción del trabajo en la muralla (texto introductorio del fuero), lo que da a entender que todos los vecinos están implicados en la conservación de la muralla, a través de trabajo físico o bien con el pago de tributos. En el fuero de $\mathrm{C}$ uenca también hay cuestiones que se rigen de acuerdo con las murallas de la villa. Este fuero fijaba la cuantía de las arras entregadas a una novia, que eran el doble para una joven de la villa frente a una aldeana (Claramunt 1982, 309).

En el fuero de Sepúlveda de 1076, se hace una mención a la exención de pago de portazgo en ningún mercado a los habitantes de la villa. Esta podría ser la única mención de la muralla en este fuero, si se supone que este impuesto se cobraba en alguna de sus puertas.

Las referencias a l a construcción de l a muralla o a $\mathrm{s}$ u conservación también se encuentran en algunos fueros. Gacto Fernández $(1977,37)$ extrae del fuero de Salamanca la mención de la construcción de una nueva muralla que cerque la ciudad en su totalidad ya que la antigua muralla no es suficiente. Según este dato la nueva muralla se comenzaría a construir en torno a 1147:

"que fagan el muro et quando fuer fecho el muro de la cidat fagamos otro muro en la arravalde per $u$ vieren por bien los alcaldes e los jurados del concejo. Et los de la ciudat 
affien a los de la arravalde que quando fecho fuer el muro de la cidat que los aiuden a feçer el muro de la arravalde".

En las Partidas de Alfonso $X$, se dice que deben quedar libres las calles que están cerca de los muros de las villas, de manera que no se puede adosar edificios a ellas. También define un espacio a respetar de 15 pies en caso de realizarse un edificio cercano (Partida III, Titulo XXXII, Ley XXII). Existen otras referencias a la muralla que instan a los habitantes a mantener y reparar los muros de las villas, para evitar su ruina. Indica que es una responsabilidad de todos, y especifica que el rey debe encargar ese trabajo a hombres señalados y entendidos. Hace una referencia muy clara a la necesidad de que todos los vecinos incluidos caballeros, clérigos, viudas y huérfanos no queden eximidos de colaborar en la conservación de la muralla, por medio de trabajo físico o económicamente.

Félix Benito $(2000,122)$ hace referencia al fuero de Sahagún de 1255 , otorgado por Alfonso X, donde se permite "hacer casas juntadas con el muro". La aparición de esta medida en los fueros puede indicar que la función defensiva de la muralla en la villa comenzaba a desdibujarse en el siglo XIII, dando paso a otras prioridades.

Sin embargo, originalmente la razón principal de la muralla era su carácter defensivo. La cerca que protegía la villa era de gran resistencia, difícil de franquear. En las 7 partidas de Alfonso $X$, se dice que las murallas ofrecían gran seguridad y gran amparo para todos: "Honra debe el rey hacer a su tierra, y señaladamente con mandar cercar las ciudades y las villas y los castillos de buenos muros y de buenas torres, pues esto la hace ser más noble y más honrada y más apuesta; además es gran seguridad y gran amparo de todos comunalmente para en todo tiempo; otrosí debe honrar con sus palabras alabando las bondades de ella" (Partida II, Título XI, Ley II).

Aun así, la defensa no era el único objetivo de la muralla, como ya se deja entrever en las palabras de Alfonso $X$, que habla también de honradez, nobleza y belleza. Sus muros, sus puertas y otros elementos cumplían diversas funciones en la ciudad: política, económica y jurídica. Tal y como describe Julio Valdeón (1991, 84), las puertas de la muralla eran puntos neurálgicos de la población, zonas de mercancías y puntos de gran afluencia y aglomeración de personas. Por ejemplo, el mercado se situaba en estos puntos o muy cercano a ellos. La muralla era una garantía de protección para los mercaderes. Asimismo, las puertas eran los únicos lugares de acceso a la población y se empleaban para el cobro de impuestos. Estaban fuertemente vigiladas con este propósito y tratar de acceder a la Villa evitando las puertas era castigado. En el aspecto político la muralla cumplía un papel de representación, era una manifestación de pujanza económica, de fortaleza, un símbolo de poder. Según Valdeón (85) la muralla se utilizaba en las grandes celebraciones, sus lienzos se engalanaban, se decoraban sus puertas con telas y estandartes y junto a ella se hacían representaciones y actos para luego acceder a la villa por la puerta más importante. Alfonso $\mathrm{X}$ consideraba que las murallas y sus puertas son santas cosas, que no han de quebrantarse ni horadarse y que no han de cruzarse si no es a través de sus puertas, delitos sujetos a pena de muerte (Partida III, Título XXVIII, Ley $\mathrm{XV})$. 
Las murallas en las Comunidades de Villa y Tierra de la Diócesis de Segovia en los siglos XI a XIII. Técnica y sistemas constructivos de la arquitectura defensiva medieval.



Fig. 3.5 Fragmento del grabado de la ciudad de Segovia que muestra la ciudad vista desde el norte con espacios vacíos en el interior de sus murallas, o con cultivos aparentes de árboles. Dibujo extraído del portal digital la Biblioteca Nacional de Francia. Pertenece al conjunto "Atlas Géographique Contenant Les Cartes d'Espagne, de Portugal, et d'Italie", cuyos autores son Jean de Beaurain y Jean-Claude Dezauche y fue publicado en París en 1749. El autor del grabado es Israël Silvestre, y data de mediados del siglo XVII. Fuente: Biblioteca Nacional de Francia http://gallica.bnf.fr/ark:/12148/btv1b59719000 [Consultado el 5/10/2015].



Fig. 3.6 Dibujo de la ciudad de Ávila de 1908 de Charles Cottet. Fuente: Biblioteca del Instituto Nacional de Historia del Arte en Francia, colección Jacques Doucet. http://www.purl.org/yoolib/inha/3856 [Consultado el 11/2/2016]

La morfología de I a muralla y su asentamiento en el territorio tiene algunas características que se repiten en varios casos. Aunque no de forma tan intensa como en el caso de castillos aislados, se sigue buscando la ventaja de una localización poco accesible, se ubica habitualmente junto a un río o en la confluencia de dos y se aprovechan las elevaciones del terreno. Las murallas se construían en los bordes de acantilados, y se ajustaban a los desniveles del territorio, aspecto que mejoraba su capacidad defensiva. Como resultado, las formas regulares en pl anta no s on 
habituales en estas murallas, sino que los recintos son irregulares. El caso de Ávila es una excepción que muestra una forma casi rectangular en planta.

El recinto amurallado en las villas era de extensión considerable. En la actualidad todavía se puede ver esta extensión en muchas villas: Segovia, Ávila, Salamanca, Soria, Olmedo, Sepúlveda y otras. El recinto amurallado abarcaba incluso grandes espacios vacíos destinados a cultivo o a ganado. En un fragmento de un grabado de la ciudad de Segovia (Fig. 3.5), es visible la muralla que rodea la ciudad y se pueden ver áreas dentro del recinto que están vacías o que están destinadas al cultivo. Aunque este plano date de una fecha muy posterior a la época de construcción delas murallas, es posible que los espacios vacíos se hayan mantenido con escasa variación en ese tiempo. Incluso en I a actualidad, la zona norte de S egovia posee amplios espacios sin edificación, ahora incluidos en grandes parcelas. José María Monsalvo $(2003,90)$ hace referencia a las "pueblas urbanas" para indicar que todavía en el siglo XIII se produjo la instalación de nuevos pobladores en la zona intramuros de la ciudad, poniendo de manifiesto que las áreas amuralladas no estaban colmatadas.

El dibujo siguiente (Fig. 3.6) muestra el recinto amurallado de la ciudad de Ávila, vista desde el Este. Se ven grandes espacios vacíos en $\mathrm{s} u$ interior y un c aserío de apariencia modesta. La muralla no apa rece representada con exactitud, ya que se cuentan menos torres que las existentes en la actualidad. El origen de la muralla de Ávila es controvertido y se ha investigado intensamente acerca de su origen (González de la Reina 2010). También son conocidas las representaciones de ciudades españolas de Anton van den Wyngaerde entre las que se encuentran Segovia, Toledo o Valencia. El autor Richard Kagan $(1998,14,200)$ reúne estos dibujos junto con los de otros autores que representan las ciudades españolas del siglo de oro. En los dibujos de Wyngaerde también son visibles grandes áreas vacías dentro del recinto amurallado.

La muralla es un "elemento vivo en continua transformación" (Valdeón 1991, 81) que, en función del crecimiento de la ciudad y de los nuevos asentamientos a su alrededor, podía modificar su trazado, creando nuevos recintos. La anterior referencia al fuero de Salamanca, que habla de una nueva muralla que englobe el arrabal, es un ejemplo del cambio y expansión permanente de la muralla. Otro ejemplo donde son visibles varios recintos es la muralla de Cuéllar, que muestra dos recintos amurallados.

La muralla de la villa es, en definitiva, un elemento asociado de forma muy estrecha a la ciudad medieval. En cualquiera de los aspectos sobre los que se asienta un modelo urbano, el aspecto económico, territorial, político, jurídico o social, la muralla tiene un papel que será visible a través sus elementos, las puertas o torres, o a través del espacio que abarque su trazado. 
Las murallas en las Comunidades de Villa y Tierra de la Diócesis de Segovia en los siglos XI a XIII. Técnica y sistemas constructivos de la arquitectura defensiva medieval.

\subsection{La oligarquización del sistema de concejos}

A partir de mediados del siglo XII se inicia un cambio en el sistema de concejos. Las condiciones que dieron paso a esta estructura se han diluido y los nuevos factores que intervienen alteran el equilibrio inicial. El desplazamiento de la frontera hacia el sur aleja la retaguardia de este territorio. La situación de la península ibérica a principios del siglo XIII (Fig. 3.7) ha cambiado. La frontera con el mundo musulmán se sitúa al sur del río Tajo e incluso supera el Guadiana. Las repoblaciones de Alfonso VII y Alfonso VIII se extienden por la cuenca de estos ríos, ampliando la extensión del reino.

De acuerdo con José M. Monsalvo $(2003,98)$, a finales del siglo XII, se produjo una nueva definición de la calificación económica de los alfoces. Se realiza una fijación de espacios de pasto y áreas de labranza, así como de cuáles eran sus usuarios. Se produjo una distinción de los bienes comunales de los pueblos y de todos los habitantes del concejo. Según este autor, estos son indicativos de que s e estaba pasando de una economía de guerra, apoyada en espacios concejiles de naturaleza pastoril y difusa a una verdadera política económica concejil, con términos concretos y respaldada por la monarquía. El alejamiento de la frontera y el protagonismo que tenían desde finales del XII las órdenes militares en la vanguardia bélica, liberaron a los concejos de una implicación militar permanente.

El siglo XII fue un siglo de expansión económica (Monsalvo 2003, 95), factor que contribuyó a este proceso de cambio. La afluencia de nuevos pobladores, la toma de ciudades con sus habitantes y riquezas, los botines que se obtenían en las incursiones de los caballeros villanos y la actividad de mercado que empieza a formar parte de las actividades militares y ganaderas, son aspectos que influyeron en la capacidad económica de la Extremadura. El esquema de villa central con un alfoz era favorecedor para el mercado, se centralizaba la actividad mercantil en un punto que era seguro y estaba protegido.

Además de los factores territoriales y económicos, se produce un cambio en la estructura social. En un modelo que estaba basado inicialmente en la igualdad y la libertad, se abre paso "el progreso de las desigualdades y las discriminaciones" (Monsalvo 2003, 93). El caballero villano, por su importancia como ejército y por su capacidad para beneficiarse de los botines de guerra, se convirtió en una figura poderosa en los concejos y tuvo ocasión de enriquecerse aprovechando las condiciones del sistema de concejos. Luis M. García Villar (1986, 194-196) compara la situación de los caballeros con la de los clérigos para explicar cómo fueron poco a poco exonerados del conjunto de tributos exigidos a la población. En las familias de fueros derivados delos de Salamanca y Ávila, se contempla una igualdad entre clérigos y caballeros. Esta igualdad se mantiene a lo largo del siglo XIII, a diferencia de lo que ocurre con el resto de la población. Los caballeros villanos eran muy numerosos y con una función guerrera importante de la que dependía la supervivencia de los concejos y del reino. A través de estas ventajas, el grupo de caballeros prevalece sobre el resto y va monopolizando cargos y funciones políticas. El sistema concejil ha permitido que este grupo social acceda al poder de forma paulatina. Portela (1985, 114) apunta que los caballeros villanos son el resultado más singular de la labor de repoblación castellanoleonesa de las tierras al sur del Duero. 




Fig. 3.7 Plano de la península ibérica en 1214. La frontera se sitúa ya más allá del río Tajo. El territorio de los concejos de Villa y Tierra se encontraba ya asegurado. Fuente: Elaboración propia a partir de planos de José. L. Martín Rodríguez (1993, 192-193) y Salvador de Moxó (1979, 224bis).

Las villas de es ta investigación aparecen citadas en el documento con fecha 23 de abril de 1181, firmado en Seligenstadt por Alfonso VIII y Federico I de Alemania cuando conciertan el matrimonio de sus hijos Berenguela y Conrado. En este documento, se enumeran, entre otras, las villas de Coca, Cuéllar, Fuentidueña, Pedraza, Maderuelo y Sepúlveda. Los caballeros villanos de estas villas forman parte de la decisión política y asienten al compromiso matrimonial. Este documento muestra por un I ado el cambio de mentalidad de la época, ya que las villas tenían una representación en este tipo de acuerdos, y por otra parte la posición privilegiada de los caballeros villanos que figuran como garantes de un compromiso de gran importancia social y política (González 1960, 857-863, Doc. nº 499).

Además de es tas consideraciones generales acerca de la época que favoreció la formación de las Comunidades de Villa y Tierra, en cada uno de los casos estudiados se han señalado fechas conocidas a partir de documentación histórica, que ayudan a situar a cada villa en su contexto. Todas las villas de esta investigación figuran en dos documentos históricos de importancia además del indicado en el párrafo anterior, correspondientes al año 1123, cuando el papa Calixto II define los límites de I a Diócesis de Segovia, y al año 1136, fecha en la que Alfonso VIII enumera las villas que han de ceder el diezmo a la iglesia católica. En cada una de las villas se han señalado otros documentos históricos en los que aparecen mencionadas y la cantidad de menciones difiere en cada caso. El análisis bibliográfico muestra que las villas de Cuéllar, Fuentidueña y Sepúlveda han sido estudiadas con mayor intensidad desde un punto de vista histórico frente a Pedraza, Maderuelo o Coca, donde los estudios 
Las murallas en las Comunidades de Villa y Tierra de la Diócesis de Segovia en los siglos XI a XIII. Técnica y sistemas constructivos de la arquitectura defensiva medieval.

encontrados son más escasos, debido probablemente a la ausencia de fuentes históricas. Esta escasez documental puede deberse al carácter oral de es tas sociedades, basadas en los pobladores y no en los integrantes de la sociedad más cultos como el religioso o el nobiliario, de donde proceden habitualmente los documentos que se conservan. Frente a esta falta de información escrita, las murallas ganan especial importancia como documento construido. El análisis de sus restos físicos aporta nueva información acerca de esta época y también pone de manifiesto el potencial que tiene su correcta gestión.

A través de los datos extraídos en cada villa, se hace visible cómo a partir del siglo XIII, los concejos van siendo paulatinamente cedidos por los monarcas a manos de señores que se hacen con el control de la villa y su alfoz. Máximo Diago $(2012,98)$, habla de tierras de titularidad pública para referirse al territorio de realengo, que fue reduciéndose paulatinamente durante la baja Edad Media e incluso en Ias primeras décadas del siglo XVI, por la cesión de heredades que efectuaban los mismos monarcas a figuras nobiliarias. No obstante, aunque se redujo la extensión de los términos de realengo, se conocen conflictos entre villas y aldeas que datan del siglo $\mathrm{XVI}$, donde se disputan las rentas producto del arrendamiento de estos términos de realengo (111). Este autor señala que en el siglo XVII figura un número importante de licencias otorgadas por la monarquía para que los concejos pudiesen ceder a renta los aprovechamientos de las rentas de sus términos realengos y responder así a la presión fiscal bajo la que se encontraban sometidos (113).

Aunque con cambios estructurales de gran importancia, se pone de manifiesto que la tradición comunitaria de las comunidades de Villa y Tierra perduró a lo largo del tiempo. Por una parte, la consolidación de prácticas de aprovechamiento colectivo a través de las rentas anteriormente mencionadas y su economía ganadera contribuyeron al arraigo de estos territorios comunitarios. Por otra parte, la relación de subordinación entre las aldeas y el núcleo cabecera en el ámbito político y jurisdiccional se mantuvo hasta la disolución del Antiguo Régimen, en el siglo XIX (Diago Hernando 2012, 86). Incluso después de su abolición, tras las Desamortizaciones de 1835 y 1858, se mantienen vestigios de este comunalismo, visibles en la actualidad. En el campo de la toponimia, se observa cómo muchos de los núcleos que rodean estas villas conservan todavía el apellido de la villa principal, aún constituyendo en la actualidad un municipio diferente. Es el caso de pueblos como Fresneda de Cuéllar, Narros de Cuéllar, Calabazas de Fuentidueña, Fuentesaúco de Fuentidueña, Bernuy de Coca, Moraleja de Coca, Alconada de Maderuelo, Valleruela de Sepúlveda o Aldealengua de Pedraza.

En definitiva, conocer los resultados de la investigación histórica en estas comunidades es necesario para entender qué sociedad habitaba estas villas y bajo qué preceptos se organizaba. Es probable que estos aspectos influyeran en la construcción física de las villas y por tanto también en la construcción de sus defensas. El carácter comunitario de es ta sociedad, así como la diversidad de orígenes des us pobladores pueden ser de ayuda para entender los métodos empleados en la construcción de las murallas. 


\section{4}

\section{Métodos y \\ herramientas de trabajo}

La fuente principal de este trabajo son los restos de murallas existentes. La muralla es en sí misma un documento arquitectónico del que se puede extraer mucha información valiosa. El método empleado en esta investigación es por una parte el análisis visual de los restos existentes, apoyado con fotografías, dibujos y toma de dimensiones. Este análisis visual se complementa con un a nálisis dimensional y de elementos constructivos realizado a posteriori, con la intención de i dentificar las técnicas constructivas empleadas. De estos análisis han resultado dibujos, fotografías, levantamientos, ortofotografías y otros nuevos documentos que se han empleado para extraer las soluciones constructivas empleadas y la configuración detallada de la más utilizada. Esta nueva documentación se ha r ealizado de forma extraordinariamente exacta, con alzados de tramos de muralla en los que se han empleado sistemas de representación muy actuales y que son por sí mismos un avance del conocimiento, pues no existen como tal en la fecha de hoy. Se trata de información que servirá para conocer el estado de la muralla si por cualquier circunstancia esta desapareciera o se deteriorara. Sobre estos alzados se hace, además, un análisis constructivo realizado con un interés especial en la tapia como unidad constructiva. Este análisis permite diferenciar los paños de las murallas en función de sus técnicas constructivas y compararlos con los de otras próximas en el espacio y el tiempo.

Este método, enfocado directamente al ámbito de la construcción arquitectónica, se complementa con otros dentro de la investigación. El análisis de la época histórica que rodea la construcción del as murallas se ha pl anteado como sistema para contextualizar estas edificaciones. Por otra parte, se ha tenido en cuenta la geografía que rodea los recintos amurallados como aspecto intrínsecamente relacionado con las murallas y su asentamiento en el territorio. Se ha abordado igualmente el trazado de la muralla en la escala urbana, también con una intención contextualizadora. En esta investigación, se ha tratado de cruzar información de distintos orígenes, como el histórico, geográfico y el constructivo con el objetivo de entender con mayor claridad los factores que rodearon la construcción de la muralla y su significado.

Este capítulo de metodología se ha estructurado en varios apartados. El primero de ellos es la recogida de datos, que incluye el trabajo de c ampo, la búsqueda bibliográfica o la descarga de datos a través de Internet. El segundo apartado trata el tratamiento de los datos, que explica la gestión y modificación de los datos recogidos realizada para permitir un análisis posterior más sencillo. La creación de dibujos y o la 
Las murallas en las Comunidades de Villa y Tierra de la Diócesis de Segovia en los siglos XI a XIII. Técnica y sistemas constructivos de la arquitectura defensiva medieval.

rectificación de imágenes es un ejemplo del tratamiento de datos llevado a cabo. El tercer apartado explica los métodos de análisis de datos que se han realizado sobre los datos recogidos y tratados.

\subsection{Recogida de datos}

\subsubsection{Trabajo de campo}

En esta investigación se han realizado visitas programas en repetidas ocasiones a cada uno de los casos estudiados. Además de los casos estudiados, se han visitado otras villas amuralladas que se ha considerado necesario visitar bajo la óptica de esta investigación, por compartir características con los casos estudiados o por formar parte de estudios de otros investigadores que se han consultado. Estas villas son: en la provincia de Valladolid, Olmedo, Medina del Campo, Peñafiel, Peñaflor de Hornija, Tordehumos, San Pedro de Latarce, Belver de los Montes, Urueña, Portillo, Torrejón de la Nava, Eván de Arriba y Eván de Abajo; en la provincia de Ávila, Ávila capital y Arévalo, Haza en Burgos, Atienza en Guadalajara, Medinaceli en Soria, Vertavillo en Palencia, Ayllón en Segovia, Salamanca capital y Madrid capital.

Con anterioridad a la visita de los restos de muralla se han realizado estudios previos de cada villa, que consisten en un estudio de la documentación disponible. De forma general se ha analizado la fotografía aérea, el plano de catastro y planos topográficos del entorno de la villa. El objetivo es localizar con exactitud los restos existentes e identificar los lugares a visitar donde existan restos de murallas o fortificaciones. También se han buscado pistas en el trazado urbano que permitan encontrar restos menos evidentes o menos famosos en la villa. Se ha contactado con alguno de los ayuntamientos de las villas visitadas, con el objeto de obtener datos acerca de los restos de muralla, información acerca de las restauraciones realizadas y otros datos que pueda resultar de interés. En los casos en los que existe bibliografía acerca de la muralla a visitar, se ha consultado con anterioridad a la visita para extraer información útil para la visita. El material empleado en el trabajo de campo es el siguiente: cámara fotográfica, varias tarjetas de memoria y cable de batería; material para anotar datos y de dibujo; metro láser y metro convencional. Se detallan en este capítulo las características de cada uno de estos materiales.

En el núcleo a visitar se ha realizado, en algunos casos, una visita al Ayuntamiento en busca de i nformación, de ayuda o c on el objeto de da $r$ a c onocer que se está realizando un estudio de la muralla. Cuando existía, se ha visitado la oficina de turismo y se han recogido panfletos y otros documentos relacionados con la muralla. Se trata de documentos que recogen información sucinta, pero en ocasiones es útil y actual. Ofrece una visión de la relación que tiene el núcleo con sus restos de arquitectura defensiva. Se ha consultado igualmente a los habitantes de la villa acerca de la arquitectura defensiva.

Para la toma de datos se ha realizado un recorrido completo del trazado de la muralla y de s us elementos, puertas, portillos, torres, visitando lugares cercanos o relacionados que permitan entender la muralla como construcción defensiva. Se han 
visitado otros tipos de arquitectura defensiva cuando existe, como castillos, torres aisladas o casas fuertes. De todo ello se han tomado fotografías. Estas fotografías han sido por una parte de tipo general, de conjunto, de manera que se vean todos los elementos y su relación entre sí. Por otra parte, se han realizado fotografías de detalle, retratando elementos particulares, los distintos aparejos o detalles de interés. En este tipo de fotografías, es de interés colocar un metro que aparezca en la fotografía, para que funcione como escala y la fotografía aporte datos dimensionales en el análisis posterior. Con el objeto de poder realizar un alzado rectificado, se han realizado fotografías por tramos, siguiendo un método que permitirá posteriormente combinar y escalar estas fotografías. Este sistema se explica en el apartado "Fotogrametría digital" de este mismo capítulo. Se han tomado otro tipo de fotografías que buscan recopilar datos e i nformación: las fotografías de panel es de i nformación turística contienen planos, fotos y otra información que es de utilidad para conocer, por ejemplo, qué estudios se han realizado en las murallas.

Además de la toma de fotografías, se anotan datos y detalles que se observen in situ. A través de dibujos y esquemas se recoge la forma de los restos arquitectónicos y sus soluciones constructivas. Se realizan mediciones de las dimensiones generales de puertas, torres, grosores de lienzos. También se toman medidas de los elementos constructivos, en el caso de la tapia se anotan la altura, anchura de cada tapia, la posición de sus mechinales en relación con la tapia, la distancia de los mechinales entre sí, dentro del mismo cajón y entre distintos cajones.

La toma de muestras para su análisis en laboratorio se ha planteado como una opción en esta investigación y finalmente se ha descartado. Esta cuestión es delicada ya que no parece adecuado retirar material de restos de arquitectura centenaria, que además es considerada Bien de Interés Cultural desde hace más de 50 años. En primer lugar se debería valorar si es necesario o no tomar muestras. Si no es necesario para el estudio a realizar, no se deben tomar. En caso de determinar que sí es necesario, la opción más adecuada sería solicitar un permiso y estudiar de qué manera la toma de muestra sería menos perjudicial. Sería de interés que en caso de realizarse la toma de muestras, estas se catalogasen y fuesen accesibles a otros investigadores de distintas disciplinas para evitar nuevas tomas de muestras.

Posteriormente a la visita, se ha procedido al etiquetado de imágenes, dibujos y notas con fecha de la visita y el lugar. En cuanto a las imágenes, se procede también a su clasificación en función de su uso o aplicación. Por ejemplo, se agrupan las imágenes que van a e mplearse en la realización de al zados rectificados, las imágenes de detalles o elementos constructivos o imágenes de conjunto.

El trabajo de campo realizado permite la realización de una ficha breve, un documento que reúne las características principales de los restos encontrados. Esta ficha incluye datos recogidos in situ como la localización de restos defensivos en el núcleo, las características generales de estos restos y su estado de conservación. Además de estos datos, se aportan los estudios realizados sobre el núcleo o las posibles investigaciones en curso sobre algunos de los restos arquitectónicos defensivos. Las fichas se pueden consultar en el apartado de "Anexos". 
Las murallas en las Comunidades de Villa y Tierra de la Diócesis de Segovia en los siglos XI a XIII. Técnica y sistemas constructivos de la arquitectura defensiva medieval.

\subsubsection{Fuentes históricas}

Se han consultado fuentes históricas con el objeto de encontrar menciones, dibujos o grabados acerca de la construcción de murallas en la Edad Media que arrojen luz sobre su configuración. Las fuentes consultadas se han encontrado en internet, en varios portales que ofrecen ejemplares escaneados.


Fig. 4.1. Captura de pantalla del portal PARES. A la derecha, página del catastro de Ensenada, correspondiente a la villa de F uentidueña. Fuente: http://pares.mcu.es/Catastro/ [Consultado el $12 / 11 / 2015]$

El Diccionario Geográfico-Estadístico-Histórico de España y sus posesiones de ultramar, redactado por Pascual Madoz en 1847, se ha analizado a través de la copia existente en la página web de la Biblioteca Virtual de Andalucía ${ }^{15}$. La consulta del Diccionario de $\mathrm{M}$ adoz no ha a rrojado mucha información acerca del estado de las murallas en la época en la que fue redactado, en 1848. En algunos casos, no se hace ninguna referencia a m uralla o c astillo, como ocurre en Montejo de la Vega de la Serrezuela (Madoz 1848, Tomo XI, 543) donde se describe la situación de la población "SIT. en un hondo circumbalado de alturas", pero no s e hace mención al as construcciones que se ven hoy en día situadas en es as alturas. En otros casos, se encuentran menciones indirectas, como ocurre con Fuentidueña (Madoz 1848, Tomo VIII, 252) donde al describir la situación de dos hospitales se dice " $y$ el otro estramuros llamado de Peregrinos", haciendo referencia a la muralla, pero sin hacer más mención en la descripción de la población. En Coca se hace mención al castillo y sí que se realiza una descripción de los restos de la muralla "se conserva todavía un resto de muralla de cal y canto y una puerta en ella titulada de La Villa que da entrada á la calle

\footnotetext{
${ }^{15}$ http://www.bibliotecavirtualdeandalucia.es/ [Consultado el 22/6/2016]
} 
principal de la pobl., observándose por los demás lados de ella, restos y cimientos de la muralla conque en lo ant. estuvo circundada; sobre el arco de la puerta citada y en el espesor de la misma muralla, hay otra cárcel que es la que comúnmente usaban los alcaldes mayores para custodiar los presos que dependían de su autoridad." (Madoz 1848, Tomo VI, 497). En Íscar (Madoz 1848, Tomo IX, 458) se hace una referencia a un castillo arruinado propiedad de los condes de Miranda.

El Catastro de Marqués de la Ensenada se ha consultado a través de la página web Portal de Archivos Españoles (PARES) ${ }^{16}$ del Ministerio de Educación, Cultura y Deporte. De forma general describe aquellos bienes que producen ganancias económicas y los gastos no se detallan en demasía. No se ha encontrado mención a murallas o castillos en los casos estudiados.

La Biblioteca Nacional de E spaña ofrece una amplia selección de documentos históricos digitalizados que se pueden consultar en su página web. En la Biblioteca Nacional de Francia también se ofrece acceso a ejemplares digitalizados. Se pueden encontrar dibujos de gran interés de varias ciudades españolas (Fig. 4.2).

Se ha consultado documentación acerca de los casos de estudio en la página web del Instituto del Patrimonio Cultural de E spaña, en el apartado de la Planoteca ${ }^{17}$. La información disponible en este portal ha sido principalmente planos de proyectos de restauración realizados durante la segunda mitad del siglo XX.



Fig. 4.2. Captura de pantalla que muestra el portal de la BNF Gallica donde se pueden consultar documentos históricos. En la imagen, perfil de la ciudad de Badajoz por Israël Silvestre Fuente: Biblioteca Nacional de Francia. http://gallica.bnf.fr/ark:/12148/btv1b5971901d/ [Consultado el 18/5/2016].

\footnotetext{
${ }_{17}^{16} \mathrm{http}: / /$ pares.mcu.es/ [Consultado el 26/5/2016]

$17 \mathrm{http}: / /$ ipce.mcu.es/documentacion.html [Consultado el 26/5/2016]
} 
Las murallas en las Comunidades de Villa y Tierra de la Diócesis de Segovia en los siglos XI a XIII. Técnica y sistemas constructivos de la arquitectura defensiva medieval.

\subsubsection{Bibliografía y proyectos de investigación}

Gran parte de la bibliografía empleada en esta investigación se ha consultado y obtenido a través de préstamo en las bibliotecas de I a Universidad de $\mathrm{V}$ alladolid, principalmente en la Escuela de Arquitectura y en las facultades de Filosofía y Letras y de Derecho. Algunos ejemplares se han solicitado a través de préstamo interbibliotecario al Campus de Segovia. También se han solicitado artículos a la plataforma Dialnet ${ }^{18}$ a través del mismo sistema interbibliotecario. Algunos ejemplares se han consultado en la sección de investigación de la Biblioteca Pública de Valladolid.

La búsqueda bibliográfica se ha orientado en varias direcciones. Por una parte, se ha buscado bibliografía relacionada con el contexto histórico de la investigación, con el objeto de documentarse acerca de este periodo y tratar de entender la situación política, económica y social de es tas villas en el momento de construcción de las murallas. Por otra parte, se ha orientado la búsqueda hacia investigaciones acerca de arquitectura defensiva llevadas a cabo en los casos de estudio y en ot ros territorios españoles, concretamente sobre murallas. Finalmente, se ha realizado una búsqueda bibliográfica orientada a los estudios acerca de la construcción medieval en general y en particular de las murallas. Esta última dirección de búsqueda, por ser la más específica, ha sido también la que ha arrojado menos resultados.

La estancia en la Universidad de Toulouse llevada a cabo en el año 2015, permitió el acceso a las bibliotecas de la red universitaria de Toulouse. Se consultaron ejemplares en las bibliotecas siguientes: Bibliothèque Olympe de Gouges, Bibliothèque Universitaire Centrale (BUC Mirail) y el laboratorio de investigación en Arquitectura (Laboratoire de Recherche en Architecture LRA), donde se ha consultado la biblioteca del arquitecto Christian Darles. La biblioteca BUC Mirail posee una sección importante dedicada exclusivamente a publicaciones españolas.

En cuanto a la bibliografía utilizada, se ha tratado, en primer lugar, de localizar las publicaciones relacionadas directamente con murallas de los casos de estudio y también aquellas de carácter histórico que traten los núcleos estudiados. Igualmente, se han bus cado las investigaciones acerca de murallas en ot ras zonas de España, primando aquellas que tenían un enfoque constructivo, con la intención de conocer la manera de anal izar las soluciones constructivas de o tros equipos de investigación españoles. Las publicaciones acerca de la construcción medieval en general también se han consultado. Por otra parte, se ha consultado la bibliografía existente en torno al fenómeno de las Comunidades de Villa y Tierra. En este sentido, se han consultado publicaciones que explican la situación política, económica y social de la época en este territorio y también aquellas que interpretan fueros de villas relacionadas con los casos de estudio.

La bibliografía utilizada se encuentra listada en el capítulo final de la tesis denominado "Bibliografía" y se organiza por orden alfabético. Se escribe de acuerdo con el Chicago Manual Style de la Universidad de C hicago, $16^{\text {a }}$ edición, empleando el sistema de autor-fecha.

\footnotetext{
${ }^{18}$ http://dialnet.unirioja.es [Consultado el 26/5/2016]
} 


\subsection{Tratamiento de datos}

\subsubsection{Selección de casos de estudio}

Las fichas realizadas a partir del trabajo de campo se han utilizado para realizar una selección de los casos de estudio. En esa investigación se ha valorado positivamente la presencia de restos de muralla y la ausencia de investigaciones en curso con enfoque arquitectónico. A raíz de estas valoraciones se han seleccionado seis casos de estudio siguientes: Coca, Cuéllar, Fuentidueña, Maderuelo, Pedraza y Sepúlveda.

4.2.2 Creación de Sistema de Información Geográfica (SIG) para la creación de planos y como método de trabajo.

En cada recinto amurallado estudiado, se ha creído oportuno describir, por medio de planos, algunos aspectos relacionados con la muralla: la localización, la topografía y el parcelario. Para la realización de estos planos se ha c onstruido un Sistema de Información Geográfico (SIG) de trabajo, utilizando el programa ArcGIS ArcMap 10. Para implementar la base de datos se han utilizado, a modo de base, datos de varias instituciones que los ofrecen en formato geolocalizado. El Instituto Geográfico Nacional $(\text { IGN })^{19}$ permite la descarga de información en formatos SHP (Shape), MDB (Base de datos espacial), ECW (imagen ráster georreferenciada), entre otros. Se puede igualmente consultar y descargar planos topográficos o utilizar un servicio de mapas (WMS) del Plan Nacional de Ortofotografía Aérea (PNOA) desde cualquier aplicación SIG. Este instituto ofrece acceso al visor IBERPIX ${ }^{20}$ donde se han consultado y descargado datos de los núcleos analizados de tipo topográfico e histórico.

La web de la Infraestructura de Datos Espaciales de Castilla y León ${ }^{21}$ también permite la descarga de datos en formato SHP; incluye planos de localidades con información sobre edificaciones, hidrografía, caminos, curvas de ni vel y otros. El portal de Infraestructura de D atos Espaciales de Valladolid IDEVall ${ }^{22}$, de la Diputación de Valladolid ofrece acceso a un visor donde ha sido posible consultar y descargar información cartográfica. Para la obtención de cartografía de I os núcleos de l a provincia de Segovia, se ha contactado con el Centro de Información Territorial de la Junta de Castilla y León.

En la página web de la Dirección General del Catastro ${ }^{23}$, ha sido posible consultar los planos catastrales de las villas estudiadas. Se ha empleado esta información en la realización de planos, visualizando la información catastral como base en el programa ArcGIS ArcMap 10, a través del servicio de mapas que ofrecen. Se ha procedido también a la descarga en formato SHP del parcelario de las localidades estudiadas, lo que ha permitido un análisis más exhaustivo de la forma en relación con el recorrido

\footnotetext{
${ }^{19}$ http://www.ign.es/ [Consultado el 26/5/2016]

${ }^{20} \mathrm{http}: / /$ www.ign.es/iberpix2/visor/ [Consultado el 26/5/2016]

${ }^{21} \mathrm{http}: / /$ www.cartografia.jcyl.es/ [Consultado el 26/5/2016]

22 http://idevall.diputaciondevalladolid.es/visor/ [Consultado el 26/5/2016]

${ }^{23}$ http://www.catastro.meh.es/ [Consultado el 26/5/2016]
} 
Las murallas en las Comunidades de Villa y Tierra de la Diócesis de Segovia en los siglos XI a XIII. Técnica y sistemas constructivos de la arquitectura defensiva medieval.

de la muralla. La página web de Catastro permite la descarga de estos datos si se accede a la plataforma con Certificado Digital.

El portal Archivo del Planeamiento Urbanístico y Ordenación del Territorio Vigente ${ }^{24}$ ha permitido la descarga de información urbanística de los casos estudiados. En algunos de ellos, existe valiosa información acerca del recorrido de la muralla. Los archivos disponibles para descarga se encuentran en formato PDF. Cuando ha sido necesario, han sido trasladados a formato JPG para su goerreferenciación y añadidos al SIG creado.

Por último, se han utilizado otros visores como herramientas de trabajo. El visor Goolzoom ${ }^{25}$ permite visualizar, a través de distintas capas, los datos provenientes de servidores de mapas institucionales. Se ha empleado para la preparación del trabajo de campo y para la medición de áreas y distancias en el proceso de elaboración de la tesis doctoral. Se ha empleado igualmente Google Maps ${ }^{26}$ para consultar la fotografía aérea disponible o la nomenclatura de calles y se ha utilizado durante la realización del trabajo de campo a través de un teléfono inteligente.

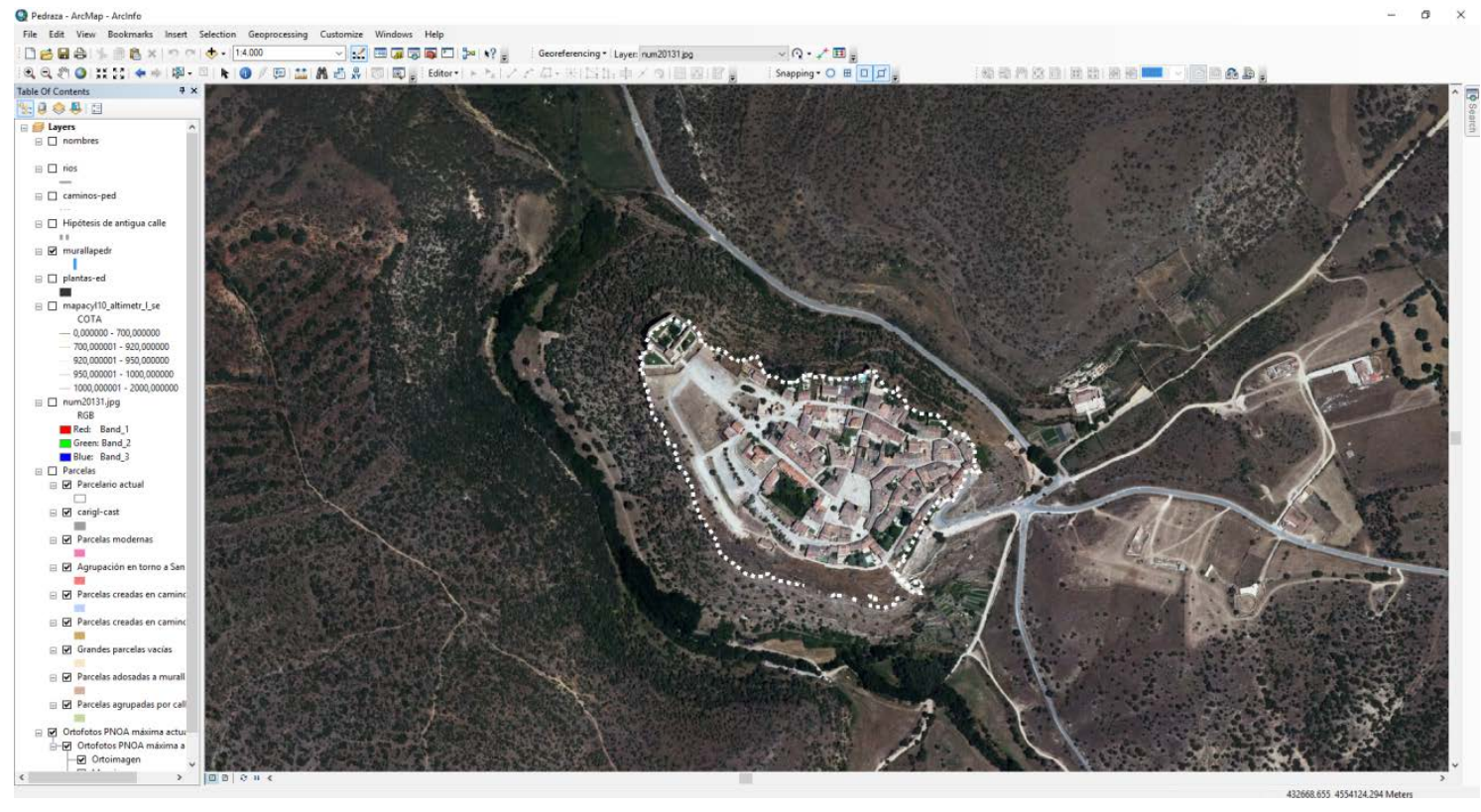

Fig. 4.3. Captura de pantalla del programa ArcGIS ArcMAP 10 donde se observa la villa de Pedraza. La base empleada es una ortofotografía aérea del PNOA. Se ha dibujado un esquema del recorrido de la muralla. Fuente: elaboración propia con datos del PNOA.

El empleo de esta herramienta permite llevar a cabo un análisis territorial y urbano del recinto amurallado. Estos datos, disponibles a través de las descargas de los portales web de instituciones mencionadas anteriormente, se añaden como nuevas capas de datos que se combinan con la documentación obtenida a través del trabajo de campo. Esta combinación permite realizar un análisis de la orografía del recinto amurallado y

\footnotetext{
${ }^{24}$ http://servicios.jcyl.es/PlanPublica/default_plau.do [Consultado el 26/5/2016]

${ }^{25} \mathrm{http}: / /$ es.goolzoom.com/ [Consultado el 26/5/2016]

${ }^{26}$ https://www.google.es/maps/ [Consultado el 26/5/2016]
} 
de su relación con la población facilitando la identificación del trazado de la muralla, de sus ampliaciones, de los barrios en su interior y del crecimiento de barrios nuevos desde sus lienzos.

\subsubsection{Fotogrametría digital a través del software Agisoft PhotoScan}

Se ha aplicado la técnica de la fotogrametría digital para el análisis de los lienzos de muralla. La fotografía rectificada es un sistema útil para crear alzados con información fotográfica u o rtoalzados. El software Agisoft PhotoScan, a través del proceso denominado 3D Model Reconstruction, gestiona las imágenes y los datos introducidos por el usuario y crea un modelo en tres dimensiones del objeto fotografiado. Posteriormente, es posible extraer los alzados de este modelo tridimensional. Para el estudio de las murallas, el interés final de este procedimiento es conseguir un alzado rectificado y en verdadera magnitud de una parte del lienzo, para tener así la posibilidad de realizar mediciones sobre el dibujo. La exportación del modelo en 2D va a permitir obtener esas visuales en modo alzado. El equipo desarrollador del software ofrece unas instrucciones y facilita procedimientos útiles da la hora de realizar las fotografías ${ }^{27}$. En los casos fotografiados en es ta investigación, se han realizado fotografías seriadas, en orden y tratando de mantener la misma distancia al lienzo de muralla. Las fotografías se han realizado a lo largo de una línea imaginaria paralela al lienzo de muralla, a una distancia relativamente próxima de manera que la perspectiva no deforme las fotografías demasiado. En este caso se ha fotografiado a una distancia que permitía a la cámara abarcar la altura del lienzo. Cada fotografía se ha realizado sobre esa línea imaginaria, desplazándose lateralmente un tramo de I ongitud constante para cada fotografía. Entre cada fotografía es necesario asegurar una superposición de al menos un $30 \%$, de forma que el software identifique adecuadamente la continuidad de unas imágenes con otras. Las instrucciones del equipo desarrollador del software proponen, en los casos de fotografía aérea, superposiciones de $60 \%$ e incluso $80 \%$. Para garantizar el éxito de un alzado rectificado, siempre será recomendable que se hagan más imágenes y con un mayor solape frente a ajustar demasiado y no tener suficientes imágenes para completar el alzado.

De cara a la toma de medidas que se pretende realizar en la fotografía rectificada, es necesario tomar puntos de referencia en el momento de hacer las fotografías. Estos puntos de referencia se pueden tomar de varias maneras: se pueden anotar directamente las coordenadas de al menos dos puntos que luego se introducirán en el programa; se puede anotar la distancia entre dos puntos conocidos y fácilmente identificables en la fotografía; otra opción es incorporar un metro visible en la fotografía o una retícula de puntos situados a una distancia o coordenadas conocidas.

\footnotetext{
${ }^{27}$ http://www.agisoft.com/support/tips-tricks/ [Consultado el 26/5/2016]
} 
En la realización de estas fotografías seriadas, siempre aparecen cuestiones que dificultan el trabajo. En las zonas de gran desnivel no es posible alejarse de los lienzos de muralla para realizar las fotografías adecuadas. Los objetos o el ementos que se sitúan cercanos a I os lienzos se convierten en obstáculos visuales a la hora de fotografiar los lienzos. Es habitual encontrar árboles, coches, construcciones muy próximas, cableado y otros objetos que ocultan parte del objeto a fotografiar.

El tiempo del día elegido para la realización de I a fotografía también tiene una incidencia en el resultado. Cuando el día es demasiado soleado, se produce la proyección de sombras en el paramento que hacen más compleja la interpretación de los elementos fotografiados. Fotografiar en un día nublado puede evitar la aparición de contrastes entre luces y sombras en las fotografías.



Fig. 4.4. Captura de pantalla del software Agisoft Photoscan. Se muestra un tramo de la muralla de Cuéllar. Fuente: Elaboración propia.

Se puede r esumir de forma simplificada el proceso de obt ención de los alzados rectificados con este software. La creación del modelo 3D se compone de cinco pasos o comandos. El primero de ellos es la adición de las fotografías con las que se quiere componer el alzado. El segundo es alinear o posicionar las fotografías. El programa analizará las fotografías suministradas y las alineará automáticamente. El tercer paso es el de construir una nube de puntos densa. A partir de la posición de la cámara, el programa es capaz de construir el relieve del objeto fotografiado, en este caso el relieve del lienzo, reflejando las irregularidades e imperfecciones. En este punto podemos posicionar y dimensionar correctamente el modelo en caso de necesitarlo. El cuarto paso es la construcción de la malla que define el modelo representándolo en polígonos. El quinto paso permite la aplicación del a textura sobre el modelo, ofreciendo el resultado final del modelo 3D. Las instrucciones de creación de modelos en 3D se detallan con profundidad en las guías redactadas por el propio software, y se 
encuentran disponibles en internet ${ }^{28}$. Una vez creado el modelo $3 \mathrm{D}$, el programa permite exportar alzados del modelo en $2 \mathrm{D}$, a través de archivos ráster.

\subsubsection{Dibujo en AutoCAD sobre fotografía rectificada}

Una vez obtenida la fotografía rectificada en verdadera magnitud de un lienzo de muralla, se ha introducido en el programa de dibujo AutoCAD. Sobre esta fotografía se han dibujado los elementos constructivos visibles: líneas de encofrado, mechinales, piedras dispuestas de forma ordenada y piedras o el ementos singulares. Se ha identificado también las diferencias en el paramento, debidas a reparaciones o a otras razones. Se dibuja directamente en la foto rectificada, ayudándose con otras fotos tomadas de la zona para interpretar mejor los elementos, con fotos que sean más cercanas o que permitan identificar los detalles de forma más acertada, ya que en la foto rectificada puede verse enmascarado o haber perdido resolución en el proceso.



Fig. 4.5. Captura de pantalla que muestra el dibujo sobre la fotografía rectificada en AutoCAD. Se trata de una parte de la muralla de Sepúlveda. Fuente: Elaboración propia.

${ }^{28}$ http://www.agisoft.com/pdf/photoscan-pro_1_2_en.pdf [Consultado el 26/5/2016] 
Las murallas en las Comunidades de Villa y Tierra de la Diócesis de Segovia en los siglos XI a XIII. Técnica y sistemas constructivos de la arquitectura defensiva medieval.

En función del estado de conservación de los lienzos, o de si se han producido reparaciones en los mismos, las marcas constructivas serán más o menos evidentes. Muchos de los elementos constructivos como los mechinales o las divisiones verticales de las tapias no son visibles. Aun así, es posible deducir la posición hipotética de muchos de ellos teniendo en cuenta los elementos constructivos visibles y su relación entre sí: por su posición o por la distancia entre mechinales.

A través del dibujo de elementos constructivos, se extraen las medidas de los mismos y se reflejan en una tabla Excel, o en formato CSV. Dado el empleo de la tapia en todos los casos, se han extraído los datos dimensionales de este elemento: anchura, altura, grosor, separación de mechinales, número de mechinales.

\subsubsection{Dibujo sobre fotografía sin rectificar}

El dibujo sobre fotografías sin rectificar se ha utilizado en zonas donde es difícil obtener las fotografías necesarias para un alzado rectificado, donde es complicado tomar medidas o donde existen elementos que ocultan el paramento. Este procedimiento no se emplea para la toma de medidas sino que se utiliza para resaltar elementos constructivos o singulares. El objetivo de este sistema es el de observar los paramentos y señalar los distintos elementos constructivos. Se trata de un sistema útil para analizar y describir una fotografía que permite resaltar elementos no evidentes en una imagen y clasificarlos por categorías en función de criterios como el color, el material o la forma.

\subsection{Análisis de datos}

\subsubsection{Análisis general de casos: localización, topografía y parcelario}

Para cada caso de e studio se ha realizado un anál isis general que muestra la localización del recinto amurallado en el territorio. Se ha analizado la topografía que rodea el núcleo amurallado, a través del dibujo de un plano que arroja datos como la altitud del núcleo y del territorio circundante, los elementos geográficos que rodean el asentamiento como ríos o ar royos. La ex istencia de c aminos es otro elemento de interés que se ha reflejado en los planos de análisis de los núcleos. Este análisis territorial permite entender el recorrido de la muralla, de gran extensión en varios de los casos analizados y muy vinculado con los desniveles de terreno o los ríos y arroyos.

Ya en el ámbito urbano, el parcelario actual se ha analizado de forma general, para observar la relación que mantiene con el recorrido de la muralla. Se ha incluido la información parcelaria en el plano del recinto amurallado con un código de colores que indica las distintas zonas urbanas identificadas. La forma de las parcelas y su tipo de agrupación puede servir de ay uda en la interpretación de los restos de muralla. La dirección de las calles o la forma que han adquirido permite entender la estructura 
urbana del núcleo. Es habitual observar agrupaciones de parcelas en torno a un edificio religioso o reconocer estructuras similares de calles a su paso por puertas de muralla.

\subsubsection{Análisis del recinto amurallado y sus elementos}

En cada caso de estudio, se han descrito los restos amurallados y cada uno de sus elementos como lienzos, torres y puertas. Para ello se ha numerado en el plano del recinto amurallado las torres con la nomenclatura $T$ - seguida de una numeración consecutiva y las puertas con la nomenclatura P- también seguida de una numeración consecutiva. Se ha tomado como ejemplo el sistema empleado por Miguel Ángel Blanco $(2014,166)$ para nombrar las torres del recinto de Segovia. Las torres de cada puerta también poseen numeración de torre. Se ha seguido el ejemplo de M. Dolores Martín Aymerich $(1990,140)$ al numerar también las torres que componen una puerta para poder referirse a ellas de forma individual. Los lienzos se han numerado a partir de las torres que los delimitan, cuando ha sido posible por la existencia de torres, resultando nombres de este tipo T1-T2 para referirse a un lienzo entre las torre T1 y T2. Cuando existe un lienzo flanqueado únicamente por una sola torre, se ha utilizado la nomenclatura de la torre y la dirección cardinal en la que parte el lienzo. De esta forma T1-oeste haría referencia a un lienzo que desde la torre T1 parte hacia el oeste. Cuando no existen torres, se ha utilizado la nomenclatura L- seguida de una numeración consecutiva para referirse al lienzo. Cuando ha sido necesario situar un tramo dentro de un lienzo de gran longitud sin torres ni puertas, se ha indicado la longitud a recorrer desde uno de los extremos y en qué sentido cardinal. T1-oeste100, situaría un tramo a 100m de muralla en dirección oeste desde la torre T1.

El análisis del recinto amurallado incorpora una descripción general del asentamiento y una descripción de cada uno de los elementos integrantes a la muralla. En ocasiones se ha considerado necesario describir otros elementos, que aún no siendo parte de la muralla, guardan una relación con la misma que se considera de interés. Se ha ilustrado con fotografías de cada uno de los tramos y torre.

\subsubsection{Análisis constructivo}

En el análisis constructivo se realiza una i dentificación de s oluciones constructivas encontradas en la muralla, a través de fotografías de cada una de ellas. A través de una tabla, se indica la localización de las técnicas constructivas identificadas. Además de la identificación de técnicas empleadas, se seleccionan lienzos o partes de lienzos, puertas o torres para un análisis constructivo más pormenorizado, que se explica a continuación. 
Las murallas en las Comunidades de Villa y Tierra de la Diócesis de Segovia en los siglos XI a XIII. Técnica y sistemas constructivos de la arquitectura defensiva medieval.

\subsubsection{Identificación de elementos}

En cada uno de los casos, se han seleccionado un número de lienzos de la muralla para un estudio constructivo más profundo. Para ello se ha elegido los tramos que se ha creído que reunían el mayor interés y aquellos a los que se ha tenido acceso. El estudio se ha basado en la identificación de las tapias empleadas para su construcción, caracterizando cada uno des us parámetros, con el objeto de clasificarlas de acuerdo con su tipología. Las medidas de las tapias y de los elementos que las componen se han extraído en tablas y se han determinado con la ayuda de técnicas estadísticas. Se han empleado los alzados realizados con fotogrametría digital, cuya creación se describe en este mismo capítulo. Los pasos que se han seguido para el análisis de los paramentos son los siguientes:

- Identificación de líneas que delimitan las tapias, visibles en sentido horizontal y vertical

- Identificación de los mechinales visibles en el lienzo

- Identificación de tapias en función de límites verticales, horizontales y de los mechinales encontrados.

- Identificación de o tros elementos singulares, construidos con sillares, mampuestos o ladrillo.

- Identificación de líneas verticales de tramo que delimiten tramos de muralla.

- Búsqueda de tapias residuales, realizadas así por tratarse de un espacio que falta por rellenar, habitualmente de dimensiones más pequeñas. De acuerdo con Cobos $(2012,122-123)$ este sistema es útil para identificar el orden de construcción de tapias. La existencia de piedras colocadas en el límite vertical de la tapia pueden dar pistas acerca de la construcción del encofrado.

- Análisis de Ios mechinales encontrados: posición en la tapia, sección, profundidad, dimensiones, materiales empleados en su construcción, existencia de $v$ erdugadas en I a línea de $m$ echinales, existencia de desniveles en línea de mechinales.

- Extracción de medidas de elementos visibles en tablas: altura y anchura de las tapias identificadas, separación de los mechinales en la misma tapia y entre tapias diferentes.

- Hipótesis para la situación de límites de tapias o posición de mechinales. A partir de los datos recogidos visibles y de acuerdo con las dimensiones extraídas, sería posible situar de forma hipotética los límites de las tapias y la posición de sus mechinales, diferenciando con claridad qué elementos son visibles y cuáles se han situado de forma hipotética.

\subsubsection{Tipología constructiva}

Varios equipos de investigación han ideado sistemas de clasificación de tapias en los últimos años. Aquellos que han resultado de mayor interés para esta investigación son dos métodos desarrollados por Amparo Graciani y Miguel A. Tabales $(2008,139)$ en el 
área sevillana y por Ignacio J. Gil Crespo $(2013,554-557)$ en la provincia de Soria. Este último autor realiza una des cripción de otras clasificaciones que agrupan exclusivamente las tapias de tierra compactada o que se limitan a un número de casos concreto (549-552).

El sistema de Amparo Graciani y Miguel A. Tabales divide los tipos de tapia en dos grandes grupos, el tipo monolítico y el tipo mixto. El tipo mixto tiene gran protagonismo en esta clasificación, de casi el $90 \%$, subdividiéndose en tres categorías: verdugados, encadenados y de fraga. Cada una de estas categorías se subdivide en función del material empleado en machones. A su vez, cada uno de los tipos monolítico y mixto presenta varias soluciones de mechinal (Tabla 4.1). Esta clasificación es muy visual y de comprensión sencilla, por la diferenciación de los dos tipos. Permite obtener una idea rápida de la naturaleza de la tapia.

Tabla 4.1. Resumen interpretativo de la clasificación tipológico-estructural de Amparo Graciani y Miguel A. Tabales $(2008,139)$ en el área sevillana. No se ha incluido la información acerca de periodos cronológicos.

\begin{tabular}{|c|c|c|c|c|c|}
\hline & \\
\hline & & & & Mechinal & Verdugada \\
\hline \multirow{2}{*}{\multicolumn{4}{|c|}{ Monolítico }} & Sin remate & \multirow[b]{2}{*}{ Sin verdugada } \\
\hline & & & & Remate mampuesto & \\
\hline \multirow{13}{*}{ Mixto } & \multirow{3}{*}{\multicolumn{3}{|c|}{ Verdugado }} & Sin remate & En mampuesto \\
\hline & & & & Sin remate & \multirow{2}{*}{ En ladrillo } \\
\hline & & & & Remate latericio & \\
\hline & \multirow{5}{*}{ Encadenados } & \multirow{2}{*}{\multicolumn{2}{|c|}{ En ladrillo }} & Sin remate & \multirow{5}{*}{ Sin verdugada } \\
\hline & & & & Remate latericio & \\
\hline & & \multirow{3}{*}{\multicolumn{2}{|c|}{ En piedra }} & Sin remate & \\
\hline & & & & Remate mampuesto & \\
\hline & & & & Remate latericio & \\
\hline & \multirow{5}{*}{ De fraga } & \multicolumn{2}{|c|}{ Encadenado pétreo } & $\begin{array}{c}\text { Verdugada en } \\
\text { mampuesto }\end{array}$ & Verdugada en ladrillo \\
\hline & & \multicolumn{2}{|c|}{ Témpanos mixtos } & & \\
\hline & & \multirow{3}{*}{ Latericio } & \multirow{2}{*}{$\begin{array}{l}\text { Varios } \\
\text { cajones }\end{array}$} & Remate latericio & $\begin{array}{c}\text { Verdugada simple de } \\
\text { ladrillo }\end{array}$ \\
\hline & & & & Sin remate & $\begin{array}{c}\text { Verdugada doble de } \\
\text { ladrillo }\end{array}$ \\
\hline & & & $\begin{array}{l}\text { Cajón } \\
\text { único }\end{array}$ & Sin remate & $\begin{array}{c}\text { Verdugada doble de } \\
\text { ladrillo }\end{array}$ \\
\hline
\end{tabular}

En esta investigación la gran mayoría de tapias empleadas se incluye en el tipo monolítico. No obstante, algunas de las tapias de este estudio no se ven reflejadas en esta clasificación. Son tapias monolíticas, pero con variables no ex istentes en e sa categoría. Estas variables requerirían de la ampliación del apartado monolítico indicando características como por ejemplo verdugadas del mismo material cuando la tapia es de mampuestos, o la utilización de los muretes de piedra para el cierre lateral del cajón. En esta clasificación la sola existencia de v erdugadas nos lleva a la 
Las murallas en las Comunidades de Villa y Tierra de la Diócesis de Segovia en los siglos XI a XIII. Técnica y sistemas constructivos de la arquitectura defensiva medieval.

inclusión de una tapia en la tipología mixta, cuando la impresión al contemplar la tapia es de homogeneidad. La existencia o no de verdugada es una variable similar al mechinal, que existe para todas las tapias, pues indica cómo está resuelto el límite horizontal de Ia tapia. La consideración de la existencia o no de verdugada como variable en lugar de cómo tipo puede simplificar la clasificación. Esta variable está presente en todos los tipos.

El sistema planteado por Ignacio J. Gil Crespo abarca gran cantidad de variables que definen la tapia. En este sistema se agrupan la tipología constructiva de las tapias en siete categorías que se nombran con letras de la "A" a la "G". Esta última categoría presenta cuatro subcategorías que reciben las letras de la "a" a la "d". Las categorías A-G identifican el material de construcción, la compactación del tapial, la función constructiva, el encofrado, el acabado superficial, si existe combinación de materiales, la posición y profundidad de los mechinales y finalmente qué forma y sección tienen (Tabla 4.2). Por un lado, se trata de una clasificación que desgaja muchas variables y que permite el añadido de nuevas variables si no están contempladas en la tabla. Por contra, no permite obtener una visión rápida de la solución constructiva si se da el nombre de la tapia de forma alfanumérica: A3/D1/C2/D-3/E-4/F-1/G-a2-b3-c1-d1.

Tabla 4.2. Resumen de la tipología constructiva de tapias de acuerdo con la clasificación de Ignacio J. Gil Crespo $(2013,554-557)$

\begin{tabular}{|c|c|}
\hline A. Material de construcción & $\begin{array}{l}\text { 1. Tierra } \\
\text { 2. Tierra con tongadas de cal } \\
\text { 3. Tierra hormigonada (con cal y reble) } \\
\text { 4. Cal y canto } \\
\text { 5. Mampostería }\end{array}$ \\
\hline B. Compactación del material & $\begin{array}{l}\text { 1. Con pisón } \\
\text { 2. Vertido }\end{array}$ \\
\hline C. Función constructiva & $\begin{array}{l}\text { 1. Fábrica principal } \\
\text { 2. Relleno de paramentos. } \\
\text { 3. Relleno interior de muros de piedra o ladrillo }\end{array}$ \\
\hline D. Encofrado & $\begin{array}{l}\text { 1. Cajones independientes con tapiales testeros o fronteras } \\
\text { 2. Cajones que hacen hilos continuos con junta inclinada } \\
\text { 3. Cajones que se construyen como rellenos de los cuarterones entre } \\
\text { machones de ladrillo, piedra o adobe }\end{array}$ \\
\hline E. Acabado superficial & $\begin{array}{l}\text { 1. Tierra apisonada sin revestimiento } \\
\text { 2. Capa calicostrada } \\
\text { 3. Tierra sin acabado } \\
\text { 4. Capa externa de sillería o de mampostería }\end{array}$ \\
\hline F. Combinación de materiales & $\begin{array}{l}\text { 1. Solo tierra } \\
\text { 2. Con verdugadas de ladrillo } \\
\text { 3. Brencas de cal }\end{array}$ \\
\hline $\begin{array}{l}\text { G. Mechinales } \\
\text { G-a. Situación }\end{array}$ & $\begin{array}{l}\text { 1. Situación en el propio hilo } \\
\text { 2. Situación cajeados en el hilo inferior } \\
\text { 3. Situación en el espesor de la verdugada de ladrillo } \\
\text { 4. Situación fuera de la fábrica encofrada o de tapia }\end{array}$ \\
\hline G-b. Profundidad & $\begin{array}{l}\text { 1. Medias agujas } \\
\text { 2. Agujas pasantes }\end{array}$ \\
\hline
\end{tabular}




\begin{tabular}{|l|l|}
\hline G-c. Formación & 1. Formación aguja embebida en la fábrica \\
& 2. Formación aguja recuperable \\
& 3. Formación con cielo de mampuestos o ladrillos, o teja \\
4. Formación con cajeado con interrupción de verdugada de ladrillo \\
G-d. Sección & 1. Cuadrangular \\
& 2. Rectangular \\
3. Plana & 4. Circular \\
5. Varillas pareadas & 6. Sector de circunferencia \\
\hline
\end{tabular}

\subsubsection{Aproximación al análisis estadístico de datos: utilización del programa $R$}

En el análisis de las dimensiones de los elementos constructivos empleados en Ia construcción de murallas se ha considerado de utilidad el empleo de la estadística. Al tratarse de una construcción artesanal o manual, se aprecia gran irregularidad en las dimensiones empleadas. En la toma de datos de un mismo tramo de muro, es posible que la medición de la altura de 25 tapias arroje resultados diversos de manera que sea difícil afirmar cuál es la altura de tapia más habitual. Por esta razón, se han utilizado herramientas de estadística descriptiva para manejar los datos recogidos en I os lienzos de muralla. Para el cálculo y la creación de gráficas, se ha utilizado el programa informático R. La herramienta empleada ha sido el "diagrama de caja" o boxplot, una gráfica sencilla que ofrece una imagen completa de la distribución de los datos de una variable. El gráfico muestra una caja, un cuadro que se dibuja orientado en paralelo con el eje de ordenadas y tiene la misma escala que el conjunto de datos.



Fig. 4.6. Diagrama de caja de la altura de tapias de de los restos de "El Caserón" en Montejo, Segovia. Fuente: Elaboración propia con el programa R.
Separación mechinales en tapia



Fig. 4.7. Diagrama de caja de la separación de mechinales entre distintas tapias de "El Caserón" en Montejo, Segovia. Fuente: Elaboración propia con el programa $\mathrm{R}$. 
Las murallas en las Comunidades de Villa y Tierra de la Diócesis de Segovia en los siglos XI a XIII. Técnica y sistemas constructivos de la arquitectura defensiva medieval.

De acuerdo con la documentación disponible en la página web del programa ${ }^{29}$, la parte superior e inferior del rectángulo coinciden respectivamente con el tercer cuartil y el primer cuartil de los datos. La caja está dividida por una línea horizontal gruesa que marca la mediana del $50 \%$ datos. La altura de la caja coloreada se denomina rango intercuartílico. Cuanta menor sea su altura, mayor será la concentración de datos y menor la distribución. Se denominan "bigotes" a las líneas que parten de la parte inferior y superior de la caja, que se extienden hasta la mayor observación de los datos, si estos se encentran dentro de un paso (el paso se define como una vez y media el rango intercuartílico). Cuando existen valores atípicos, estos se representan más allá del límite de Ios bigotes. El diagrama de caja es un gráfico sencillo pero eficaz. Se utiliza para ilustrar un conjunto de datos, para estudiar la simetría de ese conjunto o para comparar entre diferentes conjuntos. En los ejemplos a continuación, se muestra como ejemplo los datos extraídos del muro de "El caserón" en Montejo de la Vega de la Serrezuela. La altura de tapias (Fig. 4.6) muestra un rango intercuartílico entre $115 \mathrm{~cm}$ y $118 \mathrm{~cm}$, con un valor de $3 \mathrm{c} \mathrm{m}$. La m ediana de I os datos, que se considerará como la altura más habitual empleada es de $117 \mathrm{~cm}$. Se identifican dos valores como atípicos en el conjunto de datos. En el caso de la separación entre mechinales dentro de una misma tapia (Fig. 4.7), se observa que la caja se mantiene entre los valores $125-129 \mathrm{~cm}$, con un rango intercuartílico de $4 \mathrm{~cm}$. La mediana de los datos es de $127 \mathrm{~cm}$, por lo que podría afirmarse que la medida más habitual se sitúa en los $127 \mathrm{~cm}$.

Esta herramienta permite representar de forma más visual qué medidas de tapia se están manejando en un tramo de muralla. Dado el carácter artesano de la construcción medieval, es evidente una ausencia de normalización de dimensiones como se conoce en la actualidad. Sin embargo, al representar mediante este procedimiento las dimensiones de cada tapia, se observa que todas ellas son diferentes, pero sus valores se concentran mayoritariamente en un rango concreto y tienden a una $c$ ifra que podría considerarse más habitual. Este hecho implica un cierto consenso en los constructores de tapias, cuyo origen podría encontrarse en las dimensiones de los tapiales o tal vez tuviera razones más funcionales como la eficacia de un volumen de tapia para un número de trabajadores concreto o por el tiempo de construcción de una tapia en relación con las horas de luz de un día.

Para la comparación de varios lienzos de muralla, aportando varias características de cada uno de ellos, como las dimensiones de las tapias, las dimensiones de sus elementos, sus formas, sus materiales o la posición de elementos en las tapias, es posible aplicar un $\mathrm{m}$ étodo de reducción de di mensionalidad denominado "Componentes Principales". Esta técnica permite realizar una síntesis de la información cuando se manejan datos con muchas variables. De acuerdo con Luis César Herrero Prieto $(1990,649)$ este método consiste en obtener variables nuevas a partir de una combinación lineal de las variables originales y en número menor, para que reflejen la mayor proporción posible de la dispersión existente en los datos iniciales. El cálculo de estas nuevas variables se realiza con el programa $R$ y pasan a

${ }^{29}$ https://cran.r-project.org/doc/contrib/grafi3.pdf [Consultado el 15/6/2016] 
sustituir a las variables iniciales. Se toman las dos primeras variables, que constituirán las componentes principales. Son estas dos variables con las que se va a pode $r$ construir un gráfico bidimensional, permitiendo de esta forma plasmar las múltiples variables que afectan a cada uno de los lienzos. El gráfico en formato biplot posee las abscisas y ordenadas las dos componentes principales, cada uno de los casos se sitúa en esas coordenadas y se aproxima a otros casos en función de su afinidad. De forma superpuesta, quedan representadas mediante vectores las variables iniciales el conjunto de datos señalando la dirección de tendencia para el conjunto de datos. A continuación se muestra un ejemplo de extracción de componentes principales del programa $\mathrm{R}^{30}$ :



Con el uso de esta herramienta se hace posible una visión objetiva de un conjunto de datos con gran número de $v$ ariables. El resultado permite valorar la afinidad de algunos casos con otros y también la relación de unas variables con otras, cuando se oponen o van en la misma dirección los vectores de distintas variables. Desde un punto de vista constructivo, puede permitir relacionar un rango de espesor con un tipo de tapial empleado o la existencia de verdugadas de acuerdo con el tipo de piedra utilizado.

\footnotetext{
${ }^{30}$ Se pueden consultar los datos completos en el anexo 2, para la gráfica Fig. 5.7.53
} 
Las murallas en las Comunidades de Villa y Tierra de la Diócesis de Segovia en los siglos XI a XIII.

Técnica y sistemas constructivos de la arquitectura defensiva medieval.

\subsection{Material y herramientas utilizados}

En la lista a continuación se encuentra reflejado el material y las herramientas empleadas en la investigación. Las características técnicas de los dispositivos electrónicos se detallan en los anexos.

- Cámara fotográfica Olympus SZ-16 DZ-105 (Fig. 4.8)

- Medidor láser BOSCH PRL 25 (Fig. 4.9)

- Material de dibujo

- Material para toma de notas

- Metro convencional para medir distancias

- Ordenador de mesa con sistema operativo Windows 10, 64 bits y ordenador portátil con sistema operativo Windows 7,64 bits, con el software siguiente:

- AutoCAD Map 3D 2011

- Adobe Photoshop CS5 Extended, versión 12.0

- ESRI ArcGIS ArcMAP 10.0

- Microsoft Office 2007: Microsoft Word, Microsoft Excel, Microsoft Power Point.

- Agisoft PhotoScan Professional Edition, versión 1.0.3, Multi-view 3D reconstruction.

- Adobe Acrobat X Pro, versión 10.0.0

- $\quad R$, versión 3.3.0

- Smartphone con sistema operativo Android y software siguiente:

- Google Maps

- Cámara de fotos de apoyo

- Google Drive

- Acceso a internet. En internet está disponible una pa rte importante de la bibliografía consultada para la realización de esta tesis doctoral. Internet ofrece la posibilidad de consultar numerosos artículos, libros y fuentes históricas que se encuentran en línea. Algunas instituciones poseen una biblioteca digital donde ponen a disposición del público muchas publicaciones. Además, como ya se ha mencionado en este capítulo, internet da acceso a bases de datos de tipo catastral o topográfico.

La herramienta Google Académico ha permitido consultar algunas publicaciones de forma parcial. Se han empleado otros buscadores para localizar artículos en revistas o actas de congresos. Además del ya mencionado Dialnet, se han consultado otras plataformas como SCIMAGO ${ }^{17}$ JSTOR $^{18}$ o ProQuest ${ }^{19}$. A través de la página web de la Fundación Española

\footnotetext{
${ }^{17}$ http://www.scimagojr.com/ [Consultado el 26/5/2016]

${ }_{18}^{18} \mathrm{http}: / /$ www.jstor.org/ [Consultado el 26/5/2016]

${ }^{19} \mathrm{http}: / /$ www.proquest.com/ [Consultado el 26/5/2016]
} 
para la Ciencia y la Tecnología (FECyT $)^{20}$ se ha consultado las bases de datos de Web of Science (WOS) ${ }^{21}$ y SCOPUS ${ }^{22}$. En aquellas plataformas donde es requerida una clave de acceso, se ha accedido a través de la suscripción que tiene a este efecto la Universidad de Valladolid. El portal Urbadoc también ha resultado de utilidad $^{23}$. A través del Repositorio Documental de la Universidad de Valladolid ${ }^{24}$ también se ha podi do acceder a trabajos de i nvestigación realizados en esta universidad.



Fig. 4.8. Cámara de fotos Olympus SZ-16 DZ-105. Fuente: imagen del fabricante.



Fig. 4.9. Medidor láser BOSCH PRL 25. Fuente: imagen del fabricante.

\subsection{Formación investigadora}

4.5.1 Conocimiento de otros métodos de investigación: estancia en una universidad extranjera

Durante el año 2015 se realizó una es tancia de tres meses en la Universidad de Toulouse Jean Jaurès, concretamente en el centro Maison de la Recherche, bajo la tutela de $\mathrm{N}$ elly Pousthomis-Dalle, profesora de Historia del Arte y Arqueología Medieval. La estancia comenzó el 20 de julio de 2015 y finalizó el 30 de octubre de 2015. El objetivo de esta estancia ha sido conocer la metodología de investigación del equipo de arqueólogos de TRACES de la Universidad de Toulouse Jean Jaurès con la finalidad de aplicar algunos de su metodología y puntos de vista en la presente investigación. Esta estancia ha permitido también la solicitud de la mención internacional para esta tesis doctoral.

La estancia se ha c ompuesto de $v$ arias etapas, la primera etapa consiste en I a participación en la excavación arqueológica de un hábi tat rural de la Edad Media denominado la Coume Païrounell, en el municipio de A ngoustrine-Villeneuve-des-

\footnotetext{
${ }^{20} \mathrm{https}: / / w w w . r e c u r s o s c i e n t i f i c o s . f e c y t . e s /$ [Consultado el 26/5/2016]

$21 \mathrm{http}: / /$ www.webofscience.com/ [Consultado el 26/5/2016]

$22 \mathrm{https}: / /$ www.scopus.com/ [Consultado el 26/5/2016]

${ }^{23} \mathrm{http}: / /$ www.urbadoc.com/ [Consultado el 12/8/2016]

${ }^{24} \mathrm{http}: / /$ uvadoc.uva.es/ [Consultado el 26/5/2016]
} 
Escaldes, en los Pirineos Orientales. La excavación estaba dirigida por la arqueóloga Noémie Luault. Este yacimiento se ha es tudiado al o largo de varios años, identificando edificaciones de origen doméstico y de carácter aislado. Se trata de edificaciones de forma rectangular y dimensiones variables.

Para este periodo se ha continuado con la excavación de una de es tas edificaciones, en una superficie de $10 \times 10 \mathrm{~m}$ aproximadamente, donde se encuentra una gran acumulación de piedras que podrían ser el resultado de una progresiva demolición del edificio. Según va avanzando la excavación, se van identificando y exponiendo piedras ordenadas, alineadas, que muestran la existencia de muros. La aparición de trozos de cerámica procedente de vasijas, permite proceder a una datación y da pistas acerca del carácter de las construcciones de época medieval.



Fig. 4.10. Restos de edificio integrante del hábitat rural medieval de Coume Païrounell [A.S.E. 25/7/2015].



Fig. 4.11. Base del muro de una de la edificación excavada del hábitat rural medieval de Coume Païrounell [A.S.E. 29/7/2015].

En un segundo periodo, se ha participado en la excavación arqueológica en la zona norte de la Abadía de Santa María de Orbieu. Esta abadía se encuentra en Lagrasse, población cercana a Carcassonne. En el interior de la abadía, así como en varias de sus fachadas, se han llevado a c abo análisis estratigráficos de los paramentos, sacando a la luz estructuras ocultas (Fig. 4.12). Además del análisis visual y a través de dibujos y levantamientos, así como la identificación de unidades constructivas, se procede a eliminar unidades estratigráficas, con el objeto de descubrir nuevas bajo las más exteriores, de la misma manera que ocurre en una excavación convencional. De esta manera, se eliminan capas de $r$ evestimiento o de enl ucidos para continuar estudiando las capas interiores.

En el jardín norte de la abadía, en los denominados jardines del Abad, se llevó a cabo una excavación que expuso varios muros de piedra y una canalización medieval. Se excavó en un rectángulo de $6 \times 10 \mathrm{~m}$, con una extensión de $3 \times 3 \mathrm{~m}$ en el lado norte del rectángulo, dando lugar a una superficie completa de $69 \mathrm{~m}^{2}$. Se inició la excavación con una pala mecánica, que descendió hasta la profundidad de 1,20 m. A este nivel ya se podían observar restos de construcciones. A partir de este nivel, se redujo el área de excavación en $1 \mathrm{~m}$ por cada lado, con el objeto de realizar una ex cavación 
escalonada en profundidad para evitar desplomes de terreno. Se continuó con una excavación manual, dividiendo la superficie en dos sectores de $4 \mathrm{x} 4 \mathrm{~m}$ aproximadamente. Al final de la excavación se pudo observar un tramo de muro de gran espesor, cercano a los $2 \mathrm{~m}$, a una profundidad de $3 \mathrm{~m}$, formando un ángulo recto. Sobre éste se observa como apoya el muro descubierto en primer lugar, de menor espesor (Fig. 4.13).



Fig. 4.12. Interior de la Abadía de Lagrasse [A.S. E. $17 / 8 / 2015]$



Fig. 4.13. Excavación en el jardín norte de I a Abadía de Lagrasse [A.S.E. 5/9/2015]

4.5.2 Puesta en común de los avances de la investigación: publicaciones y participación en congresos

En los últimos años, en la enseñanza universitaria de doctorado, se ha hecho hincapié en la importancia de publicar artículos en libros y revistas y en asistir a congresos durante el periodo en el que se está realizando la tesis doctoral. Esta cuestión choca con la postura de otras épocas, en las que la tesis debía elaborarse en la más estricta privacidad. En el desarrollo de esta tesis doctoral, se ha participado en varios congresos, compartiendo parte de las investigaciones realizadas. En el año 2014, se participó en el XI CIATTI 2014, el Congreso Internacional de Arquitectura de Tierra, con la comunicación "Aproximación al sistema constructivo del as murallas de Fuentidueña, Segovia”, donde se expuso un análisis constructivo inicial de la muralla de esta villa (Sainz Esteban 2015a). Ese mismo año se participó en las Jornadas "Los espacios del poder regio (ca. 1050-1385). Procesos políticos y representaciones" donde se contribuyó con una ponencia acerca del conjunto amurallado de Fuentidueña denominada "Análisis del conjunto amurallado de Fuentidueña, Segovia. La muralla como documento histórico". Este congreso, organizado por la Universidad de Navarra, se componía principalmente de investigadores en Historia Medieval, cuyos enfoques son distintos a los arquitectónicos y permitieron ampliar la visión sobre la investigación. En el año 2015, se participó en el IX Congreso Nacional y I Congreso Internacional Hispanoamericano de Historia de la Construcción, en el que que se presentó la comunicación "Sistema constructivo de las murallas en I as comunidades de V illa y Tierra. Los casos de Coca, Cuéllar y Montejo, Segovia" (Sainz Esteban 2015b). En 2016, se participó en un congreso a nivel internacional, organizado por la Universidad 
Las murallas en las Comunidades de Villa y Tierra de la Diócesis de Segovia en los siglos XI a XIII. Técnica y sistemas constructivos de la arquitectura defensiva medieval.

de Cambridge en el Queens College, con la comunicación "Constructive similarities and differences in the walls in 'Comunidades de Villa $y$ Tierra' in the Diocese of Segovia, Spain" (Sainz Esteban 2016). La participación en un congreso organizado en el extranjero permite familiarizarse con los métodos empleados por equipos de investigación foráneos, y también difundir parte dela investigación en la lengua inglesa.

La participación en congresos, con la presentación de un aspecto de la investigación y su publicación, resulta de utilidad para el proceso mismo de elaboración de la tesis doctoral. En primer lugar, pone en conocimiento a la comunidad científica de que se está llevando a cabo una nueva investigación y también queda publicada una parte de ella a disposición de todos. Se produce además un contacto del doctorando con otros investigadores o equipos de investigación que estén trabajando en temas similares o que hayan concluido estudios de utilidad para el doctorando. Este contacto puede dar lugar a nuevos encuentros científicos o colaboraciones futuras.

De cara al avance de la investigación, la participación en congresos también tiene un efecto. Por una parte se ordenan conceptos para permitir su explicación a terceros y se elabora y selecciona material gráfico con ese mismo objetivo. Se realizan análisis de resultados y se plantean conclusiones parciales que ayudan a cuestionar y corregir los apartado equivalentes de la tesis doctoral. Finalmente, se reciben opiniones contrastadas e impresiones por parte de otros investigadores, que en muchos casos aportan ideas, hacen preguntas de interés que descubren carencias en la investigación o señalan puntos fuertes de la misma.

\subsubsection{Cursos realizados}

La asistencia a cursos contribuye a la adquisición de conocimientos complementarios de utilidad para la investigación. En el año 2015, se realizó el "Curso práctico de Técnicas No Destructivas (TND) aplicadas al campo de materiales de construcción y conservación del Patrimonio Cultural" en Navares de las Cuevas en Segovia, con el objeto de ampliar la capacidad de analizar el patrimonio a través de nuevas técnicas.

En el año 2016, se ha participado igualmente en algunos de los cursos que organiza la plataforma ESDUVa (Escuela de Doctorado de la Universidad de Valladolid). El curso "Aspectos metodológicos del a tesis doctoral", impartido por Alfonso Padilla (Universidad de $\mathrm{H}$ elsinki), explica los métodos más adecuados para abordar la realización de la tesis doctoral. Hace hincapié en la importancia de la estructura del documento escrito. El curso "Estadística con R", impartido por Luis Ángel García Escudero, ofrece un primer contacto con la estadística a través del programa $\mathrm{R}$. En Arquitectura, la estadística no se aplica de forma generalizada, al menos no de la misma forma que ocurre con otras disciplinas como, por ejemplo, la Ingeniería. En esta investigación se ha realizado una aproximación a esta herramienta y ha resultado de utilidad para el análisis de las dimensiones de tapias más empleadas en determinados tramos de muralla, así como para realizar comparaciones entre cada uno de los casos. 


\section{5}

\section{Casos de estudio}

La extensión y complejidad del territorio ocupado por las Comunidades de Villa y Tierra es significativa. Para llevar a cabo este estudio ha sido necesario delimitar un territorio más pequeño donde el número de casos a estudiar sea manejable. La Diócesis de Segovia incluye diez ejemplos de villas que estuvieron amuralladas y que lo siguen estando en la mayoría de los casos, se ha marcado en ne grita los casos seleccionados en esta investigación:

1 Coca, Segovia. Esta villa conserva una parte importante de la muralla medieval, por lo que su análisis y estudio se ha incluido en esta investigación.

2 Cuéllar, Segovia. En este caso, prácticamente la totalidad de la muralla medieval se conserva, por lo que su análisis y estudio se ha incluido en esta investigación. Este ejemplo ha sido restaurado recientemente.

3 Fuentidueña, Segovia. El ejemplo de Fuentidueña es de gran interés por encontrarse en un estado de conservación que permite el análisis constructivo de los restos. Gran parte de la muralla medieval se conserva.

4 Fresno de Cantespino, Segovia. En este caso, los restos defensivos encontrados son extremadamente escasos.

5 Íscar, Valladolid. A excepción del castillo, no se ha encontrado rastro alguno de muralla medieval en este caso. Existe un pequeño resto de un muro exterior paralelo al recinto del castillo, situado en el lado sur, cuyo origen no está claro (Escribano Velasco et al. 2001, 279).

6 Maderuelo, Segovia. En esta villa se conservan los restos de muralla medieval. El modelo de c iudad amurallada es particular en es te caso, con un asentamiento que se adapta al terreno con forma de apéndi ce. El recinto amurallado traslada esa forma a su trazado.

7 Montejo de la Vega de la Serrezuela, Segovia. En este núcleo se observan varios ejemplos de arquitectura defensiva. No se conserva muralla medieval como tal. 
Las murallas en las Comunidades de Villa y Tierra de la Diócesis de Segovia en los siglos XI a XIII. Técnica y sistemas constructivos de la arquitectura defensiva medieval.

8 Pedraza de la Sierra, Segovia. El núcleo de Pedraza conserva parte de la muralla medieval. También se conserva parte del castillo.

9 Segovia. La muralla de Segovia conserva gran parte de los restos de la muralla medieval. Está siendo estudiada por el arquitecto Miguel Ángel Martín Blanco por lo que no se considerará como caso de estudio, pero sí se realizarán comparaciones entre este caso y los analizados en esta investigación.

10 Sepúlveda, Segovia. En Sepúlveda se conservan varios tramos de muralla en el núcleo. El análisis y estudio de este núcleo se ha incluido en esta investigación.

11 Turégano, Segovia. Se sitúa en el territorio de la Diócesis de Segovia, pero no se considera villa cabecera de ningún concejo. Se conservan los restos del castillo y la muralla que lo rodea, de la que se conservan algunos lienzos y varias de sus torres.

En los territorios limítrofes con la Diócesis de Segovia también existen ejemplos amurallados de interés que se han visitado y analizado.

12 Ayllón, Segovia. Se conservan muros de tapia de tierra de A yllón muy deteriorados en la zona alta del núcleo. También se conservan escasos restos de muralla en la zona del caserío.

13 Haza, Burgos. En este núcleo existen restos de la muralla y del castillo.

14 Olmedo, Valladolid. En este caso se conserva gran parte de la muralla medieval.

15 Peñafiel, Valladolid. En este ejemplo, se conserva un tramo de muralla en la zona norte del núcleo.

16 Portillo, Valladolid. En este núcleo se conserva una puerta de la muralla y el castillo.

De estos 16 casos se ha elaborado una ficha ${ }^{25}$ con el objeto de evaluar la existencia de restos y el interés de los mismos para esta investigación. Finalmente, se han seleccionado 6 casos de estudio para su análisis en profundidad. Estos casos son: Coca, Cuellar, Fuentidueña, Pedraza, Maderuelo y Sepúlveda, que se analizan a continuación.

${ }^{25}$ Estas fichas se adjuntan en el apartado final "Anexos". 


\section{1 \\ Coca}

Segovia

\subsubsection{Localización}

Coca se encuentra en la zona oeste de la actual provincia de Segovia, junto al límite de la provincia de Valladolid. Se sitúa a $60 \mathrm{~km}$ de la ciudad de Valladolid y a $50 \mathrm{~km}$ de la ciudad de Segovia. Los ríos Eresma, Voltoya y Malucas pasan por el territorio de esta Comunidad de Villa y Tierra. Las comunidades que rodean Coca son Olmedo, Íscar y Cuéllar al norte, Segovia al sureste y Arévalo al suroeste. En comparación con otras comunidades estudiadas aquí, Coca tiene un tamaño pequeño, de $315 \mathrm{~km}^{2}$ aproximadamente, similar al de Olmedo o Fuentidueña. La extensión total de este territorio queda en los límites de la provincia actual de Segovia, a diferencia de otros casos, en los que los bordes no son coincidentes.

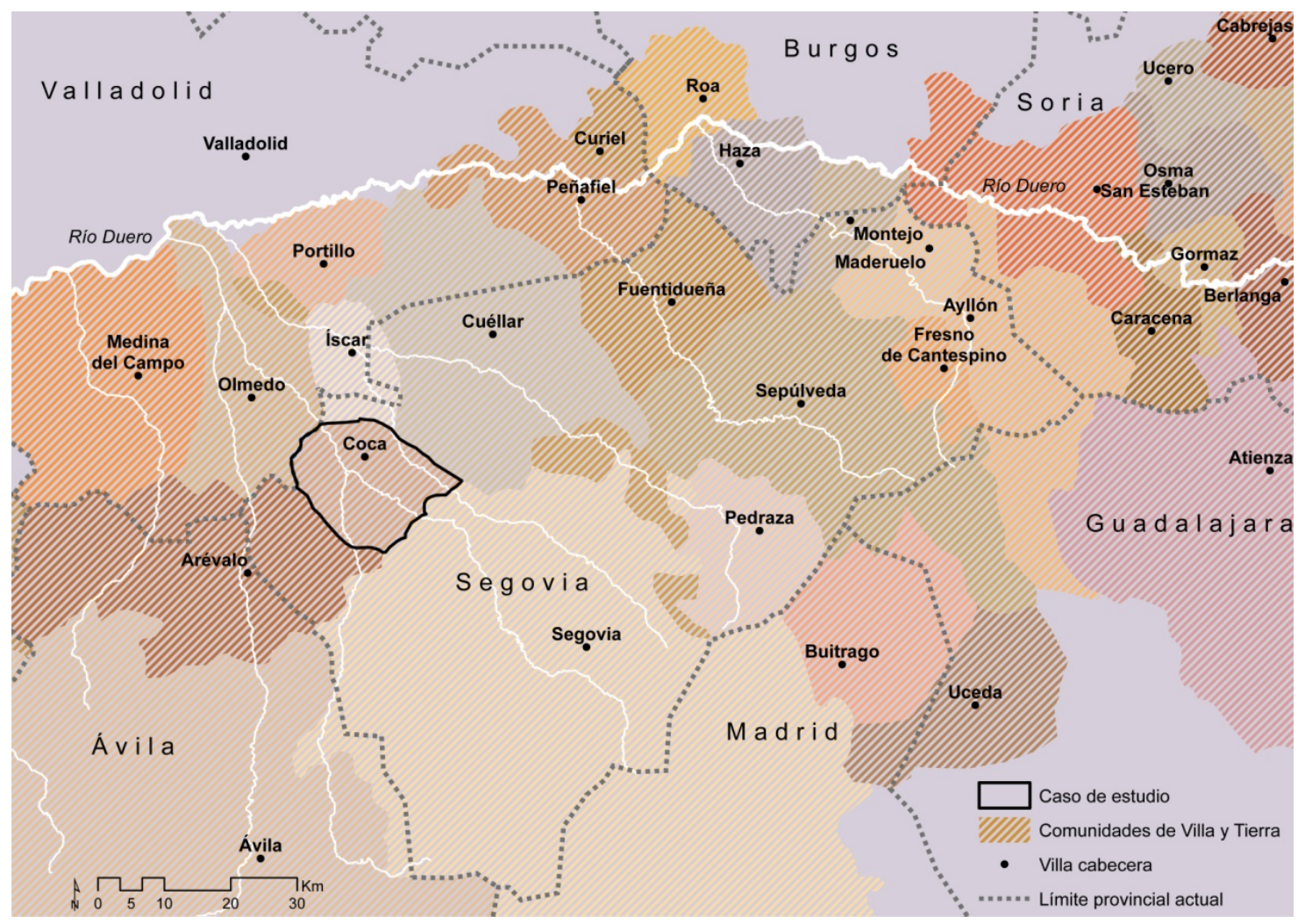

Fig. 5.1.1. Plano de localización de Coca. Fuente: Elaboración propia a partir de planos de G. Martínez Díez $(1983,11-15)$ y J.M. Monsalvo $(2010,152)$. 
El núcleo de Coca se sitúa en la confluencia de dos ríos mencionados anteriormente, el Eresma y su afluente el río Voltoya. Como ya se ha indicado, se trata de una disposición habitual en muchos de los núcleos estudiados, junto a u n río o e n la confluencia de dos de ellos. Tiene una población de 1896 habitantes, de acuerdo con los datos del Instituto Nacional de Estadística en el año 2015.

La topografía que rodea el núcleo de Coca está condicionada por el paso de los dos ríos que rodean el núcleo. En el norte, el paso del Eresma genera desniveles de casi cuarenta metros. Ocurre lo mismo al oeste con el cauce del río Voltoya situado a una altitud de $745 \mathrm{~m}$; las mesetas que lo flanquean alcanzan los $780 \mathrm{~m}$ y son muy llanas. El núcleo se sitúa en una de ellas, cercano a su borde norte. Está protegido al norte y al oeste por los desniveles de terreno descritos. Por el contrario, el acceso por el sureste no presenta desniveles de terreno.



Fig. 5.1.2. Topografía en torno al núcleo de Coca. Fuente: Elaboración propia con datos de IDECyL y Catastro.

\subsubsection{Estudios en la villa}

El Diccionario Geográfico-Estadístico-Histórico de España y sus posesiones de ultramar, redactado por Pascual Madoz en 1847, menciona en su descripción el castillo de Coca y realiza una descripción de los restos de la muralla de la villa:

"Se conserva todavía un resto de muralla de cal y canto y una puerta en ella titulada de La Villa que da entrada á la calle principal de la pobl., observándose por los demás lados de ella, restos y cimientos de la muralla conque en lo ant. estuvo circundada; sobre el arco de la puerta citada y en el espesor de la misma muralla, hay otra cárcel 
que es la que comúnmente usaban los alcaldes mayores para custodiar los presos que dependían de su autoridad." (Madoz 1848, Tomo VI, 497).

En el Catastro del Marqués de la Ensenada no se encuentra mención alguna acerca de edificación defensiva. En la respuesta a la vigésimo tercera pregunta, referente a las propiedades del común, se menciona que hay una casa destinada para cárcel, pero no se ven menciones relativas a la muralla.

Desde un punto de vista histórico, Felipe Rodríguez (1998, 2007, 2011) ha realizado varias publicaciones que tratan el núcleo de Coca a lo largo de la historia. La muralla medieval ha sido estudiada por el arqueólogo J. Francisco Blanco (1991) a través de los restos existentes y a partir de un anál isis documental del Archivo Municipal y el Parroquial de Coca, así como de otros archivos de E spaña y del examen de fotografías antiguas de la Villa. Extrae de estos documentos varias referencias a la muralla medieval. Se trata de menciones útiles para ayudar a identificar el trazado de la muralla allí donde no quedan restos. Se han trasladado a continuación varias de estas menciones:

- En el Registro para el establecimiento de la Única Contribución, con fecha de 1759, se habla de una casa que sirve de matadero y linda por el sur con la muralla (434). El matadero se encontraría en la zona noreste del recinto, entre la Avda. de José Antonio y la calle León Amores.

- En un documento de 1817, se trata un pleito relacionado con pastos, en el que Andrés Colorado, Procurador General de I os pueblos de la tierra de Coca, describe el trazado de las murallas, indicando que realiza un reconocimiento visual que parte la zona sureste de la Villa donde existe un "pequeño resto de cordón de murallas", continúa hasta el castillo, observa también "vestigios de toda la muralla antigua" en la zona norte del castillo, en la cumbre de la ladera, "hasta dar la vuelta por la ladera del río Eresma" especificando que abarca el "gran terrazgo labrantío de los Azafranales", situado al norte del núcleo, y englobando las iglesias de San Nicolás y San Adrián, hasta tocar con el cordón de muralla mencionado al principio y "quedado dentro del mismo centro el sitio qe. ocupava el matadero de esta $V^{a}$ y el qe. tiene la Nueva Fábrica de Cristales" (434).

- En un documento de 1866 se indica que en las proximidades de la puerta de la villa se derribaron cuarenta metros de muralla (434).

- En otro documento de 1877 del Archivo Municipal de Coca (Leg. 70/13: 1) figura que en esa fecha aún estaría en pie una parte hoy desaparecida y que debido a la escasez de piedra se derribó "el trozo de muralla que hay aislada entre el castillo y las murallas del Juego de Pelota" (434).

- En la Ejecutoria y Ordenanzas de la Villa y Tierra de Coca de 1583 hay varias referencias a la muralla. Se hace referencia a las puertas de la villa: "...ni entre ni salga si no fuere por las puertas principales de esta Villa..." (436), se insta a los habitantes a cultivar dentro de los muros de Coca: "...cualquier persona que tuviere tierra dentro de los muros de esta Villa y la sembrare de pan, semilla $u$ otra cosa..." (435) y se prohíbe expresamente que nadie coja materiales de la muralla para emplearlos en ot ra construcción (punto 9) "...que ninguno sea 
Las murallas en las Comunidades de Villa y Tierra de la Diócesis de Segovia en los siglos XI a XIII.

Técnica y sistemas constructivos de la arquitectura defensiva medieval.

osado de sacar arena, tierra o piedra, ni tomarlo de la cerca de esta Villa..." (437).

A partir de estos datos, el arqueólogo ha situado en el plano (439) la posición del matadero, mencionada en 1759, la posición del trozo aislado que se indica en 1877, entre el castillo y el tramo de la puerta de la Villa y por último la ubicación de los cuarenta metros de muralla derribada a la que se alude en el documento de 1866. Este arqueólogo también ha es tudiado recientemente la muralla vaccea de Coca (2014), cuyo trazado sería coincidente en la zona sur con la muralla medieval. Partiendo de las referencias a la muralla, se ha realizado una hipótesis de trazado de la muralla (Fig. 5.1.3). Esta hipótesis ha resultado más sencilla en las zonas sureste y suroeste por la existencia de restos intermitentes y por las referencias más claras de los documentos.

En la zona noroeste es de ut ilidad la mención de 1817 donde se indica que los azafranales se encuentran englobados dentro del recinto. De acuerdo con otros ejemplos donde las murallas se adaptan al terreno, se ha adaptado el trazado hipotético a los bordes del terreno, que siguen el curso del río Eresma. La zona más compleja es la parte noreste, donde es difícil plantear un trazado, ya que podrían existir varias posibilidades. El trazado curvo de la Avda. de José Antonio parece indicar el paso de la muralla siguiendo esa dirección, apoyado por la posición de la plaza de $S$ an Adrián, en c uyo vértice norte se ubicaría una de I as puertas desaparecidas. Ahora bien, la posición del matadero que se encuentra en el exterior de la curva que forma la Avda. José Antonio, obligaría a desviar el trazado hipotético más al norte, ya que según las referencias, el matadero lindaba con la muralla por el sur.

Otro factor que complica la interpretación del trazado en esta zona es el acceso por el norte de la carretera de Navas de Oro. Se trata de una zona escarpada, donde se asciende por un único camino. Parece razonable pensar que el ascenso por una única vía pudiera condicionar el acceso a la villa. Junto a la carretera existe un acceso antiguo, más empinado y directo que la carretera actual que sigue una curva para facilitar el acceso rodado. El antiguo camino de subida llega a la villa junto a la carretera. Este acceso engancha con la Avda. de José Antonio. La ausencia de una puerta justo a la llegada del camino implicaría que existe una continuación del mismo fuera el recinto amurallado, ¿tal vez hasta la puerta de San Adrián?

El último factor que dificulta el planteamiento de una hipótesis en esta zona es la forma del relieve. Si se adaptara el trazado al territorio, la hipótesis de trazado se situaría un poco más al norte.

\subsubsection{Datos históricos destacados del núcleo}

Son escasas las fuentes históricas citan Coca o que hacen referencia a hec hos acaecidos en esta zona. En 939 se cita ya como núcleo repoblado y poseedor de una fortaleza, no la que se conoce hoy en día, pero probablemente situada en el mismo sitio. Como ocurre con el resto de villas de esta investigación, Coca se ve afectada por 
las campañas de Almanzor en su batalla contra Simancas. Al parecer, el conocimiento del ataque hizo huir a la población abandonando el núcleo, antes de la llegada de los atacantes. Después del año 939, los pobladores volverían a poblar Coca. En 983, la campaña de Almanzor contra Simancas, también afecta a la población de Coca, como ocurre con otras villas de la zona como Fuentidueña, Haza o Íscar (Martínez Díez 1983, 398, 438). La repoblación de las villas de la zona promovida por Alfonso VI, anterior a 1085, impulsó el crecimiento de la villa, que se convertiría en cabeza de Comunidad.

Durante el siglo XII, Coca figura junto con otras villas de esta investigación en varios documentos históricos mencionados en el capítulo 3. Corresponden con la bula del papa Calixto II de 1123 donde se definen los límites de la Diócesis de Segovia, la cesión del diezmo para la iglesia católica por parte del rey Alfonso VII en 1136, y el matrimonio de Bergenguela y Conrado, hijos de Alfonso VIII y Federico I en 1187. Aparte de estas fechas, aparecen escasas menciones de $\mathrm{C}$ oca. Figura en un documento de 1181, de nuevo como villa integrante de la Diócesis de Segovia. Felipe Rodríguez $(1998,128)$ remite a Jiménez de Rada para indicar que en 1217 se hace la primera referencia a las murallas de Coca, cuando Doña Berenguela viaja en dirección a Segovia y es recibida en Coca con las puertas cerradas.

Ya en el siglo XV, una vez difuminado el sistema de concejos, se conoce el paso de Coca a manos del marqués de Santillana, Íñigo López de Mendoza. Años después, la propiedad de la villa recayó sobre Alonso de Fonseca, quien puso en marcha la construcción del castillo tal y como se conoce hoy en día.

\subsubsection{Tejido urbano}

Si observamos el plano de parcelas de Coca en la actualidad, se pueden distinguir áreas diferentes en función de la morfología de las parcelas. Se observa en la zona noreste un área con parcelas alargadas y estrechas, con fondos de $50 \mathrm{~m}$ y anchuras de menos de $2 \mathrm{~m}$ en al gunos casos, aunque son habitualmente de 4 a 6 metros, con ejemplos de mayor anchura. Se ven parcelas pasantes de un I ado a otro de la manzana, irregulares, retorcidas, con quiebros, también en forma de " $\mathrm{L}$ " que abren a dos calles diferentes. Las calles de esta zona tienen una anchura que ronda los $4 \mathrm{~m}$, son irregulares y en algunos casos son calles cerradas, como la calle Joaquina Ruiz o de San Nicolás, entre otras. Estas características parecen apuntar al origen medieval de este tejido.

Esta zona se encuentra delimitada al sur de forma muy evidente por la línea de la muralla existente. Los restos de muralla se disponen en línea recta a lo largo de $120 \mathrm{~m}$ aproximadamente e incluyen la Puerta de la Villa. En continuidad con el tramo de muralla existente, el tejido medieval queda limitado al este por la Avda. de José Antonio, que tiene una anchura que oscila entre los 10 y 12 metros, muy superior a la anchura de calle en el interior de la zona medieval. Esta avenida sigue un trazado curvo y continuo que rodea la zona e interrumpe de forma clara y evidente el tejido anteriormente descrito. Como se ha comentado antes, la curvatura de esta calle y su 
continuidad con el acceso norte hace pensar que la muralla medieval tuviera un trazado similar. Al noroeste, el tejido medieval es todavía visible hasta la calle Ronda, que es la continuidad de la Avda. José Antonio y cuyo nombre hace referencia a la terminología defensiva para describir el camino de ronda en una muralla. Al oeste, la calle Canongia tiene en su alzado sur las últimas parcelas con morfología medieval, pero en este frente no es tan evidente el límite de la zona medieval, sino que se torna más difuso.



Fig. 5.1.3. Plano de parcelario urbano de Coca. Fuente: Elaboración propia con datos descargados del Portal de la Dirección General de Catastro [http://www.catastro.meh.es/] y de acuerdo con J. Francisco Blanco $(1990,439)$.

Dentro del área medieval descrita también se pueden diferenciar partes o elementos que destacan sobre otros. Desde la Puerta de la Villa parten tres calles de forma diferenciada que delimitan esta área (Fig. 5.1.4). La calle Falcón Ruiz y Llorente parte en el centro y sigue un trazado curvo que engancha en el norte con la Avda. José Antonio, a cuyo encuentro se situaría la puerta de San Adrián (Fig. 5.1.5), desaparecida en la actualidad. Su trazado curvo podría delimitar una agrupación de parcelas, un ba rrio del recinto amurallado. La calle Valdenebro parte en línea recta hacia el noreste y parece que pudiera funcionar como un eje de comunicación de la villa, una calle principal. Finalmente la calle Canongia parte en línea recta hacia el noroeste, en dirección a la hipotética puerta del Molino Viejo. Resulta muy llamativa la disposición de es tas tres calles, ya que parece que parten de la puerta como si se tratara de caminos que parten hacia el exterior, en lugar de ser caminos interiores de 
un recinto. Esta disposición de caminos en una puerta es visible en otros ejemplos, como el caso de la ciudad de Zamora, donde se aprecian este tipo de camino en tridente desde la Plaza Mayor hacia el este. Félix Benito $(1996,140)$ señala este efecto de convergencia de caminos que se produce hacia el interior y hacia el exterior de la puerta de la Villa. Por otra parte, dos de estas vías, la calle Valdenebro y la calle Canongia, junto con la calle Aguililla de Ciruelos forman un triángulo que es semejante al descrito por Félix Benito $(2000,207)$ para Itero de la Vega (Palencia) que forma un triángulo que conecta las tres puertas del recinto amurallado. En el caso de Coca, dos de los vértices del triángulo coinciden con la ubicación de puertas, el tercero, más desdibujado, coincide con la posición de la torre de San Nicolás. Estos caminos han condicionado la formación del núcleo, las parcelas se han generado en sus márgenes, de la misma manera que se han adaptado a la posición de la muralla. La existencia de caminos tan claros, de puerta a puerta, sugiere que esta zona estuviera vacía en la época medieval y podría haberse ido colmatado paulatinamente según crecía el núcleo, convirtiéndose los caminos en calles. En la referencias a la muralla de las Ordenanzas de la Villa de 1583, se anima a los habitantes a sembrar en sus tierras dentro del recinto amurallado, por lo que se muestra la existencia de espacios vacíos intramuros disponibles para el cultivo.



Fig. 5.1.4. Vista de las tres calles que parten de la Puerta de la Villa hacia el interior [A.S.E. 27/04/2015].



Fig. 5.1.5. Vista desde la posible ubicación de la Puerta de San Adrián, con dos calles que parten hacia izquierda y derecha, Valdenebro y Aguililla de Ciruelos [A.S.E. 27/04/2015]

En cuanto a edificios de carácter religioso, se conservan la iglesia de Santa María la Mayor y la torre de la Iglesia de San Nicolás. Al parecer, existieron además la Iglesia de San Adrián en la zona norte, de San Juan en la zona del actual cementerio y de San Justo, desaparecidas en la actualidad. Estas construcciones religiosas, al igual que las puertas de muralla aparecen habitualmente vinculadas a plazas o es pacios abiertos, lugares donde se ubicaba la actividad del mercado (Sainz Guerra 1990, 207). La plaza mayor de Coca aparece relacionada con la posición de la iglesia de Santa María la Mayor, aunque parece haber sido ampliada hacia el sur con posterioridad. La plaza del Arco parece tener una relación con la puerta de la Villa y la plaza de San Adrián parece vinculada a la existencia de una puerta de muralla, hoy desaparecida. La posición de la plaza de la Cruz de los Caídos coincide con el tercer vértice de los caminos dispuestos en triángulo, antes mencionados. La existencia de una puerta en 
ese punto, perteneciente a un r ecinto más pequeño es difícil de valorar, pero se ha grafiado en fucsia en el plano la hipotética posición de una pue rta en este punto y hacia donde podría dirigirse un supuesto trazado de muralla. La plaza Cruz de los Caídos también podría mantener relación con la iglesia de San Nicolás, de la que solo queda la torre en la actualidad. La puerta del Molino Viejo es otra puerta que ha desaparecido (Sobrino 2011, 200) y se plantea que pudiera situarse en la zona oeste de la hipótesis de trazado.

El barrio grafiado en azul (Fig. 5.1.3), de calles rectas formando una cuadrícula, es de planificación moderna, construido en el siglo pasado. La creación de este barrio con un trazado urbano nuevo parece indicar que la zona donde se asienta se encontraba vacía de construcciones. El vaciamiento de las áreas cercanas al castillo también se da en otras villas como Cuéllar o Fuentidueña. En el Mapa Topográfico Nacional Histórico 1:50.000 de Coca (Fig. 5.1.6) se observa que el área situada entre el castillo y el núcleo está vacía de construcciones y parece destinarse a labores de cultivo. El castillo está representado de forma demasiado discreta, prácticamente no e $\mathrm{s}$ identificable como tal. La disposición del núcleo en este plano apoya la idea de un primer recinto organizado en torno a las tres calles dispuestas en triángulo, en cuyos vértices existiría una puerta. Según Felipe Rodríguez $(2011,166)$, se tiene constancia de la existencia de la judería por un documento que data del año 1450. Se encontraría entre las iglesias de San Nicolás, de la cual hoy sólo queda la torre, y de San Juan, donde se encuentra el cementerio hoy en día. En la actualidad, esta zona se encuentra vacía, existen escasas edificaciones que son de construcción moderna.



Fig. 5.1.6. Fragmento de Mapa Topográfico Nacional Histórico 1:50.000 de Coca. Fuente: Instituto Geográfico Nacional (IGN), descarga a través del visor lberpix. http://www.ign.es/iberpix2/visor/ [Consultado el 22/8/2016]. 


\subsubsection{Planeamiento y figuras de protección}

Coca dispone en la actualidad de dos figuras de planeamiento general. Las Normas Subsidiarias datan del año 2001. Dispone de un PECH Plan Especial de Protección, Reforma Interior y Catálogo del Conjunto Histórico del año 2003, con modificaciones del año 2006. Desde el año 1931, se encuentran catalogados como Bien de Interés Cultural (BIC) el castillo de Coca y la torre de San Nicolás, al norte del recinto en la categoría de Monumento. También el recinto murado de la Villa es considerado BIC desde 1931, en la categoría de Conjunto Histórico.

De acuerdo con información facilitada por el Ayuntamiento de Coca, la muralla ha sido restaurada en tres fases. La primera fase fue realizada por la Escuela Taller "Emperador Teodosio II" durante los años 1996 y 1997. En esta restauración se consolidó la mayor parte de la muralla, desde la puerta de la Villa hasta su extremo oeste, tanto por la cara sur como por la cara norte. La intervención consistió en reposición y rejuntado de mampuestos, limpieza de la capa vegetal y eliminación de cableado eléctrico. Se sustituyó el arco de piedra que queda en el interior de la Puerta de la Villa (Rodríguez 1998, 129). La segunda fase fue realizada por la Escuela Taller "Emperador Teodosio III", durante los años 1999-2000, que consolidó la cámara existente sobre la Puerta de la Villa, así como el extremo este en su fachada sur. Se instaló iluminación, se colocó el rastrillo, la puerta y las barandillas de madera. En la tercera fase se consolidó el extremo este de las murallas, en su fachada sur.

\subsubsection{Descripción general de la arquitectura defensiva}

Existen en $\mathrm{C}$ oca varios ejemplos de arquitectura defensiva que datan de di stintas épocas y tienen tipologías diferentes. El más conocido y destacado es el castillo de Coca que se sitúa al suroeste de la población, junto al desnivel oeste de la cuenca del río Voltoya. De acuerdo con Felipe Rodríguez $(2011,166)$, este castillo se construyó en el año 1453 por Alonso de Fonseca, sobre una fortaleza existente. Recientemente, en las catas motivadas por el Plan Director del Castillo de Coca en el año 2011, se ha podido confirmar que existen restos de un castillo medieval anterior. De acuerdo con el Ayuntamiento de Coca, en 1954 fue cedida la propiedad del castillo al Ministerio de Agricultura para la instalación de una Escuela de Capacitación Forestal. Se redactó el Proyecto de Reconstrucción y Adaptación de Castillo de Coca de mayo de 1955, por los arquitectos Miguel de los Santos Nicolás y Fernando Cavestany. Se realizó una restauración bajo la supervisión de la Real Academia de Bellas Artes de San Fernando y la Real Academia de la Historia, que comenzó en 1956 y terminó en 1958 (Fig. 5.1.9). De acuerdo con Fernando Cobos y José J. de Castro $(1998,22)$, este castillo se ha considerado de estilo mudéjar, pero indica que la técnica constructiva empleada y la presencia de bóvedas casamatas lo relacionan con las fortificaciones renacentistas italianas, que se construían con ladrillo. Cobos atribuye el uso del ladrillo a la capacidad de este material "para absorber los impactos de bolaños de artillería sin transmitir grietas en el muro". Otro dato conocido es la vinculación del alarife Ali Caro como maestro del castillo de Coca (29). 


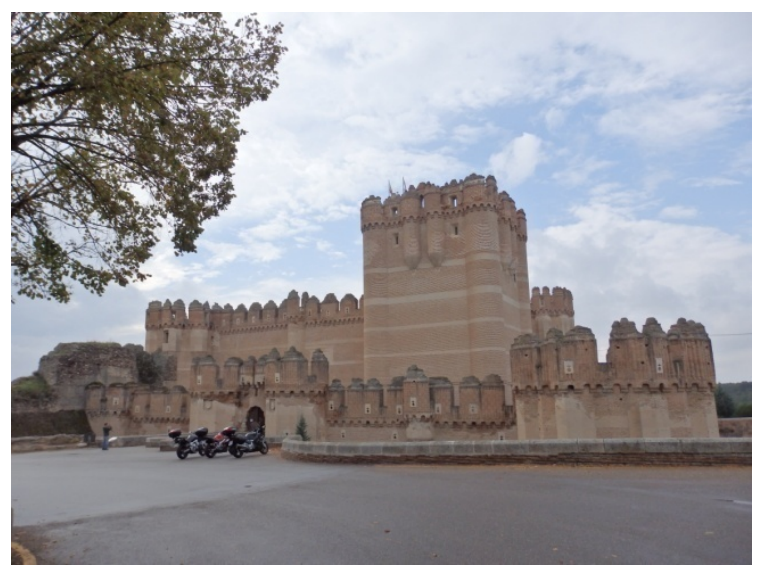

Fig. 5.1.7. Vista este del castillo de Coca [A.S.E. 11/2/2016].

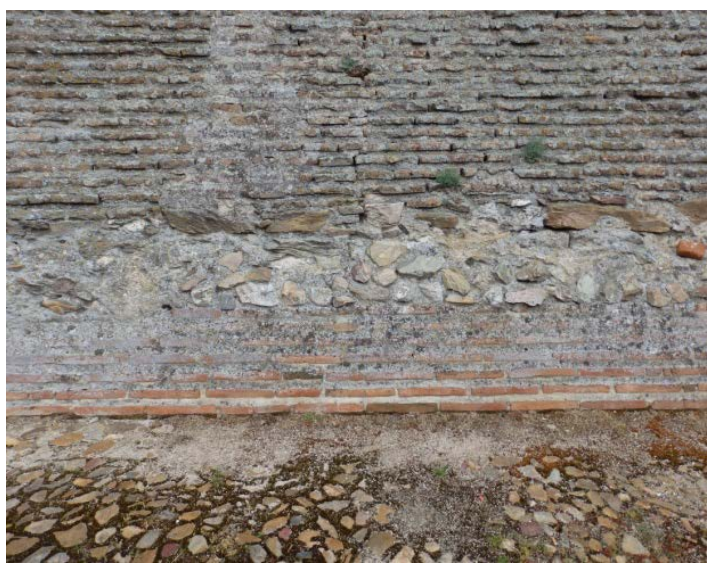

Fig. 5.1.8. Restos de aparejos de mampostería en la base del muro del castillo [A.S.E. 11/2/2016]

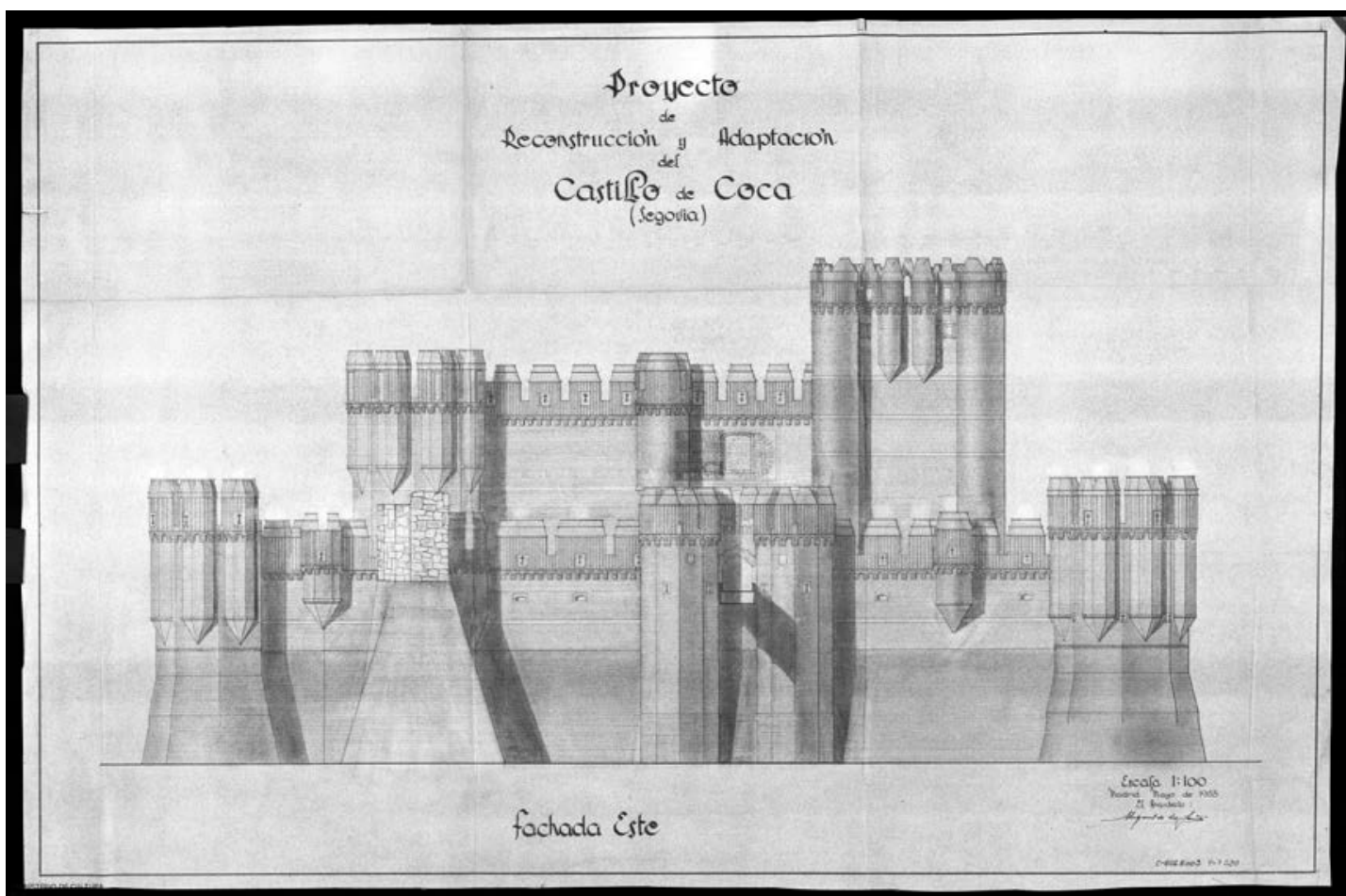

Fig. 5.1.9. Plano del Proyecto de Reconstrucción y Adaptación de Castillo de Coca de mayo de 1955, de los arquitectos Miguel de los Santos Nicolás y Fernando Cavestany. Es también visible en el dibujo parte de la muralla medieval adosada al castillo. Fuente: Planoteca del Instituto del Patrimonio Cultural de España. http://ipce.mcu.es/documentacion.html [Consultado el 20/4/2015].

Además del castillo de Coca, existen restos de la muralla medieval. Los más evidentes se encuentran en la zona sur del núcleo, donde recorren una longitud de 120 metros aproximadamente. Este tramo contiene la única puerta de la muralla que se conserva, la Puerta de la Villa (P1). En su fachada exterior, se adosan cuatro torres de plantas diferentes, dos de ellas rectangulares y otras dos circulares. La torre situada más al norte fue construida durante el siglo pasado junto a los restos de otra torre desaparecida. 


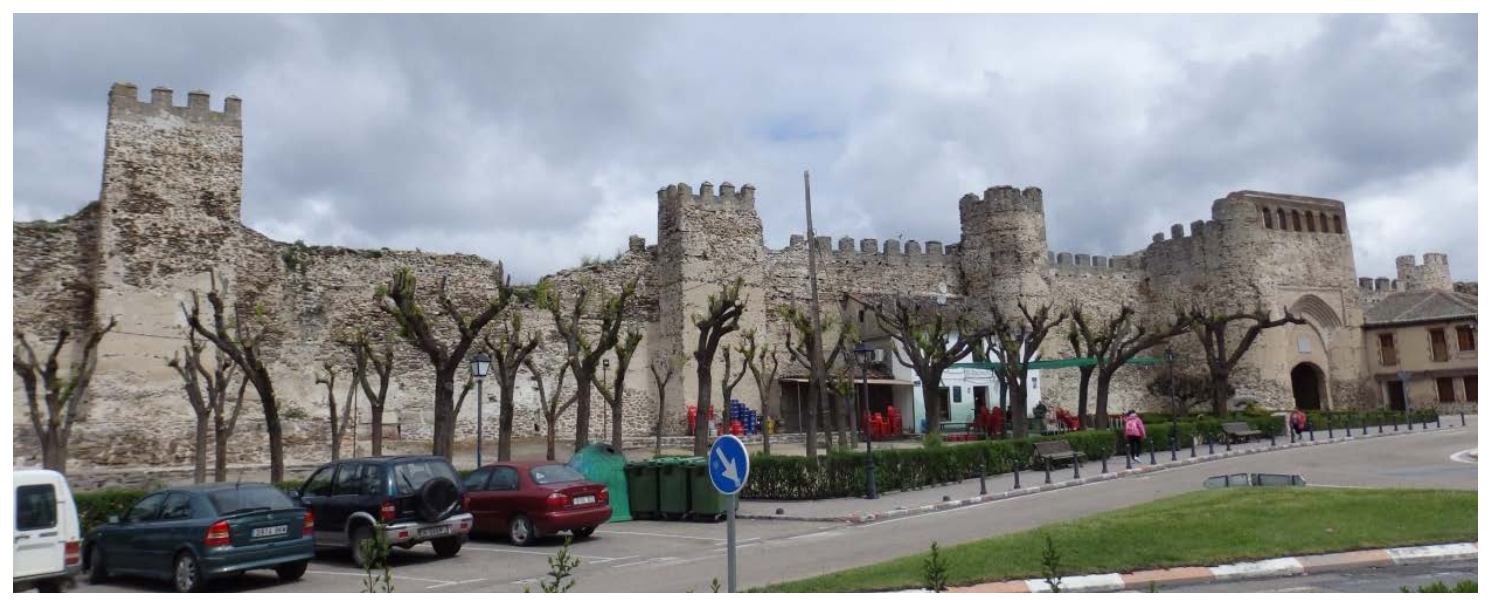

Fig. 5.1.10. Tramo sur de la muralla medieval [A.S.E. 27/04/2015].

Junto al castillo se encuentra otro fragmento de muralla medieval que comparte características con los restos anteriormente descritos. Este tramo tiene una longitud de 30 metros aproximadamente y está integrado en el castillo. Los restos visibles parten de la torre sureste del castillo en dirección noreste, atravesando el foso del castillo. Estos restos se componen de un lienzo y una torre poligonal (T8) adosada por la fachada exterior. Supuestamente, además de los restos de muro visibles, existen fotos antiguas anteriores a la restauración del mismo en 1958, que muestran que este tramo se prolongaba por la pared interna del castillo (Blanco 1991, 434). En la actualidad, son visibles restos muy escasos de mampuestos en la bases de la fachada sur del castillo (Fig. 5.1.8).

En el zócalo, se observan piedras reutilizadas de granito, arenisca y otros materiales, que tiene tamaños y formas diversos. Se colocan formando hiladas irregulares. En la parte más baja se ve una hilada de hasta cinco piezas de granito similares, con forma cuadrada, y una sexta más a la derecha con forma rectangular. Estas piedras no se ven en el resto de muralla existente, a excepción de algún caso aislado, como en la base del lienzo sur T1-T2. La torre T8 se adosa en el lado sur y tiene una planta poligonal. Se pueden contar siete caras que conforman el semicírculo poligonal. Esta disposición permite deducir que su planta es un semi-dodecágono. Torres Balbás $(1985,580)$ indica que la planta dodecagonal aparece únicamente en la Torre del Oro de Sevilla, hecho que acentúa la singularidad de es ta torre. Esta torre poligonal emplea los mismos materiales utilizados en el zócalo adyacente, piedras irregulares, sillares erosionados $y$ heterogéneos, aparentemente reutilizados de ot ras construcciones anteriores. Miguel A. Martín $(2014,167)$ establece una relación entre una torre poligonal de la muralla de Segovia y esta torre de Coca. En ambos casos, la forma de generar las aristas de las torres es muy parecida.

Existen otros restos de muralla medieval en la zona oeste de la villa, muy escasos y que apenas cuentan con $50 \mathrm{~cm}$ de altura. Se trata de restos que presentan un aspecto diferente a los restos medievales anteriormente mencionados. Se extienden a lo largo de 30 metros aproximadamente. En estos casos, fragmentos de la muralla se han desprendido y se han desplazado ladera abajo. 
Las murallas en las Comunidades de Villa y Tierra de la Diócesis de Segovia en los siglos XI a XIII. Técnica y sistemas constructivos de la arquitectura defensiva medieval.

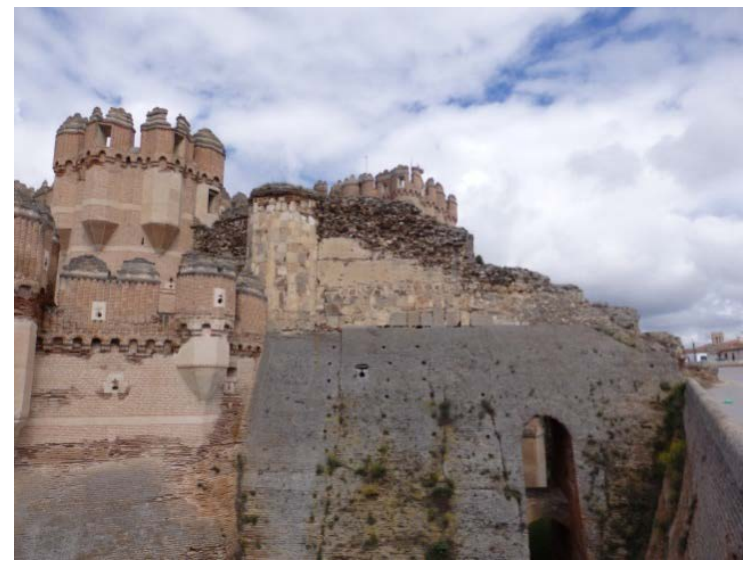

Fig. 5.1.11. Tramo medieval adosado al castillo, visible desde el exterior del castillo. Bajo el lienzo se sitúa el foso del castillo [A.S.E. 27/04/2015].



Fig. 5.1.13. Restos de muralla medieval en el Castillo de Coca.



Fig. 5.1.15. Tramo L2 de muralla, en la zona este. [A.S.E. 11/02/2014].



Fig. 5.1.12. Lienzo de muralla sobre el foso del castillo [A.S.E. 11/02/2014].

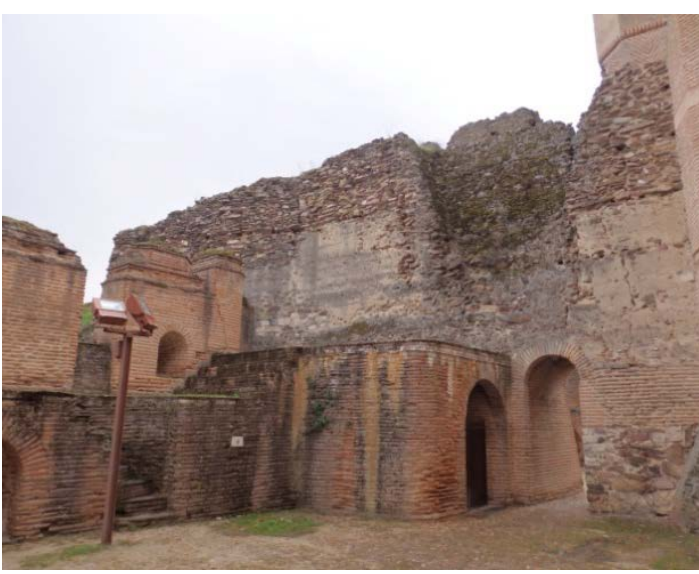

Fig. 5.1.14. Tramo medieval adosado al castillo, visto desde el interior del patio del castillo [A.S.E. 11/02/2014].



Fig. 5.1.16. Tramo L2 de muralla visto desde el oeste [A.S.E. 11/02/2014]. 




Fig. 5.1.17. Fragmento desplazado de muralla. Parece una tapia que se ha caído y rodado por la ladera [A.S.E. 11/02/2014].

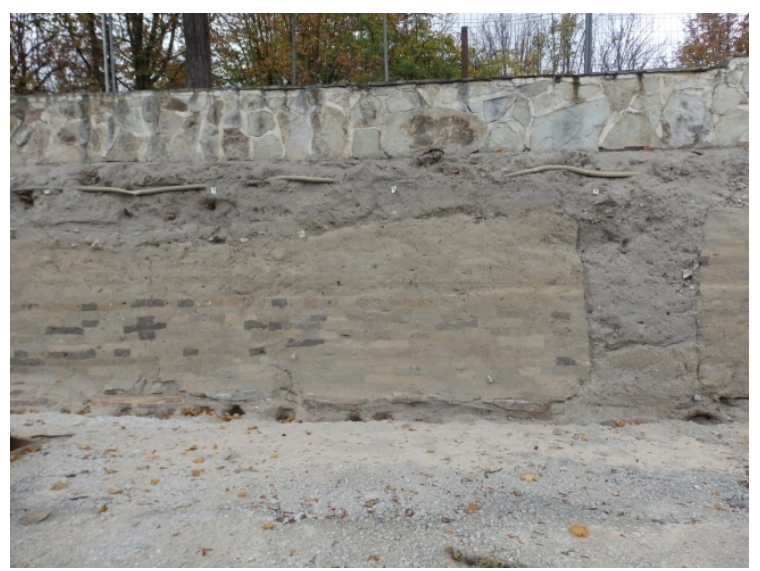

Fig. 5.1.19. Muralla vaccea descubierta en 2014, grafiada en naranja en la Fig. 5.1.3 [A.S.E. 11/02/2014].



Fig. 5.1.18. Resto $L 3$ de muralla en la zona este [A.S.E. 27/04/2015].



Fig. 5.1.20. Detalle de las hiladas de adobe [A.S.E. 11/02/2014].

Estos fragmentos desplazados han sido localizados por el arqueólogo J. Francisco Blanco $(1991,439)$ a partir de la observación del terreno. Se han po dido visitar y fotografiar los fragmentos de la zona oeste del recinto, visibles y accesibles. Los fragmentos desplazados que el arqueólogo localiza en la zona norte y este no se han podido ver, por encontrarse tal vez ocultos entre la maleza en el caso de los restos de la zona norte y por situarse en el interior de una parcela privada cerrada en el caso de los restos al este del recinto. La toma de medidas en estos bloques es muy complicada, ya que se encuentran erosionados y solo son visibles algunas de sus partes y no su totalidad. Algunos de estos bloques presentan además de cantos, tierra, cal y materiales cerámicos.

Además de los restos descritos, existen restos de una muralla vaccea encontrados recientemente. En el año 2011, durante la realización de obr as municipales en el antiguo campo de fútbol de la villa, se descubrió una pa red con varias hiladas de adobes, cuyo origen data de época vaccea. Más adelante, durante el mes de julio del año 2014, se descubrió la continuación de la muralla vaccea descubierta en 2011. Se 
trata de un nuevo tramo de $17 \mathrm{~m}$ de longitud, con 1,90m de altura aproximadamente, formado por un basamento de lajas de pizarras y cuarcitas sobre el que se apoyaban las hiladas de adobes (Blanco 2014, 78-79). La posición de la muralla vaccea descubierta es de gran interés ya que se encuentra en la misma línea que los restos de muralla medieval existentes. Es probable que la muralla medieval se construyese, al menos en este tramo, sobre la muralla vaccea.

\subsubsection{Tramos y elementos de la muralla medieval}

El tramo sur de la muralla de Coca es el más importante por la longitud de restos que se conservan, que alcanza los $120 \mathrm{~m}$. Como ya se ha mencionado en la descripción general, posee 4 torres y una puerta denominada Puerta de la Villa. Las torres T1 y T2 son afines entre sí, ambas presentan una planta rectangular de dimensiones similares. La torre T3 presenta una planta semicircular; se separa primero del lienzo en un tramo rectangular e inicia el semicírculo en el extremo más separado del lienzo. Las torres que componen la puerta de l a villa también tienen una pl anta semicircular de proporciones similares a T3, pero de mayor dimensión. La torre T4 es una torre nueva, construida con el objeto de evitar el desplome del lienzo, que se tornaba peligroso, de acuerdo con el testimonio de un habitante de Coca. Junto a esta torre T4 se ubicaba una torre original, en el lienzo es visible una zona irregular vertical, de anchura similar a la de una torre, donde parece que se hubiera arrancado material (Fig. 5.1.27).



Fig. 5.1.21. Plantas del tramo L1, al sur del núcleo, y del tramo L2, junto al castillo. Fuente: Elaboración propia sobre cartografía 1:1000 facilitada por IDECyL. 
La parte exterior de este tramo de muralla tiene varios edificios adosados. El tramo que queda al noreste de la puerta queda casi completamente oculto por las construcciones adosadas. Al suroeste de la puerta existen dos edificios adosados. Frente a la muralla existe una extensión vacía que se usa como parque. En la parte interior, la muralla no presenta elementos edificatorios adosados. Existe arbolado y mobiliario urbano junto a la muralla, a escasa distancia.

La puerta de la Villa (Fig. 5.1.22) se sitúa entre las torres T3 y T4. Se compone de dos torreones que flanquean el acceso y que se adelantan sobre el plano de la muralla siete metros aproximadamente. Los torreones se unen en la parte superior formando un frente. Las torres se construyen con tapia, empleado una piedra muy similar a la visible en el resto de los lienzos. Se pueden contar hasta 11 hiladas de tapia realizadas con la técnica de la tapia de mampostería.

Se observan varias intervenciones que se construyen en ladrillo. En primer lugar, la portada integrada entre los torreones se construye con este material. Sobre el hueco de acceso, de una anchura cercana a los $3,50 \mathrm{~m}$, se observa un arco rebajado de ladrillo colocado a sardinel. Sobre el arco rebajado se sitúa un arco ligeramente apuntado sobre el que a su vez se ubican hasta seis arcos apuntados más estrechos, a modo de arquivolta, escalonados y volando una decena de centímetros cada uno de ellos sobre el anterior. La parte superior de la portada se cierra con un marco rectangular de ladrillo. Esta portada parece realizarse con el objeto de mejorar la puerta estéticamente, incorporando elementos de moda en la época como el empleo de ladrillo. Además de la portada, en lo alto de la puerta se construyen en ladrillo seis huecos coronados con arcos de medio punto. Sobre los arcos se construye un muro de fábrica de ladrillo, en su cara exterior.



Fig. 5.1.22. Portada de la Puerta de la Villa. En comparación con el ejemplo del castillo, aquí la ejecución es más tosca [A.S.E. 27/04/2015].



Fig. 5.1.23. Vista interior de la puerta de la Villa [A.S.E. 11/02/2014].

Es probable que las intervenciones realizadas en ladrillo se añadieran con posterioridad a la realización de muralla. Son argumentos a favor de este planteamiento el hecho de que sólo en la puerta se observa el empleo de es te material, en el resto de muralla de este tramo no se emplea el ladrillo en ningún punto; 
asimismo, se trata del único punto donde ex iste ornamentación, aunque sea muy sencilla, ya que en el resto de muralla de este tramo no existe ningún elemento que no sea estrictamente defensivo; también es visible que los bloques que configuran los torreones han sido alterados, se han partido, eliminado, para poder colocar los arcos de la zona superior y la portada; además se trata de una arquitectura más culta y realizada con un planteamiento diferente del existente en la muralla.

Desde el interior, la puerta ofrece un alzado liso y rectangular (Fig. 5.1.23). En el centro se abre un arco apuntado realizado en ladrillo. En su interior y remetido hacia el interior se abre otro arco apuntado más pequeño. En este arco se conservan los restos de una representación pictórica sobre tablas, se trata de un calvario donde se distinguen las figuras de Cristo, San Juan y la Virgen María, datado en el siglo XVI (Sobrino 2011, 201). Existen dos huecos de forma rectangular sobre el arco. En la parte izquierda, se accede a través de una escalera exterior a las dependencias que existen en el interior de la puerta, que al parecer también fueron utilizadas como prisión.

En planta, la puerta tiene una forma rectangular, con unas dimensiones de 14,00 metros por 9,00 metros. Las esquinas exteriores son redondeadas, ya que se corresponden con los torreones de base semicircular. La puerta es un elemento que, aunque forma parte de la muralla, está sujeta a otras influencias y supone uno de los elementos que más se altera a lo largo del paso del tiempo.

La torre más al este, T1, posee una sección en planta rectangular, con dimensiones de 4,75 metros de ancho por 13,30 metros de altura. El alzado es liso, rectangular, sin ornamentaciones. En lo alto posee 8 almenas, 4 de ellas al frente y dos más a cada lado. Las almenas tienen forma rectangular y cada una de ellas está coronada por un tejadillo. Estas almenas parecen haberse añadido con posterioridad. La torre sobresale de la muralla una distancia de 2,10 metros. Si se observa la línea de unión entre la torre y el lienzo de muralla, se puede apreciar que ambos parecen haber sido construidos a la vez, las hiladas de la fábrica de bloques son continuas.

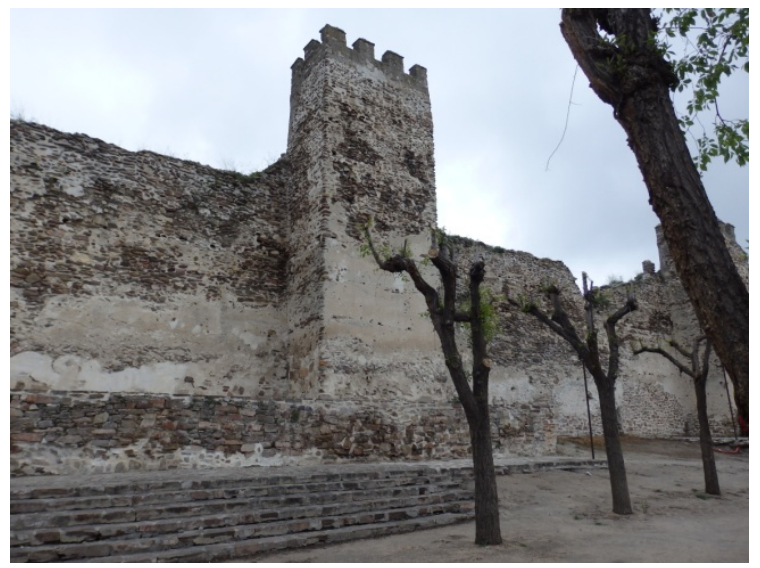

Fig. 5.1.24. Torre T1, con base rectangular [A.S.E. 27/04/2015].

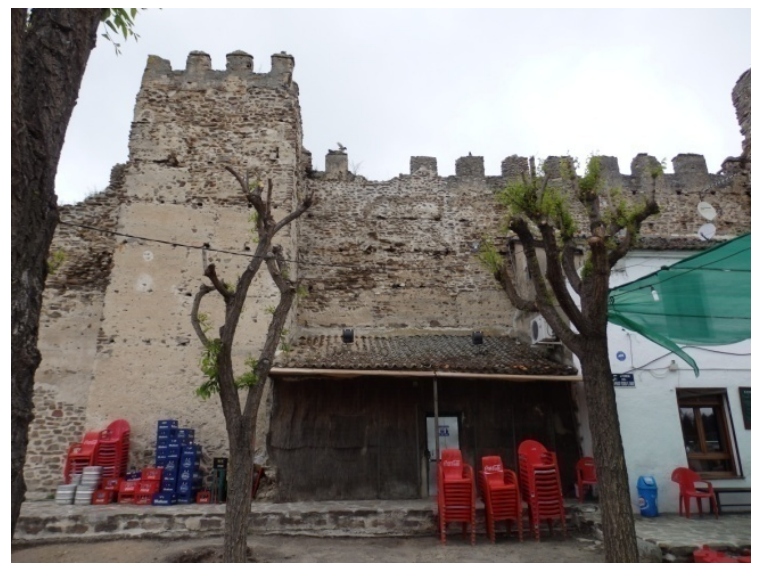

Fig. 5.1.25. La torreT2, a la izquierda, con una edificación adosada en su cara este. [A.S.E. 27/04/2015]. 
La torre T2 es similar a la T1, su planta es rectangular y su alzado es también recto y sencillo, sin ornamentación. Posee igualmente almenas, dispuestas de la misma forma que la torre T1. Sus dimensiones son de $4,80 \mathrm{~m}$ de anchura por $12,80 \mathrm{~m}$ de altura. Sobresale de la muralla una distancia de 2,60 metros. A diferencia de la torre T1, en este caso no es tan evidente la integración entre muralla y torre. En el lado oeste, se puede observar que hay una discontinuidad en las hiladas de bloques, y también es visible una ligera separación entre la torre y la muralla. No obstante, en el lado este, se observa claramente una continuidad entre los bloques de la torre y del lienzo de muralla.

La torre T3 (Fig. 5.1.26) es diferente de las dos anteriores, se separa de lienzo una distancia mayor y en el extremo se cierra con forma semicircular. Tiene una altura ligeramente superior que las torres T1 y T2, de algo más de un metro. En su paramento se observan las marcas del tapial, las hiladas de tapia se aprecian con claridad, contándose once tapias, sobre las que se yergue un almenado. En su cara oeste, se adosa una edificación de dos plantas, que también se pega al lienzo de muralla entre las torres T2 y T3, junto con otra edificación de menor entidad situada inmediatamente a su izquierda.

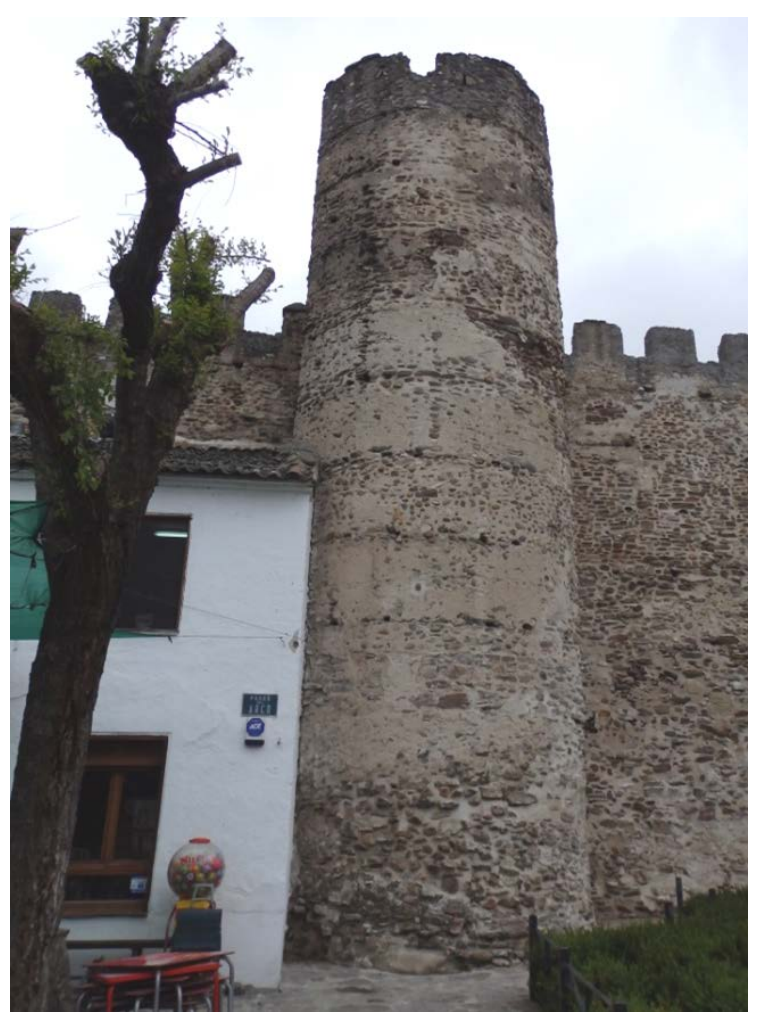

Fig. 5.1.26. Torre T3, con base semicircular. A la izquierda se adosa una edificación [A.S.E. 27/04/2015].

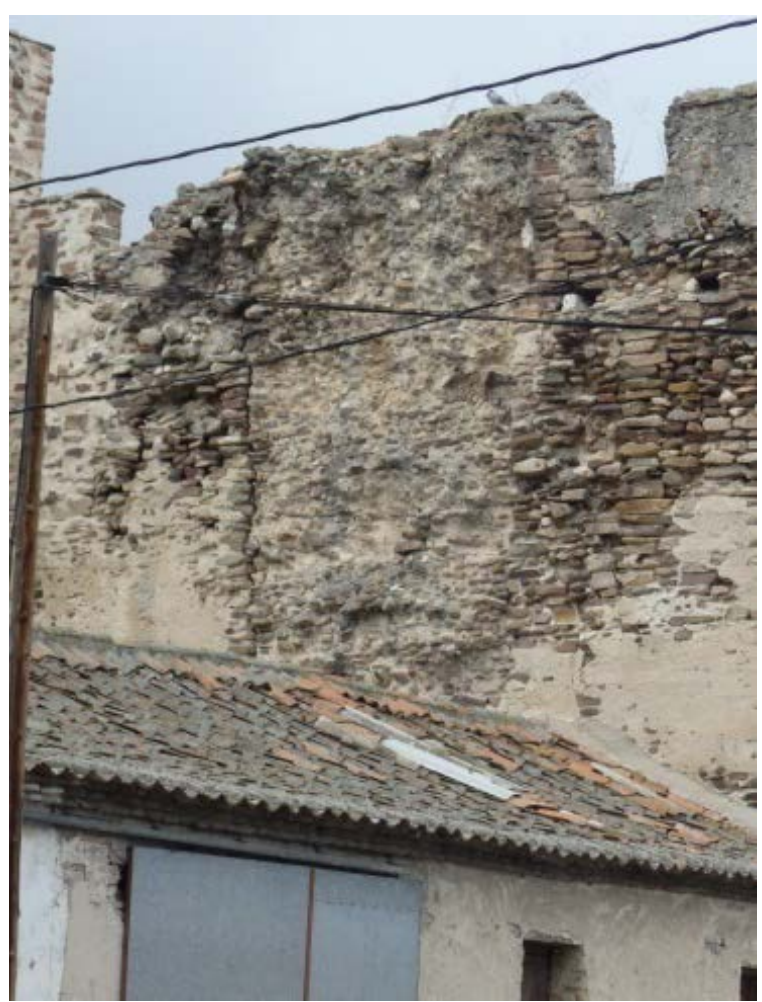

Fig. 5.1.27. Extremo este del tramo, donde se ven marcas en el paramento donde pudo existir una torre adosada (T5) [A.S.E. 11/02/2014].

Al este de la puerta de la Villa, continúa la muralla una treintena de metros. En su cara exterior se adosan varias parcelas y en algunas de el las se adosan edificaciones al lienzo. En el interior de una de las parcelas se sitúa la torre T4, de construcción 
moderna, como se ha indicando anteriormente. Tiene una planta semicircular y se construyó con un aparejo de mampuestos de juntas gruesas, tratando de i mitar el aspecto que tiene la muralla original. Junto a la torre T4 se sitúan las marcas de lo que pudo ser la torre T5 (Fig. 5.1.27). Sólo es visible parcialmente desde el exterior, ya que el lienzo se sitúa detrás de las edificaciones de las parcelas que colindan con la muralla. En la parte superior del lienzo, se observa una forma de proporción rectangular, alargada en sentido vertical. El paramento ofrece un aspecto descarnado, como si se hubiera arrancado parte del material que constituía el lienzo.

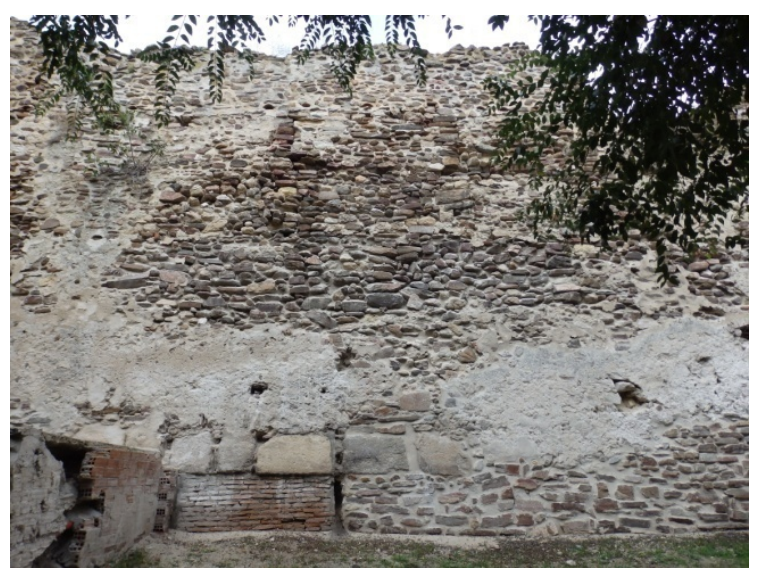

Fig. 5.1.28. Hilada de grandes piedras de granito y arenisca en la base del lienzo T1-T2, en su cara sur [A.S.E. 11/02/2014].

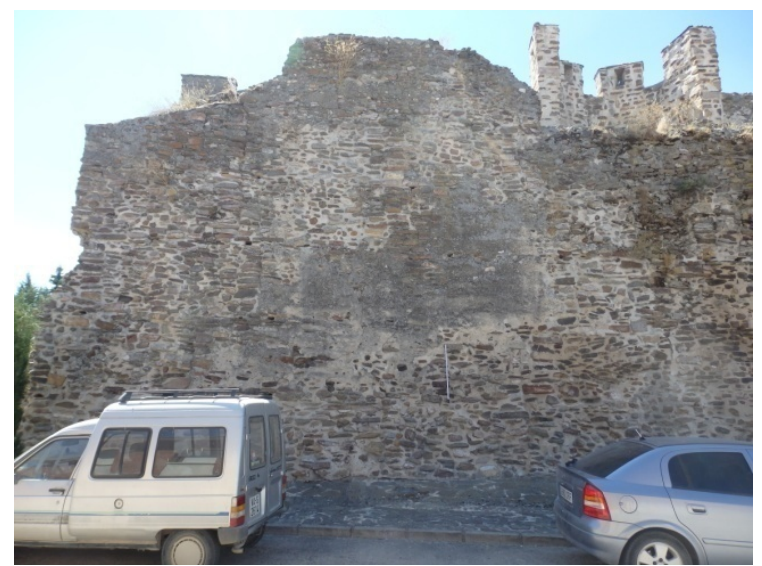

Fig. 5.1.30. Vista interior del lienzo T4-noroeste [A.S.E. 13/8/2016].

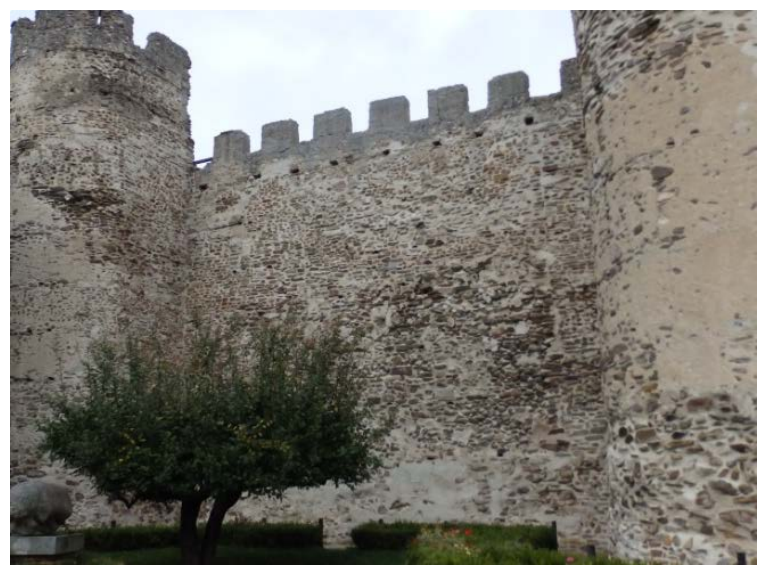

Fig. 5.1.29. Tramo T3-P1 desde el exterior [A.S.E. 11/02/2014].

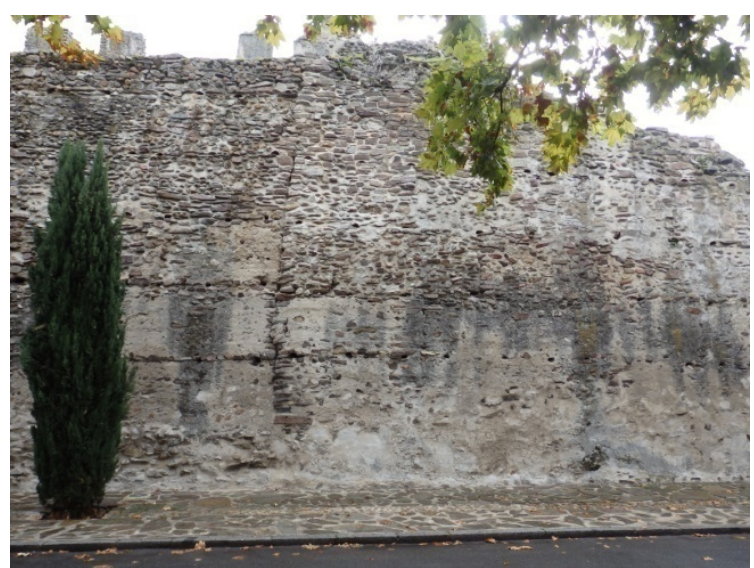

Fig. 5.1.31. Tramo interior de la muralla, a la altura de la torre T2. Se observa la tapia empleada en la construcción [A.S.E. 27/4/2015].

Los lienzos visibles en la cara exterior de este tramo son los que se sitúan entre las torres T1 y T2, desde T1 hacia este y entre la torre T3 y la puerta de la villa. Todos ellos comparten características similares: se emplea de forma mayoritaria la tapia de mampostería como sistema de construcción y se utilizan mampuestos del mismo tipo. La configuración de los lienzos es similar a lo largo de este tramo, en cuanto a anchura y altura se refiere. En la base del lienzo T1-T2 se observa el empleo de sillares en las 
bases del muro (Fig. 5.1.28). Se ve una hilada de cinco grandes piedras rectangulares de distinto material que comparten altura, pero que muestran diferencias en la anchura. Son visibles algunas reparaciones en la base del muro que han consistido en el parcheado de áreas desprendidas con un nuevo aparejo de mampuestos similares a los visibles en I a muralla original. En el tramo T1-T2 no se conserva almenado, y tampoco en el lienzo que parte desde la torre T1 hacia el suroeste. Desde la torre T2 hasta la puerta de la villa se observa un almenado que parece reconstruido con posterioridad. Desde la puerta de la villa hasta la torre T4 se ve igualmente la continuación del almenado.

La cara interior de este tramo se encuentra más despejada de edificaciones y elementos que puedan ocultar los lienzos. La puerta de la Villa se adelanta respecto del plano de I os lienzos colindantes en toda su fachada rectangular, aunque una distancia reducida. En el tramo al noroeste de la puerta de la Villa, el lienzo es continuo, sin cambios en el plano de fachada. Se observan seis tapias de altura en algunos puntos del ienzo. En dirección sureste, el lienzo muestra avances y retranqueos por tramos. En este punto se sitúa la escalera de acceso al adarve que sobresale con la mitad de su fondo respecto del plano del lienzo de muralla. El adarve es accesible entre las torres T6 y T3, esta última incluida en el área transitable. Este tramo es muy similar al existente al noroeste de la puerta de la villa, con el mismo sistema constructivo de tapia de mampostería y con una configuración general muy similar: altura relativamente homogénea, espesor de $m$ uros similar, idéntico sistema constructivo.



Fig. 5.1.32. Espesor de la muralla en el extremo noreste [A.S.E. 2/11/2014].

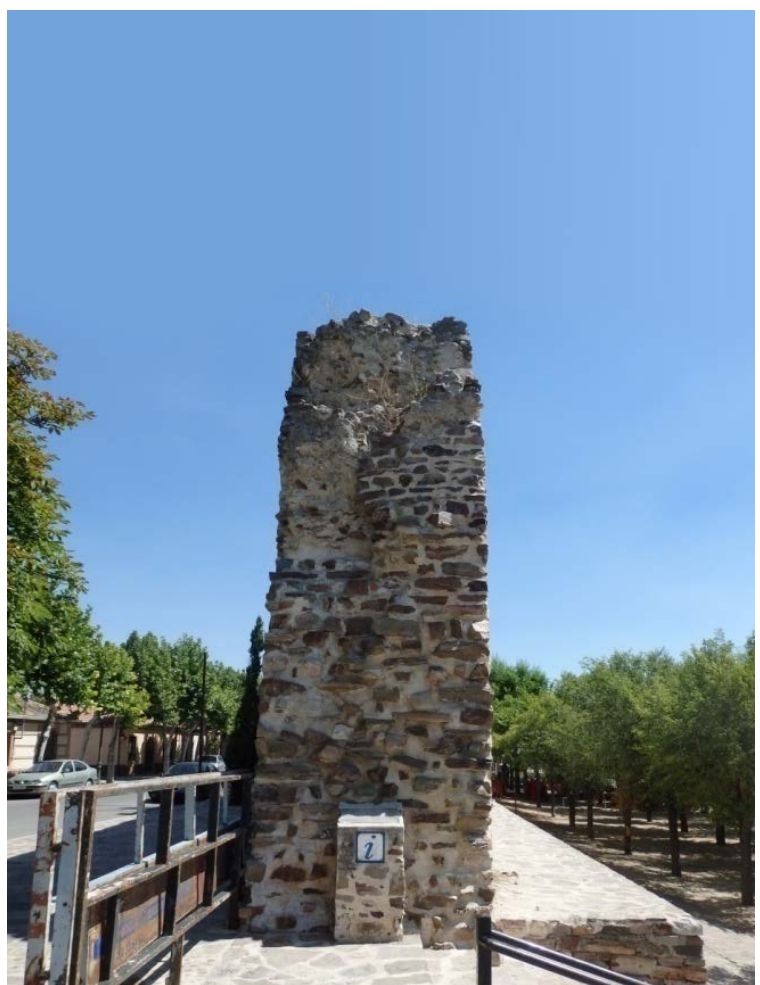

Fig. 5.1.33. Espesor de la muralla en el extremo suroeste [A.S.E.13/8/2016] 
El espesor de este tramo es visible en los extremos noreste y suroeste. En el lado noreste (Fig. 5.1.32) el espesor oscila entre los 2,00-2,10m. La base se encuentra reparada con nuevos mampuestos, colocados a modo de parche sobre la muralla. En la zona superior se observa la sección de la muralla original y se ve homogénea, sin interrupciones verticales interiores que puedan hacer pensar que existen dos hojas en el muro. En el extremo suroeste (Fig. 5.1.33) el espesor es similar, alcanza los 2,20m. La altura del lienzo en este extremo es inferior a la existente en el lado opuesto, donde se observan restos de una almena, totalmente desaparecidas en el extremo suroeste. También en este lado se observan reparaciones en la mitad derecha de la sección, y también en la base.

\subsubsection{Características principales de los elementos descritos}

A continuación, en la Tabla 5.1.1, se reflejan los distintos elementos de este recinto amurallado, las torres y la puerta existentes, indicando los datos más relevantes acerca de su configuración. Se indica si los elementos tienen algún nombre asociado, de qué tipo de torre o puerta se trata o cuál es su sección en planta. También se recoge qué dimensiones tienen las torres en planta y cuál es su relación con el lienzo. En la última columna se detalla si existe alguna base diferenciada que pueda identificarse como preexistencia o c omo cimentación construida ex profeso. A diferencia de otros casos, en este no existe un gran número de torres y puertas. Las torres existentes son ocho, de las cuales dos forman parte de la única puerta existente del recinto. Aunque desaparecidas en la actualidad, se han añadido al final dos puertas delas que no se puede e specificar ninguna característica aparte de su nombre. La posición aproximada de estas puertas se indica en el plano de la villa (Fig. 5.1.3). Tanto en la Tabla 5.1.1 como en la Tabla 5.1.2, se han incluido todos los elementos en un mismo recinto amurallado, ya que no existen evidencias que permitan delimitar otros recintos. Sin embargo, no se descarta que los hubiera.

Tabla 5.1.1. Características y dimensiones de torres y su relación con las puertas. Fuente: Elaboración propia.

\begin{tabular}{|c|c|c|c|c|c|c|c|c|}
\hline 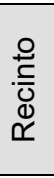 &  & $\frac{\substack{\pi \\
\frac{\pi}{2} \\
\frac{1}{2}}}{0}$ & $\begin{array}{l}\text { Nombre } \\
\text { asociado }\end{array}$ & $\begin{array}{c}\text { Tipo de puerta / } \\
\text { torre }\end{array}$ & $\begin{array}{l}\text { Sección de } \\
\text { torre }\end{array}$ & $\begin{array}{c}\text { Dimensiones } \\
\text { torres } \\
\text { (Diámetro } \varnothing, \\
\text { Fondo } \mathrm{F}, \\
\text { Ancho A) } \\
\end{array}$ & $\begin{array}{l}\text { Relación con } \\
\text { lienzo }\end{array}$ & $\begin{array}{c}\text { Zócalo/Bas } \\
\text { e }\end{array}$ \\
\hline \multirow{5}{*}{ R1 } & T1 & - & - & Flanqueo & Rectangular & $A 4,81 \times F 2,60$ & $\begin{array}{c}\text { Corresponden } \\
\text { cia de hiladas } \\
\text { de tapia }\end{array}$ & $\begin{array}{l}\text { Sí, algunos } \\
\text { sillares en } \\
\text { base }\end{array}$ \\
\hline & T2 & - & - & Flanqueo & Rectangular & $A 4,84 x F 2,60$ & $\begin{array}{c}\text { Corresponden } \\
\text { cia de hiladas } \\
\text { de tapia }\end{array}$ & No \\
\hline & T3 & - & - & Flanqueo & Semicircular & $\mathrm{A} 3,6 x \mathrm{~F} 4,00$ & $\begin{array}{l}\text { En línea con } \\
\text { el lienzo }\end{array}$ & Si, zarpa. \\
\hline & T4 & - & - & $\begin{array}{l}\text { Moderna, de } \\
\text { refuerzo }\end{array}$ & Semicircular & $\varnothing 4,10$ & $\begin{array}{l}\text { En línea con } \\
\text { el lienzo }\end{array}$ & No \\
\hline & T5 & - & - & Desaparecida & Semicircular & - & $\begin{array}{l}\text { En línea con } \\
\text { el lienzo }\end{array}$ & No \\
\hline
\end{tabular}




\begin{tabular}{|c|c|c|c|c|c|c|c|c|}
\hline 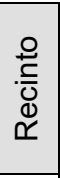 & $\stackrel{0}{0}$ & $\frac{0}{\frac{0}{0}}$ & $\begin{array}{l}\text { Nombre } \\
\text { asociado }\end{array}$ & $\begin{array}{c}\text { Tipo de puerta / } \\
\text { torre }\end{array}$ & $\begin{array}{l}\text { Sección de } \\
\text { torre }\end{array}$ & $\begin{array}{c}\text { Dimensiones } \\
\text { torres } \\
\text { (Diámetro } \varnothing, \\
\text { Fondo } F, \\
\text { Ancho A) } \\
\end{array}$ & $\begin{array}{l}\text { Relación con } \\
\text { lienzo }\end{array}$ & $\begin{array}{c}\text { Zócalo/Bas } \\
\text { e }\end{array}$ \\
\hline \multirow{5}{*}{$\mathrm{R} 1$} & T6 & \multirow[t]{2}{*}{$\mathrm{P} 1$} & \multirow{2}{*}{$\begin{array}{l}\text { Puerta de la } \\
\text { Villa o de } \\
\text { Segovia* }^{*}\end{array}$} & \multirow{2}{*}{$\begin{array}{l}\text { Composición } \\
\text { simétrica entre } \\
\text { torres }\end{array}$} & Semicircular & $\mathrm{A} 5,00 \times \mathrm{F} 7,00$ & $\begin{array}{c}\text { No hay } \\
\text { corresponden } \\
\text { cia de hiladas } \\
\text { de tapia } \\
\end{array}$ & No \\
\hline & T7 & & & & Semicircular & $\mathrm{A} 5,00 \times \mathrm{F} 7,00$ & - & No \\
\hline & T8 & - & - & Flanqueo & Poligonal & $\varnothing 3,50-4,00$ & $\begin{array}{c}\text { Distintos } \\
\text { materiales } \\
\text { que lienzo } \\
\end{array}$ & Sí \\
\hline & - & P2 & $\begin{array}{l}\text { Puerta de } \\
\text { San Adrián }\end{array}$ & Desaparecida & - & - & - & - \\
\hline & - & P3 & $\begin{array}{c}\text { Puerta del } \\
\text { Molino Viejo }\end{array}$ & Desaparecida & - & - & - & - \\
\hline
\end{tabular}

* (Sobrino 2011, 200)

En la Tabla 5.1.2, se detallan cada uno de los tramos existentes del recinto amurallado, identificados a partir de las torres u otros elementos que los delimitan. Cuando no ex isten tales elementos sino que existen lienzos aislados, se les ha asignado un nombre compuesto con la letra $L$ seguida de un número. En esta tabla se indica si se han dado reconstrucciones en los tramos señalados o en qué estado de conservación se encuentra. También se especifica la longitud de cada tramo, indicando qué partes son existentes, han desaparecido o son de nueva construcción.

Tabla 5.1.2. Características y dimensiones de los tramos de muralla. Fuente: Elaboración propia.

\begin{tabular}{|c|c|c|c|c|}
\hline 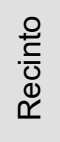 & Tramo & $\begin{array}{l}\text { Reconstrucción } \\
\text { moderna }\end{array}$ & Estado & $\begin{array}{c}\text { Longitud (m) } \\
\text { (E Existente / D } \\
\text { Desaparecido / M } \\
\text { Moderno) }\end{array}$ \\
\hline \multirow{7}{*}{ R1 } & T1-T2 & No & $\begin{array}{c}\text { Buen estado, deterioro } \\
\text { superficial }\end{array}$ & $\mathrm{E} 25,70$ \\
\hline & T2-T3 & $\begin{array}{c}\text { No, adecuación } \\
\text { escalera de acceso a } \\
\text { adarve, posiblemente } \\
\text { almenado } \\
\end{array}$ & $\begin{array}{c}\text { Buen estado, deterioro } \\
\text { superficial }\end{array}$ & E20,2 \\
\hline & T3-P1 & $\begin{array}{c}\text { Sí, adarve y } \\
\text { posiblemente almenado }\end{array}$ & $\begin{array}{c}\text { Buen estado, deterioro } \\
\text { superficial }\end{array}$ & $\mathrm{E} 17,4$ \\
\hline & P1-T5 & $\begin{array}{c}\text { Sí, construida nueva } \\
\text { torre } \mathrm{T4}\end{array}$ & $\begin{array}{c}\text { Buen estado, deterioro } \\
\text { superficial }\end{array}$ & E31,2 \\
\hline & T8-T1 & No & $\begin{array}{l}\text { Buen estado, deterioro } \\
\text { superficial }\end{array}$ & $\begin{array}{c}\mathrm{E} 29,67 / \mathrm{D} 212,89 \text { / } \\
\mathrm{E} 14,80\end{array}$ \\
\hline & $\begin{array}{l}\text { Restos en castillo } \\
\text { lateral sur }\end{array}$ & No & $\begin{array}{l}\text { Vestigios en la base del } \\
\text { muro }\end{array}$ & E29 \\
\hline & Castillo-L1 (incluido) & No & $\begin{array}{c}\text { Restos intermitentes de } \\
\text { escasa altura, } \\
\text { arruinados }\end{array}$ & $\begin{array}{c}\mathrm{D} 82 \text { / E4,37 / D4,5 / } \\
\text { E12 + } 2 \text { fragmentos } \\
\text { desplazados }\end{array}$ \\
\hline
\end{tabular}


Las murallas en las Comunidades de Villa y Tierra de la Diócesis de Segovia en los siglos XI a XIII.

Técnica y sistemas constructivos de la arquitectura defensiva medieval.

\begin{tabular}{|c|c|c|c|c|}
\hline 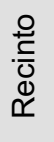 & Tramo & $\begin{array}{l}\text { Reconstrucción } \\
\text { moderna }\end{array}$ & Estado & $\begin{array}{l}\text { Longitud (m) } \\
\text { (E Existente / D } \\
\text { Desaparecido / M } \\
\text { Moderno) }\end{array}$ \\
\hline \multirow{4}{*}{ R1 } & L1-L2 (incluido) & No & $\begin{array}{l}\text { Restos intermitentes de } \\
\text { escasa altura, } \\
\text { arruinados }\end{array}$ & $\begin{array}{c}\mathrm{D} 133 \text { / E4,98 / D41,37 / } \\
\text { E54,94 + } 7 \text { fragmentos } \\
\text { desplazados }\end{array}$ \\
\hline & $\begin{array}{l}\text { L2-zona de la torre de } \\
\text { San Nicolás }\end{array}$ & No & $\begin{array}{l}\text { Desaparecido, algunos } \\
\text { restos desplazados }\end{array}$ & $\begin{array}{l}\text { D920 + } 3 \text { fragmentos } \\
\text { desplazados }\end{array}$ \\
\hline & $\begin{array}{c}\text { Zona torre de San } \\
\text { Nicolás-zona Antiguo } \\
\text { matadero }\end{array}$ & No & $\begin{array}{l}\text { Desaparecido, algunos } \\
\text { restos desplazados }\end{array}$ & $\begin{array}{l}\text { D530 + } 2 \text { fragmentos } \\
\text { desplazados }\end{array}$ \\
\hline & $\begin{array}{l}\text { Zona Antiguo } \\
\text { matadero-T5 }\end{array}$ & No & Desaparecido & D330 \\
\hline
\end{tabular}

\subsubsection{Análisis constructivo}

\subsubsection{Soluciones constructivas presentes en la muralla}

En este apartado se identifican las soluciones constructivas utilizadas en las murallas de Coca. En el tramo sur, donde más restos se conservan, se ve un empleo mayoritario de tapia de mampostería en la construcción de los muros, torres y de la puerta. La tapia empleada se construye con cuarcita roja, de color rojizo, oscuro, de forma alargada y de tamaño medio (Fig. 5.1.34). De acuerdo con J. Francisco Blanco (1991, 436), las canteras de c uarcita roja más próximas se sitúan a 18-20km de distancia. Se trata de los afloramientos paleozoicos de Santa María la Real de Nieva y Bernardos. Esta distancia no es poca, para el traslado de piedras hasta la villa sería necesario el uso de carros tirados por mulas, bueyes o caballos y un solo trayecto tendría una duración de 5 horas, si se considera que la velocidad de un carro cargado tirado por animales no necesariamente supera la de una per sona a pie, $4 \mathrm{~km} / \mathrm{h}$. Por otra parte, se observa el empleo de tapia de cal y canto, donde las piedras empleadas son cantos rodados más pequeños que los mampuestos empleados en la tapia de mampostería. Este sistema es visible en el extremo oeste del lienzo T8-noroeste, en el interior del muro (Fig. 5.1.36). Los fragmentos de muralla de la zona este, al norte del castillo, también parecen construirse con tapia de cal y canto. En uno de los puntos, se observa la presencia de trozos cerámicos (ladrillos, tejas) en el conglomerado de la tapia (Fig. 5.1.37). 




Fig. 5.1.34. Tapia de mampostería [A.S.E. $14 / 8 / 2016]$.

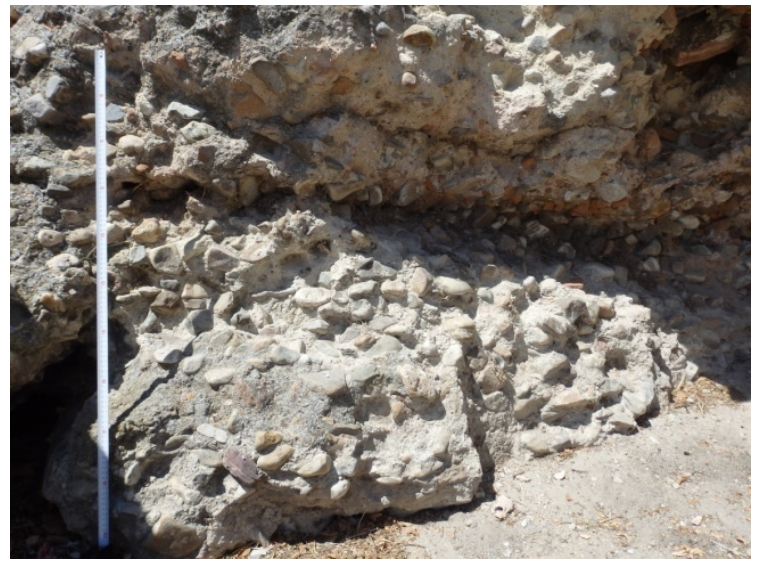

Fig. 5.1.36. Tapia de cal y cantos donde se ve el empleo de cantos rodados. El metro suma $1,00 \mathrm{~m}$ [A.S.E. 14/8/2016].

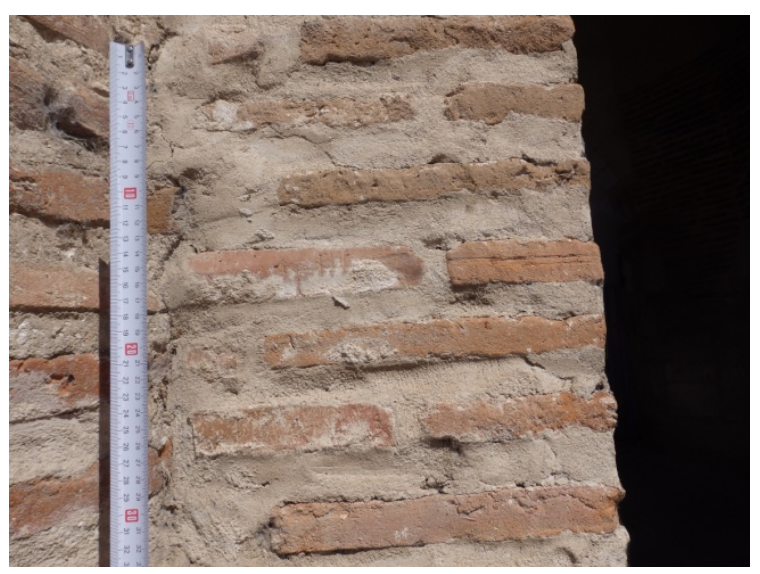

Fig. 5.1.38. Fábrica de ladrillo en el estribo izquierdo del arco de acceso de la puerta de la Villa, en su cara exterior [A.S.E. 14/8/2016].

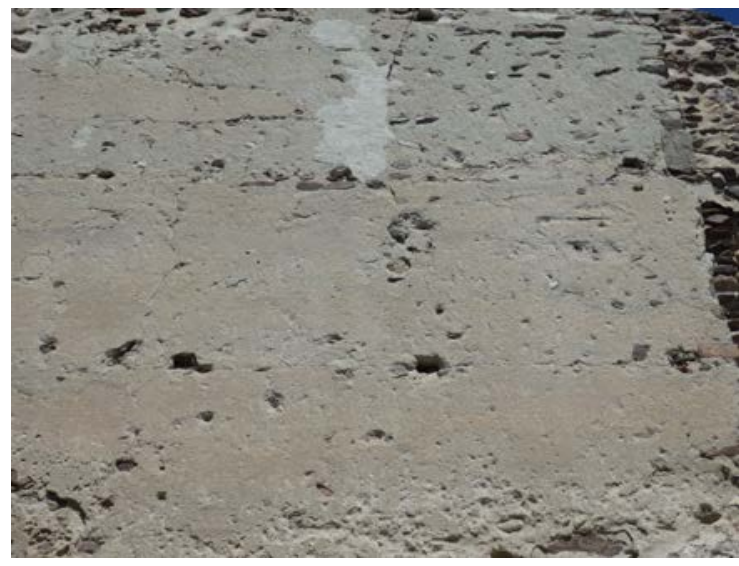

Fig. 5.1.35. Tapia de mampostería [A.S.E. 14/8/2016].

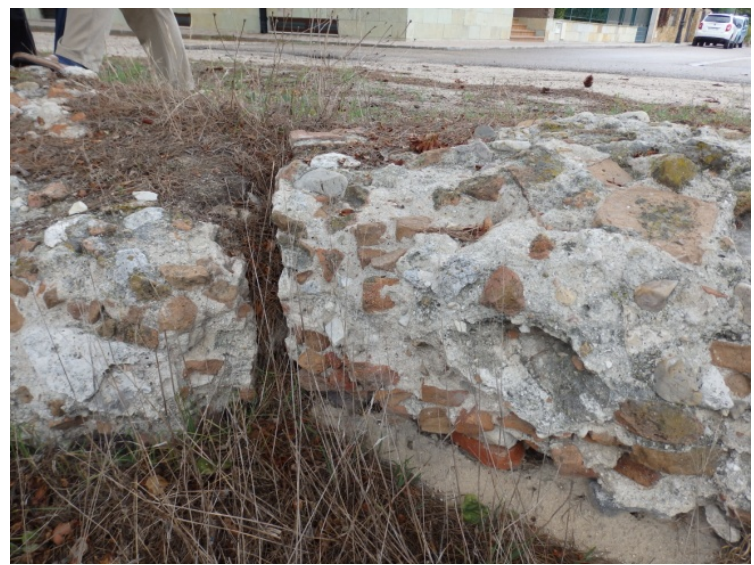

Fig. 5.1.37. Tapia de cal y canto con elementos cerámicos [A.S.E. 11/2/2014].

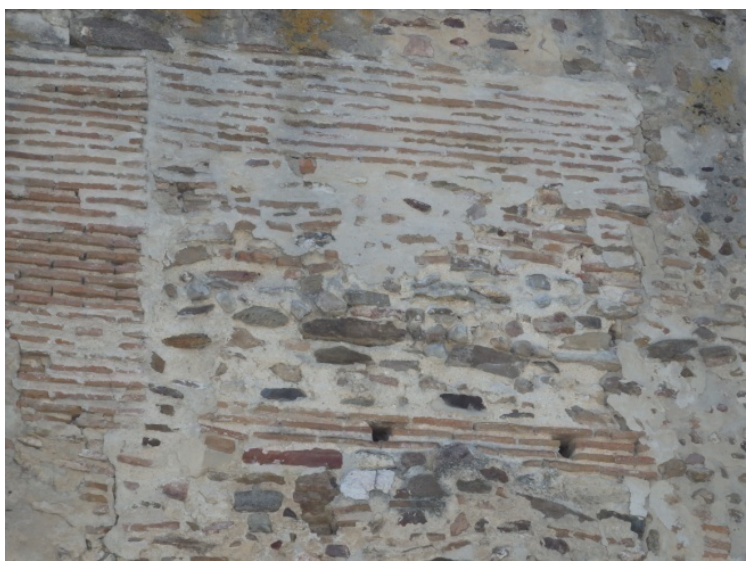

Fig. 5.1.39. Tapia mixta con verdugada cuádruple de ladrillo [A.S.E. 14/8/2016]. 
Las murallas en las Comunidades de Villa y Tierra de la Diócesis de Segovia en los siglos XI a XIII. Técnica y sistemas constructivos de la arquitectura defensiva medieval.

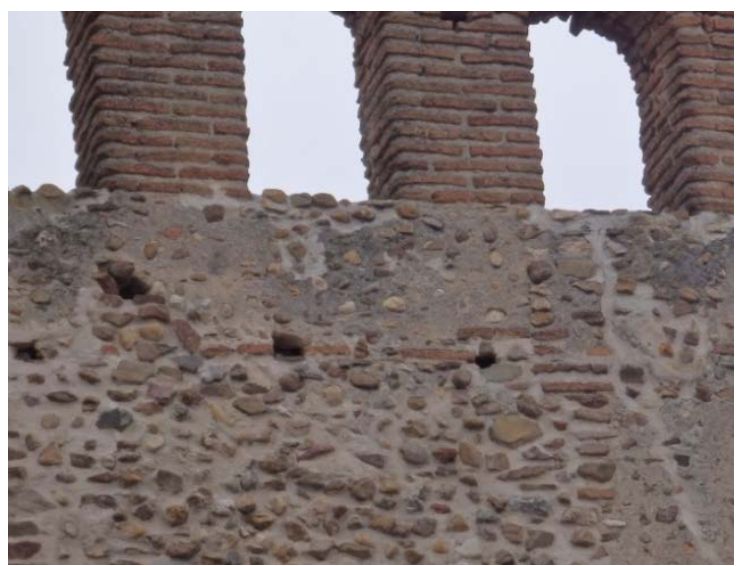

Fig. 5.1.40. Tapia mixta con verdugada sencilla de ladrillo y mechinales con remate de ladrillo [A.S.E. 27/4/2015]

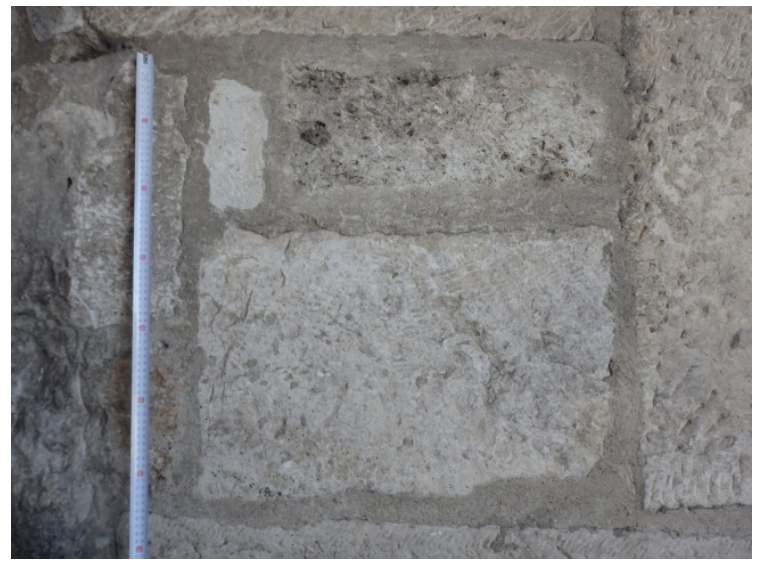

Fig. 5.1.42. Sillería en el interior del paso de acceso e la puerta de la Villa. [A.S.E. 14/8/2016].

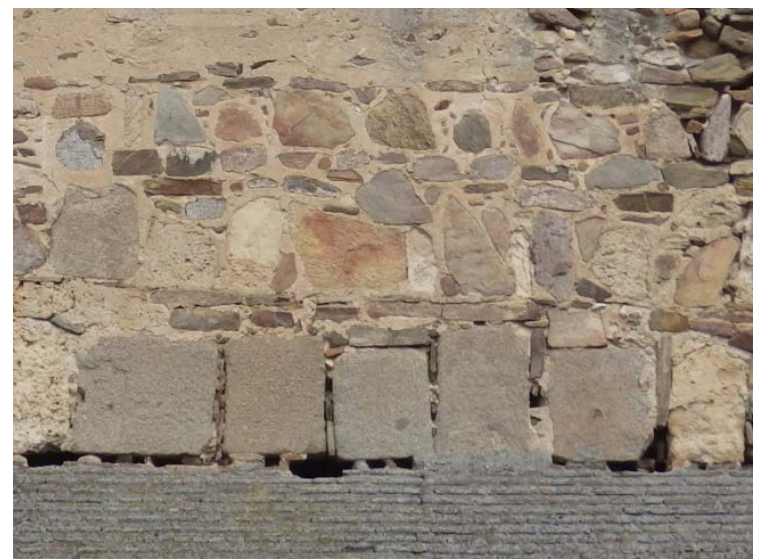

Fig. 5.1.44. Base del tramo T8-noreste, desde el exterior [A.S.E. 27/4/2015].

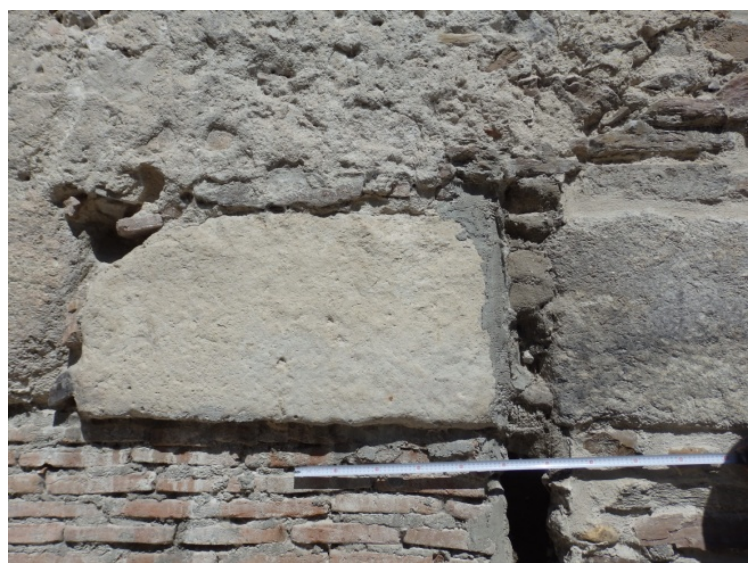

Fig. 5.1.41. Sillares en la base del tramo T1-T2 [A.S.E 13/8/2016]



Fig. 5.1.43. Empleo de sillares de granito aislados, en este caso, en la puerta de la Villa, hacia el interior [A.S.E. 14/8/2016].

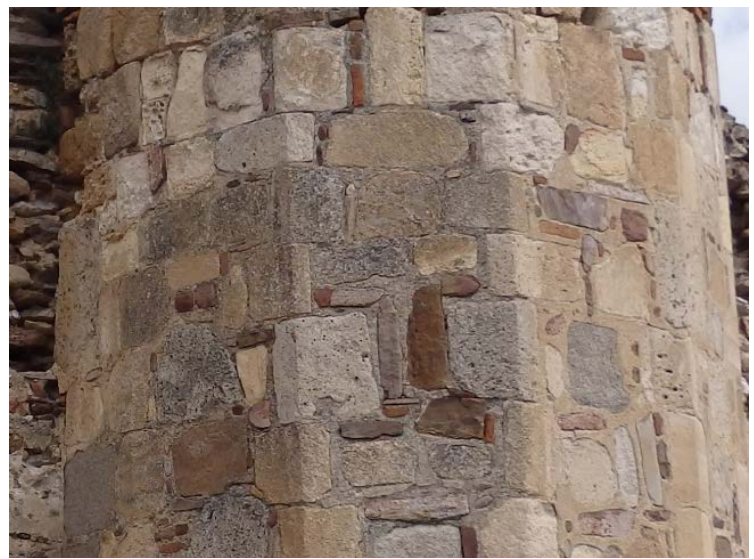

Fig. 5.1.45. Aparejo singular [A.S.E. 14/8/2016] 
En las torres T1 y T2 la tapia conserva el acabado superficial original, que no permite ver las piedras del interior. Se trata del mismo tipo de $t$ apia, es posible ver los mampuestos en las zonas desconchadas del muro (Fig. 5.1.35). En la puerta de la Villa (P1) se pueden observar más de una técnica empleada en su construcción y posteriores modificaciones. La tapia de mampostería se emplea en la construcción de las dos torres que flanquean el acceso, con la particularidad de que tienen directriz curva, lo que modifica la construcción del tapial. Además de la tapia se observa el empleo de ladrillo en la fachada exterior, en la construcción de arcos y como aparejo en el frente del acceso. El ladrillo empleado tiene unas dimensiones de $30 \mathrm{~cm}$ de anchura por $12 \mathrm{~cm}$ de altura y $3,50 \mathrm{~cm}$ de es pesor. El espesor de los tendeles oscila entre los 3,50 y $4,00 \mathrm{~cm}$ (Fig. 5.1.38).

En el alzado interior de la puerta de la villa, en la zona superior izquierda, es visible una desdibujada tapia mixta, de la que solo se ven escasas dos tapias. Se observa un machón de ladrillo, no dentado, en el lado izquierdo y unas tapias con verdugada triple de ladrillo, que aloja los mechinales. En el extremo derecho de la verdugada, se observa una cuarta hilada de ladrillo que hace la verdugada cuádruple en ese punto (Fig. 5.1.39).

El empleo de sillería también es visible en algunos puntos de la muralla. En la puerta de la Villa, se encuentra sillería en la base de los estribos de los arcos, así como en el interior del paso de acceso (Fig. 5.1.41-Fig. 5.1.43).

El empleo de sillares heterogéneos y de diversos tamaños revela la reutilización de sillares provenientes de otras construcciones más antiguas. Se encuentran sillares de granito aislados en varios puntos del recinto amurallado. En la puerta de la Villa se observa un ejemplar colocado en el estribo del arco, en el alzado interior (Fig. 5.1.43). En el lienzo exterior T1-T2, en la base, se ve un sillar de granito junto con otro sillar distinto. En el lienzo pegado al castillo, se observa el empleo de sillares de granito, de tamaños distintos, en la base exterior del muro. Sobre estos sillares de granito se configura un aparejo de aparente desorden y con piedras heterogéneas. Aun así, el aparejo muestra un orden, se ordena con dos hiladas de piedras de proporción plana, que forman una suerte de verdugada doble de piedra. Entre las verdugadas dobles de piedra se construye una hilada de piedras de mayor tamaño y proporción más cuadrada (Fig. 5.1.44). La torre T8 tiene un aparejo también desordenado y emplea piedras de formas y tamaños diversos, que han sido encajadas unas con otras para conseguir la forma deseada. Las piedras se han elegido cuidadosamente y se adaptan a la geometría poligonal en sus esquinas. En las aristas verticales de la torre, se apilan piedras diferentes, aunque de color y material similares, haciendo coincidente la esquina tallada de todas ellas. Se observa el empleo de trozos de ladrillo aislados rellenando huecos entre piedras y sillares. En la coronación de la torre se utiliza el ladrillo para construir la cornisa.

En las bases de los muros, allí donde se han producido desprendimientos de material, se han llevado a c abo reparaciones modernas. En algunos casos, la reparación ha consistido en apl icar morteros de c emento (Fig. 5.1.46); en o tros casos, se han construido parches con un aparejo de mampostería, piedras similares a las usadas en las tapias de la muralla (Fig. 5.1.47). 
Más adelante, en la Tabla 5.1.3 se refleja en qué elementos se encuentra cada una de las soluciones constructivas encontradas. Destaca el empleo de tapia en los distintos tramos de muralla. La puerta P1 presenta, además de la tapia tanto monolítica como mixta, otras soluciones como el aparejo de piedra y de ladrillo. El tramo T8-noreste también se construye con tapia, aunque destaca el empleo de un aparejo de piedra singular en su base.

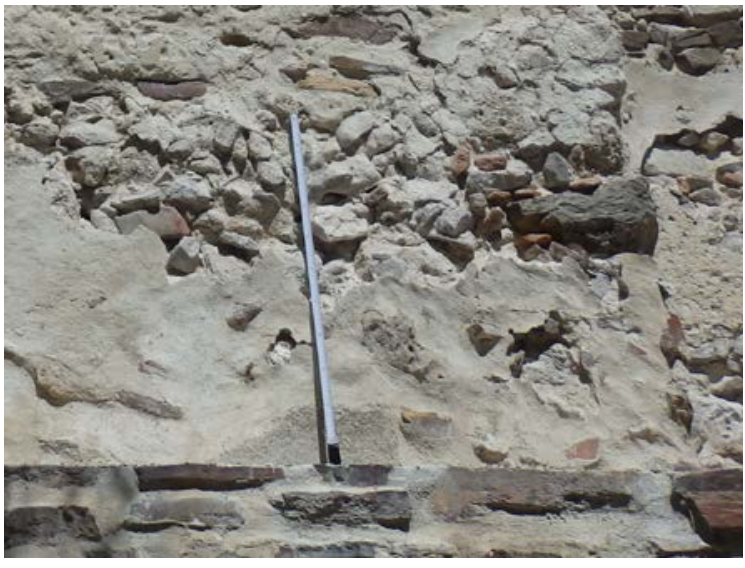

Fig. 5.1.46. Reparaciones en el frente de la base de la torre T1, con aplicación de mortero de cemento [A.S.E. 14/8/2016].

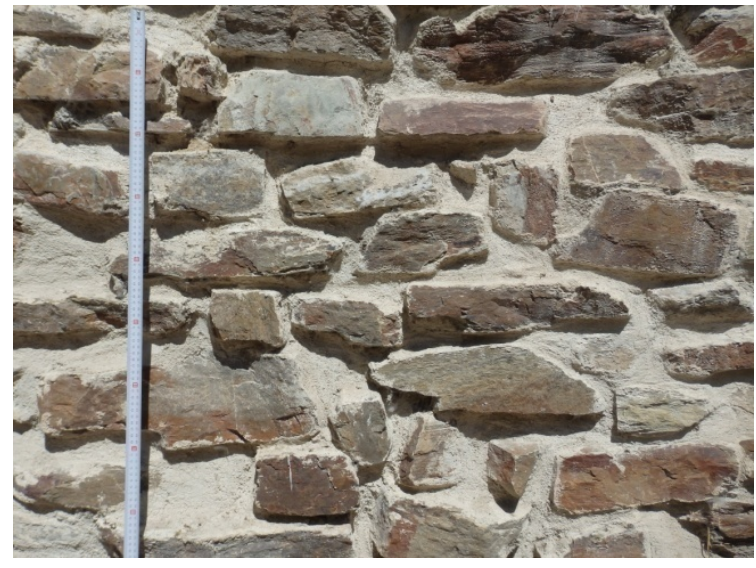

Fig. 5.1.47. Reparación con aparejo de piedras similares en la base del lienzo exterior T1-T2 [A.S.E. 14/8/2016].

Tabla 5.1.3. Soluciones constructivas localizadas por elementos de la muralla.

\begin{tabular}{|c|c|}
\hline & Elementos donde se encuentra \\
\hline $\begin{array}{l}\text { Tapia de mampostería encofrada (cuarcita } \\
\text { roja) } \\
\text { Tapia de cal y canto con cantos rodados } \\
\text { Tapia de cal y canto con elementos cerámicos } \\
\text { en la mezcla } \\
\text { Tapia mixta de ladrillo con verdugada triple y } \\
\text { machones de ladrillo }\end{array}$ & $\begin{array}{l}\text { Tramos T1-suroeste, T1-T5, T5-noreste, } \\
\text { L2, puerta P1. Torres T1, T2, T3, T6, T7. } \\
\text { L3, L4, interior L2-noreste } \\
\text { L4 } \\
\text { Puerta P1 en lado interior. }\end{array}$ \\
\hline $\begin{array}{l}\text { Sillería } \\
\text { En esquinas } \\
\text { En arcos } \\
\text { Fábrica } \\
\text { Sillarejo } \\
\text { Singular }\end{array}$ & $\begin{array}{l}\text { Puerta P1 } \\
\text { Puerta P1, estribos arco interior (arco } \\
\text { reconstruido) } \\
\text { Puerta P1 en paso. } \\
\text { Torre T8, base lienzo L2 }\end{array}$ \\
\hline $\begin{array}{l}\text { Mampostería } \\
\text { Fábrica } \\
\text { Mechinales }\end{array}$ & $\begin{array}{l}\text { T4 (nueva construcción) } \\
\text { Mechinales de la tapia de mampostería }\end{array}$ \\
\hline $\begin{array}{l}\text { Ladrillo } \\
\text { Fábrica } \\
\text { En arcos } \\
\text { Mechinales de teja } \\
\text { Almenado } \\
\text { Decoración }\end{array}$ & $\begin{array}{l}\text { Puerta P1 } \\
\text { Puerta P1 } \\
\text { Zona superior lienzo L1 } \\
\text { Torre T1, T2 } \\
\text { Puerta P1 }\end{array}$ \\
\hline Restaurado & Base T1-T2 \\
\hline Reconstruido & $\mathrm{T} 4$, parte de $\mathrm{P} 1$ \\
\hline
\end{tabular}




\subsubsection{Análisis del lienzo T1-T2, desde el interior del recinto}

El tramo L1 tiene una longitud de $57 \mathrm{~m}$ e incluye dos torres adosadas por el lado exterior (Fig. 5.1.48). En este caso, se ha analizado desde el interior, aunque es visible la posición de las torres ya que sobresalen por encima de los lienzos. Tal y como se explica en el apartado de metodología, sobre la ortofotografía se han dibujado los elementos constructivos visibles. Los elementos más evidentes son las líneas horizontales y verticales que se aprecian en el paramento y que van formando bloques rectangulares. Estas líneas delimitan las tapias visibles en el muro, las líneas horizontales identifican las hiladas de tapias y son más evidentes que los límites verticales, en muchos casos invisibles.

Se observan líneas verticales que recorren el muro desde arriba a abajo, intersecando las líneas horizontales y delimitando tres tramos constructivos de $m$ uralla. Las reparaciones y restauraciones llevadas a cabo a lo largo de los años, ocultan algunas de estas líneas, pero es posible completar los vacíos de forma probable. Fernando Cobos et al. $(2012,122)$ identifican líneas verticales similares a las presentes en el tramo L1 en los núcleos de Granadilla, Ciudad-Rodrigo y San Pedro de Latarce y las denomina línea constructiva vertical.

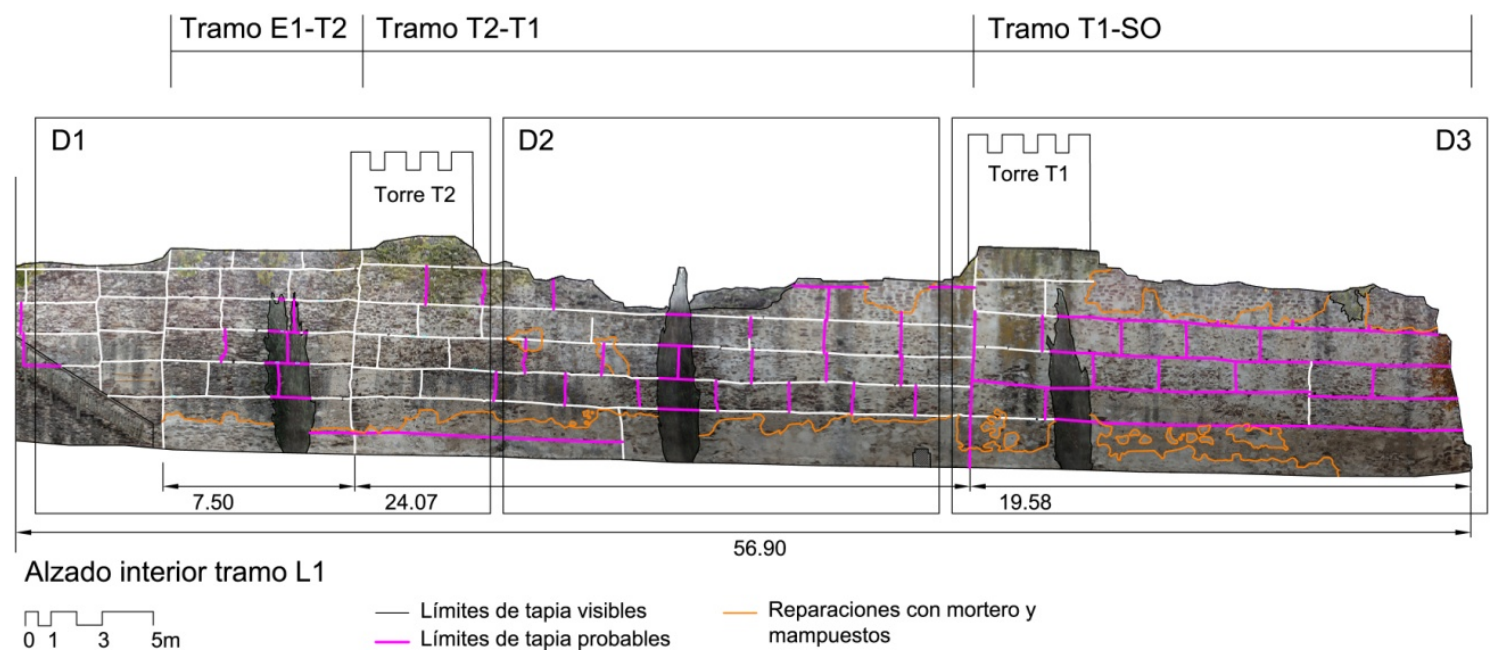

Fig. 5.1.48. Alzado interior del tramo E-F con la interpretación de los elementos constructivos del paramento, dibujado sobre el fotoalzado rectificado. Las torres se adosan por el lado exterior y sobresalen por encima de los lienzos. Fuente: Elaboración propia con fotos del 27/4/2015.

Se dibuja con líneas blancas las divisiones que son realmente visibles en el muro, mientras que se representa con líneas color fucsia aquellas que se han completado basándose en criterios probables. Los límites de los tramos E1-T2 son visibles en el paramento, por lo que se representan en color blanco. El límite de tramo situado a la altura de la torre T1 es sólo ligeramente visible en la zona superior, sin embargo, la posición de los mechinales permite identificar que existe una discontinuidad en las hiladas de tapia desde la parte superior hasta la base del muro, como se explica más adelante (Fig. 5.1.62). Los tramos delimitados tienen longitudes distintas, el primero 
suma $7,50 \mathrm{~m}$, el segundo es bastante más largo con $24 \mathrm{~m}$ y el tercero no conserva su longitud total sino que solo se conservan restos durante $19 \mathrm{~m}$. En este último tramo son especialmente visibles los mechinales, sin embargo, no son tan visibles las líneas que delimitan las tapias.

En la parte superior se observan reparaciones donde se ha añadido material y donde queda oculto el sistema constructivo original. En la base también se pueden apreciar reparaciones mediante la adición de morteros que hacen difícil el examen visual del paramento.

Además de I as líneas en el paramento, se pueden I ocalizar con facilidad los mechinales de las tapias. Se sitúan sobre a las líneas horizontales, separados entre sí distancias regulares, siguiendo un ritmo. Las formas que adoptan son variadas, se observan secciones rectangulares, circulares y semicirculares. Los recuadros D1, D2 y D3 enfocan tres partes de este lienzo interior para su análisis más pormenorizado que se corresponde con las figuras Fig. 5.1.49, Fig. 5.1.58 y Fig. 5.1.61 respectivamente.



Fig. 5.1.49. Detalle D1. Fuente: Elaboración propia.

El detalle D1 (Fig. 5.1.49) muestra uno de los tramos constructivos visibles, el de menor longitud, con $7,50 \mathrm{~m}$. A lo largo de la zona D1, la muralla tiene una altura de siete tapias, la inferior se encuentra semienterrada y la superior no se conserva en su totalidad. La base del muro se encuentra reparada en prácticamente toda su longitud, con parches de mortero de cemento y nuevos mampuestos que ocultan el aspecto original del paramento. Se ha dibujado con línea naranja el contorno de las áreas reparadas. En las hiladas centrales es donde se identifica con mayor facilidad las 
tapias empleadas en la construcción. Se ha asignado una numeración cada una de las tapias en función de la hilada en la que se encuentra, iniciándose la numeración en las hiladas inferiores. El tramo constructivo más corto tiene tres tapias de longitud. Las tapias situadas a la izquierda tienen menor anchura que el resto, por lo que es factible que se trate de tapias residuales, es decir, tienen la anchura que quedaba por cerrar en la hilada, por lo tanto arbitraria y necesariamente más pequeña que la anchura habitual. Que se trate de una tapia residual implica que fue la última tapia de la hilada en construirse, por lo que permite identificar el orden de construcción de las tapias. También implica que o bien se había planificado llegar hasta ese punto en la construcción del tramo y por eso se interrumpen las tapias o que el tramo inmediatamente a la izquierda ya estaba construido y servía de tope a las tapias de las hiladas que llegaban por la derecha.



Fig. 5.1.50. Tapia T3.5 de la parte D1. Son visibles sus límites y otros elementos constructivos. Se pueden ver tres mechinales en la base del bloque. Son levemente visibles las marcas horizontales de las tablas del tapial en la zona izquierda de la tapia [A.S.E. 27/4/2015].

Si nos acercamos a una tapia T3.5 (Fig. 5.1.50) y la examinamos aisladamente, podemos ver más detalles que nos ayudan a entender el sistema constructivo. Se puede ver el bloque rectangular de la tapia y sus límites, que son diferenciables sobre el paramento. En la base se ven tres mechinales colocados de forma simétrica, separados la misma distancia. Entre ellos, se puede ver una hilada definida de piedras de una altura similar, colocadas de forma deliberada en esa posición y que recuerda a una verdugada. No es del todo evidente que se haya reservado un sitio para los mechinales en es ta hilada de piedras, sino más bien que las agujas se colocaron previamente sobre el bloque inferior y fueron cubiertas posteriormente por la hilada de piedras para continuar con la nueva tapia. En la tapia vecina T.3.4 (Fig. 5.1.51) es visible una verdugada de piedra más definida, se observa una hilada de mampuestos irregulares que confirma la idea de que se construía expresamente y de forma 
ordenada. Parece que también se realiza una vez colocadas las agujas en la base, sirviendo para configurar también los mampuestos colocados sobre las agujas. En otros ejemplos arquitectónicos, son habituales las verdugadas en la tapia realizadas con ladrillo y con formas mucho más regulares. Aunque en este caso el resultado sea más tosco, parece evidente que la verdugada de pi edra se empleaba en l a construcción de estas tapias, quedando visible en relación con otras piedras, ocultas bajo la capa superficial de tierra y cal que se observa por encima y por debajo de la hilada de piedras.

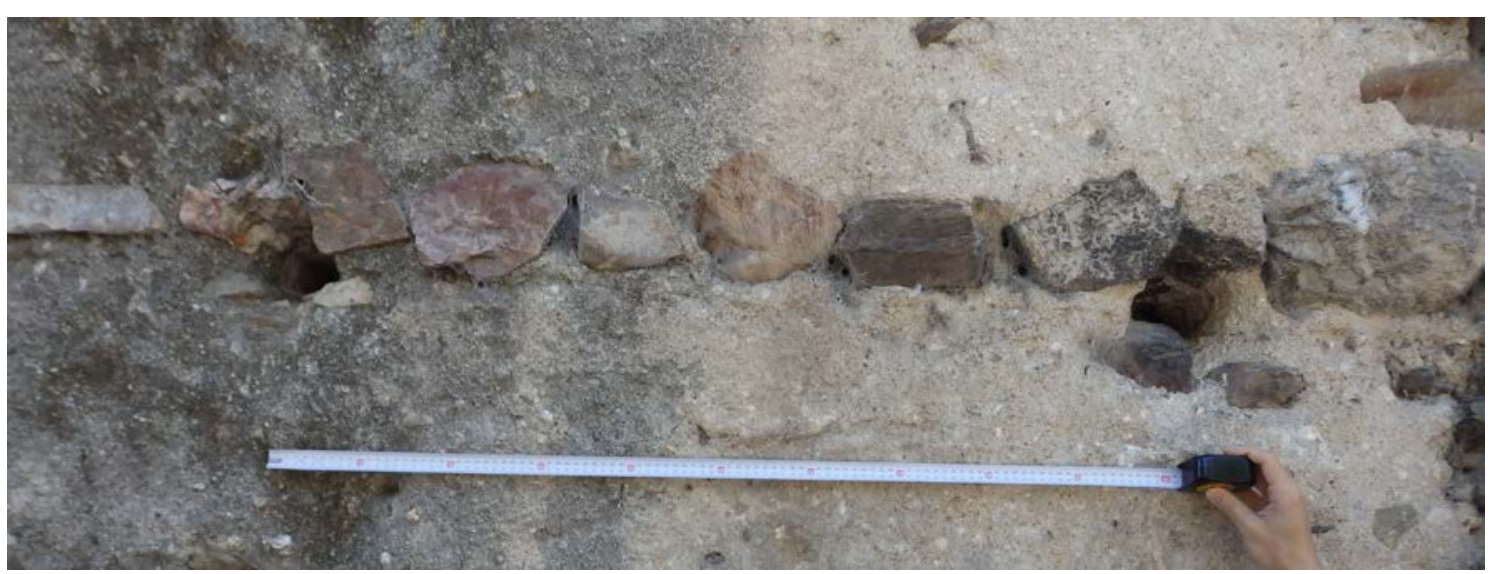

Fig. 5.1.51. Verdugada de piedra en la base de la tapia T3.4 [A.S.E. 14/08/2016]

Es visible la pérdida de material en la muralla, en concreto sobre el material más frágil que es la tierra y arena de cohesión y que también constituye la capa superficial de la tapia. En algunas zonas, la erosión muestras las piedras interiores de la tapia. En estos casos, se puede observar cómo estaban colocadas las piedras, algo que queda oculto en los bloques donde no se ha dado esta erosión. La tapia T3.5 (Fig. 5.1.50) no ha perdido material de forma tan intensa como en otros casos y el acabado que vemos muestra todavía leves marcas horizontales de las tablas del tapial, al menos en la zona izquierda de la tapia.

En el límite izquierdo de la tapia T3.5 se puede ver una disposición particular de las piedras. Son piedras planas y alargadas que han sido elegidas expresamente y colocadas de forma diferente que el resto de piedras visibles, en u na columna formando un límite vertical. Las piedras utilizadas son de color rojizo, de la misma cuarcita roja utilizada en el resto del tramo. Esta disposición recuerda al sistema constructivo existente en la cerca de San Pedro de Latarce de Valladolid, descrito por Fernando Cobos et al. (2012, 110-113), que indica que estas columnas de piedras constituyen uno de los cierres interiores del tapial. En el caso de San Pedro de Latarce, se observan "muretes a base de cantos rodados, de unos dos o tres (en ocasiones cuatro) cantos de espesor" que conforman el cierre lateral de la tapia (Fig. 5.1.53). 


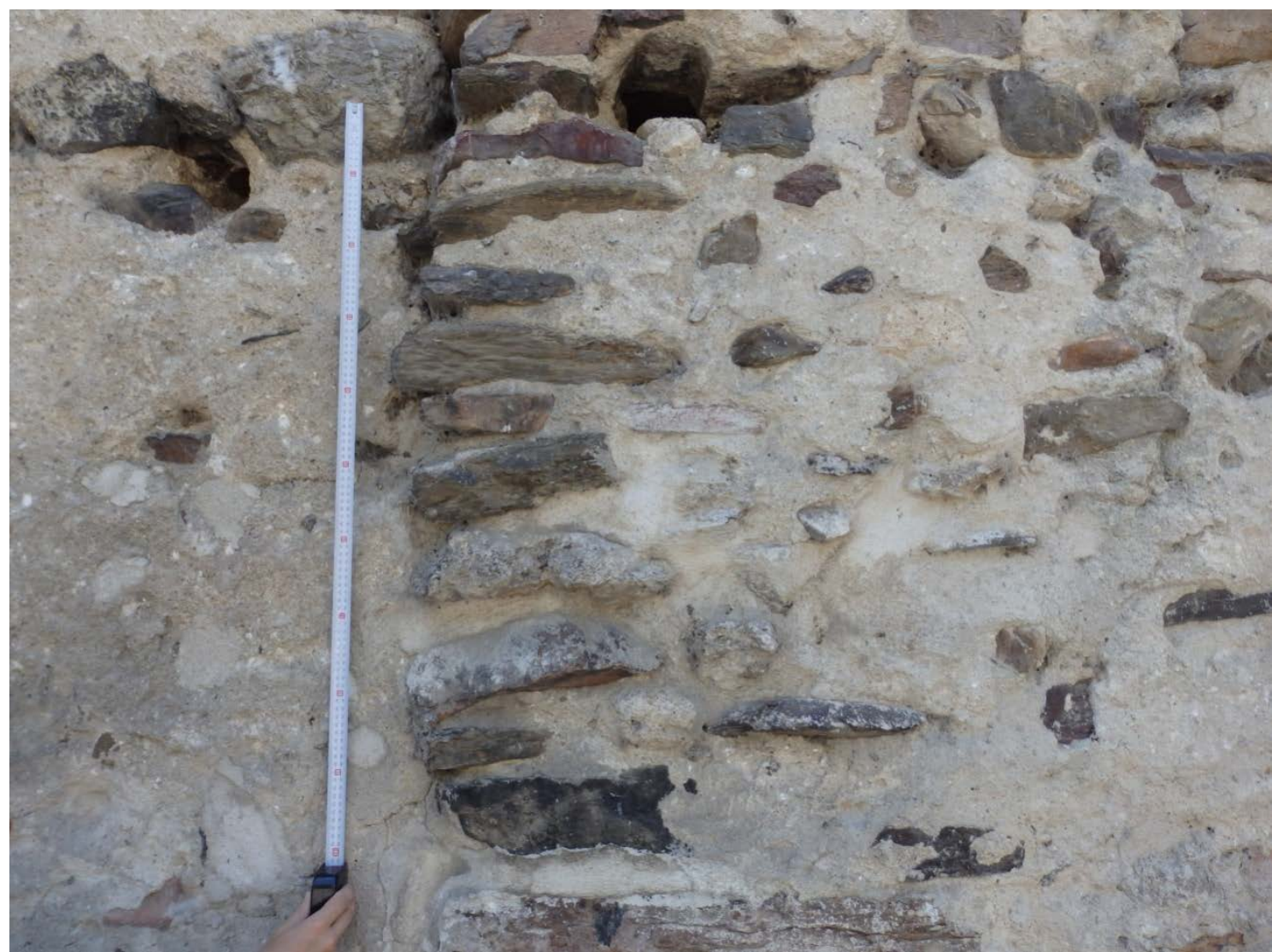

Fig. 5.1.52. Murete de piedras que cierra un lateral de la tapia T2.5 [A.S.E. 13/8/2016].

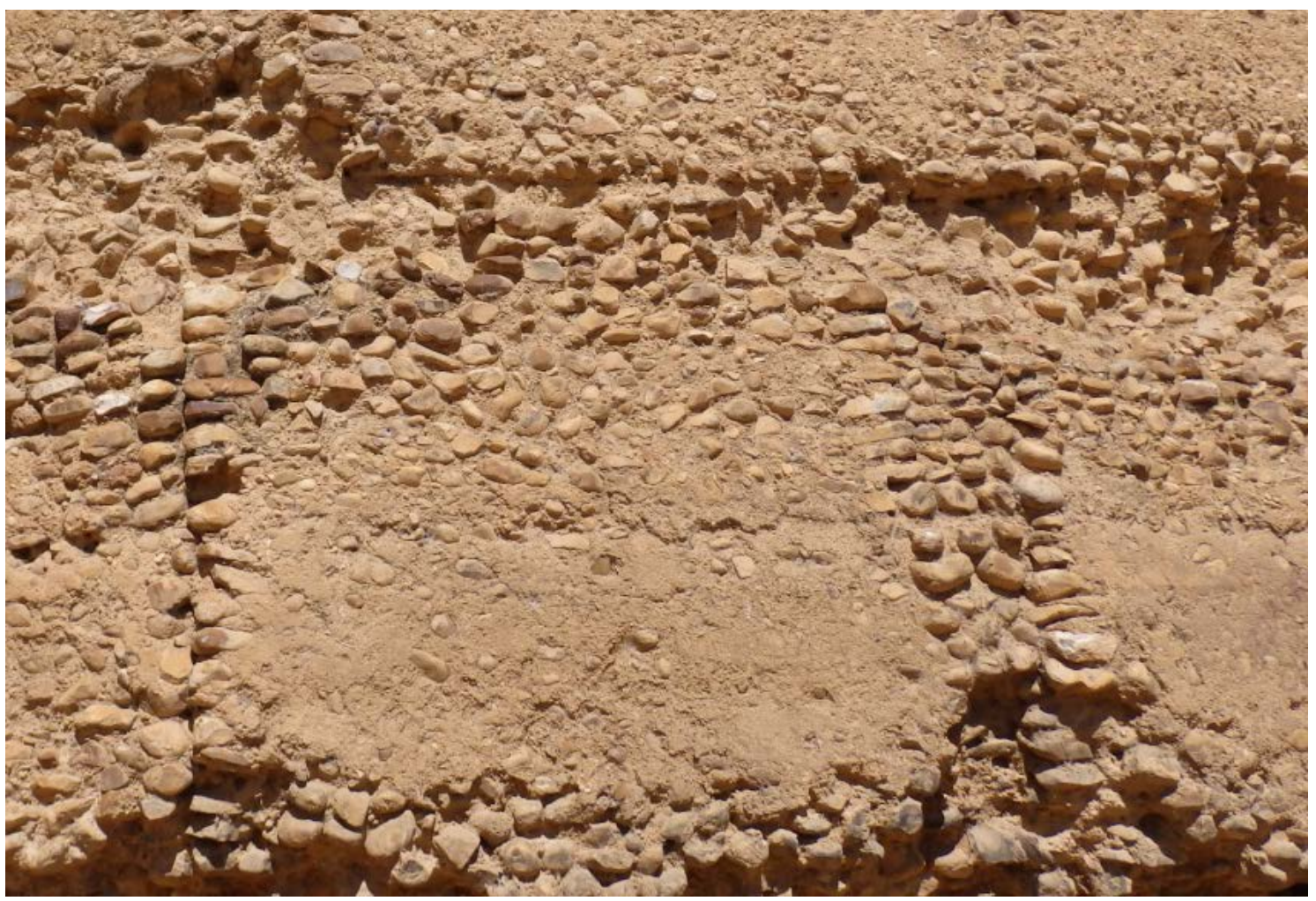

Fig. 5.1.53. Bloques de la muralla de San Pedro de Latarce, Valladolid. Se puede apreciar la colocación de las piedras formando un murete en el lateral de la tapia [A.S.E 29/06/2014]. 
La presencia de estas piedras colocadas en el lateral de las tapias de este tramo de la muralla de Coca sugiere que el sistema constructivo empleado sea similar al existente en San Pedro de Latarce. De esta forma, en la construcción del tapial, una vez cerrados los lados longitudinales con tablas y quedando uno de los lados transversales cerrado por la tapia anterior de la hilada, solo queda cerrar el lado transversal de la caja que quedaba abierto en la dirección de la construcción de las tapias. Se construía un murete de piedras planas que servía de cierre. En este caso, tiene únicamente una piedra de espesor aunque más alargada que el resto de piedras usadas en el bloque. Como explica el mismo autor en el caso de San Pedro de Latarce, este cierre de cajón con un murete también indica la dirección de construcción de las tapias, ya que se conoce cuál es el lado cerrado en úl timo lugar. En estos tramos estudiados, se ha tratado de reflejar la dirección de los bloques a través de flechas, allí donde s on visibles los muretes de cierre (Fig. 5.1.49, Fig. 5.1.58, Fig. 5.1.61). Como última observación, se puede indicar que este sistema de muretes de piedra podría ser más rápido que el sistema de cierre lateral con tablas. Con el uso del murete de piedras, no es necesario esperar a retirar el encofrado de tablas sino que la tapia siguiente podía realizarse a continuación sin espera, ya que el murete va a quedar en cualquier caso embebido en el muro.

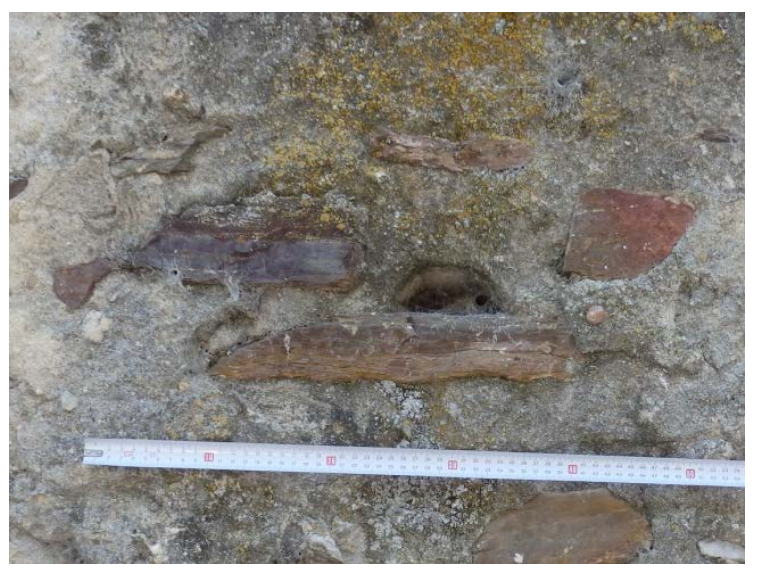

Fig. 5.1.54. Mechinal izquierdo de la tapia 3.7 [A.S.E. 13/8/2016].



Fig. 5.1.56. Dos mechinales adyacentes de distinta configuración situados bajo la escalera de acceso al adarve [A.S.E. 13/8/2016]

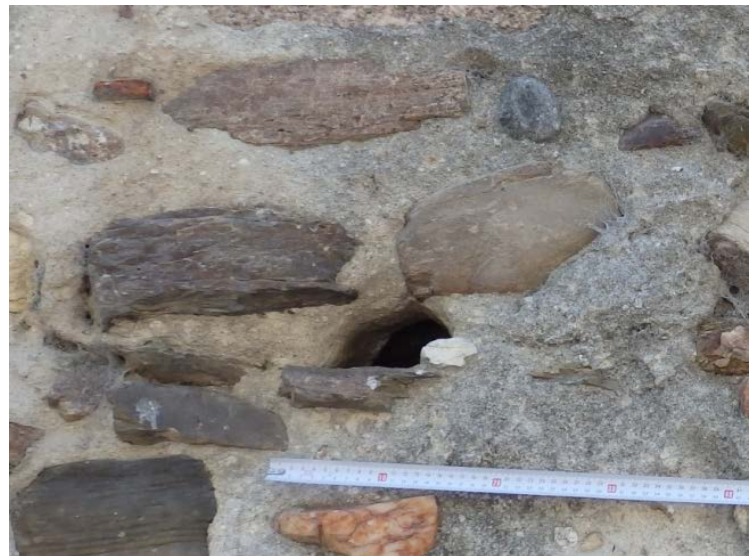

Fig. 5.1.55. Mechinal lateral derecho de la tapia T3.5 [A.S.E. 13/8/2016].

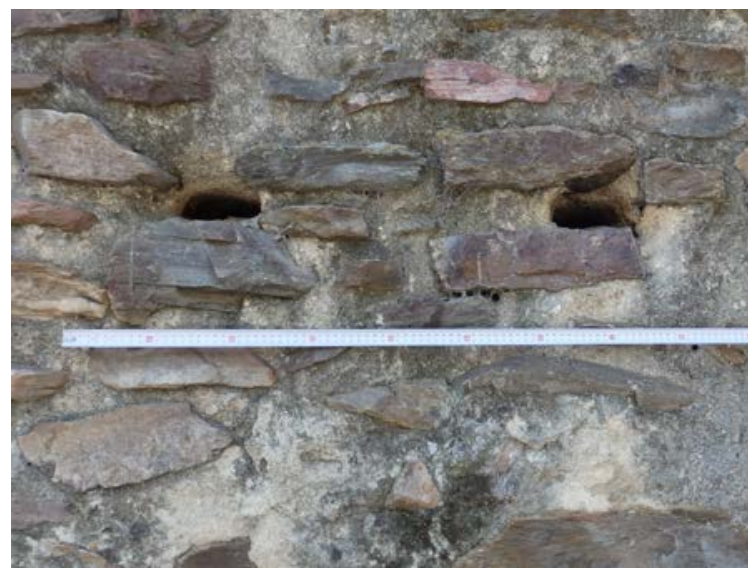

Fig. 5.1.57. Mechinales adyacentes de las tapias T3.2 y T3.3 [A.S.E. 13/8/2016]. 
Los mechinales de esta zona se configuran mayoritariamente con grupos de piedras que enmarcan el mechinal. Es habitual que se rodeen de tres piedras, dos que flanquean y una que corona el mechinal. No obstante, otras configuraciones son visibles, en ocasiones se observa una piedra que funciona de base, dos de flanqueo y apenas coronación (Fig. 5.1.54). En esta figura, se observa una sección trapezoidal en el mechinal. En otros casos, dos piedras dispuestas simétricamente configuran el mechinal (Fig. 5.1.55). También se ven otras soluciones de configuración de mechinales como el empleo de teja cobija. Esta solución es muy habitual en la hilada sexta y visible de forma puntual en las hiladas inferiores (Fig. 5.1.56, derecha). En esta figura, se observa a la izquierda un mechinal cubierto por una piedra poco habitual, de gran tamaño en comparación con las usadas en otros casos. Bajo la escalera de subida al adarve se puede ver una sucesión de cuatro grandes piedras de acabado redondeado por la erosión, tres de ellas colocadas sobre mechinales consecutivos.

En algunas tapias se hace más evidente la disposición de verdugadas de piedra por encima y debajo del mechinal (Fig. 5.1.57). La colocación de piedras planas o alargadas como base y como coronación de los mechinales se extiende más allá de la posición de estos, configurándose hiladas de mampuestos en la coronación y en la base de las tapias.



Fig. 5.1.58. Detalle D2. Fuente Elaboración propia.

En la zona D2 (Fig. 5.1.58) continúa el tramo constructivo iniciado en D1, que finaliza a su encuentro con la torre T1. En esta parte se siguen observando reparaciones en la 
base del muro con la aplicación de morteros. La hilada sexta se pierde en gran parte de esta zona, quedando completas las tapias de las hiladas tercera, cuarta y quinta. En este tramo continúan siendo visibles los límites horizontales de las tapias, pero no tanto los límites verticales. Estos últimos se han deducido en función de la posición de los mechinales visibles, de acuerdo con el sistema empleado en la zona D3, explicado más adelante, donde las marcas de las tapias son menos evidentes, pero los mechinales son testigo del sistema constructivo empleado.



Fig. 5.1.59. Mechinal lateral izquierdo de la tapia T3.10 [A.S.E. 13/8/2016].



Fig. 5.1.60. Mechinal lateral izquierdo de la tapia T3.8 [A.S.E. 13/8/2016].

Los mechinales en esta zona D2 tienen características similares a la zona explicada anteriormente. En la tapia T3.10 se observa un mechinal coronado por una piedra plana, rectangular (Fig. 5.1.59). El hueco del mechinal tiene proporción rectangular, una anchura de $10-11 \mathrm{~cm}$ y una altura de apenas $3 \mathrm{~cm}$. En la tapia T3.8 se ve un mechinal de sección trapezoidal. Sus dimensiones en la base alcanzan los $12 \mathrm{~cm}$ y su altura es de casi $5 \mathrm{~cm}$. La forma trapezoidal puede ser el resultado de emplear una aguja de madera con esa forma, consecuencia a su vez de cortar un tronco en dos mitades y eliminar la corteza a través de tres cortes longitudinales. En torno a este mechinal no se observa una configuración particular de mampuestos, ninguno de ellos es de especial entidad.

El detalle D3 (Fig. 5.1.61) muestra el trozo de muralla visible desde la torre T1 en dirección suroeste, con una longitud de $19 \mathrm{~m}$. A diferencia de lo que ocurre en los detalles anteriores, en esta parte apenas son visibles los límites de las tapias. Por el contrario, es fácil localizar los mechinales. Se organizan en hiladas, separados entre sí distancias similares, siguiendo un ritmo. A partir de la ubicación de los mechinales es posible dibujar, en primer lugar, hilada de tapias a través de una línea horizontal que une cada uno de los mechinales. En el lado izquierdo, el dibujo de las hiladas de tapia a partir de la posición de los mechinales muestra una discontinuidad entre las hiladas de tapias que se encuentran a la izquierda de la torre T1 y aquellas se sitúan a la derecha de la torre (Fig. 5.1.62). Se puede ver un salto que varía de 20 a $60 \mathrm{~cm}$ en función de la hilada que se mida. En la hilada cuarta el salto es de $24 \mathrm{~cm}$, en la hilada quinta la discontinuidad se duplica llegando a los $40 \mathrm{~cm}$ y finalmente en la hilada sexta 
el salto alcanza los $60 \mathrm{~cm}$. Esta discontinuidad de hiladas indica la existencia de un límite vertical, cuyo inicio es visible en la parte superior del muro.

La distancia que separa cada uno de los mechinales también facilita información acerca de los límites de las tapias. El ritmo que los ordena muestra que se suceden dos distancias similares, en torno a $105-110 \mathrm{~cm}$, seguidas de una separación más corta, de $60-70 \mathrm{~cm}$ aproximadamente. Si se denomina la primera distancia A y la segunda más corta $B$, el ritmo resultante es A-A-B (Fig. 5.1.63), repitiéndose en cada una de las hiladas. Comparando con otras tapias de las partes D1 o D2, se deduce con cierta facilidad los límites verticales de las tapias en función de la posición de los mechinales. Es en la distancia $B$, la más corta, donde se ubica el límite vertical. En cada tapia se sitúa un mechinal en el centro y otros dos simétricos y cercanos al borde. Al adosar una tapia con otra los mechinales en tapias diferentes quedan más próximos entre sí que los mechinales dentro de la misma tapia.



Fig. 5.1.61. Detalle D3. Fuente: Elaboración propia.

Los mechinales visibles en esta zona son mayoritariamente de sección rectangular. Se configuran mayoritariamente con un grupo de piedras, sobre todo en las tapias más bajas. Se observan algunos mechinales que están coronados por una piedra aplanada y flanqueado por otras dos piedras (Fig. 5.1.64). En este caso, se observan 
reparaciones recientes de mortero que tapan el entorno del mechinal dificultan la determinación de sus dimensiones. En otros casos, se conserva una capa superficial de tierra y cal, correspondiente al espacio entre la tablazón del tapial y las piedras de la tapia, que oculta la configuración del mechinal (Fig. 5.1.65). En esta última figura, se puede apreciar la aguja de madera que se conserva en el interior de la muralla.

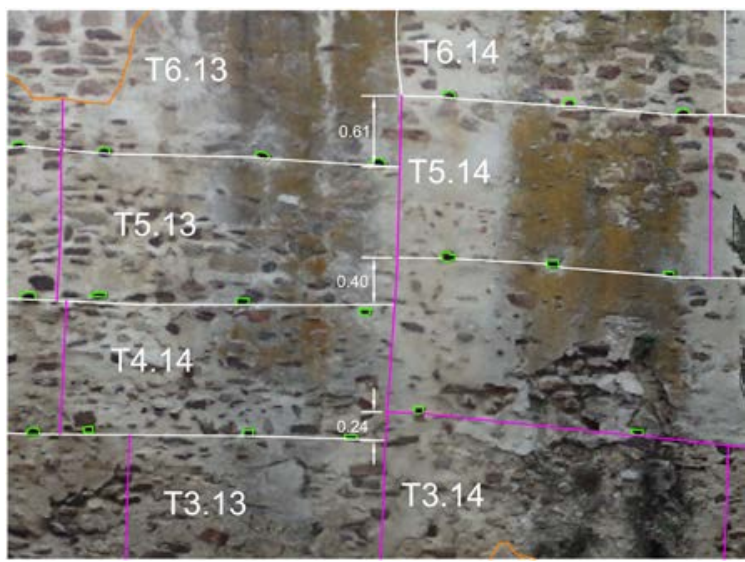

Fig. 5.1.62. Discontinuidad de tramo visible por el salto entre las líneas de mechinales. Desde la izquierda se observa la llegada de mechinales en un nivel, que no se corresponde con el nivel de los mechinales a la derecha.

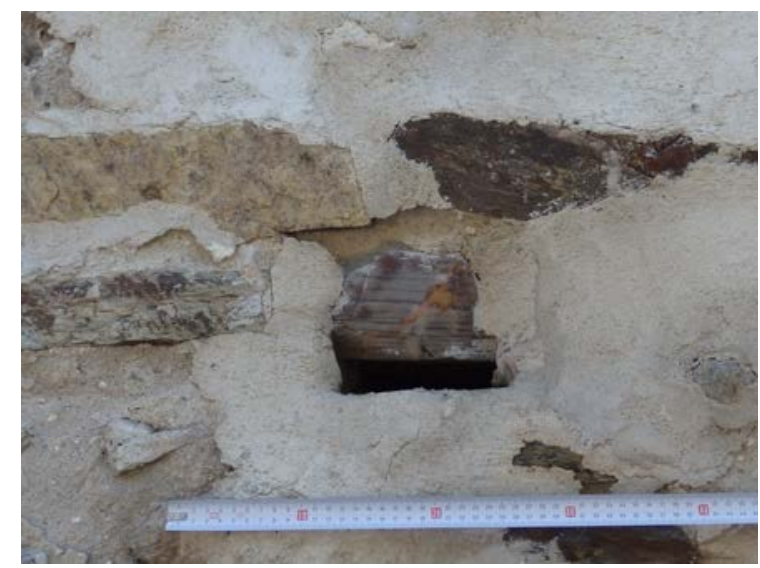

Fig. 5.1.64. Mechinal central de la tapia T3.14. Se observan reparaciones modernas con mortero [A.S.E. 13/8/2016].

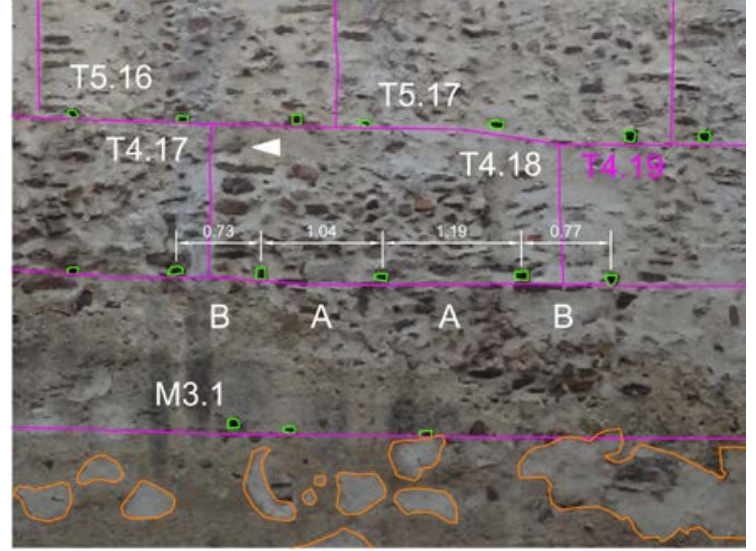

Fig. 5.1.63. El ritmo de los mechinales en este tramo es de forma general así: A-A-B, siendo B la distancia más corta y entre cuyos bordes es probable que se sitúe el límite vertical del bloque.



Fig. 5.1.65. Mechinal M3.1 en la zona D3. Su ubicación respecto de otras tapias es visible en Fig. 5.1.63 [A.S.E. 13/8/2016].

\subsection{Estudio dimensional de la tapia del tramo T1-T2}

La Tabla 5.1.4 a continuación recoge los datos dimensionales de las tapias del tramo L1. En la primera columna se indica el número asignado a la tapia en los dibujos (Fig. 5.1.49, Fig. 5.1.58, Fig. 5.1.61). La segunda columna hace referencia a si los límites de la tapia son claramente visibles, o si se han situado de forma probable a partir de la 
ubicación de los mechinales o de otros elementos circundantes. Las columnas "Ancho" y "Alto" recogen las dimensiones de las tapias. Aquellos datos marcados en color fucsia se corresponden con datos probables, tal y como se indica en la leyenda, al pie de la tabla. Las columnas siguientes hacen referencia a los mechinales de las tapias. En la columna "Sección mechinal" se recoge qué forma tienen los mechinales de cada tapia. Se ha indicado con las letras I (mechinal izquierdo), C (mechinal central) y D (mechinal derecho) seguidas de los códigos $\mathrm{R}$ ( rectangular), Ci ( circular) y Sci (semicircular). Cuando la sección del mechinal no es fácilmente clasificable, se ha marcado con Ir (irregular). No en todas las tapias son visibles los tres mechinales, por lo que en al gunos casos solo se muestra uno o dos resultados. La c olumna "Formación" recoge cómo se han configurado los mechinales, si están coronados por un mampuesto $(M)$, simplemente con tierra $(T)$ o con una teja $(T j)$. Las dos últimas columnas recogen la separación entre los mechinales. Por un lado, se han agrupado las distancias entre mechinales dentro de la misma tapia, extrayendo dos resultados por tapia, anotando primero la distancias correspondiente entre el mechinal izquierdo y el central y después la distancia entre el mechinal central y el izquierdo. La separación de mechinales entre tapias distintas se ha anotado de la misma forma, en la columna izquierda se ha marcado la distancia entre el mechinal izquierdo de la tapia y el mechinal derecho de la tapia inmediatamente anterior. En la columna derecha, se ha escrito la distancia entre el mechinal derecho y el mechinal izquierdo de la tapia siguiente. Este sistema implica la repetición de una misma distancia en dos tapias consecutivas, pero se ha creído más útil la posibilidad de consultar ambas distancias por tapia. En las gráficas y promedios no se han tenido en cuenta las distancias repetidas. Algunos valores se han marcado en color verde, para señalar que no son visibles sino que se han deducido a partir de la posición de mechinales vecinos.

Tabla 5.1.4. Dimensiones de las tapias en el lienzo interior L1. Fuente: Elaboración propia.

\begin{tabular}{|c|c|c|c|c|c|c|c|c|c|}
\hline \multirow{2}{*}{$\begin{array}{l}\text { Tapia } \\
\text { T3.1 }\end{array}$} & \multirow{2}{*}{$\begin{array}{l}\text { Límite } \\
\text { Visible }\end{array}$} & \multirow{2}{*}{$\begin{array}{r}\text { Ancho } \\
2,44 \\
\end{array}$} & \multirow{2}{*}{$\begin{array}{l}\text { Alto } \\
1,40 \\
\end{array}$} & \multirow{2}{*}{$\begin{array}{l}\text { Sección mechinal } \\
\text { (I: Izq.-C: Centro-D: } \\
\text { Dcha.) } \\
\text { C-Ci, D-R }\end{array}$} & \multirow{2}{*}{$\begin{array}{c}\text { Formación } \\
\text { M-M-M }\end{array}$} & \multicolumn{2}{|c|}{$\begin{array}{c}\text { Separación } \\
\text { mechinales } \\
\text { en tapia } \\
\text { Izq.-Dcha. }\end{array}$} & \multicolumn{2}{|c|}{$\begin{array}{c}\text { Separación } \\
\text { mechinales } \\
\text { entre tapias } \\
\text { Izq.-Dcha. }\end{array}$} \\
\hline & & & & & & & 1,38 & & 0,60 \\
\hline T3.2 & Visible & 1,78 & 1,40 & D-R & M & 1,00 & & 0,60 & 0,55 \\
\hline T3.3 & Probable & 2,79 & 1,36 & I-R, C-Ci, D-R & M-M-M & 1,07 & 1,18 & 0,55 & 0,62 \\
\hline T3.4 & Probable & 2,81 & 1,33 & I-Sci, C-Ci, D-R & Tj-M-M & 1,19 & 1,04 & 0,62 & 0,79 \\
\hline T3.5 & Visible & 2,81 & 1,08 & I-Sci, C-Sci, D-Sci & M-M-M & 0,87 & 1,03 & 0,79 & 0,82 \\
\hline T3.6 & Probable & 2,89 & 1,14 & I-Sci C-R, D-R & M-M-M & 1,12 & 0,94 & 0,82 & 0,69 \\
\hline T3.7 & Probable & 2,71 & 1,21 & I-Sci C-R, D-R & Tj-M-M & 1,07 & 1,07 & 0,69 & 0,69 \\
\hline T3.8 & Probable & 2,87 & 1,27 & I-Sci C-R & Tj-M & 0,98 & 1,13 & 0,69 & 0,90 \\
\hline T3.9 & Probable & 3,03 & 1,19 & - & - & - & - & - & - \\
\hline T3.10 & Probable & 2,87 & 1,11 & I-R C-Sci, D-R & M-Tj-M & 1,04 & 1,17 & 0,62 & 0,56 \\
\hline T3.11 & Probable & 2,50 & 1,21 & I-R,C-R & M-M-M & 0,91 & 0,8 & 0,56 & 1,10 \\
\hline T3.12 & Probable & 2,47 & 1,16 & I-R & $M$ & - & - & 1,10 & - \\
\hline T3.13 & Probable & 2,18 & 1,16 & - & - & - & - & - & - \\
\hline T3.14 & Probable & 2,92 & 1,32 & I-Sci, C-R & Tj-M & 0,95 & 1,55 & 0,22 & 0,64 \\
\hline
\end{tabular}


Las murallas en las Comunidades de Villa y Tierra de la Diócesis de Segovia en los siglos XI a XIII.

Técnica y sistemas constructivos de la arquitectura defensiva medieval.

\begin{tabular}{|c|c|c|c|c|c|c|c|c|c|}
\hline Tapia & Límite & Ancho & Alto & $\begin{array}{l}\text { Sección mechinal } \\
\text { (I: Izq.-C: Centro-D: } \\
\text { Dcha.) }\end{array}$ & Formación & \multicolumn{2}{|c|}{$\begin{array}{l}\text { Separación } \\
\text { mechinales } \\
\text { en tapia } \\
\text { Izq.-Dcha. }\end{array}$} & \multicolumn{2}{|c|}{$\begin{array}{c}\text { Separación } \\
\text { mechinales } \\
\text { entre tapias } \\
\text { Izq.-Dcha. }\end{array}$} \\
\hline \multicolumn{2}{|c|}{ Promedio hilada 3} & 2,65 & \multicolumn{2}{|l|}{1,24} & $83 \% \mathrm{M} ; 17 \% \mathrm{Tj}$ & \multicolumn{2}{|c|}{1,07} & \multicolumn{2}{|c|}{0,68} \\
\hline $\mathrm{T} 4.1$ & Probable & 2,99 & 1,24 & C-Ci, D-Ci & M-M & & 1,29 & & 0,52 \\
\hline $\mathrm{T} 4.2$ & Visible & 2,37 & 1,16 & I-R, D-R & M-M & 0,88 & 0,88 & 0,52 & 0,50 \\
\hline T4.3 & Probable & 2,45 & 1,25 & I-R, C-R,D-R & M-M-M & 0,67 & 0,85 & 0,5 & 1,08 \\
\hline $\mathrm{T} 4.4$ & Probable & 2,42 & 1,27 & I-R, C-R,D-R & M-M-M & 0,85 & 0,87 & 1,08 & 0,79 \\
\hline $\mathrm{T} 4.5$ & Probable & 2,56 & 1,23 & I-R, C-R,D-R & M-M-M & 0,84 & 1,02 & 0,79 & 0,62 \\
\hline $\mathrm{T} 4.6$ & Visible & 0,90 & 1,32 & - & - & - & - & - & - \\
\hline $\mathrm{T} 4.7$ & Visible & 2,76 & 1,28 & I-R, C-R,D-R & M-M-M & 1,08 & 1,28 & 0,66 & 0,48 \\
\hline $\mathrm{T} 4.8$ & Probable & 2,97 & 1,31 & I-R & $M$ & - & - & - & - \\
\hline $\mathrm{T} 4.9$ & Probable & 3,01 & 1,26 & I-R, C-R,D-R & M-M-M & 1,47 & 0,94 & 0,68 & 0,61 \\
\hline $\mathrm{T} 4.10$ & Probable & 2,95 & 1,31 & I-R, C-R & M-M & 1,13 & & 0,61 & \\
\hline $\mathrm{T} 4.11$ & Probable & 2,87 & 1,30 & C-R,D-R & M-M & & 0,88 & & 0,84 \\
\hline $\mathrm{T} 4.12$ & Probable & 2,92 & 1,25 & I-Sci, C-R,D-R & Tj-M-M & 1,24 & 0,95 & 0,84 & 0,61 \\
\hline $\mathrm{T} 4.13$ & Probable & 2,94 & 1,13 & I-Sci, C-R,D-Sci & Tj-M-Tj & 1,03 & 1,33 & 0,61 & 0,48 \\
\hline $\mathrm{T} 4.14$ & Probable & 2,78 & 1,12 & I-R, C-R,D-R & M-M-M & 1,35 & 0,89 & 0,48 & 0,54 \\
\hline $\mathrm{T} 4.17$ & Probable & 2,55 & 1,33 & I-Sci, C-R,D-R & Tj-M-M & 0,90 & 0,90 & 0,48 & 0,73 \\
\hline $\mathrm{T} 4.18$ & Probable & 2,99 & 1,33 & I-R, C-R,D-R & M-M-M & 1,04 & 1,19 & 0,73 & 0,77 \\
\hline $\mathrm{T} 4.19$ & Probable & 2,89 & 1,20 & I-R & $\mathrm{M}$ & - & - & 0,77 & - \\
\hline $\mathrm{T} 4.20$ & Probable & 2,50 & 1,32 & I-Ir, C-Ir, D-Ir & M-M-M & 0,77 & 1,22 & 0,42 & 0,47 \\
\hline \multicolumn{2}{|c|}{ Promedio hilada 4} & 2,66 & \multicolumn{2}{|l|}{1,26} & $90 \% \mathrm{M} ; 10 \% \mathrm{Tj}$ & \multicolumn{2}{|c|}{1,03} & \multicolumn{2}{|c|}{0,63} \\
\hline T5.1 & Probable & 3,00 & 1,22 & I-R, C-R,D-R & M-M-M & 1,15 & 1,23 & 0,43 & 0,61 \\
\hline T5.2 & Visible & 2,66 & 1,33 & I-R, D-R & M-M & 0,96 & 0,96 & 0,61 & 0,76 \\
\hline T5.3 & Visible & 2,18 & 1,25 & I-R, C-R,D-Sci & M-M-M & 0,89 & 0,78 & 0,76 & 0,67 \\
\hline T5.4 & Probable & 2,81 & 1,23 & I-R, C-Sci & $\mathrm{M}-\mathrm{Tj}$ & 0,92 & 1,01 & 0,67 & 0,98 \\
\hline T5.5 & Probable & 2,44 & 1,23 & I-Sci, C-R,D-R & Tj-M-M & 0,81 & 0,71 & 0,98 & 0,60 \\
\hline T5.6 & Visible & 2,44 & 1,27 & I-Sci, C-Sci & $\mathrm{Tj}-\mathrm{Tj}$ & 1,06 & 0,97 & 0,60 & 0,44 \\
\hline T5.7 & Visible & 2,47 & 1,27 & C-Sci, D-Sci & $\mathrm{Tj}-\mathrm{Tj}$ & 1,00 & 1,08 & 0,44 & 0,40 \\
\hline T5.11 & Probable & 2,91 & 1,26 & I-Sci, C-Ir, D-R & M-M-M & 0,94 & 1,19 & 0,67 & 0,85 \\
\hline $\mathrm{T} 5.12$ & Probable & 3,00 & 1,30 & I-R, C-R,D-Sci & M-M-M & 1,21 & 1,09 & 0,85 & 0,59 \\
\hline T5.13 & Probable & 2,87 & 1,23 & I-R, C-R,D-R & M-M-M & 1,22 & 1,03 & 0,59 & 0,69 \\
\hline $\mathrm{T} 5.14$ & Probable & 2,65 & 1,38 & I-Ir, C-R, D-R & M-M-M & 0,91 & 0,98 & 0,69 & 0,72 \\
\hline T5.15 & Probable & 3,09 & 1,41 & C-Ci, D-R & M-M & 1,48 & 0,95 & 0,72 & 0,59 \\
\hline T5.16 & Probable & 2,56 & 1,41 & I-R, C-R,D-R & M-M-M & 0,94 & 0,98 & 0,59 & 0,58 \\
\hline $\mathrm{T} 5.17$ & Probable & 2,87 & 1,35 & I-Sci, C-R,D-R & Tj-M-M & 1,12 & 1,16 & 0,58 & 0,62 \\
\hline \multicolumn{2}{|c|}{ Promedio hilada 5} & 2,71 & 1,30 & & $81 \% \mathrm{M} ; 19 \% \mathrm{Tj}$ & \multicolumn{2}{|c|}{1,03} & \multicolumn{2}{|c|}{0,64} \\
\hline T6.1 & Visible & 2,87 & 1,29 & I-Ci, C-Sci,D-Sci & M-Tj-Tj & 0,95 & 1,21 & 0,42 & 0,61 \\
\hline T6.2 & Visible & 2,64 & 1,00 & I-Sci, C-Sci, D-Ir & Tj-Tj-M & 0,95 & 0,91 & 0,61 & 0,78 \\
\hline T6.3 & Visible & 2,08 & 1,11 & I-Ir, C-Ir, D-Ir & M-M-M & 0,82 & 0,69 & 0,78 & 0,68 \\
\hline T6.4 & Visible & 2,69 & 1,17 & I-Ir, C-R, D-Sci & M-M-Tj & 1,25 & 0,9 & 0,68 & 0,50 \\
\hline T6.5 & Visible & 2,77 & 1,21 & I-Sci, C-Sci, D-Sci & Tj-Tj-Tj & 1,04 & 1,13 & 0,50 & 0,63 \\
\hline T6.6 & Probable & 2,69 & 1,50 & I-Sci, C-Sci, D-Sci & Tj-Tj-Tj & 1,03 & 0,97 & 0,63 & 0,56 \\
\hline
\end{tabular}




\begin{tabular}{|c|c|c|c|c|c|c|c|c|c|}
\hline Tapia & Límite & Ancho & Alto & $\begin{array}{c}\text { Sección mechinal } \\
\text { (I: Izq.-C: Centro-D: } \\
\text { Dcha.) }\end{array}$ & Formación & $\begin{array}{c}\text { Separación } \\
\text { mechinales } \\
\text { en tapia } \\
\text { Izq.-Dcha. }\end{array}$ & $\begin{array}{c}\text { Separación } \\
\text { mechinales } \\
\text { entre tapias } \\
\text { Izq.-Dcha. }\end{array}$ \\
\hline T6.7 & Probable & 2,27 & 1,5 & I-Sci, C-Sci, D-Sci & Tj-Tj-Tj & 0,80 & 1,00 & 0,56 & 0,53 \\
\hline T6.8 & Probable & 2,68 & 1,54 & I-R, C-Sci, D-Sci & M-Tj-Tj & 1,06 & 1,07 & 0,53 & 0,73 \\
\hline T6.12 & Probable & 2,9 & 1,32 & I-Sci, C-Sci, D-Sci & Tj-Tj-Tj & 1,09 & 1,13 & 0,60 & 0,70 \\
\hline T6.13 & Probable & 2,88 & 1,52 & I-Sci, C-Sci, D-Sci & Tj-Tj-Tj & 1,35 & 1,00 & 0,70 & 0,60 \\
\hline T6.14 & Visible & 2,8 & 1,31 & I-Sci, C-Sci, D-Sci & Tj-Tj-Tj & 1,03 & 0,96 & 0,60 & 0,74 \\
\hline Promedio hilada 6 & 2,66 & 1,32 & $75 \% T j ; 25 \% M$ & 1,02 & 0,62 \\
\hline
\end{tabular}

Los datos dimensionales de la Tabla 5.1 .4 se han representado mediante diagramas de caja para identificar cual es la distribución de las anchuras y alturas de las tapias, así como de las distancias que separan los mechinales, tanto en la misma tapia como entre distintas tapias. Como en otros casos, se ha representado por un lado el conjunto de datos visibles y por otro aquel que incluye los datos visibles más los datos probables.

Anchura de tapia visible y probable

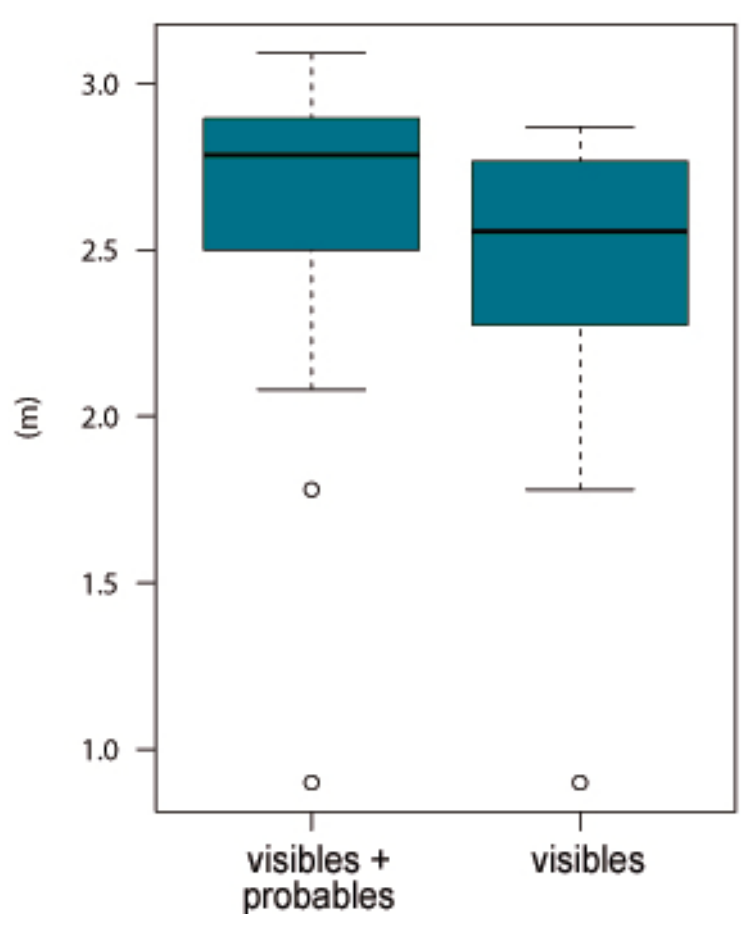

Fig. 5.1.66. Diagrama de caja que representa los datos de la anchura de las tapias visibles y probables en el tramo L1. Fuente: Elaboración propia con el programa $\mathrm{R}$.
Altura de tapia visible y probable



Fig. 5.1.67. Diagrama de caja que representa los datos de altura de las tapias visibles y probables en el tramo L1. Fuente: Elaboración propia con el programa $\mathrm{R}$. 
Si se tiene en cuenta el conjunto que incluye los datos visibles y probables, la anchura de la tapia (Fig. 5.1.66) muestra un rango intercuartílico entre $250 \mathrm{~cm}$ y $287,50 \mathrm{~cm}$, es decir, la altura de la caja alcanza los de $37,50 \mathrm{~cm}$. La mediana, grafiada con una línea negra gruesa, tiene un valor de $278,50 \mathrm{~cm}$, que se tomará con la anchura más habitual para este tramo. En la parte inferior, se observan dos valores de anchura, representados por medio de círculos pequeños. Se corresponden con las anchuras de las tapias T4.6 y T3.2. Cuando solo se contemplan los datos visibles, el rango intercuartílico se sitúa entre $225 \mathrm{~cm}-280 \mathrm{~cm}$ y tiene un valor de $55 \mathrm{~cm}$. La mediana para este caso es de $255 \mathrm{~cm}$.

La altura de las tapias (Fig. 5.1.67) se ha representado de la misma manera que la anchura, por una parte se han representado los datos visibles y por otra parte el conjunto de los visibles y los probables. El rango intercuartílico para la caja izquierda, donde se ven datos probables y visibles, se sitúa en el margen de $121 \mathrm{~cm}-132,5 \mathrm{~cm}$, con un valor de con un valor resultante de $11,50 \mathrm{~cm}$, muy inferior a los visibles para la anchura. La mediana de este conjunto de datos es de $127 \mathrm{~cm}$, que se tomará como altura representativa del tramo. En el segundo conjunto de datos, donde sólo se muestran los datos visibles, los valores descienden ligeramente, obteniéndose una mediana de $125 \mathrm{~cm}$.

Distancia entre mechinales visibles y probables

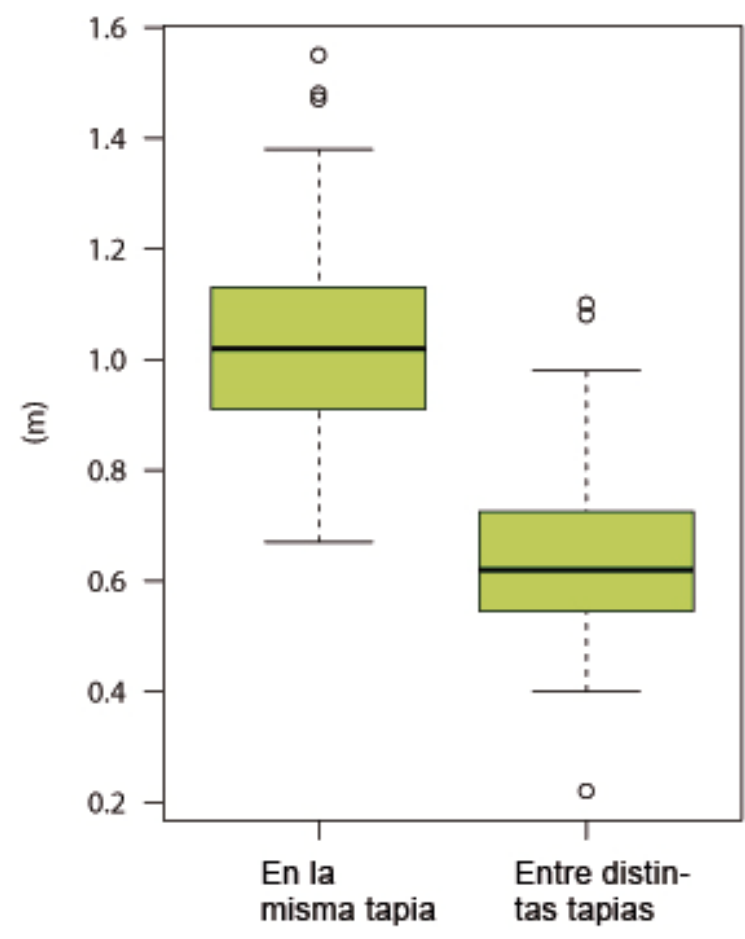

Fig. 5.1.68. Diagrama de caja que representa las distancias entre los mechinales visibles, probables y deducidos. Fuente: Elaboración propia con el programa R.
Distancia entre mechinales visibles

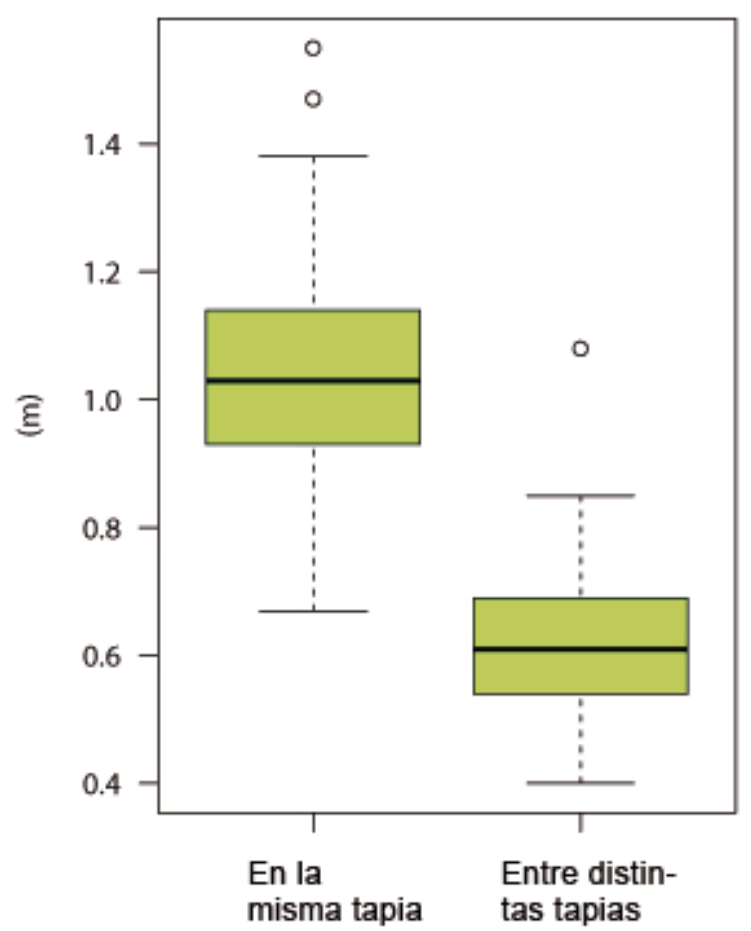

Fig. 5.1.69. Diagrama de caja que representa solo las distancias entre mechinales visibles. Fuente: Elaboración propia con el programa $\mathrm{R}$. 
Las distancias que separan los mechinales se han representado también a través de diagramas de caja. Teniendo en cuenta los datos visibles, probables y deducidos (Fig. 5.1.68), el rango intercuartílico de la distancia que separa los mechinales de una misma tapia se sitúa entre los $90 \mathrm{~cm}$ y $117 \mathrm{~m}$, con un valor de $27 \mathrm{~cm}$. La mediana de estas distancias es de $102 \mathrm{~cm}$. El rango intercuartílico de la distancia entre mechinales de tapias diferentes se sitúa entre $55 \mathrm{~cm}$ y $70 \mathrm{~cm}$, con un valor de $15 \mathrm{~cm}$. La mediana en este caso es de $62 \mathrm{~cm}$. Si no se consideran los datos probables y solo se incluyen los visibles, los datos varían ligeramente. La mediana de las distancias entre mechinales de la misma tapia es de $103 \mathrm{~cm}$ y entre mechinales de tapias distintas el margen es de $61 \mathrm{~cm}$. Los rangos intercuartílicos son muy similares a los detallados para la gráfica anterior.

Teniendo en cuenta los valores analizados y extraídos, se ha tratado de plasmar en la Tabla 5.1.5 los datos característicos de una tapia representativa de este tramo. Para ello, se han considerado los datos visibles y probables. En la columna izquierda, se indican los datos generales de la tapia. Se refleja el rango de la anchura y altura más habituales, de acuerdo con los análisis estadísticos realizados y el valor medio del rango identificado entre paréntesis. Se indica el espesor de la muralla, medido en el extremo suroeste del tramo. Se recoge si existen marcas de la tablazón del tapial, cuáles son las medidas de estas marcas y cuando es posible, se refleja qué altura de tablas componía el tapial en sus lados longitudinales.

Tabla 5.1.5. Características y dimensiones para una tapia representativa del tramo T1-T2, considerando los datos visibles y probables.

\begin{tabular}{|c|c|c|c|}
\hline Tapia & T1-T2 & Mechinales & T1-T2 \\
\hline Altura $(\mathrm{cm})$ & 127 & Sección mayoritaria & $\begin{array}{l}\text { Rectangular, } \\
\text { semicircular }\end{array}$ \\
\hline Anchura (cm) & 278,50 & Dimensiones (cm) & $5-8 \times 12-15$ \\
\hline Espesor (cm) & $200-210(\bar{x}=205)$ & Distancia en tapia & 102 \\
\hline $\begin{array}{l}\text { Restos de encofrado / } \\
\text { Tipo de tapial }\end{array}$ & $\begin{array}{c}\text { Sí / Tapial } \\
\text { independiente }\end{array}$ & $\begin{array}{l}\text { Distancia entre tapias } \\
\text { (cm) }\end{array}$ & 62 \\
\hline $\begin{array}{l}\text { Juntas más visibles en } \\
\text { paramento }\end{array}$ & Horizontales & Mechinales por tapia & 3 \\
\hline $\begin{array}{l}\text { Altura de tablas de } \\
\text { encofrado }(\mathrm{cm}) / \mathrm{n}^{\circ} \\
\text { tablas por tapia }\end{array}$ & $\begin{array}{c}\text { 25-28 / } 4 \text { tablas por } \\
\text { tapia }\end{array}$ & $\begin{array}{l}\text { Ubicación de mechinal en } \\
\text { relación con tapia }\end{array}$ & Inferior \\
\hline $\begin{array}{l}\text { Piedras exteriores } \\
\text { colocadas }\end{array}$ & Sí & Material & Mampuesto, teja \\
\hline Verdugada & $\begin{array}{l}\text { Sí, de piedra, en } \\
\text { muchos casos }\end{array}$ & Aguja perdida/recuperable & Perdida \\
\hline Materiales empleados & $\begin{array}{l}\text { Mampuestos(cuarcita } \\
\text { roja), tierra, cal, teja }\end{array}$ & $\begin{array}{l}\text { Profundidad mechinal } \\
\text { (pasante/media aguja) }\end{array}$ & - \\
\hline $\begin{array}{l}\text { Tramos constructivos } \\
\text { verticales }\end{array}$ & Sí & $\begin{array}{l}\text { Tipo de aguja } \\
\text { (pareadas/unitaria) }\end{array}$ & Unitaria \\
\hline
\end{tabular}


En base los restos del encofrado, se indica qué tapial se ha empleado, si se trata de tapial corrido o si se han empleado tapiales independientes. Se refleja igualmente si existen verdugadas en las tapias y qué materiales se emplean en su construcción. En la columna derecha, se detallan las características referentes a los mechinales. Se determina la sección mayoritaria, las dimensiones en altura y anchura, qué distancia separa los mechinales en la misma tapia o entre tapias vecinas. Se detalla cuántos mechinales se dan por tapia y en qué posición se ubican. Finalmente se indica qué material se emplea para la configuración del mechinal y qué tipo de aguja se utiliza. Con esta tabla se pretende mostrar las características de una tapia representativa de este tramo, a través de un análisis realizado desde el interior del recinto.

\subsection{Tipología de la tapia en T1-T2}

La tapia del lienzo analizado se puede clasificar igualmente de acuerdo con la clasificación de A. Graciani y M.A. Tabales, las tapias de los tramo estudiados podrían clasificarse como tapia monolítica con verdugadas de piedra y con mechinales con remate de mampuesto o con teja (Tabla 5.1.7). De acuerdo con la clasificación de I.J. Gil, estas tapias tendrían las características indicadas en la Tabla 5.1.6, situada más adelante.

Tabla 5.1.7. Tipología constructiva de las tapias del tramo T1-T2 de acuerdo con Amparo Graciani y Miguel A. Tabales $(2008,139)$ en el área sevillana.

\begin{tabular}{|l|c|c|}
\cline { 2 - 3 } \multicolumn{1}{c|}{} & Mechinal & Verdugada \\
\hline Monolítico & Mampuesto & Verdugada de piedra \\
\hline Monolítico & Teja & Verdugada de piedra \\
\hline
\end{tabular}

Tabla 5.1.6. Tipología constructiva de las tapias del tramo T1-T2 de acuerdo con la clasificación de Ignacio J. Gil Crespo (2013, 554-557)

\begin{tabular}{|l|l|}
\hline A. Material de construcción & 5. Mampostería \\
\hline B. Compactación del material & 2. Vertido \\
\hline C. Función constructiva & 1. Fábrica principal \\
\hline D. Encofrado & 1. Cajones independientes tapiales testeros o fronteras \\
\hline E. Acabado superficial & 4. Capa externa de mampostería \\
\hline F. Combinación de materiales & 4. Mampuestos tierra y cal \\
\hline $\begin{array}{l}\text { G. Mechinales } \\
\text { G-a. Situación }\end{array}$ & $\begin{array}{l}\text { 1. Situación en el propio hilo } \\
\text { G-b. Profundidad }\end{array}$ \\
$\begin{array}{l}\text { G-c. Formación } \\
\text { G-d. Sección }\end{array}$ & $\begin{array}{l}\text { 1. Formación aguja embebida en la fábrica } \\
\text { 2. Rectangular }\end{array}$ \\
\hline
\end{tabular}




\subsubsection{Torres del tramo $L 1$}

Además de los lienzos estudiados, se ha considerado de interés analizar algunas de las torres de este recinto, porque comparten características constructivas con los lienzos de muralla. Las torres de este tramo se encuentran en el lado sur del lienzo, hacia el exterior. Como se ha descrito anteriormente, existen dos torres de planta rectangular y tres torres de planta semicircular, dos de ellas integrantes de la puerta de la Villa. Todas ellas se construyen con tapia de mampostería, muy similar la visible en el lienzo.

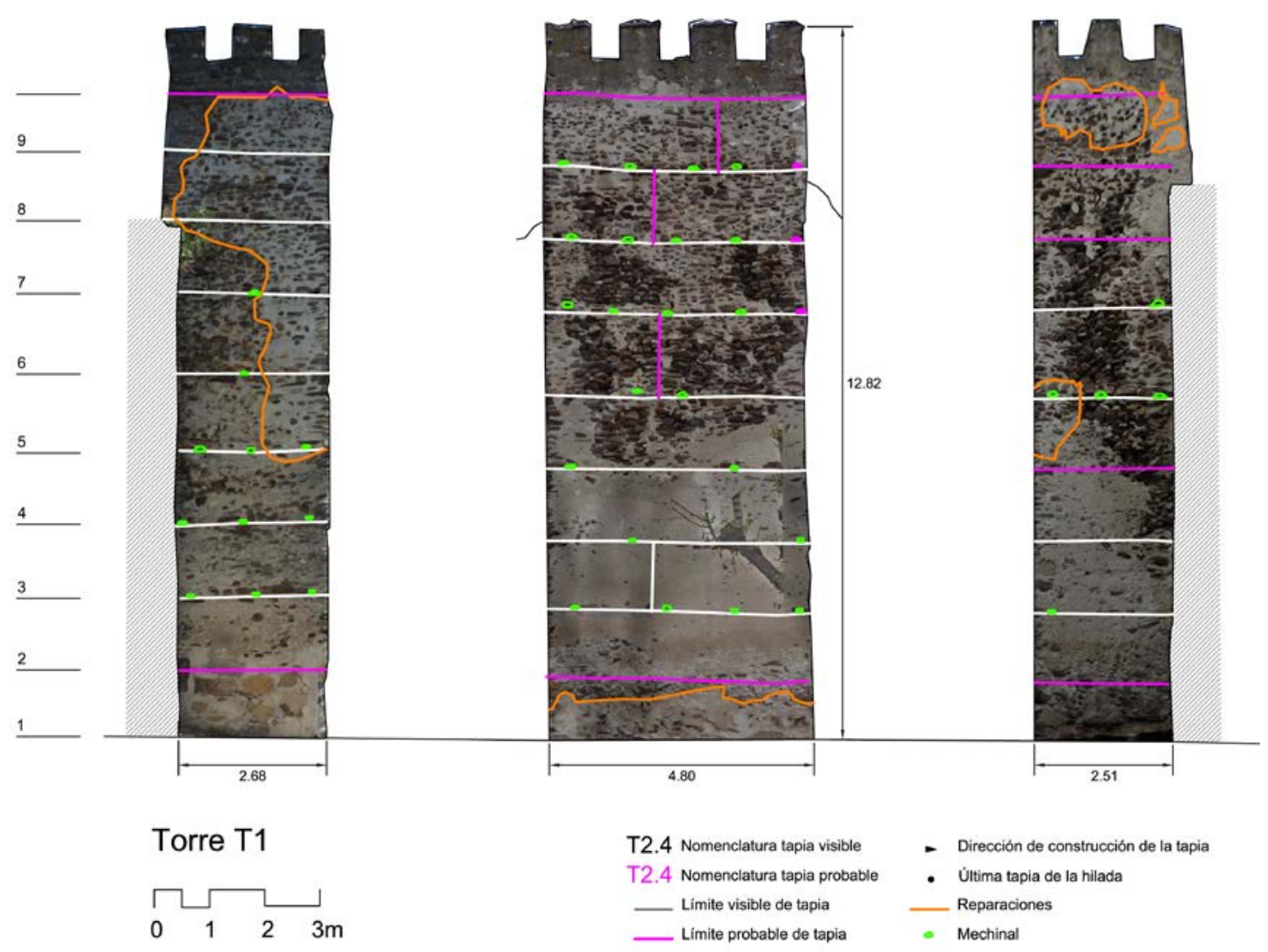

Fig. 5.1.70. Alzados de la torre T1. Fuente: Elaboración propia.

La torre T1 (Fig. 5.1.70) suma una altura de nueve tapias, sobre las que se añade un almenado que cuenta con ocho almenas. Las hiladas horizontales de t apia son relativamente fáciles de localizar, aunque algunas no son visibles y se ha supuesto su ubicación más probable. Los límites verticales de las tapias son muchos más difíciles de localizar, no son visibles de forma clara. En los alzados laterales, de una anchura que ronda los $2,50 \mathrm{~m}$, es probable que no existan límites verticales y que la anchura del alzado sea unat apia. Los mechinales en I os alzados laterales son fácilmente identificables, sobre todo en la altura intermedia del a torre. Se encuentran tres mechinales por hilada, ubicados en I a base del a tapia. En el alzado sur, 
correspondiente al frente de la torre, se ven también mechinales. En las hiladas superiores, $n^{\circ} 7,8$ y 9 , se pueden ver cuatro mechinales y aventurar la posición de un quinto en las esquinas derechas, de acuerdo con la posición de los mechinales en otras hiladas, como la $n^{0} 1 y^{0} 2$.



Fig. 5.1.71. Hilada que muestra seis mechinales en el frente de la torre T2 [A.S.E.27/4/2015].

En la torre T2, de características muy similares a la T1, se pueden ver seis mechinales en la hilada séptima (Fig. 5.1.71). El ritmo que tienen no facilita la lectura del paramento, haciendo difícil determinar los límites de las tapias.

El aspecto que ofrece el paramento de la torre es similar al visible en los lienzos, se utilizan piedras de tamaño medio e irregulares. A la altura de las hiladas 3 y 4 , el acabado es de tierra y cal, las piedras no son visibles, los mechinales se reducen a un hueco en el paramento, aunque se conoce la configuración interna, visible en ot ras zonas donde la capa superficial de tierra y cal se ha perdido. Aunque se conserve esta capa, no son tan claramente visibles las marcas de las tablas empleadas en el tapial, en comparación con otros puntos de la muralla, donde se pueden contar las tablas utilizadas por tapia.

En las esquinas de la torre se ve cómo los mampuestos han sido colocados de forma ordenada, apilados uno sobre otro, ajustándose al rincón del tapial. En algún punto aislado de las esquinas se observan piedras de mayor tamaño, semejantes a sillares, y también algún elemento cerámico. En las fachadas de la torre, los mechinales se aproximan al máximo a las esquinas, dejando a penas $10 \mathrm{~cm}$ de separación en algunos casos. En el interior de la esquina se produce entonces un cruce entre las agujas alojadas en esos mechinales. De acuerdo con el caso de la hilada tercera de la 
torre $\mathrm{T} 1$, el encuentro parece resolverse montando una aguja sobre la otra, quedando debajo la aguja del mechinal situado en el lateral (Fig. 5.1.72, Fig. 5.1.73). Dada la configuración de la torre, es probable que se empleen medias agujas en I ugar de pasantes. Las medias agujas tendrían una longitud inferior al fondo de la tapia y se fijarían a través de una punta a la tapia inferior para evitar su desplazamiento.

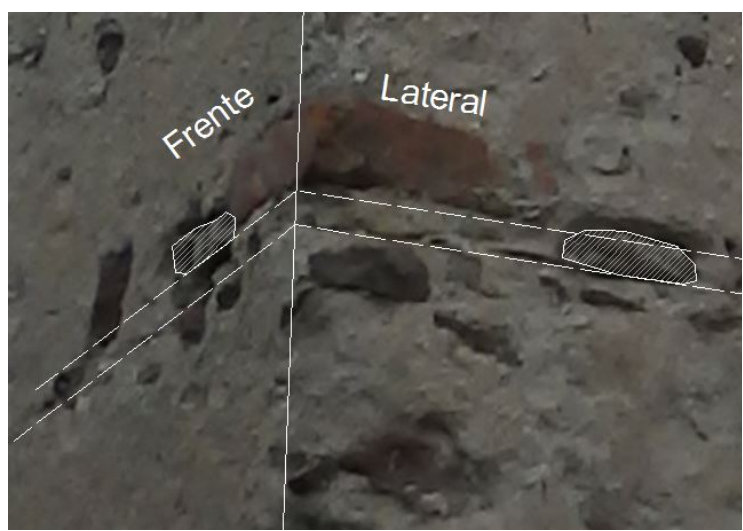

Fig. 5.1.72. Esquema de niveles de las agujas en la esquina este de la torre T1. Fuente: Elaboración propia.

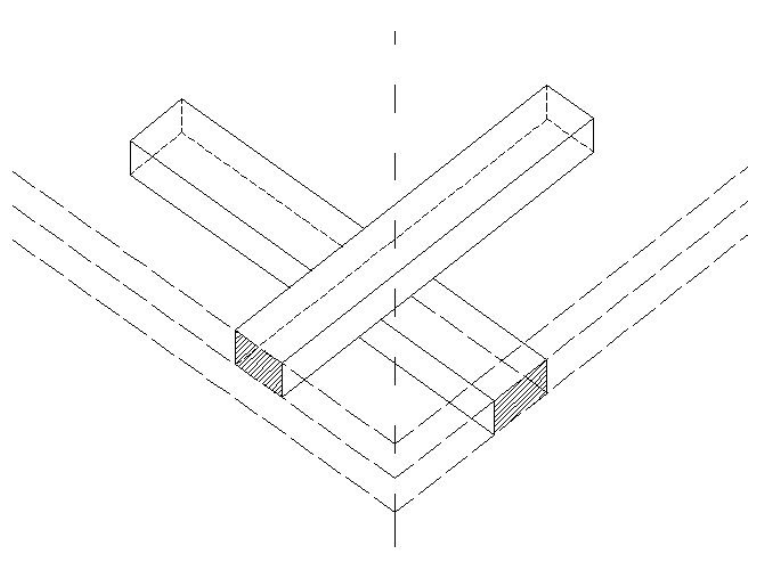

Fig. 5.1.73. Esquema en perspectiva del cruce de agujas. Fuente: Elaboración propia.

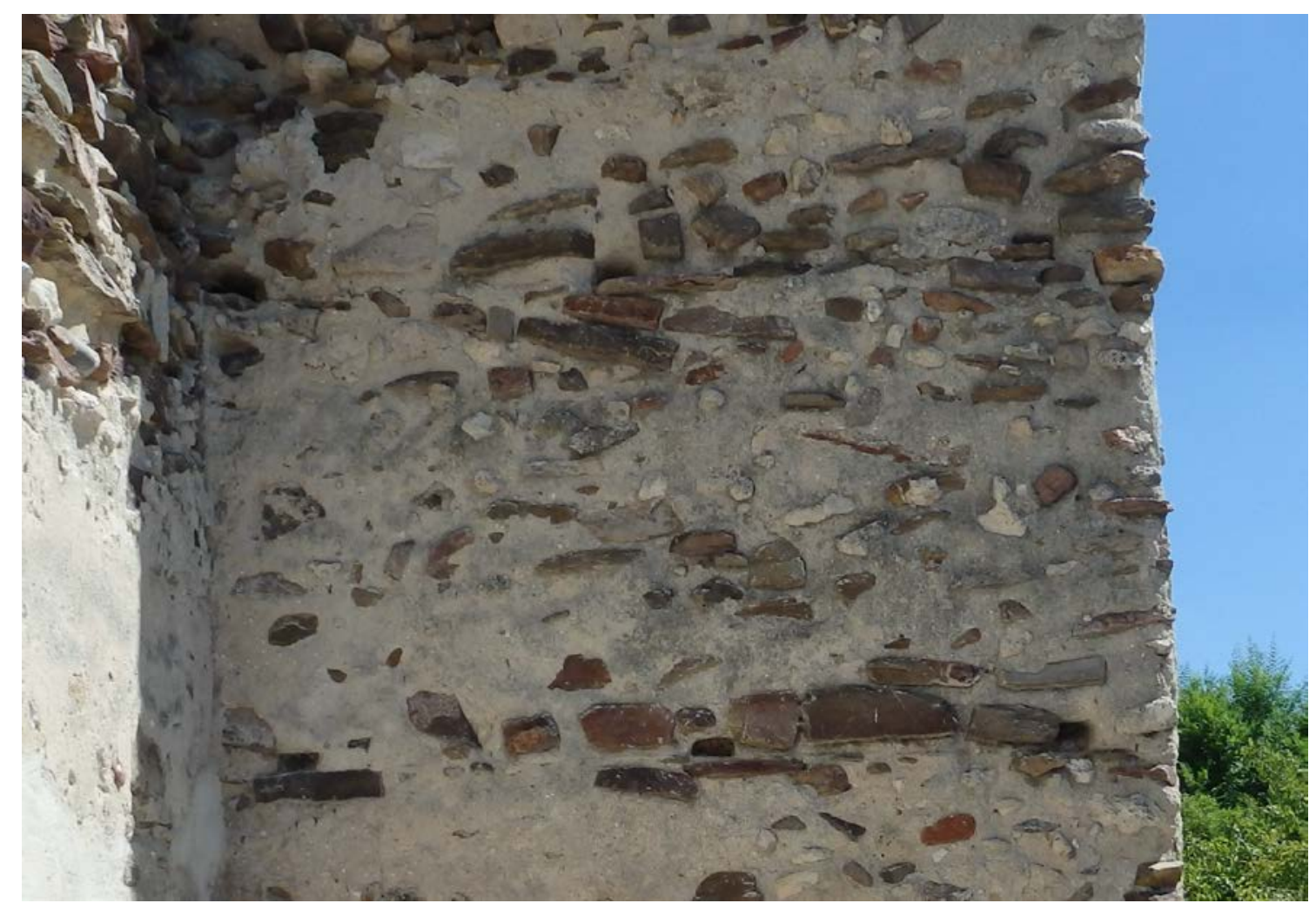

Fig. 5.1.74. Tapia en la hilada tercera del lateral oeste de la torre $T 1$ con medidas de $2,68 \mathrm{~cm} \times 1,17 \mathrm{~m}$ [A.S.E. 13/8/2016]. 


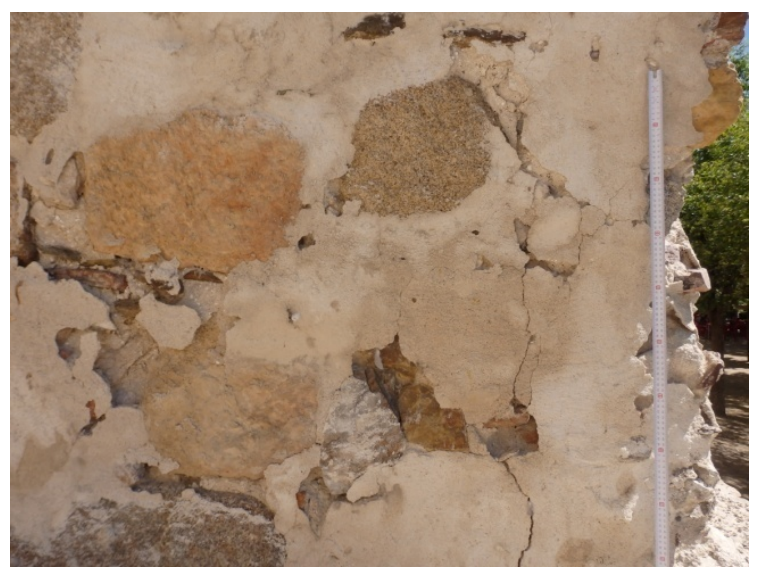

Fig. 5.1.75. Base de la torre T1 en el lateral oeste, diferente de la parte superior, con sillares irregulares [A.S.E. 13/8/2016].

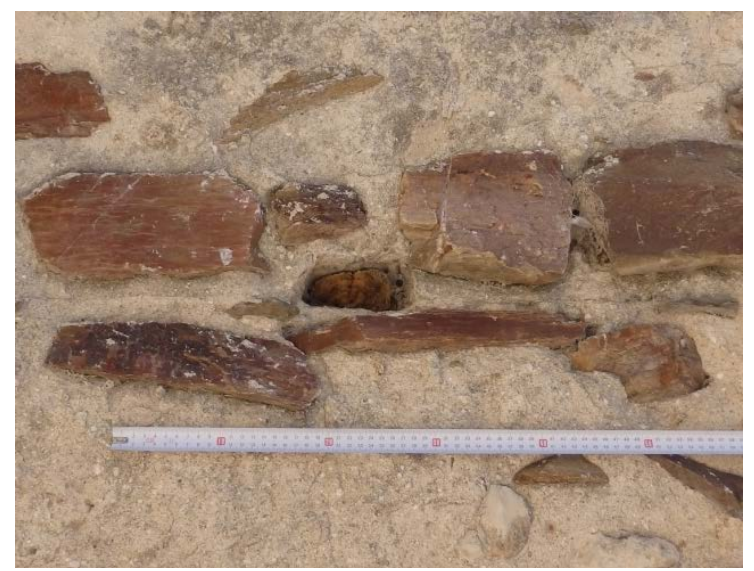

Fig. 5.1.76. Mechinal central de la tapia en la tercera hilada del lateral oeste de la torre T1. La aguja de madera es visible en su interior [A.S.E. $13 / 8 / 2016]$.

La identificación de las tapias podría ayudar a determinar de qué manera se construía la torre, en qué orden se colocaban las tapias en cada hilada, adquiriendo la forma rectangular de I a planta. Según las marcas visibles, parece que los laterales se componen de una tapia de anchura en cada hilada. Las tapias visibles en los laterales tienen una configuración similar a la visible en los lienzos. En la figura Fig. 5.1.74 se puede ver una tapia de dimensiones $2,68 \mathrm{~cm} \times 1,17 \mathrm{~m}$. Presenta tres mechinales en la base, con proporción rectangular. La configuración de estos mechinales es igualmente similar a la visible en los lienzos, el mechinal central (Fig. 5.1.76) está colocado entre dos hiladas de mampuestos. La tapia inmediatamente superior comparte las mismas características y aunque los mechinales no son visibles en todas las hiladas, es previsible que tengan la misma configuración. En el frente, donde se vería el espesor de la tapia lateral, no son evidentes los límites de las tapias. En algunos puntos parece verse una tapia completa, en otros casos parece que existen tres tapias cortas en la hilada. En la hilada séptima de la torre T2 (Fig. 5.1.71), donde se ven seis mechinales, se vislumbran tres tapias cortas, a las que correspondería dos mechinales cada una. La base de la torre T1 tiene varias hiladas de sillares, que podrían constituir una base preexistente o sillares reutilizados (Fig. 5.1.75).

En función de cada hilada, se pueden plantear hipótesis diferentes de colocación de tapias por hilada (Fig. 5.1.77). Todas ellas responden a la visión de los límites de una tapia completa en los laterales de la torre, de manera que los cambios en las posibilidades se producen en relación con la configuración visible en el frente. En la posibilidad $n^{0} 1$ se combinan dos tapias en la hilada, la primera de ellas con fondo de $2,00 \mathrm{~m}$ y la segunda con el mismo fondo que anchura, $2,60 \mathrm{~m}$. Teniendo en cuenta el espesor del lienzo, $2,20 \mathrm{~m}$, estos fondos de tapia no son disparatados. Se ha marcado la posición de los mechinales, en los laterales se cuentan tres y en el frente existen cinco. Cada hilada podría alternar la posición de las tapias, para que se produjera una trabazón. El esquema $\mathrm{n}^{\circ} 2$ se apoya en el caso de la torre T2, donde se observan seis mechinales por hilada en un caso. Sería posible plantear que las tapias se colocaran en batería, con un fondo de $1,40 \mathrm{~m}$. Finalmente el esquema $\mathrm{n}^{\circ} 3$ plantea que cada hilada se dividiese en dos tapias simétricas. 



Fig. 5.1.77. Esquemas en planta que muestra posibles colocaciones de tapias por hilada. La posición de los mechinales se ha indicado con líneas cortas. Fuente: Elaboración propia.

Las torres T3, T6 y T7 tienen una planta circular. Esta diferencia respecto de las torres rectangulares $\mathrm{T} 1$ y $\mathrm{T} 2$ no cambia el sistema constructivo empleado. En las torres circulares se emplea igualmente tapia de mampostería, realizada con la misma piedra empleada en el lienzo y en I as torres de planta rectangular. Son visibles también detalles comunes entre las torres circulares y el lienzo, como es el cierre lateral de las tapias con un murete de piedras (Fig. 5.1.80). La torre T3 se separa del lienzo en sentido perpendicular al mismo, para luego formar una semicircunferencia en el frente. Solo el lateral noreste de la torre es visible, ya que el opuesto está oculto tras una edificación adosada. En este lateral visible (Fig. 5.1.78, izquierda) se pueden contar sin dificultad las tapias empleadas en su construcción, que ascienden hasta diez y se coronan con un almenado. La distancia que separa los mechinales visibles oscila entre los $90 \mathrm{~cm}$ y los $115 \mathrm{~cm}$. Dada la configuración de este lateral, es factible que se construyeran tapias rectas en sentido perpendicular al lienzo. Observando de frente la parte curva parecen identificarse caras rectas en la hilada quinta (Fig. 5.1.79). La realización de tapias cortas siguiendo una directriz circular podría ser el sistema utilizado en este caso. En esas caras rectas se observan mechinales próximos entre sí.

La torre T6 forma parte de la puerta de la Villa, es visible su alzado lateral suroeste que tiene una anchura cercana a los siete metros (Fig. 5.1.78, derecha). Se pueden contar ocho tapias de altura, sobre las que se añade un almenado de proporciones similares al visible en las torres T1 y T2. En comparación con la torre T3, la altura de las tapias es superior, se reparte en ocho tapias una altura semejante a la de la torre T3, que suma diez. La directriz curva de esta torre no da comienzo hasta el frente, el lateral se configura en sentido perpendicular a la dirección del lienzo como si se tratara de un lienzo más. Los muretes de piedras visibles en los laterales de algunas tapias identifican el sentido de construcción de las tapias desde el lienzo hacia el exterior (Fig. 5.1.80). 
Las murallas en las Comunidades de Villa y Tierra de la Diócesis de Segovia en los siglos XI a XIII. Técnica y sistemas constructivos de la arquitectura defensiva medieval.


Fig. 5.1.78. Torres T3 y T6. Fuente: Elaboración propia.



Fig. 5.1.79. Vista frontal de la base de la torre T3 [A.S.E. 2/11/2014].

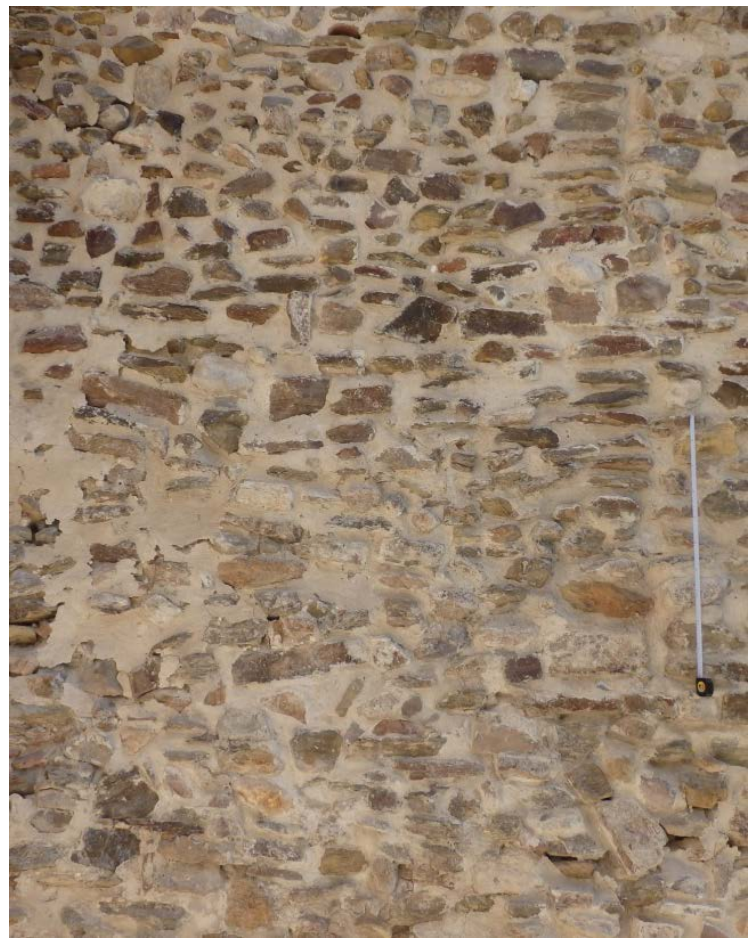

Fig. 5.1.80. Detalle de las tapias de la torre T6. [A.S.E. $13 / 8 / 2016]$ 
Las almenas que son visibles en lo alto de las torres tienen distinta morfología. Las que se encuentran en las torres T1 y T2 son de forma rectangular, prácticamente cuadradas. La anchura oscila entre los valores $70-80 \mathrm{~cm}$ y la altura es de $60-75 \mathrm{~cm}$. La separación entre almenas es menor, en torno a los $55 \mathrm{~cm}$. El fondo alcanza los $50 \mathrm{~cm}$. Tanto las almenas como parte del muro que se encuentra inmediatamente debajo están construidos con una fábrica de ladrillo alternada con mampuestos de forma desordenada. Cada almena está coronada por un tejadillo de forma piramidal (Fig. 5.1.81). En el caso de la torre T3, las almenas son más anchas y el espacio entre ellas es proporcionalmente menor. Se observan en las almenas varias saeteras, una de ellas de mayor tamaño, alargada y estrecha y otra más pequeña, configurada con piedras (Fig. 5.1.82).



Fig. 5.1.81. Almenas de la torre T1, en la fachada oeste [A.S.E. 27/4/2015].

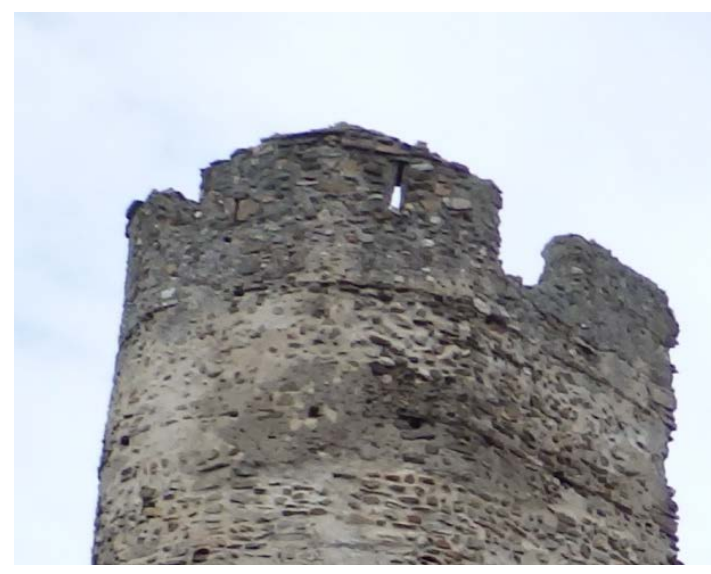

Fig. 5.1.82. Almenas en la torre T3. Se observan varias saeteras en las almenas [A.S.E. 27/4/2015].

\subsubsection{Resumen de resultados de Coca}

La muralla de Coca se conserva de forma significativa en la zona sur de la Villa, donde los restos son suficientes para analizar el sistema construido empleado, la tapia de mampostería. De acuerdo con las referencias a la muralla en documentación histórica, algunos restos aislados, la configuración del terreno y la forma del parcelario existente en la actualidad, es posible plantear una hipótesis de trazado de la muralla medieval, aunque con dudas en la zona noreste. Las calles dispuestas en forma de triángulo, en cuyos vértices podrían situarse tres puertas de muralla, una de ellas la existente, podrían indicar la presencia de una puerta en la plaza de la Cruz de los Caídos, planteando la existencia de un recinto más pequeño y de forma circular, separado del castillo.

Las dimensiones a nivel general del tramo conservado muestran un espesor cercano a los 2,00m. La altura actual de los lienzos se sitúa entre los $7,50 \mathrm{~m}$ y los $8,60 \mathrm{~m}$, variable en función del punto de medición. Las torres sobresalen por encima de la altura de los lienzos, alcanzando los $13 \mathrm{~m}$ de altura. Las plantas de las torres que se conservan son de dos tipos: rectangulares, con frentes cercanos a los 5 metros y fondos que superan 
Las murallas en las Comunidades de Villa y Tierra de la Diócesis de Segovia en los siglos XI a XIII. Técnica y sistemas constructivos de la arquitectura defensiva medieval.

los 2,50m; semicirculares con dimensiones variables, de mayor tamaño aquellas que integran la puerta de la Villa.

El análisis constructivo, permite detectar preexistencias en algunas partes de la muralla, situadas en sus bases. Son identificables principalmente por su ubicación en la base de los lienzos y porque presentan soluciones constructivas diferentes a la empleada en la zona superior de los lienzos. Se observan principalmente aparejos de sillería reutilizada, grandes piedras diferentes (granito, caliza) articuladas en un aparejo heterogéneo e irregular. La muralla que se construye sobre estas preexistencias utiliza el sistema de la tapia de mampostería. Es singular la piedra empleada en estas tapias, la cuarcita roja, que recuerda a la pizarra y con forma frecuentemente alargada. No se ha visto empleada en ninguna otra construcción de estas características. El tapial empleado es de cajón independiente, es decir, cada tapia se ha realizado con un tapial individual. En la construcción del tapial se ha utilizado la técnica del murete de piedras que cierra uno de los lados cortos del tapial, técnica visible en los lienzos y en alguna torre, donde una columna de piedras planas configura el límite de uno de los lados de cada tapia. En algunas tapias son visibles las marcas de las tablas del encofrado o tapial, contándose cuatro tablas de altura.

En cuanto a los mechinales, cada tapia presenta tres mechinales en su base. Estos son habitualmente de sección rectangular y se acomodan entre mampuestos aunque se dan muchos ejemplos de mechinales de sección semicircular cubiertos con una teja cobija. Los mechinales parecen realizarse entre dos verdugadas de piedra. Aunque se enmarcan con piedras, su configuración variada parece indicar que no se seguía una solución particular (por ejemplo, dos piedras de flanqueo y una coronando), sino que los mechinales se ubicaban en una verdugada o entre dos verdugadas de mampuestos. En la construcción del tapial, es probable que la tapia inferior se cerrase con mampuestos colocados ordenadamente, que ofrecería una hilada hacia el exterior, sobre el que se colocaban las agujas de la nueva tapia, que se cubrirían a su vez con mampuestos, generando una segunda hilada. Los mechinales visibles en la actualidad quedan encajados entre esas hiladas, irregulares y no tan evidentes en muchos casos. Las agujas parecen ser pasantes en los lienzos, observándose una correspondencia entre mechinales de un lado y otro del lienzo.

Las torres y la puerta de la Villa se construyen igualmente con tapia de mampostería. La puerta de la Villa incluye otras soluciones constructivas, como el aparejo de ladrillo o el empleo de sillares de piedra aislados. Se observa el uso de tapia mixta en la zona superior de la puerta. Las torres se construyen prácticamente en su totalidad con tapia de mampostería. En la coronación de algunas se observa el uso de ladrillo para la formación de almenado. La tapia empleada en las torres rectangulares es similar a la visible en los lienzos, aunque sus límites son más difíciles de identificar. Se observan tres mechinales por tapia y una configuración similar con mampuestos. Es probable que en el caso de las tapias de las torres, la aguja empleada no fuera pasante, sino que se emplearan medias agujas.

Se observa una tapia de distinto tipo en los restos de la zona oeste y en el interior del lienzo L2, en su extremo noreste. La tapia se realiza con cantos rodados, no se encuentra la cuarcita utilizada en el tramo L1. La escasez de restos de este tipo 
dificulta la extracción de características como el tipo de agujas empleadas o cuáles son las dimensiones más habituales. Esta diferencia de tapias, así como la ubicación de parte de el la bajo el lienzo L2, muestra la existencia de dos tipos de murallas diferentes, realizadas en tiempos tal vez próximos pero distintos.

El análisis constructivo muestra que no se construyen bases diferenciadas o cimentaciones en el arranque de los muros. Alí donde no hay preexistencias la muralla arranca directamente con la tapia de mampostería presente en el resto del lienzo. Es cierto que en este caso no es visible la roca o el firme sobre el que se asienta la muralla, ya que el entorno se encuentra urbanizado. No obstante, la visibilidad de preexistencias hace pensar que el arranque del a muralla no se encuentra a gran profundidad sino más bien cercano al nivel de suelo actual. Por otro lado, el análisis constructivo permite detectar la construcción del tramo L1 por partes. Las líneas verticales en las que se alinean las tapias en determinados puntos del muro son el testigo de una construcción por tramos, que facilitaría probablemente el trabajo. Estas partes tienen una longitud dispar por lo que no se ha identificado un módulo concreto. Aun así, dos de estas interrupciones verticales coinciden con la posición de las torres T1 y T2, por lo que es posible que exista una relación.

En cuanto a los recursos defensivos de la muralla, estos son por una parte las torres de flanqueo, que se encuentran separadas una distancia que ronda los $20-25 \mathrm{~m}$. En estas torres es visibles un almenado de proporciones cuadradas. En la zona de lienzo visitable se observa también un almenado, aunque es probable que haya sido alterado en la modificación del adarve. En la torre T3 son visibles saeteras diferentes entre sí. 



\section{2 \\ Cuéllar}

Segovia

\subsubsection{Localización}

Cuéllar se sitúa en la zona norte de la provincia de Segovia, prácticamente en el límite con la provincia de Valladolid. Se encuentra a una distancia de $60 \mathrm{~km}$ aproximadamente de la ciudad de Valladolid, y a otro tanto de la ciudad de Segovia. La comunidad se extiende en las provincias de Valladolid y Segovia. El río Cega la atraviesa entrando por el sur y saliendo por el oeste. El tamaño de la comunidad de Cuéllar alcanza los $1180 \mathrm{~km}^{2}$ aproximadamente. Es grande en relación con otras comunidades que la rodean, a excepción de la de Segovia que se extiende incluso más allá de la ciudad de Madrid. Las comunidades que colindan con la Tierra de Cuéllar son las siguientes: Por el norte, Portillo y Peñafiel; por el este Fuentidueña y Sepúlveda; por el sur, Segovia, y por el oeste, Coca e Íscar.

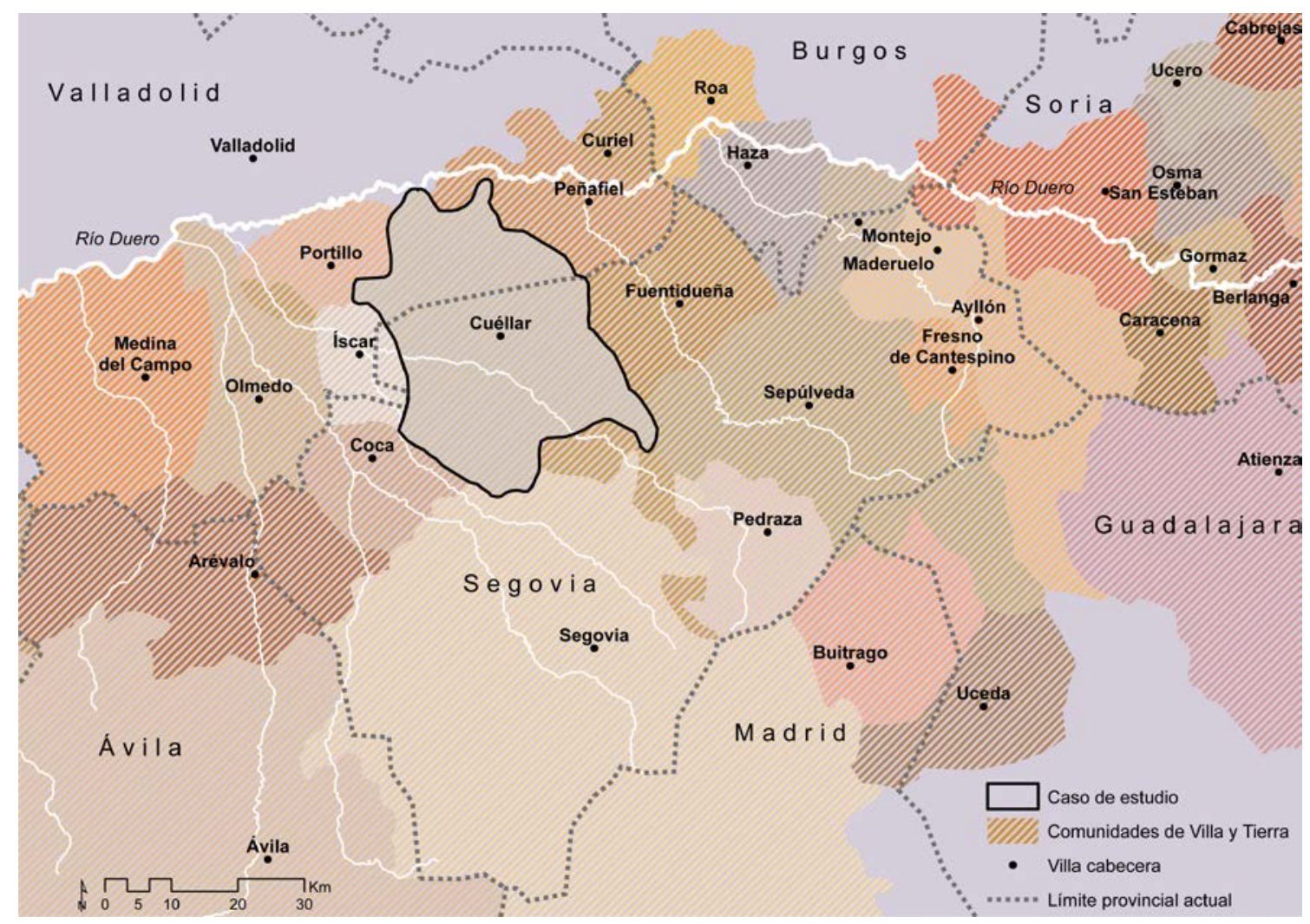

Fig. 5.2.1. Plano de localización de Cuéllar y de las comunidades colindantes. Fuente: Elaboración propia de acuerdo con planos de G. Martínez Díez (1983, 11-15) y J.M. Monsalvo $(2010,152)$. 
El núcleo de población se sitúa al norte del arroyo Cerquilla, afluente del río Cega. Se trata de una zona rodeada de pequeños cerros, que flanquean el antiguo paso de otro arroyo de escasa entidad, afluente a su vez del arroyo Cerquilla. Sobre uno de estos cerros, se ubica la zona amurallada. El arroyo que antiguamente pasaba junto al núcleo rodeaba la zona amurallada por los lados sur y este. El recorrido que tenía es visible en mapas históricos (Fig. 5.2.2).



Fig. 5.2.2. Fragmento de Mapa Topográfico Nacional Histórico 1:50.000 de Cuéllar. Se observa el arroyo que rodea el núcleo por el sur y el este y que afluye en el arroyo Cerquilla, visible en la zona sur. Fuente: Instituto Geográfico Nacional (IGN), descarga a través del visor Iberpix. http://www.ign.es/iberpix2/visor/ [Consultado el 20/6/2016].

La zona más alta del asentamiento, la correspondiente al cerro del castillo y el primer recinto amurallado, tiene una altitud de $880 \mathrm{~m}$ sobre el nivel del mar. Hacia el suroeste, el cerro continúa y se mantiene en esa altitud, con ligeras variaciones. La zona sur y la zona este del núcleo es el terreno anteriormente ocupado por el arroyo, cuyo recorrido continuaba descendiendo hacia el sur. Limitada por el arroyo, la población creció en dirección noreste, en terreno descendente, configurándose el segundo recinto amurallado. Más a este, enfrentados al cerro del castillo se sitúan los cerros de Valdesanjuán y de Los Encaños, con altitudes similares al del castillo, que contienen el crecimiento de la población actual. Al noreste, el cerro de la Florida limita también el crecimiento actual, constriñéndose la nueva edificación entre este cerro y el de Valdesanjuán. Hacia el norte, el terreno es llano, se mantiene en la altitud de los 880 sin grandes desniveles. La villa se ha extendido por esta zona con construcciones de carácter industrial y agrícola. En la zona este del núcleo, en el cerro de Valdesanjuán se sitúan los restos de un antiguo enclave defensivo. Tiene una población de 9477 habitantes, de acuerdo con los datos del Instituto Nacional de Estadística en el año 2015. 




Fig. 5.2.3. Plano topográfico y de catastro de Cuéllar. Fuente: Elaboración propia con datos del IDECyL [http://www.cartografia.jcyl.es/] y Catastro [http://www.catastro.meh.es/].

\subsubsection{Estudios en la villa}

Entre los estudios que se han realizado acerca de la villa de Cuéllar destacan los de carácter histórico. Balbino Velasco Bayón (2013 [1981]) realizó un estudio pormenorizado de la historia de la villa, en el que hace varias referencias a la muralla. Emilio Olmos (2000) trata la etapa de la Cuellar como villa cabecera de su comunidad. El castillo de Cuéllar fue estudiado por Edward Cooper (1981, Fig. 743) a través de fotografías y dibujos en planta del castillo. También analiza el recinto amurallado (1981, Fig. 601) indicando el recorrido de la muralla y la posición de accesos e iglesias. En el año 2011, se realiza una publicación editada por Víctor Muñoz Gómez, que aunque trata las Comunidades de Villa y Tierra de forma general, recurre al ejemplo de Cuéllar como caso de estudio. En esta publicación, los autores Juan C. Llorente, Fernando Nieto Criado y Jesús Nieto Criado (2012, 235-236) realizan un análisis de I as murallas de la villa y recogen un listado de doc umentos históricos donde se menciona la muralla de Cuéllar, desde el siglo XIII hasta finales del XIX. Hasta comienzos del siglo $\mathrm{XV}$, son habituales las menciones en las que se ordena la conservación de la muralla o se piden partidas e impuestos destinados a su reparación. Durante el siglo $\mathrm{XV}$, se refieren varios documentos en los que se rechazan sucesivas peticiones de pagos para la conservación de la muralla. Durante los siglos siguientes, se observan menciones que multan el arrojo de basuras bajo la cerca, la retirada de piedras, que señalan el hundimiento de paños y que solicitan licencias de derribo. A través de estos documentos, se percibe la pérdida de la función de la 
muralla en la villa, que ya se vislumbra en el siglo $X V$ y que se consolida con los derribos de Iienzos y puertas durante el siglo XIX. El derribo de las puertas de Ia Trinidad, de San Francisco, de San Andrés y de San Pedro entre 1879 y 1895 pone de manifiesto el escaso interés que siente la población por sus murallas en esas fechas. Esta tendencia continuó durante buena parte del siglo XX, hasta que durante el último tercio de siglo, se revirtió para tratar de conservar y recuperar la muralla de la villa.

En el año 2008, se inició la obra de restauración de las murallas que fue proyectada y dirigida por los arquitectos Fernando Nieto Criado y Jesús Nieto Criado (Llorente Mínguez et al. 2012, 243). La restauración se planteó en dos fases, de las cuales sólo se ha concluido la primera de ellas, que abarcó la mayor parte del recorrido de la muralla. La segunda fase tenía previsto restaurar el tramo desde la torre de Santiago hasta la plaza del Estudio, pero no s e ha i niciado. Uno del os cambios más importantes en esta restauración fue la construcción de un adarve transitable a lo largo de gran parte del primer recinto, desde el castillo hasta la puerta de San Basilio y desde el castillo hasta la puerta de $S$ antiago. También se llevó a c abo la reconstrucción de algunos tramos, que buscaban completar las partes desaparecidas del recinto amurallado. Entre el castillo y la puerta de San Basilio se ha construido un nuevo tramo de ap roximadamente $25 \mathrm{~m}$ de longitud. Este tramo incluye un ac ceso nuevo, denominado acceso del Ferial, que se cubre con un dintel moderno. De la zona este del castillo, parte el tramo sur de la muralla que en los primeros metros se encontraba desaparecido. En este punto, se han construido aproximadamente $25 \mathrm{~m}$ de nueva muralla donde se incluye también un acceso nuevo, construido con un dintel similar al del acceso del Ferial. En la zona del acceso de las Cuevas también se realiza una reconstrucción, con aproximadamente 7 nuevos metros de muralla que incluyen el acceso, también con un dintel recto. En la puerta de Santiago se aumentó la altura de la torre T8.



Fig. 5.2.4. Alzado interior de lienzo donde se aprecian las restauraciones en la base del muro. Fuente: Fernando Nieto Criado y Jesús Nieto Criado [10/8/2005].

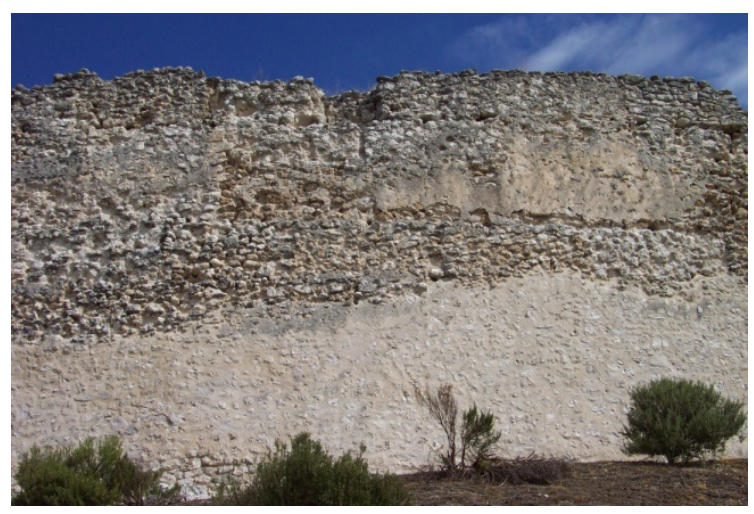

Fig. 5.2.5. Lienzo visto desde el lado exterior. Se observan las reparaciones en la base del muro. Fuente: Fernando Nieto Criado y Jesús Nieto Criado [10/8/2005].

Se han realizado otras restauraciones en la muralla, en la segunda mitad del siglo XX, aunque no de carácter general sino de algún tramo, como por ejemplo el tramo de la 
puerta de San Martín hasta la puerta de Santiago. El alzado interior de la puerta de San Basilio también se restauró a finales del siglo $X X$, aplicándole una nueva composición arquitectónica (Fig. 5.2.20). En fotografías del año 2005, facilitadas por el estudio de los arquitectos Fernando Nieto Criado y Jesús Nieto Criado, se observan reparaciones aisladas y continuas en las bases de los lienzos.

\subsubsection{Datos históricos destacados del núcleo}

De la misma manera que ocurre con la villa de Sepúlveda, de la historia de la villa de Cuéllar se desprende la importancia que ostentó como villa cabecera de su concejo. Los datos que se conocen relativos al siglo $x$ son similares a los de otras villas cercanas. Se sabe de la repoblación de la villa de Cuéllar, atribuida a los Condes de Monzón, que hubo de producirse con anterioridad al año 977. Fue desvirtuada posteriormente por la campaña de Almanzor y su hijo Abd al-Malik, quienes asolaron las villas ahuyentando a sus habitantes. En el siglo XI, la repoblación impulsada por Alfonso $\mathrm{VI}$ y atribuida a Pedro Ansúrez reinicia la actividad pobladora de la villa. La existencia de la villa ha quedado reflejada en documentos históricos donde s e describen donaciones o se recogen impuestos. Se han trasladado a este breve resumen histórico las fechas que extrae Gonzalo Martínez (1983, 407-425) que atañen a la villa de Cuéllar en su publicación acerca de estas villas de la Extremadura. $A$ finales del siglo XI y principios del XII, se conocen varias menciones a Cuéllar relacionadas con donaciones a favor de Iglesia de Santa María de Valladolid. En el año 1093, figura una donación en Vallelado, que contiene una serie de propiedades en Cuéllar, y años más tarde en 1111, aparece otra donación de la aldea de Santibáñez de Valcorba. La mención de esta aldea es significativa, y permite al autor antes mencionado concluir que todavía no se había formado la Comunidad de Cuéllar, ya que esta aldea se encuentra posteriormente dentro de la misma (414). De 1112 data el último documento de Pedro Ansúrez al frente de Cuéllar donde se aneja el Monasterio de San Boal, en el pueblo del mismo nombre, al de Santa María del Remolino.

En este mismo siglo se producen una serie de documentos donde se mencionan varias villas, entre las que se encuentra Cuéllar y otras de esta investigación. En 1120, la comunidad de Cuéllar, aparece incluida en la Diócesis de Segovia. Efectivamente, tres años más tarde figura entre las villas de la bula del papa Calixto II donde se reflejan los límites de la Diócesis de Segovia. En 1136, Cuéllar figura junto con otras villas donde el rey Alfonso VII cedió el diezmo a la iglesia católica (352).

En 1147, la Comunidad de C uéllar se presenta ya constituida, en el documento de otorgamiento de ciertos terrenos del Abad de la Armedilla (414). En 1184, se conoce la venta de cuatro aldeas por parte de Alfonso VIII al concejo de Cuéllar, por dos mil maravedís. Las aldeas vendidas fueron Perosillo, Adrados, Olombrada y Frumales y eran propiedad de Gutierre Pérez de Rinoso. En 1193, se describen los límites de Comunidad de Cuéllar con la comunidad de Peñafiel (415).

La presencia de la monarquía en Cuéllar queda reflejada en documentos de finales del siglo XII y también a principios del XIII. Es también a comienzos de este siglo cuando la 
villa de Cuéllar concreta los límites de su alfoz. De acuerdo con Balbino Velasco $(2013,87)$ se conoce la presencia del rey Sancho III en Cuéllar el 28 de junio de 1158. El rey Alfonso VIII firma varios documentos reales en esta villa con fechas de 1175 , 1178, 1181 y 1183. Concedió, en mayo de 1200, el diezmo del portazgo de Cuéllar y de otras villas a la catedral de Segovia. Este mismo monarca otorgó a la villa un documento en 1210 en el que marca los límites de la comunidad de Cuéllar (Velasco 2012, 207). El rey Enrique I visitó la villa Cuéllar en 1215, y firmó allí un documento.

Balbino Velasco $(2012,207-208)$ refiere que durante los siglos XIII y XIV, se producen disputas territoriales que dan lugar a pleitos entre comunidades. Estos litigios se tradujeron en d ocumentos donde se describen los límites de las comunidades de Peñafiel, Fuentidueña, Coca, Íscar o Aguilafuente. Estas diferencias se prolongaron durante el siglo XV, cuando son abundantes los documentos acerca de límites. Las disputas con Peñafiel se mantuvieron hasta la segunda década del siglo, y aparecieron nuevas diferencias con otros pueblos como Traspinedo, Portillo o Íscar. Durante el siglo XVI, también son abundantes los documentos que tratan los límites de la comunidad, con nuevos pleitos que buscan conservar la demarcación original. Balbino Velasco $(2012,215)$ menciona también el creciente interés por la regulación del aprovechamiento forestal, que se reflejó en sucesivas ordenanzas que se dictaron desde 1492 hasta 1547.

\subsubsection{Tejido urbano}

El análisis del parcelario de Cuéllar muestra distintos tipos de parcela en todo el núcleo. El casco histórico contiene parcelas que sugieren un origen medieval, por su tamaño, su forma alargada y estrecha y su agrupación en calles también estrechas. Al sur, al otro lado del antiguo arroyo, se observa una ag rupación de parcelas de características similares, un a rrabal que se organiza en la confluencia de los dos arroyos y junto a la iglesia de Santa María de la Cuesta. En torno a estas formaciones, la villa ha crecido incorporando nuevas parcelas al entramado urbano. Algunas de estas parcelas tienen un origen agrícola: son grandes extensiones que se incorporan al tejido urbano para cobijar industria o usos agrícolas dentro del suelo urbano y quedan ordenadas por antiguos caminos y carreteras. En otros casos, se han ido dividiendo para la construcción de vivienda. También se observan planificaciones urbanísticas en forma de sectores, donde tejidos urbanos modernos se han dibujado en el territorio, con formas geométricas muy regulares.

El tejido urbano en el casco histórico tiene una vinculación muy clara con recorrido de la muralla (Fig. 5.2.6). El primer recinto amurallado muestra en su interior parcelas alargadas y estrechas en la parte norte. Algunas de las parcelas más estrechas se sitúan en la calle San Gil, con anchuras mínimas de 2,50 a 3,00m aproximadamente, llegando al 1,85m en un caso de la plaza San Gil n¹9. Las anchuras más habituales son mayores y rondan los $10 \mathrm{~m}$. El fondo de este tipo de parcela es variable, repitiéndose valores cercanos a Ios $25 \mathrm{~m}$ y también a Ios $15 \mathrm{~m}$. Al norte del primer recinto, extramuros, existen parcelas con morfología similar al as descritas en el interior. Son todas ellas muy alargadas y estrechas, con fondo que varía entre los $20 \mathrm{~m}$ y casi $40 \mathrm{~m}$. En la calle Barrera se encuentran anchuras de parcela de $2,00 \mathrm{~m}$. 




Fig. 5.2.6. Plano de parcelario de Cuéllar y esquema del recinto amurallado. Fuente: Elaboración propia con datos de Catastro.

En la zona sur del primer recinto amurallado, las parcelas son muy grandes y se encuentran prácticamente vacías en la actualidad, están coloreadas en verde claro. Una promoción de viviendas nuevas fue iniciada en una de estas parcelas, pero su construcción se interrumpió y se encuentra parada desde hace varios años.

En el segundo recinto las parcelas se ordenan formando una suerte de conjuntos. El más evidente está coloreado en marrón y se agrupa en torno a la parroquia de San Miguel, formando un círculo. La calle principal de esta agrupación se denomina calle de la Morería, este nombre podría indicar el origen de los pobladores de este conjunto. Las parcelas tienen un tamaño similar al existente en el primer recinto, aunque se observan anchuras mayores y menor cantidad de parcelas alargadas y estrechas. Se puede observar otro conjunto coloreado en rosa y vinculado a la iglesia de Santiago, junto a la puerta del mismo nombre del primer recinto. Las parcelas se agrupan también formando un semicírculo. En este caso, aparece el nombre de calle de las Cuevas, que podría indicar otro tipo de asentamiento. En la parte norte, se sitúa otro conjunto más desdibujado en torno a la iglesia de $S$ an Esteban, grafiado en color verde azulado. Este grupo se sitúa junto a la puerta de la judería y podría tratarse del barrio judío de la villa. Las parcelas dibujadas en color dorado se encuentran entre el conjunto verde y el marrón y parecen haber sido construidas en el espacio restante entre conjuntos.

En el trazado urbano del segundo recinto, son visibles los caminos generados por la puerta de San Martín. La calle Estudio parte en línea recta hacia el noreste, en 
Las murallas en las Comunidades de Villa y Tierra de la Diócesis de Segovia en los siglos XI a XIII. Técnica y sistemas constructivos de la arquitectura defensiva medieval.

continuidad con el lienzo de muralla que parte en esa misma dirección desde la puerta. La calle Duque de Alburquerque, que continúa con la calle Morería, es el segundo camino que parte en dirección suroeste. El recorrido de la muralla genera la aparición de parcelas que se pegan a la misma tanto desde el interior como desde el exterior. Se han dibujado en color rosado las parcelas que se adosan a la muralla del segundo recinto desde el portillo de Exángel hasta la Puerta de $S$ an Andrés. Las parcelas grafiadas en verde, se adosadas a la muralla del segundo recinto en un tramo que tiene una dirección distinta del resto, que se adapta a las parcelas del conjunto de la iglesia de Santiago.

La muralla aparece representada en el plano de parcelas con un código de colores. En negro, aparece representada la muralla en el estado más próximo a su situación original, aunque con reparaciones de forma general y restauraciones de algún tramo. En color fucsia, se han representado las zonas de muralla que muestran alteraciones por la construcción de edificaciones adosadas que han abierto huecos o tiene volúmenes construidos sobre la muralla. En color amarillo anaranjado se ha reflejado las hipótesis del trazado de la muralla, allí donde ha desaparecido. En color morado se ha indicado la zona de la muralla donde sobre las bases originales se ha reconstruido un adarve transitable moderno. En color azul se ha marcado los tramos nuevos construidos desde cero como nueva muralla.

\subsubsection{Planeamiento y figuras de protección}

De acuerdo con el Archivo de Planeamiento Urbanístico de la Junta de Castilla y León, el Ayuntamiento de Cuéllar aprobó en 1996 la revisión de las Normas Subsidiarias Municipales. En 1999, se aprobó en Plan Especial de Protección del Casco Histórico, donde se recoge la muralla y su barbacana en el catálogo de bienes protegidos y se señala su carácter de BIC desde 1931. Ya en el 2011, se redactaron las Normas Urbanísticas Municipales vigentes en la actualidad. En la Planoteca del Instituto del Patrimonio Cultural de España se encuentran planos del documento de declaración de Conjunto Histórico-Artístico de Cuéllar, que datan de 1981. Este expediente se incoó en 1982 y no fue hasta 1994 cuando se declaró como tal definitivamente.

\subsubsection{Descripción general de la arquitectura defensiva}

Como se ha podido entender a raíz del análisis del parcelario, la muralla de Cuéllar tiene dos recintos amurallados identificables en la actualidad. El primero de ellos abarca una s uperficie de $6 \mathrm{Ha}$ aproximadamente. El segundo recinto es mayor en superficie y alcanza casi las $9 \mathrm{Ha}$. El total de superficie amurallada sería de $15 \mathrm{Ha}$. En el PECH de $1999^{37}$, se señala la posible existencia de un tercer recinto murado, que englobara el terreno más cercano al castillo, desde la puerta de San Basilio, pasando junto a la torre de la iglesia de San Martín, hasta el portillo de la Huerta. La superficie

\footnotetext{
${ }^{37}$ Se puede consultar en la página 127 del Catálogo de Edificios con Protección Integral.
} 
de este recinto sería de $2 \mathrm{Ha}$. También el arquitecto Marco Antonio Garcés Desmaison marca el recorrido de este tercer recinto ${ }^{38}$.

En la parte oeste del primer recinto se sitúa el castillo de Cuéllar o castillo de los Duques de Alburquerque. De acuerdo con Edward Cooper (1991, vol 3, 623-624), el castillo de Cuéllar es el cuarto recinto defensivo de la villa. Con el acceso en la parte sur, tiene una planta trapezoidal y se rodea de una barbacana con grandes troneras. La defensa del castillo estaba reforzada por el torreón de la zona suroeste (Fig. 5.2.9), el punto más vulnerable. Cooper indica que se construyó la planta baja del castillo cubierta con una bóveda nervada y atribuye la ausencia de más plantas a la voluntad de aprovechar la azotea para montar la artillería del castillo. También hace referencia a la construcción del patio, que se retrasa hasta a mediados del siglo XVI. Indica que presenta una c omposición renacentista que contrasta con el aspecto exterior del castillo. Según este autor, varios elementos visibles en la actualidad son modernos: el remate del gran torreón en la zona suroeste mencionado anteriormente, así como el remate del cubo opuesto a este primero, en la zona noroeste. Muchos de los matacanes tampoco son considerados originales por este autor, que señala que los originales tienen el arco trebolado perteneciente a la escuela toledana.

En la actualidad, la zona que rodea al castillo se encuentra vacía de construcciones, en una superficie que ronda las $2 \mathrm{Ha}$. La iglesia de San Martín se sitúa exenta en este descampado (Fig. 5.2.11). Esta iglesia posee una torre construida de forma aislada y con carácter defensivo, a la que probablemente se adosa la iglesia posteriormente. En las fachadas norte de la torre, se observa la sección de un muro de $70 \mathrm{~cm}$ de espesor construido con una hoja de ladrillo hacia el exterior y un relleno de piedra. En el lado sur, se observa el arranque de un arco de ladrillo. La torre de esta iglesia está perfectamente alineada con la carretera de $\mathrm{V}$ alladolid $(\mathrm{C}-112)$, de $\mathrm{m}$ anera que es visible al fondo de la carretera al recorrerla entrando en Cuéllar. Puede indicar la existencia de este camino a partir de la posición de la torre, que serviría de referencia a quien se acercase a la población desde el oeste. El primer recinto se compone de dos puertas principales, la puerta de San Basilio y la puerta de San Martín, otras tres puertas de menor entidad, la puerta de las Cuevas, la puerta de Santiago y la puerta de la Judería, y de un portillo, el portillo de la Huerta. El tramo sur, que parte del castillo hasta la plaza del Estudio tiene una longitud de $470 \mathrm{~m}$ aproximadamente. Junto a la puerta de la Judería continúa otro tramo de $40 \mathrm{~m}$ de longitud. Finalmente, desde la puerta de San Basilio al castillo, continúa otro tramo de $150 \mathrm{~m}$ de muralla. La longitud total es de $660 \mathrm{~m}$ aproximadamente, de los cuales $70 \mathrm{~m}$ son de nueva construcción.

\footnotetext{
${ }^{38}$ Plano 943 consultado en la Planoteca del Instituto del Patrimonio Cultural de España http://ipce.mcu.es/documentacion/archivo/fondos/planoteca.html [Consultado el 2/5/2014]
} 


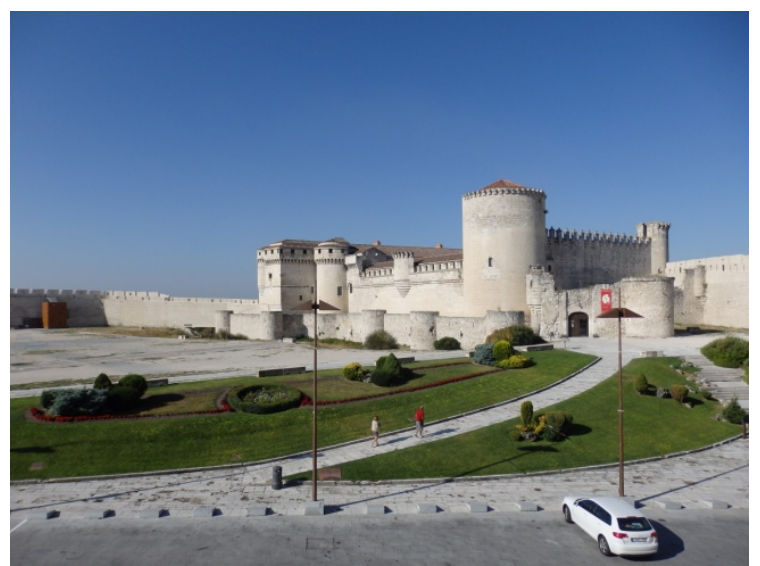

Fig. 5.2.7. Castillo de Cuéllar desde el noreste [A.S.E. 20/8/2014].

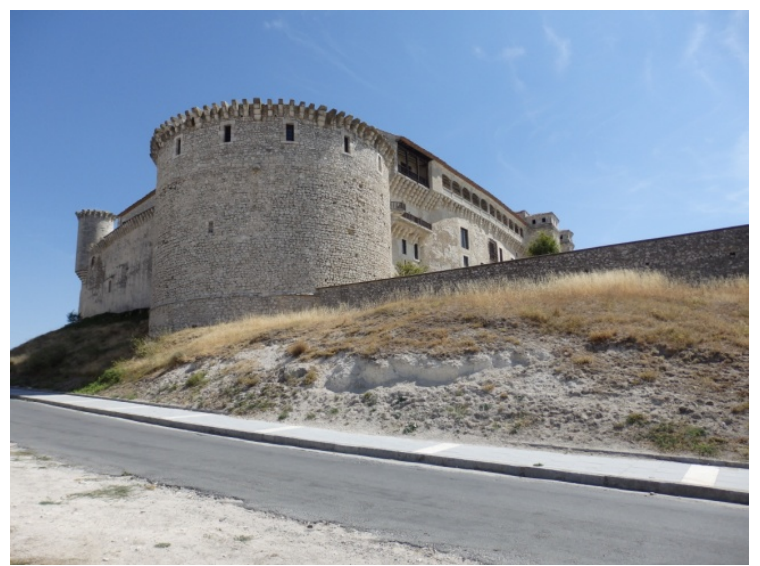

Fig. 5.2.9. Torreón del castillo de Cuéllar en el suroeste [A.S.E. 20/8/2014].

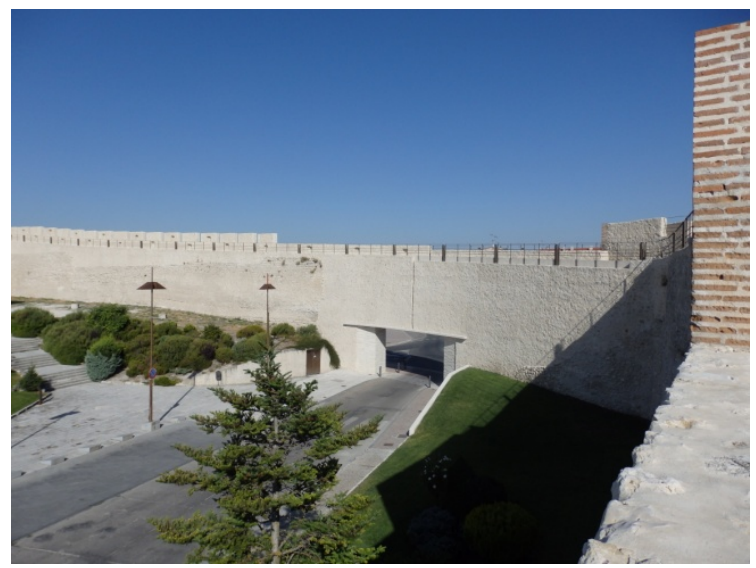

Fig. 5.2.8. Tramo junto al castillo visto desde el interior del recinto [A.S.E. 20/8/2014].

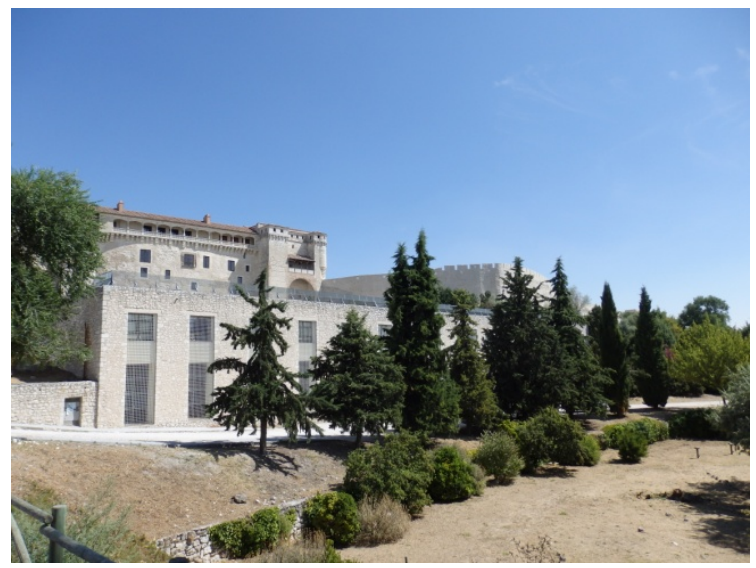

Fig. 5.2.10. El castillo visto desde el sur. Al fondo se observa el tramo de muralla que continúa hacia el este [A.S.E. 20/8/2014].

El segundo recinto amurallado tenía varias puertas, de las cuales solo en un caso, la puerta de San Andrés, se conservan elementos suficientes para identificarla como tal. Las puertas de San Pedro, de Carchena o la de la Trinidad conservan escasos restos que no permiten entender cuál era su configuración. Además de e stas puertas, existían dos portillos, el portillo de Exángel, que conserva un a rco de ladrillo, y el portillo en I a calle Nueva, configurado en per pendicular al lienzo de m uralla. Este segundo recinto presenta un tramo de $60 \mathrm{~m}$ aproximadamente desde la puerta de la Judería hasta la puerta de San Andrés, seguido de un tramo de $230 \mathrm{~m}$ aproximadamente que discurre junto a la calle Nueva. Tres tramos de $15 \mathrm{~m}$ a $25 \mathrm{~m}$ se suceden hasta la puerta de Carchena. Desde ahí $100 \mathrm{~m}$ de muralla son visibles en la calle muralla. Otros tres tramos de $15 \mathrm{~m}$ a $25 \mathrm{~m}$ se sitúan entre la iglesia de San Pedro y la puerta de la Trinidad. Desde esta puerta hasta el portillo de Exángel se conservan $100 \mathrm{~m}$ de muralla aproximadamente. Desde este portillo hasta la puerta de las Cuevas, en el primer recinto, se conservan $200 \mathrm{~m}$ de muralla. En este segundo recinto, se conserva un total de $790 \mathrm{~m}$ de muralla. 


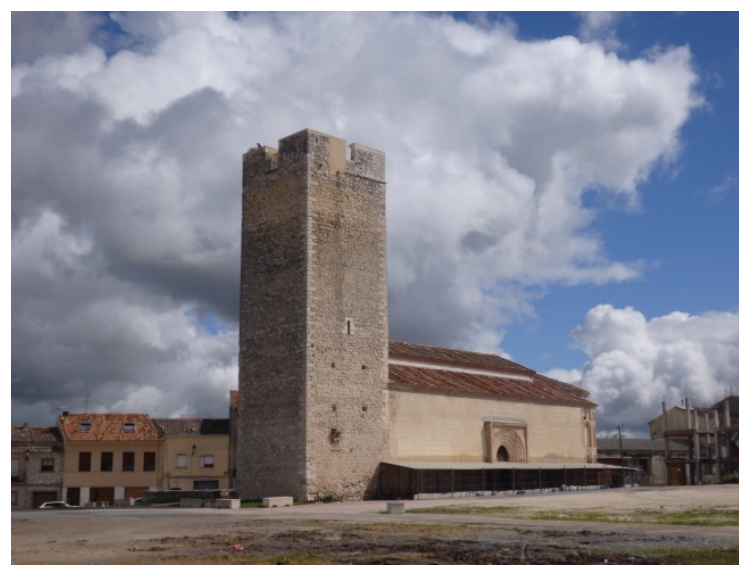

Fig. 5.2.11. Iglesia de San Martín [A.S.E. $12 / 5 / 2016]$.

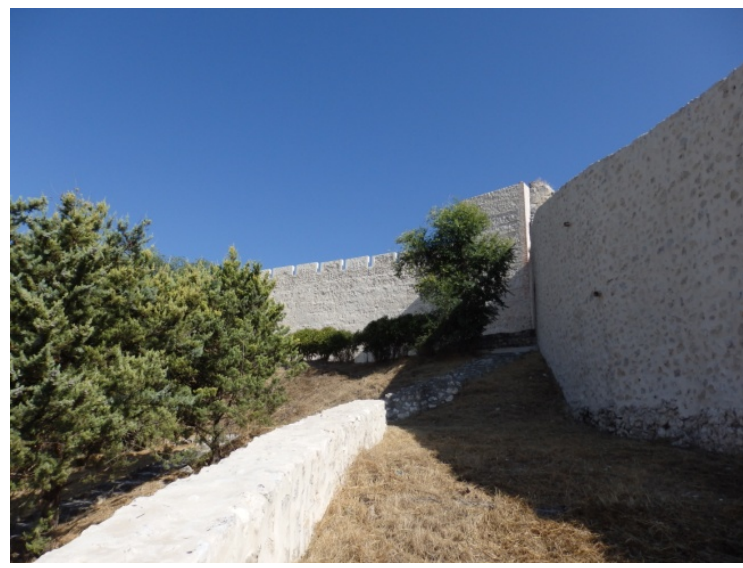

Fig. 5.2.13. Encuentro del primer recinto con el segundo, junto a la puerta de las Cuevas [A.S.E. 20/8/2014].

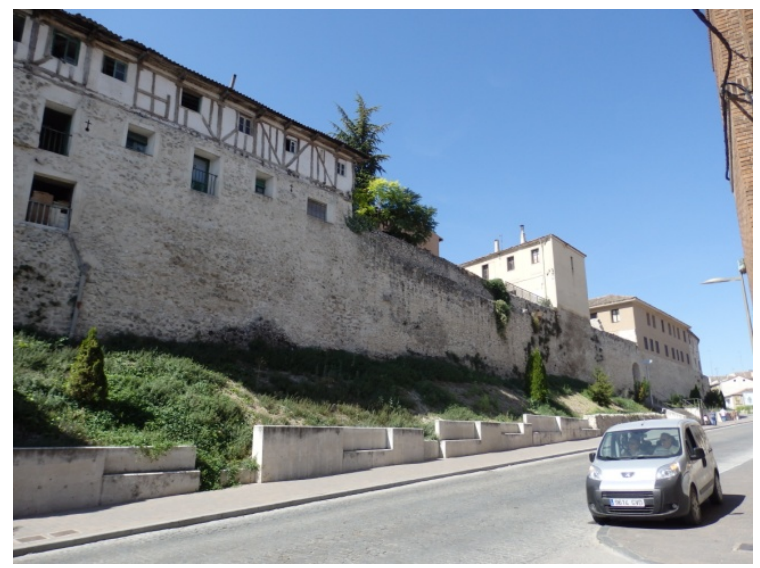

Fig. 5.2.12. Vista de la muralla desde la calle Nueva [A.S.E. 20/8/2014].

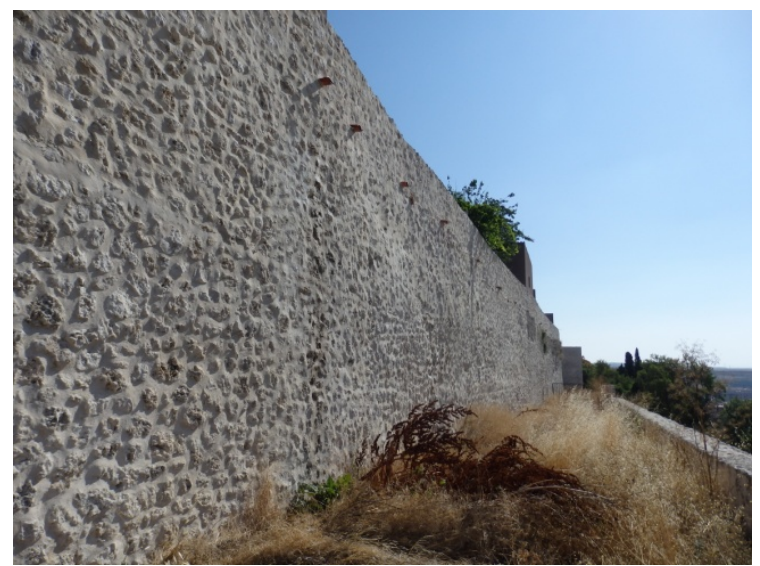

Fig. 5.2.14. Lienzo sur T9-T10 del segundo recinto [A.S.E. 20/8/2014].

\subsubsection{Tramos y elementos de la muralla medieval}

Desde el castillo hacia el norte, parte un tramo de muralla de aproximadamente $60 \mathrm{~m}$. Hasta la torre de San Basilio se ha completado con un tramo de muralla moderno que tiene un acceso que comunica la calle Palacio con el exterior del recinto. La torre de San Basilio (T1) tiene una forma circular en planta y está acompañada de dos torres rectangulares adosadas a ambos lados (T1a y T1b). Forman un conjunto singular, que no se repite en ningún otro punto de la muralla. Estas dos torres parecen encontrarse alineadas entre sí, formando un frente rectangular tras la torre T1. La torre T1 tiene un acceso en la planta baja que atraviesa su base, para el paso de una persona y cubierto con un ar co de ladrillo ligeramente apuntado. Se pueden contar hasta 10 tapias de altura, separadas entre sí por una verdugada de ladrillo colocado a soga. La altura sería todavía mayor ya que la torre se eleva sobre un pedestal de más de una tapia de altura. Las verdugadas también se observan en los bloques rectangulares adosados, que además presentan un refuerzo de ladrillo en cada una de sus esquinas. Se trata de un machón, de espesor de tres ladrillos, que se reduce a dos a partir de la quita tapia. Las torres T1a y T1b se adosan a ambos lados de la torre T1. Su sección 
es rectangular y se construye con tapia mixta. La singularidad del conjunto se debe, por un lado al importante diámetro de la torre T1, que alcanza los $8 \mathrm{~m}$. La torre T2, de directriz circular y forma ligeramente troncocónica no supera los $5 \mathrm{~m}$ de di ámetro. También tiene interés el paso existente que traviesa la base de la torre T1 en paralelo con el plano de las torres T1a y T1b. Edward Cooper (1991, vol. 2, 1540) sugirió que en la construcción de esta torre se ha incorporado el ábside de la iglesia de San Nicolás.

Entre la torre $\mathrm{T} 1 \mathrm{~b}$ y la puerta de San Basilio se encuentra un tramo de muralla de $15 \mathrm{~m}$. Antes de la restauración, tres viviendas se adosaban a este lienzo, de la misma forma que todavía se adosan construcciones a la torre T3 de la puerta de San Basilio. Aunque las hiladas de tapia no son tan evidentes como en las torres, se pueden contar 9 tapias. Se puede ver que no hay una correspondencia entre las hiladas de tapia de la torre T1b y el lienzo de muralla (Fig. 5.2.18). En el lienzo de muralla, las hiladas de las tapias se han resaltado en la restauración a través del dibujo de una línea en el mortero.

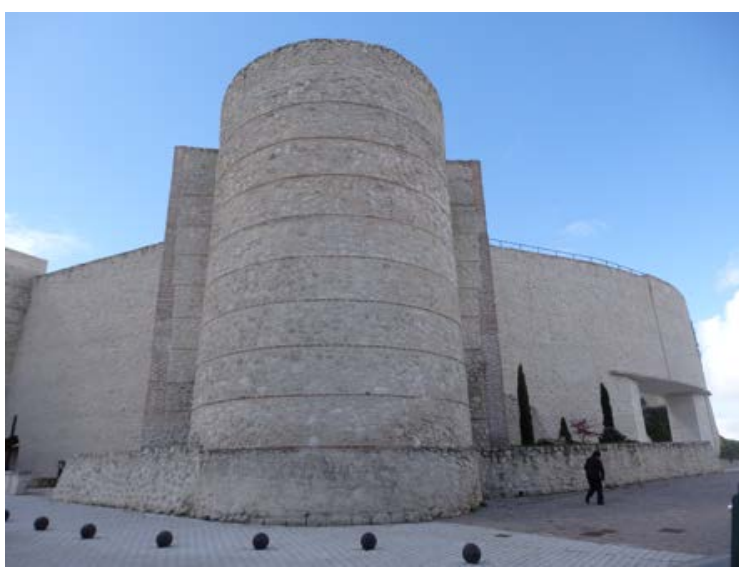

Fig. 5.2.15. Torre de San Basilio vista desde el norte [A.S.E. 12/5/2016].

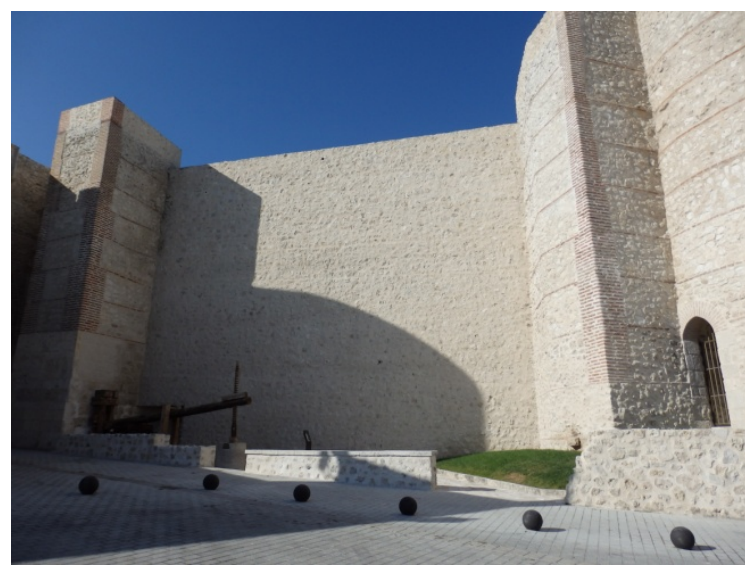

Fig. 5.2.17. Lienzo T1b-T2 [A.S.E. 20/8/2014].

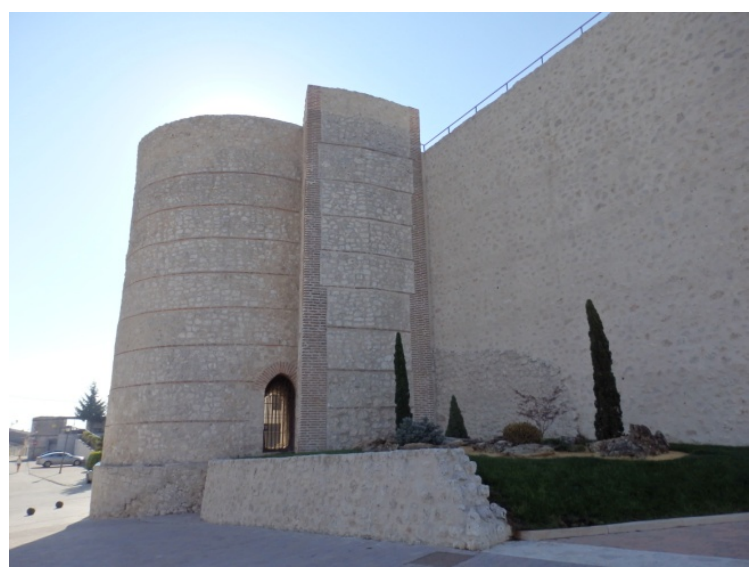

Fig. 5.2.16. Torre de San Basilio vista desde el oeste [A.S.E. 20/8/2014].

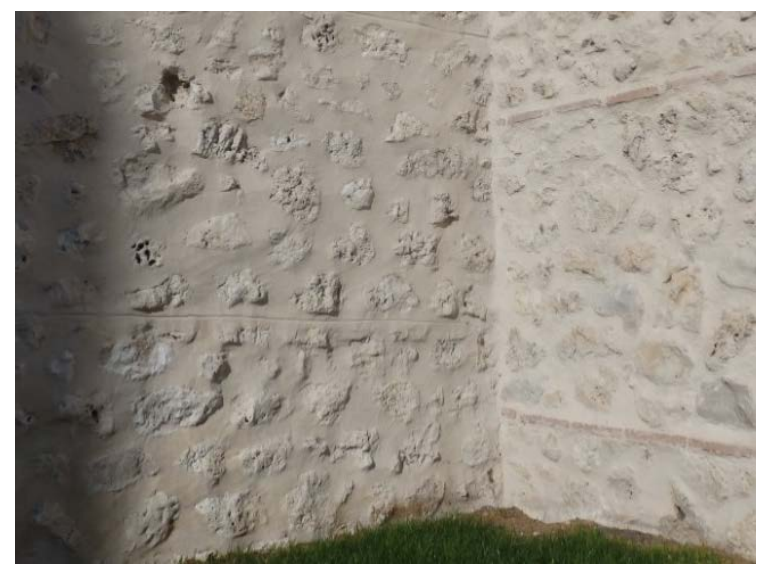

Fig. 5.2.18. Encuentro de las tapias de la torre $\mathrm{T} 1 \mathrm{~b}$ y el lienzo T1b-T2. Se observa que no hay una continuidad entre las fábricas [A.S.E. 20/8/2014]. 
La puerta de San Basilio se sitúa en dirección perpendicular al recorrido de la muralla. Se compone de dos torres que la flanquean, entre las que se construye una bóveda de acceso. La torre T2 es de planta rectangular y es maciza. En la base de observan sillares de tamaño grande y regular, aparejados de forma ordenada, hasta una altura de $3 \mathrm{~m}$. A partir de esta altura la torre se construye con tapia de mampostería, reforzada con machones de ladrillo en sus esquinas y separadas las tapias por una verdugada de ladrillo. No se observa la presencia de mechinales en estas verdugadas. Las piedras empleadas en la tapia son de tamaño medio e irregular. Los machones de las esquinas están dentados de forma irregular. En la cara noroeste de la torre, en las dos primeras tapias de la base, tienen una anchura de dos ladrillos a soga y uno a tizón, en la tercera tapia el machón se estrecha a un ladrillo a soga y otro a tizón, en la cuarta tapia de nuevo se recupera la anchura inicial para volver a estrecharse en las tapias siguientes. En la cara noreste de la torre, el mismo machón presenta un dentado distinto a partir de la cuarta tapia, que mantiene la misma anchura que la tercera. En la quita tapia, el machón aumenta un ladrillo a soga de anchura, y vuelve estrecharse en las tapias siguientes. La torre T3 es de planta semicircular y es maciza. Tiene un radio de $5 \mathrm{~m}$. Presenta una base de sillares similar a la de la torre T2 y de la misma altura. A partir de es ta base, se construye con tapias de mampostería separadas por una verdugada de ladrillo. Se observa la presencia de lo que parece un mechinal sobre la cuarta verdugada, construido con varios ladrillos (Fig. 5.2.21). La piedra utilizada en las tapias es pequeña e irregular. No se observan los límites verticales de las tapias.

El frente de la puerta muestra un arco de ladrillo de medio punto construido con una primera hilera de dos tizones de espesor. Dos arquivoltas de ladrillo se añaden a esta primera hilera, con un tizón de espesor. Sobre el arco, se construye un frente de ladrillo rectangular con aparejo a soga remarcado en los laterales por bordes de ladrillo de un tizón de espesor y coronado en la parte superior con una hilera de ladrillos colocados a sardinel y a tizón. En el centro se sitúa un escudo. Sobre este frente de ladrillo, se reconoce de nuevo la tapia de mampostería y se rematada en lo alto con dos escudos de gran tamaño. Este frente es un muro que está construido delante de la puerta, a una di stancia de $1 \mathrm{~m}$ y funciona de matacán (Fig. 5.2.22). En un segundo plano se observa un segundo arco de medio punto, construido con sillares. Sobre el arco se construye un frente rectangular de ladrillo con aparejo a soga enmarcado en los laterales por dos pilares de ladrillo y en la parte superior con un remate de ladrillo a sardinel y a tizón. El acceso se cubre con una bóveda de mampostería de piedra irregular y de tamaño medio. Hacia el interior, se construye un arco de medio punto similar al ya descrito.

La fachada interior de la puerta ofrece un aspecto distinto del exterior. Se estructura en un solo plano, con el arco de acceso a la bóveda centrado. Es un arco construido en ladrillo con una arquivolta y un frente rectangular que parece moderno y construido imitando la composición de la portada exterior. Las piedras sobre las que se apoya parecen también modernas. A la izquierda se observa un arco de paso que da acceso a una escalera que sube hasta el adarve. La restauración realizada en 2008 recreció en torno a $1 \mathrm{~m}$ las dos torres de la puerta y facilitó el acceso en la parte superior. 


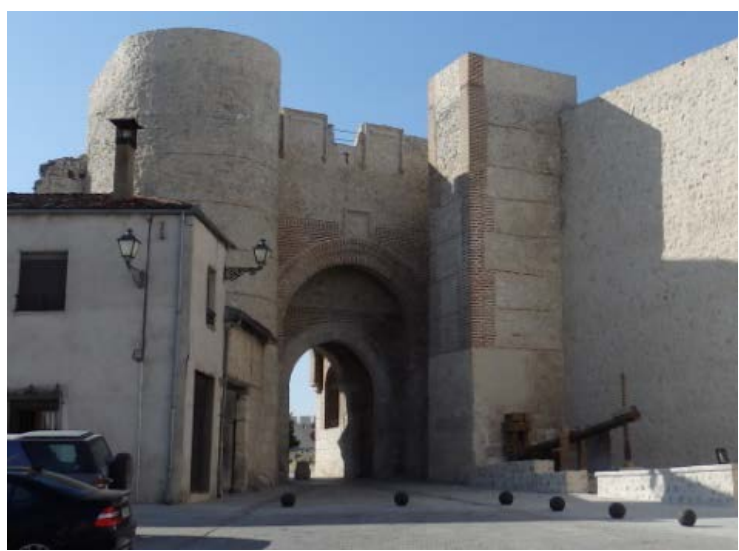

Fig. 5.2.19. Puerta de San Basilio P1 desde el exterior del recinto compuesta por las torres T2-T3 [A.S.E. 20/8/2014].

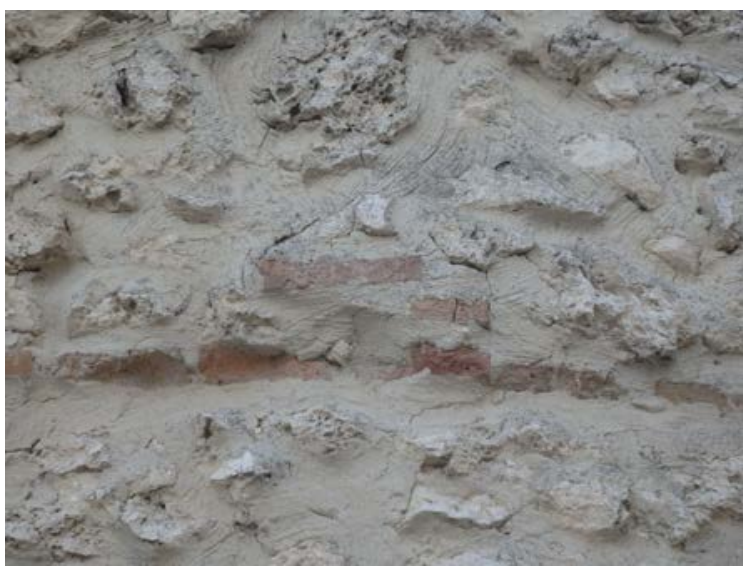

Fig. 5.2.21. Mechinal de ladrillo en la torre T3, ubicado sobre la verdugada [A.S.E. 20/8/2014].

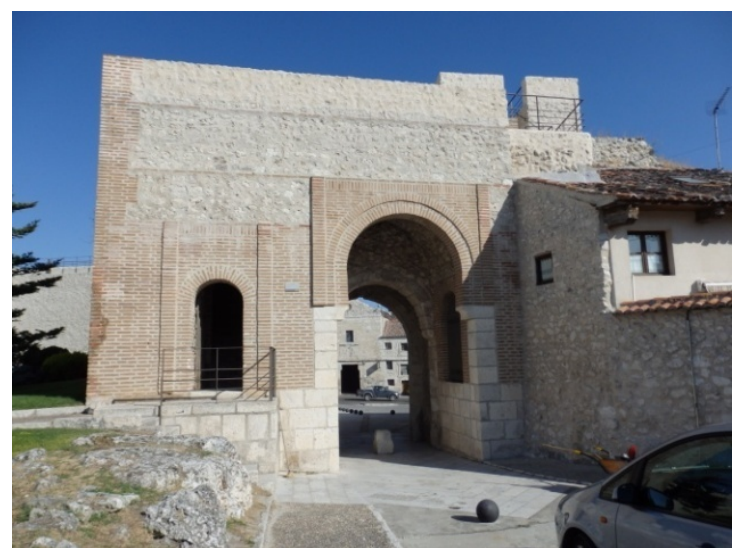

Fig. 5.2.20. Puerta de San Basilio P1 desde el interior del recinto [A.S.E. 20/8/2014].

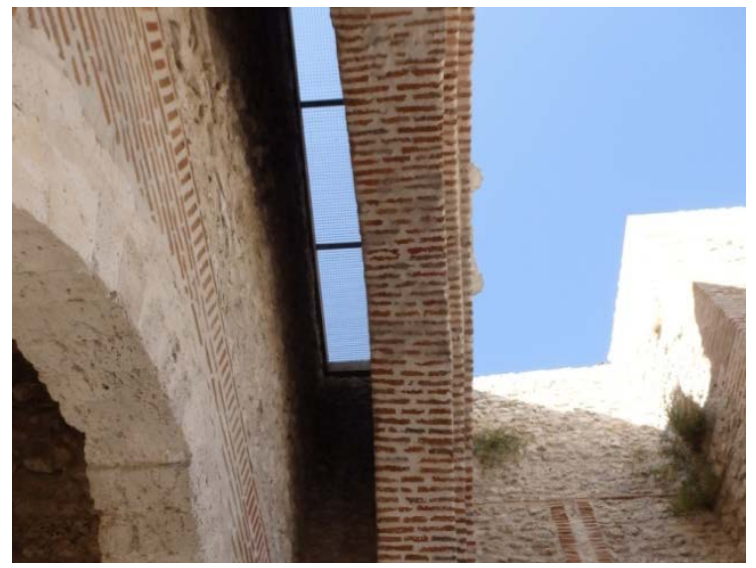

Fig. 5.2.22. Matacán de la puerta de San Basilio. Se observa a la derecha una aspillera de ladrillo cegada [A.S.E. 20/8/2014].

Junto a la torre T3 de la puerta San Basilio, la muralla queda interrumpida. Se puede observar el muñón a la izquierda de la torre semicircular sobresaliendo por encima del tejado de la vivienda (Fig. 5.2.19). La muralla continuaría siguiendo la calle Barrera, de hecho, se observan de nuevo restos en el caserío entre la calle Barrera y la plaza de San Gil. En el callejón que sale de la calle Barrera en dirección sur es posible ver restos de la muralla (Fig. 5.2.23). Este tramo se construye con aparejo de piedra de tamaño medio, desordenado, en el que no se observan marcas de encofrado (Fig. 5.2.25), como ocurre en otros casos. Desde el callejón se puede ver los restos de la torre T4 (Fig. 5.2.24), que han sido alterados con una cubierta moderna a un agua y con nuevos huecos. Los materiales visibles en la torre son piedras de tamaño y forma irregular. En la parte superior de la cara sur de la torre se ven dos verdugadas de ladrillo que encierran piedras mampuestas de tamaño grande. En el lado izquierdo se observa un machón de ladrillo dentado, que no arranca desde la base de la torre sino ya en la zona más elevada. 


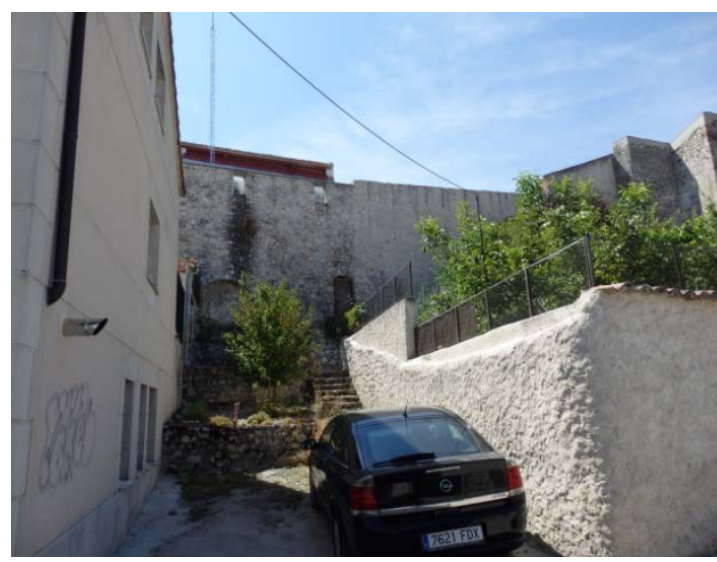

Fig. 5.2.23. Tramo puerta de la judería P2-torre T4 visible en el callejón que sale de la calle Barrera [A.S.E. 20/8/2014].

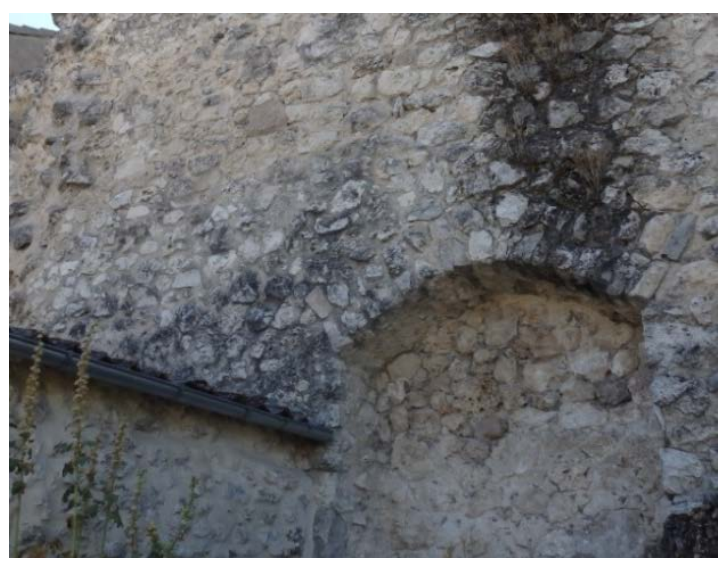

Fig. 5.2.25. Detalle del aparejo de piedra en el lienzo P2-T4 Es visible un arco cegado en la base del lienzo [A.S.E. 20/8/2014].

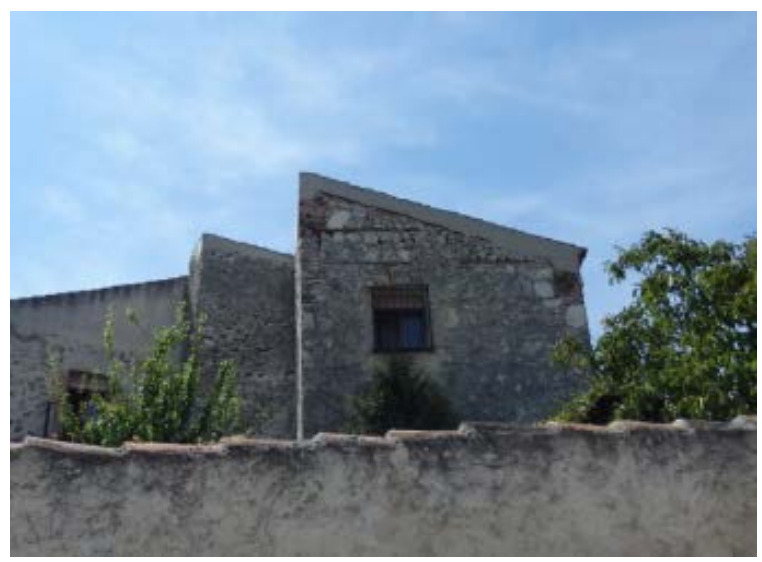

Fig. 5.2.24. Torre T4 vista desde la calle Barrera [A.S.E. 20/8/2014].

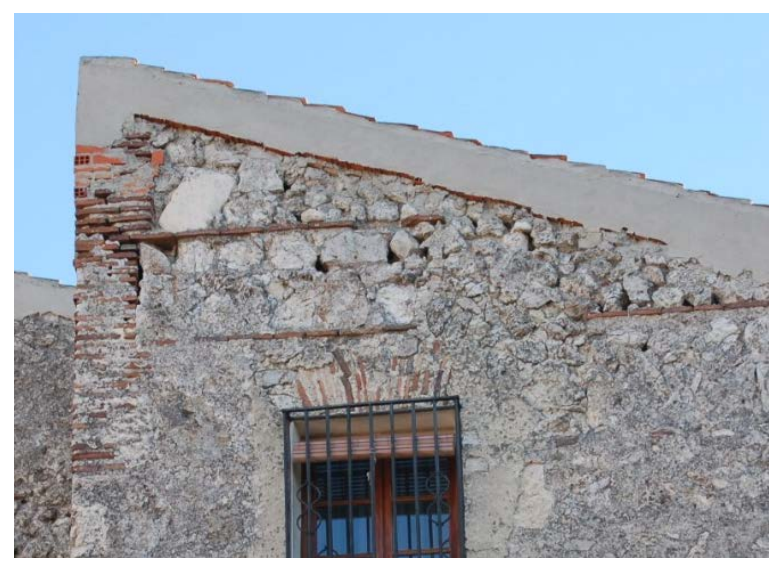

Fig. 5.2.26. Detalle del aparejo de la torre T4. Fuente: Fernando Nieto Criado y Jesús Nieto Criado $[8 / 1 / 2005]$

Los restos de la muralla continúan avanzando entre el caserío, hasta la puerta de la Judería (Fig. 5.2.27). Esta puerta es un pequeño paso en la muralla y está ubicada en un callejón estrecho. El paso está cubierto con una pequeña bóveda (Fig. 5.2.28) que se construye con sillarejo de piedra. El arco exterior ha sido renovado con piezas nuevas. Se conserva el gozne de pi edra para la puerta en la parte superior de la bóveda. Esta puerta da acceso a una callejuela muy estrecha de apenas 2,00 m de anchura. En el tramo siguiente, visible desde la calle Judería, la muralla continúa formando parte de las construcciones nuevas (Fig. 5.2.29). Las viviendas abren ventanas en el lienzo de muralla. El muro se encuentra restaurado y se ha aplicado mortero moderno. Se construye con piedras de forma irregular y tamaño medio. En el muro se ven algunos límites y marcas que muestran discontinuidades. En lo alto del muro se observan 5 saeteras, ordenadas en dos niveles. Cuatro de estas aspilleras son cruciformes, con un remate circular en la base. Están talladas en una única piedra. Son similares a las visibles en el castillo. La quinta es más sencilla, formada por la separación de dos sillares. También es visible una ménsula de piedra que sobresale del plano de la muralla (Fig. 5.2.30). 


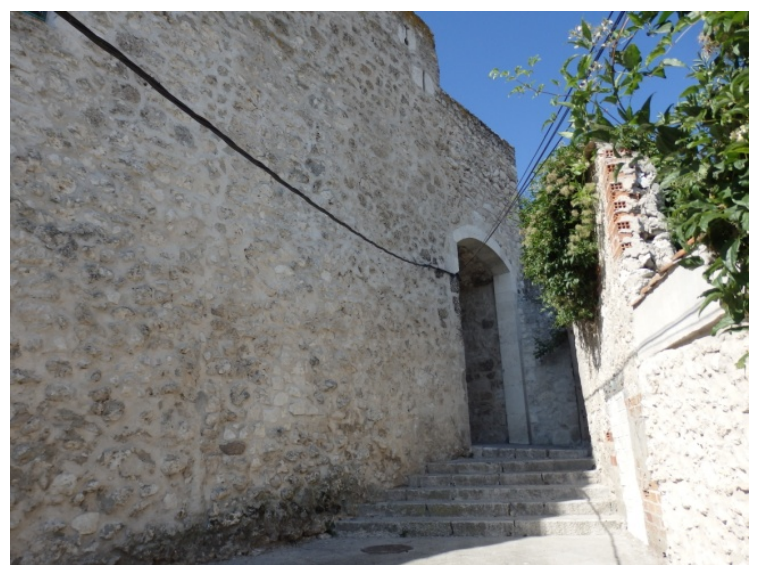

Fig. 5.2.27. Puerta de la Judería P2 vista desde el exterior [A.S.E. 20/8/2014].

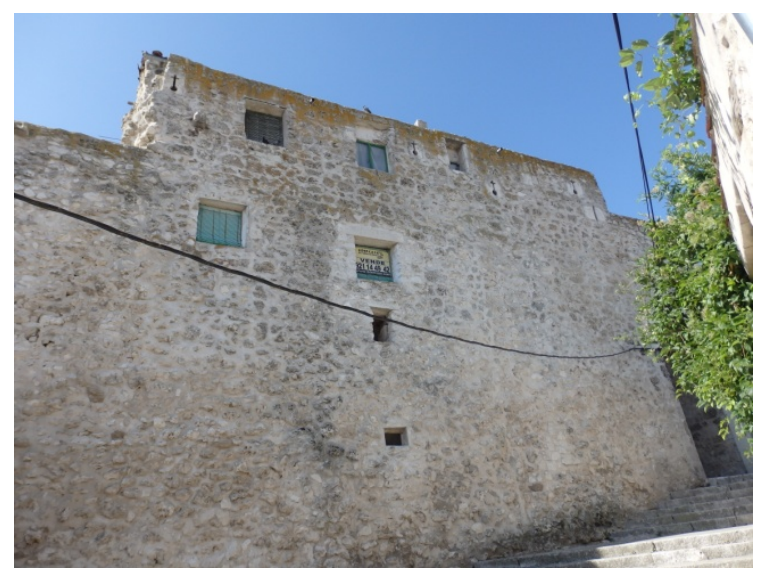

Fig. 5.2.29. Tramo de muralla junto a la puerta de la Judería. A la derecha se ve parte de la puerta [A.S.E. 20/8/2014].

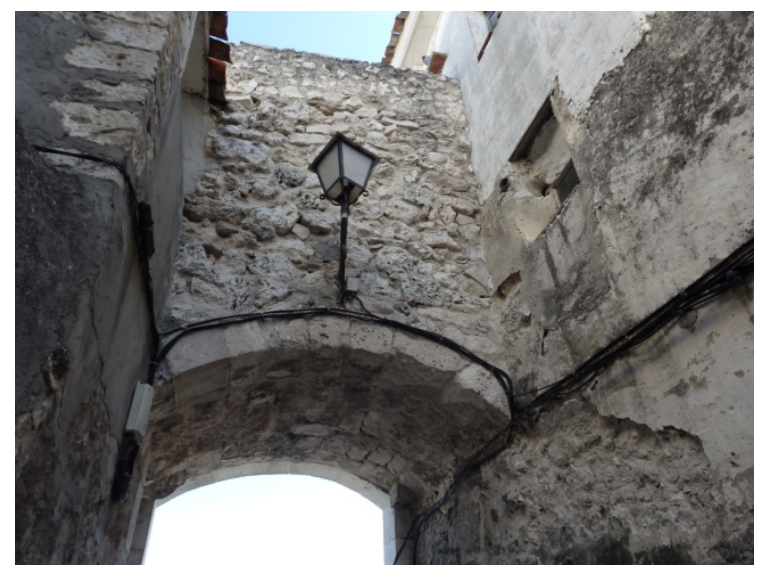

Fig. 5.2.28. Bóveda de la puerta de la Judería P2 vista desde el interior [A.S.E. 20/8/2014].

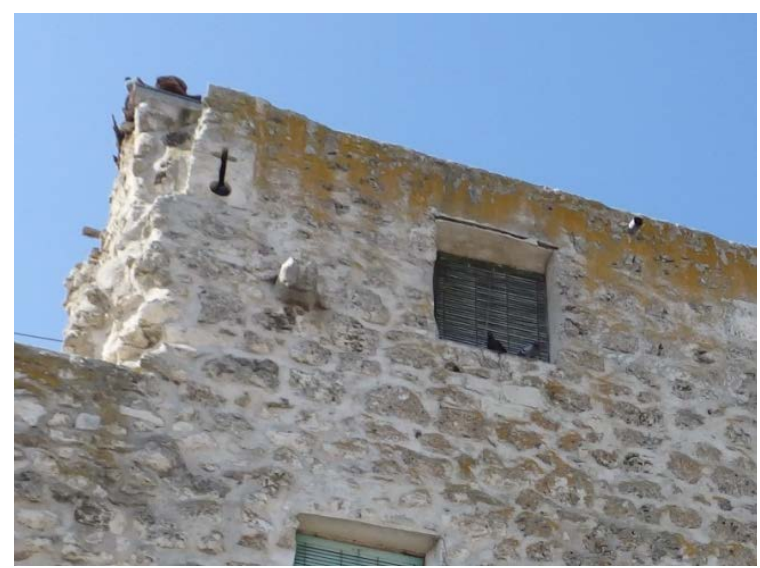

Fig. 5.2.30. Saetera visible desde la calle de la Judería. También se ve una ménsula [A.S.E. 20/8/2014].

A partir de este punto los restos de muralla se interrumpen. Más adelante, junto a la puerta de San Martín continúa el recorrido de la muralla del primer recinto. En este lugar, tiene especial interés la iglesia de San Esteban, que se ubica muy cerca y cuyos elementos podrían tener relación con el conjunto defensivo. En los planos realizados para la declaración de Conjunto Histórico Artístico con fecha de 1981, el muro noroeste se considera parte de la muralla y también se orienta hacia el sureste. La planta de la iglesia presenta un muro norte de gran espesor en comparación con otros muros de la iglesia. La torre de la iglesia de San Esteban es de planta cuadrada. En el alzado norte (Fig. 5.2.34) se puede ver que la construcción de la torre y de la iglesia es totalmente independiente. La torre es una construcción aislada que se ha rodeado posteriormente por la iglesia, que ha construido su campanario en lo alto. La torre se realiza con tapia de mampostería, son visibles los mechinales en sus fachadas donde se repiten con un ritmo constante. En las esquinas, la torre se refuerza con ladrillo. 


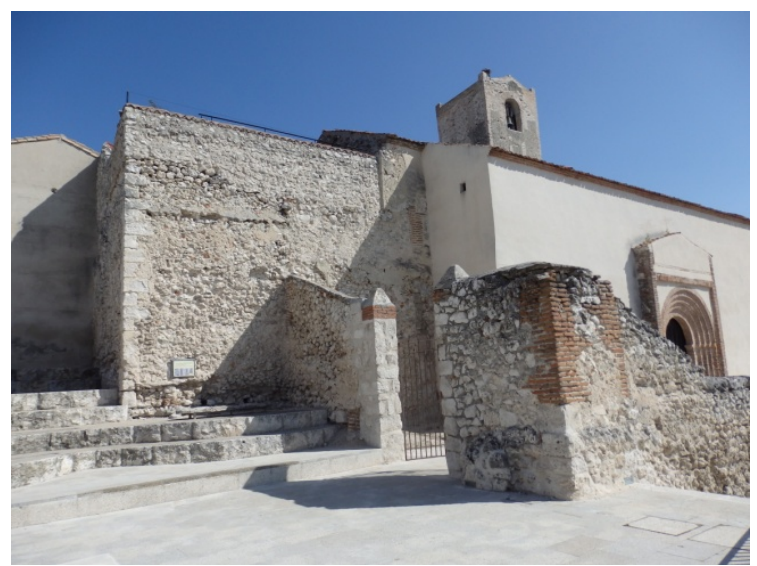

Fig. 5.2.31. Fachada sur de la iglesia de San Esteban [A.S.E. 20/8/2014].

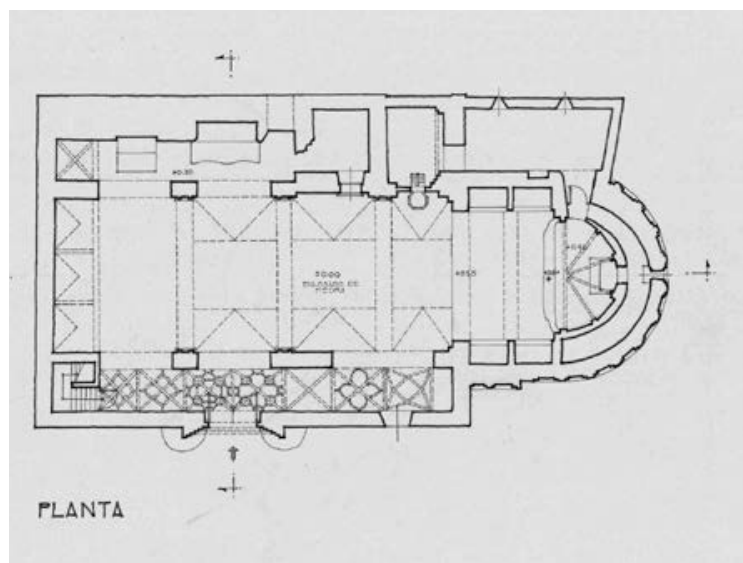

Fig. 5.2.33. Planta de la iglesia de San Esteban. El muro norte presenta un grosor que duplica el del resto. Fuente: Proyecto de Obras de Restauración de la Iglesia de 1978 a cargo de José Miguel Merino de Cáceres. Planoteca del Instituto del Patrimonio Cultural de España.

http://ipce.mcu.es/documentacion/archivo/fondos/pla noteca.html [Consultado el 28/4/2016].

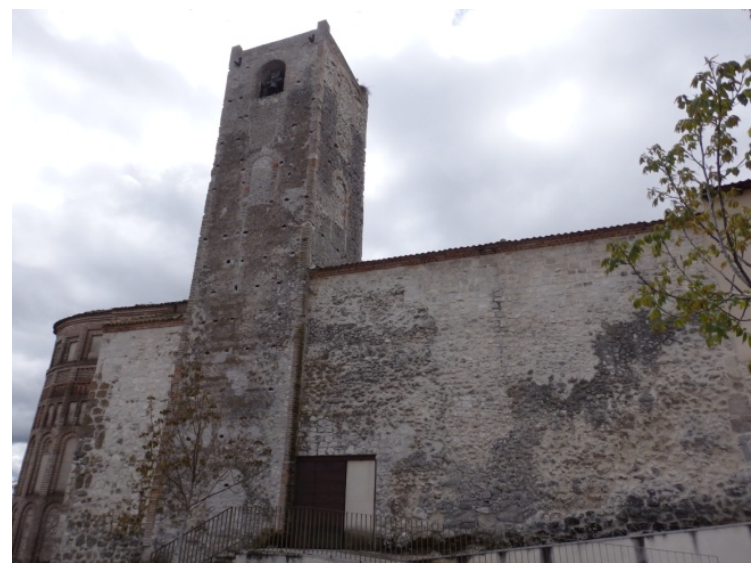

Fig. 5.2.32. Fachada norte de la iglesia de San Esteban [A.S.E. 12/5/2016].

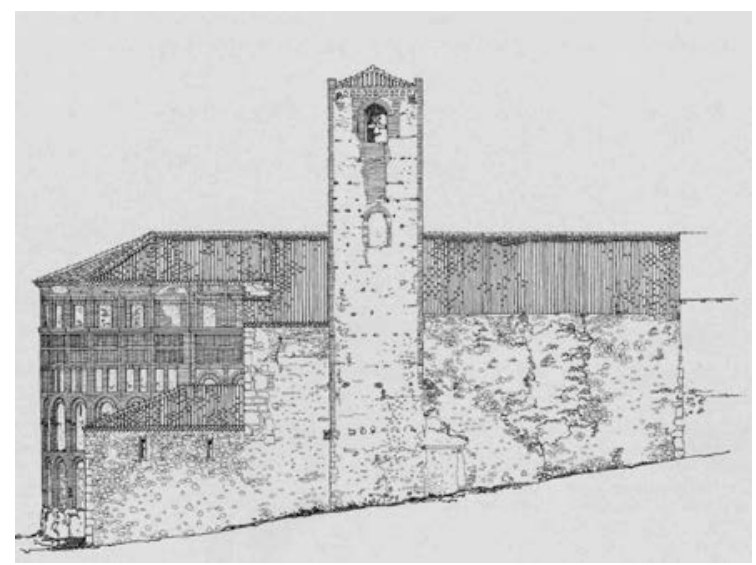

Fig. 5.2.34. Alzado Norte de la iglesia de San Esteban. Fuente: Proyecto de Obras de Restauración de la Iglesia de 1978 a cargo de José Miguel Merino de Cáceres. Planoteca del Instituto del Patrimonio Cultural de España.

http://ipce.mcu.es/documentacion/archivo/fondos/plan oteca.html [Consultado el 28/4/2016].

En esta zona, plantear una hipótesis del recorrido de la muralla resulta complicado. Varios elementos confluyen, dando Iugar a varias posibilidades. El tramo de muralla que llega desde la puerta de la Judería se interrumpe en la plaza del Estudio. A partir de ahí, la posición de la iglesia de San Esteban plantea una continuidad con su muro norte y su torre. Por otro lado la puerta de San Martín se encuentra muy próxima y sus restos junto con los restos de los lienzos cercanos plantean otras posibilidades.

La puerta de San Martín (P3) ofrece un aspecto imponente y lanza un mensaje de solidez e inexpugnabilidad. Se ubica en la zona este del recinto y su posición está alineada en relación con el lienzo de la muralla. Tanto la puerta como los lienzos junto a ella tienen una gran altura. La composición de la puerta es simétrica, el acceso está flanqueado por dos grandes torres, T5 y T6, de planta rectangular cuya posición se adelanta con respecto al plano del arco de acceso (Fig. 5.2.35). Ambas torres presentan un pedestal en la base, un zócalo que sobresale del plano de las torres, con una altura de casi $2,50 \mathrm{~m}$. Las torres presentan en las esquinas un refuerzo de sillarejo. 
De la torre T5, a la derecha del acceso, parte un I ienzo de $m$ uralla en s entido perpendicular (Fig. 5.2.37). Estas torres no son macizas. Por el aspecto simétrico de la puerta y el encuentro entre la torre T5 y el lienzo perpendicular, no sería arriesgado plantear que este último lienzo se habría realizado con posterioridad. La muralla habría continuado en línea con la puerta ofreciendo un frente hacia el este, con la puerta centrada en el mismo. La forma del tejido urbano apoyaría esta hipótesis, ya que son visibles tres caminos que parten hacia el este desde la puerta de San Martín. Dos de ellos son fácilmente identificables y son ahora la calle Estudio y la calle de los Duques de Alburquerque continuada por la calle Morería. El tercer camino no es tan claramente identificable, pero son visibles marcas de su trazado en el parcelario. La primera de ellas es la calle sin nombre que baja desde la plaza de Estudio hasta la calle Judería, que tiene escaleras. Después queda un vestigio en la calle San Esteban, a la altura del $n^{\circ} 20$, donde se aprecia un espacio entre dos edificaciones, la $n^{\circ} 18$ y 22 , ahora ocupado por una pequeña construcción retranqueada, que no consigue ocultar el carácter de calle de ese espacio. Los números 18 y 22 tienen ventanas que abren a este callejón. Esta hipotética calle está representada en el plano de par celas (Fig. 5.2.6) con una línea gruesa, gris y discontinua, que parte de la puerta de San Martín.

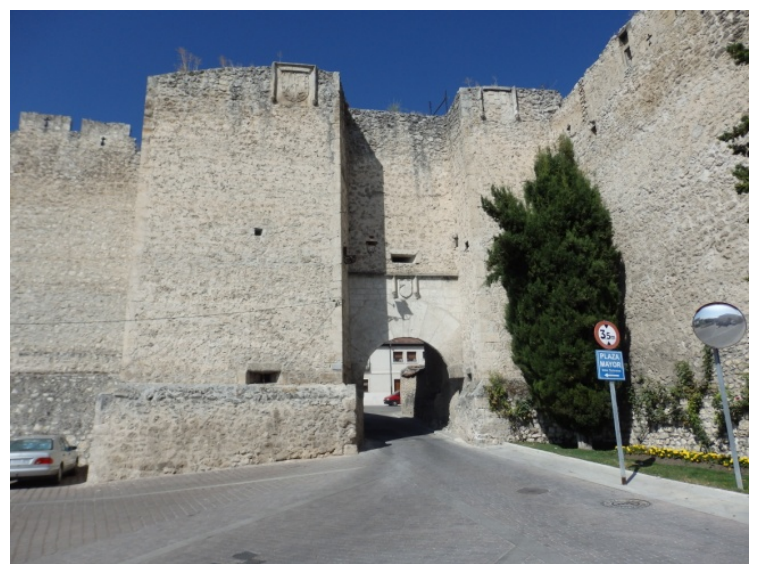

Fig. 5.2.35. Puerta de San Martín (P3) vista desde el exterior [A.S.E. 20/8/2014].

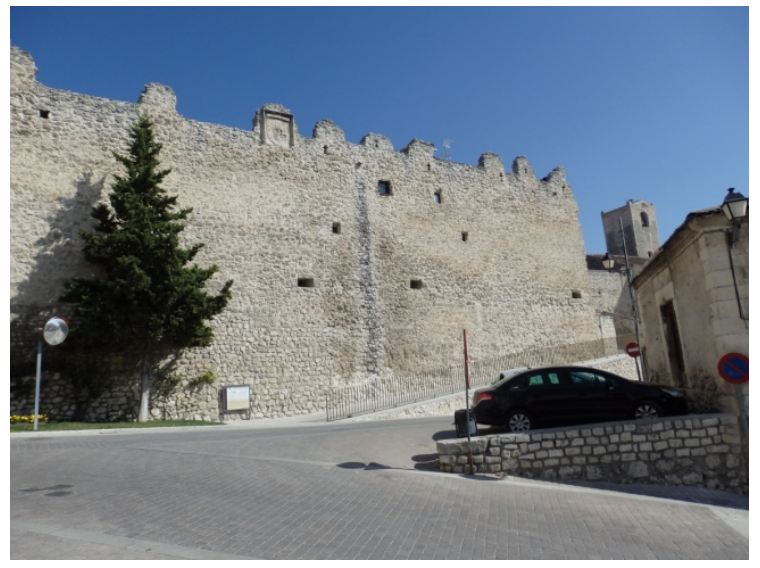

Fig. 5.2.37. Tramo perpendicular a la puerta de San Martín [A.S.E. 20/8/2014].

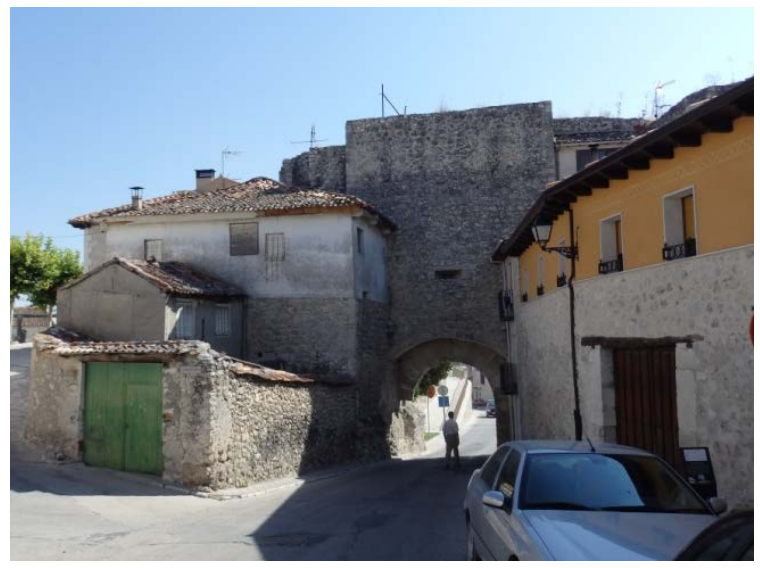

Fig. 5.2.36. Puerta de San Martín (P3) vista desde el interior [A.S.E. 20/8/2014].

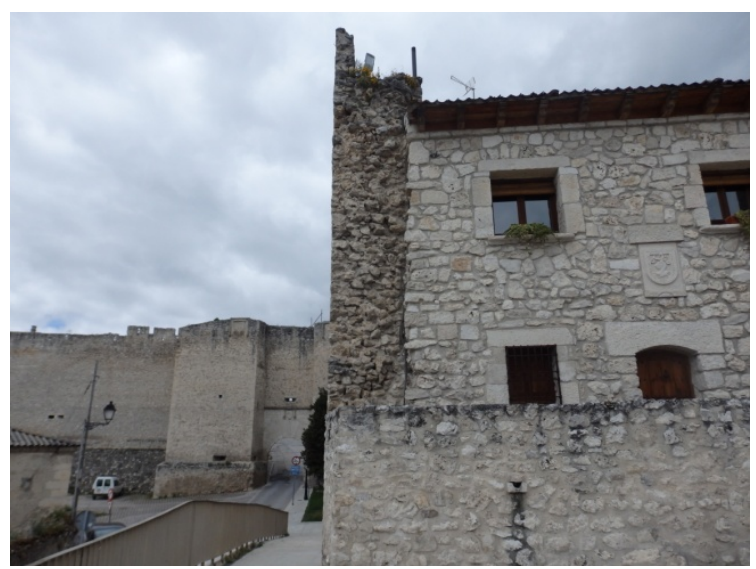

Fig. 5.2.38. Sección del tramo perpendicular a la puerta de San Martín, se puede ver la anchura y el corte del muro [A.S.E. 12/5/2016]. 
Hacia el interior, la puerta de San Martín muestra un frente prácticamente ciego construido con lo que parece ser un aparejo de piedras medianas e irregulares (Fig. 5.2.36). En el centro se puede $v$ er un huec o rectangular y alargado, pequeño y abocinado. La construcción situada a la izquierda del acceso tiene una base que podría formar parte de la torre T5.

El tramo T6-T7 ofrece un aspecto sólido y tiene gran altura. Presenta un zócalo de $2,5 \mathrm{~m}$ de altura, al menos en la base visible, junto a la torre T6. En este tramo no son visibles mechinales, que permitan identificar el aparejo de mampuestos como tapia encofrada. No obstante, son visibles líneas horizontales que podrían corresponder con hiladas de tapia (Fig. 5.2.39, abajo). En la zona más cercana a la torre T7, la piedra empleada cambia, y pasa de ser un mampuesto a asimilarse más con un sillarejo: las piedras son más regulares y forman hiladas creando un aparejo más identificable (Fig. 5.2.40). Es muy singular la saetera cruciforme en la zona inferior de la torre, ya que presenta dos travesaños en lugar de uno. Al parecer, este tipo de cruz se denomina patriarcal o arzobispal; también la cruz de Lorena tiene esta morfología.
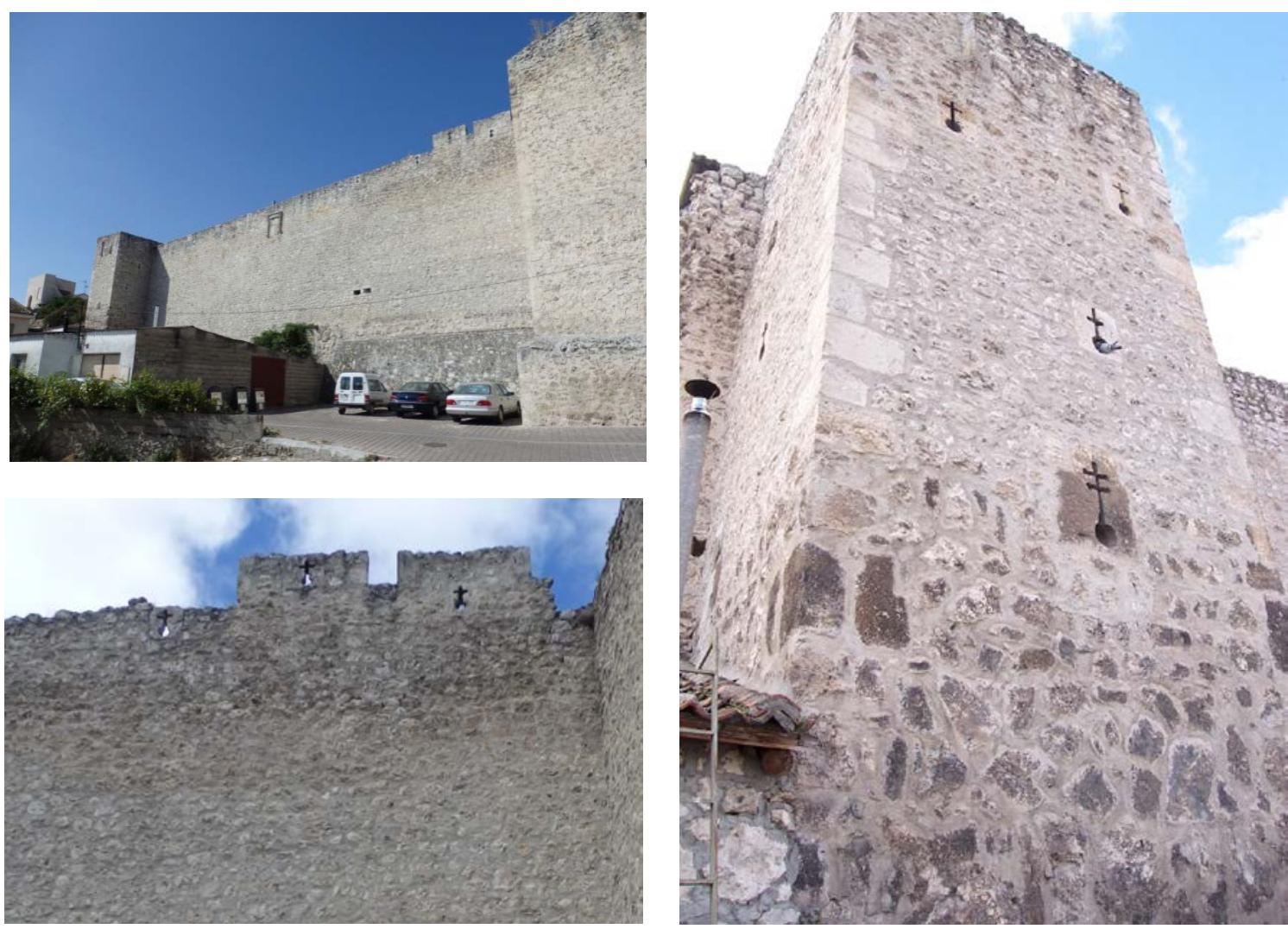

Fig. 5.2.39. Tramo T6-T7, abajo, detalle de la

Fig. 5.2.40. Torre T7. Saetera singular en la zona coronación [A.S.E. 20/8/2014]. inferior. Fuente: Fernando Nieto Criado y Jesús Nieto Criado [13/3/2001].

La puerta de Santiago se sitúa a continuación del tramo T7-T8, en la zona sur del primer recinto amurallado. Está flanqueada en su lado derecho por la torre T8 (Fig. 5.2.41). El hueco de acceso es pequeño, de escasa anchura, y está cubierto por un 
Las murallas en las Comunidades de Villa y Tierra de la Diócesis de Segovia en los siglos XI a XIII. Técnica y sistemas constructivos de la arquitectura defensiva medieval.

arco rebajado construido con sillares. Sobre el acceso se ubica un escudo recercado con una moldura de piedra. En este paso se produce un des nivel que está resuelto con escaleras que atraviesan el acceso. A partir de este punto hasta el castillo, el adarve de la muralla es transitable. Los lienzos de muralla fueron completados en su parte superior y sobre ellos se construyó el nuevo adarve en la restauración del año 2008. El acceso al adarve en este tramo se produce cerca del castillo. En el interior del recinto, se construyó una construcción de nueva planta unida a la muralla con una escalera suspendida. Desde el castillo hasta la puerta de $S$ an Basilio también se construyó un adarve moderno, cuyo acceso es libre a través de la puerta de San Basilio.

La puerta también fue recrecida en la restauración del año 2008, tanto en el lienzo donde se ubica el hueco de acceso como en la torre, y es posible distinguir por la distinta coloración del material la parte nueva de la parte original. La torre T8 es diferente a otras de este conjunto amurallado. Presenta una planta poligonal que se traduce en un alzado con caras alargadas en sentido vertical. En su lado este se adosa un volumen con planta rectangular. También se adosa un tercer volumen en lado sur, de menor altura, reforzado en sus esquinas con ladrillo y realizado con tapias con doble verdugada de ladrillo. Es difícil decir de cuantas caras consta la torre, al tener otros volúmenes que se adosan a ella, pero al menos es posible contar 6 caras visibles y como es visible al menos la mitad de la torre, la planta podría ser dodecagonal. La base de esta torre tiene especial interés. Se construye con piedras de tamaño grande que asemejan sillares. Las formas que tienen son dispares aunque están aparejadas con la intención de aparentar un sillarejo. Bases de torres similares a esta aparecen en recintos amurallados de Coca o de Segovia. A partir de una altura de $3,50 \mathrm{~m}$ la torre se construye de otra manera, con piedras irregulares de tamaño medio aparejadas de forma desordenada. En la restauración de 2008, la altura de la torre fue aumentada, reconstruyendo parte de la zona superior.

Junto a esta puerta se sitúa la iglesia de Santiago cuyos pies se encuentran inmediatamente al este de la torre poligonal. El aspecto que ofrece hoy en día es de ruina consolidada, solo el ábside está cubierto, el resto de la planta está a cielo abierto (Fig. 5.2.43). Sería interesante identificar qué papel tenía la torre T8 en la iglesia y aclarar qué función tenían los volúmenes añadidos a la torre (Fig. 5.2.44).

El recinto amurallado continúa hacia el oeste, desde la puerta de Santiago hasta la puerta de las Cuevas. La muralla se puede ver desde la calle de las Cuevas, su recorrido atraviesa las parcelas actuales (Fig. 5.2.45 y Fig. 5.2.46). En este tramo, son reconocibles las marcas de hiladas de tapia en el paramento, aunque este haya sido restaurado. En la parte superior se ha reconstruido el adarve y las almenas, que se han realizado con una forma rectangular. Los espacios entre almenas son más estrechos que la anchura de la almena, en una proporción de 1 a 5 . Se han incluido en esta zona almenada saeteras colocadas en dos niveles, alternando la posición de las saeteras en cada nivel (Fig. 5.2.48). Las saeteras son cruciformes, muy similares a las encontradas en la puerta de la Judería. 


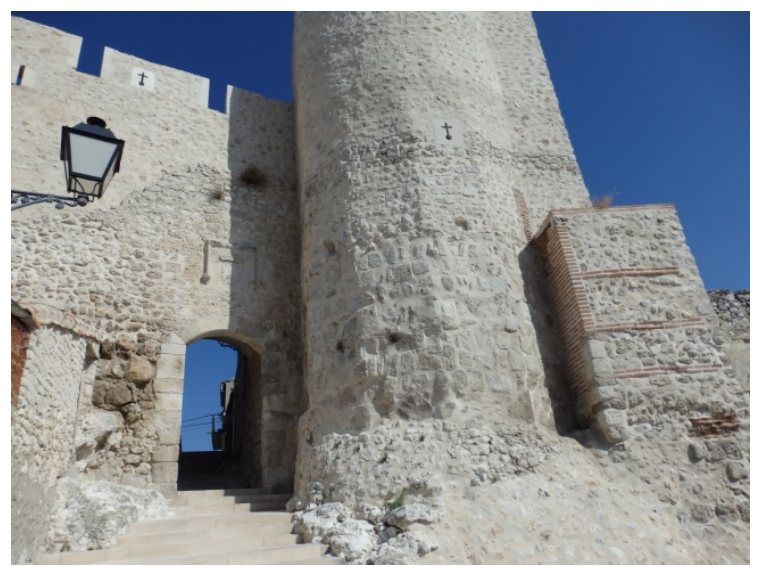

Fig. 5.2.41. Puerta de Santiago (P4) desde el exterior [A.S.E. 20/8/2014].

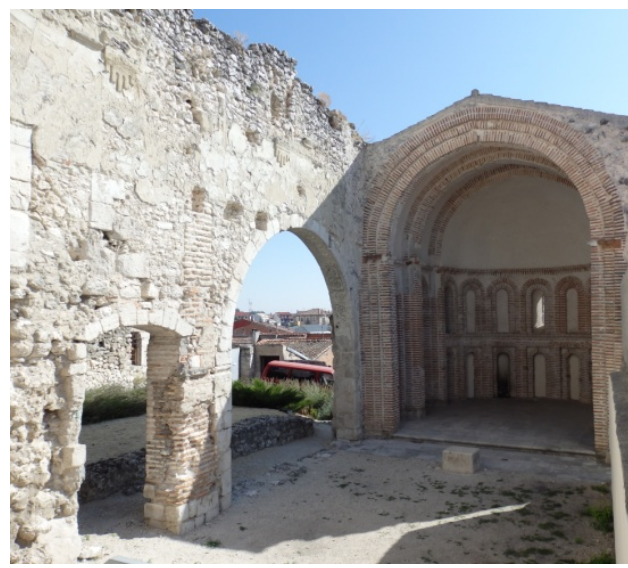

Fig. 5.2.43. Interior de la iglesia de Santiago [A.S.E. 20/8/2014].

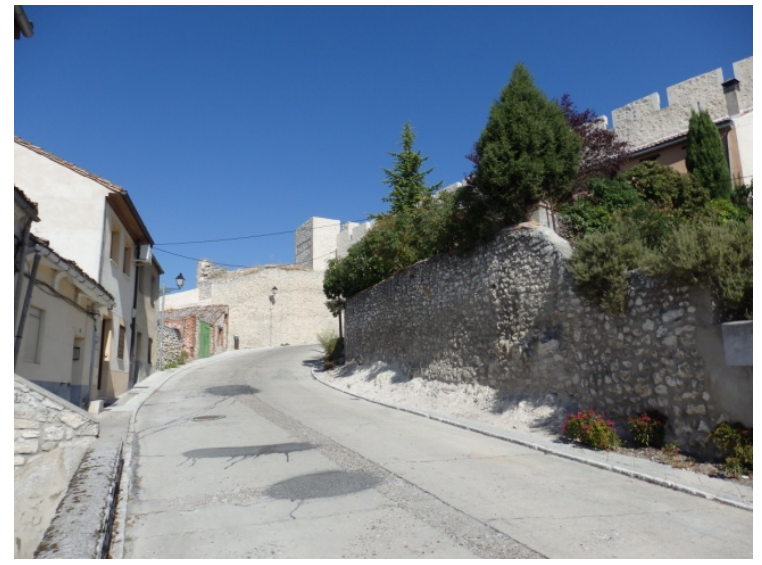

Fig. 5.2.45. Vista del lienzo P4-P5 desde la calle de las Cuevas [A.S.E. 20/8/2014].

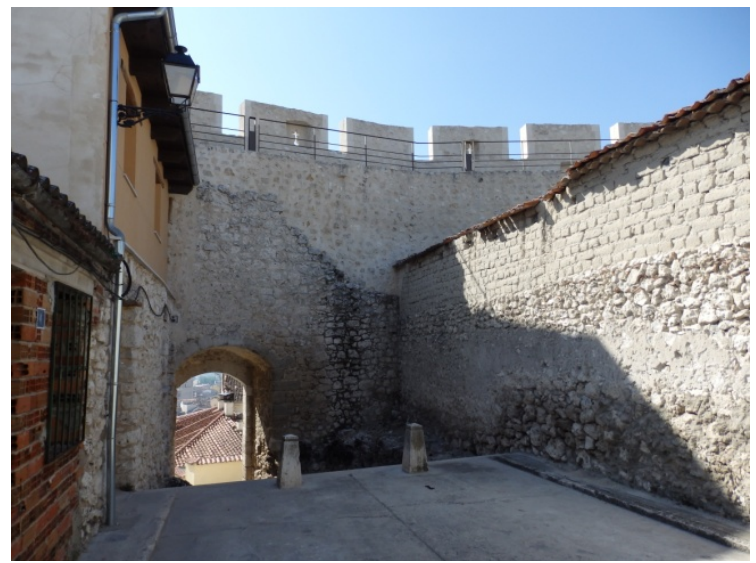

Fig. 5.2.42. Puerta de Santiago (P4) desde el interior [A.S.E. 20/8/2014].

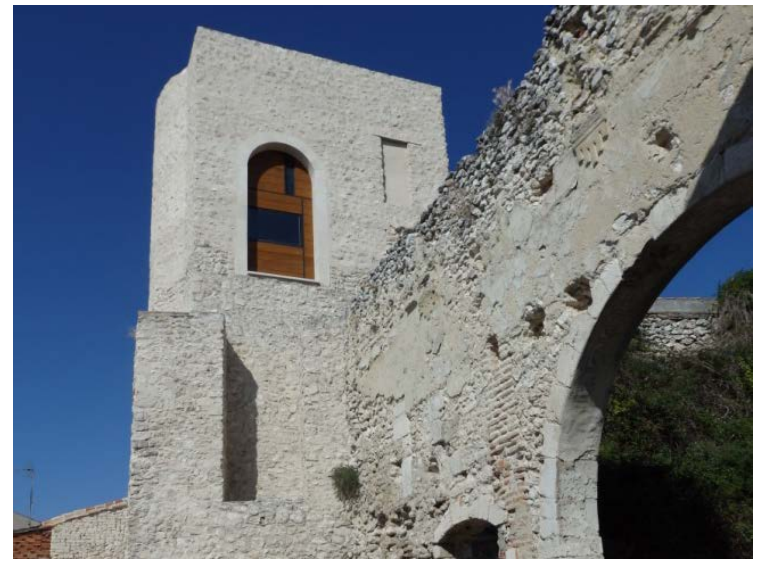

Fig. 5.2.44. Fachada este de la Torre T8 que está junto a la puerta de Santiago [A.S.E. 20/8/2014].

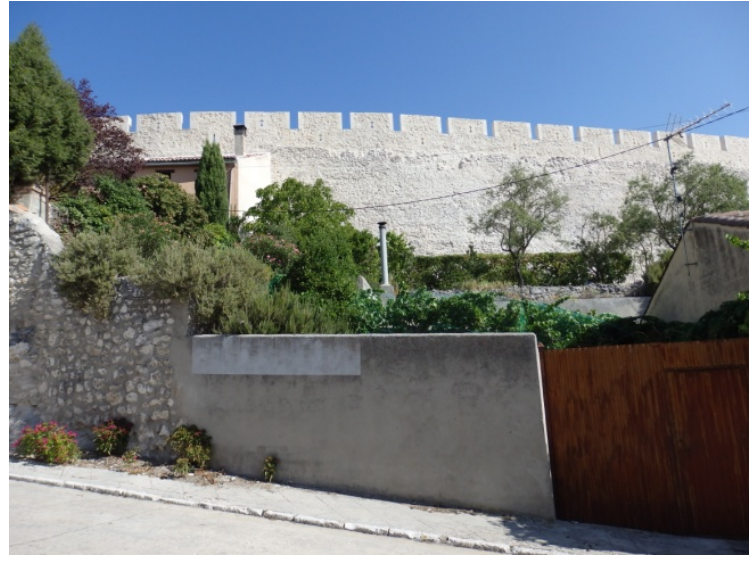

Fig. 5.2.46. Vista del lienzo P4-P5 desde la calle de las Cuevas [A.S.E. 20/8/2014]. 


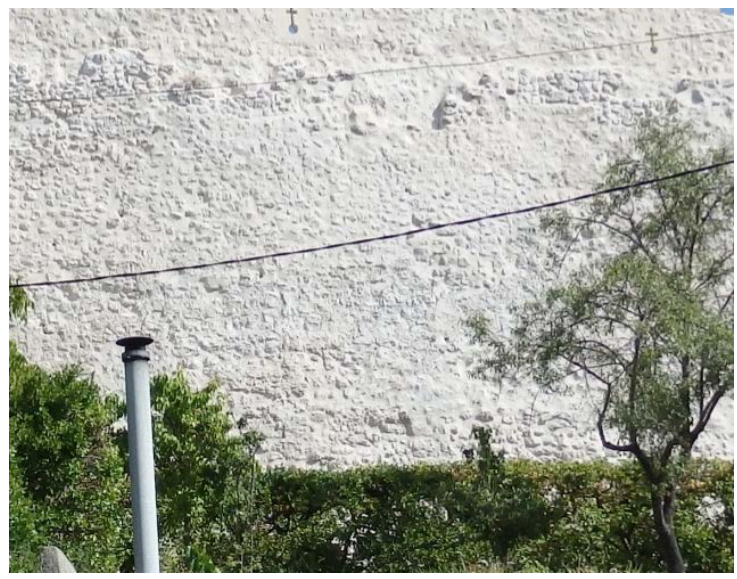

Fig. 5.2.47. Parte original del tramo P4-P5 [A.S.E. 20/8/2014].

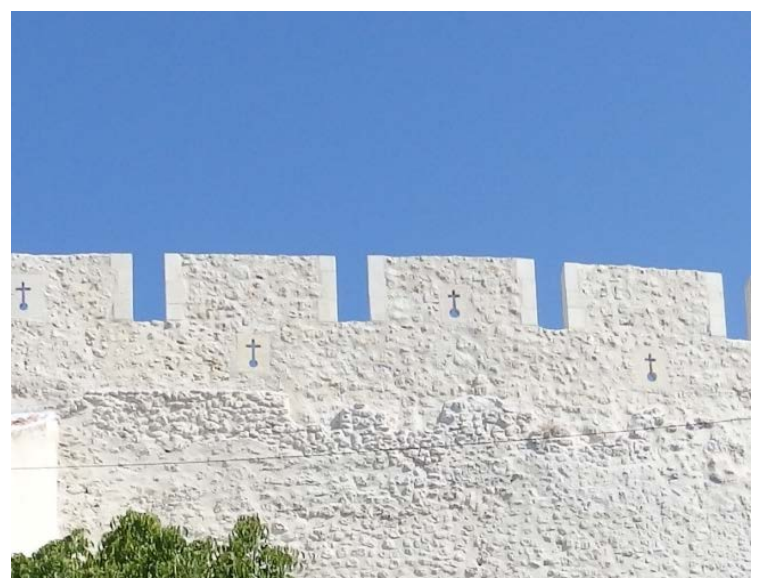

Fig. 5.2.48. Almenas reconstruidas en el tramo P4P5 [A.S.E. 20/8/2014].

La puerta de las Cuevas está dividida por el tramo del segundo recinto, que muere en la torre T9. Esta puerta fue completamente reconstruida en la restauración, cubriéndose el acceso con un dintel moderno, claramente diferenciado de las formas medievales (Fig. 5.2.49). La torre T9 es visible desde el exterior del segundo recinto (Fig. 5.2.50). Es una torre de planta rectangular, que parece afinarse según aumenta en altura. En la base se puede obs ervar un aparejo desordenado de piedra, con numerosos parches de mortero. Es visible en la esquina suroeste de la torre un refuerzo de piedras regulares, sillares de tamaño mediano (Fig. 5.2.51). A partir de una altura de $3 \mathrm{~m}$ aproximadamente, se observa la aparición de verdugadas de una sola hilada de ladrillo, separadas entre sí la altura de una tapia (Fig. 5.2.52). Es difícil situar las divisiones verticales de las tapias, pues la restauración tiende a borrar estos rastros. En las esquinas de la torre, se pueden ver machones dentados, cuyos dientes tienen la altura de la tapia. En la parte más baja, este dentado es más evidente, mientras que más arriba se desdibuja ligeramente. De acuerdo con fotos del año 2005, la parte superior de la esquina sureste de la torre estaba derruida, y ha sido reconstruida desde la cuarta tapia empezando a contar desde abajo.

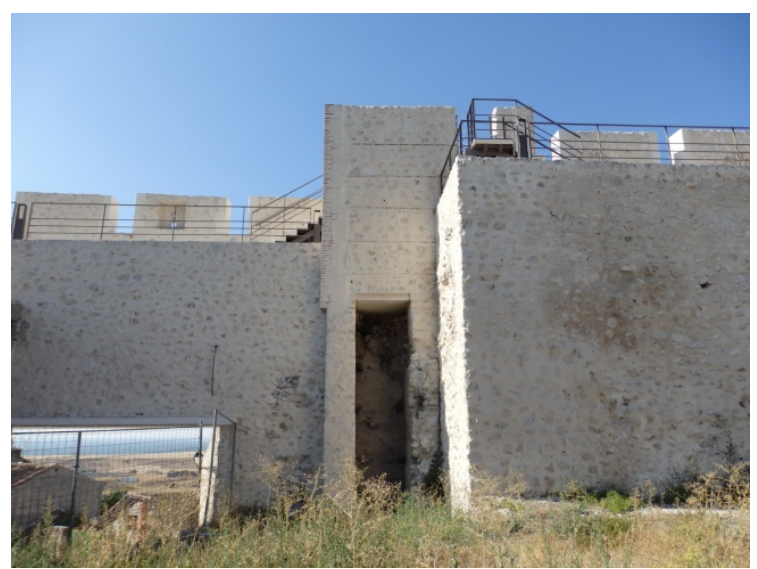

Fig. 5.2.49. Abajo a la izquierda, puerta de las Cuevas vista desde el interior. Se ve la parte interior de la torre T9 [A.S.E. 20/8/2014].

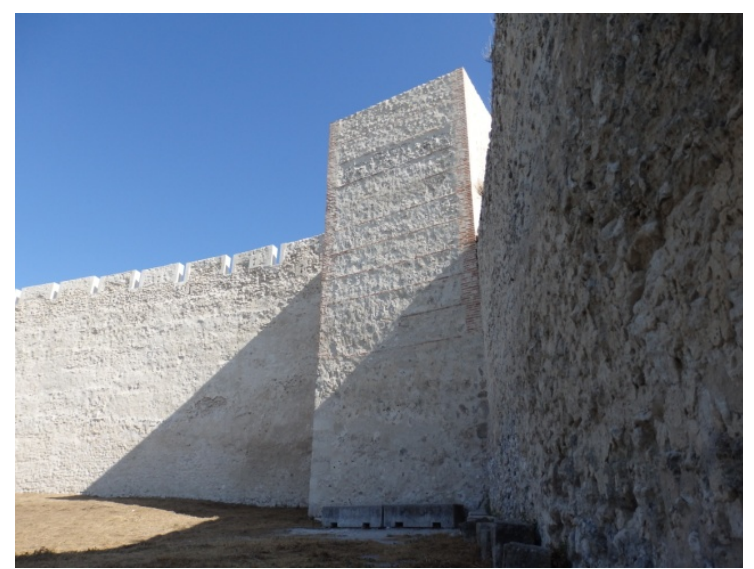

Fig. 5.2.50. Torre T9. A la derecha, el muro del segundo recinto impide ver el acceso de la puerta de las Cuevas. [A.S.E. 20/8/2014]. 


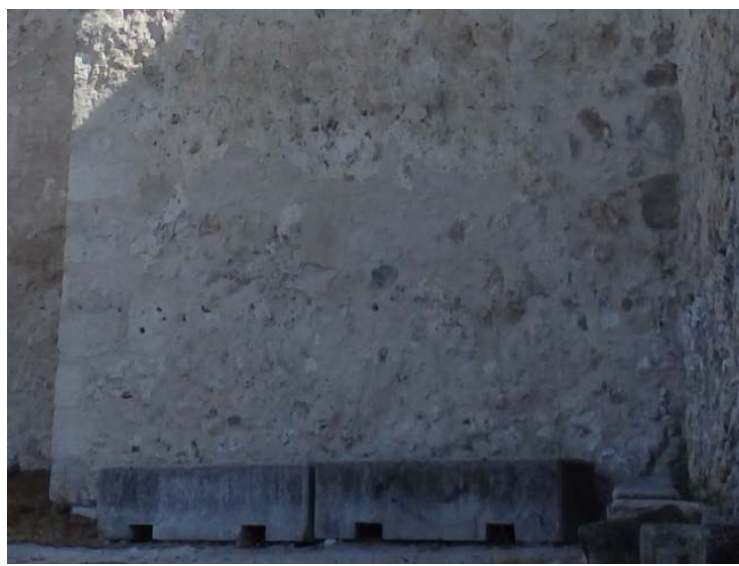

Fig. 5.2.51. Base de la torre T9 [A.S.E. 20/8/2014].

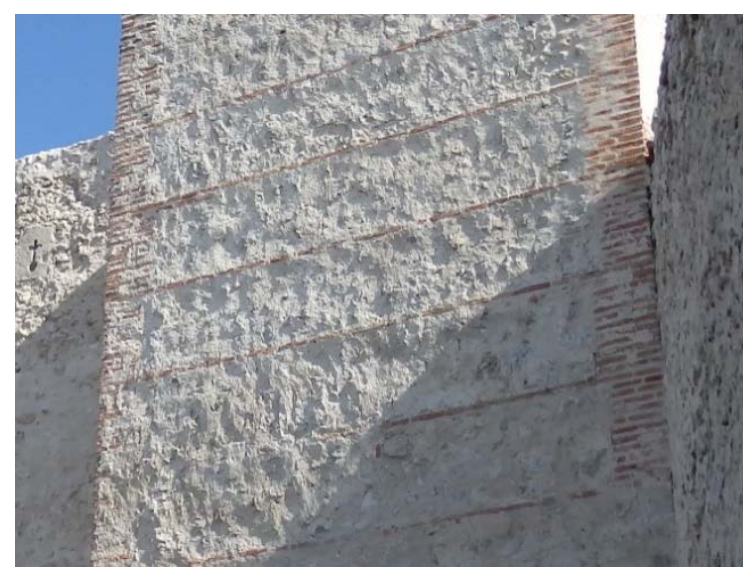

Fig. 5.2.52. Verdugadas de ladrillo y machones en la torre T9 [A.S.E. 20/8/2014].

Hacia el interior, la torre también presenta verdugadas de ladrillo y machones, con la misma forma y disposición visible en el alzado exterior. En la base, se observa de nuevo el cambio en los materiales empleados, desaparece el ladrillo. La restauración realizada parece querer mostrar en este punto la continuación del lienzo de muralla en el interior de la torre, pues se ha dejado un espacio para observar el paramento del lienzo. En este punto, es muy visible el empleo de la técnica del tapial (Fig. 5.2.49). La muralla continúa hacia el oeste desde la puerta de las Cuevas hasta el portillo de la Huerta. El lienzo en este tramo es continuo y presenta homogeneidad en $s \mathrm{u}$ construcción. Aunque la restauración tiende a ocultar los rastros constructivos, son visibles las hiladas de tapia. El aspecto de estas hiladas es irregular, y las divisiones entre tapias tienen direcciones y recorridos desordenados. En este tramo, las almenas se conservaban en parte, por lo que las partes reconstruidas son menores que en otras zonas. Se observan saeteras cruciformes, similares a las encontradas en otros tramos reconstruidos, así como en la puerta de la Judería. Se observa una saetera diferente, construida con dos piedras talladas en forma rectangular, cuya separación sirve de hueco. En la puerta de la judería también existe una saetera de esta forma. No es sencillo situar los mechinales de las tapias en este tramo.

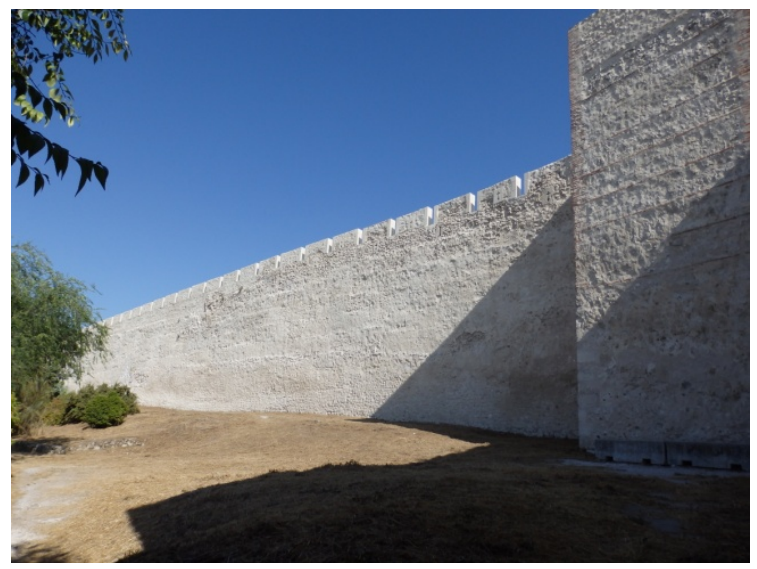

Fig. 5.2.53. Tramo T9-P6 visto desde el exterior del recinto [A.S.E. 20/8/2014].

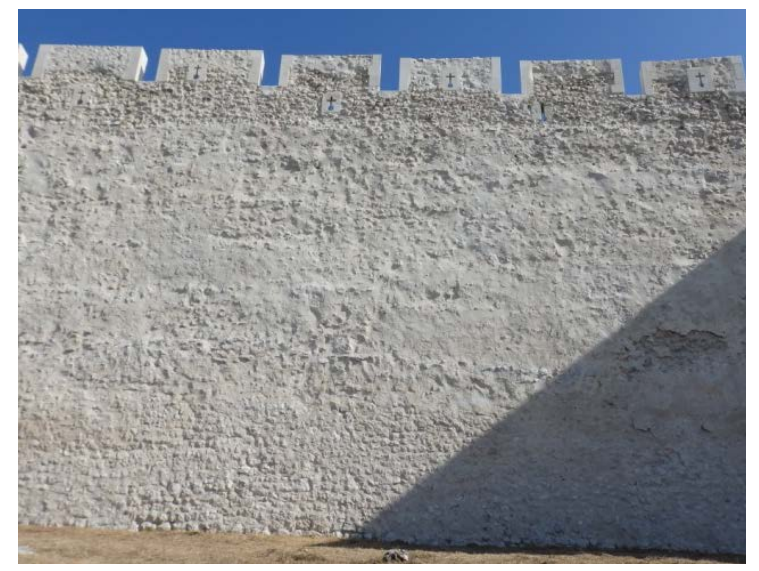

Fig. 5.2.54. Tramo T9-P6 visto desde el exterior del recinto [A.S.E. 20/8/2014]. 


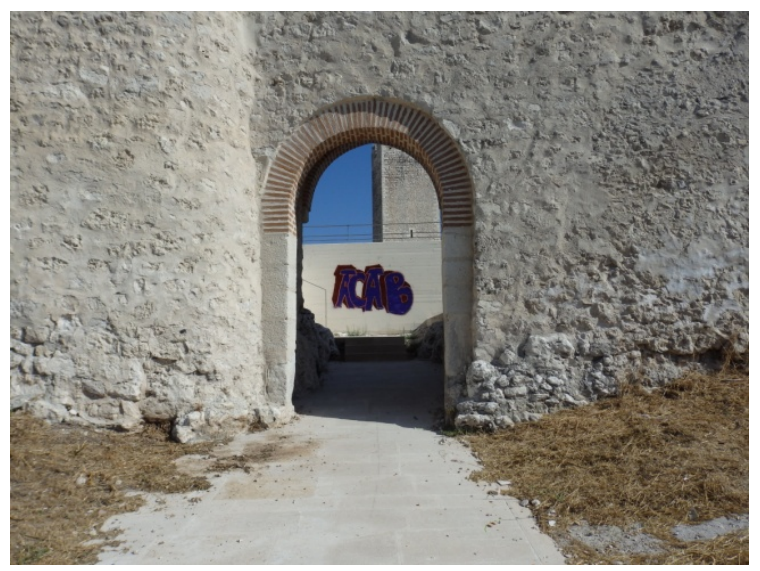

Fig. 5.2.55. Portillo de la Huerta (P6). Se observa la discontinuidad en el lienzo a la izquierda del portillo [A.S.E. 20/8/2014].

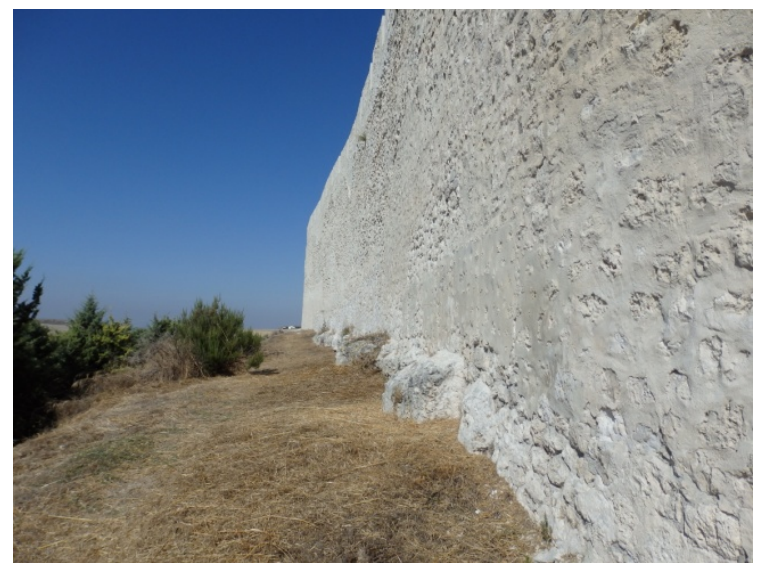

Fig. 5.2.56. Tramo P6-Castillo visto desde el exterior del recinto. En la base se observan rocas sobre las que se construye la muralla [A.S.E. 20/8/2014].

Al final de este tramo, se sitúa el portillo de la Huerta. Es un paso de pequeñas dimensiones. En la actualidad, se han reconstruido dos arcos de medio punto de ladrillo, uno a cada lado del lienzo. Se construyen sobre pilastras de sillares desde las que arrancan los arcos. En este punto, es de especial interés la discontinuidad que se aprecia a la izquierda del arco (Fig. 5.2.55). Este elemento saliente supone una interrupción en el recorrido del lienzo. Si observamos la posición de este portillo en el plano (Fig. 5.2.6), se puede que desde este punto parte el tercer recinto comentado en el apartado de "Tejido urbano". A través del portillo es visible la torre de la iglesia de San Martín, cuya relación con este tercer recinto es también significativa.

La construcción de esta zona no parece verse alterada en relación con el tramo anterior. El aspecto que presenta es muy similar, también homogeneizado por la restauración llevada a cabo. En fotos antiguas se observa que la muralla original conservaba gran altura en este tramo y son visibles almenas desdibujadas, que se han completado posteriormente en la restauración de 2008. En este punto, son visibles las rocas de apoyo de la muralla en algunos de los puntos de la base (Fig. 5.2.56).

Desde el portillo de la Huerta hasta el castillo continúa el primer recinto amurallado. Este tramo es perfectamente visible tanto desde el interior del recinto como desde el exterior. La comparación entre los dos alzados permite comprobar el desnivel que se produce entre el interior y el exterior del recinto. La altura de las murallas hacia el exterior es mayor que la altura visible desde el interior. Este desnivel también se hace patente en la puerta de Santiago, donde se construye una escalera en el mismo acceso para salvar el desnivel (Fig. 5.2.41 y Fig. 5.2.42).

En este tramo se aprecia que el sistema constructivo empleado es la tapia de mampostería. A diferencia del exterior, aquí es visible la posición de gran parte de los mechinales que alojaban las agujas del encofrado (Fig. 5.2.58). Las marcas de las hiladas de los bloques también son visibles, trabados entre sí. Finalmente, desde el castillo hasta la torre $\mathrm{T} 1$ se completa el primer recinto amurallado. Este tramo es visible también desde el exterior y desde el interior del recinto y de nuevo se observan rastros de tapia de mampostería. 


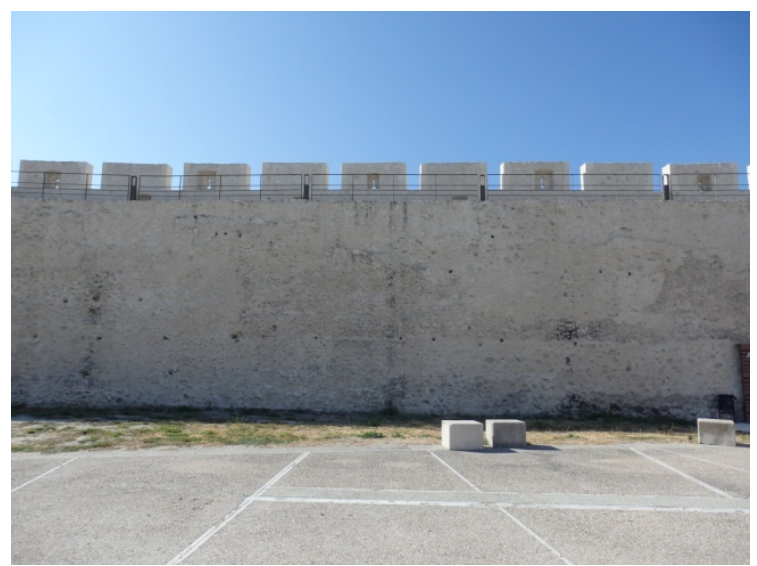

Fig. 5.2.57. Tramo del muro P6-Portillo nuevo visto desde el interior [A.S.E. 20/8/2014].

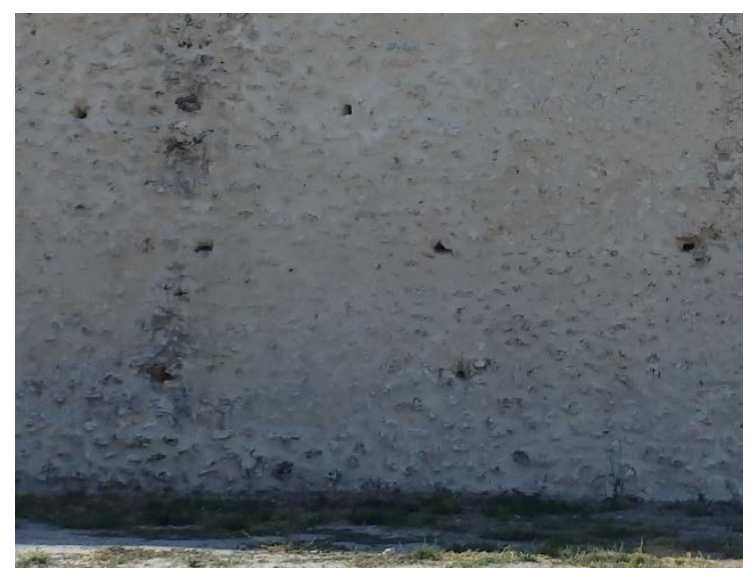

Fig. 5.2.58. Detalle de la base del muro desde el interior. Se pueden ver algunos de los mechinales de las tapias [A.S.E. 20/8/2014].

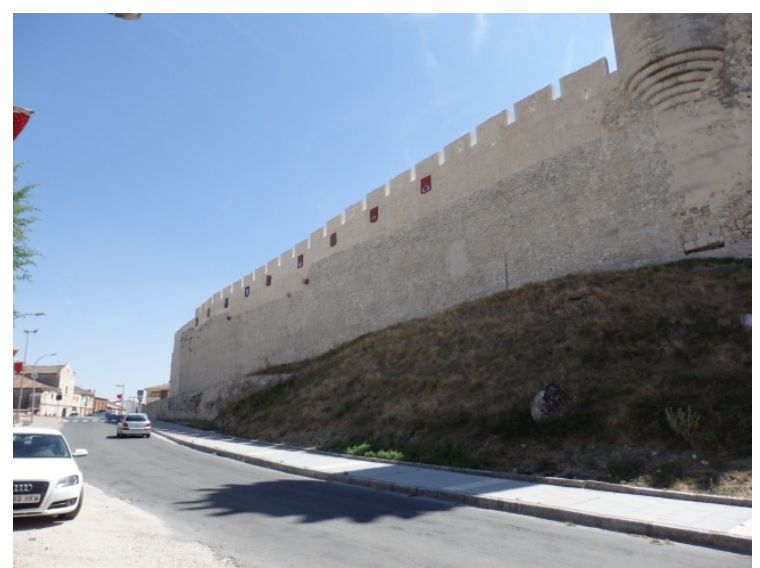

Fig. 5.2.60. Tramo C-T1 desde el exterior del recinto [A.S.E. 20/8/2014].
Fig. 5.2.59. Tramo C-T1 visible desde el interio del recinto [A.S.E. 20/8/2014].

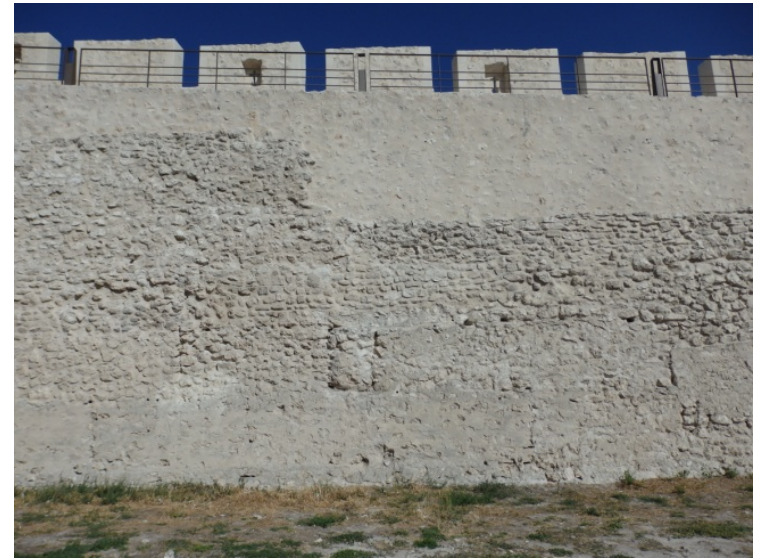

El segundo recinto parte junto a la puerta de la Judería, pasa por la puerta de San Andrés y rodea el casco antiguo en paralelo con la calle Nueva, es visible en la calle Herreros, también en la calle de la muralla, continúa en paralelo con la calle Ávila y la calle de Valladolid hasta el portillo de Exángel. En este punto se produce un encuentro con lo que parece un tramo de otro recinto. Continúa hacia el oeste formando un arco, hasta la puerta de las Cuevas.

Desde la puerta de la judería la muralla parte hacia el norte pasando entre el caserío y no es visible fácilmente. Poco antes de la puerta de San Andrés, la muralla hace un quiebro en ángulo recto hacia el este. Inmediatamente después se sitúa la puerta de San Andrés ya en la calle de la Magdalena. Se organiza en posición perpendicular al recorrido del lienzo, formando un quiebro. Desde el exterior (Fig. 5.2.61), la puerta ofrece un alzado en un único plano. El acceso no aparece flanqueado por dos torres adelantadas, como ocurre en otros casos. Está cubierto con un arco grande de $6,5 \mathrm{~m}$ de altura y $4,80 \mathrm{~m}$ de diámetro. Las dovelas son sillares de piedra con dimensiones poco habituales ya que tienen una proporción más plana. En las caras interiores del arco se ven sillares de mayor tamaño. Se observa el posible arranque de un arco más 
pequeño en la zona interior. Sobre el arco de piedra se construye un arco de ladrillo, con los ladrillos colocados a tizón. Sobre el arco se dibuja un marco rectangular de ladrillo con una sola hoja y colocado también a tizón. En la parte superior se observan restos de una fábrica de ladrillo aparejado a soga. En el centro se coloca un escudo de piedra enmarcado por molduras también de piedra. En el borde derecho se puede ver un machón de ladrillo con un dentado irregular. El alzado se construye con un aparejo de piedra irregular. No se observan marcas de encofrado o mechinales.

Desde el interior, se entiende más fácilmente la composición de la puerta (Fig. 5.2.63). Se observa en el lado derecho el volumen E1 que tiene una planta casi cuadrada de $3,26 \mathrm{~m} \times 3,70 \mathrm{~m}$ de lado aproximadamente y es completamente macizo, que fácilmente se puede i dentificar como torre, aunque realmente parece que tiene una función estructural para configurar el acceso. Es visible solo en la parte interior y no parece que originalmente sobresaliera por encima del acceso. En el lado izquierdo no se observa una torre tan claramente como el caso del volumen E1. En imágenes aéreas, en el solar inmediatamente al sur de la puerta aparece un elemento rectangular y alargado en planta, que enlaza con la continuación de la muralla. A pie de calle, este elemento no es identificable. Se observan volúmenes que podrían estar relacionados con la puerta, con forma semicircular. Desde el interior se observa que el arco de acceso se abre en un simple muro, no se trata de una zona abovedada que soporte un espacio en la zona superior.

Desde la calle Nueva, el volumen E1 es muy visible, alzándose sobre el caserío (Fig. 5.2.64) como si fuera una torre. Un pequeño tramo de la muralla parte hacia la izquierda con una longitud aproximada de $4 \mathrm{~m}$. La muralla continúa hacia el este siguiendo la dirección de la calle Nueva. Se sitúa en el interior de las parcelas, ya que estas han ido adosándose a la muralla desde el interior y exterior a lo largo del tiempo, una vez terminada su función defensiva. En este tramo se sitúa el portillo de la calle Nueva, que hacia el exterior es un arco de medio punto sin torres que lo flanqueen. Tiene un acceso quebrado en el interior, organizado de forma perpendicular al lienzo de la muralla. Desde el exterior, se puede observar el muro perpendicular al lienzo que sobresale por encima del lienzo (Fig. 5.2.67). Sobre este muro se encuentra el segundo arco que da acceso al interior del recinto. El convento de la calle de la Magdalena, en el interior del recinto amurallado, colinda con este acceso.

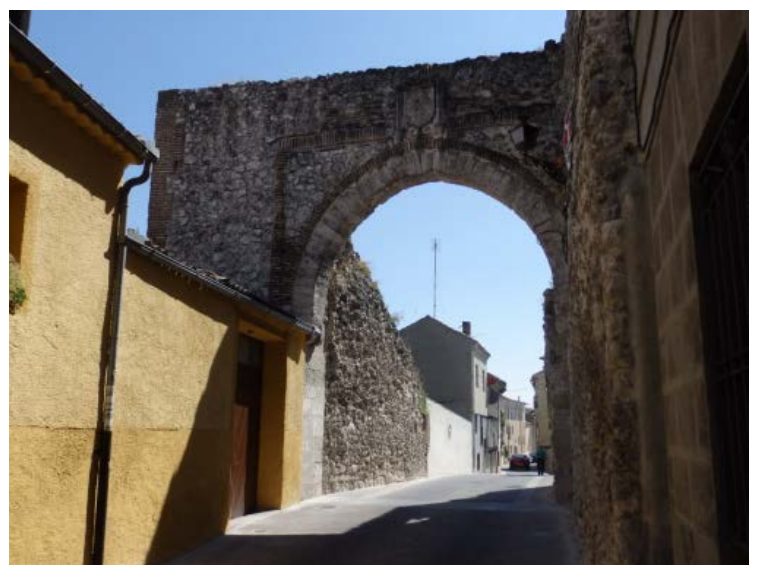

Fig. 5.2.61. Puerta de San Andrés vista desde el exterior [A.S.E. 20/8/2014].

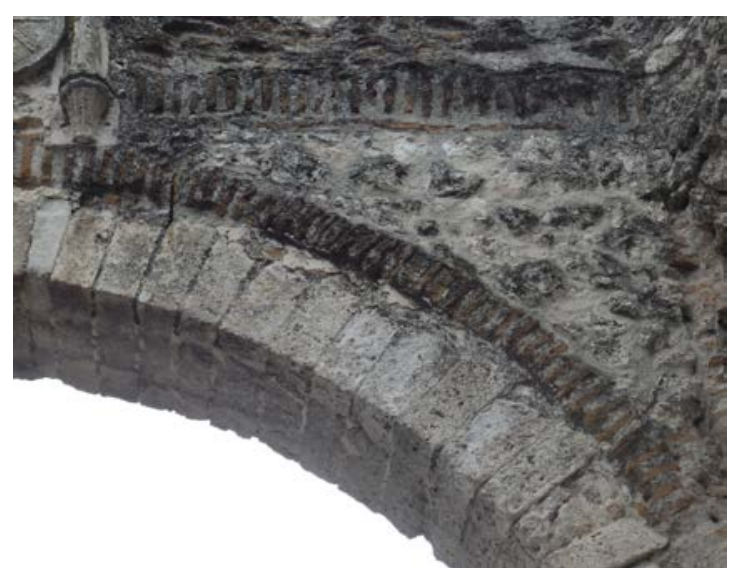

Fig. 5.2.62. Detalle del arco de la puerta de San Andrés [A.S.E. 12/5/2016]. 


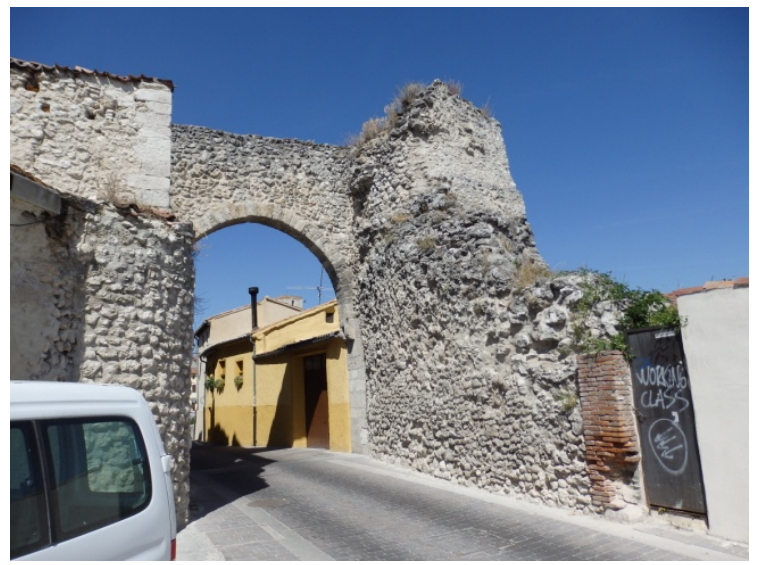

Fig. 5.2.63. Puerta de San Andrés vista desde el interior [A.S.E. 20/8/2014].

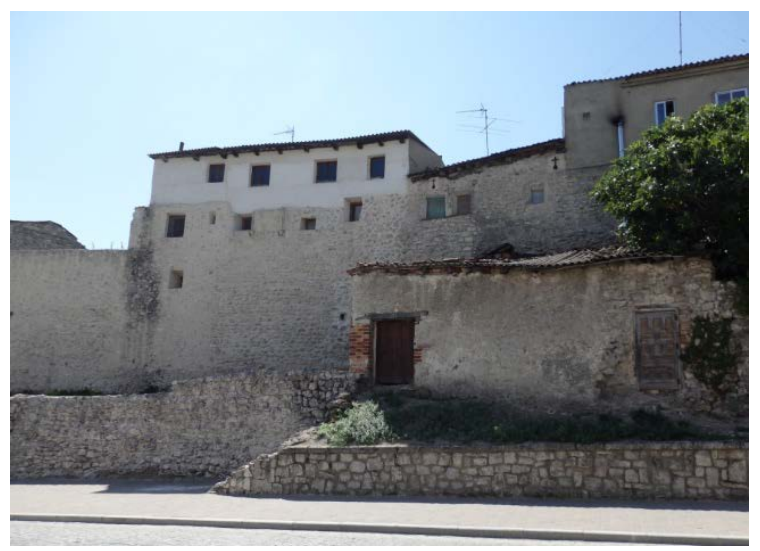

Fig. 5.2.65. Muralla en el interior de las parcelas, en la calle Nueva. Los edificios han utilizado la muralla en su construcción. Dos saeteras son visibles en una de las construcciones [A.S.E. 20/8/2014].

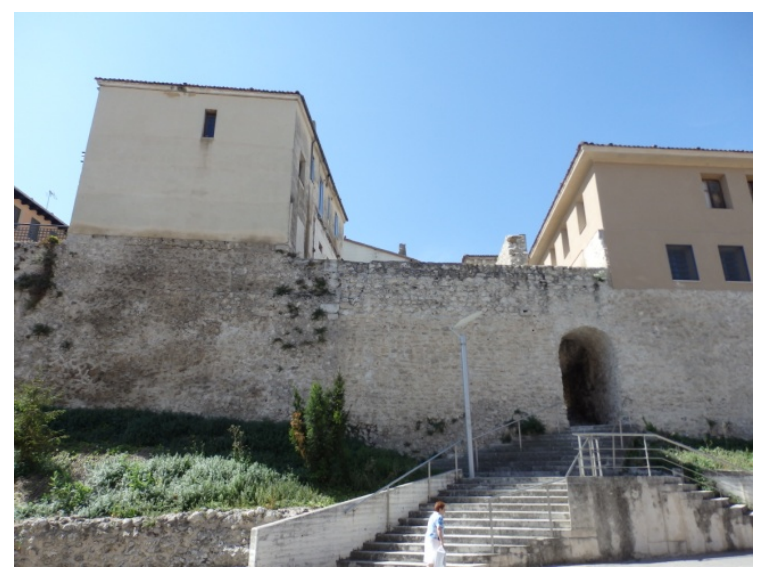

Fig. 5.2.67. Puerta de la calle Nueva [A.S.E. 20/8/2014].

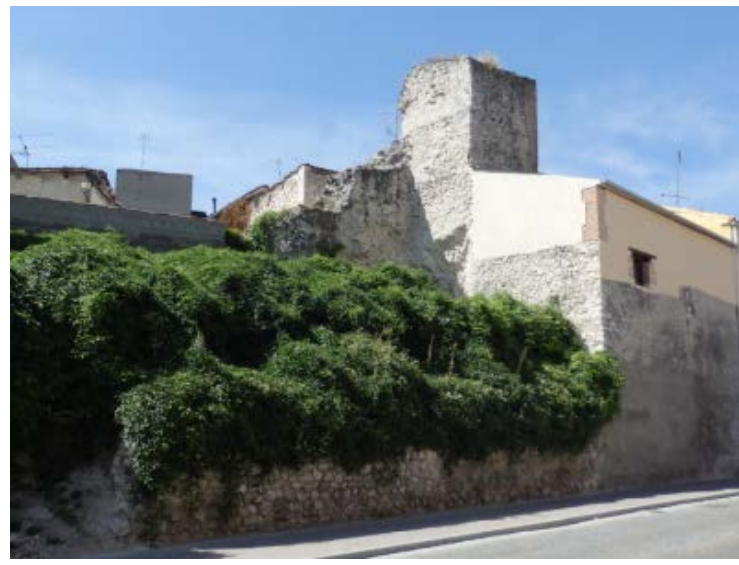

Fig. 5.2.64. Volumen E1 de la puerta de San Andrés vista desde la calle Nueva, con aspecto de torre [A.S.E. 20/8/2014].

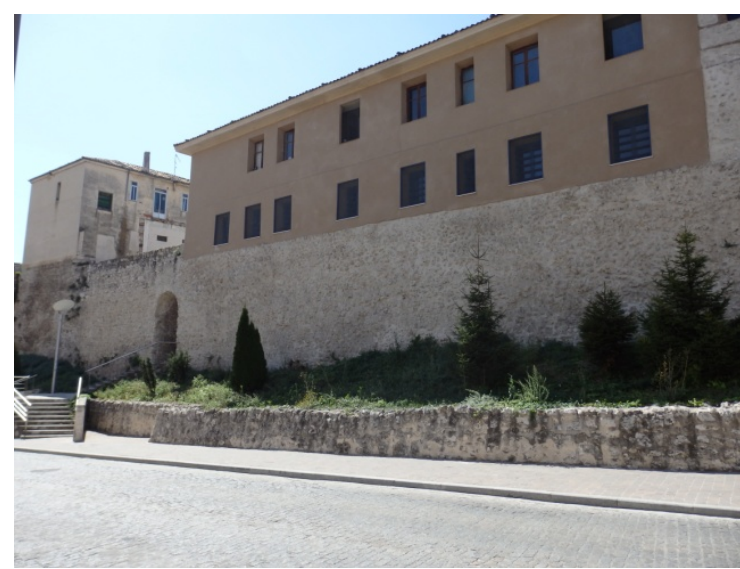

Fig. 5.2.66. Tramo de muralla en la calle Nueva. A la derecha puerta de la calle Nueva [A.S.E. 20/8/2014].

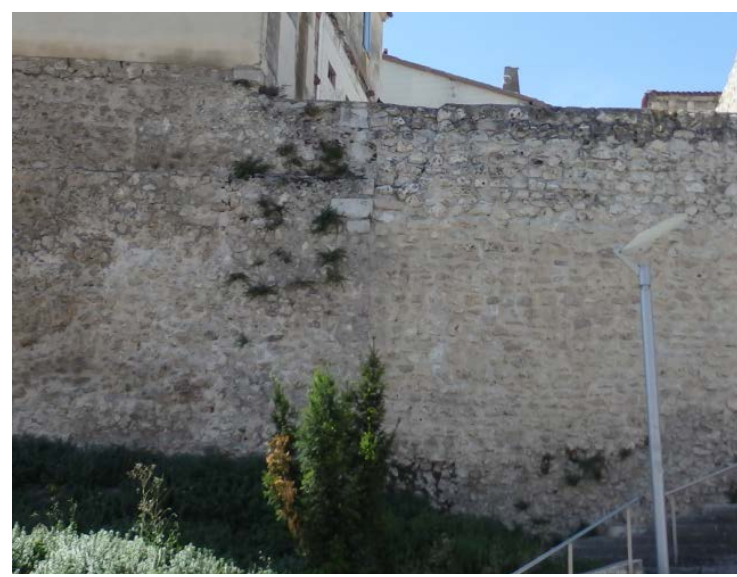

Fig. 5.2.68. Discontinuidad vertical en el tramo de muralla, visible desde el exterior a la 
Las murallas en las Comunidades de Villa y Tierra de la Diócesis de Segovia en los siglos XI a XIII. Técnica y sistemas constructivos de la arquitectura defensiva medieval.

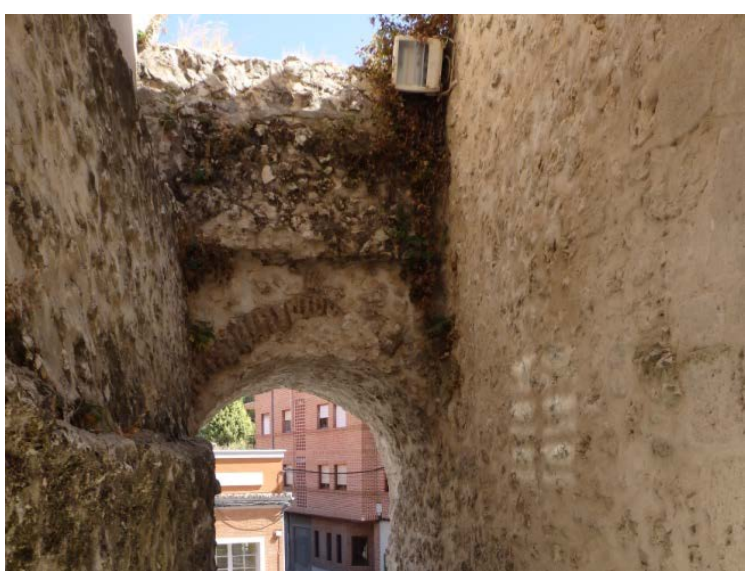

Fig. 5.2.69. Interior de la puerta de la calle Nueva [A.S.E. 20/8/2014].

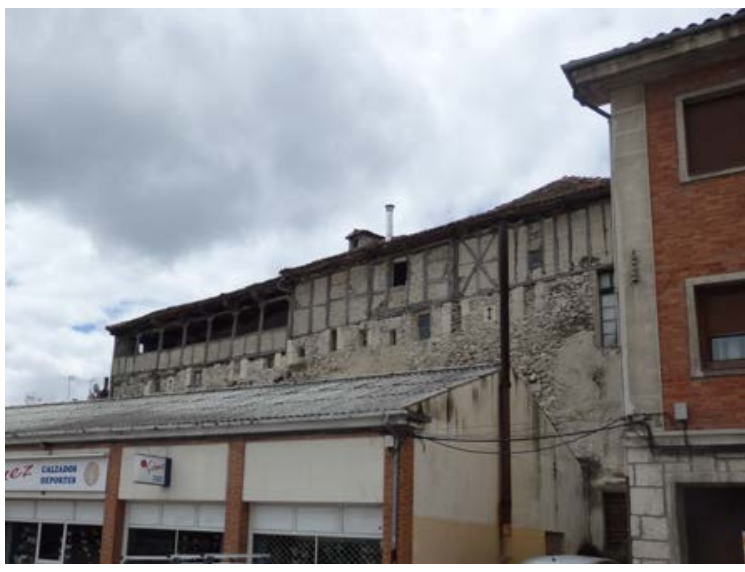

Fig. 5.2.71. Nave adosada a la muralla en la calle Nueva frente a la calle Hojalatas [A.S.E. 20/8/2014].

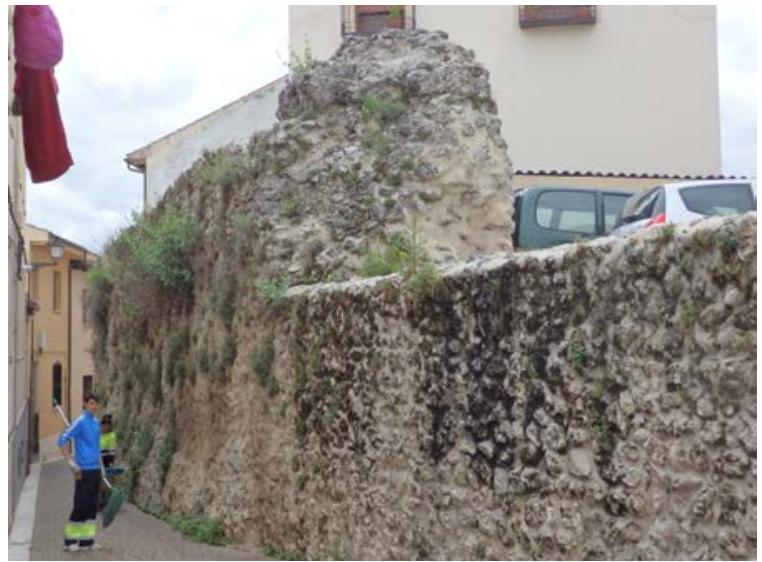

Fig. 5.2.73. Tramo de muralla visible en la calle Herreros [A.S.E. 12/5/2016]. izquierda de la puerta de la calle Nueva [A.S.E. 20/8/2014].

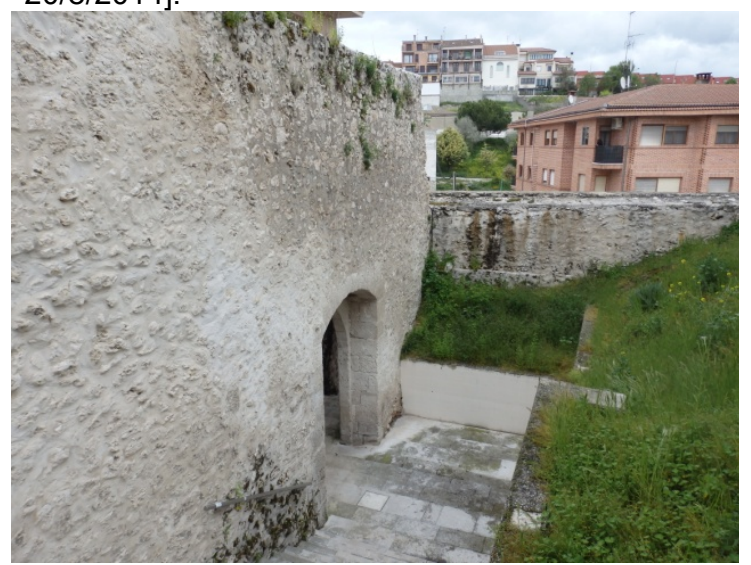

Fig. 5.2.70. Muro perpendicular al lienzo de muralla, a la altura de la puerta de la calle nueva [A.S.E. 20/8/2014].

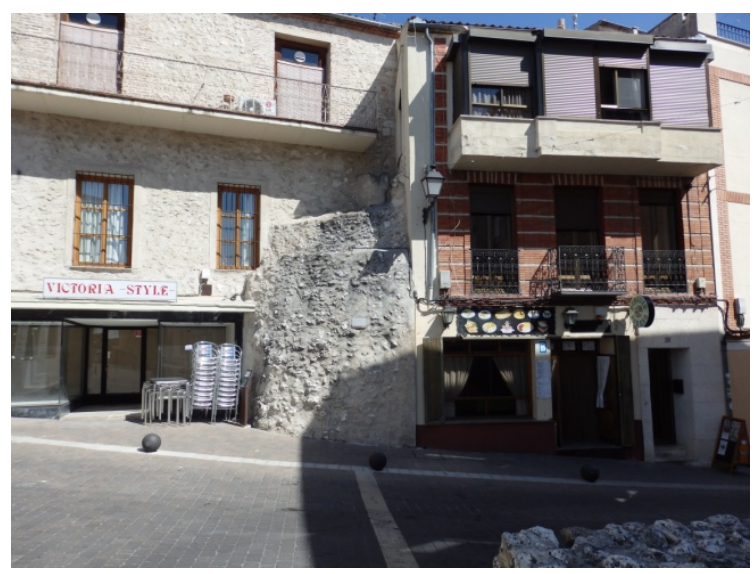

Fig. 5.2.72. Restos de la puerta de Carchena [A.S.E. 20/8/2014].

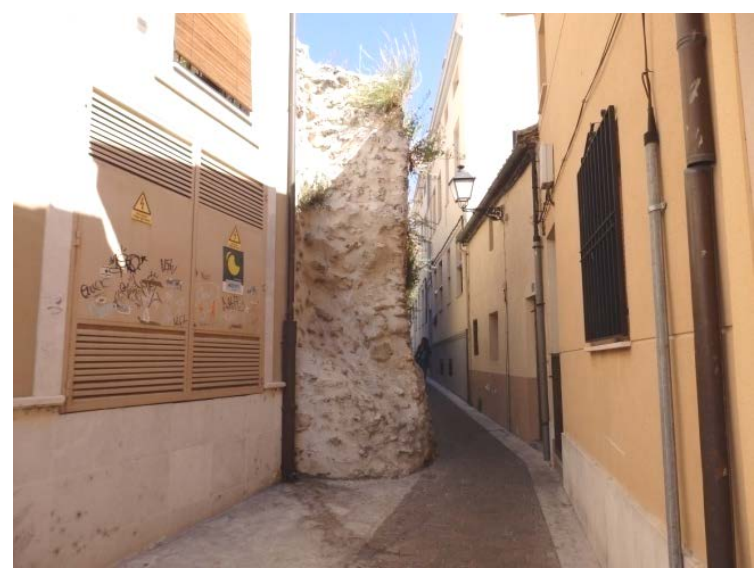

Fig. 5.2.74. Tramo en la calle de la Muralla [A.S.E. 20/8/2014]. 


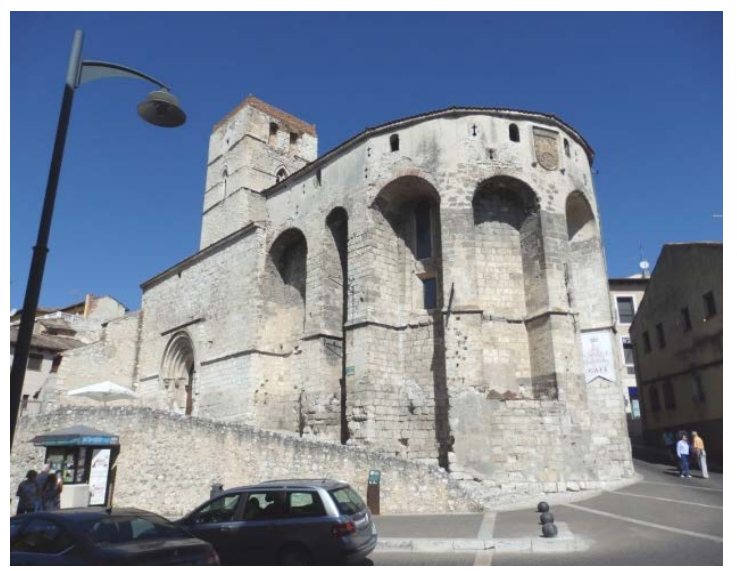

Fig. 5.2.75. Iglesia de San Pedro, situada en la posición de la puerta con el mismo nombre [A.S.E. 20/8/2014].

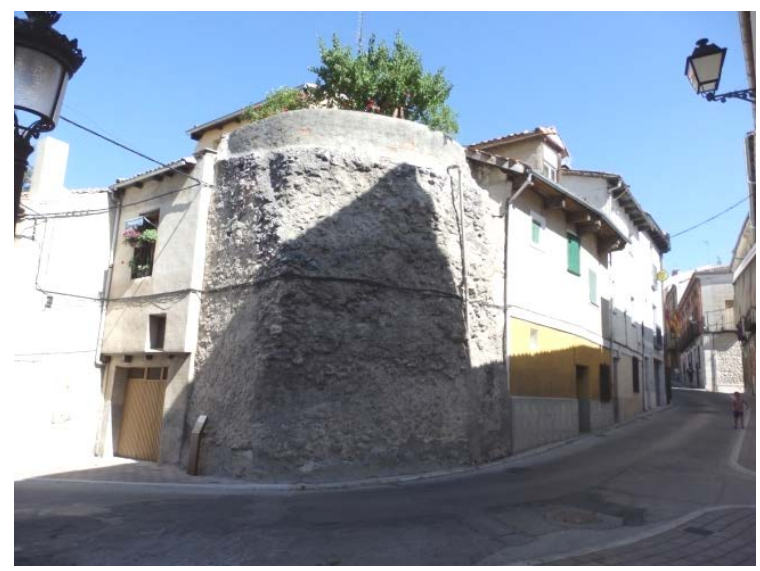

Fig. 5.2.76. Restos de la puerta de la Trinidad [A.S.E. 20/8/2014].

Un poco más al este de la puerta de la calle Nueva, hasta la puerta de Carchena, la muralla se oculta entre el caserío. Hasta ahora, las parcelas exteriores no están completamente ocupadas por la edificación. Algo más al este de la calle Lavaderos, las construcciones se adosan por el exterior a la muralla y también sobre ella (Fig. 5.2.71).

En la posición de la puerta de $\mathrm{C}$ archena, se observan restos de la muralla (Fig. 5.2.72). La puerta ya no existe de forma reconocible. Parte de los restos que quedan se encuentran encajados entre dos nuevas construcciones que han ido ganando terreno a la muralla. Estos restos continúan en la calle Herreros, donde es posible ver el grosor de la muralla, que alcanza los $2 \mathrm{~m}$. En esta parte, los restos son de escasa altura y sólo en algunos puntos se conservan partes de mayor altura, donde es posible ver el empleo de la técnica del tapial (Fig. 5.2.73). La muralla continúa por la calle de la Muralla, ocupando la mitad de su sección a lo largo de $15 \mathrm{~m}$ de calle (Fig. 5.2.74). Los restos de muralla desaparecen en este punto.

En la zona de la desaparecida puerta de San Pedro se encuentra la iglesia de San Pedro (Fig. 5.2.75). Esta iglesia tiene un aspecto hermético y sólido. Desde la ubicación de la iglesia hacia el oeste, se suceden algunos tramos de muralla dentro de las parcelas urbanas. En el encuentro con la calle Trinidad, se sitúa la puerta de la Trinidad, de la que quedan escasos restos en la actualidad (Fig. 5.2.76).

Desde la calle de los Hornos y ascendiendo por la calle Exángel, se encuentra un recoleto parque urbano situado en una parcela urbana. En Catastro, este espacio no figura como público, aunque el acceso es libre. Desde esta parcela es posible ver parte de la muralla, que contiene un arco de acceso (Fig. 5.2.77). Tiene 2,60m de anchura y casi alcanza los $6 \mathrm{~m}$ de altura, tiene forma apuntada. En la base se construye con piedra mampuesta y algún sillar pequeño en los bordes. El arco se realiza con ladrillo. En esta zona se observa una base en el muro que se construye con piedras irregulares de tamaño medio. El aparejo es desordenado (Fig. 5.2.78). 


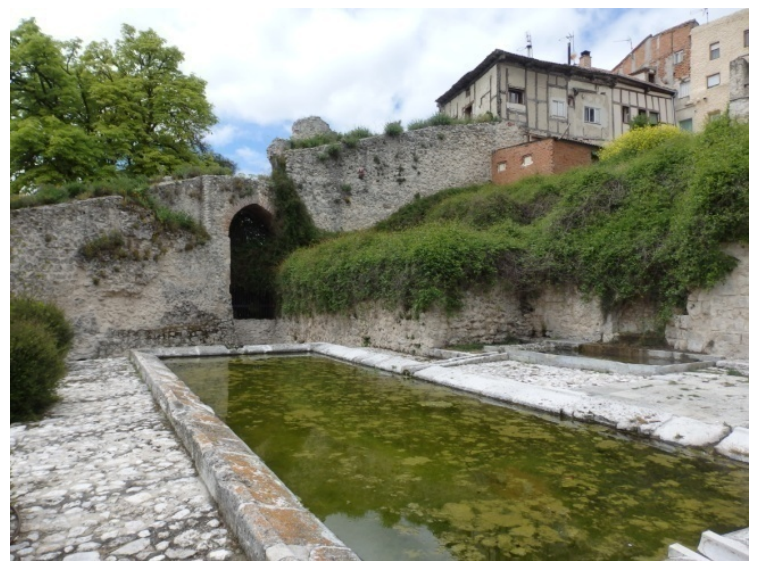

Fig. 5.2.77. Tramo en la zona de Exángel. Se observa al fondo el portillo de Exángel [A.S.E. $12 / 5 / 2016]$.

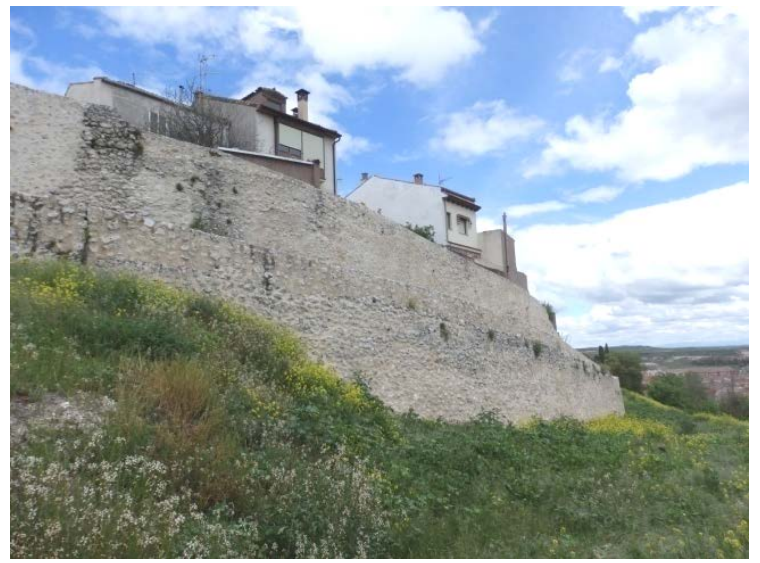

Fig. 5.2.79. Tramo entre el portillo de Exángel y la puerta de las Cuevas [A.S.E. 12/5/2016].

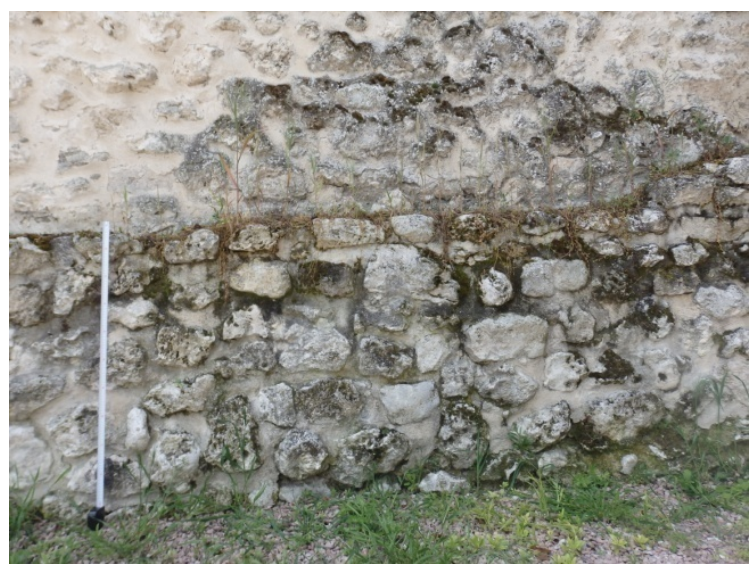

Fig. 5.2.78. Detalle de la base del muro. A la izquierda, el metro marca la longitud de $1,00 \mathrm{~m}$ [A.S.E. 12/5/2016].

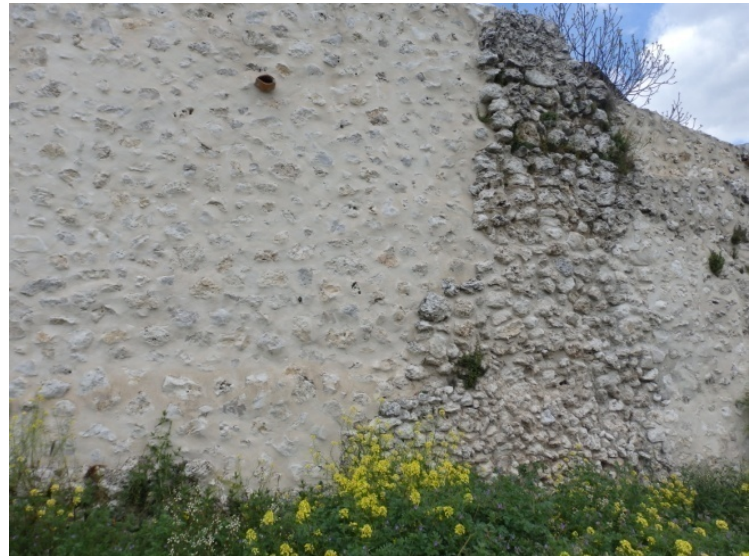

Fig. 5.2.80. Detalle del tramo, donde se observa una zona con diferencia en el acabado [A.S.E. $12 / 5 / 2016]$.

\subsubsection{Características de los principales elementos descritos}

A continuación, la Tabla 5.2.1 muestra las principales características de las torres, y las pone en relación con las puertas. Diez de las dieciséis torres del recinto forman parte de las puertas. Solo seis torres, T1, T1a, T1b, T4, T7 y T10, de las cuales las tres primeras forman un conjunto y están muy vinculadas al acceso de $S$ an Basilio, son torres de flanqueo, independiente de cualquier acceso.

Tabla 5.2.1. Características y dimensiones de torres y su relación con las puertas. Leyenda: * ${ }^{*}$ in restos suficientes, en fucsia=dato probable. Fuente: Elaboración propia.

\begin{tabular}{|c|c|c|c|c|c|c|}
\hline 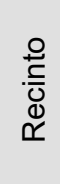 & 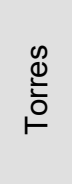 & $\begin{array}{l}\frac{n}{\pi} \\
\frac{\pi}{2} \\
\frac{1}{2} \\
0\end{array}$ & Nombre asociado & Tipo de puerta & Sección de torre & $\begin{array}{c}\text { Dimensiones } \\
\text { torres } \\
\text { (Diámetro } \varnothing, \\
\text { Fondo F, Ancho } \\
\text { A) }\end{array}$ \\
\hline \multirow[b]{2}{*}{ R1 } & $\mathrm{T} 1$ & - & - & - & Semicircular & $\varnothing 8 \mathrm{~m}$ \\
\hline & T1a & - & - & - & Rectangular & $\mathrm{A} 4,90 x \mathrm{~F} 2,45 \mathrm{~m}$ \\
\hline
\end{tabular}




\begin{tabular}{|c|c|c|c|c|c|c|}
\hline 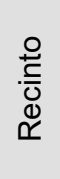 & $\stackrel{\infty}{\stackrel{\infty}{\circ}}$ & $\begin{array}{l}\frac{0}{\pi} \\
\stackrel{0}{0} \\
\Phi \\
0\end{array}$ & Nombre asociado & Tipo de puerta & Sección de torre & $\begin{array}{l}\text { Dimensiones } \\
\text { torres } \\
\text { (Diámetro } \varnothing \text {, } \\
\text { Fondo F, Ancho } \\
\text { A) }\end{array}$ \\
\hline \multirow{14}{*}{ R1 } & $\mathrm{T} 1 \mathrm{~b}$ & - & - & - & Rectangular & $\mathrm{A} 6,33 \times \mathrm{F} 3,07 \mathrm{~m}$ \\
\hline & $\mathrm{T} 2$ & \multirow{2}{*}{$\mathrm{P} 1$} & \multirow{2}{*}{ Puerta de San Basilio } & \multirow{2}{*}{$\begin{array}{l}\text { Entre torres de } \\
\text { sección distinta }\end{array}$} & Rectangular & $\mathrm{A} 2,90 \times \mathrm{F} 3,98 \mathrm{~m}$ \\
\hline & T3 & & & & Semicircular & $\varnothing 5 \mathrm{~m}$ \\
\hline & - & $\mathrm{P} 2$ & Puerta de la Judería & Arco en el lienzo & - & - \\
\hline & $\mathrm{T} 4$ & - & Torre de los Daza & - & Rectangular & A5,75xF6,15m \\
\hline & T5 & \multirow[b]{2}{*}{ P3 } & \multirow{2}{*}{ Puerta de San Martín } & \multirow{2}{*}{$\begin{array}{l}\text { Entre torres } \\
\text { simétricas }\end{array}$} & Rectangular & $\mathrm{A} 4,34 \mathrm{xF} 4,97 \mathrm{~m}$ \\
\hline & T6 & & & & Rectangular & $\begin{array}{c}\mathrm{A} 8,57 \times A 8,15 \\
m\end{array}$ \\
\hline & $\mathrm{T} 7$ & - & Torre de la Muela & - & Rectangular & $\mathrm{A} 4,03 \mathrm{xF} 3,80 \mathrm{~m}$ \\
\hline & T8 & \multirow{2}{*}{ P4 } & \multirow{2}{*}{ Puerta de Santiago } & \multirow{2}{*}{ Un sola torre } & Poligonal & $\varnothing 3,86 \mathrm{~m}$ \\
\hline & T8a & & & & Rectangular & $A 2,52 x$ \\
\hline & T9 & P5 & Puerta de las Cuevas & Dintel moderno & Rectangular & A5,41xF5,24m \\
\hline & - & P6 & $\begin{array}{c}\text { Portillo de la Huerta o del } \\
\text { Castillo }\end{array}$ & Arco en el lienzo & - & - \\
\hline & - & PN1 & Paso nuevo junto a P1 & Dintel moderno & - & - \\
\hline & - & PN2 & $\begin{array}{l}\text { Paso nuevo junto a } \\
\text { castillo }\end{array}$ & Dintel moderno & - & - \\
\hline \multirow{8}{*}{$\mathrm{R} 2$} & - & $\mathrm{P} 7$ & Portillo de Exángel & Arco en el lienzo & - & - \\
\hline & T10 & - & - & - & Rectangular & $\mathrm{A} 6,22 \mathrm{xF} 4,57 \mathrm{~m}$ \\
\hline & T11 & P8 & $\begin{array}{c}\text { Puerta de la Trinidad o de } \\
\text { Santa Marina }\end{array}$ & $\begin{array}{l}\text { Entre torres } \\
\text { simétricas }\end{array}$ & Rectangular & A5,16xF2,27m \\
\hline & - & P9 & Puerta de San Pedro & * & - & - \\
\hline & - & P10 & Puerta de Carchena & * & - & - \\
\hline & - & P11 & Portillo de la calle Nueva & Con zaguán & - & - \\
\hline & E1 & \multirow{2}{*}{$\mathrm{P} 12$} & \multirow{2}{*}{ Puerta de San Andrés } & \multirow{2}{*}{$\begin{array}{c}\text { Acceso perpendicular } \\
\text { a dirección lienzo }\end{array}$} & Rectangular & $\mathrm{A} 3,26 \times \mathrm{F} 3,70 \mathrm{~m}$ \\
\hline & E2 & & & & * & $A^{*} \times 4,27 m$ \\
\hline
\end{tabular}

Tabla 5.2.2. Características y dimensiones de los tramos de muralla. Fuente: Elaboración propia.

\begin{tabular}{|c|c|c|c|c|}
\hline $\begin{array}{l}\stackrel{0}{\stackrel{C}{0}} \\
\mathbb{d} \\
\propto 1\end{array}$ & Tramo & Reconstrucción & Estado & $\begin{array}{c}\text { Longitud } \\
\text { (E Existente / D } \\
\text { Desaparecido / M } \\
\text { Moderno) }\end{array}$ \\
\hline \multirow{6}{*}{$\mathrm{R} 1$} & P1-T4 & No & Desaparecido & $\mathrm{D} 144,47 \mathrm{~m}$ \\
\hline & T4-P2 & No & Existente & $\mathrm{E} 66,83 \mathrm{~m}$ \\
\hline & P2-F1 & No & Existente & E29,57m \\
\hline & P3-F2 & No & Existente & $\mathrm{E} 38,60 \mathrm{~m}$ \\
\hline & P3-T7 & No, en proyecto & Existente & $\mathrm{E} 39,26 \mathrm{~m}$ \\
\hline & T7-P4 & No, en proyecto & Existente & E35,85m \\
\hline
\end{tabular}


Las murallas en las Comunidades de Villa y Tierra de la Diócesis de Segovia en los siglos XI a XIII. Técnica y sistemas constructivos de la arquitectura defensiva medieval.

\begin{tabular}{|c|c|c|c|c|}
\hline 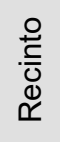 & Tramo & Reconstrucción & Estado & $\begin{array}{l}\text { Longitud } \\
\text { (E Existente / D } \\
\text { Desaparecido / M } \\
\text { Moderno) }\end{array}$ \\
\hline \multirow{7}{*}{ R1 } & P4-P5 & $\begin{array}{l}\text { Recrecido con nuevo } \\
\text { almenado y adarve } \\
\text { transitable }\end{array}$ & Existente & $\mathrm{E} 135,68 \mathrm{~m}$ \\
\hline & P5-P6 & $\begin{array}{l}\text { Recrecido con nuevo } \\
\text { almenado y adarve } \\
\text { transitable }\end{array}$ & Existente & $E 85,63$ \\
\hline & P6-PN2 & $\begin{array}{l}\text { Recrecido con nuevo } \\
\text { almenado y adarve } \\
\text { transitable }\end{array}$ & Existente & $\mathrm{E} 104,27 \mathrm{~m}$ \\
\hline & PN2-C & Completa & Moderno & $\mathrm{M} 30,20 \mathrm{~m}$ \\
\hline & C-PN1 & $\begin{array}{c}\text { Recrecido con nuevo } \\
\text { almenado y adarve } \\
\text { transitable }\end{array}$ & Existente & $\mathrm{E} 56,69 \mathrm{~m}$ \\
\hline & PN1-T1a & Completa & Moderno & $\mathrm{M} 30,29 \mathrm{~m}$ \\
\hline & T1b-T2 & $\begin{array}{l}\text { Recrecido con adarve } \\
\text { transitable }\end{array}$ & Existente & $\mathrm{E} 14,89 \mathrm{~m}$ \\
\hline \multirow{8}{*}{$\mathrm{R} 2$} & T9-T10 & No & Existente & $\mathrm{E} 162,39 \mathrm{~m}$ \\
\hline & T10-P7 & No & Existente & $\mathrm{E} 63,91 \mathrm{~m}$ \\
\hline & P7-P8 & No & Existente & $\mathrm{E} 88,40 \mathrm{~m}$ \\
\hline & P8-P9 & & Restos intermitentes & $\begin{array}{c}\mathrm{D} 13,48 \mathrm{~m} / \mathrm{E} 22,09 \mathrm{~m} / \\
\mathrm{D} 17,09 \mathrm{~m} / \mathrm{E} 29,05 \mathrm{~m} / \\
\mathrm{D} 19,89 \mathrm{~m} / \mathrm{E} 19,85 \mathrm{~m}\end{array}$ \\
\hline & P9-P10 & No & Restos intermitentes & D $47,84 \mathrm{~m} / \mathrm{E} 76,78 \mathrm{~m}$ \\
\hline & P10-P11 & No & Restos intermitentes & $\begin{array}{c}\mathrm{D} 15,05 \mathrm{~m} / \mathrm{E} 14,94 \mathrm{~m} / \\
\mathrm{D} 9,63 \mathrm{~m} / \mathrm{E} 29,70 \mathrm{~m} / \\
\mathrm{D} 23,26 \mathrm{~m} / \mathrm{E} 18,67 \mathrm{~m} / \\
\mathrm{D} 31,14 \mathrm{~m} / 97,30 \mathrm{~m}\end{array}$ \\
\hline & P11-P12 & No & Restos intermitentes & $\mathrm{E} 87,11 \mathrm{~m} / \mathrm{D} 40,00 \mathrm{~m}$ \\
\hline & P12-P2 & No & Existente & $\mathrm{E} 72,40 \mathrm{~m}$ \\
\hline
\end{tabular}

Las almenas son otro elemento de interés en el recinto. La forma que tienen no se ha encontrado en los otros casos estudiados. Las almenas son visibles en el recinto primero y en el segundo, con una lógica constructiva similar. En el castillo se encuentran saeteras similares a las visibles en el almenado. En la mayor parte del recorrido de la muralla, las almenas se han perdido o se encontraban derruidas. En fotografías antiguas se observa la existencia de almenas en el tramo P5-P6. Son visibles almenas originales en el tramo P10-P11 (Fig. 5.2.81). La forma del merlón es alargada, de 2,00-2,10 m, más ancha en comparación con el hueco que ronda los 35$40 \mathrm{~cm}$. La altura de la almena es de $1,12 \mathrm{~m}$.

Los merlones están cerrados en sus extremos por dos sillares de forma rectangular, colocados en posición vertical uno sobre otro. Los sillares tienen una longitud de 40$60 \mathrm{~cm}$ y una anchura de $35-40 \mathrm{~cm}$. A la altura de las almenas, se construyen saeteras cruciformes que se alternan en dos niveles, una cada dos merlones en el centro del mismo y otra bajo los merlones alternos (Fig. 5.2.82). El sillar-saetera tiene una 
longitud de $60 \mathrm{~cm}$ por un ancho de $40 \mathrm{~cm}$. Se ha reproducido este ritmo en la restauración de 2008 que ha reconstruido el almenado en los tramos desde la puerta de San Basilio (P1) hasta la puerta de Santiago (P4).

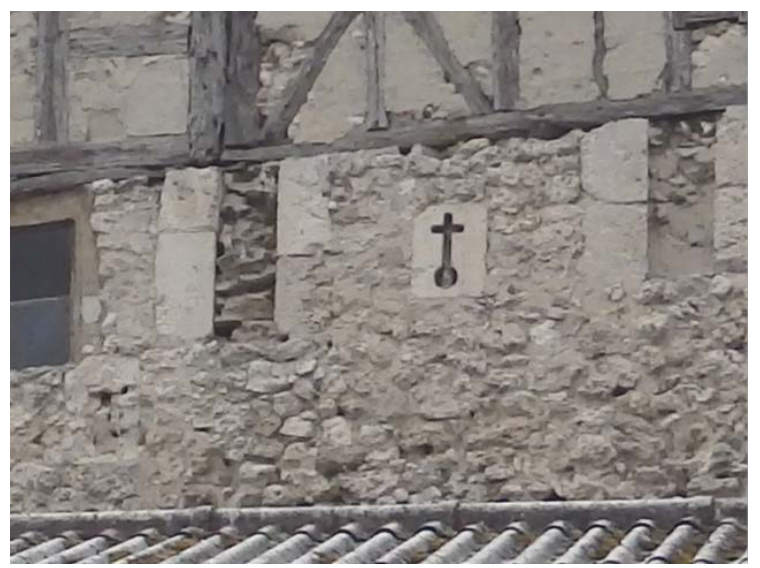

Fig. 5.2.81. Almenas en el tramo P10-P11. A la izquierda es visible una saetera parcialmente oculta en nivel inferior [A.S.E. 12/5/2016]

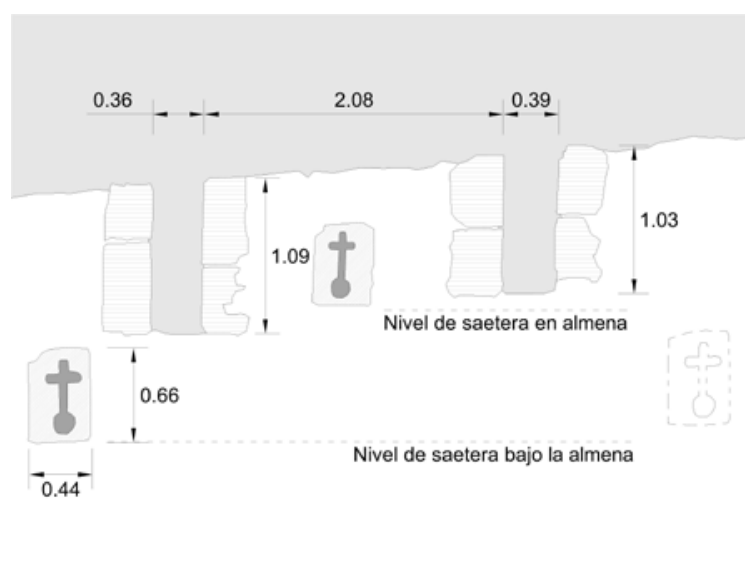

Fig. 5.2.82. Esquema de la configuración y dimensiones de las almenas en el tramo P10-P11. Fuente: Elaboración propia.

Los dibujos topográficos realizados para la restauración de 2008, elaborados por Topoinca S.L. y cuyo acceso se facilitó por los arquitectos Fernando Nieto y Jesús Nieto, arrojan información acerca de las almenas existentes antes de la restauración. En el tramo P6-P7, se observa el perfil desdibujado de las almenas y se cuentan 4 saeteras con la misma forma que las descritas para el tramo P10-P11. También la anchura de almenas es similar, cercana a los 2,00m.

En el tramo P8-P9, situado en el interior de las parcelas, se ve la existencia de almenas diferentes a las descritas anteriormente. En el dibujo, su perfil se encuentra desdibujado por la erosión y el deterioro, pero es posible identificar la proporción entre la anchura de las almenas y su separación, que se aproxima a 1. Las almenas tienen una anchura cercana a $100 \mathrm{~cm}$, y se separan entre sí aproximadamente $90 \mathrm{~cm}$.

También es necesario señalar la presencia de una modesta barbacana a lo largo del segundo recinto amurallado. Consiste en un muro que discurre en paralelo a la muralla, a una di stancia de $5-6 \mathrm{~m}$ del exterior de la misma. La anchura del muro es escasa, inferior a $1 \mathrm{~m}$. Existe en varios puntos de la villa: al norte, se ve desde la calle Nueva; también en la zona sur, a partir de la puerta de las Cuevas; al este, discurre otro tramo en el interior de parcelas (Fig. 5.2.6). 
Las murallas en las Comunidades de Villa y Tierra de la Diócesis de Segovia en los siglos XI a XIII. Técnica y sistemas constructivos de la arquitectura defensiva medieval.

\subsubsection{Análisis constructivo}

\subsubsection{Soluciones constructivas presentes en la muralla}

Se muestra a continuación un resumen de las soluciones constructivas encontradas en la muralla ${ }^{39}$. La primera y más empleada es la tapia de mampostería encofrada (Fig. 5.2.83, Fig. 5.2.84) sin verdugadas. En cada uno de los lienzos se aprecian diferencias en la ejecución de los mechinales o en las dimensiones de las tapias. La tapia de mampostería encofrada con una verdugada de ladrillo simple se encuentra en una de las torres de la puerta de San Basilio (T3) y en la torre T1, ambas de planta circular. En la torre T1 la solución constructiva se emplea en toda la altura de la torre, mientras que en la torre T3, se construye sobre una base de sillería de $3 \mathrm{~m}$ de altura. La tapia mixta con machones de ladrillo y con una verdugada simple de ladrillo se encuentra en una de las torres de la puerta de San Basilio (T2) y en la torre de la puerta de las Cuevas (T9); también se observa esta técnica en las torres T1a y T1b. En la torre T2 se ubica sobre una base de sillería de tres metros de altura; en el caso de la torre T9, se el empleo de esta técnica se construye sobre una base de más de 3,50m. También se observa esta solución en lo alto de la torre T4. En el elemento T8a (Fig. 5.2.88), una pieza adosada que podría haber formado parte de la antigua iglesia de Santiago, se observa una doble verdugada de ladrillo y una suerte de machón de ladrillo, de poca entidad por su estrecha anchura. Este elemento aparece adosado a la torre T8, pero no comparte solución constructiva. El sillarejo se emplea en algunas partes de la muralla, como la zona entre la puerta de San Martín (P3) y la puerta de Santiago (P4).

En la zona más cercana a la puerta de San Martín, el aspecto de la piedra es de mampuestos. No se observan mechinales en la fábrica, y por esta razón no se afirma que se trate de mampostería encofrada. No obstante, viendo que el sistema mayoritario empleado en el resto de la muralla es la mampostería encofrada, no parece prudente descartar que aquí también se emplee esta técnica. En la zona más cercana a la torre T7, la fábrica de piedra tiene hiladas regulares y la piedra puede identificarse como sillarejo. La mampostería es visible en varios puntos de la muralla, sin embargo, en muchos de es tos casos se trata de reparaciones posteriores realizadas con mampuestos o tapia de mampostería donde se han borrado las huellas de las tapias y sus mechinales están ocultos (Fig. 5.2.90). De forma general, no se considera que se empleara esta técnica en la construcción de la muralla sin la utilización del tapial.

\footnotetext{
${ }^{39}$ En las fotos a continuación (Fig. 84-Fig. 97) aparece un metro que tiene la longitud real de 1,00m. En algunas imágenes ( Fig. 87, Fig. 93), el metro aparece cortado, cada marca roja tiene una longitud de $10 \mathrm{~cm}$.
} 


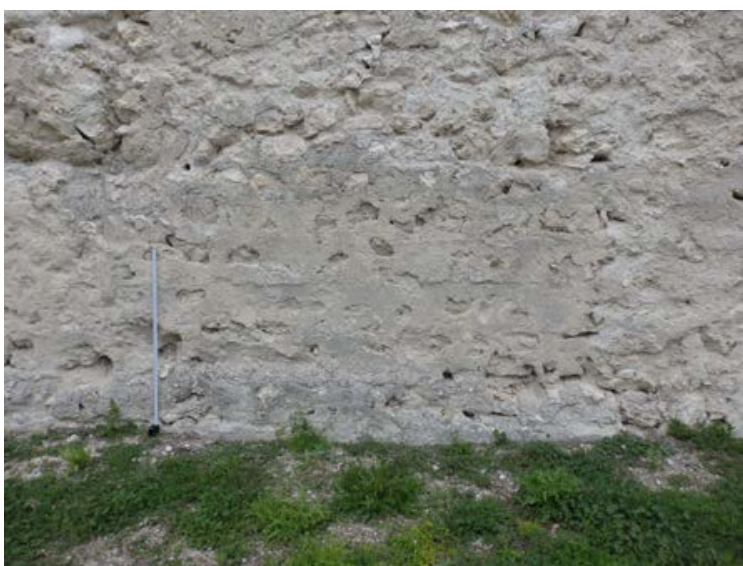

Fig. 5.2.83. Tapia en zona tramo al norte del castillo [A.S.E. 12/5/2016].

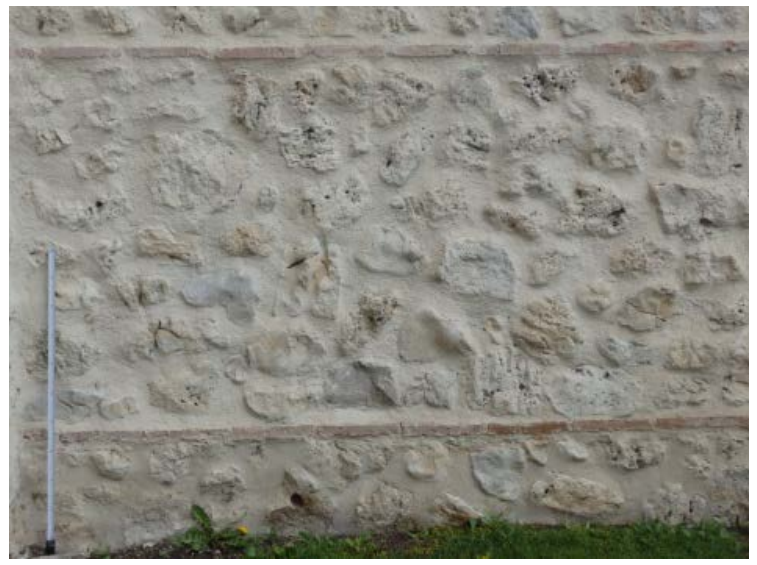

Fig. 5.2.85. Tapia con verdugada de ladrillo en torre T1b [A.S.E. 12/5/2016].

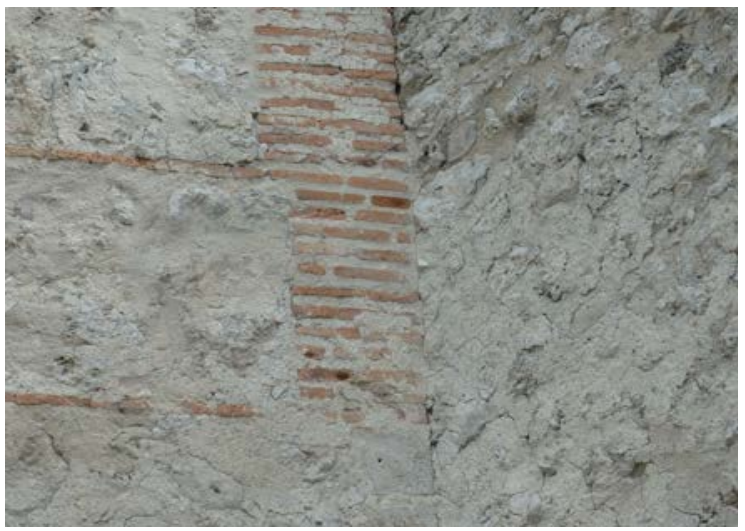

Fig. 5.2.87. Tapia mixta con verdugada simple en torre T9 [A.S.E. 12/5/2016].

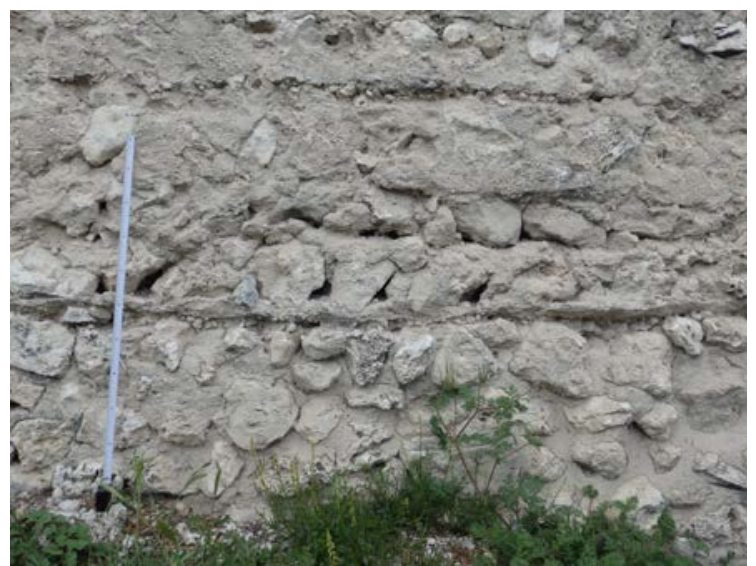

Fig. 5.2.84. Tapia junto al paso del Ferial [A.S.E. 12/5/2016].

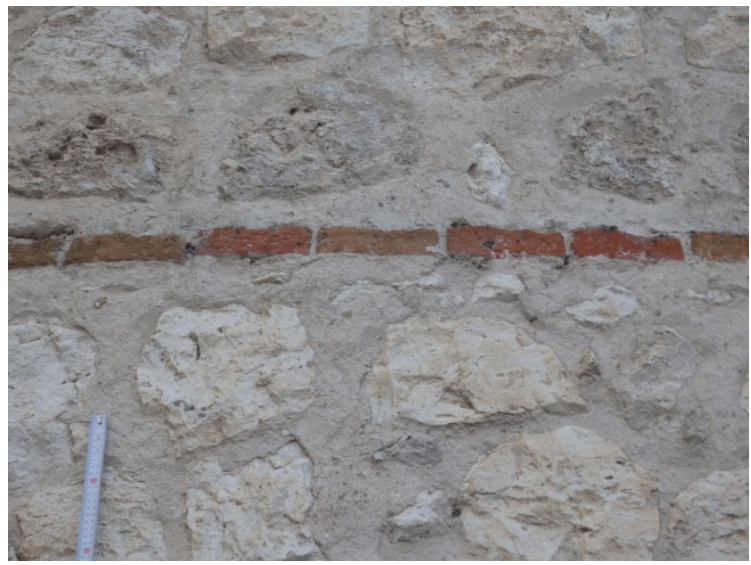

Fig. 5.2.86. Detalle de la verdugada de ladrillo en torre T1b [A.S.E. 12/5/2016].

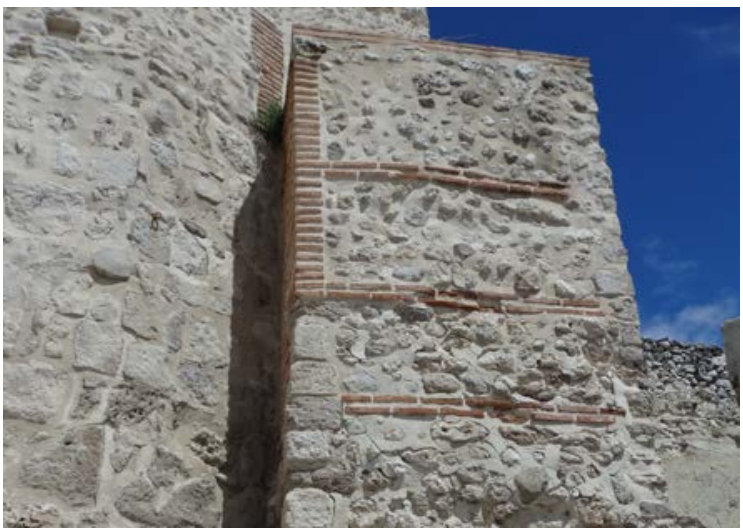

Fig. 5.2.88. Tapia mixta con verdugada doble en el elemento T8a, junto a torre de Santiago (T8). En la base el machón es de piedra [A.S.E. 12/5/2016]. 


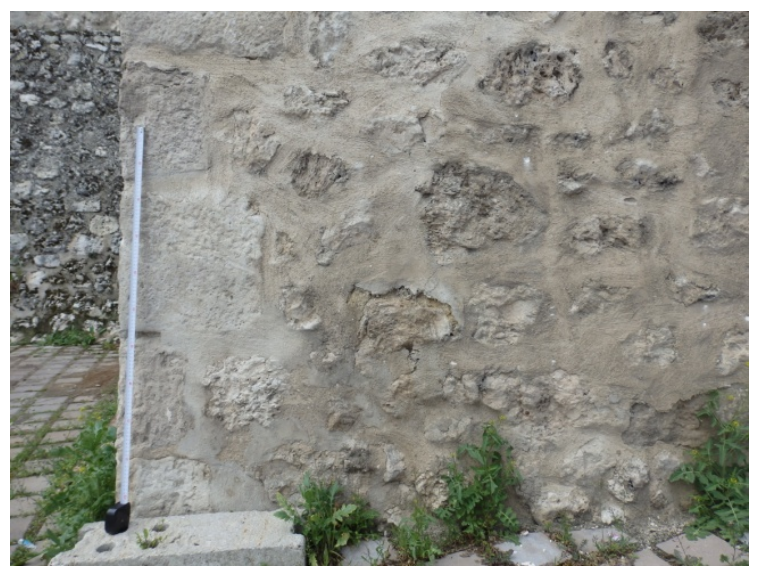

Fig. 5.2.89. Base de la torre T6 de la puerta de San Martín (P3). La esquina se resuelve con sillares. [A.S.E. 12/5/2016].

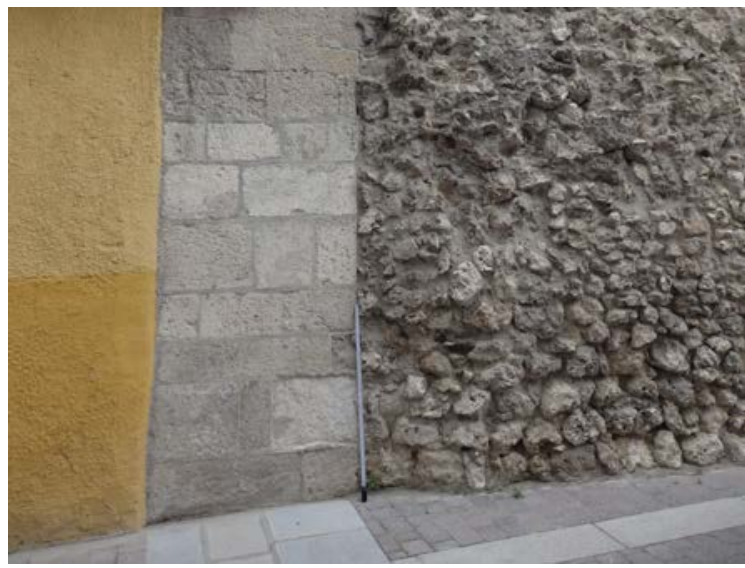

Fig. 5.2.91. Fábrica de sillería en la puerta de San Andrés (P12) [A.S.E. 12/5/2016].

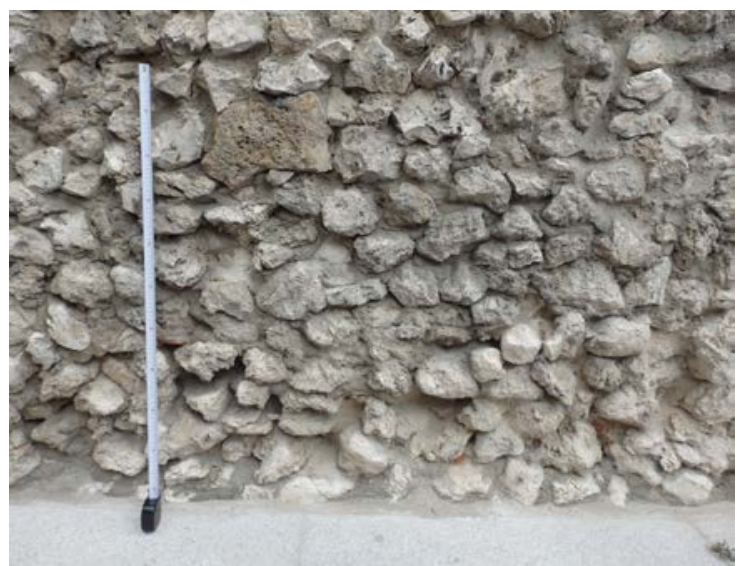

Fig. 5.2.90. Base de mampostería en la puerta de San Andrés (P12) [A.S.E. 12/5/2016].

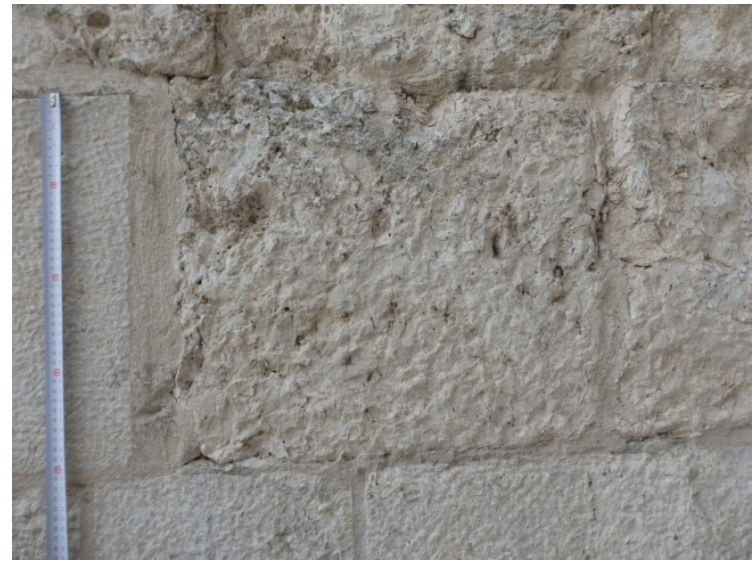

Fig. 5.2.92. Base de sillería en la puerta de San Basilio (P1). A la izquierda y abajo, parte de sillares que parecen más modernos [A.S.E. 12/5/2016].

La sillería se encuentra colocada en las esquinas de varias de las torres del primer recinto, concretamente las torres T5, T6 y T7 (Fig. 5.2.89). Se utiliza en los arcos de varias puertas, en la de San Basilio (P1) en combinación con ladrillo y en la puerta de Santiago (P6). En el segundo recinto, los arcos de las puertas Nueva (P11) y San Andrés (P12) se construye con sillares de piedra. Fábrica de sillería solo es visible en las torres T2 y T3, cuya base se construye con esta técnica. Los sillares empleados son muy regulares, de $40 \times 50 \mathrm{~cm}$ aproximadamente (Fig. 5.2.92). Las saeteras visibles en los lienzos se construyen con sillares tallados o con una combinación de do $\mathrm{s}$ sillares. Es muy singular el aparejo presente en la base de la torre T8 (Fig. 5.2.93). Las piedras empleadas son diferentes en $t$ amaño aunque tratan de formar hiladas horizontales. La base de la torre T7 (Fig. 5.2.94) presenta una solución que puede recordar al sillarejo por el tamaño de las piedras empleadas. Sin embargo, el aparejo es desordenado.

El uso del ladrillo es visible en los arcos de varias puertas, como en la puerta de San Basilio (P1) y en el portillo de la Huerta (P6). También la puerta Nueva (P11) presenta un arco de ladrillo sólo visible en el interior y la puerta de San Andrés (P12) combina el ladrillo con la piedra. Como se ha mencionado anteriormente, es visible el empleo de 
ladrillo en mechinales en la torre T3 (Fig. 5.2.21). También aparece empleado en la construcción de una saetera en la puerta de San Basilio (P1).

La restauración y reconstrucción de la muralla de Cuéllar hace necesario incluir el aspecto que ofrece la solución constructiva empleada. Las partes reconstruidas (Fig. 5.2.95) imitan el aspecto de la mampostería: piedras irregulares de tamaño medio y pequeño desordenadas, unidas entre sí con mortero de cemento blanco. Las partes reconstruidas ofrecen un aspecto similar, se ha restaurado a través de la aplicación de nuevos morteros sobre las piedras, aunque se ha tratado de conservar las marcas de encofrado como mechinales o límites de tapia (Fig. 5.2.96). En algunos casos, como se ha comentado con anterioridad, se ha dibujado la línea de la hilada de tapias para destacar su posición (Fig. 5.2.18).

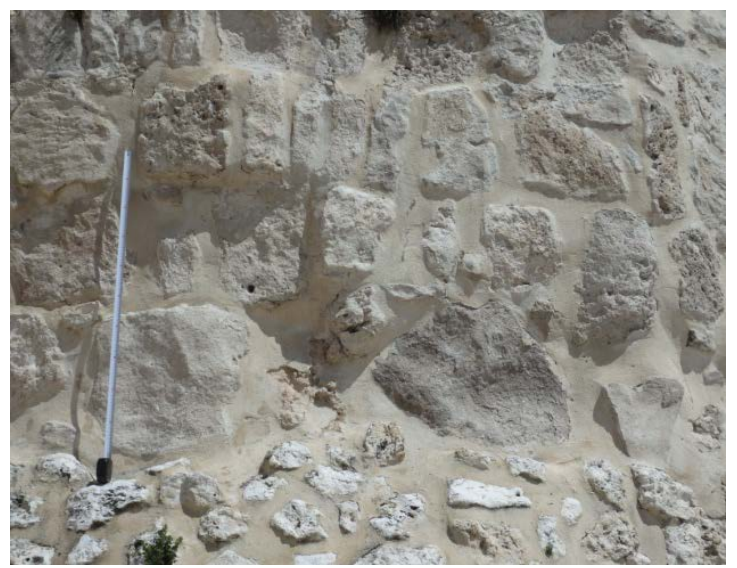

Fig. 5.2.93. Aparejo singular en la base de la torre de Santiago (P4) [A.S.E. 12/5/2016].

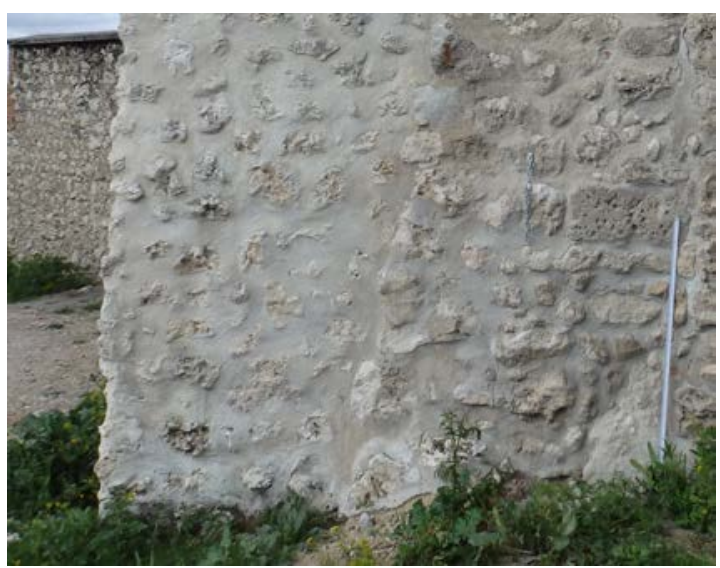

Fig. 5.2.95. A la izquierda, aspecto de parte reconstruida de la muralla. A la derecha, muralla original. En el centro, línea vertical irregular que separa [A.S.E. 12/5/2016].

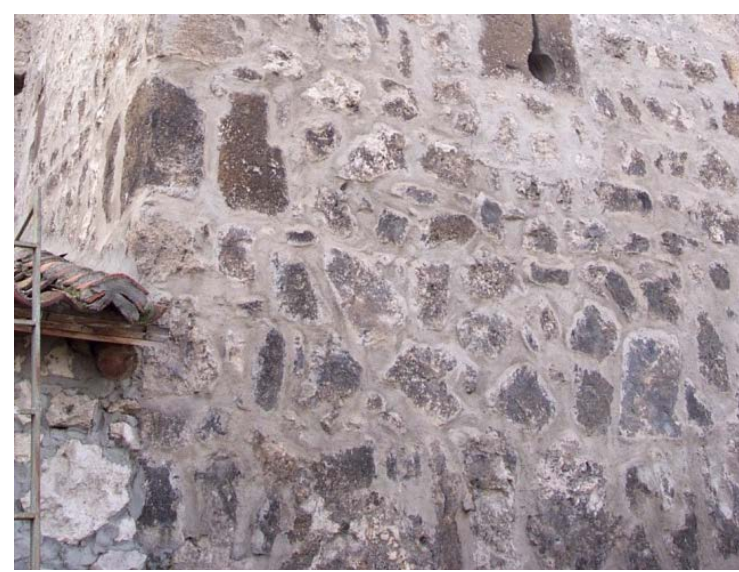

Fig. 5.2.94. Base de la torre T7. Fuente: Fernando Nieto y Jesús Nieto [13/3/2001]

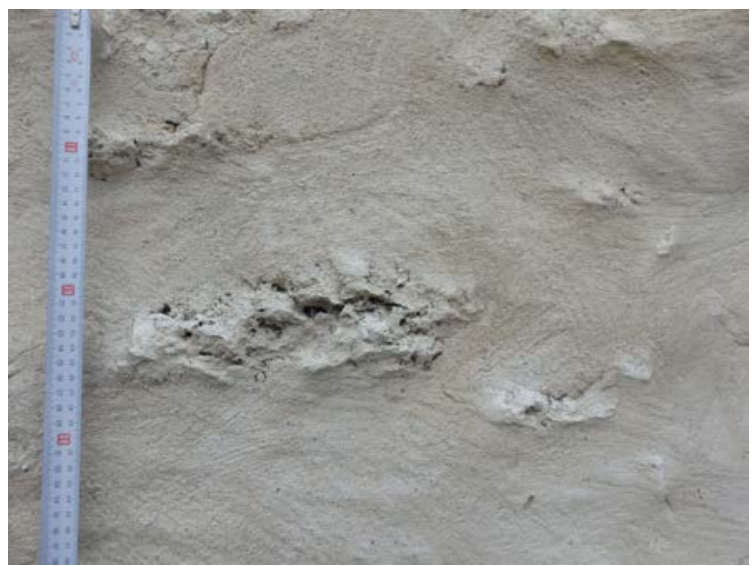

Fig. 5.2.96. Aspecto de una parte restaurada de la muralla, con nuevo mortero sobre las piedras [A.S.E. 12/5/2016].

A continuación, en la Tabla 5.2.3, se agrupan estas soluciones y se indica de forma esquemática en qué elementos de la muralla se localizan. La nomenclatura de las torres y puertas responde a la indicada en la Fig. 5.2.6. 
Las murallas en las Comunidades de Villa y Tierra de la Diócesis de Segovia en los siglos XI a XIII. Técnica y sistemas constructivos de la arquitectura defensiva medieval.

Tabla 5.2.3. Soluciones constructivas localizadas por elementos de la muralla.

\begin{tabular}{|l|l|}
\cline { 2 - 2 } \multicolumn{1}{l|}{} & Elementos donde se encuentra \\
\hline Tapia de mampostería & $\begin{array}{l}\text { Tramos C-P6, P6-P5, P5-P4, T4-P2, C-PN1, } \\
\text { P9-P10. }\end{array}$ \\
\hline $\begin{array}{l}\text { Tapia de mampostería con una verdugada } \\
\text { simple de ladrillo }\end{array}$ & Torre T1, T3 \\
\hline $\begin{array}{l}\text { Tapia mixta con verdugada simple y } \\
\text { machones de ladrillo }\end{array}$ & Torre T1a, T1b, T2, T4, T9. \\
\hline $\begin{array}{l}\text { Tapia mixta con verdugada doble y } \\
\text { machones de ladrillo }\end{array}$ & Elemento T8a \\
\hline $\begin{array}{l}\text { Tapia mixta con verdugada doble y } \\
\text { machones de piedra }\end{array}$ & Elemento T8a \\
\hline $\begin{array}{l}\text { Sillería } \\
\text { En esquinas }\end{array}$ & $\begin{array}{l}\text { Torre T5, T6, T7 } \\
\text { En Arcos }\end{array}$ \\
$\begin{array}{l}\text { Fábrica } \\
\text { Sillarejo }\end{array}$ & $\begin{array}{l}\text { Base de P1 (torres T2, T3), base de P12 } \\
\text { Base de torre T7, Tramo T6-T8 y T6-este. }\end{array}$ \\
$\begin{array}{l}\text { Saeteras } \\
\text { Almenas }\end{array}$ & $\begin{array}{l}\text { T9-P6, P2-este, T6-este. } \\
\text { Borde de almenas T9-P6. }\end{array}$ \\
\hline Aparejo singular de piedra & Base de torre T8 \\
\hline $\begin{array}{l}\text { Ladrillo } \\
\text { En Arcos } \\
\text { Mechinales } \\
\text { Saeteras } \\
\text { Decoración }\end{array}$ & $\begin{array}{l}\text { P1, P6, P11, P12 } \\
\text { T3 }\end{array}$ \\
\hline $\begin{array}{l}\text { Mampostería } \\
\text { Fábrica } \\
\text { Mechinales }\end{array}$ & \begin{tabular}{l} 
T2 1, P12 \\
\hline Restaurado
\end{tabular} \\
\hline $\begin{array}{l}\text { Reconstruido } \\
\text { Reparaciones } \\
\text { Formación de mechinal en tapia }\end{array}$ \\
Ambos recintos. \\
\hline
\end{tabular}

El empleo de tapia de mampostería está muy generalizado y es mayoritario en todo el recinto. Otras soluciones como la tapia mixta o la sillería son visibles de forma aislada en puertas y torres. La tapia es, por otra parte, la técnica menos identificada del recinto, la que queda más oculta y en ocasiones se confunde con simple mampostería. El uso de la tapia presente en prácticamente toda la longitud de la muralla requiere del análisis de algunos lienzos donde esta solución es más evidente.

En el primer recinto amurallado se conserva gran parte de los lienzos originales y es posible realizar un al zado con la técnica de fotogrametría digital. En el apartado de metodología se explica cómo se realiza este alzado con el empleo de programas informáticos. Se ha realizado un análisis constructivo del tramo C-PN1, concretamente la zona remarcada D1. También se ha analizado lienzos del tramo T9-P6, desde el interior y desde el exterior del recinto. Del segundo recinto amurallado se ha analizado el tramo existente entre P9 y P10. 


\subsubsection{Lienzo interior del tramo C-PN1, recinto 1}

Este tramo tiene una longitud de $56,70 \mathrm{~m}$ de muralla medieval que parte del alzado norte del castillo y termina metros antes del paso moderno del Ferial. La altura del lienzo medieval alcanza los 7,32m. La altura de la restauración es de 9,20 m en la parte superior del almenado. La imagen general que ofrece este alzado interior es de gran homogeneidad. El lienzo muestra el mismo color en toda su longitud, parece hacerse con los mismos materiales. La restauración también agrupa el lienzo para que se entienda como un conjunto que responde a las mismas reglas. El análisis más pormenorizado muestra los distintos elementos que componen el muro. La bas e de este tramo no muestra ninguna diferenciación respecto de las zonas más elevadas. No son visibles sillares o pi edras de mayor tamaño colocadas a modo de cimentación. Tampoco en el alzado exterior se observa un esfuerzo por construir una base o un zócalo. El almenado y la zona superior del muro son el resultado de la restauración del año 2008

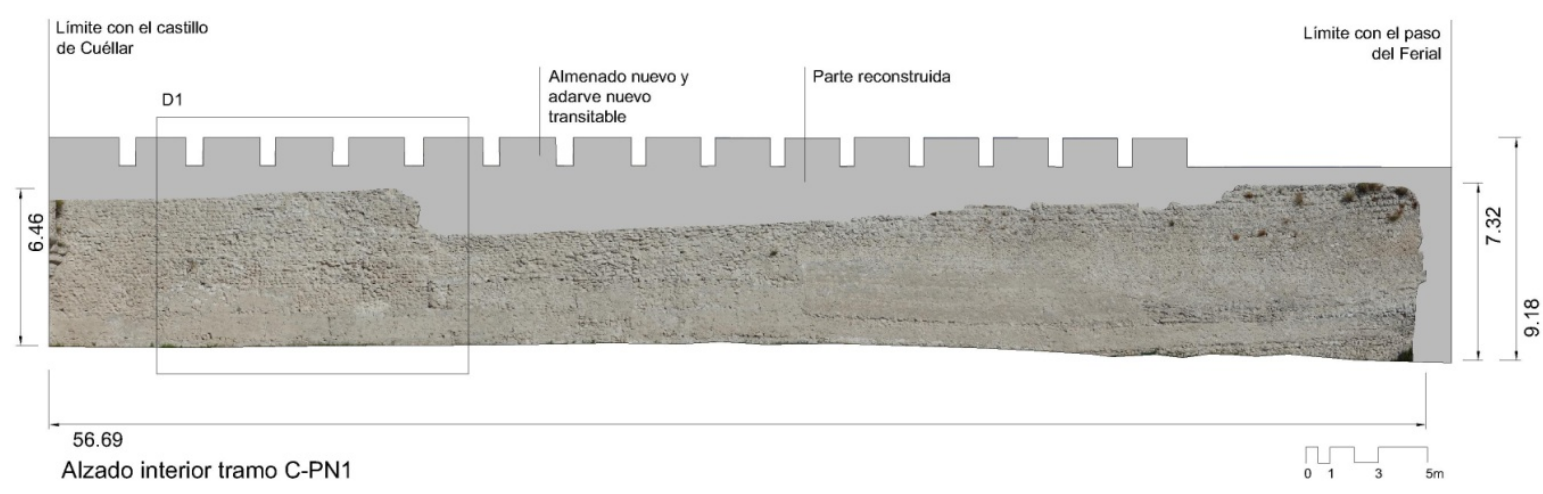

Fig. 5.2.97. Alzado realizado con fotogrametría digital de la cara interior del tramo C-PN1, visto desde el interior del recinto. Fuente: Elaboración propia con fotos tomadas el 20/8/2014.

Son reconocibles en el paramento del alzado interior las tapias que componen el muro. Su delimitación es más evidente en I a zona recuadrada como D1 del dibujo (Fig. 5.2.98) donde son visibles los límites completos de 10 tapias. La consulta de fotografías anteriores a la restauración de 2008 permite situar alguna tapia más. También es posible situar los límites de otras tapias en función de la posición de los mechinales. Los límites de la tapias dibujados en color blanco son aquellos que son visibles a simple vista. Los dibujados en fucsia son los localizados de forma probable. Los valores de anchura de tapia no son homogéneos: 2,84m;2,66m;2,71m;2,32m. Las alturas de tapia son también variables: 1,14m; 1,21m; 1,09m; 1,29m. La primera hilada de tapias visible por completo se sitúa a una distancia aproximada de $30 \mathrm{~cm}$ sobre el nivel de suelo actual lo que puede indicar la existencia de al menos una hilada de tapias parcialmente enterrada. Las hiladas de tapias son identificables en la mayor parte del lienzo, aunque no se delimiten por completo cada una de I as tapias. Se cuentan de 4 a 5 tapias de altura en este lienzo. Se sumaría una tapia más por aquella que está parciamente enterrada. 


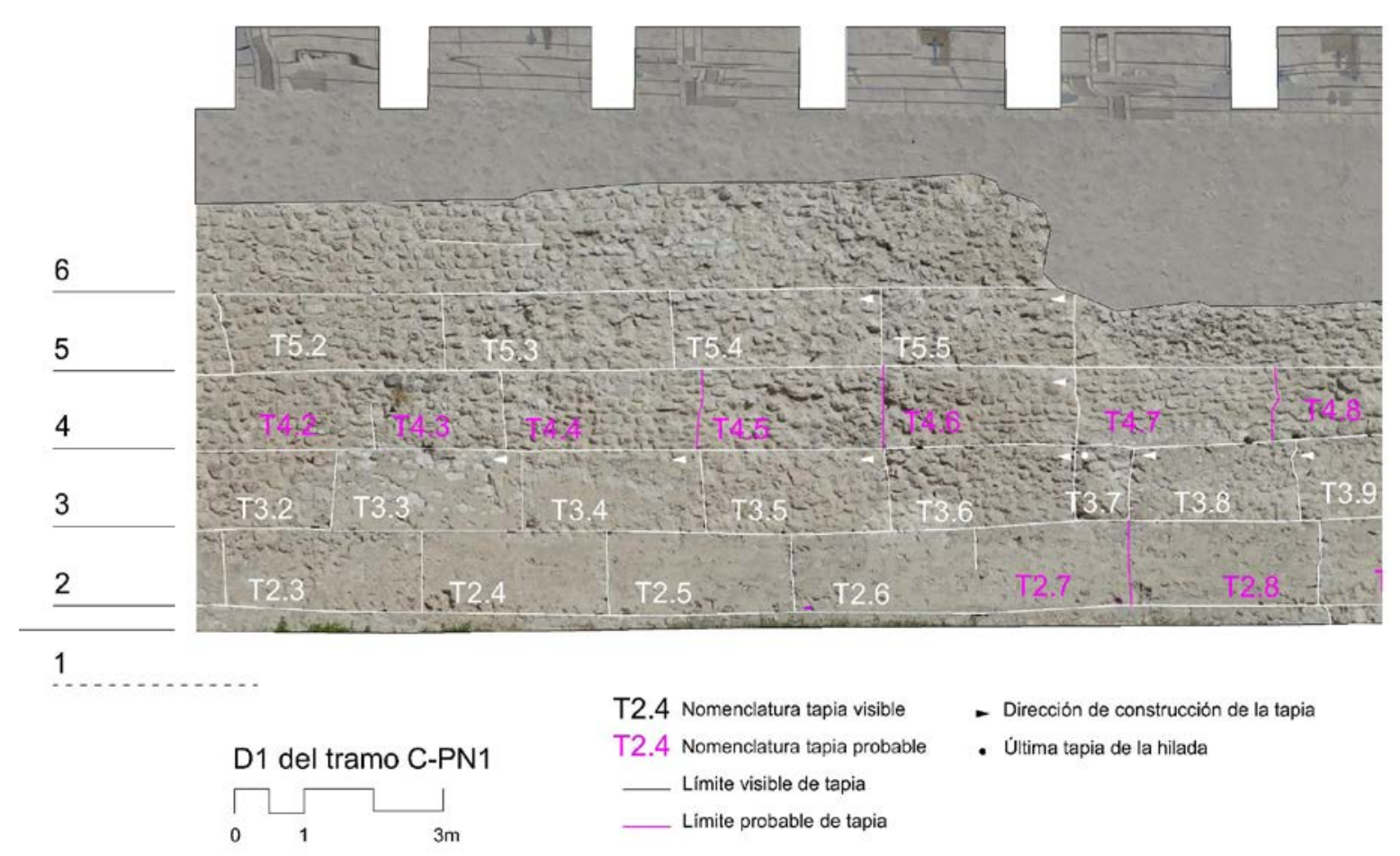

Fig. 5.2.98. Detalle del alzado D1 del tramo C-PN1. Fuente: Elaboración propia con fotos tomadas el $20 / 8 / 2014$.

El material empleado en la tapia es mampuestos de piedra caliza, tierra y cal. La dimensión de los mampuestos es de $15 \times 20 \mathrm{~cm}$, con excepciones que alcanzan los $35 \mathrm{~cm}$. Se trata de mampuestos irregulares, con tamaños y formas variadas. Las tapias en la primera hilada, en la zona inferior, se conservan especialmente bien. Al parecer, se mantuvieron enterradas durante mucho tiempo ${ }^{40}$. Es visible la capa más superficial de la tapia que oculta los mampuestos del interior, donde todavía se pueden apreciar las marcas de las tablas que conformaban el tapial. Se cuentan cinco tablas colocadas longitudinalmente (Fig. 5.2.99). La altura de las tablas en la tapia T2.5 es de $24-25 \mathrm{~cm}$. No se han encontrado tablas de encofrado en otros lugares de la muralla. En la base de la tapia se ven dos mechinales de sección rectangular alargada, cercanos a los extremos del bloque. Es probable que exista un tercer mechinal central aunque no se vea en la superficie. Las dimensiones de los dos mechinales laterales son de $13 \times 3 \mathrm{~cm}$. Se sitúan a una distancia de $22-23 \mathrm{~cm}$ del borde de la tapia, medida desde el eje del mechinal. Les separa una distancia de $220 \mathrm{~cm}$. Teniendo en cuenta el mechinal central no visible, estarían separados entre sí por $110 \mathrm{~cm}$. La forma del mechinal indica la forma y dimensión de la aguja empleada en el encofrado: una sola aguja con la forma del mechinal. Los mechinales se encuentran huecos en la zona superficial y es difícil determinar si la aguja de madera empleada se encuentra todavía en el interior del muro. Dado el espesor del muro, cercano a los $2,00 \mathrm{~m}$, es posible que la aguja no sea pasante, es decir, que no atraviese el muro en todo su espesor, sino que se trate de media aguja, sujeta en el interior del muro a poca distancia de la superficie, aunque es difícil de determinar.

${ }^{40}$ Información verbal recibida de Fernando Nieto Criado el 12/5/2016. 


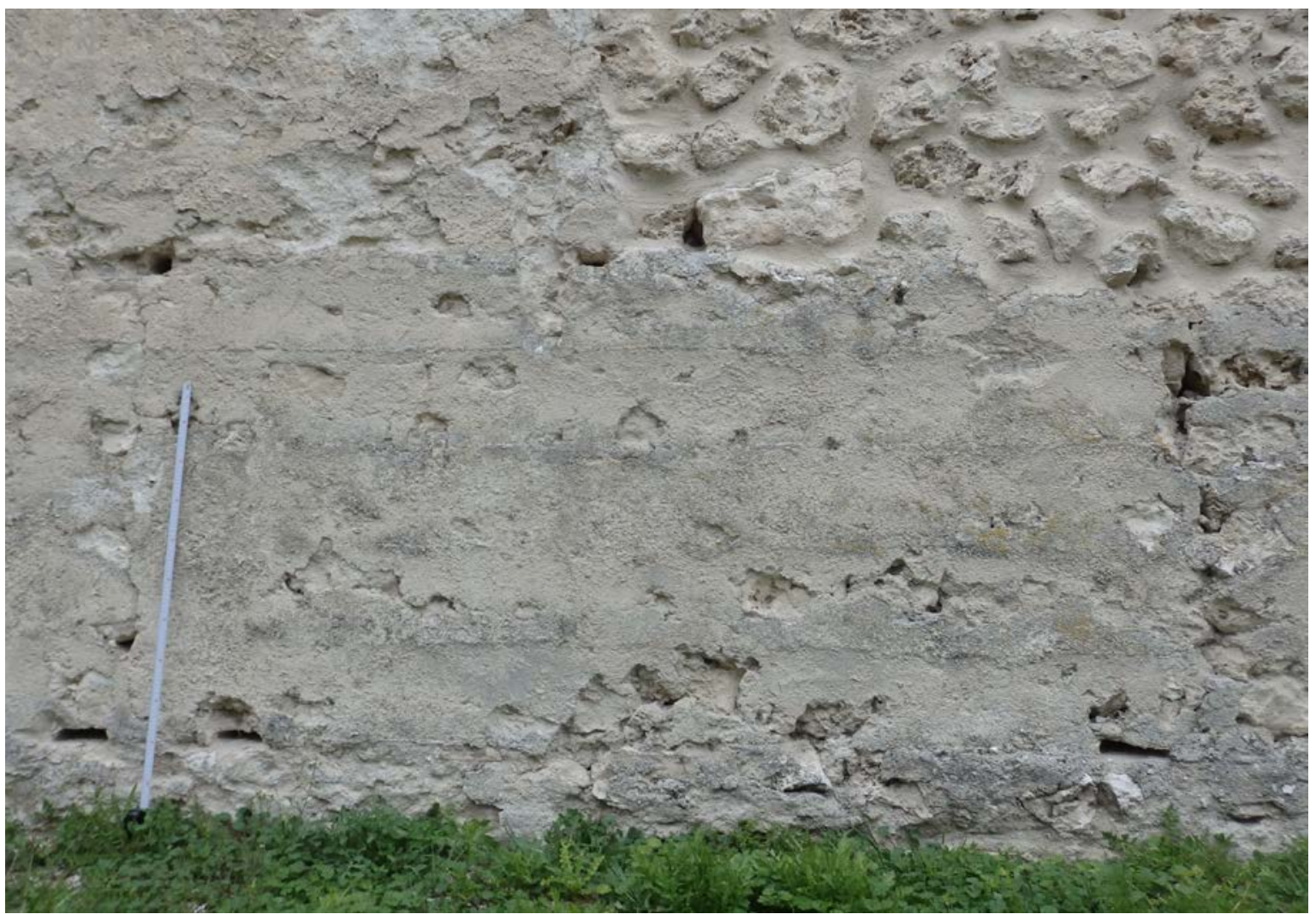

Fig. 5.2.99. Tapia T2.5 cuyos límites son visibles. Sus dimensiones son $2,66 \mathrm{~cm} \times 1,17 \mathrm{~cm}$. Cuenta con dos mechinales identificables en la base y también se aprecian líneas horizontales correspondientes a las cinco tablas empleadas en el encofrado [A.S.E.12/5/2016].

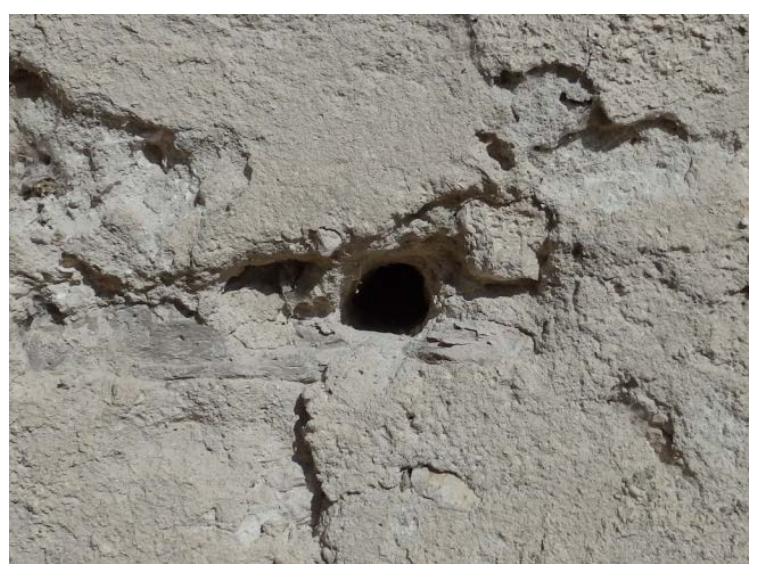

Fig. 5.2.100. Mechinal central en base de tapia T3.4 con sección circular y diámetro de $3 \mathrm{~cm}$ [A.S.E. 20/8/2014].

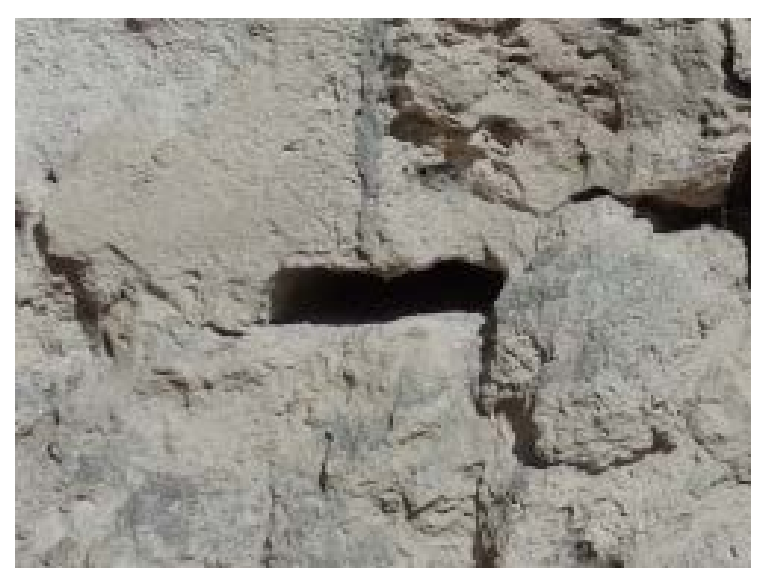

Fig. 5.2.101. Mechinal lateral derecho de tapia T3.2. La sección es rectangular alargada, de $13 \times 3$ cm [A.S.E. 20/8/2014].

La formación del mechinal no utiliza otros materiales como ladrillo o un conjunto de mampuestos, se forma directamente como negativo de la aguja empleada. Los mechinales se sitúan en el propio hilo de la tabla, sobre la tapia inmediatamente inferior. No existen verdugadas visibles de pi edra o ladrillo. De acuerdo con los mechinales visibles, la distancia entre estos a lo largo de la hilada de tapias sería de $110 \mathrm{~cm}-110 \mathrm{~cm}-42 \mathrm{~cm}-110 \mathrm{~cm}$, con un ritmo A-A-B-A-A-B. 


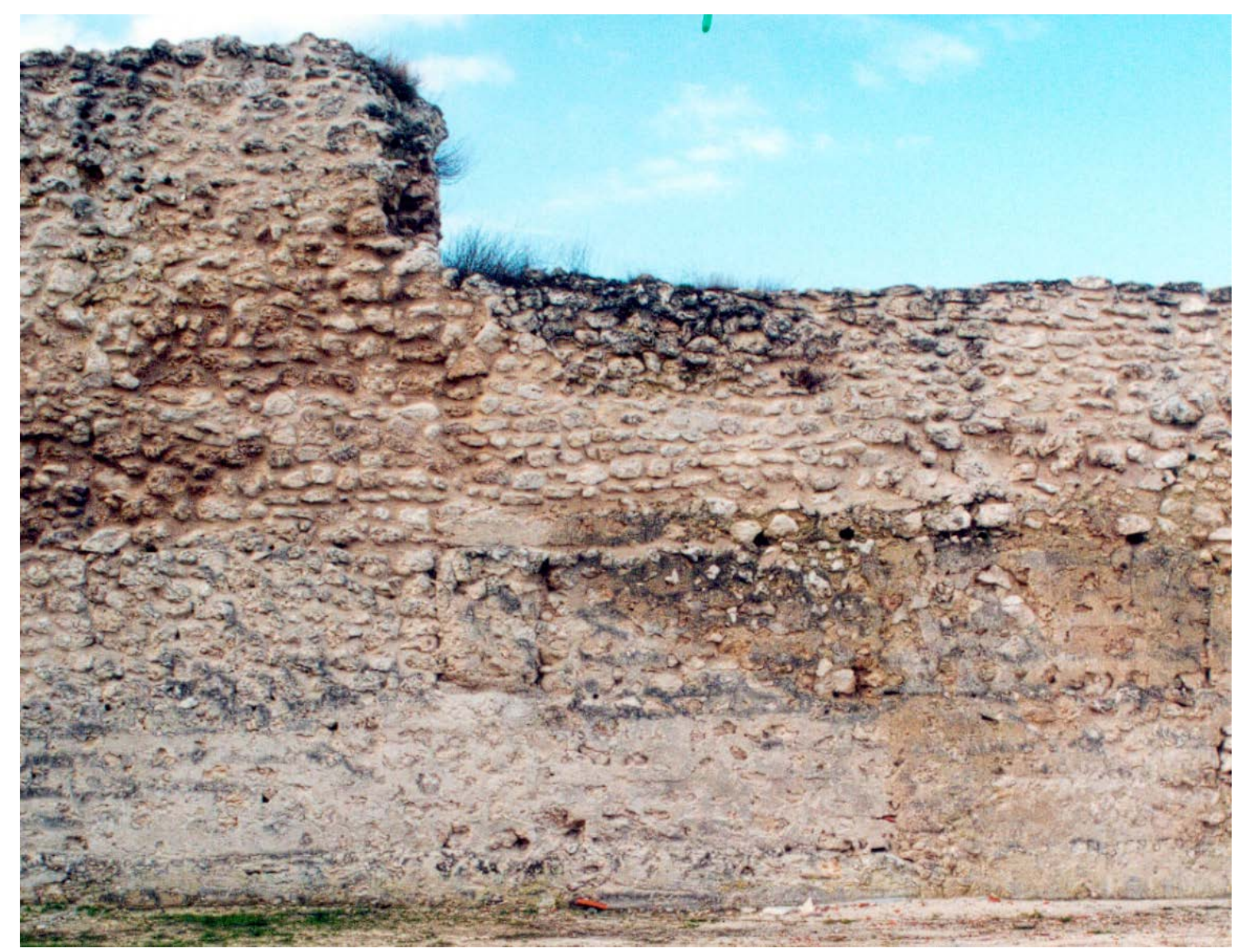

Fig. 5.2.102. Línea vertical coincidente de las tapias, donde apoya la tapia T3.7. Fuente: Fernando Nieto y Jesús Nieto, fotografía escaneada anterior al año 2008.

Además de los mechinales de tipo rectangular alargado (Fig. 5.2.101), en este tramo existen mechinales de sección circular (Fig. 5.2.100). Se cuentan más de di ez mechinales rectangulares situados exclusivamente en las hiladas 2 y 3 . En torno a siete mechinales de sección circular se sitúan desde la hilada 2 hac ia arriba. En algunos casos se ven secciones semicirculares.

Es llamativa la tapia T3.7 de este tramo por su marcada estrechez, de $78 \mathrm{~cm}$ frente a la anchura habitual de $268 \mathrm{~cm}$. Una posible interpretación de esta tapia estrecha es la finalización de una hilada de tapias contra un tramo de muralla ya construido ${ }^{41}$. En una imagen anterior a la restauración de 2008 (Fig. 5.2.102), se ve una línea vertical formada por al menos tres tapias (T3.6, T4.6 y T5.6). Contra la tapia T3.6 se adosa la T3.7, un resto de $78 \mathrm{~cm}$ que es necesario rellenar para poder continuar con la hilada superior. Este factor permite identificar el orden de $c$ onstrucción de las tapias. Suponiendo que la T3.7 se construyó la última de la hilada, es previsible que aquellas a su derecha se hayan construido antes. En la hilada de la base, no es visible la continuidad de este límite vertical de tapias. En la parte superior, es probable que la tapia sobre T5.6 termine también en la línea vertical, lo que se justifica por la rotura de la muralla en el límite de una tapia.

\footnotetext{
${ }^{41}$ Como se ha indicado en el capítulo de "Métodos y Herramientas de Trabajo", en la cerca de San Pedro de Latarce, Fernando Cobos $(2012,122-123)$ identifica tapias de este tipo como "final de construcción de aparejo".
} 
El espesor del muro en este tramo ronda los 2,00m. Su composición interna (Fig. 5.2.103) responde a los datos visibles en los alzados exteriores, en l a sección se pueden apreciar las líneas horizontales de las tapias. No parece observarse división vertical interior sino que una sola tapia ocupa el espesor total del muro.

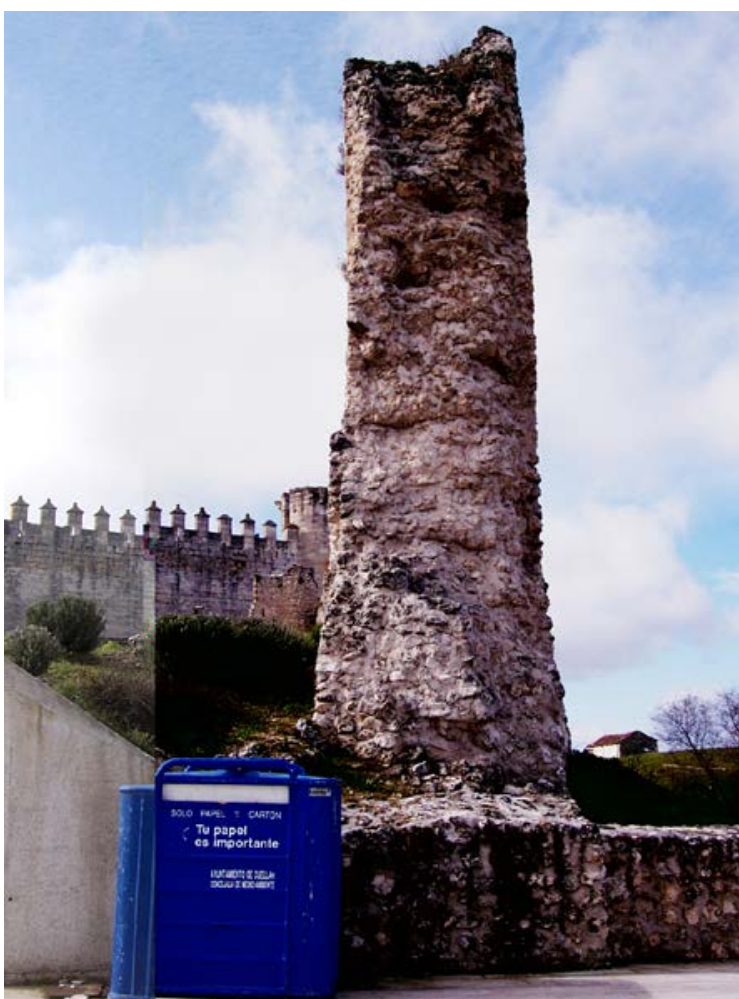

Fig. 5.2.103. Sección de la muralla al norte del tramo CA-1. Se observan las líneas de las tapias. Fuente: Fernando y Jesús Nieto [11/3/2001]

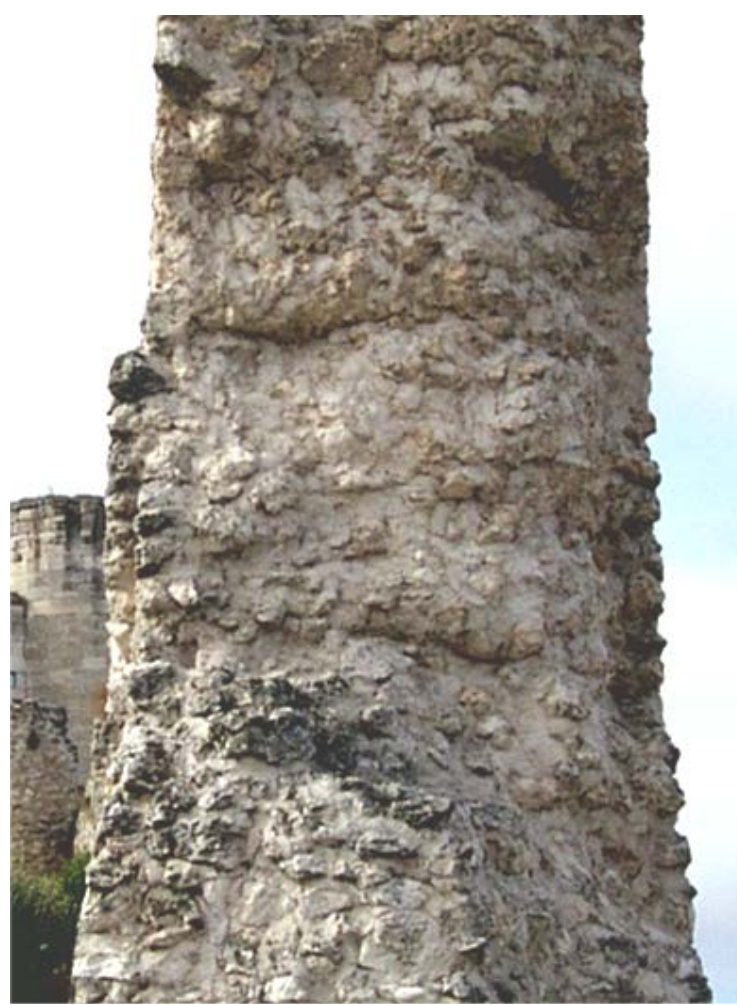

Fig. 5.2.104. Detalle de la sección. Fuente: Fernando y Jesús Nieto [11/3/2001]

\subsection{Estudio de dimensiones y características de la tapia en tramo C-PN1}

A continuación, en la Tabla 5.2.5, se han detallado las características y dimensiones de las tapias del tramo estudiado. Las dimensiones generales de las tapias, como la anchura y altura se han reflejado en todos los casos, tanto en los claramente visibles en el paramento, como en aquellos donde se ha planteado una hipótesis probable de la posición de los límites de las tapias. En el caso de los mechinales, sólo en algunas de las tapias ha sido posible determinar qué tipo de mechinal existe, cómo se ha formado o cuál es la separación entre ellos, tanto si se encuentra en la misma tapia como si se trata de mechinales de tapias diferentes.

Tabla 5.2.4. Tabla de tapias del lienzo D1 del tramo C-PN1

\begin{tabular}{|c|c|c|c|c|c|c|c|}
\hline Tapia & Límite & Ancho & Alto & Tipo mechinal & Formación & $\begin{array}{c}\text { Separación } \\
\text { mechinales } \\
\text { en tapia }\end{array}$ & $\begin{array}{c}\text { Separación } \\
\text { mechinales } \\
\text { entre tapias }\end{array}$ \\
\hline T2.1 & Visible & $0,74^{*}$ & 1,04 & & & & \\
\hline
\end{tabular}


Las murallas en las Comunidades de Villa y Tierra de la Diócesis de Segovia en los siglos XI a XIII. Técnica y sistemas constructivos de la arquitectura defensiva medieval.

\begin{tabular}{|c|c|c|c|c|c|c|c|c|c|}
\hline \multirow{2}{*}{$\begin{array}{l}\text { Tapia } \\
\text { T2.2 }\end{array}$} & \multirow{2}{*}{$\begin{array}{c}\text { Límite } \\
\text { Probable }\end{array}$} & \multirow{2}{*}{$\begin{array}{l}\text { Ancho } \\
2,64\end{array}$} & & \multirow{2}{*}{$\begin{array}{c}\text { Tipo mechinal } \\
\text { I-Ra, D-Ra }\end{array}$} & \multirow{2}{*}{$\begin{array}{c}\text { Formación } \\
\text { T-T }\end{array}$} & \multicolumn{2}{|c|}{$\begin{array}{c}\text { Separación } \\
\text { mechinales } \\
\text { en tapia }\end{array}$} & \multicolumn{2}{|c|}{$\begin{array}{l}\text { Separación } \\
\text { mechinales } \\
\text { entre tapias }\end{array}$} \\
\hline & & & & & & 1,09 & 1,09 & 0,42 & 0,58 \\
\hline T2.3 & Visible & 2,84 & 1,15 & & & & & 0,58 & \\
\hline $\mathrm{T} 2.4$ & Visible & 2,66 & 1,19 & $\mathrm{D}-\mathrm{Ra}$ & $\mathrm{T}$ & & & & \\
\hline $\mathrm{T} 2.5$ & Visible & 2,66 & 1,17 & I-Ra, D-Ra & $\mathrm{T}-\mathrm{T}$ & 1,10 & 1,10 & 0,39 & 0,43 \\
\hline T2.6 & Visible & 2,54 & 1,16 & I-Ra & & & & & \\
\hline T2.7 & Probable & 2,19 & 1,23 & D-Ci & $\mathrm{T}$ & & & & 0,42 \\
\hline $\mathrm{T} 2.8$ & Probable & 2,73 & 1,21 & $\mathrm{D}-\mathrm{Ra}$ & $T$ & & & & 0,22 \\
\hline T2.9 & Probable & 2,87 & 1,27 & & & & & 0,22 & \\
\hline \multicolumn{2}{|c|}{ Promedio hilada 2} & 2,64 & 1,20 & & & & & & \\
\hline T3.1 & Visible & $1,99^{*}$ & 1,10 & C-R, D-Sci & $\mathrm{T}-\mathrm{T}$ & & & & \\
\hline T3.2 & Visible & 3,03 & 1,11 & $\mathrm{D}-\mathrm{Ra}$ & $\mathrm{T}$ & & & & 0,55 \\
\hline T3.3 & Visible & 2,71 & 1,17 & I-Ra, D-Ra & $\mathrm{T}-\mathrm{T}$ & 1,14 & 1,14 & 0,55 & 0,44 \\
\hline T3.4 & Visible & 2,61 & 1,15 & $\mathrm{C}-\mathrm{Ci}, \mathrm{D}-\mathrm{Ra}$ & $\mathrm{T}-\mathrm{T}$ & 0,97 & 1,13 & 0,44 & \\
\hline T3.5 & Visible & 2,66 & 1,21 & & & & & & \\
\hline T3.6 & Visible & 2,66 & 1,17 & & & & & & \\
\hline T3.7 & Visible & 0,78 & 1,09 & & & & & & \\
\hline T3.8 & Visible & 2,43 & 1,09 & D-Sci & $\mathrm{T}$ & & & & 0,40 \\
\hline T3.9 & Visible & 2,92 & 1,17 & I-Sci & $\mathrm{T}$ & & & 0,40 & 0,54 \\
\hline T3.10 & Visible & 2,34 & 1,28 & & & & & & \\
\hline \multicolumn{2}{|c|}{ Promedio hilada 3} & 2,46 & 1,20 & & & & & & \\
\hline $\mathrm{T} 4.1$ & Visible & $2,99^{*}$ & 1,07 & & & & & & \\
\hline $\mathrm{T} 4.2$ & Visible & 3,25 & 1,10 & & & & & & \\
\hline $\mathrm{T} 4.3$ & Visible & 1,89 & 1,13 & & & & & & \\
\hline T4.4 & Probable & 2,82 & 1,14 & & & & & & \\
\hline $\mathrm{T} 4.5$ & Probable & 2,64 & 1,17 & & & & & & \\
\hline T4.6 & Probable & 2,81 & 1,14 & I-Sci & $\mathrm{T}$ & & & 1,04 & \\
\hline $\mathrm{T} 4.7$ & Probable & 2,79 & 1,13 & D-Sci & $\mathrm{T}$ & & & & 0,68 \\
\hline $\mathrm{T} 4.8$ & Probable & 2,78 & 0,98 & I-Sci & $\mathrm{T}$ & & & 0,66 & \\
\hline $\mathrm{T} 4.9$ & Probable & 2,77 & 1,11 & D-Sci & $M$ & & & & \\
\hline \multicolumn{2}{|c|}{ Promedio hilada 4} & 2,72 & 1,10 & & & & & & \\
\hline T5.1 & Visible & 3,13 & 1,15 & & & & & & \\
\hline T5.2 & Visible & 3,11 & 1,09 & & & & & & \\
\hline T5.3 & Visible & 3,28 & 1,11 & & & & & & \\
\hline T5.4 & Visible & 3,00 & 1,12 & & & & & & \\
\hline T5.5 & Visible & 2,77 & 1,12 & & & & & & \\
\hline \multicolumn{2}{|c|}{ Promedio hilada 5} & 3,06 & 1,10 & & & & & & \\
\hline
\end{tabular}

${ }^{*}$ medida cortada, no se incluye en promedios

\section{Probable Deducida}

I-Ra Izq. Rectangular alargado

C-R Central Rectangular

D-Sci Dcha. Semicircular
M -Mampuesto

T -Tierra

$\mathrm{Tj}-\mathrm{Teja}$ 
Con los datos recopilados en la tabla anterior, se han realizado diagramas de caja para tratar de extraer las medidas habituales de la anchura y altura de tapias. En un primer paso, se ha realizado solo con los valores visibles de las tapias (Fig. 5.2.105, Fig. 5.2.106). En el primer gráfico, correspondiente a la anchura de tapias, el diagrama presenta un rango intercuartílico entre $280 \mathrm{~cm}$ y $330 \mathrm{~cm}$, de $50 \mathrm{~cm}$. La mediana de este conjunto de datos es de $268,50 \mathrm{~cm}$. Los "bigotes" del intervalo se sitúan entre $235 \mathrm{~cm}$ y $325 \mathrm{~cm}$. Este diagrama sitúa un valor atípico inferior a $200 \mathrm{~cm}$, correspondiente a la tapia T4.3 y otro inferior a $100 \mathrm{~cm}$ correspondiente a la tapia T3.7. En el caso de la altura de la tapia, considerando los datos de altura visibles, los bigotes se sitúan entre algo menos de $1,10 \mathrm{~m}$ y poco más de $1,20 \mathrm{~m}$. El rango intercuartílico se sitúa entre y $117 \mathrm{~cm}$, con un valor de $7 \mathrm{~cm}$. La mediana de este conjunto de datos es de $115 \mathrm{~cm}$. Muestra un valor atípico de $1,27 \mathrm{~m}$, correspondiente a la tapia T2.9.

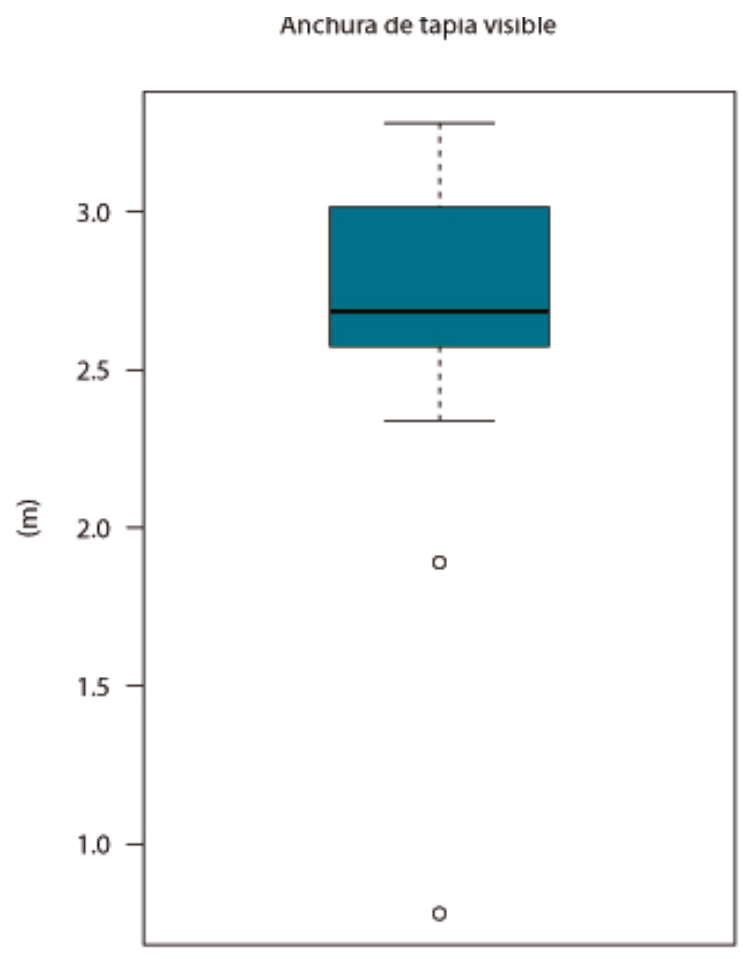

Fig. 5.2.105. Diagrama de caja de la anchura de tapias en D1, donde solo se han tenido en cuenta los datos visibles. Fuente: Elaboración propia con el programa $\mathrm{R}$.

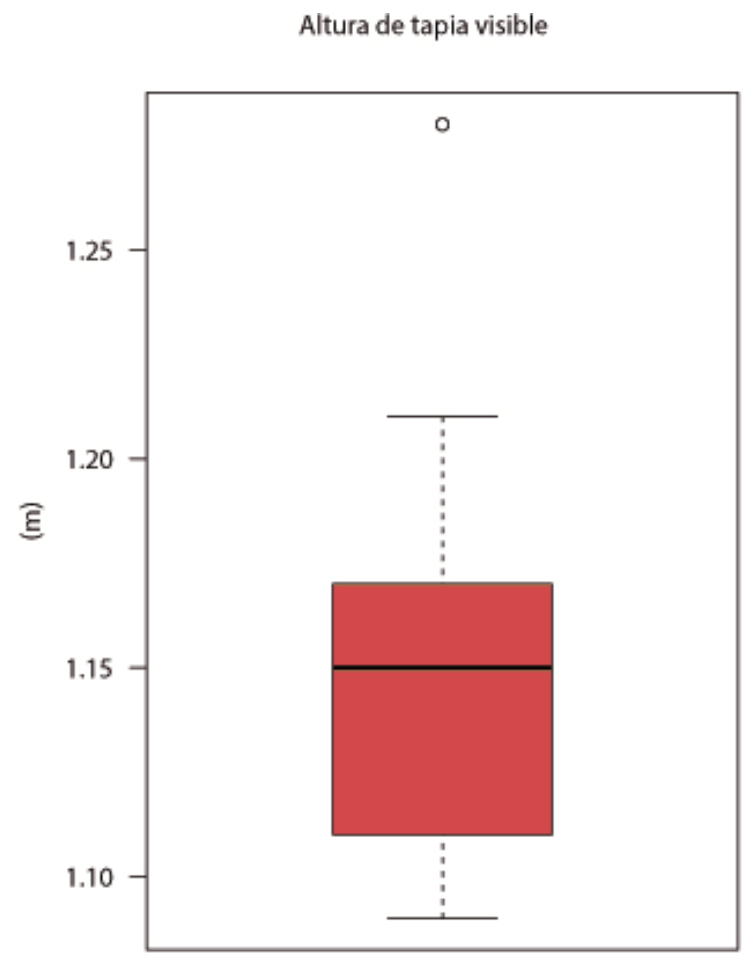

Fig. 5.2.106. Diagrama de caja de la altura de tapias en D1, donde solo se han tenido en cuenta los datos visibles. Fuente: Elaboración propia con el programa $\mathrm{R}$.

Si se consideran tanto los datos visibles como los probables de las dimensiones de las tapias, los resultados se alteran ligeramente, reduciéndose el rango de la caja y mostrando una dispersión menor. En el caso de la anchura de tapia, el rango intercuartílico se sitúa entre $262,5 \mathrm{~cm}$ y $287,5 \mathrm{~cm}$, con un valor de $25 \mathrm{~cm}$. La mediana de este conjunto de anc huras sería de $275 \mathrm{~cm}$, que se tomará como la medida de la anchura representativa de este tramo. En el caso de la altura de tapia, el intervalo de la caja no se altera considerablemente, pero sí se identifica un valor atípico en la zona inferior de la gráfica, con un valor inferior a $100 \mathrm{~cm}$. El rango intercuartílico de la altura es de $112,50 \mathrm{~cm}$ a $117 \mathrm{~cm}$, con un valor de $4,50 \mathrm{~cm}$. La mediana de este conjunto de alturas es de $114,50 \mathrm{~cm}$, que se tomará como altura representativa de este tramo. 
Las murallas en las Comunidades de Villa y Tierra de la Diócesis de Segovia en los siglos XI a XIII. Técnica y sistemas constructivos de la arquitectura defensiva medieval.

Anchura de tapia (incluye datos probables)

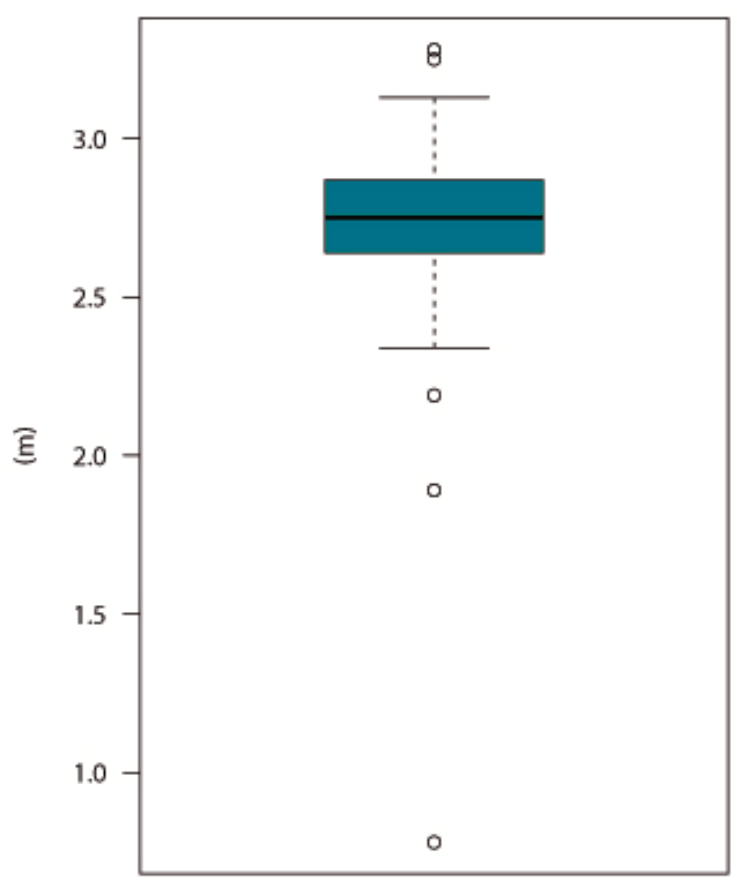

Fig. 5.2.107. Diagrama de caja de la anchura de tapias en D1, donde se han incluido los datos probables. Fuente: Elaboración propia con el programa $\mathrm{R}$.
Altura de tapia (incluye datos probables)

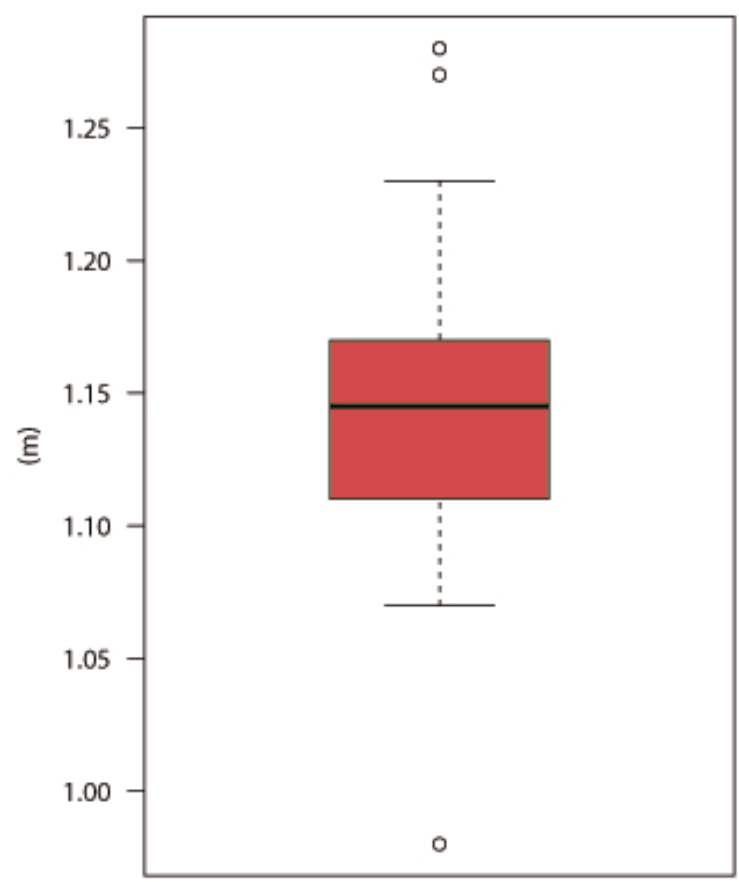

Fig. 5.2.108. Diagrama de caja de la altura de tapias en D1, donde se han incluido los datos probables. Fuente: Elaboración propia con el programa R.

Tabla 5.2.5. Tabla de características y dimensiones del tramo C-PN1.

\begin{tabular}{|c|c|c|c|}
\hline Tapias & C-PN1 & Mechinales & C-PN1 \\
\hline Altura $(\mathrm{cm})$ & 114,50 & Sección mayoritaria & $\begin{array}{l}\text { Rectangular } \\
\text { alargada, } \\
\text { semicircular }\end{array}$ \\
\hline Anchura $(\mathrm{cm})$ & 275 & $\begin{array}{l}\text { Dimensiones alto } x \text { ancho } \\
(\mathrm{cm})\end{array}$ & $4 \times 15$ \\
\hline Espesor (cm) & $180-220(\bar{x}=200)$ & Distancia en cajón & 111 \\
\hline Restos de encofrado & Sí / Tapial independiente & Distancia entre cajones & 44 \\
\hline $\begin{array}{l}\text { Altura de tablas de } \\
\text { encofrado }(\mathrm{cm})\end{array}$ & $24-25 \mathrm{~cm}$ & Material & $\begin{array}{c}\text { Tierra/solo hueco, } \\
\text { mampuesto }\end{array}$ \\
\hline $\begin{array}{l}\text { Piedras exteriores } \\
\text { colocadas }\end{array}$ & No de forma evidente. & Aguja perdida/recuperable & Perdida \\
\hline $\begin{array}{l}\text { Juntas más visibles en } \\
\text { paramento }\end{array}$ & Horizontales & Profundidad mechinal & - \\
\hline Materiales empleados & Mampuestos, tierra, cal & $\begin{array}{l}\text { Tipo de aguja } \\
\text { (pareadas/unitarias) }\end{array}$ & Unitarias \\
\hline $\begin{array}{l}\text { Tramos constructivos } \\
\text { verticales }\end{array}$ & Sí & Mechinales por cajón & 3 \\
\hline Verdugada & No & $\begin{array}{l}\text { Ubicación de mechinal en } \\
\text { relación con cajón }\end{array}$ & Inferior \\
\hline
\end{tabular}

$\overline{\mathrm{x}}$ media aritmética 
De acuerdo con estos datos, se han completado los valores de altura y anchura de tapias para el lienzo D1 del tramo C-PN1. En el caso de las distancias que separan los mechinales, los datos recogidos son escasos como para una representación con diagrama de caja, por lo que se ha plasmado únicamente la mediana de las distancias recogidas en la Tabla 5.2.4, incluyendo datos visibles, probables y deducidos.

\subsection{Tipología de la tapia en tramo C-PN1}

De acuerdo con la clasificación de A. Graciani y M.A. Tabales (Tabla 5.2.6), esta tapia sería monolítica con mechinales con remate de mampuesto y sin verdugadas. De acuerdo con la clasificación de I.J. Gil Crespo, esta tapia tendría las características indicadas en la Tabla 5.2.7.

Tabla 5.2.6. Tipología constructiva de las tapias del tramo $\mathrm{CPN}-1$ de acuerdo de Amparo Graciani y Miguel A. Tabales $(2008,139)$ en el área sevillana.

\begin{tabular}{|l|c|c|}
\cline { 2 - 3 } \multicolumn{1}{c|}{} & Mechinal & Verdugada \\
\hline Monolítico & Mampuesto & Sin verdugada \\
\hline
\end{tabular}

Tabla 5.2.7. Tipología constructiva de las tapias del tramo C-PN1 de acuerdo con la clasificación de Ignacio J. Gil Crespo (2013, 554-557)

\begin{tabular}{|l|l|}
\hline A. Material de construcción & 5. Mampostería \\
\hline B. Compactación del material & 2. Vertido. \\
\hline C. Función constructiva & 1. Fábrica principal \\
\hline D. Encofrado & 1. Cajones independientes con tapiales testeros o fronteras \\
\hline E. Acabado superficial & 4. Capa externa de mampostería \\
\hline F. Combinación de materiales & 4. Mampuestos, tierra y cal \\
\hline $\begin{array}{l}\text { G. Mechinales } \\
\text { G-a. Situación }\end{array}$ & $\begin{array}{l}\text { 1. Situación en el propio hilo } \\
\text { G-b. Profundidad }\end{array}$ \\
$\begin{array}{l}\text { 2. Agujas pasantes } \\
\text { G-c. Formación }\end{array}$ & $\begin{array}{l}\text { 1. Formación aguja embebida en la fábrica } \\
\text { 2. Rectangular } \\
\text { 3. Plana } \\
\text { 4. Circular }\end{array}$ \\
\hline
\end{tabular}




\subsubsection{Lienzo interior P6-TM1, recinto 1}

El tramo P6-TM1 abarca desde el portillo de la Huerta hasta la torre moderna de acceso al adarve, construida durante la restauración de 2008 . Este tramo tiene una longitud de $86 \mathrm{~m}$ aproximadamente. La altura medible desde el interior del recinto es de $8,18 \mathrm{~m}$ de la base hasta el almenado moderno. Es visible la diferencia entre la nueva construcción y el muro original, cuyo borde superior es irregular y presenta un altura aproximada de $5,73 \mathrm{~m}$, con zonas más elevadas y otras más bajas. El portillo de la huerta se sitúa a una altura muy inferior a la existente en el interior del recinto, sólo es visible el arco del acceso. Esta posición muestra el desnivel de suelo entre el interior y el exterior del recinto. Previsiblemente, en origen, la construcción se realizaría con el suelo al mismo nivel en ambos lados de la muralla; con el tiempo, el nivel en el interior ha subido, quedando ocultas las primeras hiladas de tapia bajo la tierra. En fotografías de 2005 se ve cómo este arco se encontraba cegado por el interior. Hacia el exterior era visible el arco, pero el acceso estaba cerrado. De este tramo de casi $100 \mathrm{~m}$, se ha analizado el lienzo D2, recuadrado en el alzado general (Fig. 5.2.109).

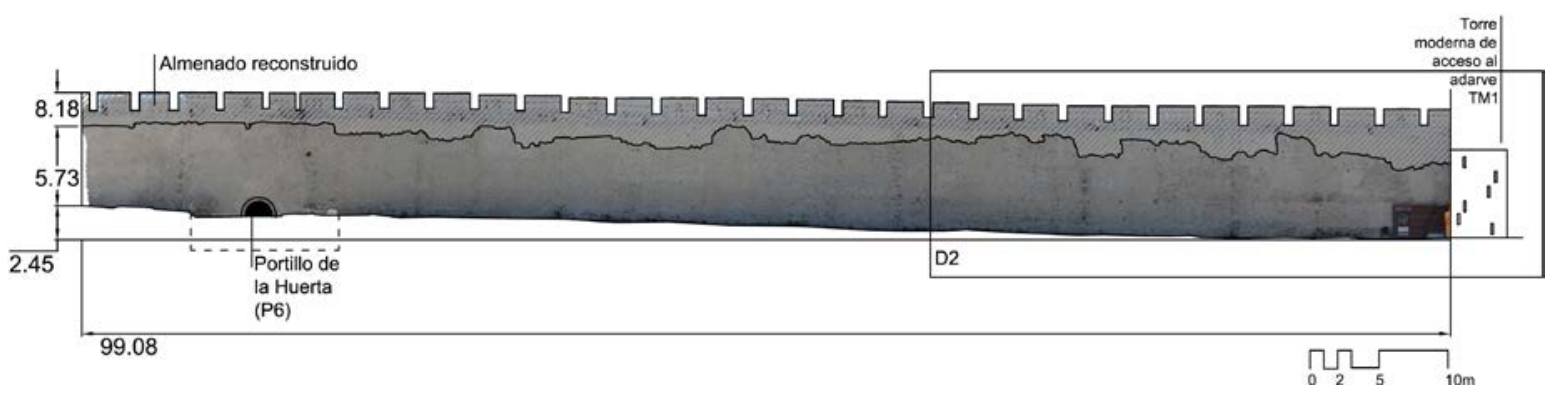

Fig. 5.2.109. Alzado interior con fotografía rectificada del tramo P6-TM1. Fuente: Elaboración propia con fotos del 20/8/2014.

El lienzo D2 se ha analizado en comparación con el estado de la muralla antes de la restauración de 2008 . Se ha podi do realizar un al zado con fotogrametría digital empleando fotografías del año 2005. En paralelo, se ha completado ese mismo tramo con fotografías actuales. Es llamativa la existencia de un elemento vertical, con escasa anchura en el frente, pero con el mismo fondo que el espesor de la muralla. Se trata de un elemento cuya función no es evidente. Sobre el portillo de la Huerta, se situaba otro elemento de similares características, ahora también desaparecido.

En este tramo, las marcas de las tapias no son tan claras como en el caso del tramo C-PN1, donde muchas de ellas son perfectamente visibles. En este caso, se aprecian las marcas horizontales de las hiladas y es posible identificar mechinales en varios puntos. No es sencillo situar los límites verticales de las tapias. Para tratar de extraer más información se ha analizado el alzado del mismo tramo con fotografías tomadas en 2005, anteriores a la restauración de 2008 (Fig. 5.2.110, arriba). En esa fecha, la muralla ya contaba con reparaciones en la base muy intensas, con la adición de nuevas piedras y morteros. Sobre esta base, son visibles algunas marcas de tapias y parte de los mechinales de las mismas. 

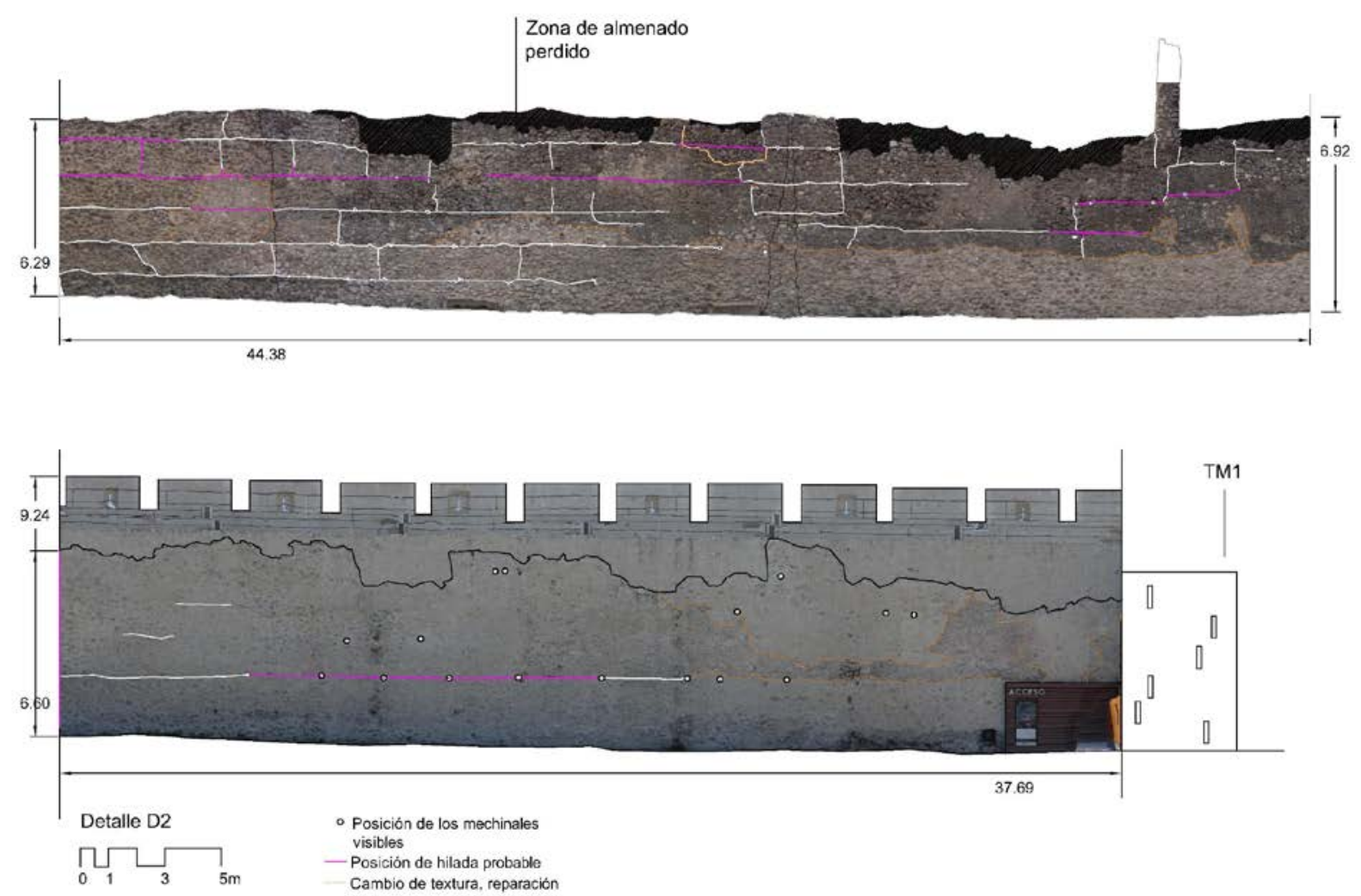

Fig. 5.2.110. Detalle D2 del tramo P6-TM1. Arriba alzado realizado con fotos del año 2005 de los arquitectos Fernando Nieto y Jesús Nieto; abajo, alzado realizado con fotos del 20/8/2014.

\subsubsection{Lienzo P6-T9, vista interior y exterior, recinto 1}

El aspecto que presenta el alzado interior de la muralla en el tramo T9-P6 es muy similar al descrito en el tramo P6-TM1. El lienzo representado (Fig. 5.2.111) tiene una longitud cercana a Ios $25 \mathrm{~m}$. Algunas de las hiladas de tapia son visibles. Las tres primeras empezando a contar desde la base tienen las siguientes alturas en orden: $1,10 \mathrm{~m} ; 1,17 \mathrm{~m} ; 1,21 \mathrm{~m}$. También son visibles algunos de los mechinales empleados para la construcción de las tapias. Apoyándose en la posición de los mechinales, es posible deducir una posición probable de las hiladas de tapias. Las tapias probables tienen una altura que oscila entre $1,18 \mathrm{~m}$ y $1,24 \mathrm{~m}$. 


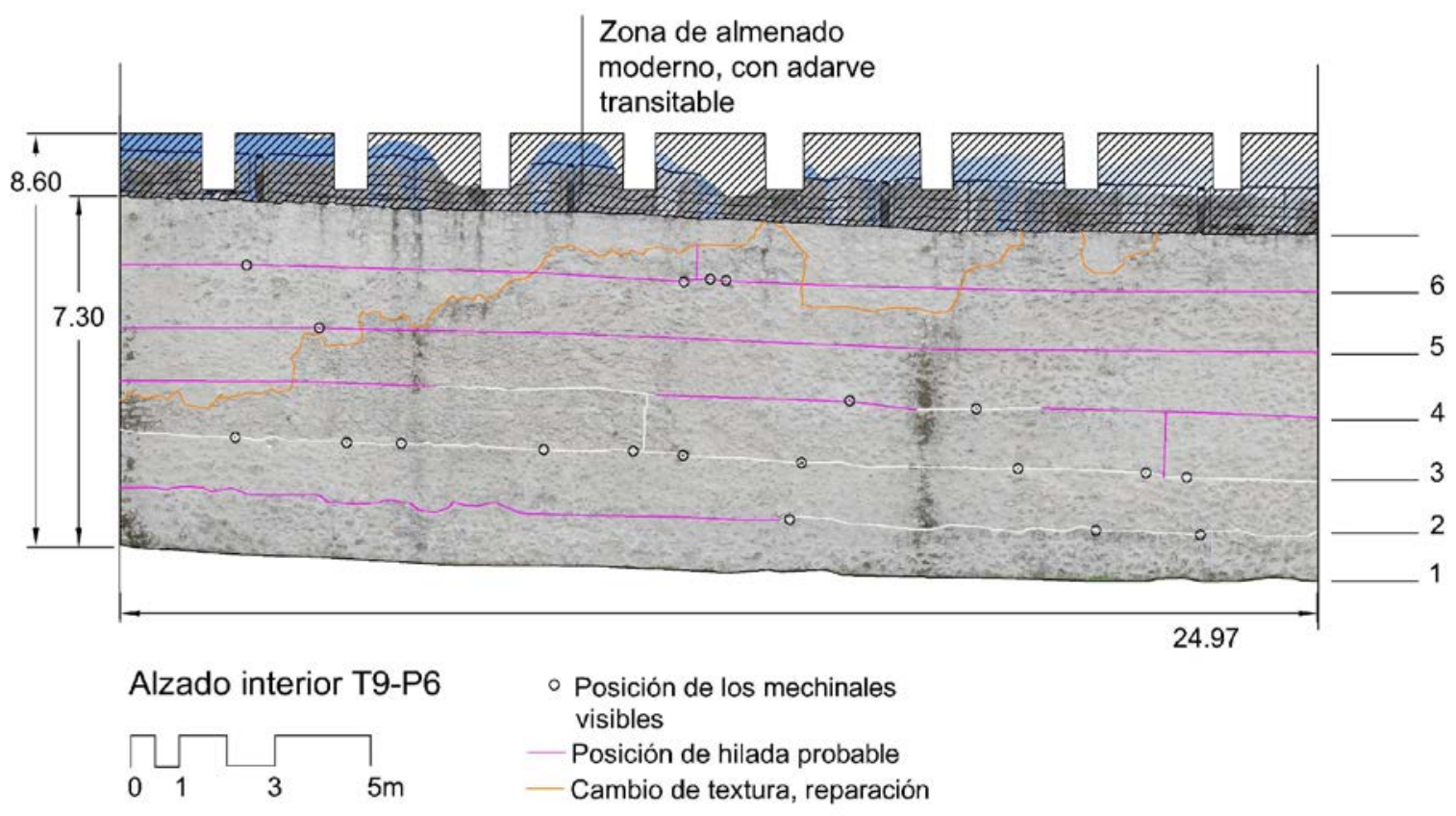

Fig. 5.2.111. Alzado interior de lienzo en el tramo T9-P6. Fuente: Elaboración propia con fotos del $12 / 5 / 2016$.

A lo largo del tramo T9-P6, es de especial interés la existencia de agujas de madera embebidas aún en las tapias, que son perfectamente visibles desde el interior del recinto. En las Fig. 5.2.112 a Fig. 5.2.117 se muestran dos mechinales que todavía contienen su aguja de madera. Se construye ambos con mampuestos, el más visible es el que corona el mechinal. El mechinal M1 (Fig. 5.2.112, Fig. 5.2.113) tiene una forma trapezoidal, con una base plana y tres lados en la zona superior que recuerda una forma semicircular. Las esquinas inferiores se encuentran ligeramente ocultas tras el nuevo mortero. En la madera es posible identificar los anillos de crecimiento del tronco empleado, tienen forma semicircular. La madera ha sido atacada por la carcoma, y se ven los huecos característicos que genera la larva de este insecto. Las dimensiones de esta aguja son de $3 \mathrm{~cm}$ de altura $\times 10 \mathrm{~cm}$ de anchura. Sobre la aguja de madera se ve una piedra irregular que configura el mechinal. La piedra está parcialmente oculta por el nuevo mortero. Es previsible que al menos otras dos piedras similares, de menor tamaño, se sitúen a ambos lados de la aguja configurando el mechinal.

El mechinal M2 (Fig. 5.2.114, Fig. 5.2.115) muestra una aguja de forma semicircular, de aspecto similar al de M1. La base es recta y en la parte superior se configura el semicírculo. La altura de la aguja es de $3 \mathrm{~cm}$, mientras que la anchura se reduce a $7 \mathrm{~cm}$. Es visible igualmente la configuración de la madera como tronco, esta vez son apreciables, en la zona izquierda de la aguja, las grietas radiales características de la sección de un tronco de madera. Estas agujas descritas parecen haberse construido cortando un tronco de árbol de $10 \mathrm{~cm}$ en dos mitades. El tronco se habría preparado eliminado la corteza mediante cortes longitudinales. 


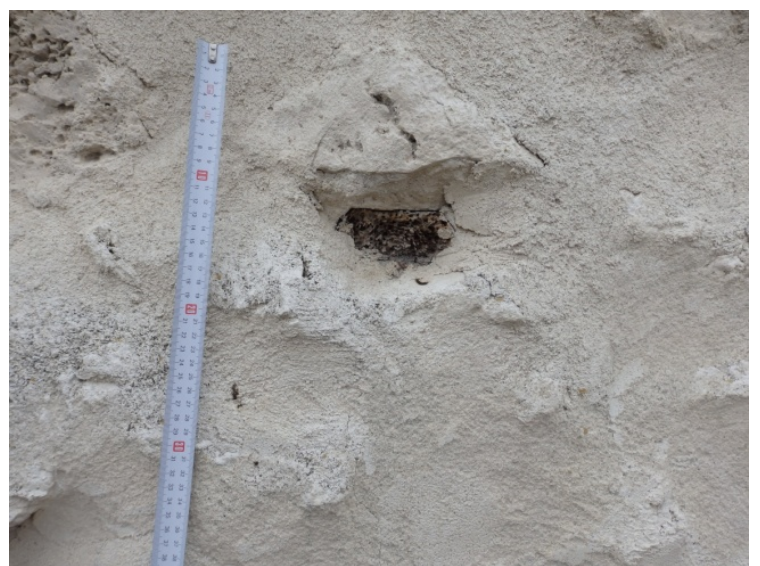

Fig. 5.2.112. Mechinal M1 que conserva la aguja de madera en su interior, situado en tramo P6-T9, visible desde la zona interior [A.S.E. 12/5/2016].

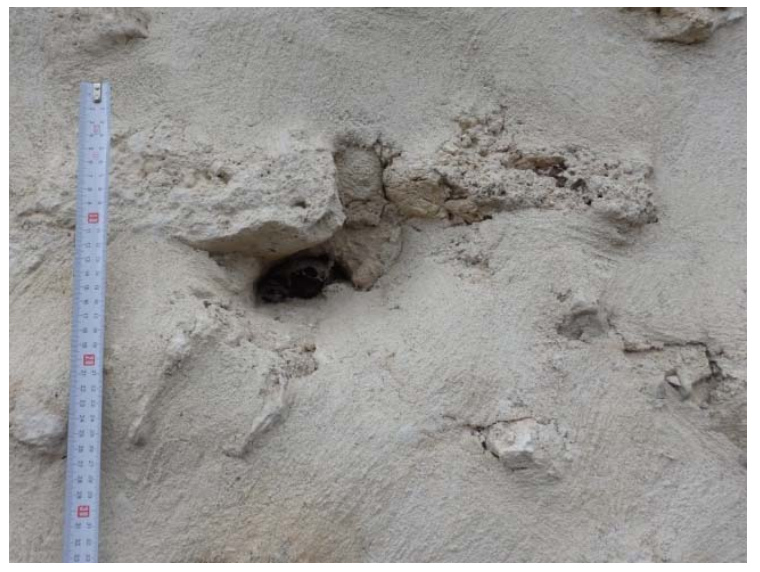

Fig. 5.2.114. Mechinal M2 que conserva la aguja de madera en su interior, situado en tramo P6-T9, visible desde la zona interior [A.S.E. 12/5/2016].

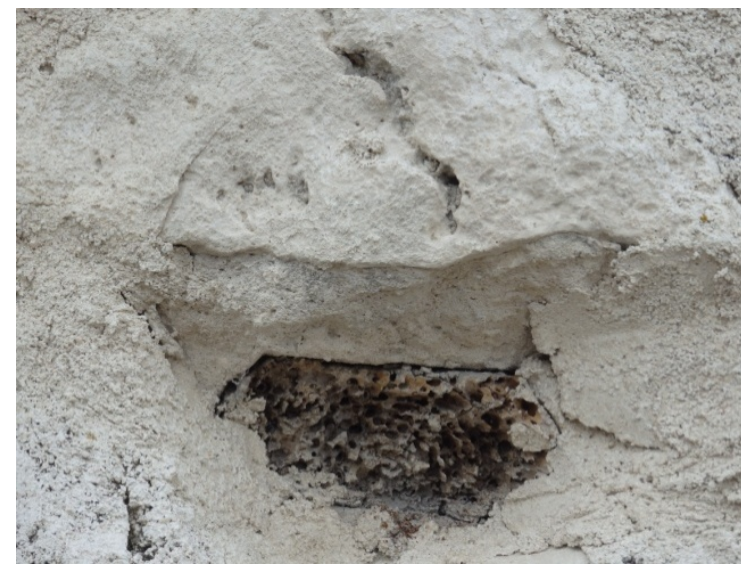

Fig. 5.2.113. Aguja de madera visible en M1 [A.S.E. 12/5/2016].

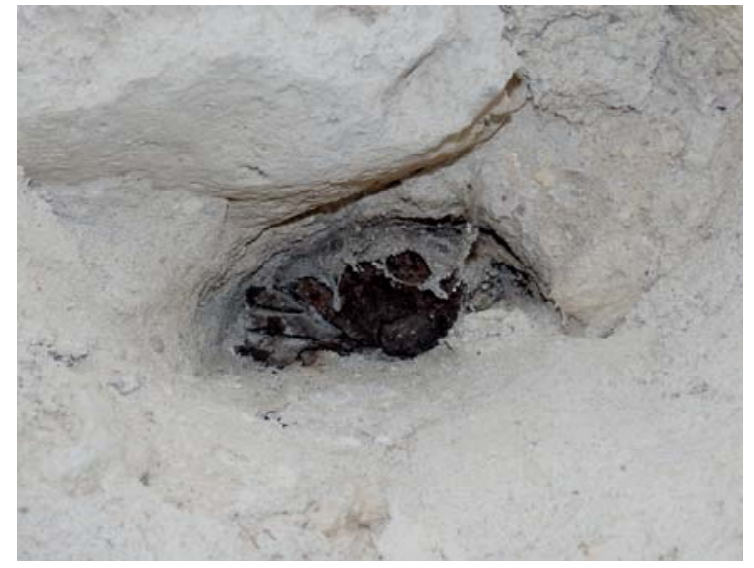

Fig. 5.2.115. Aguja de madera visible en M2 [A.S.E. 12/5/2016].

En el exterior, la muralla presenta un aspecto similar al interior. El lienzo representado a continuación (Fig. 5.2.116), tiene una longitud de casi 30 metros y parte de la torre T9 hacia el oeste. Desde el exterior, la altura de la muralla es mayor, al encontrarse el nivel del suelo más bajo que en el interior. En el interior se cuentan 6 tapias de altura hasta la base del almenado, frente a las 9 tapias en el exterior. Se ha querido reflejar la situación de la muralla antes de ser restaurada en el mismo tramo de muralla. En la imagen anterior a la restauración, se observan reparaciones intensas en toda la base que superan los $3 \mathrm{~m}$ de altura. Por encima de ese nivel se observan marcas de las tapias que componen la muralla. En la parte superior, se identifican mechinales. Son visibles igualmente tres saeteras en los restos del almenado. Dos de ellas tienen un hueco cruciforme y la tercera se compone de dos sillares separados entre sí. 


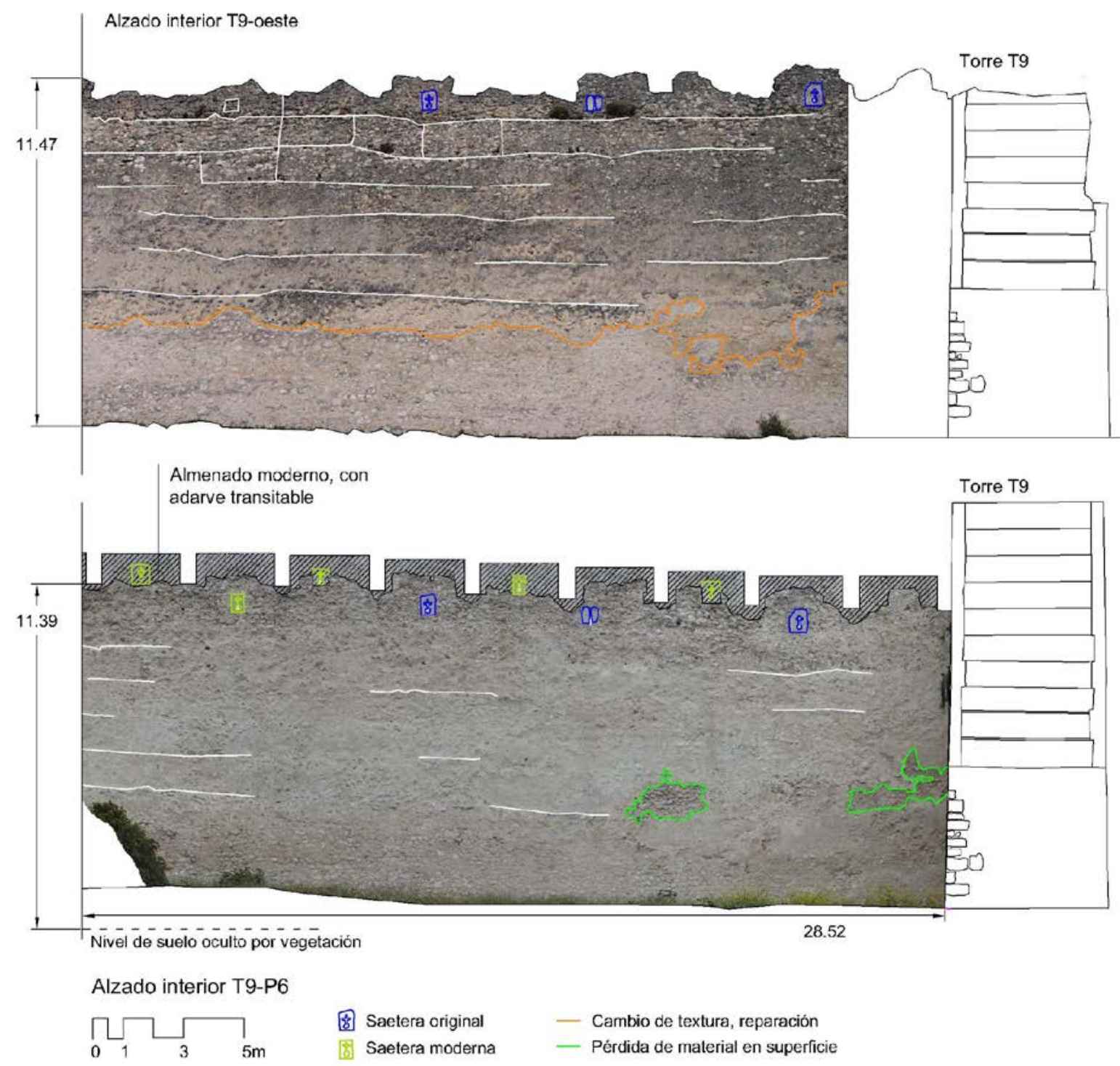

Fig. 5.2.116. Lienzo exterior del tramo T9-P6. Arriba, elaborado con fotos de 2005, facilitadas por los arquitectos Fernando Nieto y Jesús Nieto, abajo elaborado con fotos de 2016.

De forma general, las hiladas son regulares y paralelas al suelo y no presentan saltos o interrupciones. Las tapias identificables completamente en este lienzo son escasas, se encuentran cuatro en la zona superior. Las dimensiones en anchura oscilan entre los 2,50 y $2,60 \mathrm{~m}$. La altura se mantiene entre 1,00 y $1,20 \mathrm{~m}$.

\subsubsection{Lienzo P9-P10, en calle de la Muralla, recinto 2.}

Como se ha dado a entender en la descripción general, este tramo es uno de los pocos del recinto 2 que son visibles de forma completa y desde la calle. En el recinto 2 , los lienzos se encuentran mayoritariamente en el interior de pa rcelas, entre edificaciones que se han adosado a ellos paulatinamente. Este tramo muestra una 
diferencia en relación con los otros lienzos: las construcciones posteriores a la muralla no se han pegado a ella por completo. En la zona izquierda superior del esquema en planta del tramo (Fig. 5.2.117), se ven algunas parcelas adosadas al lienzo. En el resto del tramo, las viviendas se separan de la muralla. En la calle de la Muralla se sitúa la separación más pequeña, de apenas 1,40m. Esta separación se va ensanchando a medida que continúa la calle, con casi $5 \mathrm{~m}$ en la zona más cercana a la puerta de Carchena. En la calle de los Herreros, la separación más pequeña es de 2,90m. En este caso, la calle continúa hacia el oeste separándose del lienzo de muralla, punto en el que la separación de las edificaciones es de 4,60m.

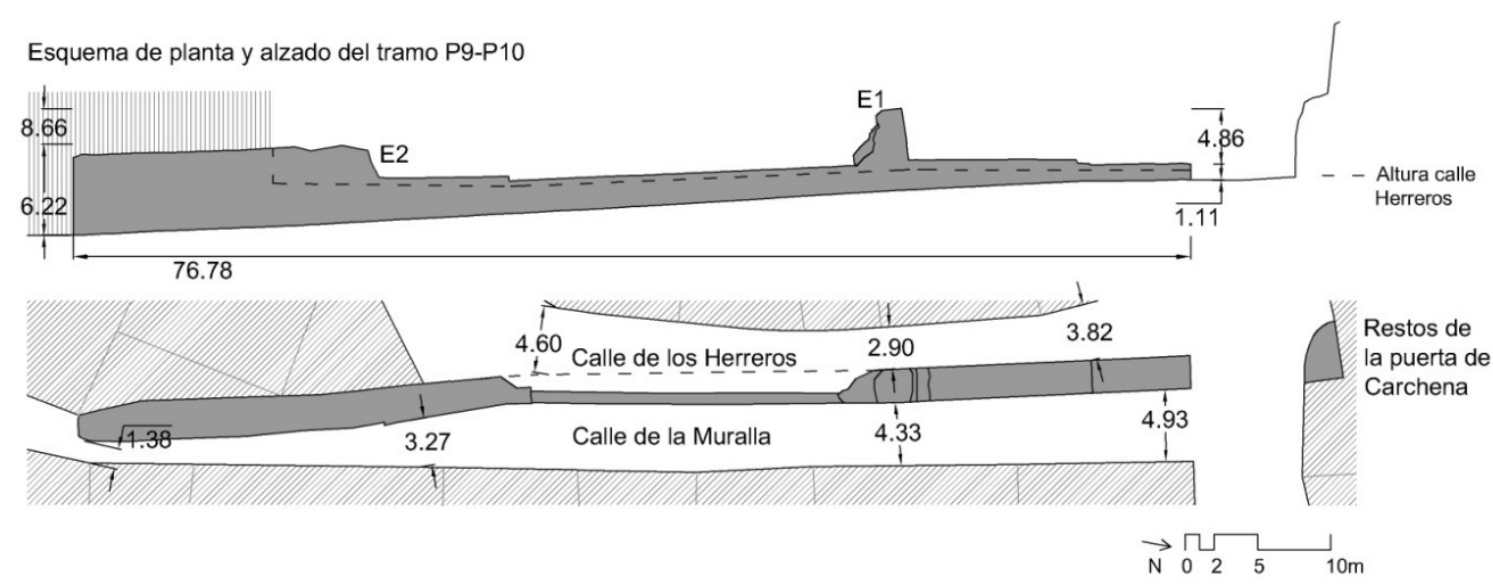

Fig. 5.2.117. Esquema de planta (abajo) y alzado (arriba) del tramo P9-P10. Realizado a partir de dibujos topográficos facilitados por los arquitectos Fernando Nieto y Jesús Nieto, elaborados por Topoinca.S.L.

La altura de este tramo es escasa, con zonas donde no supera los $1,50 \mathrm{~m}$. En la calle Herreros, la muralla se eleva apenas $50 \mathrm{~cm}$ sobre el nivel de suelo. Desde la calle Muralla, la altura visible es mayor. El elemento E1 se eleva por encima del resto del tramo, con una altura de cercana a los $4 \mathrm{~m}$. El elemento E2 se eleva sobre el resto del tramo y mantiene su altura de $6,22 \mathrm{~m}$ a lo largo de $21 \mathrm{~m}$.

Desde un punto de vista constructivo, son visibles algunos detalles que evidencian el uso del tapial también en este tramo. En el alzado a la calle Muralla, se ven líneas horizontales que marcan las hiladas de tapias. Desde la calle Herreros, se puede ver la configuración del elemento E1, ya que la sección de la muralla queda al descubierto. Son visibles, al menos, dos límites horizontales de tapia (Fig. 5.2.119, Fig. 5.2.120). El primero de ellos es más reconocible, en la sección es claramente identificable. En el segundo caso, no está tan clara su posición, ya que se separa del primero una distancia de $90-100 \mathrm{~cm}$, altura menor de I a habitual en I as tapias de los tramos estudiados de Cuéllar. En este tramo no es sencillo determinar los límites de una tapia en los alzados, pues han sido borrados por las distintas reparaciones, que han tendido a regularizar y homogeneizar. En cualquier caso, las marcas visibles son testigo del sistema de construcción empleado. También se pone de manifiesto la continuidad del sistema constructivo a lo largo de la sección del muro, es decir, no se ha construido de forma independiente una cara del muro en relación con la otra. 


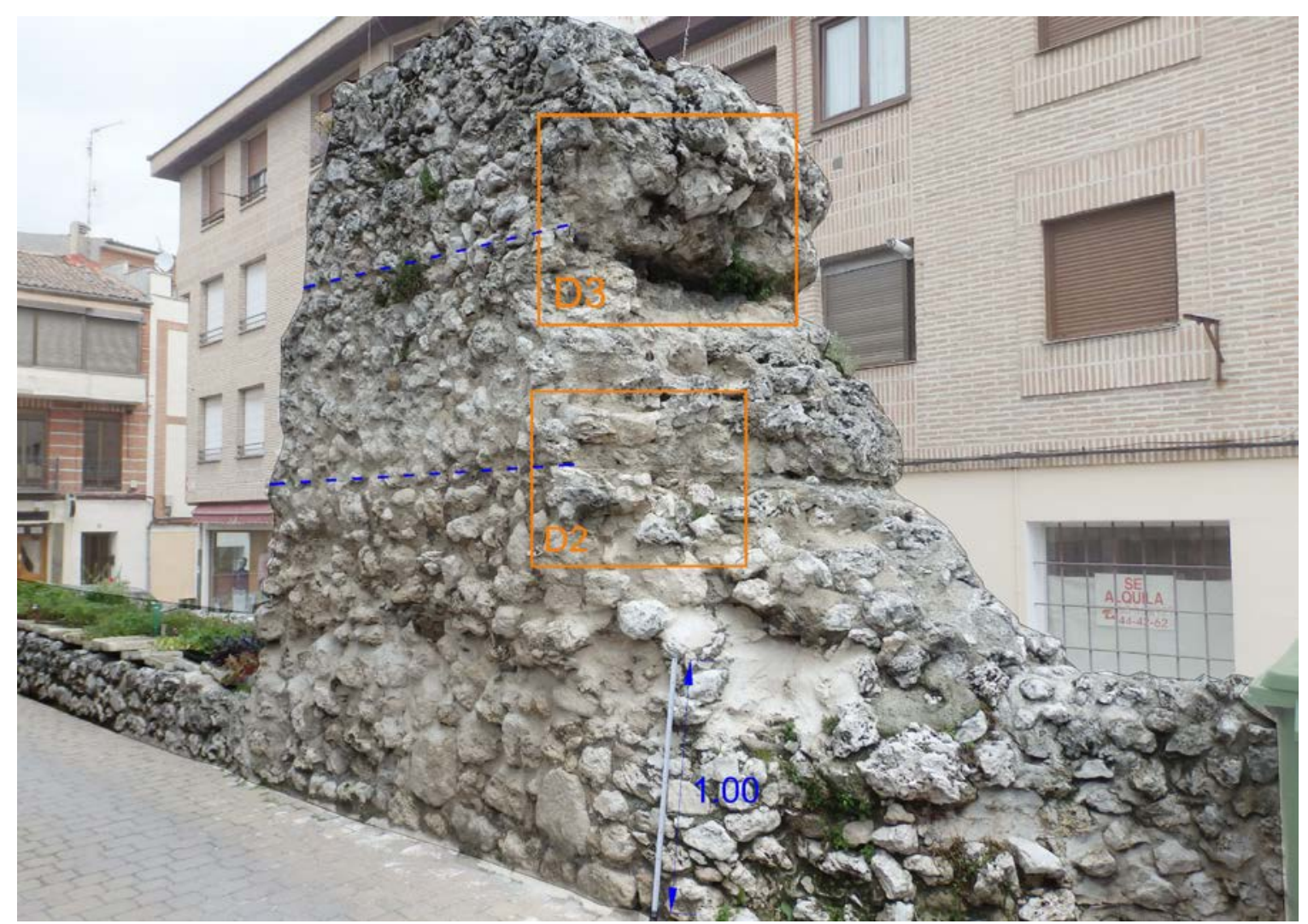

Fig. 5.2.118. Elemento E1 del tramo P9-P10, donde son visibles los límites horizontales de las tapias, marcados en línea a trazos azul. Elaboración propia sobre foto del 12/5/2016.

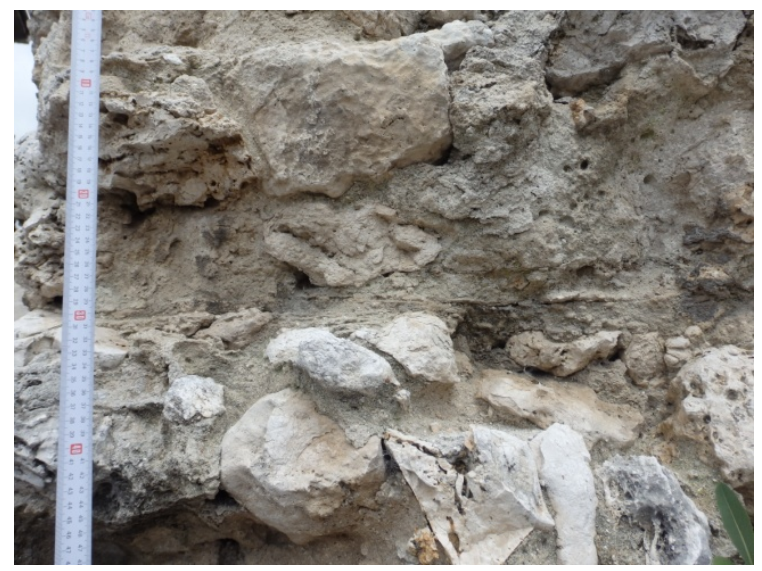

Fig. 5.2.119. Detalle D2, donde se ve la línea horizontal entre tapias

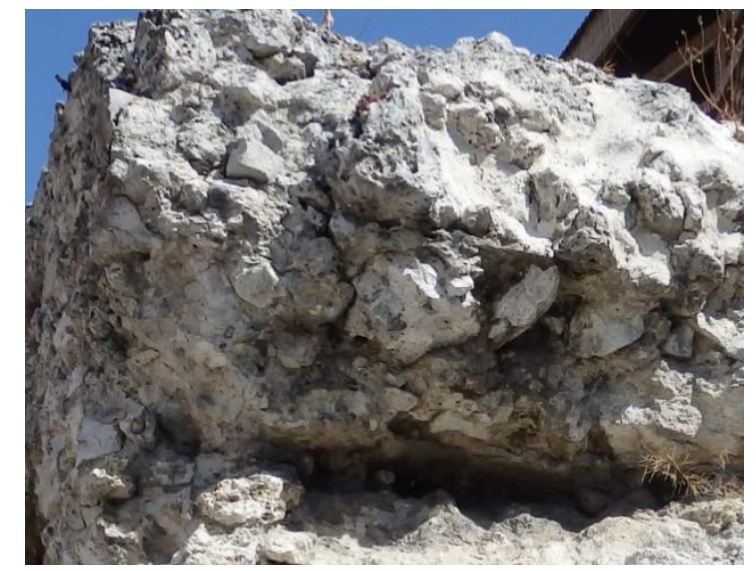

Fig. 5.2.120. Detalle D3, donde se observa el límite entre tapias.

El elemento E2 se yergue por encima de la altura media del tramo y muestra igualmente parte de la sección del muro. En este caso se observa el añadido de mortero en su restauración, lo que oculta en parte el aspecto original de la sección del muro. En este tramo, es perfectamente visible la anchura del muro, que alcanza los 2,04m (Fig. 5.2.121). 


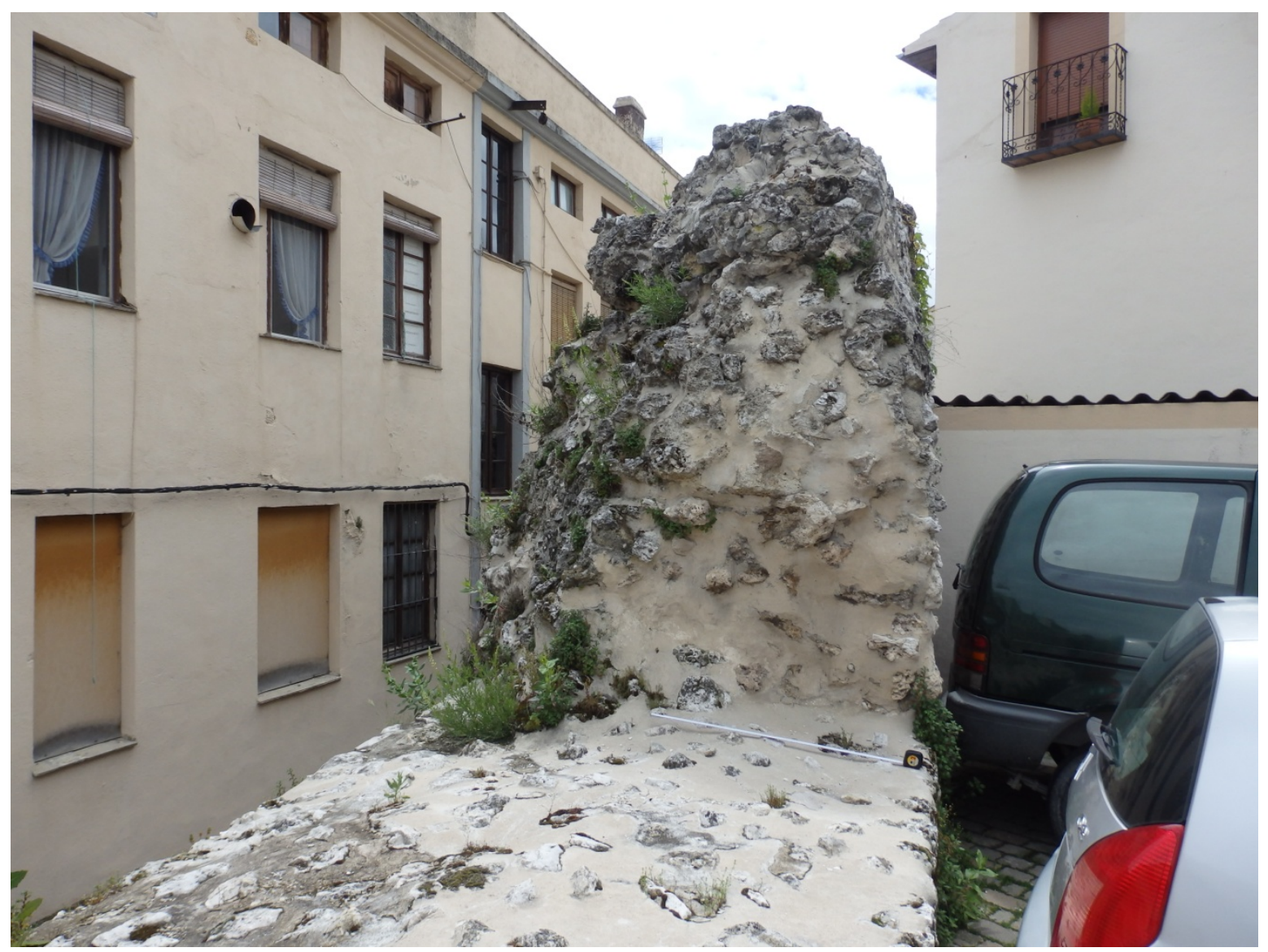

Fig. 5.2.121. Elemento E2 del tramo P9-P10. El metro marca la distancia de 1,00m. La anchura del muro en este punto es de 2,04m [A.S.E. 12/5/2016].

\subsubsection{Resumen de resultados para el caso de Cuéllar}

Es notable la abundancia de restos de muralla conservados en Cuéllar. La continuidad de estos lienzos es muy importante en el primer recinto amurallado, donde son visibles los lienzos en toda su longitud, tanto desde el exterior como desde el interior del recinto. En el segundo recinto, los restos son más inaccesibles e i ntermitentes, haciendo su estudio más difícil. La villa cuenta con dos recintos amurallados diferentes, 0 incluso tres recintos diferentes, si se tiene en cuenta las hipótesis mencionadas anteriormente acerca de un recinto a la altura de la iglesia de $S$ an Martín. El tejido urbano analizado muestra la agrupación por conjuntos, por barrios que los nuevos recintos amurallados rodean a su vez. La forma de los recintos parece responder a la inclusión de barrios nuevos y a razones topográficas. Por otra parte, las áreas que rodean al castillo se encuentras vacías en la actualidad, el trazado urbano presenta grandes parcelas que han perdido toda traza de su configuración original, que muestran un vaciamiento que parece haberse mantenido así desde que se inició.

En cuanto a las características generales de la muralla, el estudio del lienzo T9-P6 desde el exterior, arroja una altura de casi $12 \mathrm{~m}$ hasta lo alto del almenado. El espesor de los lienzos se sitúa en torno a los $2 \mathrm{~m}$ en varios puntos de la muralla. De forma 
Las murallas en las Comunidades de Villa y Tierra de la Diócesis de Segovia en los siglos XI a XIII. Técnica y sistemas constructivos de la arquitectura defensiva medieval.

general, es sorprendente la escasez de torres que se conservan en es te conjunto amurallado. Como queda reflejado en la Tabla 5.2.1, la gran mayoría de las torres que se conservan forman parte de una puerta. Sorprende la gran longitud de al gunos tramos sin torres, que llega a superar los $200 \mathrm{~m}$. No se observan puntos donde sea evidente la desaparición de una torre existente, por lo que es factible que no existieran muchas más torres de las visibles en la actualidad.

Desde un punto de vista constructivo, es significativo el empleo de mampostería encofrada en todo el recinto amurallado. Los lienzos que se conservan utilizan esta técnica, a excepción del tramo T6-T7, donde no es claramente identificable en toda su longitud. Es de especial interés que dada la existencia de dos recintos diferentes, e incluso un tercero en la zona más cercana al castillo, se comparta en estos recintos el sistema constructivo de la tapia, aunque con diferencias. También es reseñable que el espesor de estos muros también sea relativamente constante en los tres recintos. En este caso, la presencia del sillarejo, puede tener una relación con su proximidad a la puerta de San Martín (P3). Otras soluciones constructivas, como la tapia mixta, o la existencia de sillería y sillarejo, aparecen sólo en puertas y torres. Por otra parte, en el empleo de la tapia se observan diferencias en las formas de los mechinales empleados, tanto entre distintas partes de la muralla, como en los mismos lienzos. En los tramos estudiados, se han extraído características de las tapias que muestran diferencias principalmente en las formas de los mechinales empleados. En la Tabla 5.2.5 se puede consultar las características habituales de las tapias de uno de los tramos analizados. El aparejo de tapias no es totalmente identificable, y es difícil aventurar si existen tramos constructivos mediante los cuales se iba edificando la muralla. En el tramo C-PN1, se muestra un I ímite vertical de las tapias, que puede significar el final de un tramo (Fig. 5.2.102).

No se observa de forma generalizada la construcción de una base para los lienzos de muralla, construida como tal. Las tapias parten directamente del suelo, de la roca. Por contra, sí que son visibles algunas preexistencias en las bases de lienzos, como por ejemplo en el caso de la puerta de Santiago, donde la torre T8 presenta una base diferenciada con un aparejo de piedra singular.

Los recursos defensivos de la muralla son relativamente limitados. Como se ha comentado antes, es visible una aus encia de torres de flanqueo que faciliten la defensa de los lienzos de muralla. Se conserva parte del almenado original, al menos de dos tipos, de almena alargada con proporción 5 a 1 entre almena y hueco, y cuadrada con proporción 1 a 1 . Sobre las almenas se sitúan saeteras con huecos cruciformes y con huecos verticales. Aparte de las formas cruciformes en las saeteras, no se encuentran otros elementos decorativos en I os lienzos de $\mathrm{m}$ uralla. En las puertas y torres se encuentran combinaciones de materiales que tal vez tengan una intención estética, pero no así en los lienzos. 


\section{3}

\section{Fuentidueña}

Segovia

\subsubsection{Localización}

Fuentidueña se encuentra en la zona norte de la actual provincia de Segovia. El territorio de su comunidad linda con las provincias de Valladolid y Burgos. La comunidad de V illa y Tierra de Fuentidueña tenía una extensión de $460 \mathrm{~km}^{2}$ aproximadamente. Tiene un tamaño medio, menor que las superficies de $\mathrm{C}$ uéllar $\mathrm{O}$ Sepúlveda, pero superior a las de Coca o Pedraza. El río Duratón atraviesa comunidad de sur a norte. Limita al noroeste con Peñafiel y al noreste con Haza; al sureste con Sepúlveda y al suroeste con Cuéllar. El núcleo de población se sitúa a $75 \mathrm{~km}$ de la capital segoviana y a $80 \mathrm{~km}$ de la ciudad de Valladolid. La distancia de la población de Fuentidueña a otras villas cabecera vecinas ronda los $30 \mathrm{~km}$.

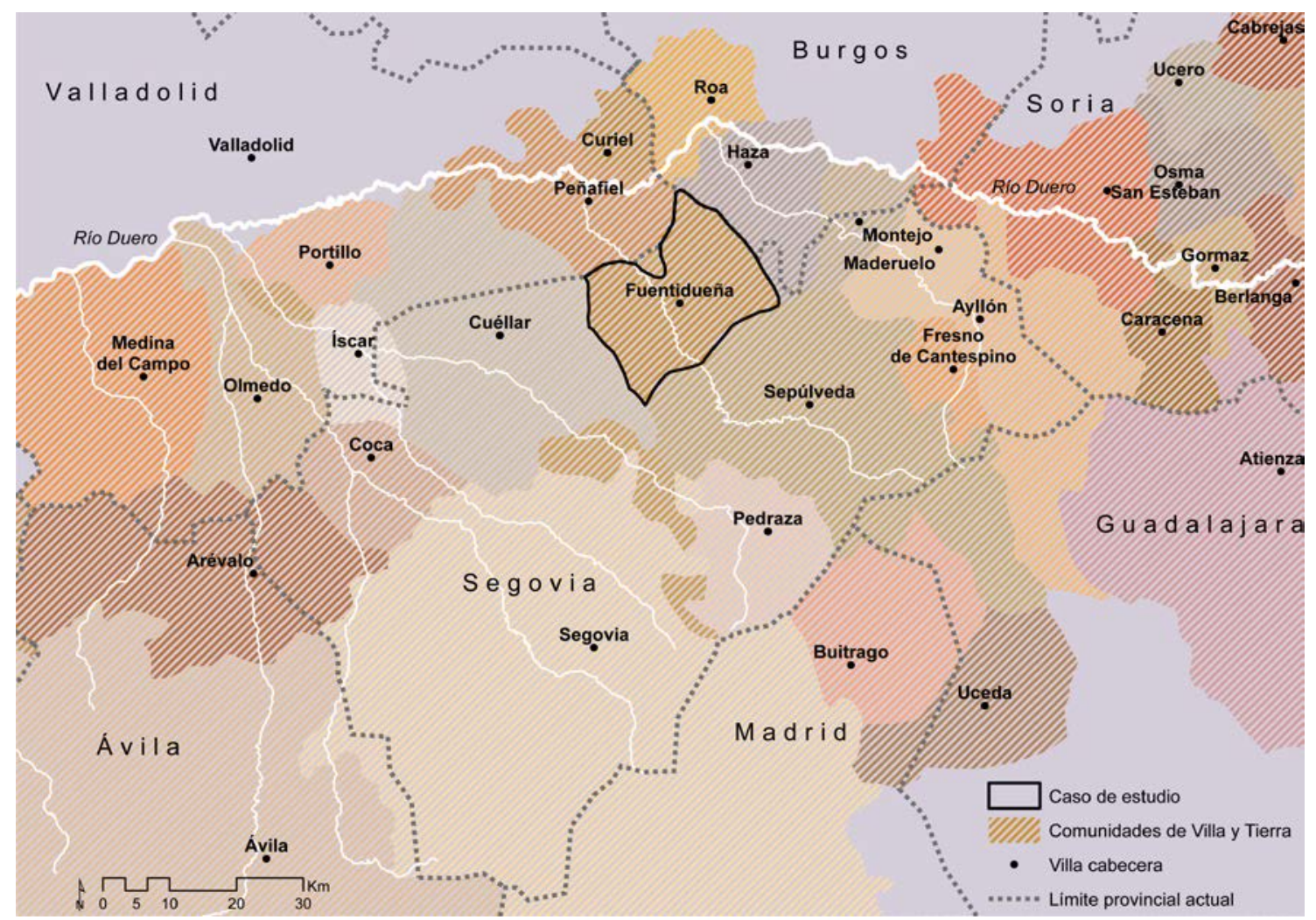

Fig. 5.3.1. Localización de la comunidad de Fuentidueña. Fuente: Elaboración propia a partir de planos de G. Martínez Díez (1983, 11-15) y J.M. Monsalvo $(2010,152)$. 
La población se localiza junto al río Duratón, cercana a la intersección con el Arroyo del Prado. Se sitúa sobre una elevación de terreno. La altitud del punto más alto del núcleo, correspondiente a los restos del castillo, es de 906 metros sobre el nivel del mar. El valle del Duratón se encuentra a $805 \mathrm{~m}$ de al titud. El caserío actual de Fuentidueña ha crecido en dirección norte, hacia el valle, buscando una zona más llana de asentamiento, quedando vacío el espacio que rodea el castillo. Hacia el noreste se eleva una colina hasta los $915 \mathrm{~m}$, en la zona de Dos Hermanas. Desde Dos Hermanas hacia el norte, en paralelo con la dirección del Duratón, la altitud del terreno alcanza los $960 \mathrm{~m}$, con topografía serpenteante. Al otro lado del río Duratón, hacia el noroeste, se eleva la ladera del Poyal dando inicio al páramo que se extiende hacia el oeste y que tiene una altitud que ronda los 930m. Tiene una pobl ación de 144 habitantes, de acuerdo con los datos del Instituto Nacional de Estadística en el año 2015.

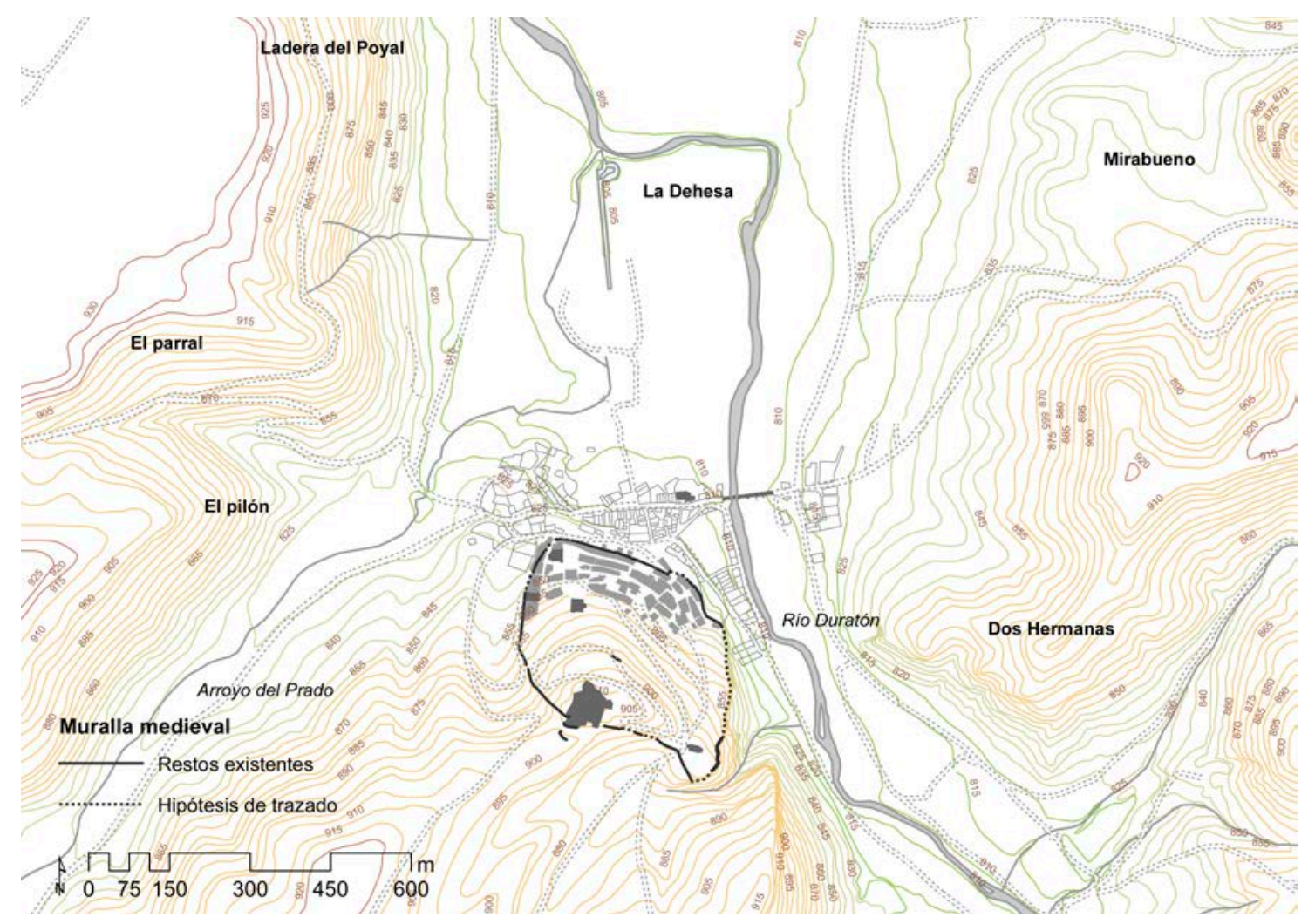

Fig. 5.3.2. Plano topográfico y de catastro de Fuentidueña. Fuente: Elaboración propia con datos del IDECyL [http://www.cartografia.jcyl.es/] y Catastro [http://www.catastro.meh.es/].

\subsubsection{Estudios en la villa}

Los estudios realizados sobre la villa de Fuentidueña no son abundantes. Desde un punto de vista histórico, es conocida la publicación de Justo Hernansanz (1985) acerca de Fuentidueña y su alfoz donde recoge acontecimientos históricos relacionados con la villa, describe su entorno y comenta los edificios de interés histórico como el castillo o las iglesias del núcleo. En cuanto a las murallas, no destina un capítulo específico para ellas, pero recoge fotografías antiguas de sus tres puertas $(64,65,72)$. También 
centrado exclusivamente en I a villa de Fuenti dueña, Juan Cuéllar $(2007,2012)$ ha realizado un análisis histórico de la misma que ha dado como resultado la realización de su tesis doctoral sobre esta villa y su alfoz. Como se desprende del apartado anterior, Gonzalo Martínez $(1983,397-405)$ recoge en su publicación sobre las Comunidades de Villa y Tierra un capítulo destinado a la Comunidad de Fuentidueña, donde menciona fechas históricas de interés para la villa y describe la configuración del territorio asociado a la misma, con una enumeración de las aldeas que existieron, algunas hoy despobladas. En la publicación de Murallas de España (Jiménez 1993, 172-179) el autor incluye la muralla de Fuentidueña entre los 45 ejemplos que recoge. Ningún otro de los casos estudiados aquí aparece en esa clasificación.

\subsubsection{Datos históricos destacados del núcleo}

Se conocen pocos datos históricos de Fuenti dueña y no abundan I as publicaciones que aborden directamente la historia del núcleo. De forma general, los investigadores que han trabajado sobre Fuentidueña han podido extraer de documentos históricos datos puntuales en los que se cita la villa de Fuentidueña casi de forma accidental en algunos casos, o donde aparece como lugar donde s e firma un acuerdo o una donación regia. El resultado de la investigación documental arroja un listado de fechas que no tienen relación entre sí, que simplemente indican que la villa existió en esos años, puesto que aparece mencionada, pero que no aporta mucha información acerca del estado de la villa y tampoco acerca de sus murallas. El sistema concejil, basado en el trabajo y la participación de los propios pobladores, no dejó documentos físicos que permitan conocer con mayor detalle hechos ocurridos en la época, y solo se dispone de documentos regios o ec lesiásticos. Durante los siglos XII y XIII, aparece documentación de la zona con mayor frecuencia (Cuéllar 2007, 48). Como queda reflejado más adelante, a diferencia de otros casos, el rey Alfonso VIII se sentía especialmente ligado a la villa de Fuentidueña, factor que ha permitido situarla en el panorama político de la época en fechas puntuales a lo largo de la vida del monarca.

Los datos recogidos por Gonzalo Martínez (1983, 397-401) de los núcleos cabecera de las Comunidades de Villa y Tierra indican algunas fechas de interés, que aportan pistas acerca de la creación de esta comunidad. En 937 se da la primera presencia castellana en lo que será la tierra de Fuentidueña. La zona aparece citada en un documento de donación del Monasterio de Santa María de Cárdaba a San Pedro de Arlanza por parte del Conde Fernán González. En el mismo siglo, en 943, el diploma de Cardeña relata la creación del condado de Monzón. Se atribuye a este nuevo condado el castillo de Sacramenia. Sacramenia aparece como cabeza de la tierra, Fuentidueña todavía no existiría aún. A finales de siglo, en 983, en las campañas de Almanzor desmantelan la repoblación de los condes de Monzón (Martínez 1984, 397398).

Ya en el siglo XI, en 1009, se conoce una segunda repoblación bajo la dirección del conde de Castilla Sancho Garcés (Martínez Díez 1983, 398). A lo largo de este siglo, en 1035, Sancho el Mayor erige la diócesis de Palencia, donde solo figuran Peñafiel y 
Las murallas en las Comunidades de Villa y Tierra de la Diócesis de Segovia en los siglos XI a XIII. Técnica y sistemas constructivos de la arquitectura defensiva medieval.

Portillo. Años más tarde, en 1059, se confirman los límites de la diócesis de Palencia por Fernando I y la villa de Fuentidueña no figura entre las villas enumeradas. Gonzalo Martínez Díez $(1983,400)$ concluye que la repoblación no podría no haber continuado tan al sur, o bien que Fuentidueña podría formar parte de Peñafiel. En 1089, se citan territorios de la zona, en documentos que relatan cuando Alfonso VI dio a M aría Peláez una heredad en el alfoz de Muñó a cambio de Membibre de la Hoz.

En el siglo XII, en 1123, la bula del Papa Calixto confirma los límites de la diócesis segoviana. Menciona lugares como Membibre, Bernuy, Sacramenia que fo rmarán parte más adelante de la comunidad de Fu entidueña. Estos lugares también se mencionan más tarde en un diploma de 1130 del arzobispo Don Raimundo. Es en 1136, cuando Fuentidueña aparece mencionada por primera vez de forma directa, Fontedomna, en la enumeración de villas donde el rey Alfonso VII cedió el diezmo a la iglesia católica. El 30 de enero de 1141, s e funda el monasterio cisterciense en la Comunidad de Fuentidueña (Martínez Díez 1983, 401). De acuerdo con Juan Cuéllar $(2007,42)$ de 1147 data un doc umento del rey Alfonso VII donde se menciona directamente a Fuentidueña "...que est in termino de Fontedonnae".

La notable expansión económica que tuvo lugar en este territorio desde mediados del siglo XII se prolongó hasta la primera mitad del siglo XIII. Juan Cuéllar $(2007,48)$ indica que esta bonanza se notó en la villa de Fuentidueña, y se trasluce en la mayor importancia que adquirió la villa el ámbito eclesiástico. Concretamente, se refieren las protestas de los clérigos de Fuentideña, Cuéllar, Sepúlveda, Pedraza y Alcazarén en relación con la aplicación demasiado rígida de decretos dictados por el arzobispo de Toledo. Estas protestas se perpetúan a lo largo de varios años, llegando el papa Inocencio III a plantear su resolución en 1206 . Quedaron sin resolver hasta el año 1218, cuando interviene el arzobispo de Tol edo corrigiendo los decretos de acuerdo con las protestas.

La importancia de Fuentidueña también queda reflejada por la presencia de la monarquía en varios momentos de su historia. Como se ha indicada anteriormente, el rey Alfonso VIII tiene un vínculo con esta villa, hasta el punto de que su testamento se firma en la misma en otoño del año 1204. Este documento muestra que el rey se encuentra en Fuentidueña, en momentos de enfermedad y debilidad, y pone de manifiesto que esta villa se utilizaba como residencia temporal y que desde la misma se tomaban decisiones políticas y territoriales como la devolución de plazas a los reinos de Navarra o de León (Martínez Sopena 2010, 108). Tres años más tarde, el monarca otorga un privilegio al monasterio de Sacramenia, confirmando todas sus heredades en Fuentidueña (Martínez Díez 1983, 401). A finales de siglo, en 1294, se conoce la visita del rey Sancho IV a Fuentidueña y otras villas cercanas como Cuéllar, Íscar, Peñafiel o Aldeamayor (Cuéllar 2007, 49).

Tras la bonanza económica, la crisis de la segunda mitad del siglo XIII afecta a las villas de e sta investigación. Juan Cuéllar $(2007,49)$ indica que en Fuentidueña se redujeron los rendimientos y la producción en el sector agrario. Para apoyar esta hipótesis, se aporta un documento de 1290 que hace referencia a Fuentepiñel y Los Valles, dos de los pueblos del alfoz de Fuent idueña, donde se describe un nú cleo arruinado, con casas sin cubierta, corrales sin puerta o cerca y viñas sin labrar. 
En continuación con la situación económica del anterior siglo, en el siglo XIV se inician los denominado "años malos" que Juan Cuéllar $(2007,49)$ refiere de acuerdo con las Crónicas de los Reyes de Castilla, donde se menciona una gran hambruna que tuvo como resultado un al to nivel de mortandad. Un documento extendido por la infanta doña Isabel que data de 1308 confirma cartas y privilegios concedidos por los antepasados en I a villa de Fuenti dueña a aquel los residentes en el interior de los muros de Fuenti dueña, con el objeto de mejorar las condiciones de la villa y atraer población de otras zonas, para que m ejore la situación (Cuéllar 2007,50). Más adelante, la peste negra se extiende en la zona afectando a la población de esta villa y de muchas otras. Aparece descrita en I a Crónica de Alfonso XI como grande pestilencia (51).

Durante el reinado de Alfonso XI, pudo ser su tutor don Juan Manuel quien entregara la villa de Fuentidueña, junto con los pueblos de su alfoz, a Rui González Castaneda. Tras disputas entre Juan Manuel y el rey, que se traducen en el asolamiento de estos territorios con la ayuda del ejército aragonés, el propio Alfonso XI dona la villa a su hijo don Tello, aunque a la muerte de este retorna de nuevo la propiedad al rey. Será Juan I quien la entregue en 1379 al hijo de Rui González, Juan Rodríguez de Castaneda, y pasará más adelante a su hijo que lleva el mismo nombre (Cuéllar 207,50). Esta conversión en señorío pone fin a la autonomía de la villa, que ya estaba anunciada de acuerdo con la mencionada oligarquización del sistema de concejos, descrita en el capítulo tercero.

En el siglo XV, el señorío de Fuentidueña pasó a manos del hijo de Juan Rodríguez Castañeda, Rodrigo. A su muerte, la villa y sus aldeas pasan de nuevo a ser propiedad del rey hasta 1443, cuando se entregaron de nuevo por Juan II a don Pedro de Luna Manuel, que tomó posesión de la villa tres años más tarde. Este nuevo señor residió en Fuentidueña hasta su muerte en 1490, cuando pasó el señorío a manos de su hijo Álvaro de Luna (Cuéllar 2007, 51).

Consolidado el control de la nobleza sobre la antigua Comunidad de Villa y Tierra, la Iglesia retoma el control de las parroquias de la diócesis de Segovia, iniciándose el proceso a través de una i nspección realizada entre 1446 y 1447 (Cuéllar 2007, 52), que pone de manifiesto que no ex istió un seguimiento intenso de las actividades de estas parroquias.

Como se ha planteado al principio, estos datos y fechas son conocidos a partir de documentos históricos puntuales, con escasa conexión entre sí. Durante los siglos $\mathrm{X}$ a XII, los datos aportados no permiten entender qué forma de gobierno existía en la villa o cuál era su funcionamiento. Sólo en los siglos XIII, XIV y XV estos datos parecen corresponderse más fácilmente con otros aspectos, como el económico o el político.

\subsubsection{Tejido urbano}

El parcelario urbano de Fuentidueña se sitúa en la zona norte del recinto amurallado, en la falda del cerro. La zona más próxima al castillo ha sido abandonada y en la actualidad aparece vacía de edificación. El núcleo urbano ha descendido y se agrupa 
Las murallas en las Comunidades de Villa y Tierra de la Diócesis de Segovia en los siglos XI a XIII. Técnica y sistemas constructivos de la arquitectura defensiva medieval.

solo en la zona norte del recinto, extendiéndose también más allá de la muralla, con parcelas que se sitúan en el valle del Duratón. Juan Cuéllar $(2007,120)$ sostiene que la mayor parte del espacio dentro del recinto nunca fuese ocupado por construcciones, e indica (121) que el número de habitantes de esta población siempre fue escaso, inferior al de otras poblaciones vecinas del alfoz, como Sacramenia.

En el interior del recinto amurallado, las calles discurren de acuerdo con la topografía, siguiendo las curvas de nivel. Las calles Nueva (840m), San Miguel Baja (845m), San Miguel Alta $(850 \mathrm{~m})$ y Bodegas $(860 \mathrm{~m})$ son paralelas y se adaptan a I a topografía. Habitualmente, las parcelas son pasantes, es decir que tienen salida en dos calles paralelas. En el interior del recinto amurallado, las parcelas que permanecen tienen una forma rectangular, con anchuras pequeñas de hasta 3,00m. Los fondos de parcela oscilan entre los 10,00 y 20,00 m aproximadamente, siendo habitual el fondo de 10,00 a $12,00 \mathrm{~m}$.

Es significativa la acumulación de parcelas en el recorrido de la muralla norte. Se adosan las parcelas por la cara interior de la muralla, con un fondo de 10 a 12 metros. Tres de es tas parcelas han rebasado la muralla y ocupan superficie de suelo en la parte exterior. En la zona oeste, se observan también parcelas que se adosan al trazado de la muralla. Se pueden observar todavía lienzos de muralla que sobresalen entre las edificaciones.

El parcelario actual nos permite observar las preexistencias del primitivo núcleo medieval intramuros. A través de las dimensiones de las parcelas y la característica adaptación de las calles a las curvas de ni vel, vemos los elementos comunes con otros núcleos próximos de la misma época, lo que confirma la identidad del tejido medieval original.

La disposición en paralelo de las calles descritas forma plazas o espacios más amplios en algunos puntos del núcleo urbano. Junto a la puerta de Palacio se sitúa la plaza de Palacio, situada frente al palacio que construyó don Álvaro de Luna al que a su vez se adosa el del conde de Montijo con la capilla del Pilar (Cuéllar 2007, 140). Más adelante se ubica la plaza de la Villa, estratégicamente ubicada frente al actual edificio del Ayuntamiento. Esta disposición y el hecho de que colinde con el trazado de la propia muralla hace pensar en una c reación moderna y no tan to en un tr azado medieval. Otros espacios abiertos se observan en la intersección de algunas calles, sin adquirir el estatus de plaza.

En la zona de la Puerta de la Calzada (P2), se puede apreciar una parcela cuya forma es diferente al resto. Se trata de la parcela catastral 03 de la manzana 83845 (Fig. 5.3.3). Esta parcela se encuentra pegada a la puerta. Es muy llamativa la forma semicircular que tiene en planta, pues recuerda a una tor re. La posición es también singular, pues se encuentra justo junto al paso de la puerta. En la actualidad, este espacio circular es un pequeño patio, cerrado con un vallado de escasa altura, sin construcción en su interior (Fig. 5.3.4). Es posible pensar que esta forma del parcelario es lo último que queda del volumen izquierdo de la puerta de la Calzada, e igualmente se podría aventurar que un s egundo volumen flanqueaba este paso en s u lado derecho, teniendo en cuenta que es habitual en las puertas de murallas medievales la 
disposición de dos torres flanqueando el acceso. Sería de gran interés llevar a cabo un sondeo arqueológico que ayudase a determinar si esta parcela tiene relación con la configuración de esta puerta. No obstante, dada la composición de la puerta, no parece haber contado con dos torres como tal sino tal vez dos volúmenes que funcionasen como base estructural del arco de acceso.

En las manzanas cuyas parcelas se adosan a la muralla se ven ocasionalmente pasos o estrechas calles, algunas de ellas en fondo de saco. Desde la calle Hospital parte una calleja que muere en la línea del lienzo de muralla, desaparecido en ese punto. En el lado opuesto del recinto se encuentra otro ejemplo de estas características, de la calle Casonas, cerca de la puerta de la Calzada (P2), parte una calle corta y estrecha que parece no llegar a ninguna parte (Fig. 5.3.5). Ahora bien, al recorrerse, se observa que hace un quiebro a la izquierda y descienden escaleras que acaban en la roca, que a su vez parece formar un c amino descendente. Este paso podría constituir originalmente un portillo de acceso, dada su configuración y su posición en la línea del lienzo de muralla.

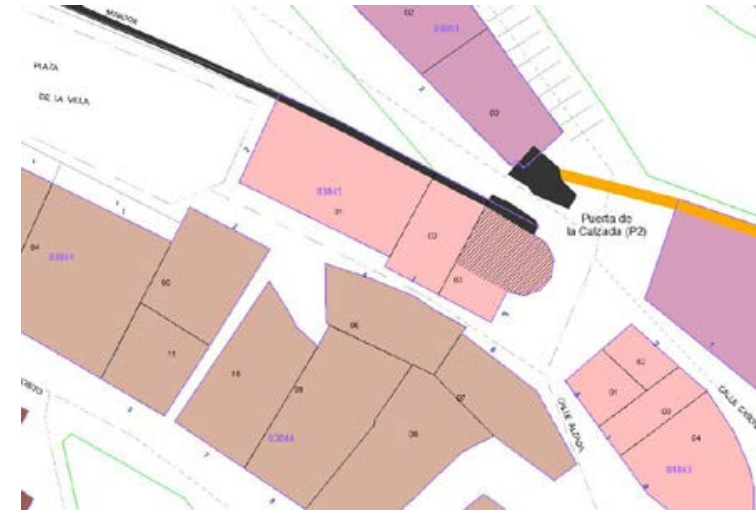

Fig. 5.3.3. Parcelas en el entorno de la puerta de la Calzada. La parcela colindante por la parte inferior tiene forma singular. Fuente: Elaboración propia con datos de Catastro.

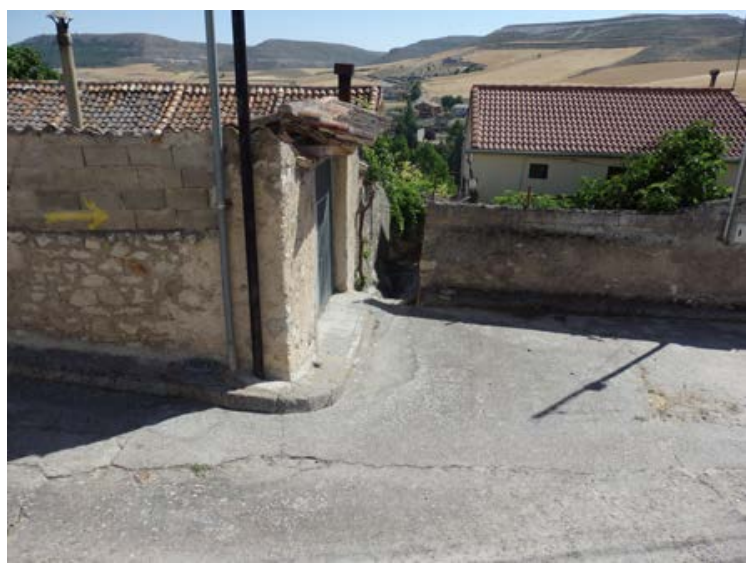

Fig. 5.3.5. Acceso al portillo [A.S.E. 8/7/2015].

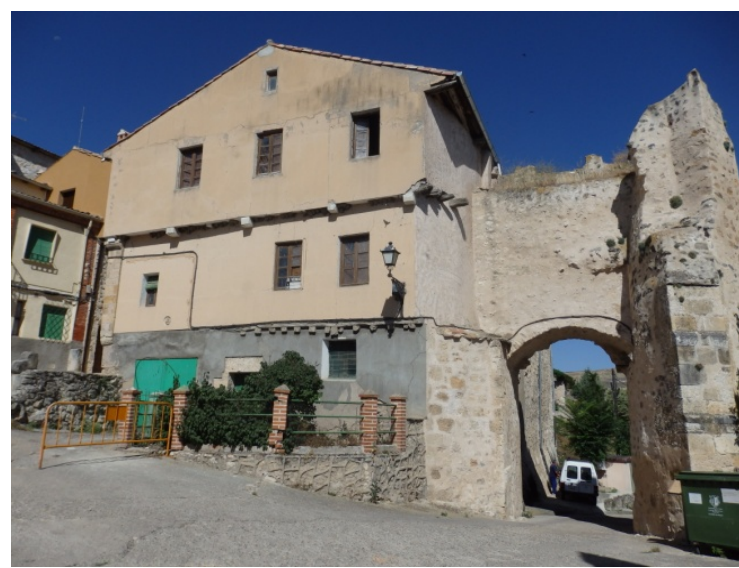

Fig. 5.3.4. Puerta de la Calzada en su cara interior [A.S.E. 08/07/2015].

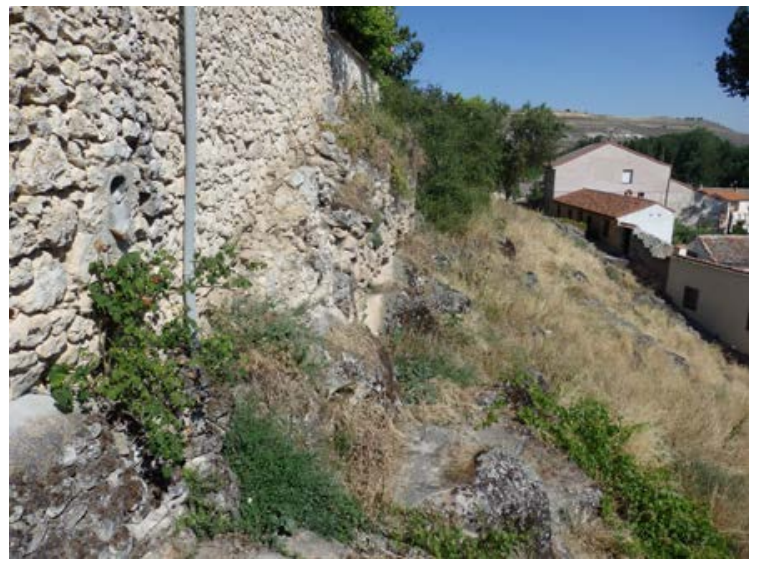

Fig. 5.3.6. Bajada del portillo por el exterior del recinto [A.S.E. 8/7/2015]. 


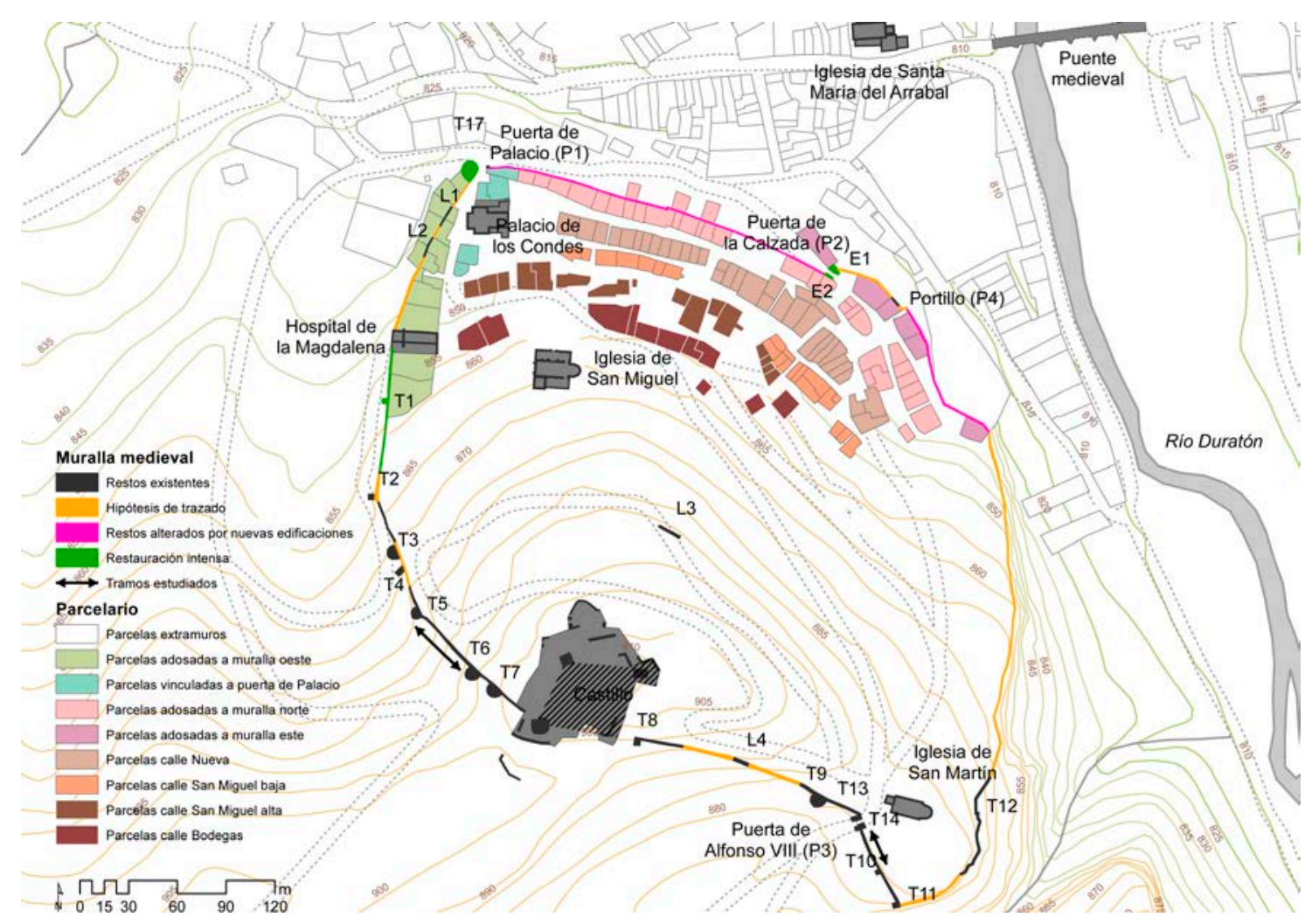

Fig. 5.3.7. Plano de parcelario y esquema del recinto amurallado de Fuentidueña. Fuente: Elaboración propia con datos de Catastro.

El plano Fig. 5.3.7 también refleja de forma esquemática el recorrido de la muralla. En color negro se han indicado los restos existentes cuya configuración se ha mantenido muy cercana a la original con reparaciones puntuales. En color fucsia se han reflejado los tramos de muralla que están significativamente alterados por haberse reutilizado en las edificaciones domésticas de la villa, que han abierto huecos sobre ella o se han construido encima. En color verde, se ha reflejado aquellas zonas que sobre las que se ha realizado un restauración intensa. Finalmente en color amarillo anaranjado, se ha indicado la hipótesis del trazado de la muralla desaparecida.

\subsubsection{Planeamiento y figuras de protección}

En al Archivo de Planeamiento Urbanístico de Castilla y León no consta ninguna figura de planeamiento en e ste municipio. En la actualidad, se están redactando unas nuevas Normas Urbanísticas Municipales junto con un Plan Especial de Protección de Casco Histórico. El castillo está considerado Bien de Interés Cultural desde el año 1996 y el pueblo obtuvo la categoría de BIC en el año 2007. La iglesia de San Martín, situada junto a la puerta de Alfonso VIII, fue clasificada como BIC en 1931. Aun así, su ábside fue cedido en 1957 a los Estados Unidos de América a cambio de pinturas románicas de San Baudelio de Berlanga (Hernansanz 1985, 168). El aspecto original 
del claustro es visible en fotografías antiguas (150). En la actualidad se exhibe en el Museo Metropolitano de Nueva York, en The Met Cloisters ${ }^{31}$.

De acuerdo con Juan Cuéllar $(2007,135)$, en el año 1988 se llevó a c abo una restauración del tramo de la muralla próximo al hospital de la Magdalena. Indica que posteriormente también se produjeron restauraciones en la zona de la plaza de la Villa, bajo Las Casonas y junto a la roca de Sopeña.

\subsubsection{Descripción general de la arquitectura defensiva}

El recinto amurallado de Fuentidueña se sitúa en una loma que es descendente hacia el valle del Duratón. La altitud en la zona más elevada, que se corresponde con la ubicación del antiguo castillo, al sur, es de $900 \mathrm{~m}$. La zona más baja es la parte norte, y la altitud en este punto es de $825 \mathrm{~m}$. Desde el oeste, la imagen que ofrece el conjunto amurallado es extraordinaria (Fig. 5.3.8). En la zona este, se produce un importante desnivel de $25 \mathrm{~m}$ que se traduce en una pared vertical de roca, muy útil para la defensa de la villa (Fig. 5.3.11). Es en esta zona donde discurre el río Duratón, una defensa natural empleada de forma habitual en la configuración de estas villas.

El recinto tiene una forma irregular, no se aprecian líneas rectas de forma general, a excepción de la zona norte, la más urbana, donde existe un tramo más regular que forma un ángulo casi recto con el tramo oeste. El conjunto cuenta con tres puertas, dos de ellas en la zona norte y una tercera al sur. Se pueden contar 11 torres en la muralla, de diversa morfología y tamaño, sobre todo localizadas en la parte suroeste del trazado. La superficie que engloba el recinto es de $11 \mathrm{Ha}$, de las cuales solo $3 \mathrm{Ha}$ están ocupadas por el caserío. La longitud del recinto sería originalmente de c asi $1500 \mathrm{~m}$, de los cuales se conservan casi $750 \mathrm{~m}$.

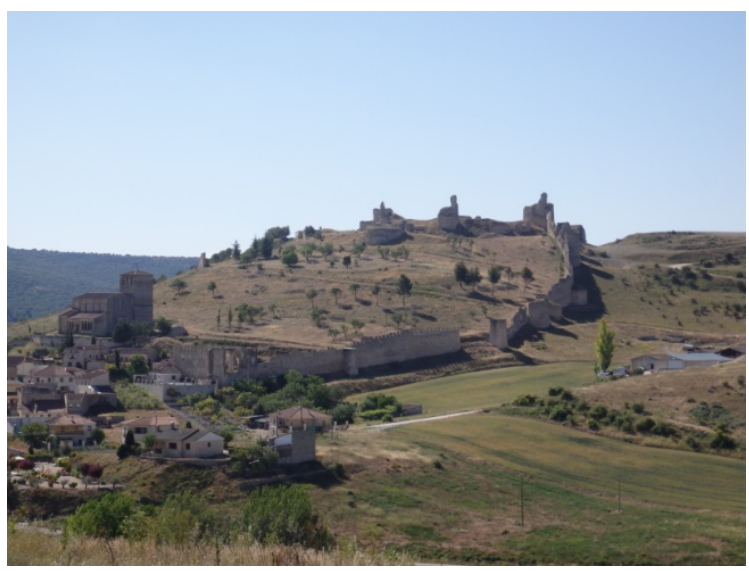

Fig. 5.3.8. Recinto amurallado visto desde el oeste, desde la ladera de EI Parral, en la carretera SG-V-2423 [A.S.E. 17/06/2014].

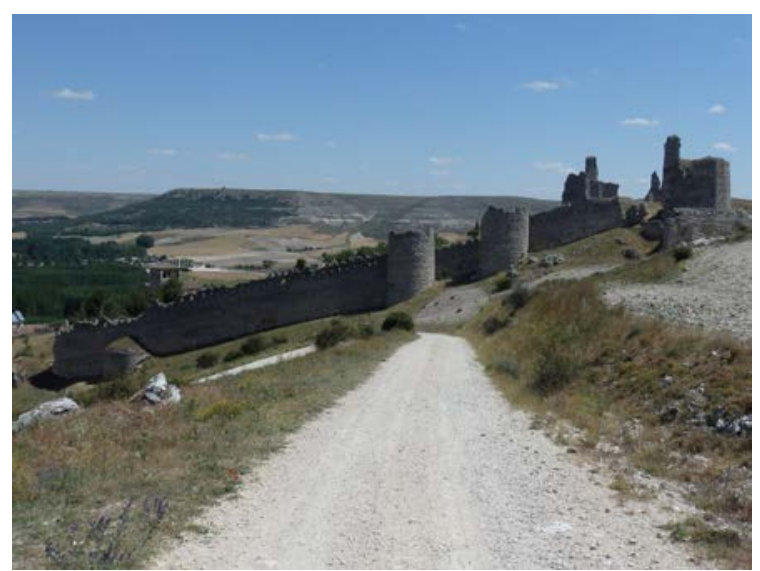

Fig. 5.3.9. Vista suroeste del conjunto amurallado. De frente se observan las torresT6y T7 [A.S.E. 17/06/2014].

\footnotetext{
${ }^{31}$ http://www.metmuseum.org/art/collection/search/472507 [Consultado el 28/11/2016]
} 


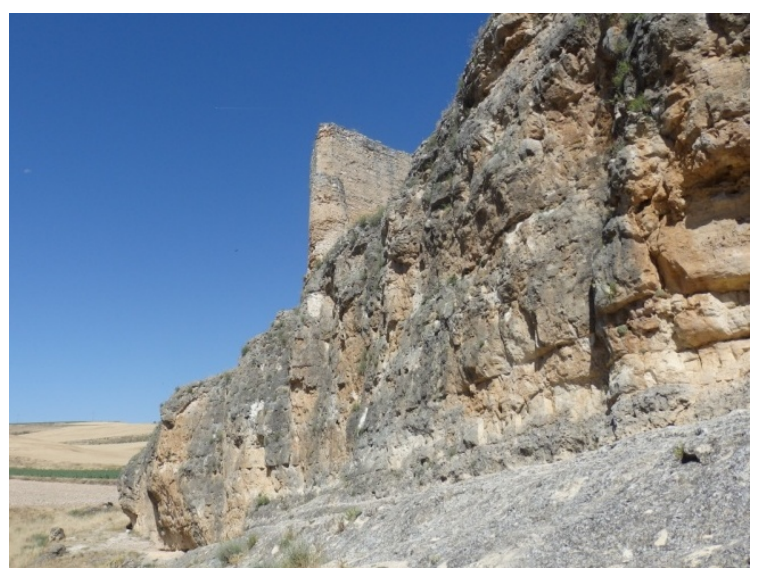

Fig. 5.3.10. Desnivel en la topografía, al sureste del recinto; en lo alto, la torre T11 [A.S.E. 8/7/2015].

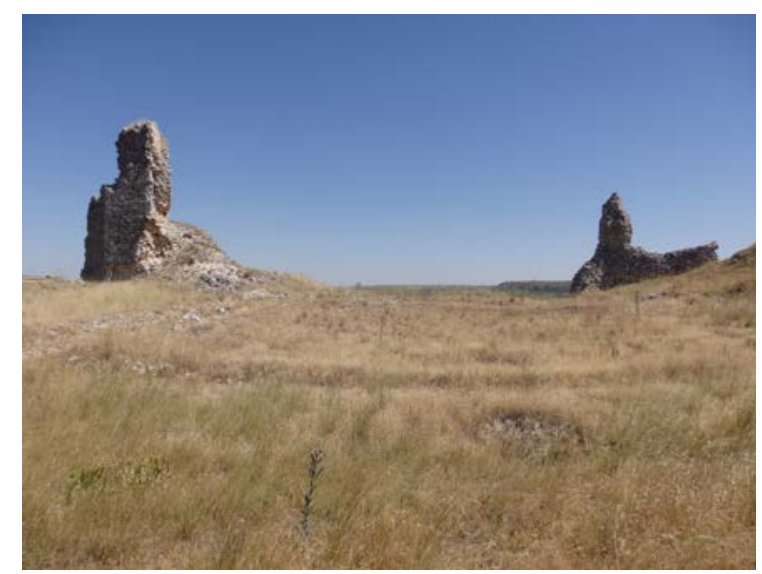

Fig. 5.3.12. Aspecto aislado de los restos del castillo [A.S.E. 7/8/2015]

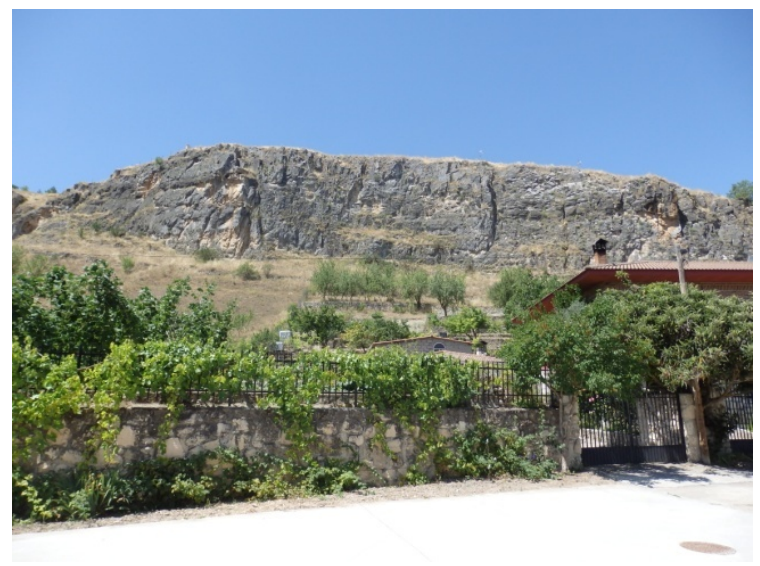

Fig. 5.3.11. Muralla natural de roca en el lado este del recinto [A.S.E.8/7/2015].

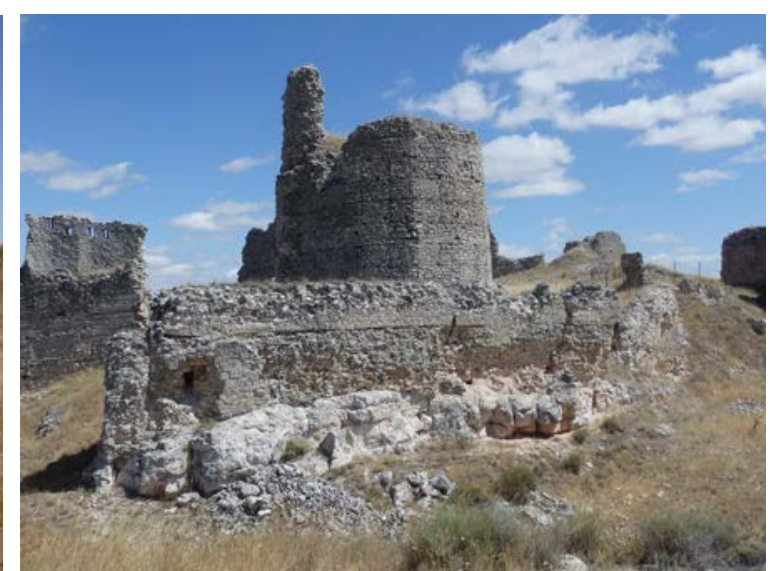

Fig. 5.3.13. Castillo visto desde el lado sur [A.S.E. $7 / 8 / 2015]$

En el interior del recinto amurallado, se observa un tramo de muralla aislado, L3 en la Fig. 5.3.7, que no s e corresponde con el trazado delos otros restos. Este tramo comparte en apariencia el sistema constructivo presente en el resto de casos; sin embargo, dada su inaccesibilidad por encontrarse dentro de una par cela vallada, es difícil determinar su naturaleza. Dada su posición podría tratarse de los restos de un recinto más pequeño.

En la parte más elevada del recinto se sitúan los restos del castillo, conocido por el nombre de Castriella de Lacer (Hernansanz 1985, 135). Las ruinas son escasas, quedan tan solo trozos de muro y torres desmochadas. Entre estos elementos parece no existir relación, no obstante, es posible identificar una forma romboidal en la planta. La planta del castillo y los ángulos que adoptan sus muros recuerda a la planta del castillo de Zamora, también romboidal. El lado del rombo que for ma el castillo de Fuentidueña tiene unal ongitud de $50 \mathrm{~m}$ aproximadamente. La di agonal principal supera los $80 \mathrm{~m}$ de longitud. La diagonal corta es de $57 \mathrm{~m}$. La orientación de la diagonal principal es suroeste-noreste, con un ángulo aproximado de $29^{\circ}$ sobre la horizontal, medidos en una planta norteada. En el caso del castillo de Zamora, la diagonal 
principal de alcanza los $100 \mathrm{~m}$, mientras que la diagonal corta se queda en $58 \mathrm{~m}$ quedando un rombo más achatado. La orientación de la diagonal principal es también suroeste-noreste, con un ángulo aproximado de $43^{\circ}$ sobre la horizontal, medido en la planta norteada. La longitud del lado se sitúa entre los 50 y $55 \mathrm{~m}$.

Junto a los restos de las torres del castillo de Fuentidueña se sitúan lo que podrían ser barbacanas, con una forma angulada. El lado sur del castillo se alinea con la dirección del lienzo de la muralla. En este lado, enfrentado al castillo, se eleva un pequeño cerro, quedando entre este cerro y el castillo una zona en un plano inferior.

\subsubsection{Tramos y elementos de la muralla medieval}

\subsubsection{Zona noroeste del recinto}

Al norte del recinto amurallado se encuentran restos de la puerta de Palacio. Conserva una torre de sección circular en su lado derecho. Esta torre tiene una planta circular de gran diámetro que casi alcanza los $10 \mathrm{~m}$. La forma de la torre es troncocónica, ya que se va reduciendo su diámetro según gana en altura (Fig. 5.3.14). Esta torre tiene un aspecto macizo, aunque se observa un hueco en su lado este que puede indicar la existencia de un espacio en su interior. La altura del hueco podría corresponderse con la altura del adarve. En sus paramentos se pueden ver mampuestos de tamaño medio y de forma irregular. No se observa un aparejo concreto. Parece haber sido objeto de reparaciones, con añadido de $\mathrm{m}$ ortero y nuevos mampuestos. Su directriz circular tiene un ángulo en su cara oeste, dando paso a un paramento recto. En una fotografía antigua (Hernansanz 1985, 65) se observa claramente el empleo de tapia de mampostería. El hueco visible en la actualidad, cerrado con una puerta, aparece en la fotografía como un boquete y no tanto como un hueco realizado ex profeso.

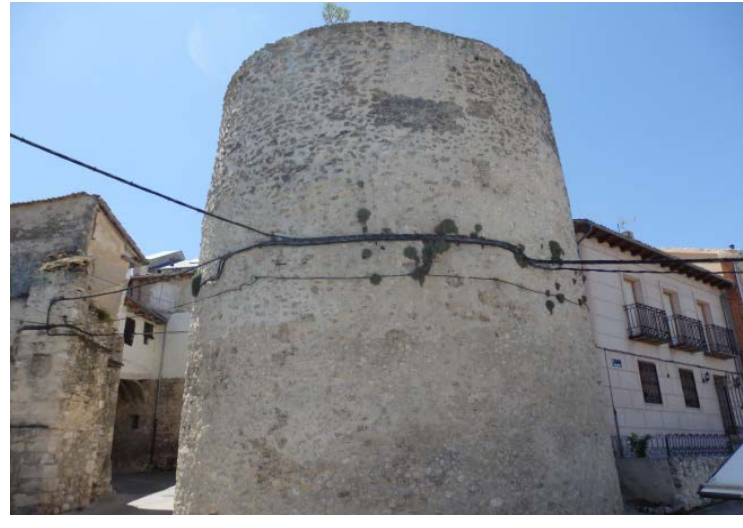

Fig. 5.3.14. Torre T15 de la puerta de Palacio vista desde el exterior del recinto [A.S.E. 08/07/2015].

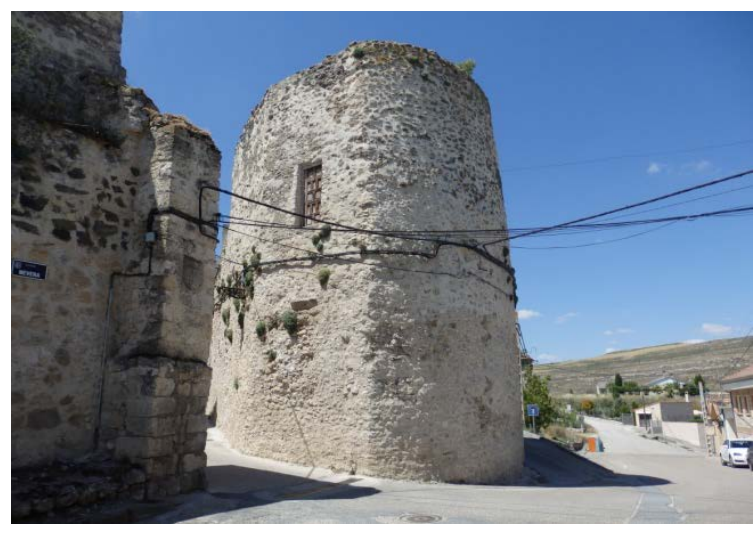

Fig. 5.3.15. Vista de la torre T15 de la puerta de Palacio (P1) desde el lado este [A.S.E. 17/6/2014]. 
Las murallas en las Comunidades de Villa y Tierra de la Diócesis de Segovia en los siglos XI a XIII.

Técnica y sistemas constructivos de la arquitectura defensiva medieval.

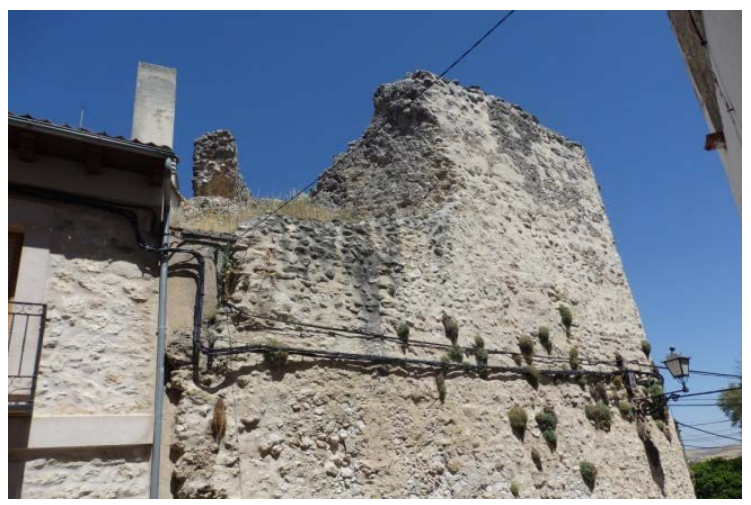

Fig. 5.3.16. Parte superior de la torre T1 desde el interior del recinto [A.S.E. 08/07/2015].

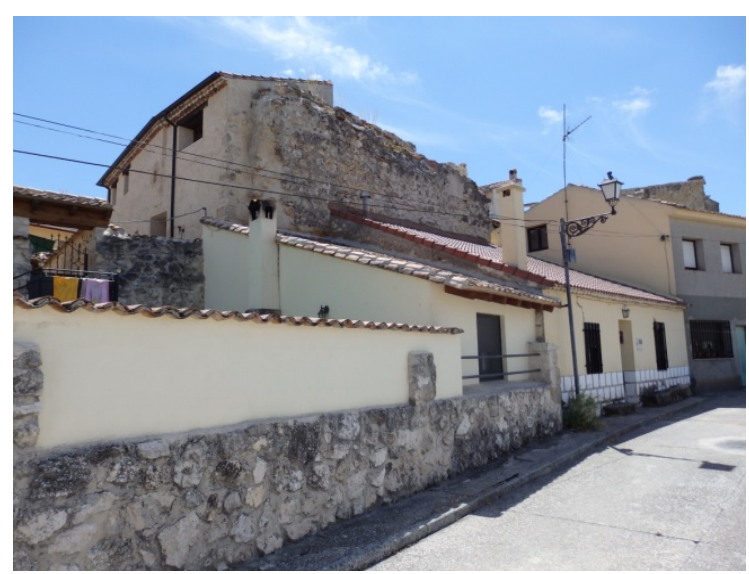

Fig. 5.3.18. Lienzo de muralla en interior de la parcela. A ambos lados se adosan edificaciones (A.S.E. 13/08/2014).

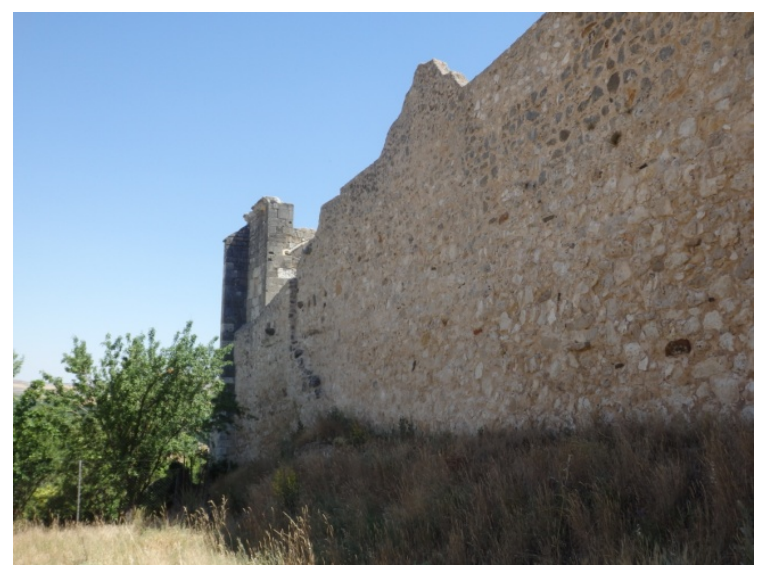

Fig. 5.3.20. Aspecto del tramo desde el hospital. Se observa una forma particular en lo alto del muro [A.S.E. 8/7/2015].

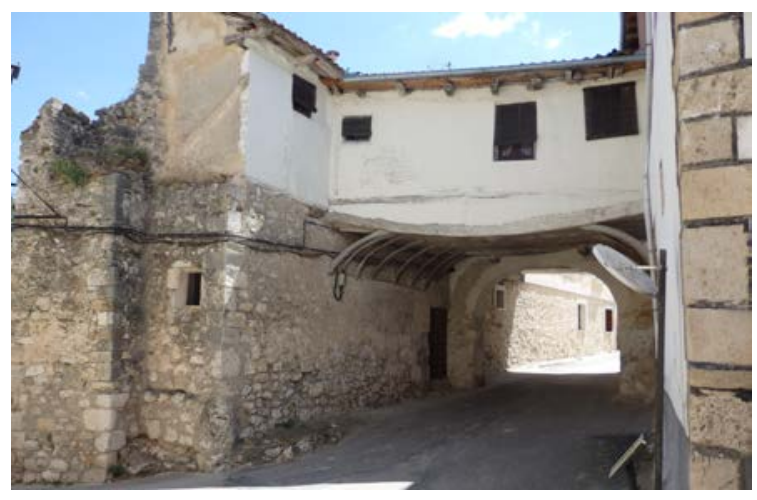

Fig. 5.3.17. Vista de la puerta desde el interior [A.S.E. 17/6/2014].

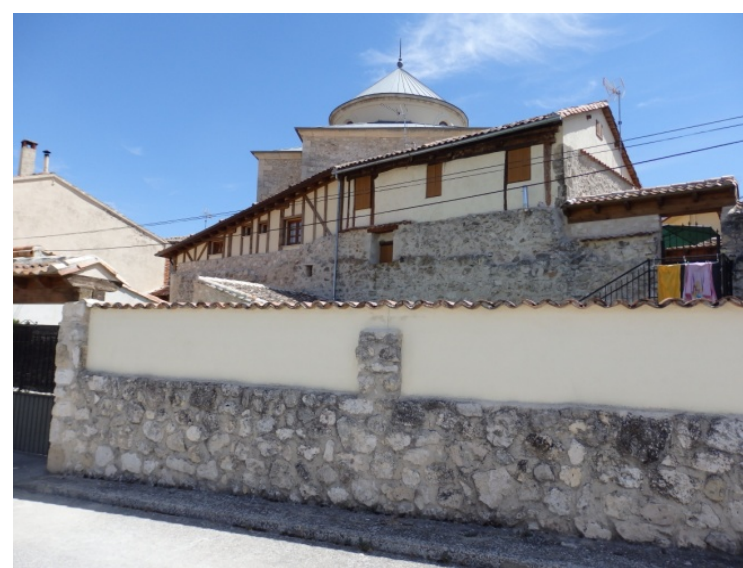

Fig. 5.3.19. Lienzo de muralla en interior de la parcela, que forma parte de la edificación (A.S.E. 13/08/2014).

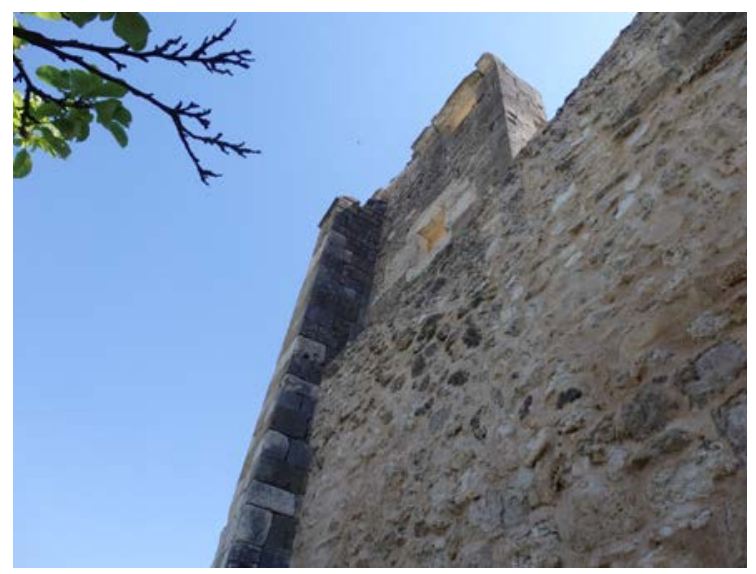

Fig. 5.3.21. Muro del hospital, construido con sillares, que sobresale del lienzo [A.S.E. 8/7/2015]. 


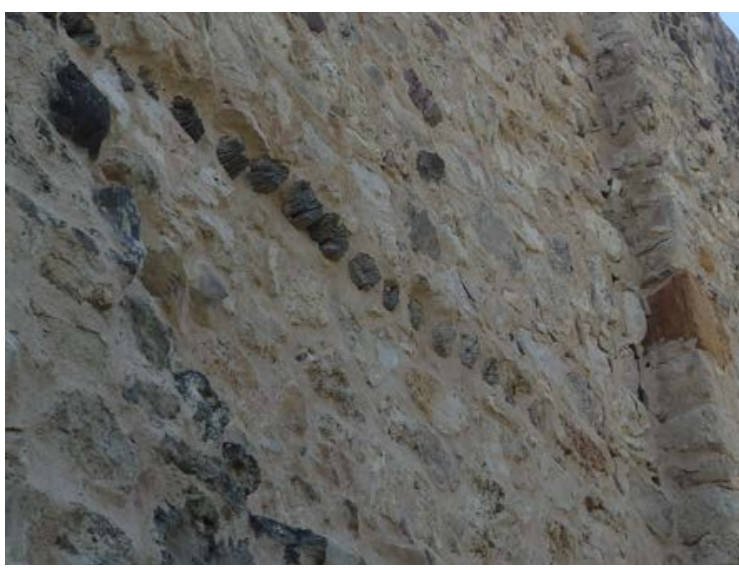

Fig. 5.3.22. Troncos embebidos en el muro del Hospital formando una hilera [A.S.E. 8/7/2015].

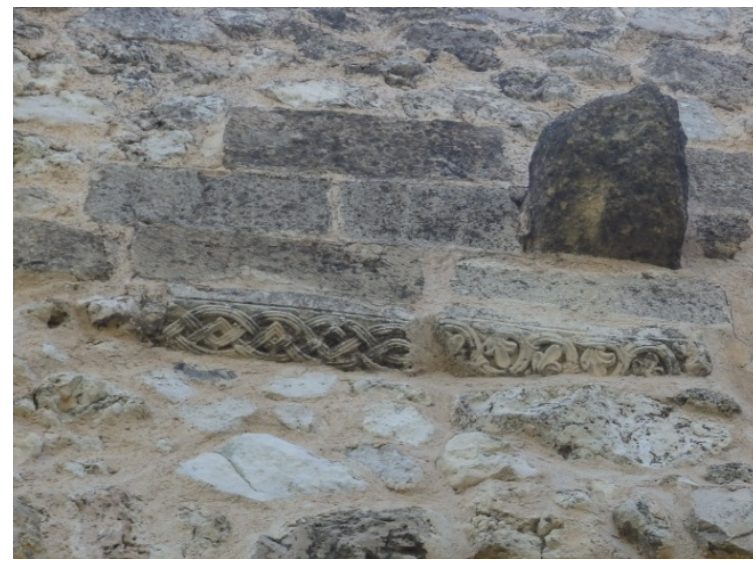

Fig. 5.3.23. Detalle en la parte superior del lienzo [A.S.E. 8/7/2015].

Al otro lado del espacio de acceso no hay otra torre sino que se ubica una suerte de contrafuerte construido con sillares (Fig. 5.3.15). Sobresale del lienzo de muralla $60 \mathrm{~cm}$ aproximadamente. Presenta una base con 7 hiladas de sillares alargados, sobre la que continúa la sillería en un plano más retrasado. Se observa un es cudo en el frente donde los dibujos están muy borrados.

La muralla continúa hacia el sur por el lado oeste de la puerta, con dos tramos intermitentes en el interior de las parcelas. Desde la calle Pajares es posible ver los restos a los que se adosan las edificaciones. El lienzo de muralla sobresale entre las construcciones, que se adosan a ambos lados del mismo (Fig. 5.3.18), o sirve de base del muro de edificaciones domésticas (Fig. 5.3.19). Los dos lienzos existentes tienen una longitud de $18 \mathrm{~m}$ y de $14 \mathrm{~m}$.

Hasta más allá del Hospital de la Magdalena no aparecen nuevos restos de muralla. Desde el hospital, continúa un tramo de $76 \mathrm{~m}$ de muralla. La disposición de los muros del hospital en relación con el trazado de la muralla parece corresponderse en un principio. El muro oeste del hospital se sitúa en la línea de la muralla (Fig. 5.3.20). Sin embargo, un contrafuerte de s illares parece estar ubicado en es a posición con anterioridad al muro que termina contra el contrafuerte (Fig. 5.3.21). Este muro presenta algunas singularidades. Posee un frente en lo alto que parece decorativo, tal vez empleado desde el interior como fondo para una figura o una composición religiosa (Fig. 5.3.20). También posee una hilera de troncos embebidos en el muro, muy juntos entre sí, cuya función no parece estar muy clara. Es posible que formen parte de un v oladizo y que hay an sido cortados con posteridad (Fig. 5.3.22). Se observa también un conjunto de sillares con una ménsula de pi edra y una imposta formada por dos piedras talladas, cada una con dibujos diferentes. La primera presenta dibujos geométricos y la segunda dibujos vegetales. 


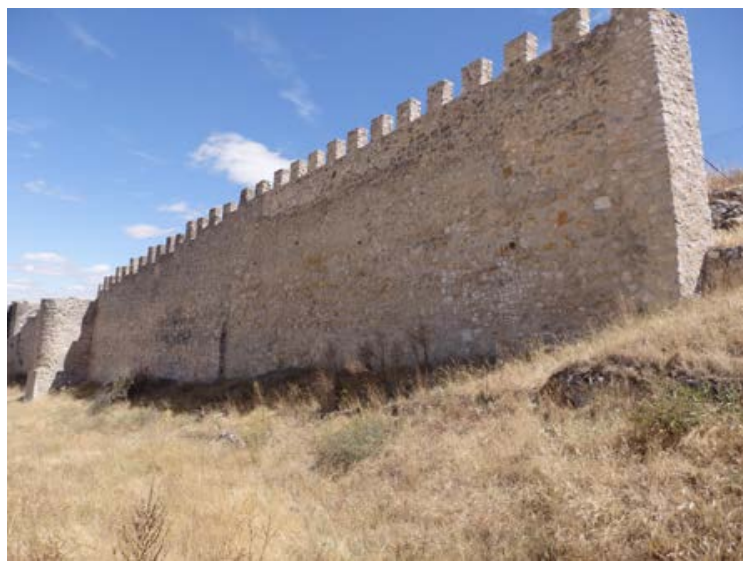

Fig. 5.3.24. Tramo T1-sur [A.S.E. 13/8/2014].

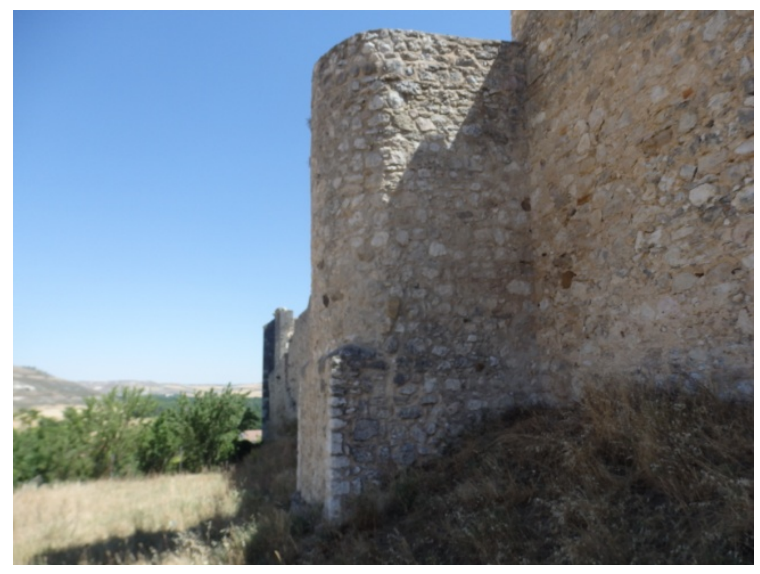

Fig. 5.3.25. Torre T1 [A.S.E. 8/7/2015].

Más al sur, la torre T1 presenta una forma singular, que no se repite en otros puntos del recinto. La base es de forma rectangular, mientras que a par tir de una al tura, la planta de la torre se torna semicircular (Fig. 5.3.25). En este sentido, Miguel A. Martín Blanco $(2014,149-150)$ describe torres similares en el recinto segoviano. Denomina discontinuidad constructiva al cambio de sección e indica que puede significar la reutilización de una base preexistente más antigua. La parte semicircular de esta torre no es comparable a las torres semicirculares del resto del recinto amurallado. En este caso, las dimensiones son mucho menores y la forma también es diferente. La parte semicircular sólo existe en el extremo de la torre más alejado del lienzo, mientras que en el resto de torres semicirculares la directriz circular parte del lienzo de muralla. La base se construye con sillarejo en las esquinas (Fig. 5.3.26). Tal y como se ha indicado anteriormente, en el tramo T1-sur se llevó a cabo una restauración a finales de los años 80. El tramo ofrece un aspecto restaurado, con la aplicación de mortero y nuevos mampuestos, así como la regularización de bor des. El almenado parece haberse reparado, reconstruido y homogeneizado. El cierre del tramo se ha reconstruido ofreciendo un acabado muy regular en la sección del muro (Fig. 5.3.24). La torre T2 se sitúa aislada, el lienzo de muralla al que se adosaba ha desaparecido. También presenta un aspecto restaurado con la aplicación de nuev o mortero y mampuestos (Fig. 5.3.27). Tiene una s ección rectangular en pl anta, prácticamente cuadrada. 


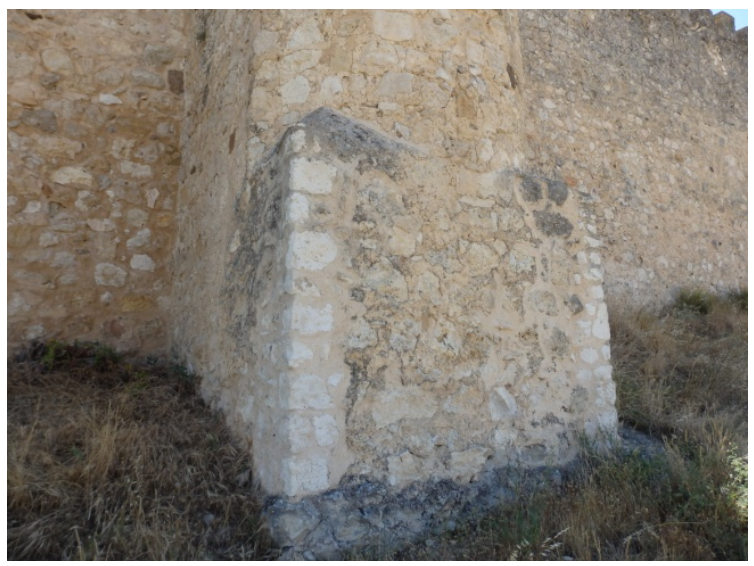

Fig. 5.3.26. Detalle de la base de la torre T1 [A.S.E. 8/7/2015]

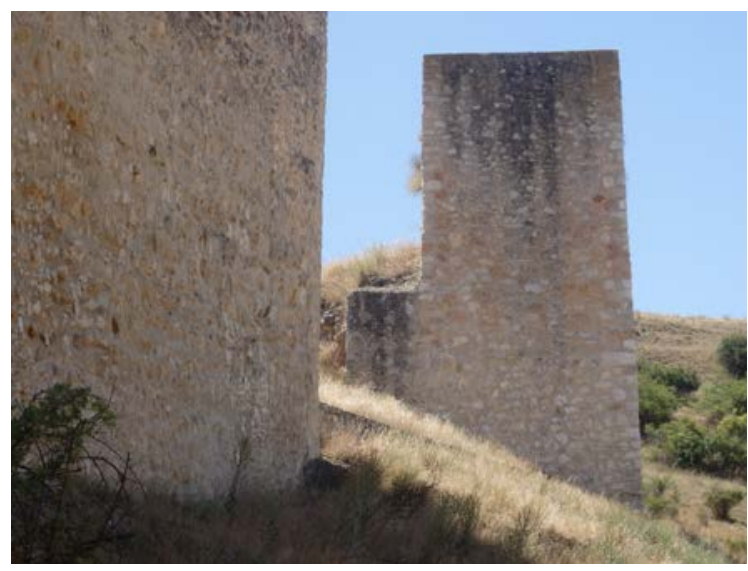

Fig. 5.3.27. Vista norte de la torre T2. En la base se observa cómo se adosa al lienzo [A.S.E. $8 / 7 / 2015]$

El tramo T2-T3 se encuentra en avanzado estado de deterioro y presenta oquedades en el lienzo (Fig. 5.3.28). La parte superior tampoco se conserva. En estos restos es visible el empleo de tapia de mampostería. Se pueden contar hasta 6 hiladas de tapia. Las piedras empleadas tienen un tamaño mayor de lo que se suele entender como mampostería. Ya en este tramo es llamativo el escaso espesor del lienzo, que llega a ser de $90 \mathrm{~cm}$. Al finalizar este tramo se encuentra la torre T3, de planta semicircular y de gran diámetro (Fig. 5.3.29). Esta torre ha perdido el lienzo al que se adosa, dejando al descubierto su cara interna; el aspecto que ofrece esta cara interna se analiza más adelante (Fig. 5.3.116). El paramento de la torre también muestra marcas de tapia, se pueden contar 8 hiladas de tapia de altura. Sobre estas hiladas de tapia se construye un almenado desdibujado, principalmente en su cara sur. A esta altura, la torre tiene su nivel de suelo, como si se tratara de un adarve. Dos de las almenas visibles poseen una saetera vertical, de forma rectangular, muy sencilla, estrecha y apenas visible (Fig. 5.3.30). No es sencillo determinar si se han añadido con posterioridad. Parece existir una diferencia entre la textura visible en las almenas y el resto de la torre.

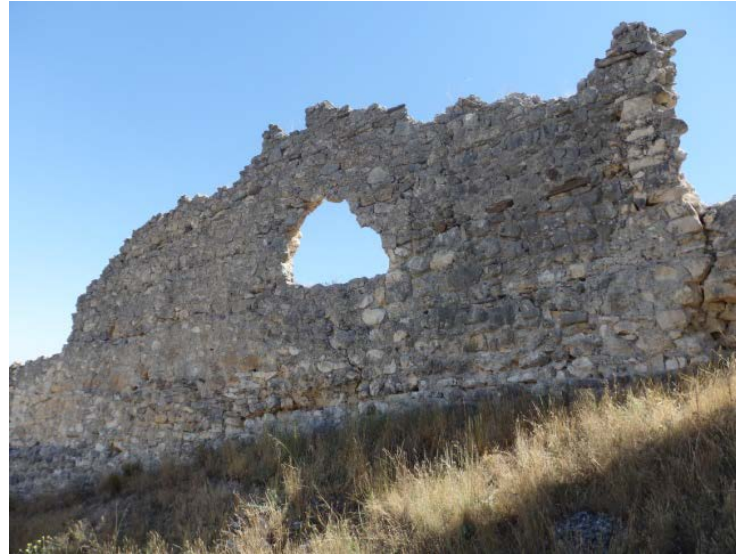

Fig. 5.3.28. Tramo al norte de la torre T3 [A.S.E. 8/7/2015].

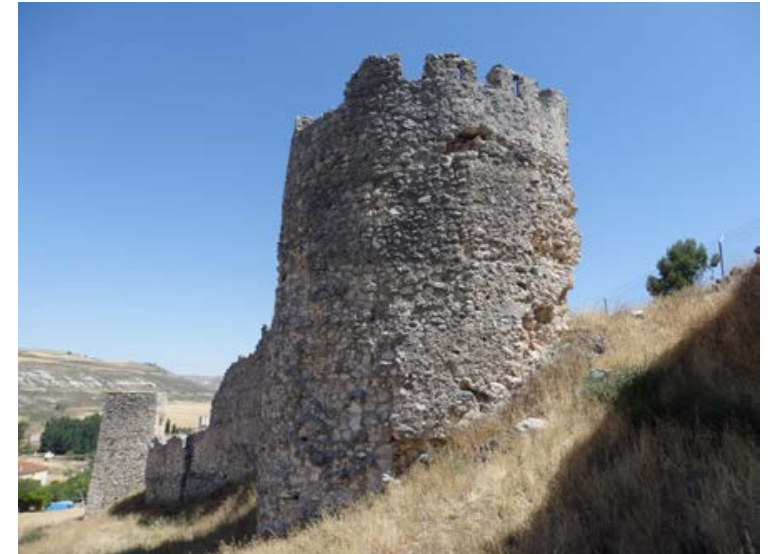

Fig. 5.3.29. Cara sur de la Torre T3. Al fondo, la torre T2 [A.S.E. 8/7/2015]. 


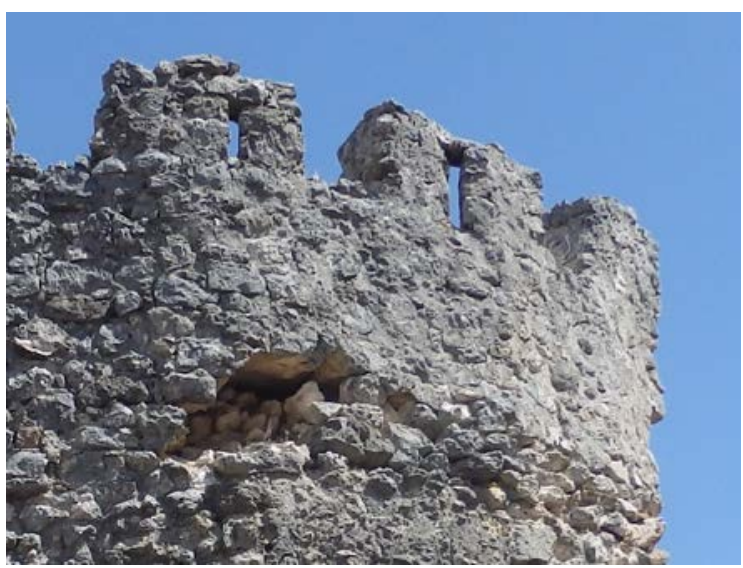

Fig. 5.3.30. Detalle de las saeteras en el almenado de la torre T3 [A.S.E. 8/7/2015].

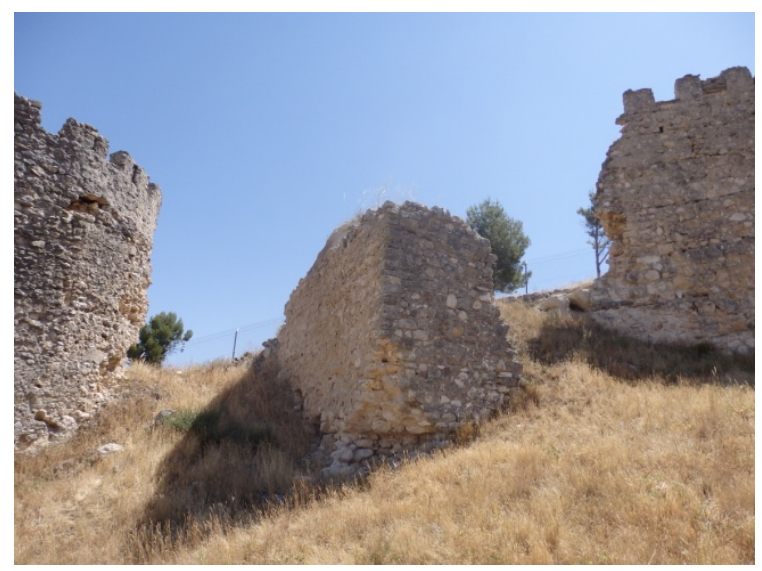

Fig. 5.3.32. Supuesta torre T4, vista desde el exterior [A.S.E. 8/7/2015].

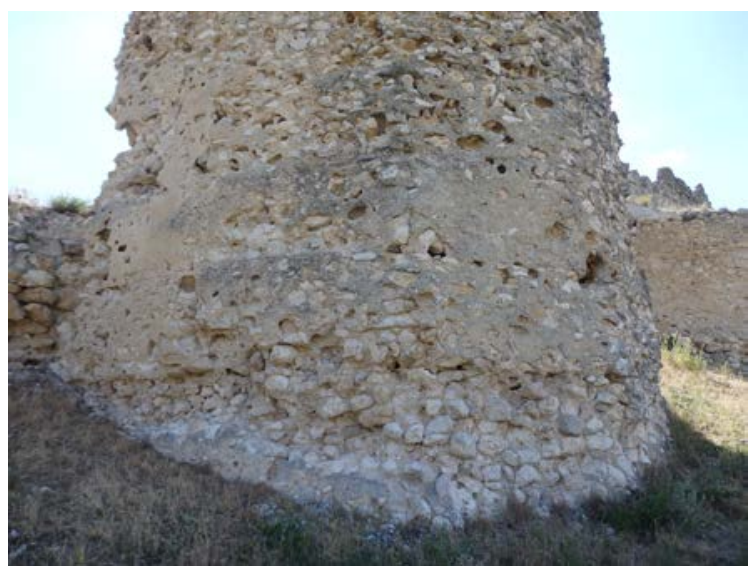

Fig. 5.3.31. Base de la torre T3, que se adosaría al lienzo hoy desaparecido. [A.S.E. 17/6/2014].

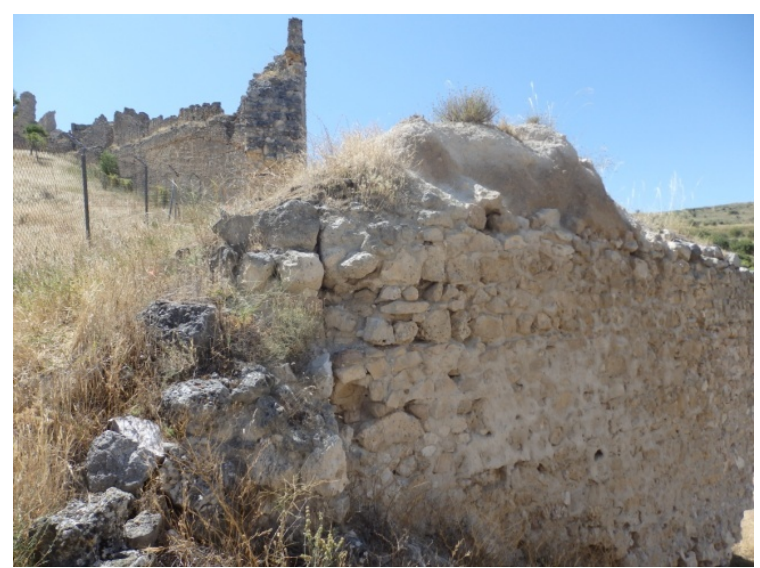

Fig. 5.3.33. Detalle del encuentro de la torre T4 con la base del lienzo [A.S.E. 8/7/2015].

La denominada torre T4 es un tanto particular y no está muy clara su naturaleza de torre. Tiene dos caras claramente identificables, la cara norte y la cara suroeste, más corta esta última, ambas formando una esquina definida. Aun así, no queda definida la cara sureste ni su correspondiente esquina con la cara suroeste, por lo que es difícil precisar si se trata de una torre o si tiene otra forma, ahora desfigurada. Parece tener una planta rectangular, sobresale más de lo habitual del lienzo de la muralla para tratarse de una torre. Tampoco tiene una posición exactamente perpendicular, como ocurre habitualmente en I as torres rectangulares, sino que forma un ángul o poco habitual con el lienzo (Fig. 5.3.32). La disposición de esta torre en relación con la torre T3 tampoco aporta pistas acerca de s u naturaleza. No comparten características formales, ya que tienen plantas distintas y tampoco presentan dimensiones similares. Desde un punto de vista constructivo, la torre T4 también se realiza con tapia. En su cara noroeste se cuentan cinco tapias de altura. Piedras especialmente elegidas se ubican en úni ca esquina definida del elemento. Por otra parte, tampoco parece establecerse una relación entre la torre T4 y el lienzo a continuación. 
La muralla ha desaparecido prácticamente en su totalidad en este tramo, aunque son visibles restos en el suelo. En esa zona, se puede observar como la torre se adosa a la muralla, es identificable una línea divisoria entre el lienzo y la torre (Fig. 5.3.33).

\subsubsection{Zona suroeste del recinto}

El tramo a continuación es relativamente homogéneo desde poco antes de la torre T5 hasta el castillo. El acabado superficial revela el empleo de tapia de mampostería en la construcción de la muralla. Las hiladas de tapias son muy visibles a lo largo de estos muros, principalmente en su cara exterior (Fig. 5.3.34, Fig. 5.3.38, Fig. 5.3.39, Fig. 5.3.41, Fig. 5.3.42). En el tramo al norte de la torre T5 (Fig. 5.3.34) se pueden contar siete tapias de altura, sobre las que se construye un almenado. En la base se observa el empleo de grandes piedras de forma irregular, que resulta difícil denominar mampuestos, dados u gran tamaño. Son visibles también algunos mechinales ubicados en la base de las tapias. Este tramo queda interrumpido en su extremo norte, donde es visible la sección del muro (Fig. 5.3.37). De nuevo, es llamativa la escasa anchura del lienzo, que se mantiene en torno a 1,00m. En la sección del muro se puede apreciar la división horizontal entre tapias, así como la sección del adarve y el almenado. La torre T5 (Fig. 5.3.35) tiene planta semicircular y se sitúa adosada al lienzo. Su altura no al canza la altura del lienzo, sino que se ha pe rdido parte del cuerpo y la coronación. En los paramentos de la torre son visibles también hiladas de tapia, testigo del sistema de construcción empleado.

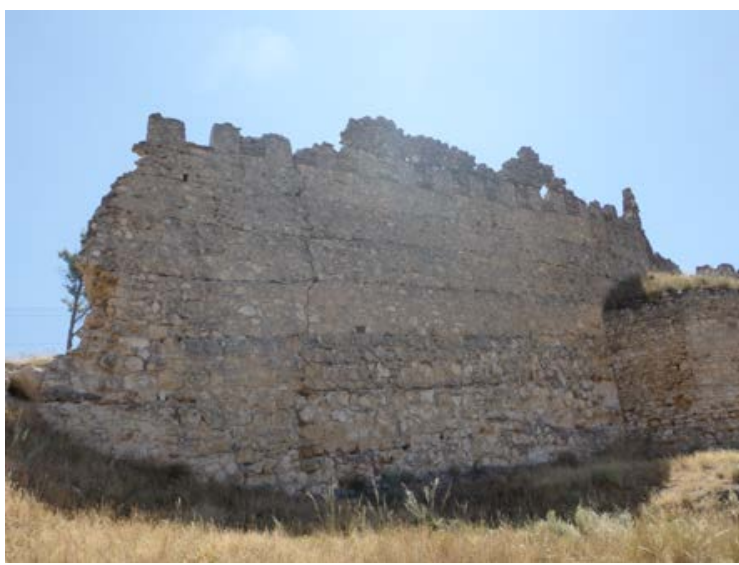

Fig. 5.3.34. Tramo al norte de la torre T5, visto desde el exterior. Se observa una grieta vertical que recorre el muro [A.S.E. 8/7/2015]

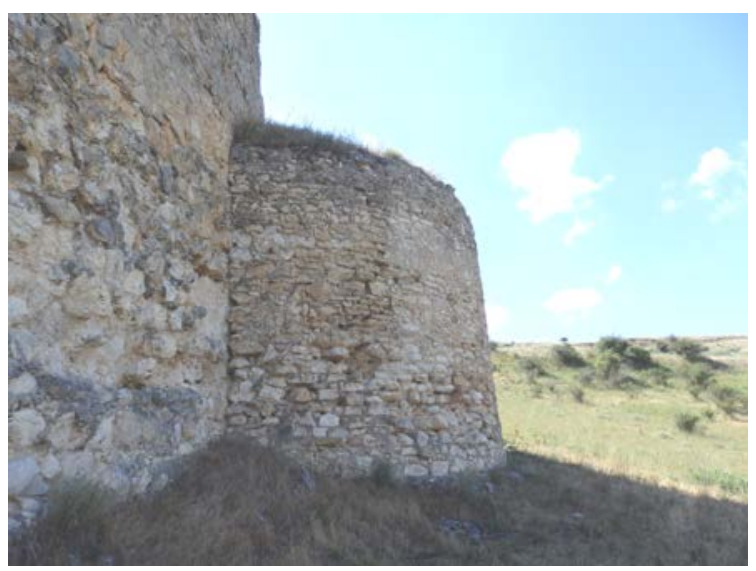

Fig. 5.3.35. Torre T5 [A.S.E. 17/6/2014]

Las almenas visibles en el tramo T5-norte son similares a las presentes en todo el tramo T5-T7. Tienen forma cuadrada y están separadas una distancia equivalente a su anchura. Tienen una relación anchura-separación con valor 1. Tanto la almena como la coronación de la separación entre almenas se remata con una o varias piedras planas. La almena parece realizada de forma individual, tal vez con un molde como el tapial, adaptado al tamaño de la almena. Sobre el almenado, se construye un muro que rellena la separación entre almenas y eleva la altura del muro (Fig. 5.3.36). En algunas partes es visible un nuevo almenado, que ha qu edado desdibujado por la 
ruina de gran parte de esta coronación. La construcción de esta franja sobre el almenado se realiza con mampuestos y, a diferencia del lienzo, no parece realizarse mediante tapias, sino con un aparejo irregular de mampuestos.

El tramo T5-T7 es la continuación del tramo iniciado al norte de la torre T5. Comparte las mismas características: se construye con tapia, el aspecto de la misma es similar, con piedras de forma irregular y grandes dimensiones. Se observa la presencia de mechinales en la base de las tapias. Esta parte de la muralla se ubica en una zona de gran desnivel, entre las torres T5 y T7 se produce una diferencia de $25 \mathrm{~m}$ de altitud. Esta dificultad se traduce en el lienzo de muralla, donde el desorden es visible en las tapias. Las hiladas tratan de ada ptarse al desnivel situándose en paralelo con el terreno. A pesar de ello, no se consigue este propósito y el resultado es un aparejo caótico con tapias que adoptan for mas trapezoidales y en c uña para resolver los encuentros y nivelar las hiladas (Fig. 5.3.38, Fig. 5.3.39).

El almenado es muy similar al descrito para el tramo T5-norte, las almenas son regulares, de forma cuadrada, con una separación similar a su anchura. A través del aparejo de mampostería el lienzo se eleva sobre el primer almenado para construir uno de mayor altura. Las nuevas almenas comparten forma y proporciones con las almenas inferiores (Fig. 5.3.39).

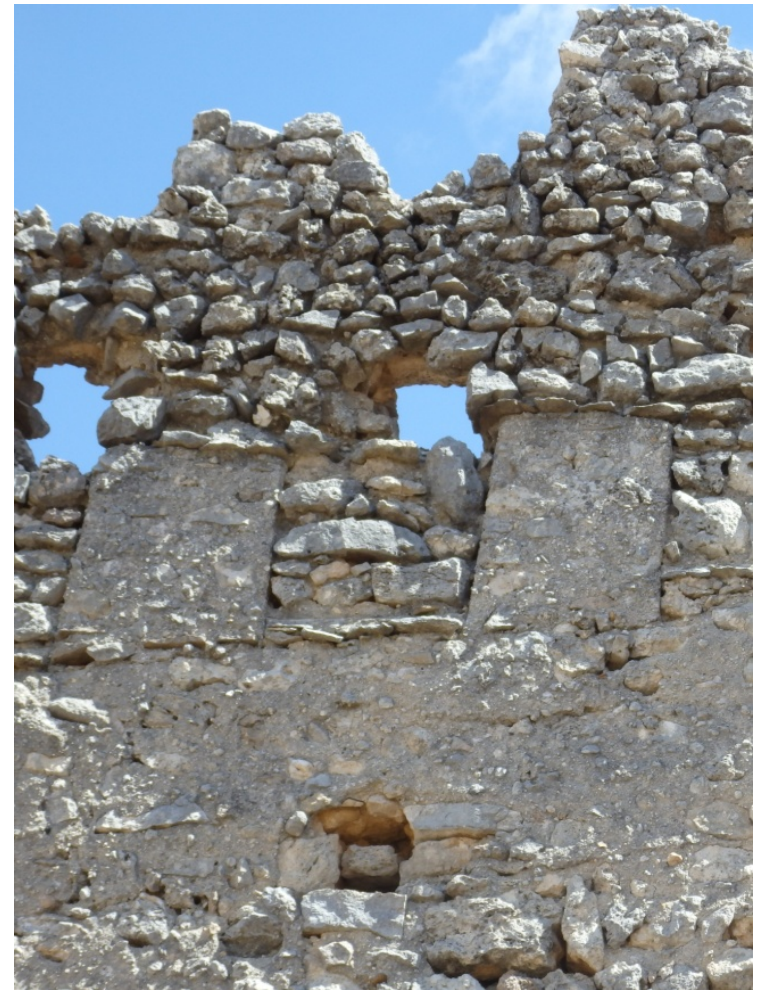

Fig. 5.3.36. Detalle de almenado [A.S.E. $13 / 8 / 2014]$

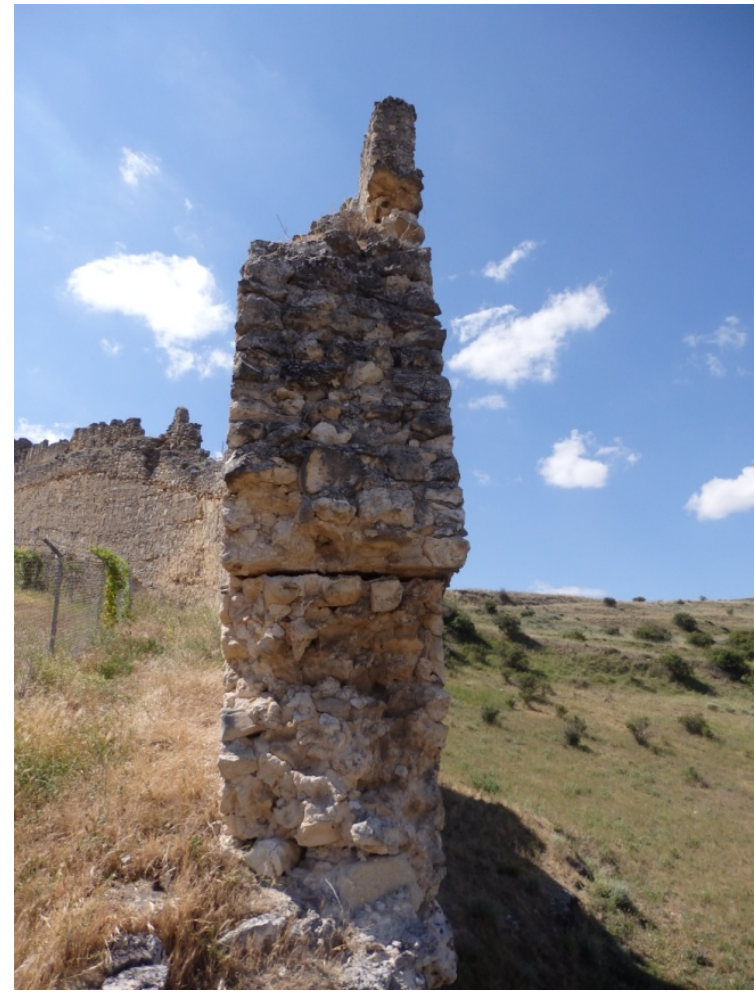

Fig. 5.3.37. Sección del muro en tramo T5-norte [A.S.E. 17/6/2014] 


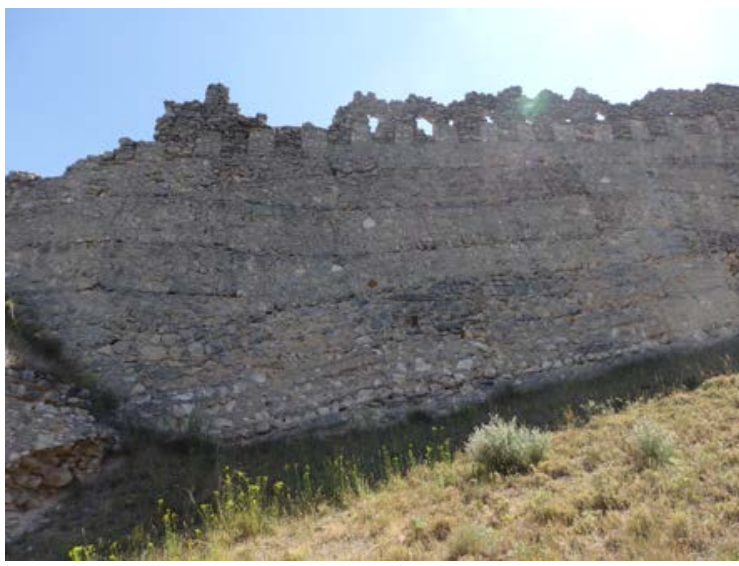

Fig. 5.3.38. Tramo al sur de la torre T5, visto desde el exterior. Se ven tapias de forma trapezoidal o en cuña [A.S.E. 17/6/2014]

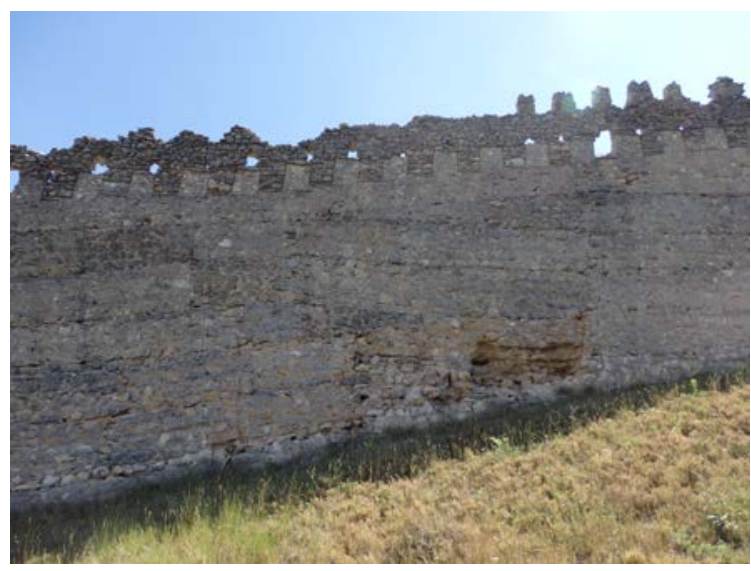

Fig. 5.3.39. Vista de parte del tramo T5-T6, se observa desorden en las tapias [A.S.E. 17/6/2014]

La torre T6 tiene planta semicircular, aunque se ve cómo la planta parece superar la línea del semicírculo, completando casi el círculo completo (Fig. 5.3.40). Según gana en altura, la torre va estrechando su sección, adoptando una forma troncocónica. La torre supera en altura el lienzo de muralla y en su coronación podrían verse restos de un posible almenado, ahora completamente desdibujado. Se cuentan diez tapias de altura en la cara norte de la torre. Es sorprendente el trazado circular tan definido que se consigue con las tapias. La torre se adosa al lienzo de muralla, en la intersección de la torre con el lienzo, se observa que es te último es independiente y ha sido construido con anterioridad. La torre es maciza, es decir, no es hueca en su interior. En la parte superior de la torre, todavía se puede identificar la plataforma de vigilancia de la torre, rodeada del almenado (Fig. 5.3.41). Desde el interior del recinto, la altura del terreno es muy superior a la del exterior, pudiéndose acceder fácilmente a esta plataforma, en la actualidad.

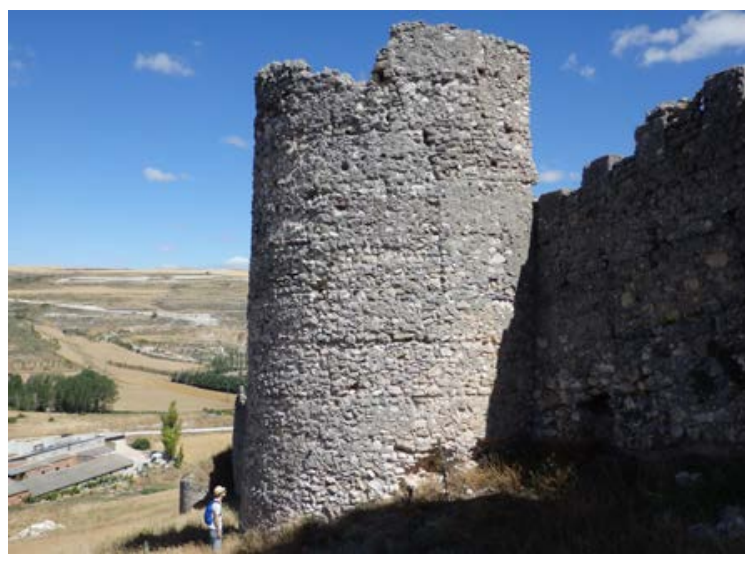

Fig. 5.3.40. Torre T6 vista desde el sureste [A.S.E. 23/7/2016].

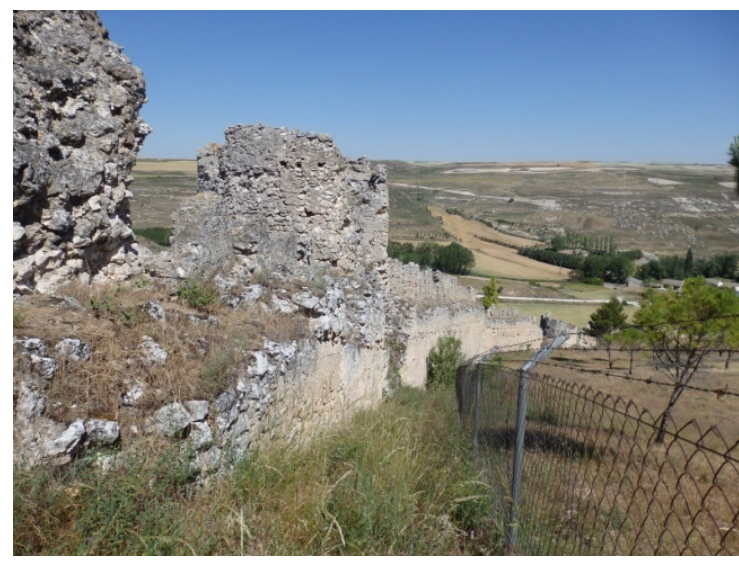

Fig. 5.3.41. Plataforma superior de la torre T7 y parte del adarve [A.S.E. 17/6/2014] 


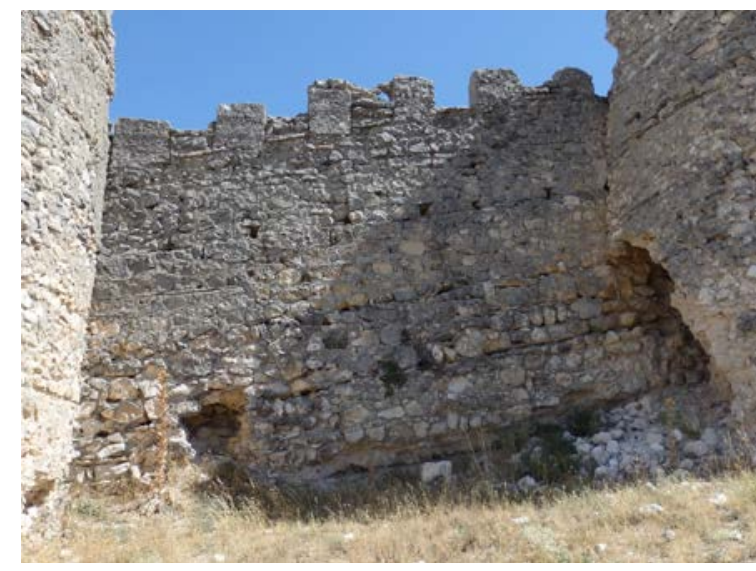

Fig. 5.3.42. Tramo entre las torres T6 y T7 [A.S.E. 8/7/2015]

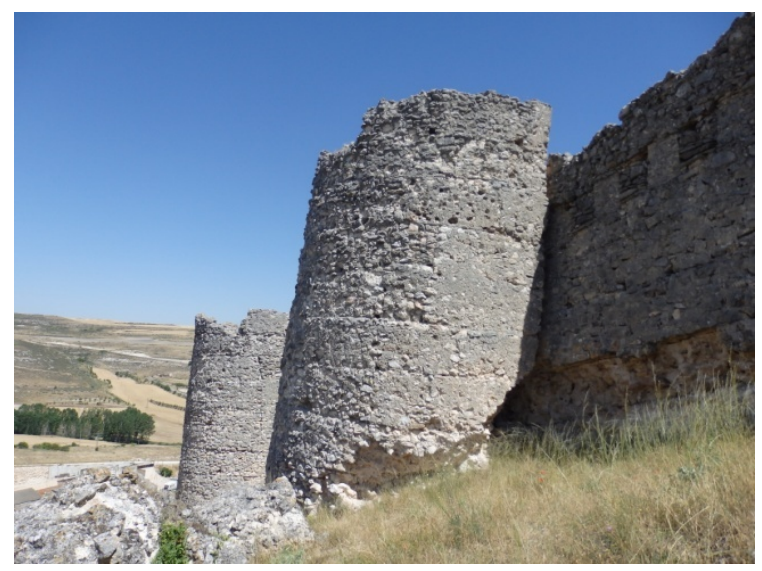

Fig. 5.3.43. Torre T7 vista desde el este. Al fondo se ve la torre T6 [A.S.E. 8/7/2015]

Las torres T6 y T7 están separadas escasos $7 \mathrm{~m}$, contando desde sus caras, y en este espacio es visible otro tramo de muralla (Fig. 5.3.42). Este tramo también se construye en zona de desnivel, pero en este caso, las hiladas de tapia son paralelas al terreno y están ordenadas. En la base, se han producido desprendimientos de algunas tapias. Las tapias de las últimas hiladas muestran en su base mechinales de mayor tamaño que los existentes en las tapias de la zona inferior. Estos mechinales se construyen con tres mampuestos, el primero a modo de coronación y los otros dos flanqueándolo. En las tapias inferiores, los mechinales se sitúan en I a línea de separación y se realizan sin mampuestos.

La torre T7 es similar a la torre T6 en forma, dimensiones y sistema constructivo. En la zona de en cuentro con el lienzo, su base se encuentra arruinada, mostrando la continuidad del lienzo detrás de la torre, poniendo de manifiesto que la construcción de la torre es posterior a la del lienzo (Fig. 5.3.43). El tramo T7-este es la continuación de los tramos anteriores y de nuevo presenta características similares. Las hiladas de tapias tratan de adaptarse al terreno y de nuevo se produce un desorden. Aparecen algunas tapias de en forma de cuña y se producen escalonamientos en las hiladas. Como en el tramo anterior, una de las hiladas muestra el empleo de mechinales de mayor tamaño, construidos con mampuestos.

En el extremo este de es te tramo, se observa una construcción que sobresale por encima el almenado (Fig. 5.3.44). Es un muro con forma curva que tiene cuatro huecos en la parte superior. Por su proximidad con el castillo, parece tener relación con las construcciones que lo configuran. Tiene un aspecto menos sólido que las otras construcciones cercanas, debido a su escasa anchura. 


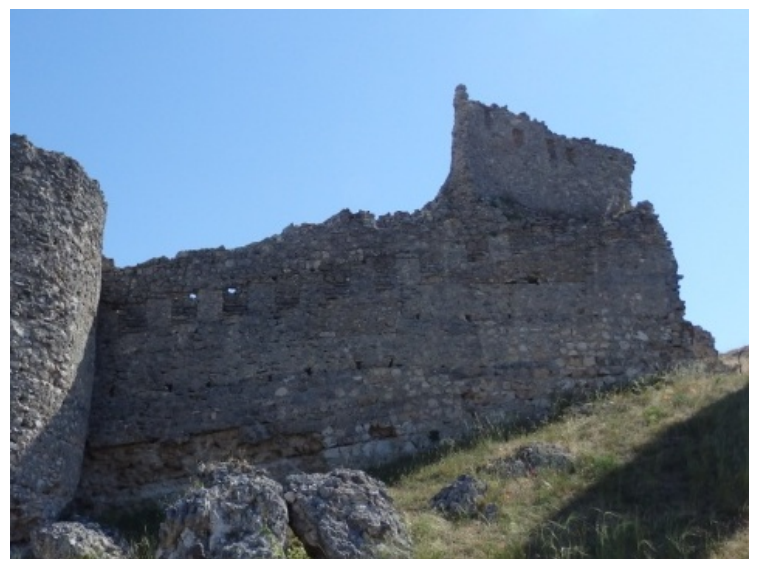

Fig. 5.3.44. Tramo desde la torre T7 hacia el sureste [A.S.E. 17/6/2014].

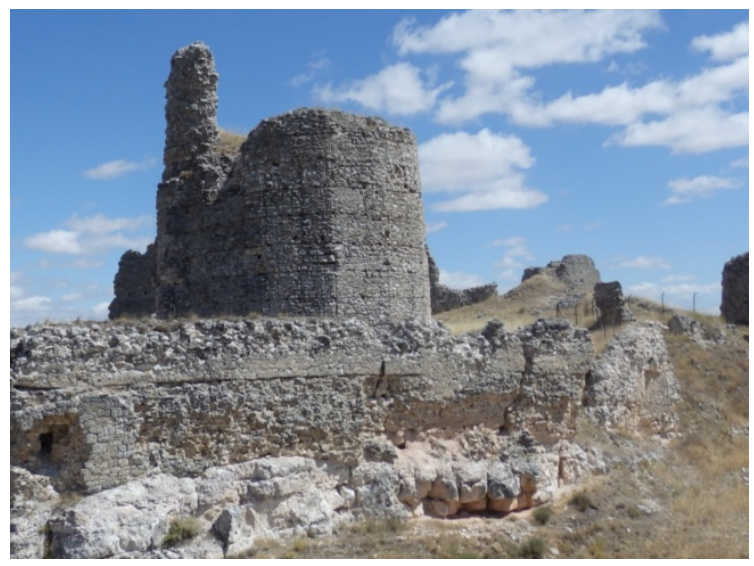

Fig. 5.3.45. Torre sur del castillo [A.S.E. $13 / 8 / 2014]$.

A su paso por la zona del castillo, la muralla queda interrumpida y en la línea de su trazado se observan construcciones de distinta índole. La tor re sur del castillo (Fig. 5.3.45) es de planta semicircular y de gran altura. Se construye con tapia, pero en este caso son visibles las aristas que forman ese alzado curvo. Frente a la torre, en su lado sur, se configura un muro adelantado a modo de barbacana. Desde el exterior, se ve como se construye directamente sobre la roca, identificable en la base del muro. Se emplea también tapia, aunque sus marcas constructivas son menos evidentes. En este muro existe un desagüe construido con dos piezas talladas de piedra (Fig. 5.3.46). La primera forma un canal y la segunda se sitúa encima, cubriéndolo. La altura a la que se encuentra se corresponde con la altura del suelo en el interior. Este muro tiene otra configuración en el interior, donde se observa una fábrica de sillares desgastados.

En la zona este, un resto de muro formando una e squina se sitúa en la línea del trazado de la muralla. En lo alto del muro, se observan los restos de una fábrica de sillería (Fig. 5.3.47).

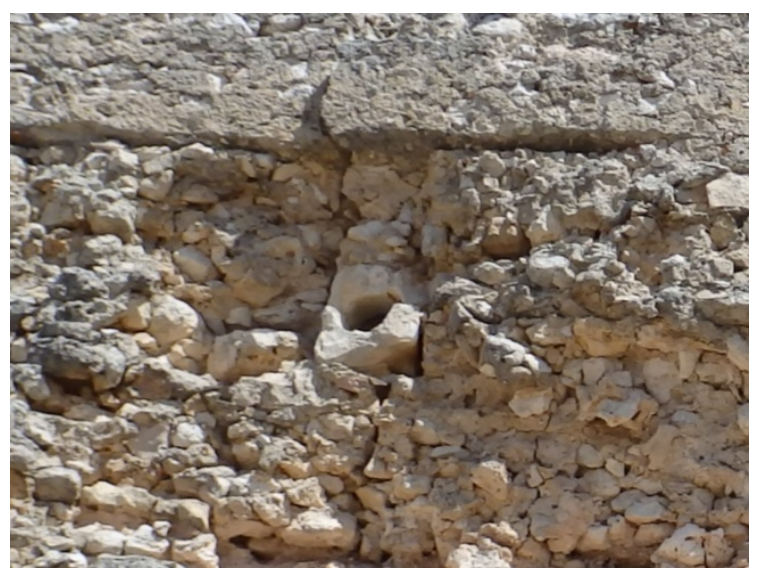

Fig. 5.3.46. Pieza tallada que parce funcionar como desagüe [A.S.E. 17/6/2014].

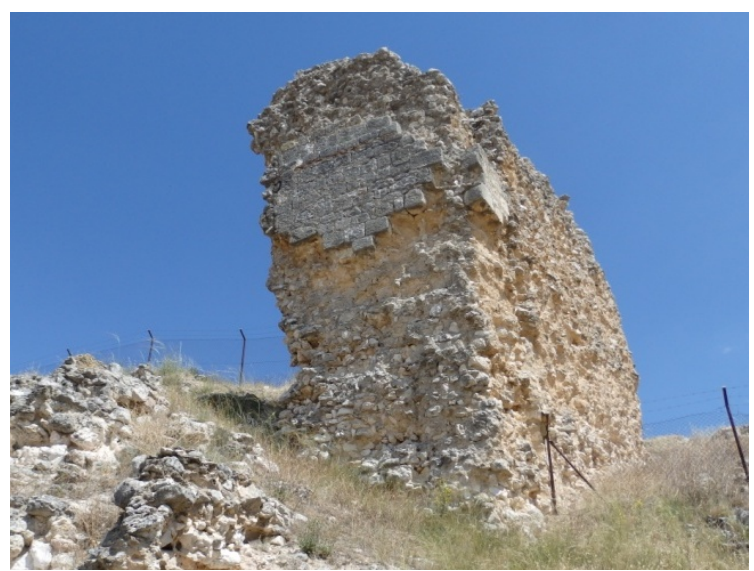

Fig. 5.3.47. Frente que queda en la línea de la muralla. Es un elemento que forma parte del conjunto de ruinas del Castillo [A.S.E. 17/6/2014]. 


\subsubsection{Zona sur del recinto}

Al este del castillo, la muralla continúa con un tramo que tiene nuevas características. Desde este punto hasta la puerta de Alfonso VIII (P3), la muralla presenta características similares. En su extremo oeste se sitúa la torre T8, de planta rectangular (Fig. 5.3.48). Se construye con tapia, alcanza una altura de diez tapias, que tienen una altura inferior a las tapias visibles en el lienzo. La altura de la torre supera ligeramente a la del lienzo. En el encuentro entre torre y lienzo se observa una discontinuidad entre los paramentos, que ha ce pensar que la torre se construyó cuando ya existía el lienzo. La coronación de la torre ha perdido su definición y no se puede identificar la presencia de almenado. El lienzo parte desde la torre T8 en dirección este. Se construye con tapial, en este caso se aprecia el empleo de piedras más pequeñas, mampuestos, a diferencia del tramo T5-T7, donde se veían piedras de gran tamaño. Las tapias se identifican claramente en el paramento, no solo las hiladas horizontales sino también sus límites verticales. En este tramo es especialmente visible la marca de las tablas horizontales empleadas en el tapial. De forma general, cada una de las tapias muestra las marcas de cuatro tablas dispuestas en sentido horizontal (Fig. 5.3.49).

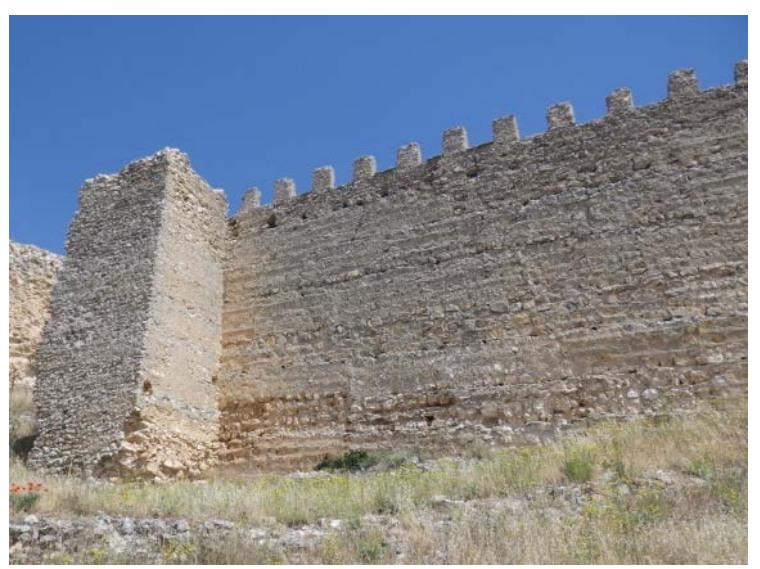

Fig. 5.3.48. Torre T8 vista desde el sur y parte del lienzo [A.S.E. 17/6/2014].

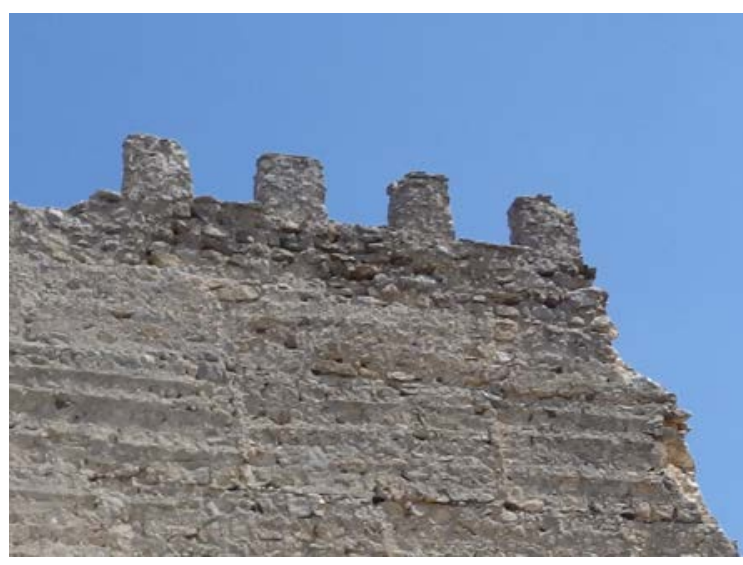

Fig. 5.3.49. Detalle del almenado y de parte de las tapias del lienzo T8-este, visto desde el exterior [A.S.E. 17/6/2014].

El almenado es similar al descrito en el tramo anterior, con almenas cuadradas y separadas entre sí una distancia similar a su anchura. No se observan recrecidos del lienzo sobre el almenado, como ocurre en el tramo T5-T7. Se observan mechinales en la base de las tapias, en la línea de división de las mismas. En la última hilada de tapia, bajo las almenas, se observan mechinales de mayor dimensión, tal vez construidos con mampuestos aunque no es evidente pues algunos elementos se han desprendido de su posición original.

Más al este se encuentra un tramo aislado de escasa longitud, cercana a los $15 \mathrm{~m}$. Las características constructivas de este tramo son similares a las descritas para el tramo T8-este. Se realiza con tapia de mampostería y las marcas de tapia son claramente visibles en el paramento. Las marcas de las tablas del tapial son también visibles y de forma general se cuentan igualmente cuatro tablas por tapia. En la base de este tramo se observa el empleo de grandes piedras colocadas formando hiladas en la tapia. En 
estas tapias de la base, no es tan evidente la marca de las tablas, parece posible que la capa de tierra en contacto con la tablazón del tapial se haya perdido en esta zona de base, dejando a la vista las piedras empleadas en la construcción del tapial.

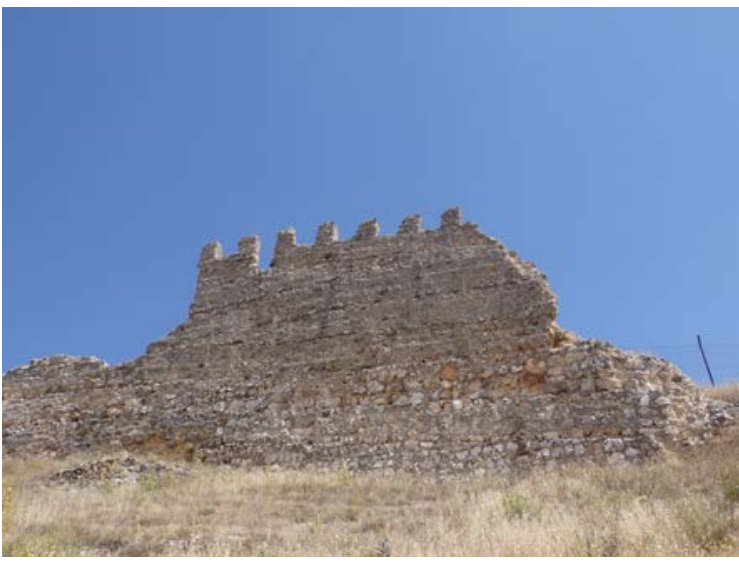

Fig. 5.3.50. Tramo aislado L4 visto desde el exterior [A.S.E. 17/6/2014].

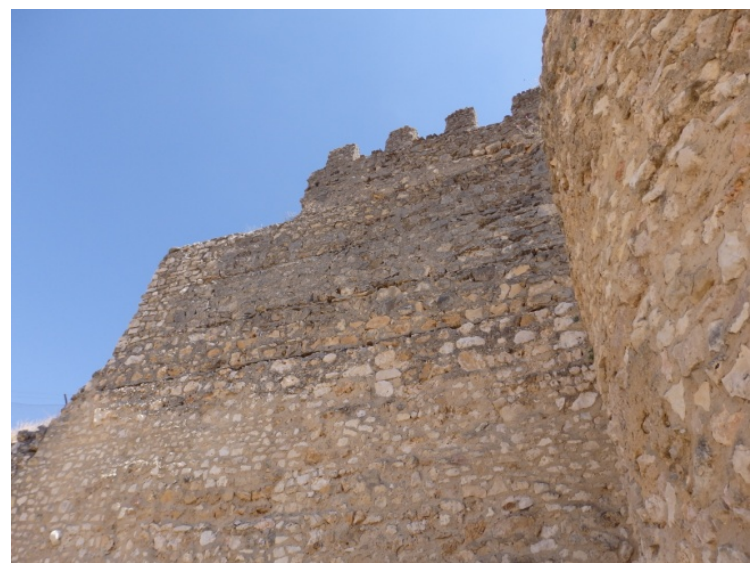

Fig. 5.3.51. Tramo al oeste de torre T9 [A.S.E. 17/6/2014].

Al norte de la torre T9 se inicia el último tramo que comparte características con los tramos descritos desde la torre T8 (Fig. 5.3.51, Fig. 5.3.52, Fig. 5.3.53). En este tramo se observan reparaciones intensas en la base que han añadido morteros $y$ mampuestos nuevos a zonas probablemente desprendidas. También el remate del extremo oeste del muro ha sido reconstruido. Estas reparaciones han borrado parte de las marcas que deja el tapial. En la zona superior se cuentan cinco tapias de altura sobre la zona de reparaciones (Fig. 5.3.51). El almenado en todo este tramo es similar al descrito al este de la torre T8. La forma de las almenas es cuadrada y se separan entre sí una distancia equivalente a la anchura de la almena. Tampoco se observa en esta zona un recrecido del lienzo sobre las almenas. El tramo entre la torre T9 y la puerta de Alfonso VIII (P3) muestra también reparaciones en la base del muro con la aplicación de nuevos morteros (Fig. 5.3.53).

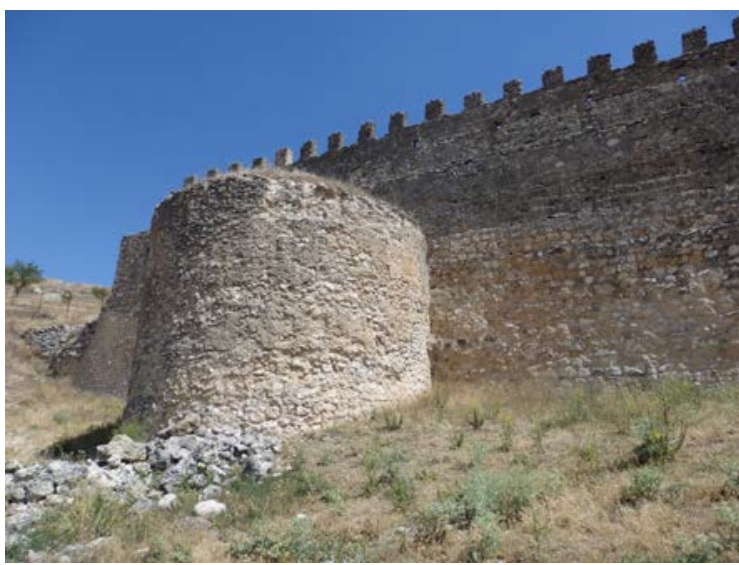

Fig. 5.3.52. Torre T9 vista desde el sur [A.S.E. $17 / 6 / 2014]$.

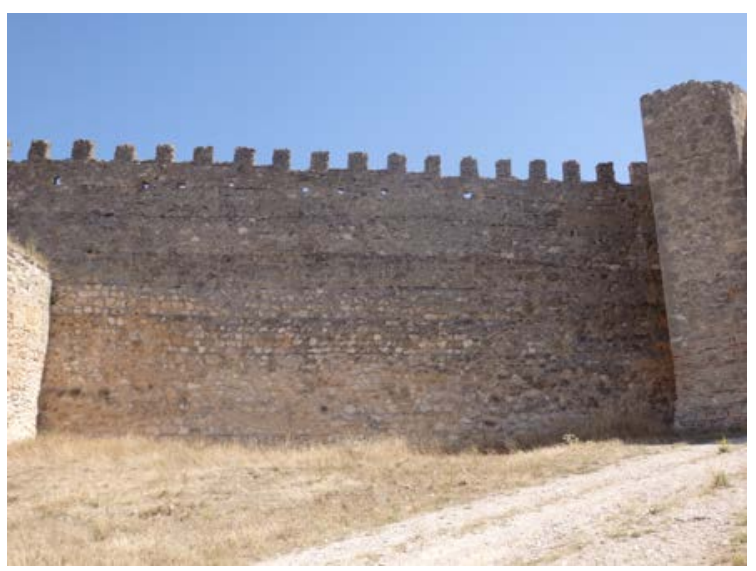

Fig. 5.3.53. Tramo T9-P3 [A.S.E. 8/7/2015]. 
La torre T9 se adosa a la muralla en este tramo y presenta una planta semicircular (Fig. 5.3.52). Su altura no alcanza la altura del lienzo, sino que se interrumpe a medio camino. El aspecto que ofrece el lienzo sobre la torre muestra la independencia de ambos elementos así como la anterioridad en la construcción del lienzo frente a la torre, que se adosa después.

La puerta de Alfonso VIII (P3) se sitúa en una pos ición singular en relación con el lienzo T9-P3. El ángulo que forman no es habitual en los encuentros de puertas y lienzos. Desde el exterior (Fig. 5.3.54), la composición de la puerta es simétrica, con dos torres de planta rectangular que flanquean el acceso. Se adelantan en relación con el plano de acceso. La base de la puerta se construye con mampostería encintada con ladrillo. Alonso Zamora y Fernando Vela $(2005,1139)$ consideran que esta zona es la más antigua del recinto amurallado. Indica que la puerta original estaba construida con el sistema constructivo de la base y fue derribada, construyéndose después una nueva con una configuración similar. Cada una de las torres muestra machones de ladrillo dentados en sus esquinas exteriores. Se completa un marco, o una caja, con verdugadas dobles de ladrillo que parten de la parte inferior y superior de cada dentado de los machones. En la caja, se construye una hilada de piedras grandes e i rregulares que están separadas por un I adrillo colocado en pos ición vertical, ofreciendo su canto (Fig. 5.3.57). Este sistema es visible también en el interior del acceso. En el centro se observan los restos de dos pilastras de ladrillo, que interrumpen la mampostería encintada y se sitúan en línea con el plano de acceso (Fig. 5.3.57).

Sobre esta base, las torres se construyen con un sillarejo muy irregular; se trata más bien de mampuestos colocados muy enrasados que generan un plano vertical muy regular. Las esquinas de las torres se resuelven con sillares de piedra colocados en contrapeado, formando un dentando. El frente de acceso se construye de forma similar. En el centro se observa un hueco pequeño, formado por sillares rectangulares. La coronación de la puerta se ha perdido y ahora ofrece un aspecto no definido.

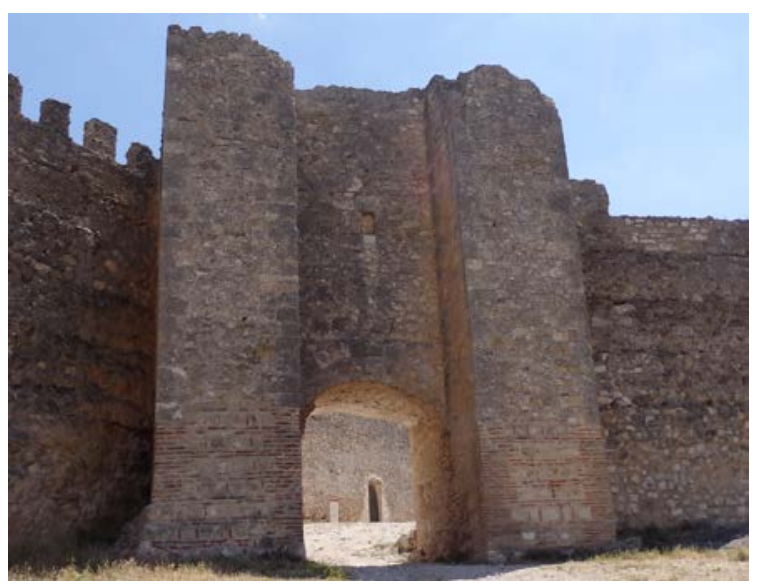

Fig. 5.3.54. Puerta de Alfonso VIII (P3) [A.S.E. $17 / 6 / 2014]$.

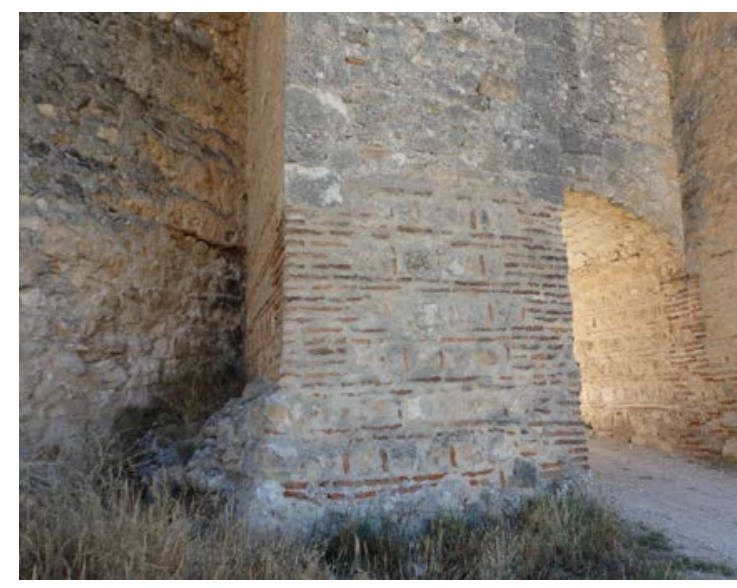

Fig. 5.3.55. Base de la torre T13, desde el exterior [A.S.E. 8/7/2015]. 


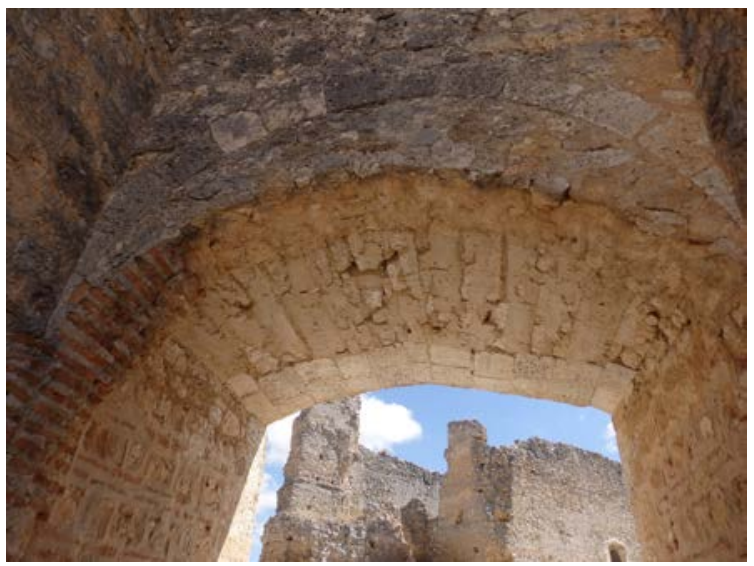

Fig. 5.3.56. Detalle de la bóveda de acceso de la puerta de Alfonso VIII (P3) [A.S.E. 13/8/2014].

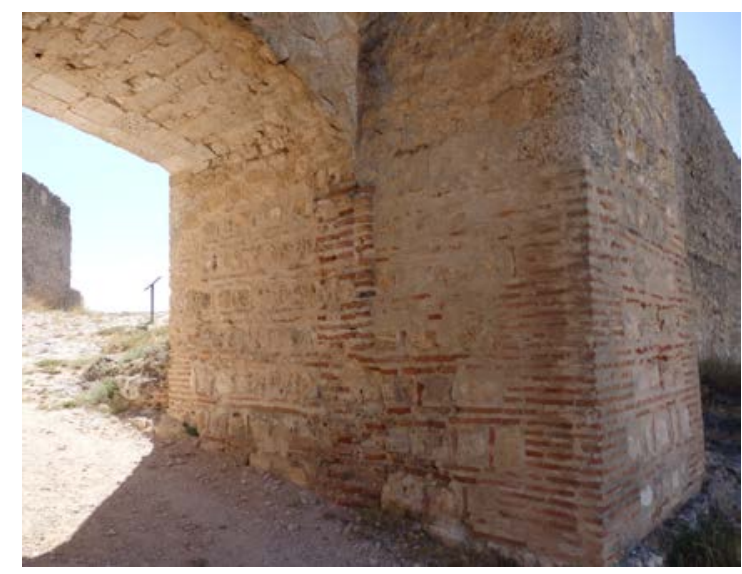

Fig. 5.3.57. Detalle de la base de la torre T14 de la puerta de Alfonso VIII (P3) [A.S.E. 8/7/2015].

El acceso se cubre con una bóveda de mampostería rebajada con restos de encofrado en su interior. Sobre esta, se observa un arco de sillares de piedra. El arranque de un arco de ladrillo es visible en el lado izquierdo del acceso y parte de la pilastra de ladrillo (Fig. 5.3.56). Junto al arranque del arco, en el interior se encuentra una piedra tallada que funcionó de gozne.

La puerta tiene un as pecto muy diferente en su alzado interior, ya no se observa la composición simétrica del exterior, sino que solo es visible un alzado liso, con un ligero quiebro en su lado derecho, compuesto en un mismo plano del hueco de acceso. El nivel del suelo se encuentra más elevado en el interior, por lo que la puerta ofrece también un aspecto más achatado en comparación con el alzado exterior. El hueco de acceso se construye con sillares de piedra, de forma cuadrada, que conforman un arco rebajado. Los sillares se emplean también en los estribos del arco, colocados con cierto contrapeado. En la base de los estribos se observan algunos restos del sistema constructivo empleado en la zona exterior (Fig. 5.3.58).

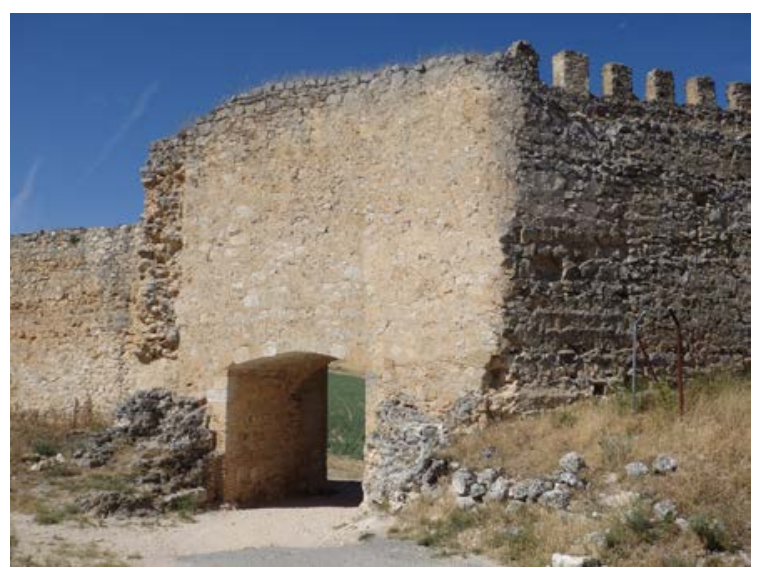

Fig. 5.3.58. Vista interior de la puerta de Alfonso VIII (P3) [A.S.E. 8/7/2015].

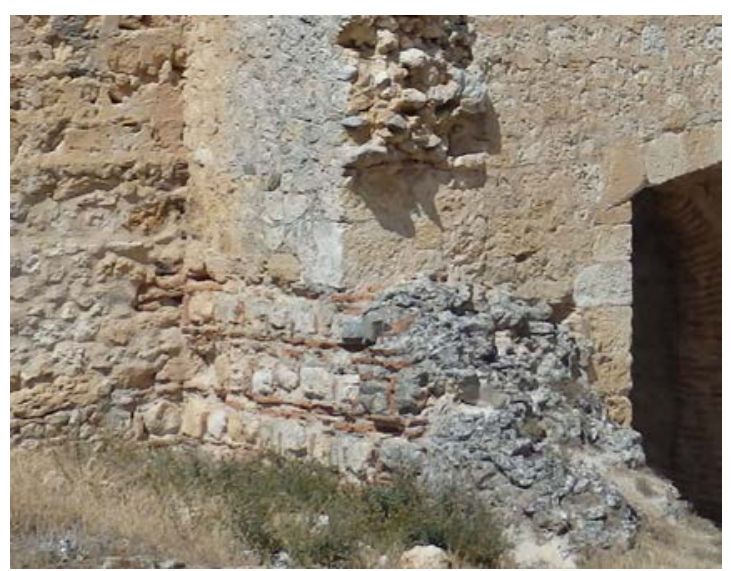

Fig. 5.3.59. Detalle de la base de la torre T14, vista desde el interior [A.S.E. 13/8/2014]. 
Las murallas en las Comunidades de Villa y Tierra de la Diócesis de Segovia en los siglos XI a XIII. Técnica y sistemas constructivos de la arquitectura defensiva medieval.

Desde el interior, se puede observar más claramente el encuentro de la puerta y el lienzo T9-P3 (Fig. 5.3.58). Los materiales empleados en cada uno de I os elementos son diferentes, el encuentro entre los dos elementos no parece planificado. No existe una continuidad entre las tapias del lienzo y la fábrica de la puerta. Es probable que el lienzo se construyera con posterioridad a la puerta, dada la solución constructiva visible y el ángulo singular de encuentro de ambos elementos. En esta cara interior, también es visible la sección de un muro que partiría del lado izquierdo de la puerta hacia el interior del actual recinto. Esta sección arranca con una altura semejante a la del hueco de acceso (Fig. 5.3.59). La dirección en la que partiría este muro podría tener relación con la torre de la iglesia de San Martín, al noreste de la puerta de Alfonso VIII. El encuentro de la puerta con el lienzo P3-T9, también parece realizado cuando la puerta ya existía. Ambos elementos se unen de forma abrupta. La esquina interior derecha de la puerta muestra un encuentro forzado (Fig. 5.3.58).

En la cara sureste de la torre T14 se observa el sistema de mampostería encintada con ladrillo en la base (Fig. 5.3.59). Se puede ver cómo el encintado se construye en la cara exterior del muro, con un objetivo decorativo o al menos de imagen. Esta cuestión choca con la ubicación de esta cara de la torre, en el interior del recinto, poco visible. Dada la posición de la puerta y de los restos de muros que parten de ella en dirección noreste, es posible pensar que la cara sureste de la torre T14 fuera una cara exterior de recinto amurallado, y se resolviera de la misma manera que el alzado exterior de la puerta, con mampostería encintada.

Desde la puerta de Alfonso VIII hasta el borde del cerro, que tiene una caída de $15 \mathrm{~m}$, se sitúa el tramo de muralla P3-T10 (Fig. 5.3.60) que comparte características con los tramos ya descritos. Tiene una I ongitud de casi $60 \mathrm{~m}$ y se puede contemplar con facilidad tanto desde el exterior como desde el interior. En este tramo se observa una base reparada, con nuevos morteros y mampuestos en aparejos regulares. Desde esta base se pueden contar 5 tapias de altura. Se observa el empleo de mampuestos en la construcción de las tapias, con piedras de gran tamaño, que tienen forma irregular. La coronación no posee ya almenado alguno en todo el tramo. Se observa en las líneas horizontales que marcan las hiladas de tapia la presencia de mechinales, de los que tan solo son visibles los huecos en la línea de la hilada, sin identificarse claramente su formación a través de mampuestos.

La torre T10 (Fig. 5.3.61) tiene planta rectangular, su lado largo está pegado al lienzo. El tamaño de esta torre es más comedido en comparación con otras torres descritas, mantiene una proporción con las dimensiones del lienzo. En el caso de las torres semicirculares de otros tramos, se observan dimensiones muy importantes en relación con la entidad de la muralla. Las tapias empleadas en la construcción de la torre T10 son similares a las del resto del lienzo. Se ven las mismas dimensiones así como el empleo de piedras similares. La altura en tapias de la torre coincide con la del lienzo, los encuentros entre ambos elementos mantienen una continuidad. Es probable que en este caso la construcción de lienzo y torre se hiciera de forma simultánea. La base de la torre también presenta reparaciones y reconstrucciones de las esquinas exteriores. 


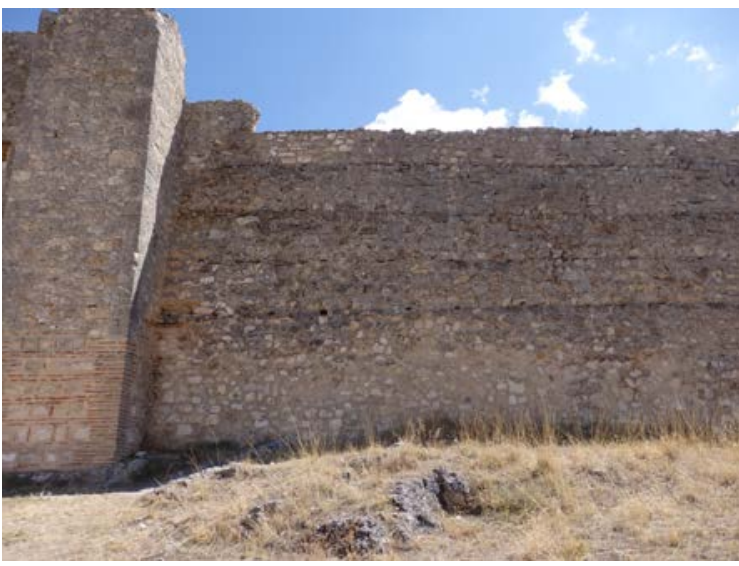

Fig. 5.3.60. Parte del tramo T14-T10 [A.S.E. $13 / 8 / 2014]$.

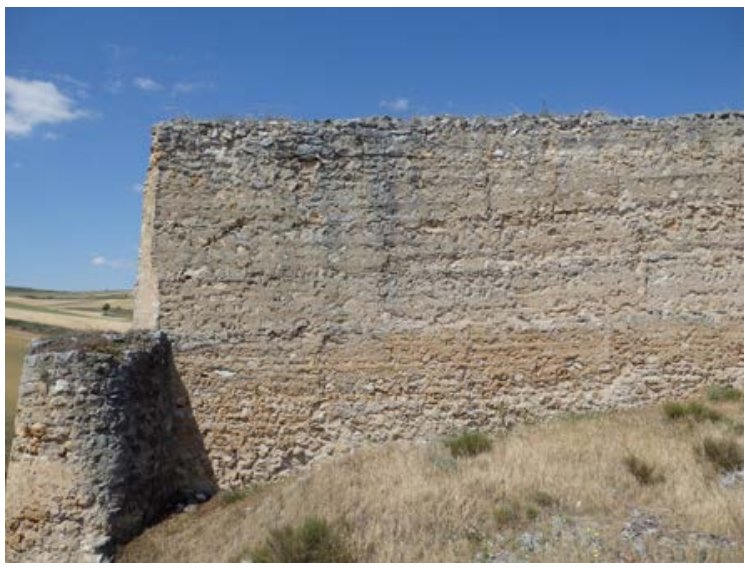

Fig. 5.3.62. Tramo T10-T11 visto desde el interior del recinto, junto a posición de torre T11. [A.S.E. 17/6/2014].

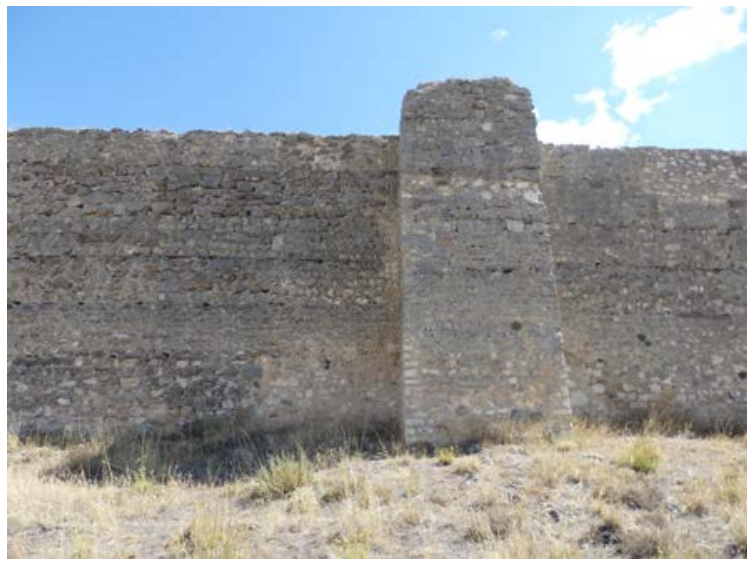

Fig. 5.3.61. Torre T10 [A.S.E. 13/8/2014].

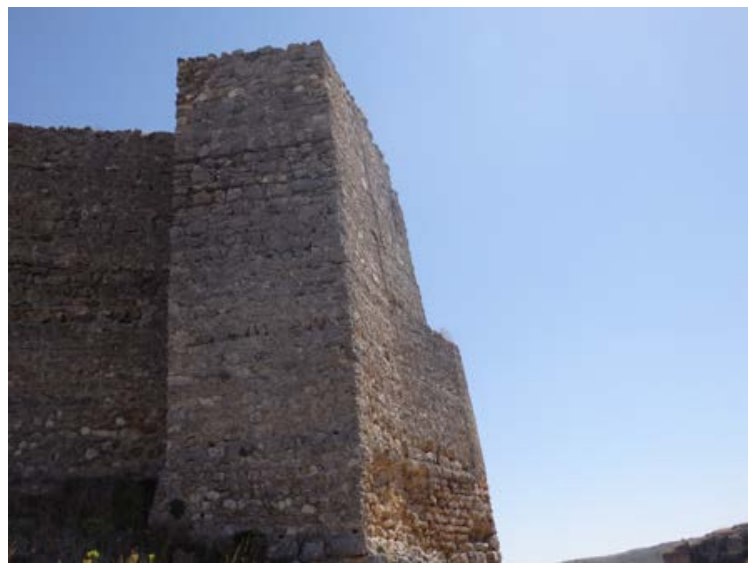

Fig. 5.3.63. Torre T11 [A.S.E. 8/7/2015].

Entre las torres T10 y T11 el lienzo se configura de forma muy similar al tramo P3-T10. Se observan reparaciones en la base y en zonas superiores, donde se han reconstruido algunos desprendimientos con nueva mampostería y morteros. La altura en tapias es la misma que en el anterior tramo. La continuidad de todo el tramo P3T11 se aprecia desde el interior del recinto donde se puede observar un muro continuo de tapia. La tapia visible en el interior muestra diferencias con respecto al exterior, en este caso se conserva mejor la capa más superficial de la tapia por lo que se ven mejor los límites horizontales y verticales de cada tapia, así como las marcas de tablazón del tapial (Fig. 5.3.62).

La torre T11 (Fig. 5.3.63) tiene una apariencia exterior similar a la torre T10, sin embargo, desde el lado este es posible ver que tiene un fondo superior a lo esperado en relación con su anchura visible desde el exterior. Se construye formando una esquina y hacia el este se produce una breve continuación de muro, adaptándose al borde del terreno. Se emplea tapia en su construcción, de la misma forma y material empleado en el lienzo. Se aprecia una continuidad entre las hiladas de tapia del lienzo y las hiladas de la torre, como ocurre también en la torre T10. En este caso también se podría decir que la construcción de torre y lienzo se ha realizado de forma simultánea. 
Aun así, desde el interior del recinto, donde se aprecia un muro continuo desde la puerta P3 hasta la torre T11, no existen marcas en la configuración de las tapias que pudieran hacer pensar que del otro lado del lienzo existen torres, la fábrica de tapias no se ve alterada.

\subsubsection{Zona este del recinto}

En la cara oeste se conservan algunos restos de muralla que se construyen serpenteantes, adaptándose a la línea del terreno (Fig. 5.3.64). Se observan hiladas de tapias construidas con piedras de gran tamaño y forma irregular. Se pueden ver recodos que recuerdan la forma de torres (Fig. 5.3.65) aunque en el lado opuesto continúan en línea con el lienzo. El encuentro entre lienzo y el recodo parece mostrar que se trata de elementos diferentes, ya que los materiales empleados son distintos y no se produce continuidad en el sistema constructivo. En las zonas desmoronadas al norte del elemento T12 es posible entrever más detalles del sistema constructivo empleado (Fig. 5.3.66). Se observan grandes piedras empleadas en la zona exterior de la tapia y una amalgama de piedras más pequeñas y mortero hacia el interior. Es visible en algunos puntos empleo de varillas pareadas para la realización del tapial. Se trata de varillas finas que se colocan en paralelo en sustitución de la aguja. En el paramento, quedan dos marcas circulares separadas entre sí una distancia de $10 \mathrm{~cm}$ aproximadamente (Fig. 5.3.67). Se ha encontrado este sistema también en el tramo T5-T7.

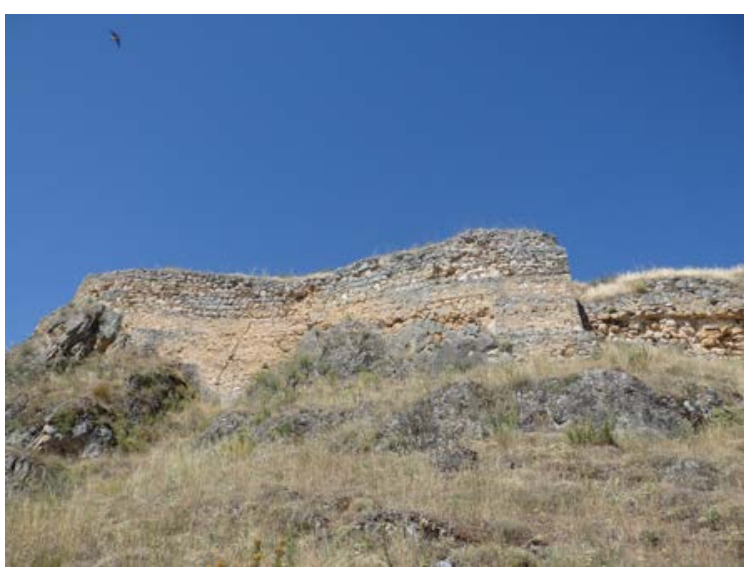

Fig. 5.3.64. Tramo T12-sur en la zona este del recinto [A.S.E. 08/07/2015].

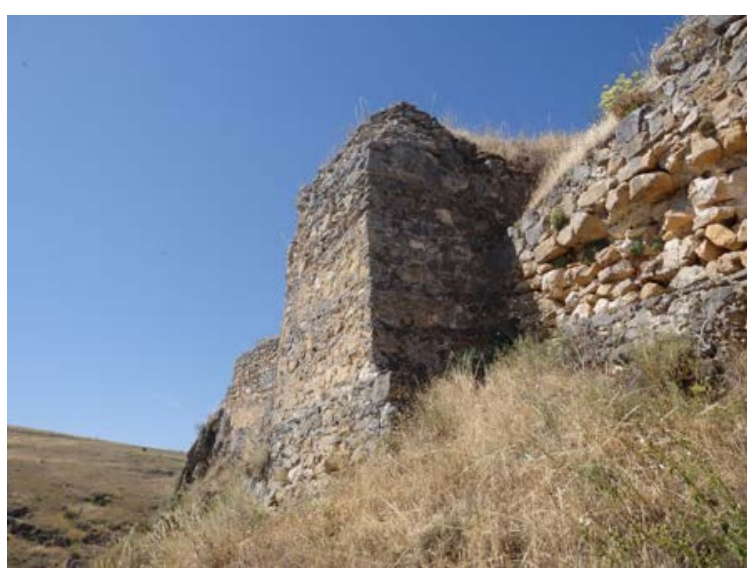

Fig. 5.3.65. Recodo con forma de torre, que se ha nombrado T12 [A.S.E. 08/07/2015].

Tras este último tramo descrito, se encuentra una gr an pared de $\mathrm{r}$ oca descrita anteriormente en cuyos bordes podría continuar la muralla, pero donde no s e hallan restos visibles. Más al norte se observa en una zona ya urbana la existencia de muros que se sitúan en la línea de trazado de la muralla y se construyen con lo que parece una aparejo de mampostería de piedra (Fig. 5.3.68, Fig. 5.3.69). Sin embargo, son visibles algunas marcas de hiladas de tapia, aunque no tan evidentes como en otros casos. El muro se encuentra reparado y modificado por las construcciones urbanas, 
por lo que no es tan evidente el carácter de lienzo como en otros casos del recinto amurallado. Antes de llegar a la puerta de la Calzada, se encuentran restos intermitentes de muralla, absorbidos y reutilizados por las edificaciones urbanas.

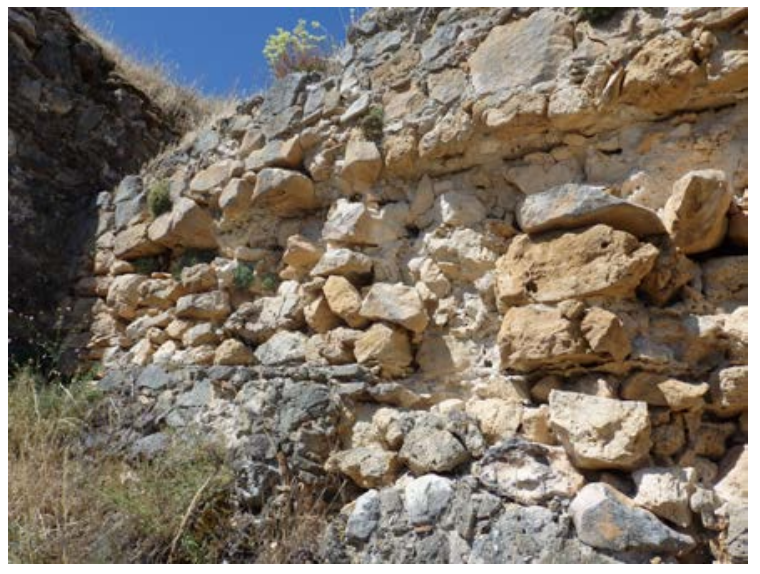

Fig. 5.3.66. Hilada de tapia que ha perdido parte de su material al norte de T12 [A.S.E. 08/07/2015].

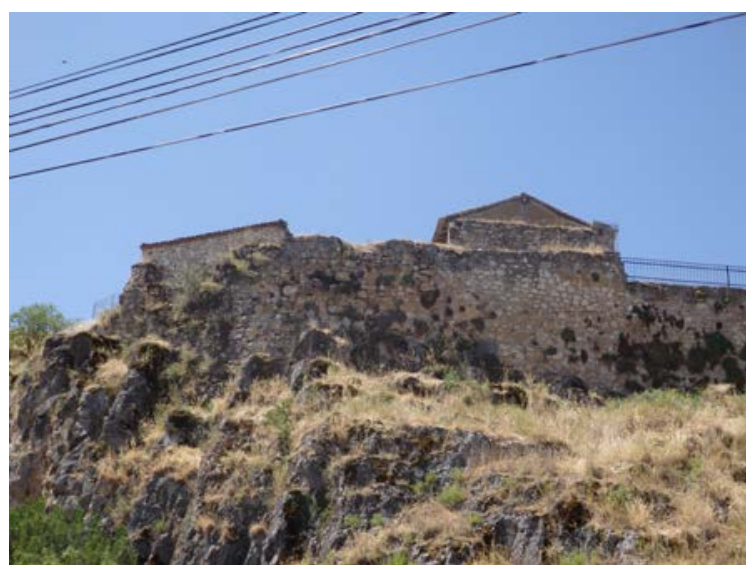

Fig. 5.3.68. Restos en la parte noreste del recinto [A.S.E. 08/07/2015].

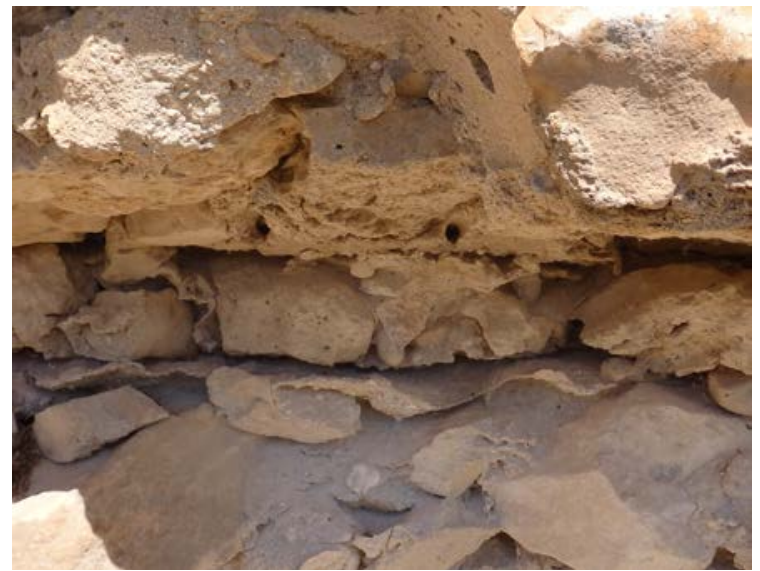

Fig. 5.3.67. Marca del empleo de varillas pareadas de una tapia en el tramo T12-norte [A.S.E. 08/07/2015].

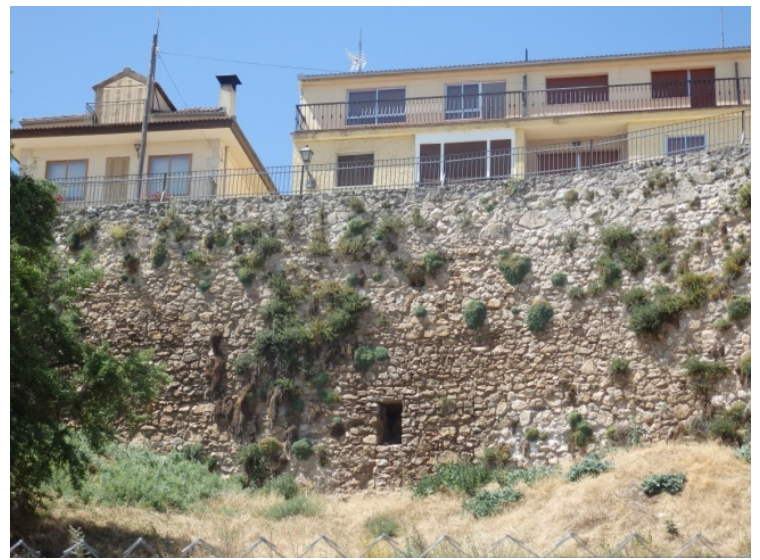

Fig. 5.3.69. Restos en la parte noreste del recinto [A.S.E. 08/07/2015].

\subsubsection{Zona noreste del recinto}

La puerta de la Calzada (P2) se sitúa en la zona norte del recinto amurallado. Su aspecto desde el exterior es sencillo, con un arco de acceso en un úni co plano (Fig. 5.3.70). No se observan torreones adelantados respecto del plano de acceso. Se sitúa en sentido perpendicular a la dirección del lienzo de muralla, formando un quiebro en el trazado. En su paramento se observa un aparejo de mampuestos con hiladas regulares. El aparejo ha sido restaurado con nuevo mortero y probablemente nuevos mampuestos. En la coronación parecen existir los restos de un almenado. El acceso se resuelve con un arco irregular, que arranca en su lado izquierdo sobre una ménsula 
de piedra. En el lado derecho se conserva una piedra tallada a modo de gozne. Sobre el arco de acceso se sitúa un pequeño escudo prácticamente ilegible.

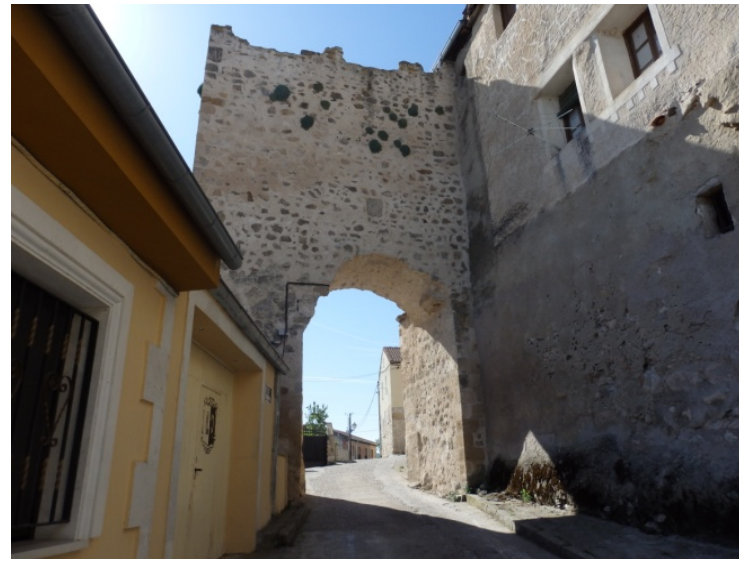

Fig. 5.3.70. Puerta de la Calzada P2 [A.S.E. 08/07/2015].

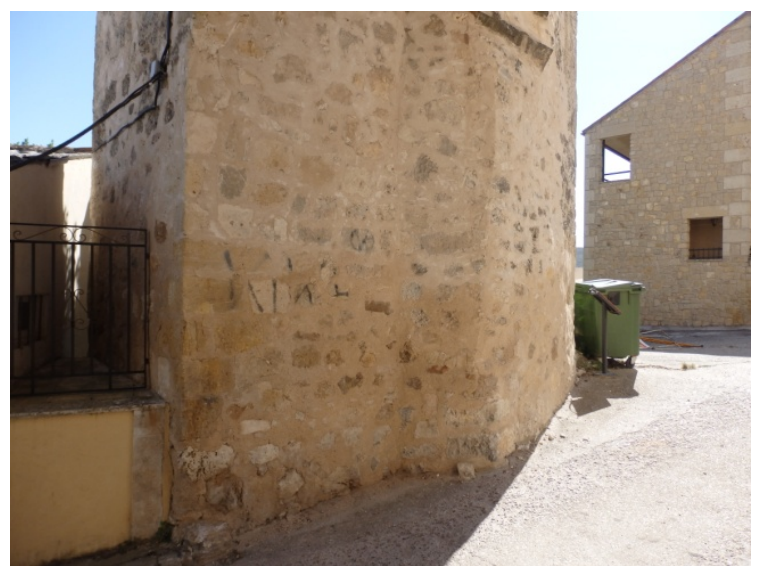

Fig. 5.3.72. Base de estribo E1 de la puerta de la Calzada [A.S.E. 08/07/2015].

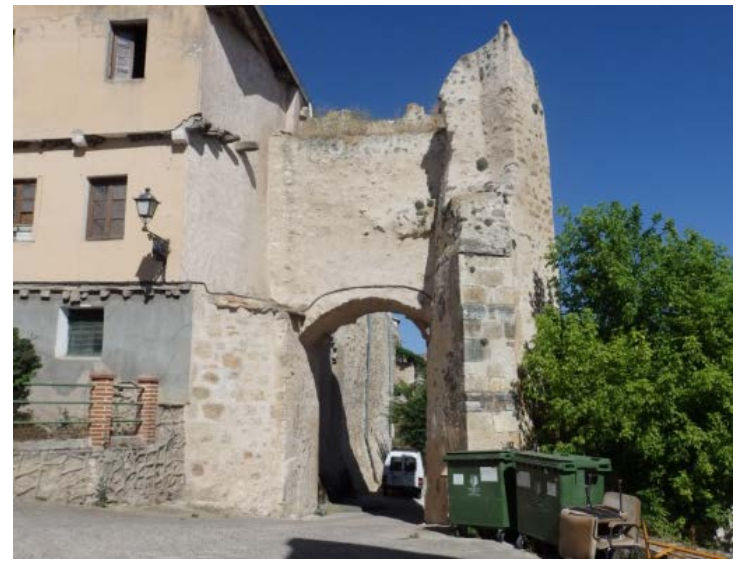

Fig. 5.3.71. Vista interior de la puerta de la Calzada (P2) [A.S.E. 08/07/2015].

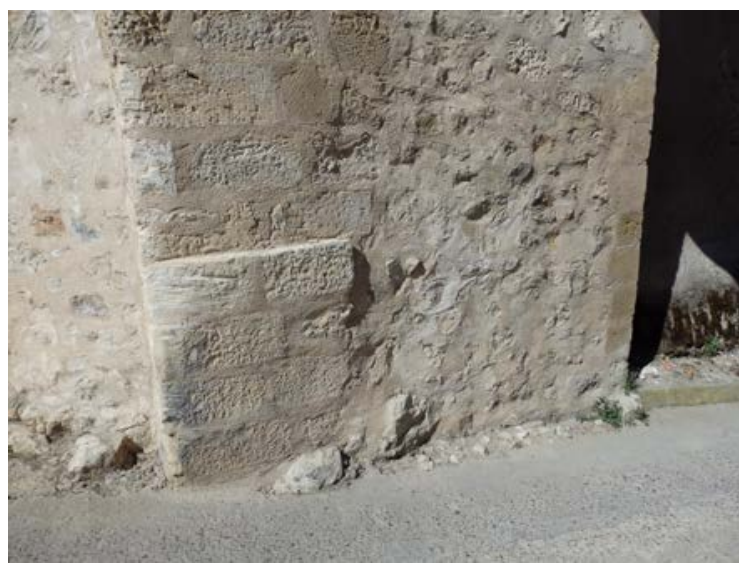

Fig. 5.3.73. Base de estribo E2 de la puerta de la Calzada [A.S.E. 08/07/2015].

En su cara interior, la puerta ofrece un as pecto muy poco definido (Fig. 5.3.71). Se podría identificar una torre en el lado derecho de planta muy irregular, no obstante, se ha preferido denominar de otra manera a este elemento, puesto que su función parece vinculada a la estabilidad de la bóveda de acceso más que a la de torre de protección del paso. Tampoco se observa una composición de alzado exterior de esta puerta que permita creer que este elemento sobresaliera como torre por encima del conjunto o se adelantara con respecto del plano de acceso. En su cara noreste podría parecer de planta rectangular, pero muestra gran irregularidad hacia el sur, con un elemento que recuerda a un contrafuerte construido con sillería. En su lado izquierdo se identifica lo que podría ser la base de otra torre que alcanza la altura del arco de acceso. La coronación de la puerta es irregular y no se identifican elementos con facilidad, pero parece que existe un adarve tras los restos de un almenado, también visible desde el exterior. 
Las caras internas del acceso son irregulares, forman ángulos singulares y tiene elementos que sobresalen del plano del muro. En el volumen E2 se observa el estribo del arco construido con sillería de piedra (Fig. 5.3.73). Como se ha mencionado en el análisis del tejido urbano, junto a esta puerta se sitúa una parcela muy singular con directriz circular, que podría sugerir la existencia de una torre de esta forma.

Desde la puerta de la Calzada (P2) hasta la puerta de Palacio (P1) continúa el último tramo de muralla de este recinto. Se trata de un tr amo modificado, alterado por las edificaciones y construcciones urbanas que se adosan en la cara interior de la muralla de forma mayoritaria, aunque también se adosan algunas por el exterior. En las viviendas cercanas a la puerta de Palacio (P1) se observan huecos en el muro, y también se puede ver zonas reforzadas o recrecidas la base de los muros (Fig. 5.3.74). Se emplean sillares irregulares de piedra en es quinas y alguna zona de la base. No se observan marcas de construcción con tapial, propias de otras zonas de la muralla. Se observan parches y arreglos modernos en este tramo de muralla.

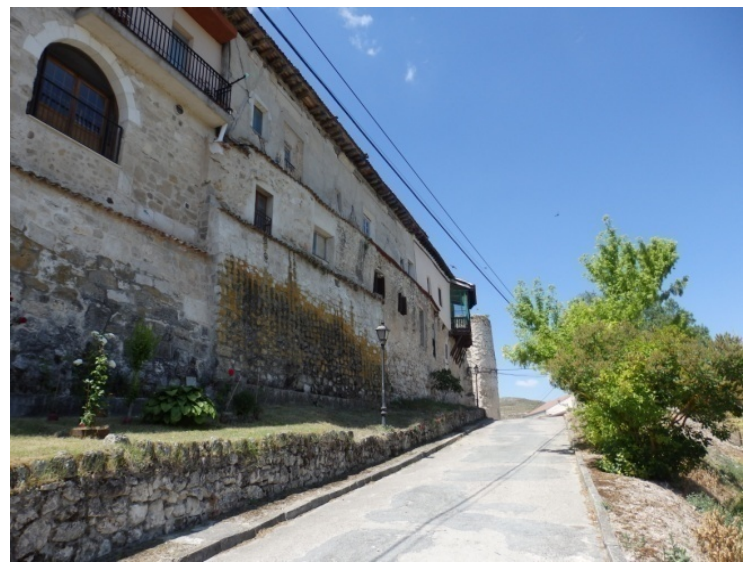

Fig. 5.3.74. Muralla en la zona norte, alterada por las construcciones adosadas [A.S.E. 17/06/2014]

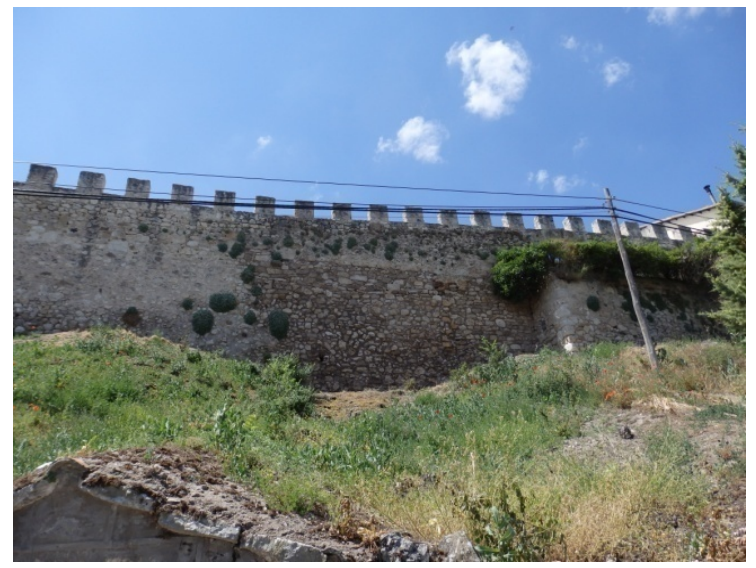

Fig. 5.3.75. Edificaciones construidas adosadas a la muralla [A.S.E. 17/06/2014]

A la altura de la plaza del Ayuntamiento, se puede observar un lienzo de muralla sin construcciones adosadas (Fig. 5.3.75). Se construye con un aparejo de piedra y no se aprecian restos de tapial. Se pueden ver distintas zonas en este lienzo, diferenciadas por el color y el aparejo de la piedra. En la zona izquierda, el color es más claro y la piedra tiene un aparejo desordenado. En la zona central, se observa un tono más oscuro y un aparejo también desordenado. A la derecha, se observa un ap arejo ordenado por hiladas horizontales, con piedras más rectangulares. En la parte superior, se aprecia una línea de división, que muestra una banda de coronación distinta de la base. En lo alto se observa una zona de almenado, que muy probablemente ha sido reconstruido.

\subsubsection{Características principales de los elementos descritos}

A continuación se refleja en las tablas siguientes un resumen de las características principales de las torres y puertas del recinto. En este recinto se conservan muchas 
Las murallas en las Comunidades de Villa y Tierra de la Diócesis de Segovia en los siglos XI a XIII.

Técnica y sistemas constructivos de la arquitectura defensiva medieval.

torres de flanqueo, además de las torres que componen las puertas (Tabla 5.3.1). Se reflejan igualmente los tramos de muralla identificados entre torres, indicando la longitud de los restos existentes y la separación entre las torres que se conservan (Tabla 5.3.2).

Tabla 5.3.1. Características y dimensiones de torres y su relación con las puertas. Fuente: Elaboración propia.

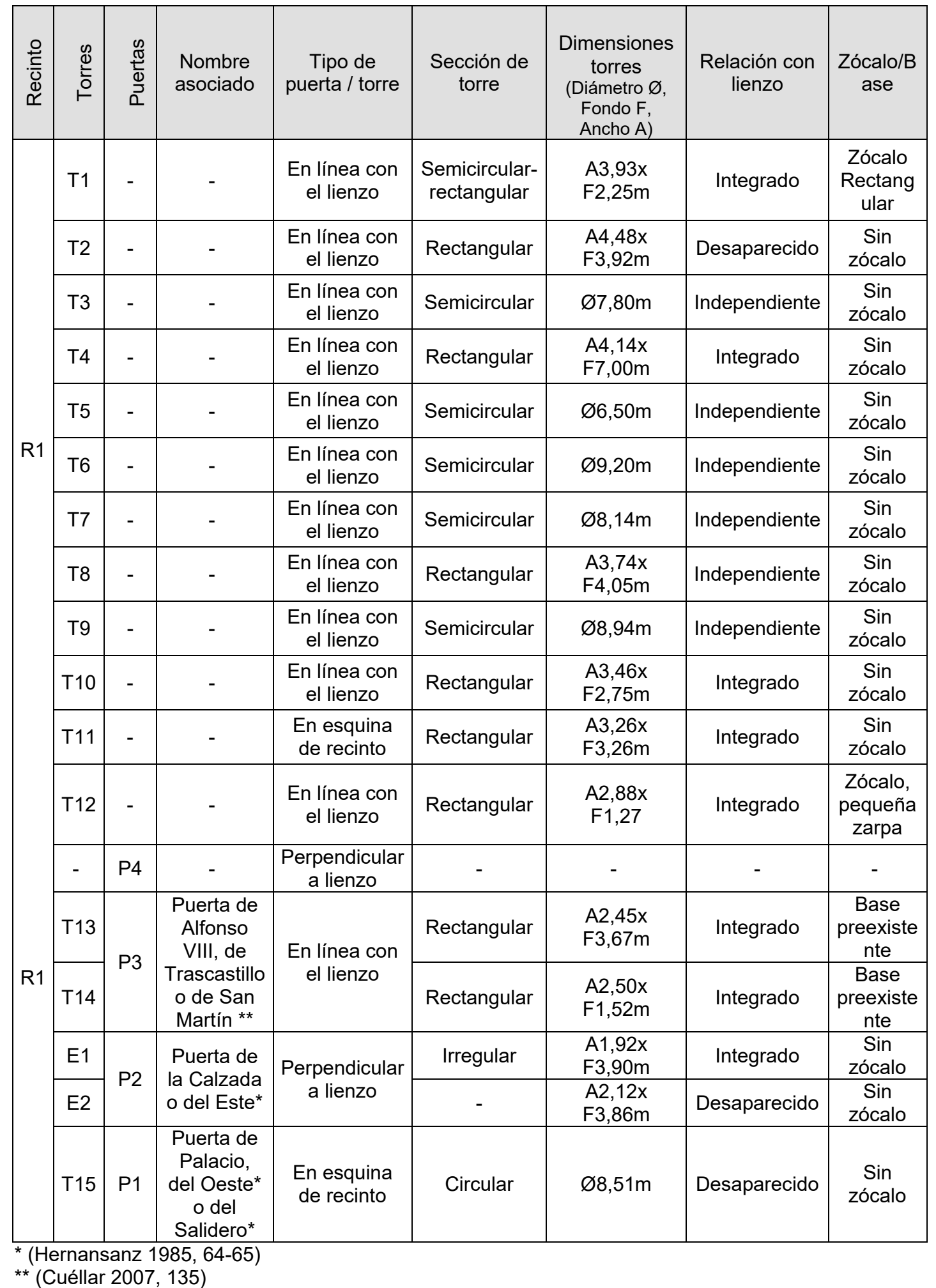


Tabla 5.3.2. Características y dimensiones de los tramos de muralla. Fuente: Elaboración propia.

\begin{tabular}{|c|c|c|c|c|c|}
\hline 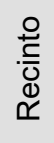 & Tramo & $\begin{array}{l}\text { Reconstrucción } \\
\text { moderna }\end{array}$ & Estado & $\begin{array}{l}\text { Longitud (m) } \\
\text { (E Existente / D } \\
\text { Desaparecido / M } \\
\text { Moderno) }\end{array}$ & $\begin{array}{c}\text { Separación } \\
\text { entre ejes de } \\
\text { elementos }(m)\end{array}$ \\
\hline \multirow{8}{*}{ R1 } & P1-T1 & No & $\begin{array}{c}\text { Modificado, } \\
\text { aprovechado en } \\
\text { nuevas edificaciones }\end{array}$ & $\begin{array}{l}\mathrm{D} 16,65 \text { / E18,44 / } \\
\mathrm{D} 4,72 \text { / E14,34 / } \\
\mathrm{D} 59,24 \text { / E32,97 }\end{array}$ & 149,34 \\
\hline & T1-T2 & No & Restaurado & E44,35 / D12,94 & 58,9 \\
\hline & T2-T3 & No & Deteriorado & D1,69 / E26,82 & 36,7 \\
\hline & T3-T4 & No & Restos intermitentes & $\mathrm{D} 13,63$ & 11,84 \\
\hline & T4-T5 & No & Deteriorado & $\mathrm{D} 4,88$ / E21,74 & 27,91 \\
\hline & T5-T6 & No & Deteriorado & E52,38 & 52,38 \\
\hline & T6-T7 & No & Deteriorado & $\mathrm{E} 16,88$ & 16,88 \\
\hline & T7-T8 & No & Ruina, deteriorado & E20,10 / D71,62 & 96,85 \\
\hline \multirow{7}{*}{ R1 } & T8-T9 & No & Restos intermitentes & $\begin{array}{c}\mathrm{E} 35,28 \text { / D27,29 / } \\
\mathrm{E} 10,38 / \mathrm{D} 55,12 \text { / } \\
\mathrm{E} 15,41\end{array}$ & 116,42 \\
\hline & T9-P3 & No & Reparado & E26,52 & 26,52 \\
\hline & P3-T10 & No & Reparado & E27,92 & 27,92 \\
\hline & T10-T11 & No & Reparado & $E 23,58$ & 23,58 \\
\hline & T11-T12 & No & Restos intermitentes & $\mathrm{D} 44,60$ / E44,49 & 89,44 \\
\hline & T12-P4 & No & Restos intermitentes & $\begin{array}{c}\mathrm{E} 33,32 \text { / D213,32 / } \\
\text { E97,36 }\end{array}$ & 339,84 \\
\hline & P4-P2 & No & Restos intermitentes & E8,04 / D38,76 & 51,12 \\
\hline \multirow[t]{2}{*}{$\mathrm{R} 2$} & P2-P1 & Sí & $\begin{array}{c}\text { Restaurado / } \\
\text { Modificado, } \\
\text { aprovechado en } \\
\text { nuevas edificaciones }\end{array}$ & E222,27 & 222,27 \\
\hline & L1 & No & Deteriorado & $\mathrm{E} 14,7$ & \\
\hline
\end{tabular}

\subsubsection{Análisis constructivo}

\subsubsection{Soluciones constructivas presentes en la muralla}

A continuación se muestran las soluciones constructivas presentes en la muralla. De forma mayoritaria se encuentra la tapia de mampostería o mampostería encofrada en prácticamente todos los lienzos de este recinto amurallado. Este sistema se encuentra en diversos estados de conservación por lo que, en ocasiones, es difícil determinar si existen diferencias reales en las tapias o si, por el contrario, la distinta textura se debe a la pérdida de material o a I a proliferación de liquen en la superficie que da un aspecto grisáceo a los paramentos. En el tramo T14-T11 se observan distintas texturas desde el exterior y desde el interior de la muralla, que son, en realidad, el mismo tipo de tapia. En el interior (Fig. 5.3.76) se ve una tapia con mampuestos, cuyo tamaño parece medio, ya que están ocultos bajo una capa superficial de tierra y cal, la 
que queda pegando con las tablas al realizar la tapia. El color de esta tapia es terroso, rojizo-amarillento. Esa tapia desde el exterior (Fig. 5.3.77) muestra grandes piedras aparejadas en cuatro hiladas, ha perdido su capa superficial y tiene un color grisáceo, oscuro.

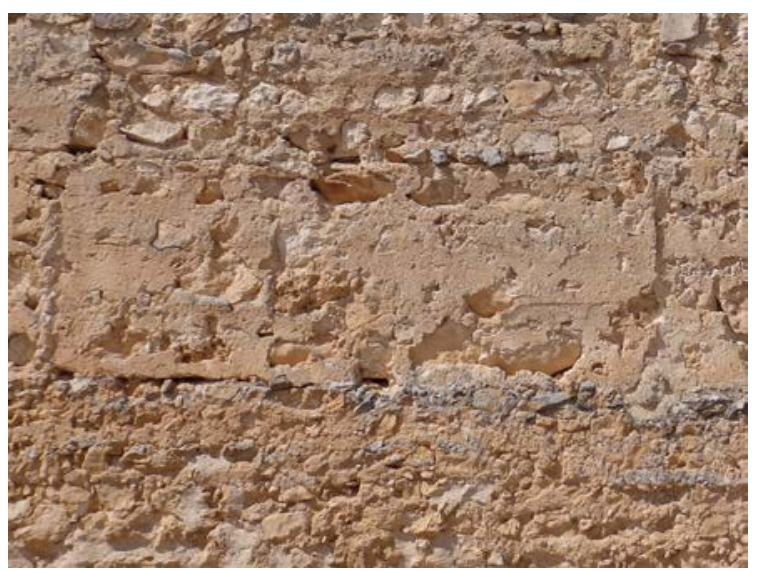

Fig. 5.3.76. Tapia de mampostería de color terroso en la cara interior del tramo T14-T11, con medidas $3,05 \mathrm{~m} \times 1,15 \mathrm{~m}$ [A.S.E. 13/8/2014].

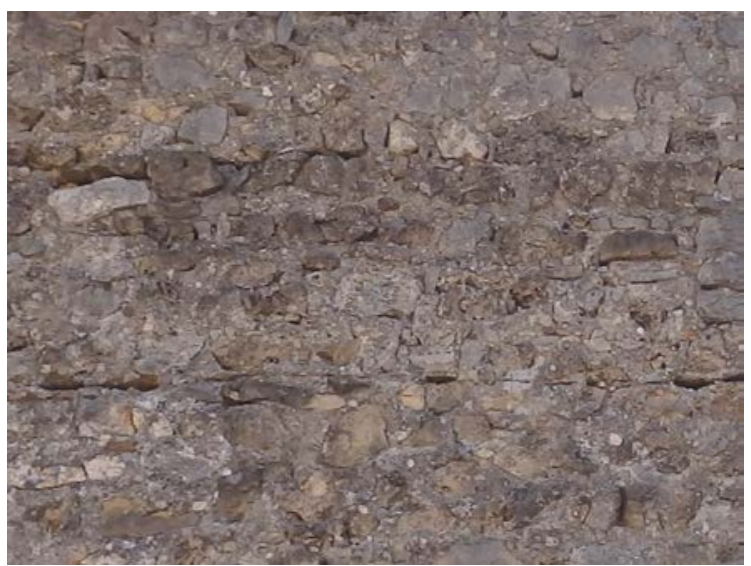

Fig. 5.3.77. Tapia de mampostería en la cara exterior del tramo T14-T11, el color es grisáceo [A.S.E. 13/8/2014].

En función del tramo, la tapia de mampostería tiene aspectos diferentes. En algunos casos, la capa en contacto con la tablazón se ha perdido y se ven piedras irregulares; mampuestos grandes, de formas irregulares y colocados formando hiladas en la tapia, ofreciendo habitualmente una cara lisa de la piedra. Estas piedras se colocarían en primer lugar dentro del tapial, colocando sus caras más lisas hacia el exterior, tal y como son visibles hoy en día (Fig. 5.3.78). En otras zonas se encuentran tapias donde las piedras empleadas parecen más pequeñas, sin embargo, esto puede deberse a que el material superficial que se fraguó entre piedras y tapial todavía se conserva y oculta parcialmente las piedras (Fig. 5.3.79). Existen diferencias entre las tapias de cada tramo de la muralla, que se observan en las dimensiones de las tapias y en la posición o la forma que adoptan los mechinales.

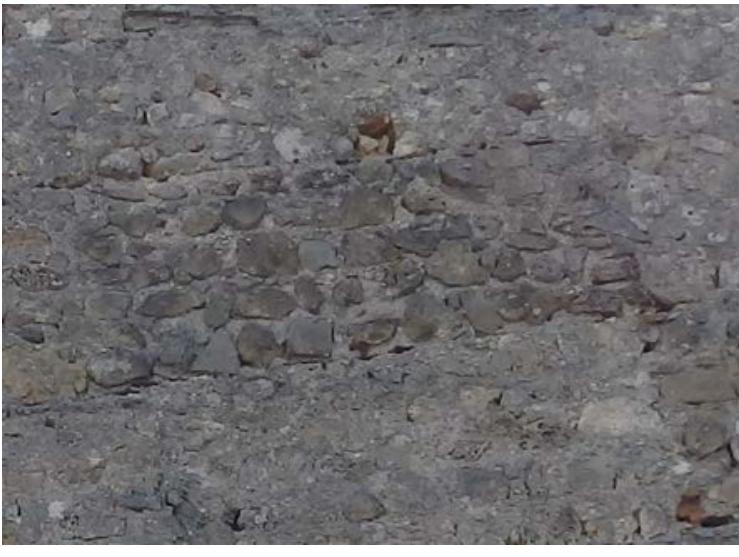

Fig. 5.3.78. Tapia T6.4 con mampostería de gran tamaño en la zona T5-T6. Se observan hiladas de piedra dentro de la tapia. Las dimensiones de la tapia son 2,81x1,17m [A.S.E. 17/6/2014].

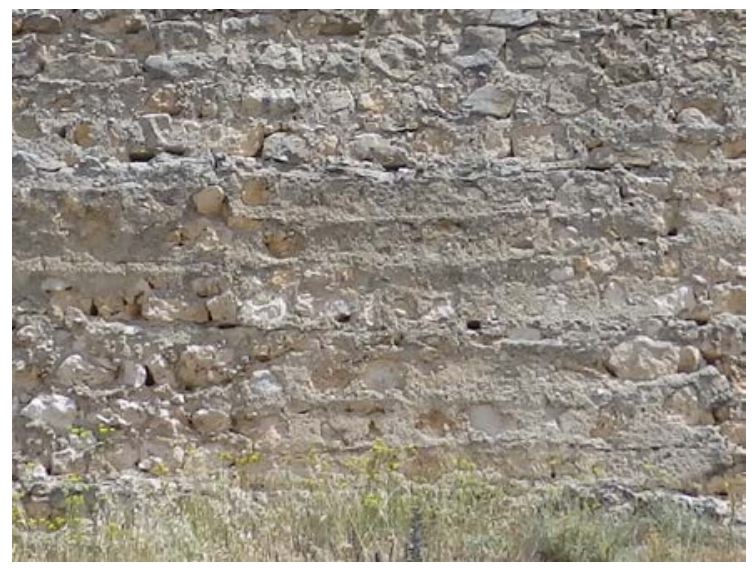

Fig. 5.3.79. Tapia de mampostería en zona T8este [A.S.E. 17/6/2014]. 


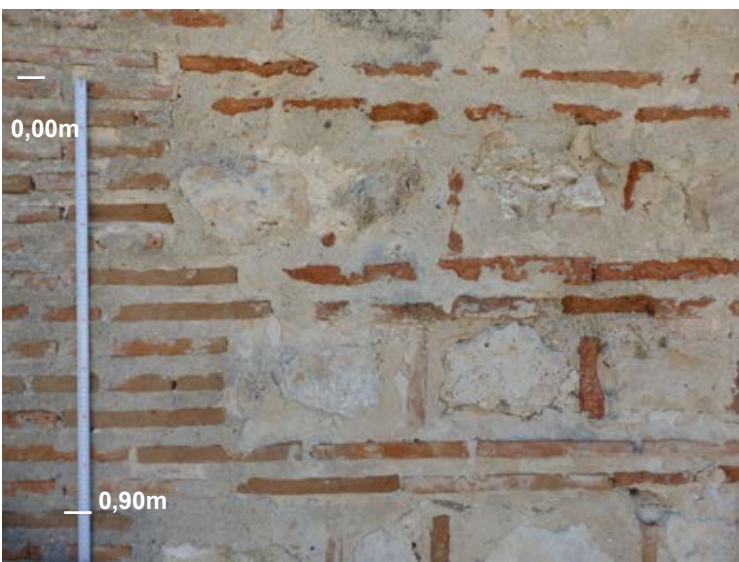

Fig. 5.3.80. Mampostería encintada con ladrillo en la puerta de Alfonso VIII [A.S.E. 8/7/2015].

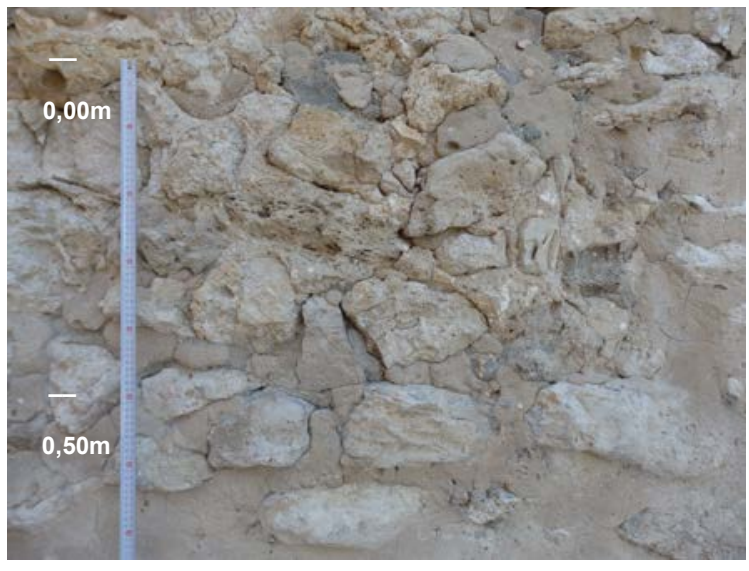

Fig. 5.3.82. Aparejo de mampostería en puerta de Palacio [A.S.E. 8/7/2015].

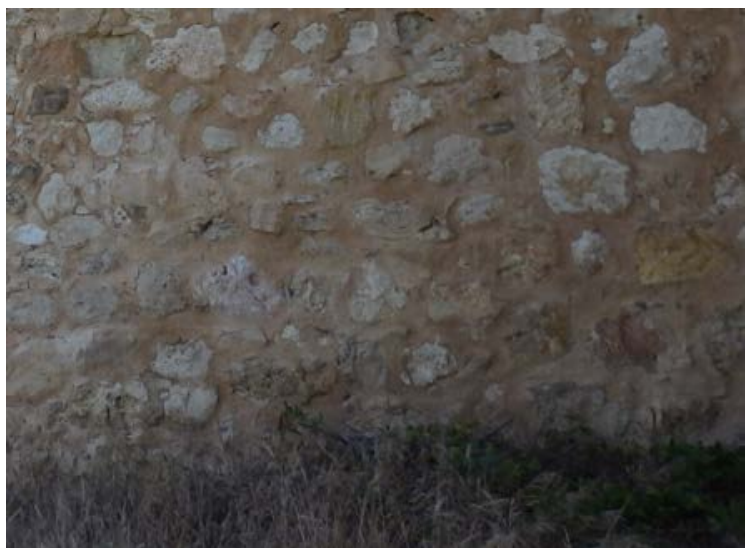

Fig. 5.3.84. Aspecto de la tapia reparada en tramo T1-sur [A.S.E. 17/6/2014]

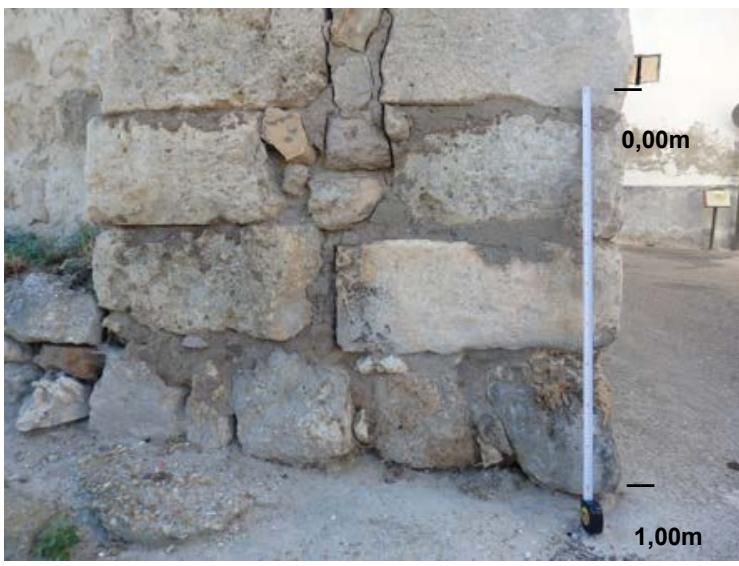

Fig. 5.3.81. Fábrica de sillería en la puerta de Palacio [A.S.E. 17/6/2014].

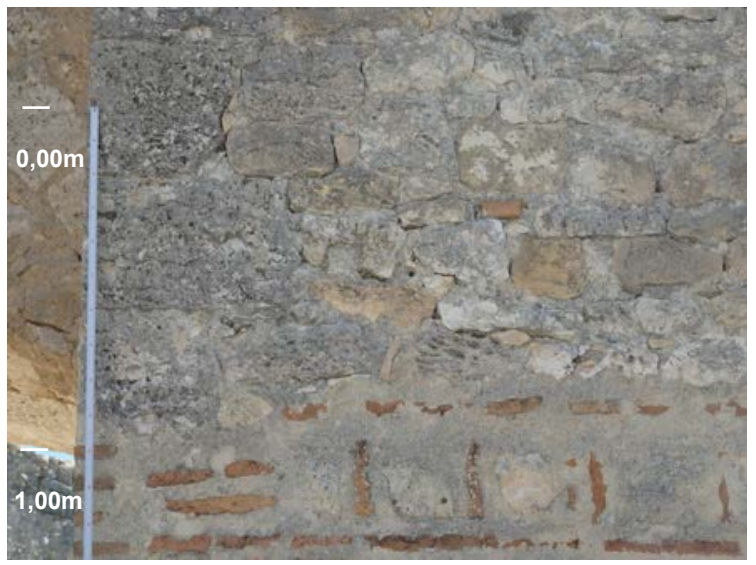

Fig. 5.3.83. Sillarejo en puerta de Alfonso VIII, sobre la base de mampostería encintada [A.S.E. 8/7/2015].

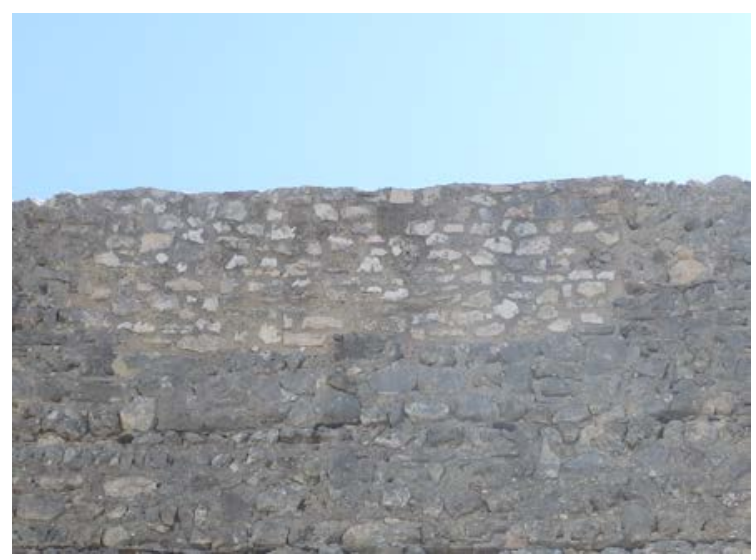

Fig. 5.3.85. Aspecto de la tapia reparada en tramo T10-T11 exterior [A.S.E. 8/7/2015] 
Se encuentran otros sistemas constructivos en puer tas o tor res. La mampostería encintada se encuentra en I a puerta de A Ifonso VIII, como se ha ex plicado anteriormente (Fig. 5.3.80). No se observa este sistema y en general el uso del ladrillo en ningún otro punto del recinto amurallado. La s illería tampoco está presente de forma intensa, se encuentra en algunos elementos vinculados al castillo y en las esquinas y arcos de puertas (Fig. 5.3.81). El sillarejo es visible en la puerta de Alfonso VIII, un tanto irregular (Fig. 5.3.83). El aparejo de mampostería se puede ver en algunos puntos, aunque no es habitual. Las reparaciones y reconstrucciones de las últimas décadas se han realizado con mampostería, con la aplicación de morteros en las juntas entre las piedras y con el añadido de nuevas piedras en elementos desmoronados o en las zonas donde se ha perdido material. En la tabla a continuación, se resumen las soluciones constructivas encontradas y el lugar de la muralla donde se han localizado.

Tabla 5.3.3. Soluciones constructivas localizadas por elementos de la muralla.

\begin{tabular}{|l|l|}
\cline { 2 - 2 } \multicolumn{1}{c|}{} & Elementos donde se encuentra \\
\hline Tapia de mampostería encofrada & $\begin{array}{l}\text { Tramo T5-T7, T8-este, L3, L4, T9-T13, T14-T11, } \\
\text { P4-sur, T12-sur, T12-norte. }\end{array}$ \\
\hline Mampostería encintada con ladrillo & Base de torres T13 y T14, en puerta P3 \\
\hline $\begin{array}{l}\text { Sillería } \\
\text { En esquinas } \\
\text { En Arcos } \\
\text { Fábrica } \\
\text { Sillarejo }\end{array}$ & $\begin{array}{l}\text { Torres T13, T14 } \\
\text { Puerta P3 } \\
\text { Puerta P2, P1. } \\
\text { Puerta P3 }\end{array}$ \\
\hline $\begin{array}{l}\text { Mampostería } \\
\text { Fábrica } \\
\text { Mechinales } \\
\text { Almenas }\end{array}$ & $\begin{array}{l}\text { Reparaciones, puerta P3 } \\
\text { Formación de mechinal en tapia } \\
\text { Piedras planas }\end{array}$ \\
\hline Restaurado & $\begin{array}{l}\text { Torres T1, T2, T4, Tramo T1-norte, Puertas P1, } \\
\text { P2. }\end{array}$ \\
\hline Reconstruido & $\begin{array}{l}\text { Tramo urbano P1-P2, Tramo urbano P4-sur, T1- } \\
\text { sur }\end{array}$ \\
\hline
\end{tabular}

En las páginas siguientes se realiza un análisis en detalle de algunos tramos seleccionados en el conjunto amurallado. Se han seleccionado los lienzos T5-T6 y P3T10. Además, se han analizado dos torres de plantas diferentes: la torre T6 cuya planta es semicircular y la torre T8, de planta rectangular.

\subsubsection{Lienzo exterior T5-T6}

El lienzo T5-T6 tiene una longitud de 40m aproximadamente y su trazado se realiza en un desnivel de más de $6 \mathrm{~m}$. Las hiladas de tapia se construyen hasta una altura de $5,60 \mathrm{~m}$. Sobre las hiladas de tapi a se construye el almenado, consistente en un parapeto de $85 \mathrm{~cm}$ sobre el que se levantan las almenas, de altura cercana a los $80 \mathrm{~cm}$ y una anc hura de $70 \mathrm{~cm}$ aproximadamente. Las almenas se separan entre sí una distancia de $70-80 \mathrm{~cm}$. El muro alcanza una altura de más de $7 \mathrm{~m}$ incluyendo las almenas. El almenado de mampostería que se construye sobre el primer almenado 
alcanza una altura de casi $9 \mathrm{~m}$. Como se ha comentado anteriormente, en este tramo es especialmente llamativo el desorden visible en el aparejo de las tapias.

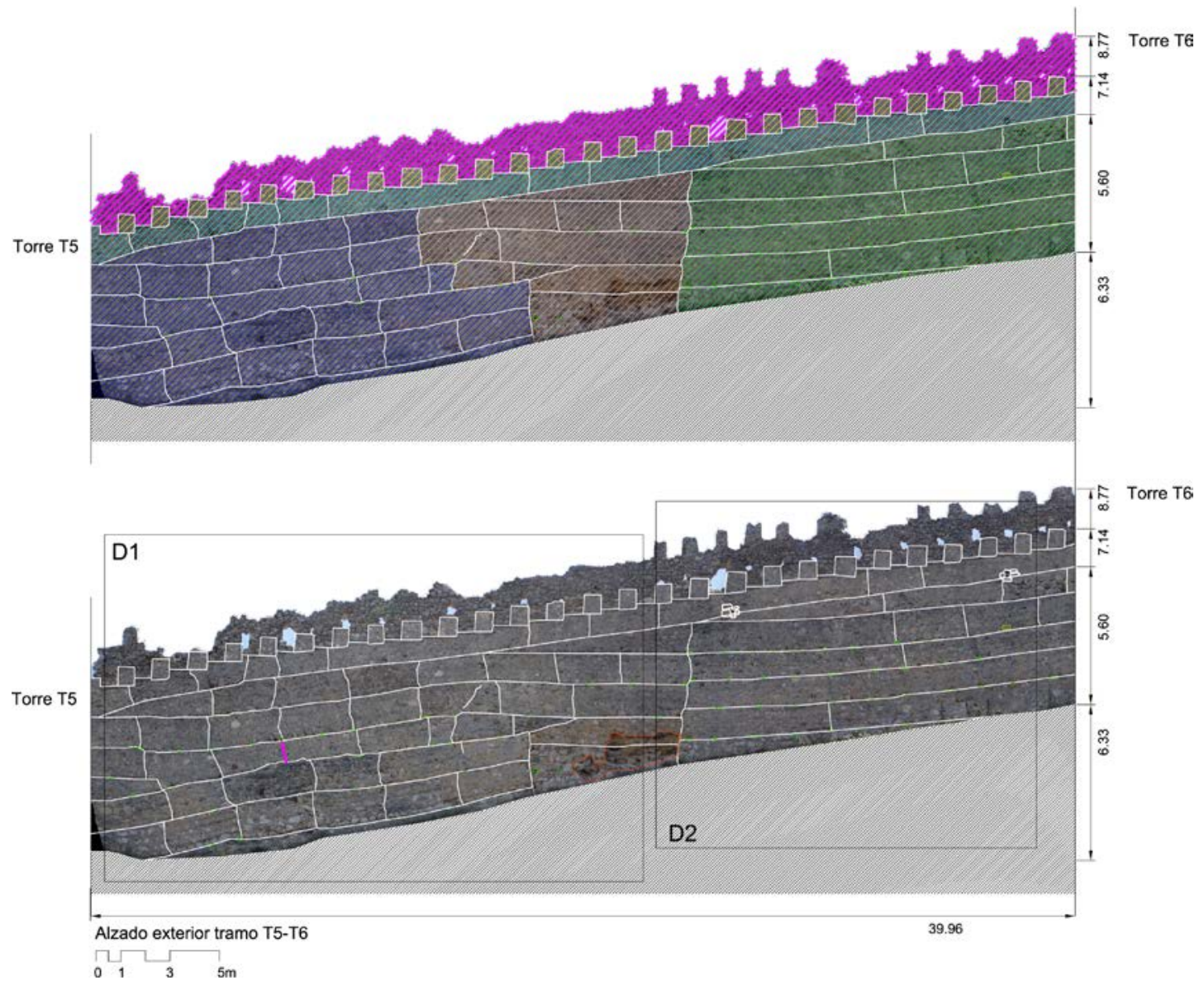

Fig. 5.3.86. Alzado exterior del tramo T5-T6. Fuente: Elaboración propia.

Las hiladas intentan mantenerse paralelas al terreno, pero en un m omento dado, se interrumpen y montan unas sobre otras. Al contemplar las tapias, parecen existir dos partes en el lienzo independientes que par ten de los extremos y que tienen gran dificultad para resolver el encuentro entre ambas (Fig. 5.3.86, arriba). En lado derecho parecen construirse cinco hiladas de tapia, la primera se encuentra semienterrada y la última, la sexta, se encarga de nivelar el adarve para la construcción del almenado. Se observa una línea vertical, ligeramente inclinada hacia la derecha, que parece dar comienzo a las hiladas del lado derecho. A la izquierda, se observan también cinco hiladas de tapia, la primera está semienterrada, prácticamente oculta, y de nuevo se realiza una última que busca nivelar la parte superior de la muralla, a través de tapias en forma de cuña, triangulares. En el centro, las hiladas de la base parecen guardar relación con la dirección de I as hiladas del lado derecho, con una ligera curva ascendente; las hiladas superiores parecen relacionadas con las hiladas superiores del lado izquierdo.

En la zona D1 (Fig. 5.3.87) es posible identificar las tapias, sus límites son visibles de forma generalizada, tanto los horizontales como los verticales. Cada una de las tapias 
se ha num erado en función de la hilada a la que pertenece. Las tapias que ti enen forma triangular se han c onsiderado residuales, es decir que s e utilizaban para concluir una hilada y adquirían esa forma como resultado de llenar el espacio que quedaba para nivelar la hilada. Por lo tanto, las últimas tapias en construirse de la hilada, aquellas que tiene forma de cuña, se han grafiado con un punto. Conocer la última tapia de la hilada permite identificar el sentido de construcción de las anteriores, que se han marcado con flechas que identifican la dirección de la construcción. El tramo analizado no abarca longitudes de hiladas completas, por lo que no es posible observar la dirección de construcción de la tapias en toda la hilada, sólo en la parte visible en este tramo.

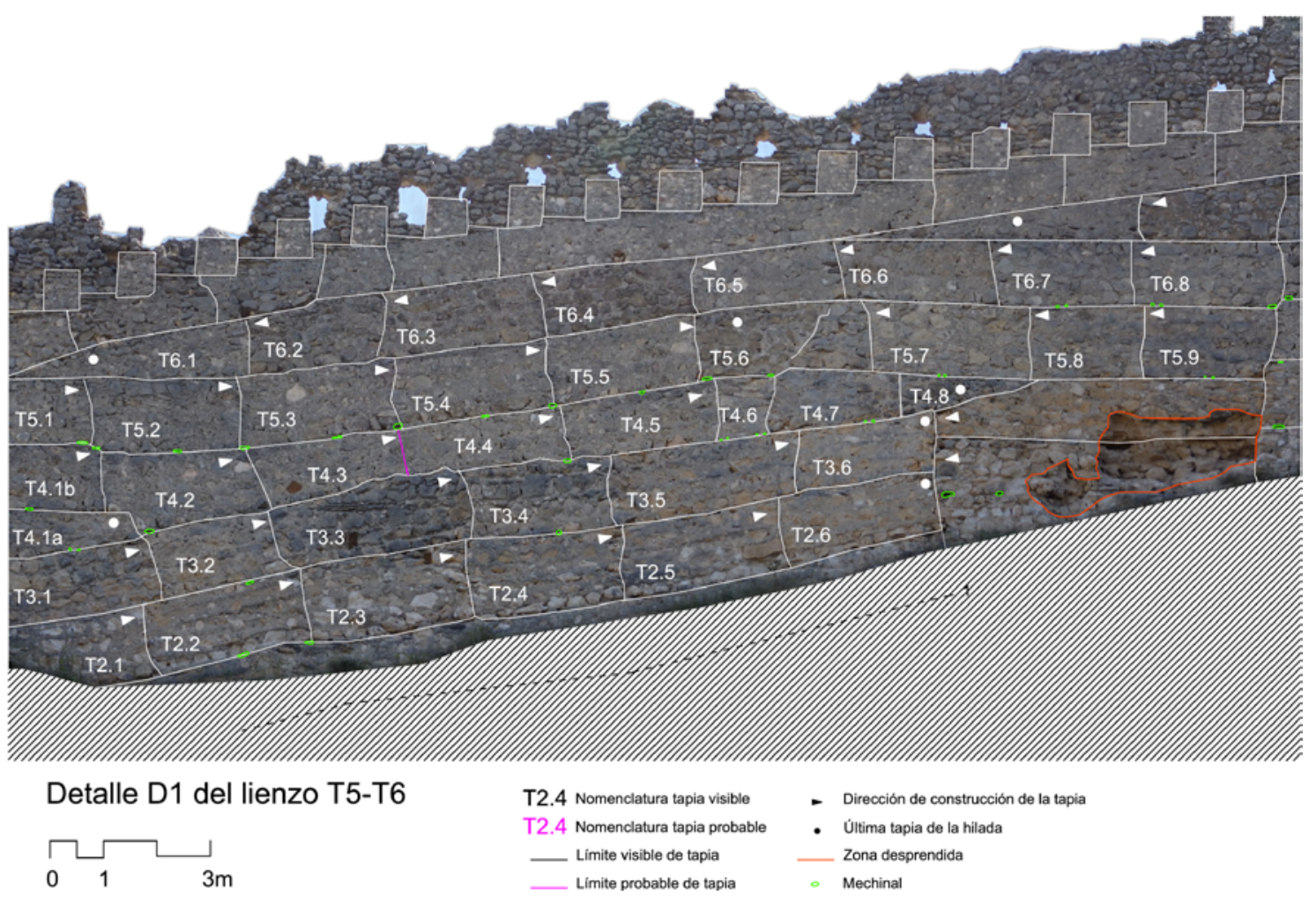

Fig. 5.3.87. Detalle de las tapias en la zona D1. Fuente: Elaboración propia.

En color verde aparecen grafiados los mechinales visibles en este tramo. No en todas las hiladas se aprecian mechinales, en muchas se encuentran ocultos o son difíciles de localizar. En la hilada quinta se observan varios que se sitúan en la parte inferior de las tapias. En esta hilada, desde la tapia T5.2 hasta T5.5, los mechinales se sitúan las distancias siguientes: 1,50-1,26-1,74-1,22-1,64-1,36-1,66-1,25m. Parecen alternar dos distancias distintas siguiendo un ritmo A-B-A-B, siendo A cercana a $1,60 \mathrm{~m}$ y B cercana a $1,25 \mathrm{~m}$.

Siguiendo en la quinta hilada, se observa un mechinal en el centro de las tapias que puede decirse sin duda que pertenece exclusivamente a esa tapia. En los extremos se observan dos mechinales más, pero en este caso parecen compartirse con las tapias 
vecinas. Esta disposición de $m$ echinales indica que el tapial empleado no e ra independiente para cada tapia, sino que s e empleaba un $\mathrm{m}$ ismo tapial para la realización de varias tapias.

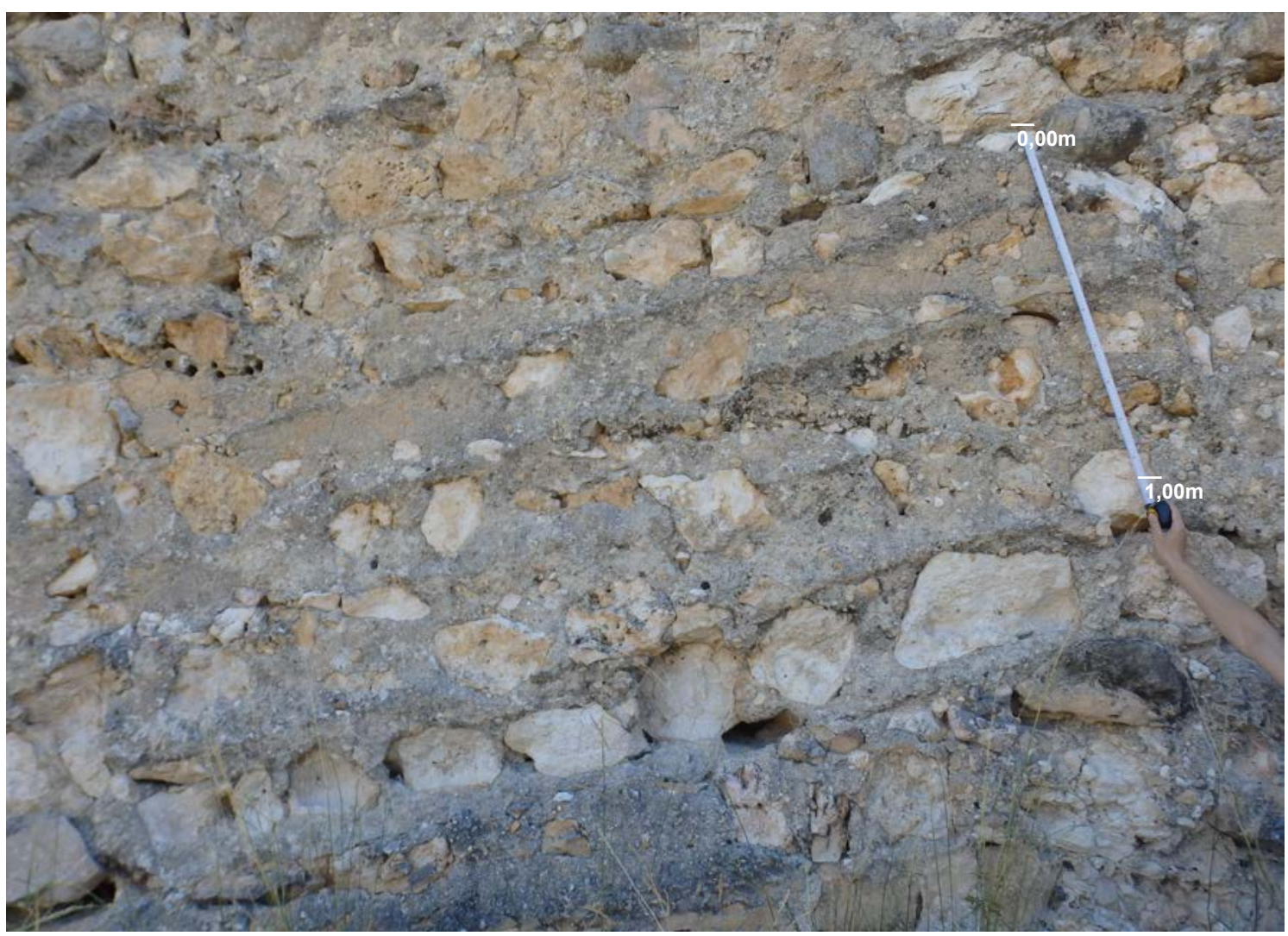

Fig. 5.3.88. Tapia T2.2 (3,08m x 1,35m). El metro marca la longitud de 1,00m [A.S.E. 23/7/2016].

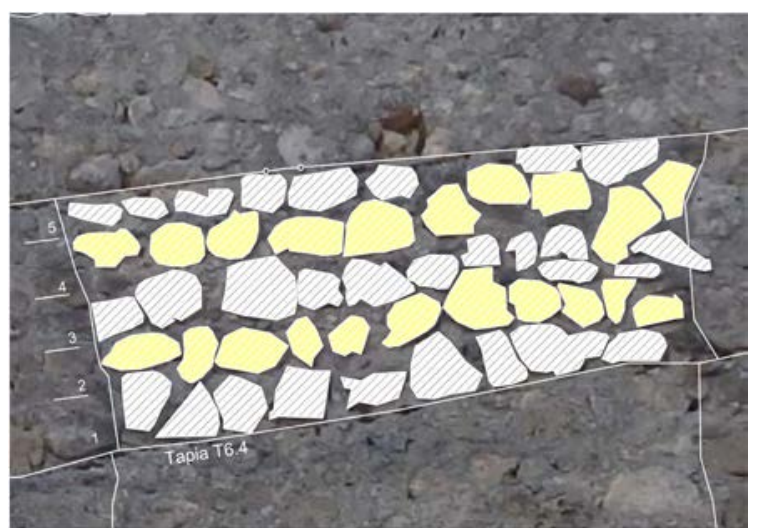

Fig. 5.3.89. Dibujo que muestra las cinco hiladas de piedra presentes en la cara exterior de la tapia T6.4. Fuente: Elaboración propia.

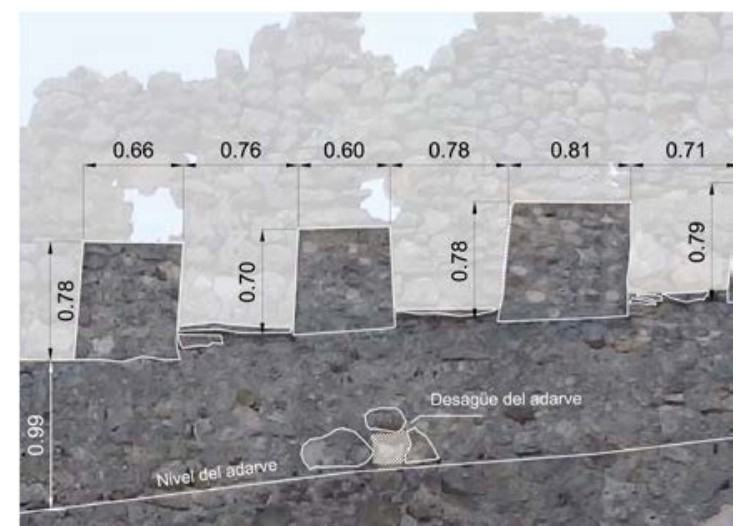

Fig. 5.3.90. Esquema de almenado en la zona D1 del lienzo T5-T6, sobre tapia T6.4. Fuente: Elaboración propia.

El acabado que ofrecen las tapias de este tramo no parece siempre el mismo. Por una parte, en algunas de las tapias se conservan marcas de la tablazón empleada en la construcción del tapial, con alturas de tabla que os cilan entre los 25 y $30 \mathrm{~cm}$. En la 
tapia T2.2 (Fig. 5.3.88) se pueden contar cuatro tablas de altura y es posible que una quinta en la parte superior. Las piedras visibles se ocultan parcialmente tras un acabado superficial de tierra y cal, que es a su vez donde han quedado marcadas las tablas del tapial.

Por otra parte, otras tapias muestran grandes piedras colocadas en la cara exterior de la tapia. El acabado superficial se ha perdido y las piedras son más visibles. Se aprecian hiladas en la colocación de las piedras que parecen haber sido colocadas en esa posición ex profeso y que denota un orden en la construcción de la tapia dentro del tapial (Fig. 5.3.89).

La configuración del almenado de este tramo se compone de un muro de casi $1 \mathrm{~m}$ sobre el que se construyen las almenas. Este muro es más estrecho que el espesor de la torre, funciona como un par apeto. En la base del muro es visible a intervalos regulares un hueco que parece un mechinal, pero que tiene un tamaño mayor de lo habitual. Es plausible que este hueco, situado al nivel del suelo del adarve, sea un desagüe del mismo. Las almenas que se construyen sobre el muro tienen una altura de $70-80 \mathrm{~cm}$ y una anchura de $60-80 \mathrm{~cm}$. Sus formas son irregulares.

5.2.7.2.1. Estudio de dimensiones y características de la tapia en el tramo T5-T6 (D1)

En la tabla a c ontinuación, se han $r$ eflejado las características de l as tapias identificadas en el detalle D1, incluyendo su nomenclatura, las dimensiones, la forma que adquiere, qué configuración tienen los mechinales visibles y la separación entre ellos.

Tabla 5.3.4. Dimensiones de las tapias del tramo D1 en el lienzo T5-T6

\begin{tabular}{|c|c|c|c|c|c|c|c|}
\hline Tapia & Límite & Ancho & Alto & $\begin{array}{c}\text { Forma de la } \\
\text { tapia }\end{array}$ & $\begin{array}{c}\text { Tipo } \\
\text { mechinal } \\
\text { Izq.C- } \\
\text { Dcha. }\end{array}$ & Formación & $\begin{array}{c}\text { Separación } \\
\text { mechinales en } \\
\text { tapia }\end{array}$ \\
\hline T2.1 & Visible & $3,06^{*}$ & 1,36 & Rectangular & - & - & - \\
\hline T2.2 & Visible & 3,08 & 1,35 & Rectangular & C-R, D-R & Tierra & 1,24 \\
\hline T2.3 & Visible & 3,09 & 1,53 & Rectangular & - & - & - \\
\hline T2.4 & Visible & 2,84 & 1,47 & Rectangular & - & - & - \\
\hline T2.5 & Visible & 3,09 & 1,36 & Rectangular & - & - & - \\
\hline T2.6 & Visible & 3,00 & 1,20 & Rectangular & - & - & - \\
\hline Promedio hilada 2 & 3,02 & 1,38 & & & & - \\
\hline T3.1 & Visible & $3,26^{*}$ & 1,26 & Rectangular & - & - & - \\
\hline T3.2 & Visible & 2,29 & 1,28 & Rectangular & C-R & Tierra & - \\
\hline T3.3 & Visible & 3,75 & 1,39 & Rectangular & - & - & - \\
\hline T3.4 & Visible & 2,56 & 1,41 & Rectangular & C-Ci & Tierra & - \\
\hline T3.5 & Visible & 3,51 & 1,34 & Rectangular & - & - & - \\
\hline
\end{tabular}




\begin{tabular}{|c|c|c|c|c|c|c|c|}
\hline Tapia & Límite & Ancho & Alto & $\begin{array}{l}\text { Forma de la } \\
\text { tapia }\end{array}$ & $\begin{array}{l}\text { Tipo } \\
\text { mechinal } \\
\text { (Izq.-C- } \\
\text { Dcha.) }\end{array}$ & Formación & $\begin{array}{c}\text { Separación } \\
\text { mechinales en } \\
\text { tapia }\end{array}$ \\
\hline T3.6 & Visible & 2,66 & 1,10 & Rectangular & - & - & - \\
\hline \multicolumn{2}{|c|}{ Promedio hilada 3} & 2,95 & 1,30 & & & & \\
\hline $\mathrm{T} 4.1 \mathrm{a}$ & Visible & $2,96^{*}$ & $0,95^{*}$ & Trapezoidal & C-VP & Tierra & - \\
\hline $\mathrm{T} 4.1 \mathrm{~b}$ & Visible & $2,19^{*}$ & 1,23 & Rectangular & C-R & Tierra & - \\
\hline $\mathrm{T} 4.2$ & Visible & 2,95 & 1,38 & Trapezoidal & I-R & Tierra & - \\
\hline $\mathrm{T} 4.3$ & Probable & 2,71 & 1,06 & Rectangular & - & - & - \\
\hline $\mathrm{T} 4.4$ & Probable & 3,08 & 0,96 & Rectangular & $D-R$ & Tierra & - \\
\hline $\mathrm{T} 4.5$ & Visible & 2,89 & 1,11 & Rectangular & - & - & - \\
\hline $\mathrm{T} 4.6$ & Visible & 1,15 & 1,1 & Rectangular & I-VP, D-VP & Tierra & 0,69 \\
\hline $\mathrm{T} 4.7$ & Visible & 2,55 & 1,18 & Trapezoidal & D-VP & Tierra & - \\
\hline $\mathrm{T} 4.8$ & Visible & 2,62 & 0,83 & Triangular & - & - & - \\
\hline \multicolumn{2}{|c|}{ Promedio hilada 4} & 2,56 & 1,11 & & & & \\
\hline T5.1 & Visible & $2,00^{*}$ & 1,24 & Rectangular & $D-R$ & Tierra & - \\
\hline $\mathrm{T} 5.2$ & Visible & 2,79 & 1,38 & Rectangular & $\begin{array}{c}\text { I-R, C-R, D- } \\
\text { R }\end{array}$ & Tierra & $1,56-1,25$ \\
\hline T5.3 & Visible & 2,83 & 1,36 & Rectangular & $\begin{array}{c}\text { I-R, C-R, D- } \\
\mathrm{Ci}\end{array}$ & Tierra & $1,71-1,17$ \\
\hline T5.4 & Visible & 2,95 & 1,31 & Rectangular & - & - & - \\
\hline T5.5 & Visible & 2,14 & 0,95 & Rectangular & - & - & - \\
\hline T5.6 & Visible & 2,84 & 1,26 & Rectangular & - & - & - \\
\hline $\mathrm{T} 5.7$ & Visible & 2,95 & 1,38 & Rectangular & C-VP & Tierra & - \\
\hline T5.8 & Visible & 2,19 & 1,37 & Rectangular & - & - & - \\
\hline T5.9 & Visible & 2,45 & 1,35 & Rectangular & C-VP & Tierra & - \\
\hline \multicolumn{2}{|c|}{ Promedio hilada 5} & 2,64 & 1,29 & & & & \\
\hline T6.1 & Visible & 4,71 & 1,08 & Triangular & - & - & - \\
\hline $\mathrm{T} 6.2$ & Visible & 2,56 & 1,26 & Rectangular & - & - & - \\
\hline T6.3 & Visible & 3,01 & 1,24 & Rectangular & - & - & - \\
\hline T6.4 & Visible & 2,81 & 1,17 & Rectangular & - & - & - \\
\hline T6.5 & Visible & 2,82 & 1,07 & Rectangular & - & - & - \\
\hline T6.6 & Visible & 2,86 & 1,18 & Rectangular & - & - & - \\
\hline T6.7 & Visible & 2,58 & 1,25 & Rectangular & C-VP & Tierra & - \\
\hline T6.8 & Visible & 2,89 & 1,23 & Rectangular & I-VP, D-R & Tierra & - \\
\hline \multicolumn{2}{|c|}{ Promedio hilada 6} & 3,03 & 1,19 & & & & \\
\hline \multicolumn{8}{|c|}{$\begin{array}{l}\text { * medida cortada, no se incluye en promedios } \\
\text { Probable }\end{array}$} \\
\hline \multicolumn{4}{|c|}{ I : Mechinal izquierdo } & \multicolumn{4}{|l|}{ R: Rectangular } \\
\hline \multicolumn{4}{|c|}{ C: Mechinal central } & \multicolumn{4}{|l|}{ Ci: Circular } \\
\hline \multicolumn{4}{|c|}{ D: Mechinal derecho } & \multicolumn{4}{|c|}{ VP: Varillas pareadas } \\
\hline
\end{tabular}


Se han el aborado dos diagramas de caja para ilustrar el conjunto de datos de las tapias en el tramo D1 del lienzo T5-T6, para los valores de anchura y altura de las tapias. Dada la gran visibilidad de los límites de las tapias, se han considerado solo los datos visibles, desestimando los únicos dos datos probables de la tabla de dimensiones. Por otra parte, solo se han considerado las tapias con forma rectangular, no se han incluido las dimensiones de las tapias triangulares o trapezoidales, por considerarse ya de por sí atípicas. El diagrama de caja de la anchura de la tapia (Fig. 5.3.91) muestra un rango intercuartílico entre los valores 250 y $300 \mathrm{~cm}$, con un valor de $50 \mathrm{~cm}$. La mediana del conjunto de datos de anchura es de $284 \mathrm{~cm}$, que se considerará representativa para este tramo. Los "bigotes" se dibujan en la franja $210 \mathrm{~cm}-350 \mathrm{~cm}$. El diagrama sitúa como anchuras de tapia atípicas los valores que superan $350 \mathrm{~cm}$ y que se corresponden con las tapias T3.3, así como el valor de $115 \mathrm{~cm}$ de la tapia T4.6. En cuanto a I a altura de tapia (Fig. 5.3.92), el rango intercuartílico de la caja se encuentran entre $118 \mathrm{~cm}$ y $137 \mathrm{~cm}$, con un valor de $19 \mathrm{~cm}$. La mediana de este conjunto de datos es de $126 \mathrm{~cm}$, altura que se considerará representativa de este tramo. Los bigotes enmarcan una fr anja de datos entre $90 \mathrm{~cm}$ y $153 \mathrm{~cm}$. No se sitúan valores atípicos en las alturas de las tapias. En comparación con la anchura, la altura de las tapias es mucho más estable en sus valores, que oscilan en un rango de $19 \mathrm{~cm}$. Los valores de anchura varían en un rango de $50 \mathrm{~cm}$, un margen dos veces superior al de la altura.

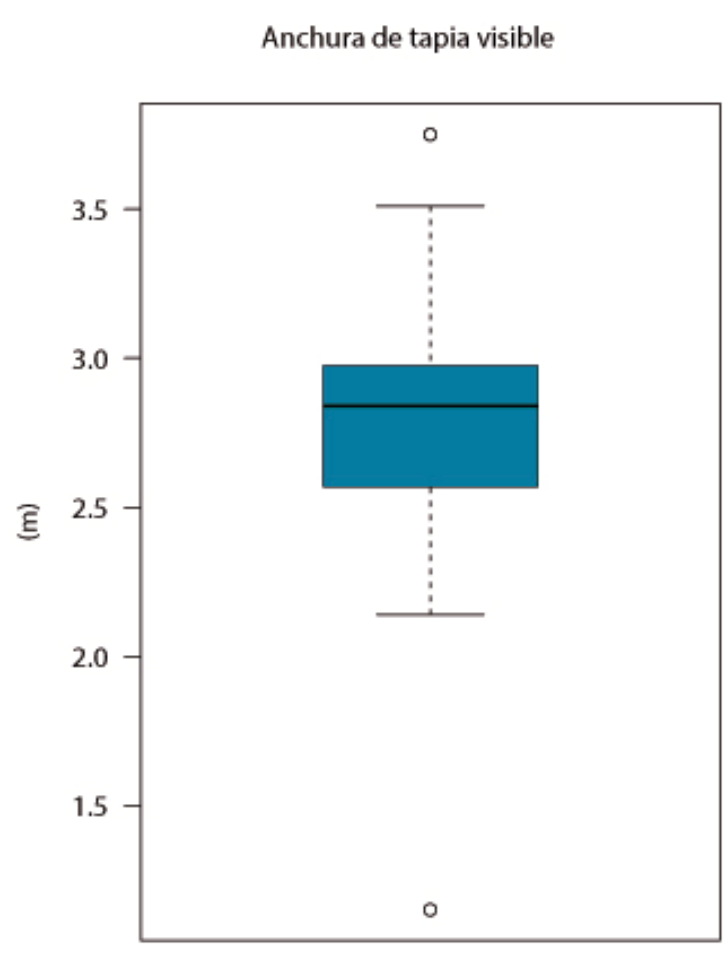

Fig. 5.3.91. Diagrama de caja de la anchura de tapia visible en tramo D1 del lienzo T5-T6. Fuente: Elaboración propia con el programa R.

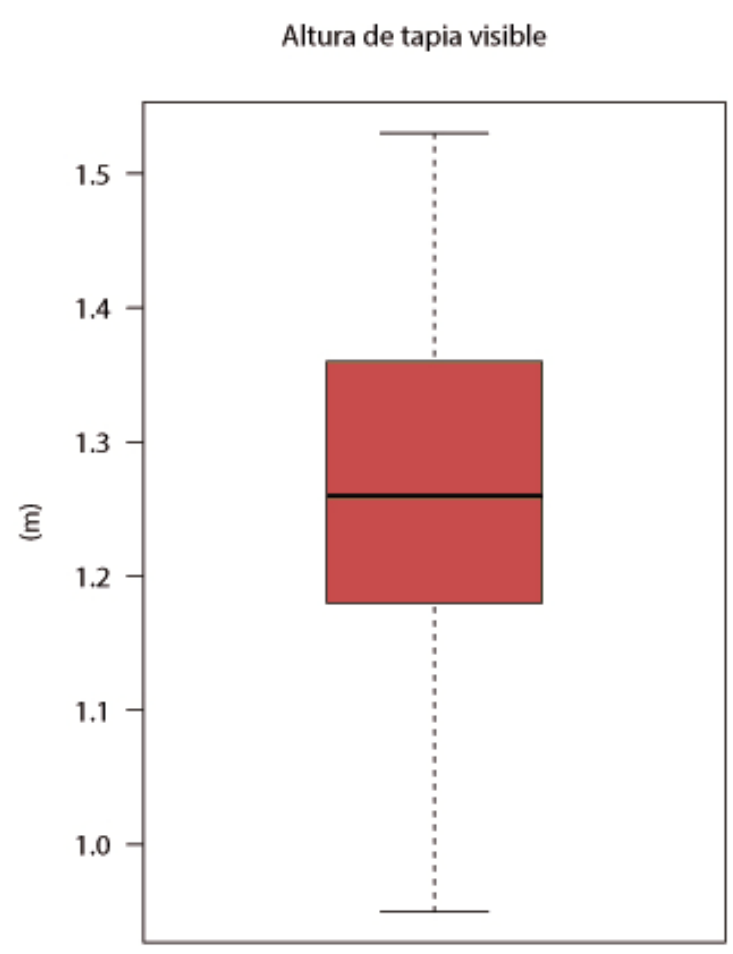

Fig. 5.3.92. Diagrama de caja de la altura de tapia visible en el tramo D1 del lienzo T5-T6. Fuente: Elaboración propia con el programa $\mathrm{R}$. 
En cuanto a los mechinales de la zona D1, se observan secciones diferentes. En la zona derecha se observa el uso de varillas pareadas en los mechinales (Fig. 5.3.93, Fig. 5.3.94). Esta solución se observa en las tapias T4.7, T5.7, T6.7, T6.8 y T5.9. Todas estas tapias se sitúan en la zona grafiada en color rojizo en el alzado del lienzo T5-T6 (Fig. 5.3.86 arriba), correspondiente a la parte central que parece construirse para cerrar el lienzo, resolviendo el encuentro de forma desordenada. El mechinal de la tapia T4.7 (Fig. 5.3.93) aparece coronado con una pi edra rectangular alargada. Teniendo en cuenta que la tapia se construye con hiladas de piedras visibles desde el exterior, es fácil que alguna de estas piedras corone las varillas, sin que ello de lugar a un método que se repite en todos los casos. Los huecos de las varillas se encuentran separados a una distancia de $12 \mathrm{~cm}$. Se observa en torno a los huecos de las varillas que estas se cubrieron con tierra y cal antes de recibir las piedras; una capa de al menos $8 \mathrm{~cm}$ incluyendo las varillas. El mechinal visible en la tapia T5.9 (Fig. 5.3.94) está coronado igualmente con piedras, en este caso dos, y se apoya a su vez sobre una piedra de la tapia inferior. La separación de los huecos de las varillas es ligeramente menor que el caso anterior, $10 \mathrm{~cm}$.

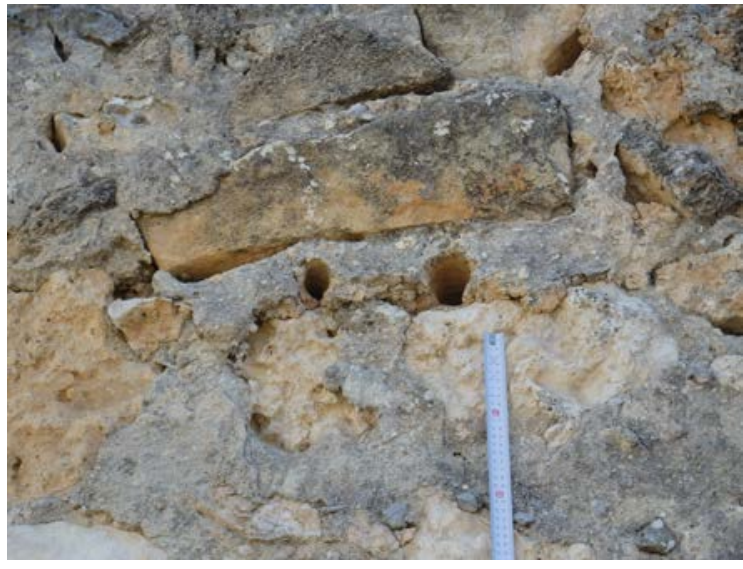

Fig. 5.3.93. Mechinal de varillas pareadas en tapia T4.7 [A.S.E. 23/7/2016].

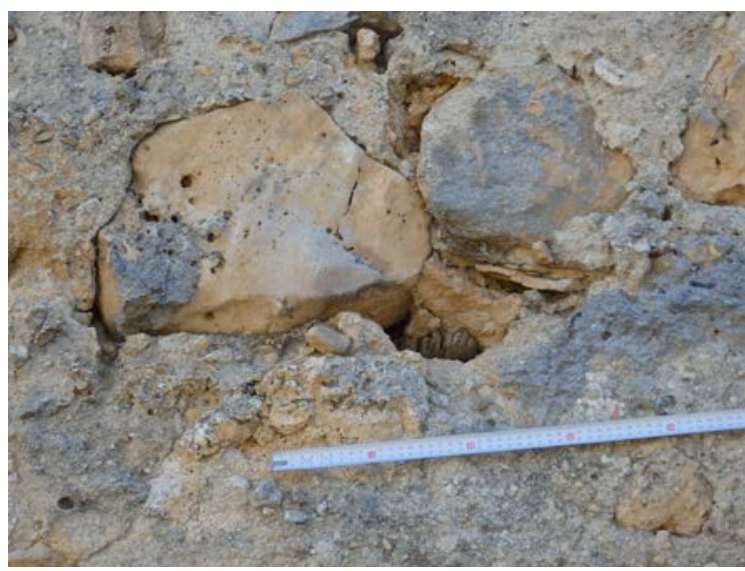

Fig. 5.3.95. Aguja de madera con sección rectangular en tapia T3.5 [A.S.E. 23/7/2016].

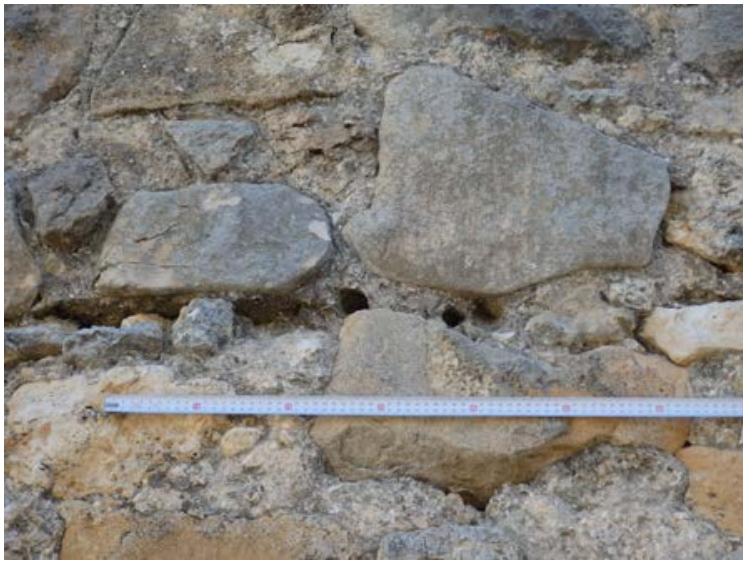

Fig. 5.3.94. Mechinal de varillas pareadas en tapia T5.9 [A.S.E. 23/7/2016].

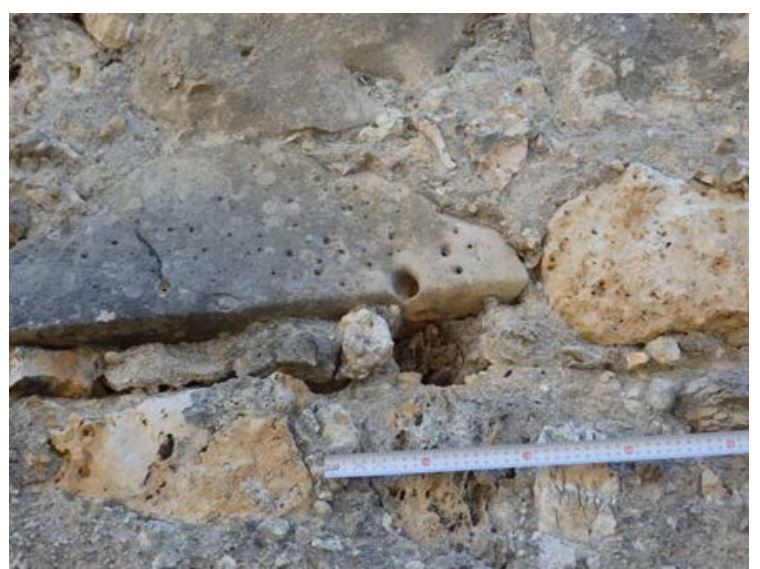

Fig. 5.3.96. Aguja de madera con sección circular en tapia T3.4 [A.S.E. 23/7/2016]. 
En la zona izquierda de la zona D1, los mechinales se componen de una única aguja de madera. En muchos de el los todavía se conserva la madera en el interior, el extremo es visible desde el exterior. El mechinal visible en la tapia T3.5 (Fig. 5.3.95) muestra en su interior una aguja de madera de sección rectangular, plana, con una dimensión de $10 \mathrm{~cm}$ de anchura por escasos $2 \mathrm{~cm}$ de altura. Otro mechinal cercano, de la tapia T3.4 (Fig. 5.3.96), muestra una aguja de m adera de sección circular con diámetro de $7 \mathrm{~cm}$.

\subsection{Estudio de dimensiones y características de la tapia en el tramo T5-T6 (D2)}

En la zona D2 del tramo T5-T6, a diferencia de D1, muchos de los mechinales son visibles claramente. También las hiladas de las tapias son fácilmente identificables. No obstante, no lo son tanto los límites verticales de las tapias, por lo que las tapias no quedan completamente definidas. Se pueden observar algunos límites verticales salpicados por esta zona del lienzo, que no permiten extraer conclusiones acerca de la forma y dimensiones de la tapia. A simple vista, los mechinales visibles parecen encontrarse a una distancia similar (Fig. 5.3.97).

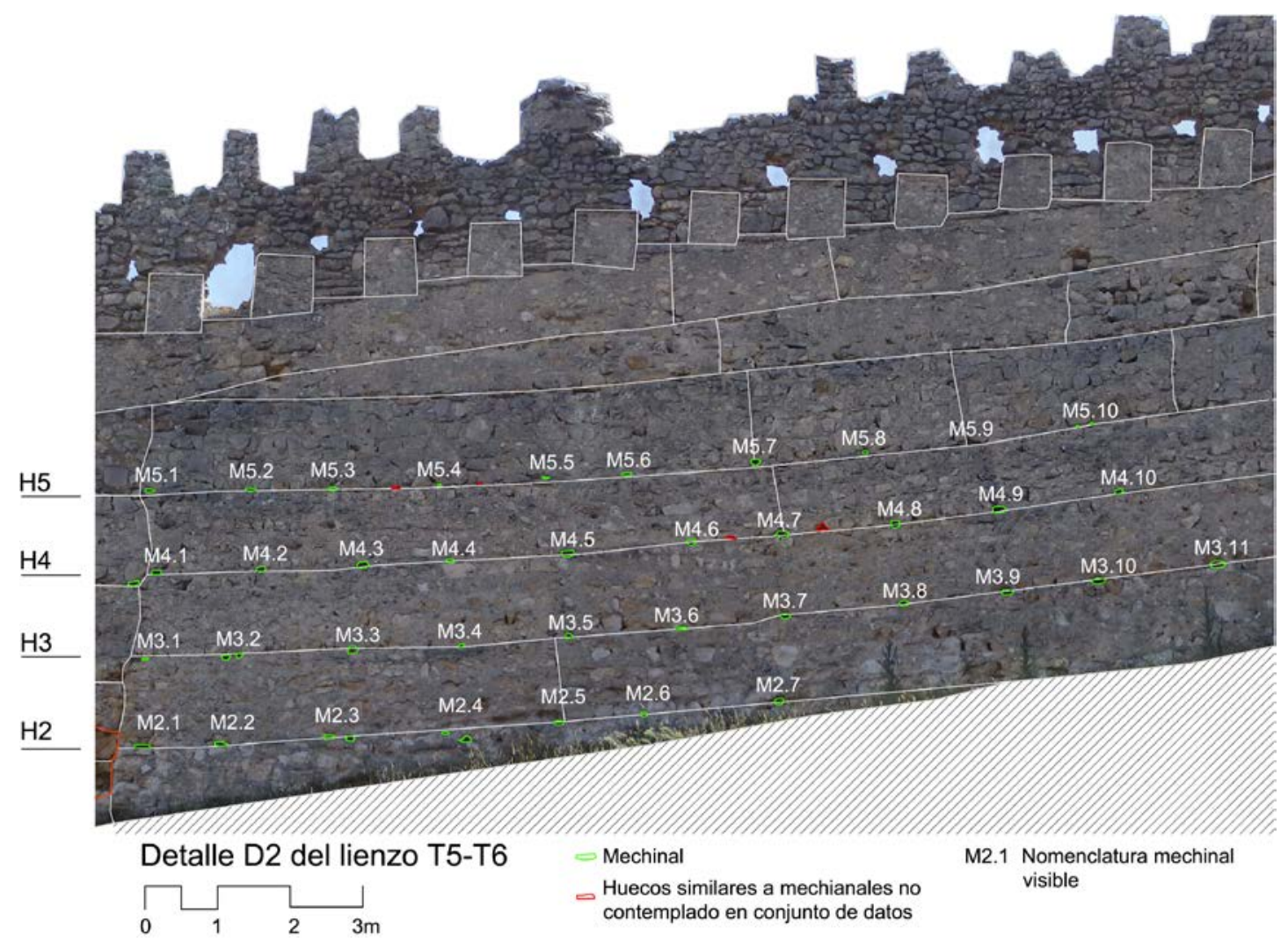

Fig. 5.3.97. Mechinales en la zona D2. Fuente: Elaboración propia.

Esta equidistancia, junto con la disposición en hiladas, produce un efecto de retícula en la configuración de los mechinales, de manera que podría indicarse su posición con coordenadas $\mathrm{x}$ e y, siendo y la hilada y $\mathrm{x}$ un valor de distancia entre mechinales. La 
ausencia de límites verticales claros, así como la equidistancia entre mechinales apunta, también en esta parte, que el encofrado en este caso podría haber consistido en un tapi al corrido. En lugar de encofrarse tapia por tapia, se realizaría un tapi al continuo, afianzado por agujas transversales colocadas con un ritmo A-A-A-A.

En la Tabla 5.3.5, se ha reflejado la distancia entre los mechinales visibles por hiladas, calculando la distancia media de cada hilada. De acuerdo con el análisis de los datos, en las hiladas $\mathrm{H} 2, \mathrm{H} 3$ y H4 la mediana de las distancias empleadas se aproxima a $1,5 \mathrm{~m}$. En la quinta hilada, se recogen datos diferentes respecto de las primeras hiladas. Hay una zona donde los mechinales detectados se aproximan mucho entre sí, representados en rojo en el alzado, prácticamente la mitad de la distancia media de las hiladas anteriores. Se ha revisado la posición de los mechinales de la hilada $\mathrm{H} 5$, donde se han retirado dos mechinales que se sitúan en posiciones atípicas respecto del resto, valorando si se está considerando mechinal un hueco en el muro que no lo es. En los diagramas de caja (Fig. 5.3.98) se han representado los datos por hiladas para su comparación entre sí. Se observa un rango intercuartílico muy amplio en la hilada $\mathrm{H} 2$, que oscila entre $113 \mathrm{~cm}-191 \mathrm{~cm}$, con una di ferencia de casi $80 \mathrm{~cm}$. En el resto de hiladas, el rango caja es menor, con valores aproximados entre $140 \mathrm{~cm}$ y $165 \mathrm{~cm}$. Independientemente de estos rangos variables, las medianas se aproximan en todas las hiladas, rondando el valor de $1,50 \mathrm{~m}$.

Tabla 5.3.5. Distancia entre mechinales en el tramo D2 del lienzo T5-T6, reflejadas por hilada.

\begin{tabular}{|c|c|c|c|c|}
\hline & $\begin{array}{l}\mathrm{H} 2 \\
(\mathrm{~m})\end{array}$ & $\begin{array}{l}\mathrm{H} 3 \\
(\mathrm{~m})\end{array}$ & $\begin{array}{l}\mathrm{H} 4 \\
(\mathrm{~m})\end{array}$ & $\begin{array}{l}\mathrm{H} 5 \\
\text { (m) }\end{array}$ \\
\hline $1-2$ & 1,13 & 1,21 & 1,44 & 1,38 \\
\hline $2-3$ & 1,63 & 1,67 & 1,41 & 1,15 \\
\hline $3-4$ & 1,74 & 1,52 & 1,23 & 1,46 \\
\hline $4-5$ & 1,32 & 1,48 & 1,63 & 1,45 \\
\hline $5-6$ & 1,17 & 1,52 & 1,72 & 1,11 \\
\hline $6-7$ & 1,91 & 1,47 & 1,28 & 1,78 \\
\hline $7-8$ & & 1,64 & 1,59 & 1,55 \\
\hline 8-9 & & 1,47 & 1,41 & 1,44 \\
\hline $9-10$ & & 1,26 & 1,69 & 1,62 \\
\hline \multirow[t]{3}{*}{$10-11$} & & 1,68 & & \\
\hline & \multicolumn{4}{|c|}{ Medianas } \\
\hline & 1,48 & 1,50 & 1,44 & 1,45 \\
\hline
\end{tabular}

Fig. 5.3.98. Diagramas de caja que representan la Tabla 5.3.5 de datos. Fuente: Elaboración propia con el programa $\mathrm{R}$.

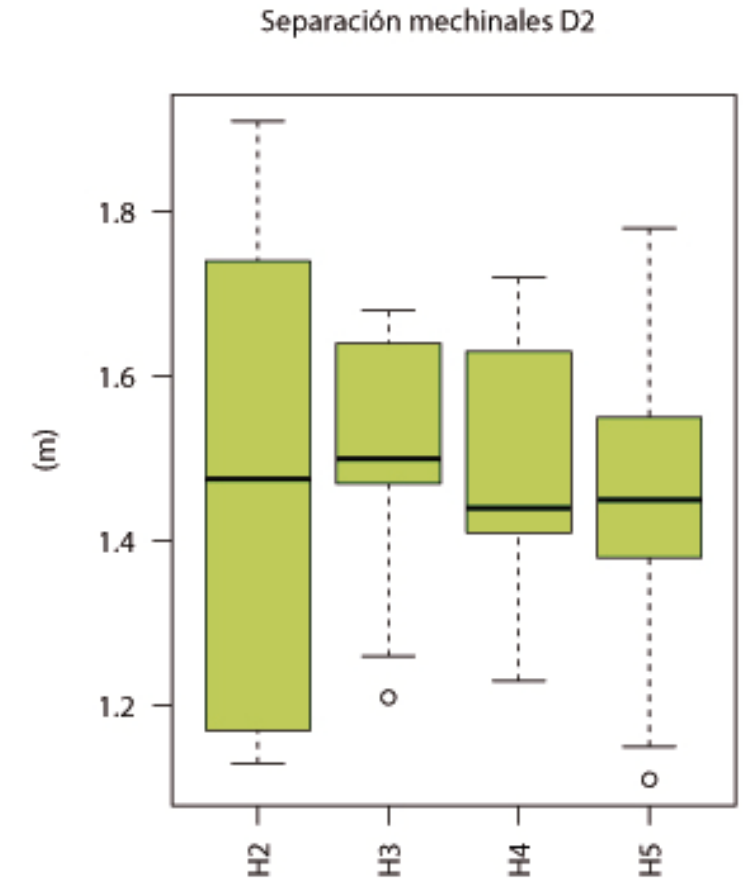




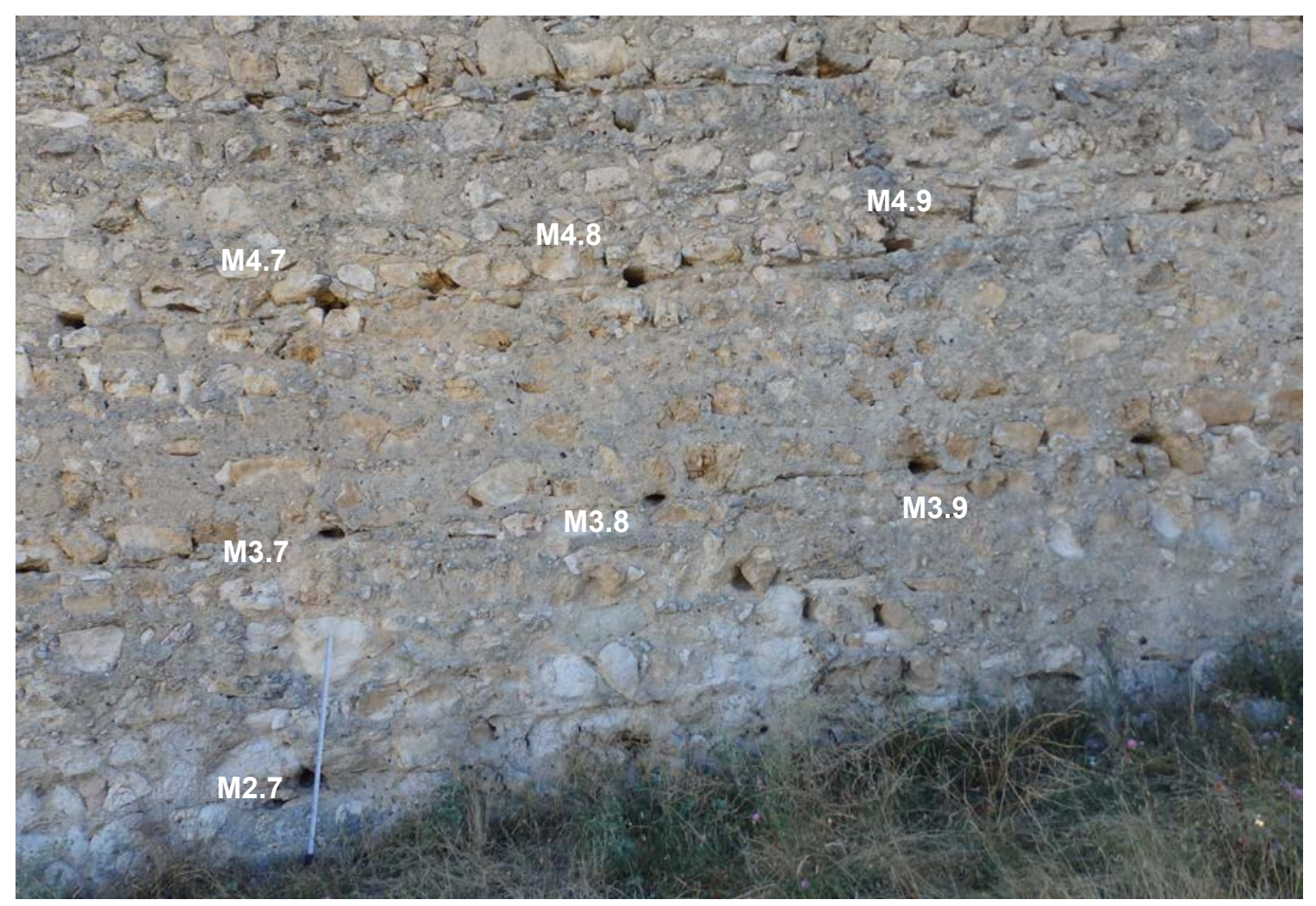

Fig. 5.3.99. Equidistancia entre los mechinales en el tramo D2 del lienzo T5-T6, donde forman una retícula [A.S.E. 23/7/2016].

La sección de I os mechinales empleados en es te tramo D2 es mayoritariamente rectangular y unitaria. En muchos de los mechinales se conservan agujas de madera de sección rectangular, con medidas y proporciones variables. El mechinal M2.1 (Fig. 5.3.100) tiene una forma rectangular alargada, plana, y mide en torno a $15 \mathrm{~cm}$ de anchura y $3 \mathrm{~cm}$ de altura. Se conserva en su interior la aguja de madera empleada. El mechinal M2.5 (Fig. 5.3.101) tiene una proporción más corta que el anterior, tiene una anchura de $9 \mathrm{~cm}$ y una altura de $3 \mathrm{~cm}$. La aguja de madera utilizada en el encofrado se encuentra alojada en el interior del muro y son visibles vetas en la sección del tronco empleado.

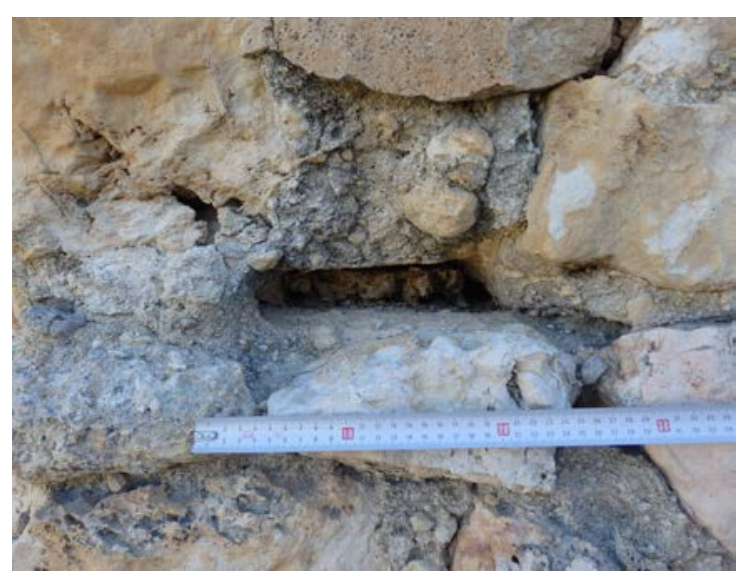

Fig. 5.3.100. Mechinal M2.1 del tramo D2 en T5T6 [A.S.E. 23/7/2016].

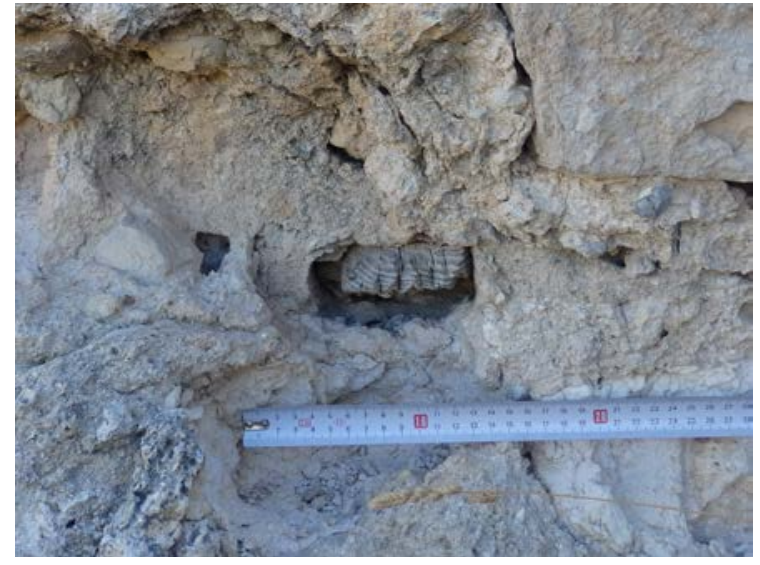

Fig. 5.3.101. Mechinal 2.5 del tramo D2 en T5-T6 [A.S.E. 23/7/2016]. 


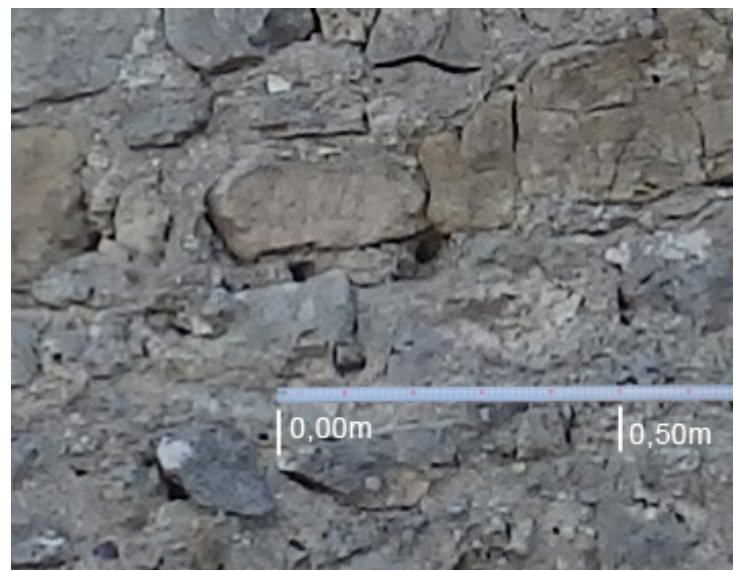

Fig. 5.3.102. Mechinal M5.9 del tramo D2 en T5T6 donde se ve el uso de varillas pareadas [A.S.E. $17 / 6 / 2014]$

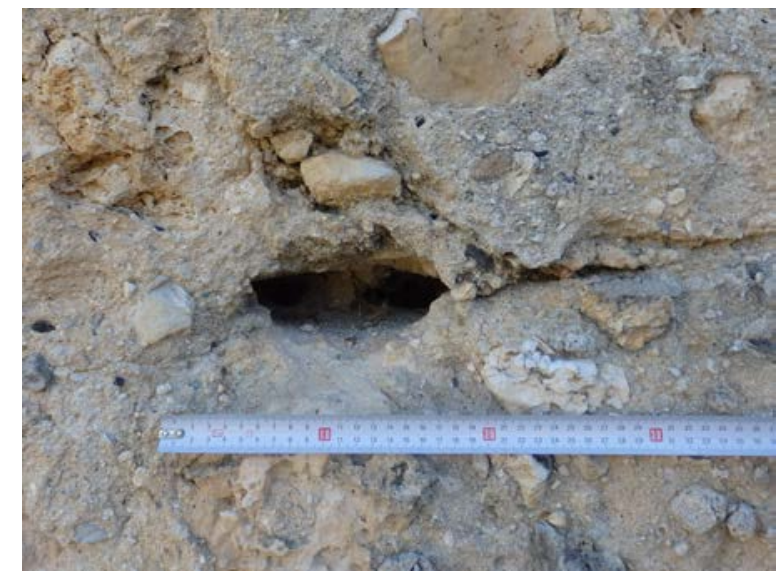

Fig. 5.3.103. Mechinal M3.7 del tramo D2 en T5-T6, cuyo interior parece albergar dos canales [A.S.E. 23/7/2016].

En algunos casos podría darse el sistema de varillas pareadas (M2.3, M3.2) aunque no está del todo claro. En el caso del mechinal M5.10 parece muy probable el uso del sistema de varillas pareadas (Fig. 5.3.102). Este mechinal se encuentra a una al tura de $3,5 \mathrm{~m}$ en relación con el suelo por lo que se ha realizado la fotografía a distancia y se ha incorporado la escala editándola con posterioridad. Se observan dos huecos que albergarían las varillas pareadas sobre los que se coloca una piedra rectangular. Están separados una distancia de $20 \mathrm{~cm}$, mayor que la visible en otros casos. El mechinal M3.7 parece componerse de un único hueco, sin embargo, en su interior se vislumbran dos canales (Fig. 5.3.103). La separación de estos es de escasos $5 \mathrm{~cm}$, mucho menor que el caso anterior y que el de otros encontrados en el recinto, por lo que no es evidente que se haya empleado el sistema de varillas pareadas.

\subsubsection{Lienzo P3-T10, vista interior y exterior}

El lienzo P3-T10 tiene una longitud de casi 35m (Fig. 5.3.104). Es accesible desde el interior y desde el exterior del recinto. El nivel del suelo en el interior es mayor que en el exterior, de manera que la altura interior del lienzo es menor. Alcanza los $6 \mathrm{~m}$ de altura frente a Ios $8 \mathrm{~m}$ visibles desde el exterior. Desde el exterior son claramente identificables las marcas horizontales de las tapias. Por el contrario, las marcas verticales no son apreciables tan claramente. En las líneas horizontales, se observa además la existencia de mechinales. En el alzado interior es sorprendente la delimitación clara de cada una de I as tapias. En el paramento se ven con facilidad cada una de las divisiones. Se observa gran regularidad en el tamaño y orden de las tapias, el aparejo alinea las tapias casi unas sobre otras, sin apenas trabazón en entre ellas.

El análisis más cercano de las tapias de este tramo (Fig. 5.3.105, Fig. 5.3.106) permite extraer las dimensiones de cada una de las tapias para un análisis conjunto. En estos alzados, se han dibujado las tapias visibles con una línea blanca y se ha dibujado en línea fucsia aquellos límites de tapias que se consideran probables, por la posición de mechinales o por la configuración de las tapias vecinas. Se han marcado con línea 
Las murallas en las Comunidades de Villa y Tierra de la Diócesis de Segovia en los siglos XI a XIII. Técnica y sistemas constructivos de la arquitectura defensiva medieval.

naranja las zonas donde se ha producido una reparación que i ncorpora nuevos mampuestos y morteros.

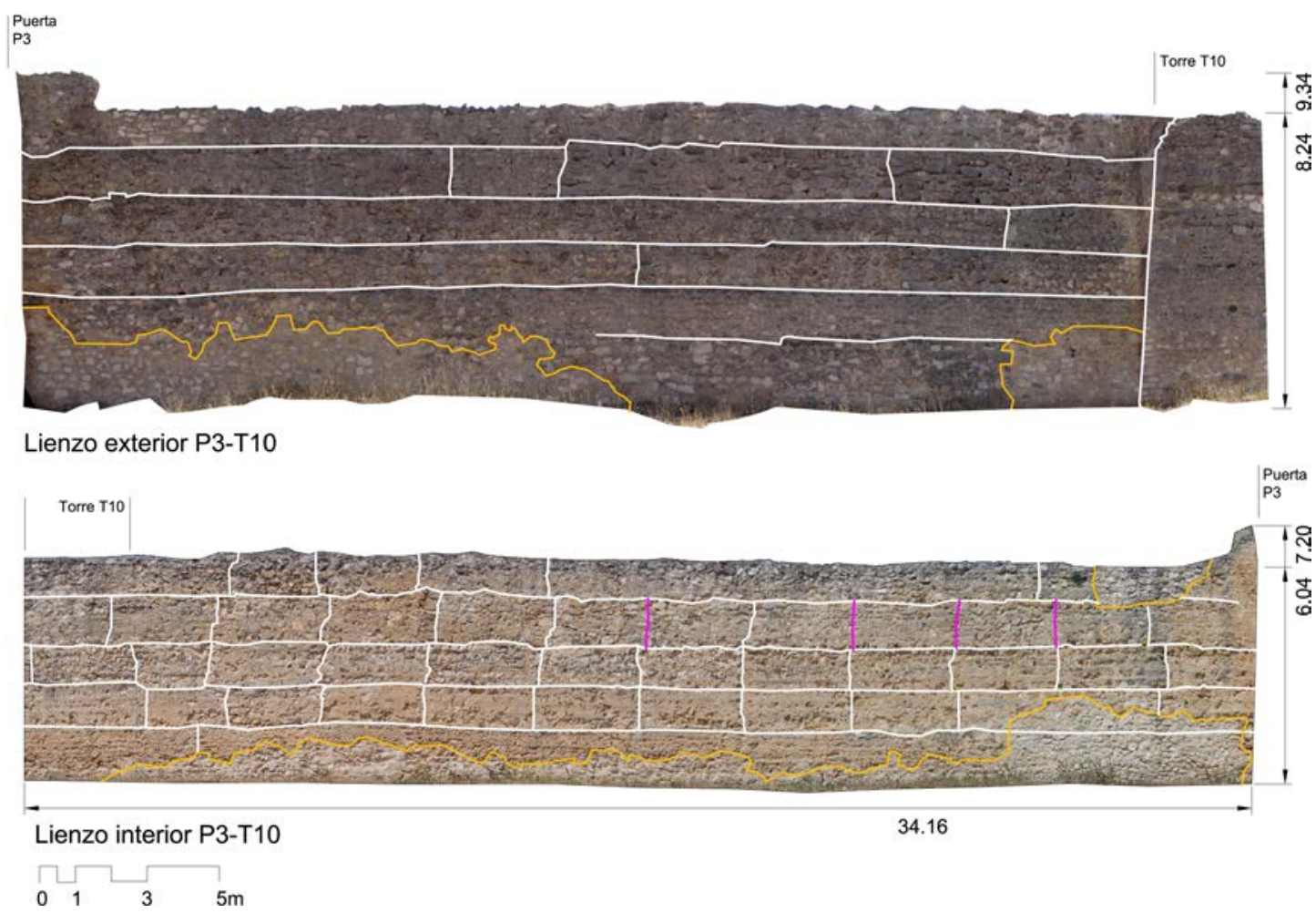

Fig. 5.3.104. Lienzos exterior (arriba) e interior (abajo) del tramo P3-T10. Fuente: Elaboración propia.

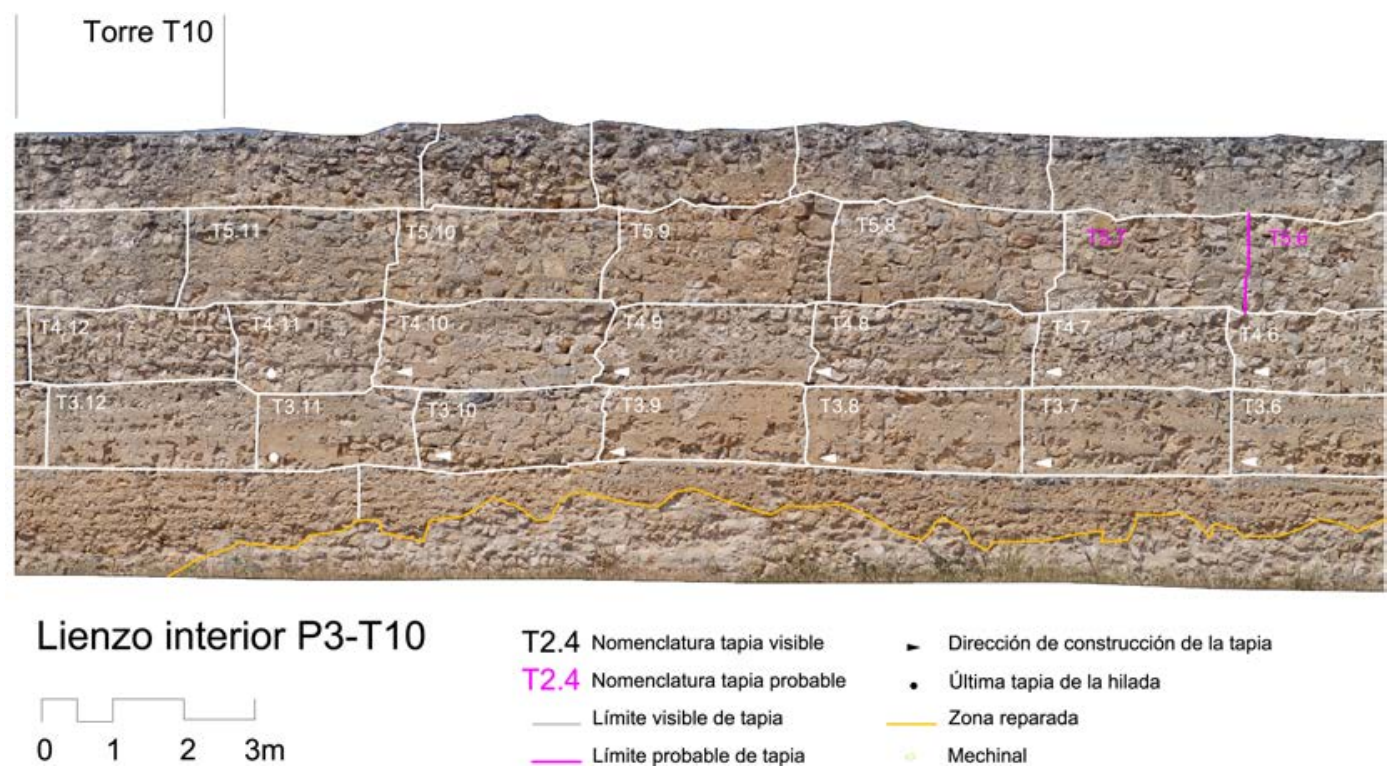

Fig. 5.3.105. Parte del lienzo P3-T10 interior (continúa en Fig. 5.3.106). Fuente: Elaboración propia. 


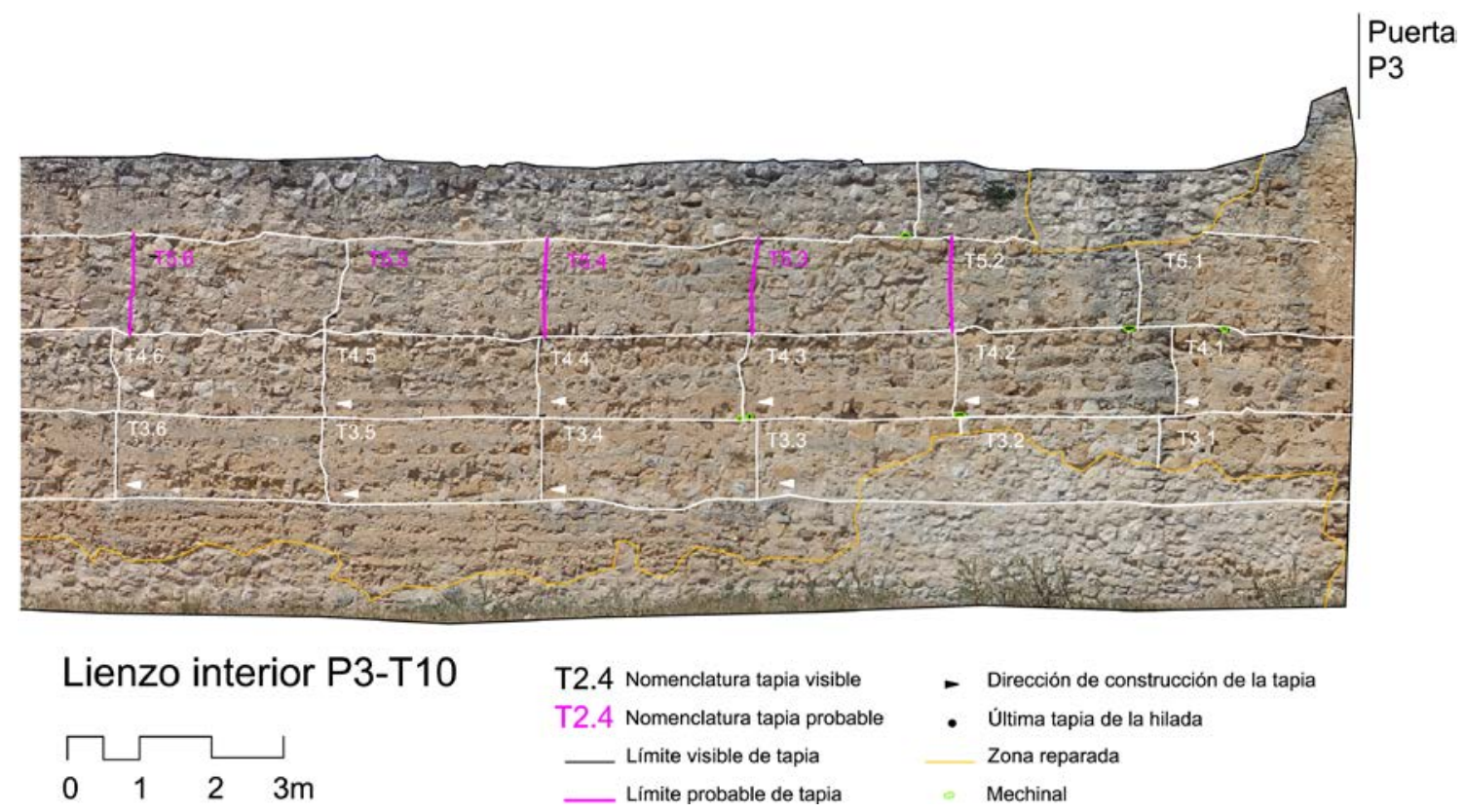

Fig. 5.3.106. Parte derecha del lienzo P3-T10 (viene de Fig. 5.3.105). Fuente: Elaboración propia.

5.2.7.3.1. Estudio de dimensiones y características de la tapia en el tramo P3-T10

La tabla a continuación (Tabla 5.3.6) reúne las dimensiones y características correspondientes al tramo P3-T10, se identifica cada tapia con su nomenclatura, sus dimensiones en altura y anchura, la configuración de los mechinales de su base y la separación entre ellos. Se han reflejado las dimensiones de las tapias visibles en el paramento, así como de aquellas que se han podido completar de manera probable de acuerdo con la configuración de las tapias vecinas.

Tabla 5.3.6. Tabla que resume las dimensiones de las tapias del tramo interior P3-T10.

\begin{tabular}{|c|c|c|c|c|c|c|}
\hline Tapia & Límite & Ancho & Alto & $\begin{array}{l}\text { Tipo mechinal } \\
\text { (Izq.-C-Dcha.) }\end{array}$ & Formación & $\begin{array}{l}\text { Separación } \\
\text { mechinales en } \\
\text { tapia }(\mathrm{m})\end{array}$ \\
\hline T3.1 & Visible & $2,65^{\star}$ & 1,22 & - & - & - \\
\hline T3.2 & Probable & 2,75 & 1,19 & - & - & - \\
\hline T3.3 & Probable & 2,83 & 1,14 & - & - & - \\
\hline T3.4 & Visible & 2,98 & 1,24 & - & - & - \\
\hline T3.5 & Visible & 3,07 & 1,19 & - & - & - \\
\hline T3.6 & Visible & 2,84 & 1,14 & C-R & $\mathrm{T}$ & \\
\hline T3.7 & Visible & 2,94 & 1,24 & - & - & - \\
\hline T3.8 & Visible & 3,03 & 1,17 & I-R, C-R & $\mathrm{T}-\mathrm{T}$ & 1,53 \\
\hline T3.9 & Visible & 2,85 & 1,08 & I-R & $\mathrm{T}$ & \\
\hline T3.10 & Visible & 2,66 & 1,11 & - & - & - \\
\hline T3.11 & Visible & 2,20 & 1,07 & C-R & $\mathrm{T}$ & \\
\hline
\end{tabular}


Las murallas en las Comunidades de Villa y Tierra de la Diócesis de Segovia en los siglos XI a XIII. Técnica y sistemas constructivos de la arquitectura defensiva medieval.

\begin{tabular}{|c|c|c|c|c|c|c|}
\hline Tapia & Límite & Ancho & Alto & $\begin{array}{l}\text { Tipo mechinal } \\
\text { (Izq.-C-Dcha.) }\end{array}$ & Formación & $\begin{array}{l}\text { Separación } \\
\text { mechinales en } \\
\text { tapia }(\mathrm{m})\end{array}$ \\
\hline T3.12 & Visible & 2,96 & 1,23 & - & - & - \\
\hline \multicolumn{2}{|c|}{ Promedio hilada 3} & 2,83 & 1,17 & & & \\
\hline $\mathrm{T} 4.1$ & Visible & $2,43^{*}$ & 1,08 & - & - & - \\
\hline $\mathrm{T} 4.2$ & Visible & 3,06 & 1,21 & I-R, C-R & $\mathrm{T}-\mathrm{T}$ & 1,44 \\
\hline $\mathrm{T} 4.3$ & Visible & 3,00 & 1,21 & I-Ci, C-R, D-R & T-T-T & $1,56-1,41$ \\
\hline $\mathrm{T} 4.4$ & Visible & 2,83 & 1,16 & I-R & $\mathrm{T}$ & \\
\hline $\mathrm{T} 4.5$ & Visible & 2,94 & 1,15 & I-R & $\mathrm{T}$ & \\
\hline $\mathrm{T} 4.6$ & Visible & 2,83 & 1,15 & I-R, C-R & $\mathrm{T}-\mathrm{T}$ & 1,47 \\
\hline $\mathrm{T} 4.7$ & Visible & 2,80 & 1,10 & $\mathrm{I}-\mathrm{Ci}$ & $\mathrm{T}$ & \\
\hline $\mathrm{T} 4.8$ & Visible & 3,12 & 1,26 & I-R, C-R & $\mathrm{T}-\mathrm{T}$ & 1,38 \\
\hline T4.9 & Visible & 2,91 & 1,11 & - & - & - \\
\hline $\mathrm{T} 4.10$ & Visible & 3,09 & 1,28 & - & - & - \\
\hline $\mathrm{T} 4.11$ & Visible & 2,02 & 1,28 & - & - & - \\
\hline $\mathrm{T} 4.12$ & Visible & 2,92 & 1,07 & - & - & - \\
\hline \multicolumn{2}{|c|}{ Promedio hilada 4} & 2,87 & 1,17 & & & \\
\hline T5.1 & Visible & $2,96^{*}$ & 1,36 & I-R, C-R & $\mathrm{T}-\mathrm{T}$ & 1,31 \\
\hline T5.2 & Visible & 2,64 & 1,26 & - & - & - \\
\hline T5.3 & Probable & 2,76 & 1,34 & D-R & $\mathrm{T}$ & \\
\hline T5.4 & Probable & 2,89 & 1,25 & - & - & - \\
\hline T5.5 & Probable & 2,82 & 1,31 & - & - & - \\
\hline T5.6 & Probable & 2,87 & 1,28 & - & - & - \\
\hline $\mathrm{T} 5.7$ & Probable & 2,60 & 1,32 & - & - & - \\
\hline T5.8 & Visible & 3,29 & 1,35 & - & - & - \\
\hline T5.9 & Visible & 3,09 & 1,38 & - & - & - \\
\hline T5.10 & Visible & 3,07 & 1,26 & C-R & $\mathrm{T}$ & \\
\hline T5.11 & Visible & 2,82 & 1,34 & - & - & - \\
\hline \multicolumn{2}{|c|}{ Promedio hilada 5} & 2,89 & 1,31 & & & \\
\hline
\end{tabular}

* medida cortada, no se incluye en promedios ni gráficas

Probable
I : Mechinal izquierdo
R: Rectangular
M: Mampuesto
C: Mechinal central
Ci: Circular
T: Tierra
D: Mechinal derecho
Sci: Semicircular
Tj: Teja

A partir de los datos de esta tabla se han extraído las medidas de anchura y altura de los tapiales de es te tramo y se han $r$ ealizado varios diagramas de caja para representar el conjunto de datos. En cuanto a la anchura de las tapias (Fig. 5.3.107), cuando se contemplan los datos de tapias visibles y probables, se obtiene un rango intercuartílico entre $281 \mathrm{~cm}-301 \mathrm{~cm}$, con un valor de $20 \mathrm{~cm}$. La mediana de estos datos es de $288 \mathrm{~cm}$, que se considerará como anchura representativa de este tramo. Cuando 
se contemplan solo los datos visibles, la caja que se desplaza ligeramente hacia arriba, con una mediana de $294 \mathrm{~cm}$. En ambos casos, aparecen dos anchuras atípicas que se corresponden con las tapias T4.11, T3.11, c uya anchura es cercana a I os 2,00m. La estrechez de estas tapias puede deberse a que fueron las últimas en construirse en la hilada, de manera que se trata de un es pacio residual cuya anchura no dependía de los tapiales. Al igual que en el tramo anterior donde existían tapias en forma de cuña, estas tapias "cortas" pueden ayudar a establecer una hipótesis acerca del orden de construcción de las tapias, partiendo de que fueron las últimas, las tapias colindantes fueron las inmediatamente anteriores en construirse y así con las tapias siguientes.

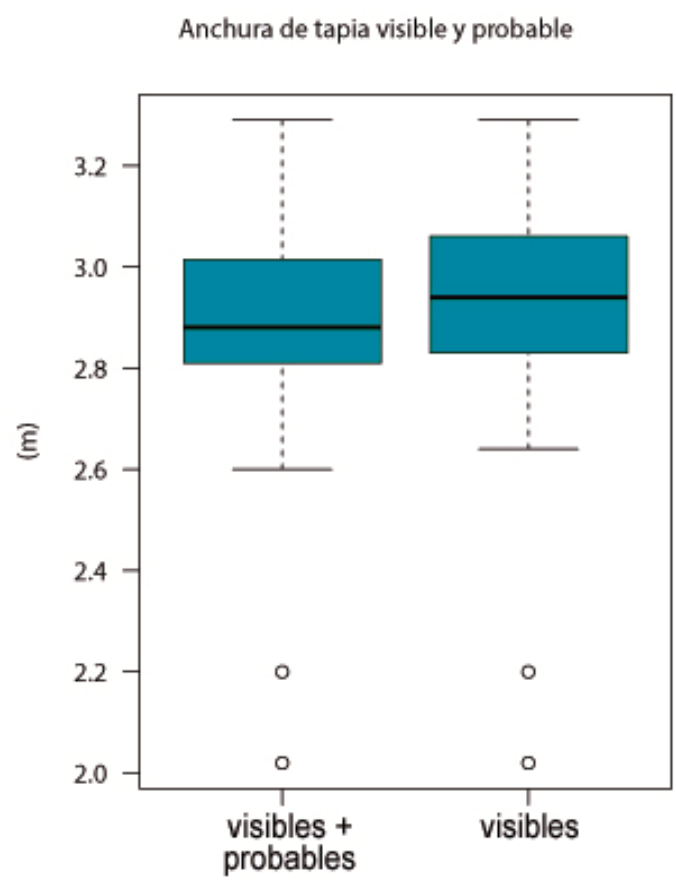

Fig. 5.3.107. Diagramas de caja que muestran el rango en el que oscilan las anchuras de tapia en el tramo interior P3-T10. Fuente: Elaboración propia con el programa $\mathrm{R}$.

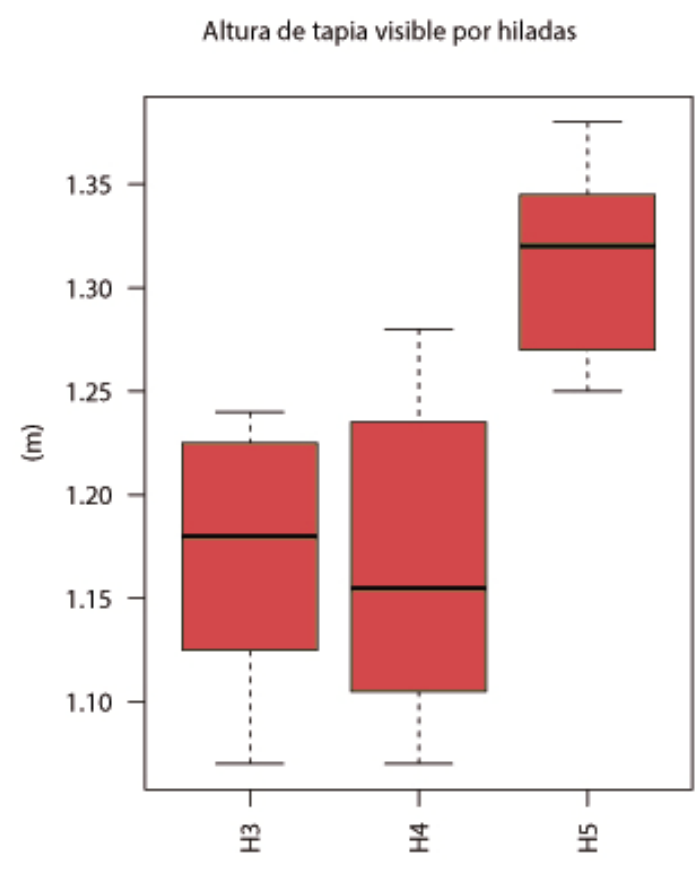

Fig. 5.3.108. Diagramas de caja que muestran las alturas de tapia por hiladas en el tramo interior P3-T10. Destaca la hilada 5 por su mayor altura. Fuente: Elaboración propia con el programa $\mathrm{R}$.

En el caso de la altura de tapias, se ha realizado una gráfica mostrando las alturas por hiladas, poniendo de manifiesto la diferencia de altura de la quinta hilada, cuyo rango intercuartílico ronda los $127-134 \mathrm{~cm}$, con una mediana de $132 \mathrm{~cm}$. En las hiladas cuarta y tercera el rango intercuartílico se sitúa en torno a $113-123 \mathrm{~cm}$, con menor dispersión en el caso de la hilada H3. La mediana para estas hiladas es de $118 \mathrm{~cm}$ en caso de H3 y $115 \mathrm{~cm}$ en caso de $\mathrm{H} 4$, con un resultado de 116,50 entre las dos, valor de altura que se tomará como representativo de este tramo.

En relación con los mechinales visibles en el alzado interior, estos son escasos y se encuentran aislados, por lo que es difícil establecer las distancias que se dan entre ellos. Desde el exterior, se observa mayor número de ellos, concretamente en la hilada 
tercera, donde se suceden hasta siete mechinales. Se sitúan a una distancia similar entre $131 \mathrm{~cm}$ y $156 \mathrm{~cm}$ con una mediana de $143,50 \mathrm{~cm}$. Dados los escasos ejemplares visibles, es difícil aventurar si existe una correspondencia entre los mechinales visibles en el exterior y en el interior. Por otra parte, existe la posibilidad de que los mechinales no sean pasantes, sino agujas cortas con una profundidad que no supera el espesor del muro. En ese caso no existiría correspondencia alguna entre las dos fachadas.

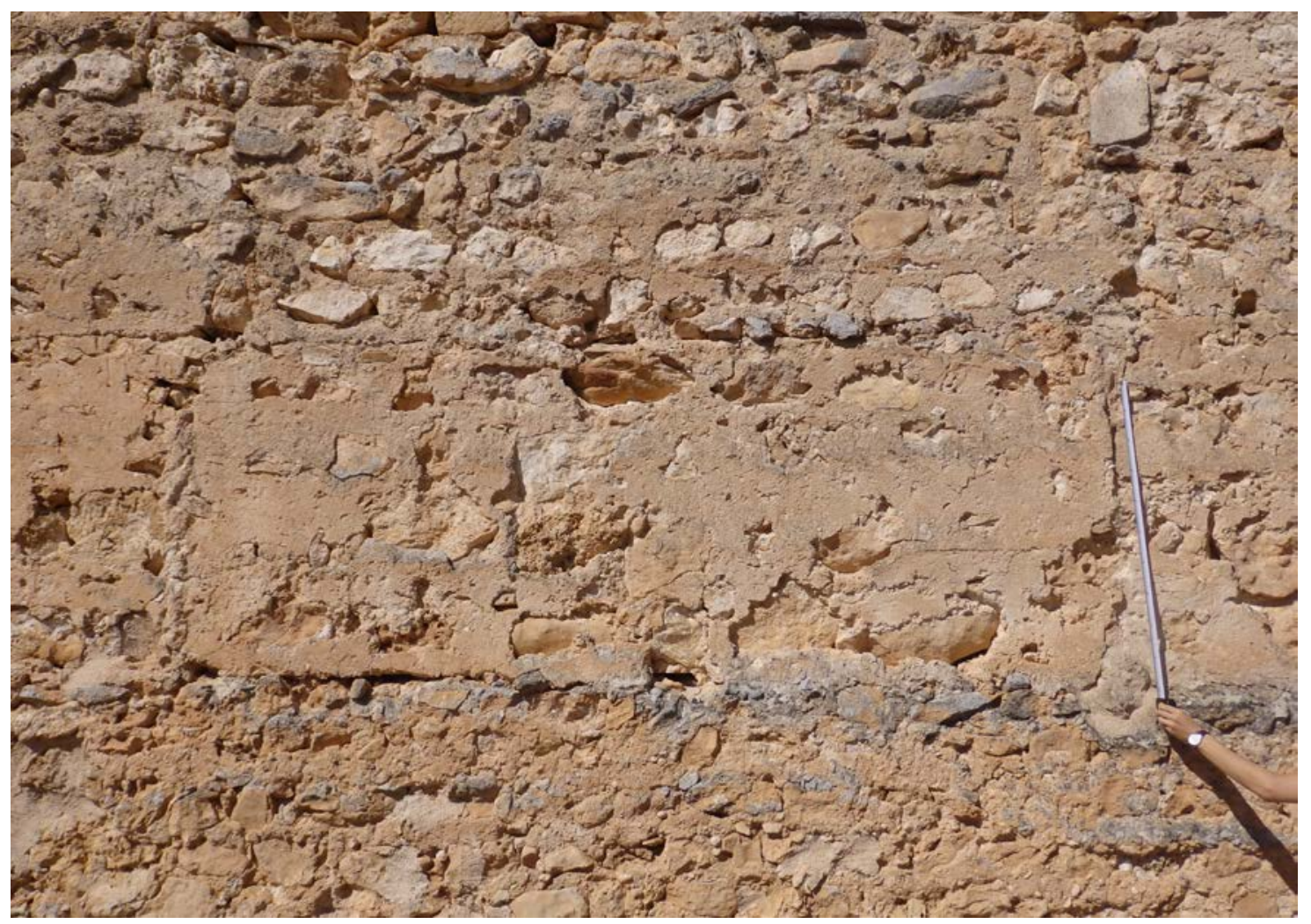

Fig. 5.3.109. Tapia T3.8 en el tramo P3-T10. [A.S.E. 23/7/2016]

Al igual que ocurre con el lienzo anterior, T5-T6, la equidistancia de los mechinales muestra que los encofrados de las tapias no se hicieron de forma individual. En este lienzo P3-T10, se observa con claridad en su cara interior, que cada tapia comparte un mechinal con las tapias adyacentes, de manera que los encofrados no son individuales sino corridos. Observando los límites verticales de las tapias, muy visibles en la cara interior del lienzo P3-T10, se entiende que aunque el encofrado fuera corrido, se realizaba el llenado por partes, en tapias de una anchura cercana a los 3,00m. En algunos mechinales es posible identificar que se encuentran a caballo entre dos tapias diferentes (Fig. 5.3.110, Fig. 5.3.111). 


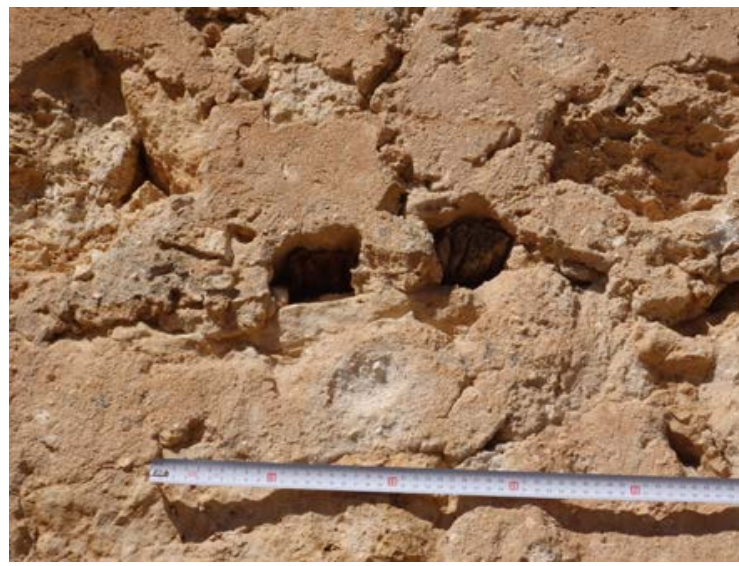

Fig. 5.3.110. Mechinal con dos agujas, situado a caballo entre las tapias T4.4. y T4.3 [A.S.E. 23/7/2016]

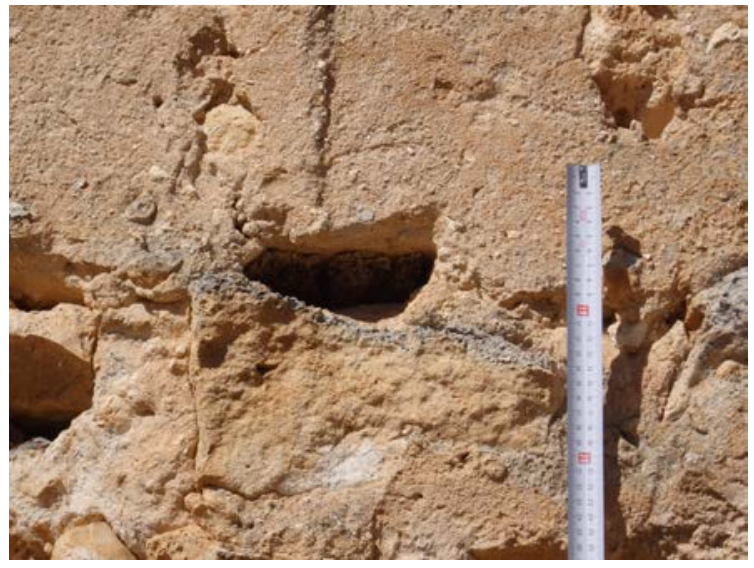

Fig. 5.3.111. Mechinal situado entre T4.4 yT4.5. Sobre el mechinal se observa la línea vertical de límite entre tapias [A.S.E. 23/7/2016]

En la tabla a continuación, se resume para cada uno de I os lienzos estudiados las características descritas de las tapias y de los mechinales, con la intención de reflejar la configuración de una tapia representativa de cada tramo, que permita más adelante comparar con otros casos.

Tabla 5.3.7. Tabla de características y dimensiones del tramo D1 de T5-T6 y P3-T10

\begin{tabular}{|c|c|c|c|c|c|}
\hline Tapia & Tramo T5-T6 & $\begin{array}{c}\text { Tramo P3- } \\
\text { T10 }\end{array}$ & Mechinal & $\begin{array}{c}\text { Tramo T5- } \\
\text { T6 }\end{array}$ & $\begin{array}{c}\text { Tramo P3- } \\
\text { T10 }\end{array}$ \\
\hline Altura $(\mathrm{cm})$ & 126 & $\begin{array}{c}116,50 \\
\text { [132 en hilada } \\
\text { H5] }\end{array}$ & Sección mayoritaria & $\begin{array}{l}\text { Rectangular, } \\
\text { circular, } \\
\text { varillas } \\
\text { pareadas }\end{array}$ & Rectangular \\
\hline Anchura (cm) & 284 & 288 & Dimensiones $(\mathrm{cm})$ & $\begin{array}{c}\text { Separación } \\
\text { varillas }(10- \\
12 \mathrm{~cm}) \\
\end{array}$ & $5-8 \times 10-15^{*}$ \\
\hline Espesor (cm) & \multicolumn{2}{|c|}{$90-130(\bar{x}=110)$} & Distancia en cajón & 145,50 & $143,50^{*}$ \\
\hline $\begin{array}{l}\text { Restos de } \\
\text { encofrado / Tipo de } \\
\text { tapial }\end{array}$ & \multicolumn{2}{|c|}{ Sí / Tapial corrido } & $\begin{array}{l}\text { Distancia entre } \\
\text { cajones }\end{array}$ & \multicolumn{2}{|c|}{ - } \\
\hline $\begin{array}{l}\text { Altura de tablas de } \\
\text { encofrado }(\mathrm{cm})\end{array}$ & $25-30 \mathrm{~cm}$ & $26 \mathrm{~cm}$ & Material & \multicolumn{2}{|c|}{$\begin{array}{c}\text { Tierra/solo hueco, } \\
\text { mampuesto }\end{array}$} \\
\hline $\begin{array}{l}\text { Piedras exteriores } \\
\text { colocadas }\end{array}$ & \multicolumn{2}{|c|}{ Sí } & $\begin{array}{l}\text { Aguja } \\
\text { perdida/recuperable }\end{array}$ & \multicolumn{2}{|c|}{ Perdida } \\
\hline $\begin{array}{l}\text { Juntas más visibles } \\
\text { en paramento }\end{array}$ & \multicolumn{2}{|c|}{ Horizontales } & $\begin{array}{l}\begin{array}{l}\text { Profundidad } \\
\text { mechinal }\end{array} \\
\end{array}$ & \multicolumn{2}{|c|}{ Pasante } \\
\hline $\begin{array}{l}\text { Materiales } \\
\text { empleados }\end{array}$ & \multicolumn{2}{|c|}{ Mampuestos, tierra, cal } & $\begin{array}{l}\text { Tipo de aguja } \\
\text { (pareadas/unitarias) }\end{array}$ & \multicolumn{2}{|c|}{ Unitarias, pareadas } \\
\hline $\begin{array}{l}\text { Tramos } \\
\text { constructivos } \\
\text { verticales }\end{array}$ & \multicolumn{2}{|c|}{ No } & $\begin{array}{l}\text { Mechinales por } \\
\text { cajón }\end{array}$ & - & $\begin{array}{c}2(1 \\
\text { compartido) }\end{array}$ \\
\hline Verdugada & \multicolumn{2}{|c|}{ No } & $\begin{array}{l}\text { Ubicación de } \\
\text { mechinal en } \\
\text { relación con cajón }\end{array}$ & \multicolumn{2}{|c|}{ Inferior } \\
\hline
\end{tabular}

$\bar{x}$ media aritmética

* menos de 10 muestras 
Las murallas en las Comunidades de Villa y Tierra de la Diócesis de Segovia en los siglos XI a XIII.

Técnica y sistemas constructivos de la arquitectura defensiva medieval.

\subsubsection{Tipología de las tapias en tramos T5-T6 y P3-T10}

De acuerdo con la clasificación de A. Graciani y M.A. Tabales, las tapias de los tramos estudiados podrían clasificarse como tapia monolítica con mechinales con remate de mampuesto y sin verdugadas (Tabla 5.3.8). De acuerdo con la clasificación de I.J. Gil Crespo, estas tapias tendrían las características visibles en la Tabla 5.3.9.

Tabla 5.3.8. Tipología constructiva de las tapias del tramo T5-T6 de acuerdo de Amparo Graciani y Miguel A. Tabales $(2008,139)$ en el área sevillana.

\begin{tabular}{|l|c|c|}
\cline { 2 - 3 } \multicolumn{1}{c|}{} & Mechinal & Verdugada \\
\hline Monolítico & Mampuesto & Sin verdugada \\
\hline
\end{tabular}

Tabla 5.3.9. Tipología constructiva de las tapias de los tramo T5-T6 y P3-T10 de acuerdo con la clasificación de Ignacio J. Gil Crespo $(2013,554-557)$.

\begin{tabular}{|l|l|}
\hline A. Material de construcción & 5. Mampostería \\
\hline B. Compactación del material & 2. Vertido. \\
\hline C. Función constructiva & 1. Fábrica principal \\
\hline D. Encofrado & 4. Cajones que hacen hilos continuos con junta vertical \\
\hline E. Acabado superficial & 4. Capa externa de mampostería \\
\hline F. Combinación de materiales & 4. Mampuestos, tierra y cal \\
\hline G. Mechinales & 1. Situación en el propio hilo \\
G-a. Situación & 2. Agujas pasantes. \\
G-b. Profundidad & $\begin{array}{l}\text { 1. Formación aguja embebida en la fábrica } \\
\text { G-c. Formación }\end{array}$ \\
G-d. Sección & $\begin{array}{l}\text { 2. Rectangular } \\
\text { 5. Pana }\end{array}$ \\
\hline
\end{tabular}

\subsubsection{Torre de planta semicircular T6}

Además de los lienzos estudiados, se ha considerado de interés analizar algunas de las torres de este recinto, porque comparten características constructivas con los lienzos de muralla. La torre T6 es una de las cinco torres semicirculares del recinto. Los paramentos de la torre muestran que tam bién se ha em pleado la tapia en su construcción. Se pueden identificar 10 hiladas de tapias en la altura de la torre. Los límites de cada hilada son muy visibles en toda la altura de la torre. Sólo algunos límites verticales de las tapias son apreciables (Fig. 5.3.112, derecha). 
Las tapias se adaptan a la forma semicircular de la torre, dando la impresión de que cada una de I as tapias tiene forma semicircular. Esta forma plantea la incógnita de cómo se realizaba el tapial para conseguir el resultado con semicircular. Las tapias con directriz circular se ven también en los molinos de viento de Tierra de Campos (Jové, Muñoz, Pahíno 2010b). En este caso, estos autores valoran dos opciones de construcción del tapial curvo. En la primera de ellas, indican que se construirían tablas talladas con forma circular y desestiman que los tablones se cortaran rectos y posteriormente se doblaran. Arguyen que para poder doblar las tablas, estas deberían ser finas y por lo tanto poco resistentes a los empujes el material fresco. En la segunda opción, plantean que los tablones se coloquen en posición vertical, consiguiendo así más facilidad para seguir la directriz circular (193). En el caso de las torres semicirculares de este recinto, parecen observarse tapias rectas en la torre T3 (Fig. 5.3.29), es decir que la construcción de las tapias en la torre T3 podría realizarse con tapiales rectos que siguen la directriz circular. En el caso de la torre T6, no es tan evidente y las tapias parecen adoptar la forma semicircular. El acabado superficial de las tapias se ha perdido, no son visibles las tablas del encofrado como ocurre en los lienzos de la muralla. No es posible determinar si las tablas estaban colocadas en posición vertical u horizontal. No obstante, teniendo en cuenta el empleo generalizado de tablas en posición horizontal, es más probable que se empleara también en esa posición. En cuanto a la construcción de las tablas, parece también más probable que se emplearan tablas dobladas, en lugar de talladas con la forma semicircular, aunque esto implicara que pudieran ser más finas, y resolver el problema de los empujes con la colocación de mayor número de costales por tapia.

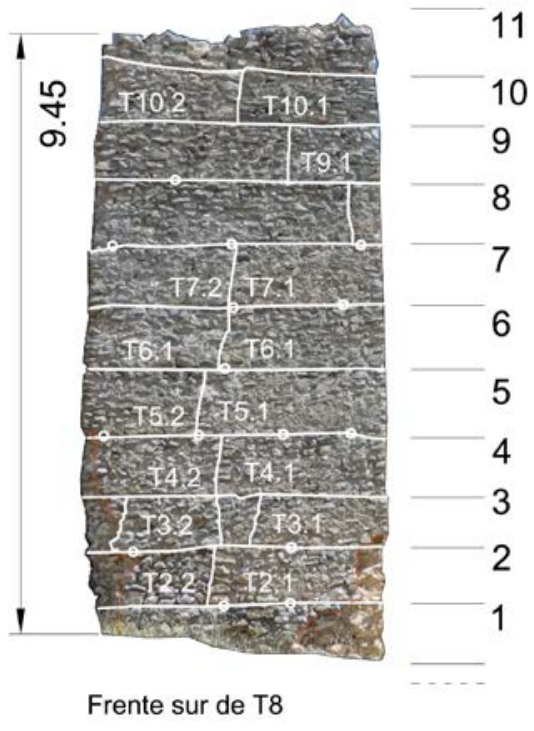

Esquemas de torres T8 y T6

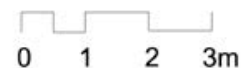

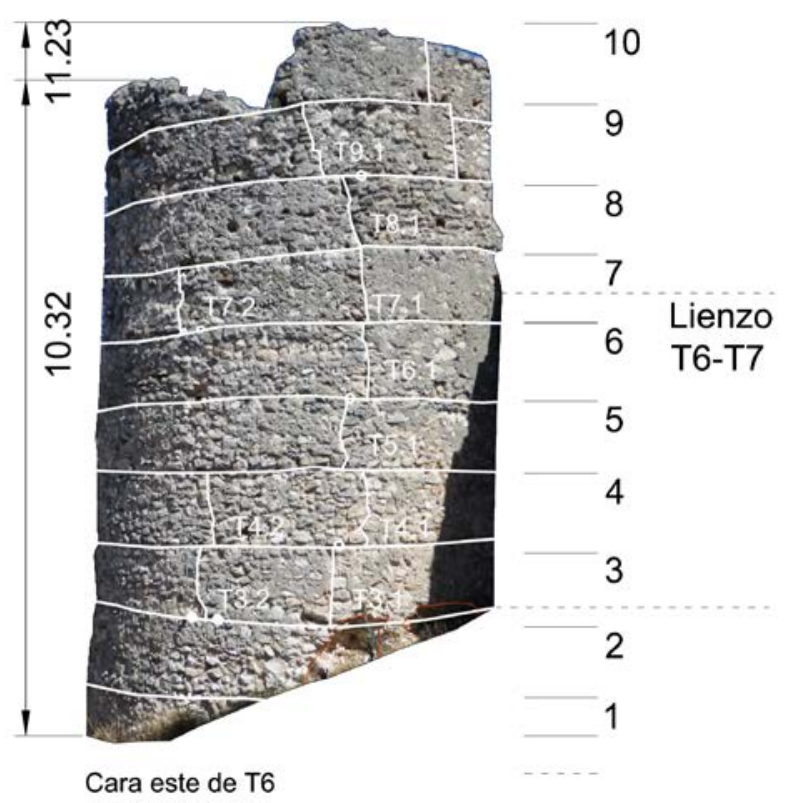

Fig. 5.3.112. Esquema de las torres T8 y T6. Fuente: Elaboración propia. 
La tapia T3.2 tiene una anchura de $2,41 \mathrm{~m}$ y una altura de 1,22. E $\mathrm{s}$ una de las pocas tapias cuyos límites pueden identificarse a simple vista (Fig. 5.3.113). Se compone de piedras irregulares en forma y en tamaño, que no par ecen organizarse por hiladas, como ocurre en otras zonas de la muralla. En la base izquierda de la tapia se ve un mechinal con forma circular (Fig. 5.3.115). Se cubre con una piedra irregular, aunque no es fácil determinar si se ha hecho ex profeso o si es habitual que el mechinal quede cubierto por una piedra, ya que es el material más numeroso en la tapia. A la izquierda de este mechinal, ya en la tapia vecina, se observa otro de características similares (Fig. 5.3.114). Tiene sección circular y se cubre con una piedra. La dimensión de ambos mechinales es similar, de 2 a $3 \mathrm{~cm}$ de diámetro.

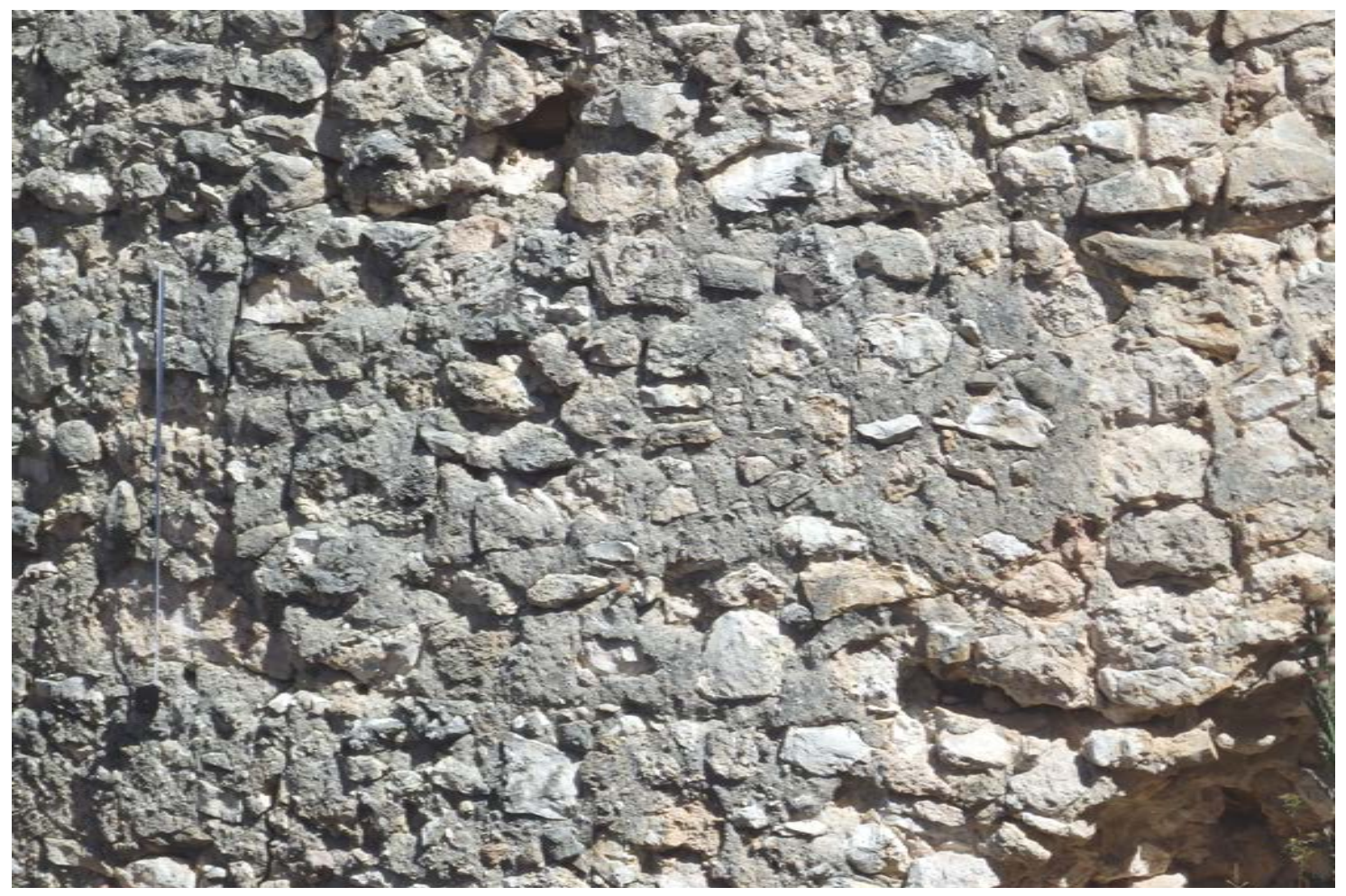

Fig. 5.3.113. Tapia T3.2 de la torre T6 [A.S.E. 23/7/2016].

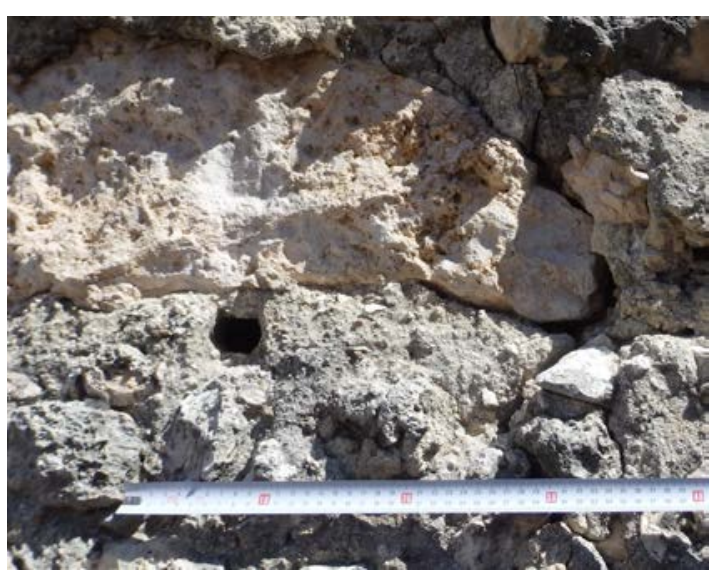

Fig. 5.3.114. Mechinal en la tapia vecina a T3.2, a su izquierda [A.S.E. 23/7/2016].

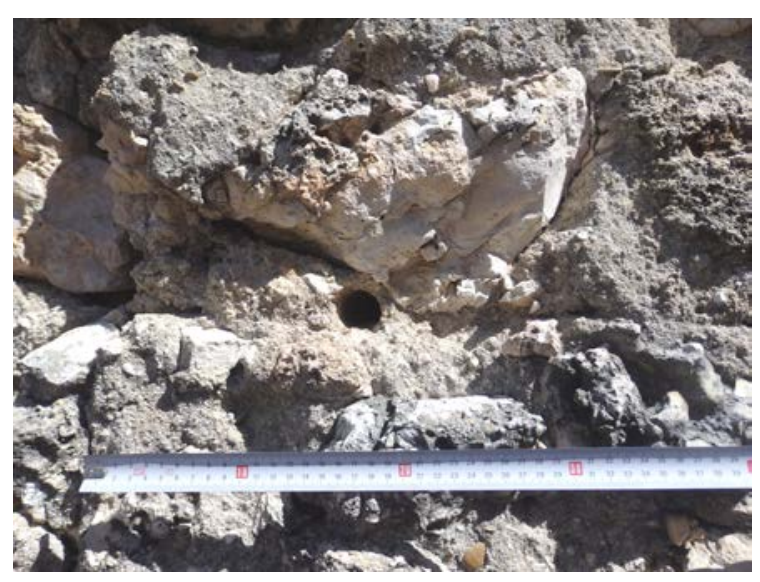

Fig. 5.3.115. Mechinal de la tapia T3.2 [A.S.E. 23/7/2016]. 
Como las otras torres semicirculares, la torre T6 se adosa al lienzo, construyéndose con posterioridad a este. La torre T3 (Fig. 5.3.116) ha perdido el lienzo sobre el que se apoyaba, por lo que es visible la cara interior de la torre, aquella que estaría oculta en caso de que existiera todavía el lienzo. Este alzado oculto y ahora visible muestra un carácter macizo de la torre, no se ve la sección vertical de ningún muro que pudiera componer la torre.

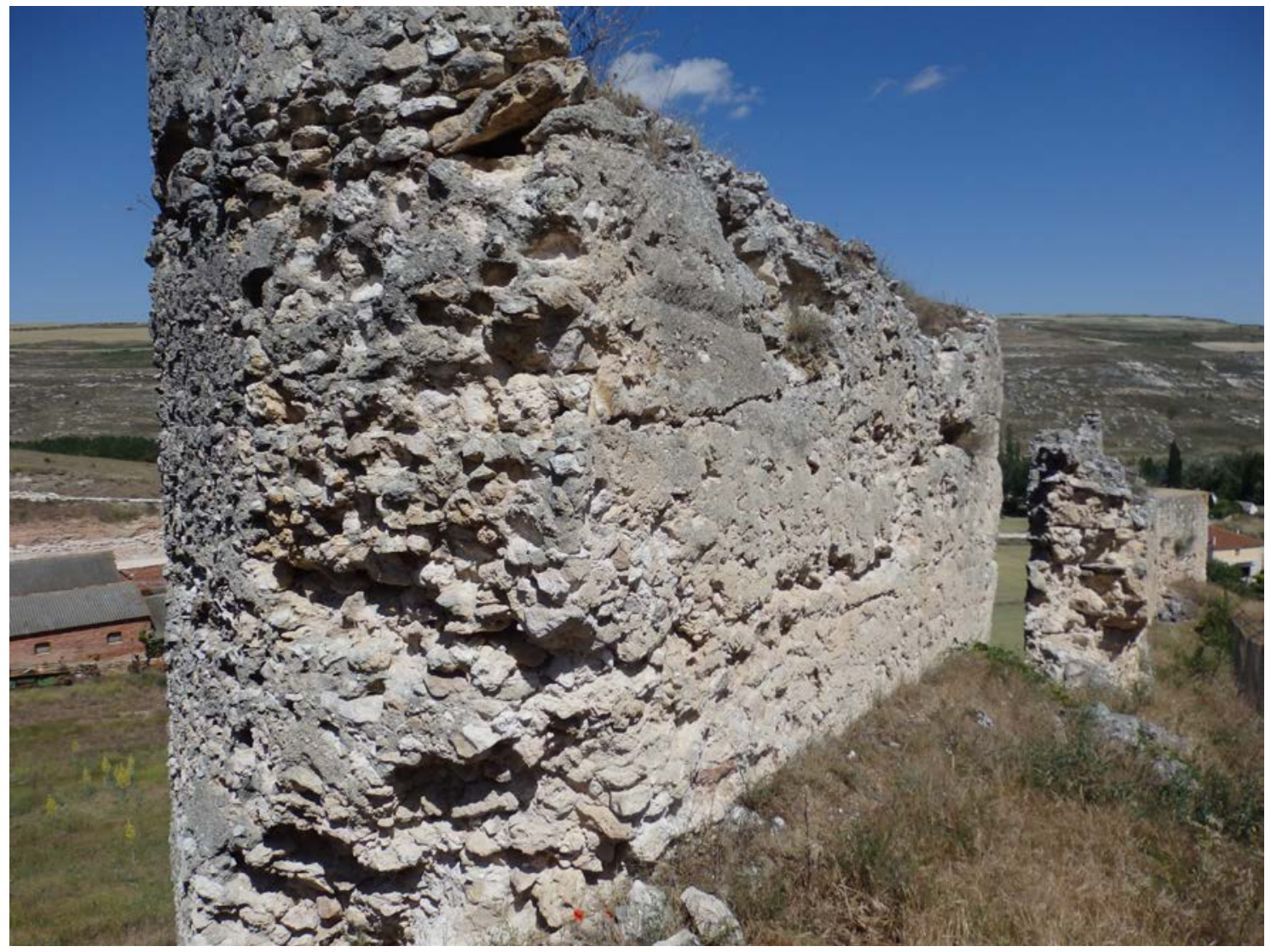

Fig. 5.3.116. Parte de la torre T3 que quedaría oculta si el lienzo de muralla se conservara en este punto [A.S.E. 17/6/2014].

Se observan dos líneas horizontales que se corresponden con las hiladas de tapia que se ven desde el exterior. Este alzado aclara que la torre no se realiza a través de la construcción de un $\mathrm{m}$ uro con forma semicircular que pos teriormente se rellena con tierra o piedras. Si fuese así, debería verse en cada extremo del alzado la sección de dos muros y observarse una diferencia en el material central, que evidenciara que se trata de un relleno. A diferencia de lo que ocurre en los alzados exteriores, donde se ven fácilmente las hiladas de tapia con las que se construye la torre, en este alzado interior esas marcas no son evidentes. ¿Qué tapial se empleaba en la construcción de las tapias de la torre? Se han pens ado varias opciones de la configuración de las tapias por hilada, para entender cómo se podría construir esta torre maciza (Fig. 5.3.117). La primera opción contempla la idea planteada inicialmente, un muro que sigue una directriz circular formando un hueco en el interior, que luego se rellena. Esta opción parece descartada por el aspecto que ofrece el alzado interior de la torre, donde no s e observa marcas de muros o r ellenos. La opc ión segunda plantea la 
construcción de tapias en forma de sector circular, que en principio parece improbable, pero que por otra parte implicaría la construcción de un tapial de dos lados, puesto que el tercero se apoya sobre la tapia anterior. La tercera opción plantea la posibilidad de que la opción 2 s e ejecutara en dos fases, para evitar el encofrado tan largo de la opción 2 que es equivalente al radio de la torre. La cuarta opción propone adosar dos primeras tapias al lienzo de muralla, para después configurar el frente semicircular con tapias más pequeñas.

1

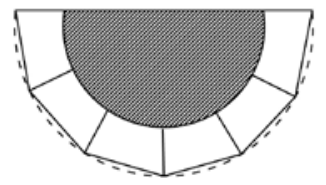

2

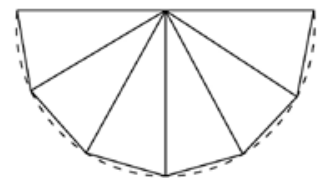

3

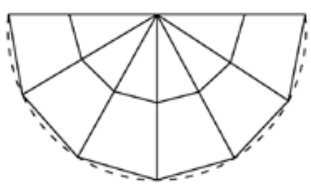

4

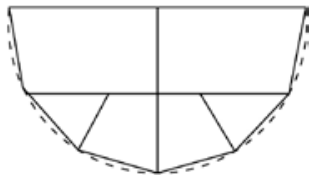

Fig. 5.3.117. Posibles configuraciones en planta de cada hilada de tapia en la torre T6. Fuente: Elaboración propia.

\subsubsection{Torre de planta rectangular T8}

La torre T8 es de planta rectangular. También parece adosada al lienzo, teniendo en cuenta que no se produce una correspondencia entre las tapias del lienzo y las tapias de la torre, que son más numerosas. Presenta 11 tapias de altura, aunque la primera se encuentra semienterrada y la última está erosionada (Fig. 5.3.112). En la cara sur, se observan tanto los limites horizontales de tapia como los verticales. Se ven aproximadamente dos tapias por hilada en este frente.

En muchas de las tapias se observa en su lado izquierdo una columna de piedras con forma alargada, colocadas una sobre otra. En la tapia T2.1 (Fig. 5.3.118) se observa una columna de seis piedras, diferentes de las empleadas en el resto de la tapia. Son más grandes y parecen haber sido seleccionadas por su forma. Esta disposición es similar a la descrita por Fernando Cobos $(2012,110-112)$ en la cerca de San Pedro de Latarce, donde durante la construcción del tapial, se construye un murete de piedras en el lado corto del tapial, a modo de encofrado, y que queda integrado en el muro. En este caso, es factible que el murete se construyera también con ese propósito. La posición de este murete indica además la dirección de construcción de las tapias, puesto que el lado del murete es aquel que se cerró en último lugar. Dada la dificultad existente en la lectura de estos paramentos, puede ser complicado identificar a qué tapia pertenece el murete, en cuyo caso será difícil deducir el orden de construcción de las tapias.

En el frente sur de la tapia T8, son visibles varios mechinales por hilada. No son suficientes para determinar cuál es la distancia habitual entre ellos ni qué ritmo tienen en cada hilada. En la tapia T2.1, son visibles dos mechinales en la base, el primero se sitúa debajo del murete de pi edras (Fig. 5.3.119) y tiene forma circular, con un diámetro de 2 a $3 \mathrm{c} \mathrm{m}$. El segundo mechinal se sitúa a la derecha donde parece verse 
una de las varillas pareadas que lo compone. Está separado del primero una distancia de $1,05 \mathrm{~m}$. En las tapias superiores se observa quel os mechinales emplean mayoritariamente el sistema de las varillas pareadas. En la quinta hilada, se ven dos mechinales cercanos entre sí, que muestran los dos huecos característicos del sistema de varillas pareadas (Fig. 5.3.120).

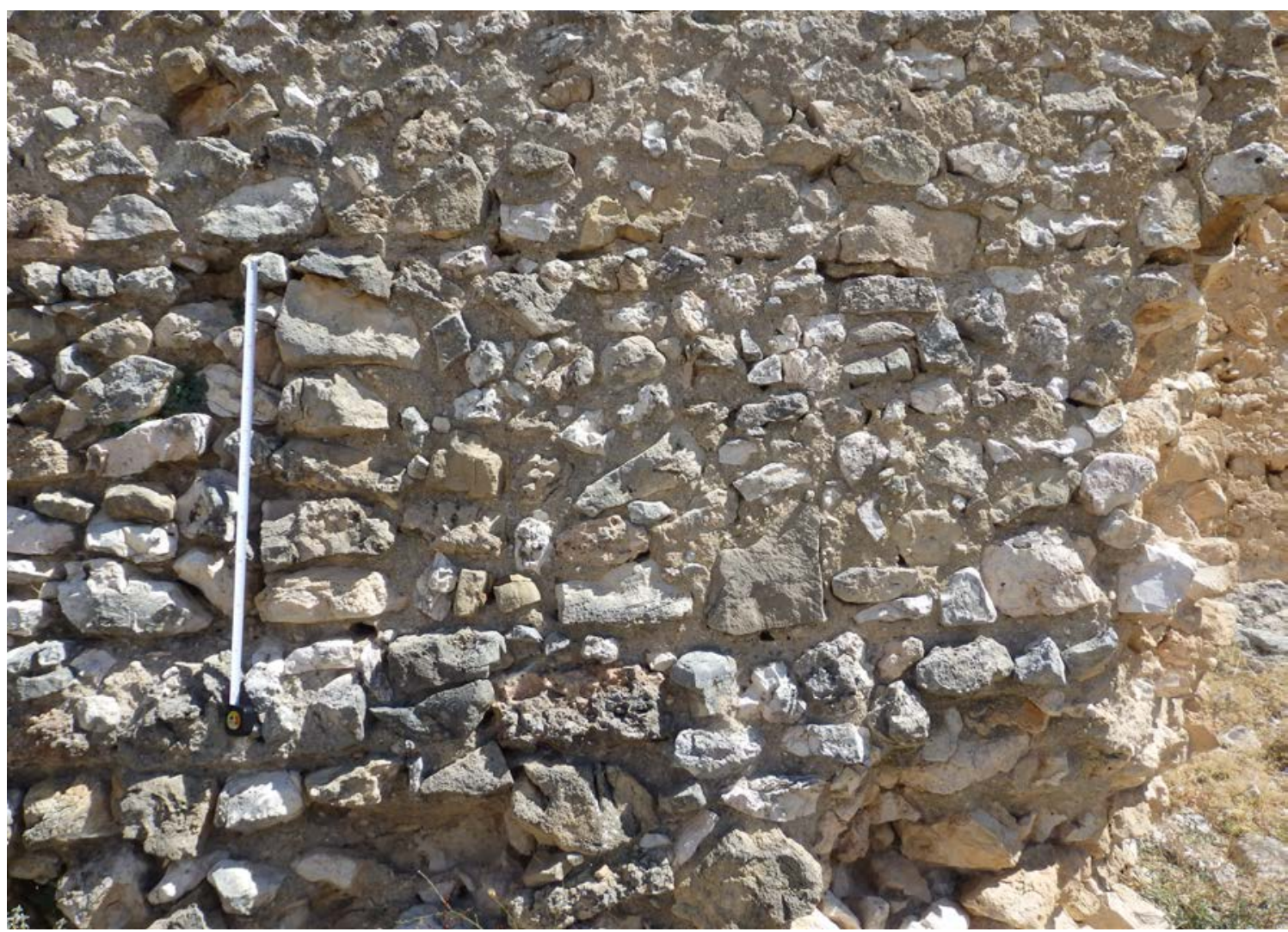

Fig. 5.3.118. Tapia T2.1 de la cara sur de la torre T8. El metro marca la distancia de 1,00m [A.S.E. 23/7/2016].

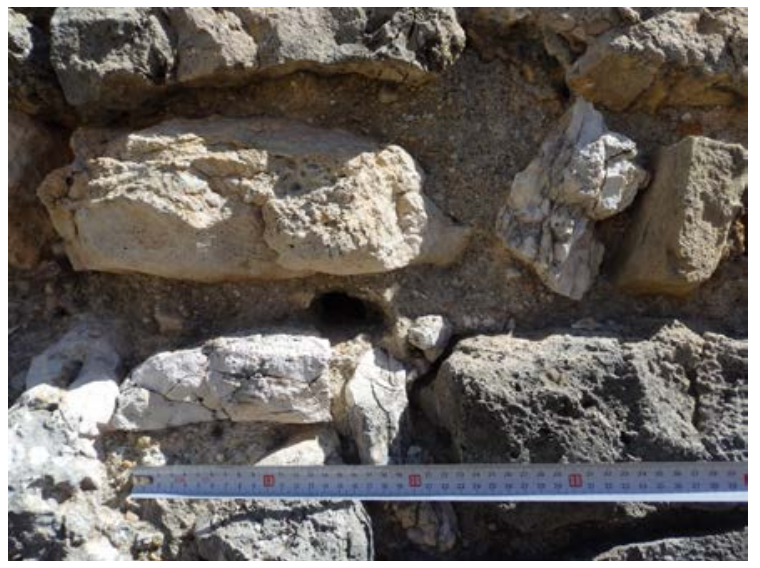

Fig. 5.3.119. Mechinal de la tapia T2.1 [A.S.E. 23/7/2016]

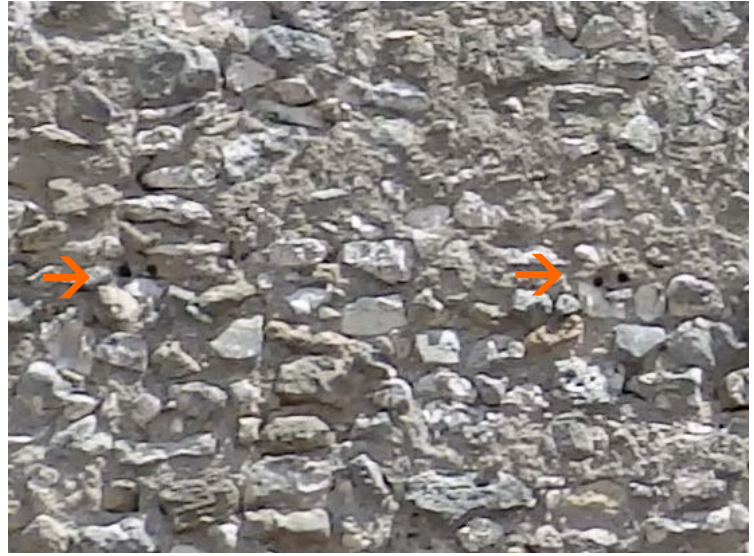

Fig. 5.3.120. Dos mechinales de varillas pareadas en la hilada 5 de la torre T8. Los separa una distancia de 1,07m [A.S.E. 17/6/2014]. 
Las murallas en las Comunidades de Villa y Tierra de la Diócesis de Segovia en los siglos XI a XIII. Técnica y sistemas constructivos de la arquitectura defensiva medieval.

\subsubsection{Resumen de resultados para el caso de Fuentidueña}

La muralla de Fuentidueña es un ejemplo extraordinario de murallas construidas con tapia. Se conservan grandes longitudes de lienzo que atestiguan el uso de esta técnica en esta arquitectura defensiva. En gran parte de el los el uso de la tapia es muy evidente. Los restos que se conservan permiten identificar el trazado de la muralla, e incluso plantear la existencia de un recinto más pequeño apoyándose en la presencia de un muro de características similares a los lienzos de muralla en la zona cercana al castillo.

En cuanto a las características generales de la muralla, es especialmente notable el escaso espesor que presentan los lienzos de muralla, que baja hasta los $90 \mathrm{~cm}$ en muchos puntos. Esta delgadez no parece afectar a su solidez, incluso aunque los lienzos superen la altura de 7 y $8 \mathrm{~m}$. Las torres del recinto presentan hasta tres formas diferentes en planta, destacando particularmente las torres semicirculares de la zona oeste y sur por su descomunal diámetro. La no integración de es tas torres con el lienzo muestra que la muralla se construyó con grandes longitudes sin torres. Las torres de sección rectangular tienen un tamaño proporcionado con los lienzos, y en su mayoría se construyeron integradas con estos.

Desde un punto de vista constructivo, se observa un us o mayoritario de la tapia de mampostería en todo el recinto, si bien se observan diferencias en las técnicas empleadas en unos puntos frente a otros. El uso del tapial corrido es evidente en el tramo T5-T6. En otros puntos es muy probable su utilización, dada la equidistancia en mechinales o la compartición de un mechinal entre dos tapias en el tramo P3-T11 y T8-este. Las agujas empleadas presentan soluciones variadas en todos los lienzos de la muralla, observándose las agujas circulares, planas y de varillas pareadas. En los tramos urbanos de la muralla, el aspecto original se ha perdido y no son visibles, al menos de forma evidente, marcas de tapial. Es notable la utilización de grandes mampuestos en la construcción de la tapia, que además se colocan en las caras exteriores formando hiladas. Esta disposición es más evidente en el tramo T5-T7.

La singularidad del lienzo T5-T6 por la presencia de hiladas de tapias extremadamente desordenadas puede arrojar pistas acerca de la construcción de estos lienzos. En este tramo parece producirse el encuentro entre dos lienzos que hay que resolver en un punto de gran desnivel. Parece vislumbrarse una falta de $p$ lanificación o desconocimiento en la construcción de tapias en una zona de desnivel, o tal vez una falta de coordinación entre distintas cuadrillas de constructores. La variedad de agujas empleadas en es te lienzo también podría apoyar la existencia de varios grupos de constructores, cada uno con sus tapiales y con sus técnicas. Otra variable es la velocidad con la que construyó ese tramo, si el tiempo apremiara, el resultado sería previsiblemente más caótico y desafortunado.

No se observa la construcción de una base diferenciada desde la que arranquen los lienzos de muralla. En muchos casos es visible la roca y se observa como las tapias se construyen directamente sobre ella. La puerta de Alfonso VIII presenta una base diferente que se identifica como una preexistencia; también es visible un zócalo en la torre T1, pero se trata de casos aislados. 
Es en las puertas donde se encuentran técnicas constructivas diferentes, como por ejemplo el empleo de sillería o de ladrillo. La puerta Alfonso VIII presenta una base construida con mampostería encintada con ladrillo, descrita por varios investigadores (Zamora, Vela 2005, 1139; Martin Aymerich 1990, 134) como la parte más antigua del recinto, un elemento preexistente, anterior al resto de la muralla.

Los recursos defensivos de e sta muralla no son especialmente numerosos. Se observa un almenado relativamente constante a lo largo de todo el recinto. Las torres de flanqueo son numerosas y parecen haber tenido almenado. Son macizas, por lo que solo se pueden usar desde la parte superior. Ninguna de ellas se separa del lienzo a modo de tor re albarrana. La distancia entre las torres rectangulares del tramo P3T11 es de 23 a 27 c m. En otras zonas no es visible un patrón, se ve casos muy próximos (T6-T7, con 15m de separación a ejes) o muy alejados entre sí (T5-T6 con casi $60 \mathrm{~m}$ de separación a ejes). 



\section{4}

\section{Maderuelo}

Segovia

\subsubsection{Localización}

Maderuelo se sitúa en el límite noreste de la provincia de Segovia, y su comunidad linda con la provincia de Soria. Se sitúa a $120 \mathrm{~km}$ de Valladolid y a $100 \mathrm{~km}$ de Segovia. La extensión de la comunidad queda incluida en la actual provincia de Segovia. Es de tamaño pequeño, similar al de Coca, y alcanza una superficie aproximada de $250 \mathrm{~km}^{2}$. El río Riaza atraviesa la comunidad, aunque es el embalse de Linares del Arroyo el que se encuentra junto al núcleo de Maderuelo. La comunidad linda al noroeste con Montejo de la Vega de la Serrezuela, al suroeste con Sepúlveda, al sur con Fresno de Cantespino, al sureste con Ayllón y al noreste con San Esteban. La población del núcleo de Maderuelo es de 119 habitantes en el año 2015, con tendencia descendente desde el año 2007, cuando contó con 189 habitantes, el número más elevado desde, al menos, el año $1996^{32}$.

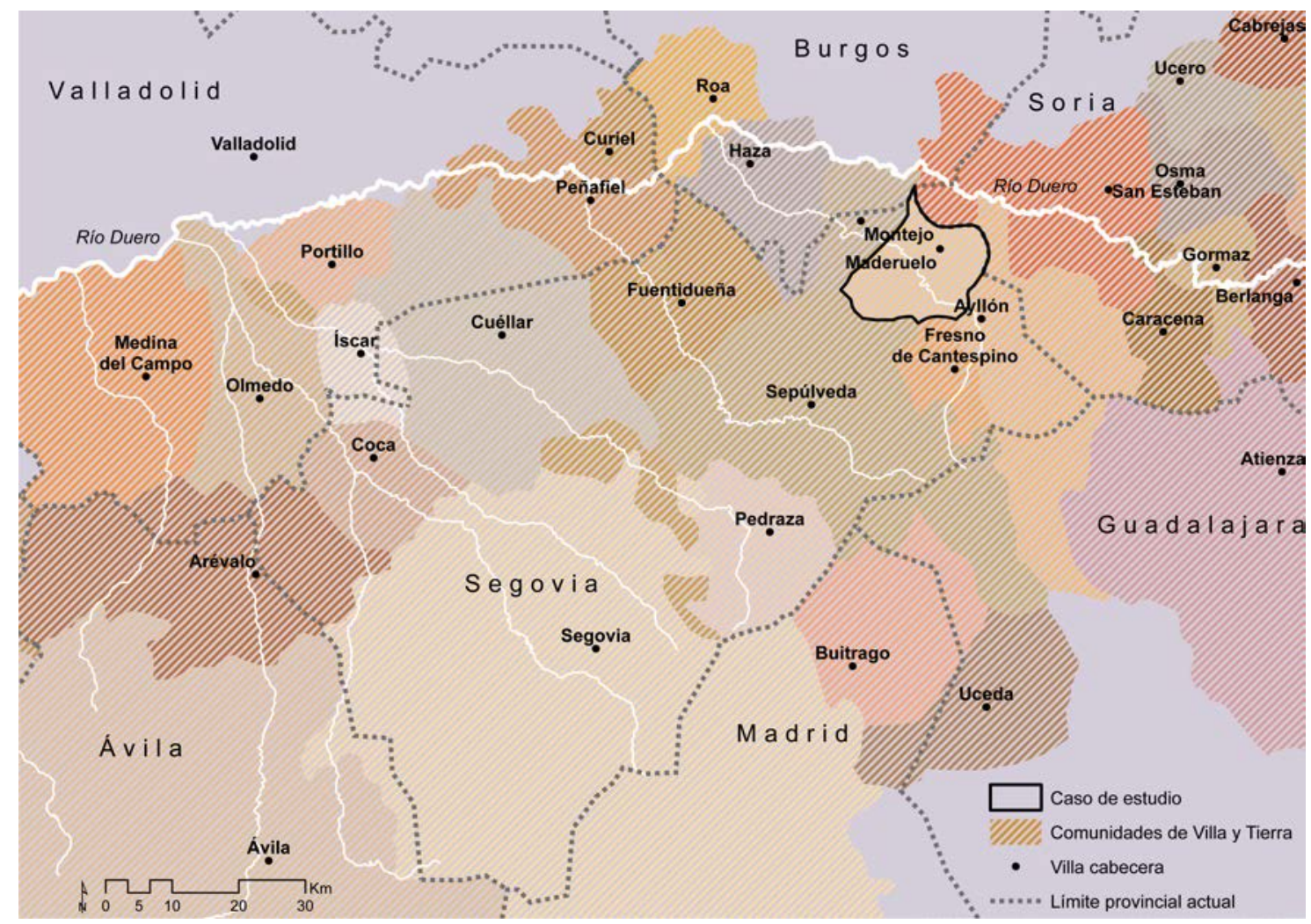

Fig. 5.4.1. Plano de localización de Maderuelo. Fuente: Elaboración propia a partir de planos de G. Martínez Díez (1983, 11-15) y J.M. Monsalvo $(2010,152)$.

\footnotetext{
${ }^{32}$ Datos extraídos de la página web del Instituto Nacional de Estadística. http://www.ine.es/jaxiT3/Datos.htm?t=2894 [Consultado el 28/3/2016]
} 
El núcleo de Maderuelo está limitado por el cerro en el que se asienta. Se trata de una elevación alargada y estrecha, cuyas dimensiones no superan los $90 \mathrm{~m}$ en anc hura mientras que en longitud sobrepasa los $600 \mathrm{~m}$, parece un apéndice en prolongación del páramo que se encuentra al sur. Este apéndice está flanqueado por el río Riaza, ahora convertido en el embalse de Linares del Arroyo, y por el arroyo de San Andrés. La altitud dentro del núcleo alcanza los $950 \mathrm{~m}$ sobre el nivel del mar. El lecho de los ríos que lo rodean por el este, norte y oeste se sitúa en $920 \mathrm{~m}$ sobre el nivel del mar. Se puede acceder al mismo nivel desde el lado sur. Enfrente del promontorio se elevan hasta los 960m los páramos que flanquean el embalse y el arroyo.

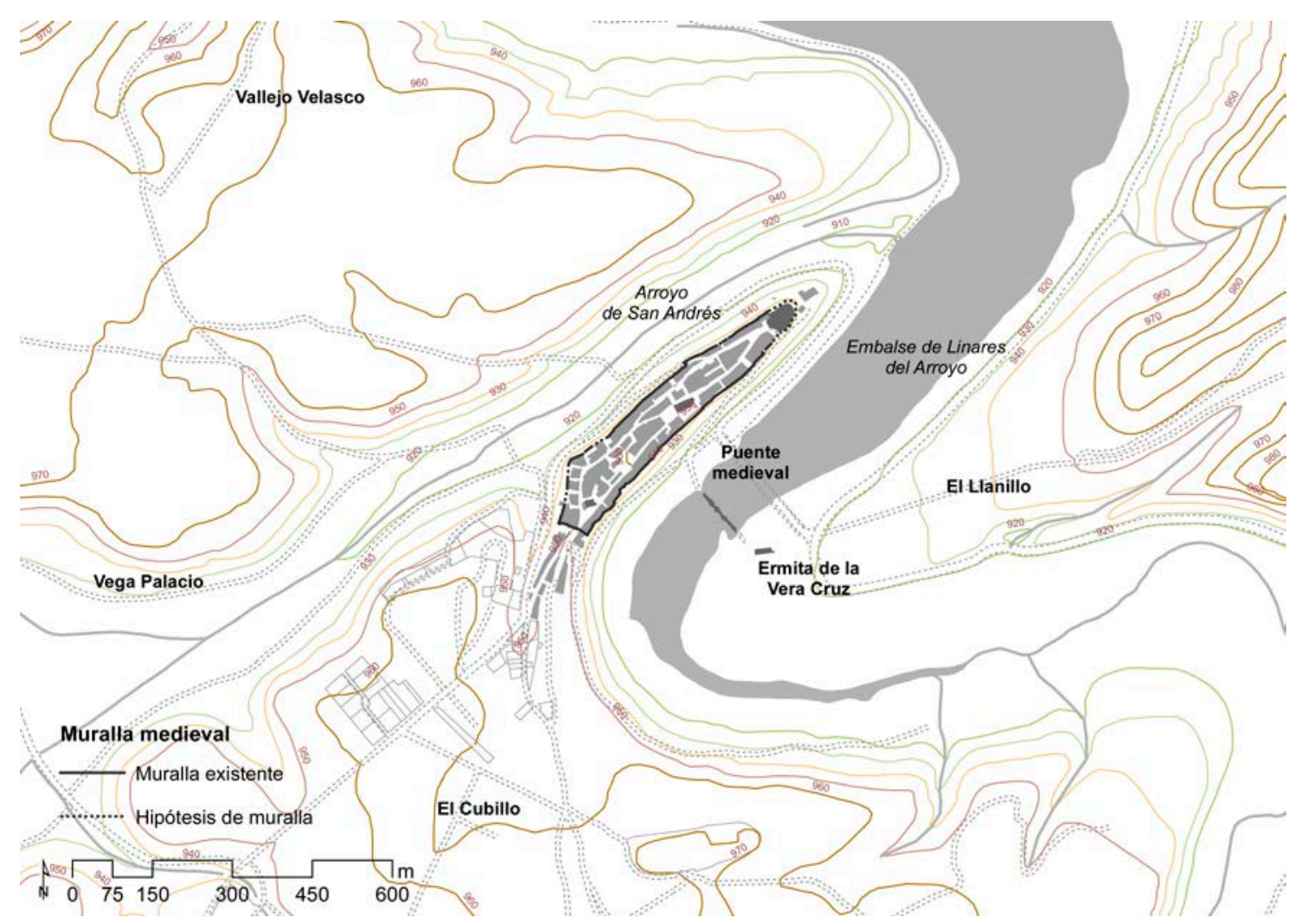

Fig. 5.4.2. Topografía en torno al núcleo de Maderuelo. Fuente: Elaboración propia con datos de IDECyL y Catastro.

\subsubsection{Estudios en la villa}

Son escasos los estudios realizados sobre la villa de M aderuelo. En los años 90 Ronald Cueto (1995) realiza un breve estudio acerca de la Comunidad de Villa y Tierra de Maderuelo. No se han encontrado estudios acerca de la muralla. De acuerdo con el Catálogo de $\mathrm{B}$ ienes Arqueológicos del $\mathrm{PECH}$ de $\mathrm{M}$ aderuelo (Ficha 2 pág. 14) ${ }^{33}$, existen dos informes técnicos resultado de excavaciones arqueológicas en la muralla y el castillo de Maderuelo, que datan de 1987 y del año 2007, de los autores P. Bahona Tejedor e I. M arqués Martín respectivamente, disponibles en el Servicio Territorial de Cultura de Segovia.

\footnotetext{
${ }^{33}$ Consultado en el Archivo de Planeamiento Urbanístico de Castilla y León. http://servicios.jcyl.es/PlanPublica/default_plau.do [Consultado el 7/6/2016]
} 


\subsubsection{Datos históricos destacados del núcleo}

En comparación con otras villas de este estudio, Maderuelo aparece mencionada en escasos documentos. En 912 s e conoce la repoblación de Maderuelo por parte de Gonzalo Fernández, después de las villas de Roa, Clunia, Osma y San Esteban (Martínez Díez 1983, 312). En 1109 apar ece mencionada como Castro Maderolum incluida en la diócesis de Burgos. En 1011, el autor remite a Rodrigo Jiménez de Rada cuando menciona a Maderuelo entre las fortalezas recuperadas por el conde Sancho Garcés (307). Aparece mencionada en documentos ya señalados en el capítulo 3, donde figura junto a las otras villas de es ta investigación. Es el caso de la bula de Calixto II de 1123, por la que se conoce la integración de Maderuelo en la Diócesis de Segovia. Más adelante, en 1136 aparece citada entre las villas donde el rey cede el diezmo a la iglesia católica. Igualmente, figura en 1187 en el documento de matrimonio entre Berenguela y Conrado, hijos de Alfonso VIII y Federico I.

Se conoce poca información acerca de la villa de Maderuelo tras su función de villa cabeza de su comunidad. En la Edad Moderna, se produjo un cierto aislamiento de la villa, alejándose del protagonismo obtenido de époc as anteriores. Maderuelo pudo contar con hasta una decena de iglesias, de las que se conservan solo cuatro en la actualidad (Rivas et al. 2009, 477).

\subsubsection{Tejido urbano}

La estructura urbana de Maderuelo está limitada por la topografía. Se ha producido un tímido crecimiento del núcleo hacia el sur, fuera del recinto amurallado. En comparación con otros núcleos estudiados, el crecimiento de este ha sido muy escaso más allá del recinto amurallado.

El recinto amurallado engloba una superficie de casi $5 \mathrm{Ha}$. Las calles se organizan de forma longitudinal, en paralelo con el eje longitudinal de núcleo. La calle de Abajo atraviesa el núcleo en el lado noroeste y la calle de Arriba es paralela a la primera, pero recorre el núcleo en el lado sureste. Ambas parten de la puerta de la Villa en el sur, desde la plaza de San Miguel y se encuentran en la plaza del Castillo, al norte. En su recorrido en paralelo, se comunican a través de calles transversales, como la calle de Santa María, la calle del Castillo y a través de plazas como la plaza de P érez Seoane o la plaza de Santa María. Se observan varias calles en fondo de saco que se sitúan en paralelo con las calles de Abajo y de Arriba, en la zona existente entre ambas. Una de ellas es la calle Zorrilla, cercana a la puerta del Barrio, o la calle Norte que parte de la plaza Seoane. El callejón de San Miguel parte hacia el norte de la plaza con el mismo nombre, en una disposición similar a las otras calles descritas.

El núcleo posee dos iglesias en el interior del recinto amurallado, la iglesia de Santa María, situada en el centro del recinto, y la iglesia de San Miguel que se encuentra junto a la puerta de la Villa. Además de esta puerta, se sitúa al noroeste la puerta del Barrio, orientada en per pendicular a la dirección del lienzo de la muralla. Dada la estructura del núcleo, es posible que hubiera una puerta en el camino de abajo, que conecta con el puente sobre el Riaza, en el lado sureste. 
La zona norte del recinto se encuentra más vacía que el resto del núcleo, donde las parcelas están definidas y agrupadas. En el norte, se hallan dos parcelas grandes y se aprecia una desestructuración del tejido urbano: las calles terminan en la plaza del castillo y para llegar a las viviendas situadas en el borde norte (representadas en color verde en la Fig. 5.4.3) es necesario atravesar parcelas privadas, aunque físicamente exista un camino.

En el plano de parcelario se ha dibujado el recorrido de la muralla, tratando de indicar a través de un código de colores qué partes de la muralla se conservan, cuáles han sido alteradas y cuál sería su trazado allí donde no quedan r estos. Gran parte del recorrido se ha incluido en el tipo "Zonas reconstruidas o muy alteradas", con esto se pretende expresar que se trata de muros que se sitúan en el trazado de la muralla original, que conservan un as pecto defensivo por tratarse de un $\mathrm{m}$ uro de piedra sin huecos, cuyas bases podrían conservar piedras o cimentación original, pero que han sido profundamente transformados, reparados o incluso reconstruidos.

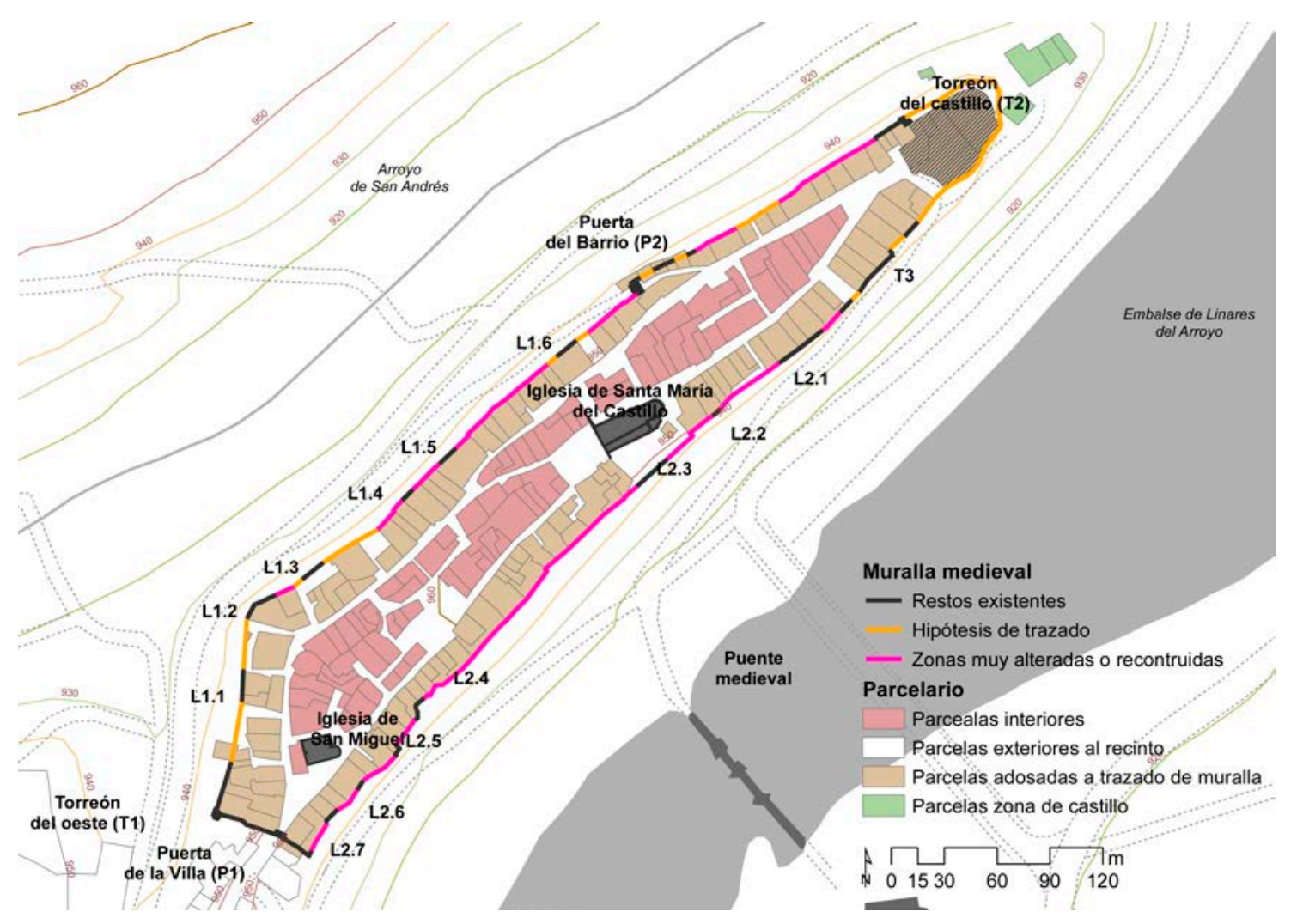

Fig. 5.4.3. Estructura urbana de Maderuelo y esquema del recinto amurallado. Fuente: Elaboración propia con datos de Catastro e IDECyL.

Se ha grafiado en color negro el tipo "Restos" que son aquellas zonas que conservan muros donde todav ía son reconocibles partes de $\mathrm{m}$ uralla que no han $\mathrm{s}$ ido reconstruidas, tal vez reparadas o revocadas, pero donde se reconocen elementos que se identifican como originales, como por ejemplo restos de tapia de mampostería o bases de sillería. En ocasiones, estos restos han sido completados con zonas nuevas, pero al menos existe una parte original. "Hipótesis de trazado" indica donde 
continuaría la muralla en los puntos donde no existe ninguna construcción, o donde las construcciones que existen son claramente de nueva factura, donde no se conservan bases o restos que atestigüen el paso de la muralla.

Las parcelas coloreadas en $m$ arrón son aquellas que se encuentran adosadas al trazado de la muralla por la cara interior. Cuando esta se conserva, las edificaciones aprovechan sus muros y los integran en la nueva construcción. Es previsible que cuando la muralla funcionaba como elemento defensivo, cualquier edificación estaba separada de los lienzos, quedando una calle interior para vigilar y acceder a las murallas. En el tejido urbano actual no se observan restos evidentes de la existencia de estas calles. Tal vez en la zona oeste del recinto, al norte del torreón del Oeste (T1) puedan quedar restos de lo que fue una c alle de ronda. Desde poco antes del lienzo L1.1 hasta el tramo L1.4 se ven espacios vacíos junto a la muralla, en el interior del recinto, que se suceden de forma intermitente. En el lado sureste, entre los restos L2.1 y L2.2 se observa una calle con características similares, junto a la muralla. Al norte del L2.1 existe una parcela cuyo fondo forma una $L$ hacia el norte, como si hubiera incorporado a posteriori ese espacio, una calle paralela a la muralla. Este fondo de parcela es visible también en otros casos del recinto, como por ejemplo al norte del resto L2.4.

\subsubsection{Planeamiento y figuras de protección}

Se aprobaron en el año 2005 las Normas Urbanísticas Municipales de Maderuelo, donde se realiza una primera delimitación del Plan Especial del Conjunto Histórico de la Villa, junto con una exposición de objetivos y criterios de actuación (Título Octavo de la Normativa Urbanística págs. 83-85). En el año 2007 se llevó a cabo la redacción del Plan Director de Restauración de las Murallas de Maderuelo, encargo realizado por el estudio de ar quitectos Álvaro Planchuelo. El proyecto de r estauración plantea la reconstrucción de varias torres y lienzos de la muralla. Data de 2011 la aprobación del Plan Especial de Protección, Reforma Interior, Mejora Urbana y Catálogo del Conjunto Histórico. En este plan se establecen áreas de pr otección para la arquitectura defensiva del núcleo. También se plantea una propuesta de reconstrucción de torres y lienzos de la muralla desaparecidos. La villa fue declarada Bien de Interés Cultural (BIC) en la categoría de Conjunto Histórico en el año 1993.

\subsubsection{Descripción general de arquitectura defensiva}

La muralla de Maderuelo recorre el contorno del núcleo, situándose en los bordes de los desniveles que ofrece la topografía. En su extremo sur se ve un alzado de $60 \mathrm{~m}$ de longitud que incluye el torreón del oeste y la puerta de la Villa. Continúa por el lado noroeste, de forma entrecortada, con alguna construcción adosada (Fig. 5.4.6). Las nuevas edificaciones han empleado lienzos de la muralla como muros propios, modificándolos con huecos y tubos de saneamiento y ya forman parte de la nueva construcción (Fig. 5.4.7). En estas zonas, se observan divisiones verticales, muchas veces coincidentes con límites de parcela, discontinuidades, reparaciones, añadidos o elementos adosados. 
En la zona norte del recinto, la muralla se interrumpe al llegar a una torre de la que se conservan sólo dos de sus muros (Fig. 5.4.8). Es probable que, por el lugar donde se encuentra, esta torre tenga alguna relación con el castillo que se ubica en esta posición. En la ficha arqueológica del Plan Especial de Maderuelo, la torre se describe como integrada en el castillo. Se hace referencia a la tronera del torreón (Fig. 5.4.9), se indica que está construida en uno de I os frentes orientados a la población y se deduce por ello que el castillo era independiente del recinto amurallado ${ }^{34}$. Se encuentran en esta área restos de muros que pertenecieron al conjunto fortificado.

Desde la posición del castillo la muralla continuaría en el lado sureste. Las parcelas y las construcciones urbanas aprovechan los muros y los integran en la edificación doméstica. En ocasiones abren huecos o han realizado reparaciones.

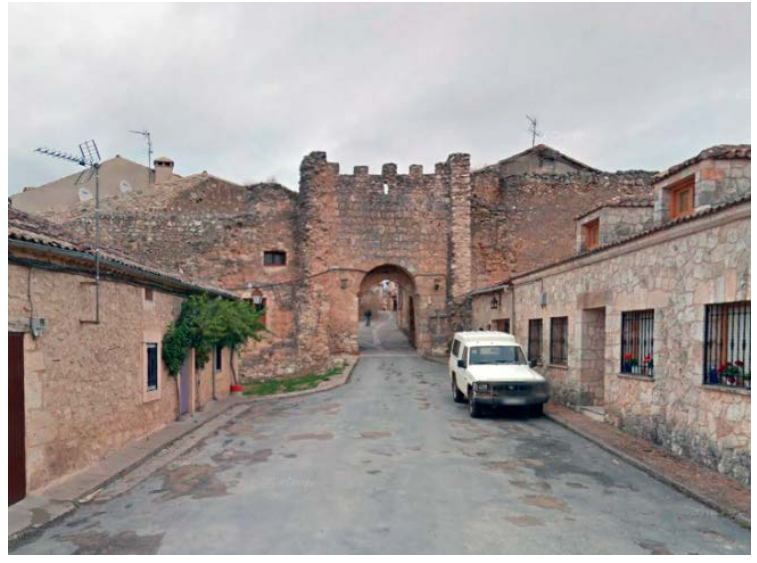

Fig. 5.4.4. Frente suroeste con la puerta de Maderuelo. Fuente: Google Street View (Oct-2013).

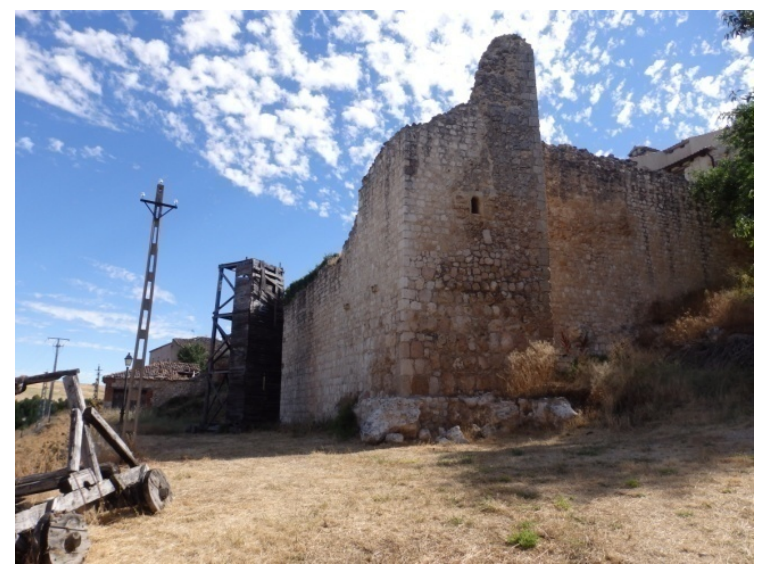

Fig. 5.4.6. Torreón del Oeste [A.S.E. 23/7/2016].

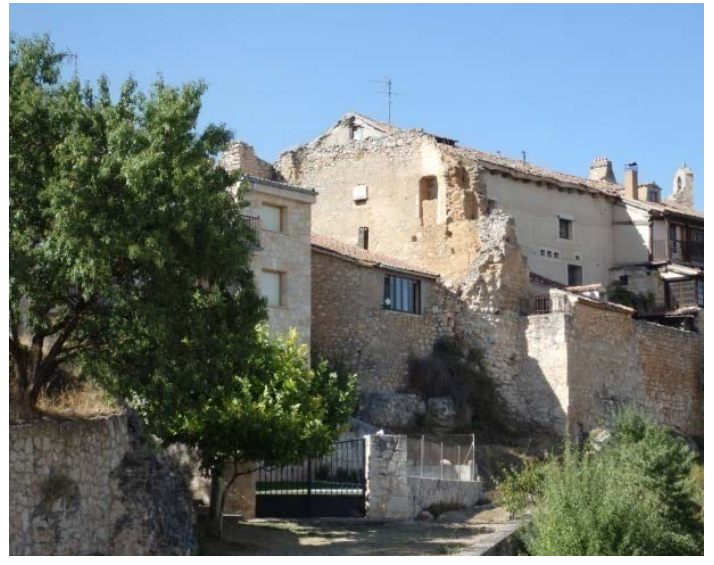

Fig. 5.4.5. Vista de la esquina sur [A.S.E. 3/9/2014]

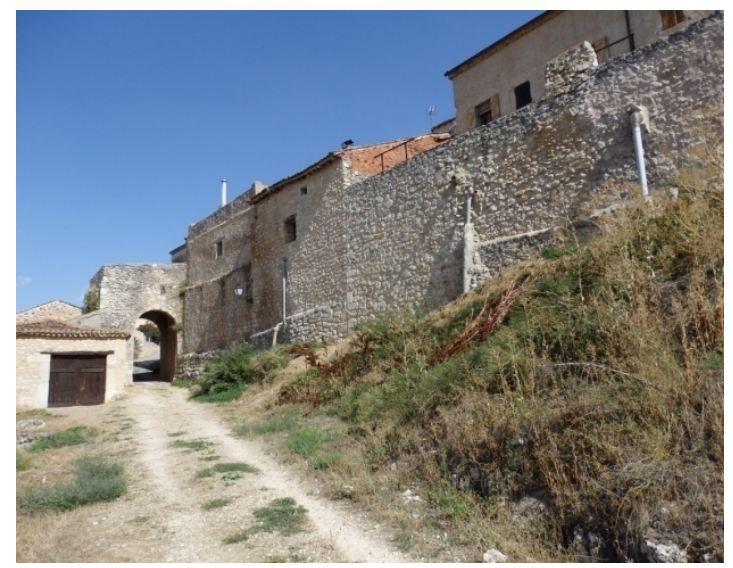

Fig. 5.4.7. Tramo noroeste de la muralla. Al fondo se observa la puerta del Barrio. Las viviendas se apoyan en la muralla y sacan tubos de saneamiento que descienden sobre los lienzos [A.S.E. 3/9/2014].

\footnotetext{
${ }^{34}$ Ficha 01-Castillo de Maderuelo. Pág. 5 del Capítulo 4. Catálogo de Bienes Arqueológicos Inventariables del PE de Protección Reforma Interior, Mejora Urbana y Catálogo del Conjunto Histórico aprobado en el año 2011.

http://www.jcyl.es/plaupdf/40/40115/286523/4.CATALOGO\%20DE\%20BIENES\%20ARQUEOL\%D3GICO S\%20INVENTARIABLES.pdf [Consultado el 9/6/2016]
} 


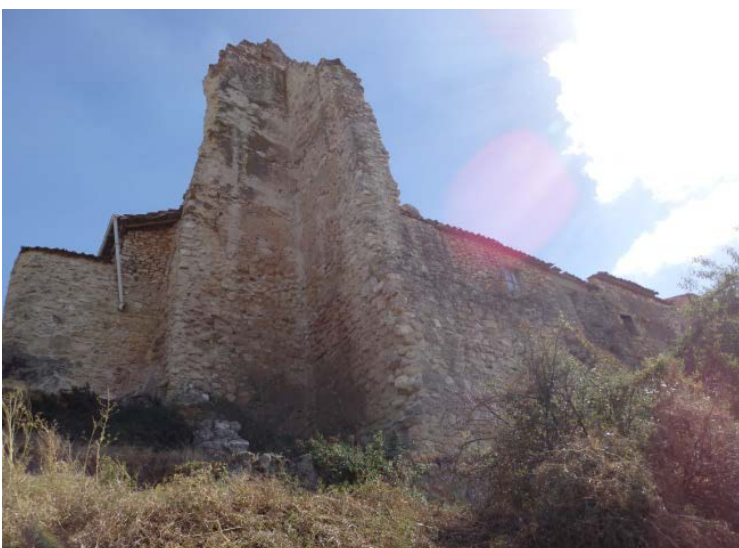

Fig. 5.4.8. Parte de la torre T2 en la zona del antiguo castillo de Maderuelo [A.S.E. 3/9/2014].

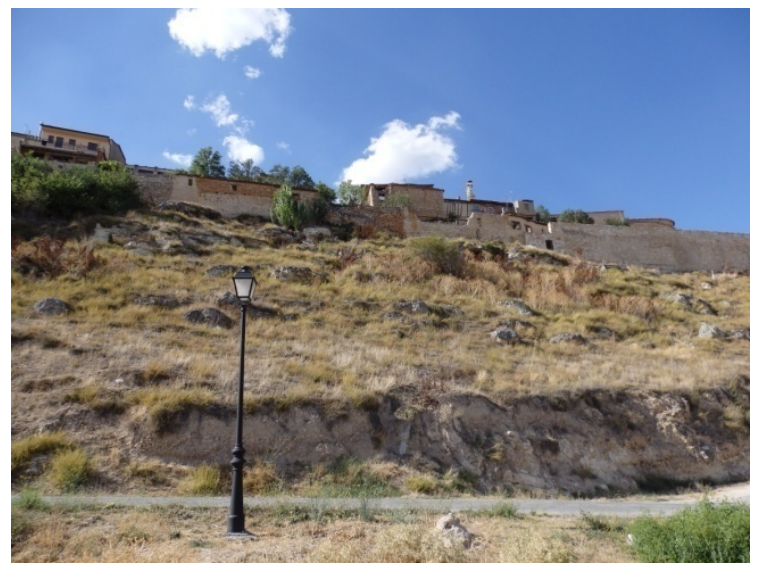

Fig. 5.4.10. Vista del lado sureste del núcleo desde la salida del puente medieval [A.S.E. 3/9/2014].

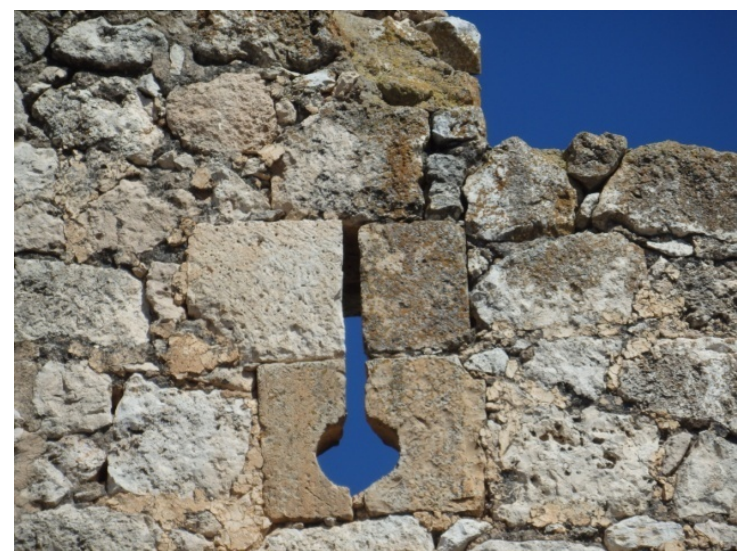

Fig. 5.4.9. Tronera en el alzado sureste de la torre del castillo [A.S.E. 23/7/2014].

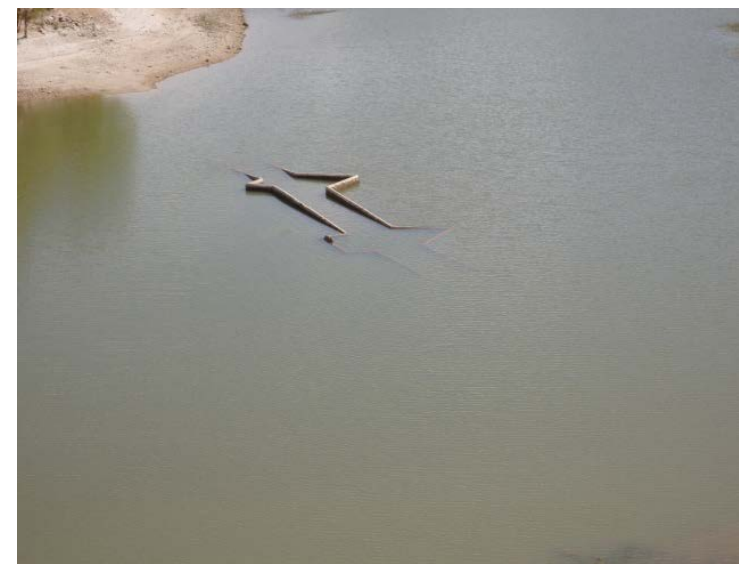

Fig. 5.4.11. Puente medieval sumergido en el embalse, algunos de sus espolones son visibles por la bajada del nivel del agua [A.S.E. 3/9/2014].

En determinadas épocas del año, cuando las aguas del embalse de Linares del Arroyo tienen un nivel bajo, es visible parte del puente medieval que une I as dos márgenes del río Riaza (Fig. 5.4.11). El puente se compone de tres ojos. Presenta dos espolones que forman un ángulo cerrado y flanquean el ojo central, más ancho. En la margen izquierda, tiene un tercer espolón menos definido, ausente en el lado derecho. Al otro lado del río se sitúa la ermita de la Vera Cruz. La presa de este embalse, situada $5 \mathrm{~km}$ más al norte, se terminó de construir en 1951. Junto al puente medieval, a escasos $100 \mathrm{~m}$, se construyó el puente que se usa en la actualidad.

\subsubsection{Tramos y elementos de la muralla medieval}

A la entrada de la villa, en el sur, se sitúa la puerta de la Villa. Ofrece un aspecto poco habitual, ya que el arco de acceso está flanqueado por la sección de dos muros que ha quedado expuesta tras la desaparición de aquello que integraban. Es probable que estos muros formasen parte de las torres que protegían el acceso. Junto a la puerta, a la izquierda, es visible la sección de lo que parece un muro, separado de la puerta una 
distancia semejante a la anchura de una torre. Esta sección de muro es visible solo a partir de una altura, no se aprecia en la base. La altura de la puerta, medida desde el exterior hasta lo alto del almenado alcanza los $11 \mathrm{~m}$. La anchura del frente es $8,70 \mathrm{~m}$ y si consideramos la hipótesis de que estaba flanqueada por dos torres, la anchura de la puerta alcanzaría los $18 \mathrm{~m}$.

El hueco de acceso visible desde el exterior (Fig. 5.4.12) se construye mediante un arco de medio punto, empleando como dovelas sillares de piedra. Tiene una anchura de $3 \mathrm{~m}$ y una altura de $5 \mathrm{~m}$. A ambos lado del arco se ven dos huecos cuadrangulares formados con cuatro piedras dispuestas en cada uno de $s$ us lados. De los huecos sobresalen sendas vigas de madera de sección cuadrangular con $20 \mathrm{~cm}$ de lado. Sobre el arco, se sitúa un a parejo de $p$ iedra organizado de $\mathrm{m}$ anera regular en hi ladas horizontales siendo visibles ocho hiladas de piedra. Las piedras empleadas no son regulares, pero a través de las hiladas horizontales, de una altura que oscila entre 35 y $40 \mathrm{~cm}$, se consigue un efecto de regularidad. Sobre este paño regular de piedra se eleva un almenado construido con piedras mampuestas, con un aparejo diferente del existente en zonas inferiores y con un hueco saetero en el centro. Podría haber sido reconstruido recientemente. Suman un total de 5 almenas de proporción cuadrada, con una al tura de $60 \mathrm{~cm}$, una anchura de $75 \mathrm{~cm}$ y una separación entre almenas de $70 \mathrm{~cm}$, dimensiones que son aproximadas.

Este frente descrito se sitúa separado del paño interior, generando un hueco sobre el arco de acceso que funciona de matacán (Fig. 5.4.14). Es visible en segundo plano, ya en el interior de la puerta, otro arco donde se ubica la puerta que cierra el acceso. Desde el interior del recinto, se observa el arco intermedio (Fig. 5.4.13), también construido con dovelas de piedra. Este arco tiene una directriz más rebajada y tiene un aspecto más tosco. En el alzado interior de la puerta, es visible un tercer arco de medio punto construido con sillares de piedra. La altura de este arco es mayor que la de los dos precedentes, supera los $7 \mathrm{~m}$. La bóveda que cubre el espacio entre el arco intermedio y el arco del alzado interior de a pu erta se construye con piedras planas, muy estrechas (Fig. 5.4.15).

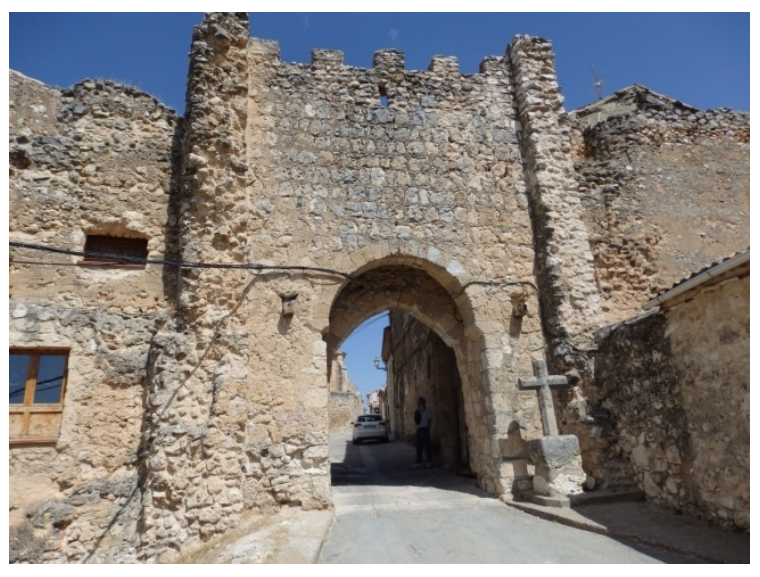

Fig. 5.4.12. Puerta de la villa de Maderuelo [A.S.E. 3/9/2014]

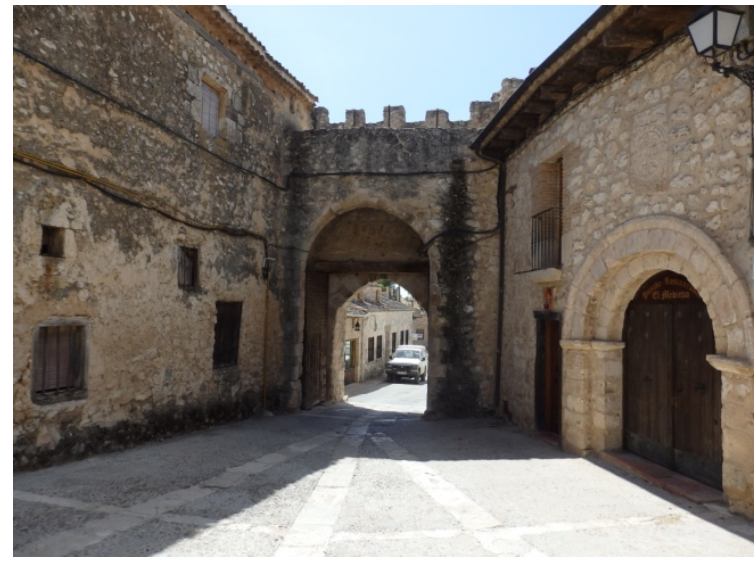

Fig. 5.4.13. Vista interior de la puerta de la Villa [A.S.E. 3/9/2014] 


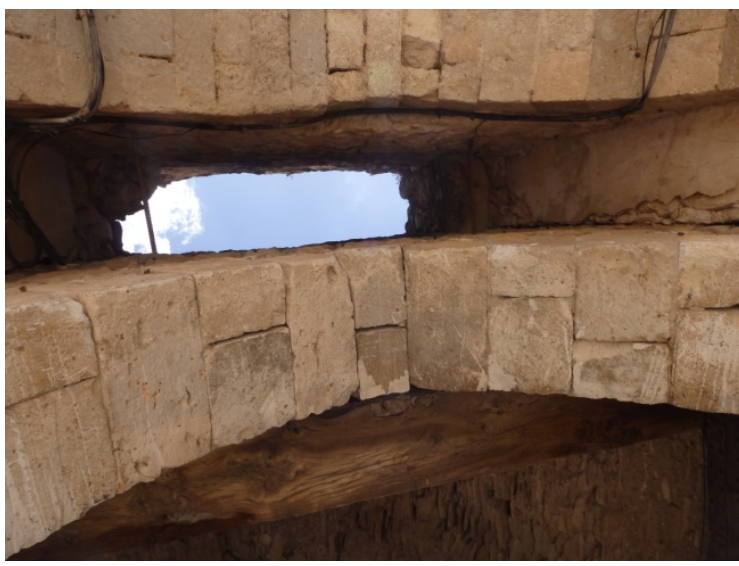

Fig. 5.4.14. Matacán entre el arco del alzado exterior y el arco intermedio. Arriba se ve el arco exterior y abajo el arco intermedio [A.S.E. 3/9/2014].

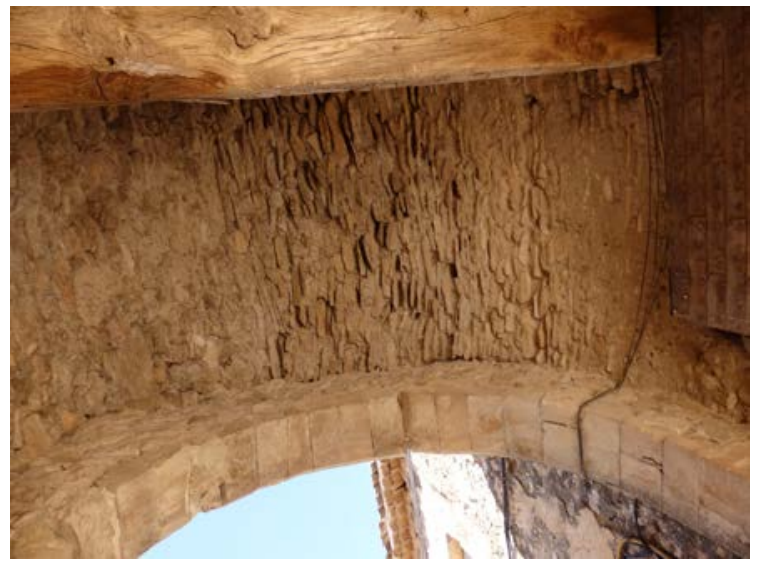

Fig. 5.4.15. Bóveda entre el arco intermedio de la puerta y el arco del alzado interior de la puerta. Arriba se ve la viga que sujeta la puerta en el arco intermedio y abajo se puede ver el arco del alzado interior [A.S.E. 3/9/2014].

En este acceso se conserva una puerta de madera de dos hojas de mismo tamaño. En la hoja derecha existe una pequeña puer ta con tamaño para una persona. La puerta está forrada de pi ezas de hierro sujetas con tachones de c abeza redonda. Estas piezas metálicas tienen forma rectangular alargada y se fijan con seis tachones. Se colocan con una pequeña superposición sobre la pieza inmediatamente inferior. Con estas piezas se forra la puerta por completo, aunque muchas de ellas se han perdido. Se ajustan a la forma de la puerta adaptándose al portillo, que tiene a su vez forro metálico de las mismas características. En los bordes, dan la vuelta sin interrupción, formando una curva, para continuar por el reverso.

Hacia el este de la puerta de la villa, se conservan restos de lienzo de muralla, modificado por las nuevas viviendas, que han ido abriendo huecos en el mismo, a lo largo de una longitud de $17 \mathrm{~m}$. Sobre el muro se ve cómo sobresale el testero de una vivienda, traduciéndose la inclinación de la cubierta a dos aguas en lo alto del lienzo (Fig. 5.4.16). Se pueden contar tres huecos en una altura equivalente a la planta baja, dos de ellos muy similares en dimensiones y proporciones, y muy cercanos entre sí. En la altura correspondiente a una planta primera, se observa un hueco situado directamente sobre otro de la planta baja y cuyos bordes se definen con sillares tallados, que forma incluso un voladizo en la parte inferior. El dintel tiene lo que parece un reloj de sol tallado en la piedra. Otro hueco pequeño y de proporción alargada se sitúa en el extremo más cercano a la puerta de la Villa. Son visibles en el paramento marcas de tapi a, líneas horizontales incompletas e interrumpidas por huecos o parches de reparaciones. En la base de este lienzo se ven mampuestos de piedra. En esta zona se ha perdido el acabado superficial de la tapia y, por otra parte, se han realizado reparaciones con nuevos mampuestos y nuevos morteros que buscan destacar las piedras individualmente aunque no sean sillares. 


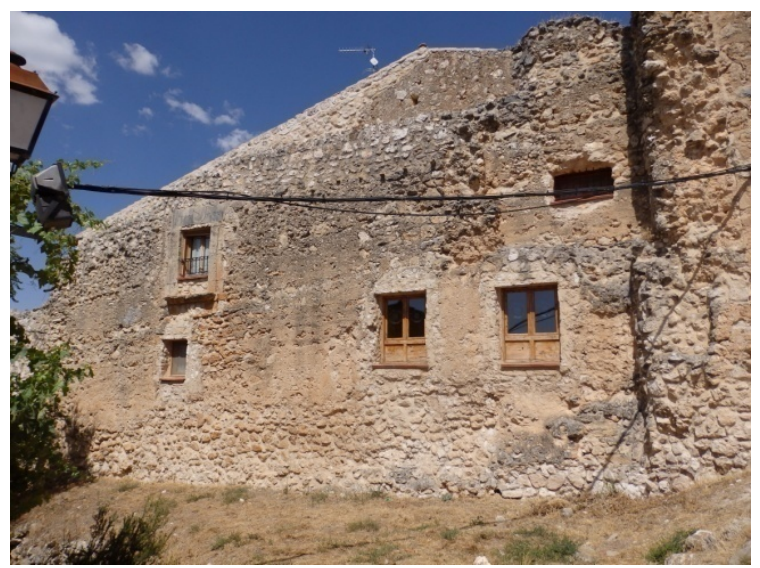

Fig. 5.4.16. Tramo de muralla a la izquierda de la puerta de la Villa (P1-este), vista desde el exterior del recinto [A.S.E. 3/9/2014].

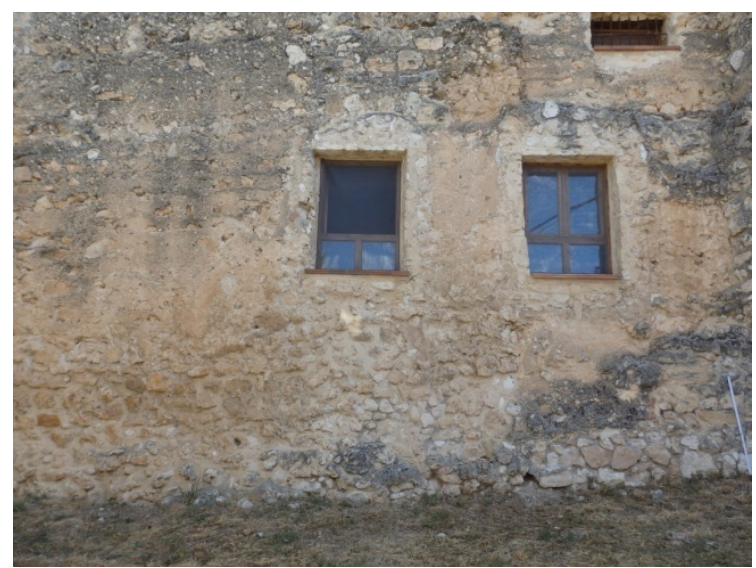

Fig. 5.4.17. Aspecto del paramento en P1-este [A.S.E. 23/7/2016].

Más al este, el lienzo desciende con el terreno casi $5 \mathrm{~m}$ y muestra otras técnicas constructivas. Aparece un tramo resuelto con sillarejo de piedra, de hiladas muy regulares, horizontales (Fig. 5.4.18, derecha) que tiene una longitud de $7,50 \mathrm{~m}$. El siguiente tramo, escasos $5 \mathrm{~m}$ antes de la torre T1, r ecupera de nue vo la tapia de mampostería, en su zona más alta, donde se pueden identificar cuatro hiladas de tapia (Fig. 5.4.18, parte superior y Fig. 5.4.19). Desde media altura del lienzo hasta el suelo, se observa un sillarejo ordenado, regular, cuyas piedras van ganando tamaño según se acercan al suelo. En las hiladas más bajas se observa el uso de sillares de tamaño grande. La roca natural sobresale del muro en un punto de la base, rodeada por el lienzo como un i slote. Se observa un c analón o un desagüe de pi edra cercano al suelo, a una altura de poco más de un metro (Fig. 5.4.18, abajo).

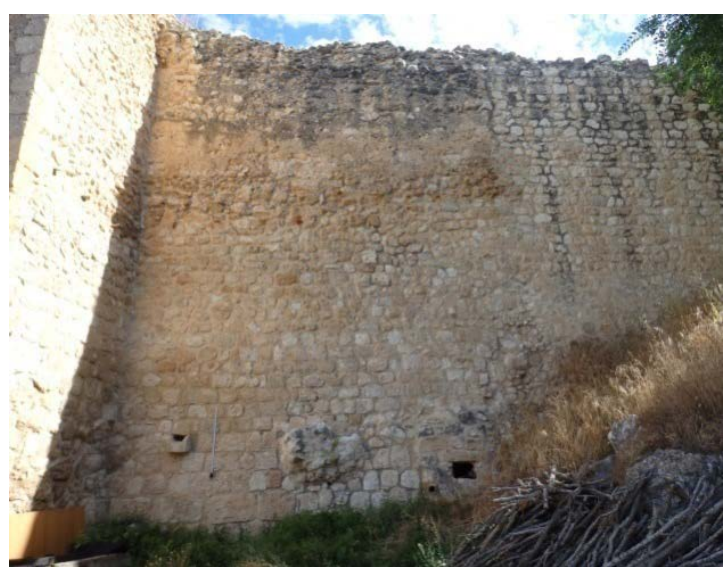

Fig. 5.4.18. Tramo T1-oeste [A.S.E. 23/7/2016].

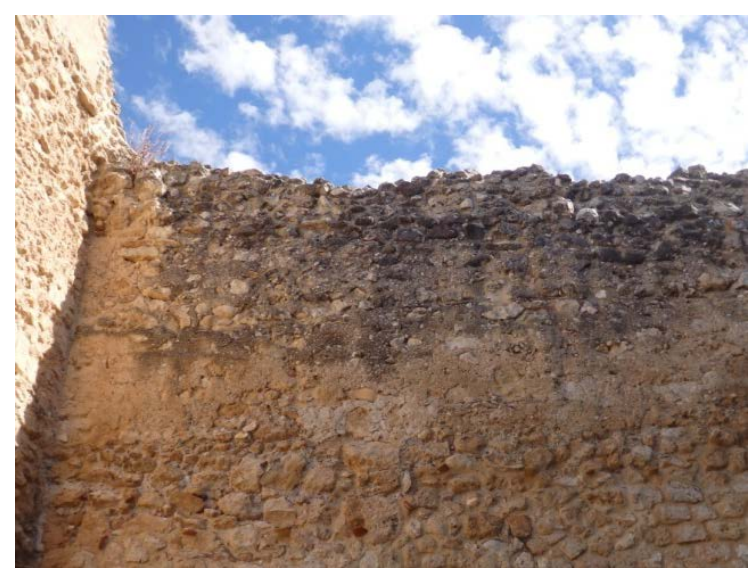

Fig. 5.4.19. Detalle de la parte superior del tramo T1-oeste [A.S.E. 23/7/2016].

Al final de este lienzo se sitúa el denominado torreón del Oeste (T1), de pl anta cuadrada con $5,60 \mathrm{~m}$ de lado en su frente sur y una altura de $14,51 \mathrm{~m}$. Sobresale del lienzo T1-P1 una distancia de 2,70m. Su cara oeste queda en el mismo plano que el 
lienzo que continúa hacia el norte. Las dos esquinas de la torre se resuelven en toda su altura con sillares, contrapeados en la zona superior. En la base, durante una altura de tres metros, se utilizan sillares irregulares, de for mas distintas, elegidos por tamaños para ser colocados formando hiladas de al turas constantes. El aparejo es irregular y poco homogéneo. Sobre esta base, se construye con un aparejo de mampuestos formando hiladas regulares. En la cara sur parece observarse la reconstrucción de parte de la torre, la esquina oeste. Se observa una línea de división desde una altura de tres metros, pasando a la izquierda del hueco visible en el centro, hasta la parte superior de la torre. También se observan reparaciones con nuevas piedras y morteros en la zona inferior al hueco antes mencionado (Fig. 5.4.20).

La cara oeste de la torre T1 no s obresale del lienzo, sino que queda en su mismo plano (Fig. 5.4.21). Este lado muestra un aparejo de piedra muy regular, diferente del visto en la cara sur. En la base se emplean sillares irregulares, pero formando hiladas ordenadas, aunque de di ferentes alturas. Sobre esta base, se construye un sillarejo ordenado y regular similar al encontrado en la parte central del tramo P1-T1. Esta regularidad parece indicar que se trata de partes reparadas. Este lienzo mantiene esta configuración durante $20 \mathrm{~m}$ hacia el norte. En ese punto se observa una división vertical en el lienzo, que continúa hacia el norte con la misma configuración que se desdibuja poco a poco quedando en un sillarejo regular. En todo este tramo se ve como la muralla se apoya sobre la roca, visible en algunos puntos.

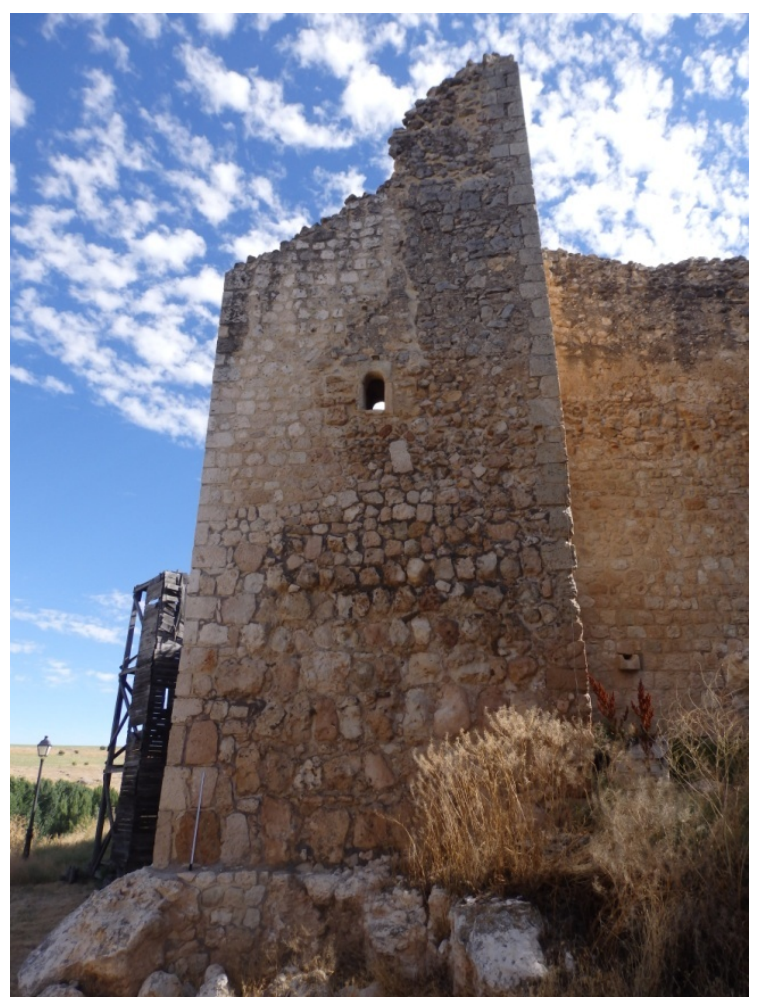

Fig. 5.4.20. Alzado sur de la torre del Oeste [A.S.E. 23/7/2016].

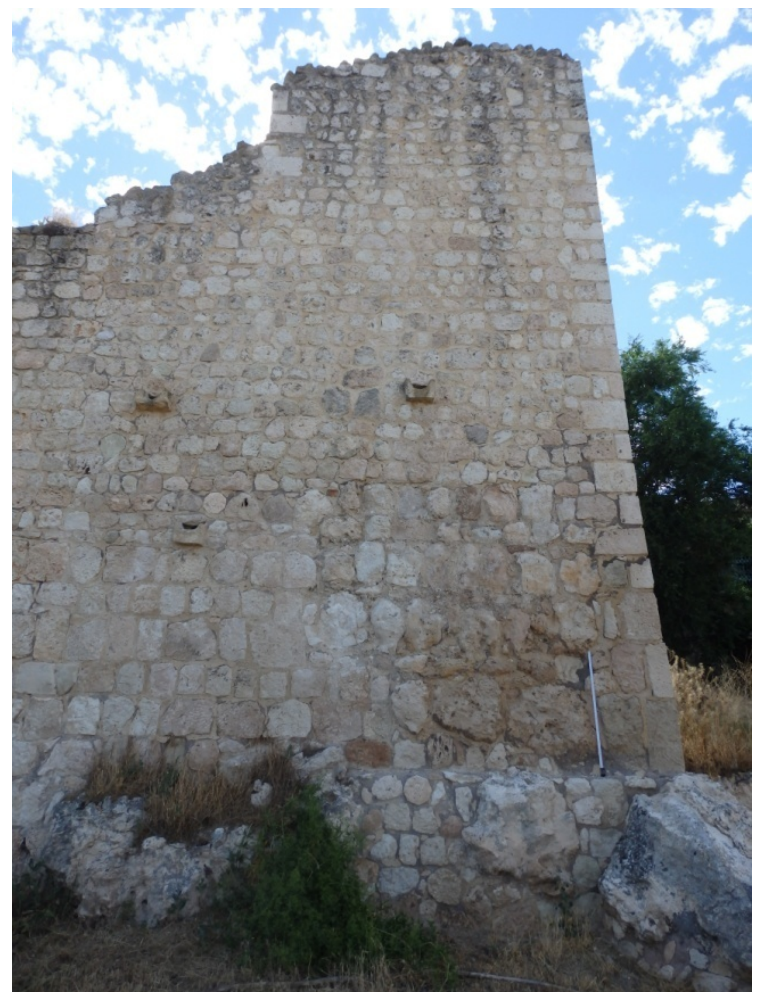

Fig. 5.4.21. Alzado oeste de la torre del Oeste [A.S.E. 23/7/2016]. 
Nuevos restos de muralla se ven en el lienzo L1, siguiendo en dirección norte. En este punto se observa un muro al que se ha adosado por el interior una edificación (Fig. 5.4.22, Fig. 5.4.23). Se construye con tapia de mampostería, las marcas del encofrado se encuentran desdibujadas, pero son visibles. En el punto más alto del muro, se pueden contar cuatro hiladas de tapia. Es visible algún mechinal aislado, construido con un grupo de mampuestos.

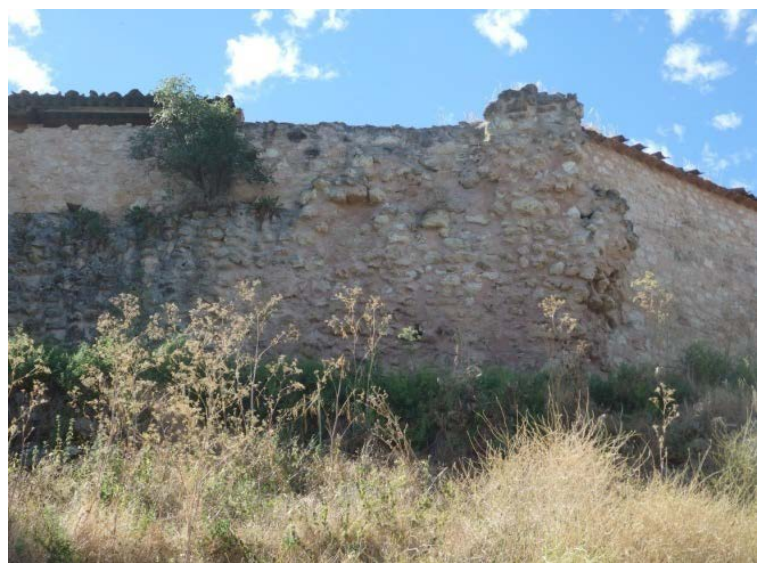

Fig. 5.4.22. Restos L1.2 en la zona noreste [A.S.E. 23/7/2016].

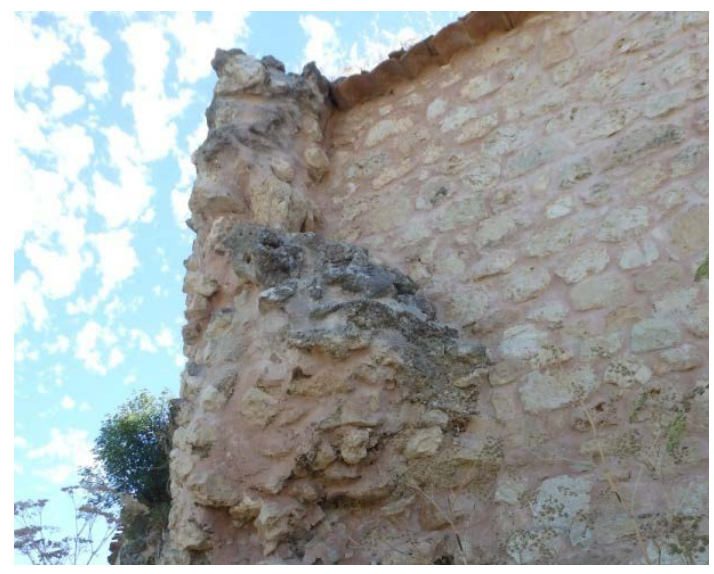

Fig. 5.4.23. Restos L1.2 en la zona noreste [A.S.E. 23/7/2016].

A continuación es visible un tramo que muestra cómo la muralla ha sido modificada con el tiempo por las viviendas de la villa (Fig. 5.4.24). En el tramo M1 se pueden ver muros construidos con un apar ejo de $\mathrm{m}$ ampuestos. Sus bases son ciegas y habitualmente sólo en I a parte superior se abren huecos. Son visibles divisiones verticales que se corresponden con el límite de las parcelas. Estos muros han sido profundamente modificados, con reparaciones y con reconstrucciones. Es posible que las piedras empleadas hayan pertenecido a la muralla, pero el muro se ha transformado de forma intensa, de manera que no es posible identificar soluciones constructivas concretas, aparte de un aparejo de mampostería, el empleo de sillares aislados y la presencia de alguna marca de tapia, difícilmente reconocible. La ausencia de continuidad, marcada por los límites descritos coincidentes con las parcelas, resta autenticidad a estos muros. En la base de algunos de estos muros se pueden apreciar zócalos, o zonas que presentan discontinuidades, sobre las que se continúa construyendo el muro. Estos zócalos podrían constituir restos de $\mathrm{m}$ uralla que s e aprovechan como base para el muro.

Casi a la altura de la puerta del Barrio (P2) se sitúan unos restos que conforman un muro cercano a los $12 \mathrm{~m}$ de longitud (Fig. 5.4.25). Este muro se construye con piedras de tamaño medio e irregulares. Aunque el muro está en mal estado de conservación, es posible identificar lo que par ecen hiladas de tapia. Se observa algún mechinal aislado. 


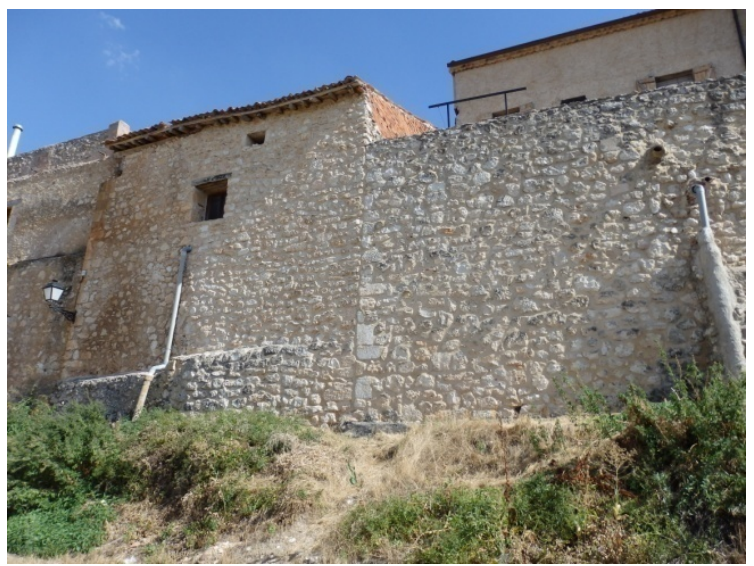

Fig. 5.4.24. Parte del tramo modificado P2suroeste. Se observan divisiones verticales por parcelas. También es visible una base diferenciada a la izquierda [A.S.E. 3/9/2014]

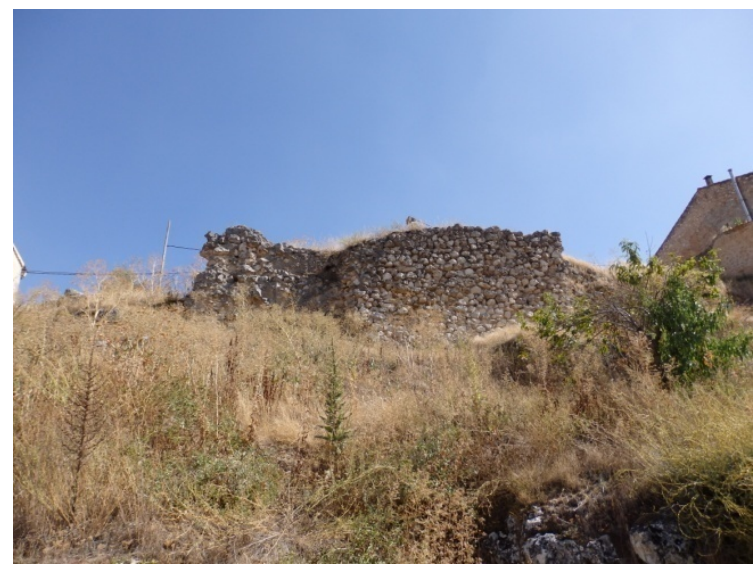

Fig. 5.4.25. Restos del tramo L1.6 [A.S.E. 3/9/2014]

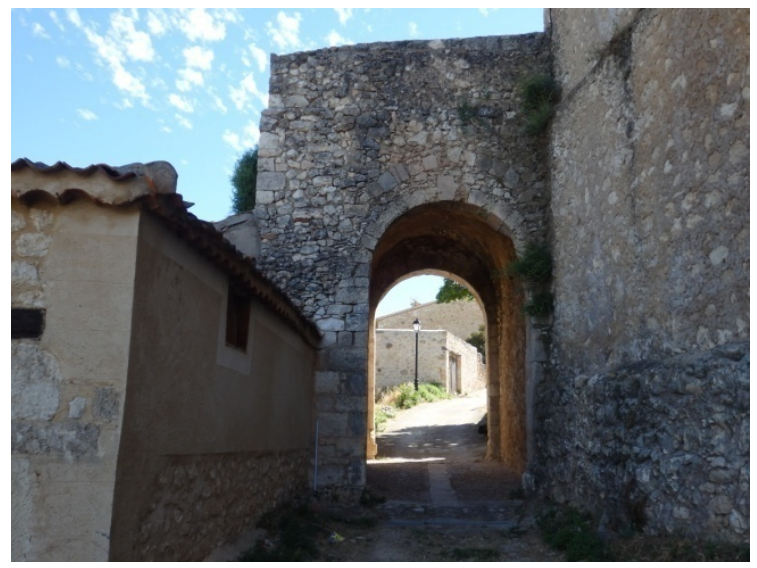

Fig. 5.4.26. Alzado exterior de la puerta del Barrio [A.S.E. 23/7/2016].

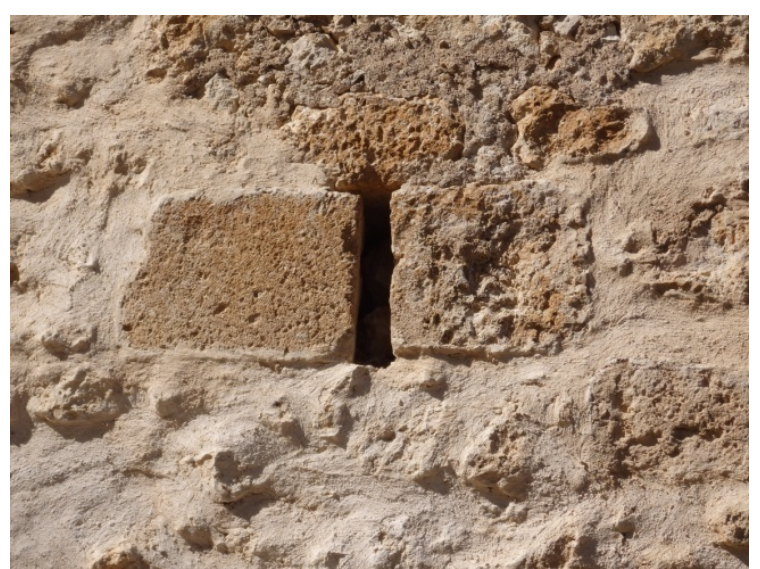

Fig. 5.4.28. Saetera visible en el edificio junto a la puerta del Barrio, visible desde el interior del recinto [A.S.E. 23/7/2016].

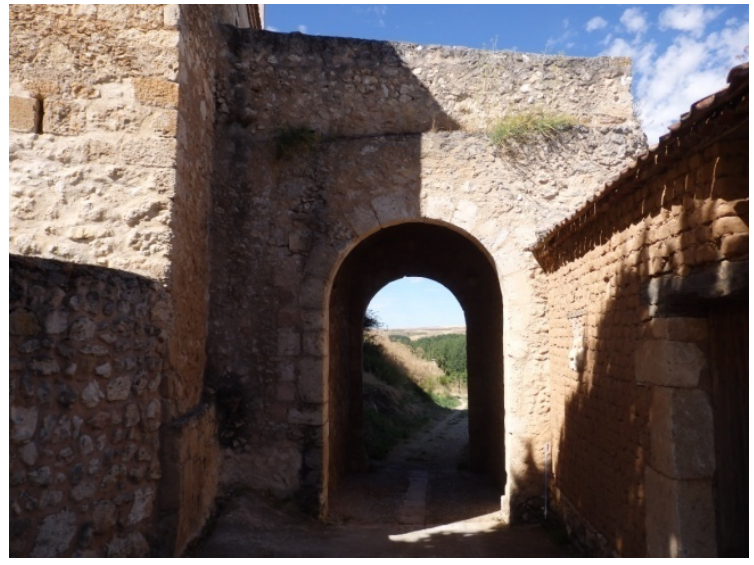

Fig. 5.4.27. Alzado interior de la puerta del Barrio [A.S.E. 23/7/2016].

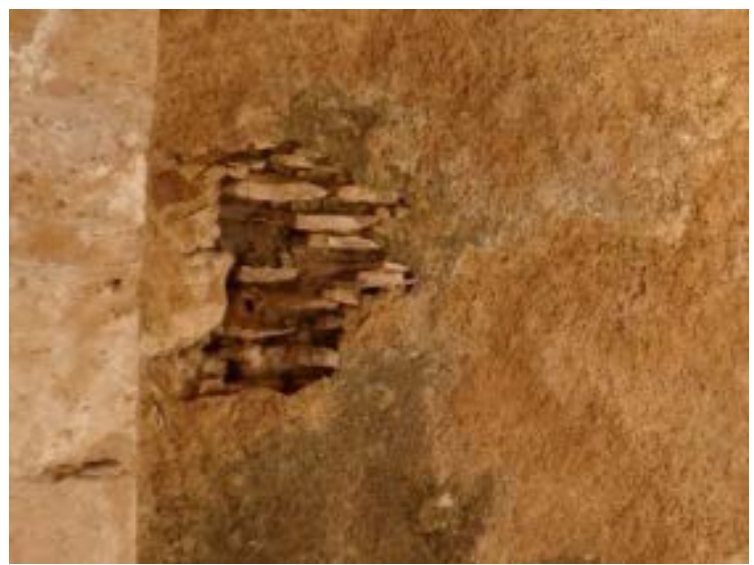

Fig. 5.4.29. Detalle de la bóveda de la puerta del Barrio [A.S.E. 23/7/2016]. 
La puerta del Barrio se sitúa en sentido perpendicular con respecto a la dirección del lienzo. En su alzado exterior (Fig. 5.4.26), esta puerta muestra un arco de medio punto construido con sillería en los estribos. El arco se realiza también con sillares, que tienen una proporción cuadrada. La clave sobresale por encima del resto, con una forma alargada en sentido vertical. Sobre el arco, se dibuja un segundo arco en el paramento, con sillares similares a los empleados en el arco inferior. Sobre el acceso se ve un frente recto sin decoración y sin elementos adelantados respecto del plano de acceso. La franja superior se encuentra ligeramente retrasada con respecto al plano de acceso. El acceso se produce bajo una bóveda, superior en altura a la altura del arco, posiblemente correspondiente con la altura del arco embebido en el frente, anteriormente descrito. Un desconchón del revestimiento de I a bóveda permite apreciar cómo se construye (Fig. 5.4.29). Se observan piedras planas, finas y alargadas, colocadas como dovelas formando la bóveda. El alzado interior de la puerta (Fig. 5.4.27) es similar al exterior, se observa un arco de medio punto conformado con dovelas de piedra, de proporción cuadrada. Los estribos se construyen con piedras similares. El frente es recto y homogéneo, sin decoración ni elementos adelantados respecto del plano de acceso. Se observa nuevamente una franja superior ligeramente retrasada respecto del plano de acceso. Junto a la puerta, en el interior, se sitúa un edificio de muros de pi edra. Es visible en uno des us paramentos una s aetera realizada mediante la separación de dos piedras regulares (Fig. 5.4.27 izquierda, Fig. 5.4.28).

Desde la puerta del Barrio hasta la torre del castillo, en el extremo norte, la línea del recorrido de muralla se sitúa en los límites traseros de las parcelas. Se observan muros de piedra irregular, de tamaño medio, con aparejos desordenados (Fig. 5.4.30). En algunos casos se observan hiladas más regulares (Fig. 5.4.31). Estos muros conforman las fachadas traseras de las parcelas urbanas; en muchos casos, aunque presentan un aspecto defensivo (pétreo, sin huecos) parecen encontrarse profundamente modificados y reparados. En algunos casos se observan muros que tienen un aspecto moderno, o han sido reparados de forma muy intensa (Fig. 5.4.32, Fig. 5.4.33). En otros casos, se observan líneas verticales en los muros coincidentes con las parcelas y cambios en el aspecto del aparejo en cada parcela.

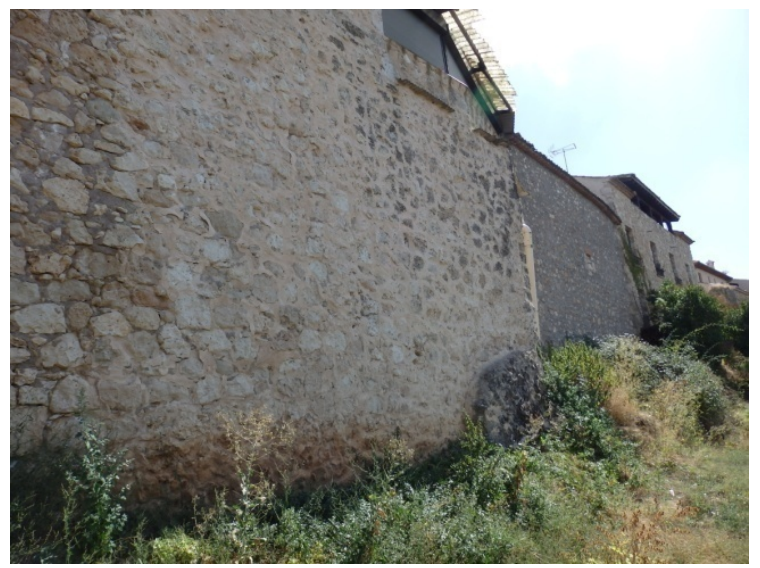

Fig. 5.4.30. Base de muro en el tramo P2-T2 [A.S.E. 3/9/2014].

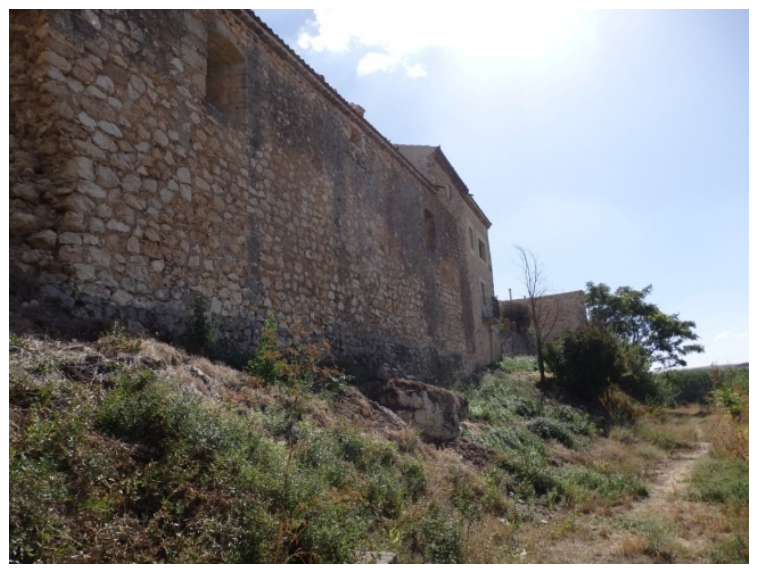

Fig. 5.4.31. Muro en el tramo P2-T2 [A.S.E. 3/9/2014]. 


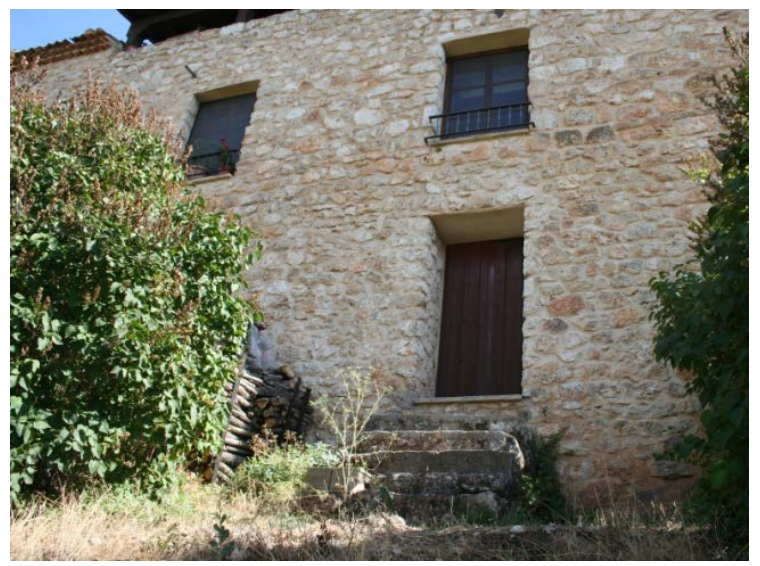

Fig. 5.4.32. Vivienda nueva en el trazado de la muralla [J.L.S.G. 3/9/2014].

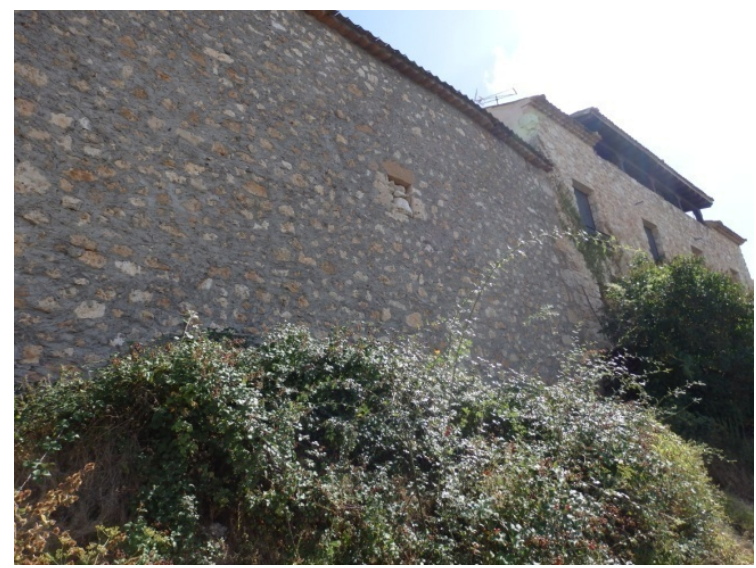

Fig. 5.4.33. Muro de nueva construcción o tal vez reparado de forma muy intensa mediante la aplicación de mortero de cemento.

Junto a la torreT2 se sitúa un tramo que parece haber sufrido menos reparaciones que las observadas en las parcelas anteriores. En esta zona, son claramente visibles hiladas de tapia en el muro (Fig. 5.4.35). Se pueden ver dos hiladas de tapia y sobre estas otras dos menos claras, de alturas incompletas. Estas tapias muestran un acabado terroso, sólo en la hilada inferior son visibles las piedras empleadas en su construcción. Se pueden identificar algunos mechinales en las bases de las tapias, aunque son escasos. En algunos puntos el muro se ha derruido y es visible su interior, de piedras irregulares y tierra. También se observan reparaciones en la base de este muro, con aplicaciones de mortero de cemento y de nuevos mampuestos.

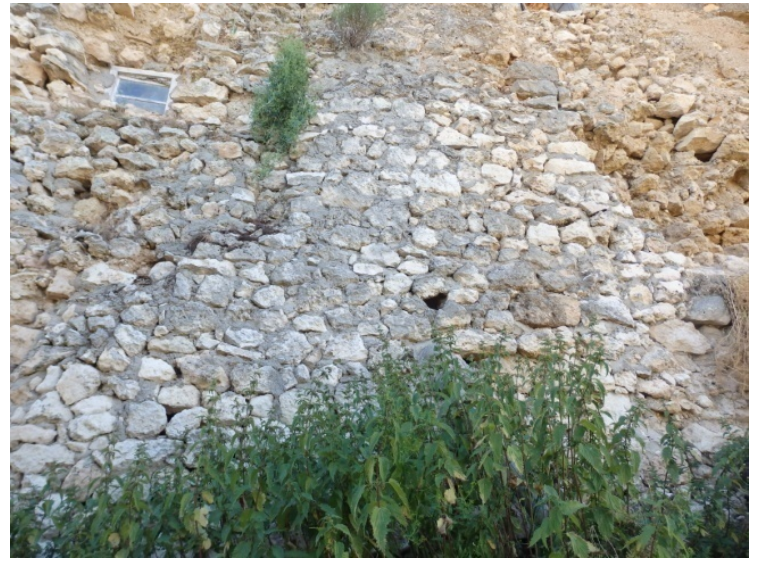

Fig. 5.4.34. Base del muro T2-suroeste [A.S.E. $23 / 7 / 2016]$

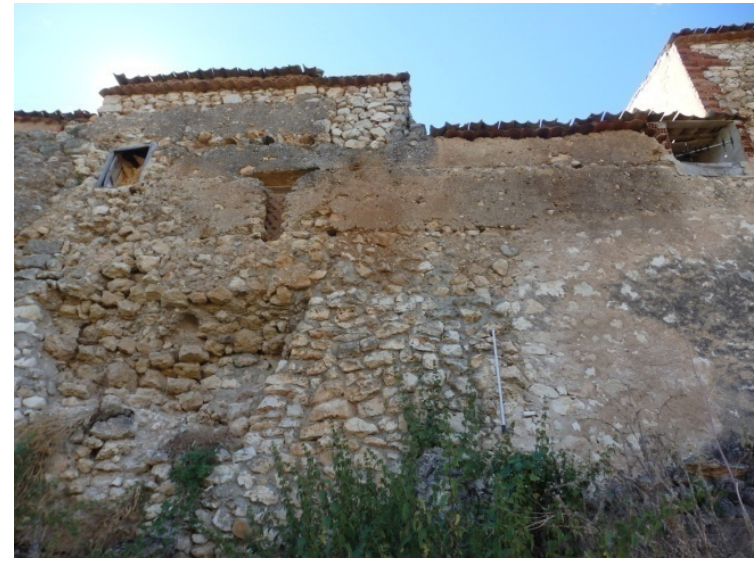

Fig. 5.4.35. Hiladas de tapia visibles en el tramo T2-suroeste [A.S.E. 23/7/2016]

A continuación se sitúa la torre T2, que como se ha comentado anteriormente estaría relacionada con la posición del castillo. Quedan tan solo los muros sureste y suroeste, formando un ángulo recto. Los bordes de es tos muros parecen haberse rematado recientemente a lo largo de toda s u altura, a modo de consolidación. La anchura del muro suroeste en la base es cercana a los $3,50 \mathrm{~m}$. En el interior de la torre es visible el empleo de tapia de mampostería (Fig. 5.4.36). Se pueden identificar 9 tapias de altura 
desde el interior de la torre, con una al tura de 1,00m. Las fachadas sureste (Fig. 5.4.39) y suroeste (Fig. 5.4.38) muestran hacia el exterior una coronación de sillarejo sobre los muros de tapia. La esquina se resuelve con sillares contrapeados. En el alzado suroeste son visibles las hiladas de tapia empleadas en la construcción. Se pueden identificar dos mechinales en una de I as hiladas, cercanos entre sí, situados una distancia de $75 \mathrm{~cm}$ aproximadamente. La sección es rectangular, de proporción cercana al cuadrado, con pequeño tamaño y de aproximadamente $3 \times 5 \mathrm{~cm}$ de ancho.

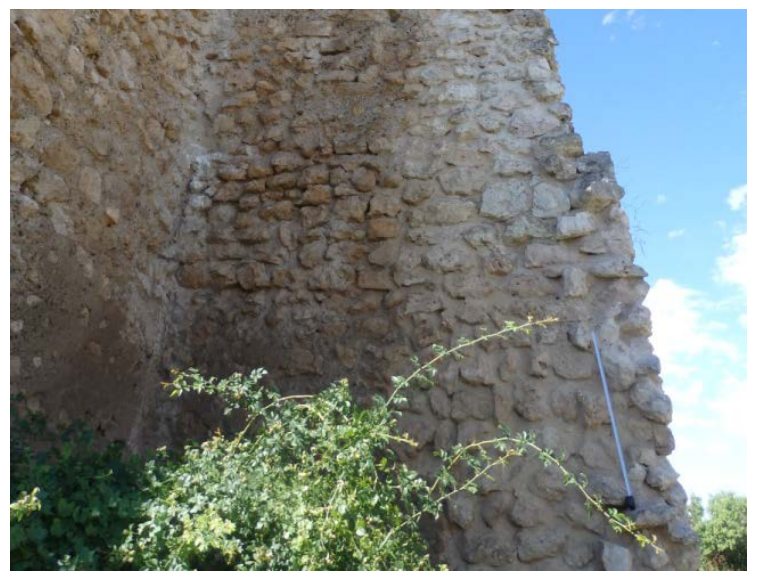

Fig. 5.4.36. Interior de la torre T2 [A.S.E. 23/7/2016].

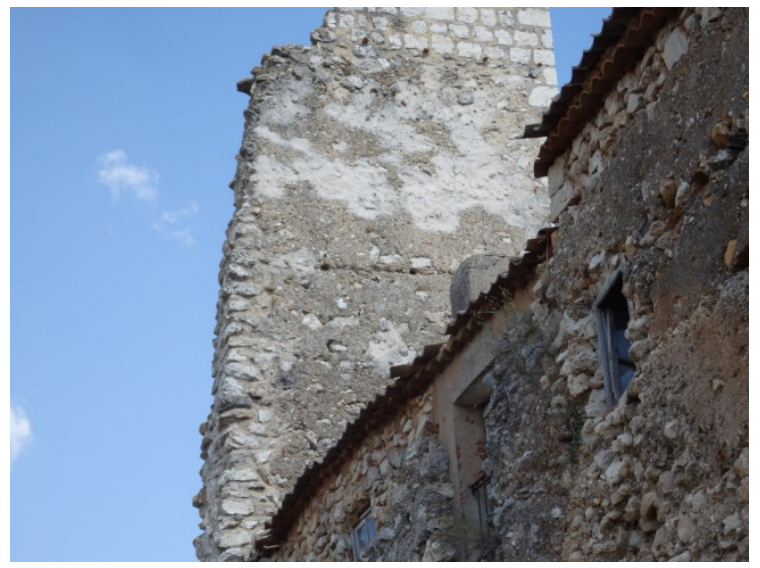

Fig. 5.4.38. Alzado suroeste de T2 desde el exterior [A.S.E. 23/7/2016].

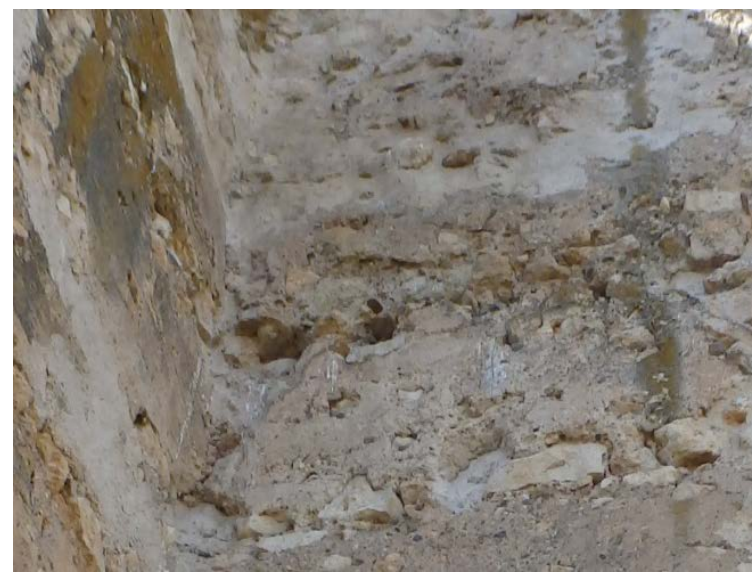

Fig. 5.4.37. Posibles mechinales en la base de la tapia [A.S.E. 23/7/2016]

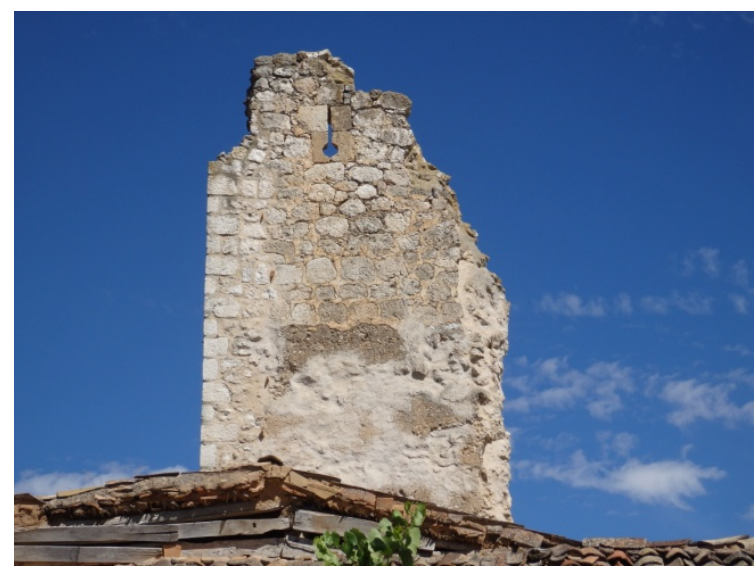

Fig. 5.4.39. Cara sureste de la torre T2 [A.S.E. 23/7/2016].

La parte sureste del recinto presenta en su extremo norte los restos de un muro que parece constituir un resto de muralla medieval (Fig. 5.4.40, Fig. 5.4.41). Se construye sobre la roca y tiene una altura que está superada por las nuevas edificaciones que sobresalen en segundo plano. Se observa la pérdida de material en la base. Tiendo en cuenta la altura de la pérdida de piedras, que se sitúa al alcance de la mano, es posible que la pérdida de material se deba a la retirada de piedras para su reutilización en nuevas edificaciones. Otros casos similares se han dado en ejemplos de patrimonio arquitectónico, donde se conocen testimonios que confirman la reutilización de piedras en las nuevas edificaciones. El deterioro del muro es otra razón de pérdida de 
material. El paramento visible muestra el empleo de piedras de tam año medio, irregulares, pero colocadas con orden. Las zonas donde se han perdido estas piedras más superficiales muestran un agl omerado de pi edras pequeñas, tierra y probablemente cal. Es muy posible que este muro se haya construido con la técnica del tapial, aunque las marcas características no son visibles, a excepción de una línea horizontal que podría marcar una hilada. Es llamativo que las viviendas que se adosan por el interior construyan un nuevo muro adosado, cuando lo habitual es aprovechar la existencia de un muro para construir directamente los muros perpendiculares al mismo.

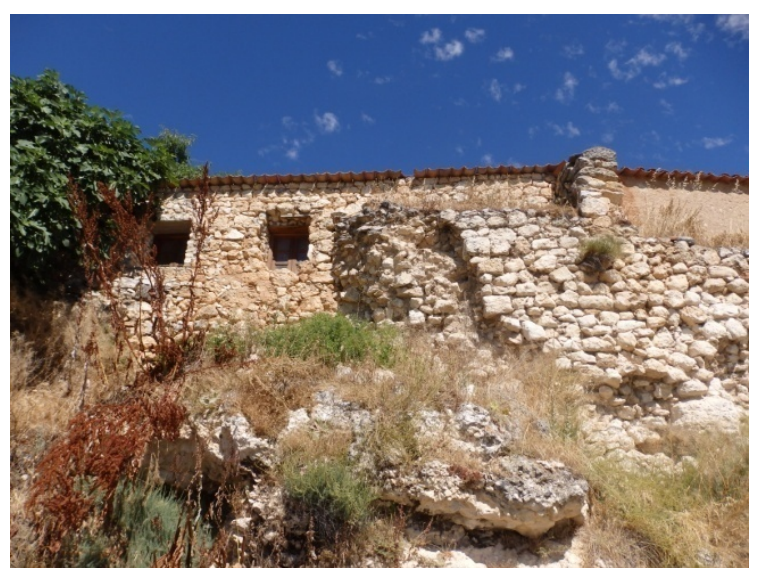

Fig. 5.4.40. Restos T3-noreste [A.S.E. 23/7/2016].

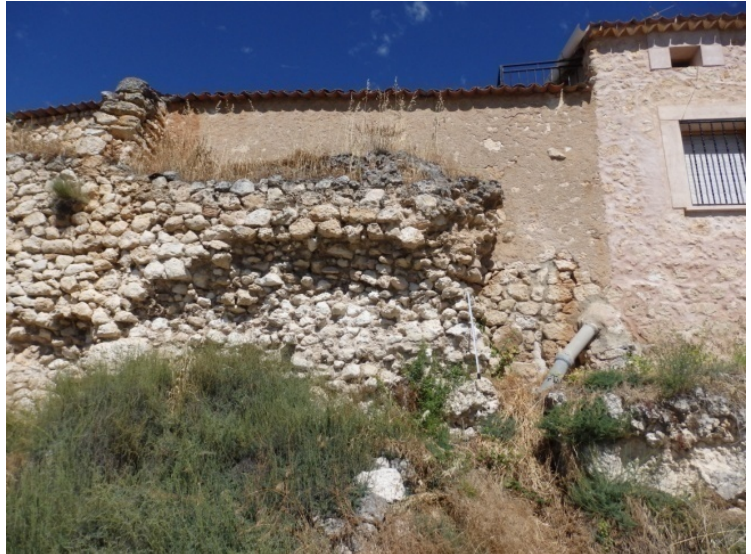

Fig. 5.4.41. Restos T3-noreste [A.S.E. 23/7/2016].

Desde este punto hac ia el suroeste, se suceden los cerramientos de las distintas parcelas cuyos límites traseros coinciden con el trazado de la muralla. De nuevo se ven aparejos de pi edra irregulares, con tramos que c oinciden con los límites de parcelas, con nuevos aparejos en cada parcela (Fig. 5.4.42). Por estas razones, es difícil identificar estos tramos como restos de muralla original. Es posible que parte de ellos, sus bases o algunas de sus piedras constituyan parte de la muralla original, pero en todo caso se trata de tramos muy modificados y reconstruidos. El punto T3 muestra un quiebro en el trazado de las construcciones actuales, un tacón cuya base muestra un aparejo de pi edras grandes irregulares y una es quina resuelta con sillares contrapeados. Sobre esta base se construye con una fábrica de adobe. Esta base podría tener como origen una torre de la muralla medieval (Fig. 5.4.43), aunque tampoco resulta evidente, puesto que se han producido modificaciones y añadidos que dificultan la interpretación. 


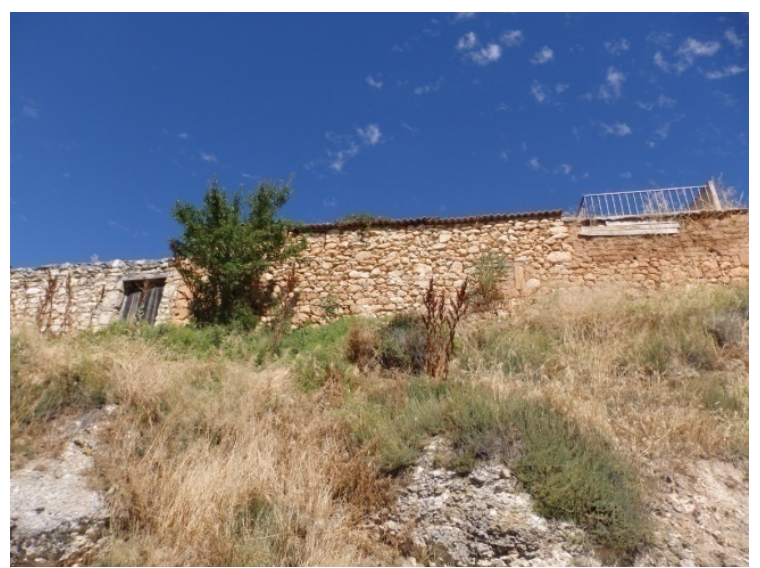

Fig. 5.4.42. Muro que muestra distintos aparejos en función de las parcelas [A.S.E. 23/7/2016]

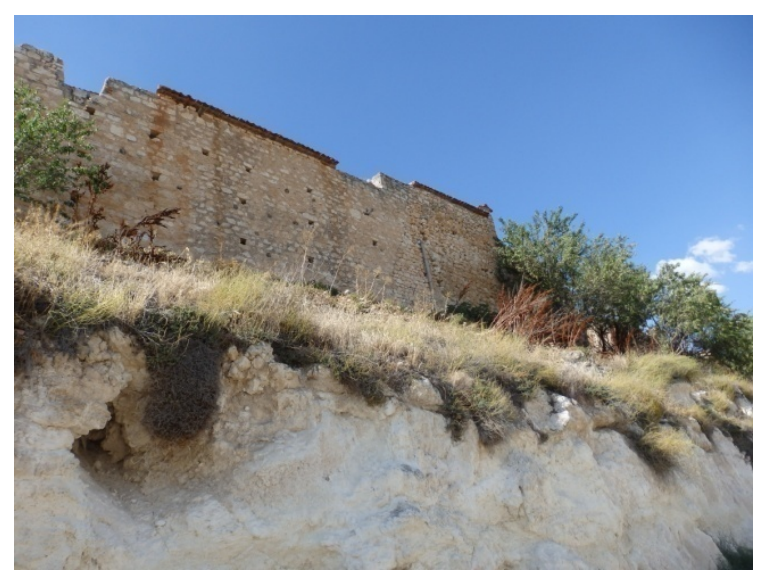

Fig. 5.4.44. Parte reconstruida [A.S.E. 23/7/2016].

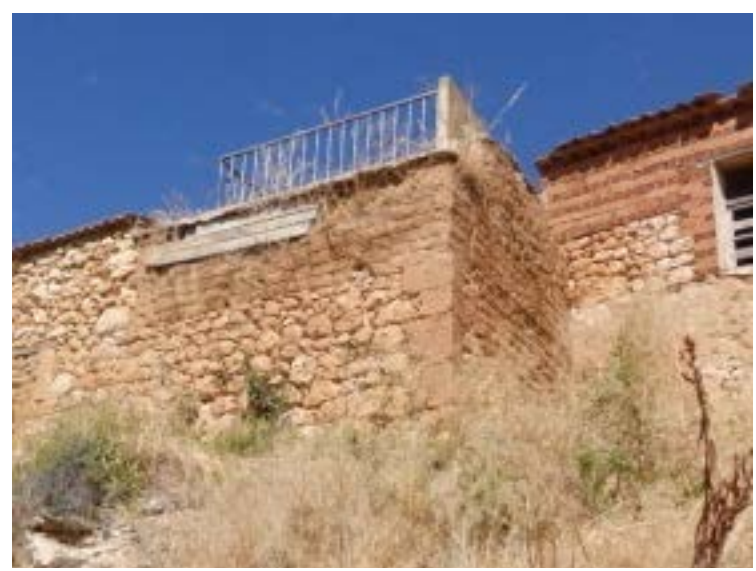

Fig. 5.4.43. Esquina que podría ser una antigua torre [A.S.E. 23/7/2016].

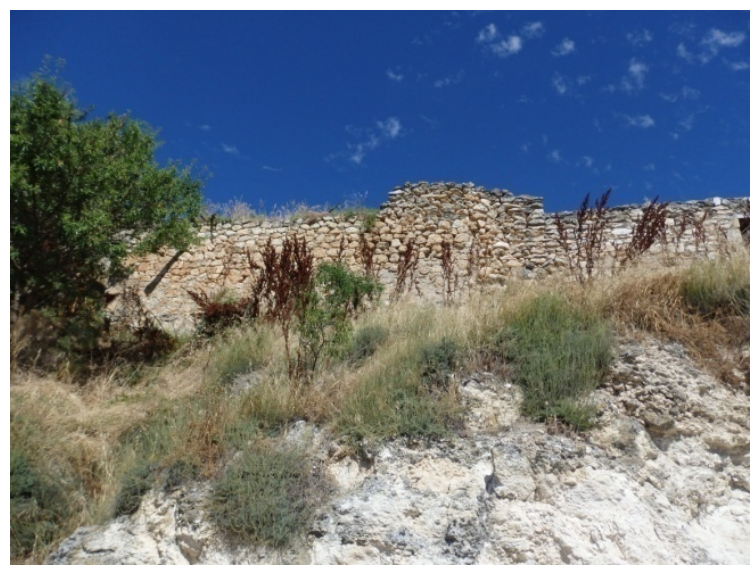

Fig. 5.4.45. Muro en el tramo T3-L3 [A.S.E. 23/7/2016]

Algunas parcelas muestran reconstrucciones completas de los muros (Fig. 5.4.44), con muros con sillarejo de hiladas muy rectas y regulares. En otras zonas se conservan muros de mampostería seca que no han sido recrecidos con posterioridad por la construcción de nuevas viviendas (Fig. 5.4.45).

En la zona cercana a la iglesia de Santa María del Castillo se sitúan los tramos L3 y L4, donde se conservan restos que parecen originales. L4 m uestra una ba se de mampuestos irregulares y de pequeño tamaño, que han sido reparados a través de la aplicación de nuevos morteros, pero que conservan un carácter que recuerda a la tapia de mampostería. Sobre estos restos y en su lateral izquierdo se ha construido un muro nuevo con piedra de tamaño medio, ordenada en hiladas rectas (Fig. 5.4.46, Fig. 5.4.47). 


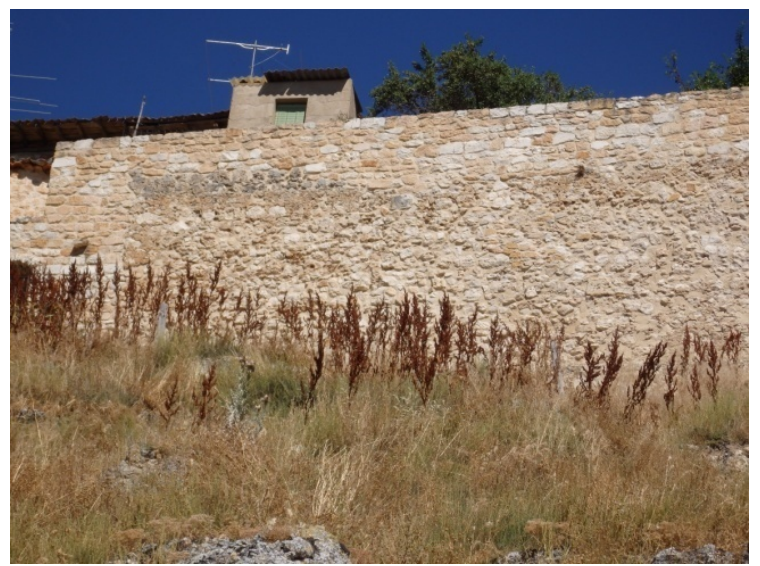

Fig. 5.4.46. Base de muro restaurada que podría tratarse de muralla medieval [A.S.E. 23/7/2016]

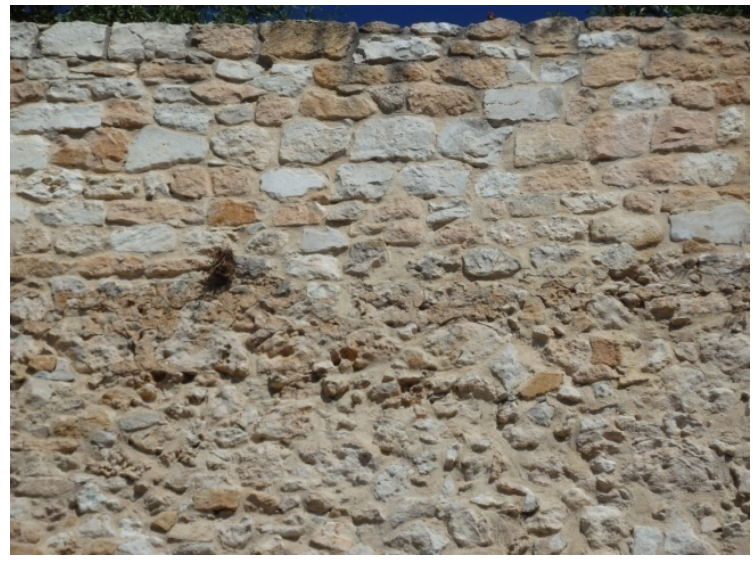

Fig. 5.4.47. Detalle de la parte nueva en sillarejo que se construye sobre una base existente, probablemente de tapia [A.S.E. 23/7/2016]

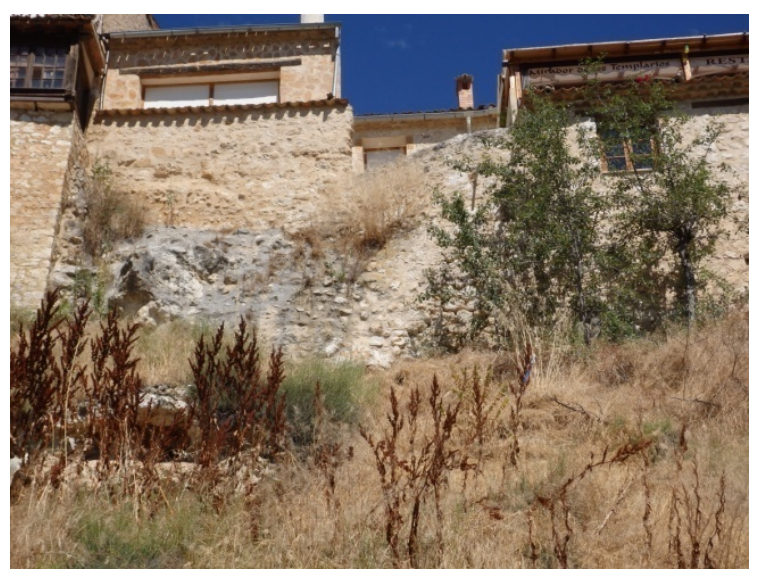

Fig. 5.4.48. Restos de muralla medieval en las bases de los muros de la zona sureste [A.S.E. 23/7/2016].

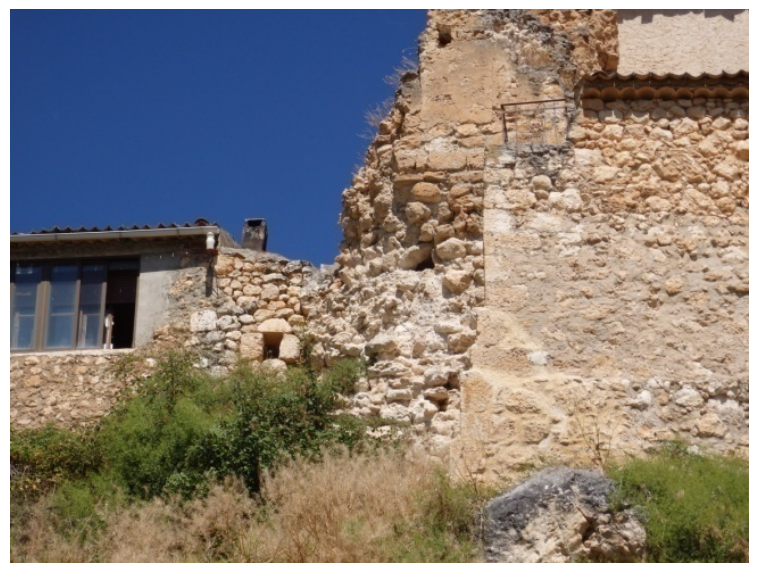

Fig. 5.4.50. Esquina sur del recinto [A.S.E. 23/7/2016].

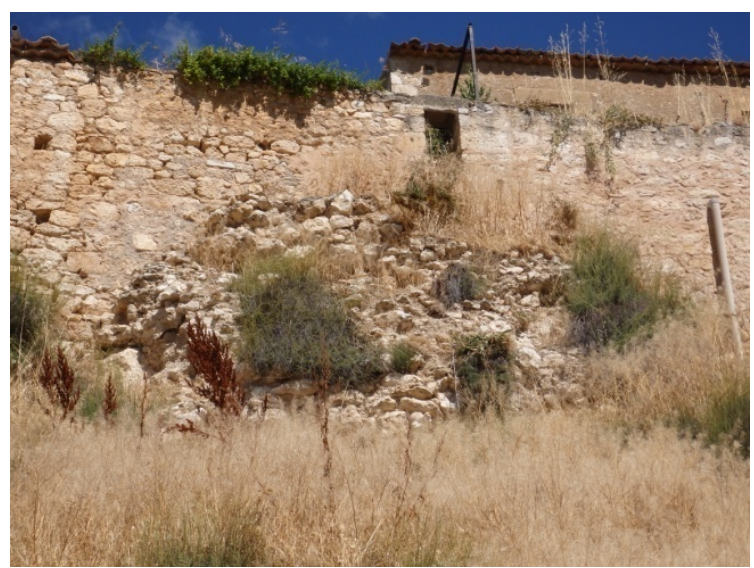

Fig. 5.4.49. Restos de muralla medieval en las bases de los muros de la zona sureste [A.S.E. 23/7/2016].

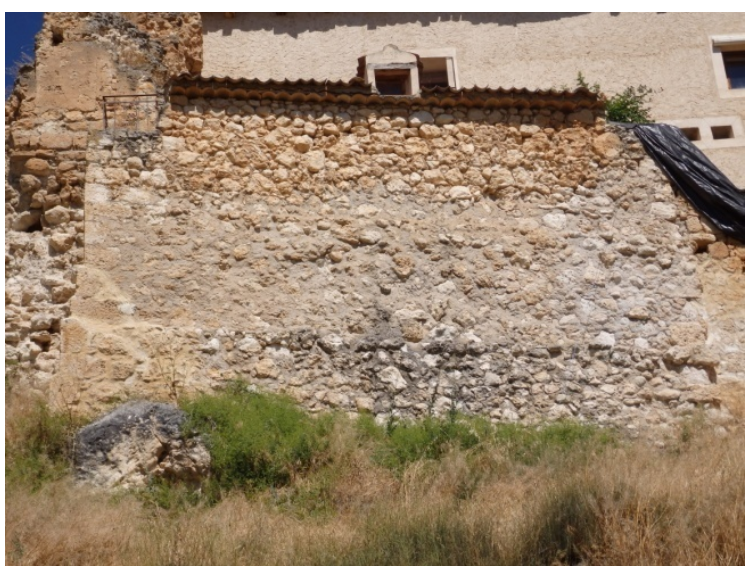

Fig. 5.4.51. Esquina sur del recinto, posible torre T4 [A.S.E. 23/7/2016]. 
En la zona cercana a la iglesia de San Miguel se sitúan otros restos, L5 y L6, que se conservan en las bases de los muros. Se trata de restos desdibujados, donde es difícil reconocer formas y técnicas constructivas, pero que pueden identificarse como restos medievales (Fig. 5.4.48, Fig. 5.4.49).

En el extremo sur del recinto, se conservan restos de una esquina del recinto, tal vez una torre (Fig. 5.4.50, Fig. 5.4.51). Se observa una esquina formada con sillares que es escalonan en la parte inferior y se colocan contrapeados. En la base de e sta esquina que recuerda a una tor re, se observan restos que podrían constituir parte de la muralla medieval. Se completa en la zona superior con una mampostería de piedra diferente, al igual que en el lado derecho, donde se construye un muro con base de sillares y sillarejo regular.

\subsubsection{Características principales de los elementos descritos}

Las tablas a continuación recogen los elementos descritos y los ordenan, indicando su nomenclatura y características. En el caso de las torres y puertas (Tabla 5.4.1), se indica qué nombre asociado tienen, y si las torres integran una puerta o no. Se menciona el tipo de torre, la sección así como sus dimensiones. Se trata de definir la relación de las torres con los lienzos donde se integran y también si se observa un zócalo o una diferenciación de material o forma en la base. Se observan un total de seis torres, de las cuales tres de ellas se consideran solo de naturaleza probable, dados los escasos restos. Las plantas de todas las torres son de tipo rectangular y sus dimensiones oscilan entre los $3 \mathrm{~m}$ y $5 \mathrm{~m}$.

Tabla 5.4.1. Características y dimensiones de torres y su relación con las puertas. Fuente: Elaboración propia.

\begin{tabular}{|c|c|c|c|c|c|c|c|c|}
\hline 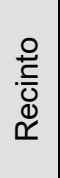 & $\begin{array}{l}\stackrel{\infty}{\varrho} \\
\stackrel{0}{0} \\
\vdash\end{array}$ & $\begin{array}{l}\infty \\
\frac{\pi}{2} \\
\frac{1}{2} \\
0\end{array}$ & $\begin{array}{l}\text { Nombre } \\
\text { asociado }\end{array}$ & $\begin{array}{c}\text { Tipo de } \\
\text { puerta / torre }\end{array}$ & $\begin{array}{l}\text { Sección de } \\
\text { torre }\end{array}$ & $\begin{array}{c}\text { Dimensiones } \\
\text { torres } \\
\text { (Diámetro } \varnothing, \\
\text { Fondo } \mathrm{F}, \\
\text { Ancho A) }\end{array}$ & $\begin{array}{l}\text { Relación con } \\
\text { lienzo }\end{array}$ & Zócalo/Base \\
\hline \multirow{8}{*}{ R1 } & T1 & & $\begin{array}{l}\text { Torreón } \\
\text { del Oeste }\end{array}$ & En esquina & Rectangular & $\begin{array}{l}\text { A5,16x } \\
\text { F2,70m }\end{array}$ & Integrado & $\begin{array}{l}\text { Sí, aparejo } \\
\text { singular }\end{array}$ \\
\hline & \multirow{2}{*}{-} & \multirow{2}{*}{ P2 } & \multirow{2}{*}{$\begin{array}{c}\text { Puerta del } \\
\text { Barrio }\end{array}$} & \multirow{2}{*}{$\begin{array}{l}\text { Puerta } \\
\text { perpendicular } \\
\text { a lienzo }\end{array}$} & \multirow[b]{2}{*}{ - } & \multirow[b]{2}{*}{ - } & \multirow[b]{2}{*}{-} & Sí, sillería \\
\hline & & & & & & & & Sí, sillería \\
\hline & T2 & & $\begin{array}{c}\text { Torreón } \\
\text { del Castillo }\end{array}$ & & Rectangular & $\mathrm{A} 3,5 \times \mathrm{F} 3,5 \mathrm{~m}$ & Independiente & No \\
\hline & T3 & & - & Flanqueo & Rectangular & - & Desaparecido & No \\
\hline & $\mathrm{T} 4$ & & - & En esquina & Rectangular & - & Desaparecido & Sí \\
\hline & T5 & \multirow[b]{2}{*}{ P1 } & \multirow{2}{*}{$\begin{array}{l}\text { Puerta de } \\
\text { la Villa }\end{array}$} & \multirow{2}{*}{$\begin{array}{c}\text { Puerta } \\
\text { simétrica, } \\
\text { alineada con } \\
\text { lienzo }\end{array}$} & Rectangular & A5xF3m & Integrado & No \\
\hline & T6 & & & & Rectangular & $\mathrm{A} 5,1 \mathrm{xF} 3 \mathrm{~m}$ & Integrado & No \\
\hline
\end{tabular}

Datos probables. 
La relación de las torres con el lienzo es de tipo integrado mayoritariamente, es decir, no parecen haber sido adosadas con posterioridad, aunque en tr es de los casos el encuentro con el lienzo original ha desaparecido. En cuatro de las torres se observa un zócalo de sillería.

La tabla que recoge los tramos de muralla (Tabla 5.4.2) indica la nomenclatura del tramo, refleja si se ha producido o no una r econstrucción en el mismo, cuál es el estado de conservación y su longitud, detallando si se refiere a z onas existentes, desaparecidas o alteradas.

Tabla 5.4.2. Características y dimensiones de los tramos de muralla. Fuente: Elaboración propia.

\begin{tabular}{|c|c|c|c|c|}
\hline 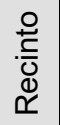 & Tramo & Reconstrucción & Estado & $\begin{array}{c}\text { Longitud (m) } \\
\text { (E Existente / D Desaparecido / A } \\
\text { Alterado-modificado ) }\end{array}$ \\
\hline \multirow{9}{*}{$\mathrm{R} 1$} & P1-T1 & Sí & Buen estado & $\mathrm{E} 41,37$ \\
\hline & T1-L1.2 (incluido) & Sí & Buen estado & $\begin{array}{c}\mathrm{E} 29,34 \text { / D33,36 / E 18,88 / D29,83 } \\
\text { / E22,21 }\end{array}$ \\
\hline & L1.2-L1.4 (incluido) & No & $\begin{array}{c}\text { Restos } \\
\text { intermitentes } \\
\end{array}$ & $\begin{array}{c}\text { A 11,66/ D5,97/ E 15,39 / D30,02 / } \\
\text { A21,70 / E8,55 } \\
\end{array}$ \\
\hline & L1.4-P2 & No & $\begin{array}{l}\text { Restos } \\
\text { intermitentes }\end{array}$ & $\begin{array}{c}\mathrm{A} 20,85 / \mathrm{E} 12,91 / \mathrm{A} 70,73 \text { / D6,65 / } \\
\mathrm{E} 14,51 / \mathrm{D} 8,00 / \mathrm{A} 34,39\end{array}$ \\
\hline & P2-T2 & No & $\begin{array}{l}\text { Restos } \\
\text { intermitentes }\end{array}$ & $\begin{array}{c}\mathrm{D} 34,61 \text { / A26,41 / D28,22 / A65,41 } \\
\text { / E22,75 }\end{array}$ \\
\hline & T2-T3 & No & $\begin{array}{c}\text { Restos } \\
\text { intermitentes }\end{array}$ & D 155,73 / E 11,51 / D12,07 \\
\hline & T3-L2.2 (incluido) & No & $\begin{array}{c}\text { Restos } \\
\text { intermitentes }\end{array}$ & $\begin{array}{c}\text { E32,83 / D5,71 / E9,57 / A14,50 / } \\
\text { E30,86 / A42,70 / E5,75 }\end{array}$ \\
\hline & L2.2-L2.6 (incluido) & Sí & $\begin{array}{c}\text { Restos } \\
\text { intermitentes } \\
\end{array}$ & $\begin{array}{c}\text { A38,18 / E23,01 / A174,86 / E15,87 } \\
\text { / A16,87 / E9,43 / A23,31 / E6,12 } \\
\end{array}$ \\
\hline & L2.6-P1 & No & $\begin{array}{c}\text { Restos } \\
\text { intermitentes }\end{array}$ & A16,23 / E10,62 / A18,54 / E23,80 \\
\hline
\end{tabular}

Reconstrucción: implica la construcción de nueva muralla Alterado-modificado: implica la alteración al integrarse en construcciones urbanas Datos probables.

\subsubsection{Análisis constructivo}

\subsubsection{Soluciones constructivas presentes en la muralla}

La tapia de mampostería se emplea en varios puntos del recinto amurallado. En el tramo P1-T1 es visible esta técnica en varios puntos, combinada con otras. En la zona más cercana a la torre T1 se cuentan varias tapias de altura en la zona superior del lienzo. En la parte más próxima a la puerta de la Villa se puede identificar, aunque con mayor dificultad, el empleo de tapia de mampostería (Fig. 5.4.52). Se pueden apreciar las hiladas de tapia, aunque no es fácil identificar todos los límites de las tapias. Se conservan en muchos puntos las marcas de la tablazón con alturas de $25 \mathrm{~cm}$. En la zona noroeste también se encuentra la tapia de mampostería. Los restos L1 tienen al menos dos hiladas de tapia y son visibles los restos de algún mechinal (Fig. 5.4.53). 
En la zona T1-P1, bajo las tapias anteriormente descritas se ve una base de sillarejo (Fig. 5.4.57) de hiladas regulares. Las piedras tienen proporción rectangular y forman hiladas de una altura cercana a los $20 \mathrm{~cm}$. Sillares de mayor tamaño que alcanzan los $40 \mathrm{~cm}$ de altura se ven en las hiladas más bajas. El aparejo de piedra presente en el frente de I a puerta de I a villa tiene una $r$ egularidad creada a par tir de una uniformización de la altura de sus hiladas, y consigue un apar ejo ordenado aunque emplee piedras de forma irregular (Fig. 5.4.56). Esta solución solo es visible en la puerta de la Villa, no se repite en otros puntos del recinto. La torre T1 o la puerta del Barrio presentan sillares en sus bases, sin un orden por hiladas, sino que tiene un aparejo desordenado (Fig. 5.4.54, Fig. 5.4.55).

En los restos encontrados, es habitual la existencia de una base diferenciada a través de una discontinuidad en el plano del muro (Fig. 5.4.58). Es posible que se trate de restos originales restaurados sobre los que se ha construido una nueva edificación, de carácter doméstico. Por otra parte, se observan reparaciones en $\mathrm{m}$ uchos de los lienzos realizadas con mampostería y empleando mortero de cemento (Fig. 5.4.59).

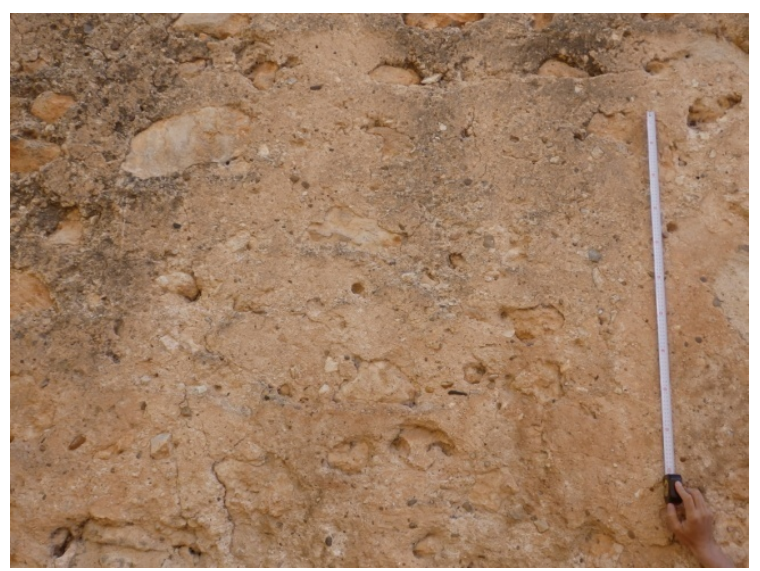

Fig. 5.4.52. Tapia de mampostería en zona P1-T1 [A.S.E. 23/7/2016].

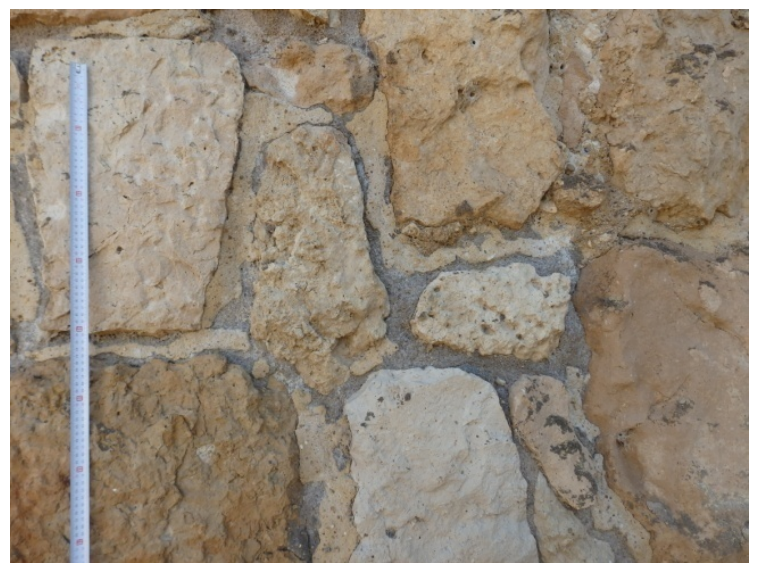

Fig. 5.4.54. Sillería irregular en la base de la cara sur de la torre del Oeste [A.S.E. 23/7/2016]

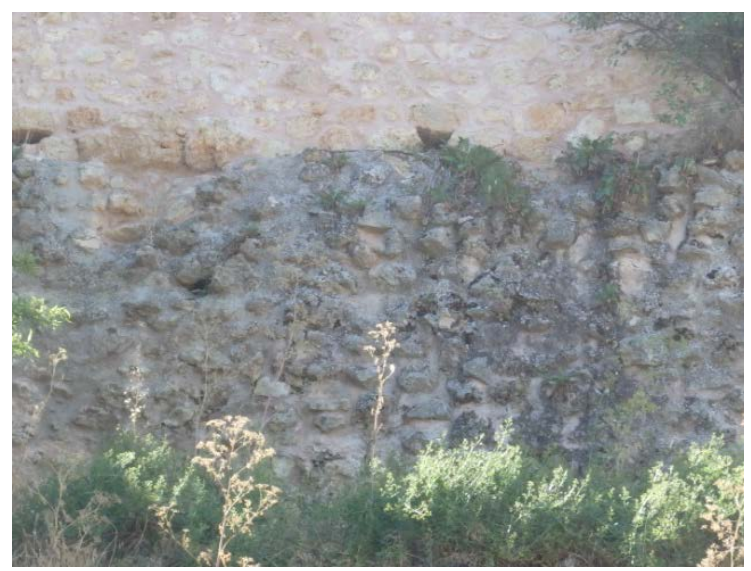

Fig. 5.4.53. Tapia en L1.1 [A.S.E. 23/7/2016].

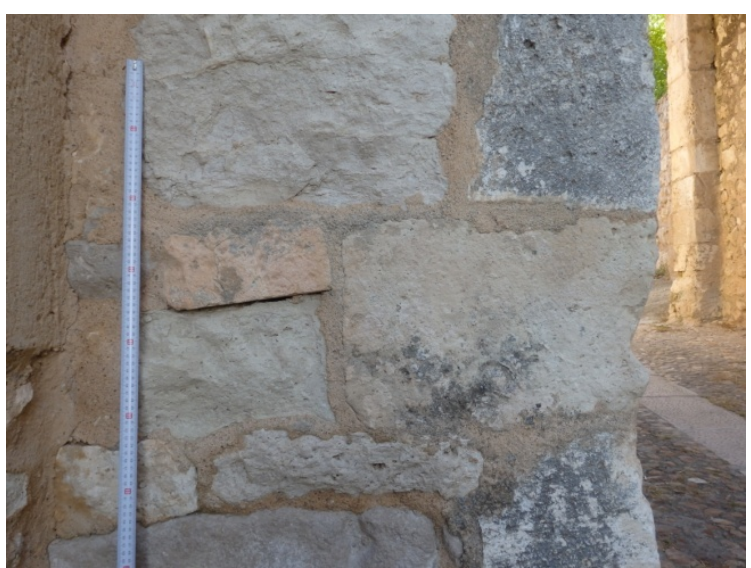

Fig. 5.4.55. Sillería irregular en puerta del Barrio [A.S.E. 23/7/2016], 


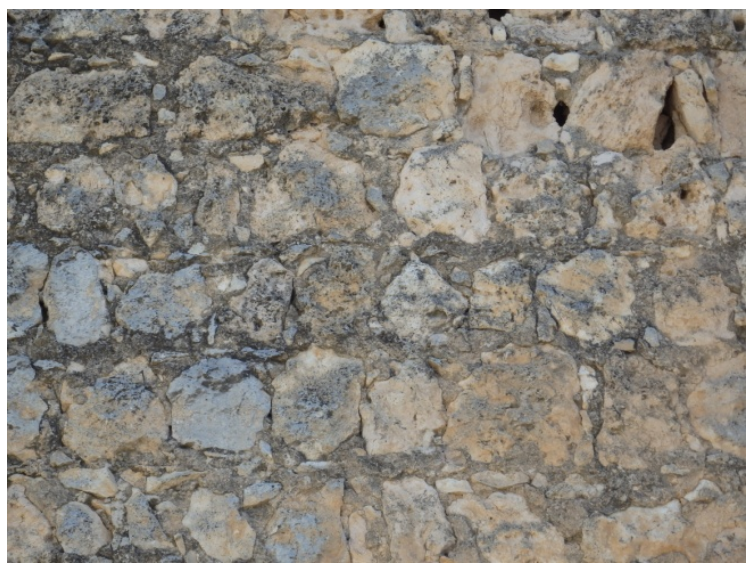

Fig. 5.4.56. Aparejo singular en el frente de la puerta de la Villa [A.S.E. 23/7/2016].

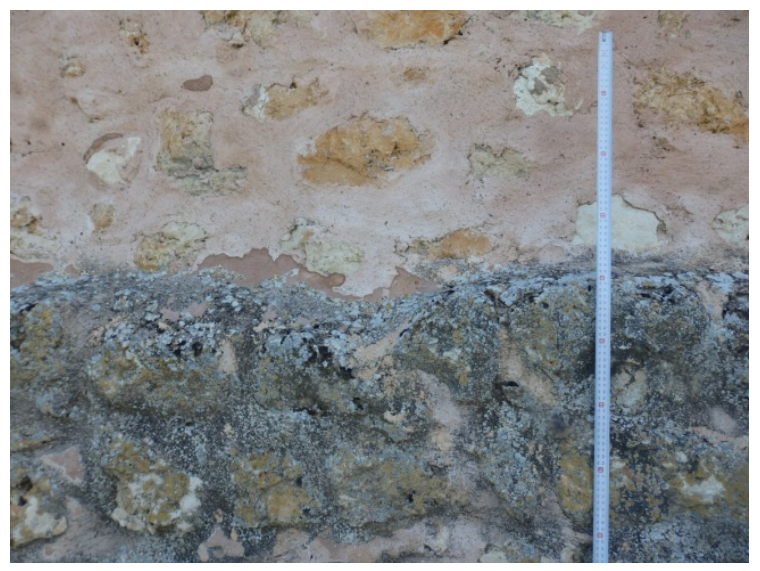

Fig. 5.4.58. Base sobre la que se ha construido [A.S.E. 23/7/2016].

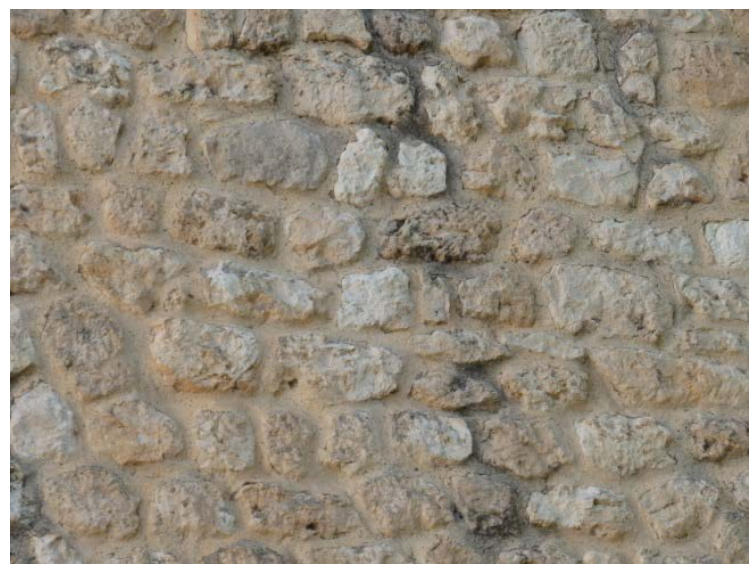

Fig. 5.4.57. Sillarejo en tramo P1-T1 [A.S.E. 23/7/2016].

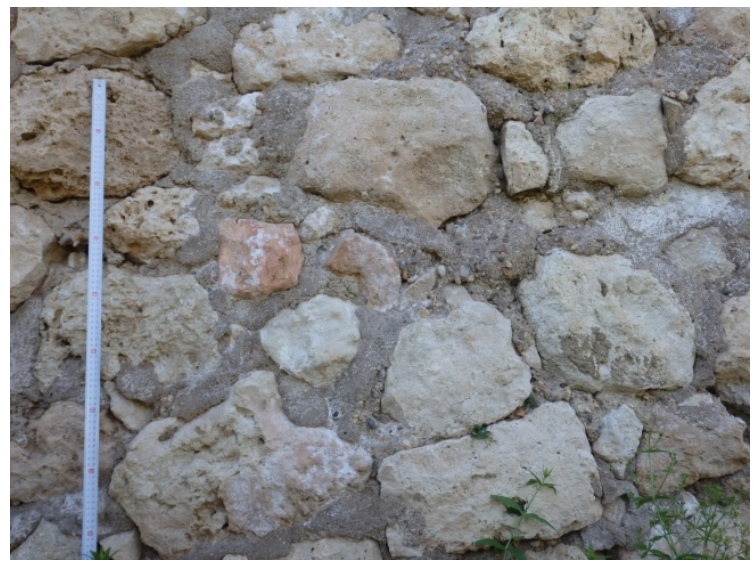

Fig. 5.4.59. Mampostería en zona reparada [A.S.E. 23/7/2016].

En la Tabla 5.4 .3 se detalla dónde se han enc ontrado las distintas soluciones constructivas detectadas. Se observa la presencia de tap ia de mampostería en la mayoría de los lienzos encontrados. En el lienzo de mayor longitud, T1-P1, se observan otras técnicas como la sillería, el sillarejo, vinculadas a la puerta de la Villa y al torreón del Oeste (T1). La mampostería es visible en las reparaciones realizadas a modo de parches en las zonas donde se ha desprendido el material original.

Tabla 5.4.3. Soluciones constructivas localizadas por elementos de la muralla.

\begin{tabular}{|l|l|}
\cline { 2 - 2 } \multicolumn{1}{c|}{} & Elementos donde se encuentra \\
\hline Tapia de mampostería & Tramos P1-T1, L1, L2, L4 (base) \\
\hline Sillería & Torre T1 \\
En esquinas & Puertas P1, P2 \\
En Arcos & Puertas P1, P2, tramo T1-norte. Torre T1 \\
Fábrica & Tramos T1-P1 \\
Sillarejo & Puerta P1 (frente) \\
Aparejo singular & \\
\hline
\end{tabular}




\begin{tabular}{|l|l|}
\hline $\begin{array}{l}\text { Mampostería } \\
\text { Fábrica } \\
\text { Mechinales } \\
\text { Almenas }\end{array}$ & Reparaciones contemporáneas \\
\hline Reconstruido & T2-suroeste \\
\hline
\end{tabular}

Para un análisis constructivo más pormenorizado, se han seleccionado dos tramos del recinto amurallado. El primero de ellos corresponde a Ia zona donde se conservan más restos, el tramo P1-T1. El segundo tramo se corresponde con la zona norte del recinto, junto a la torre $\mathrm{T} 2$.

\subsubsection{Lienzo exterior T1-P1}

El tramo T1-P1 es el tramo de mayor longitud del recinto amurallado y es también el más accesible. Desde la puerta de la Villa (P1) hasta el torreón del Oeste (T1) se conserva un lienzo de una treintena de metros. La parte más cercana a la puerta se construye aproximadamente al mismo nivel, para luego, tras haber recorrido $20 \mathrm{~m}$, iniciarse una caída de terreno de casi $5 \mathrm{~m}$.

La zona más cercana a la puerta de la villa muestra un acabado realizado con mampuestos, sin tratarse de apar ejos regulares. Los mampuestos son visibles en algunas zonas, colocados de forma desordenada y en otras aparecen ocultos tras un acabado de tierra. Algunas marcas horizontales son visibles en zonas del lienzo, lo que permite plantear que este se realiza con tapia de mampostería. Es imposible delimitar una tapia individual, solo se ven líneas de las hiladas y en algunos puntos, las marcas de las tablas empleadas en el tapial.

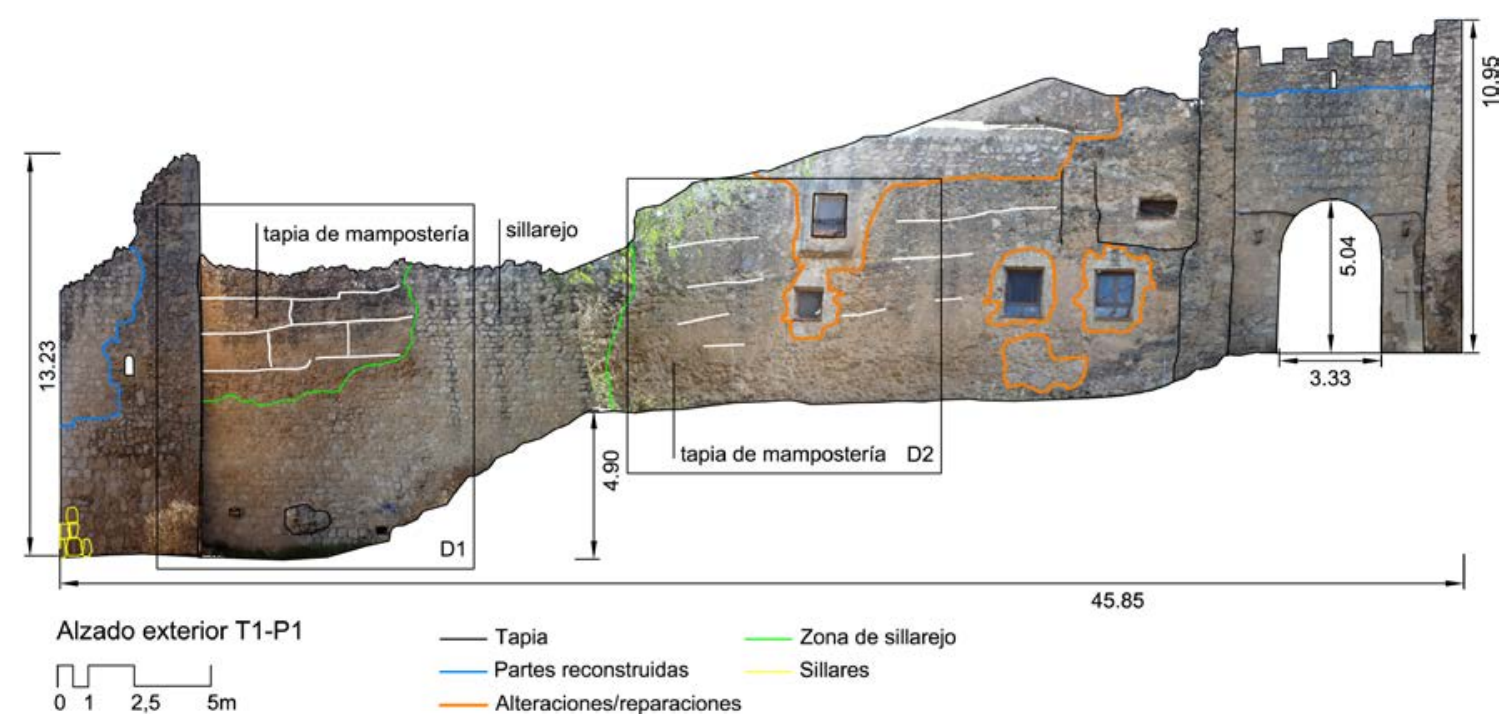

Fig. 5.4.60. Alzado del tramo T1-P1. Fuente: Elaboración propia. 
En la base del muro los mampuestos se observan de for ma más clara, aparecen delimitados más claramente. Las reparaciones de las zonas bajas de los lienzos, muy comunes por la erosión que se produce en estas zonas, suelen realizarse de la misma manera que en un muro de sillería o sillarejo, resaltando los límites de cada piedra. En este caso, las reparaciones suelen resaltar los mampuestos, cuando originalmente se encontraban ocultos. Los huecos que salpican el lienzo están rodeados de una franja de nueva construcción consistente en mampuestos y mortero de cemento. En torno a los dos huecos situados a la izquierda, uno sobre otro, parece haberse producido una reconstrucción completa del muro que incorpora la formación de pendi ente de la cubierta de la construcción que se adosa por el interior. En el detalle D2 (Fig. 5.4.61, derecha) se han marcado las líneas visibles de las hiladas de tapia, aunque son en muchos casos difíciles de identificar.

En la zona más cercana a la torre T1 se produce un cambio en el aspecto que ofrece el paramento. En la base del muro, hasta una altura de $5 \mathrm{~m}$, se ve un apar ejo de piedras relativamente regulares, colocadas en ordenadas hiladas horizontales. Las hiladas más bajas, las dos primeras visibles muestran sillares de gran tamaño, con $40 \mathrm{~cm}$ de altura y $80 \mathrm{~cm}$ de anchura. En seguida se reducen a la mitad, con altura de $25 \mathrm{~cm}$ y anchuras de $45 \mathrm{~cm}$. En esta zona se ve como la roca sobresale del lienzo como un islote y es sorteada por los sillares que la rodean según van construyendo el muro. A partir de $3 \mathrm{~m}$, la forma rectangular de las piedras desaparece y se intenta conservar la regularidad del aparejo a través de hiladas cuidadas. Este aparejo de sillarejo asciende por el desnivel y llega a las zonas superiores en la parte central del tramo. Esta zona central conserva el orden con un aparejo de piedras irregulares, pero de hiladas regulares. Esta zona parece haberse reconstruido para completar un hue co entre dos tramos y conseguir un frente completo.

El detalle D1 (Fig. 5.4.61, izquierda) muestra la parte que colinda con la torre T1. Sobre el aparejo anteriormente descrito se observan tres hiladas de tapia de al tura irregular. En la primera hilada se hace posible identificar dos tapias y una ter cera queda incompleta en su lado derecho. La altura de las tapias oscila entre $110 \mathrm{~cm}$ y $125 \mathrm{~cm}$, con un valor medio de $117,50 \mathrm{~cm}$, que se tomará como anchura representativa de este tramo. Las tapias T1.2 y T2.1 tienen una anchura cercana a $260 \mathrm{~cm}$, que se tomará como anchura representativa. La tapia T1.1 tiene una altura de 1,25m y una anchura de 2,23m. En esta tapia son visibles algunas marcas de la tablazón empleada en el tapial, sobre todo en la parte superior. La marca visible muestra una tabla colocada en sentido horizontal, con una altura de $25 \mathrm{~cm}$. De acuerdo con esta medida y con otras marcas menos evidentes en la tapia, es probable que el tapial se compusiera de 4 tablas. En ningún punto de esta zona de tapia se han localizado mechinales. No se observan huecos en I as bases de I as tapias, posiblemente ocultos en al guna reparación. Es probable que es te sistema constructivo se extendiera en I a parte inmediatamente a la derecha, que ahora muestra un aparejo de sillarejo. 
Las murallas en las Comunidades de Villa y Tierra de la Diócesis de Segovia en los siglos XI a XIII.

Técnica y sistemas constructivos de la arquitectura defensiva medieval.

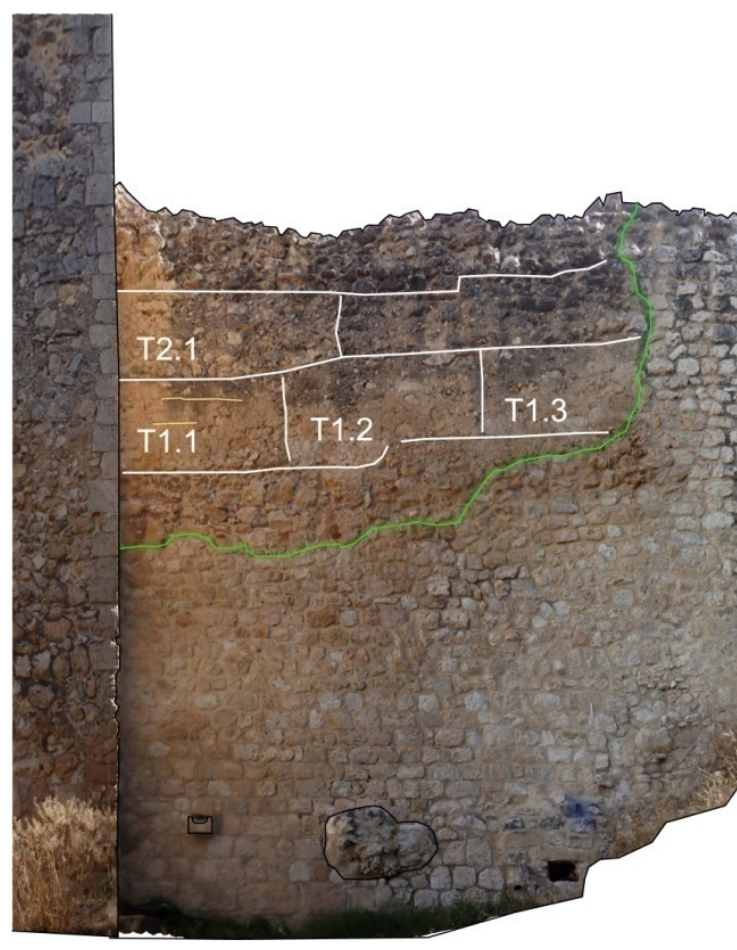

Detalle D1

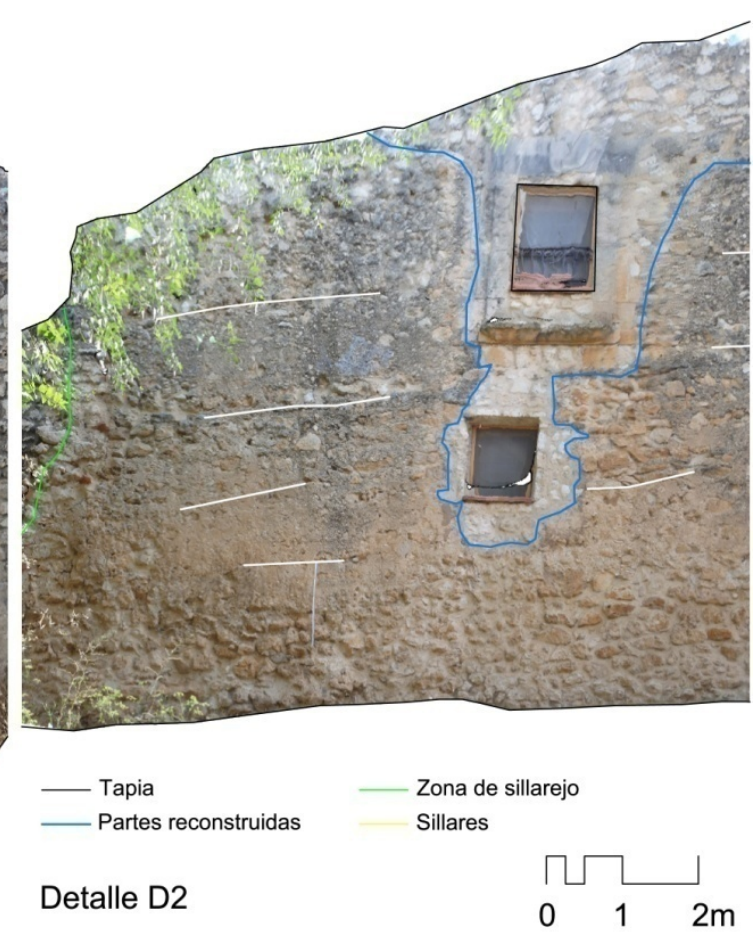

Fig. 5.4.61. Detalles del tramo T1-P1. Fuente: Elaboración propia.

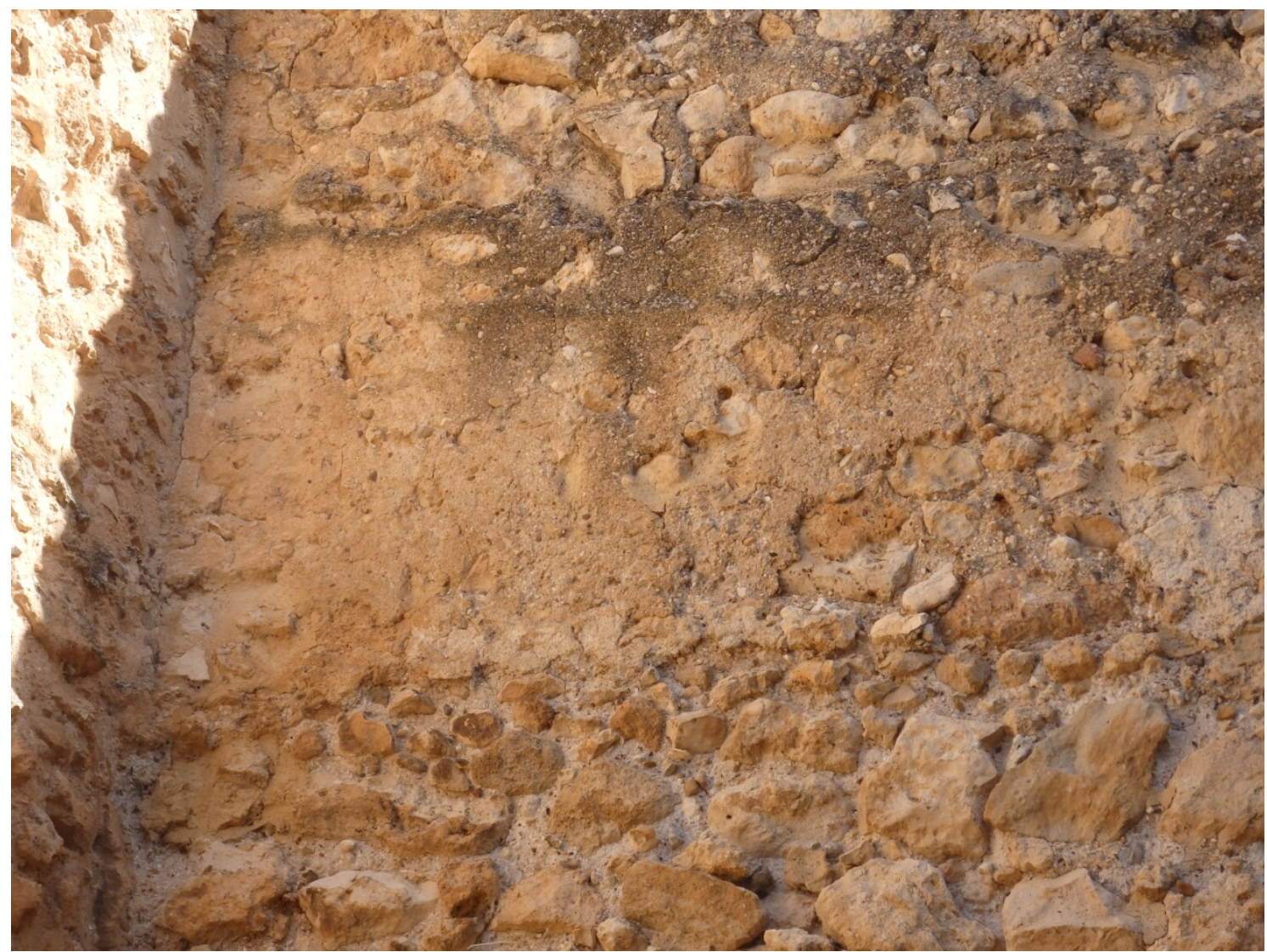

Fig. 5.4.62. Tapia T1.1. con $1,25 \mathrm{~m}$ de altura y 2,23 de anchura. Son visibles algunas marcas de la tablazón en la parte superior, ligeramente oscurecida. [A.S.E. 24/7/2016] 


\subsubsection{Lienzo exterior T2-suroeste}

Este tramo se sitúa junto a la torre T2 y se extiende en dirección suroeste una veintena de metros. La base del muro muestra reparaciones consistentes en un aparejo de nuevos mampuestos y mortero de cemento. Estas reparaciones tienen altura variable, alcanzando en el punto central casi $4 \mathrm{~m}$. Sobre estas reparaciones se observan desprendimientos, aparejos de piedra y tapia de mampostería. El alzado realizado con fotogrametría digital ofrece un aspecto parcheado (Fig. 5.4.63). En gran parte se debe al parcheado original visible en el lienzo, a raíz de las reparaciones, reconstrucción y adición de huecos. Por otra parte, se observan interrupciones en forma de sombra que se deben a I a distinta iluminación de las fotografías tomadas para la realización del alzado. El desnivel de la zona y la densa vegetación dificultan la toma de fotografías y condicionan el resultado final del dibujo.

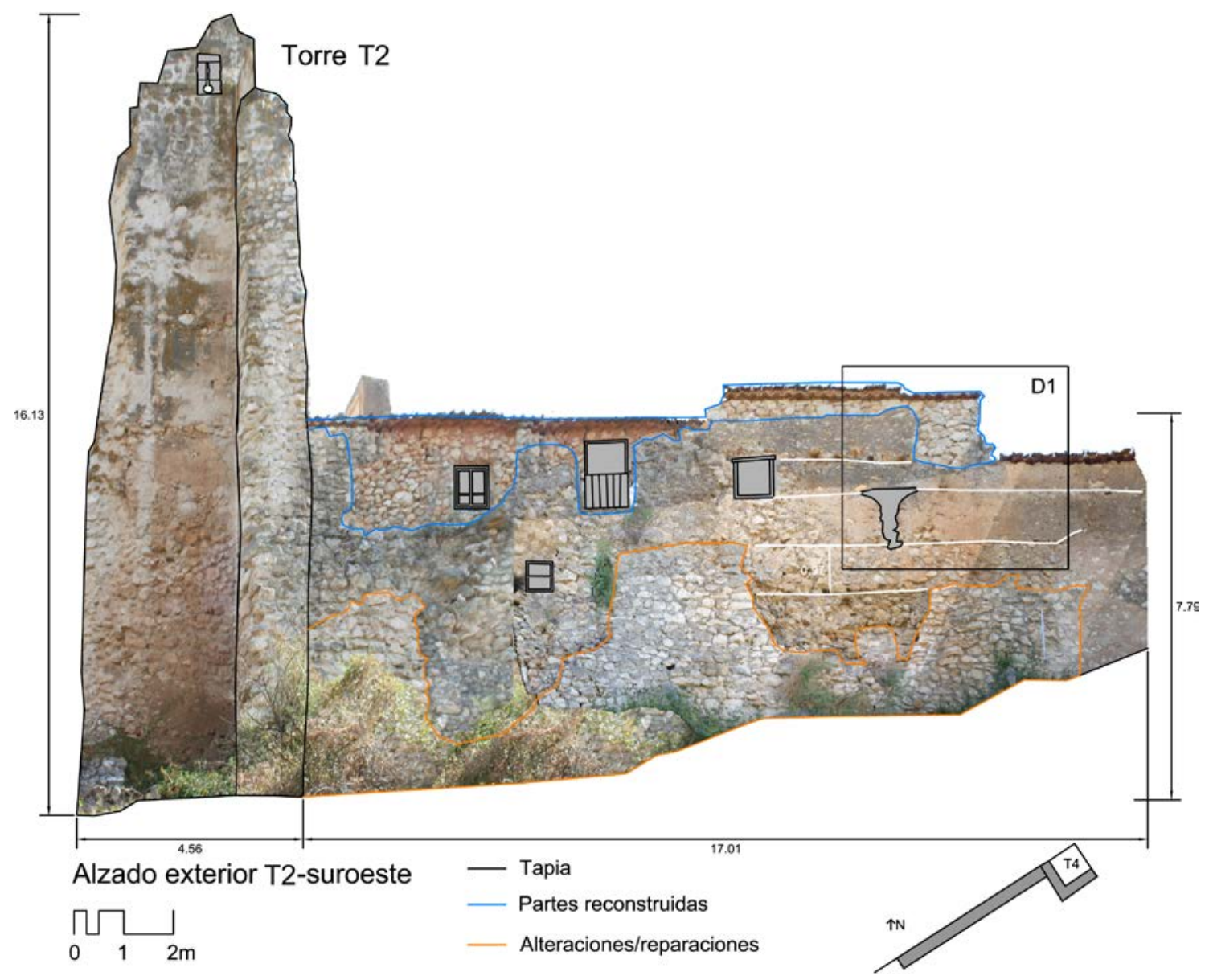

Fig. 5.4.63. Alzado del tramo T2-suroeste. Fuente: Elaboración propia.

En la zona denominada D1 (Fig. 5.4.64), se puede v er de for ma más clara la existencia de tapia de mampostería. Se observan tres hiladas de ta pia, visibles a través de las líneas horizontales que se dibujan en el paramento. La altura de la tapia ronda el valor de $1,00 \mathrm{~m}$, siendo las alturas de las dos hiladas de tapia visibles de 1,03 y $0,97 \mathrm{~m}$. El acabado de estas hiladas es tierra y allí donde se ha desprendido se observan los mampuestos que configuran la tapia. En algunos puntos son visibles 
mechinales, testigos del empleo de tapial para la construcción del muro. En esta zona los mechinales se sitúan en la base de la hilada cuarta. Están separados entre sí una distancia de $2 \mathrm{~m}$.

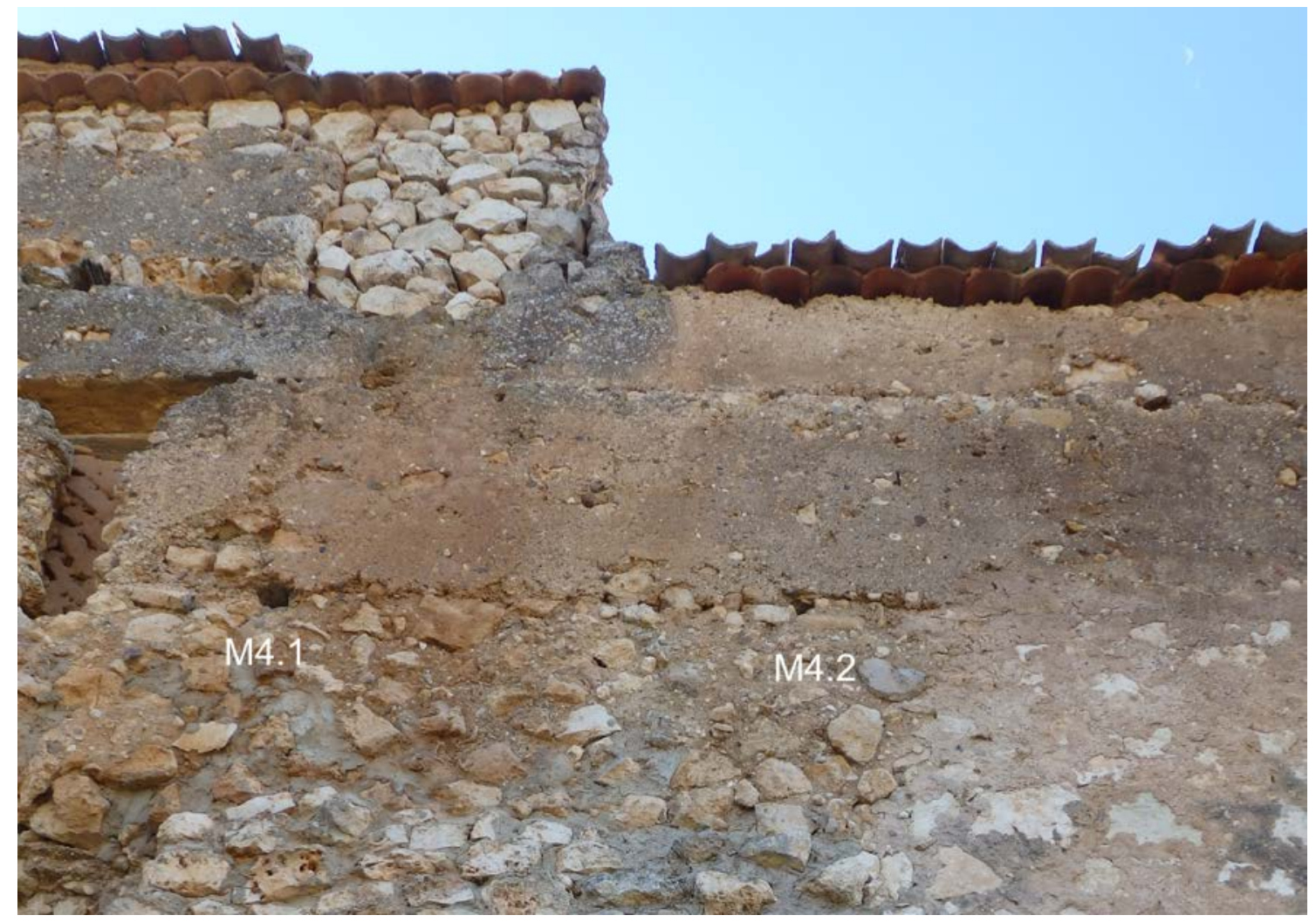

Fig. 5.4.64. Detalle D1 del muro en el tramo T2-suroeste. Fuente: Elaboración propia en foto del $24 / 7 / 2016$.

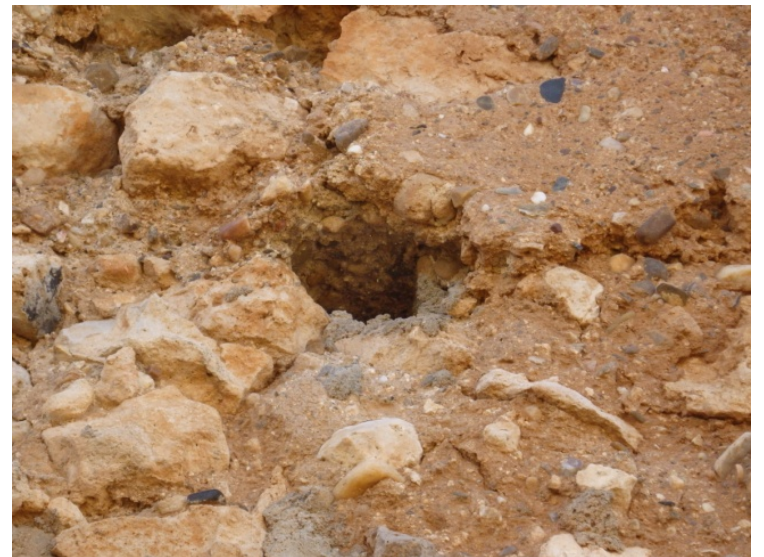

Fig. 5.4.65. Mechinal M4.1 [A.S.E. 24/7/2016]

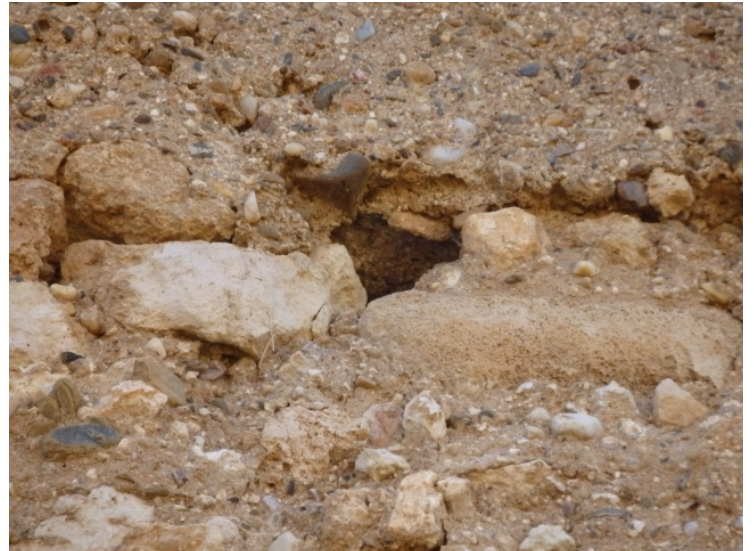

Fig. 5.4.66. Mechinal M4.2 [A.S.E. 24/7/2016]

El mechinal M4.1 (Fig. 5.4.65) muestra una oquedad c on forma rectangular probablemente rodeada de mampuestos, aunque no sean completamente visibles por conservarse el acabado terroso de la tapia. Las dimensiones del mechinal son de $10 \mathrm{~cm}$ de anchura por $8 \mathrm{~cm}$ de altura. El mechinal M4.2 se apoya sobre dos mampuestos, visibles en el paramento al haberse desprendido en esa zona el 
acabado de terroso. Tiene una forma de proporciones rectangulares, aunque el contorno del hueco es irregular, sin líneas ni ángulos rectos. Es ligeramente más pequeño que el mechinal vecino, donde la anchura no llega a los $10 \mathrm{~cm}$, alcanzando solo $8 \mathrm{~cm}$ y cuya altura se queda en $6 \mathrm{~cm}$.

Los restos de tapia de mampostería son muy escasos en este caso. Extraer todas las características de una tapia representativa se hace muy complejo, teniendo en cuenta que además se dan tapias de distinta altura en los dos tramos estudiados. Aun así, es posible extraer muchos datos que permiten conocer qué tipo de tapia se ha empleado en este recinto.

Tabla 5.4.4. Tabla de características y dimensiones de acuerdo con los tramos T1-P1 y T2-suroeste

\begin{tabular}{|c|c|c|c|c|c|}
\hline Tapia & T1-P1 & $\begin{array}{c}\text { T2- } \\
\text { suroeste }\end{array}$ & Mechinal & T1-P1 & $\begin{array}{c}\text { T2- } \\
\text { suroeste }\end{array}$ \\
\hline Altura $(\mathrm{cm})$ & $117,50^{*}$ & 100 & Sección mayoritaria & \multicolumn{2}{|c|}{ Rectangular } \\
\hline Anchura (cm) & $260^{*}$ & No visible & Dimensiones $(\mathrm{cm})$ & $8-10^{* *} \mathrm{~cm}$ & $6-8^{* *} \mathrm{~cm}$ \\
\hline Espesor (cm) & \multicolumn{2}{|c|}{$150 * *$} & Distancia en cajón & \multicolumn{2}{|c|}{-} \\
\hline $\begin{array}{l}\text { Restos de encofrado / } \\
\text { Tipo de tapial }\end{array}$ & \multicolumn{2}{|c|}{ Sí / Tapial corrido } & Distancia entre cajones & \multicolumn{2}{|c|}{-} \\
\hline $\begin{array}{l}\text { Altura de tablas de } \\
\text { encofrado }(\mathrm{cm})\end{array}$ & \multicolumn{2}{|c|}{ No visible } & Material & \multicolumn{2}{|c|}{ Mampuesto } \\
\hline $\begin{array}{l}\text { Piedras exteriores } \\
\text { colocadas }\end{array}$ & \multicolumn{2}{|c|}{ Sí } & $\begin{array}{l}\text { Aguja } \\
\text { perdida/recuperable }\end{array}$ & \multicolumn{2}{|c|}{-} \\
\hline $\begin{array}{l}\text { Juntas más visibles en } \\
\text { paramento }\end{array}$ & \multicolumn{2}{|c|}{ Horizontales } & Profundidad mechinal & \multicolumn{2}{|c|}{-} \\
\hline Materiales empleados & \multicolumn{2}{|c|}{ Mampuestos, tierra, cal } & $\begin{array}{l}\text { Tipo de aguja } \\
\text { (pareadas/unitarias) }\end{array}$ & \multicolumn{2}{|c|}{ Unitarias } \\
\hline $\begin{array}{l}\text { Tramos constructivos } \\
\text { verticales }\end{array}$ & \multicolumn{2}{|c|}{ Sí } & Mechinales por cajón & \multicolumn{2}{|c|}{-} \\
\hline Verdugada & \multicolumn{2}{|c|}{ No } & $\begin{array}{l}\text { Ubicación de mechinal } \\
\text { en relación con cajón }\end{array}$ & \multicolumn{2}{|c|}{ Inferior } \\
\hline
\end{tabular}

${ }^{*}$ menos de 10 muestras

** medida estimada de acuerdo con catastro.

$\overline{\mathrm{X}}$ media aritmética

\subsubsection{Tipología de las tapias de lienzos T1-P1 y T2-suroeste}

De acuerdo con la clasificación de A. Graciani y M.A. Tabales, las tapias de los tramos estudiados podrían clasificarse como tapia monolítica con mechinales con remate de mampuesto y sin verdugadas (Tabla 5.4.5). En cuanto a la clasificación de I.J. Gil Crespo, algunos de esos detalles no es posible conocerlos en los tramos estudiados, por encontrarse muy pormenorizadas cada una de las características de las tapias. En la Tabla 5.4 .6 se recogen las características que se han podido identificar. 
Las murallas en las Comunidades de Villa y Tierra de la Diócesis de Segovia en los siglos XI a XIII.

Técnica y sistemas constructivos de la arquitectura defensiva medieval.

Tabla 5.4.5. Tipología constructiva de I as tapias de los tramos estudiados de acuerdo de A mparo Graciani y Miguel A. Tabales $(2008,139)$ en el área sevillana.

\begin{tabular}{|l|c|c|}
\cline { 3 - 3 } \multicolumn{1}{c|}{} & Mechinal & Verdugada \\
\hline Monolítico & Mampuesto & Sin verdugada \\
\hline
\end{tabular}

Tabla 5.4.6. Tipología constructiva de las tapias de los tramos T1-P1 y T2-suroeste de acuerdo con la clasificación de Ignacio J. Gil Crespo $(2013,554-557)$

\begin{tabular}{|l|l|}
\hline A. Material de construcción & 5. Mampostería \\
\hline B. Compactación del material & 2. Vertido. \\
\hline C. Función constructiva & 1. Fábrica principal \\
\hline D. Encofrado & - \\
\hline E. Acabado superficial & 4. Capa externa de mampostería \\
\hline F. Combinación de materiales & 4. Mampuestos, tierra y cal \\
\hline $\begin{array}{l}\text { G. Mechinales } \\
\text { G-a. Situación }\end{array}$ & 1. Situación en el propio hilo \\
G-b. Profundidad & - \\
G-c. Formación & 1. Formación aguja embebida en la fábrica \\
G-d. Sección & 2. Rectangular \\
\hline
\end{tabular}

\subsubsection{Resumen de resultados para el caso de Maderuelo}

La villa de Maderuelo sorprende por su ubicación, en este apéndice alargado que se adelanta hacia el noreste en el encuentro de dos ríos. La muralla que se construye en sus bordes, adaptándose a su relieve, conserva tramos aislados de escasa longitud. En sus lados más largos, se conservan restos que han sido profundamente alterados. En comparación con otros casos, en Maderuelo no es sencillo encontrar partes de muralla que no hayan sido modificadas a través de reparaciones, modificaciones o reconstrucciones. Parece existir un único recinto, del que se conservan dos puertas. La puerta de la Villa, de composición simétrica parece haber sido flanqueada por dos torres, cuyas marcas han quedado en I os lienzos adyacentes. La puer ta del Barrio tiene una disposición en ángulo recto con el trazado de la muralla y un carácter secundario.

En cuanto a las características generales de la muralla, el tramo T1-P1 muestra un altura de 9 a $10 \mathrm{~m}$, aunque no se observan lienzos claramente completos, por lo que la altura podría ser superior. Los restos de la torre de este tramo alcanzan los $13 \mathrm{~m}$, y la puerta de la Villa supera los $10 \mathrm{~m}$. El espesor de este tramo no ha podido ser medido físicamente, ya que no se ha tenido acceso a la sección del muro. Se ha considerado 
que el espesor podría ser cercano al 1,50m, de acuerdo con los planos de parcelario, aunque podría variar en otras zonas del recinto.

Se conservan dos torres claramente identificables, en el suroeste del recinto y en el norte, en la zona del castillo. No son torres macizas sino que tienen un espacio en su interior. Las torres que flanquearían la puerta de la Villa serían también huecas, dadas las marcas en el paramento de una de ellas. En otros puntos del recinto se pueden ver las bases de lo que podrían haber sido torres de flanqueo, en este caso de carácter macizo. Solo se conservan quiebros en el recorrido de la muralla, bases con formas de talud, que hacen pensar en la posible naturaleza de torre de esas construcciones.

Los tramos existentes permiten conocer algunas técnicas empleadas en la construcción. La tapia de mampostería se encuentra en la torre del castillo así como en los restos de lienzos en los lados largos del recinto. El frente sur también emplea esta técnica en partes del lienzo, aunque muestra paños construidos con sillería y sillarejo. La puerta de la Villa y la torre del Oeste se construyen con sillarejo y emplean sillares en esquinas y arcos.

En cuanto a la existencia de bas es diferenciadas en los lienzos, no se observa una intención por construir bases o cimentaciones de los muros. En el tramo T1-P1 se observa una base diferente en la zona más cercana a la torre T1. Por una parte se observan sillares de grandes dimensiones sobre los que se construye un muro de sillarejo.

Los recursos defensivos del recinto son escasos. No se conserva almenado, a excepción de la puerta de la Villa, donde parece haber sido reconstruido. Apenas se conservan torres por lo que es difícil entender qué funcionamiento tendrían en el recinto amurallado. 



\section{5}

\section{Pedraza de la Sierra}

Segovia

\subsubsection{Localización}

La comunidad de Pedraza se encuentra en el límite septentrional de la provincia de Segovia. Su límite en la zona está marcado por el recorrido de de la sierra de Guadarrama. La población cabecera se sitúa cercana a la ciudad de Segovia, a aproximadamente $40 \mathrm{~km}$ de distancia. Está más alejada de la ciudad de Valladolid, a $120 \mathrm{~km}$. La extensión de esta comunidad es de casi $400 \mathrm{~km}^{2}$ y tiene un tamaño medio en relación con las comunidades vecinas. Linda al norte con la comunidad de Sepúlveda, al este con Buitrago, al sur con Madrid, y al oeste con Segovia y con territorios eclesiásticos. El río Cega pasa por la comunidad de Pedraza, atravesándola de sur a norte. Este territorio es escarpado e irregular, debido a su proximidad con el Sistema Central.

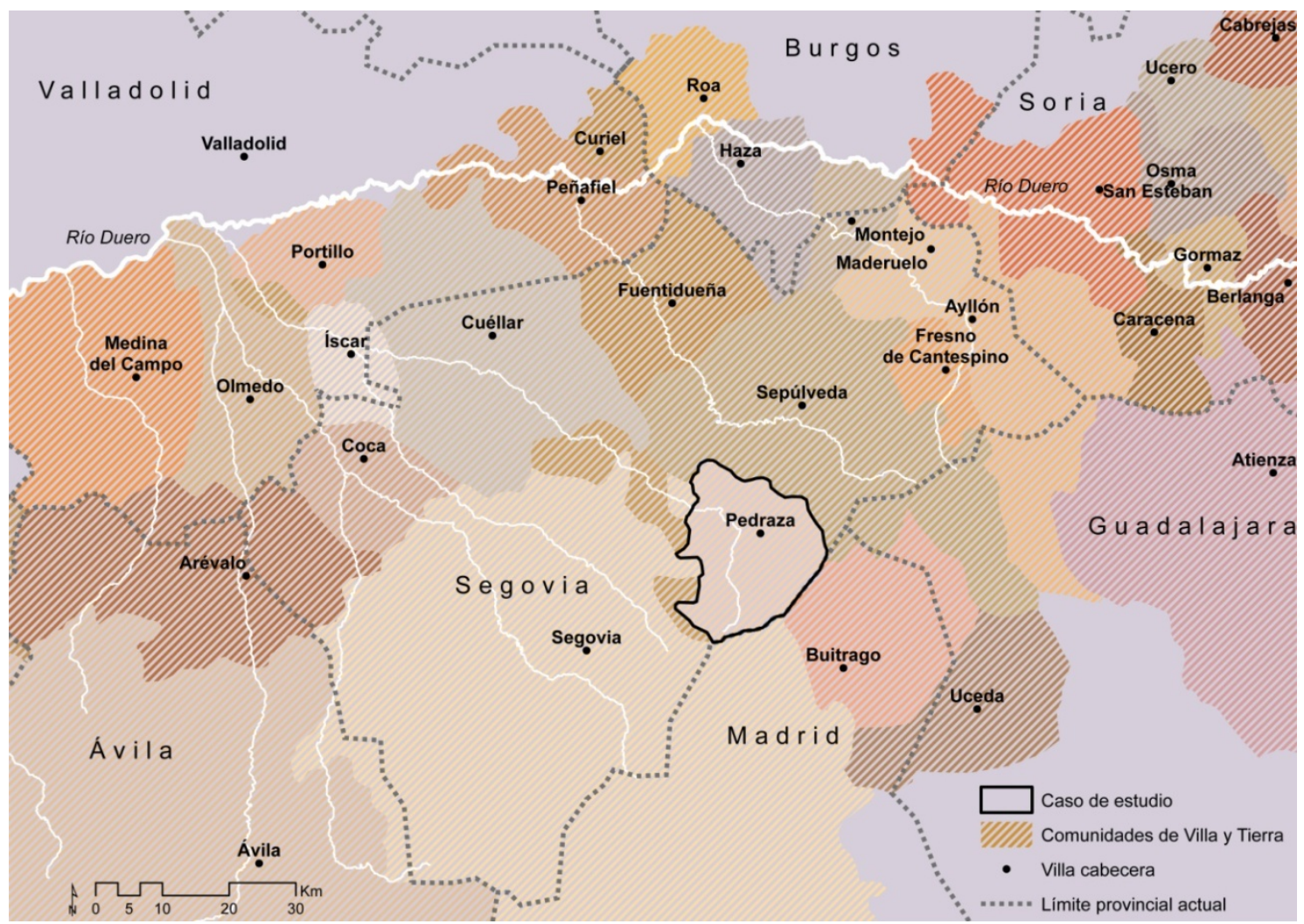

Fig. 5.5.1. Plano de localización de la comunidad de Pedraza. Fuente: Elaboración propia a partir de planos de G. Martínez Díez (1983, 11-15) y J.M. Monsalvo (2010, 152). 
Las murallas en las Comunidades de Villa y Tierra de la Diócesis de Segovia en los siglos XI a XIII. Técnica y sistemas constructivos de la arquitectura defensiva medieval.

El núcleo de pobl ación se encuentra en la intersección de los arroyos Vadillo y Encinarejo, sobre un cerro con una al titud de 1060m sobre el nivel del mar. Está rodeado por las hoces de los arroyos que discurren a una altitud que ronda los $1000 \mathrm{~m}$. Esta posición dota al núcleo de gran capacidad defensiva, con $60 \mathrm{~m}$ de desnivel, y con un dominio visual inmejorable del territorio circundante. Sólo existe una vía de acceso en esta población, la puerta de la Villa, que se sitúa al este. A apenas $2 \mathrm{~km}$ hacia el oeste pasa el río Cega, donde afluyen los dos arroyos que rodean el núcleo. El cerro donde se asienta la población está rodeado de otros cerros cuya altitud ronda los $1080 \mathrm{~m}$. Al norte se sitúa el cerro de las Tongueras, al este el Rayo, al sur los Molares y la Griega y al oeste el Culebral y el Llano Vadillo. El núcleo tiene una población de 416 habitantes, de acuerdo con los datos del Instituto Nacional de Estadística en el año 2015.

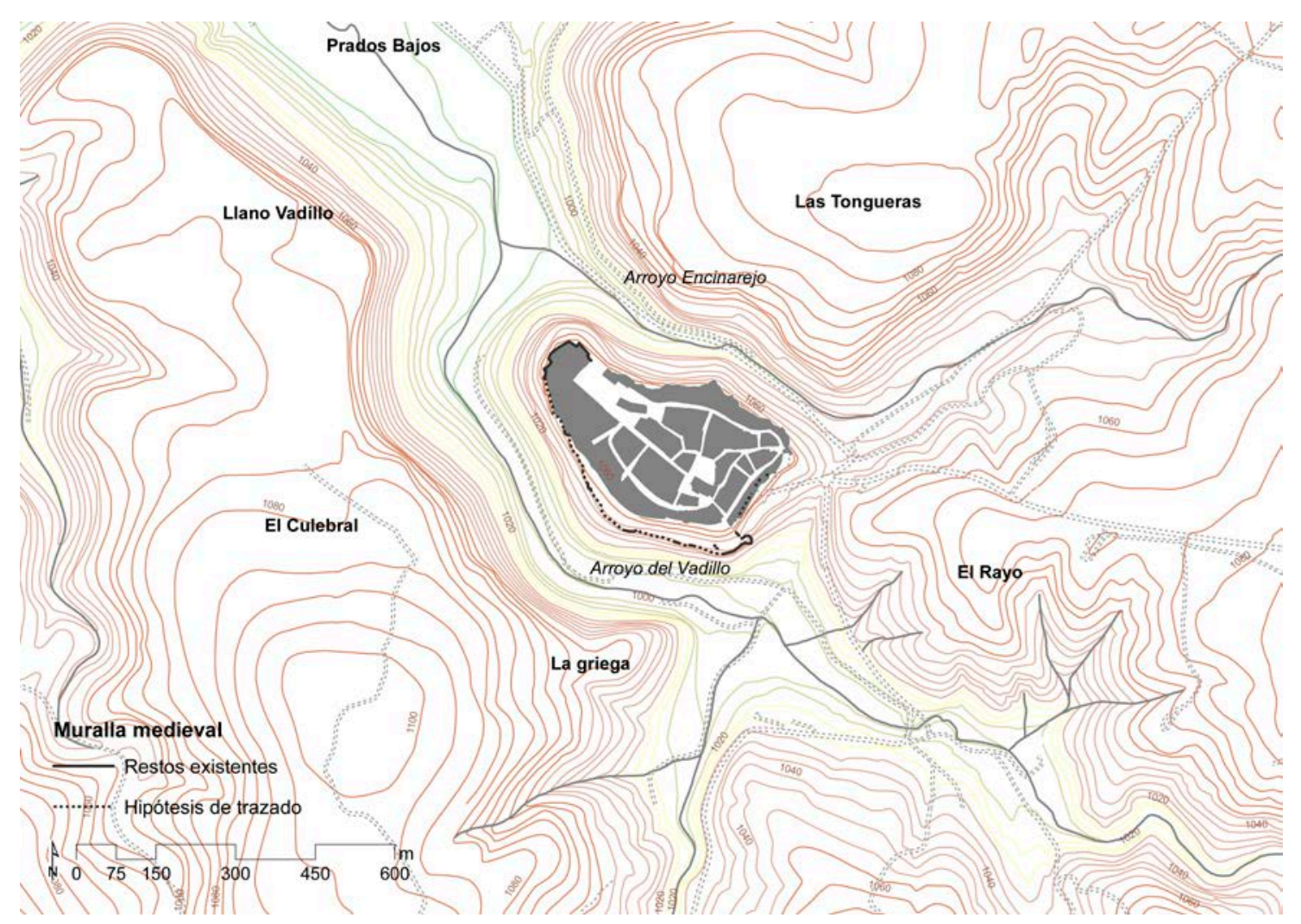

Fig. 5.5.2. Plano del territorio que rodea la villa de Pedraza. Fuente: Elaboración propia con datos del IDECyL [http://www.cartografia.jcyl.es/] y Catastro [http://www.catastro.meh.es/].

\subsubsection{Estudios en la villa}

No existen estudios publicados que traten la muralla de Pedraza de forma exclusiva. Desde el punto de vista histórico, se han estudiado las ordenanzas de la villa en los siglos XIV y XV donde el autor señala una mención a la muralla (Franco Silva 1991, 112). Esta mención aparece en las ordenanzas de 1523 promulgadas por el Conde de Haro y especifica, en uno de sus puntos, que la mitad de las multas que se imponen en las ordenanzas se destine a la reparación de las murallas. La otra mitad se 
destinará a "los guardas del campo", figura muy mencionada a lo largo de este texto. Estas ordenanzas regulan de forma principal la caza y la pesca en el territorio bajo la influencia de la villa, castigando en algunos casos con prisión en la fortaleza a quien las incumpliera. Las iglesias románicas de la villa han sido estudiadas y documentadas a través de fotografías y de levantamientos arquitectónicos (Santamaría 1971).

En el año 2009 se inició la restauración de varios de los restos existentes de muralla. El ministerio de Fomento sufragó las obras con la fórmula del "1\% Cultural" que incluyeron la torre de Hontanillas, el Portillo, los lienzos de muralla y el camino de ronda entre el Mirador y la Florida.

\subsubsection{Datos históricos destacados del núcleo}

Pedraza aparece nombrada en muy pocos documentos históricos. Apenas es mencionada, más allá de los documentos señalados al final del capítulo 3 , don de figuran todas las villas de es ta investigación. Las pocas referencias dan fe de su existencia al menos a partir del siglo XI. Alfonso VI incluye la tierra de Pedraza dentro de Sepúlveda cuando en 1076 establece límites territoriales al confirmar sus fueros. Pedraza no aparece definida como concejo sino que se encuentra bajo la influencia de Sepúlveda (Martínez Diez 1983, 326, 359). En el siglo XII, figura ya segregada de Sepúlveda, puesto que aparece como villa independiente entre las villas nombradas en la bula del papa Calixto II de 1123, donde s e confirman los límites de la diócesis segoviana. Más adelante en 1136, aparece enumerada junto con otras villas a raíz de la cesión del diezmo a I a iglesia católica por parte del rey Alfonso VII (352). Igualmente, figura en 1187 en el documento de matrimonio entre Berenguela y Conrado, hijos de Alfonso VIII y Federico I.

Más adelante, en el siglo XIV, Pedraza sería cedida a Fernán Gómez Albornoz por el rey Enrique II. El tamaño de la villa en el siglo XVI podría evaluarse de acuerdo con las cuatro parroquias que disponía en la villa y otras veintiséis en el alfoz (Martínez Díez 1983, 367). La villa se mantendría como señorío hasta la llegada del siglo XIX.

\subsubsection{Tejido urbano}

El recinto amurallado, que cubre la totalidad del cerro de Pedraza, tiene una superficie aproximada de $10 \mathrm{Ha}$. Pedraza conserva una puerta de muralla, la puerta de la Villa y también un portillo, el de Hontanillas, pero que no es posible utilizarlo como acceso en la actualidad. Desde la puerta de la Villa parten tres calles o caminos: la calle del Matadero al norte, la calle Real en el centro y la calle de las Cuestas hacia el sur. Las calles del Matadero y de las Cuestas discurren en paralelo a los lienzos de muralla que se sitúan al norte y al este respectivamente. Estas calles parecen rodear lo que pudo ser el núcleo de la población, una agrupación que parece girar en torno a la iglesia de San Juan Bautista. La calle la Florida y la directriz circular de varias parcelas en torno a la plaza Mayor generan un círculo en torno a la mencionada iglesia. En la parte oeste, este círculo se desdibuja, en la manzana delimitada por la calle Mayor de la 
calle de la Florida. La calle Real muestra un quiebro a la altura de la oficina de turismo; sería posible aventurar que ex istiría una c ontinuación de esta calle hasta su continuación con la calle del Monte. Algo similar ocurre poco antes en la calle Real: se bifurca hacia el sur en la calle Cordovilla. Desde esta agrupación central parten varias calles en sentido radial: la calle del Monte, la calle Angosta, la calle Real, la calle Hontanillas, la travesía de la Florida. La c alle Mayor también parte radialmente en sentido oeste, pero parece responder a otro orden. Esta calle une de forma rectilínea y directa la iglesia de San Juan con el castillo, situado en el extremo noroeste de la población. Prácticamente en continuación con este eje se alinea la torre de Hontanillas.

El caserío actual se ubica de forma más densa en la zona noreste, la más cercana a la puerta de la Villa. La zona más próxima al castillo se encuentra más vacía, la densidad de construcciones se reduce mucho, quedando grandes espacios sin construir.

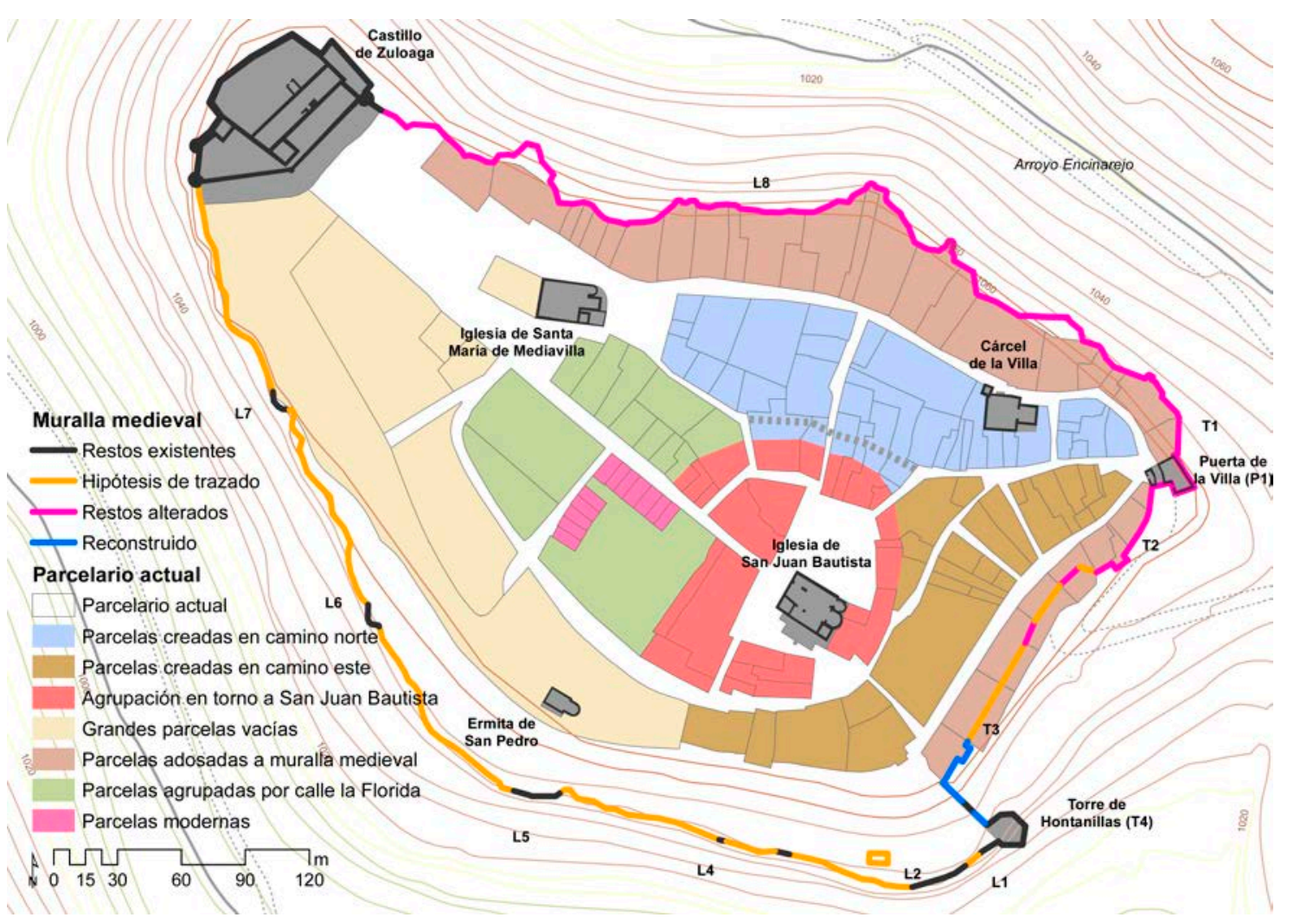

Fig. 5.5.3. Parcelario urbano de Pedraza. Fuente: Elaboración propia con datos de Catastro [http://www.catastro.meh.es/] e IDECyL [http://www.cartografia.jcyl.es/]

La muralla se ha representado a lo largo de su trazado con cuatro colores diferentes. El color negro representa los tramos de $\mathrm{m}$ uralla existente, que conserva sus características originales. El color fucsia representa las zonas donde se sitúan restos de muralla, pero estos han sido alterados de forma significativa al incorporarse en nuevas construcciones o completarse en sus zonas superiores para dar servicio al nuevo uso urbano o doméstico. En color naranja se han representado los tramos desaparecidos, por donde se considera que discurriría la muralla, de acuerdo con los 
datos que aportan los restos existentes y la propia topografía. El color azul indica qué tramos han si reconstruidos por completo, con una nueva construcción, moderna, cuya función es de nueva muralla que busca completar los vacíos de la muralla original.

\subsubsection{Planeamiento y figuras de protección}

De acuerdo con el Archivo de Planeamiento Urbanístico de la Junta de Castilla y León, Pedraza cuenta actualmente con unas Normas Urbanísticas Municipales y Plan Especial de Conjunto Histórico que se aprobaron en el año 2013. En estos planes se reflejan los restos de muralla situados en la cara norte y este del núcleo. Se incluyen dentro de I a categoría de Bien de Interés Cultural (BIC) el castillo, desde 1949, y también la villa como conjunto histórico desde el año 1951.

\subsubsection{Descripción general de la arquitectura defensiva}

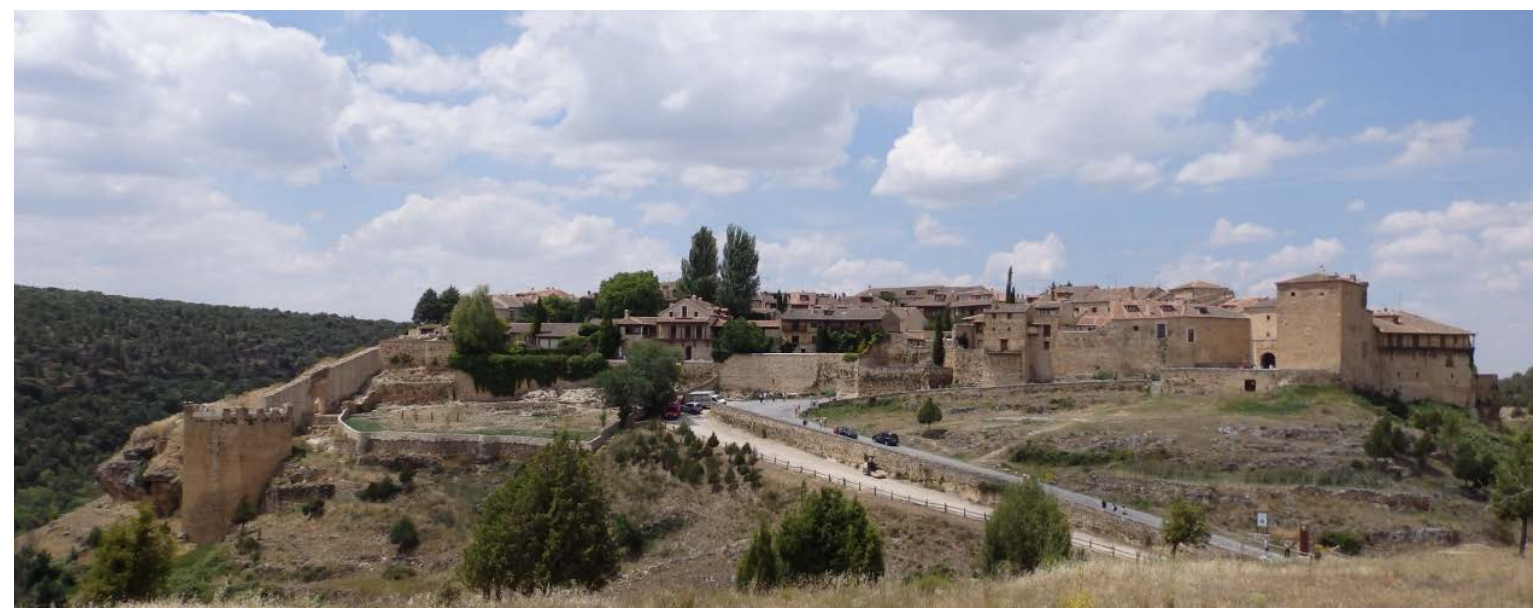

Fig. 5.5.4. Imagen de la villa amurallada, vista desde el cerro del Rayo, en el sureste. Se observa a la derecha la puerta de la villa, y la izquierda la torre de Hontanillas [A.S.E. 5/7/2014].

El recinto amurallado de Pedraza se adapta a los bordes del cerro donde se asienta. Los lados norte, oeste y sur ofrecen desniveles pronunciados que se traducen en paredes verticales de roca. Al borde de es tas paredes arrancan los lienzos de la muralla. En la zona este, el desnivel es menor, y es donde se encuentran los dos accesos. Este frente del recinto amurallado se compone de la Puerta de la villa, situada en el extremo este, y de un tr amo de muralla visible desde la carretera de acceso. Este lienzo se oculta después en el caserío hasta llegar a la torre de Hontanillas (Fig. 5.5.6). Desde la torre de Hontanillas y a lo largo del frente suroeste, los restos de muralla son escasos e intermitentes. Se encuentran pequeños tramos en el borde del cerro en torno a los $1050 \mathrm{~m}$ de altitud (Fig. 5.5.5, Fig. 5.5.7). Estos restos aislados son visibles en todo este tramo suroeste, hasta el castillo.

En el extremo noroeste se encuentra el castillo, ubicado en el borde del cerro. Desde esta orientación, el castillo ofrece un as pecto inexpugnable (Fig. 5.5.8), con un desnivel de $70 \mathrm{~m}$, desde el valle. Edward Cooper $(1991,630)$ habla de la existencia de 
un castillo primitivo que se componía de un recinto irregular y un torreón, situado en la posición de la torre de homenaje visible en la actualidad. Este autor menciona la construcción, en el siglo $\mathrm{XV}$, de un lienzo de entrada muy sólido que incorpora una hilera de $m$ atacanes. También indica que en el siglo XVI los muros del recinto se transformaron en crujías y se incorporaron dos recintos hacia el exterior. Asimismo, destaca el alzado sureste del recinto que ofrece el castillo a la población, que tiene una puerta, cubos, garitas y buzones (Fig. 5.5.9). En la actualidad, el castillo contiene el museo Ignacio Zuloaga, quien lo compró y restauró en los años 20 del siglo pasado.

En la zona norte, el recinto amurallado continúa más allá del castillo, en dirección este, adaptándose escrupulosamente al terreno. En esta zona las edificaciones se han pegado a la muralla y han ido modificándola progresivamente, apoyándose sobre ella las construcciones urbanas y reconstruyendo algunas partes. La muralla se construye directamente sobre la roca (Fig. 5.5.10).

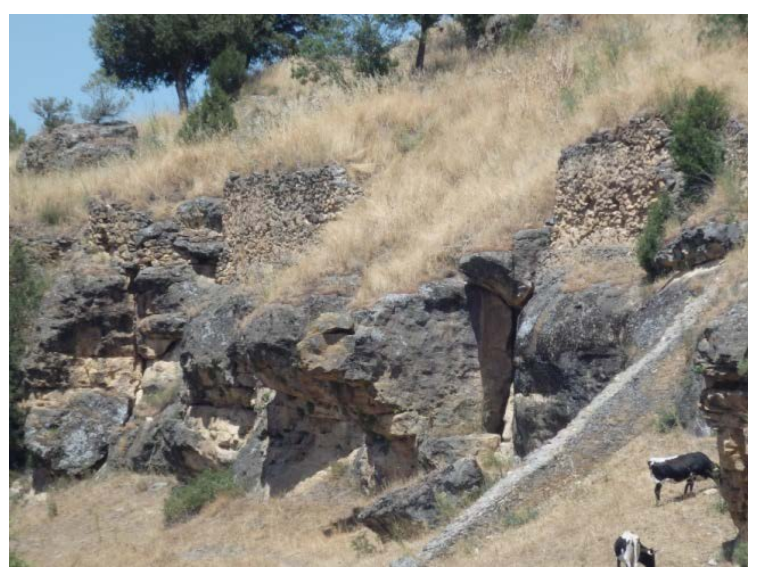

Fig. 5.5.5. Restos de muralla sobre el borde del cortado en el lado suroeste. Se observa una rampa de bajada moderna para salvar el desnivel [A.S.E 24/7/2016].

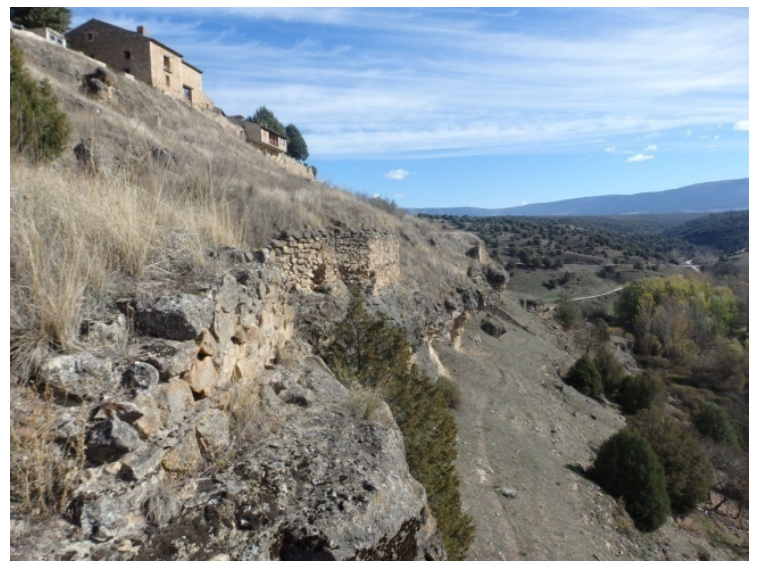

Fig. 5.5.7. Restos de muralla sobre el borde del cortado suroeste. Se aprecia el dominio visual del cerro sobre el territorio [A.S.E. 18/11/2015].

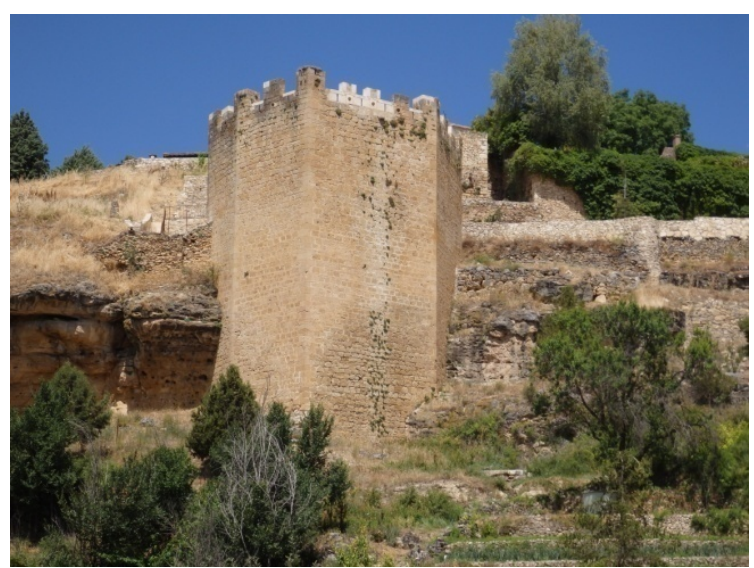

Fig. 5.5.6. Torre de Hontanillas vista desde el lado sureste [A.S.E. 34/7/2016]

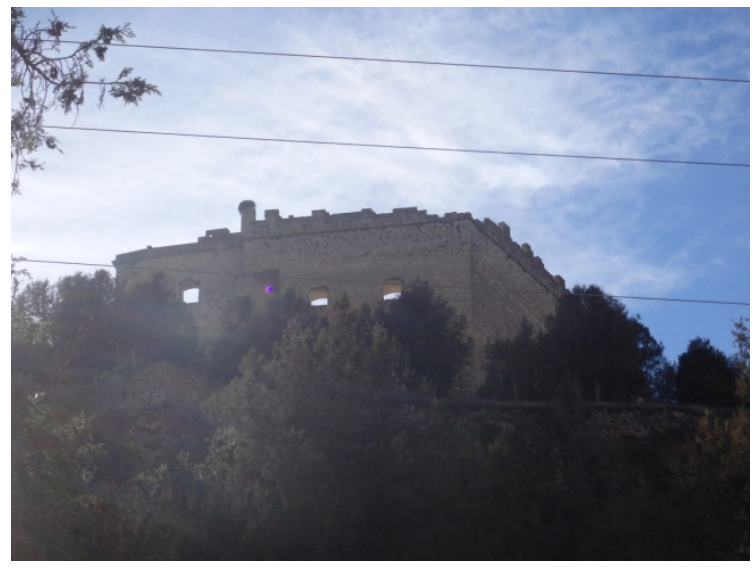

Fig. 5.5.8. Vista del castillo desde abajo, en el lado norte [A.S.E. 18/11/2015]. 


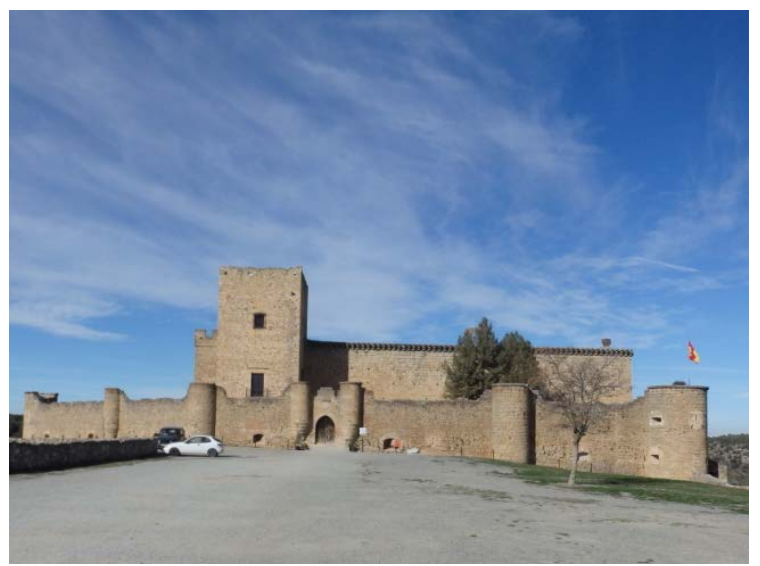

Fig. 5.5.9. Vista sureste del castillo [A.S.E. 18/11/2015].

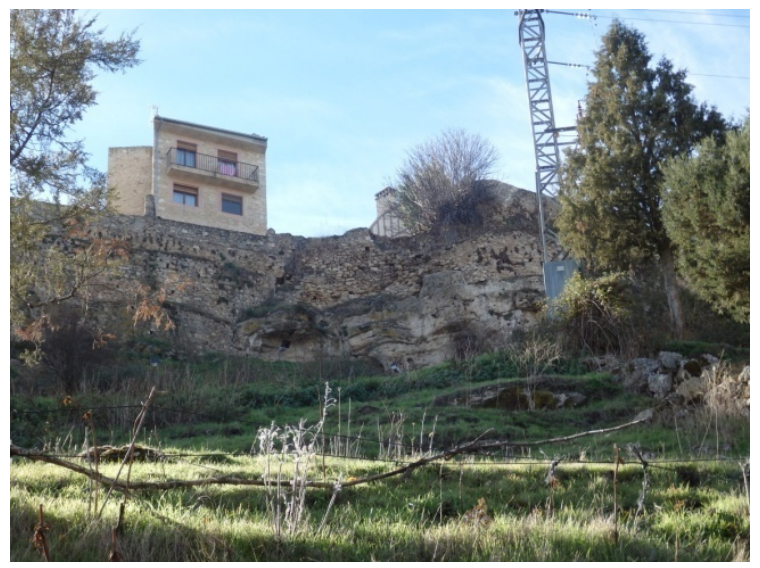

Fig. 5.5.10. Vista noreste del recinto amurallado. La muralla se alza directamente sobre la roca [A.S.E. 18/11/2015].

\subsubsection{Tramos y elementos de la muralla medieval}

\subsubsection{Puerta de la Villa}

La puerta de la Villa se encuentra en el borde este del recinto. Se compone de un cuerpo rectangular en planta, flanqueado en el lado derecho por otro cuerpo rectangular de pr oporciones similares, de mayor altura y orientado en s entido perpendicular al primero. El hueco de acceso se encuentra en el primer volumen rectangular. Desde el interior es visible una puerta cubierta por un arco de medio punto que permite el paso al espacio sobre la bóveda de acceso. De acuerdo con el estudio histórico de PEP de Pedraza ${ }^{35}$, esta puerta se reconstruyó y se amplió en 1577.

La portada del acceso se encuentra decorada con ladrillo (Fig. 5.5.13). El arco de acceso se construye con dos hiladas de ladrillo, la primera de ellas a tizón y la segunda a soga. Se produce un desnivel en los arranques del arco, iniciándose más abajo el lado izquierdo del mismo. Sobre el arco, se construye un frente de ladrillo que tiene un ap arejo singular, orientándose a $45^{\circ}$ en I as esquinas y sin formar una trabazón convencional en el resto de la fábrica. Las dimensiones de los ladrillos son irregulares. A continuación se dibujan dos hiladas de ladrillo formando un dentado. Sobre esta línea de imposta, se continúa con cuatro hiladas de ladrillo a soga. Sobre estas, se decora con ladrillos agrupados de cuatro en cuatro y ofreciendo su tabla. En el lado izquierdo, tres grupos de cuatro ladrillos se organizan formando un rombo entre sus sogas. En el lado derecho, la organización cambia, y algunos de los ladrillos han cambiado su disposición. En el centro se sitúa el escudo de la villa. Sobre esta suerte de friso, se sitúa un a parejo de ladrillo a soga. Después se construye una línea de imposta que abarca la totalidad del alzado, con piedra tallada formando un chaflán. A ambos lados de la portada de ladrillo y hasta la línea de imposta de piedra la fachada se encuentra revestida y muestra un esgrafiado con dibujos geométricos.

35 Consultado en el Archivo de $\mathrm{P}$ laneamiento Urbanístico de I a Junta de C astilla y León http://servicios.jcyl.es/PlanPublica/default_plau.do [9/9/21016]. 


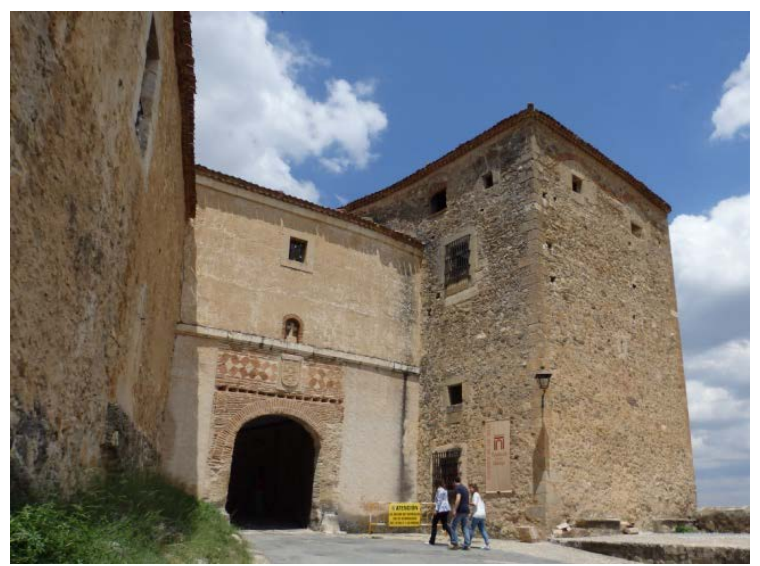

Fig. 5.5.11. Puerta de la villa vista desde el exterior. A la derecha se adosa un volumen rectangular en sentido perpendicular [A.S.E. 5/7/2014].

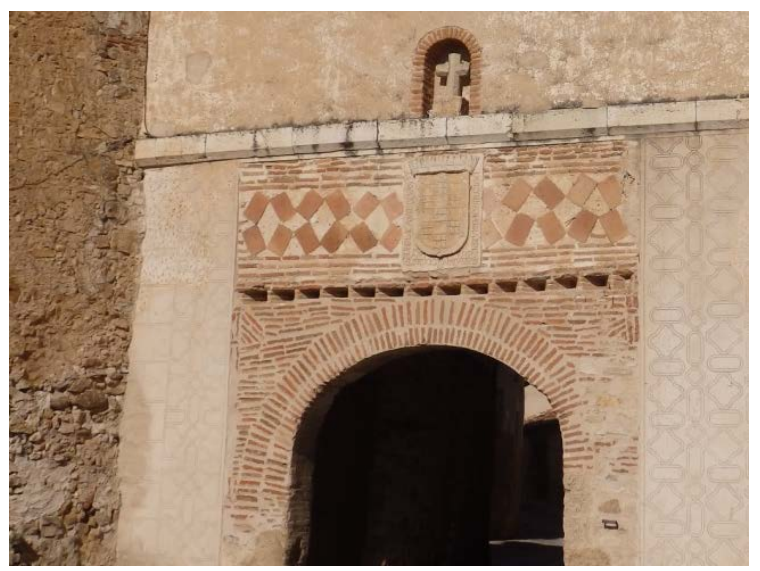

Fig. 5.5.13. Decoración de ladrillo en el frente exterior de la puerta de la Villa [A.S.E. 18/11/2015].

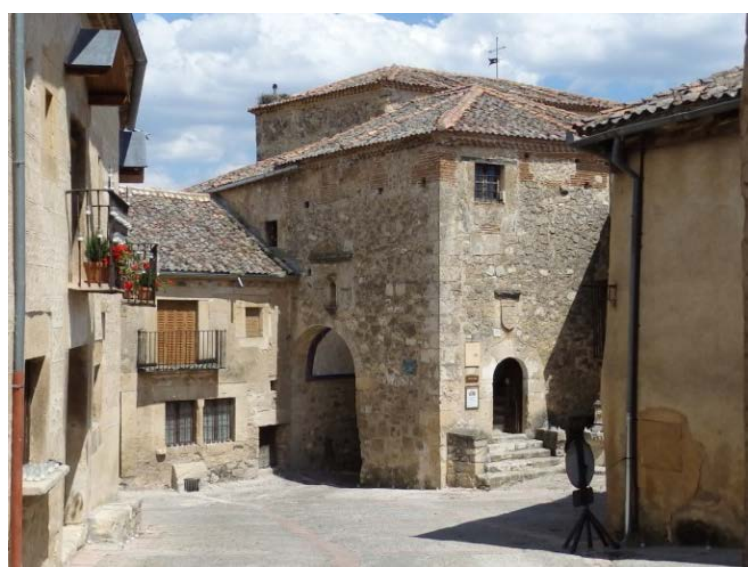

Fig. 5.5.12. Puerta de la villa vista desde el interior del recinto. A la izquierda se ve el hueco de acceso. A la derecha se encuentra la puerta de acceso al interior del edificio [A.S.E. 5/7/2014].

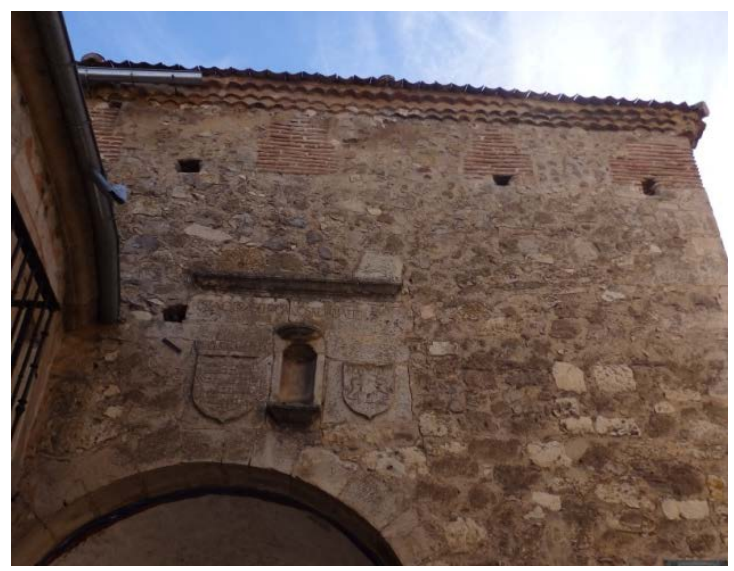

Fig. 5.5.14. Coronación del volumen de acceso de la puerta de la villa [A.S.E. 18/11/2015].

Desde el interior, la construcción de la puerta muestra un aparejo de sillarejo de tamaño medio. La esquina visible se construye con sillares rectangulares que alternan soga y tizón, formando un dentado. El arco interior de acceso también se resuelve con sillares, incluyendo los arranques desde el suelo que también presentan un dentado. En la actualidad, la coronación de esta puerta es una cubierta de teja. En la parte superior, desde el interior del recinto, se puede apreciar lo que parece ser el arranque de varios machones de ladrillo dentados, entre los que se sitúa piedra mampuesta (Fig. 5.5.14).

\subsubsection{Frente sur del recinto}

La muralla continúa hacia el sur, visible desde la calle de acceso a la puerta de la villa. Se apoya directamente sobre la roca, también visible (Fig. 5.5.15). En este tramo, las construcciones del pueblo se apoyan sobre la muralla, modificándola y añadiendo huecos. Los materiales visibles en los lienzos son mampuestos de tamaño medio y pequeño, con un aparejo desordenado. Tras $35 \mathrm{~m}$ de lienzo de muralla se sitúa la torre 
T2 (Fig. 5.5.16) que sobresale del plano de la muralla aproximadamente $3 \mathrm{~m}$. Se eleva varios metros por encima de la altura de los lienzos que la rodean. Se han abi erto varios huecos y construido un balcón en el alzado suroeste de la torre. En el alzado sureste, se observa una importante mezcla de materiales. En la base de la torre se utilizan mampuestos de tamaño medio, con aparejo irregular. Parte de las esquinas están construidas con ladrillo. En la actualidad, la coronación de la torre está resuelta con una cubierta de teja a un agua. De la torre T2 destaca la presencia de una base diferente, que desde la cara frontal muestra una forma de talud (Fig. 5.5.17). La diferencia no se aprecia tanto en el material utilizado, se emplean también mampuestos des imilar tamaño. A la altura de dos metros, se produce una discontinuidad en el paramento, visible de forma más pronunciada en la cara suroeste de la torre (Fig. 5.5.18).

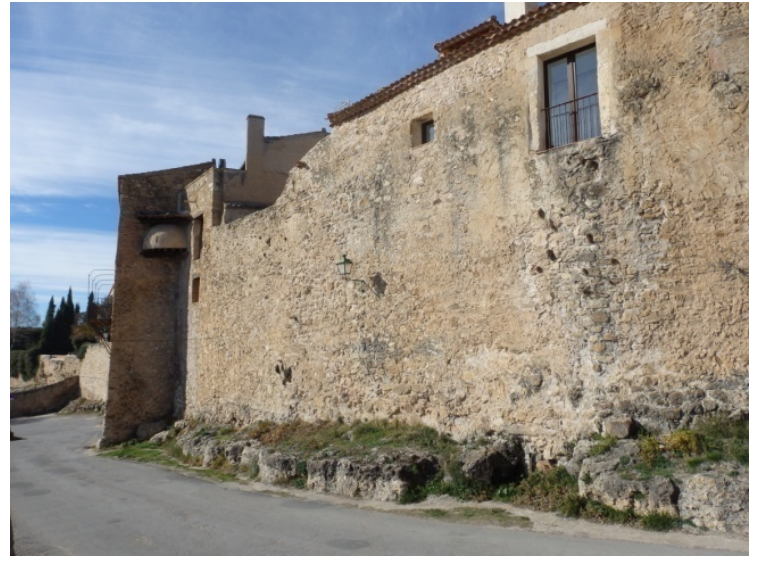

Fig. 5.5.15. Tramo de muralla desde la puerta de la Villa hacia el sur. Se observa el arranque de la muralla, directamente sobre la roca. Al fondo se ve la torre T2 que sobresale del plano del lienzo [A.S.E. 18/11/2015].

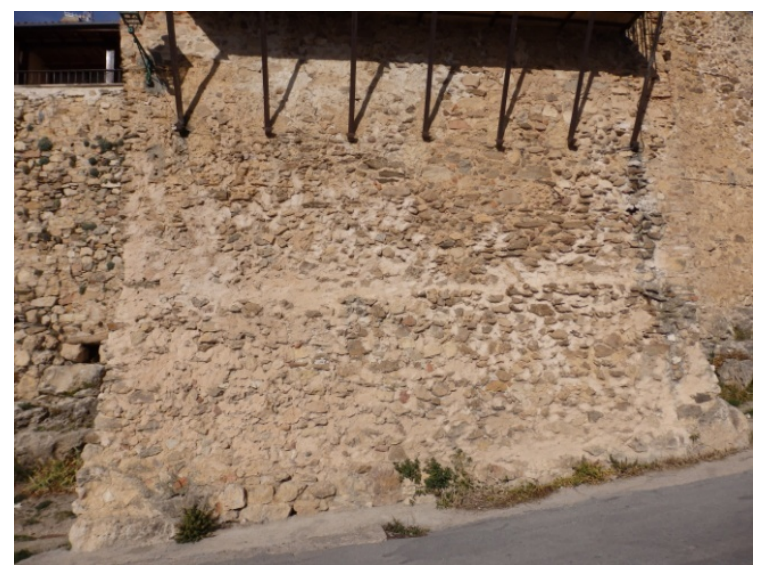

Fig. 5.5.17. Base en forma de talud del frente de la torre T2 [A.S.E. 18/11/2016].

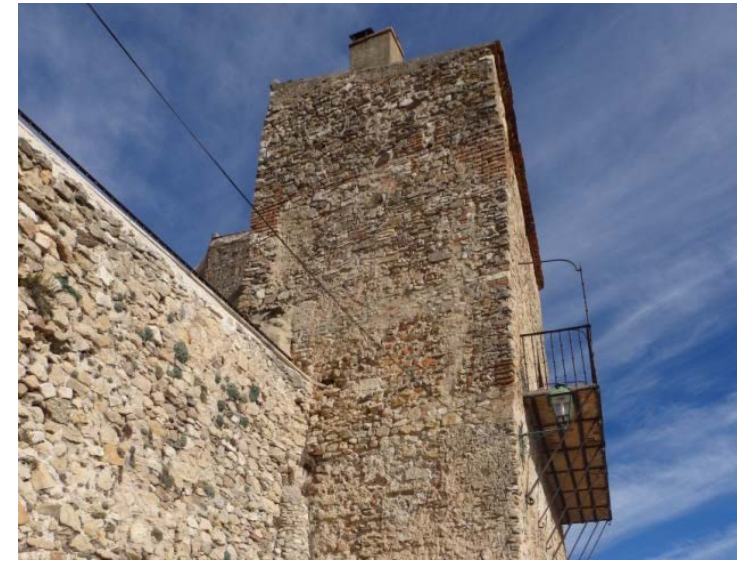

Fig. 5.5.16. Vista suroeste de la Torre T2 [A.S.E. 18/11/2015].

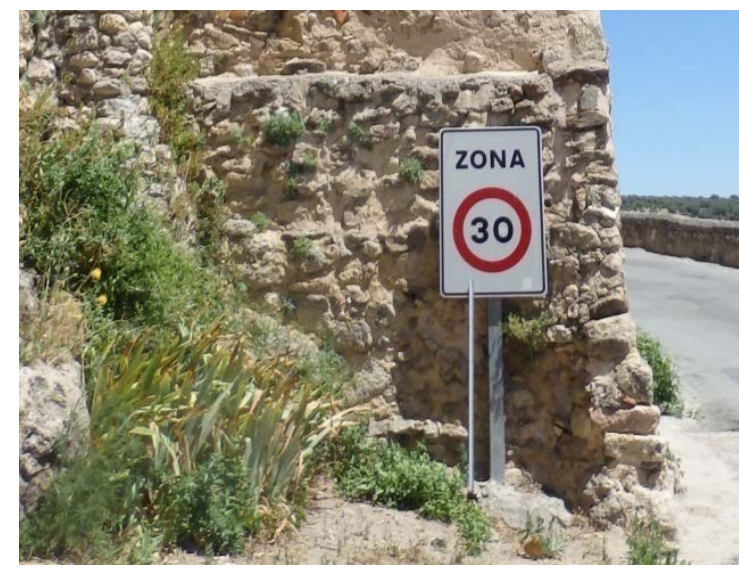

Fig. 5.5.18. Base de la cara suroeste de la torre T2 [A.S.E. 24/7/2016]. 


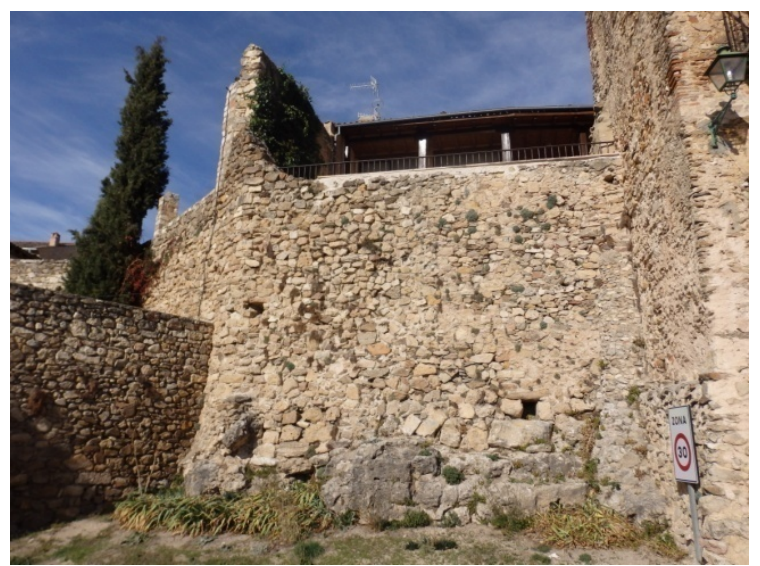

Fig. 5.5.19. Lienzo al sur de la torre T2 [A.S.E. 18/11/2015].

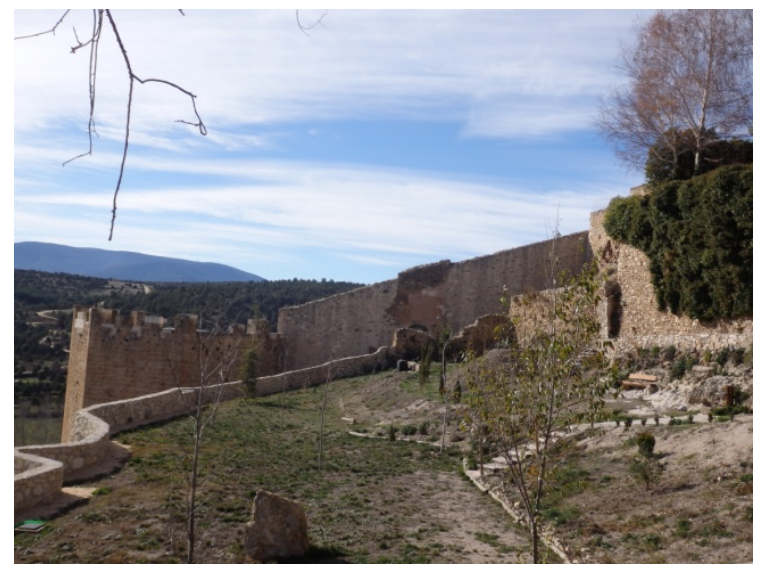

Fig. 5.5.21. Vista norte de la torre de Hontanillas (T4) y el acceso adyacente [A.S.E. 18/11/2015].

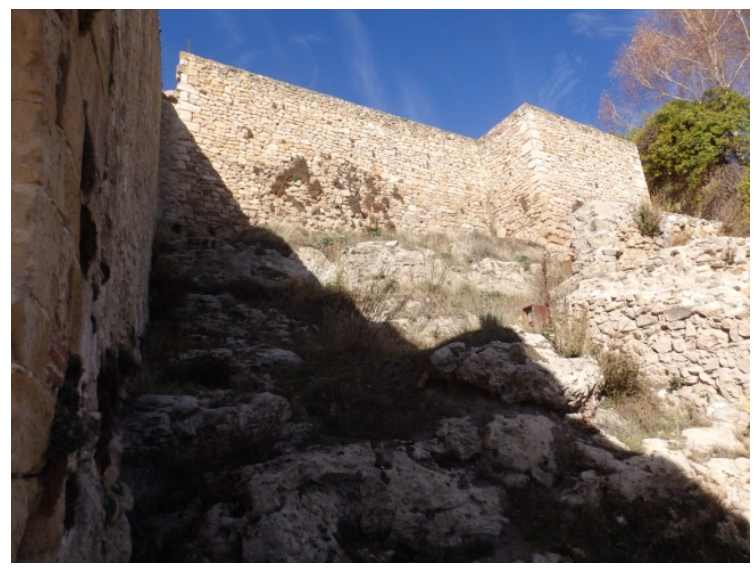

Fig. 5.5.20. Vista exterior de la torre T3 [A.S.E. 18/11/2015].

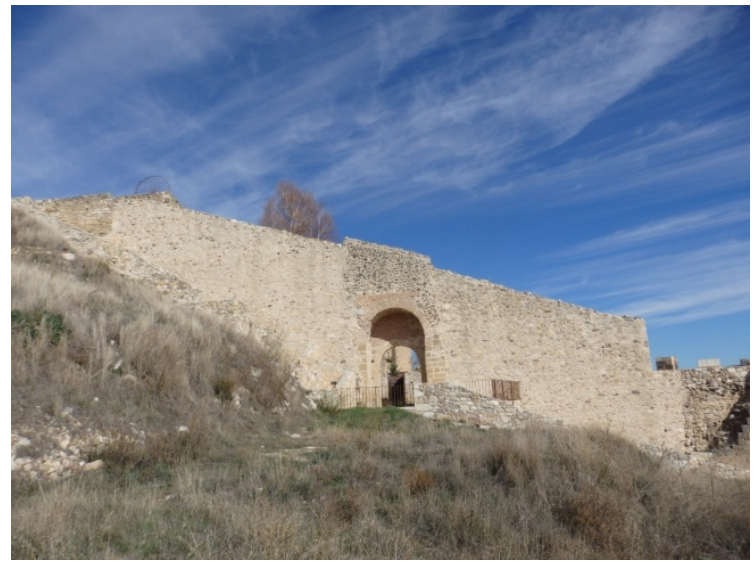

Fig. 5.5.22. Vista sur del tramo de Hontanillas. Los tramos a ambos lados del postigo fueron reconstruidos. [A.S.E. 18/11/2015].

Al sur de la torre T2, continúa un tramo de lienzo de muralla, todavía visible desde la carretera de acceso a la puerta de la Villa (Fig. 5.5.19). En este tramo, de escasos 7 metros de longitud, se observan piedras grandes y con cierta regularidad, colocadas directamente sobre la roca, de forma desordenada. Las piedras disminuyen de tamaño en la parte superior, pero mantienen su desordenado aparejo. Una vivienda se apoya sobre este muro, visible en la parte superior. A partir de este punto, la muralla continúa por el interior de las parcelas, por lo que no es visible desde la calle. A través de la fotografía aérea y de los datos de las NUM de Pedraza del año 2013 en esa zona, se ha podido estimar el trazado de la muralla y situar algunos restos existentes. La torre T3 (Fig. 5.5.20) es visible desde el postigo de Hontanillas.

\subsubsection{Zona de Hontanillas}

En el extremo sur del recinto amurallado, se sitúa la torre de las Hontanillas. Se utilizó como pozo en el pasado, por lo que es habitual que se denomine pozo delas Hontanillas. La m isma palabra hontanillas hace referencia a hontana, fuente. Se 
separa del recinto una distancia de 26 metros aproximadamente. La torre T4 tiene una planta poligonal de seis lados que no forman un hexágono regular y una altura cercana a los $15 \mathrm{~m}$. Se construye con sillares de tamaño medio, con un aparejo regular. Está coronado por almenas que se sitúan en cada vértice. No se trata de una torre maciza sino que el interior de la torre es hueco. En la actualidad es visitable a través de un acceso situado en la cara sureste, al que se baja por una escalera desde la calle de las Cuestas.

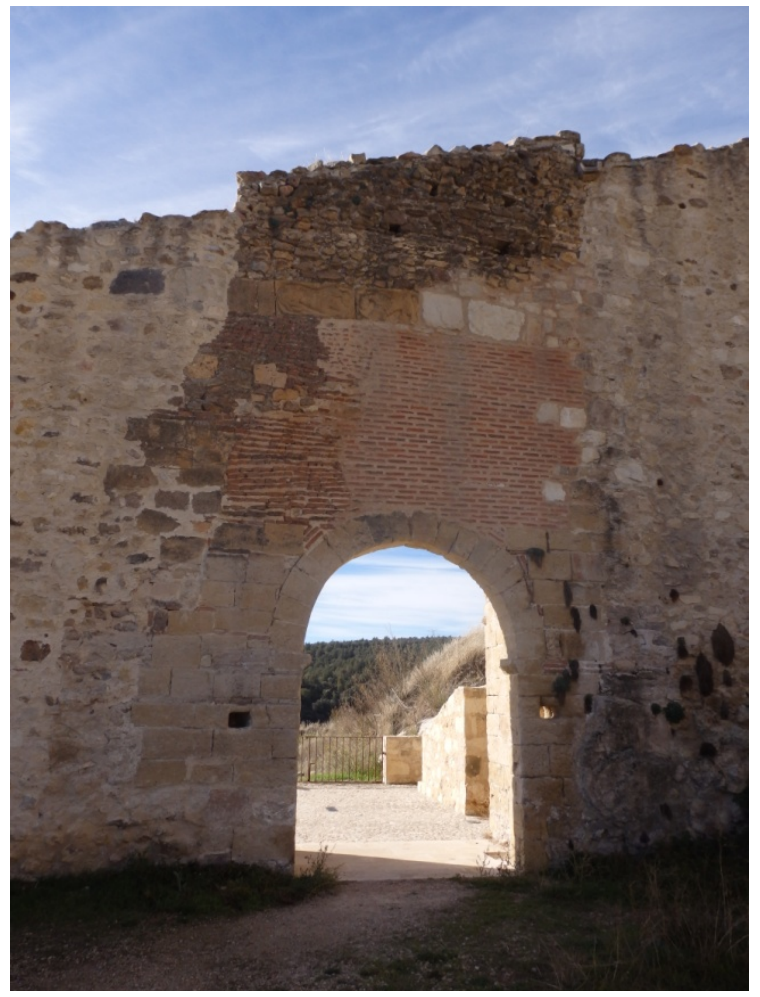

Fig. 5.5.23. Vista noroeste del postigo de Hontanillas [A.S.E. 18/11/2015].

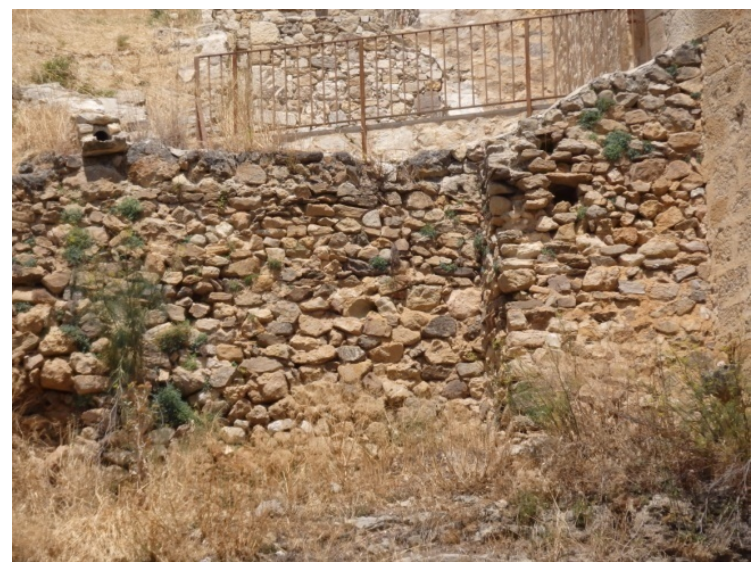

Fig. 5.5.25. Tramo L1 [A.S.E. 24/7/2016].

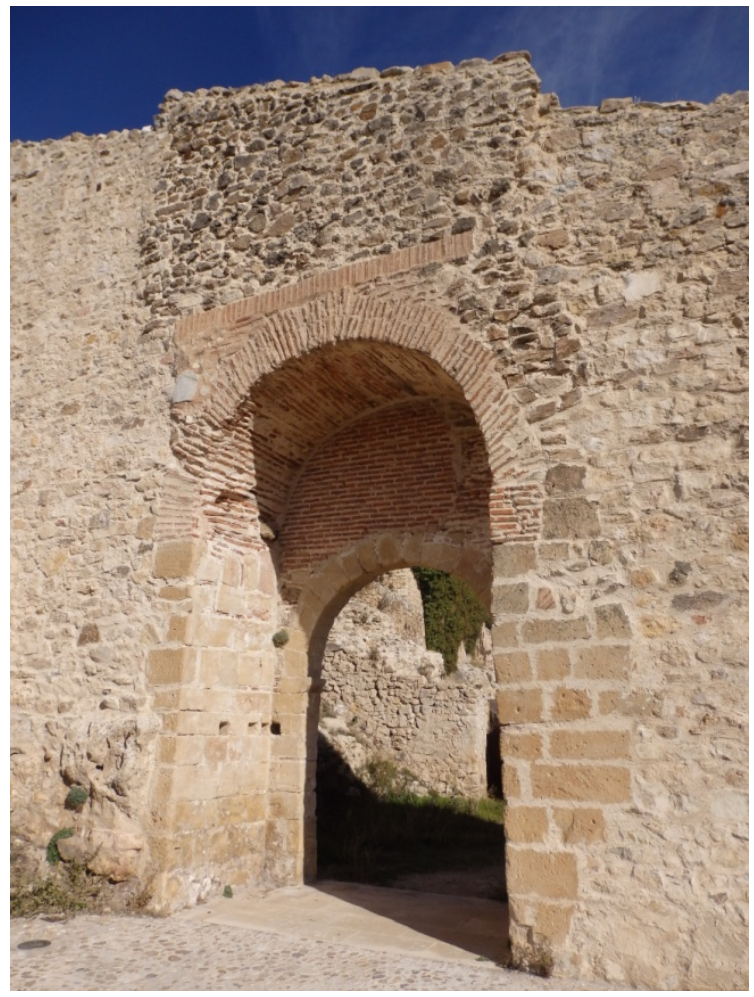

Fig. 5.5.24. Vista noroeste del postigo de Hontanillas [A.S.E. 18/11/2015].

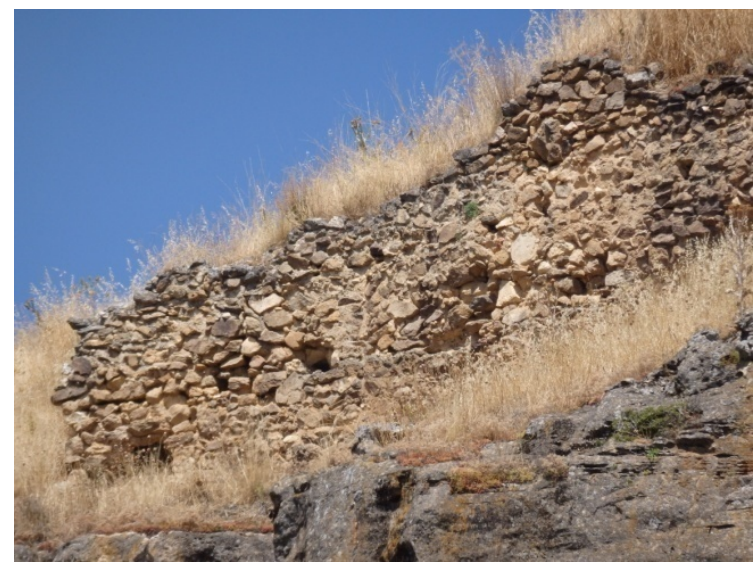

Fig. 5.5.26. Tramo L2 [A.S.E 24/7/2016]. 
Las murallas en las Comunidades de Villa y Tierra de la Diócesis de Segovia en los siglos XI a XIII. Técnica y sistemas constructivos de la arquitectura defensiva medieval.

El tramo de muralla que separa la torre T4 del lienzo en la zona urbana fue reconstruido en la restauración del año 2009 , en l a que se desenterró el postigo de Hontanillas, del que sólo era visible la parte superior ${ }^{36}$. El alzado exterior de la puerta se orienta hacia el noreste (Fig. 5.5.23). El acceso se cubre con un arco de medio punto construido con sillares de tamaños variables. En su imposta, el arco se apoya sobre dos sillares tallados con forma de capitel. Los pilares del arco se construyen también con sillares. A ambos lados del arco se conserva parte del muro de sillares en el que se integraba el arco. Sobre el arco se observa una fábrica de ladrillo. En su mayor parte, se trata de una fáb rica de ladrillo moderna, reconstruida durante la restauración. En la parte izquierda se observa una fábr ica de I adrillo irregular, desordenada, orientada en distintas direcciones a modo de relleno. Ladrillos aislados se encuentran introducidos entre sillares, rellenando huecos. Esta fábrica recuerda la encontrada en la puerta de la Villa. Sobre esta fábrica, se ubica una hilera de sillares grandes, dos de el los muestran un $r$ elieve tallado que representa dos caballos enfrentados de los que se habla más adelante (Fig. 5.5.50). A la derecha, los dos sillares con tono más claro han sido añadidos en la restauración. Sobre la hilera de sillares se organizan hasta tres hiladas de mampostería encofrada, donde son visibles las tapias con algunos de sus mechinales.

Hacia el interior, la cara suroeste, es visible una bóveda de l adrillo que c ubre el acceso, con una altura y una anchura superior al arco (Fig. 5.5.24). El arco exterior se compone de dos hiladas de ladrillos colocados a soga. La bóv eda se apoya sobre muros construidos con sillares de piedra, que cubren el grosor del muro y parte del alzado. En su apoyo derecho, la bóveda se afianza sobre un muro de ladrillo antes de iniciar su recorrido circular. Los ladrillos iniciales presentan una inclinación forzada para tratarse del arranque de la bóveda. En el lado izquierdo, la posición de los ladrillos está más compensada y la bóveda arranca directamente sobre el muro de sillares. Sobre la bóveda, se sitúa una hilada de ladrillos a tizón, a modo de imposta, no visible en las fotografías antiguas de esta zona, por lo que se presupone añadida en la restauración. Sobre la hilada de I adrillos se observa un apar ejo de p iedra mampuesta de tamaño medio, donde no s on apreciables los elementos constructivos presentes en el alzado opuesto. Es probable que se trate de tapia de mampostería, de acuerdo con el lado opuesto y con fotografías anteriores a la restauración de 2009.

\subsubsection{Zona suroeste del recinto}

Desde la torre T4 hasta el castillo, se suceden cinco restos aislados de muralla, construidos en el borde del cortado. Esta zona está poblada de vegetación y los restos se encuentran parcialmente ocultos. El desnivel es considerable y algunos de los restos se sitúan en lugares que son poco accesibles. Junto a la torre T4 se observa un primer tramo de escasa longitud, seguido por otro más largo. El material empleado es el mampuesto de piedra. Se puede identificar algunas marcas de tapia en los restos

\footnotetext{
${ }^{36}$ En el enlace a continuación, se puede consultar una imagen de agosto de 2007 donde se ve el estado anterior a la restauración de esta zona de la muralla. El enlace muestra una fotografía de un usuario de la plataforma web Flickr. https://www.flickr.com/photos/pibepa/3093271052 [Consultado el 31/5/2016]
} 
(Fig. 5.5.25, Fig. 5.5.26). En esta zona se ubica la ruina de una construcción de planta rectangular, usada a modo de palomar. La posición de este elemento está ligeramente retranqueada en relación con el recorrido de l a muralla, y sus dimensiones son similares a las de las torres T2 y T3 del recinto amurallado. Más al sur, el resto L3 (Fig. 5.5.27) se encuentra parcialmente cubierto por la vegetación. Tiene un as pecto masivo, se compone de piedras mampuestas irregulares de tamaño medio. Es difícil identificar sistemas de construcción en este resto.

Más al este, se ubica el tramo L4 (Fig. 5.5.28) donde se reconoce más fácilmente el carácter de muro. Este tramo se compone de piedras de tamaño medio, irregulares. Es reconocible en algunos puntos la traza del uso de encofrado para la construcción del muro. En la sección del muro, se observa la línea horizontal divisoria entre tapias. El tramo L5 (Fig. 5.5.29) tiene una I ongitud de 10m aproximadamente. Se eleva una altura de escasos $200 \mathrm{~cm}$ sobre la roca. Se observan líneas horizontales correspondientes al límite de las tapias, así como algunos mechinales. El muro se yergue en el mismo borde la roca y se adapta a s u recorrido arbitrario. En algunos puntos, apenas se conservan cuatro hiladas de piedra sobre la roca (Fig. 5.5.30).

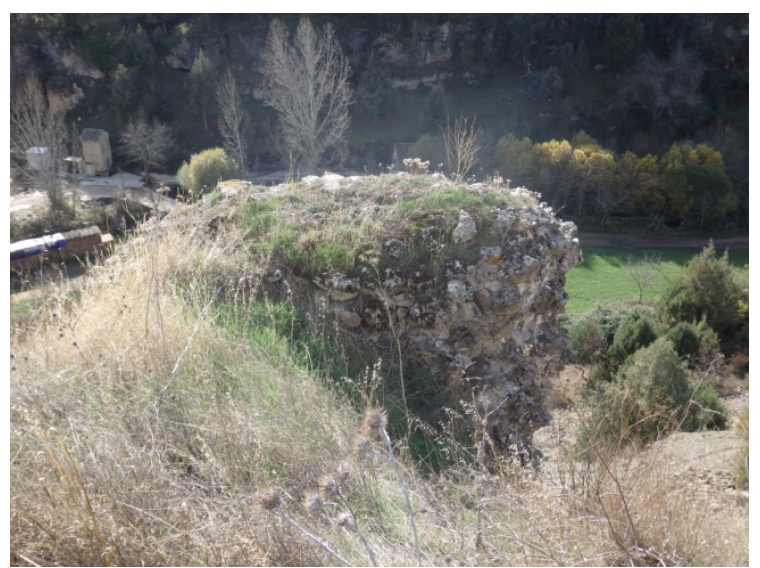

Fig. 5.5.27. Resto L3 en la zona sur del núcleo [A.S.E. 18/11/2015].

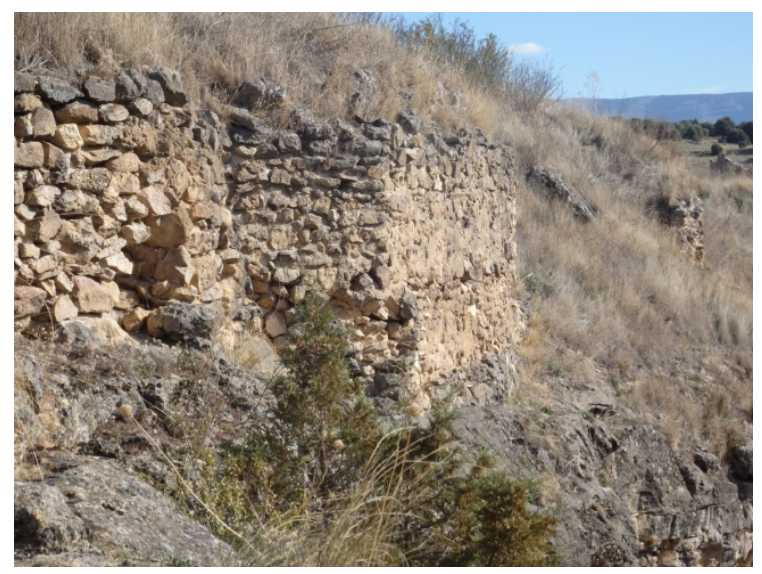

Fig. 5.5.29. Tramo L5 en la zona sur del núcleo [A.S.E. 18/11/2015].

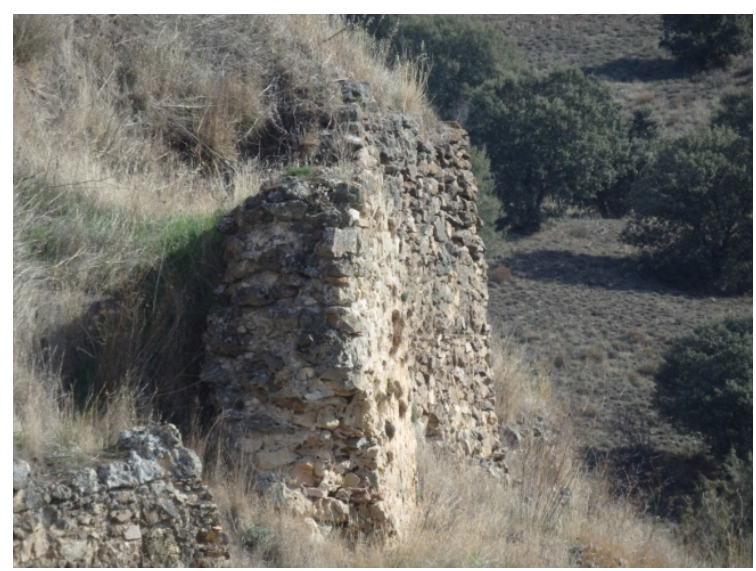

Fig. 5.5.28. Resto L4 en la zona sur del núcleo [A.S.E. 18/11/2015].

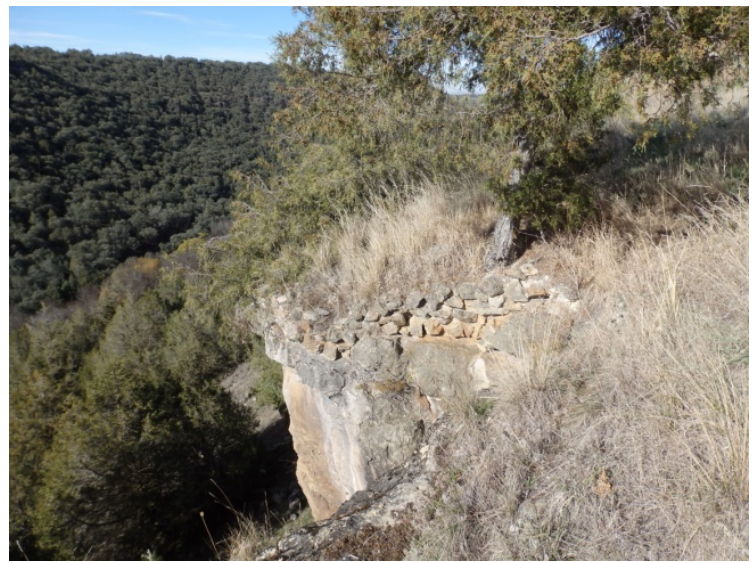

Fig. 5.5.30. Resto L6 en la zona este del núcleo [A.S.E. 18/11/2015]. 
Las murallas en las Comunidades de Villa y Tierra de la Diócesis de Segovia en los siglos XI a XIII. Técnica y sistemas constructivos de la arquitectura defensiva medieval.

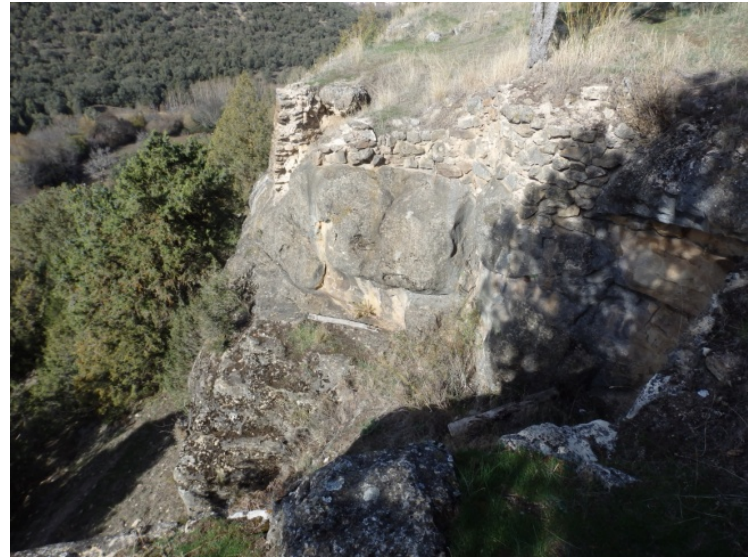

Fig. 5.5.31. Resto L7 sobre la roca [A.S.E. 18/11/2015].

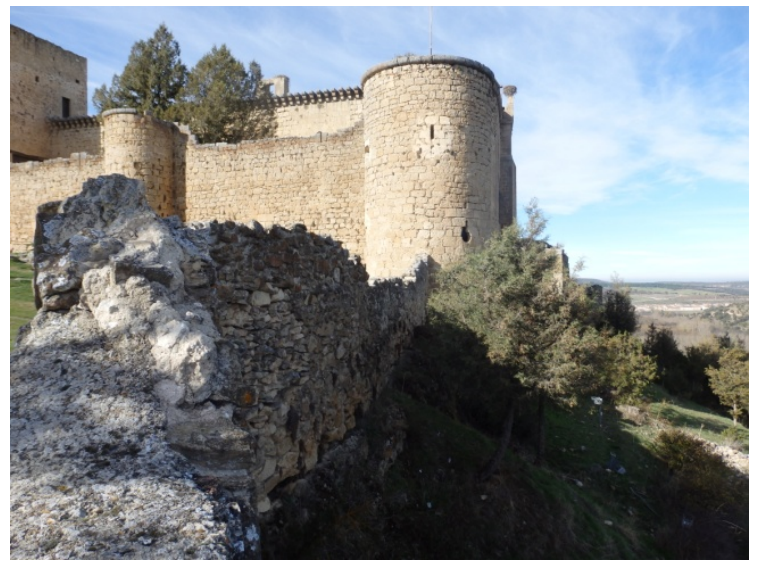

Fig. 5.5.33. Tramo de muralla junto al castillo [A.S.E. 18/11/2015].

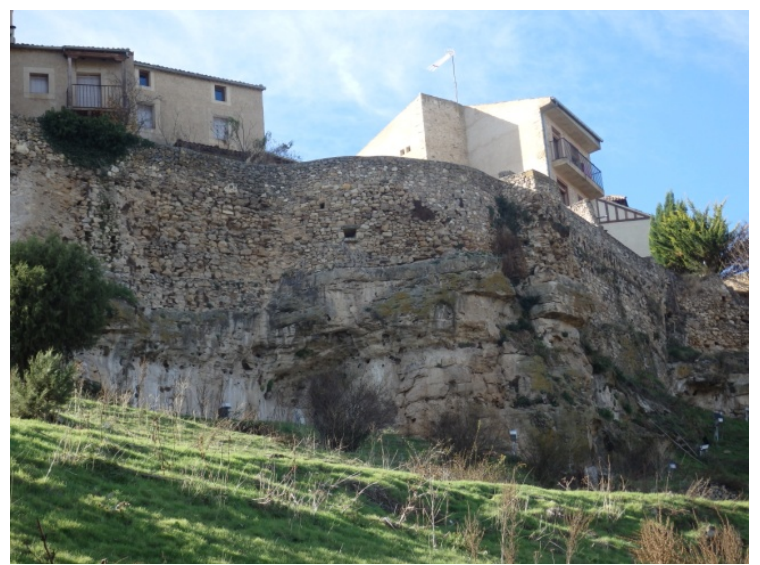

Fig. 5.5.35. Lienzo de muralla a la altura de la parcela Matadero 7 [A.S.E. 18/11/2015].

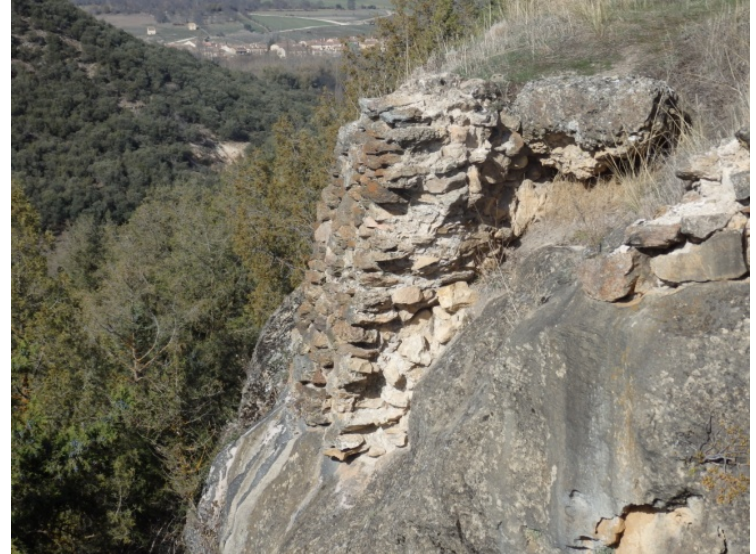

Fig. 5.5.32. Parte de L7 [A.S.E. 18/11/2015].

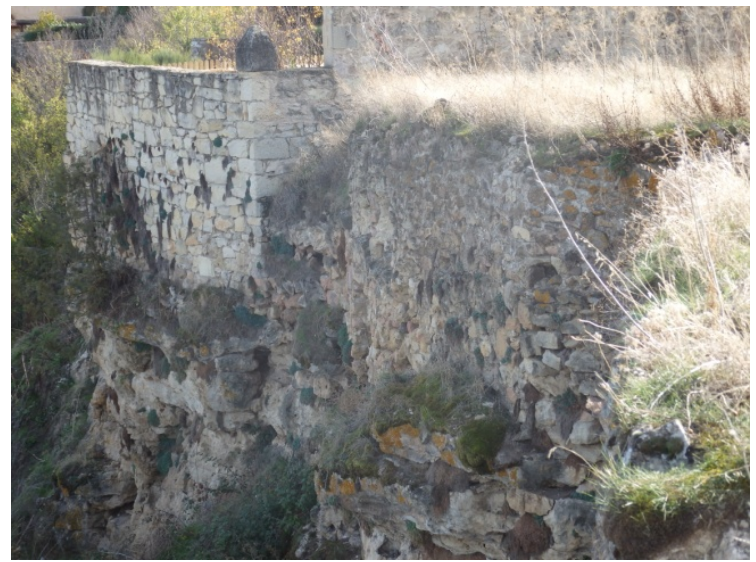

Fig. 5.5.34. Parte de la muralla y zonas reconstruidas [A.S.E. 18/11/2015].

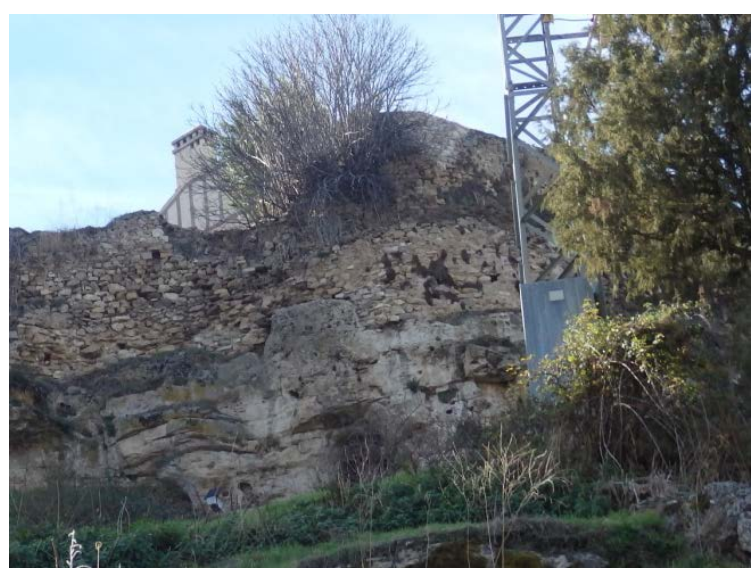

Fig. 5.5.36. Lienzo de muralla en la zona norte del núcleo [A.S.E. 18/11/2015]. 
Muy cerca del castillo se encuentran los restos L7 (Fig. 5.5.31), cuya altura no alcanza los dos metros sobre la roca. El grosor del muro es de apenas $100 \mathrm{~cm}$. Se construye de nuevo con piedras irregulares, mampuestos. No se observa un esfuerzo por construir una cimentación con piedras más grandes o más regulares. Se observa el empleo de piedras diferentes en estos restos. En una parte las piedras son más planas y de menos tamaño, mientras que en otra zona, las piedras son ligeramente más grandes y de forma más redondeada.

Desde el castillo hacia el este, en la zona norte del núcleo, continúa el recorrido de la muralla. Sólo es visible desde la parte exterior del recinto, ya que hacia el interior las parcelas privadas llegan hasta la misma muralla. En la mayor parte de estas parcelas, las nuevas construcciones no se apoyan sobre la muralla, a excepción de la zona junto a la puerta de la villa, donde las construcciones utilizan parte de la muralla como base de sus muros (Fig. 5.5.38). Parte del volumen que forma la puerta de la Villa se ubica en el borde del cortado, mostrando diferencias en su sistema constructivo en relación con el visible en los lienzos (Fig. 5.5.37).También en el borde de la roca, se yerguen los lienzos construidos con piedras de tam año medio e irregulares. Todavía se ven marcas de las tapias empleadas en su construcción. A la altura de las parcelas de la calle Matadero 7 (Fig. 5.5.35) se pueden contar hasta 5 tapias de altura sobre la roca. Se observan igualmente algunos de los mechinales empleados en su construcción. Las partes superiores de los muros se encuentran modificadas y rematadas como petos de cierra de las parcelas.

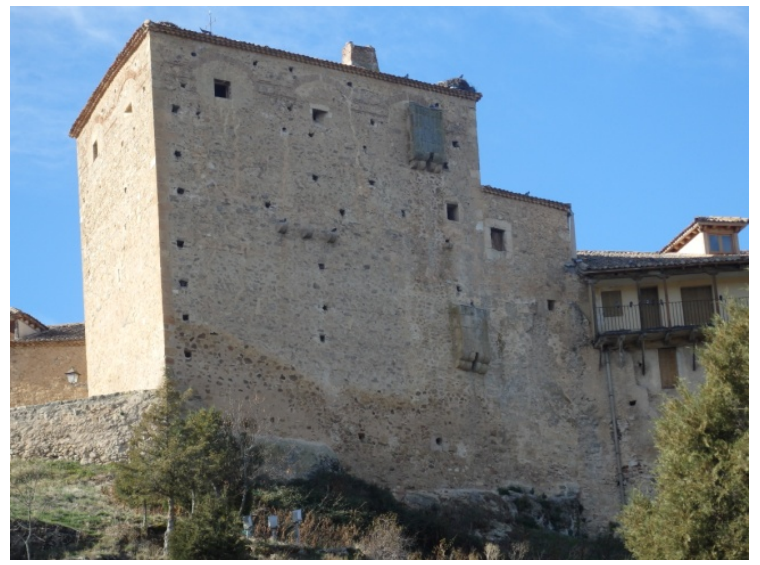

Fig. 5.5.37. Puerta de la villa desde el noroeste [A.S.E. 18/11/2015].

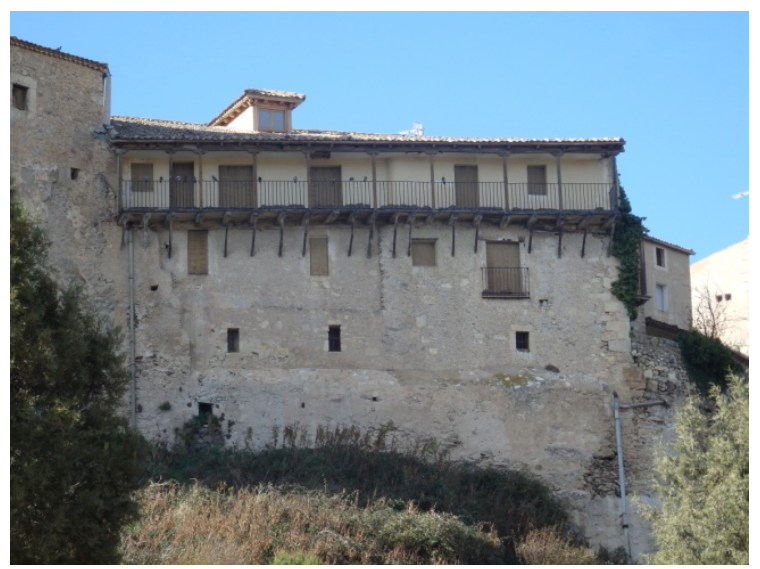

Fig. 5.5.38. Construcciones sobre la muralla junto a la puerta de la villa, hacia el norte [A.S.E. 18/11/2015].

\subsubsection{Características principales de los elementos descritos}

Las características de este recinto se han tratado de resumir a través de las dos tablas siguientes. En la Tabla 5.5.1, se identifican cada una de I as torres y puertas del recinto, relacionándolas entre sí en caso de integrarse las torres en la composición de las puertas. El número total de torres es de cuatro, considerándose sólo una de ellas integrante de la puerta de la Villa. Se trata de un número escaso de torres para un recinto amurallado de e stas dimensiones. La to rre T4 des taca sobre el resto por la 
Las murallas en las Comunidades de Villa y Tierra de la Diócesis de Segovia en los siglos XI a XIII. Técnica y sistemas constructivos de la arquitectura defensiva medieval.

forma poligonal de su planta y por la importancia de su diámetro, en comparación con las medidas más modestas de las torres T2 y T3. La tor re T1, que fl anquea el lado derecho del acceso de la Villa también se distancia del resto por su carácter de edificio que alberga, además de la función defensiva, un uso en su interior.

En la Tabla 5.5.2 se han detallado los tramos del recinto, indicando para cada uno de ellos si se ha llevado a cabo alguna reconstrucción moderna, en qué estado se encuentra y qué longitudes se conservan, han desaparecido o han sido alteradas a raíz de nuevas construcciones o restauraciones.

Tabla 5.5.1. Características y dimensiones de torres y su relación con las puertas. Fuente: Elaboración propia.

\begin{tabular}{|c|c|c|c|c|c|c|c|c|}
\hline 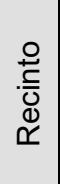 & $\stackrel{\mathscr{0}}{\stackrel{0}{\circ}}$ & $\begin{array}{l}0 \\
\frac{0}{2} \\
\frac{1}{2} \\
0\end{array}$ & Nombre asociado & $\begin{array}{l}\text { Tipo de } \\
\text { puerta / } \\
\text { torre }\end{array}$ & $\begin{array}{l}\text { Sección de } \\
\text { torre }\end{array}$ & $\begin{array}{l}\text { Dimensiones } \\
\text { torres } \\
\text { (Diámetro } \varnothing \text {, } \\
\text { Fondo F, Ancho } \\
\text { A) }\end{array}$ & $\begin{array}{l}\text { Relación con } \\
\text { lienzo }\end{array}$ & $\begin{array}{c}\text { Zócalo/ } \\
\text { Base }\end{array}$ \\
\hline \multirow{5}{*}{$\mathrm{R} 1$} & T1 & $\mathrm{P} 1$ & Puerta de la Villa & $\begin{array}{c}\text { En } \\
\text { esquina }\end{array}$ & Rectangular & $\mathrm{A} 10,50 \times \mathrm{F} 12 \mathrm{~m}$ & - & No \\
\hline & T2 & - & - & $\begin{array}{c}\text { En línea } \\
\text { con lienzo }\end{array}$ & Rectangular & $\mathrm{A} 7,40 \mathrm{xF} 4,10 \mathrm{~m}$ & Integrado & $\begin{array}{l}\text { Sí, en } \\
\text { talud }\end{array}$ \\
\hline & T3 & - & - & $\begin{array}{c}\text { En línea } \\
\text { con lienzo }\end{array}$ & Rectangular & $\mathrm{A} 7,10 \mathrm{xF} 2,50 \mathrm{~m}$ & Integrado & No \\
\hline & $\mathrm{T} 4$ & - & $\begin{array}{c}\text { Torre o pozo de } \\
\text { Hontanillas }\end{array}$ & $\begin{array}{c}\text { En } \\
\text { esquina }\end{array}$ & $\begin{array}{l}\text { Hexágono } \\
\text { irregular }\end{array}$ & $\varnothing 16,75 \mathrm{~m}$ & Integrado & No \\
\hline & - & $\mathrm{P} 2$ & $\begin{array}{l}\text { Postigo de } \\
\text { Hontanillas }\end{array}$ & $\begin{array}{l}\text { Arco en } \\
\text { lienzo }\end{array}$ & - & $\mathrm{A} 2,52 \mathrm{~m}$ & Integrado & No \\
\hline
\end{tabular}

Tabla 5.5.2. Características y dimensiones de los tramos de muralla. Fuente: Elaboración propia.

\begin{tabular}{|c|c|c|c|c|}
\hline 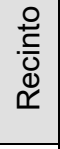 & Tramo & $\begin{array}{l}\text { Reconstrucción } \\
\text { moderna }\end{array}$ & Estado & $\begin{array}{c}\text { Longitud }(\mathrm{m}) \\
\text { (E Existente / D } \\
\text { Desaparecido / M Moderno } \\
\text { / A Alterado) }\end{array}$ \\
\hline \multirow{11}{*}{ R1 } & T1-T2 & No & Restaurado & A91 \\
\hline & T2-T3 & No & Restaurado & $\begin{array}{c}\text { A9 / D8 / A13 / D20 / } \\
\text { A11 / D54 } \\
\end{array}$ \\
\hline & T3-T4 & Sí & Restaurado & M41 / E8 / M7 / E 45 \\
\hline & L1-L2 & No & Deteriorado & E11/ D8 \\
\hline & L2-L3 & No & Deteriorado & E27 / D60 \\
\hline & L3-L4 & No & Deteriorado & E7 / D23 \\
\hline & L4-L5 & No & Deteriorado & E3 / D78 \\
\hline & L5-L6 & No & Deteriorado & E22/ D105 \\
\hline & L6-L7 & No & Deteriorado & E14 / D105 \\
\hline & L7-Castillo & No & Deteriorado & E14 / D109 \\
\hline & L8 & Sí & Alterado & A 512 \\
\hline
\end{tabular}




\subsubsection{Análisis constructivo}

\subsubsection{Soluciones constructivas presentes en la muralla}

A continuación se detallan las distintas soluciones constructivas empleadas en la muralla. En los restos intermitentes de la zona suroeste, desde la torre de Hontanillas hasta el castillo, se observa el uso de mampostería encofrada (Fig. 5.5.39). En el postigo de Hontanillas, también se encuentra esta técnica sobre el arco de acceso, en su cara exterior. Se utilizan mampuestos de proporción alargada (Fig. 5.5.40). En este postigo se combinan otras técnicas, como la sillería o el aparejo de ladrillo. El ladrillo también se utiliza como relleno, en algunas zonas de la sillería (Fig. 5.5.43). La reconstrucción realizada a ambos lados de la puerta se realiza tratando de emular una mampostería. La torre de Hontanillas se realiza prácticamente en su totalidad con un aparejo de sillería. Este sistema sólo es visible en es ta torre (Fig. 5.5.45). Más adelante, en la Tabla 5.5.3, se indican las soluciones constructivas encontradas y se detalla en qué elementos de la muralla se han localizado.

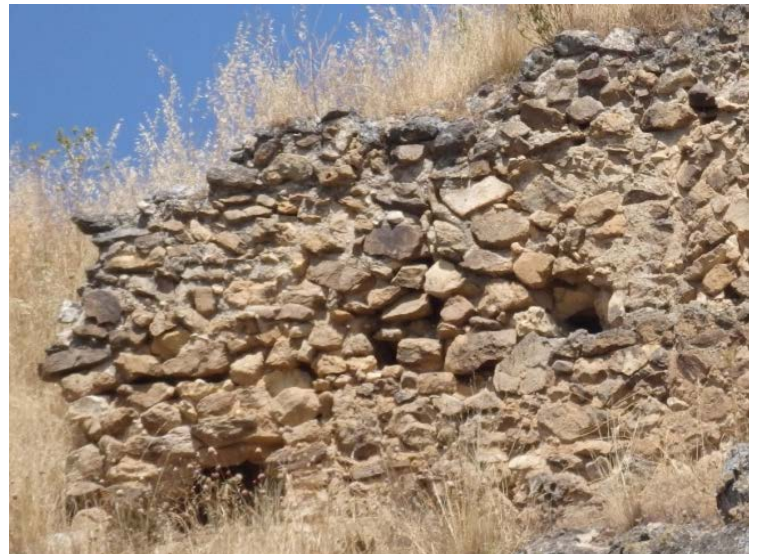

Fig. 5.5.39. Tapia de mampostería [A.S.E. 24/7/2016]

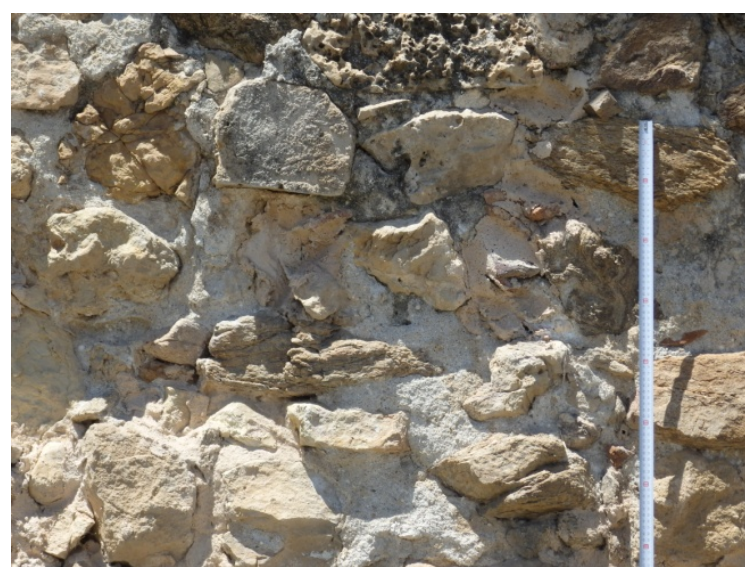

Fig. 5.5.41. Mampostería en tramo P1-T2 [24/7/2016].

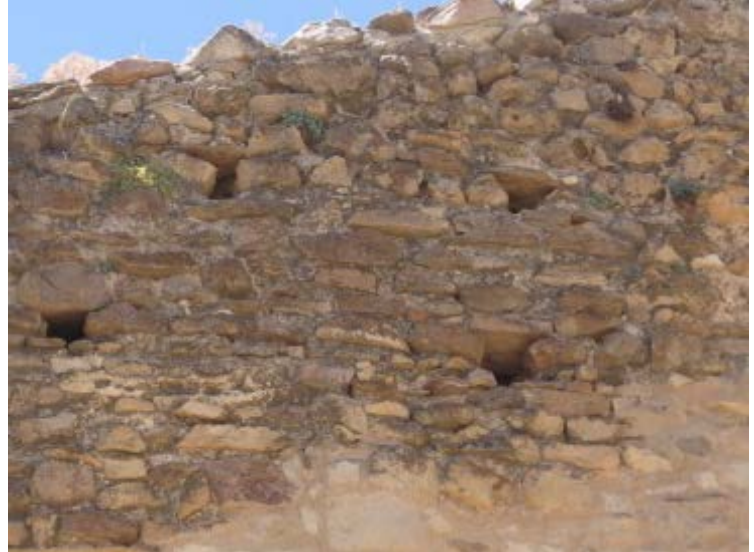

Fig. 5.5.40. Tapia de mampostería con piedras planas [A.S.E 24/7/2016]

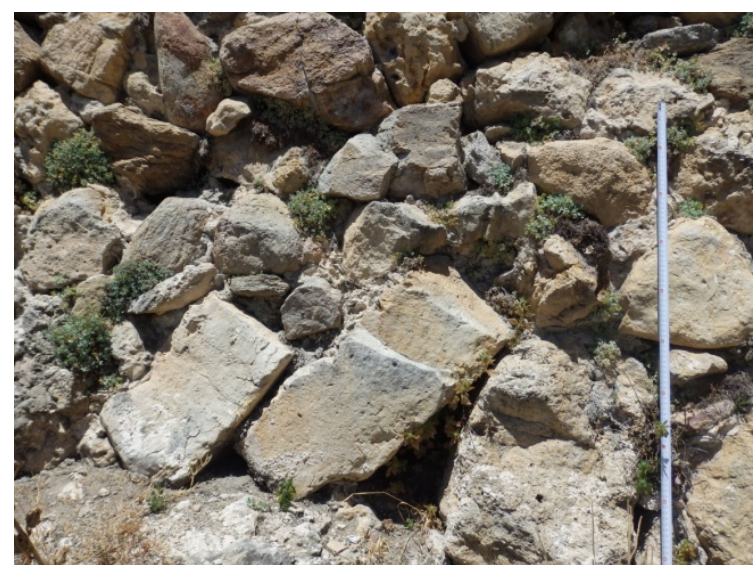

Fig. 5.5.42. Mampostería en tramo P1-T2 [A. S. E. 24/7/2016]. 
Las murallas en las Comunidades de Villa y Tierra de la Diócesis de Segovia en los siglos XI a XIII. Técnica y sistemas constructivos de la arquitectura defensiva medieval.

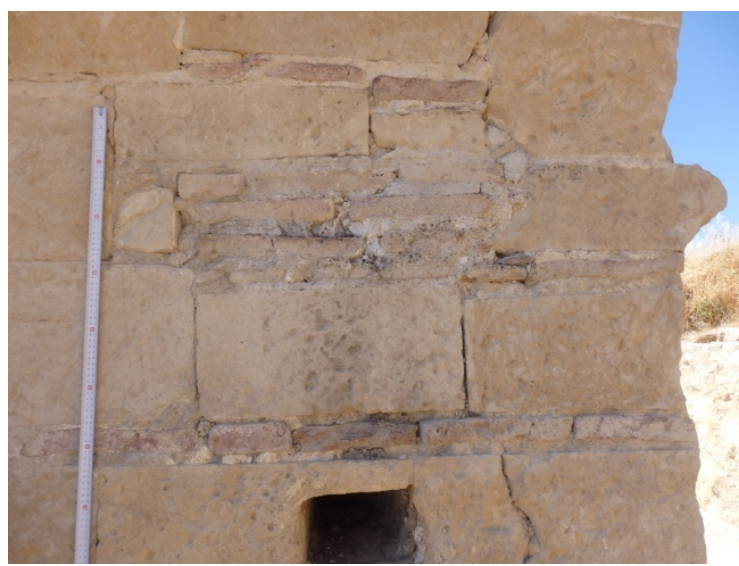

Fig. 5.5.43. Sillería en el alzado exterior del postigo de Hontanillas. Se observan hiladas de ladrillo entre los sillares [A.S.E 24/7/2016].

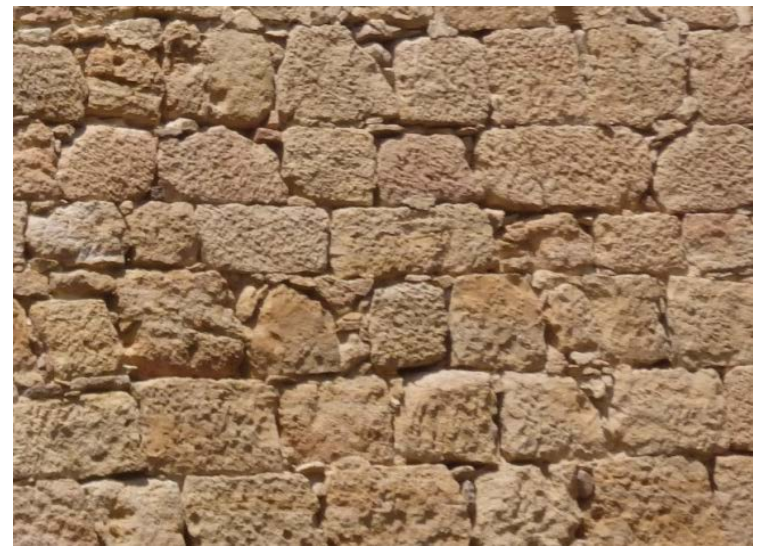

Fig. 5.5.45. Sillería de la torre de Hontanillas [A.S.E. 24/7/2016].

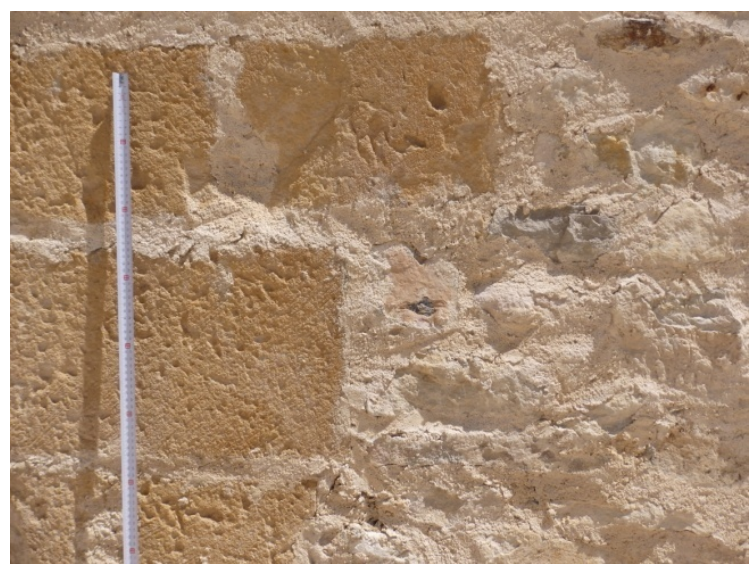

Fig. 5.5.44. Sillería en el alzado interior del postigo de Hontanillas [A.S.E 24/7/2016].

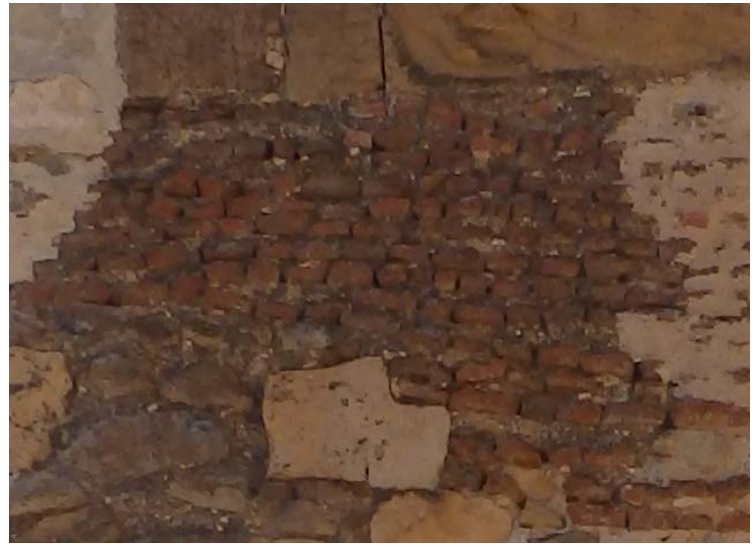

Fig. 5.5.46. Fábrica de ladrillo singular en la cara exterior del postigo de Hontanillas [A.S.E. 24/7/2016].

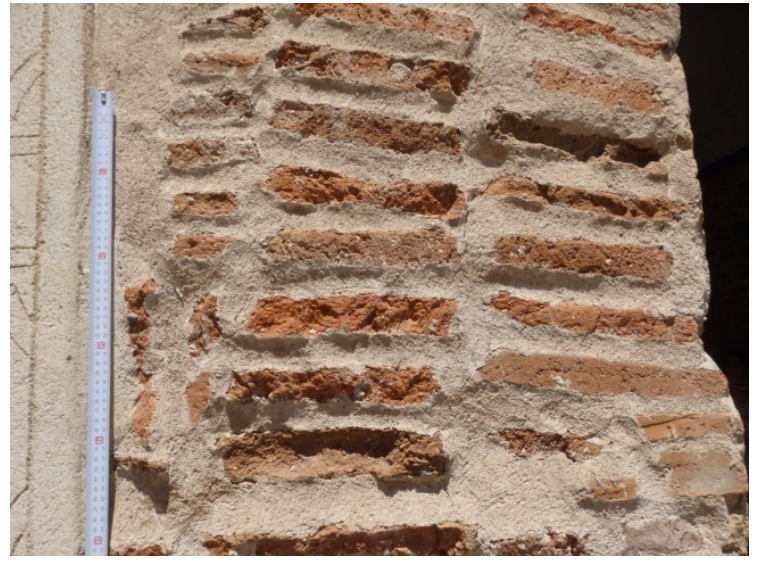

Fig. 5.5.47. Ladrillo en la cara exterior del arco de la Villa [A.S.E 24/7/2016].

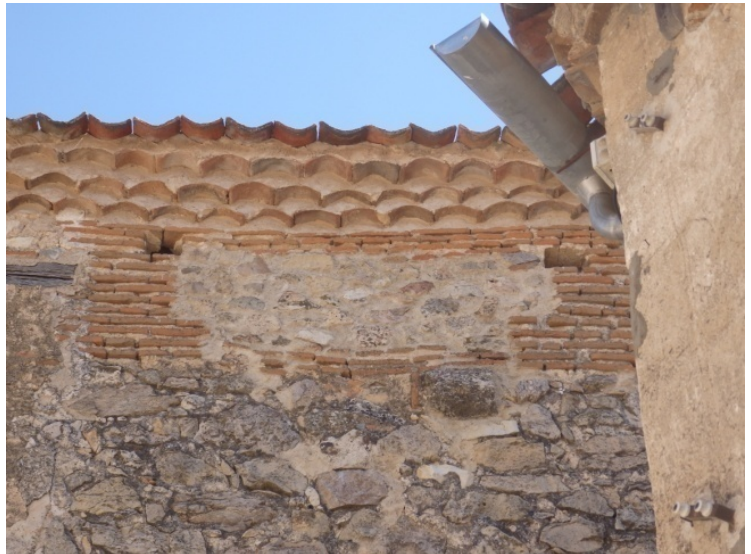

Fig. 5.5.48. Tapia mixta en la coronación del alzado interior de la puerta de la villa [A.S.E 24/7/2016]. 
Tabla 5.5.3. Soluciones constructivas localizadas por elementos de la muralla.

\begin{tabular}{|l|l|}
\cline { 2 - 2 } \multicolumn{1}{l|}{} & Elementos donde se encuentra \\
\hline $\begin{array}{l}\text { Tapia de mampostería encofrada } \\
\text { Tapia mixta de ladrillo con verdugada triple y y } \\
\text { machones dentados }\end{array}$ & Puerta P1 \\
\hline $\begin{array}{l}\text { Sillería } \\
\text { En esquinas } \\
\text { En arcos }\end{array}$ & $\begin{array}{l}\text { Puerta P2 } \\
\text { Fábrica } \\
\text { Sillarejo }\end{array}$ \\
\hline $\begin{array}{l}\text { Mampostería } \\
\text { Fábrica } \\
\text { Mechinales }\end{array}$ & $\begin{array}{l}\text { Torre Hontanillas } \\
\text { Torre Hontanillas }\end{array}$ \\
\hline $\begin{array}{l}\text { Ladrillo } \\
\text { Fábrica }\end{array}$ & \\
En arcos & Mechinales de la tapia de mampostería \\
\hline Decoración & Puerta P1 y P2 \\
\hline Restaurado & Puertas P1 y P2 \\
\hline Reconstruido & Puerta P1 \\
\hline
\end{tabular}

\subsubsection{Postigo de Hontanillas}

El entorno del postigo de Hontanillas fue restaurado y reconstruido en el año 2011. Gran parte del tramo en el que se ubica este postigo es de nueva construcción. En el alzado dibujado sobre la fotografía rectificada (Fig. 5.5.49) se ha identificado las zonas reconstruidas. Al observar las zonas reconstruidas y las existentes, es posible dudar que se conservara en pie. Hay que señalar que en el lado interior del lienzo se conserva una par te mayor del muro. Por otra parte y como ya se ha ex plicado anteriormente, esta zona se mantuvo parcialmente enterrada hasta su restauración. La reconstrucción se realiza mayoritariamente con un aparejo de mampuestos, aunque se observan zonas con fábrica de ladrillo o sillares en continuidad con la solución constructiva original. Los restos originales muestran varias soluciones constructivas empleadas en el postigo. En apenas siete metros de anchura por casi diez de altura se encuentra hasta tres técnicas diferentes. El arco y sus estribos se realizan con sillería. Tiene una anchura de $2,52 \mathrm{~m}$ y alcanza la altura de 3,51 . Las hiladas tienen una altura irregular, que oscila entre los $15 \mathrm{~cm}$ y $45 \mathrm{~cm}$, siendo frecuente la altura de $20-30 \mathrm{~cm}$. El arco se compone de sillares de anchura cercana a los $25 \mathrm{~cm}$, aunque algunas dovelas son más estrechas. Las más anchas llegan a los $30 \mathrm{~cm}$. El arranque del arco muestra una pieza de sillería que forma una ménsula hacia el interior del arco. En varios puntos de la sillería que compone el arco se insertan hiladas de ladrillo aisladas que parecen querer rellenar los huecos que han quedado entre las piedras.

Sobre el arco, se observa una fábrica de ladrillo particular, con ladrillos de tamaño irregular, colocados a tizón de forma apretada, sin apenas juntas verticales. Aunque se identifica como aparejo a tizón, cada ladrillo tiene una longitud diferente. Las llagas horizontales son más visibles, se produce una s eparación mayor que en sentido vertical, donde prácticamente no hay llaga (Fig. 5.5.46). Las hiladas de este aparejo no 
son completamente horizontales sino que se aprecia una inclinación que pu ede deberse a un asiento del muro en esa zona.

La hilada de sillares inmediatamente superior también presenta esa inclinación. Se ven dos grandes sillares directamente sobre la fábrica de ladrillo. El primero, situado a la izquierda, tiene una anc hura de $100 \mathrm{~cm}$ y una altura de $45 \mathrm{~cm}$. El segundo tiene la misma altura, pero su anchura se reduce a $80 \mathrm{~cm}$. En ambos sillares se observa un relieve tallado que representa la figura de lo que podrían ser dos caballos o toros. Cada sillar presenta la figura de uno de estos animales, ocupando todo el espacio posible. Se colocan en posición enfrentada, situándose sus cabezas en el encuentro de los dos sillares. Además de la cabeza, son identificables las patas y las colas de los caballos. Sobre esta hilada de sillares es visible el empleo de tapia de mampostería en los siguientes tres metros de muro. Esta zona no es muy extensa, por lo que no es sencillo identificar tapias completas, sino tan solo algunos elementos como mechinales o límites de tapia. Las piedras empleadas en las tapias son de tamaño medio y pequeño, con formas alargadas. Se ordenan en hiladas irregulares. Se observan en la tapia más baja dos columnas de piedras, hileras verticales de piedras colocadas una sobre otra. En estas tapias se observan con cierta facilidad cuatro mechinales, dos en la base de la segunda hilada de tapia y otros dos en la base de la tercera.

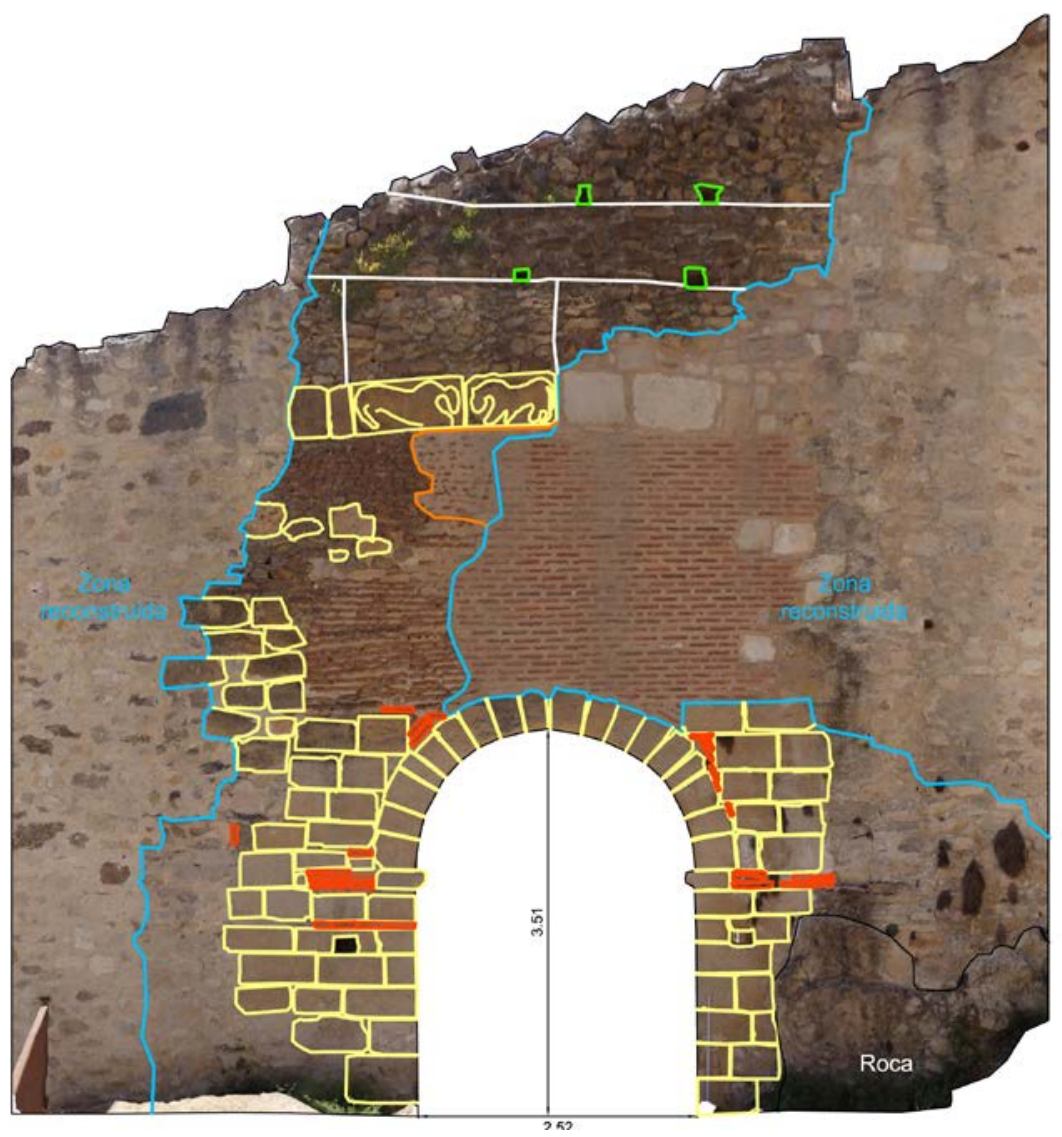

Limite visible de tapia Sillería Ladrillo

Reparaciones

Reconstrucciones

- Mechinal

\section{Postigo de} Hontanillas

Fig. 5.5.49. Alzado exterior del postigo de Hontanillas. Fuente: Elaboración propia con fotos del 24/7/2016. 


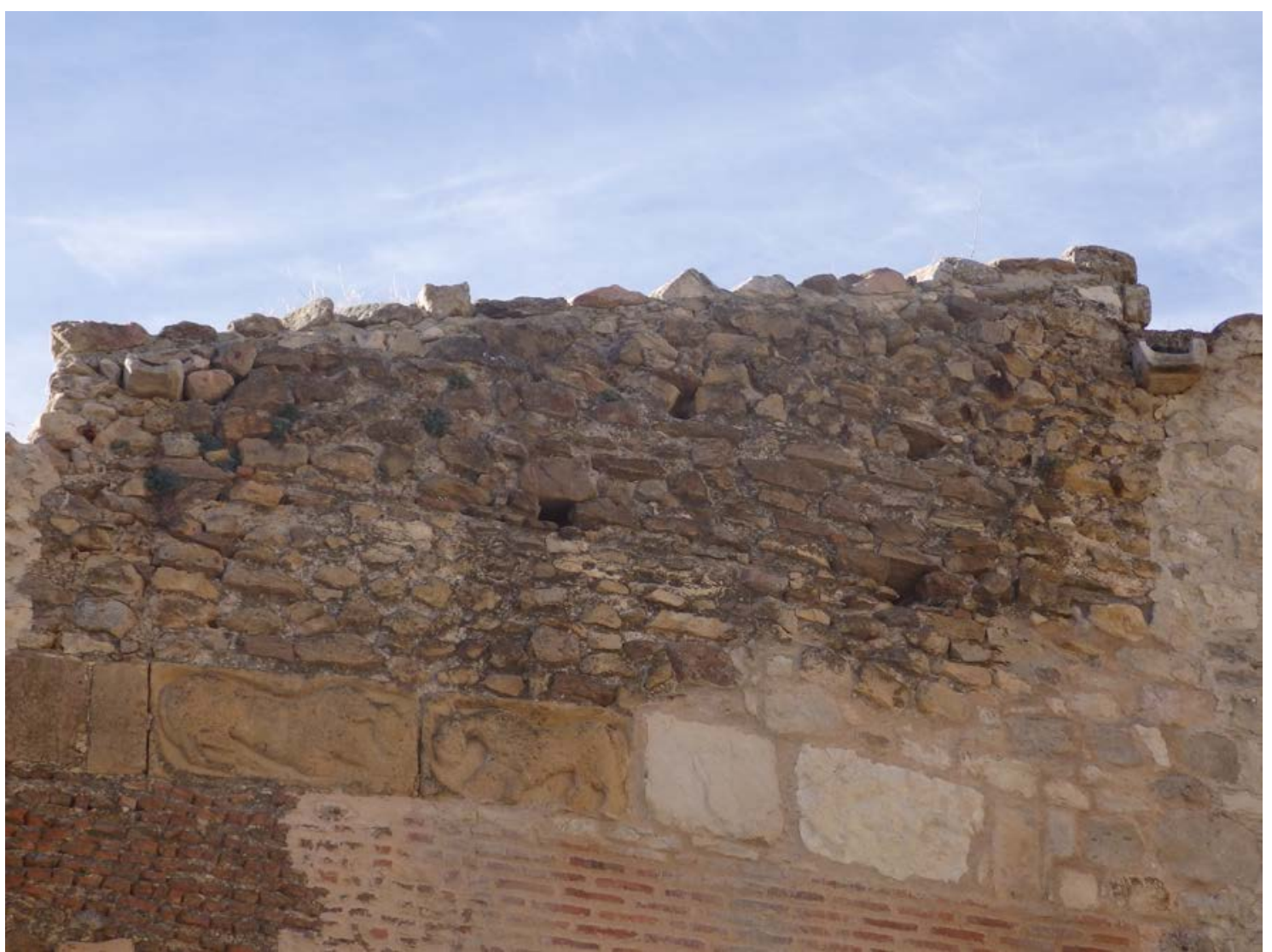

Fig. 5.5.50. Detalle de las tapias sobre el postigo de Hontanillas. Se observan los [A.S.E 24/7/2016].

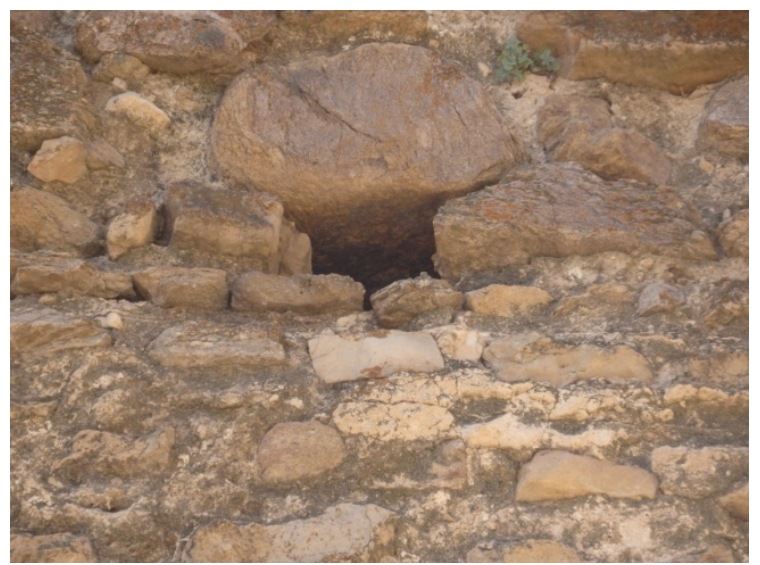

Fig. 5.5.51. Mechinal M2.1 visto desde abajo [A.S.E. 24/7/2016].

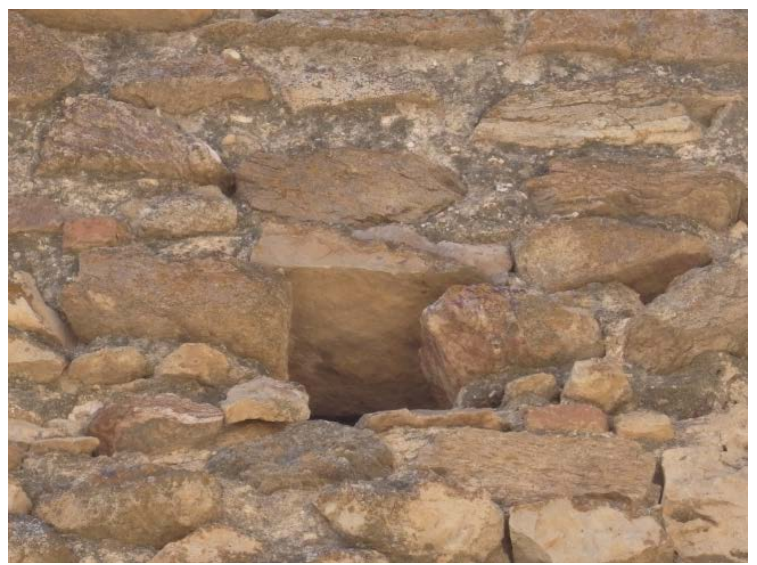

Fig. 5.5.52. Mechinal M2.2 visto desde abajo [A.S.E. 24/7/2016].

Los mechinales tienen sección cuadrangular y se configuran con mampuestos. Se sitúan en la base de las tapias. En la segunda hilada se observa un primer mechinal configurado con tres mampuestos (Fig. 5.5.51). Dos de ellos flanquean el hueco y tienen una anchura similar de $10-20 \mathrm{~cm}$ y una altura de $15 \mathrm{~cm}$ aproximadamente. El tercer mampuesto corona el mechinal y tiene un tamaño mayor, cercano a los $30 \mathrm{~cm}$ de anchura y $20 \mathrm{~cm}$ de altura, con una forma redondeada. En la misma hilada, el segundo mechinal se configura igualmente con tres piedras. Las de flanqueo son similares a las descritas en el anterior mechinal y la de coronación tiene una anchura parecida pero 
una altura muy inferior, de apenas $8 \mathrm{~cm}$, quedando una forma rectangular y plana (Fig. 5.5.52). Hay que señalar que es tas dos últimas imágenes se han to mado desde el nivel del suelo, con un ángulo forzado que ofrece una imagen fugada de los mechinales y donde se ven las caras inferiores de las piedras. La separación entre los mechinales es de $1,60 \mathrm{~cm}$ en la segunda hilada y de 1,15 en la tercera hilada. En la segunda hilada, inmediatamente bajo los mechinales, es visible una hilada de mampuestos relativamente planos, colocados a modo de verdugada (Fig. 5.5.50, Fig. 5.5.51).

Dada la escasez de tapias identificadas, en este caso no es posible realizar una representación estadística de los datos. No obstante, se ha tratado de reflejar en la Tabla 5.5.4 las características de esta tapia. La altura de las tapias es significativamente escasa, no al canza siquiera el metro, se encuentran entre $69 \mathrm{y}$ $87 \mathrm{~cm}$, por lo que se ha tomado $78 \mathrm{~cm}$ como altura representativa de este conjunto. La medida de $69 \mathrm{~cm}$ de una de I as tapias es especialmente reducida, poco habitual. La anchura es igualmente reducida y tomada de una sola tapia visible, con $190 \mathrm{~cm}$. Ha sido también difícil determinar si el tapial empleado es corrido o individual, aunque se ha considerado finalmente la primera opción. No se ven en estas tapias resto alguno de las tablas empleadas en la construcción del tapial. En cuanto a los mechinales, se especifica cuál es la sección mayoritaria, que en este caso es cuadrangular para todos los mechinales, se indica igualmente la formación del mechinal con mampuestos. Tampoco ha sido posible determinar en este caso si se han empleado medias agujas o agujas pasantes. La distancia entre mechinales se ha medido en escasos puntos, con resultados que se sitúan entre 115 y $160 \mathrm{~cm}$, con un valor medio de $137,50 \mathrm{~cm}$.

Tabla 5.5.4. Tabla de características y dimensiones de la tapia sobre el postigo de Hontanillas (P2)

\begin{tabular}{|c|c|c|c|}
\hline Tapias & P2 & Mechinales & P2 \\
\hline Altura $(\mathrm{cm})$ & $78^{*}$ & Sección mayoritaria & Cuadrangular \\
\hline Anchura (cm) & $190^{*}$ & Dimensiones $(\mathrm{cm})$ & $15 \times 15^{*} \mathrm{~cm}$ \\
\hline Espesor (cm) & $200-220(\bar{x}=210)$ & Distancia en tapia $(\mathrm{cm})$ & \multirow{2}{*}{$137,50^{*}$} \\
\hline $\begin{array}{l}\text { Restos de encofrado / } \\
\text { Tipo de tapial }\end{array}$ & Sí / Tapial corrido & $\begin{array}{l}\text { Distancia entre tapias } \\
\text { (cm) }\end{array}$ & \\
\hline $\begin{array}{l}\text { Altura de tablas de } \\
\text { encofrado }(\mathrm{cm})\end{array}$ & No visibles & Material & Mampuestos \\
\hline $\begin{array}{l}\text { Piedras exteriores } \\
\text { colocadas }\end{array}$ & Sí & $\begin{array}{l}\text { Aguja } \\
\text { perdida/recuperable }\end{array}$ & Perdida \\
\hline $\begin{array}{l}\text { Juntas más visibles en } \\
\text { paramento }\end{array}$ & Horizontales & Profundidad mechinal & - \\
\hline Materiales empleados & Mampuestos, tierra, cal & $\begin{array}{l}\text { Tipo de aguja } \\
\text { (pareadas/unitarias) }\end{array}$ & Unitarias \\
\hline $\begin{array}{l}\text { Divisiones verticales } \\
\text { visibles }\end{array}$ & No & Mechinales por cajón & - \\
\hline Verdugada & Sí, de piedra & $\begin{array}{l}\text { Ubicación de mechinal } \\
\text { en relación con tapia }\end{array}$ & Inferior \\
\hline
\end{tabular}

* Menos de 10 muestras 


\subsubsection{Tipología de las tapias en el postigo de Hontanillas (P2)}

De acuerdo con la clasificación de A. Graciani y M.A. Tabales, las tapias de este tramo podrían clasificarse como tapia monolítica con mechinales con remate de mampuesto y con verdugada de piedra (Tabla 5.5.5). De acuerdo con la clasificación de I.J. Gil Crespo, estas tapias tendrían las características de la Tabla 5.5.6.

Tabla 5.5.5. Tipología constructiva de las tapias del tramo P2 de acuerdo de Amparo Graciani y Miguel A. Tabales $(2008,139)$ en el área sevillana.

\begin{tabular}{|l|c|c|}
\cline { 2 - 3 } \multicolumn{1}{c|}{} & Mechinal & Verdugada \\
\hline Monolítico & Mampuesto & Verdugada de piedra \\
\hline
\end{tabular}

Tabla 5.5.6. Tipología constructiva de las tapias de los tramo P2 de acuerdo con la clasificación de Ignacio J. Gil Crespo (2013, 554-557)

\begin{tabular}{|l|l|}
\hline A. Material de construcción & 5. Mampostería, piedras medianas \\
\hline B. Compactación del material & 2. Vertido \\
\hline C. Función constructiva & 1. Fábrica principal \\
\hline D. Encofrado & 4. Cajones que hacen hilos continuos con junta vertical. \\
\hline E. Acabado superficial & 4. Capa externa de mampostería \\
\hline $\begin{array}{l}\text { F. Combinación de materiales } \\
\text { G. Mechinales }\end{array}$ & 4. Mampuestos, tierra y cal \\
G-b. Profundidad & 1. Situación en el propio hilo \\
G-c. Formación & - \\
G-d. Sección & 1. Formación aguja embebida en la fábrica \\
\hline
\end{tabular}

\subsubsection{Lienzo exterior L8, fondo de parcelas calle Matadero 7}

Los lienzos de la zona noreste se sitúan en áreas poco accesibles. Desde el interior, son el cierre de par celas privadas, y desde el exterior el desnivel y los vallados dificultan una aproximación completa. Esta dificultad ha complicado la posibilidad de realizar alzados rectificados con medidas reales, como se ha hecho en otras partes de la muralla o en otr os casos. Por otra parte, como ya se ha dicho, estos lienzos han sido alterados por las construcciones urbanas, que se han apoyado en ellos. Aun así es visible en algunos puntos el sistema constructivo original (Fig. 5.5.53).

En la fotografía analizada, se observa un tramo de aproximadamente seis metros, donde se pueden contar cuatro tapias de altura y una quinta incompleta sobre la que 
Las murallas en las Comunidades de Villa y Tierra de la Diócesis de Segovia en los siglos XI a XIII. Técnica y sistemas constructivos de la arquitectura defensiva medieval.

se ha construido un muro de mampostería moderno para configurar un peto que acaba en línea recta. Aunque no es visible en la imagen, la roca es ya de por sí una pared de altura importante, equivalente a la altura de la muralla. Directamente sobre la roca comienza la primera hilada de tapia. En ese límite entre roca y tapia es visible uno de los mechinales que alojaron la primera aguja colocada sobre la roca (Fig. 5.5.54).

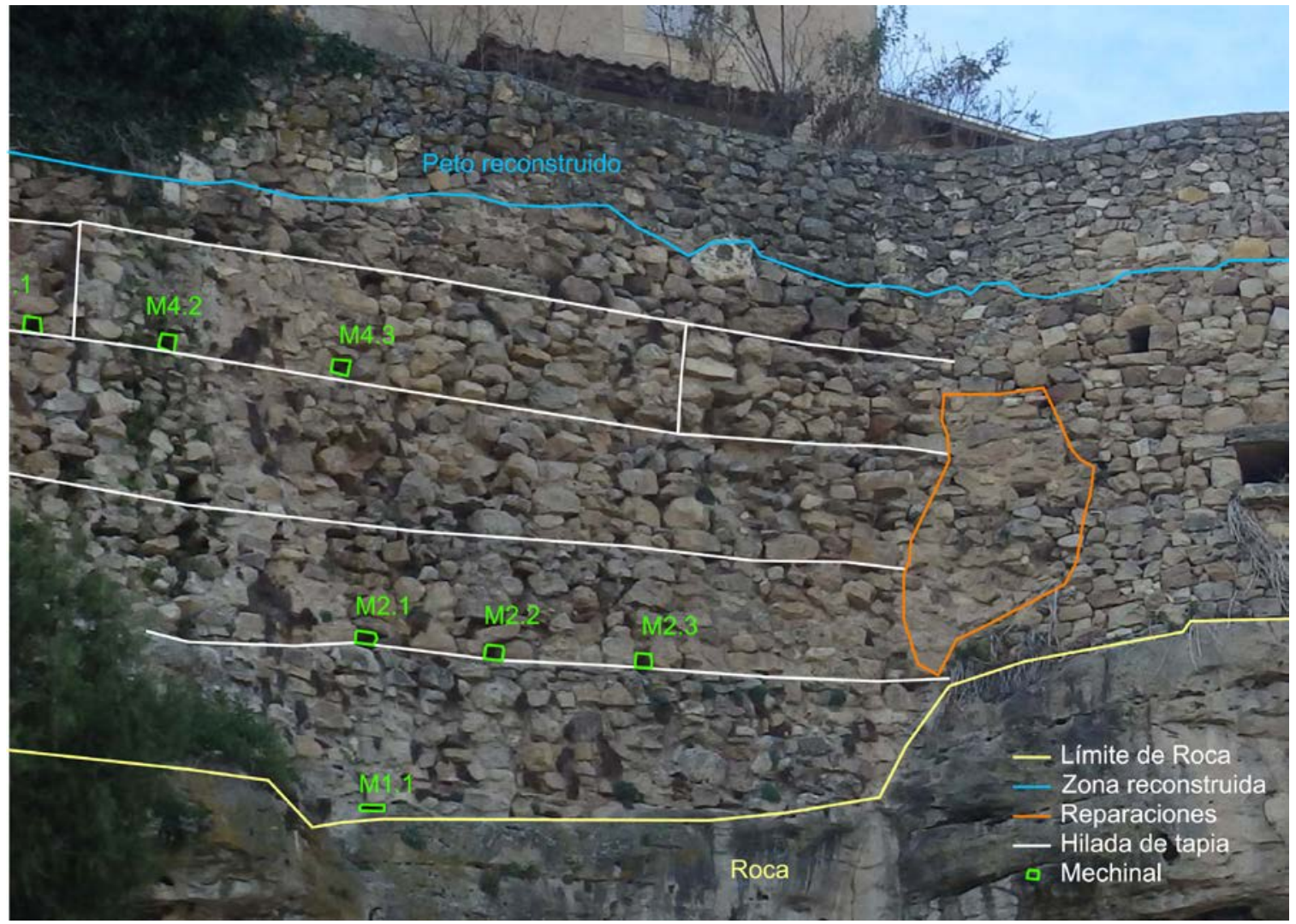

Fig. 5.5.53. Esquema sobre fotografía de lienzo L8 en la zona noreste donde se resaltan los elementos constructivos. Se sitúa en la zona posterior de las parcelas de la calle Matadero 7. Fuente: Elaboración propia sobre foto del 18/11/2015.

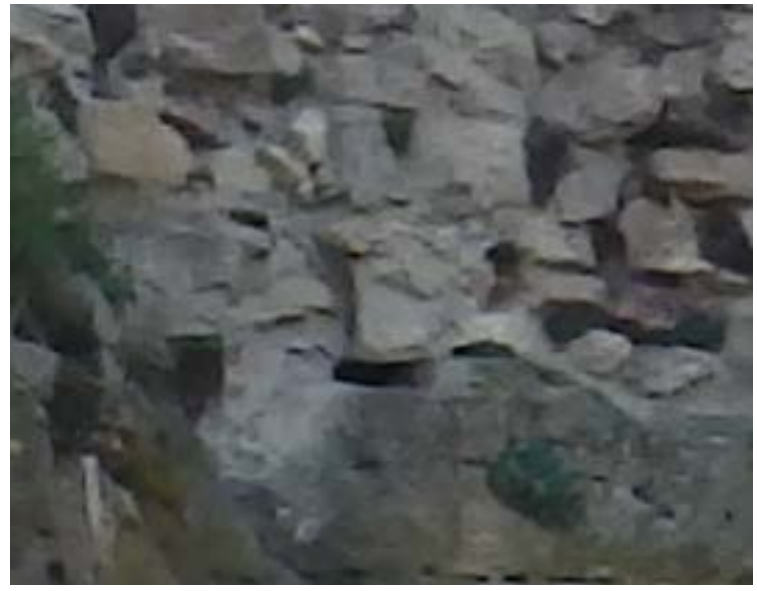

Fig. 5.5.54. Mechinal M1.1 directamente sobre la roca [A.S.E. 24/7/2016]

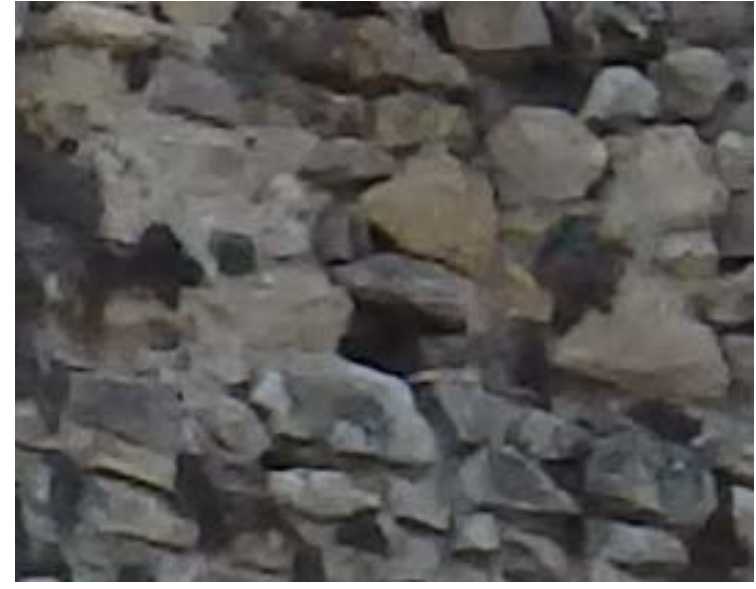

Fig. 5.5.55. Mechinal M2.1 coronado por un mampuesto [A.S.E 24/7/2016] 
La fotografía se ha tomado desde la carretera, a una di stancia de $70 \mathrm{~m}$, por lo que la definición no es destacable. Aun así es posible identificar el mechinal y observar que tiene una forma rectangular alargada. La pos ición de es te mechinal sobre la roca indica que no se realizó ninguna preparación antes de iniciar la construcción de la tapia. Otros mechinales en $\mathrm{p}$ osiciones más elevadas tienen una proporción más cuadrangular (Fig. 5.5.55). Se configuran, como en otros casos, con un conjunto de mampuestos que flaquean y coronan el mechinal.

\subsubsection{Lienzo exterior $L 2$}

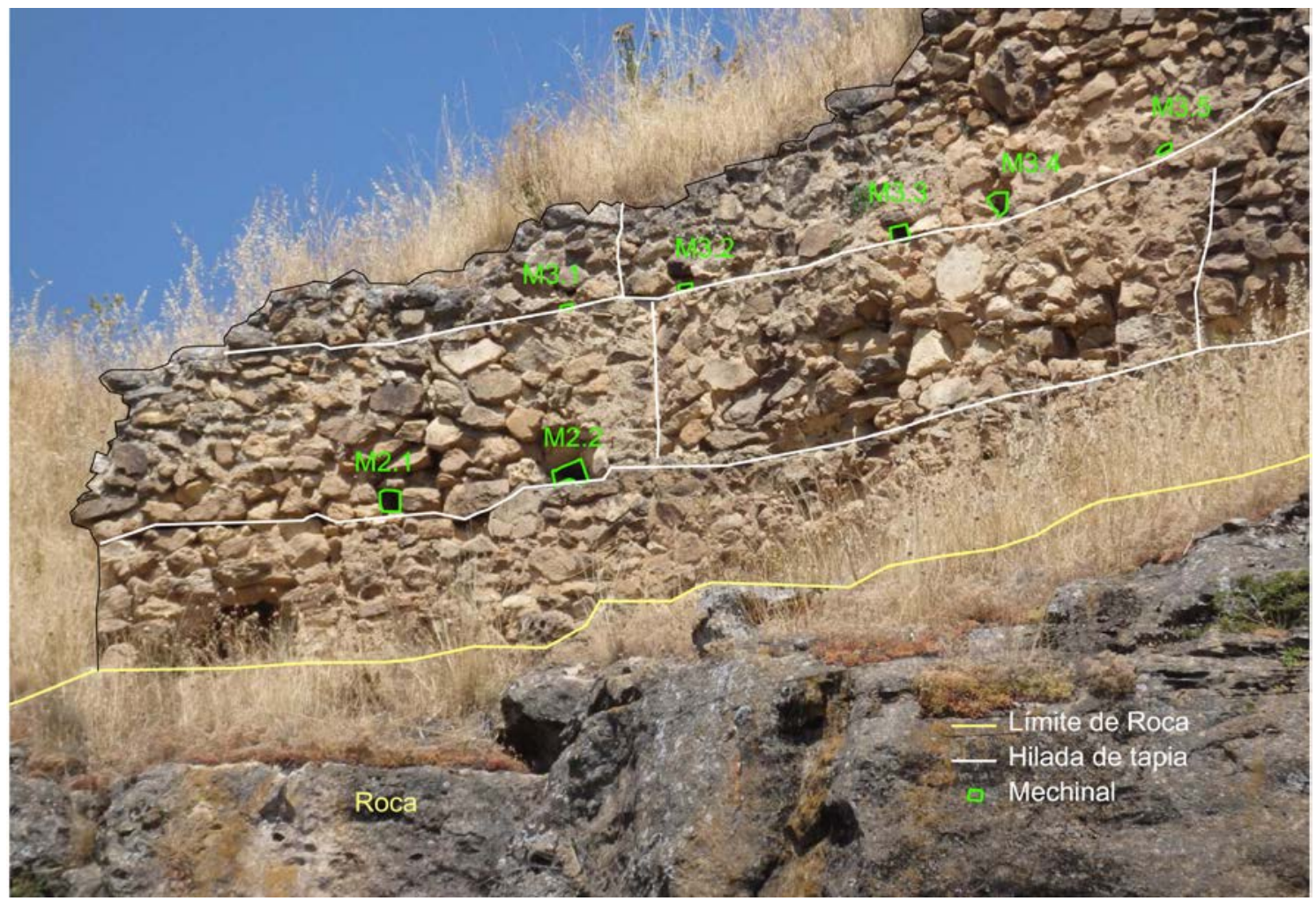

Fig. 5.5.56. Esquema sobre fotografía del lienzo L2 donde se resaltan los elementos constructivos. Fuente: Elaboración propia sobre foto del 18/11/2015.

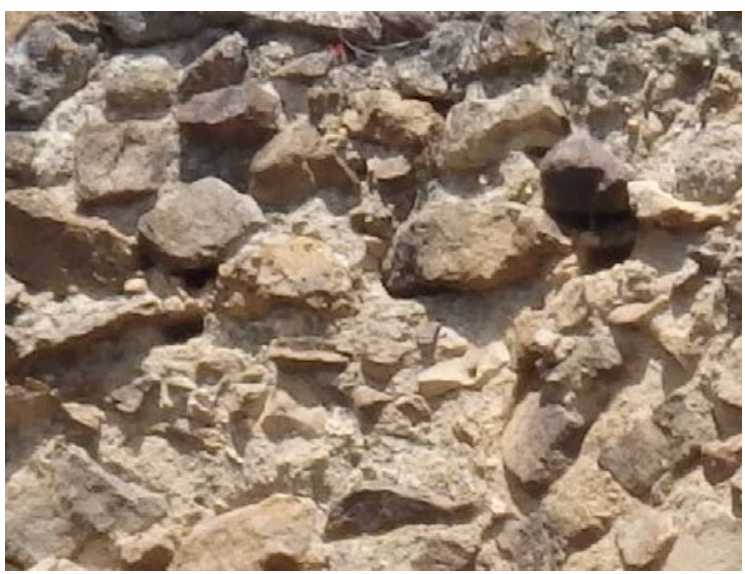

Fig. 5.5.57. Mechinales M3.1 y M3.2 [A.S.E. 24/7/2016].

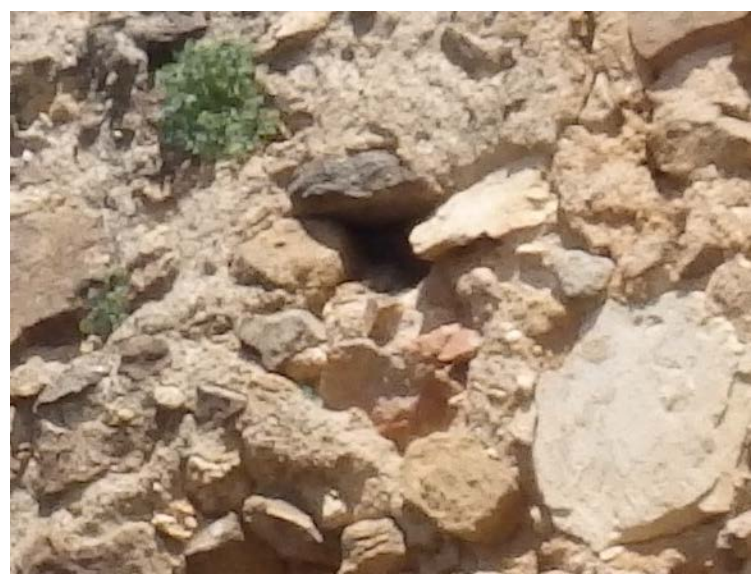

Fig. 5.5.58. Mechinal M3.3 [A.S.E. 24/7/2016]. 
Las murallas en las Comunidades de Villa y Tierra de la Diócesis de Segovia en los siglos XI a XIII. Técnica y sistemas constructivos de la arquitectura defensiva medieval.

En el lado sureste, cercano a la torre de Hontanillas (T4), se sitúa el lienzo L2 (Fig. 5.5.56). Se yergue en el mismo borde del terreno, ligeramente retranqueado, aprovechando la pared vertical de roca como base. Como en el caso anterior, acercarse a este lienzo no es sencillo. Desde el exterior el desnivel es muy importante y no se puede realizar una aproximación al lienzo. Las fotografías empleadas en el análisis se han realizado a una di stancia de $120 \mathrm{~m}$, por lo que no $\mathrm{h}$ a sido posible aportar una escala que permita realizar mediciones. Tampoco se ha podido componer un alzado de ortofotografía, como se ha realizado en otros ejemplos.

Desde el interior el acceso hasta el lienzo es posible, sin embargo, la vegetación y el carácter escarpado no permiten acercase hasta el borde sin peligro. Aun así, en las fotografías tomadas es posible identificar el empleo del tapial para la construcción del lienzo. La primera tapia se asienta directamente sobre la roca y sobre ella se añaden dos tapias más, aunque la última no está completa sino que ha pe rdido la parte superior. En la base de la segunda hilada se pueden identificar dos mechinales. Presentan una sección cuadrangular y similar en dimensiones. En la base de la tercera hilada se identifican hasta cinco mechinales, con secciones rectangulares y cuadrangulares. Las dimensiones de estos mechinales son variables, M3.1 y M3.2 muestran un tamaño menor en comparación con el resto de casos.

\subsubsection{Resumen de resultados para el caso de Pedraza de la Sierra}

La villa de Pedraza se sitúa en un enclave topográfico de gran interés, accesible tan solo en su lado sureste y muy protegido por el desnivel en el resto de orientaciones, hasta el punto de concentrar los dos accesos en ese lado, practicable sólo uno en la actualidad. La muralla se construye en el mismo borde del terreno, asomándose al vacío, como es visible en los restos del lado sur y del lado norte. Este caso no conserva tantos restos como en otros casos estudiados, donde se conservan lienzos de grandes longitudes sin edificaciones adosadas y con altura nada desdeñable. Aquellos que se conservan se encuentran en su mayor parte alterados al haberse integrado en nuevas construcciones. Los restos menos alterados son escasos y poco accesibles y se sitúan en el lado sur. Se presentan en tramos intermitentes y tienen baja altura.

A partir de los restos existentes es difícil obtener datos generales de la muralla. En el tramo analizado del postigo de Hontanillas, se puede extraer una altura actual de casi 10 metros, pero tal vez no sea representativo del conjunto amurallado. En caso de que existiera almenado, la altura sería todavía mayor. El espesor de la muralla en es ta zona supera los $2,00 \mathrm{~m}$. En el resto de tramos identificados no se han podido realizar una medición del espesor. Las torres existentes en el recinto se concentran en el lado sureste y son dispares. Existe por un I ado la torre singular de for ma hexagonal, construida con posterioridad a la muralla objeto de estudio, al menos tal y como se ve en la actualidad. La puerta de la Villa se compone en su lado norte por otra torre, también diferente a las torres de muralla habituales, ya que tiene también una función de edificio y no exclusivamente como flanqueo de un acceso. De las cuatro torres que se conservan en Pedraza, la torre T2 es tal vez la que más se aproxima a las 
características de los lienzos de este recinto. La torre T1, integrante de la puerta de la Villa, es un volumen que alberga en su interior un uso, un edificio que protege el acceso adelantándose respecto del plano de acceso, pero cuya función no es exclusivamente defensiva. La torre T4 es única en el recinto. Su planta poligonal, su disposición que parece separarse de la línea del lienzo y el aparejo de sillería son características que la alejan de la identidad más tosca, modesta y humilde de los lienzos de tapia de mampostería. La torre T3 es rectangular, se adosa al lienzo y se construye con mampuestos. Su aspecto renovado hace probable que haya sido objeto de una r econstrucción. La tor re T2 ofrece paramentos alterados, con materiales constructivos diversos en su aparejo, mampuestos y ladrillo.

En el campo constructivo, se observa el uso de mampostería en gran parte de los restos analizados. Tanto la zona noreste como la sureste se encuentra alterada, al haberse integrado los paños de muralla en las construcciones existentes. Aun así, en varios puntos del recinto se puede identificar este sistema como el mayoritario empleado en los lienzos. Otras técnicas son visibles en las puertas o en la torre de Hontanillas; la sillería se emplea para la ejecución de arcos y sus estribos o en el aparejo de la torre. El ladrillo se utiliza como sistema de ornamentación en la puerta de la villa, además de para la ejecución del arco de acceso. La tapia mixta se observa en la coronación del volumen sur que configura la puerta de la Villa.

No se ha observado ningún zócalo o base diferenciada a modo de cimentación o de preparación para el arranque de los lienzos. Se observa que parten directamente apoyados en la roca, sin elementos intermedios. Tampoco se ha detectado de forma evidente la reutilización de muros existentes como base para los lienzos. Las piedras talladas visibles en el postigo de Hontanillas fueron tal vez recuperadas de otras construcciones y ubicadas en la posición actual.

Desde un punto de vista defensivo no se pueden enumerar muchos recursos utilizados en este recinto. Aunque es probable que los lienzos contasen con almenado, no se ha localizado restos del mismo en ni nguno de los lienzos. Las torres T2 y T3 son las únicas torres de flanqueo del recinto. La torre T4 parece responder a una configuración defensiva más sofisticada. Con una disposición similar a la de las torres albarranas y con una pl anta poligonal, incorpora técnicas defensivas más evolucionadas que las simples torres de flanqueo. Estas características junto con el tipo de almenado que posee, permiten indicar que la torre T4 se construyó o se modificó con posterioridad, recibiendo mejoras en materia defensiva. 



\section{6}

\section{Sepúlveda}

Segovia

\subsubsection{Localización}

Sepúlveda se sitúa en la provincia de Segovia, en el centro oeste de la misma, junto al Parque Natural de las Hoces del Río Duratón. Se encuentra, aproximadamente, a 60 $\mathrm{km}$ de la ciudad de S egovia, a $110 \mathrm{~km}$ de la ciudad de $\mathrm{V}$ alladolid y a $130 \mathrm{k} \mathrm{m}$ de Madrid. La comunidad de villa y tierra de Sepúlveda, tal y como la delimitan Gonzalo Martínez $(1983,326-329)$ y José M. Monsalvo $(2010,152)$ tendría una superficie aproximada de $1360 \mathrm{~km}^{2}$, grande en c omparación con las comunidades de e ste estudio. Limitaba al norte con las comunidades de Fuentidueña, Haza, Montejo y Maderuelo; al este con Fresno de Cantespino y Ayllón, al Sur con Pedraza, Buitrago y Uceda y al oeste con Cuéllar. La zona sur de la comunidad incluye parte del Sistema Central. El territorio de esta comunidad sobrepasaba los límites de la actual provincia de Segovia, extendiéndose en la provincia de Guadalajara.

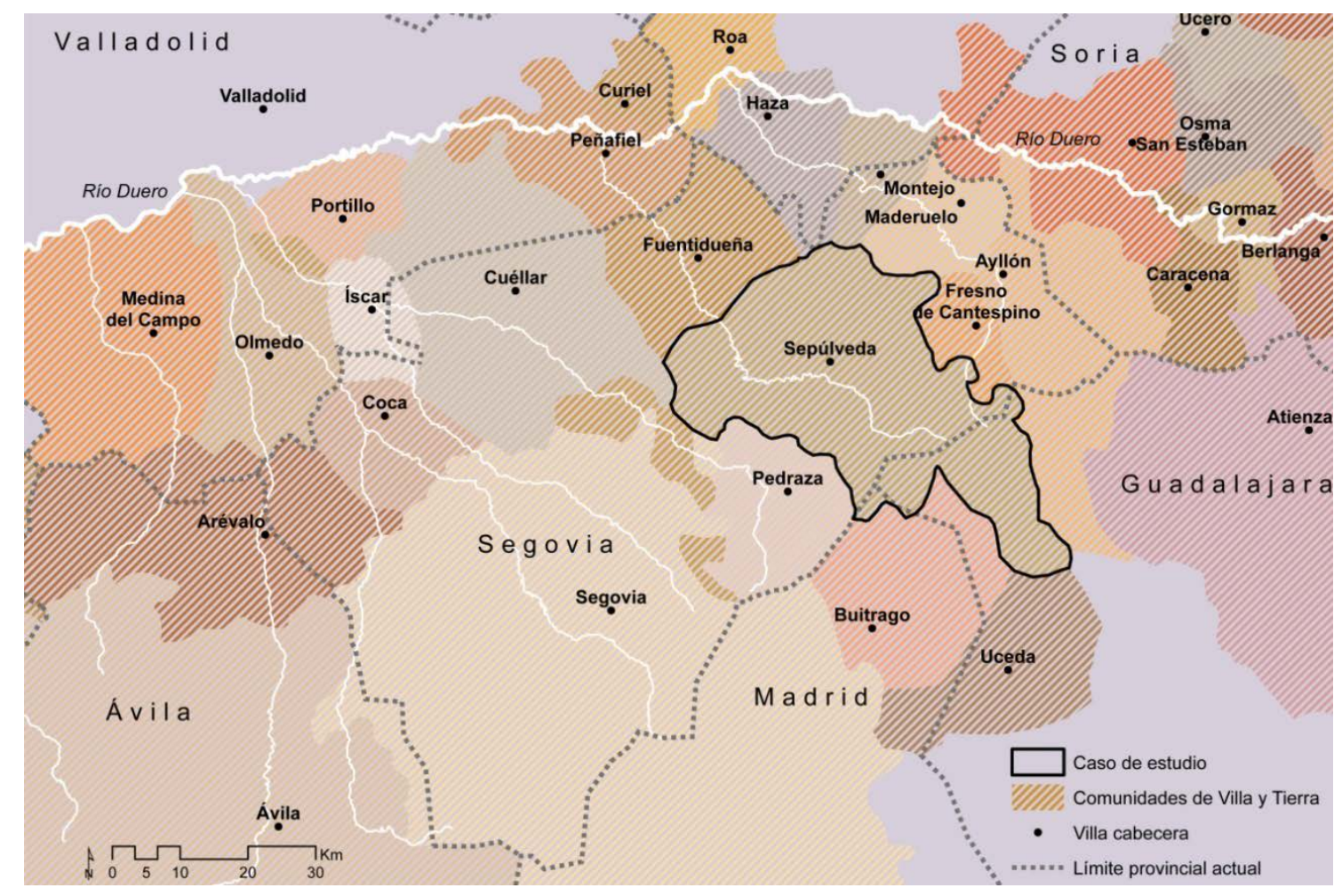

Fig. 5.6.1. Localización de la comunidad de Sepúlveda. Fuente: Elaboración propia a partir de planos de G. Martínez Díez (1983, 11-15) y J.M. Monsalvo $(2010,152)$. 
La población se asienta junto al río Duratón y su afluente el río Caslilla, que discurren por el norte y el sur de la población respectivamente. La orografía de la zona es accidentada, el cerro de Somosierra está rodeado por el profundo cañón donde serpentea el río Duratón. Se produce un desnivel de más de $100 \mathrm{~m}$ entre la altitud del cauce del río y la del punto más alto del cerro, que alcanza los $1036 \mathrm{~m}$ sobre el nivel del mar. El caserío actual se sitúa a una altitud que ronda los $980 \mathrm{~m}$, en la zona donde se aproximan los cauces de los dos ríos. La carretera antigua que atraviesa la población adaptándose al nivel del terreno se ha tor nado calle y el tráfico ha sido desviado a una nueva carretera que atraviesa el núcleo por medio de un túnel que pasa bajo la villa. Tiene una población de 1168 habitantes, de acuerdo con los datos del Instituto Nacional de Estadística en el año 2015.

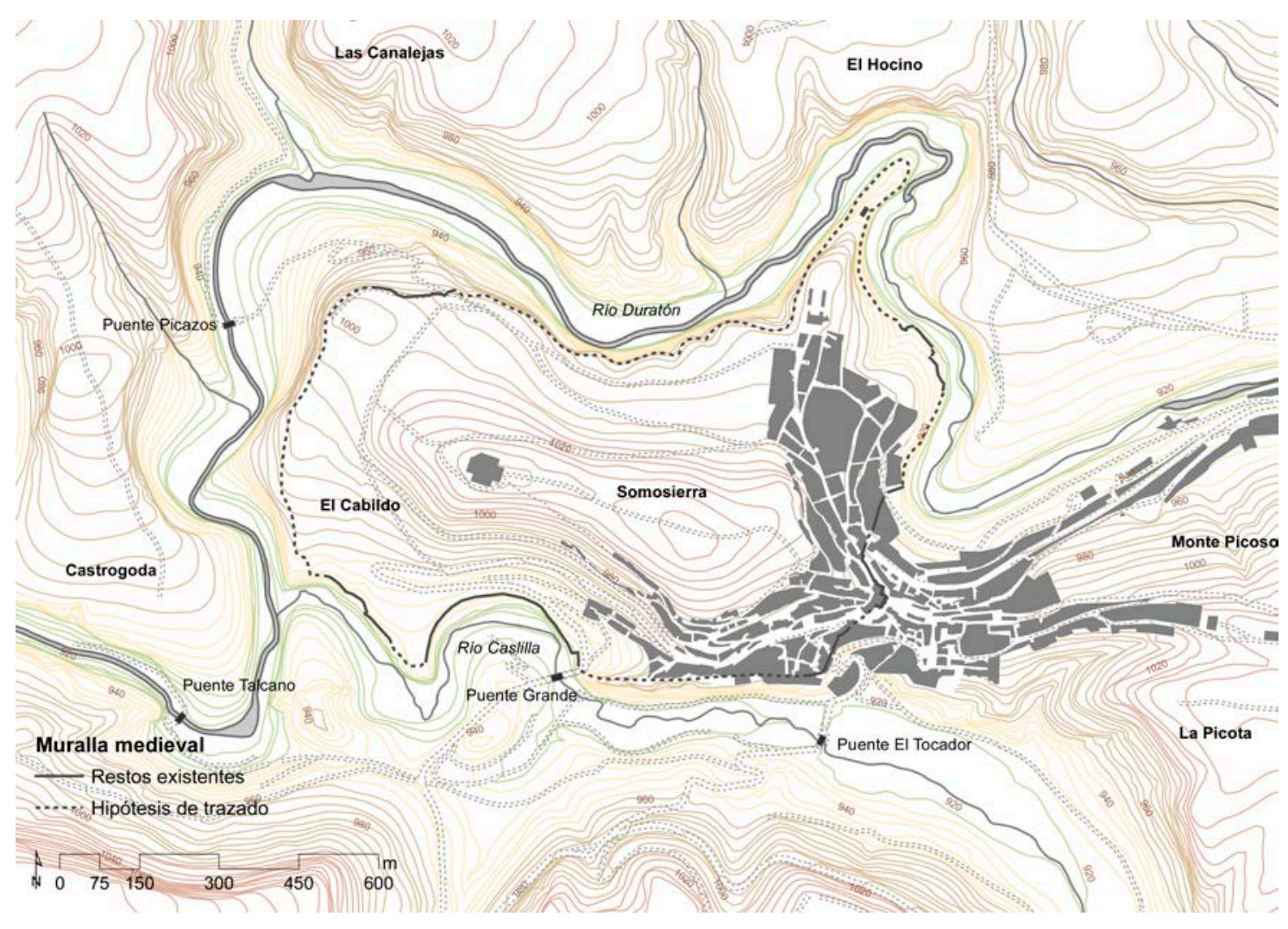

Fig. 5.6.2. Plano topográfico del entorno de Sepúlveda. Fuente: Elaboración propia con datos descargados de IDECyL [http://www.cartografia.jcyl.es/] y Catastro [https://www.sedecatastro.gob.es/].

\subsubsection{Estudios en la villa}

La villa de Sepúlveda tiene gran interés histórico y esto se refleja en la relativa abundancia de bibliografía existente en torno a este núcleo, con especial interés en los fueros de I a villa (Sáez et al. 1953; Linage Conde 1972; S uárez Bilbao, 2008; González Cristóbal et al. 2011). Los estudios que se han realizado concretamente sobre las murallas de Sepúlveda no son tan cuantiosos. La publicación de M. Dolores Aymerich, Teresa Tardío y Alonso Zamora (1990) realiza un análisis detallado de los aspectos que rodean el recinto amurallado de Sepúlveda. Se puso en marcha a raíz 
del proyecto de restauración de las murallas de 1987, momento en el que constataron que no existía un estudio previo de los restos amurallados, que permitiese realizar una restauración adecuada. Este estudio hace una descripción de la geología, geomorfología y el paisaje que rodea la población, así como del relieve y del propio asentamiento. Analiza la historia de la población de acuerdo con fechas señaladas en las que se conoce la existencia de población continua, desde el siglo IV a.C. Lleva a cabo una descripción de los lienzos, puertas y cubos existentes en el tramo urbano de la muralla, desde la zona de EI Postiguillo, al noreste de la población, hasta la Puerta del Río, al sur, incluyendo también referencias a otros tramos situados fuera del núcleo urbano.

Es especialmente exhaustivo el análisis de fondos documentales, que extrae datos relativos a la muralla y sus elementos. En relación con las puertas, se extraen referencias a impuestos destinados a la construcción y reparación de las mismas, o fragmentos donde aparecen citadas por su nombre. Se extraen igualmente referencias que citan los lienzos como límite para la exención de tributos, para indicar que ha de protegerse la villa cerrando sus puertas o citando la muralla como parte de una descripción. Se enumeran menciones de obras en las murallas. En un documento de 1367 se menciona el envío de dinero por parte el concejo de Cardoso de la Sierra que reclamaba caballeros, escuderos y hombres buenos de Sepúlveda para las cercas, adarves y muros (105). En otro documento de 1518 se mencionan materiales constructivos empleados en las reparaciones: se habla de madera para andamios, de cal y arena a pie de obra, se menciona la reutilización de sillares y piedras y se habla de la realización de nuevos sillares. En un documento de 1606, se habla del encargo de que se adereze las paredes de los muros de trascastillo de cal y canto (106). Tres años más tarde se hace referencia a la necesidad de reparación de los muros. A partir de 1650, apar ecen partidas que ti enen como objeto el derribo de elementos de la muralla, por su situación de ruina. A finales del siglo XIX, aparecen repetidas solicitudes de particulares que piden abrir puertas y otros huecos en los lienzos de muralla. De acuerdo con estas fuentes, los autores también realizan un análisis de la evolución de los distintos nombres del as puertas (142). Se estudia pormenorizadamente una inscripción encontrada en uno de los cubos y se analizan los aparejos empleados en la construcción de los lienzos analizados. Se extraen tres tipos de aparejos diferentes, A, B y C, que s e comentan más adelante en el análisis constructivo de es te caso. En función de las prospecciones arqueológicas que los autores realizaron en el término municipal (20), no se han encontrado restos o huellas firmes que muestren la presencia de población romana ni tampoco visigoda.

\subsubsection{Datos históricos destacados del núcleo}

La villa de Sepúlveda tiene un reconocimiento histórico mayor que otras villas de esta investigación. Su fama se debe a distintos aspectos, entre ellos la existencia de datos históricos que sitúan la villa como pionera en la repoblación de es te territorio. La conservación del fuero que lleva el nombre de la villa contribuye a nutrir la leyenda de villa de importancia en la época medieval. También el enclave donde se sitúa la villa es un lugar extraordinario, rodeado por el cañón del río Duratón, que dota a la villa de 
Las murallas en las Comunidades de Villa y Tierra de la Diócesis de Segovia en los siglos XI a XIII. Técnica y sistemas constructivos de la arquitectura defensiva medieval.

gran singularidad. Sin embargo, José A. Linage Conde $(2011,12,14)$ parece querer advertir que hay que ser prudentes a la hora de evaluar la historia de la villa y evitar dejarse llevar por el misticismo, para aproximarse con mayor realismo a los acontecimientos históricos.

De acuerdo con los datos recopilados por Gonzalo Martínez $(1983,325)$ para la villa de Sepúlveda, aparecen desde el siglo x alusiones a la misma. En 940, se menciona la repoblación de la villa realizada por Fernán González, en un contexto en el que todavía se están aplicando las formulas de repoblación empleadas en el norte del Duero. José A. Linage Conde $(2011,17)$ se refiere a es te poblamiento como arriesgado e inseguro, con altibajos, y efectivamente años después, en 979 y 984, las campañas de A Imanzor arrasan Sepúlveda por completo (Martínez 1983, 325). De 1009 a 1011 se menciona una nueva repoblación de la villa, de la mano del conde de Castilla Sancho Garcés. Se indica que el conde da a Sepúlveda sus fueros antiguos y otorga a c aballeros castellanos exenciones fiscales, regulando sus obligaciones militares. Se inicia la repoblación, pero se refiere que es ta no será efectiva hasta varios decenios más tarde y se justifica argumentando que en el año 1076 todavía se aplica a Sepúlveda el apellido de otras zonas (326).

En 1076 Alfonso VI confirma fueros anteriores de Sepúlveda, y otorga a la Villa un primer texto escrito foral dondes e incluyen los límites y los términos de Ti erra sometida a la jurisdicción de la Villa. Estos primeros parecen comprender al Norte las que años más tarde serán tierras de Sepúlveda, Pedraza, Fresno, Maderuelo y parte de Ayllón (Martínez Díez 1983 326, 359). José A. Linage Conde $(2011,18)$ señala que fue en el reinado de este monarca cuando se construyeron las primeras iglesias románicas sepulvedanas. También comenta la creación del territorio que denomina diócesis de Sepúlveda y que cede a Toledo, recién conquistada. En este sentido, En 1107, Sepúlveda aparece incorporada a la Diócesis de Toledo, por Diploma de Alfonso VI. Dos años más tarde, se delimita la Diócesis de Burgos, que limita con Sepúlveda (Martínez Díez 1983, 331). Solo en 1123, Sepúlveda aparece incluida en los límites de Diócesis de Segovia, señalados por el papa Calixto II (414).

Ya en el siglo XII, la Batalla de Candespina de 1111 marca un momento tras el cual Gonzalo Martínez (1983, 331, 351 ) considera que queda configurada la Tierra de Sepúlveda. Otras fechas agrupadas por este mismo autor mencionan la villa: en 1122, y en nom bre de A Ifonso I de A ragón, consta que el tenente Enneco Simeonis dominaba Sepúlveda

Al igual que ocurre con otras villas de esta investigación, la villa de Sepúlveda aparece enumerada junto con las villas en las que el rey cede el diezmo a la iglesia católica, en 1136. En este caso la villa figura como cabecera de Comunidad por primera vez. José A. Linage Conde $(2011,19)$ indica que dur ante el antiguo régimen las sesiones municipales de Villa y Tierra eran frecuentes, al igual que las sesiones de la villa, implicando así la vigencia del fuero de la villa, y el ansia de ampliar su territorio incorporando despoblados. En este sentido, en 1139, consta una escisión de Fresno de Cantespino, que pertenecía a Sepúlveda, aunque tr einta años más tarde ambas comunidades se pusieron de acuerdo para compartir territorio, acuerdo ratificado por el rey Alfonso VIII, quien lo confirmó en 1207. 
En relación con otras villas de esta investigación, esta villa se diferencia por la existencia de su Fuero, que per mite validar las libertades que se atribuyen a es tas sociedades. Confirmado por el rey Alfonso VI en 1076, c omo se ha adelantado en párrafos precedentes, existen indicios de que existió en formato no escrito con anterioridad, otorgado por las figuras que lideraron anteriores repoblaciones. José A. Linage Conde $(2011,20-21)$ indica que, en primeros análisis, este fuero se consideró copiado del Fuero de Cuenca, conclusión que tilda de simplista, señalando que si Sepúlveda fue considerada cabeza del derecho en la Extremadura es porque su fuero sería precursor y no tanto una c opia posterior. La evolución del Fuero hasta el Fuero Extenso Castellano en la segunda mitad del siglo XIII muestra su importancia en el derecho de la villa hasta incluso fechas contemporáneas. Este fuero se extendió a otras villas y también a regiones donde se conservaba el modelo señorial, como aquellas bajo el control de órdenes religiosas. Linage Conde $(2011,21)$ señala que los señores en Sepúlveda fueron escasos y los que hubo no prolongaron su dominio a lo largo del tiempo. El nombre del castillo de Sepúlveda, que actualmente se dedica a Fernán González apoya el hecho de que ni ngún otro señor llegado posteriormente consiguió mantener su nombre en esa propiedad.

Según José A. Linage Conde $(2011,22)$, la función de Sepúlveda como ciudad fronteriza duró tan solo una década tras la toma de Toledo por parte del rey Alfonso VI. Menciona las murallas de es a época, de las que s e conservan bases de sillería principalmente en la zona actualmente poblada del núcleo, como las únicas que contaron con función defensiva efectiva. A raíz de es tas consideraciones, el autor advierte de la tendencia a creer que la villa entra en decadencia en la Edad Moderna, aunque acepta que la función de la villa en este periodo no es reseñable.

\subsubsection{Tejido urbano}

El parcelario actual de Sepúlveda se organiza en la ladera este del cerro de Somosierra, adaptándose las calles a las curvas de nivel. Las calles se organizan paralelamente a la caída del cerro, rodeándolo. La forma del parcelario actual es una suerte de hélice de tres hojas, con el castillo en el centro y tres ramas que se extienden hacia el norte, este y oeste. Solo una parte del caserío actual se encuentra en el interior de recinto amurallado. El castillo de Sepúlveda se sitúa en I a misma muralla y en un punto central del parcelario actual. Desde el oeste y el norte, las calles que rodean el cerro terminan confluyendo en el propio castillo (Fig. 5.6.4, Fig. 5.6.5). Hacia el este, la plaza mayor se abre frente al castillo y de el la parten calles que continúan hacia el este. La confluencia de varias calles en el castillo desde el interior de la muralla y la plaza formada frente al mismo recuerda la configuración habitual en una puerta de muralla. La posición del castillo actual podría haber sido una de las puertas de la muralla originalmente, de acuerdo con la forma del tejido urbano. La posición del castillo en la actualidad es vulnerable, es la zona oeste y la norte la más protegida del núcleo, gracias al río Duratón. La zona sur presenta un frente bastante escarpado hacia el río Caslilla, y la zona sureste, el punto donde se sitúa el castillo en la actualidad, es la más abierta y accesible. 
Las murallas en las Comunidades de Villa y Tierra de la Diócesis de Segovia en los siglos XI a XIII. Técnica y sistemas constructivos de la arquitectura defensiva medieval.

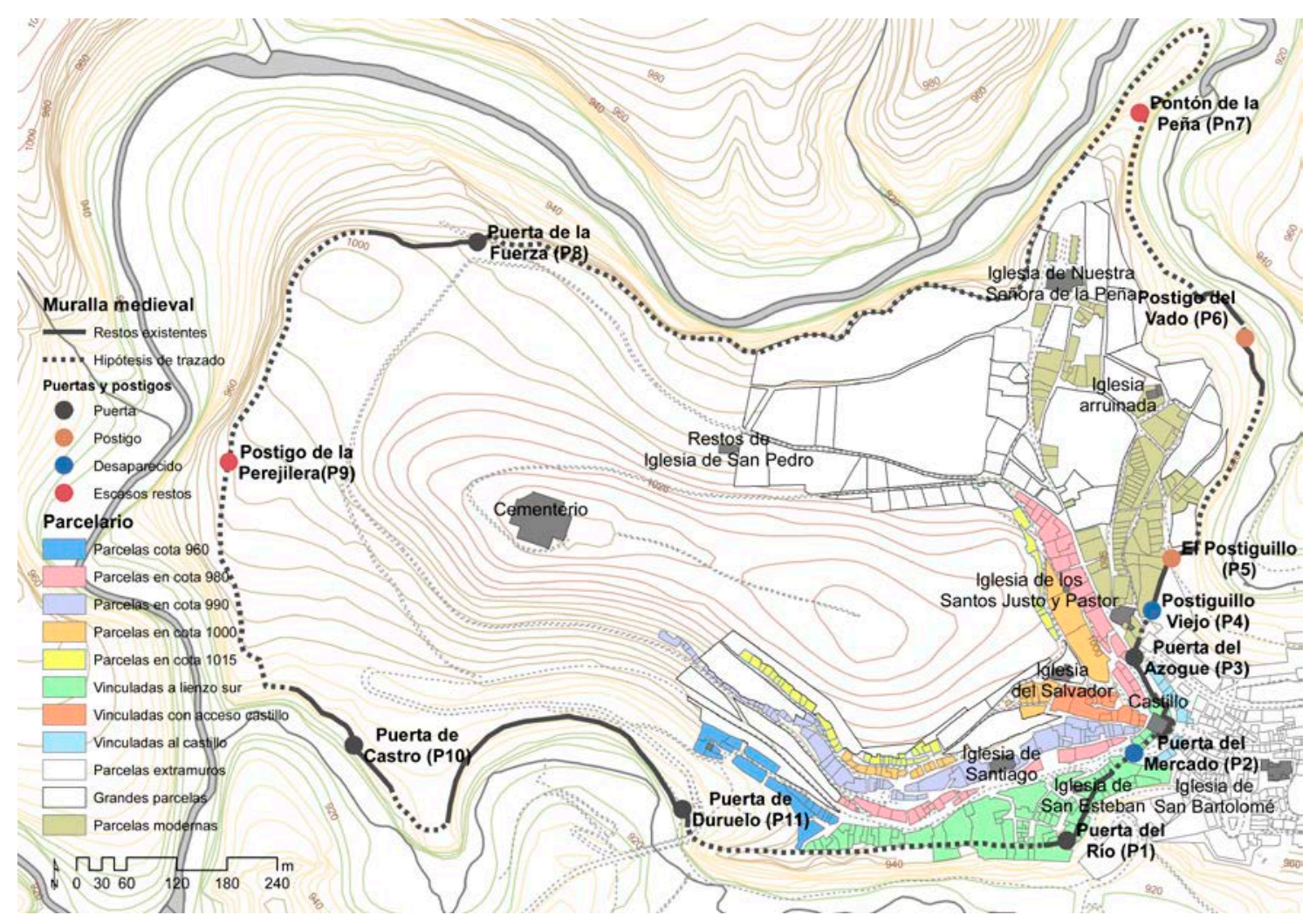

Fig. 5.6.3. Plano de par celario de S epúlveda. Fuente: Elaboración propia con datos geográficos de Catastro e IDECyL y datos de otros investigadores (Martín Aymerich et al. 1990, 26, 140).

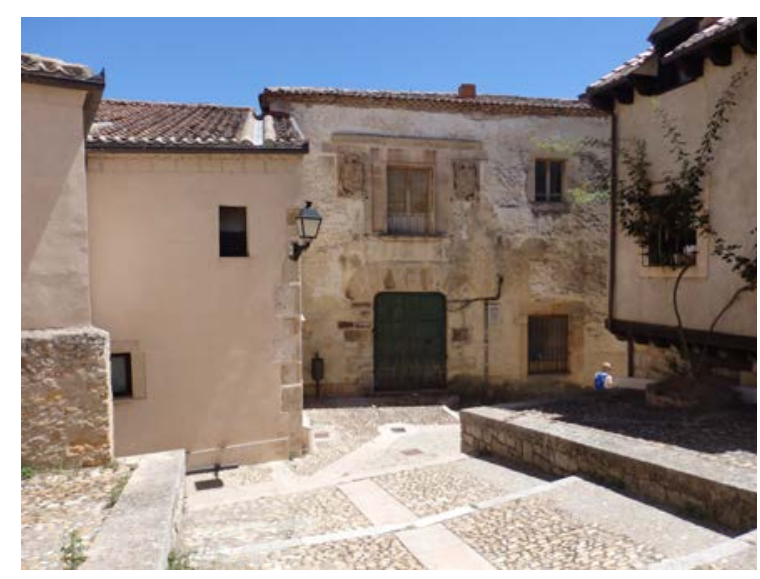

Fig. 5.6.4. Vista de la parte posterior del castillo, donde confluyen tres calles desde norte (izquierda, calle Fernán González), noroeste (desde donde se toma la fotografía, subida a EI Salvador) y suroeste (derecha, calle Conde Sepúlveda) [A.S.E. 23/7/2016].

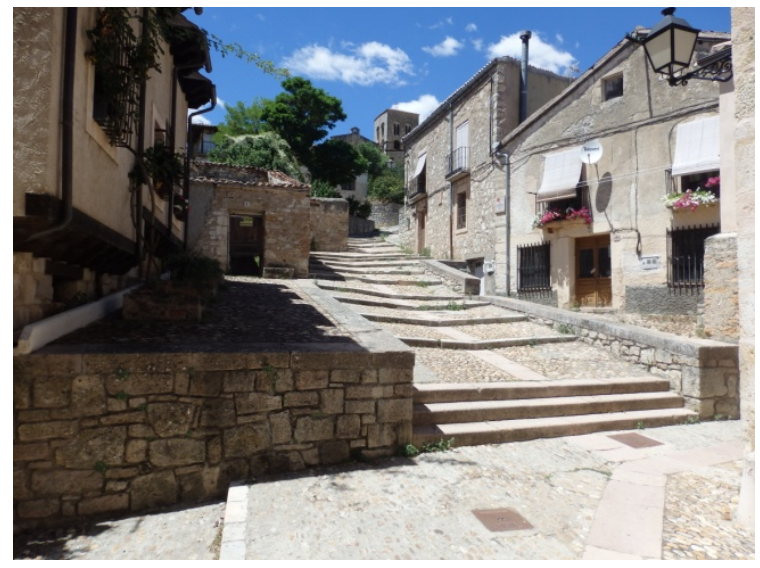

Fig. 5.6.5. Bajada hacia la parte posterior del castillo, desde el noroeste del núcleo, denominada "subida a El Salvador" [A.S.E. 23/7/2016].

Es habitual que el castillo se sitúe en las zonas más escarpadas e inaccesibles del territorio, como ocurre en incontables ejemplos de la geografía castellana. Otras zonas del recinto amurallado son más adecuadas para la ubicación de un castillo en tiempo de guerra. La zona oeste del recinto amurallado es bastante inaccesible. La situación 
del cementerio o el alto del cerro de Somosierra es un lugar de difícil acceso, idóneo para ubicar una fortaleza. La iglesia de Nuestra Señora de la Peña, cercana al castillo actual pero 40 metros más arriba, es igualmente un punto más fácil de defender que el castillo actual situado en la zona más llana de la población.

\subsubsection{Planeamiento y figuras de protección}

La villa de Sepúlveda dispone de una figura de planeamiento general, las Normas Subsidiarias Municipales (NNSS) del año 1998, que ha s ido modificada en diversas ocasiones en los años 2004, 2007 y 2015. La zona de la muralla que se encuentra en suelo rústico está clasificada con "Protección Ecológica", debido a su proximidad con el Parque Natural de las Hoces del Río Duratón. El catálogo de elementos protegidos recoge los muros y defensas naturales, el torreón junto a la puerta del río, la puerta de Tormo, Postiguillo, el castillo y casa González de Sepúlveda, todos ellos con categoría A. Conservación Integral. Dentro de I as normas se realiza una delimitación de Conjunto Histórico, que incluye la superficie del recinto amurallado. Dentro del recinto amurallado, al norte del mismo y en continuación con el tejido urbano existente, se sitúa un sector de suelo urbanizable. Se acaba de aprobar recientemente, en abril de 2016, una modificación de I as NNSS relativa a I a muralla y al límite del conjunto histórico. Se ha aprobado simultáneamente un Plan Especial de Conjunto Histórico.

En el catálogo arqueológico de las NNSS, se describe el yacimiento arqueológico VI Somosierra ${ }^{37}$ que se define como "Núcleo urbano" y al que se asignan, entre otras, las siguientes atribuciones culturales: visigodo, bajomedieval cristiano y moderno (s. XVIXVIII). Este yacimiento se extiende en la zona del cerro de Somosierra, hoy vacía.

En 1951 se declaró conjunto monumental a la villa de Sepúlveda, y se considera en la actualidad Bien de Inter és Cultural (BIC), en la categoría de C onjunto Histórico. El castillo de Sepúlveda es igualmente BIC, de acuerdo con el decreto de 1949 que puso bajo protección del Estado a todos los castillos de la geografía española.

\subsubsection{Descripción general de la arquitectura defensiva}

Los restos de muralla existentes en Sepúlveda permiten intuir la gran superficie que albergaba la muralla, cercana a las $70 \mathrm{Ha}$. En la zona urbana, donde se encuentra el caserío actual, se conservan partes de la muralla situadas entre las construcciones. En la zona sur, se sitúa la Puerta del Río o de las Pucherillas, junto a la que se conserva una centena de metros de muralla, sobre la que se apoyan las viviendas del pueblo (Fig. 5.6.6). Desde este punto hasta el castillo, situado más al este, ya en la plaza mayor, no se observan restos a simple vista, pero es probable que la muralla continuara su recorrido hasta el castillo. Antes de llegar a éste, se situaba la Puerta del Mercado o de la Villa, derribada en 1952 ( Martín Aymerich 1990, 144). Tal y como refieren M. Dolores Martín Aymerich y su equipo, Atilano G. Ruiz-Zorrilla (Sáez et al.

\footnotetext{
37 Se ha consultado las NNSS disponibles en el Archivo de Planeamiento Urbanístico de Castilla y León (PLAU), la ficha VI Somosierra se encuentra en la página 470 del Catálogo Arqueológico. http://www.jcyl.es/plaupdf/40/40195/280158/sgc46arq.pdf [Consultado el 30/3/2016]
} 
1953, 886) considera que existió un acceso denominado Puerta del Castillo, e indica que el desaparecido acceso del Mercado o de la Villa se realizó de nueva planta al hacerse la carretera. Los primeros autores se muestran en desacuerdo, indicando que consideran que no existió puerta alguna denominada así. La denominación de la Puerta del Castillo puede tal vez estar relacionada con la posición del castillo actual, que como se ha indicado anteriormente se sitúa en un I ugar poco elevado, en Ia confluencia de varias calles y frente a una pl aza. De la misma manera que existen puertas que se emplean con posterioridad como prisiones, podría haberse modificado su uso y convertido en castillo, aprovechando su posición privilegiada y más accesible.
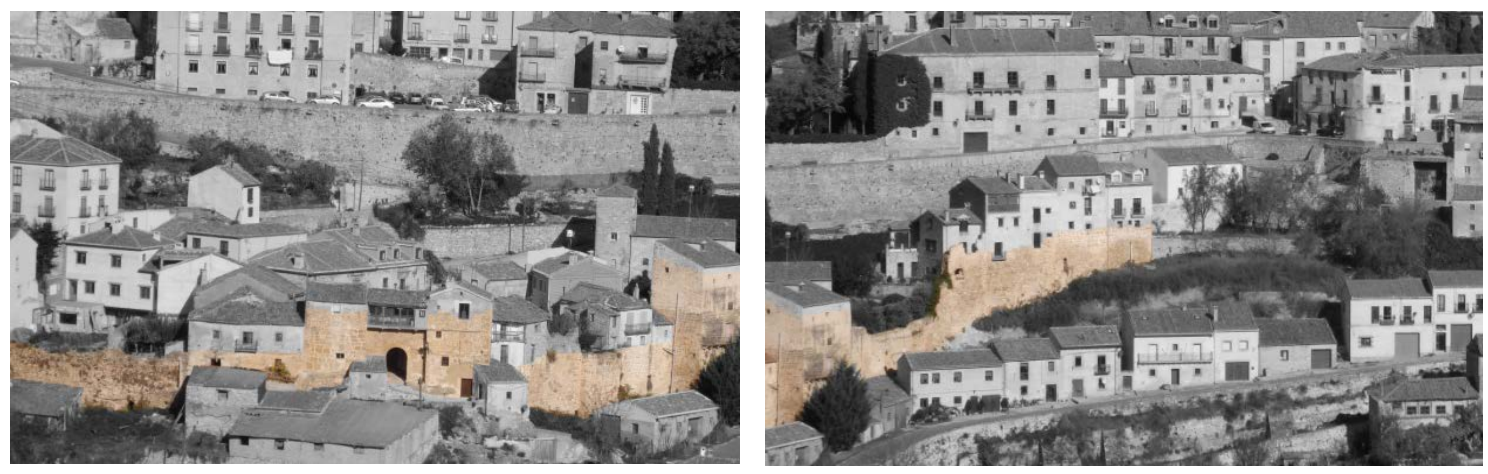

Fig. 5.6.6. Fotografías tratadas para destacar los restos de muralla en el caserío. Fuente: elaboración propia con fotos del 11/11/2015.

Desde el castillo hacia el norte continúan los restos de muralla, con una longitud de 70m aproximadamente, siguiendo la calle la Barbacana, hasta llegar a la puerta del Azogue o del Ecce Homo. Poco más al este, continúa un tr amo de $9 \mathrm{~mm}$ aproximadamente, hasta el cortado del río Duratón. En este último tramo se sitúa el Postiguillo, un paso que ahora atraviesa la calle de EI Postiguillo. M. Dolores Martín Aymerich y su equipo $(1990,141)$ sitúan cerca de El Postiguillo lo que denominan el Postiguillo Viejo y lo consideran un portillo de época árabe defendido por dos cubos. Algunos de los tramos descritos han sido reconstruidos, como el que se encuentra en la calle de la Barbacana donde se observa un almenado moderno.

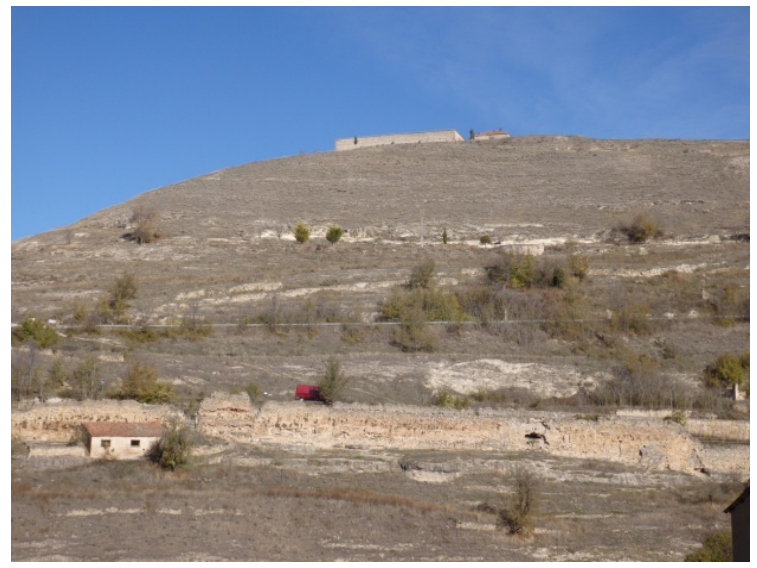

Fig. 5.6.7. Vista de la muralla en la base del cerro [A.S.E. 11/11/2015].

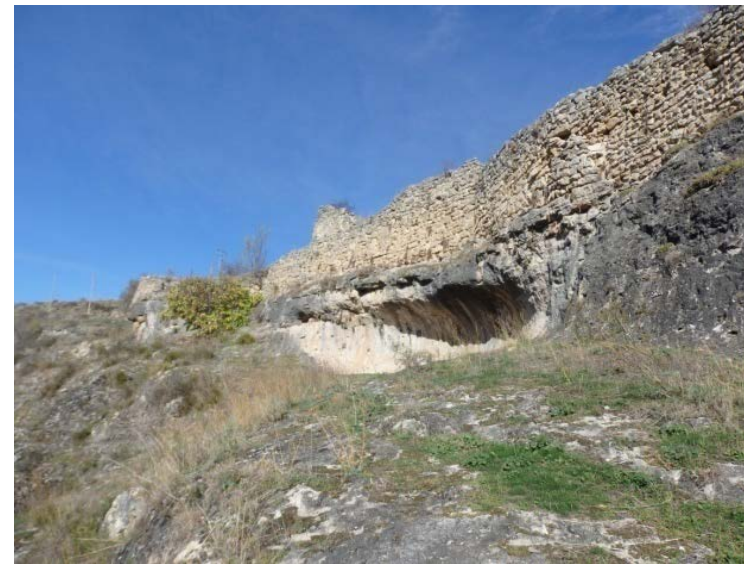

Fig. 5.6.8. Vista de la muralla junto a la Puerta de Castro [A.S.E. 11/11/2015]. 
Fuera del actual caserío, se encuentran restos de lienzos de muralla y varias puertas. Al oeste de la Puerta del Río, junto a I a carretera de S egovia y prácticamente escondida, se sitúa la Puerta de Duruelo. Entre estas dos puertas hay una distancia de $500 \mathrm{~m}$ aproximadamente y una zona de gran desnivel en cuyos bordes podría situarse la muralla original, aprovechando la defensa natural. A partir de la puerta de Duruelo, hacia el Oeste, la muralla continúa formando un arco, adaptándose al terreno, hasta llegar a la Puerta de Castro, también Ilamada de la Guerrilla o Postigo Sopeña. Otro tramo de muralla parte de esta puerta, de nuevo adaptándose al desnivel. En la parte oeste del cerro de S omosierra el desnivel es muy importante y configura unas defensas naturales muy potentes. En esta zona la muralla se situaría en los bordes, reforzando el ya inexpugnable lugar. Los restos del postigo de la Perejilera son un testigo del paso de la muralla por esta zona. Más adelante, al norte, se sitúa la Puerta de la Fuerza (Fig. 5.6.9), atravesada por la calzada romana (Martín Aymerich et al. $1990,76)$. Junto a la puerta, en dirección noroeste se ven restos de muralla de una longitud aproximada de $150 \mathrm{~m}$. La zona norte del cerro de Somosierra presenta grandes desniveles que funcionan como defensa natural, siguiendo las curvas del río Duratón y en cuyos bordes se situaría la muralla. Ya en la zona oeste, se observan restos de muralla junto a la Puerta del Vado.

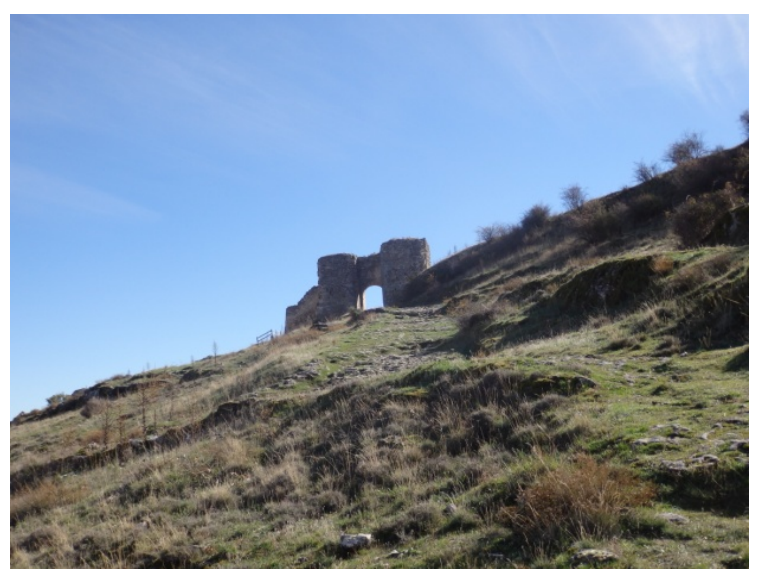

Fig. 5.6.9. Vista de la puerta de la Fuerza desde el exterior del recinto amurallado [A.S.E. 11/11/2015].

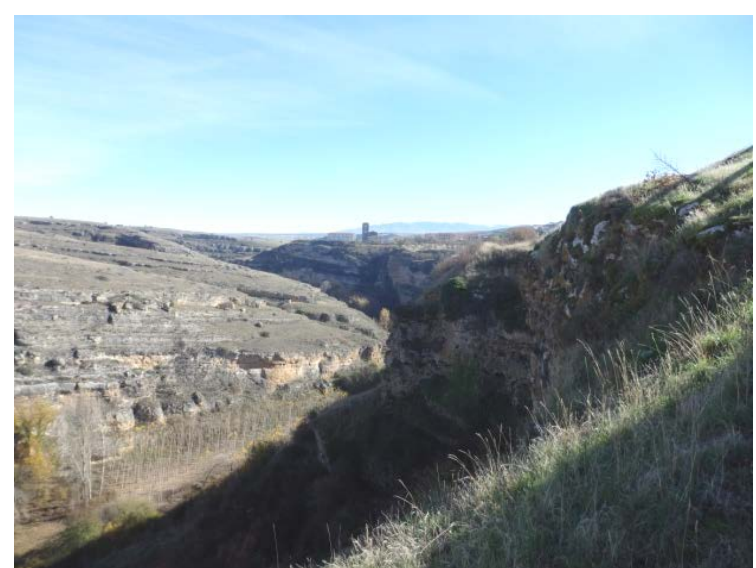

Fig. 5.6.10. Defensas naturales en la zona norte del cerro de Somosierra, al fondo es visible la torre de la iglesia de Nuestra Señora de la Peña [A.S.E. $11 / 11 / 2015]$.

En la zona norte del núcleo se sitúa la iglesia de Nuestra Señora de la Peña, cuya torre resulta de interés por la posición que ocupa, en el borde de la zona amurallada. Esta torre es visible desde la posición de la puerta de la Fuerza (Fig. 5.6.10).

Se ha considerado adecuado utilizar la misma numeración para los cubos de muralla empleada en el estudio de M. Dolores Martín Aymerich et al. $(1990,140)$, pues de cara a investigaciones futuras resultaría confuso asignar números diferentes a las torres. Esta numeración abarca principalmente al tramo urbano, desde la Puerta del Río hasta la zona del Postiguillo. En las zonas fuera del núcleo se ha tenido en cuenta la numeración general para numerar las puertas (26). 
Las murallas en las Comunidades de Villa y Tierra de la Diócesis de Segovia en los siglos XI a XIII. Técnica y sistemas constructivos de la arquitectura defensiva medieval.

\subsubsection{Tramos y elementos de la muralla}

Para el estudio de la muralla se han identificado los elementos más importantes como puertas o torres y se han definido tramos que comparten características constructivas. Se ha iniciado el estudio por la Puerta del Río, que se sitúa en la zona sur del núcleo, y se ha continuado en dirección este, donde la muralla se adentra en el caserío.

\subsubsection{Tramo Puerta del Río a Castillo Fernán González (P1-T13)}

La puerta del Río, también llamada de las Pucherillas (Martín Aymerich et al.1990, 142), se sitúa en una zona de de snivel donde el camino serpentea hasta el acceso (Fig. 5.6.11). La puerta se compone de dos torres de sección cuadrada, con un lado de entre 5 y $6 \mathrm{~m}$. Se construyen con sillares grandes en las zonas más bajas, aparejados de forma poco ordenada. En las zonas más altas, los sillares pasan a ser piedras más irregulares y de tamaño más pequeño, también aparejadas de forma desordenada. Entre las torres, se sitúa un muro que contiene un arco de medio punto, construido con sillares de piedra. No se observa bóveda que conforme el acceso, como es visible en otras puertas del recinto. En la actualidad, la puerta se ha convertido en una construcción más del pueblo, y son visibles huecos de ventana y balcones en su alzado exterior (Fig. 5.6.11), que muestran que se encuentra en uso. Hacia el interior, otras edificaciones se han pegado a las torres, siendo visible solamente la zona del acceso.

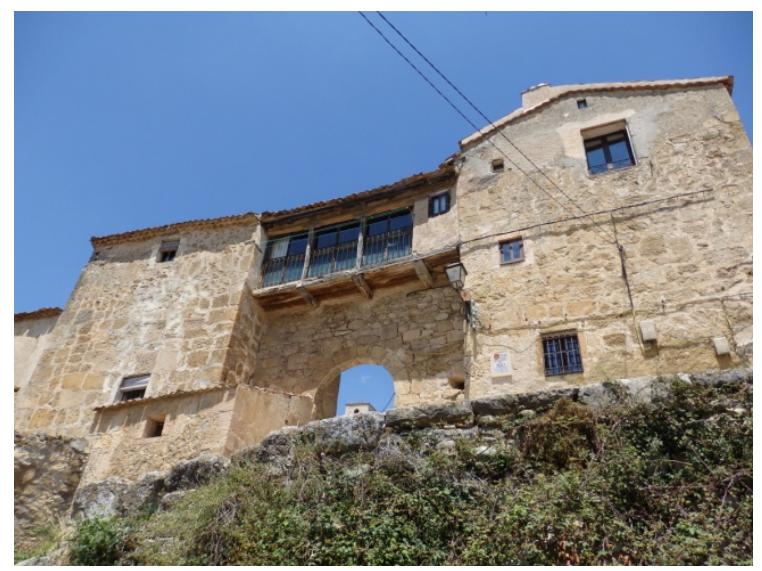

Fig. 5.6.11. Vista de la Puerta del Río, torres T18 (izq.) y T19 (dcha.) [A.S.E. 5/7/2014].

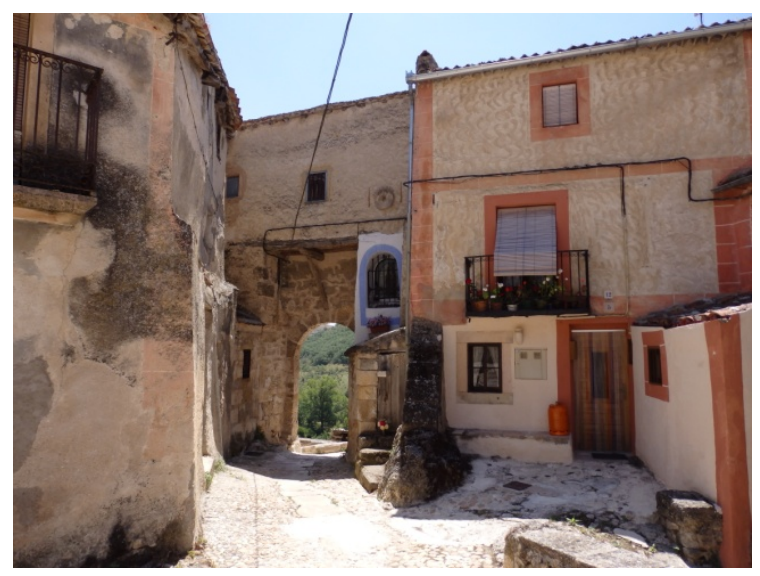

Fig. 5.6.12. Vista interior de la Puerta del Río [A.S.E. 5/7/2014].

Este tramo, descrito de forma general en la Fig. 5.6.6, conserva los restos de la torre T17 que sobresale ligeramente del muro (Fig. 5.6.13), como si de un contrafuerte se tratara y de una segunda torre de planta rectangular y de grandes dimensiones (T16). El aparejo visible en este tramo es de sillares irregulares, de gran tamaño, combinado con piedras más pequeñas, que no forman hiladas regulares. 


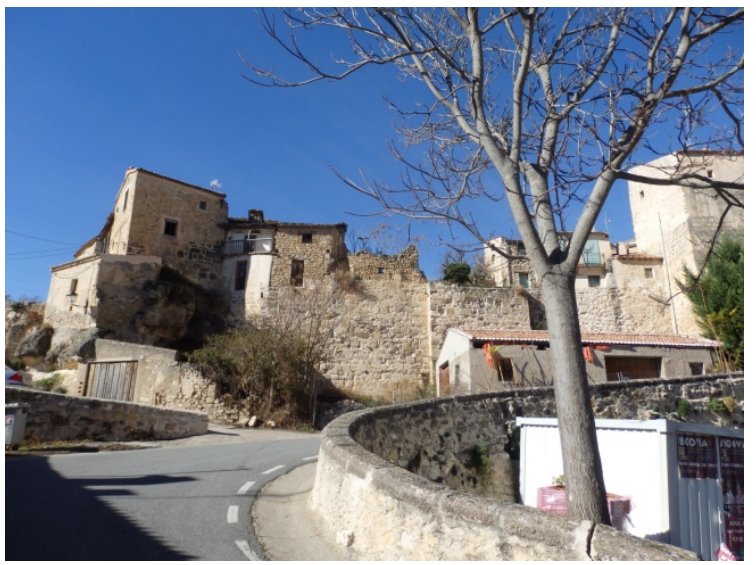

Fig. 5.6.13. Restos de muralla junto a la puerta del Río. Es visible la torre T17 que sobresale ligeramente del plano del lienzo [A.S.E. $11 / 11 / 2015]$.

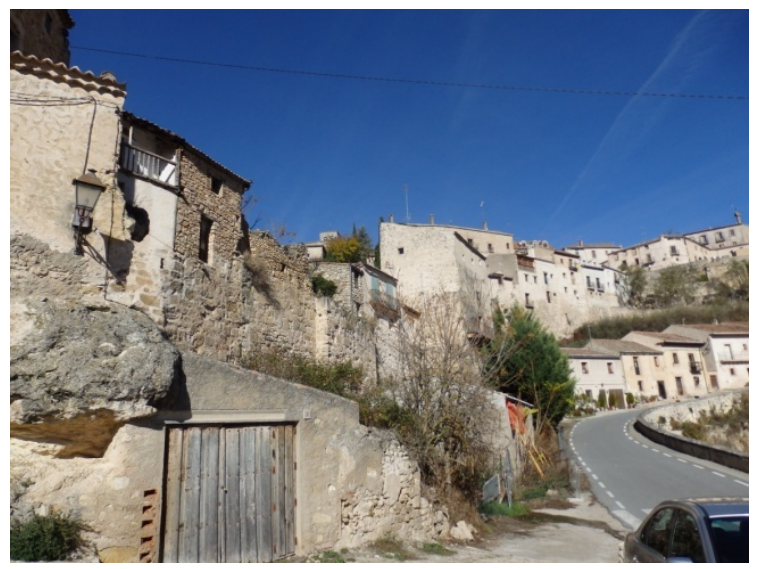

Fig. 5.6.15. Tramo desde la puerta del Río hacia el noreste.

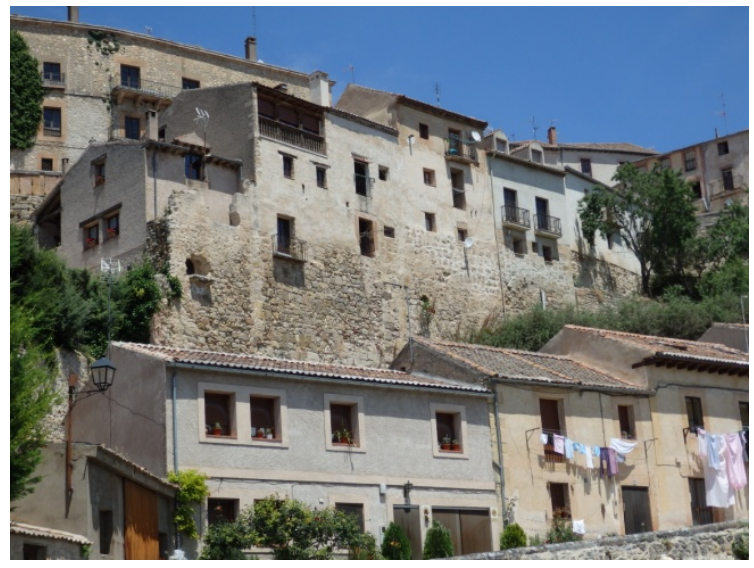

Fig. 5.6.14. En segundo plano, restos de muralla junto a l a puerta del Río, sobre los que se han construido viviendas [A.S.E. 5/7/2014].

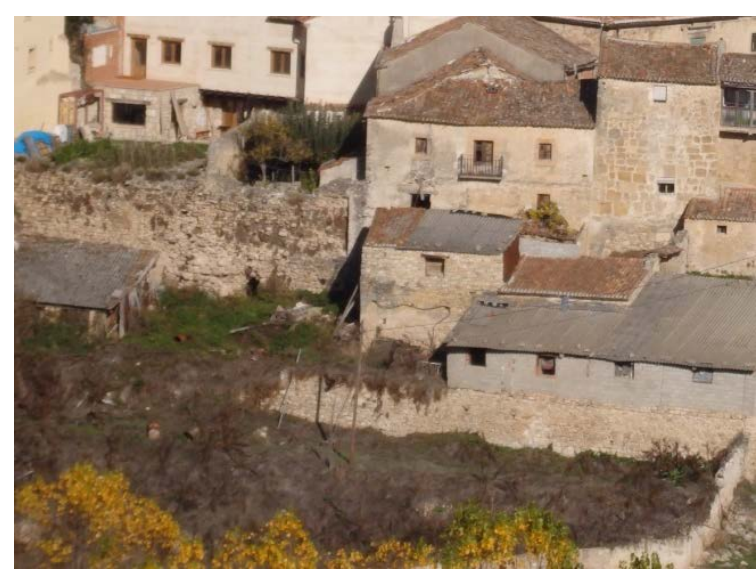

Fig. 5.6.16. En la parte izquierda de I a imagen, restos de muralla al oeste de la puerta del Río, visible parcialmente a la derecha [A.S.E. 11/11/2015].

\subsubsection{Castillo de Fernán González}

Los restos del castillo sobresalen por encima de edificaciones contemporáneas que están adosadas y los ocultan parcialmente. Solo es posible ver los restos que superan la altura del edificio del Ayuntamiento, adosado en su cara exterior. El castillo conserva tres torres de sección semicircular. La central es de sección más importante que las laterales y sobre ella se eleva una espadaña construida posteriormente. En los lienzos se han abierto huecos y se ha adosado un balcón. Según M. Dolores Aymerich (1990, 140 ), el castillo data del siglo XII y fue recrecido en el siglo XV.

En su fachada a la plaza, es visible un aparejo de piedra irregular y desordenado. La piedra empleada, de tamaño aproximado de $20 \mathrm{~cm}$, irregular y sin tallar, recuerda la técnica de la mampostería encofrada, aunque no son visibles marcas evidentes de las tapias. Todavía se observan algunas líneas horizontales, pero son escasas. Se han 
Las murallas en las Comunidades de Villa y Tierra de la Diócesis de Segovia en los siglos XI a XIII. Técnica y sistemas constructivos de la arquitectura defensiva medieval.

consolidado los restos existentes, aplicando nueva argamasa y realizando reparaciones. En la parte superior de las torres, se ve una aspillera construida con piedra tallada (Fig. 5.6.21).
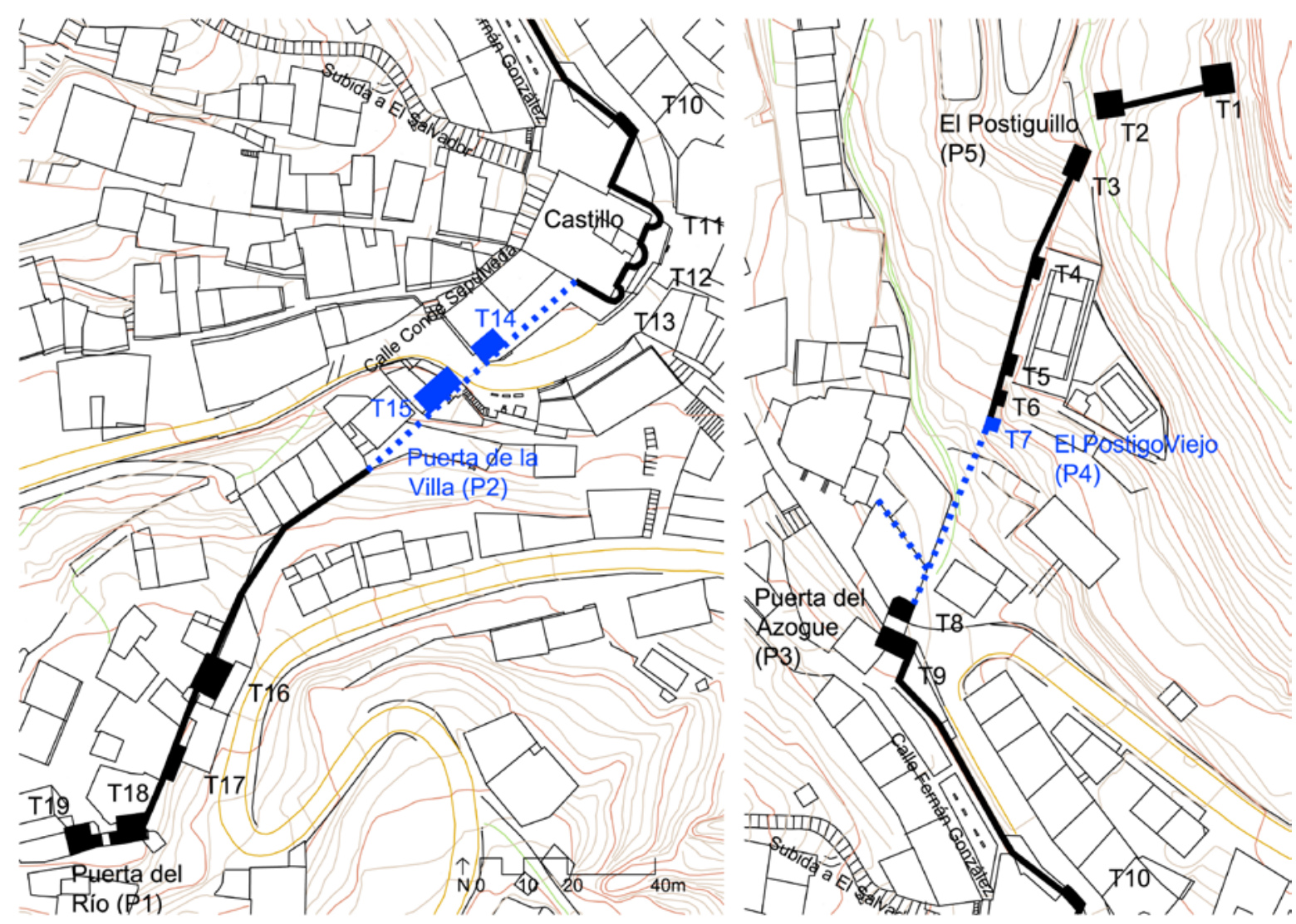

Fig. 5.6.17. Plano del recorrido de la muralla. A la izquierda, tramo entre la puerta del Río y el Castillo. A la derecha tramo desde el Castillo y la torre T1. Fuente: Elaboración propia sobre cartografía de IDECyL. En azul, hipótesis de Martín Aymerich et al. (1990, 140).

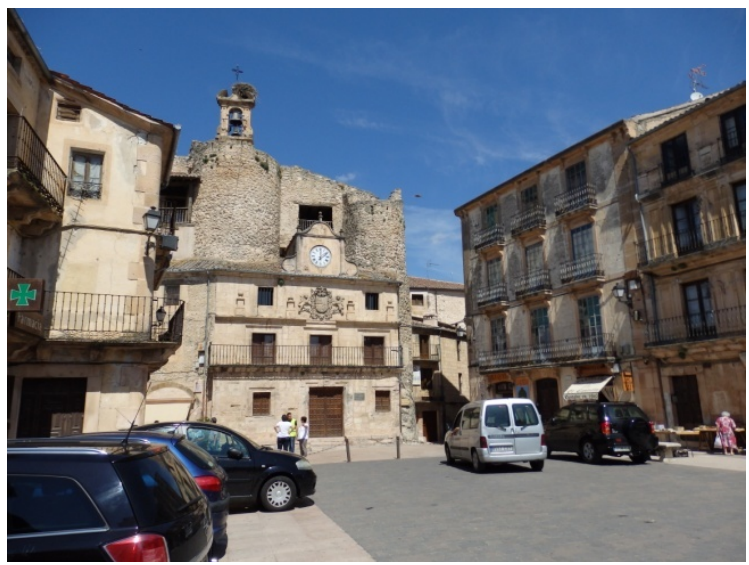

Fig. 5.6.18. Fotografía del Castillo desde la Plaza Mayor. Son visibles dos de las tres torres semicirculares (T12 y T11) [A.S.E. 5/7/2014].

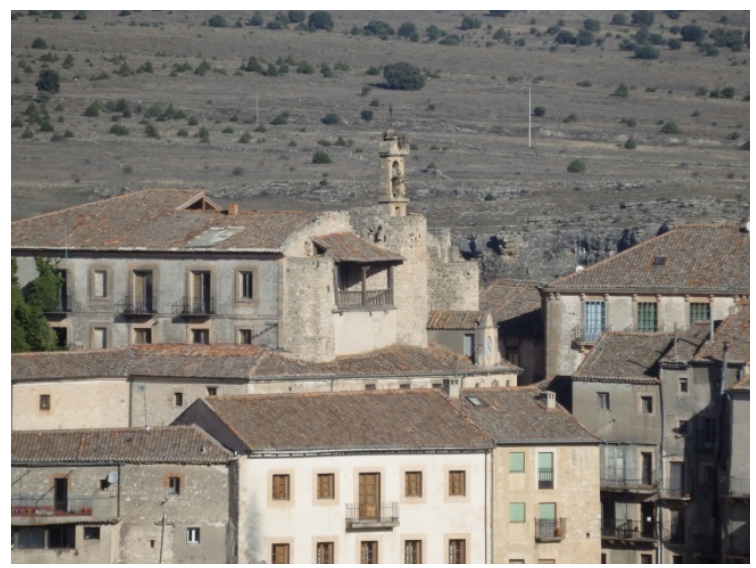

Fig. 5.6.19. Vista del Castillo desde el mirador de la carretera SG-232. Se pueden ver las tres torres semicirculares (T13-T11) entre el caserío [A.S.E. $11 / 11 / 2015]$. 


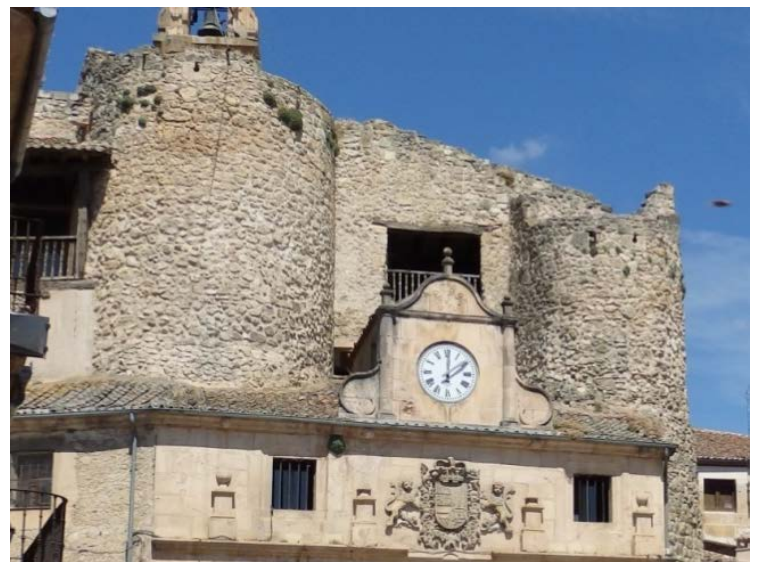

Fig. 5.6.20. Torres T11 y T12 [A.S.E. 5/7/2014].

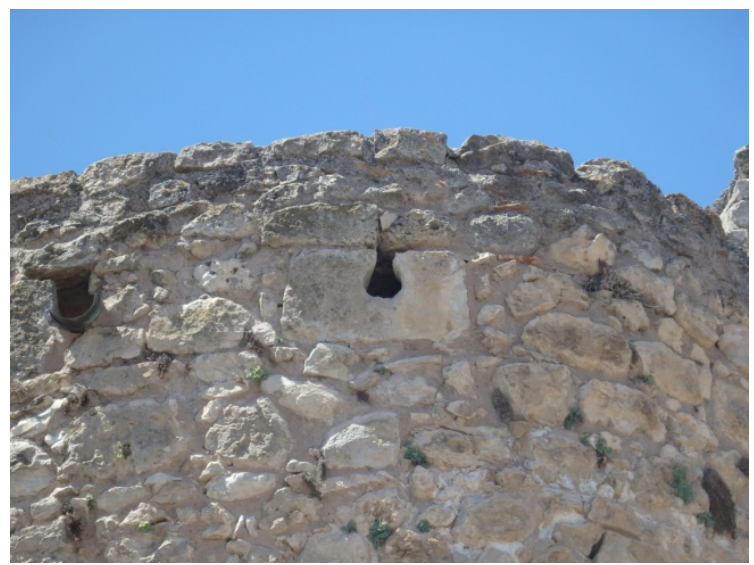

Fig. 5.6.21. Detalle de aspillera en la torre T11 [A.S.E. 23/7/2016]

\subsubsection{Tramo Castillo Fernán González a Puerta del Azogue (P3)}

El tramo T9-T10 tiene una longitud de 70m aproximadamente, y una altura media de $7 \mathrm{~m}$. Es visible gran parte de este tramo desde la calle Barbacana, donde se puede observar el aparejo de sillares que compone el muro. Los sillares son diferentes entre sí, muestran tamaños dispares, algunos de e llos son más regulares y otros son redondeados en sus aristas. Se identifican algunas hiladas horizontales, pero el aparejo es irregular. La parte superior está coronada con almenas, que han sido añadidas con posterioridad. En la base del muro, es visible que este se apoya directamente sobre la roca. Se observan dos piezas que sobresalen del plano vertical del muro, similares a las bases de dos torres. Se construyen junto a la roca, con sillares de gran tamaño. M. Dolores Martín Aymerich $(1990,49)$, define estos elementos como zarpas árabes. Indica que es muy probable que la zarpa fuese continua. En relación con el resto del muro, indica que se observa gran cantidad de sillares reaprovechados, contemplando la posibilidad de que se haya reconstruido con los mismos materiales tras algún hundimiento. Define la posición de los sillares como anárquica, detallando que hay zonas bien asentadas, frente a otras recalzadas con cascajo o sillarejo que transmiten la impresión de ha berse llevado a c abo una reparación urgente.

La puerta del Azogue se sitúa inmediatamente a continuación del tramo descrito. Presenta dos torres de sección rectangular a ambos lados del acceso, con una composición simétrica. La torre izquierda está adelantada $3,5 \mathrm{~m}$ aproximadamente frente al a posición de la torre derecha (Fig. 5.6.24). El acceso se encuentra retranqueado con respecto a las dos torres y está cubierto con un arco de medio punto. En su cara interna (Fig. 5.6.25), se observa la bóveda de acceso construida con sillares. Sobre la bóveda, se ven marcas horizontales de mampostería encofrada. 


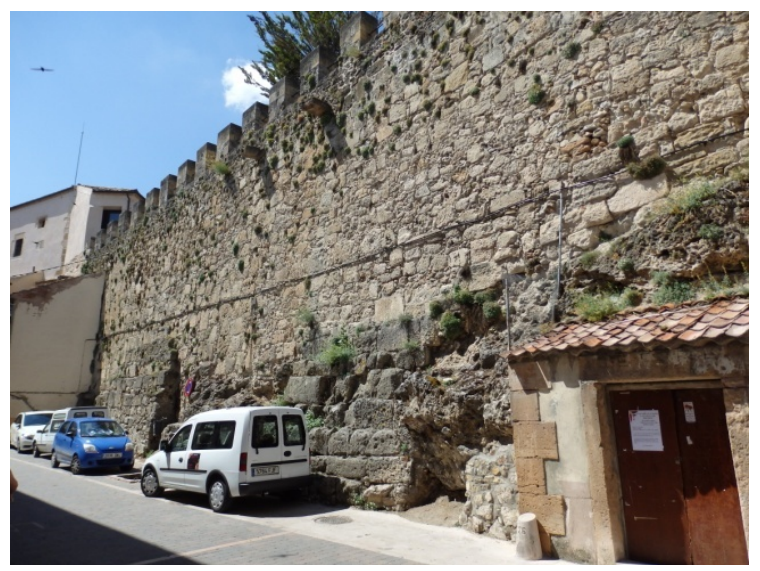

Fig. 5.6.22. Tramo de muralla en la calle Barbacana [A.S.E. 5/7/2014]

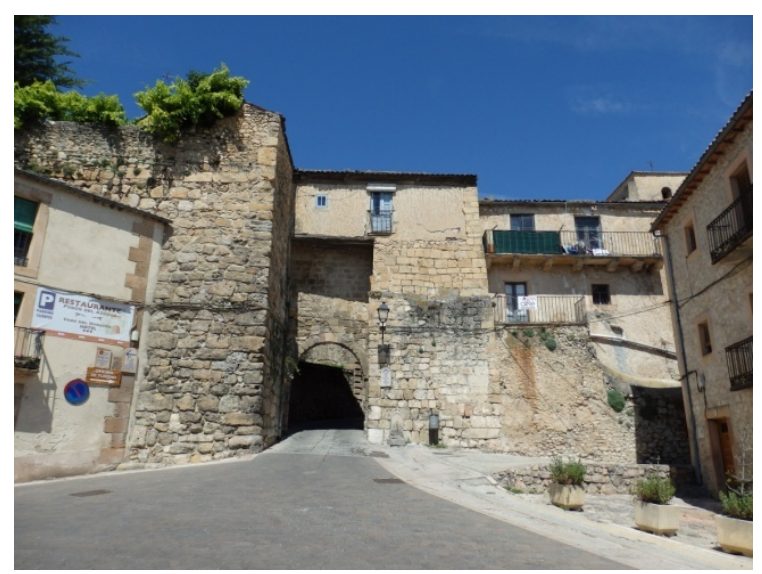

Fig. 5.6.24. Alzado exterior de la puerta del Azogue [A.S.E. 5/7/2014].

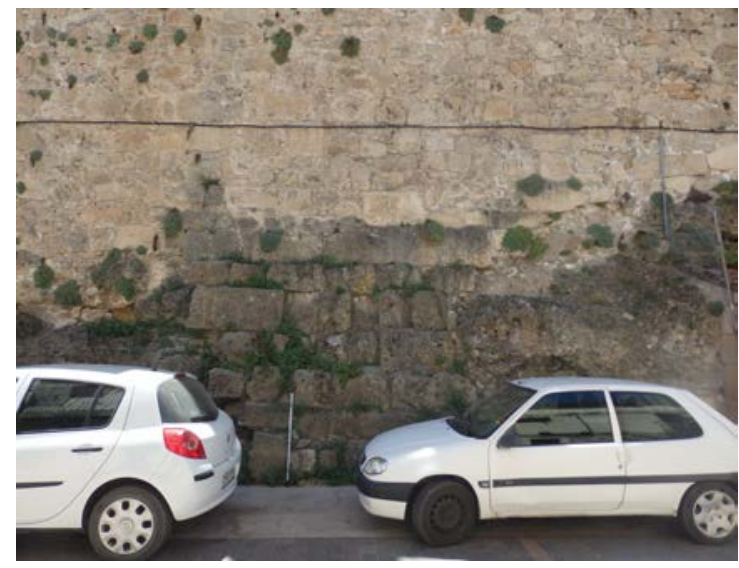

Fig. 5.6.23. Base del lienzo [A.S.E. 23/7/2016].

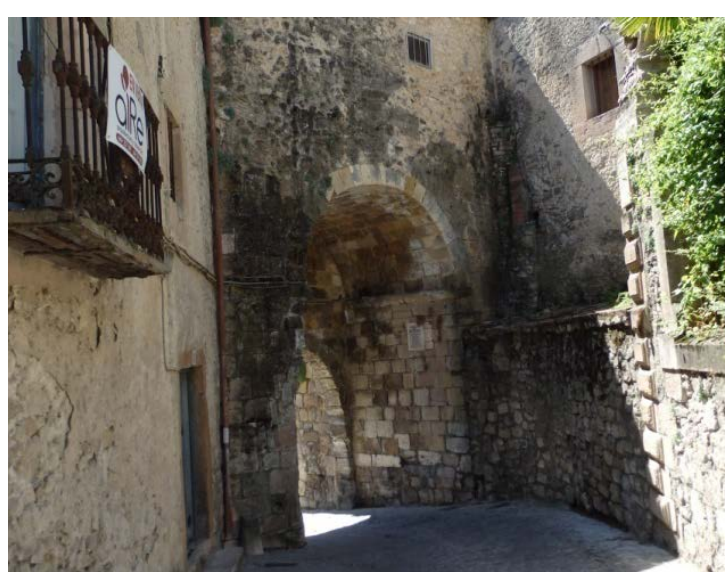

Fig. 5.6.25. Alzado interior de la puerta del Azogue [A.S.E. 5/7/2014].

\subsubsection{Zona del Postiguillo}

Poco más al este de la puerta del Azogue, da comienzo un tramo que llega hasta la zona del Postiguillo. Desciende con el terreno hasta llegar al cortado del valle, donde se interrumpe. Se compone de varias torres e incluye la puerta del Postiguillo (Fig. 5.6.26). La puerta conserva tan solo dos torres de sección rectangular que sobresalen ligeramente del plano de los lienzos adyacentes, el probable arco de acceso entre ellas se ha perdido. Se construyen con sillares de distintos tamaños y proporciones. El aparejo es irregular y no se organiza en hiladas ordenadas. Solo en la torre izquierda se puede ver un cierto orden en las hiladas, que se organizan paralelas al suelo. El tramo T1-T2 muestra un aparejo desordenado y caótico. Las piedras empleadas tienen formas, tamaños y materiales diferentes entre sí y el resultado es un aparejo anárquico (Fig. 5.6.28). En los dibujos de los arqueólogos Aymerich, Tardío y Zamora (1990, Plano 6D), se mide un es pesor de muro en este tramo de $3,00 \mathrm{~m}$ en la zona más cercana a T2 y de 2,50m en la parte más próxima a T1. En el tramo T3-T4, se observa un aparejo similar al descrito para la torre T3 con sillares irregulares en la base. Se 
pueden ver en la zona superior del muro restos de otro tipo de fábrica, con piedras pequeñas y desordenadas, que forman lo que parece mampostería encofrada. No se ha tenido acceso a los lienzos comprendidos entre las torres T3 y T7 por encontrarse en el interior de una parcela, así como parcialmente ocultos por la vegetación. Se han consultado los datos relativos a esta zona en el estudio de los arqueólogos Martín Aymerich, Tardío y Zamora (1990, 55-59, fotografías 49-52).

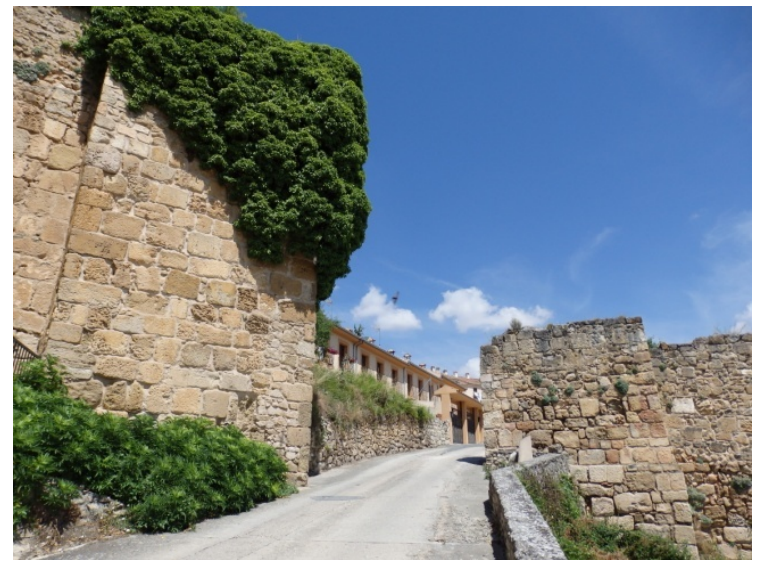

Fig. 5.6.26. Vista del paso del Postiguillo [A.S.E. 5/7/2014].

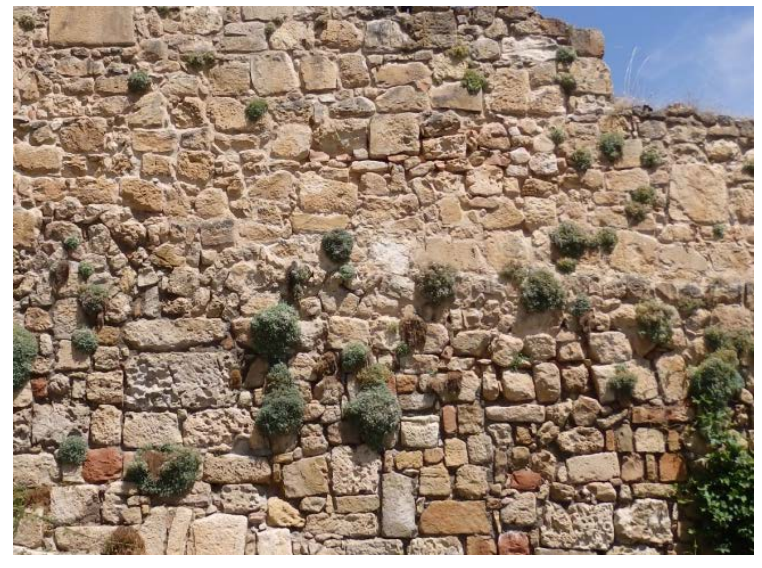

Fig. 5.6.28. Detalle del aparejo irregular en el tramo T1-T2. [A.S.E. 5/7/2014].

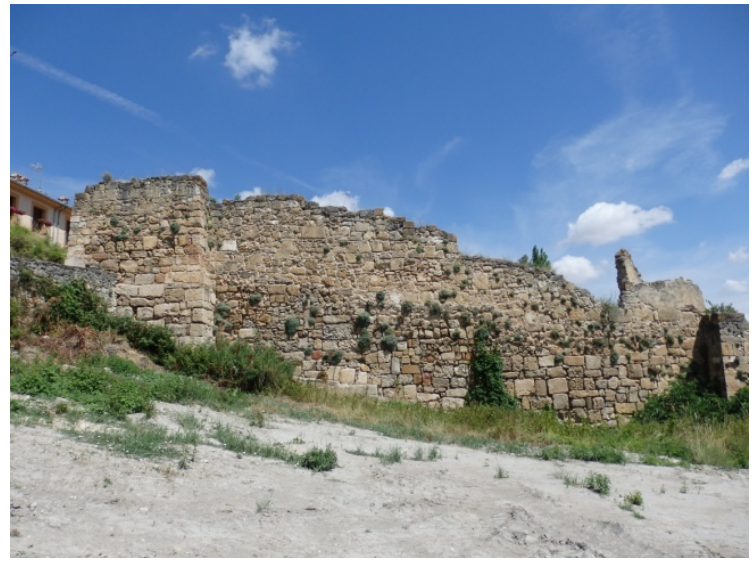

Fig. 5.6.27. Lienzo T1-T2 en la zona del Postiguillo [A.S.E. 5/7/2014].

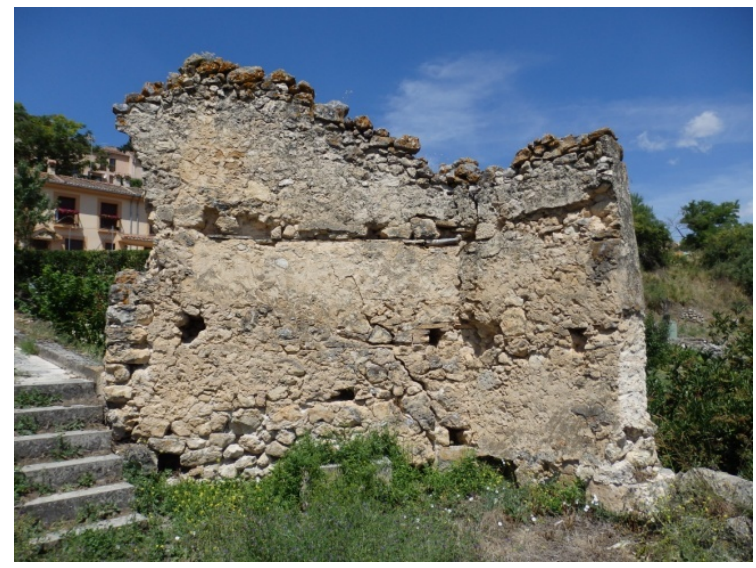

Fig. 5.6.29. Tapias en la zona interior de la torre T1 [A.S.E. 5/7/2014].

\subsubsection{Zona del postigo del Vado (T1-Pn7)}

Desde la torre T1 hacia el norte y siguiendo el trazado del río Duratón se encuentran otros restos. Para acceder a ellos se ha de recorrer la calle del Vado hacia el norte y descender después por la ladera. Estos restos se componen de muros de escasa altura construidos en el borde del cortado, sobre la roca, con tramos entrecortados que tiene longitudes máximas de $70 \mathrm{~m}$ aproximadamente (Fig. 5.6.30, Fig. 5.6.31). El trazado de estos muros se adapta a las formas del terreno, adquiriendo un recorrido 
sinuoso, ondulante y con quiebros. Se construyen con un aparejo de piedras irregular, donde no se aprecia un orden particular en las hiladas. Enfrentado a estos muros, en posición paralela, se yergue una porción de muro de una longitud cercana a los $3 \mathrm{~m}$ y una altura que alcanza los $4 \mathrm{~m}$. El muro se construye sobre el borde de la roca, en un nivel inferior a los muros descritos anteriormente. A ras de suelo, es visible la base del muro que continúa hacia el este. Previsiblemente, este muro formaría un quiebro en ángulo recto para unirse con muros visibles en las figuras Fig. 5.6.30 y Fig. 5.6.31, configurando un acceso de la muralla, el postigo del Vado. En este paso, son visibles en el suelo de roca marcas de haber sido tallada, se observa lo que podrían ser escalones y también un paso que recuerda a una trinchera, es decir, un pasillo tallado en la roca, de escasa profundidad. La cara suroeste del muro situado en paralelo (Fig. 5.6.32) se encuentra reparada, se observa la aplicación de morteros. Se pueden identificar al menos dos hiladas de tapia en esta cara del muro, aunque no son evidentes. En el reverso, la cara noreste (Fig. 5.6.33), es mucho más claro el empleo de tapia de mampostería para la construcción del muro. Se pueden c ontar cuatro tapias de altura e incluso es visible la marca de la tablazón empleada en el tapial.

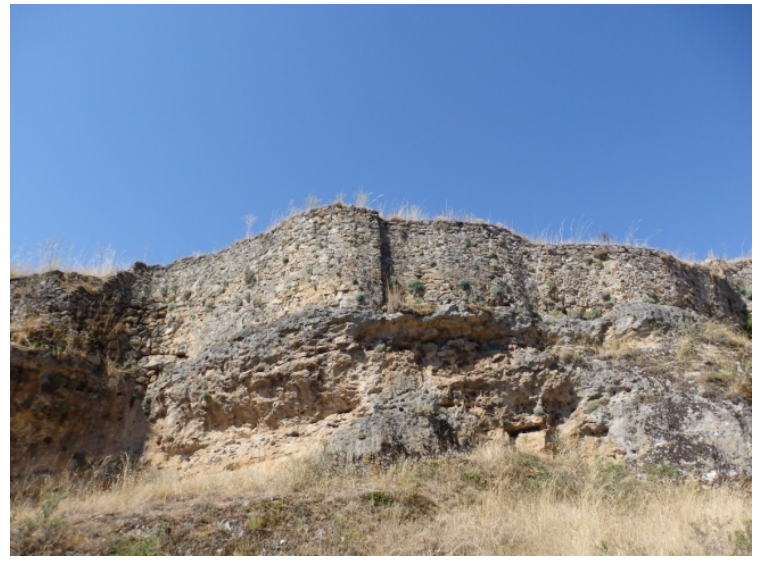

Fig. 5.6.30. Restos de muralla sobre la roca en la zona del postigo del Vado [A.S.E. 14/8/2016]

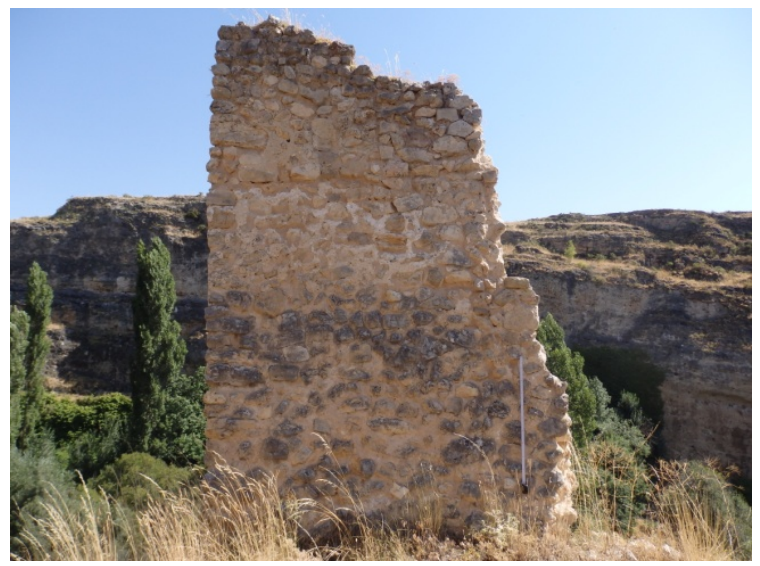

Fig. 5.6.32. Restos del postigo del Vado [A.S.E. $14 / 8 / 2016]$

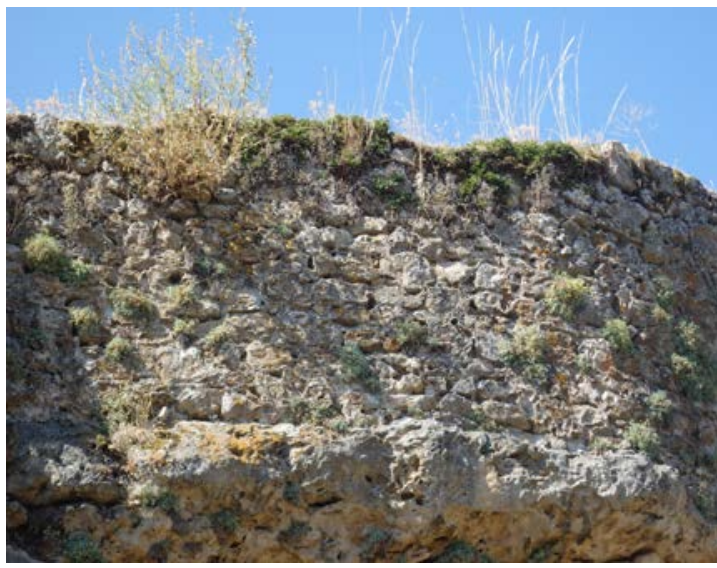

Fig. 5.6.31. Restos de muralla sobre la roca en la zona del postigo del Vado [A.S.E. 14/8/2016]

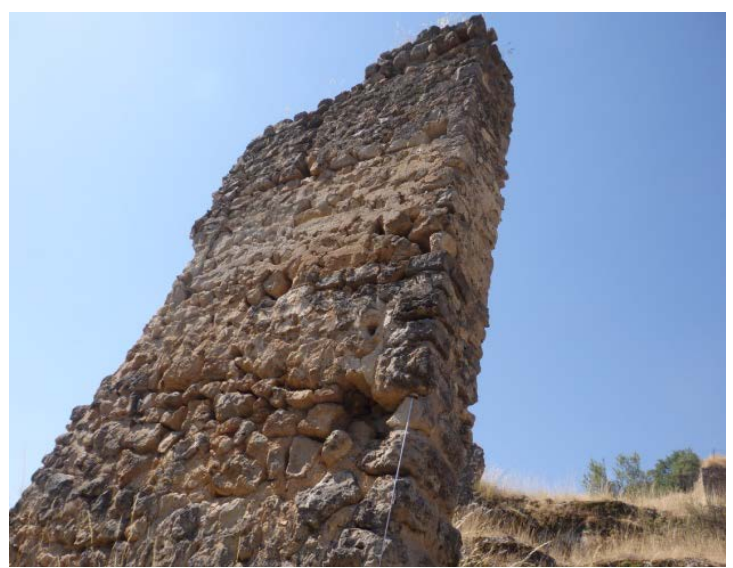

Fig. 5.6.33. Restos del postigo del Vado [A.S.E. $14 / 8 / 2016]$ 


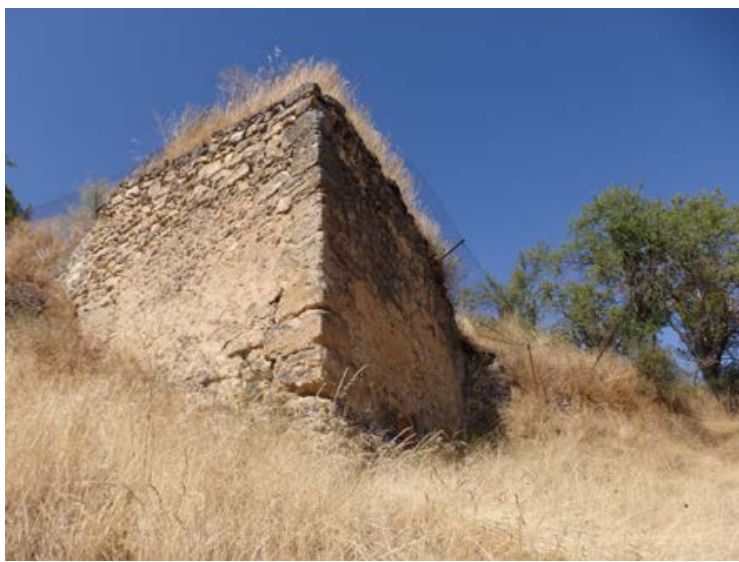

Fig. 5.6.34. Construcción que recuerda la base de una torre [A.S.E. 2377/2016].

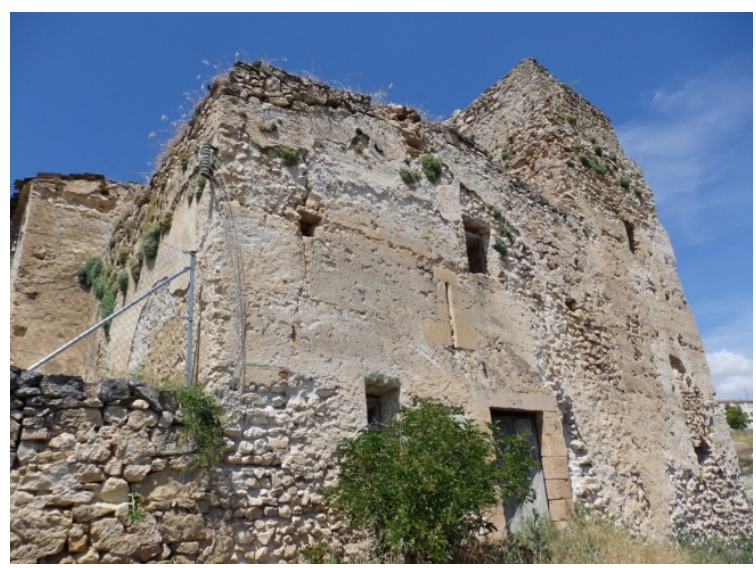

Fig. 5.6.35. Iglesia arruinada en la zona del postigo del Vado [5/7/2014].

\subsubsection{Tramo desde la puerta de Duruelo (P11) hacia el oeste}

La puerta de Duruelo se compone de dos torres de planta rectangular entre las que se produce el acceso, cubierto por una bóveda y retranqueado respecto de las torres. Las torres poseen sillería en las esquinas y en el interior del paso. En el resto del paramento, se observa el empleo de mampuestos y se vislumbran posibles hiladas de tapia, aunque no es del todo evidente. Martín Aymerich, Tardío y Zamora (1990, 81 y fotografía 117) explican que la restauración llevada a c abo en es ta puerta incluyó varias modificaciones. En la torre T21, al oeste, se sustituyeron los sillares en la parte baja de la esquina suroeste, en toda la esquina sureste, así como en la cara este, en el interior del acceso. Además, se añadió sillarejo en la parte inferior del lateral sur, correspondiente al alzado exterior. Explican que par a estas sustituciones se emplearon piedras antiguas, románicas, algunas de ellas con marca de cantero y se aclara que no corresponde con la obra antigua de la puerta. También se explica que se han eliminado reparaciones anteriores y se revelan actuaciones desafortunadas como el tapado de m echinales que alojaban el leño que sostenía los goznes de las puertas o el picado del arco y las pilastras del interior del acceso, tal y como se ve en la actualidad.

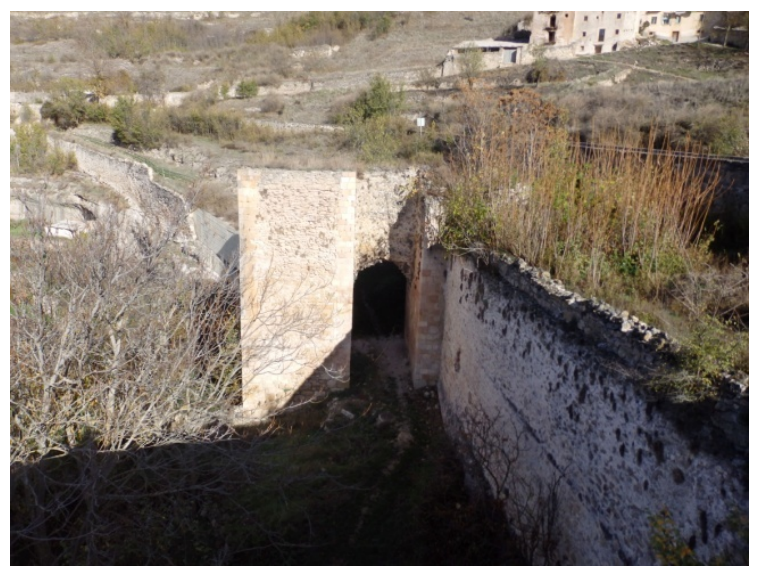

Fig. 5.6.36. Vista de la puerta de Duruelo desde la carretera [A.S.E. 11/11/2015].

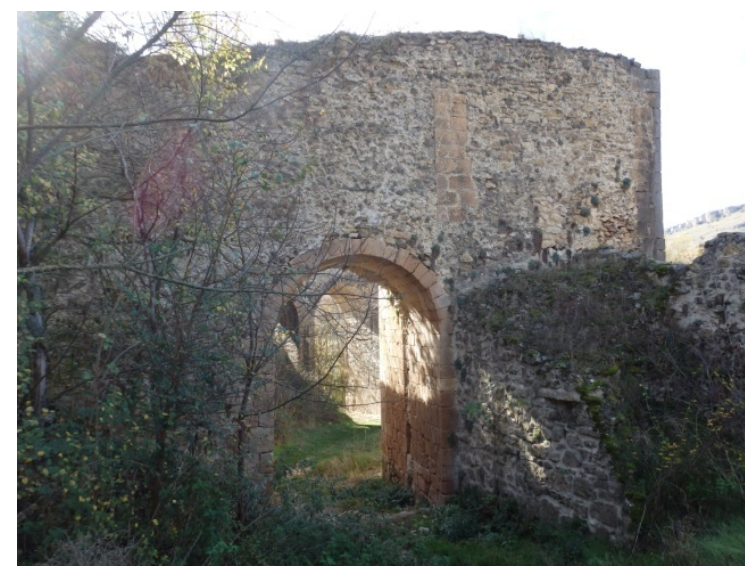

Fig. 5.6.37. Vista interior de I a puerta de Duruelo [A.S.E. 11/11/2015]. 


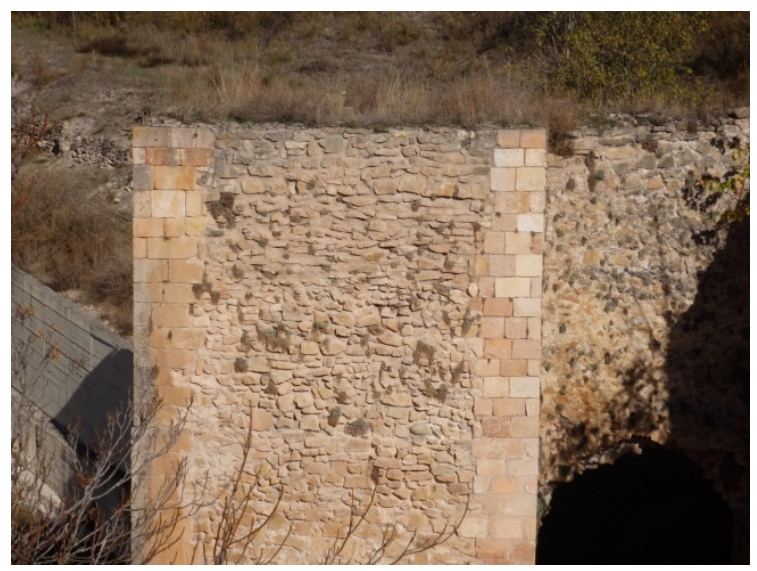

Fig. 5.6.38. Fábrica de la torre, se observan sillares en las esquinas [A.S.E. 11/11/2015].

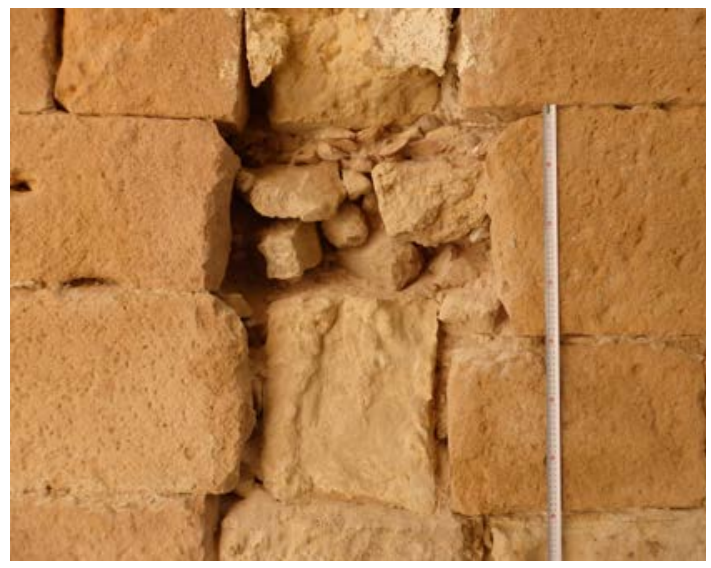

Fig. 5.6.39. Posición del estribo del arco de acceso. A Ambos lados, sillería ubicada en la restauración de 1987 [A.S.E. 11/11/2015].

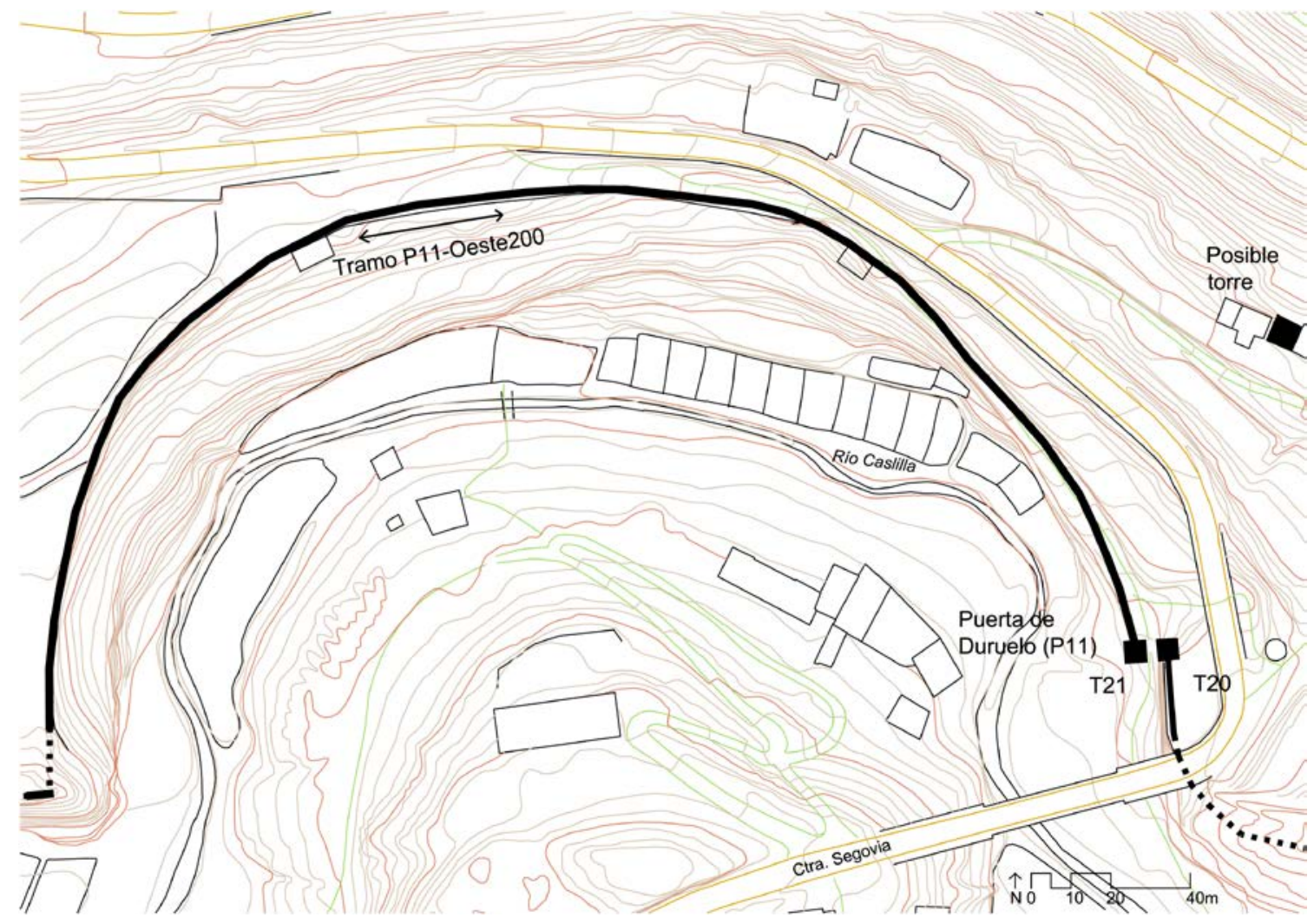

Fig. 5.6.40. Plano del tramo en ar co desde la puerta de D uruelo hacia el oeste. Fuente: Elaboración propia sobre cartografía de IDECyL.

En relación con la torre T20, al este (82), los autores señalan que no se encuentra alineada en su lado norte con la torre anterior, factor que interpretan como indicativo de que se construyó con posterioridad a la torre T21. Añaden que en la parte superior del lado sur existía un acceso escalonado hacia el interior. Describen la restauración de esta torre indicando que se reconstruyó la esquina de sillares suroeste y el paño oeste, correspondiente al interior del acceso. 


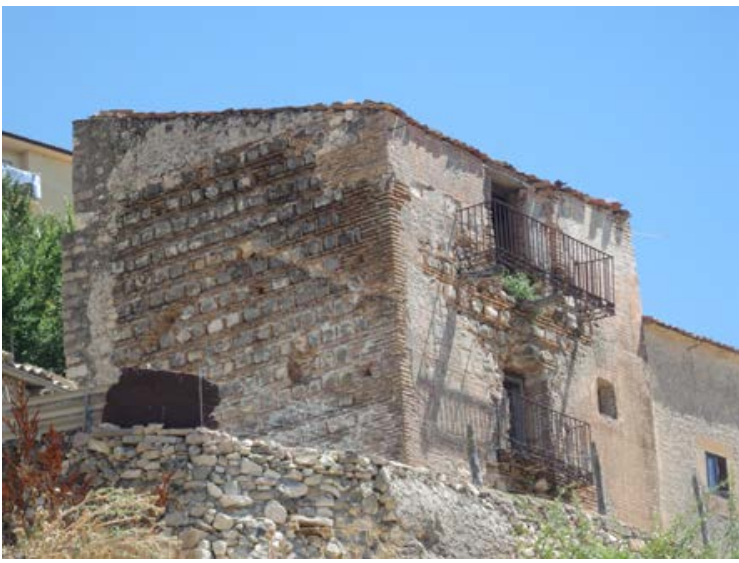

Fig. 5.6.41. Construcción al norte de la puerta de Duruelo [A.S.E. 23/7/2016].

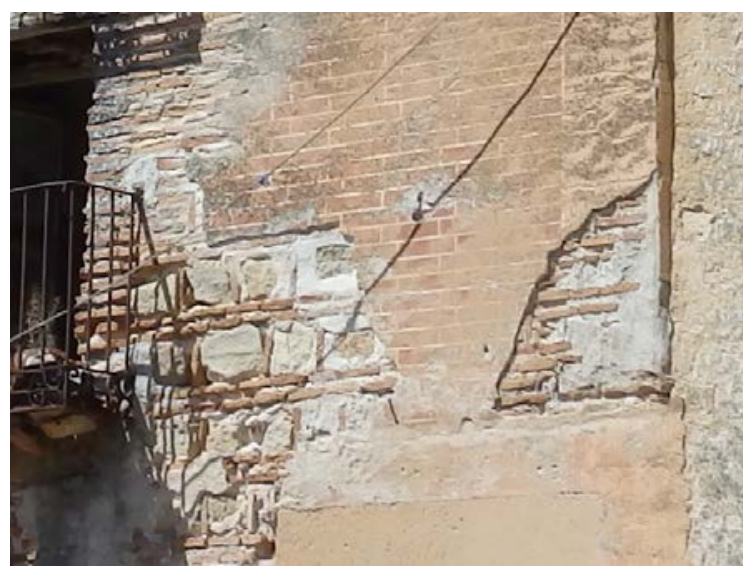

Fig. 5.6.42. Detalle de la técnica constructiva del muro [A.S.E 23/7/2016].

Ochenta metros al norte de la puerta de Duruelo, dentro del recinto amurallado, se sitúa una construcción que a primera vista tiene aspecto de vivienda (Fig. 5.6.41). La fachada principal muestra cuatro niveles de vivienda, planta baja más tres pisos. Se abren varios huecos en la fachada un balcón en cada piso y dos huecos en la planta baja. La planta tiene forma cuadrada y a partir de los planos de catastro se puede extraer una medida de $6,50 \mathrm{~m}$ de lado. La altura, cercana a los $13 \mathrm{~m}$, es importante en relación con las dimensiones de su planta. El sistema constructivo empleado es lo que en un principio atrae la atención sobre esta construcción. En varios puntos de sus fachadas, se puede ver el empleo de mampostería encintada con ladrillo o cloisonné. Esta técnica original se ocultó posteriormente bajo una capa de mortero que imita un aparejo de I adrillo convencional, a s oga (Fig. 5.6.42). La s ituación de r uina que presenta el edificio permite observar el sistema constructivo original de e sta construcción, presente también en otras construcciones defensivas como la puerta de Alfonso VIII de Fuentidueña, donde se observa este sistema en la base de sus dos torres. Martín Aymerich et al. $(1990,134)$ llaman la atención sobre este edificio y también se refieren a la presencia de ladrillo en Fuentidueña como ejemplo similar. Por una parte, las dimensiones y proporciones de esta edificación recuerdan el aspecto de una torre, por otra parte, el sistema constructivo empleado en sus muros puede ayudar situar cronológicamente su construcción al menos de forma relativa.

\subsubsection{Tramo desde la puerta de Castro (P10) hacia el oeste}

Los restos de la puerta de Castro son escasos, apenas es identificable la estructura de la puerta. Se conserva un muro junto al acceso, de reducidas dimensiones tal vez por la escasez de espacio para asentarse debido a lo escarpado de lugar (Fig. 5.6.43). Se construye con piedras irregulares, de tamaño medio. Es difícil indicar si se trata de una fábrica realizada con encofrado, ya que las marcas son escasas. No se observa la presencia de sillares. Martín Aymerich, Tardío y Zamora $(1990,80)$ indican la presencia de un enjarje en es ta pared, un enlace con un $\mathrm{m}$ uro en s entido perpendicular, que parte hacia el este y del que son visibles restos a ras de suelo. Este 
enjarje es identificable a través de un grupo de piedras que sobresale del plano del muro, a la izquierda del acceso.

Junto a es ta puerta se observa un tramo de muralla de una c entena de metros de longitud, construido directamente sobre la roca, con piedras irregulares, de tamaño medio, que se realiza con la técnica del tapial. Son visibles los mechinales grandes, de forma rectangular, colocados con ritmos regulares, y realizados con un grupo de tres piedras, una de las cuales lo corona. Se observan dos hiladas de tapia que completan la altura de lo que queda del muro (Fig. 5.6.46).

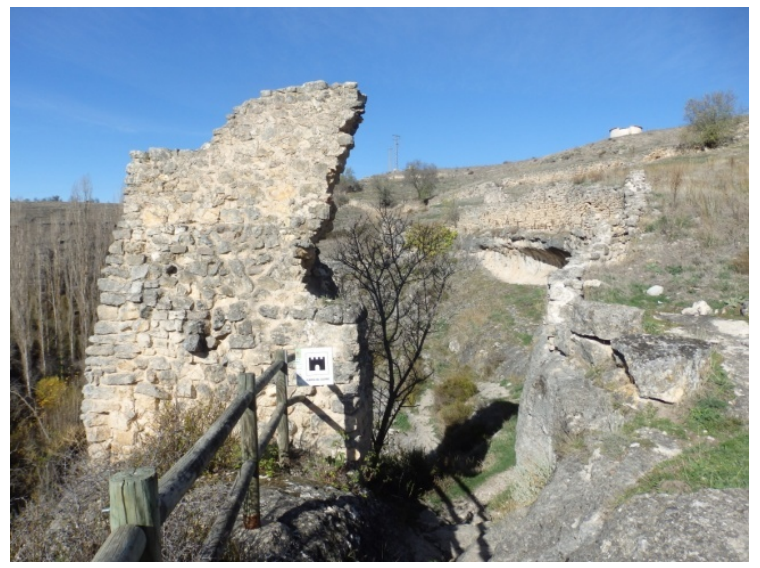

Fig. 5.6.43. Vista de la puerta de C astro desde el interior del recinto. [A.S.E. 11/11/2015].

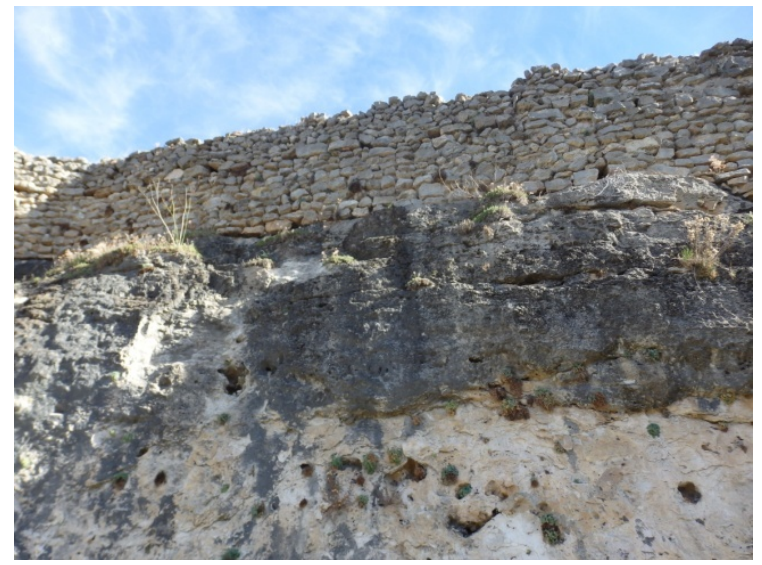

Fig. 5.6.45. Tramo de muralla sobre la roca, junto a la puerta de Castro [A.S.E. 11/11/2015].

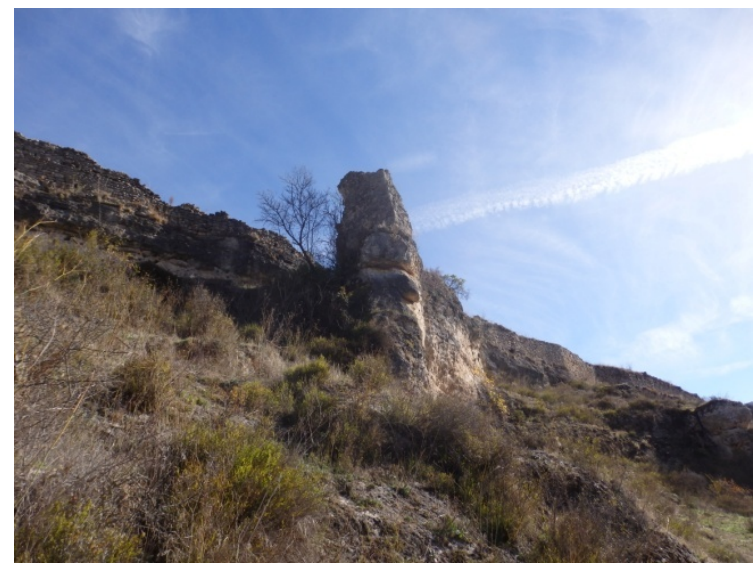

Fig. 5.6.44. Vista de la puerta de Castro desde el exterior del recinto [A.S.E. 11/11/2015].

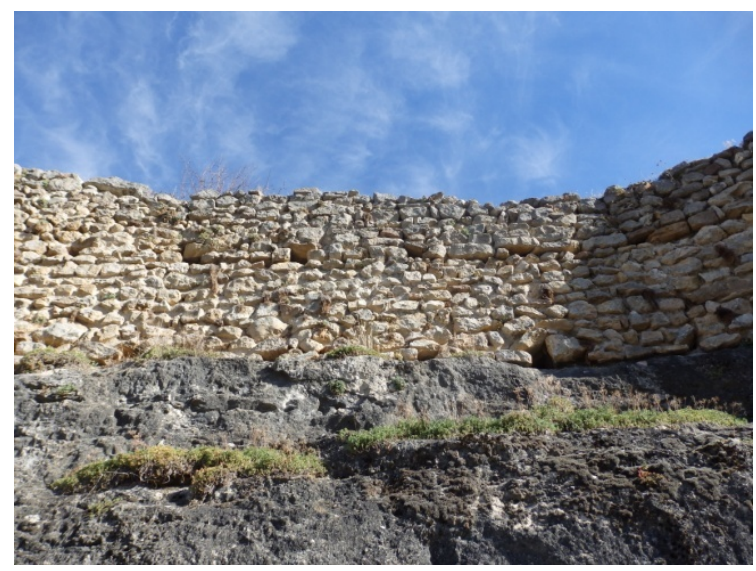

Fig. 5.6.46. Detalle del tramo de muralla junto a la puerta de Castro. Son visibles los mechinales y las dos hiladas de tapias [A.S.E. 11/11/2015].

\subsubsection{Zona de la puerta de la Fuerza (P8)}

La puerta del a Fuerza se compone de dos torres de bas e rectangular, bien diferenciadas en el alzado exterior (Fig. 5.6.47). El acceso se sitúa retranqueado con respecto de las torres y se cubre con un arco de medio punto construido con sillares. Tiene una anchura de $2,90 \mathrm{~m}$. El paso a través de la puerta se cubre con una bóveda 
de sillería de hiladas con altura no constante. Es visible en el interior una viga de madera que conserva las marcas de los goznes de la puerta. También en el suelo se observa una pi edra tallada que al ojaría un ej e vertical de la puerta. En el alzado interior (Fig. 5.6.48), las dos torres se desdibujan dando lugar a una fachada recta con un arco de medio punto, construido con sillares, que da paso a la bóveda que cubre el acceso. En cuanto a los materiales empleados para su construcción, se observa en la base de las torres el uso de sillares grandes y regulares, hasta una altura de $2,00 \mathrm{~m}$. También se observa el uso de sillares en las esquinas de las torres y en el arco y la bóveda de acceso. En la parte superior de las torres, en el alzado exterior, es visible un aparejo de mampuestos. Este aparejo se puede identificar como tapia, a partir de las marcas horizontales visibles en el paramento y por la presencia de algunos mechinales. En el alzado interior, también es visible el uso de es ta técnica en las zonas superiores.

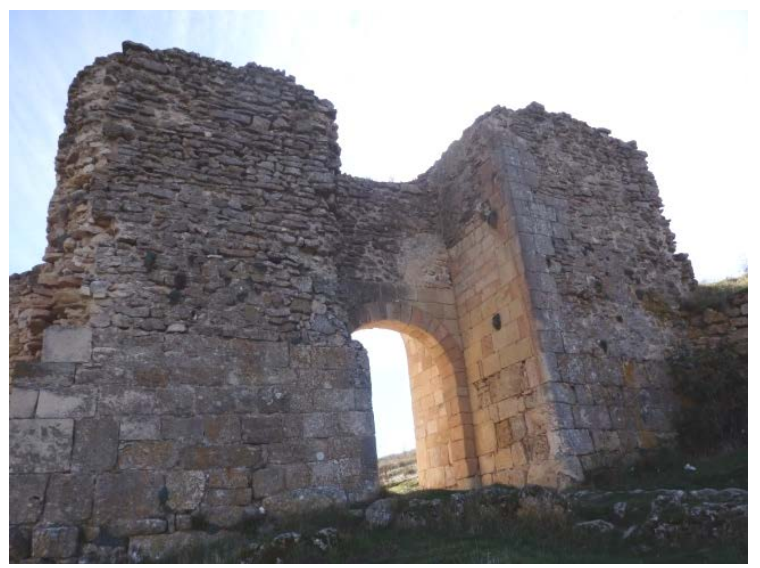

Fig. 5.6.47. Vista exterior de l a puerta de l a Fuerza [A.S.E. 11/11/2015].

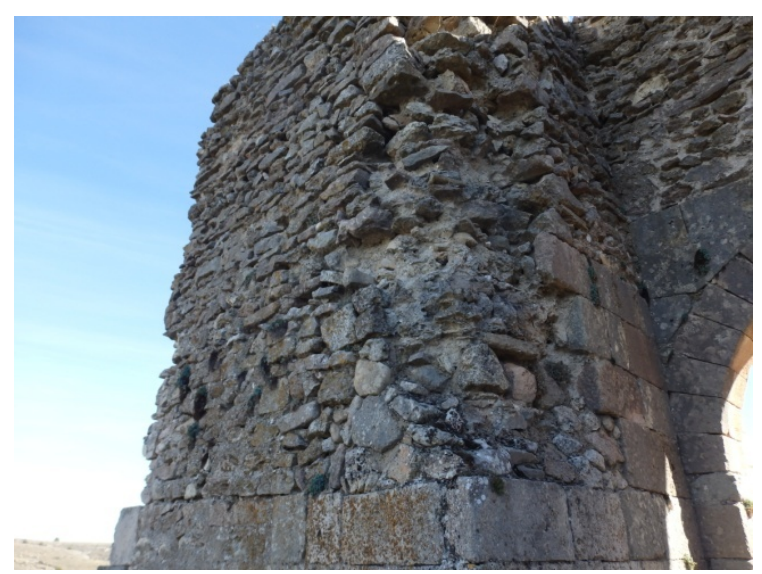

Fig. 5.6.49. Mampostería encofrada la torre T23. [A.S.E. 11/11/2015].

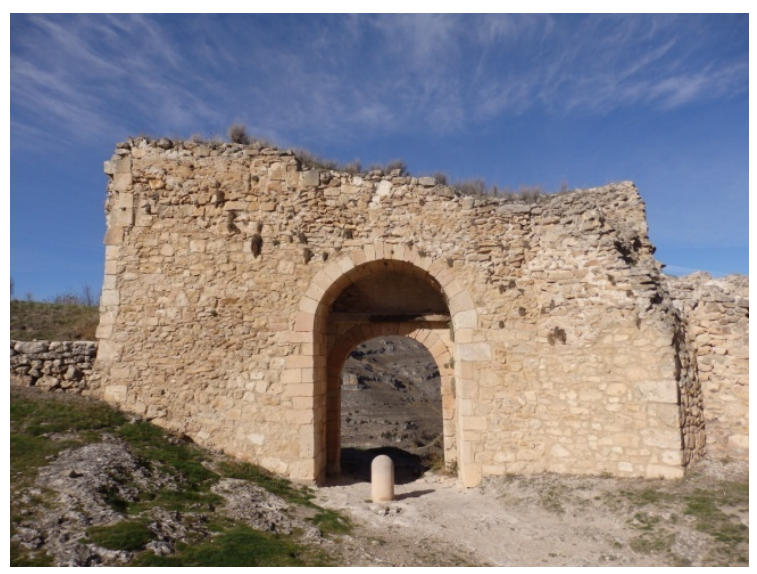

Fig. 5.6.48. Vista interior de la puerta de la Fuerza [A.S.E. 11/11/2015].

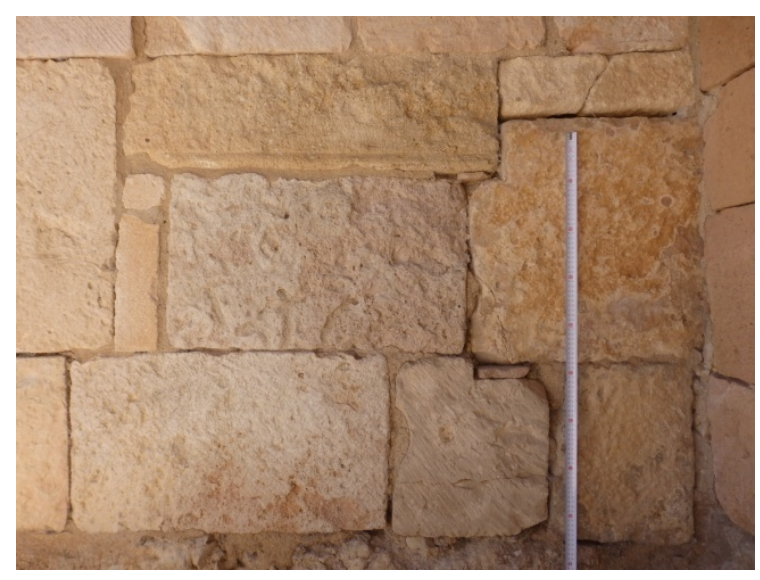

Fig. 5.6.50. Sillería sustituida en base de la puerta de la Fuerza, en el interior del paso de acceso [A.S.E. 23/7/2016] 
Martín Aymerich et al. $(1990,145)$ indican que se trata de una puerta construida sobre unos basamentos anteriores, de posible origen árabe. Estos basamentos corresponderían con la base de sillería visible desde el exterior de la puerta. La restauración llevada a cabo en la puerta a finales de los 80 implicó la renovación de la sillería en las esquinas de las torres y prácticamente en todo el paso interior. Las dovelas del arco y la bóveda también fueron renovadas, así como las pilastras que lo sostienen. Otra restauración en to rno a los años 60 c olocó sillería románica en el acceso (76).

Junto a es ta puerta, en dirección oeste, parte un tramo de muralla del que quedan restos de escasa altura y entidad. Se construye directamente sobre el borde la roca y muestra una fábrica de mampuestos desordenada e irregular. Es singular la presencia de aparejo de piedra en forma de espina de pez (Fig. 5.6.51).

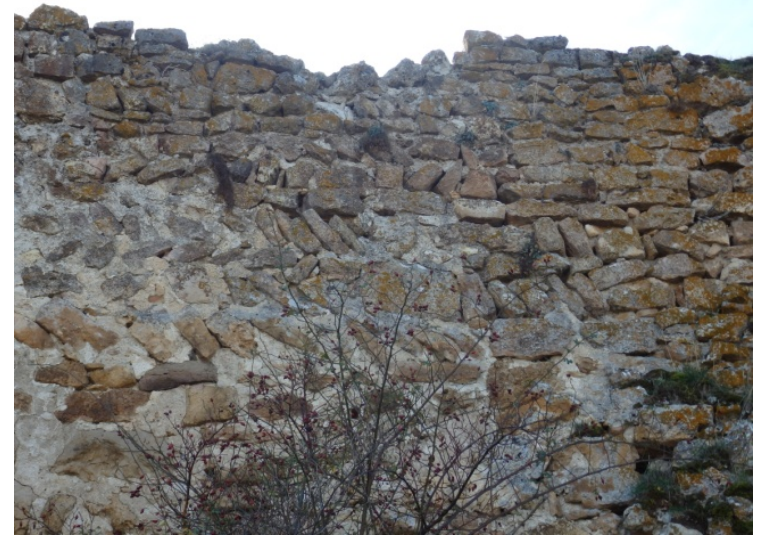

Fig. 5.6.51. Aparejo en espina de pez en tramo de muralla junto a pu erta de la Fuerza [A.S.E. 11/11/2015].

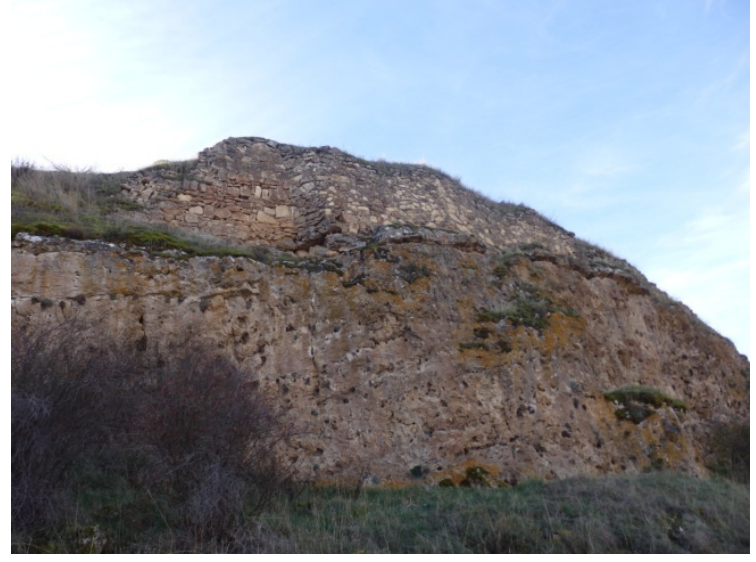

Fig. 5.6.52. Tramo de muralla junto a la puerta de la Fuerza construido sobre la roca [A.S.E. $11 / 11 / 2015]$.
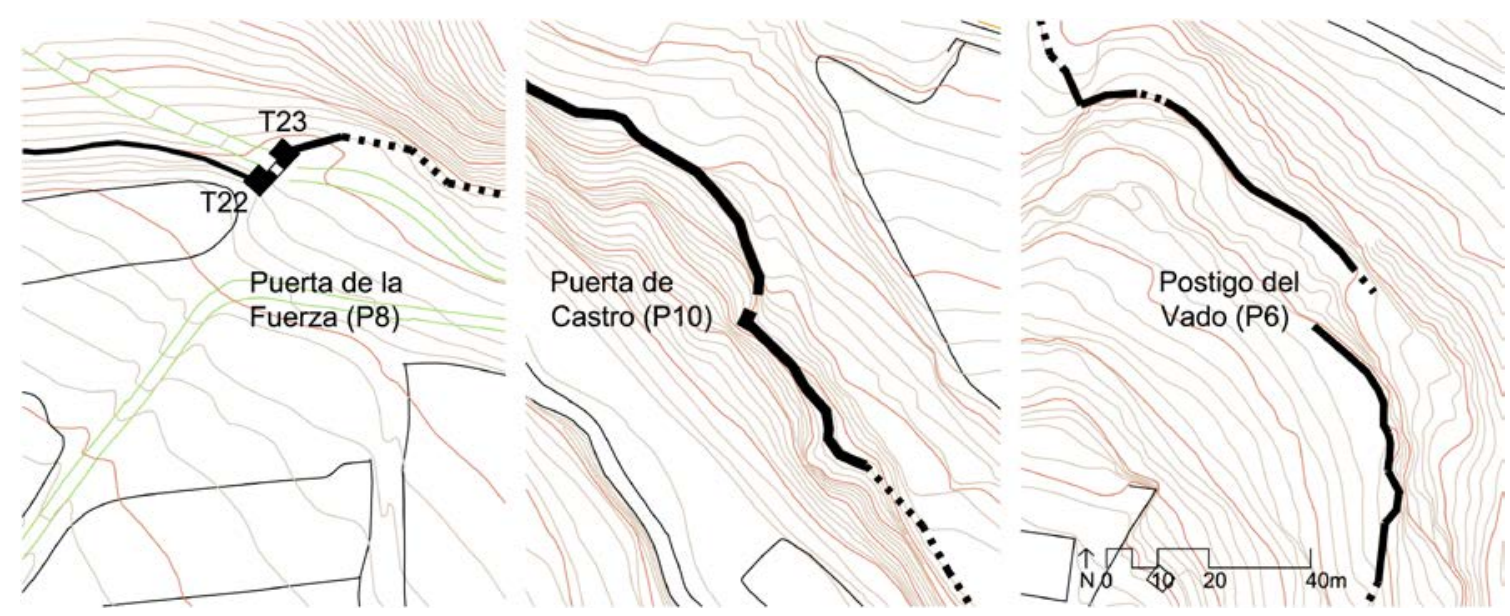

Fig. 5.6.53. Tramos de muralla. De izquierda a derecha, la puerta de la Fuerza, la puerta de Castro y el Postigo del Vado. Fuente: Elaboración propia sobre cartografía de IDECyL. 


\subsubsection{Características principales de los elementos descritos}

En la Tabla 5.6.1, a c ontinuación, se recogen las características generales de las torres del recinto y sus puertas. Se puede c onstatar el alto número de tor res del recinto, que llega a 20, de las cuales la mitad configuran cinco puertas. Prácticamente todas las torres tienen una planta rectangular, a excepción de las tres torres del actual castillo, que son semicirculares. La casi totalidad de las torres presentan una base diferenciada, construida con un material o solución constructiva diferente de la visible en las zona superiores. Las puertas son también numerosas. Cinco de el las se componen de dos torres que $\mathrm{fl}$ anquean el acceso y se sitúan alineadas con la dirección del trazado de la muralla, a excepción de la puerta de Duruelo, que realiza un quiebro en ángulo recto. Alonso Zamora $(2011,156)$ señala que, frente a la leyenda que plantea que en Sepúlveda existieron siete puertas, el total, considerando portillos o postigos, es de once. Tampoco si se cuentan solo las puertas más importantes ( $\mathrm{P} 1$, $\mathrm{P} 11, \mathrm{P} 8, \mathrm{P} 5$, aunque esta última no deja de ser un pos tigo y $\mathrm{P} 2$, sobre la que hay dudas en cuanto a su ubicación original) se alcanza el número siete.

La tabla siguiente, la Tabla 5.6.2, muestra datos acerca de los tramos del recinto amurallado, delimitados entre torres y puertas. Se indica si el tramo ha sido objeto de reconstrucción, cuál es su estado de conservación y se ofrecen datos acerca de la longitud del tramo existente, desaparecido o construido recientemente.

Tabla 5.6.1. Características y dimensiones de torres y su relación con las puertas. Fuente: Elaboración propia.

\begin{tabular}{|c|c|c|c|c|c|c|c|c|}
\hline 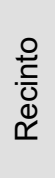 & 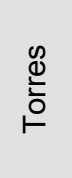 & $\begin{array}{l}\frac{\infty}{\pi} \\
\frac{1}{0} \\
\frac{1}{2} \\
0\end{array}$ & $\begin{array}{l}\text { Nombre } \\
\text { asociado }\end{array}$ & $\begin{array}{c}\text { Tipo de puerta / } \\
\text { torre }\end{array}$ & $\begin{array}{l}\text { Sección de } \\
\text { torre }\end{array}$ & $\begin{array}{l}\text { Dimensiones } \\
\text { torres } \\
\text { (Diámetro } \varnothing, \\
\text { Fondo F, Ancho } \\
\text { A) }\end{array}$ & $\begin{array}{l}\text { Relación } \\
\text { con lienzo }\end{array}$ & $\begin{array}{c}\text { Zócalo/ } \\
\text { Base }\end{array}$ \\
\hline \multirow{11}{*}{$\mathrm{R} 1$} & $\mathrm{~T} 1$ & - & - & $\begin{array}{l}\text { En línea con } \\
\text { lienzo }\end{array}$ & Rectangular & $\mathrm{A} 7,00 \times \mathrm{F} 7,20 \mathrm{~m}$ & Integrado & Sí \\
\hline & $\mathrm{T} 2$ & \multirow{2}{*}{ P5 } & \multirow{2}{*}{ El Postiguillo } & $\begin{array}{l}\text { En línea con } \\
\text { lienzo }\end{array}$ & Rectangular & $\mathrm{A} 5,70 \times 5,70 \mathrm{~m}$ & Integrado & Sí \\
\hline & T3 & & & $\begin{array}{l}\text { En línea con } \\
\text { lienzo }\end{array}$ & Rectangular & $\mathrm{A} 5,75 \mathrm{xF} 1,80 \mathrm{~m}$ & Integrado & Sí \\
\hline & $\mathrm{T} 4$ & - & - & $\begin{array}{l}\text { En línea con } \\
\text { lienzo }\end{array}$ & Rectangular & $\mathrm{A} 4,00 \mathrm{xF} 2,50 \mathrm{~m}$ & Integrado & - \\
\hline & $\mathrm{T} 5$ & - & - & $\begin{array}{l}\text { En línea con } \\
\text { lienzo }\end{array}$ & Rectangular & $\mathrm{A} 5,80 \times \mathrm{F} 3,60 \mathrm{~m}$ & Integrado & - \\
\hline & $\mathrm{T} 6$ & \multirow[t]{2}{*}{ P4 } & \multirow{2}{*}{$\begin{array}{l}\text { Postiguillo } \\
\text { Viejo* }\end{array}$} & $\begin{array}{l}\text { En línea con } \\
\text { lienzo }\end{array}$ & Rectangular & $\mathrm{A} 6,50 \mathrm{xF} 3,50 \mathrm{~m}$ & Integrado & - \\
\hline & $\mathrm{T} 7$ & & & Desaparecida & - & - & - & - \\
\hline & $\mathrm{T} 8$ & \multirow{2}{*}{ P3 } & \multirow{2}{*}{$\begin{array}{l}\text { Puerta del } \\
\text { Azogue o del } \\
\text { Ecce Homo }\end{array}$} & $\begin{array}{l}\text { En línea con } \\
\text { lienzo }\end{array}$ & Rectangular & $\mathrm{A} 4,90 \times \mathrm{F} 9,05 \mathrm{~m}$ & Integrado & Sí \\
\hline & T9 & & & $\begin{array}{l}\text { En línea con } \\
\text { lienzo }\end{array}$ & Rectangular & $\mathrm{A} 2,90 \times \mathrm{F} 5,33 \mathrm{~m}$ & Integrado & Sí \\
\hline & T10 & - & - & $\begin{array}{c}\text { En línea con } \\
\text { lienzo }\end{array}$ & Rectangular & & Integrado & $\begin{array}{c}\text { Sí, } \\
\text { zarpa }\end{array}$ \\
\hline & T11 & - & Castillo & Avanzada & Semicircular & $\varnothing 3,87 \mathrm{~m}$ & Sí & Sí \\
\hline
\end{tabular}


Las murallas en las Comunidades de Villa y Tierra de la Diócesis de Segovia en los siglos XI a XIII. Técnica y sistemas constructivos de la arquitectura defensiva medieval.

\begin{tabular}{|c|c|c|c|c|c|c|c|c|}
\hline 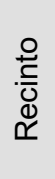 & $\stackrel{\infty}{\varrho}$ & 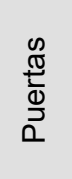 & $\begin{array}{l}\text { Nombre } \\
\text { asociado }\end{array}$ & $\begin{array}{l}\text { Tipo de puerta / } \\
\text { torre }\end{array}$ & $\begin{array}{l}\text { Sección de } \\
\text { torre }\end{array}$ & $\begin{array}{l}\text { Dimensiones } \\
\text { torres } \\
\text { (Diámetro } \varnothing, \\
\text { Fondo F, Ancho } \\
\text { A) }\end{array}$ & $\begin{array}{l}\text { Relación } \\
\text { con lienzo }\end{array}$ & $\begin{array}{c}\text { Zócalo/ } \\
\text { Base }\end{array}$ \\
\hline \multirow{16}{*}{ R1 } & T12 & - & & $\begin{array}{l}\text { respecto del } \\
\text { lienzo }\end{array}$ & Semicircular & $\varnothing 5,59 \mathrm{~m}$ & Sí & $\begin{array}{c}\text { No } \\
\text { visible }\end{array}$ \\
\hline & T13 & - & & & Semicircular & $\varnothing 3,39 \mathrm{~m}$ & Sí & $\begin{array}{c}\text { No } \\
\text { visible }\end{array}$ \\
\hline & T14 & \multirow{2}{*}{ P2 } & \multirow{2}{*}{$\begin{array}{l}\text { Puerta de la } \\
\text { Villa, del } \\
\text { Mercado, } \\
\text { Trascastillo o } \\
\text { Castillo }\end{array}$} & \multirow{2}{*}{ Desaparecida } & - & - & - & - \\
\hline & T15 & & & & - & - & - & - \\
\hline & T16 & - & - & $\begin{array}{l}\text { En línea con } \\
\text { lienzo }\end{array}$ & Rectangular & $A 7,84 x F 5,25 m$ & Integrado & Sí \\
\hline & T17 & - & - & $\begin{array}{l}\text { En línea con } \\
\text { lienzo }\end{array}$ & Rectangular & $\mathrm{A} 5,33 \mathrm{xF} 0,80 \mathrm{~m}$ & Integrado & Sí \\
\hline & T18 & \multirow{2}{*}{ P1 } & \multirow{2}{*}{$\begin{array}{c}\text { Puerta del Río } \\
\text { o de las } \\
\text { Pucherillas }\end{array}$} & $\begin{array}{l}\text { En línea con } \\
\text { lienzo }\end{array}$ & Rectangular & $\mathrm{A} 6,00 \mathrm{xF} 5,75 \mathrm{~m}$ & Integrado & Sí \\
\hline & T19 & & & $\begin{array}{l}\text { En línea con } \\
\text { lienzo }\end{array}$ & Rectangular & $\mathrm{A} 6,00 \mathrm{xF} 5,50 \mathrm{~m}$ & Integrado & Sí \\
\hline & T20 & \multirow[b]{2}{*}{ P11 } & \multirow{2}{*}{$\begin{array}{l}\text { Puerta de } \\
\text { Duruelo, } \\
\text { Duruela o } \\
\text { Duruelo } \\
\text { Sopeña }\end{array}$} & \multirow{2}{*}{$\begin{array}{l}\text { Perpendicular a } \\
\text { lienzo }\end{array}$} & Rectangular & $\mathrm{A} 5,00 \times \mathrm{F} 5,30 \mathrm{~m}$ & Integrado & $\begin{array}{c}\text { Sí, } \\
\text { sillería }\end{array}$ \\
\hline & T21 & & & & Rectangular & $\mathrm{A} 5,20 \times 5,20 \mathrm{~m}$ & Integrado & $\begin{array}{c}\text { Sí, } \\
\text { sillería }\end{array}$ \\
\hline & - & P10 & $\begin{array}{c}\text { Puerta de } \\
\text { Castro, de } \\
\text { Guerrilla, } \\
\text { Sopeña, } \\
\text { Sopeña } \\
\text { Castrón o } \\
\text { Sopeña Castro }\end{array}$ & $\begin{array}{l}\text { Perpendicular a } \\
\text { lienzo }\end{array}$ & Rectangular & $\mathrm{A} 1,75 \mathrm{xF} 0,60 \mathrm{~m}$ & Integrado & No \\
\hline & - & P9 & $\begin{array}{l}\text { Postigo de la } \\
\text { Perejilera* }\end{array}$ & - & - & - & - & - \\
\hline & T22 & \multirow{2}{*}{ P8 } & \multirow{2}{*}{$\begin{array}{c}\text { Puerta de la } \\
\text { Fuerza }\end{array}$} & \multirow{2}{*}{$\begin{array}{l}\text { Perpendicular a } \\
\text { lienzo }\end{array}$} & Rectangular & $\mathrm{A} 4,30 \mathrm{xF} 4,00 \mathrm{~m}$ & Integrado & $\begin{array}{c}\text { Sí, } \\
\text { sillería }\end{array}$ \\
\hline & T23 & & & & Rectangular & $\mathrm{A} 3,76 \mathrm{~m} \times 4,00 \mathrm{~m}$ & Integrado & $\begin{array}{l}\text { Sí, } \\
\text { sillería }\end{array}$ \\
\hline & & P6 & $\begin{array}{l}\text { Postigo del } \\
\text { Vado }\end{array}$ & $\begin{array}{c}\text { Perpendicular a } \\
\text { lienzo }\end{array}$ & - & - & - & No \\
\hline & \multicolumn{2}{|c|}{ Pn7 } & $\begin{array}{l}\text { Pontón de la } \\
\text { Peña }\end{array}$ & - & - & - & - & - \\
\hline
\end{tabular}

* Nombrado así por M. Dolores Martín Aymerich et al. (1990, 26, 141)

Hipótesis de arqueólogos Martín Aymerich, Tardío y Zamora (1990, 140 y 144).

Tabla 5.6.2. Características y dimensiones de los tramos de muralla. Fuente: Elaboración propia.

\begin{tabular}{|c|c|c|c|c|}
\hline 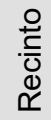 & Tramo & Reconstrucción & Estado & $\begin{array}{c}\text { Longitud }(\mathrm{m}) \\
\text { (E Existente / D Desaparecido / M } \\
\text { Moderno) }\end{array}$ \\
\hline & P1-T13 & No & $\begin{array}{c}\text { Modificado, aprovechado en } \\
\text { nuevas edificaciones }\end{array}$ & E117,59 / D60,39 \\
\hline
\end{tabular}




\begin{tabular}{|c|c|c|c|c|}
\hline $\begin{array}{l}\stackrel{0}{. \frac{1}{O}} \\
\stackrel{\Phi}{\simeq}\end{array}$ & Tramo & Reconstrucción & Estado & $\begin{array}{c}\text { Longitud }(\mathrm{m}) \\
\text { (E Existente / D Desaparecido / M } \\
\text { Moderno) }\end{array}$ \\
\hline \multirow[t]{3}{*}{ R1 } & T13-T8 & $\begin{array}{l}\text { Sí, parte superior y } \\
\text { almenado T10-T9 }\end{array}$ & $\begin{array}{l}\text { Modificado, aprovechado en } \\
\text { nuevas edificaciones }\end{array}$ & E113,27 \\
\hline & T8-T1 & No & $\begin{array}{l}\text { Buen estado, reparado. } \\
\text { Invadido por vegetación }\end{array}$ & D35,40 / E98,86 \\
\hline & T1-Pn7 & No & Ruina & D200 / 185,25 \\
\hline \multirow{4}{*}{$\mathrm{R} 1$} & Pn7-P8 & No & Escasos restos & $\mathrm{D} 1462,42$ / E12,80 \\
\hline & P8-P10 & No & Escasos restos & E146,13 / D666,69 / E102,69 \\
\hline & P10-P11 & Sí, en una parte & Deteriorado, P11 restaurada & $\begin{array}{c}\text { E78,98 / D90,79 / E346 / } \\
\text { M26,85 / E25,90 }\end{array}$ \\
\hline & $\mathrm{P} 11-\mathrm{P} 1$ & No & Escasos restos & $\mathrm{E} 22,30$ / D440,02 / E18,81 \\
\hline
\end{tabular}

\subsubsection{Análisis constructivo}

\subsubsection{Soluciones constructivas presentes en la muralla}

A continuación, se han identificado las soluciones constructivas empleadas el recinto amurallado. La tapia de mampostería se puede encontrar en varios puntos del recinto amurallado. Es una técnica difícil de identificar ya que, en ocasiones, no se aprecian sus marcas características. La zona más evidente es el tramo que parte de la puerta de Duruelo (P11) en dirección oeste, formando un gran arco en planta hacia la puerta de Castro (P10). Se trata de una zona poco accesible y cuyo estado de conservación no es bueno. Se observan desprendimientos importantes en los lienzos. En estos paramentos se pueden identificar principalmente las hiladas de tapia, siendo más difícil aislar tapias completas. En algunas de las tapias visibles, es posible identificar mechinales y también muretes de cierre de cajón, que se configuran con piedras planas en un I ateral de Ia tapia (Fig. 5.6.54). En el lienzo al oeste de la puerta de Castro es también visible el uso de tapia, con el empleo de mechinales grandes y tal vez la compartición de estos en di stintas tapias (Fig. 5.6.55). De forma menos evidente, se puede encontrar tapia de mampostería en la puerta de Duruelo (P11) y también en la puerta de la Fuerza (P8). La puerta del Azogue (P3) muestra el empleo de tapia en la parte superior de la torre T9. También se observa el empleo de esta técnica en el postigo del Vado, donde la tapia se identifica claramente, sobre todo en la cara noreste del muro aislado visible en las figuras Fig. 5.6.32 y Fig. 5.6.33. El aparejo de mampostería es visible en al gunos puntos de l a muralla, aunque en ocasiones puede confundirse con la tapia de mampostería. Las reparaciones de esta última pueden transformar la tapia en un aparejo de mampostería. La puerta de Castro (Fig. 5.6.56) puede ser un caso similar. Se observa un aparejo de mampostería en ese caso, que podría ser los restos de un muro de tapia de mampostería. La puerta de la 
Las murallas en las Comunidades de Villa y Tierra de la Diócesis de Segovia en los siglos XI a XIII. Técnica y sistemas constructivos de la arquitectura defensiva medieval.

Fuerza presenta, sobre una base de sillares, tapia de mampostería. La torre T1 presenta en su interior los restos de lo que parece una tapia de mampostería, con un mechinal visible, construido en Iadrillo (Fig. 5.6.57). Representa un caso aislado, no encontrado en más elementos del recinto.

La sillería es visible en varios puntos de la muralla. La sillería de aparejo regular y homogéneo se encuentra en las puertas del Río (Fig. 5.6.58), en la base de la puerta de Fuerza (Fig. 5.6.59) y en varios puntos de la puerta Duruelo (Fig. 5.6.63). En este último caso, tal y como se ha indicado en la descripción general, se ha producido una importante sustitución de sillares con la incorporación de sillares antiguos reubicados en la restauración de 1987. Los sillares empleados en este caso son muy definidos y forman un aparejo muy regular y ordenado. Se puede encontrar este aparejo en Ia parte interior del acceso de la puerta de la Fuerza, también restaurada con el mismo sistema (Martín Aymerich et al. 1990, 76). Se encuentra una mampostería de piedra singular en el tramo cercano a la puerta de la Fuerza, que muestra un aspecto desordenado y zonas con piedras dispuestas en espina de pez (Fig. 5.6.64).

El análisis que realizan Martín Aymerich y otros investigadores (1990, 131-133) acerca de los aparejos existentes en este recinto amurallado arroja tres tipos distintos, que se denominan $A, B$ y $C$, este último dividido en tres subtipos. Los aparejos $A$ y $B$ recogerían los paramentos realizados en sillería, mientras que el $C$ recoge paramentos como sillarejo, mampostería o tapia. El aparejo A se efectúa con sillares grandes, de dimensiones superiores a $40 \times 40 \mathrm{~cm}$ colocadas en las caras exteriores de los muros configurando un muro de dos hojas con un relleno interior. Se indica que estos sillares están erosionados en las esquinas, que el aspecto de su pulimento los acerca a los de las obras públicas romanas. Se plantea que es probable que s e trate de piedras reaprovechadas de otras construcciones. Las construcciones con este aparejo datan de fines de siglo IX y X. Se identifica este tipo de aparejo en las zarpas de los lienzos T10-T9 y de la torre T5, así como en el tramo T1-T6 (Fig. 5.6.61, Fig. 5.6.62). El aparejo tipo B lo constituyen los aparejos donde se han empleado sillares del tipo A en muros que han sido reconstruidos tras un derrumbe o una alteración, complementados con piedras más pequeñas y que ofrece un aspecto de haber sido reformados o haber sufrido una nueva disposición de sus piedras (Fig. 5.6.58, Fig. 5.6.60). Se localiza principalmente en el tramo de la puerta del Río T19-T16 aunque también se encuentra en otras zonas del recinto amurallado. Se data de acuerdo con una inscripción situada en la torre T17, en torno a 1063.

El tipo $C$ se divide en tres subtipos. El subtipo $\mathrm{C}-1$ hace referencia a paramentos efectuados con piedra de tamaño regular, con una dimensión máxima de $30 \times 30 \mathrm{~cm}$, organizada en hi ladas horizontales y de fo rma regular. Este subtipo se asocia principalmente a las bases de los cubos de planta semicircular del castillo, aunque también se sitúa en otros puntos del recinto. Aunque se analiza el uso romano de cubos semicirculares, se opta por situar el subtipo C-1 en la época medieval, en la época de constitución de las Comunidades de Villa y Tierra, en 1076 o 1086. 


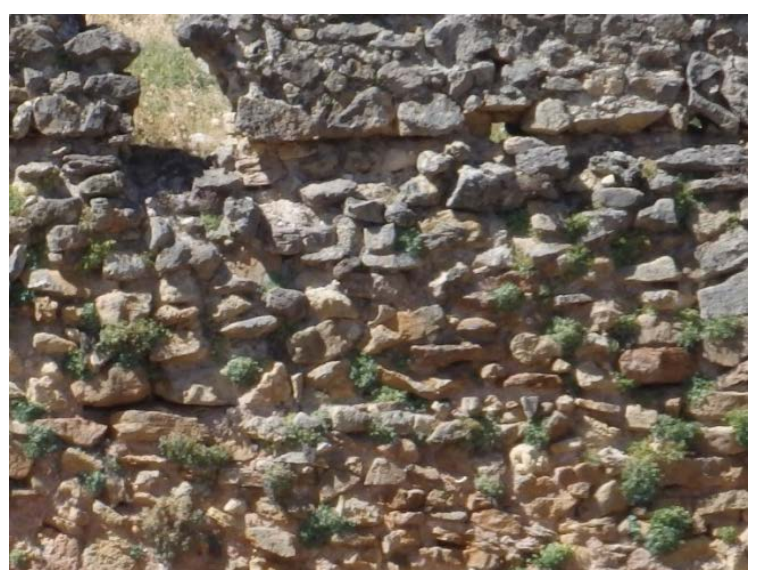

Fig. 5.6.54. Tapia de mampostería en tramo P11oeste, al oeste de la puerta de Duruelo (P11) [A.S.E. 23/7/2016].

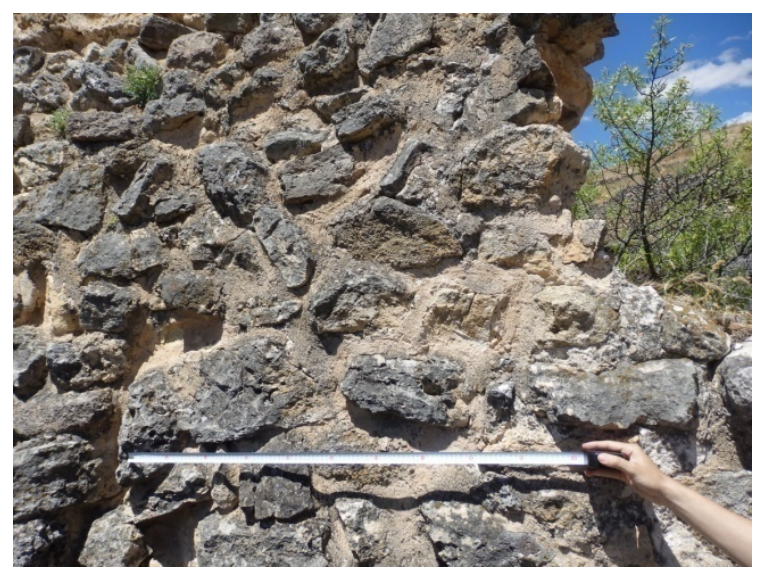

Fig. 5.6.56. Aparejo de $\mathrm{p}$ iedra en I a puerta de Castro. El metro marca la distancia de $1,00 \mathrm{~m}$ [A.S.E. 23/7/2016].

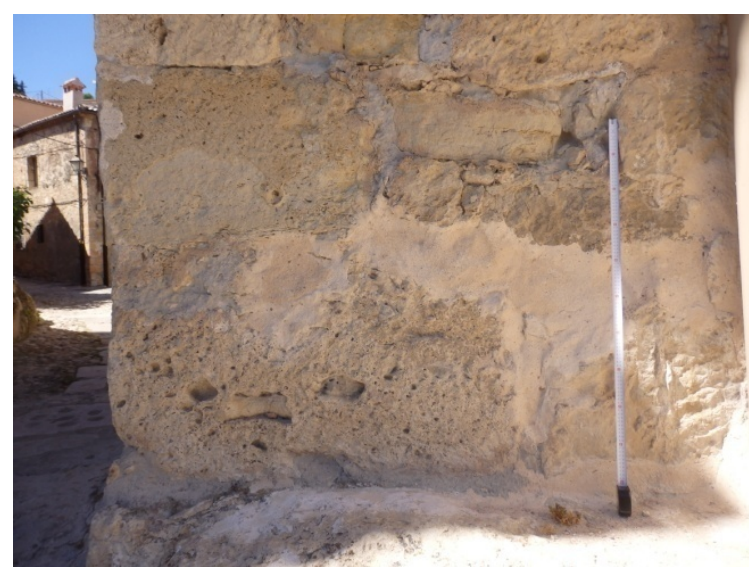

Fig. 5.6.58. Sillería en la puerta del Río, aparejo B de Martín Aymerich et al. $(1990,133)$ [A.S.E. 23/7/2016]

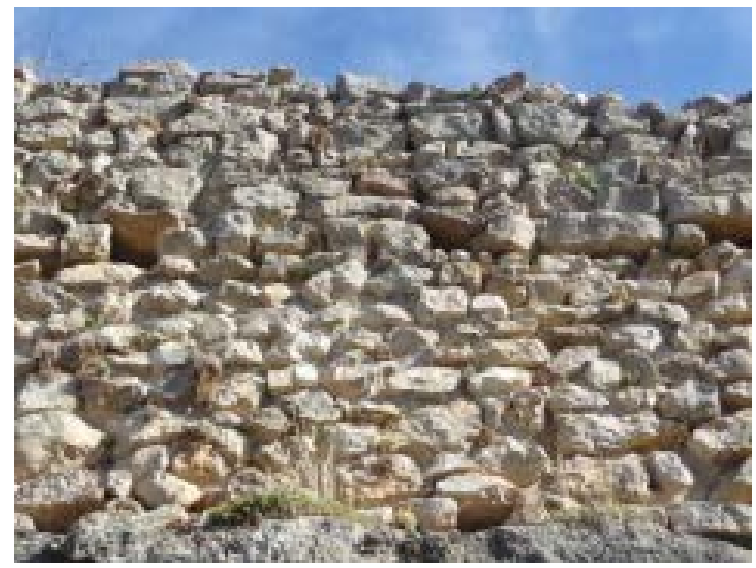

Fig. 5.6.55. Tapia de mampostería al noroeste de la puerta de Castro [A.S.E. 23/7/2016].

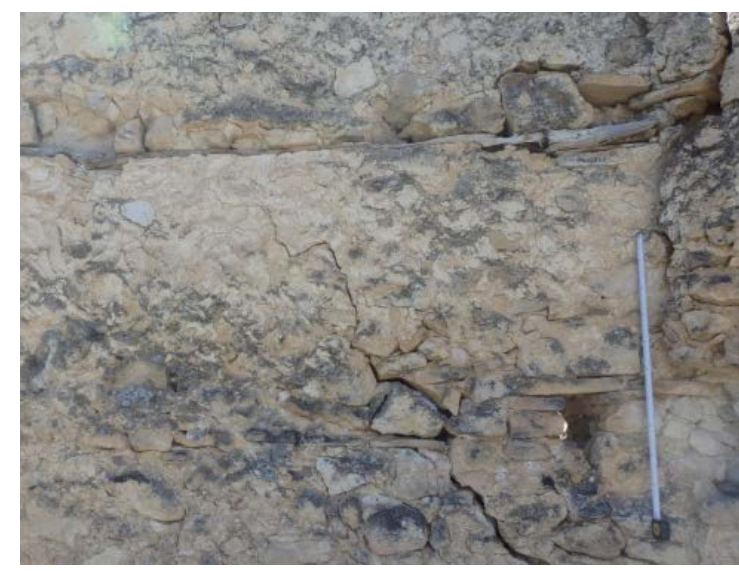

Fig. 5.6.57. Tapia en t orre $\mathrm{T} 1$ de l a zona del Postiguillo [A.S.E. 23/7/2016]

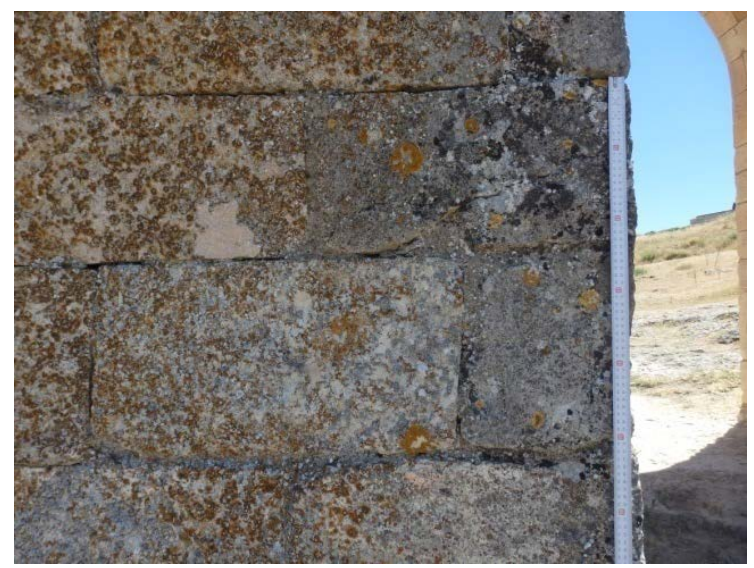

Fig. 5.6.59. Sillería en base de puerta de la Fuerza, en el lado exterior [A.S.E. 23/7/2016] 
Las murallas en las Comunidades de Villa y Tierra de la Diócesis de Segovia en los siglos XI a XIII. Técnica y sistemas constructivos de la arquitectura defensiva medieval.

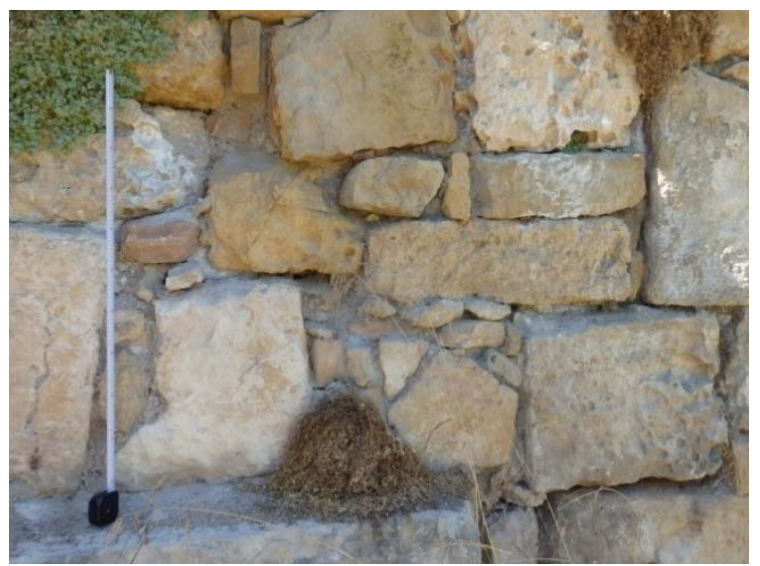

Fig. 5.6.60. Sillería-sillarejo de aparejo desordenado T1-T2. Aparejo B de Martín Aymerich et al. (1990, 131) [A.S.E. 23/7/2016]

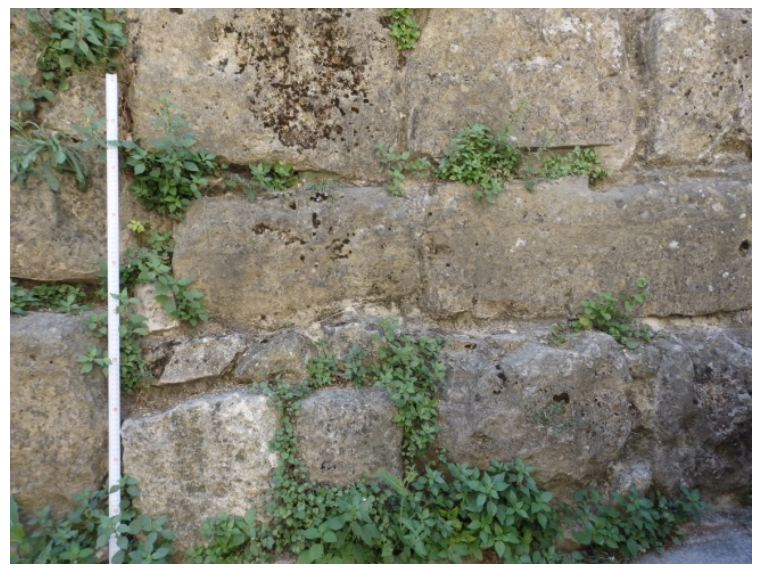

Fig. 5.6.62. Piedras en la base del tramo T10-T9. Aparejo A del estudio de Martín Aymerich et al. $(1990,131)$ [A.S.E. 23/7/2016].

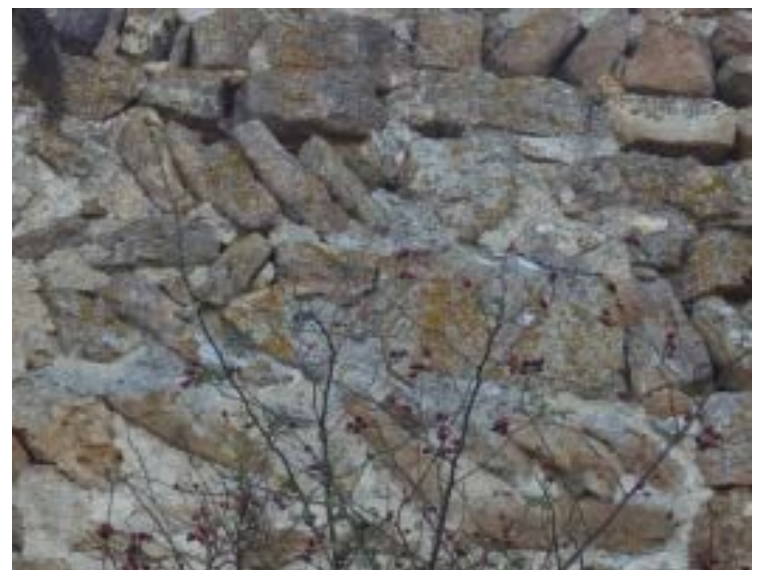

Fig. 5.6.64. Aparejo singular en tramo al norte de la puerta de la Fuerza, en espina de pez [A.S.E. $11 / 11 / 2015]$

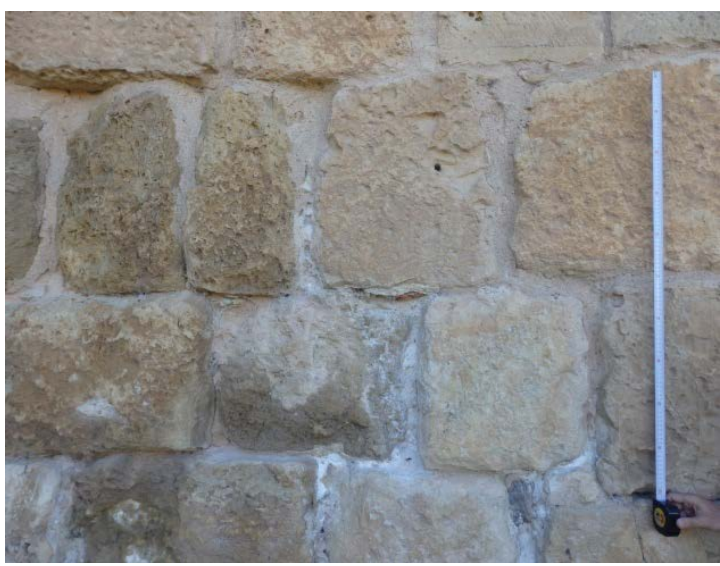

Fig. 5.6.61. Sillería en la base de I a torre T3, aparejo A del estudio de Martín Aymerich et al. $(1990,131)$ [A.S.E. 23/7/2016]

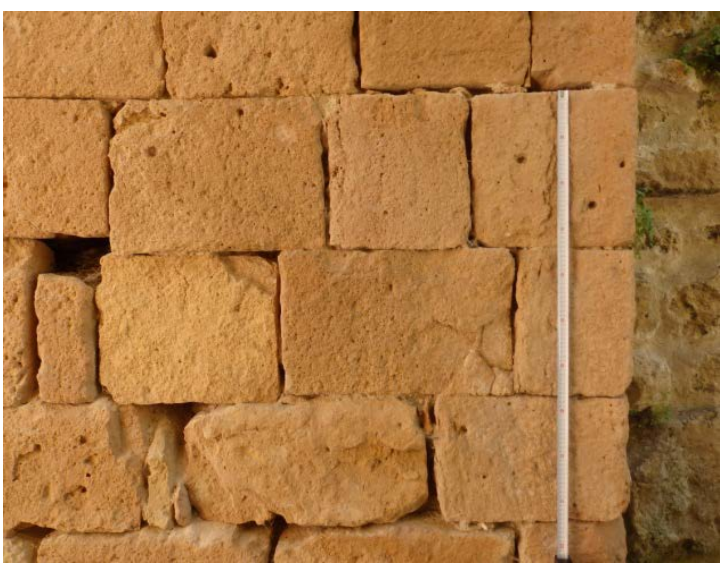

Fig. 5.6.63. Sillería reutilizada en la restauración de la puerta de D uruelo de 1987 [A.S.E. 23/7/2016]

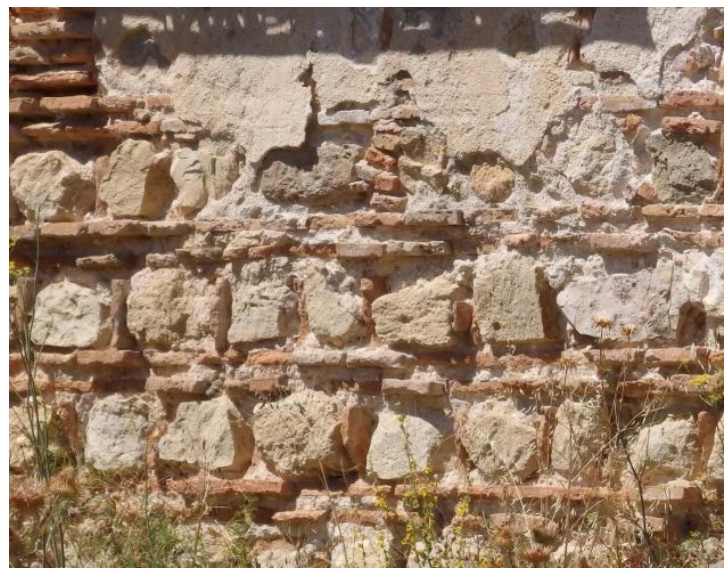

Fig. 5.6.65. Mampostería encintada con ladrillo en una construcción cercana a P11 en el interior del recinto amurallado [A.S.E 2377/2016]. 
El tipo C-2 se define como un aparejo de piedra de tamaño medio a pequeño, de dimensiones en torno a los $20-25 \mathrm{~cm}$, colocada sin orden, con cal que sobresale entre las juntas, ofreciendo la imagen de un lienzo casi enfoscado. Se localiza en las zonas superiores de las torres y lienzos de la zona de la puerta del Río, la parte superior de las torres que conforman el castillo y de nuevo las partes superiores del tramo de la calle Barbacana hasta la zona del Postiguillo. Se localiza este aparejo en otras zonas del recinto, principalmente en las partes superiores y recrecidos. La fecha que se asigna para este aparejo es del siglo XV, aduciendo que solo llegada esa fecha es necesario recrecer las defensas desde la creación de las Comunidades de $\mathrm{V}$ illa y Tierra. El tipo C-3 se define como un aparejo de piedra de menor tamaño que en C-2, con un acabado exterior generalmente enfoscado en su totalidad, con marcas visibles de encofrado. Se localiza en puntos similares a los descritos para el tipo C-2, en las zonas superiores de lienzos y torres desde la Puerta del Río hasta el Postiguillo y otros puntos del recinto amurallado. Se considera un aparejo posterior al siglo XV. De forma simplificada, la Tabla 5.6.3 incluye la localización de c ada uno de es tos aparejos. Además se resume en qué el ementos del recinto amurallado se pueden enc ontrar cada una de las soluciones constructivas mencionadas.

Tabla 5.6.3. Soluciones constructivas localizadas por elementos de la muralla.

\begin{tabular}{|c|c|}
\hline & Elementos donde se encuentra \\
\hline $\begin{array}{l}\text { Tapia de mampostería encofrada } \\
\text { Con machón de sillería }\end{array}$ & $\begin{array}{l}\text { Tramos P11-oeste, P10-oeste. } \\
\text { Puertas P8, P11, P3 (T9), P6. } \\
\text { T21, T22 }\end{array}$ \\
\hline $\begin{array}{l}\text { Sillería } \\
\text { En esquinas } \\
\text { En Arcos } \\
\text { Fábrica }\end{array}$ & $\begin{array}{l}\text { P8, P11 } \\
\text { P8, P1, P3 } \\
\text { Puertas P1, P8, P3. Bases de tramos P1- } \\
\text { T16, T1-T10. }\end{array}$ \\
\hline $\begin{array}{l}\text { Mampostería } \\
\text { Fábrica } \\
\text { Fábrica singular (espina de pez) } \\
\text { Mechinales } \\
\text { Almenas } \\
\text { Encintada en ladrillo } \\
\end{array}$ & $\begin{array}{l}\text { Puertas P9, P10, tramo P6-sureste. } \\
\text { Tramo P8-oeste. } \\
\text { Tramo P11-oeste } \\
\text { Posible torre en interior del recinto. }\end{array}$ \\
\hline $\begin{array}{l}\text { Aparejos según Martín Aymerich et al. } \\
(1990,131-139) \text {. } \\
\text { Aparejo A (s. fin IX- ppo.x) }\end{array}$ & $\begin{array}{l}\text { Zarpas de tramo T10-T9 y de T5. Base de } \\
\text { los tramo T3-T6. T2, Tramo T1-T2. Bases de } \\
\text { las torres T6, T5, T4, T3, T2 (cara norte), T1 } \\
\text { (cara sur), T22, primera hilada T23. }\end{array}$ \\
\hline Aparejo B (en torno a 1063) & $\begin{array}{l}\text { Bases de los tramos T19-T16, T16-este. } \\
\text { Bases de las torres T3-T2,T2-T1, } \\
\text { Torre } \mathrm{T} 1, \mathrm{~T} 2, \mathrm{~T} 22, \mathrm{~T} 23\end{array}$ \\
\hline $\begin{array}{l}\text { Aparejo C-1 (1076-1086) } \\
\text { Aparejo C-2 (s. XV) } \\
\text { Aparejo C-3 (posterior a s. XV) }\end{array}$ & $\begin{array}{l}\text { Bases de tramo T13-T11, bases de torres } \\
\text { T13, T12, T11. Parte media y superior de } \\
\text { T10. } \\
\text { Partes superiores de las torres T19,T18, } \\
\text { T13, T12, T11, } \\
\text { Partes superiores de P1, de T10-T9, de P2, }\end{array}$ \\
\hline
\end{tabular}


Las murallas en las Comunidades de Villa y Tierra de la Diócesis de Segovia en los siglos XI a XIII. Técnica y sistemas constructivos de la arquitectura defensiva medieval.

\begin{tabular}{|l|l|}
\hline & de tramo T6-T1. \\
\hline $\begin{array}{l}\text { Restaurado } \\
\text { Sillería antigua reubicada 1987 }\end{array}$ & $\begin{array}{l}\text { P11 (sur-interior acceso), P8 (interior } \\
\text { acceso). }\end{array}$ \\
\hline Reconstruido & $\begin{array}{l}\text { Parte superior de T10-T9, tramo de P11- } \\
\text { oeste. }\end{array}$ \\
\hline
\end{tabular}

\subsubsection{Lienzo exterior P11-Oeste 200 , visto desde el exterior del recinto amurallado}

Este tramo analizado tiene una longitud de $32 \mathrm{~m}$ y una altura de 6 a $7 \mathrm{~m}$. Se localiza partiendo desde la puerta de Duruelo (P11) y siguiendo la muralla $200 \mathrm{~m}$ en dirección oeste. Es accesible en la zona interior, aunque no fácilmente visible, ya que el nivel del terreno en el interior se sitúa a la altura del adarve. Desde ese punto, es posible tomar medidas de la anchura de la muralla, que alcanza los $2,00 \mathrm{~m}$.

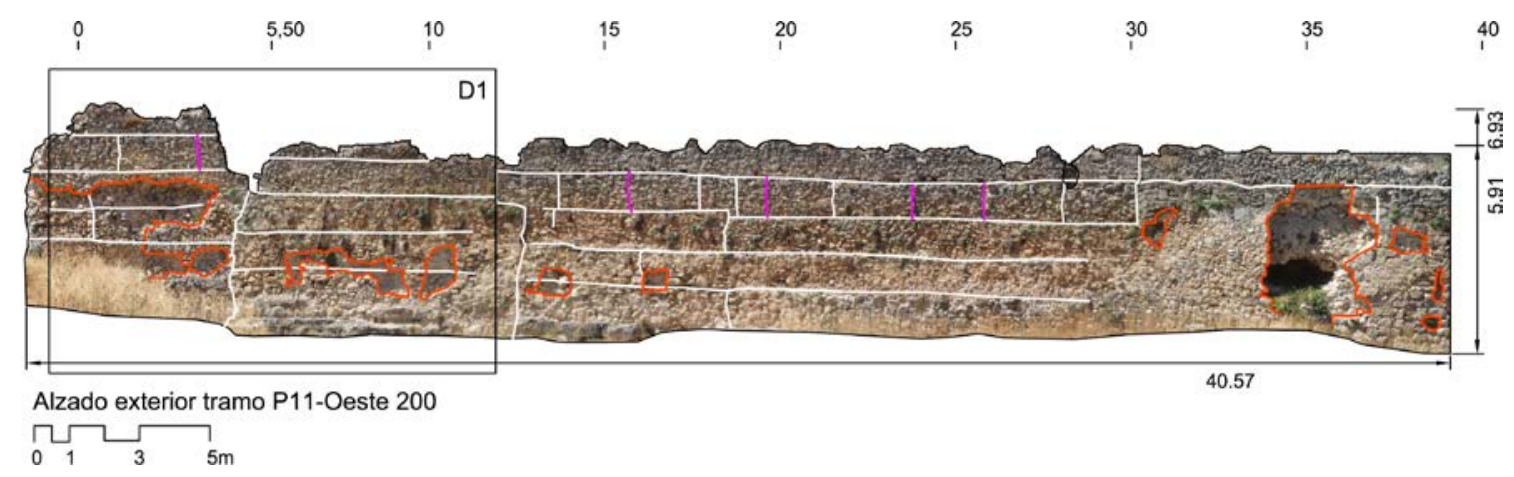

Fig. 5.6.66. Tramo P11-oeste 184. Fuente: Elaboración propia con fotos del 23/7/2016 y del 11/11/2015.

Desde el exterior, el acceso es más complicado y difícil, por lo escarpado del territorio. En un principio puede parecer difícil afirmar que este tramo de muralla esté construido con tapia, en una primera impresión se observa un aparejo de piedra irregular. Pero de nuevo son visibles marcas horizontales en el paramento y también se observa una disposición de pi edras en $v$ ertical, formando divisiones. También se encuentran mechinales en I as líneas horizontales, configurados muy frecuentemente con el sistema de varillas pareadas.

A diferencia de otr os casos estudiados, en este recinto no s on identificables un número suficiente de tapias como para representar a través de l a estadística sus márgenes dimensionales. La visibilidad de las hiladas de tapia permite realizar una muestra de alturas medidas en cada hilada cada $5 \mathrm{~m}$. A lo largo del tramo P11-oeste 200 , se han tomado las alturas de las hiladas de tapia en seis puntos distintos del lienzo, separados entre sí la distancia de $5 \mathrm{~m}$ (Tabla 5.6.4). Los datos obtenidos muestran que en I as hiladas $\mathrm{H} 2$ a $\mathrm{H} 5$ tienen rangos intercuartílicos entre 80 y $110 \mathrm{~cm}$, con medianas entre $103 \mathrm{~cm}-107 \mathrm{~cm}$ y una mediana resultante de $103,50 \mathrm{~cm}$, que se tomará como altura representativa del tramo. En la hilada $\mathrm{H} 1$, esa altura aumenta a $119,50 \mathrm{~cm}$. 


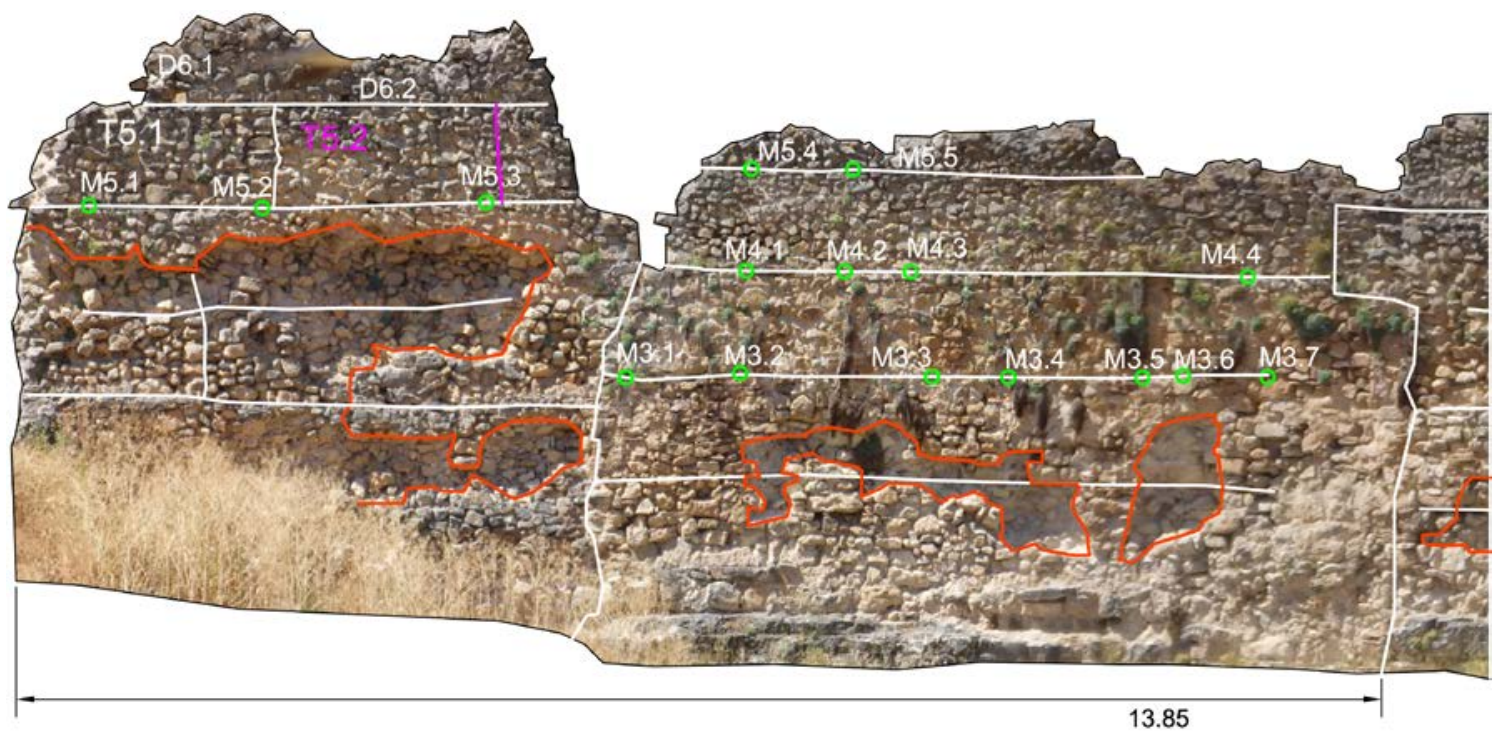

\section{Detalle D1}

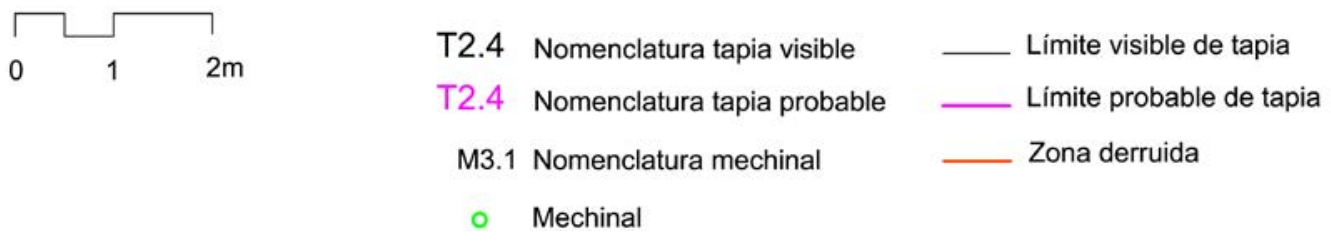

Fig. 5.6.67. Detalle D1 del tramo P11-oeste 200.

Tabla 5.6.4. Altura de hiladas medida cada $5 \mathrm{~m}$.

\begin{tabular}{|l|c|c|c|c|c|c|}
\hline Distancia & $0 \mathrm{~m}$ & $5,5 \mathrm{~m}$ & $10 \mathrm{~m}$ & $15 \mathrm{~m}$ & $20 \mathrm{~m}$ & $25 \mathrm{~m}$ \\
\hline Hilada 5 & 1,03 & - & - & - & - & - \\
\hline Hilada 4 & 1,11 & 1,03 & 0,98 & 1,08 & 1,12 & 1,02 \\
\hline Hilada 3 & 0,81 & 1,09 & 1,05 & 1,10 & 1,00 & 1,17 \\
\hline Hilada 2 & - & 1,03 & 1,09 & 0,97 & 1,04 & 0,96 \\
\hline Hilada 1 & - & - & - & - & 1,20 & 1,19 \\
\hline
\end{tabular}

Altura de hiladas $\mathrm{H} 2$ a $\mathrm{H} 5$

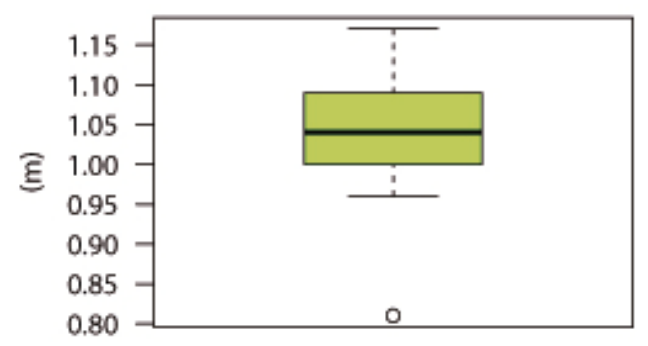

Fig. 5.6.68. Diagrama de caja de las alturas de las hiladas $\mathrm{H} 2 \mathrm{a}$ H5. Fuente: Elaboración propia con el programa $\mathrm{R}$.

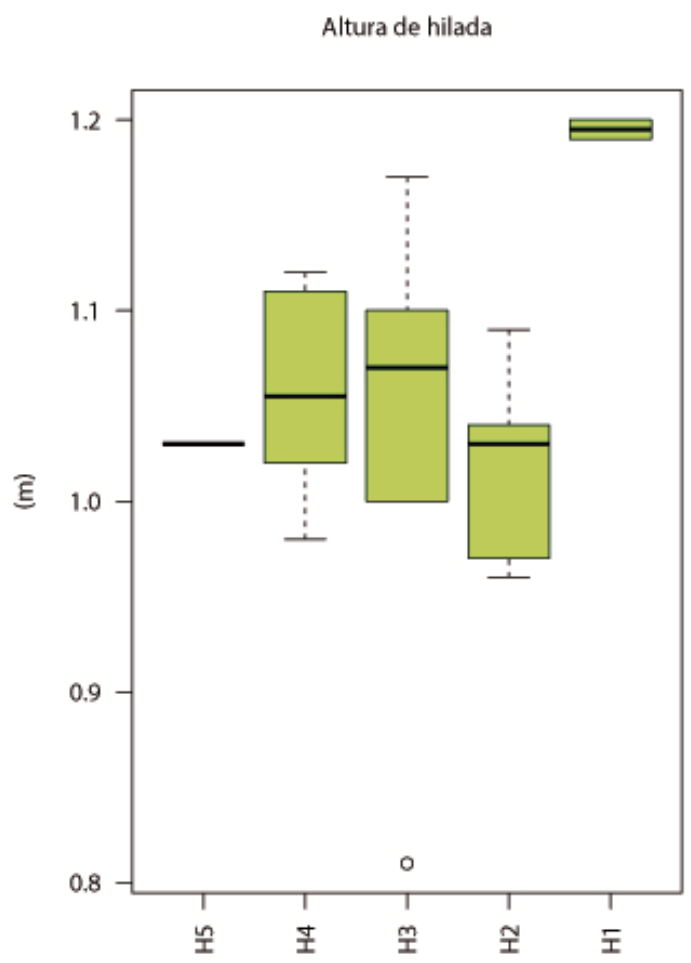

Fig. 5.6.69. Diagrama de caja de las alturas por hilada en el tramo P11-este 184. Fuente: Elaboración propia con el programa R. 
Aunque las tapias en este tramo no son fácilmente identificables, se ven los límites de algunas de ellas. La tapia T5.1 (Fig. 5.6.70) tiene una altura de $104 \mathrm{~cm}$ y una anchura de $269 \mathrm{~cm}$, que se ha tomado como anchura representativa. El lado izquierdo de la tapia está desdibujado, se ha perdido material a raíz al deterioro del lienzo. En el lado derecho de la tapia se observa una columna de pi edras relativamente planas que cierra ese lado de I a tapia. Se pueden c ontar nueve piedras de fo rmato similar, colocadas una sobre otra. Esta disposición de las piedras podría formar parte de la construcción del tapial, construyéndose como muro de cierre del cajón de madera y formando parte de la tapia final. En el resto de la tapia se observa el uso de piedras de tamaño pequeño-medio, con forma irregular, sin un or den aparente. En la base son visibles dos mechinales de varillas pareadas, situados en los extremos de la tapia.

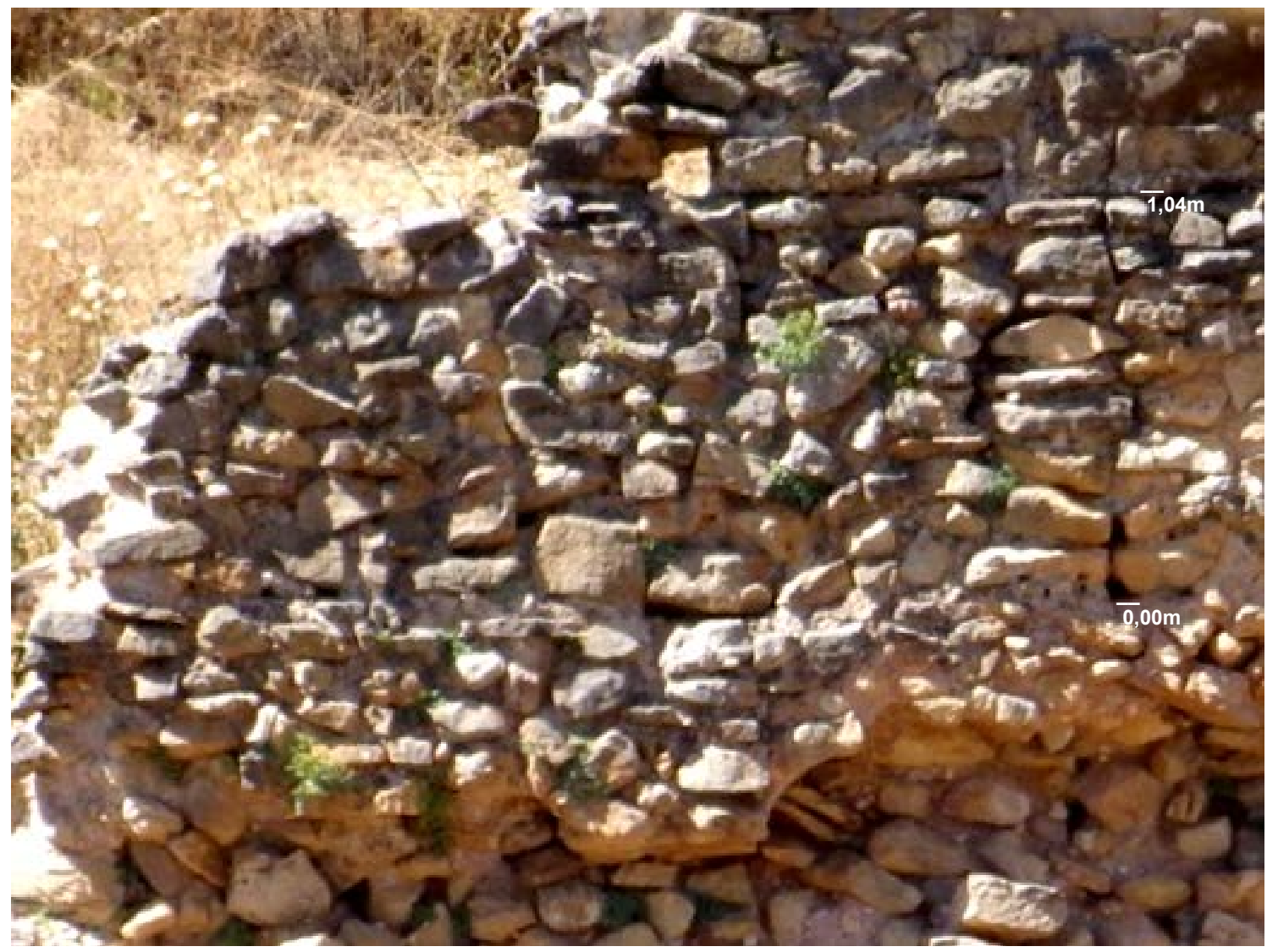

Fig. 5.6.70. Tapia T5.1. A la derecha se observa un murete de piedras planas, que limita la tapia por ese lado. En lo alto, se ve un hueco que podría ser un desagüe, si tenemos en cuenta que está a la altura del suelo del adarve [A.S.E. 23/7/2016]

En este tramo, se observan la presencia de varios mechinales realizados con el sistema de las varillas pareadas. Prácticamente la totalidad de los mechinales localizados en este tramo se realiza con este sistema. Las varillas se separan una distancia de en torno a $12 \mathrm{~cm}$ aproximadamente y tienen un diámetro de 1,50-2,00cm. Suelen coronarse con una piedra y en ocasiones se asientan sobre otra (Fig. 5.6.71, Fig. 5.6.72). En el caso del mechinal M3.10 (Fig. 5.6.71), la fotografía se ha tomado 
desde un plano inferior, por lo que la escala del metro visible aparece ligeramente más corta, marcando una distancia entre varillas cercana a los $20 \mathrm{~cm}$, cuando no supera los $15 \mathrm{~cm}$, de acuerdo con el alzado general.

Tabla 5.6.5. Tabla de características y dimensiones de acuerdo con la tapia T5.1 del tramo P11-Oeste 200

\begin{tabular}{|c|c|c|c|}
\hline Tapias & P11-Oeste 200 & Mechinales & P11-Oeste 200 \\
\hline Altura $(\mathrm{cm})$ & $\begin{array}{c}103,50 \\
{\left[119,50^{*} \text { en hilada } \mathrm{H} 1\right]}\end{array}$ & Sección mayoritaria & Varillas pareadas \\
\hline Anchura (cm) & $269^{*}$ & Dimensiones $(\mathrm{cm})$ & $\begin{array}{c}\text { Separación varillas (10- } \\
12 \mathrm{~cm})\end{array}$ \\
\hline Espesor (cm) & $2,10-2,20(\bar{x}=2,15)$ & Distancia en cajón & - \\
\hline $\begin{array}{l}\text { Restos de encofrado / } \\
\text { Tipo de tapial }\end{array}$ & Sí / Tapial corrido & Distancia entre cajones & - \\
\hline $\begin{array}{l}\text { Altura de tablas de } \\
\text { encofrado }(\mathrm{cm})\end{array}$ & No visible & Material & $\begin{array}{c}\text { Tierra/solo hueco, } \\
\text { mampuesto }\end{array}$ \\
\hline $\begin{array}{l}\text { Piedras exteriores } \\
\text { colocadas }\end{array}$ & No & $\begin{array}{l}\text { Aguja } \\
\text { perdida/recuperable }\end{array}$ & Perdida \\
\hline $\begin{array}{l}\text { Juntas más visibles en } \\
\text { paramento }\end{array}$ & Horizontales & Profundidad mechinal & Pasante \\
\hline Materiales empleados & Mampuestos , tierra, cal & $\begin{array}{l}\text { Tipo de aguja } \\
\text { (pareadas/unitarias) }\end{array}$ & Pareadas \\
\hline $\begin{array}{l}\text { Divisiones verticales } \\
\text { visibles }\end{array}$ & Sí & Mechinales por cajón & - \\
\hline Verdugada & No & $\begin{array}{l}\text { Ubicación de mechinal } \\
\text { en relación con cajón }\end{array}$ & Inferior \\
\hline
\end{tabular}

*Menos de 10 muestras.

$\overline{\mathrm{x}}$ media aritmética

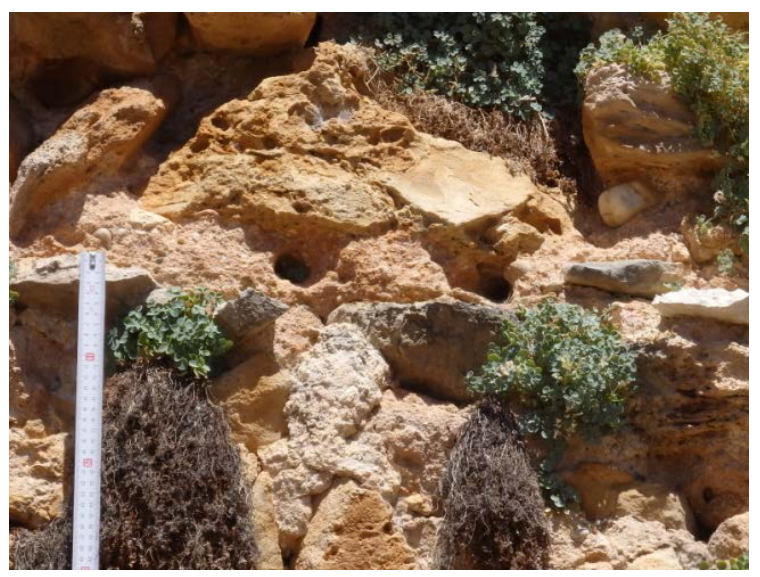

Fig. 5.6.71. Mechinal M3.10 de varillas pareadas [A.S.E. 23/7/2016]

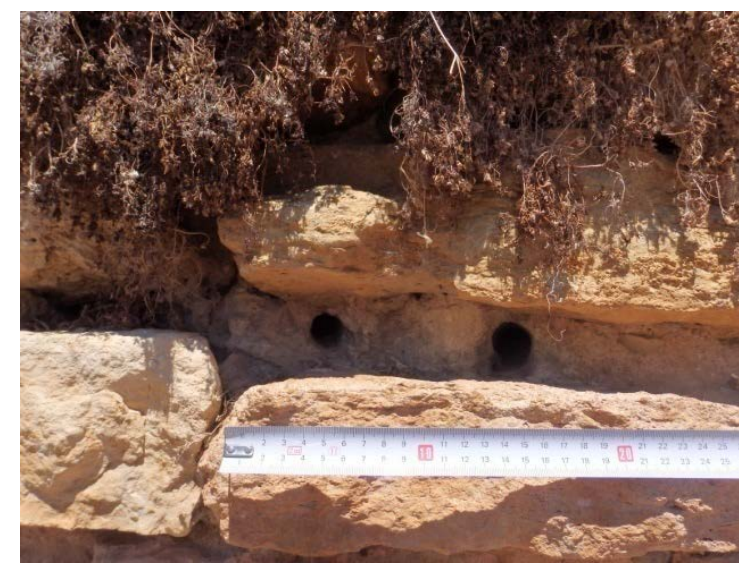

Fig. 5.6.72. Mechinal de varillas pareadas, con una separación de $9 \mathrm{~cm}$. [A.S.E. 23/7/2016] 


\subsubsection{Puerta de la Fuerza (P8)}

La puerta de la Fuerza muestra dos fases constructivas en su alzado exterior. La base de sus dos torres tiene un apar ejo de sillería hasta la altura de dos metros. Este aparejo muestra sillares organizados en hiladas regulares. La altura de I as hiladas ronda los $30 \mathrm{~cm}$. Los sillares que la componen tienen esa misma altura, aunque luego su anchura es variable, dándose casos de sillares alargados y otros más cuadrados. En el lado izquierdo de la torre T23 se observan algunos sillares que doblan la altura habitual y ocupan dos hiladas. Consiguen encajar sin generar un des orden en el aparejo. El color de I os sillares se ha tor nado gris, probablemente a r aíz de la proliferación de líquenes.

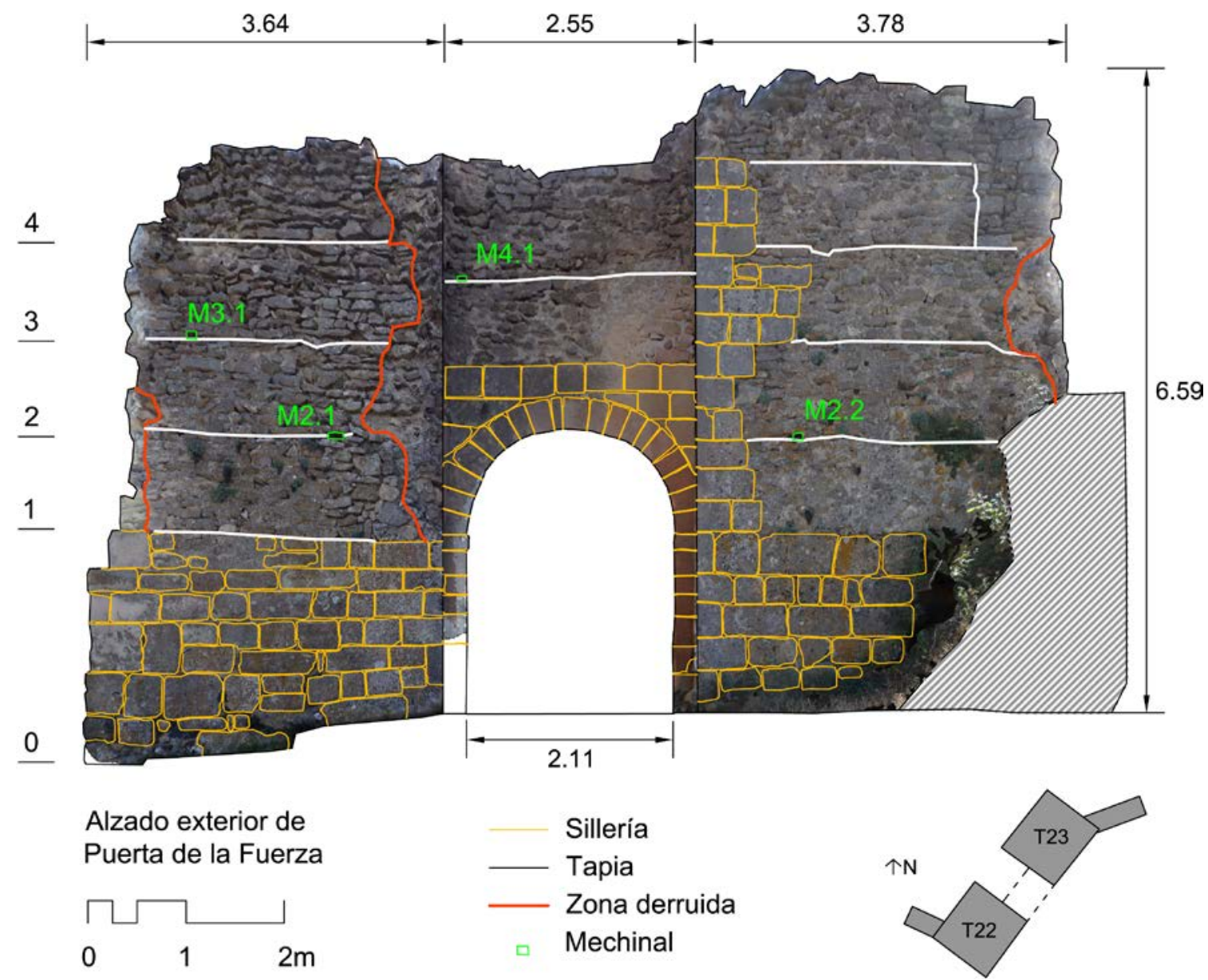

Fig. 5.6.73. Alzado exterior de la puerta de la Fuerza. Fuente: Elaboración propia con fotos de los días $8 / 11 / 2015$ y $23 / 7 / 2016$.

La torre T2 presenta cuatro hiladas cuya altura es de aproximadamente $30 \mathrm{~cm}$ y una última, la superior, que s upera los $40 \mathrm{~cm}$. Aunque estos sillares han s ido cuidadosamente seleccionados para confeccionar este aparejo de hiladas regulares, la existencia de pi edras de di versos tamaños que s e consiguen encajar con éxito muestra que las piezas no se tallaron para la ocasión sino que se reutilizaron de otras construcciones, tras un proceso de selección. La sillería asciende en la esquina norte 
de la torre T22. Las otras esquinas no presentan sillería, pero se encuentran rotas, desdibujadas, han perdido la definición. El arco de acceso se construye con dovelas talladas en piedra y se corona con una hilada de sillares, también de $30 \mathrm{~cm}$ de altura. Tal y como se ha indicado en la descripción general, la cara interior del acceso tiene sillería sustituida en la restauración de 1987. La ausencia de coronación en la puerta impide conocer el carácter que podría tener el almenado de estas torres.

Sobre la sillería se observan varias hiladas de tapia de mampostería. Lo que podr ía parecer un apar ejo de pi edras medianas y pequeñas, de hi ladas desordenadas, muestra marcas de tapial (Fig. 5.6.74). En la torre T23 se cuentan tres tapias de altura más una última tapia incompleta. La altura de las tapias oscila en torno a 1,00m. No es posible identificar una tapia completa, por lo que no se han podido extraer datos de su anchura. Los mampuestos que componen la tapia son medianos y pequeños. Tienen una proporción rectangular alargada. Aparecen desordenados, aunque muestran seguir en muchos casos un cierto orden por hiladas.

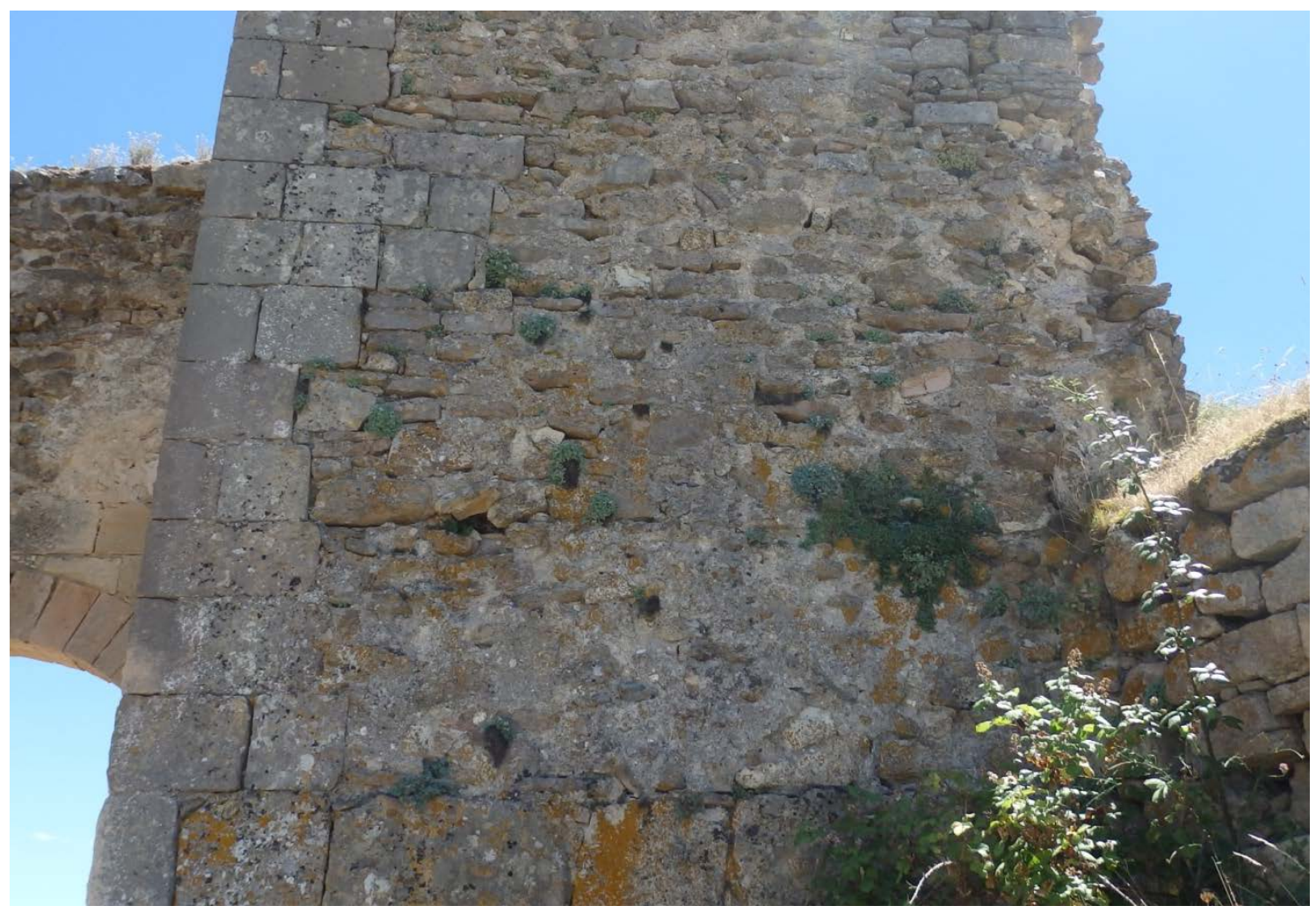

Fig. 5.6.74. Frente exterior de I a torre T22. Se observan tapias sobre la base de s illares [A.S.E 23/7/2016].

En las hiladas de tapia 2 y 3 de la torre T23 (Fig. 5.6.75) se pueden observar varias hiladas de mampuestos que se ordenan a lo largo de la tapia. En los límites superior e inferior de la hilada segunda, se identifican hiladas de mampuestos a m odo de verdugada, donde se pueden ver algunos mechinales. La disposición de los mampuestos en la tapia muestra dos hiladas colocadas en sentido diagonal, inclinadas con un ángulo de $10^{\circ}$ descendente de izquierda a derecha. Aunque se intenta ordenar 
los mampuestos por hiladas, la diferencia de tamaños y formas obliga a di sponer muchos de ellos en distintas direcciones, encajándolos para que completen hasta el último resquicio del tapial.

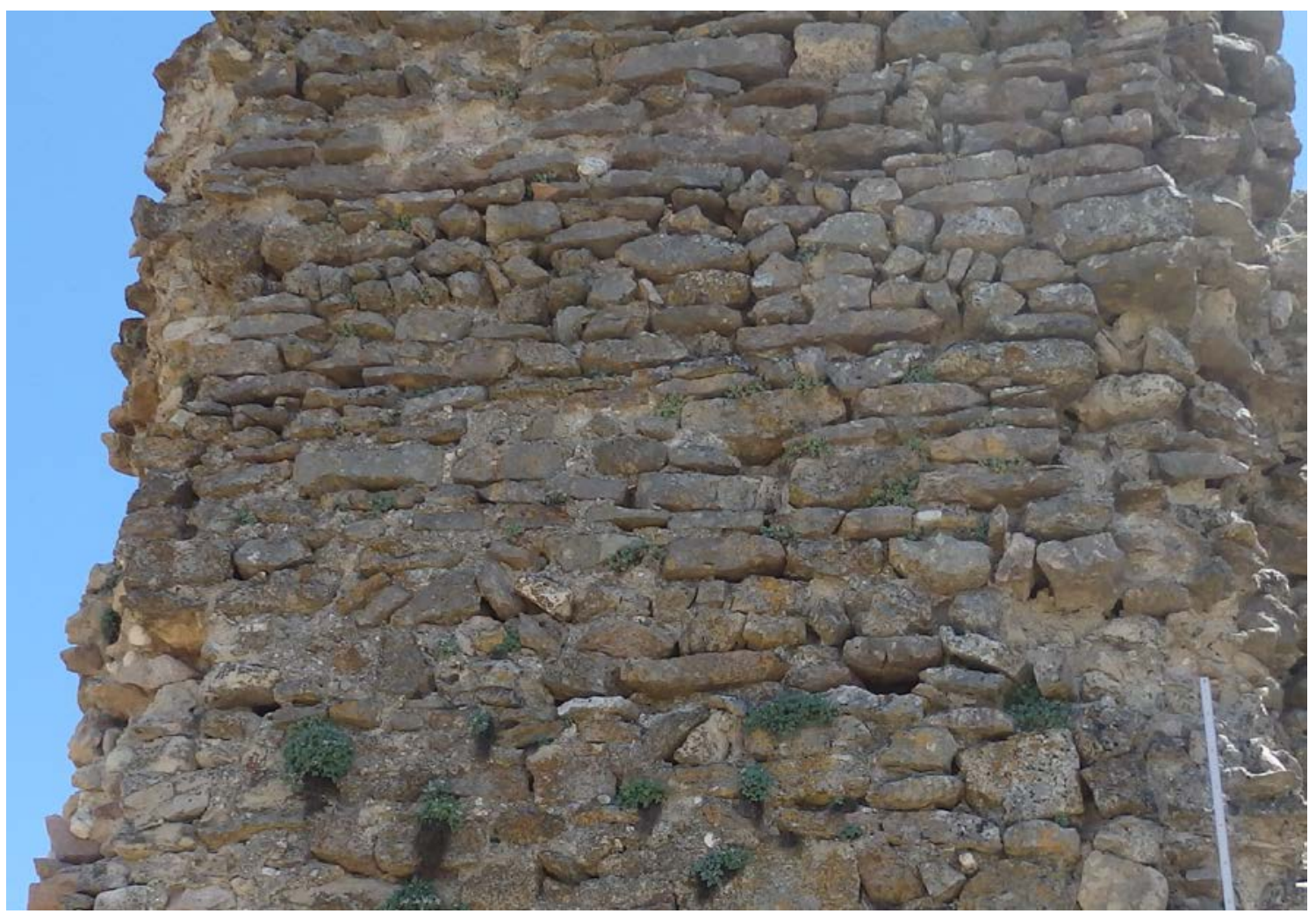

Fig. 5.6.75. Disposición de mampuestos en I as tapia de l a parte superior de la torre T23 [A.S.E 23/7/2016].

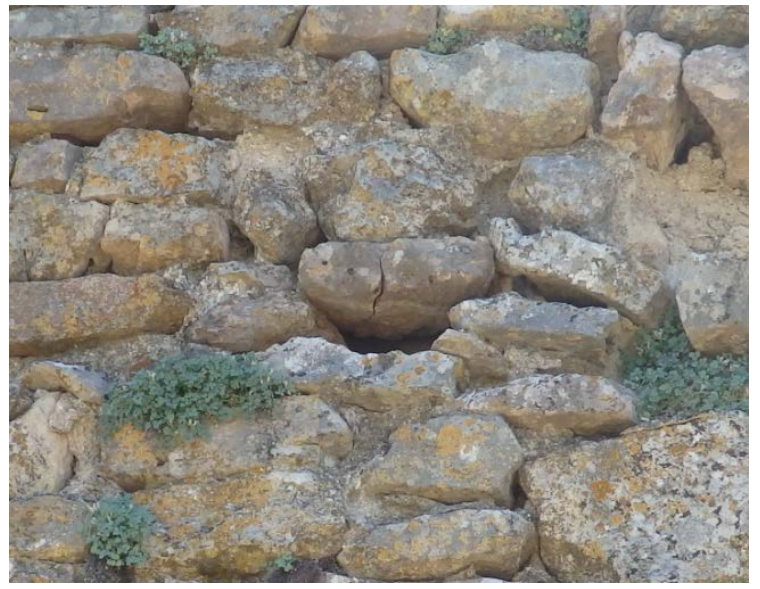

Fig. 5.6.76. Mechinal M2.1 [A.S.E. 23/7/2016].

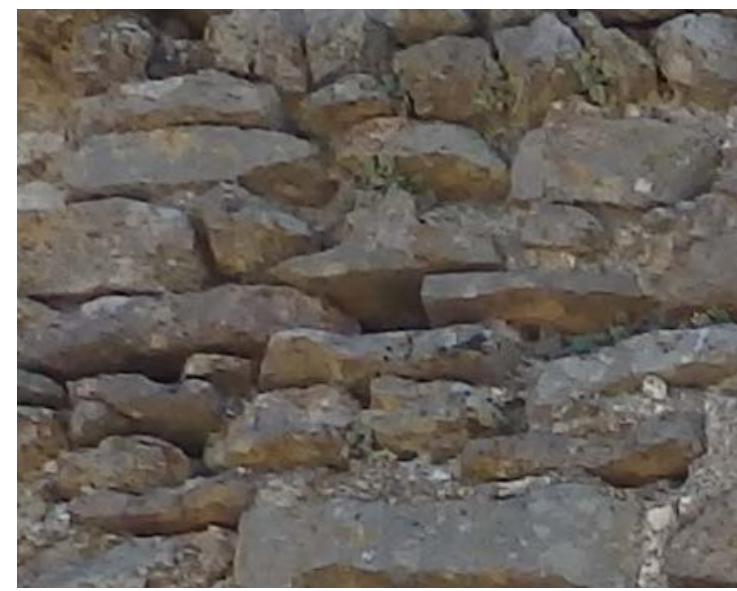

Fig. 5.6.77. Mechinal M3.1 [A.S.E. 23/7/2016].

Se han podi do localizar cuatro mechinales visibles en Ios límites de Ias hiladas. El mechinal M2.1 (Fig. 5.6.76) se apoya sobre un mampuesto y está rodeado en sus tres otros lados por otros mampuestos. La for ma de los mampuestos es rectangular alargada, con una altura estrecha, de $6-8 \mathrm{~cm}$ y una anchura que alcanza los $20 \mathrm{~cm}$. El 
mechinal M3.1 (Fig. 5.6.77) tiene una disposición muy similar, con un mampuesto en la base, dos que lo flanquean y un cuarto que lo corona. Las piedras son todavía más estrechas y alargadas en este caso.

El acabado superficial de I as tapias se ha perdido en la mayoría de I os casos, mostrando directamente los mampuestos. En la primera tapia sobre la sillería de la torre T22 se conserva un acabado de tierra y cal, que oculta parcialmente los mampuestos (Fig. 5.6.74). No se identifican marcas de tablazón en este acabado, pero podría corresponderse con el acabado original de la tapia.

La configuración de la esquina norte de T22 parece sugerir que las otras esquinas desmochadas pudieran contar con una c adena de sillares similar que resolviera la arista. Ante esta configuración se podría formular las preguntas siguientes: ¿la sillería se empleó en l a construcción del tapial? ¿Funcionó la cadena de s illares como machón? La configuración de las tapias en la torre T22 en relación con la sillería parece mostrar una equivalencia entre ambas. La al tura de la tapia se corresponde exactamente con tres hiladas de piedra al menos en las tres primeras hiladas de tapia (Fig. 5.6.74). La des aparición de las aristas también fomenta la hipótesis de que estuvieran configuradas con sillares, piezas codiciadas para su reutilización en otras construcciones y por ello desaparecidas.

\subsubsection{Puerta de Duruelo (P11)}

La cara exterior de I a puerta de D uruelo muestra la torre T21 reforzada en s us esquinas suroeste y sureste con una cadena de sillería de altura cercana a los $30 \mathrm{~cm}$, y anchuras variables, en torno a los $50-60 \mathrm{~cm}$. Se trata de s illares de a specto homogéneo, con dimensiones y proporciones similares. Tal y como se ha indicado en la descripción general, muchos de los sillares visibles en I a actualidad fueron colocados en la restauración de los años 90. En el alzado exterior de la puerta (Fig. 5.6.78) se ha indicado por medio de un c ódigo de colores los sillares que fuer on colocados en esa época de ac uerdo con las fotografías de Martín Aymerich et al . $\left(1990,231\right.$ fot. $\left.\mathrm{n}^{0117}\right)$. En la imagen indicada se observa la puerta en proceso de restauración. Gran parte de los sillares visibles hoy en la esquina sureste de T21 no se encuentran en la imagen de los años noventa, que ofrece esquinas desdibujadas, sin aristas definidas. Se pueden ver las marcas de los sillares retirados en el material interior que hay en las esquinas. De nuevo se plantea la misma pregunta que en el caso del a puerta de I a Fuerza, acerca de si se emplearon los sillares como integrantes del tapial.

Entre las cadenas de sillería se puede v er un par amento realizado a bas e de mampuestos. Aunque con dificultad, es posible identificar algunas marcas de hiladas de tapia en el paramento. Muchas de ellas solo son visibles en tramos cortos, dificultando la identificación de una tapia al completo. La altura de las hiladas visibles ronda el valor de $1,00 \mathrm{~m}$. Como también ocurre en la puerta de la Fuerza, las hiladas de tapia parecen corresponderse con tres hiladas de sillería. 


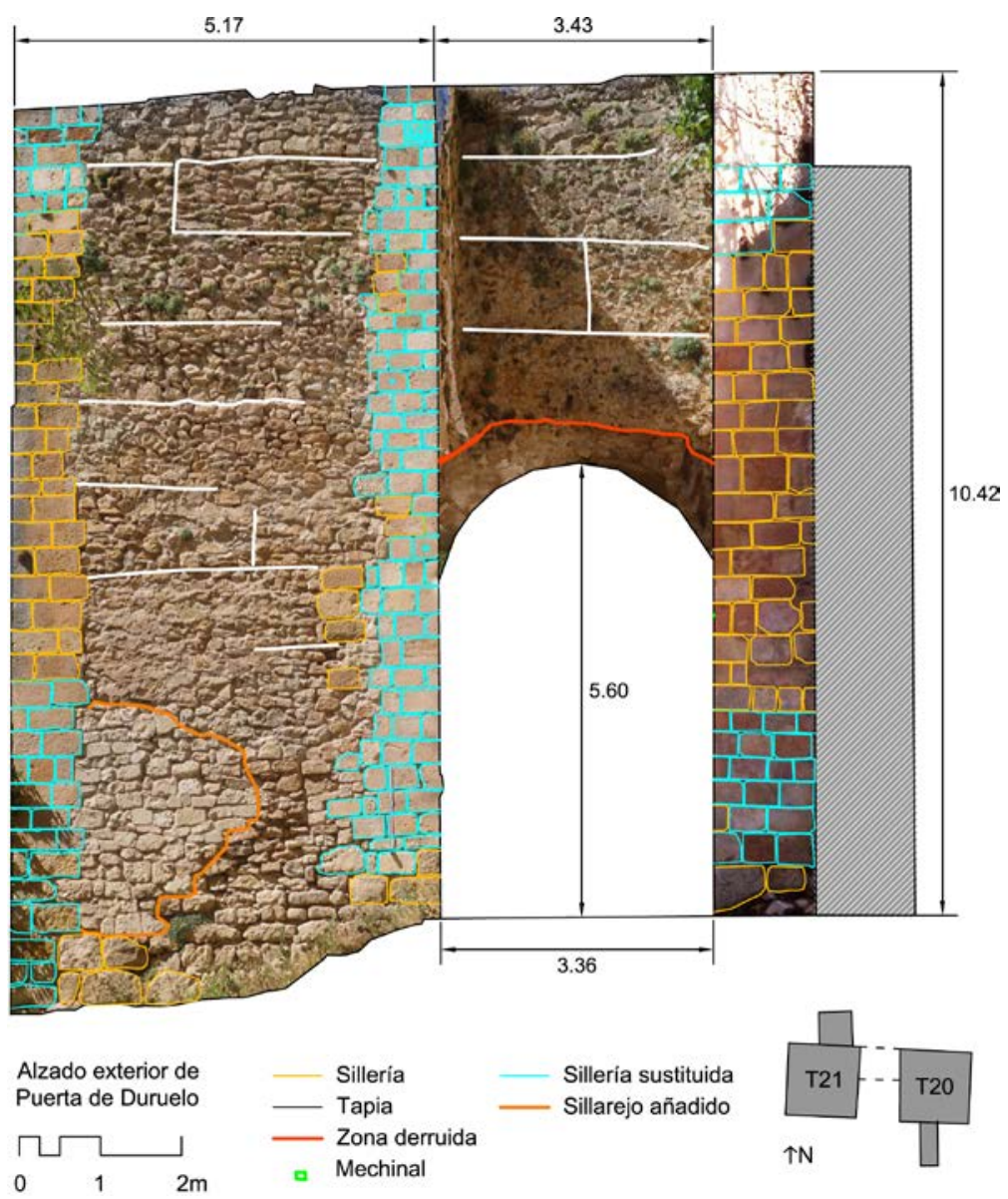

Fig. 5.6.78. Alzado exterior de la puerta de Duruelo (P11). Fuente: Elaboración propia con fotos de los días $8 / 11 / 2015$ y $23 / 7 / 2016$.

En el lado interior de la puerta se ven tapias de mampostería similares a las visibles del lado exterior (Fig. 5.6.80). Se ven marcas horizontales más oscuras que indican el límite horizontal de las hiladas de tapia, con alturas que rondan también 1,00m. En este alzado interior se observa la misma disposición de sillares en las esquinas noroeste y noreste de la torre T21. La tapia de mampostería parece absorber la cadena de sillares de la esquina noreste, que queda rodeada tanto por los laterales como por la parte superior e inferior. En la parte superior, se ve como una hilada de tapia se construye sobre esta cadena de sillares, completando la construcción de la torre. La tapi a de $\mathrm{m}$ ampostería parece emplearse para reconstruir una tor re ya existente. El cordón de sillares en la cara norte de la torre T21 parece demostrar que la torre se construyó antes del paño sobre el acceso, y por otra parte, que la sillería ya existía o se construyó a la vez que las tapias de la torre.

\subsubsection{Tipología de las tapias del lienzo P11-Oeste200}

De acuerdo con la clasificación de A. Graciani y M.A. Tabales, las tapias de los tramos estudiados podrían clasificarse como tapia monolítica con mechinales con remate de 
mampuesto y sin verdugadas. Como novedad en este caso frente al resto, se refleja en esta clasificación la existencia de tapias con machones de piedra.

Tabla 5.6.6. Tipología constructiva de I as tapias del lienzo P11-Oeste200 de acuerdo de A mparo Graciani y Miguel A. Tabales $(2008,139)$ en el área sevillana.

\begin{tabular}{|c|c|c|c|c|}
\hline & & & Mechinal & Verdugada \\
\hline \multicolumn{3}{|c|}{ Monolítico } & Mampuesto & Sin verdugada \\
\hline Mixto & Encadenado & En piedra & Mampuesto & Sin verdugada \\
\hline
\end{tabular}

Tabla 5.6.7. Tipología constructiva de las tapias de los tramo P11-oeste 200 de acuerdo con la clasificación de Ignacio J. Gil Crespo $(2013,554-557)$

\begin{tabular}{|l|l|}
\hline A. Material de construcción & 5. Mampostería \\
\hline B. Compactación del material & 2. Vertido. \\
\hline C. Función constructiva & 1. Fábrica principal \\
\hline D. Encofrado & 1. Cajones independientes con tapiales testeros o fronteras \\
\hline E. Acabado superficial & 4. Capa externa de mampostería \\
\hline F. Combinación de materiales & 4. Mampuestos, tierra y cal \\
\hline $\begin{array}{l}\text { G. Mechinales } \\
\text { G-a. Situación }\end{array}$ & $\begin{array}{l}\text { 1. Situación en el propio hilo } \\
\text { G-b. Profundidad } \\
\text { G-c. Formación }\end{array}$ \\
\begin{tabular}{l} 
G-d. Sección \\
\hline
\end{tabular} & $\begin{array}{l}\text { 1. Formación aguja embebida en la fábrica } \\
\text { 2. Rectangular } \\
\text { 5. Varillas pareadas }\end{array}$ \\
\hline
\end{tabular}

De acuerdo con la clasificación de I.J. Gil Crespo, las tapias de los distintos tramos tendría las características indicadas en la Tabla 5.6.7. El material de construcción se aprecia fácilmente en muchas partes del paramento, se trata de mampostería. No se observan líneas de tongadas en el paramento ni tampoco en las zonas donde se ha desprendido material. Es visible en algunos puntos restos de encofrado, por lo que la compactación de material se realiza muy probablemente con un vertido del relleno, después de haber colocado los mampuestos en las caras visibles de las tapias. Dadas las escasas marcas visibles del tapial, con un claro predominio de las marcas horizontales, es difícil establecer si el tapial empleado es de cajones independientes o corridos, aunque se ha considerado finalmente corrido ya que no s e han encontrado evidencias de que sea individual. La escasez de mechinales visibles también impide detectar qué patrón de distancias siguen, lo que podría arrojar alguna luz sobre esta cuestión. El acabado superficial es variable, en función del estado de conservación de la tapia. Aunque lo habitual es contemplar un muro de mampuestos, todos ellos visibles, es previsible que el acabado superficial fuera una capa de ti erra, cal y 
Las murallas en las Comunidades de Villa y Tierra de la Diócesis de Segovia en los siglos XI a XIII. Técnica y sistemas constructivos de la arquitectura defensiva medieval.

pequeñas piedras, integrante del vertido en I a construcción de la tapia, que ha quedado con la forma del molde, y muestra las marcas de la tablazón empleada.

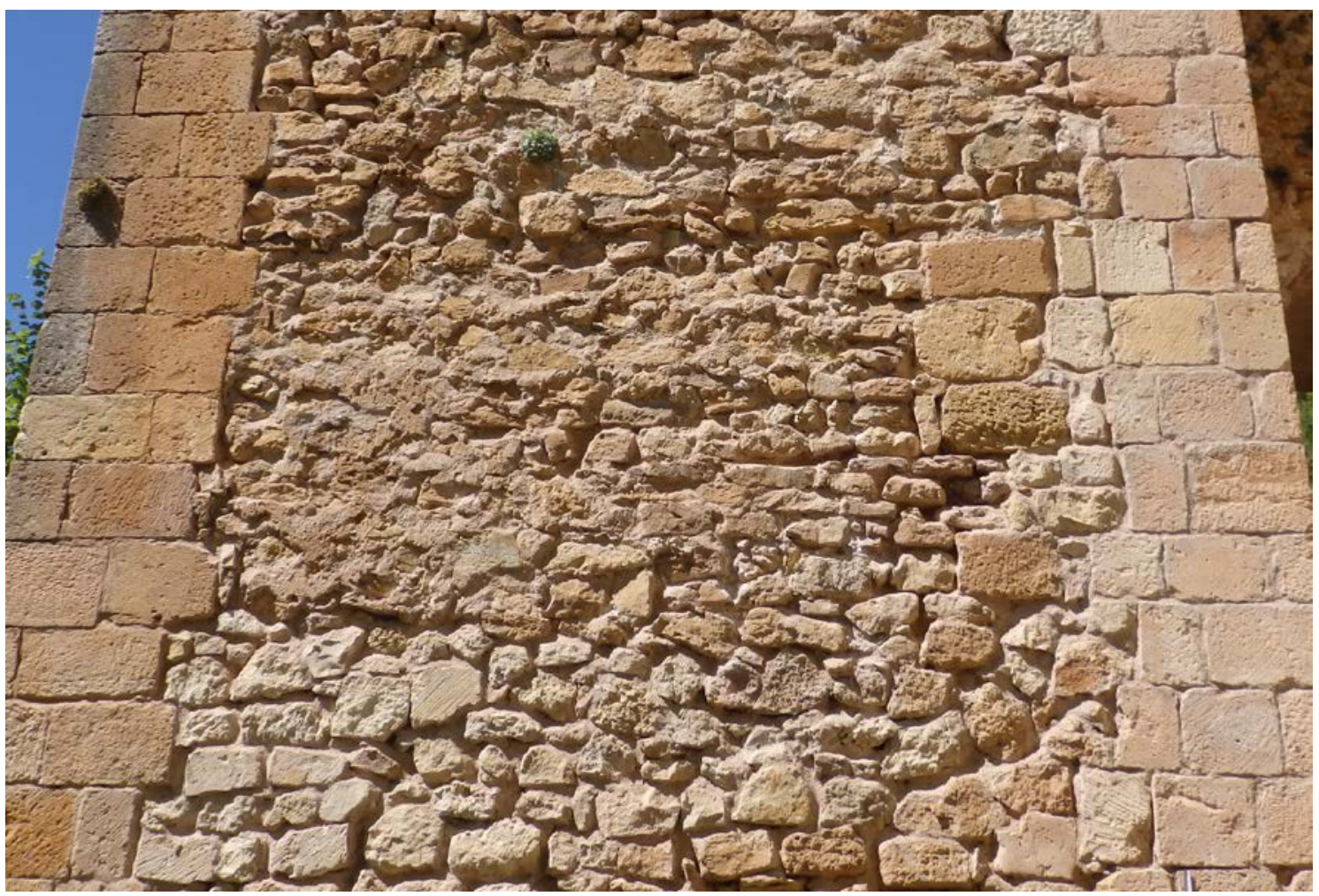

Fig. 5.6.79. Aparejo de la torre T21 en su cara sur [A.S.E. 23/7/2016]

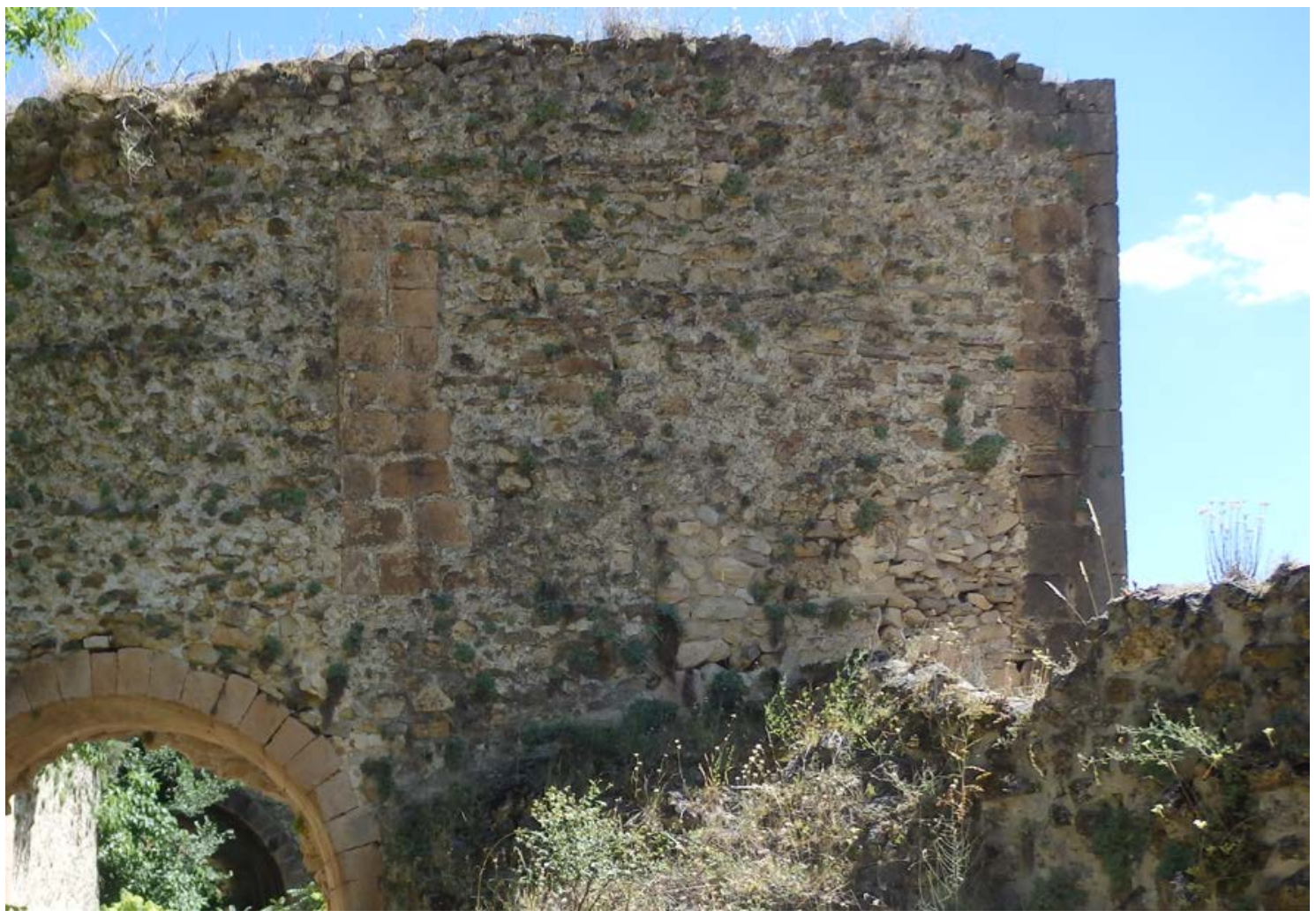

Fig. 5.6.80. Cara norte de la torre T21 [A.S.E. 23/7/2016]. 
La combinación de materiales es mínima en las tapias. Sólo se emplean mampuestos, tierra y probablemente cal. No se observa el empleo de ladrillo. En las puertas se observa el uso de sillería en las esquinas, pero no está claro si los sillares se emplean como parte del encofrado, a modo de machones o de si se añaden con posterioridad. Los mechinales son escasos y se ven de forma aislada. En el tramo P11-Oeste200 predomina el empleo de varillas pareadas, mientras que en la puerta de la Fuerza (P8) se observan mechinales de sección rectangular configurados con mampuestos.

\subsubsection{Resumen de resultados para el caso de Sepúlveda}

La muralla de Sepúlveda tiene una extensión muy importante, muy superior a los otros casos estudiados, y comparable a la extensión del recinto amurallado de la ciudad de Segovia. Esta gran extensión hace pensar en la existencia de recintos más pequeños que el que se intuye en la actualidad, aunque los restos existentes no permiten lanzar una hipótesis de otros recintos. La forma y disposición de las parcelas en la actualidad tampoco permite deducir la existencia de agrupaciones como ocurre en otros casos estudiados. Se traduce en el parcelario la importancia de la posición del castillo, visible a través de la propia plaza que se extiende ante el mismo y de la confluencia de calles hacia ese punto, tanto desde el interior del recinto, como a partir de este punto hacia el exterior, donde se observan parcelas que se organizan en semicírculo. Estos factores, además de los ya expuestos en el breve análisis parcelario, referentes a la escasa altitud de la ubicación del castillo actual, podrían indicar que este último era originariamente una puerta.

En la mayoría de los tramos y puertas de muralla se observa la presencia de partes preexistentes de muralla, visibles en muchas de las bases de los muros y de las torres. La presencia de sillería de grandes y medianas dimensiones en las bases de lienzos y torres muestra que la muralla tuvo varias fases de construcción y ha sido reconstruida en varias ocasiones durante el periodo medieval. Se observan aparejos diversos en todo el recinto, desde grandes sillares, sillarejo, tapia o aparejos de mampostería singulares. Se hace evidente también la reutilización de sillería de otras construcciones, así como la reconstrucción de torres existentes en el siglo IX, pero también la reconstrucción de nuevos tramos desde cero como el existente al noroeste de la puerta de Duruelo (P11).

El lienzo analizado tiene una altura de 6 a $7 \mathrm{~m}$. Las puertas estudiadas tienen alturas dispares, en el caso de la puerta de la Fuerza, los restos solo alcanzan la altura de $6,50 \mathrm{~m}$, mientras que la puerta de Duruelo (P11) tiene dimensiones más importantes, superando los $10 \mathrm{~m}$ de altura. Las torres del recinto presentan secciones rectangulares en planta de forma general, a excepción de las torres que integran el castillo. Se ha podido cuantificar el espesor del lienzo en algunos puntos de la muralla. Oscila entre 2 y 3 metros en el tramo T1-T2 y es de $2 \mathrm{~m}$ en el tramo al oeste de la puerta de Duruelo (P11). Es particular la disposición de este tramo en relación con el terreno, pues aunque su cara exterior es visible en toda s u altura, el alzado interior se encuentra 
Las murallas en las Comunidades de Villa y Tierra de la Diócesis de Segovia en los siglos XI a XIII. Técnica y sistemas constructivos de la arquitectura defensiva medieval.

pegado al terreno de manera que el nivel de suelo se sitúa a la altura del adarve. Esta disposición es visible también en el tramo T10-T9, donde hacia el exterior se observa la altura completa del lienzo, mientras que en el interior se transita a la altura del almenado.

Las puertas de la Fuerza, de Duruelo, del Río y del Azogue muestran una tipología similar, de dos torres de base rectangular que flanquean el acceso, con el frente de este último retranqueado. El Postiguillo también comparte esta disposición. En el caso de Duruelo, la posición de la puerta en relación con el lienzo difiere del resto, se sitúa en quiebro, formando un ángulo recto con la dirección de trazado de la muralla.

Las técnicas constructivas visibles en las bases de lienzos y torres son en muchos casos sillares de tam año medio y grande, de aristas y vértices erosionados. Se observan fábricas de sillería grande, de hiladas ordenadas, también se ve la reutilización de sillares en nuevos aparejos de piezas de tamaños diversos encajadas de forma caótica. Se ven igualmente recrecidos de muros existentes y nuevos tramos, construidos con tapia de mampostería encofrada. Este sistema aparece incluido en otras investigaciones (Aymerich et al. 1990, 138) dentro de un tipo de aparejo fechado durante el siglo XV o posterior. El empleo tan intenso de tapia de mampostería para la reconstrucción de I a muralla de S epúlveda, visible en I os recrecidos de I ienzos y puertas o en nuevos tramos de grandes longitudes, hace posible plantear que es te sistema constructivo se empleara con anterioridad al siglo XV, durante los siglos XII y XIII, en el contexto de la fortificación de las Comunidades de Villa y Tierra.

Los recursos defensivos de la muralla no son numerosos. No se conservan restos de almenado que per mitan analizar su morfología. En el tramo P11-oeste se puede identificar la existencia de un adarve y los restos de una base de almenado, pero insuficientes para llevar a c abo un anál isis. En la zona T10-T9 se reconstruyó un almenado moderno. En cuanto a torres de flanqueo como recurso defensivo, solo se conservan seis torres de estas características, todas ellas en la zona urbana y muy vinculadas a las preexistencias. En el tramo P11-oeste destaca la ausencia de torres a lo largo de una distancia considerable, cercana a los 400m. Por otra parte, es un lienzo que se construye apoyado en el terreno, lo que le confiere estabilidad. 


\section{6}

\section{Análisis y discusión de resultados}

En este apartado se va a comparar cada uno de I os casos estudiados, analizado principalmente los resultados obtenidos en el estudio constructivo del os lienzos analizados. Aunque esta tesis ha tenido un enfoque constructivo, se cree conveniente aprovechar este capítulo para comentar otros aspectos que rodean la construcción de estas murallas. En primer lugar, se comenta la posición de las villas en el territorio, teniendo en cuenta las distancias que las separan y se compara su posición con la de las villas vecinas, para averiguar qué relación existe entre ellas. Se realiza una breve comparación del asentamiento de los núcleos amurallados, donde s e confronta la extensión que abarca la muralla, de cuántos recintos dispone o qué porcentaje de ocupación actual tiene. En segundo lugar, se habla de la muralla en sí, de cuáles son sus características generales y qué elementos posee, con el objeto de identificar cuestiones comunes o señalar diferencias. Finalmente se aborda el tema relativo a los sistemas constructivos empleados en las murallas, y concretamente se desgrana las características de las tapias utilizadas en c ada uno de los casos, comparando sus dimensiones, la configuración de sus mechinales y otras marcas de los tapiales empleados.

\subsection{Las villas en el territorio}

A lo largo de esta investigación, se ha tenido en cuenta el papel representado por las villas estudiadas en su contexto histórico y territorial. Se ha considerado que el estudio de la muralla a nivel constructivo no puede abstraerse del contexto que ha rodeado su construcción. Aunque el enfoque constructivo sea muy específico y afecte a un aspecto muy concreto y limitado de las murallas, no se ha querido olvidar que forma parte de un conjunto y que para avanzar en su conocimiento es necesario contemplar el panorama completo, aunque no se haga en profundidad.

Se ha comentado en cada caso de estudio cual era la distancia que separaba la villa de aquellas que son colindantes. La distancia entre la villa y sus villas vecinas es siempre cercana a $30 \mathrm{~km}$, reduciéndose en el caso de Pedraza-Sepúlveda a $20 \mathrm{~km}$ (Fig. 6.1). Se trata de una di stancia que se puede cubrir a pie en 7-8 horas y podría corresponder aproximadamente con una jornada de viaje en la Edad Media. Esta distancia es similar entre todas las villas y muestra que tenían una relación entre sí. 
Las murallas en las Comunidades de Villa y Tierra de la Diócesis de Segovia en los siglos XI a XIII.

Técnica y sistemas constructivos de la arquitectura defensiva medieval.

Apoya la idea que estas villas forman parte de una malla de núcleos organizados para controlar el territorio.

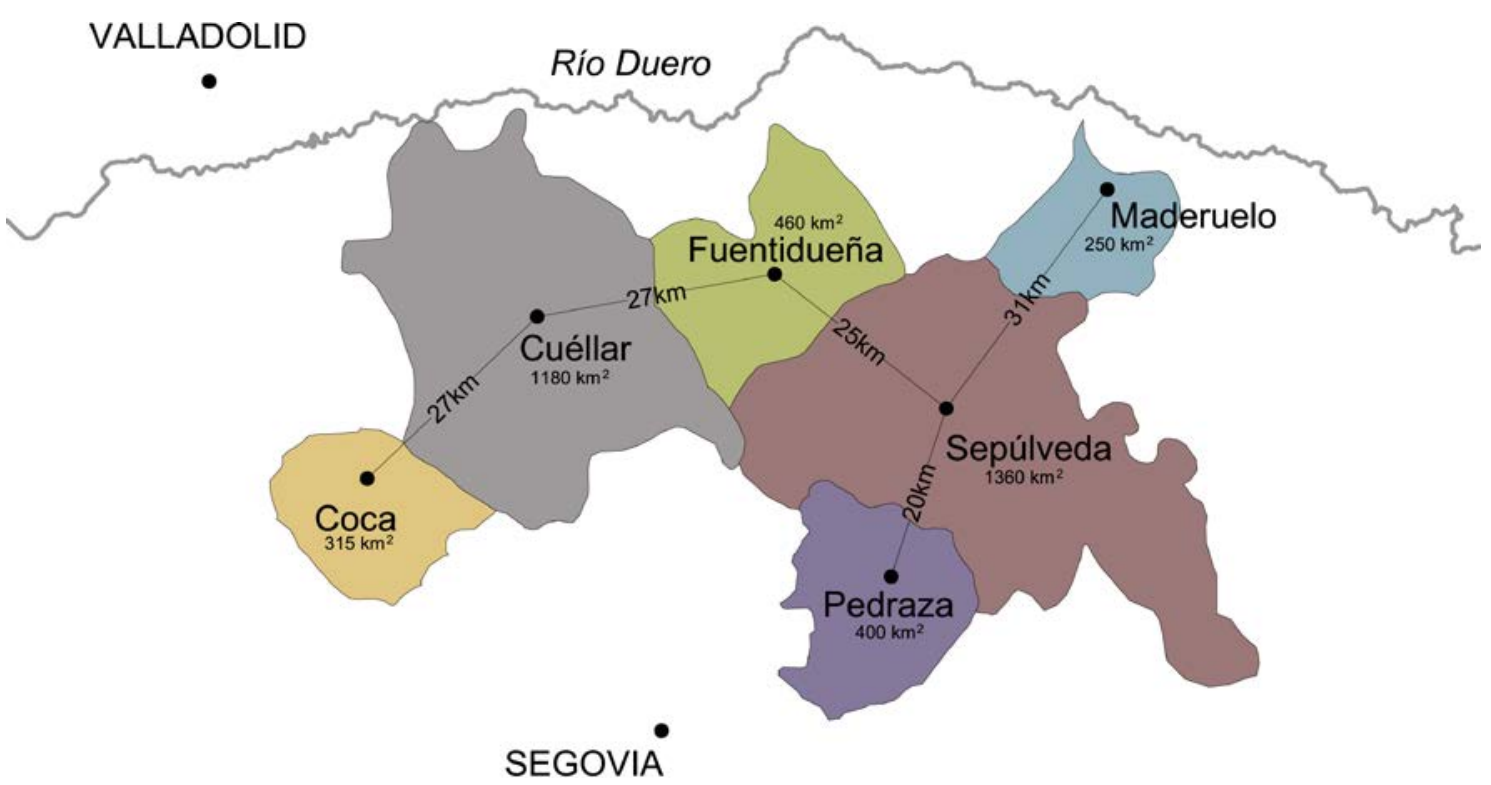

Fig. 6.1. Territorios asignados a las villas amuralladas, con la superficie indicada. Se observa la distancia que separa cada villa de la villa vecina, cercana a $30 \mathrm{~km}$. Fuente: Elaboración propia.

Tabla 6.1. Distancias en kilómetros de las villas entre sí. La di stancia indicada hace referencia a I as carreteras actuales, mientras que entre paréntesis se indica la distancia en línea recta de una villa a otra. Fuente: Elaboración propia.

\begin{tabular}{|c|c|c|c|c|c|c|}
\cline { 2 - 7 } \multicolumn{1}{c|}{} & Coca & Cuellar & Fuentidueña & Maderuelo & Pedraza & Sepúlveda \\
\hline Coca & - & $34(27)$ & $64(52)$ & $116(90)$ & $81(61)$ & $82(66)$ \\
\hline Cuellar & $34(27)$ & - & $31(27)$ & $91(67)$ & $66(52)$ & $51(50)$ \\
\hline Fuentidueña & $64(52)$ & $31(27)$ & - & $58(39)$ & $40(38)$ & $37(25)$ \\
\hline Maderuelo & $116(90)$ & $91(67)$ & $58(39)$ & - & $58(47)$ & $34(28)$ \\
\hline Pedraza & $81(61)$ & $66(52)$ & $40(38)$ & $58(47)$ & - & $25(20)$ \\
\hline Sepúlveda & $82(66)$ & $51(50)$ & $37(25)$ & $34(31)$ & $25(20)$ & - \\
\hline
\end{tabular}

Las distancias que separan unas villas de otras (Tabla 6.1), son en muchos casos, múltiplos de 30 . Fuentidueña se separa de Coca una distancia cercana a $60 \mathrm{~km}$, que viene a ser el doble de la distancia que separa a las villas más cercanas. Maderuelo se encuentra a $90 \mathrm{~km}$ en línea recta de Coca, en este caso, tres veces la distancia de $30 \mathrm{~km}$. Se ha reflejado en la tabla la distancia a través de las carreteras actuales, pero se ha considerado más útil indicar cuál es la distancia en línea recta, escrita entre paréntesis. Aun así, es posible que el recorrido de c arreteras actuales no difiera demasiado del existente en las vías medievales ya que no se han salvado obstáculos geográficos importantes por medio de puentes o túneles en el último siglo, a excepción del túnel que pasa bajo la población de Sepúlveda. 
La posición de estas villas, separadas distancias semejantes entre sí no puede ser fortuita, sino que parece responder a una planificación. A la hora de repoblar esta área y erigir nuevas murallas, ¿por qué no potenciar aquellas villas situadas en puntos de interés, separados unos de otros una distancia controlada que permita conservar una comunicación eficaz entre ellos?

\subsection{La muralla en la villa}

Confirmando lo que y a indican otros investigadores (Villar García 1986, 95; Benito $2000,79)$ en todos los recintos analizados se observa una adaptación muy clara de los lienzos de muralla al territorio donde se asienta la villa. Por una parte se ve un intenso aprovechamiento de los desniveles del terreno, las paredes verticales de roca se utilizan como defensa natural, construyendo los lienzos en sus mismos bordes. Los casos más claros son aquellos que se sitúan en $z$ onas más montañosas, como Sepúlveda, Pedraza o Maderuelo.
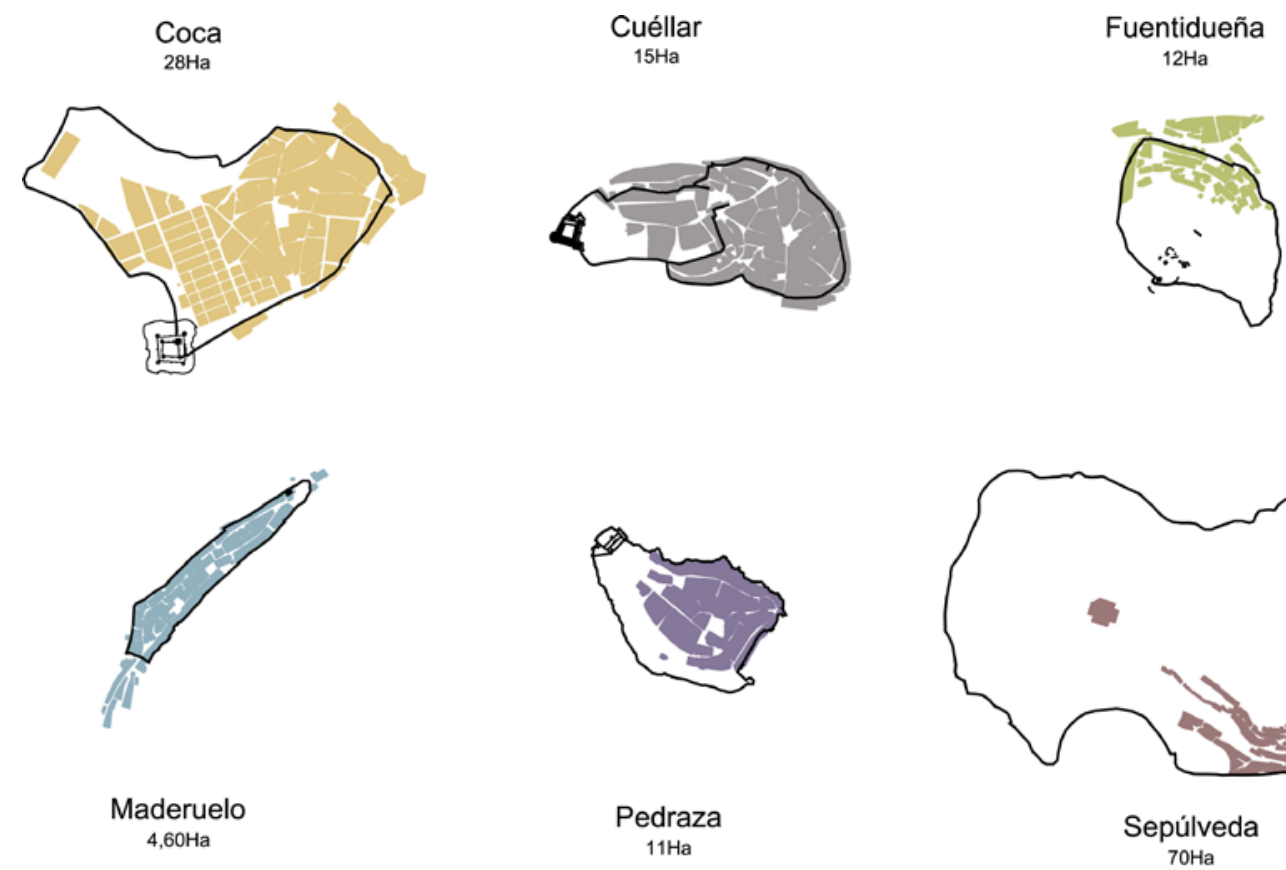

$4,60 \mathrm{Ha}$

edraza $70 \mathrm{Ha}$

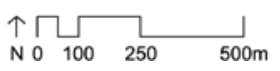

Fig. 6.2. Esquemas comparativos de los recintos amurallados. Para simplificar, se han dibujado los recintos sin diferenciar entre los restos existentes y las hipótesis de trazado. Esa información se puede consultar en el apartado correspondiente a cada uno de los casos. Fuente: Elaboración propia.

En el caso de Maderuelo y Pedraza el territorio limita el crecimiento de las villas. En estos dos casos, las villas no pueden crecer en cualquier dirección, el territorio tiene grandes desniveles que i mpiden la expansión de los núcleos. En el caso de Maderuelo, solo es posible extenderse desde el lado suroeste y aun así el territorio es estrecho. En el caso de Pedraza, el terreno sólo es accesible en el lado sureste y con 
Las murallas en las Comunidades de Villa y Tierra de la Diócesis de Segovia en los siglos XI a XIII.

Técnica y sistemas constructivos de la arquitectura defensiva medieval.

todo no se ha producido expansión urbana en esa dirección. En el resto de casos, esta limitación sólo se produce en algunas zonas, ya que no todas son necesariamente tan escarpadas. La forma caprichosa de los recintos amurallados, sin apenas líneas ni ángulos rectos, corrobora la adaptación de su trazado a las volubles formas del territorio (Fig. 6.2).

Aun así, no todos los lienzos quedan limitados por la forma del territorio. En el caso de Coca, el frente sureste muestra una línea casi recta que cierra la villa por ese lado, situando el límite allí por otras razones. En el caso de Cuéllar, el segundo recinto sólo aparece limitado por el territorio en la zona sur, quedando los límites norte y el este en una zona más llana. En el caso de Fuentidueña, la cara este presenta un borde natural con gran desnivel, pero la parte noroeste está en una zona más Ilana. En Maderuelo, sólo la zona suroeste se ha cerrado en esa posición por razones distintas a los límites del terreno. En Pedraza, todo el contorno queda sujeto a las formas del terreno, aunque sea más accesible en la zona sureste. En Sepúlveda, solo la zona suroeste se libra de la tiranía del territorio.

Las superficies de cada uno de los casos no son siempre comparables. El recinto más pequeño es el de Maderuelo, que no llega a las $5 \mathrm{Ha}$ de superficie. A continuación se sitúa Pedraza con el doble de superficie, que alcanza las $11 \mathrm{Ha}$. La constricción del territorio en estos dos casos puede justificar la escasa expansión que en ellos se ha producido. La ampliación de una villa de e stas características hubiese implicado la creación de un nuev o recinto en la zona este en el caso de P edraza y una continuación en la zona sur en el caso de Maderuelo. En esta última villa, la expansión contemporánea se está produciendo en e sta dirección, aunque e s escasa. Los recintos de Fuentidueña y Cuéllar (contabilizando sus dos recintos) tienen una superficie superior a la de Pedraza, pero no superan las $15 \mathrm{Ha}$. Coca tiene casi el doble de superficie, se queda a las puertas de las $30 \mathrm{Ha}$. Finalmente, Sepúlveda se desmarca del resto con una superficie extraordinaria de $70 \mathrm{Ha}$, muy superior a la de las otras villas.

Tabla 6.2. Datos generales de los recintos amurallados. Fuente: Elaboración propia.

\begin{tabular}{|l|r|c|c|c|c|c|}
\hline & $\begin{array}{c}\text { Superficie } \\
(\mathrm{Ha})\end{array}$ & $\begin{array}{c}\text { Superficie en } \\
\text { comparación con } \\
\text { Cuéllar }\end{array}$ & $\begin{array}{c}\text { Longitud } \\
(\mathrm{m})\end{array}$ & $\begin{array}{c}\text { Posición } \\
\text { castillo }\end{array}$ & $\begin{array}{c}\text { Recintos } \\
\text { visibles }\end{array}$ & $\begin{array}{c}\text { Ocupación } \\
\text { actual del } \\
\text { recinto }\end{array}$ \\
\hline Coca & 28,00 & $\begin{array}{c}\text { Casi } 2 \text { veces sup. } \\
\text { Cuéllar }\end{array}$ & 2400 & Sur & 1 & $65 \%$ \\
\hline Cuéllar & 15,00 & - & 1800 & Oeste & 2 & $85 \%$ \\
\hline Fuentidueña & 12,00 & $4 / 5$ de sup. Cuéllar & 1400 & Suroeste & 2 & $30 \%$ \\
\hline Maderuelo & 4,60 & $1 / 3$ de sup. Cuéllar & 1350 & Noreste & 1 & $95 \%$ \\
\hline Pedraza & 11,00 & $3 / 4$ de sup. Cuéllar & 1600 & Noroeste & 1 & $60 \%$ \\
\hline Sepúlveda & 70,00 & $\begin{array}{c}\text { Casi 5 veces sup. } \\
\text { Cuéllar }\end{array}$ & 4350 & Sureste & 1 & $25 \%$ \\
\hline
\end{tabular}

La longitud de los recintos está relacionada con la superficie, aunque no en todos los casos. Fuentidueña y Maderuelo tienen superficies dispares (la primera casi triplica la segunda), poseen una longitud de lienzo similar, cercana en am bos casos al os 
$1400 \mathrm{~m}$. Cuéllar y Pedraza se aproximan en longitud y su superficie es relativamente similar. La diferente longitud de los lienzos en cada uno de los casos, pone de manifiesto la diferencia en coste económico que supondría tener una muralla que no llega a dos mil metros, frente a una que supera los cuatro mil.

La posición del castillo es distinta en cada uno de los casos. En muchos de ellos el castillo se sitúa en la zona menos accesible. En Pedraza, Cuéllar o Maderuelo, el castillo se ubica en punto de más difícil acceso del recinto, al borde de un cortado o rodeado de desniveles. En comparación con Maderuelo o Pedraza, Cuéllar no cuenta con la misma ventaja, ya que sólo en la zona sur su defensa está favorecida por el territorio. En el caso de Coca, aunque la posición del castillo se encuentra defendida naturalmente en s u lado oeste, la zona noroeste del recinto parece todavía más inaccesible desde un $\mathrm{p}$ unto de $\mathrm{v}$ ista natural. Algo similar ocurre con Fuentidueña, donde su castillo se sitúa en el punto más alto, aunque no se aproxima al lado este del recinto, donde el terreno construye una muralla natural. Es probable que en estos casos, otros factores influyeran además del de aprovechar las defensas naturales, como por ejemplo el de dominio visual sobre el territorio circundante. En el caso de Sepúlveda, el castillo actual se sitúa en el centro del centro urbano actual, aunque como se plantea en el capítulo correspondiente a esta villa, es probable que un castillo anterior se situara en las zonas más elevadas de este cerro y no en una zona tan accesible como la actual.

En todos los casos se ha producido un vaciamiento de las zonas en torno al castillo, que es visible en la actualidad. Tal y como se explica en el caso de Coca, aunque la ocupación actual del recinto se sitúa en un $65 \%$ del total de la superficie, una extensa zona entre el castillo y el área de tejido medieval se ha construido, en el siglo pasado, en un es pacio vacío. En Cuéllar, las parcelas que rodean el castillo están vacías y poseen un uso ocasional de feria que aprovecha su carácter de es pacio libre de edificaciones. Fuentidueña muestra un vaciamiento muy intenso del interior del recinto amurallado, hasta tal punto que la mayor parte de la superficie amurallada no tiene uso urbano. Maderuelo es el caso donde s e conserva mayor ocupación del recinto, alcanzando el $95 \%$. Aun así, es la zona donde se situaría el antiguo castillo donde se ha producido ese $5 \%$ de vaciamiento. Pedraza presenta una ocupación del $60 \%$ y, como ocurre en el resto de los casos, es la zona cercana al castillo la que pi erde densidad hasta estar vacía en la actualidad, en continuidad con la parte sur. El caso de Sepúlveda es el más llamativo, ya que tiene una ocupación del recinto amurallado de solo $25 \%$, creciendo el núcleo actual en dirección este, fuera del recinto amurallado.

En algunos casos se conservan restos que atestiguan la existencia de varios recintos amurallados. El caso más claro es el de Cuéllar, donde se ve de forma evidente que al menos existieron dos recintos, ya que se conserva gran parte de ambos. En Fuentidueña se conserva un pequeño tr ozo que podría indicar la existencia de otro recinto más pequeño del que se ve en la actualidad. En el resto de casos, no se conservan restos que confirmen la existencia de otros recintos. No obstante, es muy probable que existiesen varios recintos más pequeños en los otros casos. En Coca y Sepúlveda, donde las superficies son grandes, es factible que existiesen recintos que 
Las murallas en las Comunidades de Villa y Tierra de la Diócesis de Segovia en los siglos XI a XIII.

Técnica y sistemas constructivos de la arquitectura defensiva medieval.

posteriormente se ampliaron hasta la situación actual. En el caso de Coca, se han descrito en el capítulo correspondiente a esta villa, indicios en su trazado urbano que podrían sugerir la existencia de un pr imer recinto que contase con una puerta en la zona de la plaza Cruz de los Caídos. En el caso de Sepúlveda existe una posible torre situada en el interior del recinto, descrita en el capítulo correspondiente, que podría ser una pista de un posible recinto más pequeño. Félix Benito $(2000,178)$ establece que esta villa solo conoció un recinto y lo atribuye a varias razones: por una parte a una fecha más tardía del inicio de su evolución urbana, por otra parte al hecho de que responde a una idea de cerca como delimitación del suelo a poblar y finalmente, por la singularidad defensiva de su emplazamiento.

\subsection{Dimensiones generales de las murallas}

Se ha llevado una comparación de las dimensiones generales de los lienzos en los tramos estudiados (Tabla 6.3). Se observan diferencias entre las alturas medidas desde el interior del recinto y las visibles desde el exterior, siendo esta última mayor en la mayoría de los casos. En los casos de Maderuelo, Coca o Cuéllar, la altura exterior es igual o superior a $10 \mathrm{~m}$. En Fuentidueña y Pedraza la altura se queda en $9 \mathrm{~m}$. En el caso de Sepúlveda, la altura es de 7 metros en el tramo estudiado, correspondiente a P11-Oeste 200. Desde el interior, la altura de la muralla se reduce en todos los casos. El caso más marcado es el de Sepúlveda, donde desde el interior el adarve se sitúa prácticamente a nivel de suelo, llegando a la altura de $1 \mathrm{~m}$, medida desde el interior. Esta disposición recuerda la definida por otros investigadores (Cobos et al. 2012, 117) como tapial contra terraplén que sitúan en Mansilla de las Mulas (León) y Ciudad Rodrigo (Salamanca), o Villalpando (Zamora). En el resto de casos, la altura en el interior se reduce aproximadamente dos metros en los tramos analizados. En varios recintos esta altura interior varía, aumentando en algunos puntos, como en el caso de Fuentidueña. En el caso de P edraza, el tramo analizado se corresponde con la posición de una puerta, por lo que las alturas son idénticas desde ambos lados de la muralla. En otras zonas, los restos tienen escasa altura y no se adivina ningún almenado que permita plantear una altura del lienzo.

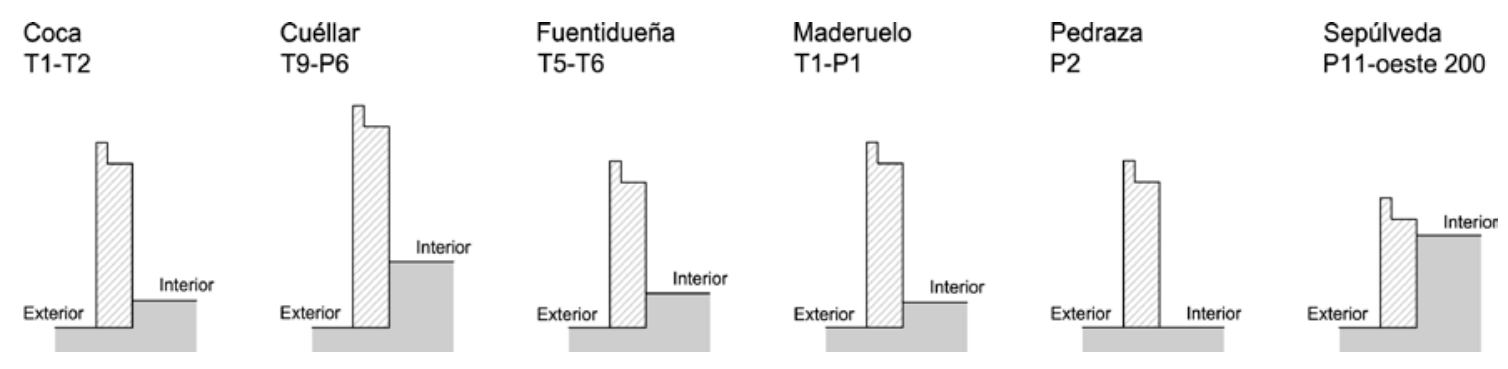

Fig. 6.3. Comparativa de alturas que muestra el desnivel habitual entre el interior y el exterior de cada tramo estudiado. Fuente: Elaboración propia.

La diferencia de altura entre la zona interior y exterior puede deberse a la acumulación de sedimentos en el interior del recinto por el paso del tiempo. En el exterior, esta 
acumulación puede ser menor debido a la localización habitual de los lienzos en el borde de la roca, visible parcialmente en muchos de los alzados de los lienzos. Por otra parte, la diferencia de al tura podría haber sido también intencionada en la construcción de los lienzos, para tener un acceso más fácil desde el interior al adarve, o también para generar una impresión de mayor altura en las murallas. En cualquier caso, la parte enterrada de los lienzos se encuentra protegida frente a agresiones climatológicas o de c ualquier tipo, por lo que es posible que se encuentre en buen estado de conservación, manteniendo marcas claras de tapial u otr os restos de interés.

Aunque el espesor es variable a lo largo del recinto amurallado, es posible extraer una medida a l a que ti ende de for ma generalizada. En todos los casos el espesor se aproxima a los dos metros a excepción del caso de Fuentidueña, que presenta un espesor sorprendentemente reducido, cercano a un metro (Tabla 6.3). En los casos donde ha sido posible observar una sección del muro, por encontrarse expuesta, como ocurre en Coca, en Fuentidueña, o en Cuéllar donde también se ha contado con una fotografía anterior a la reconstrucción del tramo C-PN1, se ha podido comprobar que no existe una división interna que pueda hacer creer que el muro tiene dos hojas o que existía un $m$ uro inicial al que s e ha ados ado otro por el exterior. En el caso de Sepúlveda, el espesor se ha podido medir de forma aproximada en la parte superior del lienzo P11-oeste 200. En el caso de Maderuelo, se ha e stimado el espesor analizando el parcelario urbano. En cuanto a los resultados, el caso de Fuentidueña destaca sobre el resto por la delgadez de sus lienzos. No se han encontrado restos de muros anteriores a los que pu diera haberse adosado y tampoco se han visto protuberancias de $\mathrm{m}$ aterial o $\mathrm{m}$ arcas particulares en la cara interior que pudieran haberse originado al emplearse como parte del molde un muro anterior. En la cara interior de los lienzos analizados, se observa la presencia de mechinales, que tal vez no serían pasantes si se hubiera adosado el lienzo a una muralla existente. También se observan marcas de tablazón, que de nuevo no hubieran sido necesarias si hubiese existido un muro al que adosarse, que funcionaría de molde al menos en unos de los lados. Un dato que se desprende de estos muros tan delgados es la eficacia de esta construcción, tan esbelta y con tramos de gran longitud que han resistido con notable éxito el paso del tiempo, sin apenas mantenimiento.

Para comparar las murallas con otras construcciones defensivas, se han consultado los datos de espesores que ofr ecen otros autores. Pablo Rodríguez Navarro (2008, 241) hace referencia a $m$ uros de torres con espesores variables, que tienen un promedio de 1,45m, con valores habituales de 1,30m y de 1,60m. Juan Eslava Galán $(1984,275)$ menciona espesores de muros de 1,65m para el castillo del Ferral, 1,50m para la muralla de A ndújar y $1,20 \mathrm{~m}$ en el caso de I a muralla de B adajoz. Refiere espesores de un codo $(40 \mathrm{~cm})$ para los castillos de A renas e Ir uela, en puntos no expuestos a máquinas de asedio. Indica que no existía una unidad de criterios en cuanto al espesor y establece una relación entre el espesor y la altura de las murallas. Jacinto Canivell $(2010,25)$ refiere espesores de casi dos metros para la "tapia de hormigón" que contendría tierra, cal y guijarros. 
Las murallas en las Comunidades de Villa y Tierra de la Diócesis de Segovia en los siglos XI a XIII. Técnica y sistemas constructivos de la arquitectura defensiva medieval.

\subsection{Elementos de las murallas}

\subsubsection{Puertas}

Como se ha visto a lo largo de los ejemplos descritos, en cada uno de los recintos amurallados se encuentran distintos elementos de la muralla. En algunos casos se han conservado numerosas puertas, como en Cuéllar o en Sepúlveda, que superan ambos casos la decena de ellas, incluyendo postigos y portillos (Tabla 6.3). En otros casos solo se conserva una puerta, como en Coca, y en el resto de casos se conservan dos o tres puertas. En los casos donde se conservan escasas puertas tampoco hay indicios de que existieran muchas más, aunque la huella de caminos que parten de las villas o las características de la orografía podrían ayudar a localizar la posición de otras puertas desaparecidas. En Coca, es probable que existieran dos puertas más y en el caso de Fuentidueña puede que existiera algún postigo o portillo más. En Maderuelo es también posible que existiera una tercera puerta en el lado sureste. En ninguno de estos cuatro casos, teniendo en c uenta las posibles puertas desaparecidas, estas son superiores a c inco, lo que representa una diferencia importante frente a l as otras dos villas que triplican o c uadruplican el número de accesos. En el caso de Sepúlveda, la gran extensión podría ser una razón por la que el número de puer tas es superior. Por el contrario, el caso de $C$ uéllar, donde se conserva el mayor número de ellas, tiene una superficie muy similar al resto. Es cierto que el primer recinto cuenta con seis de ellas y las otras seis forman parte del segundo recinto. Otra razón por la que es tas villas tuvieran más puertas es que la actividad económica que se desarrollara en ellas fuese mucho mayor y que por ello hubiesen necesitado construir mayor número de accesos que ordenaran el flujo de visitantes. Esta superioridad en número de accesos también se produce en superficie de territorio asignado; los casos de Cuéllar y Sepúlveda cuadruplican la superficie de los territorios de otras comunidades (Fig. 6.1). Es probable que en este sistema de territorio con un poder centralizado en villas, el control de un ter ritorio mayor se tradujera en una villa más grande y con mayor número de accesos y barrios, en definitiva más compleja.

En cuanto a la tipología de las puertas, es habitual encontrar puertas flanqueadas por torres de planta rectangular, con una composición simétrica, colocadas en la dirección del lienzo. En los casos de Fuentidueña, Sepúlveda y Cuéllar se encuentran puertas de estas características. En Coca, la única puerta en pi e del recinto tiene una composición simétrica, aunque sus torres son de planta semicircular. Este último es un ejemplo de la modificación que se produce en las puertas de muralla con el paso del tiempo. Con el objeto de modernizar las puertas adaptándolas a nuevos estilos, de decorarlas o para hacer gala de bonanza económica, se añaden portadas, se recrecen o se incorporan escudos. En el caso de Coca, se observa la construcción de una portada de ladrillo sobre el arco de acceso y una coronación decorada con arcos de ladrillo. Otras diferencias son visibles en el interior de la en la puerta de Coca. La altura del paso no se corresponde con la de los arcos a a mbos lados, sino que se eleva considerablemente. Se suceden planos que albergan una puerta exterior de dos hojas y un rastrillo que se levanta en sentido vertical. En la parte interior podría existir otra puerta, dejando entremedias un espacio estratégico donde se ven cuatro huecos con la función de matacanes que permitirían defenderlo. Los otros tres ejemplos no 
tienen un hueco de acceso tan complejo, cuando hay bóvedas, son una prolongación del arco de acceso y el interior solo muestra las marcas en la piedra de los goznes de las puertas. En el caso de I a puerta de I a Villa de $M$ aderuelo, es visible una complejidad similar en el acceso, con la existencia de un matacán sobre la puerta de dos hojas.

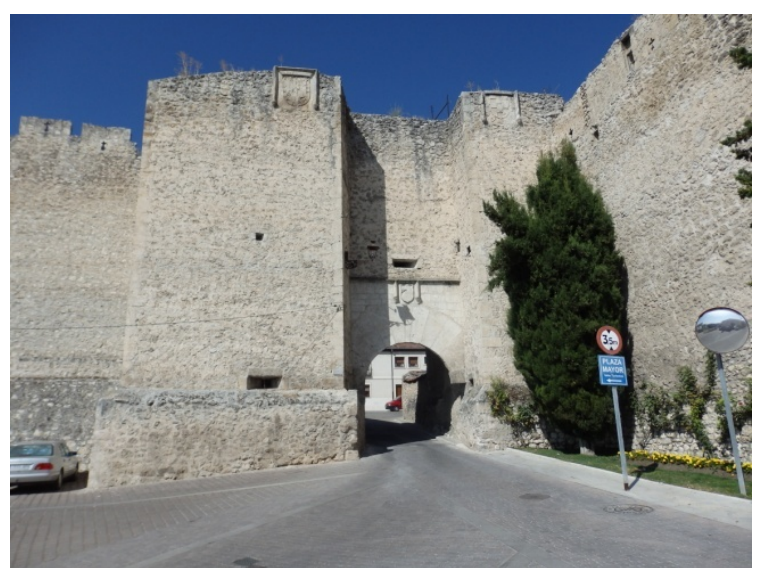

Fig. 6.4. Puerta de San Martín en Cuéllar, de composición simétrica [A.S.E. 20/8/2014].

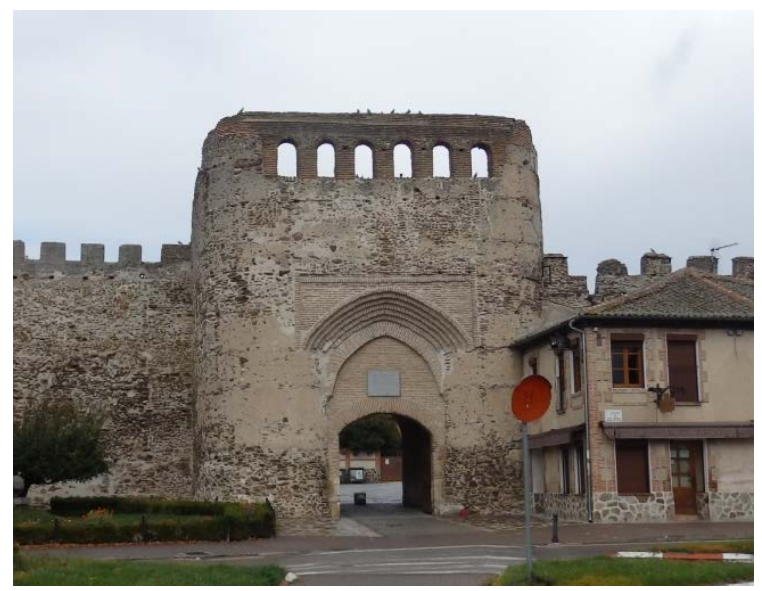

Fig. 6.6. Puerta de la Villa en Coca, de composición simétrica [A.S.E. 2/11/2014].

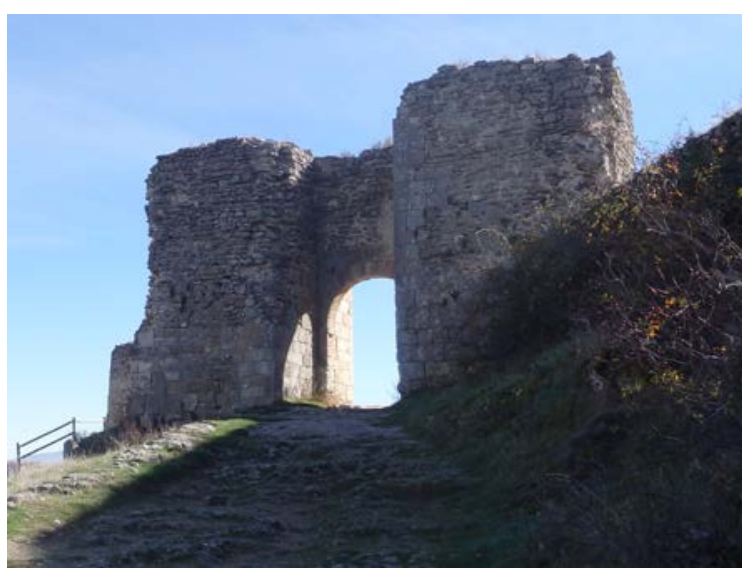

Fig. 6.5. Puerta de la Fuerza en Sepúlveda, de composición simétrica [A.S.E. 11/11/2015].

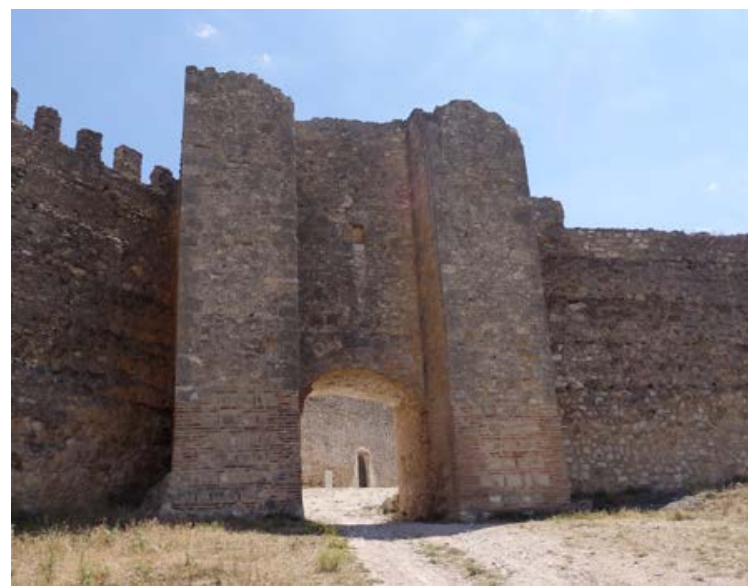

Fig. 6.7. Puerta de Alfonso VIII en Fuentidueña, de composición simétrica [A.S.E. 17/6/2014].

Otras puertas habituales en es tos recintos son las que se colocan en s entido perpendicular a la dirección del lienzo. En varios de los casos, se encuentra este tipo de puerta, habitualmente de m enor importancia que aquel las cuya disposición es simétrica. En un tramo de lienzo se realiza un ligero quiebro que permite la construcción de un acceso, a través de un camino que discurre en paralelo con el lienzo. En la mayoría de los casos, esta disposición en quiebro tampoco presenta torres que flanqueen el acceso, sino más bien volúmenes visibles en la parte interior que parecen tener una función estructural. En la puerta de San Andrés de Cuéllar (Fig. 6.8), la puerta de la Calzada en Fuenti dueña (Fig. 6.9) o la puerta del Barrio en Maderuelo (Fig. 6.10) se observa un frente liso sin torres adelantadas. La puerta de 
Duruelo en Sepúlveda (Fig. 6.11) tiene una configuración simétrica con dos torres de planta cuadrada, adelantadas con respecto del arco de acceso, y que se posiciona en perpendicular al lienzo. En este caso, el lienzo que parte en sentido perpendicular parece haberse añadido con posterioridad, por lo que es ta disposición quebrada podría no ser la original. Existen otros ejemplos de puertas con esta disposición, que combinan una torre de planta circular con una torre de planta rectangular. En Cuéllar, la puerta de San Basilio tiene esta configuración (Fig. 5.2.4, pág. 152), que también puede verse en la puerta de San Andrés de Segovia. Esta composición parece ser una evolución de la puerta en posición perpendicular con una configuración más compleja.

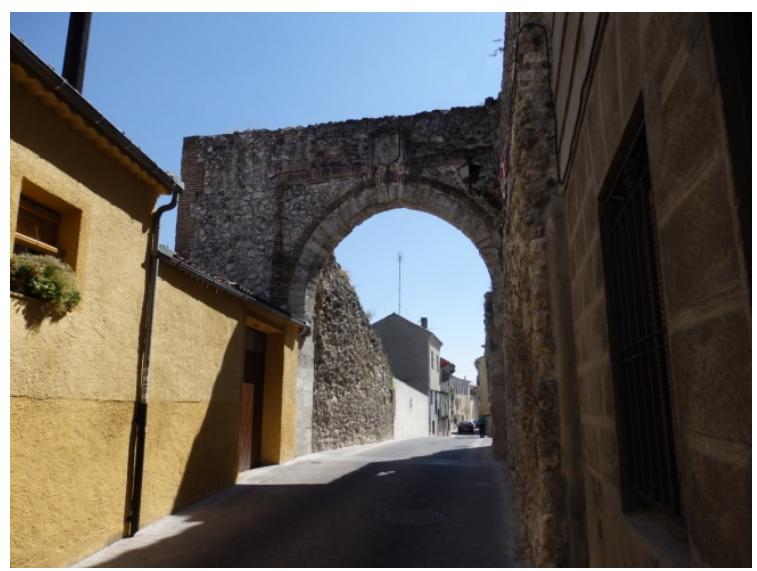

Fig. 6.8. Puerta de San Andrés en Cuéllar [A.S.E 20/8/2014]

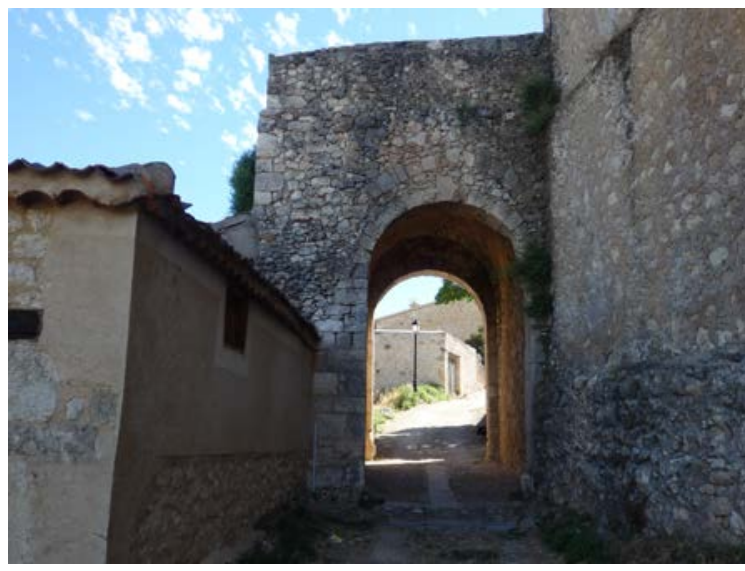

Fig. 6.10. Puerta del Barrio en Maderuelo [A.S.E. 24/7/2016].

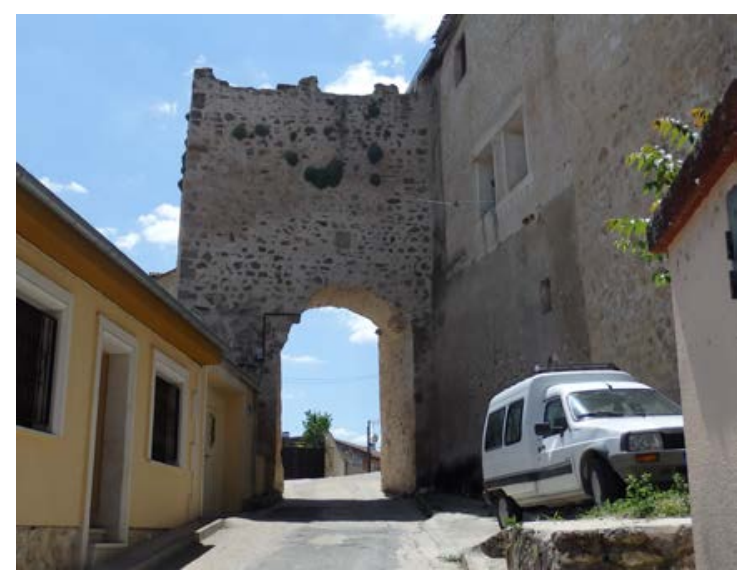

Fig. 6.9. Puerta de la Calzada en Fuentidueña [A.S.E. 17/6/2014].

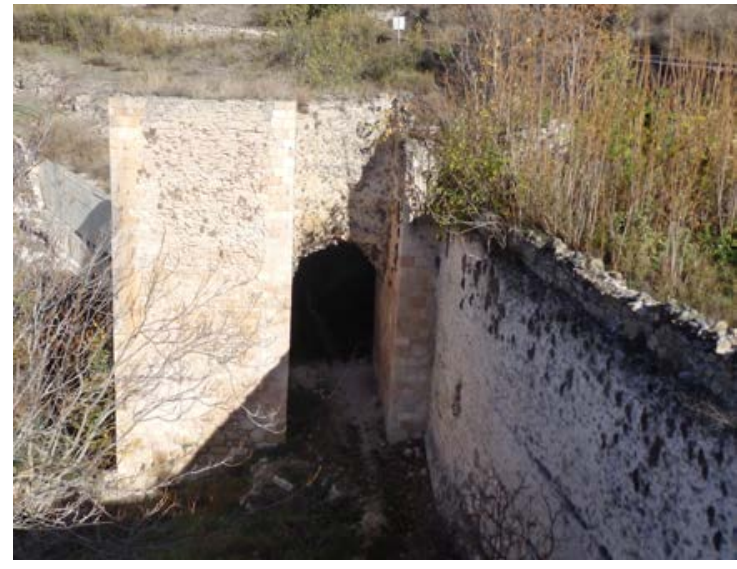

Fig. 6.11. Puerta de Duruelo en Sepúlveda [A.S.E. $11 / 11 / 2015]$.

Los postigos o portillos están situados en I ugares más discretos. Son accesos de menor importancia y esto se traduce en la sencillez de su composición. Se abre simplemente un paso en el mismo lienzo, realizado por medio de un arco de medio punto. Pretende pasar desapercibido y no está tan protegido como otros accesos. En casi todos los recintos estudiados existen accesos de este tipo (Fig. 6.12, Fig. 6.13). 


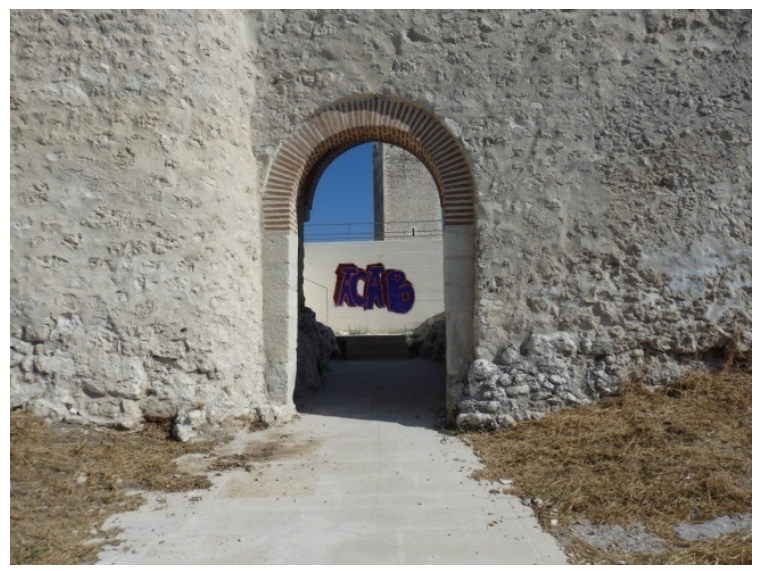

Fig. 6.12. Portillo de la Huerta en Cuéllar [A.S.E. 20/8/2014].

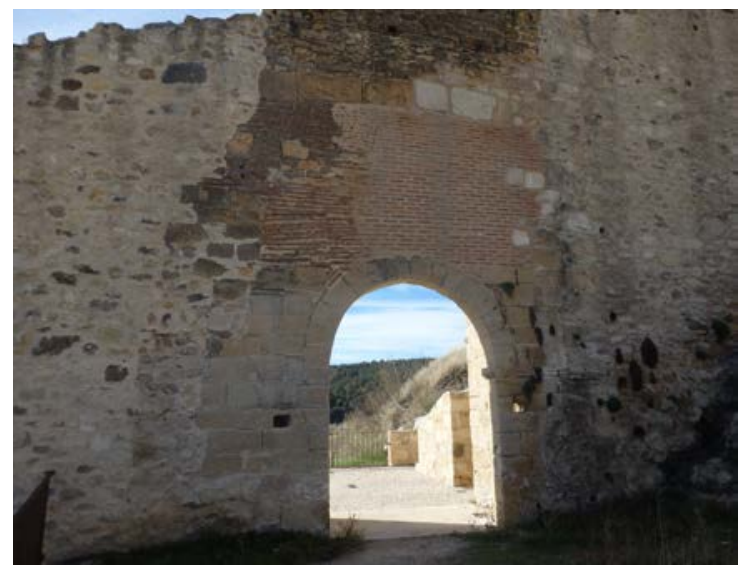

Fig. 6.13. Postigo de Hontanillas en Pedraza [18/11/2015].

Parece habitual esperar que las puertas de las murallas muestren uno o $\mathrm{v}$ arios escudos en su portada o en lo alto de las torres que flanquean el acceso. En el caso de Cuéllar, se observan escudos en las puertas de San Andrés, de San Basilio y de San Martín (Fig. 6.4) La presencia de escudo no es tan evidente en el resto de casos. En Fuentidueña es visible un modesto escudo ilegible en la puerta de la Calzada y otro de mayor tamaño en la puerta de Palacio. En Coca no se observan escudos en la puerta. En la actualidad posee una pl aca colocada en los años cuarenta que rememora el nacimiento de Flavio Teodosio el Grande en Coca, en el año 345. En Maderuelo no se observan escudos en sus puertas. En Pedraza se observa una composición de dos escudos que fl anquean una hor nacina, colocada en I a parte interior de la puerta de la Villa, sobre el arco. En el frente exterior también se ve un tercer escudo, centrado sobre el acceso. En Sepúlveda no se observan escudos sobre las puertas.

Aunque presentan composiciones similares, las puertas ofrecen un as pecto variado, con diferentes soluciones incluso dentro de un mismo recinto amurallado. Las torres no suelen compartir dimensiones y la composición es en algunos casos muy sencilla y elemental y en otros más elaborada. En comparación con los lienzos estudiados, de gran sencillez y escasos recursos defensivos, algunas puertas incorporan otros materiales como el ladrillo, la sillería o muestran mejoras defensivas con elementos como los matacanes, que las distancian de la época de construcción de los lienzos. Es probable que las puertas que s e construyeran simultáneamente al os lienzos se hicieran con el mismo material, como ocurre en las dos torres de la puerta de la Villa de Coca, cuyas tapias de mampostería son idénticas a las visibles en los lienzos. Aunque luego se hayan incorporado otros materiales y formas, las torres y los lienzos comparten la misma técnica constructiva.

Se ha comentado anteriormente la capacidad de las puertas de muralla de generar espacios urbanos vinculados a el la. El cobro de impuestos que se realizaba en I os accesos y el paso de viajeros y habitantes generaba espacios donde se ubicaba el mercado, plazas que en muchos casos se conservan todavía frente a las murallas. Una vez desaparecida la función defensiva, esas plazas o lugares principales de las villas confieren a su vez importancia a estas construcciones y perpetúan su carácter 
de representación. Esta capacidad de representación las convierte en elementos a los que añadir decoraciones, adornos o modificaciones que hablan de distintas épocas. Al final, las puertas son los elementos más modificados en un recinto amurallado, donde mayor cantidad de soluciones constructivas se acumulan, donde se añaden escudos 0 se modifican volúmenes para adaptarlos a nuevas corrientes. Los lienzos de muralla no incorporan esos cambios, son menos protagonistas y acaban demolidos o fagocitados por la nueva edificación, pero no se utilizan como objeto de propaganda, por lo que conservan técnicas originales de construcción.

\subsubsection{Torres}

En cuanto a las torres, se observa un número dispar en cada villa amurallada. La que menos torres presenta es Maderuelo, que s olo conserva tres. Después le sigue Pedraza, con cuatro torres, de las cuales una parece haber sido reconstruida y la otra se integra en la puerta de la Villa, también alterada. En Coca suman ocho torres, una de ellas se hal evantado recientemente y no es original. Fuentidueña, Cuéllar y Sepúlveda poseen más de 15 tor res. En los casos de Cuéllar y Sepúlveda más de la mitad de l as torres forman parte de puer tas, por lo que teniendo en c uenta el importante número de puertas se explica el gran número de tor res. En el caso de Fuentidueña se produce un salto importante entre el número de accesos y el de torres, que se dispara en relación con las villas que compartían un número similar de puertas.

Las torres que s e conservan presentan plantas de for mas distintas. El número de torres de pl anta rectangular supera al de otr as formas excepto en $\mathrm{C}$ oca, donde se observan tres torres semicirculares, dos de ellas integrando la puerta de la Villa, frente a dos torres rectangulares. En el resto de casos, se observa un número muy superior de torres rectangulares. En Cuéllar y en Fuentidueña estas torres superan la decena y en Sepúlveda casi alcanzan la veintena.

Tabla 6.3. Elementos y dimensiones generales de lienzos estudiados. Fuente: Elaboración propia.

\begin{tabular}{|c|c|c|c|c|c|c|c|c|c|c|}
\hline & \multicolumn{2}{|c|}{ Altura $(m)^{*}$} & \multirow[b]{2}{*}{$\begin{array}{l}\text { Espesor } \\
(\mathrm{m})^{*}\end{array}$} & \multirow[b]{2}{*}{ Almenado } & \multirow[b]{2}{*}{$\begin{array}{l}\frac{\pi}{\pi} \\
\frac{\pi}{0} \\
0 \\
0\end{array}$} & \multicolumn{5}{|c|}{ Torres } \\
\hline & 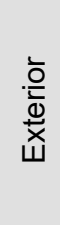 & 高 & & & & $\begin{array}{l}\bar{\sigma} \\
\frac{\pi}{0} \\
\frac{0}{0} \\
\frac{0}{\tilde{0}} \\
\frac{5}{z}\end{array}$ & 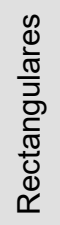 & 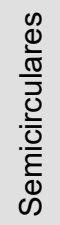 & 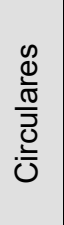 & $\begin{array}{l}\frac{\mathscr{0}}{0} \\
\frac{0}{0} \\
\overline{0} \\
\frac{.0}{0} \\
0\end{array}$ \\
\hline Coca & 10 & 9 & $\begin{array}{l}2,00-2,10 \\
(\bar{x}=2,05)\end{array}$ & Sí (L1) & 1 & $\begin{array}{c}8(2 \text { en } \\
\text { puerta, } 1 \\
\text { moderna) } \\
\end{array}$ & 2 & 3 & 0 & 1 \\
\hline Cuéllar & 12 & 10 & $\begin{array}{l}180-220 \\
(\bar{x}=2,00)\end{array}$ & Sí, reconstruido & 12 & $\begin{array}{l}16(10 \text { en } \\
\text { puertas })\end{array}$ & 12 & 2 & 0 & 1 \\
\hline Fuentidueña & 9 & 6 & $\begin{array}{c}90-130 \\
(\bar{x}=1,10)\end{array}$ & Sí & 3 & $\begin{array}{l}17 \text { ( } 5 \text { en } \\
\text { puertas })\end{array}$ & 10 & 6 & 1 & 0 \\
\hline Maderuelo & 10 & 8 & $1,50^{\star *}$ & Sí (P1) & 2 & 3 & 3 & 0 & 0 & 0 \\
\hline
\end{tabular}




\begin{tabular}{|c|c|c|c|c|c|c|c|c|c|c|}
\hline & \multicolumn{2}{|c|}{ Altura $(m)^{*}$} & \multirow[b]{2}{*}{$\begin{array}{l}\text { Espesor } \\
\qquad(\mathrm{m})^{*}\end{array}$} & \multirow[b]{2}{*}{ Almenado } & \multirow[b]{2}{*}{ 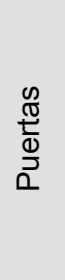 } & \multicolumn{5}{|c|}{ Torres } \\
\hline & 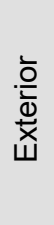 & 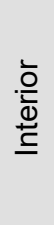 & & & & 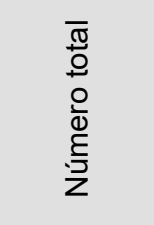 & 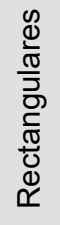 & 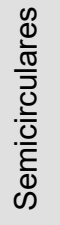 & 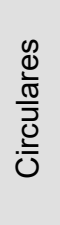 & 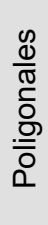 \\
\hline Pedraza & 9 & 9 & $\begin{array}{l}200-220 \\
(\bar{x}=2,10)\end{array}$ & Desaparecido & 2 & $\begin{array}{l}4 \text { (1 en } \\
\text { puerta) }\end{array}$ & 3 & 0 & 0 & 1 \\
\hline Sepúlveda & 7 & 1 & $\begin{array}{l}2,10-2,20 \\
(\bar{x}=2,15)\end{array}$ & $\begin{array}{l}\text { Sí, sin apenas } \\
\text { restos (P11- } \\
\text { oeste 200) }\end{array}$ & 9 & $\begin{array}{l}21 \text { (12 en } \\
\text { puertas) }\end{array}$ & 18 & 3 & 0 & 0 \\
\hline
\end{tabular}

* medidas tomadas en los tramos estudiados

** medida estimada de acuerdo con catastro.

$\bar{x}$ media aritmética

Las torres semicirculares son escasas y sólo en el caso de Fuentidueña alcanzan los seis ejemplares. Las murallas de Coca, Cuéllar o Sepúlveda tienen de dos a tres torres semicirculares. En Maderuelo y Pedraza no existe ninguna. En cuanto a torres circulares, solo se conserva una en Fuentidueña y se sitúa en una esquina del recinto, y su forma es muy similar a al gunas del as torres semicirculares. Las torres poligonales se encuentran tres casos, el primero en Coca, donde la torre forma un semidodecágono. En Cuéllar, la torre poligonal casi completa el contorno circular, con seis caras visibles. En el lado este se adosa a un v olumen rectangular. La tor re poligonal de Pedraza es casi exenta y tiene seis lados. Forma un hexágono irregular unido al lienzo en su lado oeste. Esta torre no parece guardar ninguna relación con las otras dos, aunque todas ellas sean poligonales. En los otros dos casos, se establece una relación también constructiva que se comenta más adelante.

Algunas de las torres rectangulares de estos recintos son similares entre sí, como ocurre entre las torres rectangulares de Coca (Fig. 6.14) y de Fuentidueña (Fig. 6.15). Ambas tienen dimensiones similares, poseen un fondo que casi alcanza los $3 \mathrm{~m}$ en el caso de Coca y que los supera ligeramente en el caso de Fuentidueña. La altura es superior en el caso de Coca, donde la torre T2 supera los $12 \mathrm{~m}$, con almenado visible, frente al caso de Fuentidueña, donde la torre T8 no I lega a los $10 \mathrm{~m}$, sin almenado conservado. Es posible que este último caso ganara 2 metros más con la coronación y el almenado que ha perdido. 
Las murallas en las Comunidades de Villa y Tierra de la Diócesis de Segovia en los siglos XI a XIII. Técnica y sistemas constructivos de la arquitectura defensiva medieval.

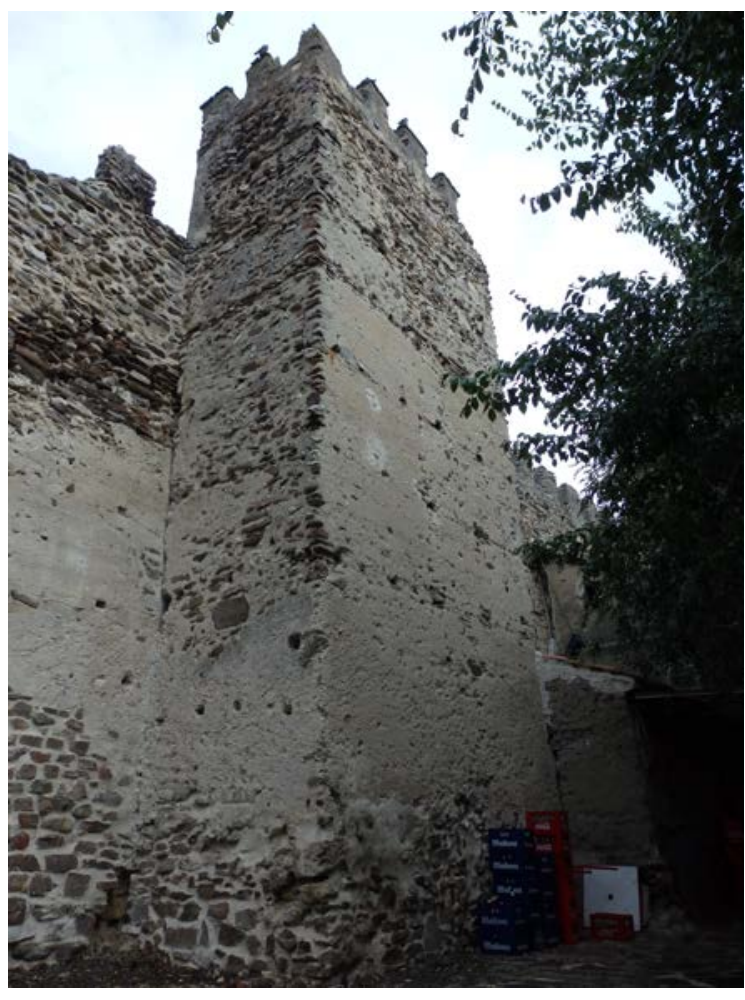

Fig. 6.14. Torre rectangular T2 en Coca

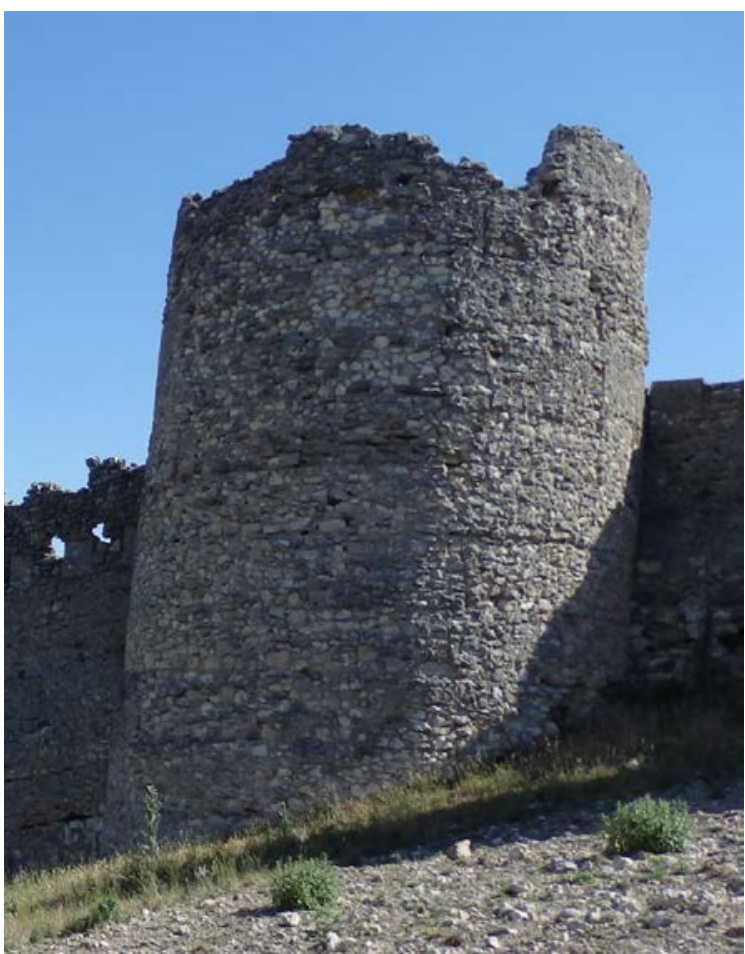

Fig. 6.16. Torre T6 de Fuentidueña [A.S.E. $17 / 6 / 2014]$

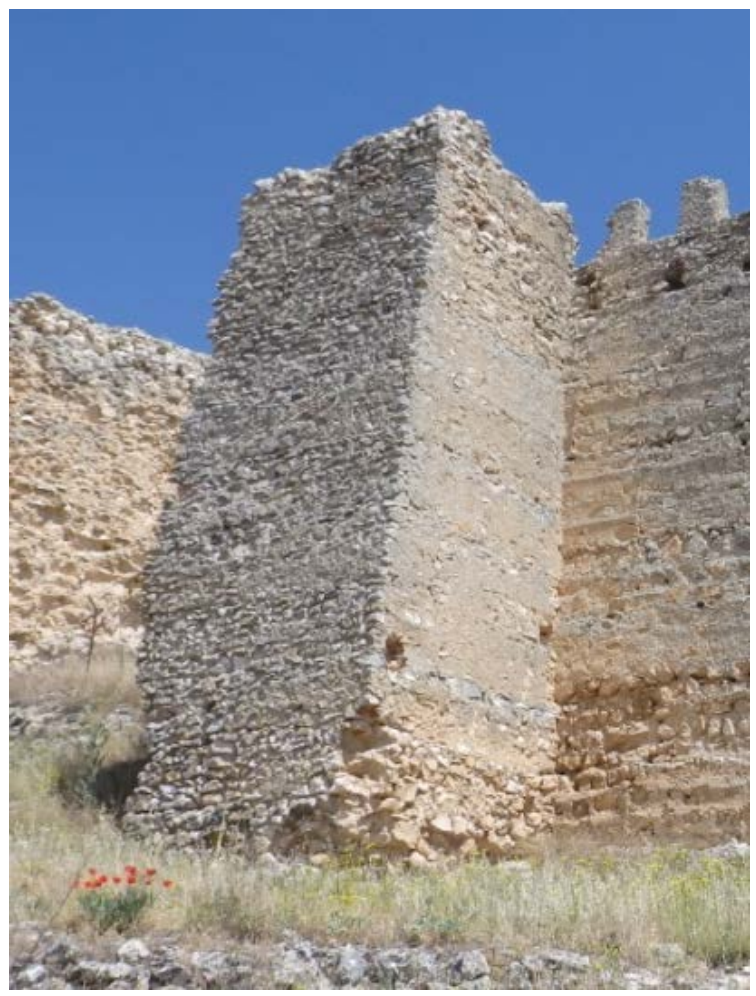

Fig. 6.15. Torre rectangular T8 en Fuentidueña

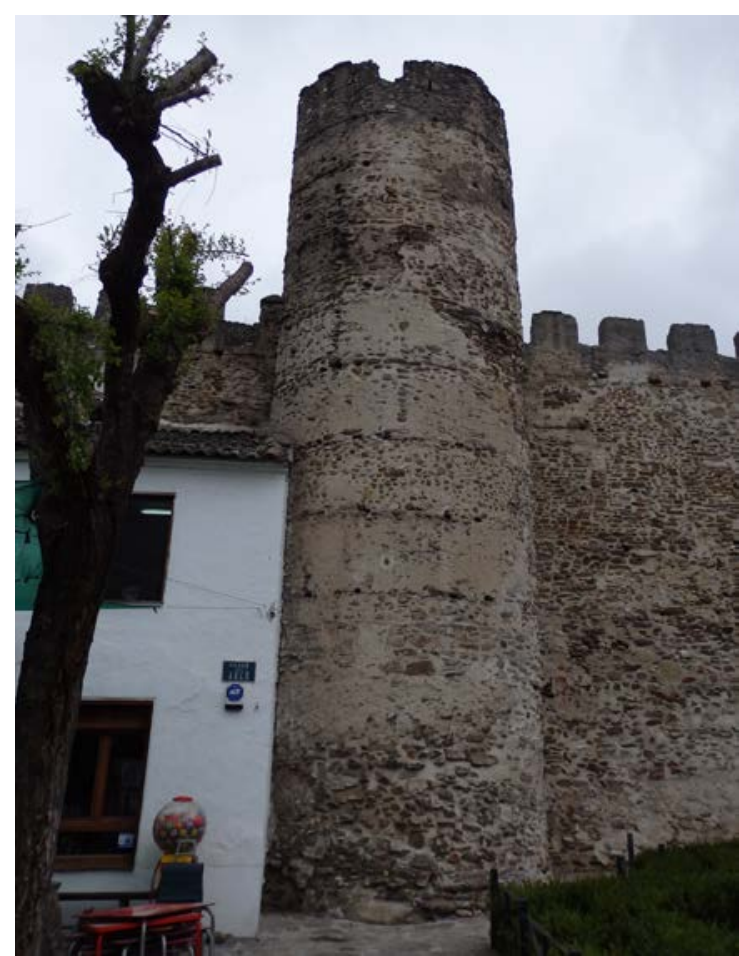

Fig. 6.17. Torre T3 de Coca [A.S.E. 24/7/2015]. 
En los dos casos se trata de tor res macizas que s e construyen con tapia de mampostería. En el frente de la torre T2 de C oca son visibles hasta seis mechinales en una de las hiladas, aunque sea habitual ver sólo cinco. En la torre T8 de Fuentidueña se ven en torno a cuatro o cinco mechinales por hilada de tapia. No parece existir integración de la torre T8 con el lienzo en el caso de Fuentidueña, las hiladas de tapia del lienzo son menores que las de la torre, no existe correspondencia, por lo que no se construyeron a la vez si no el lienzo en primer lugar y posteriormente la torre. En el caso de la torre T2 de Coca parece existir una correspondencia entre las tapias del lienzo y las de la torre, por lo que es posible que se construyeran de forma simultánea.

En el caso de las torres de planta semicircular, presentes en Fuentidueña (Fig. 6.16) y en Coca (Fig. 6.17), se observan diferencias notables, aunque ambas torres tengan la misma forma en planta. La masividad de las torres semicirculares de Fuentidueña no se repite en ningún caso, salvo tal vez en la torre T1 de Cuéllar (Fig. 6.19). El diámetro de estas torres es muy distinto, muy superior en el caso de la torre de Fuentidueña que casi alcanza los $10 \mathrm{~m}$, frente a los escasos $4 \mathrm{~m}$ de la torre de Coca.

La altura de la torre T3 de Coca supera los $13 \mathrm{~m}$ y la torre T6 de Fuentidueña apenas supera los $11 \mathrm{~m}$, aunque es posible que medida desde el lado norte se aproxime a los $13 \mathrm{~m}$. Esta diferencia se debe al desnivel de terreno en la zona donde se sitúa la torre T6 de Fuentidueña. Ambas torres se construyen con tapia de mampostería. En los dos casos se plantea la duda de cómo se realiza el encofrado de estas torres. Por una parte aparece la dificultad añadida de generar una forma curva y en s egundo lugar, para el caso de Fuentidueña, el tamaño del diámetro plantea la dificultad de llenar de material el interior. En el capítulo de Fuenti dueña, se han ex puesto algunas posibilidades de construcción de las tapias para conformar cada una de las hiladas de la torre.

En los casos señalados de tor res rectangulares y semicirculares, se observan tipologías arquitectónicas diferentes en las torres y un mismo sistema constructivo, la tapia de mampostería.

En la torre T2 de Pedraza (Fig. 5.5.17, pág. 307) se observa una base ataludada, visible de forma más evidente desde el frente. Pablo Rodríguez Navarro (2008) describe torres valencianas ataludadas como la torre de Muza (180), la torre de Raçef (189) o la torre de Alcàsser (209). Clasifica las cimentaciones de las torres estudiadas en dos tipos, el primero se apoya sobre una base de forma ataludada y el segundo se apoya en el suelo directamente con sus muros (248). Indica que la elección de un tipo y otro depende de la resistencia del terreno, de manera que cuando este tiene escasa resistencia, la ampliación de la base de la torre con un talud realiza un reparto de menor carga por unidad de superficie. En el caso de la torre T2 de Pedraza no se ha determinado si la elección de esta base se debe a una menor resistencia del terreno, ya que el terreno en este asentamiento es principalmente rocoso. 


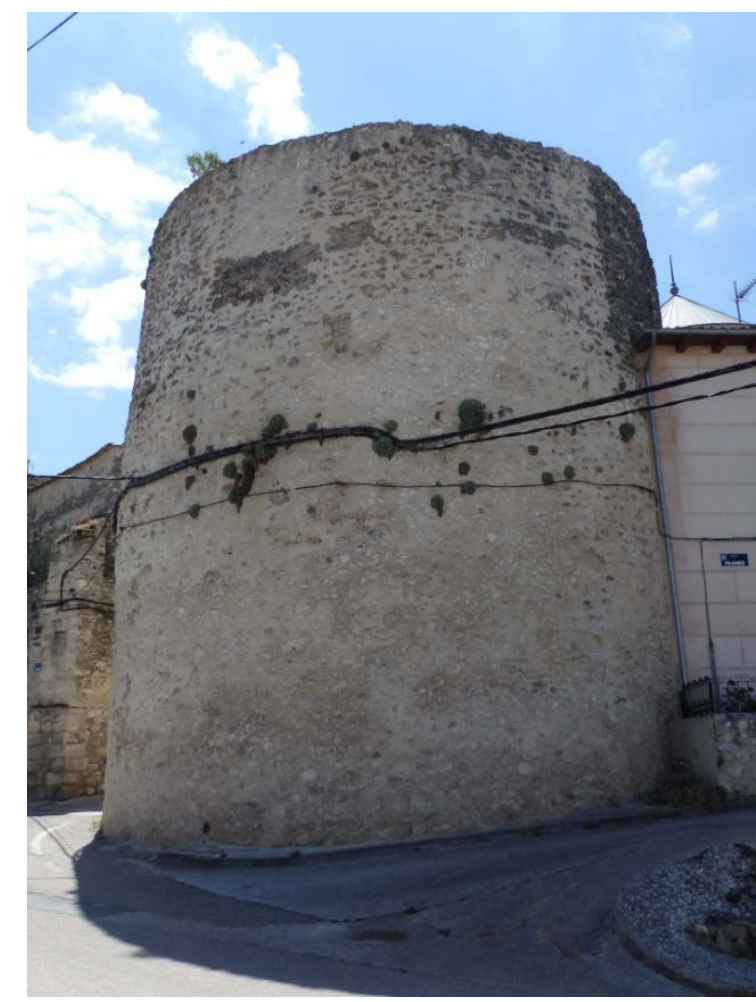

Fig. 6.18. Torre T15 circular de Fuentidueña

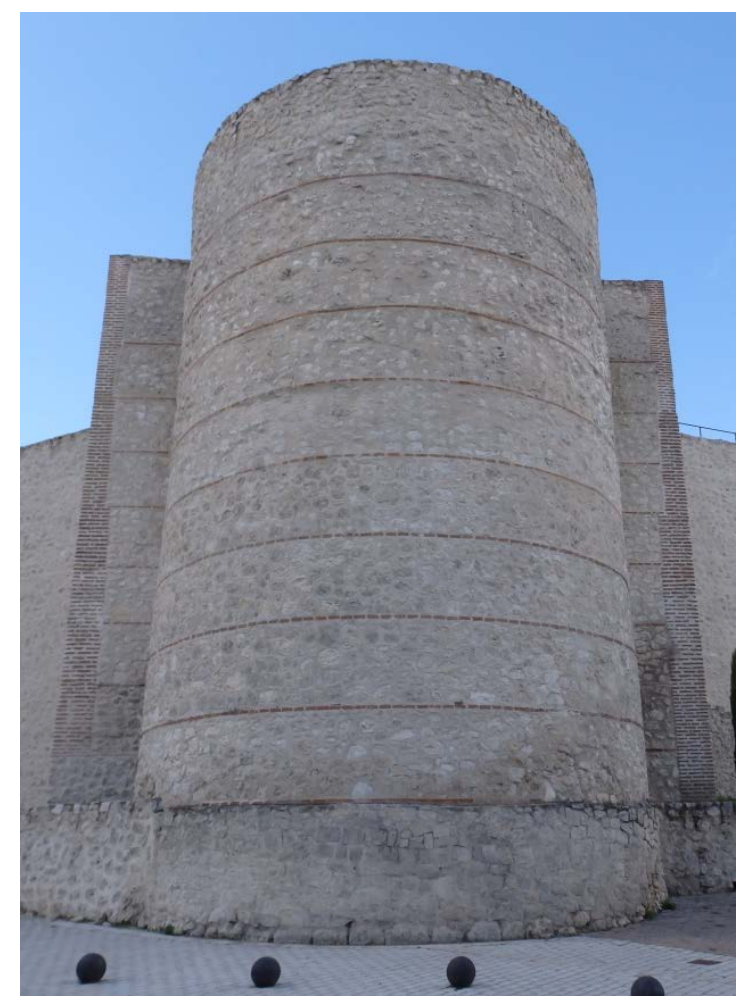

Fig. 6.19. Torre T1 de Cuéllar

- Torres macizas y torres huecas

Los ejemplos de torres que se han comentado para ilustrar las similitudes existentes tienen en común la característica de que la gran mayoría de ellas son macizas. Los casos de torres huecas que albergan un espacio en su interior son menores. En Coca, no se encuentran torres huecas en el recinto amurallado. En Cuéllar, algunas torres poseen un espacio interior como la torre T7; la torre T1 tiene un pasillo que atraviesa su base y en la puerta P1 existe un acceso con escaleras para alcanzar la salida al adarve. En Fuentidueña solo la torre T15 (Fig. 6.18) muestra una puerta a la altura de una primera planta que puede at estiguar la existencia de un e spacio interior. En fotografías antiguas se observa en ese punto un huec o que $r$ ecuerda un desprendimiento o un agujero. El resto de torres son macizas. En Maderuelo las torres T1 y T2 son huecas y es posible que las torres de flanqueo de la puerta de la Villa también lo fueran, de acuerdo con las marcas que se conservan en el lienzo. En Pedraza, la torre que flanquea la puerta de la villa es una construcción que alberga un uso interior y en el caso de la torre T4, el pozo de Hontanillas, también existe un espacio interior. En Sepúlveda las torres que flaquean la puerta del Río contienen un espacio interior en cada una de sus torres. 


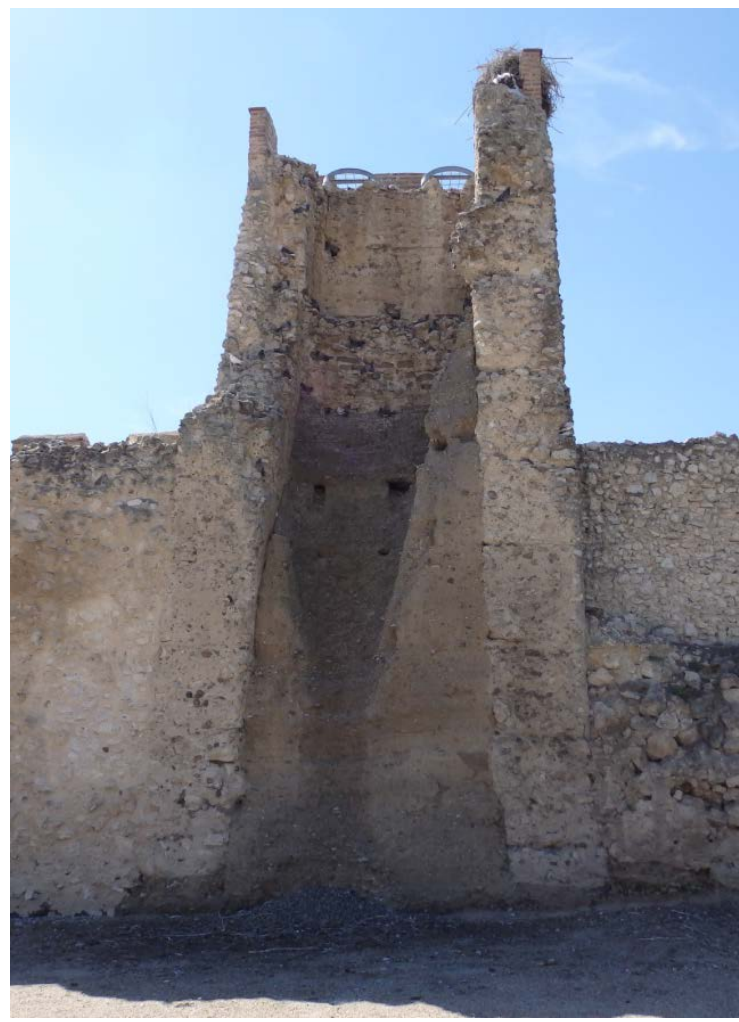

Fig. 6.20. Torre del recinto amurallado de Olmedo (Valladolid), visible desde el interior en el patio del Palacio del Caballero de Olmedo [A.S.E 1/9/2014].

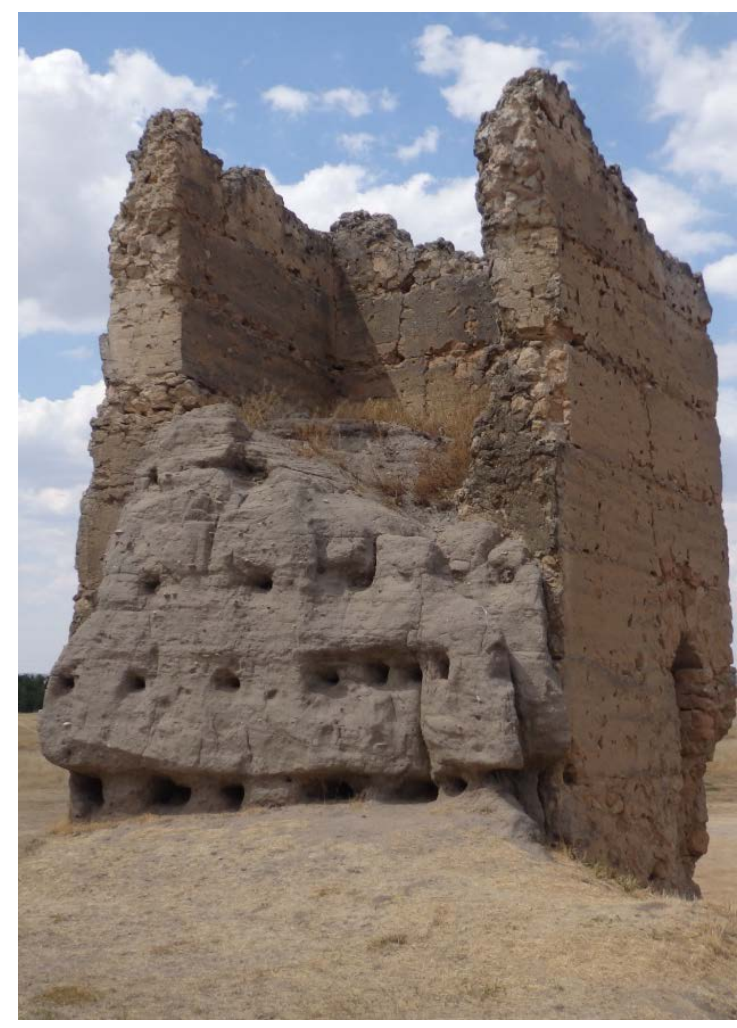

Fig. 6.21. Torre de la muralla del castillo de Turégano, Segovia. [A.S.E. 15/8/2016].

En los casos analizados no se han encontrado casos de torres que tengan el interior construido con tierra. En otras murallas de villas cercanas, como Olmedo (Valladolid), se encuentran torres de planta rectangular cuyo interior es diferente de los muros exteriores y se compone de tierra. Una de las torres situadas a la altura del palacio del Caballero de Olmedo, desde cuyo patio es posible ver la cara interior de la muralla, muestra el interior construido con tierra (Fig. 6.20). En este caso, se trata de diferenciar si la tierra visible se empleó como relleno o si, por el contrario, existió originalmente unator re de ti erra que $s$ e forró posteriormente con tapia de mampostería. Tal y como se ve en la actualidad, la parte de tierra no sobrepasa los muros de tapia de mampostería, sino que am bas fábricas quedan i gualadas en un mismo plano. La parte de tierra tiene algunos huecos en el paramento, visibles en la parte superior. También se adivinan tongadas, pequeñas hiladas de es casos centímetros altura, capas de tierra horizontales. En la vista interior de esta torre, se observa cómo los lienzos a cada lado se apoyan sobre la torre, es posible plantear que los muros de la torre ya estaban construidos cuando se construyeron los lienzos.

Otro caso cercano es el de las torres del castillo de Turégano (Fig. 6.21), en Segovia, que tienen una forma rectangular en planta. En su interior se observan tapias de tierra, que sobresalen del plano de la torre. La tapia de mampostería parece forrar una torre de tierra. Las tapias que sobresalen del plano podrían constituir una antigua muralla de tapia de tierra. 
Las murallas en las Comunidades de Villa y Tierra de la Diócesis de Segovia en los siglos XI a XIII.

Técnica y sistemas constructivos de la arquitectura defensiva medieval.

\section{- Distancia entre las torres}

La distancia a la que se sitúan las torres no es fácilmente medible en los casos estudiados, ya que no se conserva gran número de torres próximas entre sí. En Fuentidueña se observan distancias a ejes cercanas a los $30 \mathrm{~m}$ entre las torres rectangulares del tramo P3-T11. Las torres semicirculares se separan distancias más dispares, de $30 \mathrm{~m}$, más de $50 \mathrm{~m}$ o que apenas superan los $15 \mathrm{~m}$. En Coca, las torres rectangulares T1 y T2 se separan $25 \mathrm{~m}$. La distancia se reduce a 20 entre T2 y T3, similar a la distancia entre T3 y la puerta de la Villa. En Cuéllar la zona entre la puerta de Santiago y de San Martín tiene separaciones que rondan los 45m. En Maderuelo la distancia entre el torreón del Oeste y la puerta de la Villa es de una treintena de metros. En Pedraza, la primera torre más cercana a la puerta de la Villa se sitúa a $42 \mathrm{~m}$.

Tabla 6.4. Distancias entre las torres de cada recinto analizado. Solo se han contemplado las torres próximas entre sí, separadas por distancias menores de $65 \mathrm{~m}$. La distancia está medida a ejes de las torres. Fuente: Elaboración propia.

\begin{tabular}{|c|c|c|c|c|c|c|c|c|c|c|c|}
\hline \multicolumn{2}{|c|}{ Coca } & \multicolumn{2}{|c|}{ Fuentidueña } & \multicolumn{2}{|c|}{ Cuéllar } & \multicolumn{2}{|c|}{ Maderuelo } & \multicolumn{2}{|c|}{ Pedraza } & \multicolumn{2}{|c|}{ Sepúlveda } \\
\hline Tramo & (m) & Tramo & $(\mathrm{m})$ & Tramo & $(\mathrm{m})$ & Tramo & (m) & Tramo & (m) & Tramo & $(\mathrm{m})$ \\
\hline $\mathrm{T} 1-\mathrm{T} 2$ & 25 & T1-T2 & 58 & $\mathrm{~T} 1-\mathrm{T} 2$ & 24 & T1-P1 & 31 & P1-T1 & 42 & $\mathrm{~T} 1-\mathrm{T} 2$ & 25 \\
\hline T2-T3 & 21 & T2-T3 & 36 & T6-T7 & 46 & & & & & T3-T4 & 25 \\
\hline T3-T6 & 17 & T3-T4 & 9 & T7-T8 & 45 & & & & & T4-T5 & 23 \\
\hline T7-T5 & 28 & T4-T5 & 28 & & & & & & & T5-T6 & 8 \\
\hline & & T5-T6 & 53 & & & & & & & T9-T10 & 64 \\
\hline & & T6-T7 & 17 & & & & & & & T18-T17 & 17 \\
\hline & & T9-T13 & 28 & & & & & & & T17-T16 & 21 \\
\hline & & T14-T10 & 28 & & & & & & & & \\
\hline & & T10-T11 & 27 & & & & & & & & \\
\hline
\end{tabular}

En la Tabla 6.4 se ha marcado en colores las medidas que guardan relación. En rojo destacan las distancias que rondan los $15-20 \mathrm{~m}$. En verde se sitúan aquellas que rondan los $25-30 \mathrm{~m}$ y que son las más habituales. En naranja se muestran las medidas que rondan los $45 \mathrm{~m}$. En azul se reflejan aquellas distancias que se aproximan a $60 \mathrm{~m}$. En morado se indican aquellas que no l legan a la decena de metros, sólo visibles en dos recintos. Se han dejado en blanco algunas distancias que no es posible agrupar en los colores mencionados. Aunque hay distintas separaciones entre torres, es visible una repetición más intensa de la separación que oscila entre 25 y $30 \mathrm{~m}$, visible en 12 tramos y con al menos un caso en todos los recintos, a excepción de Pedraza. Las otras distancias indicadas se ven en menor frecuencia.

Ya se ha indicado con anterioridad la existencia de tramos muy largos que no ti enen torres. La ausencia de torres en largas distancias es visible en casos como Fuentidueña, Cuéllar o Sepúlveda. En estos casos, la ausencia no se debe a la pérdida de la torre por demolición o desaparición. En Coca es visible la pérdida de la torre $\mathrm{T} 5$ en el lienzo L1; quedan marcas en el paramento que hacen pensar en la existencia de un torreón. En el caso de Cuéllar, el tramo sur que parte del castillo tiene 
una gran longitud y no se observan marcas o restos que atestigüen que existieron torres en su trazado. Tampoco se observan tales marcas en el tramo al oeste de la puerta de Duruelo, en Sepúlveda. En Fuentidueña existen varias torres a lo largo de recorrido amurallado. Las torres T5 y T9 han perdido su parte superior, sobresaliendo la muralla por encima de la altura de las torres. Originalmente, es probable que las torres superasen la altura del lienzo, como ocurre en las torres T6 y T7. El aspecto del muro en la zona sobre las torres T5 y T9 no se diferencia del resto del lienzo, de manera que si hubieran existido torres similares a lo largo del lienzo, no se podrían localizar por el aspecto del paramento. Esta cuestión parece apoyar lo que s e ha planteado anteriormente, que el lienzo se construyó con anterioridad a las torres, teniendo entonces más de un centenar de metros de recorrido sin torres. En los casos de Pedraza o M aderuelo no es fácil aventurar si existieron grandes longitudes de lienzo sin torres. Los recintos amurallados sin torres son conocidos en varios puntos al norte del Duero. El caso de San Pedro de Latarce presenta una cerca completa de más de $7.000 \mathrm{~m}^{2}$, con un per ímetro de $\mathrm{p}$ oco más de $300 \mathrm{~m}$, con forma de c írculo deformado sin ninguna torre. También se realiza con tapia y sus lienzos tienen gran altura. En León tam bién se observa un recinto cercado con una muralla sin torres, cuyo perímetro no alcanza los $200 \mathrm{~m}$. Estos ejemplos presentan longitudes de lienzos menores de las visibles en las murallas estudiadas y formas en planta cuyas curvas contribuyen a dotar de mayor resistencia a los lienzos. Las longitudes sin torres en los casos estudiados tienen un trazado en línea recta durante centenas de metros.

\section{- Integración / independencia torre-lienzo}

La relación de las torres con los lienzos a los que pertenecen es otra variable que permite establecer relaciones y diferencias entre los recintos estudiados. En Fuentidueña, las torres semicirculares se separan físicamente de los lienzos algunos centímetros, a raíz del avance del deterioro del conjunto. Esta separación muestra la independencia lienzo-torre a ni vel constructivo de for ma muy evidente. El ejemplo señalado anteriormente de las torres que han perdido altura y muestran el lienzo sobre ellas también apoya la independencia torre-lienzo. Otros casos no son tan evidentes y es necesario buscar otros indicios. En el caso de la torre rectangular T8 del mismo conjunto, ya se ha señalado con anterioridad la diferencia en altura de hiladas de tapia entre el lienzo y la torre, resultando mayor en el caso de la torre. Esta diferencia señala una etapa constructiva diferente entre los dos elementos, ya que parece lógico pensar que si se realizasen torre y lienzo a la vez se emplearía tapial de la misma altura en los dos casos. Siguiendo este mismo razonamiento, se puede argumentar la integración de las torres rectangulares T10 y T11 de Fuentidueña con el lienzo, ya que se produce una continuidad en las hiladas de tapia del lienzo y de las torres. En el caso de Coca, las torres T1 y T2 muestran la misma continuidad de hiladas con el lienzo, por lo que también parecen pertenecer a una misma etapa constructiva. 


\subsubsection{Almenado}

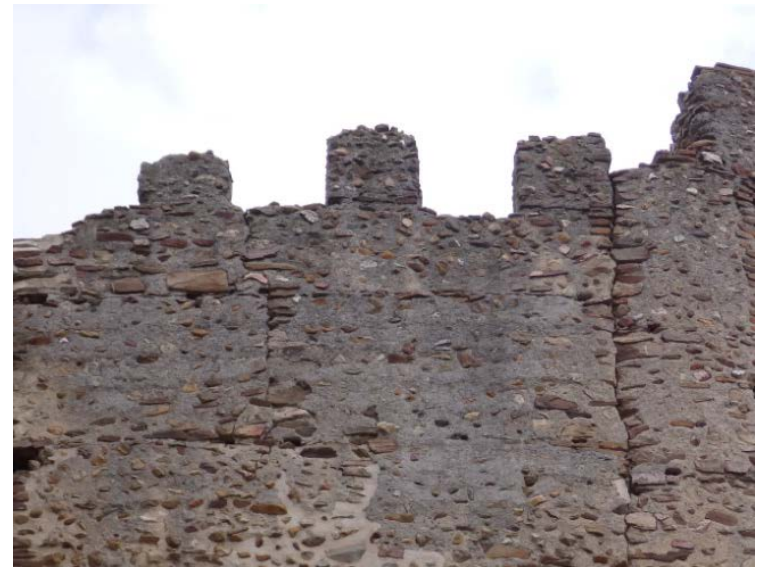

Fig. 6.22. Almenas en un lateral de la puerta de la Villa, en Coca [A.S.E. 2/11/2014].

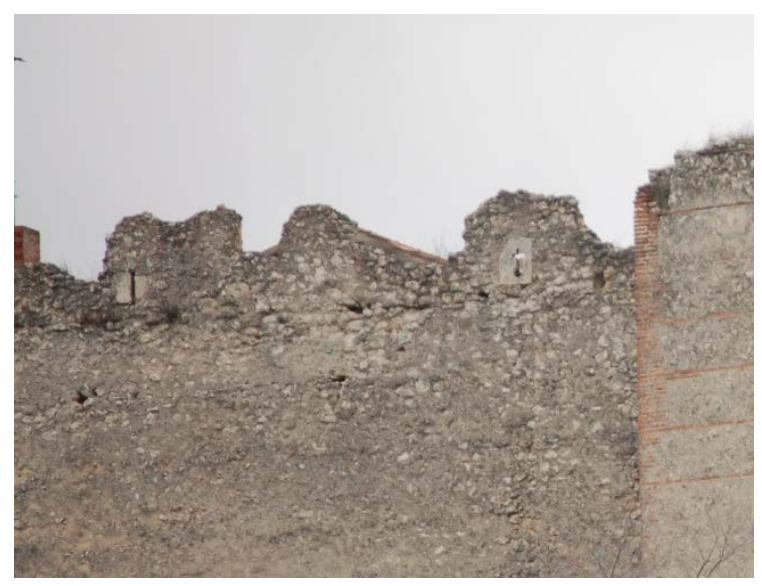

Fig. 6.24. Almenado de Cuéllar antes de su restauración, junto a la torre T6. Fuente: Fotografía facilitada por Fernando Nieto y Jesús Nieto.

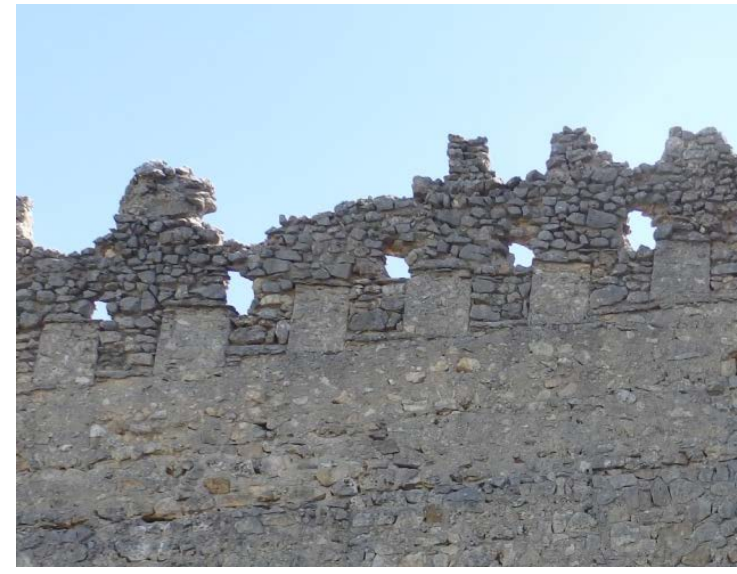

Fig. 6.23. Almenas en Fuentidueña en el lienzo T5-T6 [AS.E. 17/6/2014].

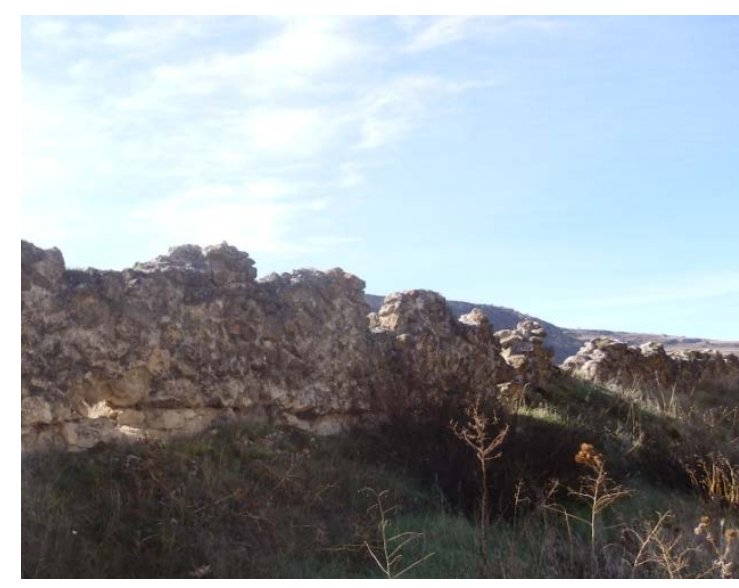

Fig. 6.25. Posibles restos de almenado en Sepúlveda

En varios de los ejemplos se conserva almenado o restos de él. En Maderuelo solo se observa almenado en la puerta de la Villa y en Pedraza no se conservan apenas restos de almenado, solo en la torre de Hontanillas, de una época y con características diferentes de los elementos analizados en esta investigación. Las almenas visibles en Fuentidueña y en Coca son de pequeño tamaño y proporción prácticamente cuadrada.

El almenado de Cuéllar muestra una configuración mucho más elaborada que el resto. Las almenas son bastante más anchas que el hueco entre ellas. Presentan sillares de piedra que cierran sus lados y en su centro aparece una saetera cruciforme tallada en piedra. Es llamativo que esta solución aparezca en prácticamente todo el recinto, independientemente de que I a restauración de 2007 I as haya reconstruido con esa forma. En el primer recinto es visible esta configuración en el tramo P6-oeste (Fig. 6.24) y también en la zona de la puerta de la judería (Fig. 6.26). En la zona sur se observa un almenado diferente del resto, donde las almenas tienen proporción cuadrangular (Fig. 6.27). La configuración de I as almenas no per mite establecer relaciones claras entre los distintos recintos amurallados. El ejemplo de $\mathrm{C}$ uéllar se 
distancia de todos los casos, la configuración de sus almenas no se repite en las otras murallas. Por otra parte, el almenado es una parte de la muralla que fácilmente puede haberse visto sujeto a modificaciones, por tratarse de la zona superior del muro. El hecho de que en am bos recintos de $C$ uéllar se observe el mismo almenado, tan singular por otra parte, parece sugerir que en al gún momento se unificó. La inclusión de sillería en el almenado sugiere que hay una i ntención decorativa o de ennoblecimiento de los lienzos, a través del empleo de piedra tallada en las esquinas y en las saeteras. Es posible que la construcción de estas almenas respondiera ya no sólo a una razón defensiva sino también a una nec esidad de representación o de muestra de potencia económica.

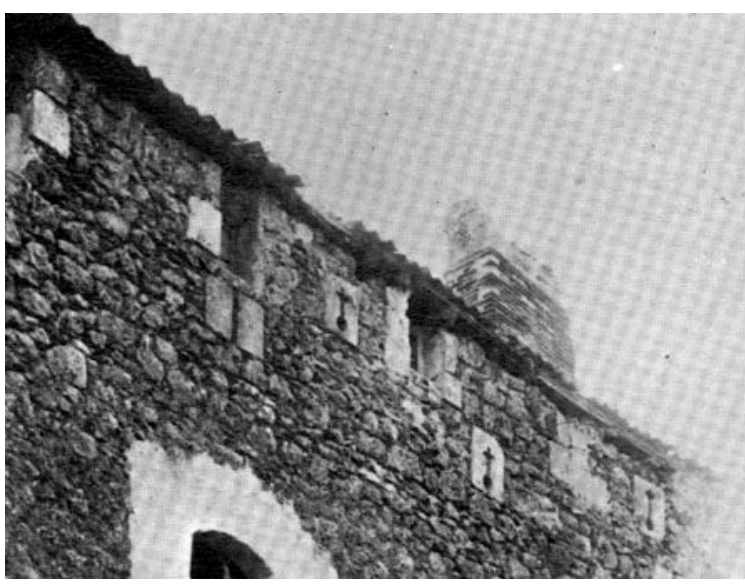

Fig. 6.26. Detalle de fotografía antigua junto a la puerta de la Judería. Fuente: Fotografía facilitada por los arquitectos Fernando Nieto y Jesús Nieto.

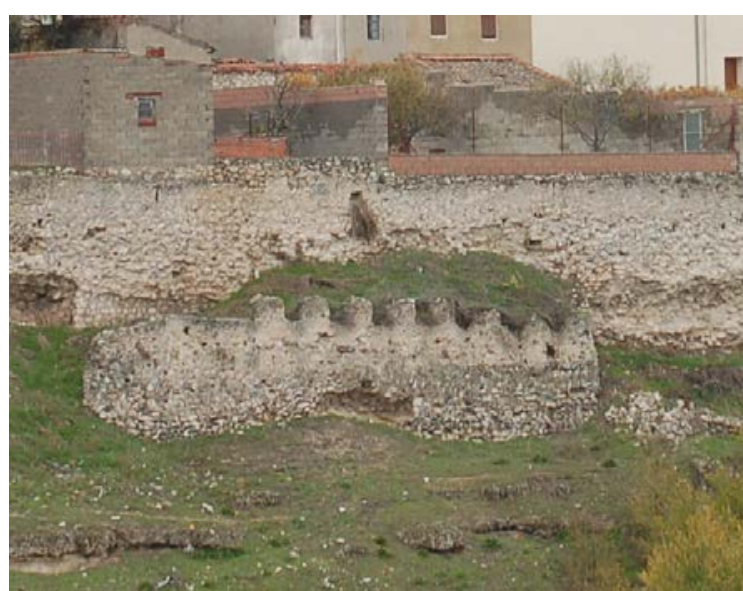

Fig. 6.27. Almenado de proporción cuadrada en la barbacana de la zona sur del recinto de Cuéllar. Fuente: Fotografía facilitada por los arquitectos Fernando Nieto y Jesús Nieto.

La relación entre anchuras de almena y huecos entre almenas se acerca al valor 1 en la mayoría de los casos, superándolo en el caso de $\mathrm{C}$ oca y sin llegar a él en Fuentidueña. En el caso de C uéllar esta relación se dispara llegando al valor 5, mostrando que la anchura de la almena es cinco veces superior al espacio entre ellas. Las dimensiones de cada almena varían de un ejemplar a otro, habitualmente con más de $10 \mathrm{~cm}$ de diferencia, por lo que se ha estimado un valor aproximado de las dimensiones de altura, anchura y anchura de hueco entre almenas (Tabla 6.5). En el caso de Sepúlveda los restos de almenado se encuentran muy desdibujados, por lo que no es posible realizar una medición que sea fiable.

Tabla 6.5. Dimensiones de altura y anchura del almenado. Las medidas han sido tomadas en los tramos estudiados. Fuente: Elaboración propia.

\begin{tabular}{|l|c|c|c|c|c|}
\cline { 2 - 5 } \multicolumn{1}{c|}{} & $\begin{array}{c}\text { Altura de } \\
\text { almena } \\
(\mathrm{cm})\end{array}$ & $\begin{array}{c}\text { Anchura de } \\
\text { almena } \\
(\mathrm{cm})\end{array}$ & $\begin{array}{c}\text { Anchura de } \\
\text { hueco entre } \\
\text { almenas }(\mathrm{cm})\end{array}$ & $\begin{array}{c}\text { Relación entre } \\
\text { anchura de almena y } \\
\text { hueco }\end{array}$ & $\begin{array}{c}\text { Sistema } \\
\text { constructivo }\end{array}$ \\
\hline Coca & 68 & 75 & 55 & 1,36 & $\begin{array}{c}\text { Tapia de } \\
\text { mampostería }\end{array}$ \\
\hline
\end{tabular}


Las murallas en las Comunidades de Villa y Tierra de la Diócesis de Segovia en los siglos XI a XIII. Técnica y sistemas constructivos de la arquitectura defensiva medieval.

\begin{tabular}{|c|c|c|c|c|c|}
\hline & $\begin{array}{l}\text { Altura de } \\
\text { almena } \\
(\mathrm{cm})\end{array}$ & $\begin{array}{l}\text { Anchura de } \\
\text { almena } \\
(\mathrm{cm})\end{array}$ & $\begin{array}{l}\text { Anchura de } \\
\text { hueco entre } \\
\text { almenas }(\mathrm{cm}) \\
\end{array}$ & $\begin{array}{c}\text { Relación entre } \\
\text { anchura de almena y } \\
\text { hueco }\end{array}$ & $\begin{array}{c}\text { Sistema } \\
\text { constructivo }\end{array}$ \\
\hline Cuéllar & 100 & 200 & 40 & 5,00 & $\begin{array}{c}\text { Tapia de } \\
\text { mampostería con } \\
\text { sillería en } \\
\text { esquinas }\end{array}$ \\
\hline Fuentidueña & 80 & 70 & 80 & 0,88 & $\begin{array}{c}\text { Tapia de } \\
\text { mampostería }\end{array}$ \\
\hline Maderuelo & 60 & 75 & 70 & 1,07 & Mampostería \\
\hline Pedraza & - & - & - & - & - \\
\hline Sepúlveda & - & - & - & - & $\begin{array}{c}\text { Tapia de } \\
\text { mampostería }\end{array}$ \\
\hline
\end{tabular}

\subsubsection{Base de las murallas}

En todos los ejemplos estudiados se observa el reaprovechamiento de anti guas defensas, sobre las que se construye las nuevas, o que se modifican recreciéndose con nuevas formas. Este reaprovechamiento es visible en las bases de muchos de los lienzos, puertas y torres. También se observa la ubicación de murallas medievales siguiendo el trazado de murallas antiguas. En el caso de Coca la muralla medieval sigue, al menos en una zona, el mismo recorrido que la muralla vaccea. Por otra parte también se observan lienzos que crecen directamente sobre la roca, que no aprovechan otras construcciones existentes, sino que s e yerguen como obra de primera planta. En estos casos, sorprende la ausencia de cimentaciones. Cuando no se observan preexistencias, tampoco se ve una preocupación por construir una base sobre la que luego se construya el lienzo.

\section{- Preexistencias en las murallas}

En las bases de muchos lienzos y torres se encuentran lo que podría denominarse discontinuidades, zócalos construidos con materiales o formas diferentes. Se ven, por ejemplo, aparejos de sillería o también se observan resaltes en las bases de los muros, denominados zarpas por otros investigadores (Martín Aymerich 1990, 49; Martín Blanco 2014, 150). En algunos casos se observa una sillería relativamente homogénea, en otros se ve una sillería heterogénea en material, en forma y dimensiones. Se trata de elementos que se han reaprovechado para la construcción de nuevas murallas, a par tir de I a reutilización de piedras obtenidas de o tras construcciones o bien construyendo directamente sobre los restos de una construcción anterior.

La reutilización de material se observa a través de la aparición, en las bases de las murallas, de sillares de granito o de piedra caliza, colocados sin orden aparente, en ocasiones de forma aislada. Cuando se observan aparejos, las proporciones y tamaños de las piedras son distintos en cada caso, aunque se observa una selección de los sillares para conseguir hiladas de la misma altura, o para hacer coincidir aristas. Los vértices y aristas de los sillares reutilizados son redondeados, están desgastados y erosionados. 


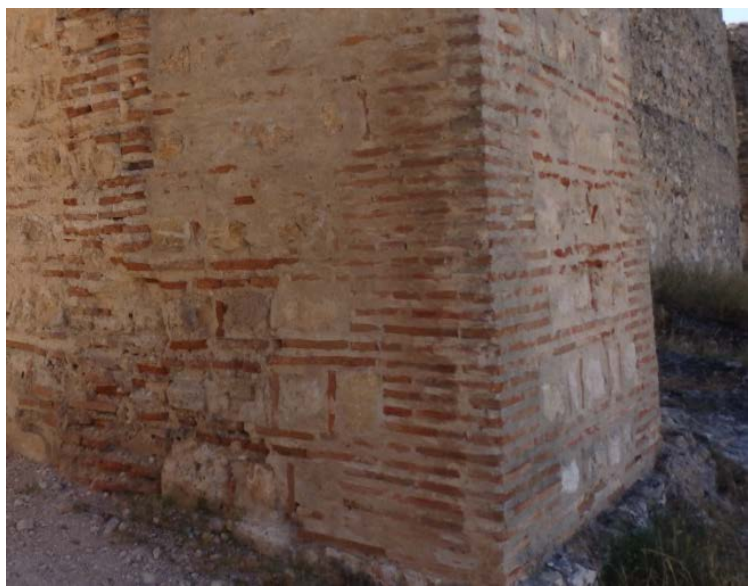

Fig. 6.28. Mampostería encintada en la torre T9 de Fuentidueña, integrante de la puerta de Alfonso VIII [A.S.E 24/7/2016].

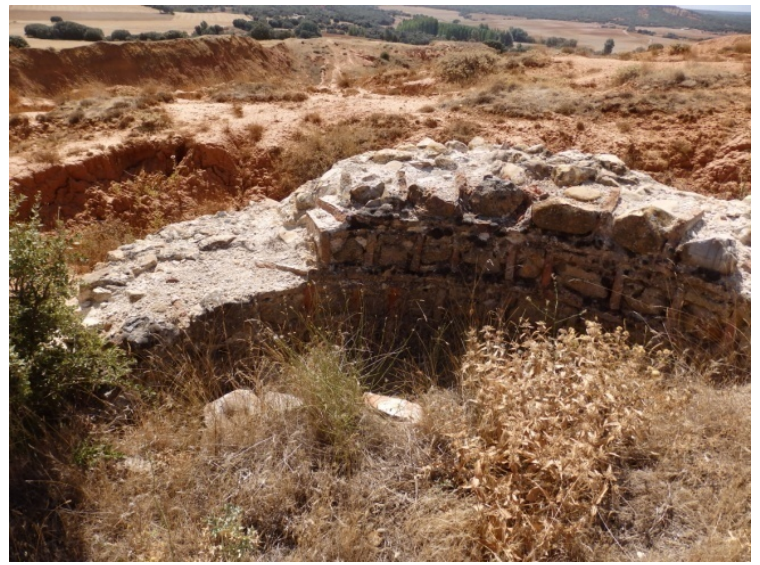

Fig. 6.30. Mampostería encintada en la cara interior del muro semicircular en Fresno de Cantespino [A.S.E 3/9/2014].

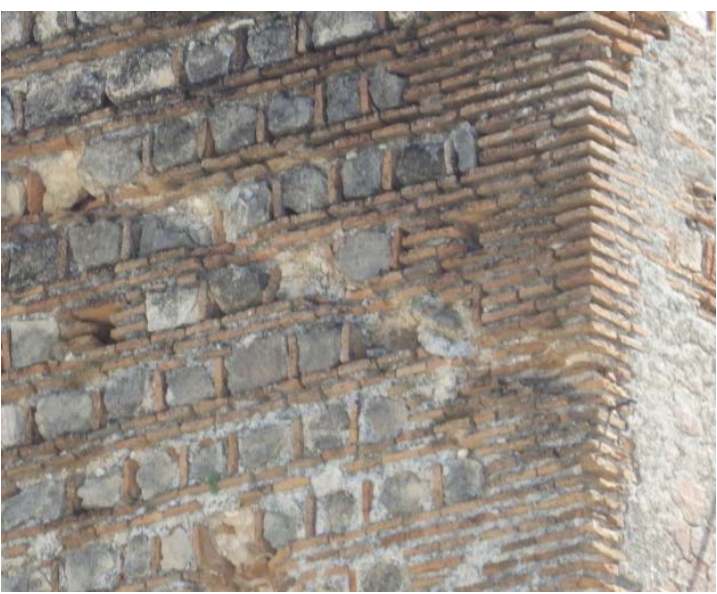

Fig. 6.29. Mampostería encintada en la posible torre en el interior del recinto de Sepúlveda [A.S.E $24 / 7 / 2016]$.

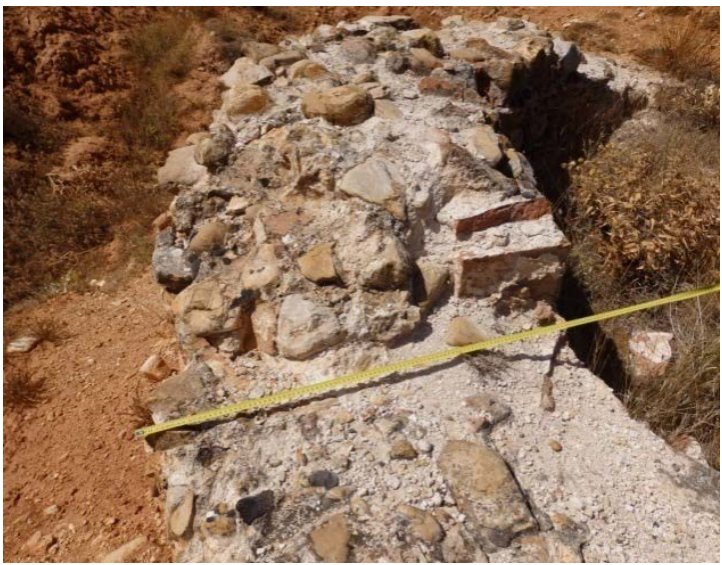

Fig. 6.31. Sección del muro, donde se ve uno de los ladrillos que encintan por la cara interior en Fresno de Cantespino [A.S.E 3/9/2014].

Las construcciones consideradas como preexistentes emplean técnicas que se observan en $r$ ecintos amurallados diferentes, aunque no es fácil relacionar directamente las técnicas encontradas en las distintas villas. Un ejemplo es la técnica de la mampostería encintada en ladrillo, presente en la base de las torres de la puerta de Fuentidueña. Esta técnica se encuentra también en los muros de una construcción del recinto amurallado de $S$ epúlveda, que po dría haber sido una torre, dadas sus características. M. Dolores Martín Aymerich et al. $(1990,134)$ ya establecieron esta relación en los años noventa, mencionando además los casos de Ayllón, Fresno de Cantespino y Segovia e indicando que este sistema constructivo implica "la presencia de mano de obra árabe" en esas construcciones. Alonso Zamora y Fernando Vela (2005, 1138-1143) establecen esta relación entre estas construcciones incluyendo otros ejemplos de la geografía española. 


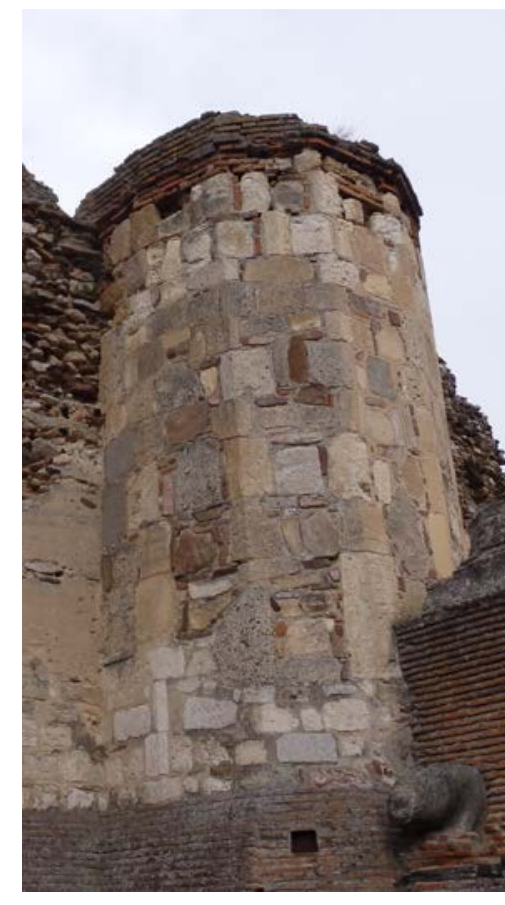

Fig. 6.32. Torre T8 en Coca [A.S.E 2/11/2014].

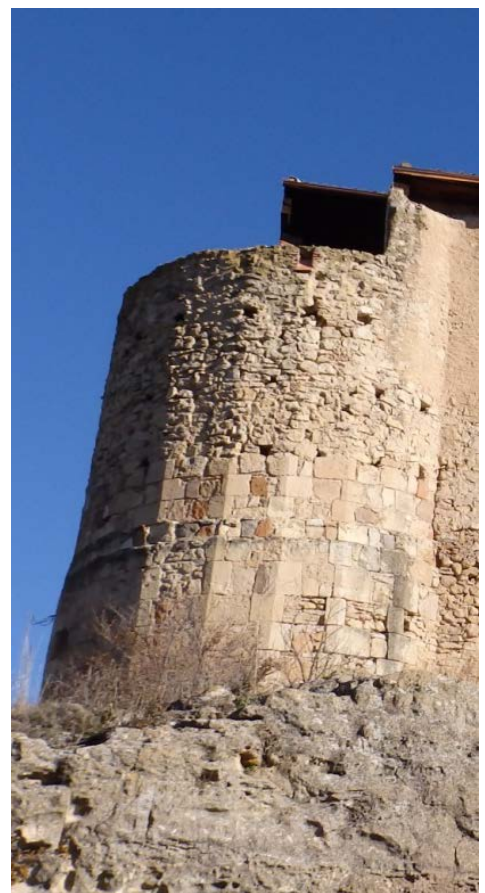

Fig. 6.33. Torre T81 en el recinto amurallado de Segovia [A.S.E 30/12/2014].

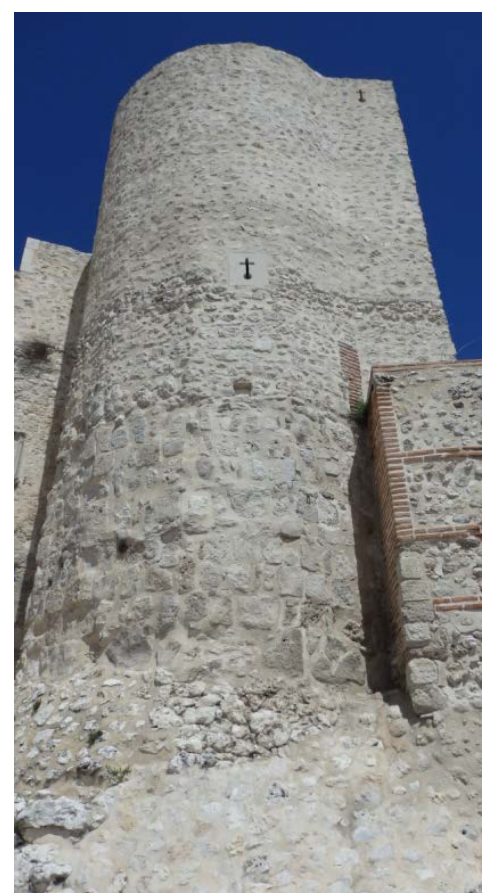

Fig. 6.34. Torre T8 de Cuéllar, en la puerta de Santiago [A.S.E $12 / 5 / 2016]$.

Otra relación existente entre técnicas preexistentes es la señalada por el investigador Miguel Ángel Martín Blanco $(2014,167)$, que establece una analogía entre la torre T8 del recinto amurallado de Coca, situada junto al castillo, y la base de la torre que numera como T81 del recinto amurallado de S egovia. La torre T8 del recinto amurallado de $\mathrm{C}$ uéllar tiene una planta también poligonal y el aparejo tiene semejanzas con el existente en los otros dos casos. Los casos de Coca y Segovia tienen una característica muy particular y es la alineación de piedras talladas en las aristas verticales de la torre. En el caso de Cuéllar, no se observan esas piedras talladas, sino que con otras piedras aparejadas se consigue crear la forma poligonal. No obstante, la parte superior de la torre T81 resuelve las aristas de forma similar a la visible en la torre T8 de Cuéllar, conservando los planos que vienen dados por la forma de la base, pero con lo que parece tapia de mampostería.

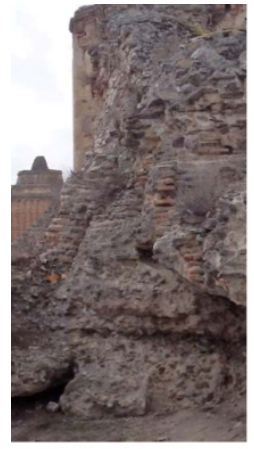

1. Coca

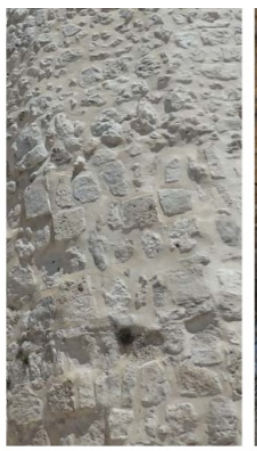

2.Cuéllar

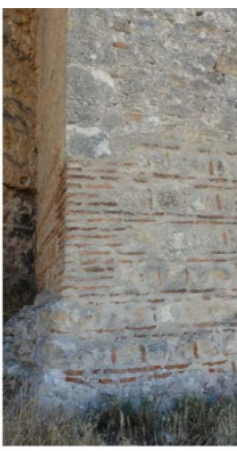

3. Fuentidueña

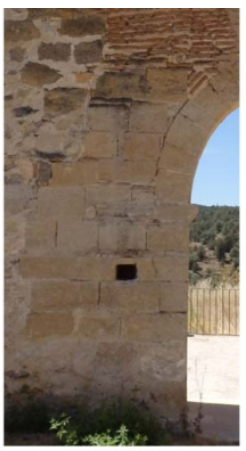

4. Pedraza

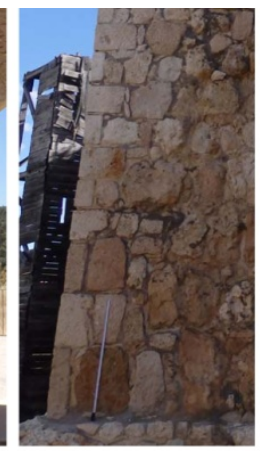

5. Maderuelo

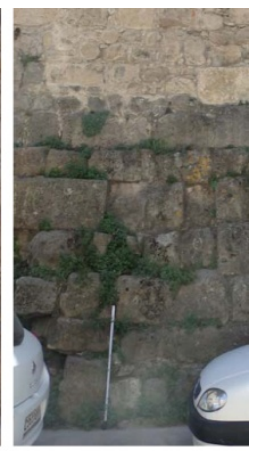

6. Sepúlveda

Fig. 6.35. Bases de lienzos, puertas y torres con preexistencias. Fuente: Elaboración propia. 
Estas fábricas o apar ejos singulares, este reempleo de sillares ajustados como un puzle o estas soluciones constructivas con ladrillo enmarcando piedras adquieren mayor interés por el hecho de s on raras, aisladas y destacan sobre un c onjunto relativamente homogéneo. En Coca, se observa el reempleo de sillería o un aparejo singular en lugares puntuales, en relación con el conjunto de lienzos. En Cuéllar, la existencia de preexistencias es también puntual. En Fuentidueña, las bases de la puerta de Alfonso VIII destacan sobre el resto delienzos porque presentan una solución constructiva atípica. Sepúlveda es tal vez un ejemplo distinto, ya que g ran parte de sus lienzos poseen bases con aparejos de sillares reutilizados.

- Base sin preexistencias ni cimentación

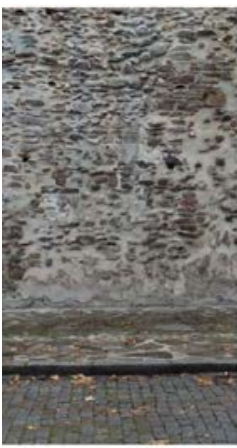

1. Coca

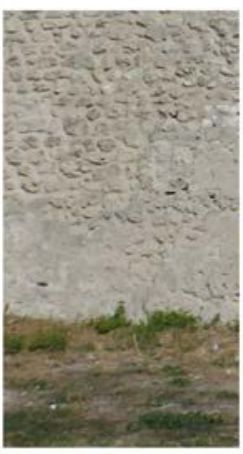

2.Cuéllar

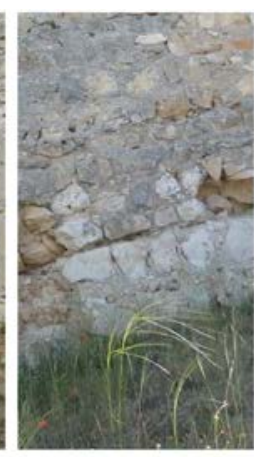

3. Fuentidueña

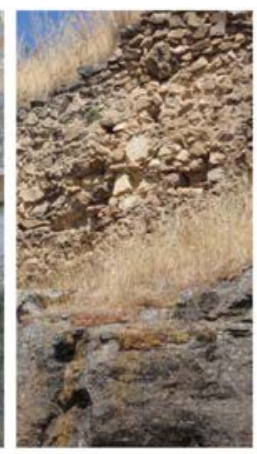

4. Pedraza

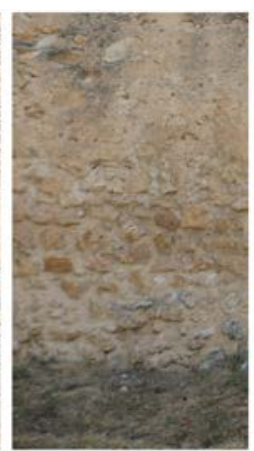

5. Maderuelo

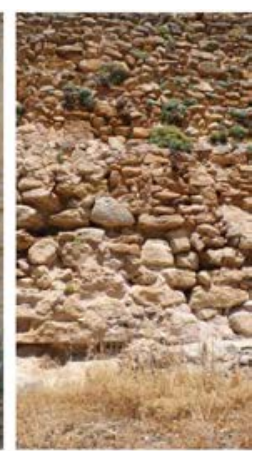

6. Sepúlveda

Fig. 6.36. Bases de muralla sin preexistencia

En todos los ejemplos estudiados hay tramos que no presentan una base distinta del resto del lienzo. No se observa el aprovechamiento de muros existentes, ni la reutilización de sillares de otras construcciones. Directamente sobre el firme, en algunos casos la roca, se comienza la construcción de la tapia. En ninguno de los lienzos se ha observado cimentación alguna. En Coca, el lienzo L1 se construye en su base de la misma manera que en I a zona superior, con tapia de mampostería. En Cuéllar ocurre lo mismo, en la zona sur se ven partes del lienzo donde la tapia de mampostería se apoya directamente sobre la roca. Los lienzos de Fuentidueña también arrancan directamente del terreno, sin verse diferencias entre las tapias de la base y las superiores. En el caso de Pedraza, se observa en varios restos de muralla cómo esta se apoya sobre el terreno rocoso directamente. Además, en uno de sus lienzos, se observa un ejemplo de mechinal directamente sobre la roca, indicando que se iniciaba la construcción de la tapia colocando las agujas directamente sobre la roca desnuda (Fig. 5.5.54, pág. 322). En Maderuelo también se ven lienzos cuyas tapias se construyen sobre el firme. En Sepúlveda, el tramo P11-Oeste pone igualmente de manifiesto la construcción de tapias desde la roca.

Aunque en todos los casos se observa la reutilización de bases de murallas anteriores o se emplea material tomado de otras construcciones, en mayor o menor medida, la muralla construida con tapia se realizaba sin una cimentación diferenciada, las tapias 
Las murallas en las Comunidades de Villa y Tierra de la Diócesis de Segovia en los siglos XI a XIII.

Técnica y sistemas constructivos de la arquitectura defensiva medieval.

arrancan desde el suelo firme. De todas formas, es importante señalar que en muchos de estos casos, la parte inferior del muro se encuentra semienterrada, por lo que no es visible el verdadero arranque del muro. Sin embargo, en otros como Fuentidueña, Cuéllar, Pedraza o Sepúlveda, la roca sobre la que se apoyan los lienzos está a la vista, quedando visible la ausencia de cimentación.

\subsubsection{Imagen proyectada de la construcción defensiva}

En todos los ejemplos analizados se ha podido comprobar la ausencia de decoración visible tanto en lienzos como en puertas y torres. Solo en algunos casos se observa el empleo de otros materiales como el ladrillo para generar formas o contrastes con la piedra, pero de for ma muy elemental y discreta. Esta escasa decoración parece apuntar a una fal ta de estrategia en c uanto al deseo de proyectar una i magen. Ancestralmente, los símbolos, señales, colores o dibujos se han utilizado para dar una imagen de autoridad o de prosperidad.

Podría decirse que al mismo tiempo, más al sur, lo que ocurre en la arquitectura defensiva almohade es muy distinto. Esta incluye decoración en las tapias de tierra a través de cintas y revestimientos de cal (Márquez Bueno, Gurriarán Daza 2008, 134). Los mencionados autores indican que los almohades buscaban ofrecer una imagen que distinguiera con claridad su arquitectura militar de otras, utilizando tres recursos: la decoración de las tapias con acabados superficiales, torres representativas de planta poligonal y accesos monumentales (116). Ninguno de estos recursos se emplea en las murallas estudiadas en esta investigación, que destacan por la escasa decoración visible. Las torres poligonales que se encuentran en los recintos estudiados no se construyen en ninguno de los casos como torres de nueva planta con la técnica de la tapia de mampostería, sino que se construyen sobre una base poligonal existente que condiciona la forma de la totalidad de la torre.

Una posible explicación de esta diferencia es la ausencia o alejamiento de una figura de autoridad que represente al monarca o a la iglesia y que exija esa imagen en la arquitectura militar que representa a su reino o institución. Otra razón posible es una acuciante necesidad de protegerse que primara la función defensiva frente a otras.

\subsection{Soluciones constructivas en las murallas}

En cada uno de los casos estudiados se ha podido comprobar la existencia de varias soluciones constructivas diferentes en sus murallas. En todos ellos se ha indicado donde se emplea cada sistema constructivo encontrado. En la tabla a continuación se han relacionado todos los casos entre sí (Tabla 6.6). Entre los sistemas constructivos identificados, se encuentra sillería en forma de fábrica o como refuerzo en esquinas y arcos de acceso. También cuando aparece en elementos defensivos como saeteras o almenado. La pi edra aparece en otros formatos, como el sillarejo o en apar ejos singulares que surgen en muchos de los casos, con hiladas en es pina de pez o 
empleando piedras de formas y materiales diferentes. La mampostería es otra solución visible, en fábricas o por su colocación en almenas o configuración de mechinales.

En relación con el uso de sillería, su uso en esquinas en forma de cadena es común en todos los casos. Se observa sillería en esquinas de algunas torres y puertas. Se observa también el uso de sillería en arcos de las puertas, al menos en una puerta de cada caso. La fábrica de sillería también es visible en bases de puertas y en las bases de algunos tramos. El empleo de sillería en saeteras o en almenado sólo es visible en el caso de Cuéllar.

El sillarejo es, en ocasiones, difícil de diferenciar de la sillería, ya que esta última no es totalmente regular sino que está erosionada o desgastada y puede haber perdido su regularidad. Se encuentra sillarejo en $v$ arios tramos de la muralla de $C$ uéllar, de Maderuelo y en la puerta de Alfonso VIII de Fuentidueña. La torre de Hontanillas, en Pedraza, también presenta alguna zona con sillarejo. También se localizan, en varios de estos casos, aparejos singulares que solo se encuentran en un punto de la muralla y que no se observan en otros recintos. En Coca, la torre pegada al castillo y el lienzo en el que se integra presentan un aparejo muy singular. En Cuéllar se observa en la torre de S antiago (T8) una bas e con un apar ejo poco habitual. La puerta P1 de Maderuelo muestra un apar ejo de mampuestos colocado en hiladas regulares que consiguen un efecto de sillarejo. Finalmente, en Sepúlveda se observa un aparejo de mampuestos colocados en espina de pez.

La fábrica de mampostería es un sistema muy fácil de atribuir en estas construcciones, donde encontrar un aparejo con mampuestos es sencillo. Sin embargo, al final suele convertirse en un cajón de sastre, donde se incluyen todos aquellos aparejos que no se ha podido asignar a otro tipo. De hecho, los dos casos asignados como fábrica de mampostería son efectivamente mampuestos aparejados de al gunas puertas de Sepúlveda o de Fuentidueña, donde no se ha identificado otra solución constructiva. La degradación de la tapia de mampostería o las reparaciones que se producen con el añadido de mampuestos y el borrado de marcas de tapial, pueden convertirla en un aparente aparejo de mampostería. La mampostería puede localizarse en las almenas de la puerta de la villa de Maderuelo, que podrían haber sido reconstruidas. En el caso de Fuentidueña, en el tramo T5-T7 se observa un almenado construido probablemente con un molde. Se observa el empleo de piedras planas a modo de coronación de las almenas y del espacio entre ellas.

El empleo del ladrillo no es muy frecuente en las murallas estudiadas. Se localiza en el arco de la puerta de Coca y en varias puertas de la muralla de Cuéllar. Solo en Cuéllar se encuentra una saetera construida con ladrillo, en la torre T2 de la puerta de San Basilio. Se observa decoración en ladrillo en dos puertas de Cuéllar y también podría considerarse decorada con ladrillo la puerta de la Villa de Coca. También en Pedraza se observa una decoración particular de la puerta de la Villa, con los ladrillos mostrando su tabla y formando rombos. En cuanto al almenado, solo se observa ladrillo en las almenas de Coca, en las torres T1 y T2. La torre T8 tiene ladrillo en su parte superior, pero no formando almenas como tal, sino que apar ece entre las piedras, a modo de relleno, como ocurre también en la puerta P2 de Pedraza. Tal y como se comenta anteriormente, la solución de mampostería encintada con ladrillo se 
Las murallas en las Comunidades de Villa y Tierra de la Diócesis de Segovia en los siglos XI a XIII. Técnica y sistemas constructivos de la arquitectura defensiva medieval.

encuentra en la base de las torres de la puerta de Alfonso VIII en Fuentidueña y en una construcción de Sepúlveda, que no se encuentra en el recorrido del recinto amurallado, pero que tiene un carácter defensivo.

Es en las puertas donde se ha visto mayor concentración de té cnicas constructivas distintas. Se encuentra sillería en arcos y en esquinas de forma principal, pero también en fábrica situada en los estribos del arco o en el frente de la puerta. El ladrillo también aparece en algunas puertas de Cuéllar, en la puerta principal de Coca y en las puertas de Pedraza. Aparece en la base de las puertas de Fuentidueña, pero no es visible en Maderuelo ni en Sepúlveda. En Coca y Sepúlveda se observa el empleo de tapia de mampostería en algunas de sus puertas. En el caso de Coca, se aplica en Ias torres de la puerta con planta semicircular. En Sepúlveda, las puertas donde se ve esta técnica tienen torres de forma rectangular y presentan machones de sillería.

Destaca el uso de tapia de mampostería en todos los casos, se observa la utilización de este sistema en I os lienzos de muralla y en muchos casos durante longitudes importantes. Solo algunos lienzos presentan otras técnicas diferentes de la tapia de mampostería. Por ejemplo, se observa fábrica de sillería en Maderuelo y Sepúlveda o sillarejo en Cuéllar y en Maderuelo. Se ven aparejos singulares en muchos de los casos, realizados con sillares reutilizados en el caso de Coca y Cuéllar o con mampostería aparejada de forma particular en el caso de Maderuelo o Sepúlveda.

La tapia de mampostería presenta, en algunos casos, verdugadas de piedra. Es más evidente en el caso de Coca, donde en algunos casos destaca la verdugada de piedra en la base mientras que el resto de la tapia conserva el acabado superficial terroso. Teniendo en cuenta que todo el tapial se rellena con piedras, colocadas en mayor o menor medida, es difícil en muchos casos dilucidar si se ha construido expresamente una verdugada o no. Se han señalado los casos donde se observa esta solución de forma clara y evidente, pero no es descartable que se haya empleado en otros puntos y no sea evidente en el resultado final.

Otro recurso empleado también en Coca de forma generalizada, a diferencia de otros casos, es el cierre lateral del tapial empleando un murete de piedras. También en la torre T8 de Fuentidueña es visible esta solución en alguno de los tapiales. No es visible en otros ejemplos, aunque como se ha indicado anteriormente estos aparejos pueden quedar enmascarados.

La tapia de cal y canto que e mplea cantos rodados en I ugar de mampuestos irregulares es visible en algunos restos del lado oeste de $\mathrm{C}$ oca, donde también se encuentran trozos cerámicos en la mezcla. No se observa la tapia con cantos rodados en ningún otro recinto. La tapi a de tierra no aparece en ninguno de los casos, ni siquiera en el interior de torres que esté a la vista.

El material empleado para la formación de mechinales es en todos los casos un grupo de mampuestos. Sólo en el caso de Coca se observa además el empleo de tejas cobijas para la configuración del mechinal. El uso de esta solución se produce mayoritariamente en las hiladas superiores del lienzo. 
La tapia mixta se encuentra en algunos casos estudiados. En el caso de Cuéllar es el que más soluciones de este tipo incluye. Incorpora verdugadas de ladrillo en las tapias de dos torres de su recinto, ambas de planta semicircular. Se observa algún mechinal configurado con ladrillo. En otras cinco torres, utiliza, además de verdugada de ladrillo, machones dentados del mismo material. El elemento adosado a la torre T8, denominado T8a tiene doble verdugada de ladrillo y presenta machones de ladrillo en su base de piedra, aunque de escasa entidad. Este elemento parece no tener carácter defensivo. Una fotografía de la ruina de la iglesia de Santiago (Fig. 6.37) la apoya idea de que este adosado era realmente un muro que integraba la construcción religiosa y no forma parte de la muralla.

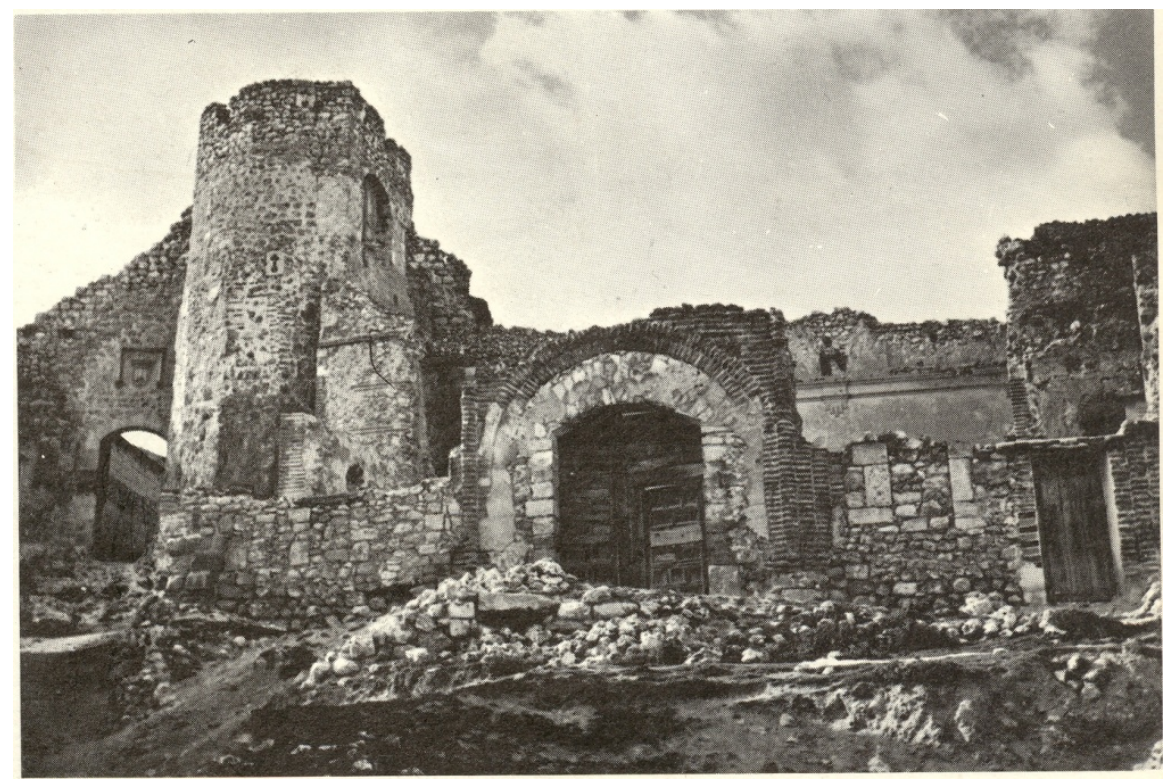

Fig. 6.37. Fotografía antigua de la iglesia de Santiago, en Cuéllar. Fuente: Imagen facilitada por Fernando Nieto y Jesús Nieto.

La tapia mixta con ladrillo aparece de forma minoritaria en Coca, en la parte interior de la puerta de la Villa, con la esquina superior izquierda configurada con machones de ladrillo y hasta cuatro verdugadas de ladrillo. Se observa una solución similar en la parte interior de la puerta de Pedraza, en la zona superior de la construcción. En el resto de recintos amurallados no se observa el empleo de tapia mixta con ladrillo. En los casos donde aparece, se encuentra en puertas o torres, pero no en los lienzos de muralla. Los machones des illería de pi edra aparecen en al gunas puertas de Sepúlveda. Es una técnica no vista en otros casos. Se observa solo el machón, sin verdugadas entre tapias.

De forma sintética, se podrían indicar varias cuestiones. La sillería se emplea en varias puertas y torres de todos los casos, principalmente para resolver arcos y esquinas. El ladrillo se emplea sólo en algunos casos y también exclusivamente en puertas y torres. La tapia de mampostería es común en los lienzos de todos los casos estudiados, sin la combinación de materiales, a excepción de Coca, que incorpora mechinales con teja en algunas de sus tapias. La tapia mixta con ladrillo se emplea de forma puntual en algunos ejemplos, de nuevo solo en torres y puertas. 


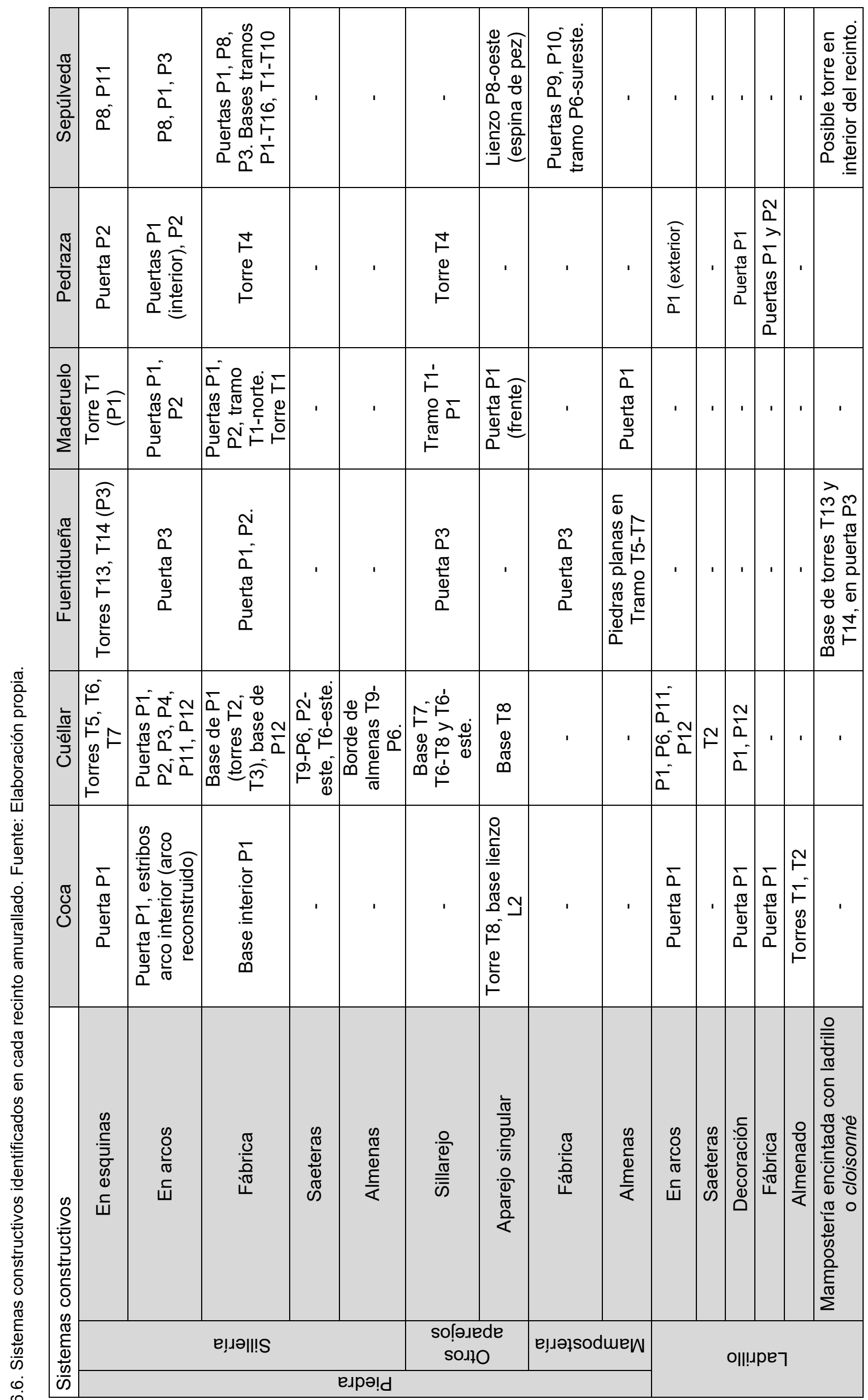




\begin{tabular}{|c|c|c|c|c|c|c|c|c|c|c|c|c|c|c|c|}
\hline \begin{tabular}{l}
$\frac{\pi}{0}$ \\
0 \\
$\frac{1}{2}$ \\
\hdashline 0 \\
0 \\
$\infty$
\end{tabular} & 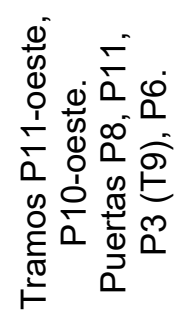 & ' & ' & ' & ' & 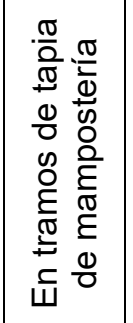 & & ' & & ' & ' & ' & 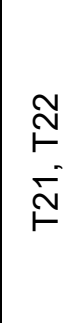 & & \\
\hline $\begin{array}{l}\mathbb{N} \\
N \\
\mathbb{N} \\
\frac{0}{0} \\
0 \\
0\end{array}$ & 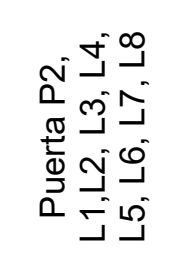 & ' & ' & ' & ' & 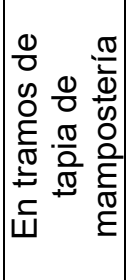 & & ' & & & ' & 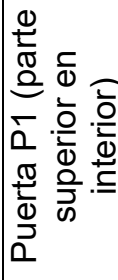 & ' & & \\
\hline $\begin{array}{l}\frac{0}{0} \\
\frac{1}{2} \\
\frac{0}{0} \\
\frac{\pi}{\pi} \\
\sum\end{array}$ & 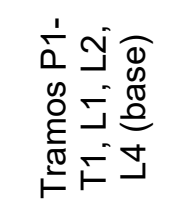 & ' & ' & ' & ' & 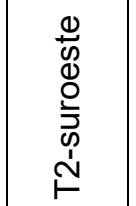 & ' & ' & & I & ' & ' & I & ' & \\
\hline $\begin{array}{l}\frac{0}{2} \\
\frac{2}{0} \\
\frac{2}{2} \\
\frac{0}{2} \\
\frac{1}{0} \\
\frac{1}{4}\end{array}$ & 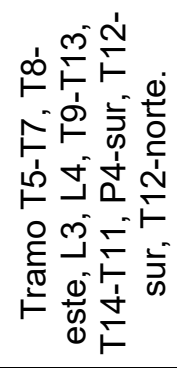 & ' & $\begin{array}{l}\stackrel{\infty}{\bullet} \\
\stackrel{\infty}{0} \\
\stackrel{0}{\bullet}\end{array}$ & ' & ' & 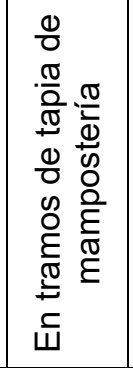 & I & ' & ' & I & ' & ' & ' & ' & \\
\hline $\mid \begin{array}{l}\frac{\bar{\sigma}}{\bar{\sigma}} \\
\frac{\bar{d}}{J} \\
0\end{array}$ & 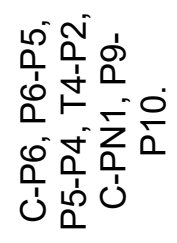 & ' & ' & ' & ' & 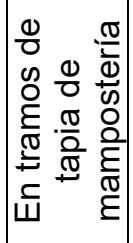 & ' & $\begin{array}{l}\stackrel{\rho}{\mapsto} \\
\check{F}\end{array}$ & 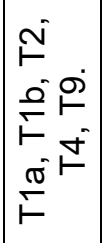 & $\begin{array}{l}\frac{\pi}{0} \\
0 \\
0 \\
+\frac{0}{c} \\
0 \\
\frac{E}{0} \\
\frac{0}{W}\end{array}$ & 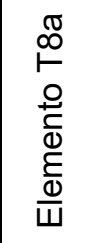 & ' & ' & 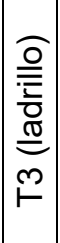 & \\
\hline $\begin{array}{l}0 \\
0 \\
0 \\
0\end{array}$ & 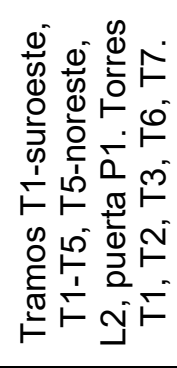 & 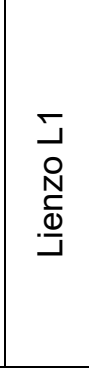 & $\begin{array}{l}5 \\
\\
N \\
\frac{1}{1} \\
\frac{1}{1}\end{array}$ & 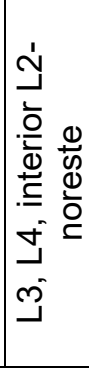 & 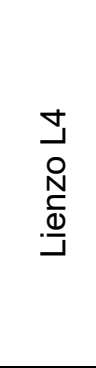 & 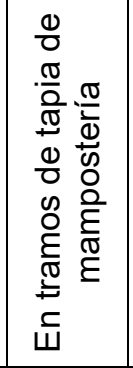 & 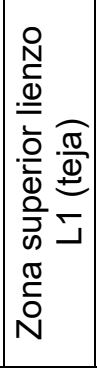 & ' & & & ' & 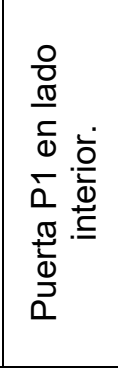 & ' & & \\
\hline 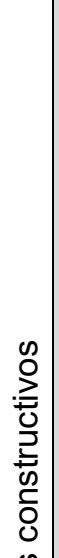 & 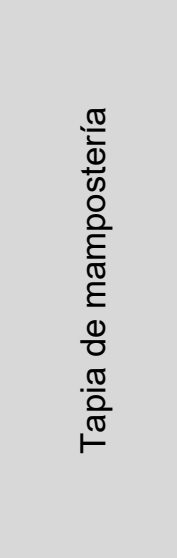 & 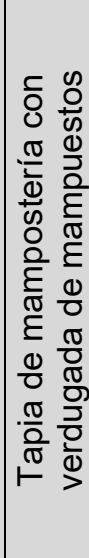 & 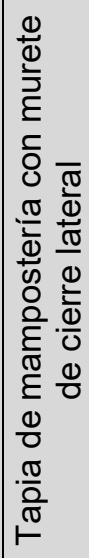 & $\begin{array}{l}0 \\
\frac{0}{0} \\
\frac{\pi}{0} \\
\frac{0}{2} \\
0 \\
0 \\
\frac{0}{10} \\
0 \\
\frac{1}{0} \\
0 \\
\frac{\pi}{0} \\
\frac{0}{0} \\
1\end{array}$ & 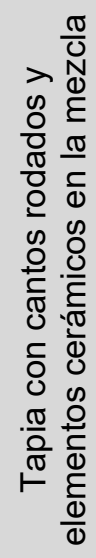 & 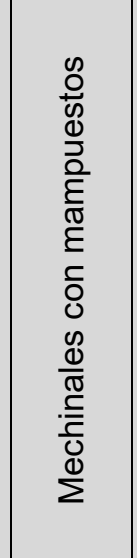 & $\begin{array}{l}\frac{\pi}{0} \\
\frac{\pi}{0} \\
\frac{0}{0} \\
0 \\
\frac{0}{\pi} \\
. \frac{5}{D} \\
\frac{0}{0} \\
\sum\end{array}$ & 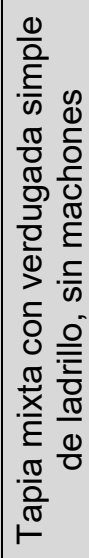 & 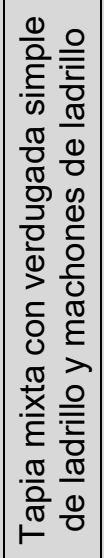 & 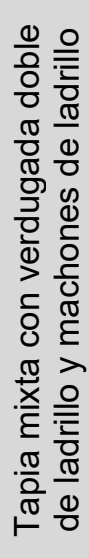 & 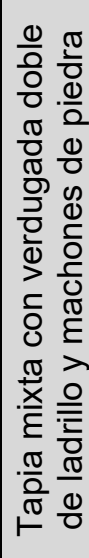 & 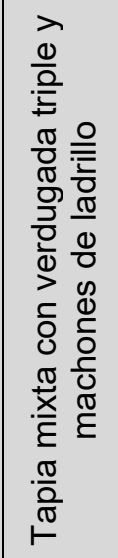 & 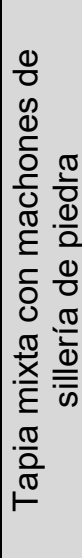 & 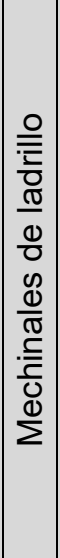 & $\begin{array}{l}\frac{\pi}{2} \\
\stackrel{0}{\sigma} \\
\frac{0}{0} \\
\frac{\pi}{0} \\
\frac{\pi}{0} \\
\frac{\sigma}{\circ}\end{array}$ \\
\hline$\stackrel{0}{\mathscr{Q}}$ & \multicolumn{7}{|c|}{ oұueo $K$ ןеo әр e!̣de $\perp$} & \multicolumn{7}{|c|}{ ełx!u e!de $\perp$} & \\
\hline$\frac{\infty}{\infty}$ & \multicolumn{15}{|c|}{ e!de। } \\
\hline
\end{tabular}




\subsubsection{Tapia de mampostería}

La síntesis de sistemas constructivos empleados en las murallas estudiadas (Tabla 6.6) identifica la tapia de mampostería como un sistema muy utilizado en la construcción de las murallas de estas villas. En todas ellas los lienzos se construyen utilizando esta técnica. No en todos los elementos como torres y puertas se emplea esta técnica, pero es visible en muchos de el los. A continuación, se realiza una comparación de los distintos parámetros que definen la tapia, para evaluar en qué medida se producen coincidencias o diferencias. Los parámetros analizados son los extraídos en c ada uno de I os casos, es decir, dimensiones, tipo de tapi al, la configuración del aparejo de mampuestos o las características de los mechinales empleados.

\subsubsection{Dimensiones: altura y anchura de la tapia}

La comparación de las dimensiones de anchura y altura de la tapia representativa de cada tramo estudiado muestra una semejanza en casi la totalidad de los casos (Fig. 6.38). Para los casos de Fuentidueña, Coca, Cuéllar, Maderuelo o Sepúlveda las alturas de tapia se sitúan entre $103 \mathrm{~cm}$ y $127 \mathrm{~cm}$, siendo la tapia de menor altura la del tramo estudiado de Sepúlveda y la de mayor altura las de Fuentidueña y Coca. Se sitúa muy por debajo la altura del caso de Pedraza. Las anchuras de tapia son también similares en la mayoría de los casos, situándose entre $260 \mathrm{~cm}$ y $288 \mathrm{~cm}$. De nuevo el caso de Pedraza queda atrás, sin alcanzar los $200 \mathrm{~cm}$ de anchura.

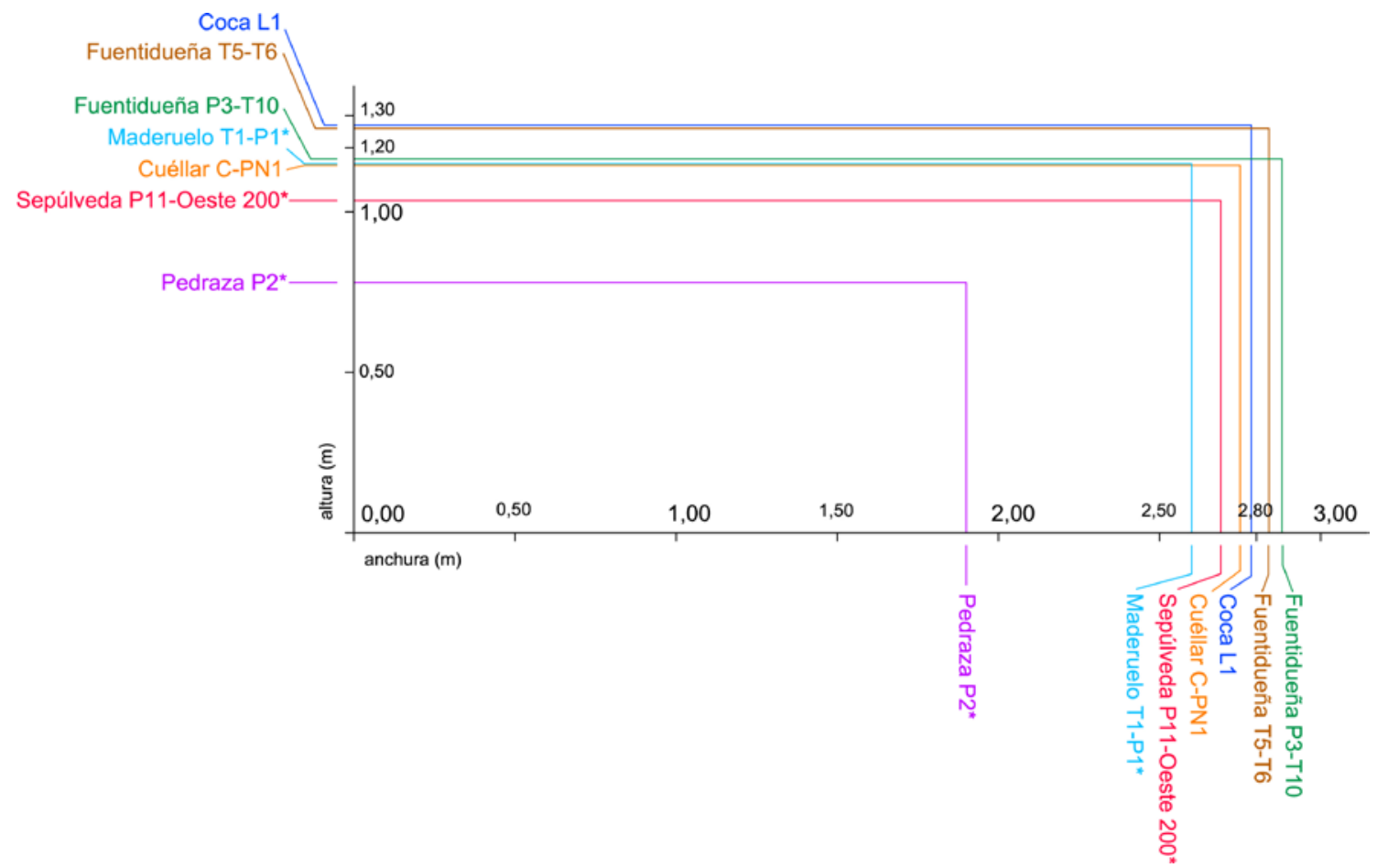

Fig. 6.38. Esquema comparativo de las dimensiones de las tapias de cada caso de estudio. Cada uno de los rectángulos muestra la dimensión de una tapia representativa del tramo estudiado. Se ha marcado con un asterisco los casos menos fiables, por disponerse de menos muestras. Fuente: Elaboración propia. 
Algunas tapias se acercan mucho en uno de los dos valores, anchura o altura, y luego esa proximidad no se refleja en segundo valor. Por ejemplo, se observa gran cercanía en la altura de las tapias de Cuéllar-C-PN1, Maderuelo T1-P1 y Fuentidueña P3-T10, entre $114 \mathrm{~cm}$ y $117 \mathrm{~cm}$, que luego no se refleja en la anchura, donde Maderuelo T1-P1 y Fuentidueña P3-T10 se sitúan en posiciones con $29 \mathrm{~cm}$ de diferencia y Cuéllar se sitúa a medio camino. En el caso de Coca L1 y Fuentidueña T5-T6 se produce una coincidencia en altura con $126-127 \mathrm{~cm}$ mientras que en la anchura hay una diferencia de $5 \mathrm{~cm}$.

La relación entre altura y anchura de la tapias de Coca L1 y Fuentidueña T5-T6 oscila entre 0,44 y 0,45, resultando un tapia más "alta". Los tramos de Fuentidueña P3-T10 y Cuéllar C-PN1 también son similares, con una anchura ligeramente mayor en Fuentidueña P3-T10. En estos dos tramos la relación entre altura y anchura oscila entre de 0,40 y 0,41 , resultando una tapia más alargada.

En ocasiones, el tamaño de la tapia presenta variaciones de altura en un mismo tramo de muralla. Es el caso de Fuentidueña en el tramo P3-T10, donde la quinta hilada de tapia tiene una altura significativamente superior a las hiladas inferiores (Fig. 5.3.105, pág. 252), pasando de una altura de $116,50 \mathrm{~cm}$ a $132 \mathrm{~m}$. En Sepúlveda se produce algo similar en el tramo P11-Oeste 200, donde la altura de la primera hilada se diferencia del resto alcanzando $119,5 \mathrm{~cm}$, frente al valor de la altura del resto de hi ladas, de $103,50 \mathrm{~cm}$. La razón de este cambio de altura en una sola hilada es difícil de interpretar. Para ello, es necesario utilizar un tapial diferente del empleado en I as hiladas inferiores.

En el caso de Fuentidueña, concretamente en el tramo T5-T6, se observan tapias que no tienen forma rectangular, sino triangular o trapezoidal. Estas tapias son de tipo residual, es decir se rellenan con esta forma para cerrar una hilada en paralelo con el terreno. Cuando el terreno es inclinado, como ocurre en este tramo, los espacios residuales adquieren esta forma triangular, dando lugar a tapias de esta forma. No se observan tapias de es tas características en otros recintos, donde las tapias visibles tienen forma rectangular. En ocasiones, se observan tapias de tipo residual, pero que conservan su forma rectangular. Son más cortas en anchura, modificando su proporción. Estas tapias son el resultado de un cierre de tramo constructivo. Cuando se construyen tapias que fi nalizarán en un momento dado, no es probable que la última tapia de la hilada quepa con su tamaño habitual, sino que queda un espacio residual más corto que se llena con una tapia de proporción más cuadrada. Se ven ejemplos evidentes de estas tapias en Coca o en Cuéllar (Fig. 5.1.49, pág. 124 y Fig. 5.2.102, pág. 190).

El caso de Pedraza se aleja del resto de los casos, tanto en anchura como en altura. Es importante señalar que el caso analizado de Pedraza es diferente del resto. Las tapias localizadas son escasas y se sitúan en un acceso, cosa que no ocurre en el resto de casos, donde se ha podido analizar partes de lienzos y mayor número de tapias. La dificultad para acceder a algunos restos de muralla en Pedraza ha impedido extraer más datos dimensionales que mejoren este resultado. 
Las murallas en las Comunidades de Villa y Tierra del reino de Castilla en los siglos XI-XIII dentro de la Diócesis de Segovia. Técnica y sistemas constructivos de la arquitectura defensiva medieval.

\subsubsection{El tapial: configuración del encofrado}

- Tipo de tapial

Los casos de Coca (tramo L1) y Cuéllar (tramo C-PN1) no ofrecen duda a la hora de establecer qué tipo de encofrado se ha utilizado en su construcción. En ambos casos se puede identificar un encofrado independiente, con tres agujas en la base que solo se emplean en la construcción de una tapia. Las agujas laterales se aproximan a los bordes, generando una composición simétrica con una aguja centrada y dos laterales separadas la misma distancia del borde (Fig. 6.39, izq.).
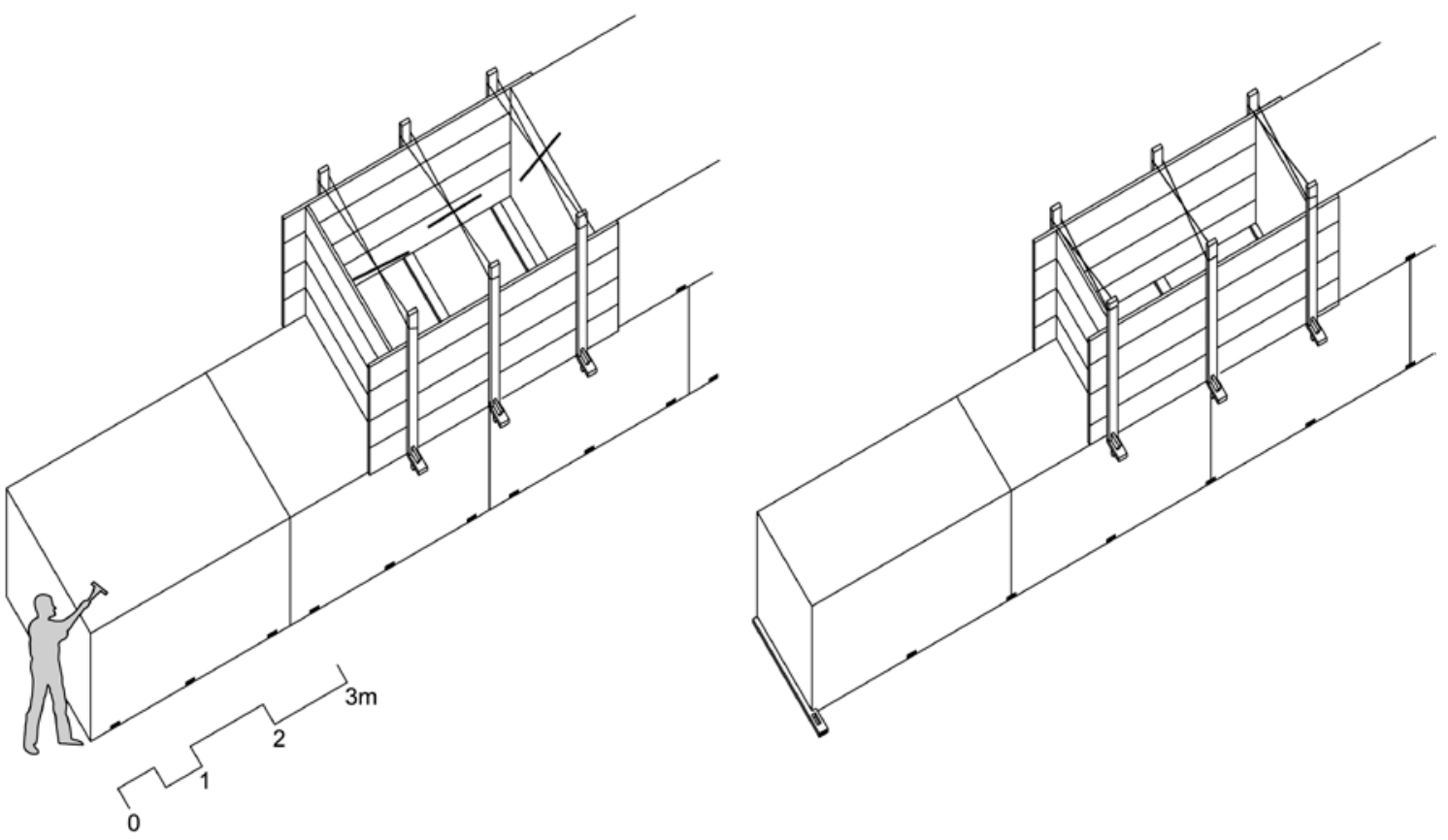

Fig. 6.39. A la izquierda, tapial independiente, propio de las murallas de Coca o Cuéllar. A la derecha, tapial con mechinal lateral compartido, propio del tramo P3-T10 de Fuentidueña. Fuente: Elaboración propia.

En el resto de murallas, los tramos estudiados muestran soluciones diferentes en el tapial empleado. Uno de los tramos más llamativos es el T5-T6. D2 de Fuentidueña, donde se observa una retícula regular de mechinales situados a la misma distancia (Fig. 5.3.99, pág. 250). Esta disposición, alineada tanto en sentido horizontal como vertical, plantea que el encofrado empleado ya no es realizado tapia por tapia como ocurre en los dos casos anteriores, sino que los mechinales muestran la construcción de un encofrado más largo, que se utiliza tal vez para encofrar varias tapias o que se va construyendo por un lado y retirando progresivamente por otro según las tapias van fraguando. En cualquier caso, la equidistancia de mechinales muestra que el tapial empleado no es independiente (Fig. 6.40, izq.). En otra zona de Fuentidueña, el tramo P3-T10 también muestra tapias cuyos mechinales no son exclusivos sino que se comparten entre tapias (Fig. 6.39, dcha.). Las divisiones verticales de las tapias, visibles en este tramo, se sitúan centradas sobre el mechinal o inmediatamente al lado, poniendo de manifiesto que la aguja se comparte entre dos tapias contiguas. El hecho de que se comparta aguja puede significar que el tapial tiene una I ongitud 
mayor de una tapia, por ejemplo dos tapias, pero el hecho de haya una marca intermedia vertical de I ímite de tapi a implica que una $v$ ez montado un tapi al de hipotética longitud doble, se realizaba un cierre transversal y se llenaba la primera tapia, para luego continuar con la segunda. Se ha ahorrado el tiempo de montaje del tapial de una de las tapias y se ha ahorrado en agujas, utilizando 2 agujas por tapia en lugar de 3. Otra opción es que se colocasen tres agujas para realizar una tapia y que posteriormente, al retirar el encofrado, se conservase al menos una aguja sobresaliendo del plano del lienzo, aquella situada en el lado por donde se va a continuar construyendo la nueva tapia, para montar el tapial de I a siguiente tapia reutilizando la aguja de la tapia anterior. De esta forma se puede ahorrar en agujas, como en el caso anterior, aunque no se ahorraría tiempo de montaje de tapial, puesto que se montaría dos veces, una por tapia, como si se tratara de una tapia unitaria.

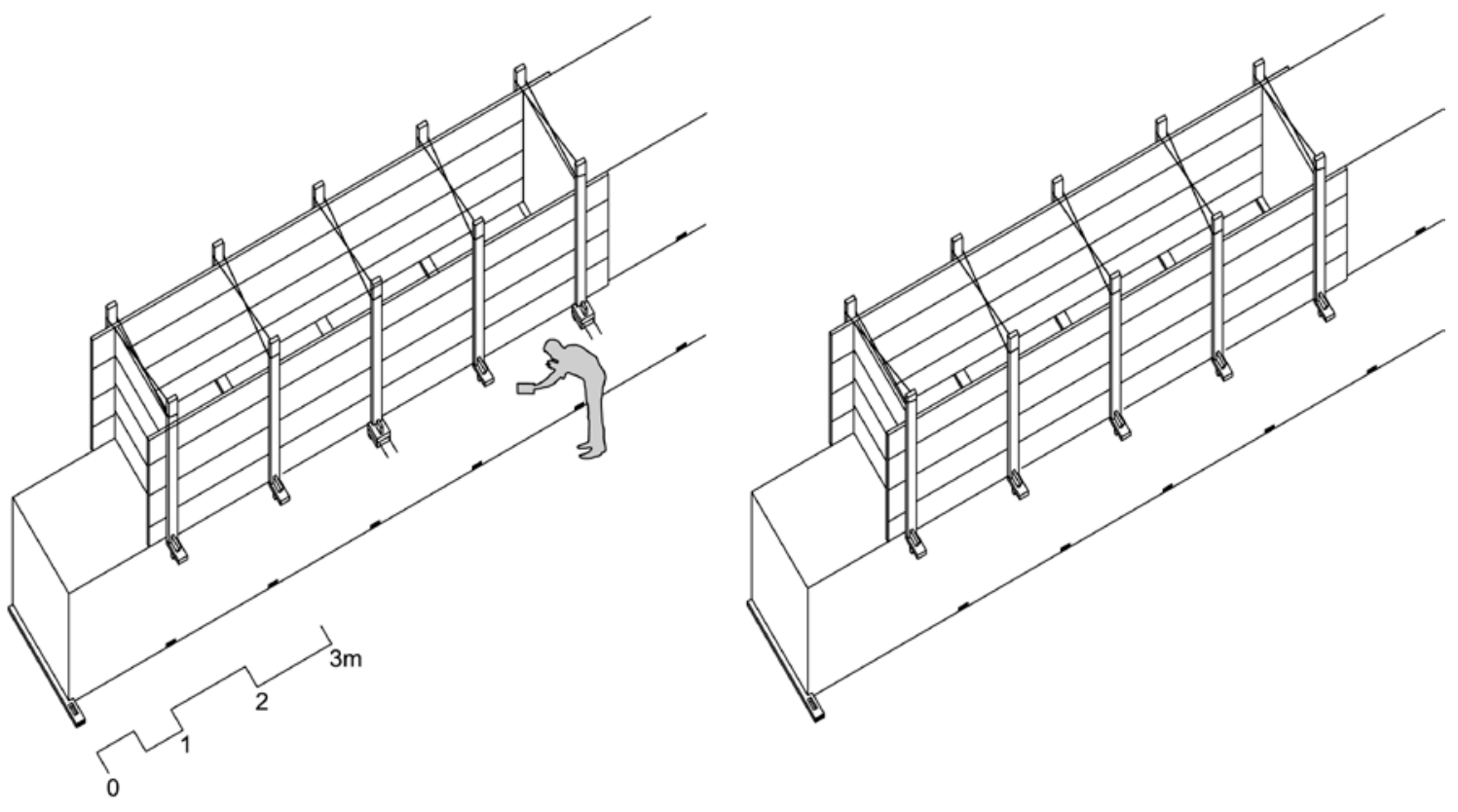

Fig. 6.40. A la izquierda, tapial corrido con mechinales alineados verticalmente, visible en el tramo T5T6.D2 de Fuentidueña. A la derecha, mismo tapial esta vez con mechinales no alineados verticalmente, habitual también en Fuentidueña. Fuente: Elaboración propia.

- Juntas visibles en paramento. Límites de las tapias

Los tipos de tapial comentados anteriormente pueden explicar el hecho de que en algunas murallas se vean con mayor claridad los límites verticales de cada tapia. En los tapiales independientes es más probable que se distingan mejor los límites verticales de las tapias, mientras que los tapiales corridos, que permiten la realización de varias tapias con el mismo tapial, enmascaran más fácilmente las divisiones entre tapias, hasta tal punto que pueden ser indistinguibles unas tapias de otras. Aun así parece evidente que incluso utilizando encofrados de mayor longitud, que engloben varias tapias, no se realizan tapias muy alargadas o de dobl e longitud, sino que se conserva una proporción rectangular común en casi todos los casos.

Las marcas horizontales son fácilmente visibles en todos los tramos estudiados, aunque en ocasiones quedan ocultas por diversas razones. Cuando esto ocurre, la 
posición de los mechinales permite localizar de forma muy probable las distintas hiladas del muro. La identificación de los límites de las tapias es importante para determinar que el sistema constructivo empleado es la tapia. Muchas veces, el estado de conservación de estas construcciones puede hacer dudar del sistema constructivo empleado. En ocasiones, las reparaciones intensas pueden enmascarar este sistema, dando como resultado un muro con una mampostería inclasificable.

\section{- Tablas del tapial}

Las marcas de la tablazón del encofrado no siempre son visibles en todos los casos analizados. En cuatro de I os casos analizados, Coca, Cuéllar, Fuentidueña y Maderuelo, ha sido posible contar el número de tablas empleadas en algunas de las tapias. Es habitual ver las marcas horizontales que han dejado cuatro tablas colocadas en posición horizontal. La medida de la tabla oscila habitualmente entre 25 y $30 \mathrm{~cm}$ en todos los casos, aunque se ven algunas marcas que superan el límite de $30 \mathrm{~cm}$. En todo el tramo T8-este de Fuentidueña se ven especialmente bien estas marcas, se ha conservado muy bien el acabado superficial de las tapias (Fig. 5.3.49, pág. 226). En otros ejemplos se observan puntualmente zonas donde se ha conservado el acabado, o tapias aisladas donde se puede contar las tablas empleadas.

\subsubsection{Aparejo de mampuestos en el tapial}

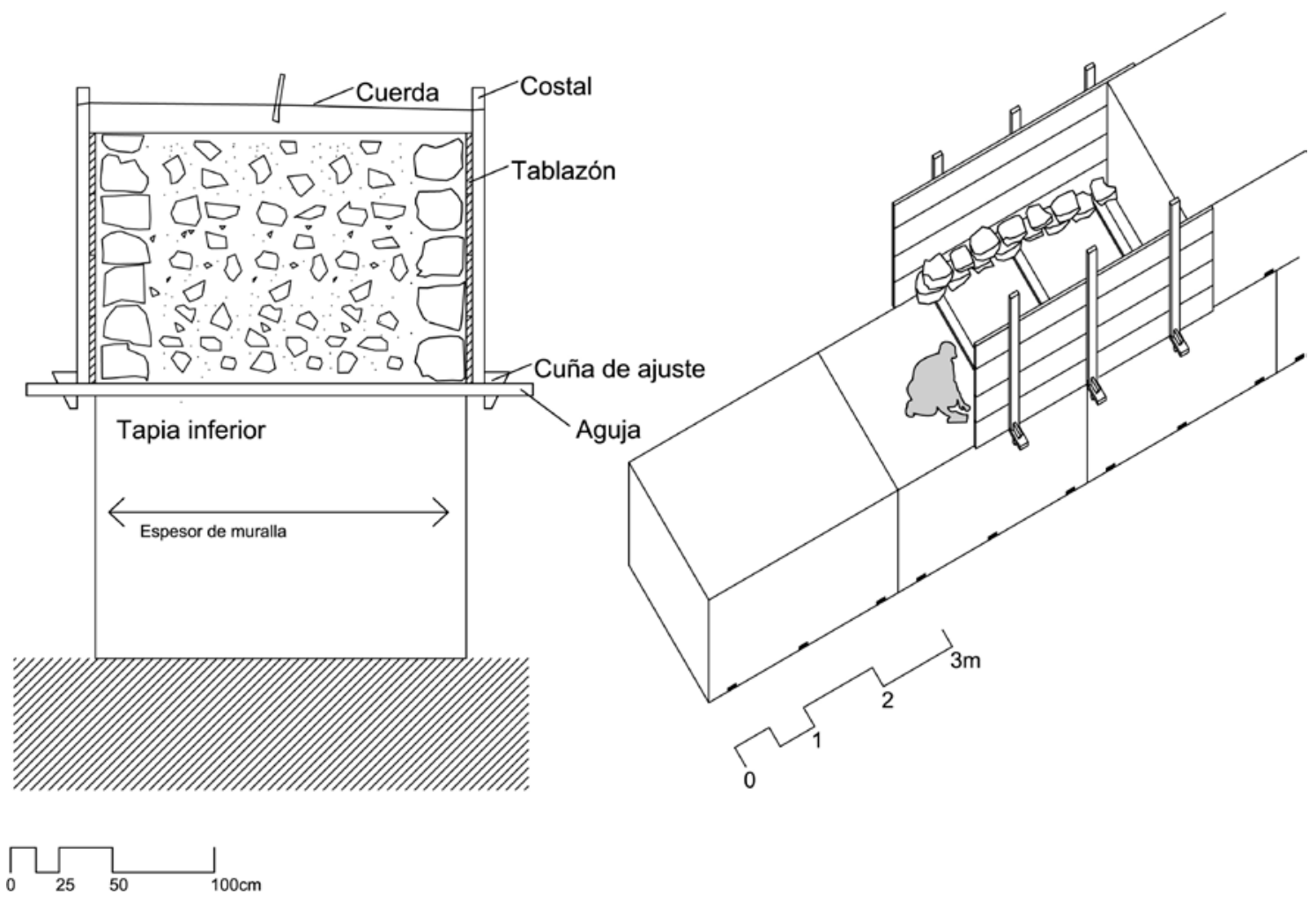

Fig. 6.41. A la izquierda, sección de la tapia con su tapial, que muestra el aparejo de las piedras exteriores. A la derecha, tapial independiente, propio de Coca, con piedras aparejadas en los lados exteriores de la tapia. Fuente: Elaboración propia. 
El llenado del tapial con la mezcla de $m$ ampuestos, tierra y cal requiere una planificación. El bloque tiene un volumen aproximado de $6,5 \mathrm{~m}^{3}$, cuando el espesor de la muralla ronda los $2 \mathrm{~m}$. A modo de c omparación, el volumen de una ba ñera doméstica no al canza la tercera parte de $1 \mathrm{~m}^{3}$. Por una parte se han de colocar los mampuestos y por otra la mezcla de tierra y cal. Las marcas de tablazón visibles en la superficie de las tapias indican que la mezcla tenía una proporción importante de agua, era un magma que podía verterse entre los mampuestos y rellenar los espacios entre ellos.

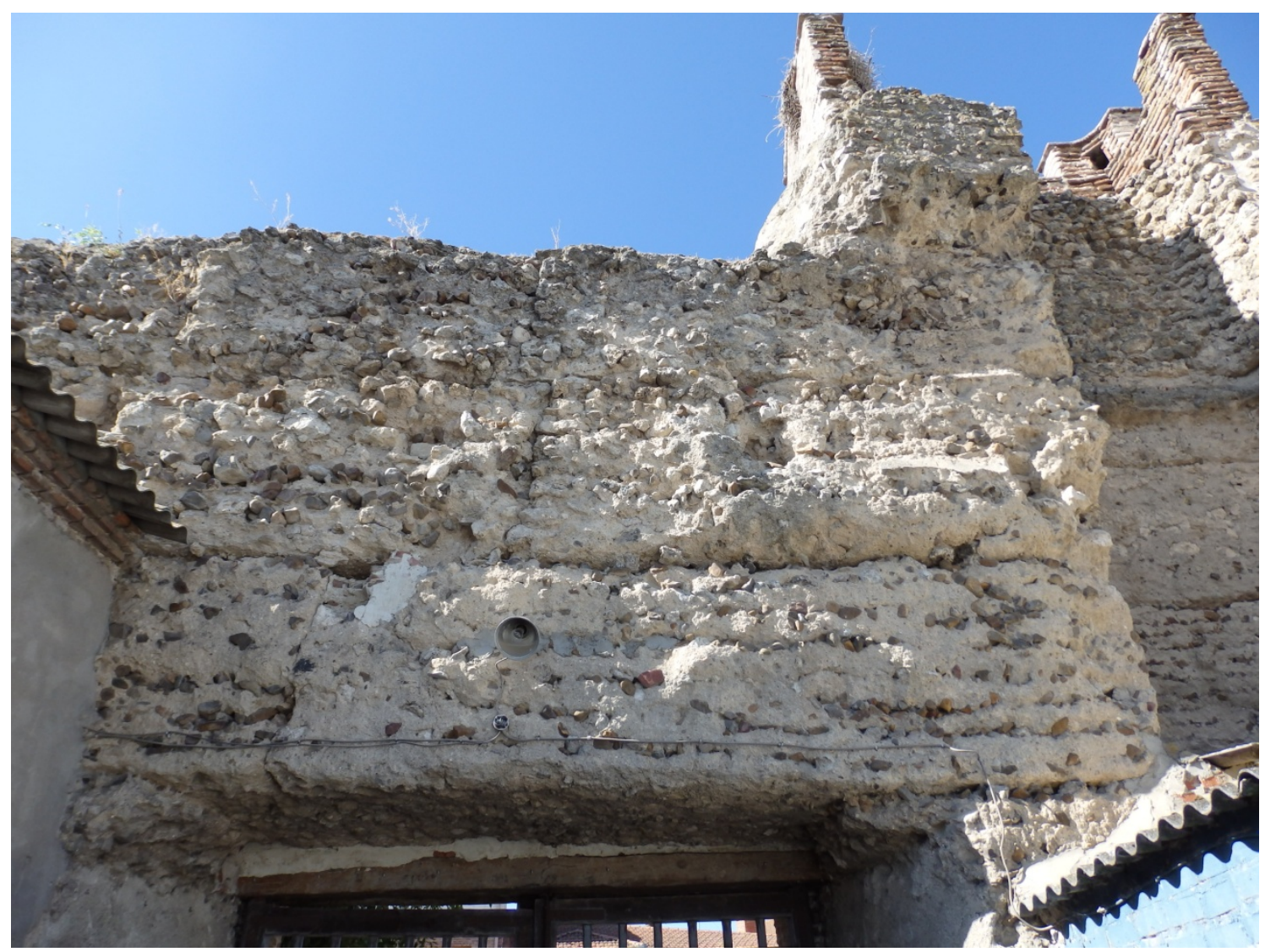

Fig. 6.42. Tapia de cal y canto en Olmedo. Se observa una colocación de los cantos rodados por hiladas [A.S.E. 1/9/2014].

Como es visible en muchos de los tramos analizados, la cara exterior de la tapia, cuando los mampuestos son visibles, muestra un cierto orden en la colocación de las piedras, a través de hiladas aunque estas sean irregulares. Es aceptable pensar que se realizase un aparejo de piedras al menos en las dos caras exteriores. Este aparejo se realizaría con piedras seleccionadas, que ofrecen su cara más lisa hacia el exterior, pegando con el molde. No es fácil determinar si el llenado con tierra y cal se produce gradualmente, según se realizan las hiladas de piedra o si, por el contrario, se realizan los aparejos de I as caras exteriores para luego rellenar con el vertido de otr os mampuestos, tierra y cal. Para un correcto reparto de la mezcla líquida de tierra, cal y agua entre los mampuestos, parece lógico pensar que el vertido se realizaría por partes, para asegurar que I lene todos los resquicios entre mampuestos y entre mampuestos y las tablas del tapial. En caso de no al canzar todos los resquicios, 
después del fraguado se retiraría el encofrado y se desprenderían aquellos mampuestos a los que la mezcla no haya alcanzado.

En la muralla de Olmedo, es visible en una de sus caras interiores, la forma de colocar los cantos rodados en la tapia (Fig. 6.42). Se observan hiladas de cantos rodados, que alternan con una c apa de ti erra y cal. El llenado de la tapia se realiza por capas horizontales, se coloca una cama de una especie de "mortero" de tierra y cal sobre la que se coloca una c apa de c antos rodados, con altura de un c anto. Después se alterna con otra capa de la mezcla tierra y cal y así sucesivamente. Otra cuestión que se observa en estas tapias de Olmedo es la irregularidad que se aprecia en el plano vertical, hacia el interior. Esta irregularidad podría deberse a que este muro se adosó a otro existente, que funcionó como parte del tapial. La tapia adquiriría la forma del muro existente en su cara interior, con todas sus irregularidades. Teniendo en cuenta que las torres presentan una parte interior de tierra, es posible que existieran igualmente lienzos de tierra.

\section{- Verdugada de la tapia}

Las verdugadas en I os lienzos aparecen en algunos casos, y se realizan con mampuestos. La verdugada tiene, además de un resultado estético, una función en la confección de la tapia. Ayuda a organizar la colocación de las agujas sobre la tapia inferior (Fig. 6.43 dcha.). En el frente visto, la verdugada se ve como una hilada de mampuestos, que al llegar a la posición de la aguja, la sortea, colocando mampuestos en los flancos y sobre la aguja. Es probable que las piedras se colocaran con el objeto de fijar la posición de las agujas y evitar así desplazamientos de las agujas durante la construcción del tapial. Las verdugadas pueden fácilmente confundirse con una hilada más de la mampostería en el frente de la tapia, por esta razón no son siempre identificables de forma evidente.

\section{- Murete transversal}

El murete transversal de piedras que cierra un lateral de la tapia no tiene un uso generalizado en los recintos estudiados. Como ya se ha comentado, se aplica en el lienzo L1 de Coca, de forma generalizada, y se observa de forma aislada en algunos lugares, como la torre T8 de Fuentidueña o en el tramo P11-Oeste 200 de Sepúlveda. Tal y como ocurre con las verdugadas de piedra, este sistema puede pas ar desapercibido en al gunos casos, ya que I a tapia ofrece en m uchas ocasiones un alzado de piedras que podrían enmascararlo. Este sistema ha sido documentado en San Pedro de Latarce, en Valladolid (Cobos et al 2012,112), donde se observa un murete compuesto de cuatro columnas de cantos rodados. Tanto en el caso de Coca como en Fuentidueña, el murete tiene una sola columna de mampuestos, elegidos de forma alargada. En el resto de casos no se observa de forma evidente el empleo del cierre de la tapia con un murete de piedras. En el tapial independiente, este sistema podría acelerar la producción de tapia. El tapial independiente hace necesario esperar a que se retire el encofrado de madera para poder continuar con la tapia siguiente, al menos para poder retirar el cierre transversal de madera, por lo que el proceso sería 
muy lento. La construcción del murete transversal permite encadenar un tapial con el siguiente, sin necesidad de esperar a la retirada del tapial anterior, dejando el murete transversal sepultado entre las dos tapias.
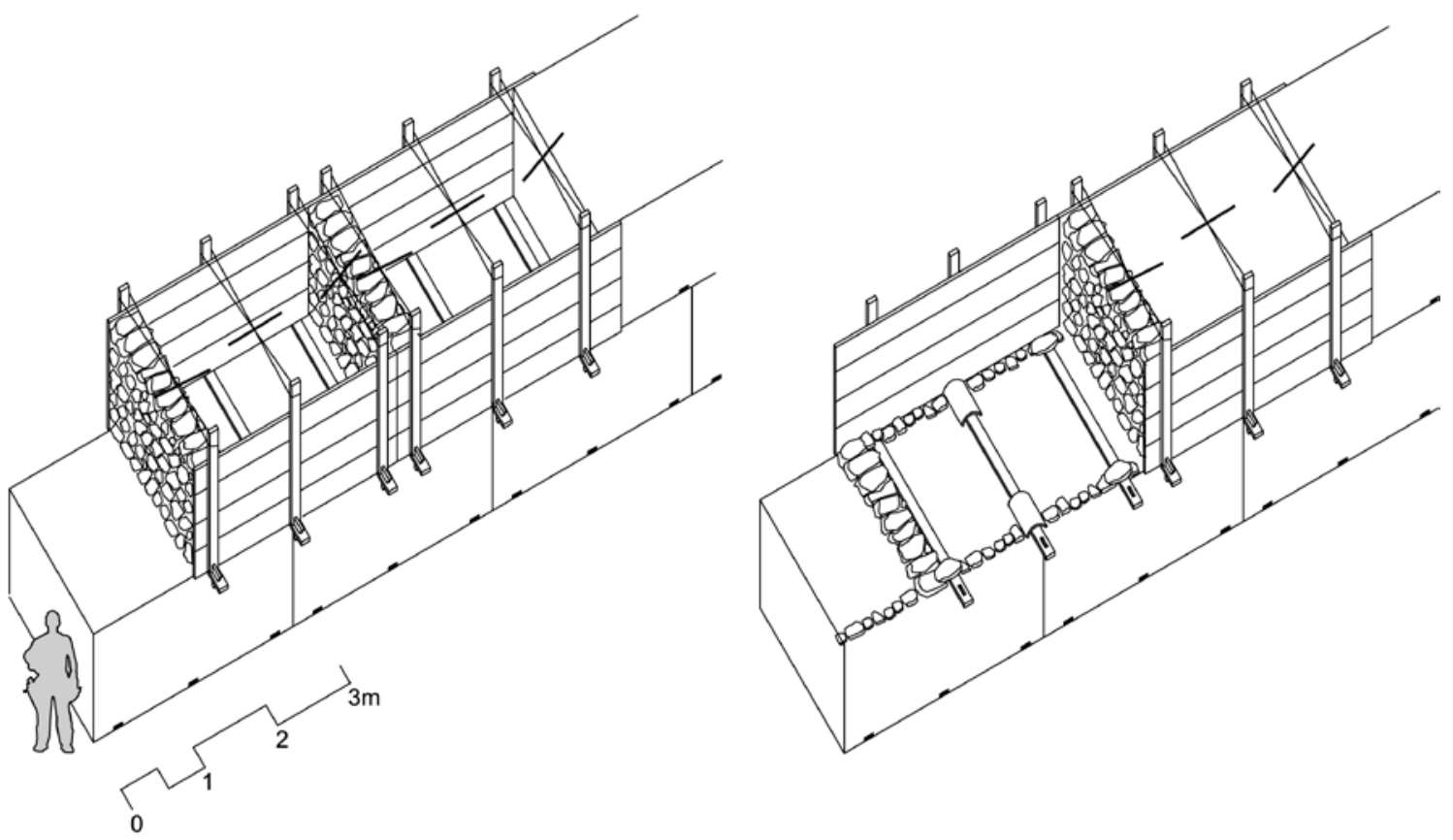

Fig. 6.43. Tapial independiente, propio de Coca, realizado con muretes transversales (izq.). A la derecha, colocación de verdugadas en el interior del tapial. Fuente: elaboración propia.

En la Fig. 6.39 (izq.) se ha descrito un tapial independiente, construido con dos caras longitudinales formadas por tablas y sujetas por tres costales y una cara transversal, también de tablas, que cierra el tapial formando un molde. Se construye a continuación de la anterior tapia realizada para aprovecharla como cierre transversal. Se podrían construir más cajones a continuación y ser rellenados posteriormente, pero entonces sería necesario abandonar el cierre transversal del tapial en el interior del muro. En la Fig. 6.43 (izq.) se observa un tapi al muy similar, pero que r esuelve su cierre transversal con el murete de pi edras, lo que permite realizar varios tapiales consecutivos sin necesidad de es perar a qu e se retire el tapial del primero. Los muretes quedan dentro del muro y son visibles en la superficie, en los laterales de cada una de las tapias.

\section{- Piedra empleada}

Los mampuestos empleados en las tapias de los recintos estudiados son de un tipo de piedra fácil de enc ontrar en c ada uno de I os asentamientos. Se trata de pi edras sedimentarias como la piedra caliza y más raramente arenisca. Como ya se ha adelantado, el caso de Coca difiere del resto, presentando un tipo de piedra diferente, identificado como cuarcita roja y pizarra (Blanco 1991, 436), que ya no es sedimentaria sino de tipo metamórfico. 
Las murallas en las Comunidades de Villa y Tierra del reino de Castilla en los siglos XI-XIII dentro de la Diócesis de Segovia. Técnica y sistemas constructivos de la arquitectura defensiva medieval.

\subsubsection{Tramos constructivos}

- Orden de construcción de tapias.

Como ya se ha comentado en el capítulo de Coca, la existencia de un murete lateral de la tapia permite identificar qué lado de la tapia se ha terminado en úl timo lugar, ayudando a determinar qué tapia se construyó antes y por tanto cuál es el sentido de construcción del as tapias dentro de una hilada. Otro factor que c ontribuye a determinar el orden de construcción de tapi as son las tapias residuales descritas anteriormente. En algunos casos son tapias más cortas, de for ma rectangular o triangular en el caso de Fuentidueña, quelas identifica como tapias creadas para cerrar espacios residuales y por lo tanto $\mathrm{c}$ onstruidas en úl timo lugar. Esta interpretación del orden de construcción de las tapias se aplicó en San Pedro de Latarce por el equipo de Fernando Cobos (2012, 122-123).

El análisis del orden de construcción de tapias pone de manifiesto la existencia de un punto de origen de construcción de la primera tapia de la hilada, así como de una tapia última de la hilada. La pregunta tras este planteamiento sería qué Iongitud tiene una hilada o cuándo se comienza a construir la segunda hilada, es decir, si se programa tramos constructivos de longitudes constantes os i no existe tal planificación. Simultáneamente con la determinación del orden de construcción de las tapias, se ha tratado de localizar tramos constructivos visibles en el paramento. En la mayoría de los casos no se han encontrado tramos constructivos. En Fuentidueña, las hiladas de tapias son de gran longitud y los encuentros son en algunos casos caóticos. El caso de Coca tiene tramos constructivos fácilmente identificables por ser más cortos y por ser visible claramente una línea vertical donde se alinean los límites verticales de las tapias. Algunos tramos no alcanzan la decena de metros. También en Cuéllar existe una división similar en el tramo C-PN1, aunque no tan evidente como las visibles en Coca. En este último caso, parece producirse una relación entre las torres T1 y T2 y los tramos constructivos, que coinciden con su posición. Este dato podría apoyar la idea planteada anteriormente que establece que estas dos torres se construirían de forma integrada con los lienzos. 


\begin{tabular}{|c|c|c|c|c|c|c|c|c|c|c|}
\hline & 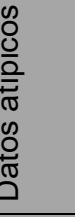 & $\begin{array}{l}\mathbb{N} \\
\mathbb{N} \\
\frac{\pi}{0} \\
0 \\
0\end{array}$ & $\begin{array}{l}\mathbb{N} \\
\mathbb{N} \\
\frac{\mathbb{Z}}{\sigma} \\
0 \\
Q\end{array}$ & 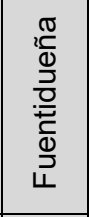 & 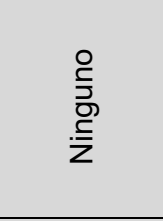 & $\begin{array}{l}\stackrel{\circ}{5} \\
\stackrel{5}{5} \\
\stackrel{5}{z}\end{array}$ & $\begin{array}{l}\stackrel{\circ}{5} \\
\stackrel{5}{\bar{z}} \\
\stackrel{5}{z}\end{array}$ & $\begin{array}{l}\stackrel{\circ}{5} \\
\stackrel{5}{5} \\
\frac{5}{z}\end{array}$ & $\begin{array}{l}\text { ర్ } \\
\text { ن }\end{array}$ & $\begin{array}{l}\stackrel{0}{5} \\
\stackrel{5}{\bar{z}} \\
\stackrel{5}{z}\end{array}$ \\
\hline \multicolumn{2}{|c|}{ 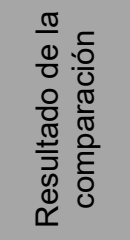 } & 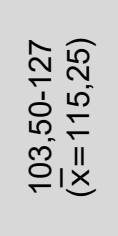 & 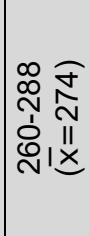 & 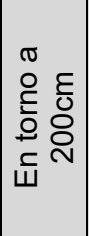 & 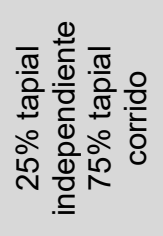 & 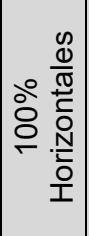 & 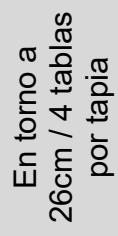 & 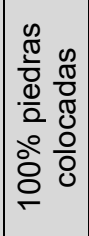 & 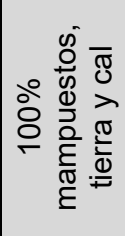 & 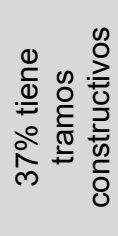 \\
\hline $\begin{array}{l}\frac{\pi}{0} \\
\frac{0}{0} \\
\frac{0}{3} \\
0 \\
\infty\end{array}$ & 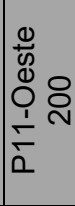 & 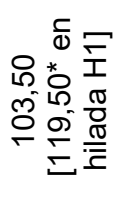 & 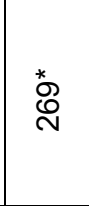 & 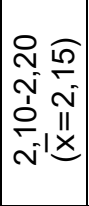 & 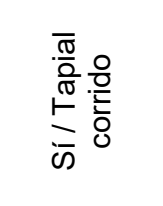 & 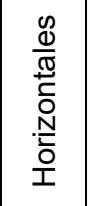 & $\begin{array}{l}\frac{0}{0} \\
\frac{0}{00} \\
\frac{0}{2} \\
\frac{0}{2}\end{array}$ & $\bar{s}$ & 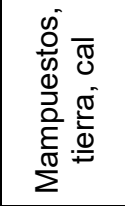 & $\bar{\omega}$ \\
\hline $\begin{array}{l}\mathbb{N} \\
\mathbb{N} \\
\frac{\widetilde{T}}{0} \\
\mathbb{0} \\
0\end{array}$ & 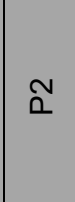 & $\stackrel{*}{\stackrel{*}{\infty}} \stackrel{0}{ }$ & 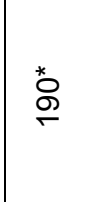 & 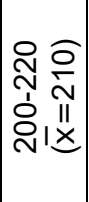 & 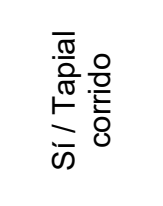 & 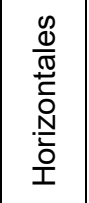 & $\begin{array}{l}\frac{0}{0} \\
\frac{0}{0} \\
\frac{0}{20} \\
\frac{0}{2} \\
\frac{0}{2}\end{array}$ & $\bar{c}$ & 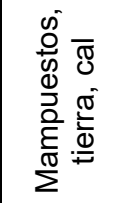 & ㅇ \\
\hline \multirow{2}{*}{$\begin{array}{l}\frac{0}{0} \\
\frac{2}{20} \\
\frac{0}{0} \\
\sum\end{array}$} & 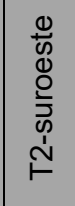 & $\stackrel{*}{\circ} \stackrel{0}{\circ}$ & $\begin{array}{l}\frac{0}{0} \\
\frac{0}{00} \\
\frac{0}{2} \\
\frac{0}{2}\end{array}$ & 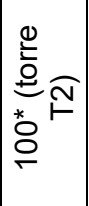 & 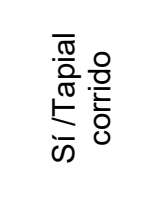 & 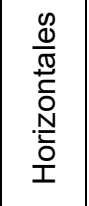 & $\begin{array}{l}\frac{0}{0} \\
\frac{0}{0} \\
\frac{0}{60} \\
\frac{0}{2} \\
0 \\
2\end{array}$ & $\bar{\omega}$ & 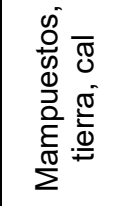 & 은 \\
\hline & $\frac{\bar{\phi}}{\dot{1}}$ & 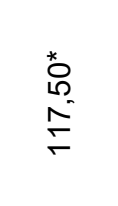 & $\begin{array}{l}* \\
\stackrel{*}{\circ} \\
\stackrel{0}{*}\end{array}$ & $\begin{array}{l}\text { 菅 } \\
\stackrel{\circ}{\circ}\end{array}$ & 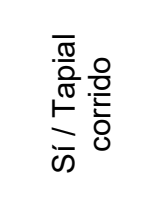 & 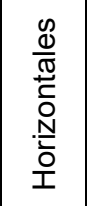 & $\frac{\nabla}{\stackrel{N}{N}}$ & $\bar{s}$ & 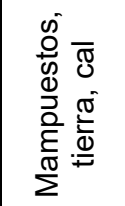 & 은 \\
\hline \multirow{2}{*}{ 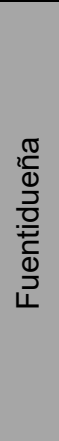 } & 욷 & 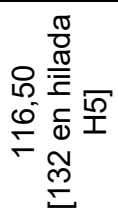 & $\begin{array}{l}\infty \\
\stackrel{\infty}{\sim}\end{array}$ & 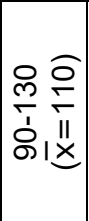 & 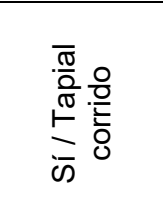 & 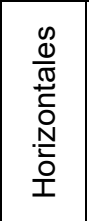 & $\frac{\nabla}{\stackrel{N}{N}}$ & $\bar{c}$ & 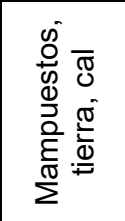 & 은 \\
\hline & $\begin{array}{l}0 \\
\stackrel{1}{b} \\
\dot{b} \\
\frac{1}{0} \\
\frac{0}{0}\end{array}$ & $\stackrel{\mathscr{N}}{\stackrel{N}{*}}$ & 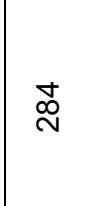 & 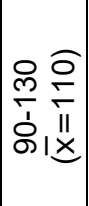 & 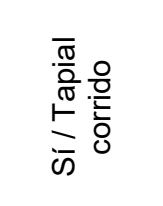 & 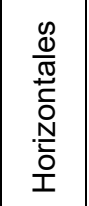 & 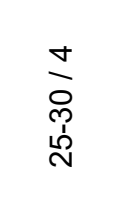 & ळ & 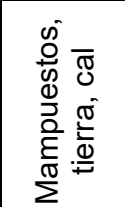 & 을 \\
\hline$\frac{\bar{\omega}}{\frac{\pi}{\pi}}$ & $\begin{array}{l}\check{z} \\
0 \\
u\end{array}$ & 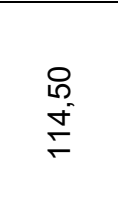 & $\stackrel{10}{\stackrel{2}{N}}$ & 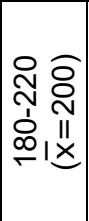 & 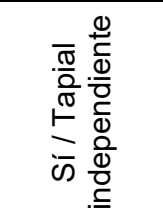 & 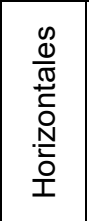 & 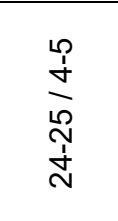 & $\bar{\omega}$ & 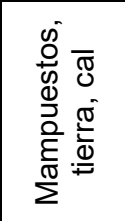 & $\bar{\omega}$ \\
\hline $\begin{array}{l}\text { ర్ } \\
0\end{array}$ & $\Xi$ & $\stackrel{N}{N}$ & 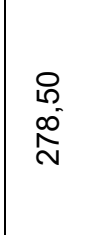 & 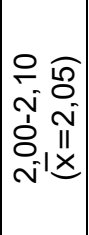 & 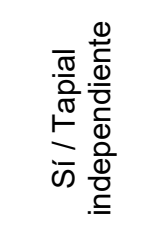 & 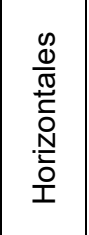 & $\begin{array}{l}+ \\
\stackrel{+}{\infty} \\
\stackrel{\omega}{\sim}\end{array}$ & i & 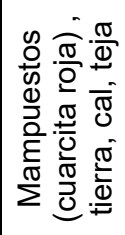 & $\bar{\omega}$ \\
\hline$\stackrel{\mathbb{N}}{=}$ & 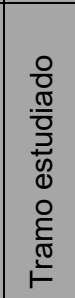 & 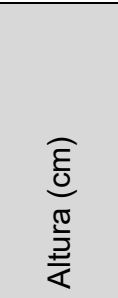 & 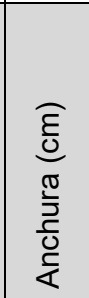 & 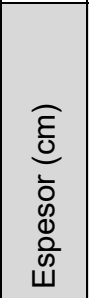 & 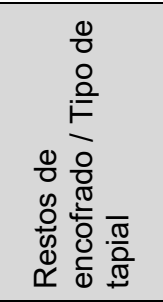 & 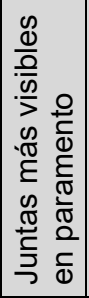 & 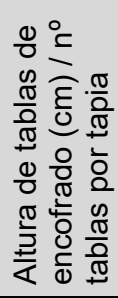 & 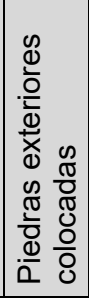 & 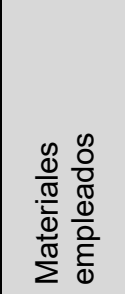 & 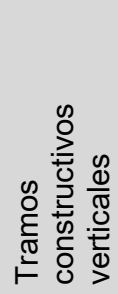 \\
\hline
\end{tabular}



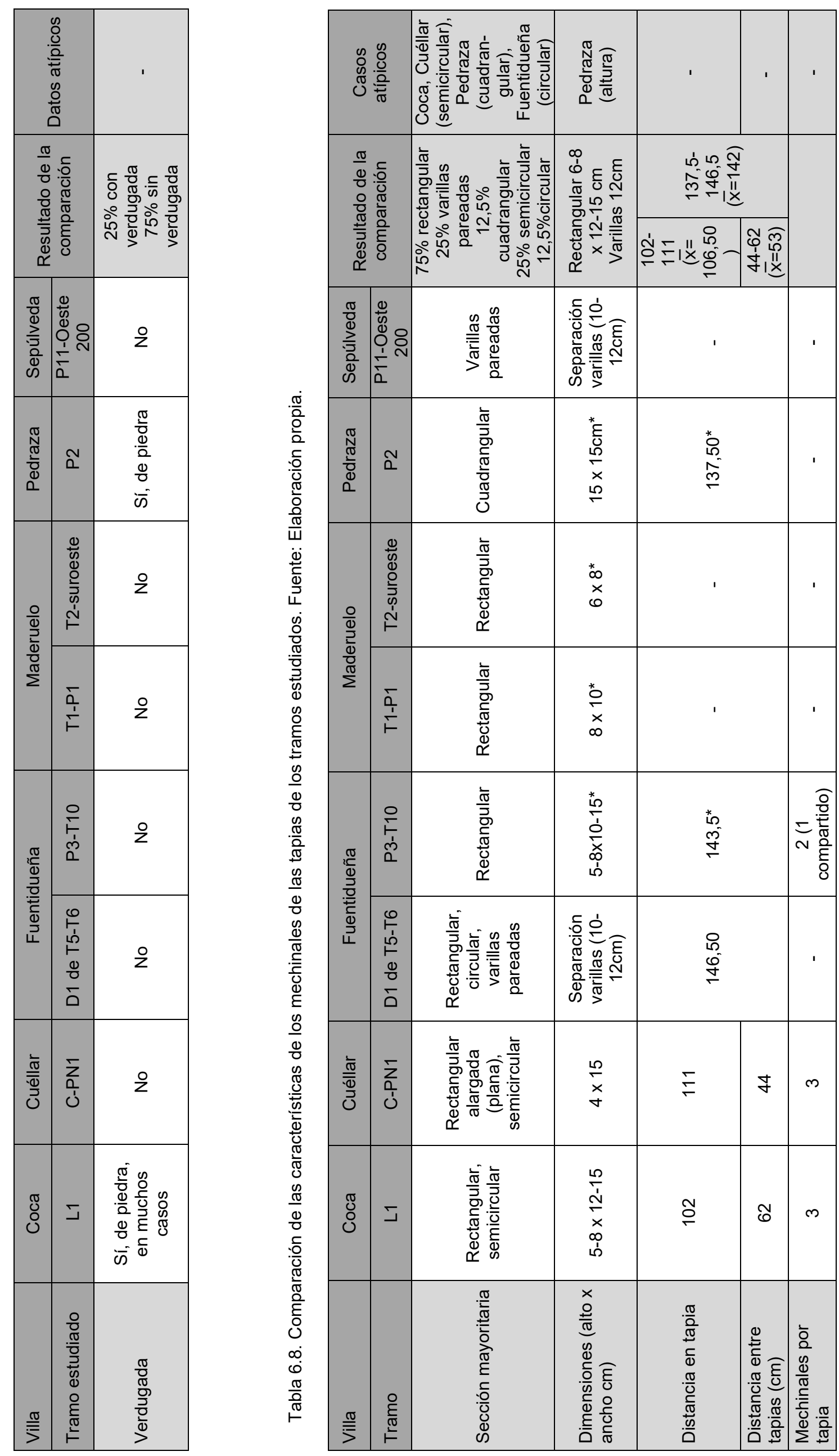


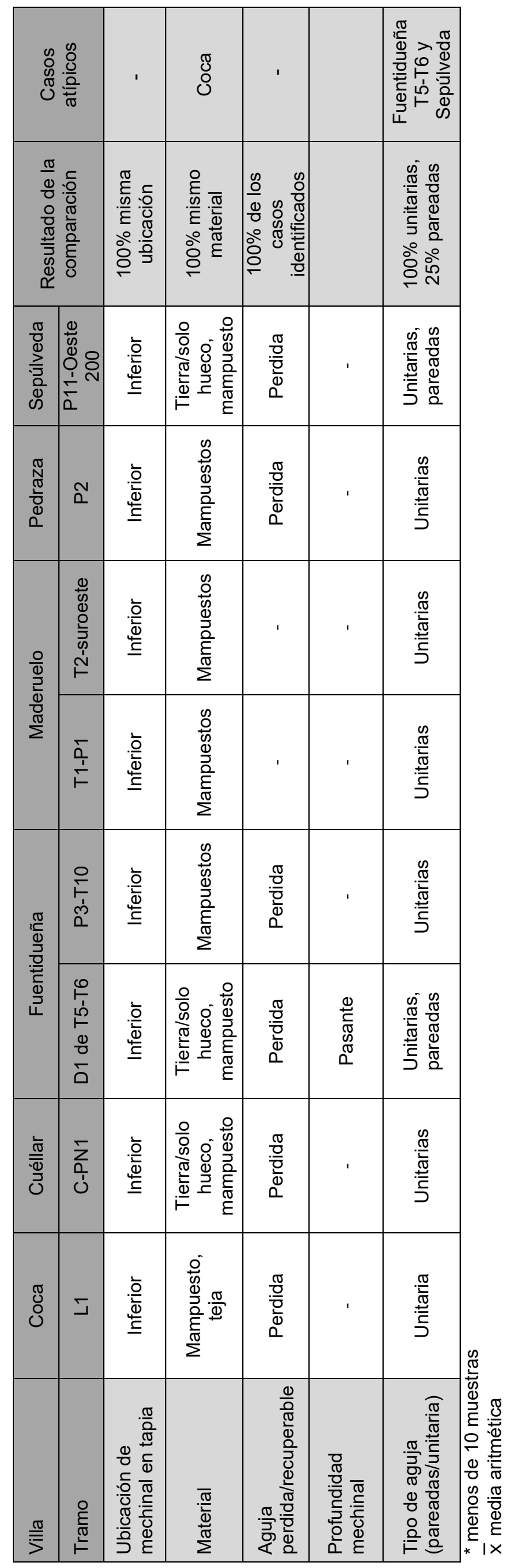


Las murallas en las Comunidades de Villa y Tierra del reino de Castilla en los siglos XI-XIII dentro de la Diócesis de Segovia. Técnica y sistemas constructivos de la arquitectura defensiva medieval.

\subsubsection{Mechinales y agujas}

- Posición y distancia entre mechinales

La posición de los mechinales en todos los casos de las tapias estudiadas es similar. En todos los casos los mechinales se sitúan en la zona inferior de la tapia. Cuando los mechinales se sitúan exactamente en el hilo de di visión de I as tapias, se ha considerado igualmente la parte inferior de la tapia. Se entiende que cuando las agujas se colocan sobre una tapia ya fraguada, forman parte de la nueva tapia, colocándose en su base.

Puede parecer que la solución de colocar las agujas en la base del nuevo bloque sea una solución habitual; ahora bien, en la arquitectura defensiva se dan casos de tapias construidas con las agujas en la parte superior de las tapias. En el caso del Castillo de Montejo de la Vega de la Serrezuela, en Segovia, se conserva un lienzo de longitud de $25 \mathrm{~m}$ aproximadamente, con una torre en su extremo norte. En la cara oeste del lienzo se pueden identificar las tapias de mampostería empleadas en su construcción. Los mechinales son fácilmente localizables, son de tamaño considerable y de sección cuadrangular. Se colocan en la parte superior de las tapias, preparándose así en la tapia inferior los mechinales que servirán para afianzar el tapial de la tapia superior. Las líneas de las tapias son perfectamente visibles, el mechinal queda embebido en la parte superior de I a tapia (Fig. 6.44). Por otra parte, es muy probable que los mechinales colocados en la parte superior sirvieran también para el encofrado de esa misma tapia, aunque luego se reaprovecharan en la superior.

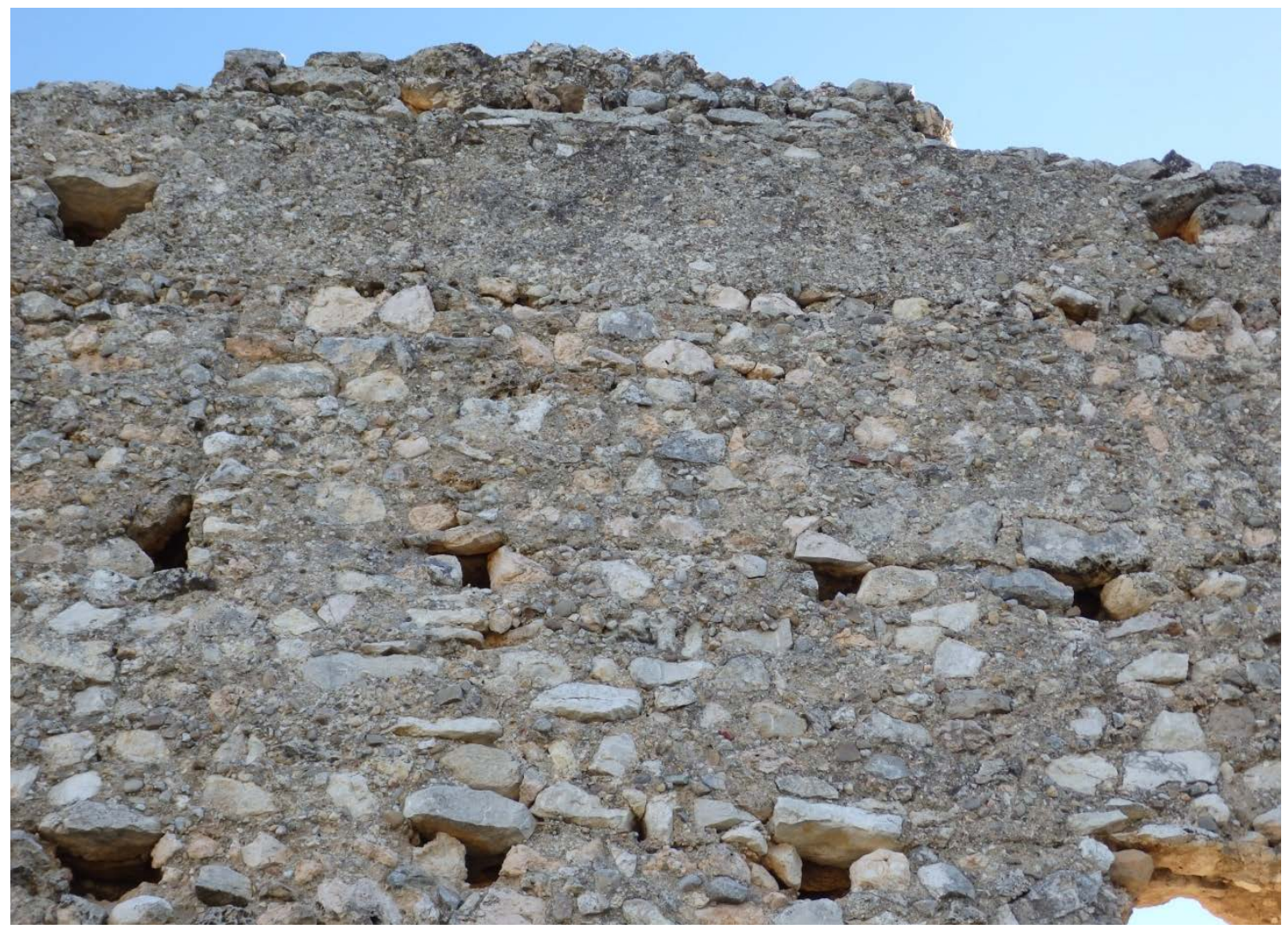

Fig. 6.44. Tapias del castillo de Montejo de la Vega de la Serrezuela, donde se observa la ubicación de mechinales en la zona superior de las tapias [A.S.E. 10/12/2014]. 
- Profundidad del mechinal. Aguja perdida o recuperable.

La profundidad del mechinal resulta difícil de evaluar y no ha podido ser determinada en tres de los casos estudiados. Sólo si se tiene acceso a ambas caras de un mismo lienzo se tiene la oportunidad de determinar esta característica. En los casos de Coca, Cuéllar, Fuentidueña y Sepúlveda se ha considerado que la profundidad de la aguja empleada es el total del espesor del muro, pero solamente en Fuentidueña se ha podido ratificar con total seguridad. En el caso de Sepúlveda, se ha considerado que el uso de varillas pareadas requiere de piezas pasantes, que superen el espesor del muro, por la dificultad que tendría fijar una de estas varillas en el interior de la tapia sin que se deslizara en el momento del vertido. En relación con la reutilización de agujas, en todos los casos se emplean agujas perdidas. Es posible ver muchas de ellas todavía embebidas en los muros. El escaso espesor de la muralla de Fuentidueña podría facilitar la reutilización de agujas y es visible algún mechinal vacío. No obstante, la presencia de agujas en la muralla hace creer que se abandonaban en el lienzo.

- Ritmo de mechinales en el lienzo y número de agujas en la tapia

El ritmo de mechinales en el lienzo de muralla es el reflejo del tipo de tapial empleado en la construcción de las tapias. A falta de límites de tapia visibles, permite identificar el tapial empleado en la construcción del lienzo. La tapia independiente identificada en Coca o en Cuéllar tiene un ritmo similar en los dos casos, B-A-A, siendo B el tramo corto entre los mechinales laterales de dos tapias colindantes y A la separación de los mechinales dentro de la misma tapia. Se correspondería con el tipo 1 marcado en la Fig. 6.45. El tipo 2 (Fig. 6.46), muestra un ritmo constante A-A donde los mechinales se sitúan todos a una distancia similar. Tal y como se ha mencionado anteriormente, la división de las tapias se sitúa sobre un mechinal o inmediatamente al lado, dando pie a dos opciones. La primera implica que el tapial construido era de longitud mayor, por ejemplo doble, y que se realizaba una tapi a primero y una vez fraguada esta se realizaba la segunda, por lo que se ve la división entre ellas. La segunda opción sería que se realizaba una tapia completa, se retiraba el tapial y para la construcción del siguiente tapial se reutilizaba el mechinal compartido entre las dos tapias. Cualquiera de estas dos opciones podría haberse empleado en el tramo P3-T11 de Fuentidueña. Al compartirse un mechinal entre dos tapias colindantes, el número de mechinales por tapia se reduce a dos.

El tipo 3 (Fig. 6.47) muestra un ritmo de mechinales constante A-A, pero no es visible la división vertical del as tapias. Así ocurre en I a zona D2 del lienzo T5-T6 de Fuentidueña, donde es imposible identificar los límites verticales de las tapias. En este caso, se observa cómo los mechinales también se alinean en s entido vertical, formando una retícula ortogonal de mechinales.

El tipo 4 (Fig. 6.48) es muy similar al tipo tres, porque tienen un ritmo de mechinales constante, A-A. La diferencia radica en que los mechinales no se alinean en sentido vertical, sino que se desplazan en una hilada con respecto a la inferior. Teniendo en cuenta la dificultad de alinear mechinales en estas construcciones irregulares, es posible que el tercer tipo y el cuarto sean el mismo. La formación de retículas podría 
coincidir y no buscarse expresamente. De todas formas, en la cara interior del lienzo P6-TM1 de Cuéllar (Fig. 5.2.110, pág. 197) se observa un grupo de mechinales con esta disposición. En algunos de los casos analizados, Pedraza, Maderuelo o Sepúlveda, el ritmo de mechinales se identifica con dificultad, por el deterioro de los lienzos a raíz de una situación ruinosa o de intensas reparaciones que obstaculizan la localización de los mechinales.

1

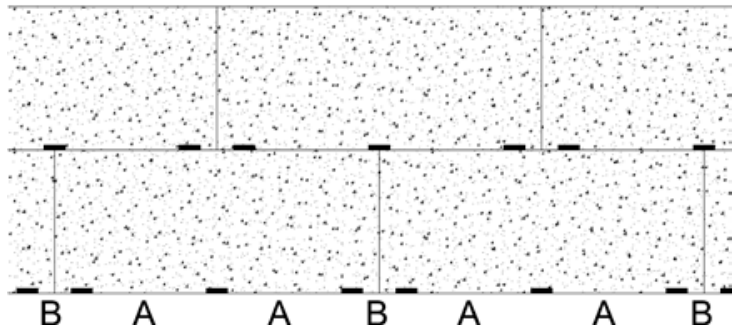

Fig. 6.45. Tipo 1: Ritmo B-A-A de mechinales. Fuente: Elaboración propia.

3

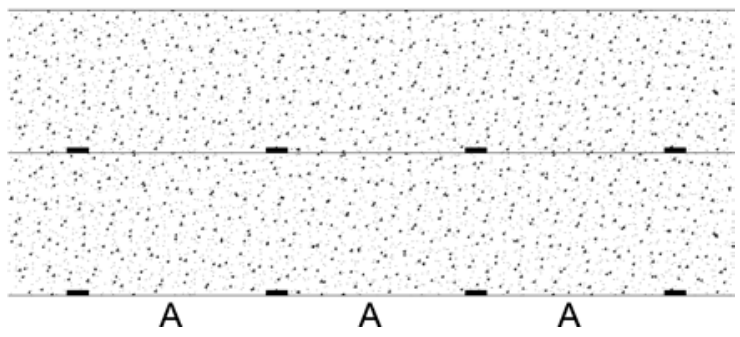

Fig. 6.47. Tipo 3: Ritmo A-A sin límites verticales de tapia. Fuente: Elaboración propia.
2

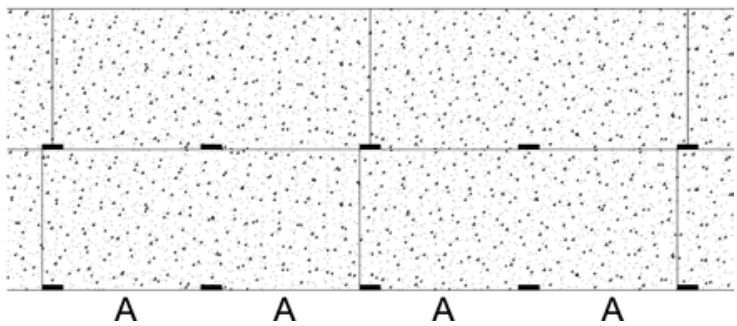

Fig. 6.46. Tipo 2: Ritmo A-A de mechinales. Fuente: Elaboración propia.

4

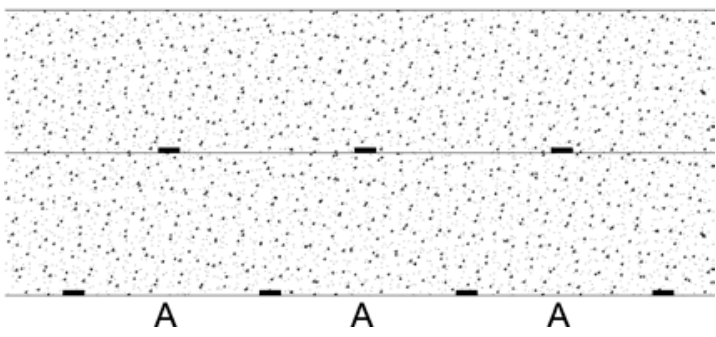

Fig. 6.48. Tipo 3: Ritmo A-A sin límites verticales de tapia y mechinales no alineados en sentido vertical Fuente: Elaboración propia.

- Sección y dimensiones

La sección de los mechinales es muy variada en los tramos analizados (Fig. 6.49). La más habitual es la sección rectangular, que aparece en casi todos los casos, excepto en la puerta P2 de Pedraza, donde la sección es cuadrangular, y en Sepúlveda, donde el tramo P11-Oeste $200 \mathrm{pr}$ esenta mechinales de $\mathrm{v}$ arillas pareadas. Las varillas pareadas se encuentran también en el tramo T5-T6 de Fuenti dueña, en algunos puntos. Además, en este tramo se observan mechinales de sección circular. De forma atípica, en Coca se observan mechinales con forma semicircular, cubiertos con una teja cobija. No se encuentra esta solución con teja en ningún otro recinto estudiado. Estas secciones identifican ya una predominancia de la aguja unitaria, presente en todos los casos, frente a la pareada, sólo presente en dos de ellos.

Algunas de las secciones de mechinales varían en función del estado de conservación de la tapia. El acabado superficial de I as tapias no $m$ ostraría en or igen los mampuestos empleados, al menos tal y como se ven ahora. En Coca se observan 
tapias con mampuestos al descubierto, pero también alguna conserva el acabado superficial, resultado del vertido, donde se observan marcas de tablas del tapial. La sección del mechinal puede variar en función del acabado existente en la actualidad. Allí donde se ve un acabado superficial terroso, el mechinal adopta la forma de la aguja y se encuentran secciones propias de piezas de madera, planas, trapezoidales como resultado del corte de un tronco, semicirculares por el empleo de medio tronco, o circulares, cuando se emplea un tronco completo, aunque sea de es caso diámetro. Cuando el acabado superficial muestra un grupo de mampuestos, estos suelen formar una oquedad rectangular que no muestra la forma original de la aguja, a menos que se conserve parte de la mezcla o la propia aguja todavía en el interior del mechinal.

$\begin{aligned} & \text { Varillas } \\ & \text { pareadas con } \\ & \text { mampuesto }\end{aligned}$
$\begin{aligned} & \text { Varillas } \\ & \text { pareadas }\end{aligned}$

Fig. 6.49. Configuración de los mechinales visibles en los casos analizados. Fuente: Elaboración propia.

\subsubsection{Tipología de tapia}

Las tapias analizadas son muy semejantes entre sí si se clasifican con el sistema de Amparo Graciani y Miguel A. Tabales $(2008,139)$ realizado en el área sevillana, que desarrolla de forma más intensa la clasificación de las tapias mixtas. Para las tapias monolíticas, solo se pueden establecer diferencias en el tipo de m echinal, si este posee algún remate de otro material o si se observan verdugadas.

Tabla 6.9. Tipología constructiva de las tapias analizadas de acuerdo de Amparo Graciani y Miguel A. Tabales $(2008,139)$ en el área sevillana.

\begin{tabular}{|l|c|c|c|}
\cline { 2 - 4 } \multicolumn{1}{c|}{} & Tipo de tapia & Mechinal & Verdugada \\
\hline \multirow{2}{*}{$\begin{array}{l}\text { Coca } \\
\text { L1 }\end{array}$} & Monolítica & $\begin{array}{c}\text { Remate de } \\
\text { mampuesto }\end{array}$ & Verdugada de piedra \\
\cline { 2 - 4 } & Monolítica & Remate de teja & Verdugada de piedra \\
\hline $\begin{array}{l}\text { Cuéllar } \\
\text { C1-PN1 }\end{array}$ & Monolítica & $\begin{array}{c}\text { Remate de } \\
\text { mampuesto }\end{array}$ & Sin verdugada \\
\hline $\begin{array}{l}\text { Fuentidueña } \\
\text { T5-T6 }\end{array}$ & Monolítica & $\begin{array}{c}\text { Remate de } \\
\text { mampuesto }\end{array}$ & Sin verdugada \\
\hline
\end{tabular}




\begin{tabular}{|c|c|c|c|c|c|}
\hline & \multicolumn{3}{|c|}{ Tipo de tapia } & Mechinal & Verdugada \\
\hline $\begin{array}{l}\text { Maderuelo } \\
\text { T1-P1 }\end{array}$ & \multicolumn{3}{|c|}{ Monolítica } & $\begin{array}{l}\text { Remate de } \\
\text { mampuesto }\end{array}$ & Sin verdugada \\
\hline $\begin{array}{l}\text { Pedraza } \\
\text { P2 }\end{array}$ & \multicolumn{3}{|c|}{ Monolítica } & $\begin{array}{l}\text { Remate de } \\
\text { mampuesto }\end{array}$ & Verdugada de piedra \\
\hline \multirow{2}{*}{$\begin{array}{l}\text { Sepúlveda } \\
\text { P11-oeste } 200\end{array}$} & \multicolumn{3}{|c|}{ Monolítica } & $\begin{array}{l}\text { Remate de } \\
\text { mampuesto }\end{array}$ & Sin verdugada \\
\hline & Mixta & Encadenado & En piedra & $\begin{array}{l}\text { Remate de } \\
\text { mampuesto }\end{array}$ & Sin verdugada \\
\hline
\end{tabular}

En los tramos estudiados, los mechinales se rematan de forma semejante en todos ellos, o bien con mampuestos o sin ningún remate. En el caso de Coca, además de mampuestos en el remate, se ven tejas cobijas. Sólo en dos casos se observa de forma evidente la presencia de verdugadas de piedra en la base de las tapias, en Coca y en Pedraza. De forma general la tipología de estas tapias sería monolítica, con remate en mechinales de mampuesto y sin verdugadas.

En la tipología de Ias tapias según la clasificación planteada por Gil Crespo (Tabla 6.10), las tapias compartirían muchos de los apartados: el material de construcción, con mampuestos en todos los casos; la compactación del material, realizada por vertido; la posición y la formación de los mechinales, que se sitúan en el propio hilo de las tapias y cuya formación se configura con mampuestos, aunque es cierto que en el caso de Coca se utiliza también teja, como se ha comentado anteriormente. Los materiales empleados son también coincidentes, mampuestos, tierra y cal. El acabado superficial se ha reflejado como "capa externa de mampostería", para reflejar que en la construcción de la tapia existe un es fuerzo de aparejar mampuestos en las caras exteriores. Sin embargo, se has eñalado en v arias ocasiones que el acabado superficial de estas tapias tendría un aspecto terroso, resultado del fraguado del material vertido que llenaría los huecos entre mampuestos. Este acabado es visible en muchas zonas de las murallas estudiadas y es allí donde se aprecian las marcas de las tablas del tapial. Algo similar ocurre con el parámetro "mechinales-formación" donde se ha indicado para todos los casos que se produce la formación con un cielo de mampuestos, ladrillo o teja. Se observan muchos mechinales con formas planas o rectangulares que no es tán rodeados por piedras, sino que s e destacan en un acabado terroso, de manera que solo un hueco es visible. Tal y como se ha comentado al hablar de la sección de los mechinales, al no tratarse estas de tapias de tierra, los mechinales donde se ve un hueco sobre el acabado terroso también se rodean de mampuestos ocultos bajo esa capa superficial. Al menos, se ve así en aquellas tapias que han perdido esa capa y muestran los mampuestos que la conforman. 


\begin{tabular}{|c|c|c|c|c|c|c|c|c|c|c|c|}
\hline $\begin{array}{l}\frac{\pi}{0} \\
\frac{0}{0} \\
\frac{0}{0} \\
: \frac{0}{0} \\
\frac{0}{0} \\
\frac{\pi}{0} \\
\frac{0}{\pi} \\
\frac{\pi}{U} \\
\frac{0}{0} \\
\frac{\pi}{0}\end{array}$ & 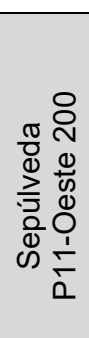 & 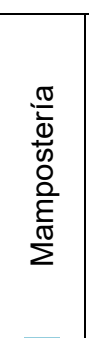 & $\begin{array}{l}\frac{O}{0} \\
\frac{0}{0} \\
\text { Dे }\end{array}$ & 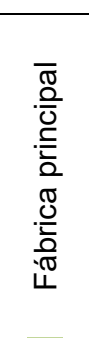 & 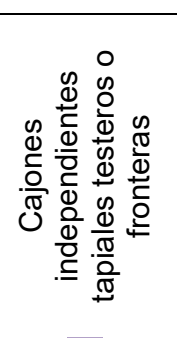 & 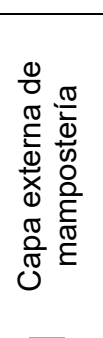 & 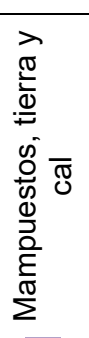 & 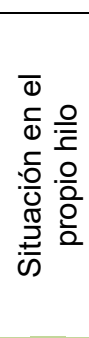 & 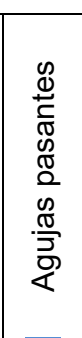 & 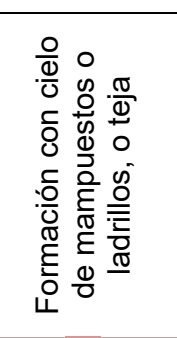 & 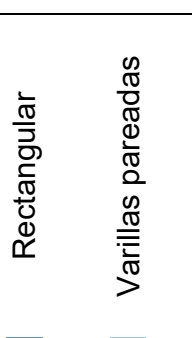 \\
\hline 崫 & & 10 & N & - & $\theta$ & $\theta$ & $\theta$ & $r$ & N & $m$ & $N$ \\
\hline 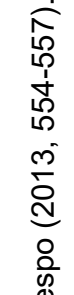 & $\begin{array}{l}\mathbb{N} \\
\mathbb{N} \\
\frac{\mathbb{N}}{0} \\
0 \\
0\end{array}$ & 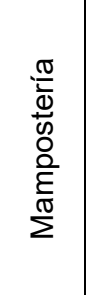 & 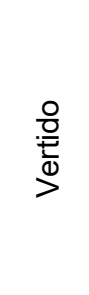 & 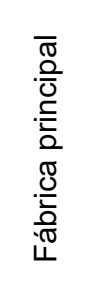 & 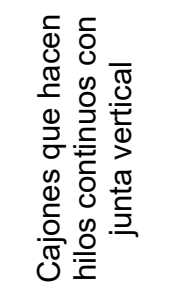 & 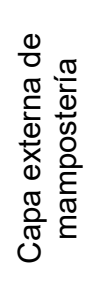 & 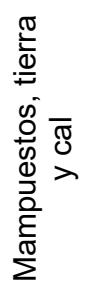 & 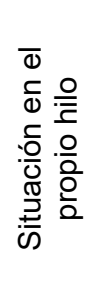 & ' & 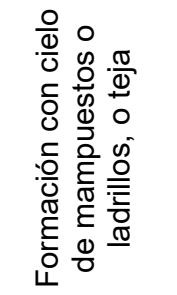 & 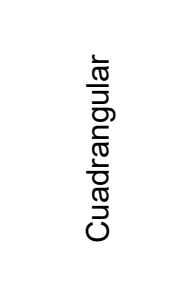 \\
\hline 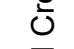 & & in & N & $\tau$ & $\theta$ & $\nabla$ & $\nabla$ & r & ' & $m$ & - \\
\hline 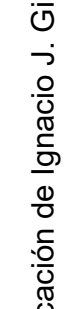 & $\begin{array}{l}\frac{0}{0} \\
\frac{2}{2} \bar{F} \\
\frac{0}{0} \frac{1}{a} \\
\sum\end{array}$ & 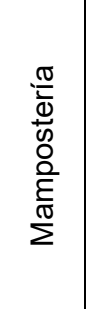 & $\begin{array}{l}\frac{0}{0} \\
\frac{0}{0} \\
\frac{0}{D}\end{array}$ & 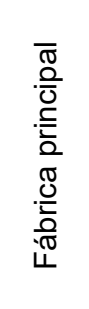 & ' & 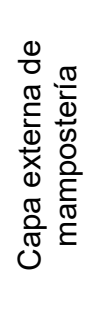 & 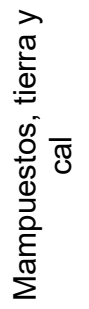 & 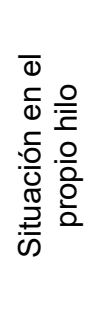 & ' & 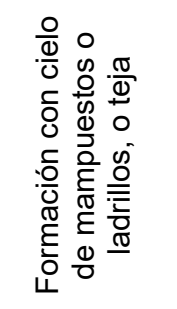 & 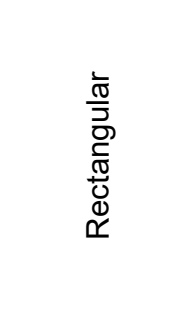 \\
\hline$\frac{\frac{5}{5}}{\infty}$ & & 10 & N & - & ' & $\theta$ & $\theta$ & $r$ & ' & $m$ & $N$ \\
\hline $\begin{array}{l}\frac{\pi}{0} \\
\frac{\pi}{0} \\
\overline{0} \\
0 \\
0 \\
\frac{0}{0} \\
\frac{0}{0} \\
0 \\
0 \\
0 \\
0 \\
0\end{array}$ & 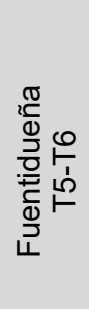 & 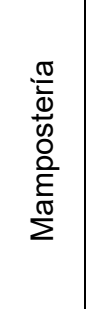 & $\begin{array}{l}\frac{0}{\circ} \\
\frac{0}{0} \\
\frac{0}{>}\end{array}$ & 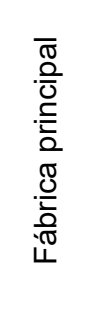 & 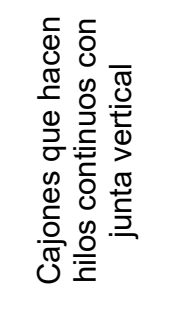 & 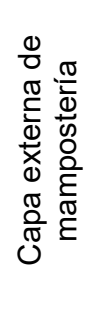 & 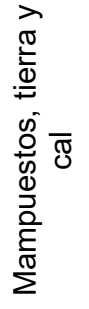 & 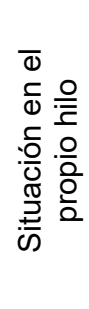 & 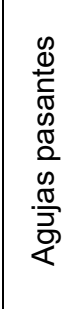 & 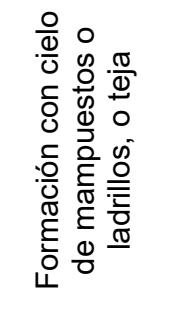 & 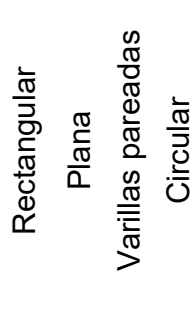 \\
\hline$\frac{7}{\pi}$ & & L & N & - & $\nabla$ & $\nabla$ & $\theta$ & $r$ & N & $m$ & $N M$ m \\
\hline 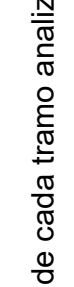 & 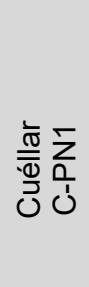 & 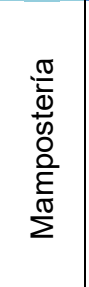 & $\begin{array}{l}\frac{0}{\circ} \\
\frac{0}{0} \\
\frac{0}{>}\end{array}$ & 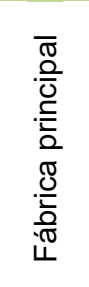 & 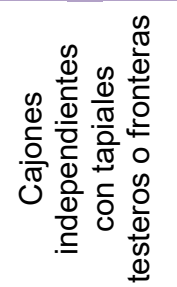 & 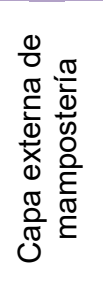 & 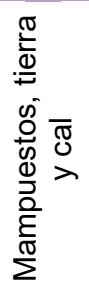 & 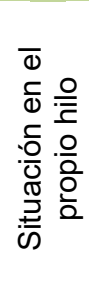 & 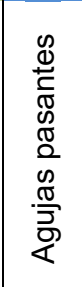 & 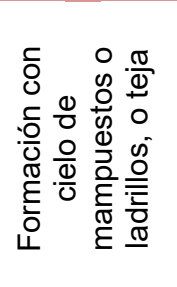 & 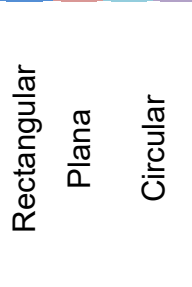 \\
\hline . & & م & N & 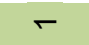 & - & $\nabla$ & $\nabla$ & $r$ & N & $m$ & $\sim m \quad \nabla$ \\
\hline 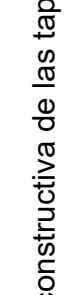 & பூ & 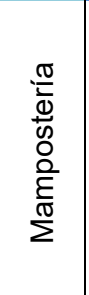 & $\frac{\frac{0}{\circ}}{\frac{0}{0}}$ & 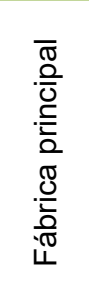 & 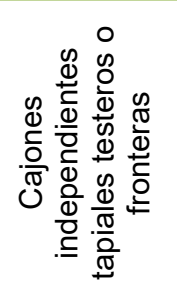 & 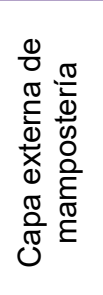 & 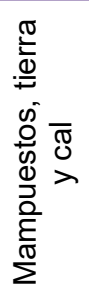 & 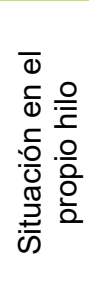 & 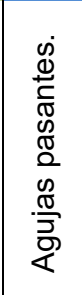 & 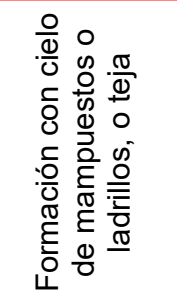 & 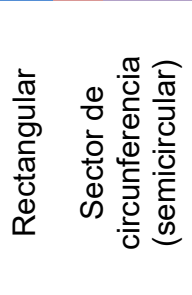 \\
\hline$\frac{\pi}{\pi}$ & & 10 & N & $r$ & r & $\nabla$ & $\nabla$ & $r$ & N & $m$ & $N \quad 0$ \\
\hline $\begin{array}{l}\circ \\
\frac{0}{6} \\
\frac{\pi}{0}\end{array}$ & & 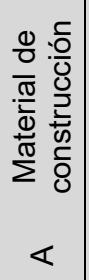 & 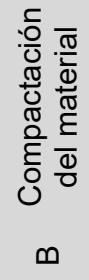 & 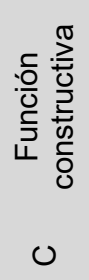 & 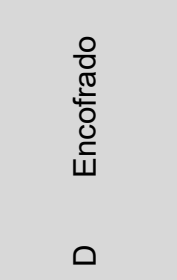 & 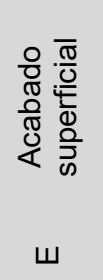 & 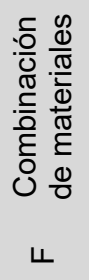 & 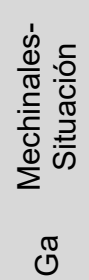 & 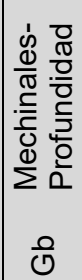 & 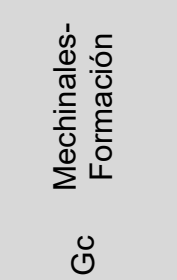 & 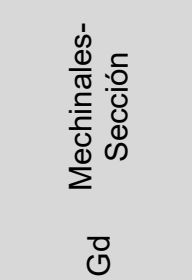 \\
\hline
\end{tabular}


Los parámetros donde se observan diferencias son el encofrado y la sección de los mechinales. En Cuéllar y Coca se utilizan cajones independientes frente al resto de casos, que utilizan tapiales para hilos continuos de tapia o corridos. El caso de Fuentidueña es fácilmente identificable, pero no así en el resto de casos, donde existen escasos restos o muy deteriorados, lo que dificulta la lectura. La sección de mechinales es sin duda el parámetro que muestra mayor diversidad. Aunque la gran mayoría de ellos presenta la sección rectangular, en cuatro de los casos se utiliza además otra solución alternativa. En cuanto al parámetro de I a profundidad de mechinales, no está completo en todos los tramos estudiados, por la dificultad que conlleva en algunos casos averiguar si el mechinal atraviesa todo el muro o, por el contrario, su longitud es menor. Al existir tantos parámetros, no es posible dar un nombre general de las tapias empleadas aquí que recoja todos ellos.

\subsubsection{Comparativa de las tapias representativas utilizando la Estadística}

Para esta comparativa se han utilizado los datos relativos a las tapias (Tabla 6.7), pero no se han incluido los que afectan al os mechinales, ya que varios parámetros relativos a estos se desconocen para algunos casos. En Maderuelo, Pedraza, Sepúlveda y uno de I os tramos de Fuentidueña no se han podido extraer todas las características de las agujas empleadas.

La identificación de una tapia representativa de cada caso, encontrada en el análisis de un tramo de cada muralla, tiene como objetivo listar las características de cada caso para levar a cabo una comparación. Ahora bien, la lectura de una tabl a que compara hasta diez parámetros de cada tapia puede ser muy complicada de analizar, por lo que ofrecer una i magen de conjunto que per mita indicar qué casos se aproximan entre sí y cuáles se alejan puede resultar muy complicado e i ncluso subjetivo.

A través de una her ramienta estadística, basada en la teoría de componentes principales, es posible reducir la dimensión 10 de los parámetros iniciales a dimensión 2 y poder así plasmar los resultados en un gráfico convencional de dos dimensiones. La superposición de d os gráficos, de puntos y vectorial en un mismo origen de coordenadas ofrece una relación entre los casos y los parámetros analizados (Fig. 6.50 y Fig. $\left.6.51^{38}\right)$.

De la Tabla 6.7 no se han utilizado los diez parámetros sino tan solo siete de ellos. Esto se debe a que I a técnica estadística utilizada permite comparar como máximo tantos parámetros como casos. En este estudio, se cuenta con siete tapias representativas de cada tramo estudiado en cada villa, con dos de ellas situadas en Fuentidueña. No es posible comparar más de siete parámetros, por lo que se han descartado tres. Se han desestimado aquellos parámetros donde todos los casos son

\footnotetext{
${ }^{38}$ Estas gráficas han sido modificadas cuando los datos se superponían dificultando su legibilidad; las gráficas originales se adjuntan al final del anexo 2.
} 
coincidentes, como por ejemplo "Juntas más visibles en el paramento" que en todos los casos es la horizontal, "Altura de tablas de encofrada / $\mathrm{n}^{\circ}$ de tablas por tapia" donde la altura es $25-30 \mathrm{~cm}$ en todos los casos, con cuatro tablas por tapia o "piedras colocadas en caras exteriores" por ser también constante en todos los casos. El espesor y el tipo de piedra empleada son dos parámetros que s olo presentan un ejemplo diferente del resto, Fuentidueña en relación con el espesor y Coca en relación la piedra empleada.

Los casos analizados son L1 en Coca, que en la gráfica se simplifica indicando solo "Coca", C-PN1 en Cuéllar, que igualmente se simplifica con "Cuéllar". En Fuentidueña, T5-T6 está marcado como "Fuentidueña 1" y P3-T10 sería "Fuentidueña 2". En Maderuelo se analiza el tramo T1-P1 identificado como Maderuelo, en Pedraza ocurre lo mismo con la zona P2 y en Sepúlveda se analiza el tramo P11-Oeste 200 y se nombra en la gráfica como "Sepúlveda".

Los parámetros analizados son la altura y anchura de la tapia, su espesor, qué piedra se ha empleado, qué tipo de tapial se ha utilizado, la existencia o no de verdugadas, y finalmente si se producen tramos constructivos. El resultado es una gráfica (Fig. 6.50) que muestra los nombres del os casos colocados en coordenadas concretas y vectores que parten del origen de coordenadas en distintas direcciones. La posición de los casos indica la afinidad que existe entre ellos, acercando aquellos que presentan características similares y alejando los que muestran una configuración distinta. Los vectores permiten entender la posición de los casos y señalan la dirección de los valores más altos. En el caso de los parámetros dimensionales, altura, anchura y espesor, los vectores apuntan a los valores más altos de estas variables. La altura y la anchura más altas corresponden a los casos de Fuentidueña, Cuéllar, Coca, frente al caso de Pedraza que se opone a I a dirección de los vectores, por lo que presenta valores más bajos en estos parámetros. Maderuelo y Sepúlveda no s erían representativos en estas variables. En el caso del espesor, los valores más bajos se situarían en dirección opuesta al vector de es ta variable, como ocurre con los dos tramos de Fuentidueña.

Algunas variables no son dimensionales, sino que los valores son del tipo Sí/No, como ocurre con "Tramos", "Verdugada", que recogen si se construye o no con tramos o si se añaden verdugadas a las tapias. En estos casos, los valores Sí/No se representan con los números $1 / 0 \mathrm{r}$ espectivamente, de for ma que los valores más altos corresponderán con el 1, por lo tanto con el Sí. Coca y Cuéllar se aproximan al vector "Tramos", que indica que poseen una construcción por tramos.

Las variables "Tapial" o "Piedra" no son dimensionales y tampoco arrojan resultados del tipo Sí/No, sino que identifican tipos de piedra o de tapial. Estos tipos se representan a través de números. En el caso del "Tapial", el número 1 corresponde con el tipo de tapial independiente y 2 el tipo de tapial corrido. De esta forma, el vector "Tapial" se opone a la posición de los casos de Coca o C uéllar, que pos een tapial independiente. En el caso de la "Piedra", el número 1 es la cuarcita roja y el número 2 la piedra caliza, por lo que el vector señala en la dirección de este último valor. 


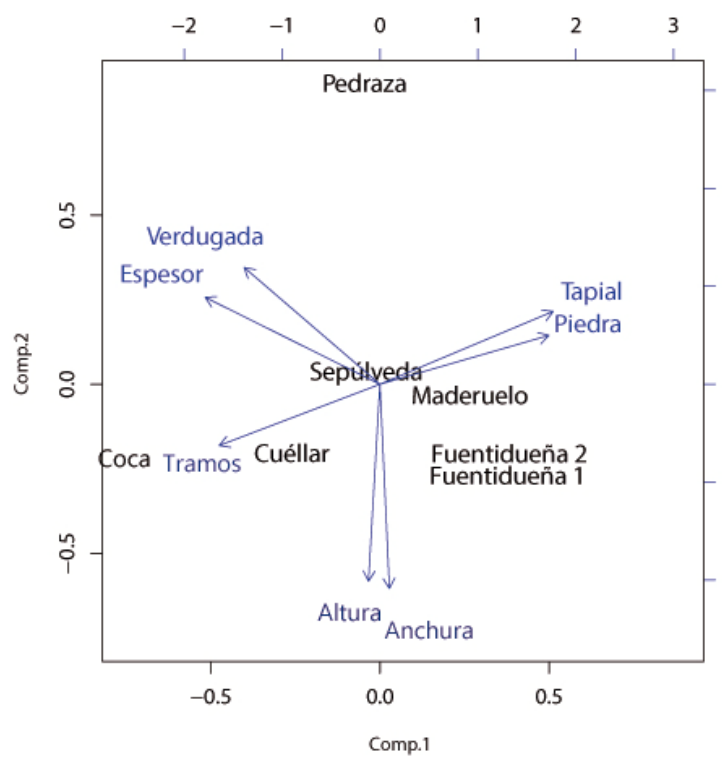

Fig. 6.50. Gráfica que compara los casos en función de varios parámetros de la tapia. Fuente: Elaboración propia con el programa R. Los comandos utilizados para la realización de esta gráfica se encuentran en los anexos.

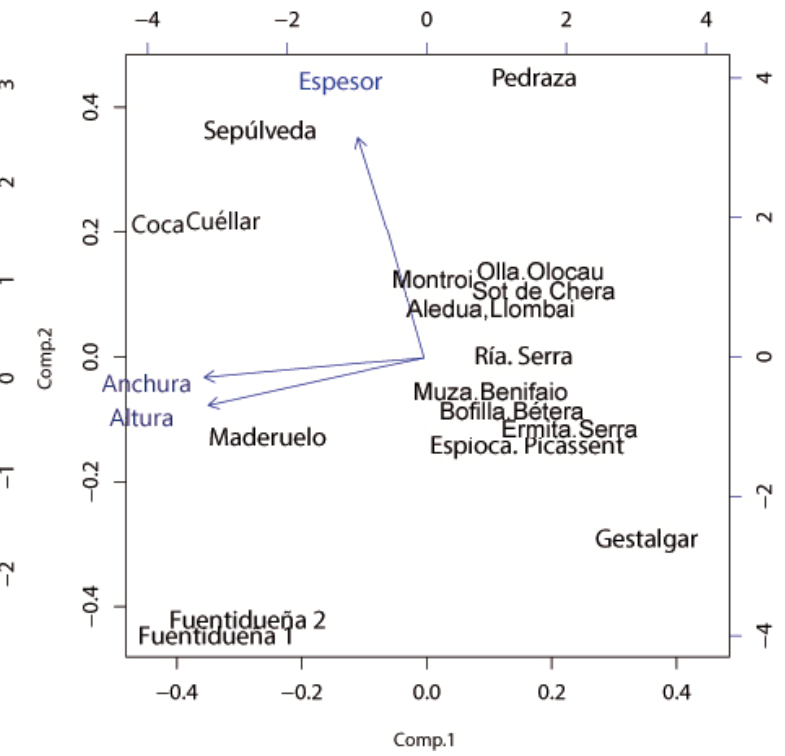

Fig. 6.51. Gráfica que compara altura, anchura y espesor de las tapias de los casos estudiados aquí, con las tapias de las torres valencianas. Fuente: Elaboración propia con el programa $\mathrm{R}$ y con datos de Pablo Rodríguez Navarro $(2008,241)$.

Si se hace una lectura general, la gráfica en la Fig. 6.50 muestra un ai slamiento intenso en el caso de Pedraza, que se aleja del resto de los casos, principalmente en dirección opuesta a la que señalan los parámetros de altura y anchura. Coca también parece alejarse en la dirección que señala los tramos constructivos, con Cuéllar a la zaga. Estos dos casos se posicionan en dirección opuesta a la piedra empleada y al tipo de tapial con el número asignado más alto, que se ha indicado anteriormente que es el de ti po corrido. Maderuelo, los dos casos de Fuen tidueña y Sepúlveda se encuentran relativamente próximos. Cuéllar se aleja ligeramente, en la dirección que marca altura y anchura, y tramos constructivos, alejándose del tipo de tapial empleado. Maderuelo y Fuentidueña parecen afines en cuanto a dimensiones, tipo de piedra y tapial se refiere. Sepúlveda, aunque próxima a el los, se sitúa en el origen de coordenadas, lo que indica que no destaca de forma significativa en ninguno de los parámetros.

A través de esta gráfica (Fig. 6.50) se pueden plantear algunas afinidades entre los casos. Es significativa la situación aislada de Pedraza, en posición opuesta a I os parámetros dimensionales, que la aleja del resto de casos. Por otra parte, Sepúlveda, Maderuelo y los dos casos de Fuentidueña muestran una cierta proximidad. Finalmente, Coca y Cuéllar también presentan una afi nidad, condicionada por la existencia de tramos constructivos y el tipo de tapial empleado.

Con el objeto de comparar estas tapias con otras empleadas en otras zonas de la península ibérica, se han tomado las medidas de las tapias de las torres valencianas estudiadas por Pablo Rodríguez Navarro (2008, 241). Las dimensiones extraídas de estas torres son la altura, la anchura y el espesor y solo se han contemplado aquellos casos en los que se dispone de las tres medidas, un total de diez. En la gráfica Fig. 6.51 , se han comparado los tres parámetros, anchura, altura y espesor con las tapias 
de esta investigación. Se observa que las tapias de las torres se agrupan en la zona central derecha de la gráfica, mientras que las tapias de las murallas quedan en la zona izquierda, más dispersas, con algunos casos próximos, como Coca, Cuéllar y Sepúlveda o los dos tramos de Fuentidueña. Pedraza se aleja hacia la derecha, aunque no llega juntarse con el grupo de las torres.

\subsection{Ambigüedad en la terminología del tapial}

A lo largo de la redacción de es ta tesis, se ha dudado en m uchas ocasiones de la terminología a emplear, principalmente en aquella que hace referencia a Ia tapia. EI sistema es a primera vista sencillo, pero esconde gran cantidad de variantes y elementos que intervienen en su construcción. La palabra tapia hace referencia tanto al bloque individual como al propio muro, conjunto de las tapias. El Diccionario de la Real Academia Española (DRAE) lo define como "cada uno de los trozos de pared que se hacen de una s ola vez con tierra amasada y apisonada en un enc ofrado" e igualmente como "pared formada de tapi as". En el Diccionario de Construcción Tradicional (Hoz et al. 2003, 189) se define como "pared o muro, o parte de él (...)". Por otra parte, el tapial puede denominarse también encofrado, molde, caja o cajón, término este último que en oc asiones también pueden uti lizarse para referirse a la tapia. En el Diccionario de Construcción Tradicional (82), el término cajón posee ambas acepciones, tanto para referirse a la tapia como al tapial. Según este mismo diccionario (189), la palabra tapial presenta dos acepciones, la primera se refiere a la pared conformada con tapias y la segunda acepción hace referencia su concepto de encofrado. EI DRAE recoge igualmente ambas acepciones.

\subsubsection{Tapia de cal y canto, tapia de mampostería, mampostería encofrada}

Dentro de la tapia como sistema constructivo, la variante de cal y canto también es otro ejemplo de di ficultad a la hora de di ferenciar a qué tipo de tapia se hace referencia. La tapia de cal y canto, también escrita calicanto, abarcaría cualquier tapia realizada con "obra de mampostería" según el DRAE o sería un "compuesto de cal y canto" según el Diccionario de Construcción Tradicional (Hoz et al. 2003, 83). Algunos autores hacen referencia a la tapia de cal y canto como un sinónimo de la tapia de mampostería (Gil Crespo 2013, 16) y otros marcan una diferencia entre la tapia de cal y canto y la de mampostería encofrada (Cobos et al. 2012, 105, 118) indicando que "cuando no había cantos la mampostería también se encofra", lo que parece dar a entender que se diferencia el término canto del de mampuesto. El término canto se define en el DRAE y en el Diccionario de Construcción Tradicional (85) como "trozo de piedra". Mampuesto se define como "piedra sin labrar que se puede colocar en obra con la mano" en el Diccionario de Construcción Tradicional y tiene una definición muy similar en el DRAE. La definición de canto es entonces muy amplia y abarcaría cualquier tipo de piedra, mampuesto inclusive. Por extensión la tapia de cal y canto podría incluir cualquier tipo de pi edra, también el mampuesto. La definición de mampuesto como piedra sin labrar excluiría el concepto de canto rodado, material que 
se observa en muchos ejemplos de tapia de cal y canto, algunos de ellos mencionados aquí como San Pedro de Latarce, León o Torrejón de la Nava.

Dada esta variedad de acepciones, en es ta tesis se ha de nominado tapia de mampostería a aquella en la que se colocan mampuestos relativamente ordenados y luego se vierte una mezcla de piedras, tierra y cal como si de hormigón se tratara. Se ha considerando mampuesto a una pi edra de tamaño medio sin labrar, es decir, con vértices y aristas de orden y forma aleatorio, diferenciada de un canto rodado. Se ha considerado esta tapia como un tipo de tapia de cal y canto distinto de aquel que utiliza cantos rodados. Cuando se ha hecho referencia a tapia realizada con cantos rodados, se ha procurado especificar que s e trata de c antos rodados, para evitar cualquier confusión. Se ha utilizado mampostería encofrada como locución equivalente a tapia de mampostería.

\subsubsection{Tapia de tierra}

La tapia de tierra no aparece en ninguna de las seis murallas estudiadas. En ninguno de los casos se han encontrado restos de esta técnica constructiva. Se diferencia de la técnica de la tapia de mampostería en que se emplea tierra como material constructivo y que además se apisona por capas para conferirle dureza. En el caso de la tapia de mampostería, tal y como se ha explicado, la compactación del material se realiza por vertido, como si de un hormigón moderno se tratara. En la tapia de tierra, se tiene en cuenta la proporción de arcilla y en al gunos casos se podría añadir cal o materia vegetal para ganar en consistencia. En francés esta técnica recibe el nombre de "pisé" y al parecer se identifica con la técnica de la tapia solo cuando esta se realiza con tierra. La té cnica del pisé implica el acto de comprimir el material con un pisón, de manera que no es aplicable en el caso de la tapia de mampostería. No se ha encontrado traducción literal de Ia tapia de mampostería en la lengua francesa. La traducción literal de esta técnica podría ser maçonnerie coffrée.

\subsection{Tiempos de construcción de la tapia de mampostería}

El estudio del proceso de fabricación de la tapia de mampostería puede ayudar a establecer cuánto tiempo se podía tardar en construir un lienzo de muralla. Para conocer ese dato, es necesario averiguar la capacidad de producción o extracción de los materiales necesarios, la piedra, la tierra y la cal para la mezcla y la madera para el tapial, cuyas piezas se perdían en cada aplicación, al menos las agujas. Juan Eslava Galán (1984, 273-274) indica que las proporciones de esta tapia es de 5 a 7 partes de arena, una parte de tierra cocida y otra parte de cal. No detalla en qué consiste la tierra cocida y tampoco especifica la proporción de piedras necesarias. Es posible aventurar que en las tapias estudiadas aquí, la proporción de cal fuera similar. En este caso, podrían tratarse de 5 a 8 partes de tierra y una parte de cal. 


\subsubsection{Obtención de materiales: piedra, tierra, cal y madera}

La piedra se extraería de canteras cercanas. Dada la singularidad de la piedra usada en Coca, la cuarcita roja, es posible plantear una distancia relativamente lejana desde la que se podría trasladar esta piedra, cuya cantera más cercana se sitúa a $18-20 \mathrm{~km}$ de distancia (Blanco 1990, 436), tal y como se ha indicado en el capítulo correspondiente al caso de Coca. También se adelantó el cálculo del tiempo necesario para trasladar un carro cargado de pi edras tirado por animales, que rondaría las 5 horas por trayecto. En el resto de los casos, es más probable que la piedra se extrajera desde canteras más cercanas. La tierra parece necesariamente más fácil de obtener. En las villas estudiadas no parece difícil obtener tierra en puntos cercanos o arena en los ríos a los que las villas se aproximan. Alberto Garín $(1996,385)$ distingue entre abastecedores y constructores, indicando que los abastecedores serían los caleros y en este caso los canteros aunque no los cite como tal. La piedra necesaria en estas murallas no es piedra tallada, sino piedras irregulares sin tallar, por lo que su obtención sería más sencilla y rápida. Entre los constructores, este autor sitúa a los carpinteros (393) aunque no r efleja expresamente su labor como constructor de tapiales. La madera sería necesaria para la construcción de tapiales y su extracción estaría vinculada a un pr oceso de tala, secado y carpintería para la fabricación de tablas, agujas y otros elementos integrantes del tapial.

La cal es otro elemento indispensable para la construcción de tapia de mampostería y que requeriría un proceso de transformación. El proceso de fabricación de la cal en la Edad Media sería posiblemente similar al sistema tradicional que se conoce en la actualidad, utilizando caleras $\mathrm{u}$ h ornos de $\mathrm{c}$ al para hornear la piedra caliza y transformarla en cal viva. De acuerdo con Beatriz Sanz y Gustavo Pedrosillo (2005, 63), el horno de cal tradicional tiene habitualmente forma de pozo cilíndrico de 3 a $4 \mathrm{~m}$ de profundidad de 2 a $3 \mathrm{~m}$ de diámetro. Sus paredes están recubiertas con arcilla que facilita la conservación del calor. En el fondo del pozo, a una al tura de $70 \mathrm{~cm}$, se construye una repisa, que servirá de apoyo para ir colocando las piedras para su cocción. Bajo la repisa se sitúa la leña que se prende para formar un fuego que se alimentará con más combustible durante el proceso de cocción. Para acceder a este espacio en el fondo del pozo, se construye una rampa desde la superficie que permite al calero alimentar la hoguera. En ocasiones se construye la calera en una ladera para aprovechar el desnivel de terreno y facilitar el acceso al fogón desde la parte más baja. También se aprovechan los montículos naturales o se construye uno ex profeso que deja al descubierto en la base una boca de acceso al fuego, protegida por muros que la flanquean.

Para la cocción de la piedra, se construye una falsa bóveda en el interior del pozo cuyas primeras hiladas se apoyarán en la repisa del fondo del pozo. Se rellena el pozo de esta manera, dejando espacios entre las piedras para garantizar el paso del aire en el pozo, que funciona como una chimenea cuando se inicia el fuego. La puesta en marcha el horno se reserva para las estaciones de primavera y otoño, momentos apropiados para la combustión (64). Se cuece la piedra durante 3 días y 2 noches, requiriendo el proceso de una alimentación continua del fuego, que permitirá alcanzar temperaturas de $900-1000^{\circ} \mathrm{C}$. Los autores indican que par a la realización de este 
proceso eran necesarias en torno a seis o siete personas. Este proceso era objeto de festejo, reuniendo a grupos de personas que incluso festejaban en torno a la calera. Cuando concluye el proceso de cocción, a los tres días, se interrumpe la alimentación del fuego y se tapa la boca del pozo, dejando una abertura a modo de tiro. Se deja cerrado el pozo durante una semana para que vaya perdiendo temperatura. La cal viva se extrae una vez se ha enfriado el horno.

El estudio de trece hornos tradicionales de cal existentes en Lecároz, Navarra (Vidal Pérez Villareal 1989), aporta más información acerca del sistema de producción de la cal. El funcionamiento de estas caleras se sitúa en el siglo XVIII, en el contexto del descubrimiento de la técnica de encalado de las tierras de labor que impulsó la revolución del maíz (377). El autor denomina "horno de cocido intermitente de llama larga" al horno que usa el sistema de cocción anteriormente descrito y considera que se trata del más antiguo sistema de producción de cal (379). Los hornos que describe este autor tienen una for ma ovoide alargada, no superan los $4 \mathrm{~m}$ de di ámetro y alcanzan una altura de $6 \mathrm{~m}$, llegándose en ocasiones a los $55 \mathrm{~m}^{3}$ de volumen (385). En cuanto al proceso de cocción, se indica que podía durar cinco o seis días (393); se valoraba su finalización en función del descenso del nivel de la carga de piedra caliza, que va reduciendo su volumen según avanza su cocción (394). En relación con la mano de obr a, se habla primero de los mantenedores del horno, tres o cuatro personas que se suceden cada doce horas para mantener el fuego $v$ ivo $y$ posteriormente se menciona varios grupos de siete $u$ ocho hombres que se iban turnando para controlar el proceso de c occión. La duración del proceso de enfriamiento se fija en dos días. Este autor habla también de otro sistema de cocción que apareció más tarde denominado "de llama corta" en el que se colocaban de forma alternada trozos de roca caliza y combustible vegetal y según se extraía por la parte inferior la cal viva, se introducía por la parte superior nuevas capas alternadas de piedra caliza y madera. Este sistema recibió el nombre de "calera de capa de producción continua" y sería más rápido.

Como se ha planteado el principio de este apartado, este proceso de fabricación de cal tradicional podría ser muy similar al existente en la época medieval. Se revela como un sistema complejo, que requiere de un conocimiento de la técnica y de mano de obra numerosa. Está limitada su producción por el tamaño del horno, que es probable que no pudiera superar un diámetro concreto, tal vez de $3 \circ 4 \mathrm{~m}$. La indicación de que se realice la cocción en primavera y tal vez en otoño, también supone un límite para la producción.

Alberto Garín $(1996,385)$ indica que el oficio de calero aparece caracterizado en tres fueros, cantidad que considera muy reducida al no figurar en muchos otros fueros. Indica que los caleros aportaban la cal molida al mercado donde se comercializaba al peso. En particular, detalla que el fuero de Carmona recoge la medida en fanegas. En la villa de Cuéllar, Juan C. Llorente et al. $(2012,236)$ recoge una mención a la muralla de 1484 , en la que se refiere la compra de 500 fanegas de cal en piedra para reparar un tramo de la muralla, desde la puerta de Carchena hasta arriba. En la producción de cal para la construcción de la muralla, es posible que esta no se adquiriera en el mercado común sino que las cuadrillas de constructores de la muralla contaran con un 
grupo de caleros específico. Teniendo en cuenta que se daban épocas adecuadas para producir cal, en primavera, es posible que se produjera cal con anterioridad, para disponer de ella en el momento de construcción de las tapias. Juan Eslava Galán $(1984,273)$ hace referencia a la necesidad de "pudrir la tierra" en el caso de la tapia de tierra, que i mplica airearla desde el otoño y dejarla secar durante cinco meses, expuesta a las lluvias, con el objeto de permitir un lavado de materia orgánica. No especifica una preparación de este tipo en el caso de la tapia de calicanto.

En relación con la tapia de calicanto, este último autor indica que además de cal, se podía añadir a la mezcla cerámica molida y cenizas de forja (273-274), señalando que la proporción de cal podía variar en función de si las tapias se ubicaban en la base o en la parte superior del lienzo, ganando en solidez cuanta más proporción de cal se añadiera. Las partes reforzadas serían las primera dos tapias del muro o las zonas más expuestas a impactos de máquinas de asedio.

\subsubsection{Construcción de la tapia}

De acuerdo con los datos dimensionales de las tapias estudiadas, se ha extraído unas dimensiones medias para una tapia, con el objeto de extraer el volumen de material necesario. Para evaluar el tiempo de construcción, se ha estimado un tramo de $11 \mathrm{~m}$ de muralla. Se ha pensado en un equipo de 12 personas para esta tarea, teniendo en cuenta que realizaría el trabajo por partes, con cuadrillas de constructores o albañiles.

Tapia: Anchura: 2,75m. Altura: 1,15m. Espesor: 2,00m. Volumen $=6,30 \mathrm{~m}^{3}=6.300$ litros.

Tramo: Longitud de $11 \mathrm{~m}$. Altura de $8 \mathrm{~m}=$ cuatro tapias por hilada, siete tapias de altura, un total de 28 tapias.

El ensamblado del tapial incluiría los pasos siguientes: Colocación de aguj as, colocación de paneles longitudinales, colocación de costales, cierre transversal, atado de costales en zona superior. Tiempo: 30min. Personas: 2-4.

Colocación de piedras pegadas contra la tablazón y sobre las agujas. Muro de $(2,75 \mathrm{x}$ 0,30 x1,15)x2. Tiempo: 3-4h. Personas: 2-3.

Vertido de la mezcla tierra y cal: Para garantizar que el material llega a todas las esquinas, es posible que se alternaran hiladas de piedra con el vertido tierra y cal en formato líquido. Tiempo: 3-4h. Personas: 2-3. Es posible plantear que las cuatro tapias de la primera hilada se podrían completar en una j ornada de trabajo con los 12 trabajadores planteados inicialmente.

Fraguado: El tiempo de fraguado de una tapia de es tas características es difícil de determinar. Comparado con los tiempos de fraguado en la actualidad, de acuerdo con Nelson Afanador $(2013,58)$ el tiempo de fraguado para una tapia pisada de material areno-arcilloso es de 16 días. Otros investigadores hablan de 30 días de fraguado para los morteros de cal (López et. al. 2010, 8), e indican que el fraguado del mortero de cal es más lento que otr os elaborados con arena y cemento (10). Dentro del periodo de fraguado, sería posible retirar el encofrado antes de que finalice el fraguado 
y poder reutilizar así el encofrado. En relación con el hormigón armado, de acuerdo con la Instrucción de Hormigón Estructural (EHE), el artículo 75 referente al descimbrado, desencofrado y desmolde, se establecen varios valores para el encofrado vertical, en función de la temperatura superficial del hormigón, que varía de 9 a 30h. De nuevo no se trata del mismo material, pero puede ser orientativo para determinar en qué momento se podía retirar la tapia. Desencofrado: 48-72h.

La construcción de la segunda hilada sobre la primera debería esperar al fraguado completo de la tapia. La primera hilada del tramo requeriría entonces de 30 días de espera antes de poder construir la segunda: primera hilada de 4 tapias: 30 días $\times 7$ hiladas: 210 días para un tramo de $11 \mathrm{~m}$ de muralla.

Teniendo en cuenta que lo que más tiempo requiere es el fraguado, parece lógico pensar que con tramos más largos se ahorraría tiempo, puesto que las tapias de una misma hilada fraguarían simultáneamente. En un tramo del doble de longitud, $22 \mathrm{~m}$, una hilada de 8 tapias se realizaría igualmente en $30+1$ días, un total de 217 días para $22 \mathrm{~m}$ de muralla. En tramos más largos, con una primera hilada de 28 tapias y longitud de $78 \mathrm{~m}$, necesitaría de los 30 días de fraguado más 7 días más que se han invertido en colocar tapiales y rellenarlos, con el mismo ritmo de 4 tapias por día par a 12 trabajadores. Un total de 259 días.

El empleo de tapia corrida, o de tapia individual con muretes transversales de piedra permite llenar más tapiales de forma simultánea y ahorrar tiempo en esa fase. La diferencia entre tapia independiente y tapia corrida parece muy importante en un principio, en cuanto a ahorro de tiempo se refiere, sin embargo, la larga espera de fraguado resta eficacia al tapial corrido. Por otra parte, ahorra trabajo de montaje.

\section{8 ¿Quién construye las murallas de tapia de mampostería?}

En la estructura social descrita en el apartado que describe las Comunidades de Villa y Tierra, se hace referencia a la existencia de una contribución fiscal dentro de los concejos que aparece asociada a servicios-tributo de tipo militar y municipal. Se planteaba la posibilidad de que la construcción de la muralla o su mantenimiento fuera un servicio-tributo. De la misma forma que la monarquía utiliza un sistema de repoblación que divide el territorio en porciones y que apuesta por que, a c ambio de ventajas fiscales y libertades individuales, sean los propios habitantes quienes defiendan una porción de ter ritorio, parece lógico pensar que en la villa serán los propios habitantes quienes se hagan cargo de la construcción de la muralla, tal vez con instrucciones acerca de su trazado o de su extensión. Juan Eslava Galán (1984, 273) indica que "la construcción con tapia de ti erra es propia de núcleos humanos pobres en recursos pero ricos en mano de obra"; teniendo en cuenta que la estrategia para controlar este territorio ha sido la de repoblar, parece lógico plantear que el mayor aporte a estos núcleos era el de mano de obra.

Alberto Garín (1996, 384) comenta la ausencia de referencias al oficio de cantero en los fueros de villas situadas al sur del sistema central, mientras que otros oficios, como 
el carpintero, tejero o calero aparece mencionados en numerosas ocasiones. A raíz de esta ausencia, se lanza la hipótesis de que el fuero estuviera dirigido a ciudadanos que no pueden per mitirse la construcción con piedra tallada. La aus encia de piedra tallada en I as murallas indicaría que está construida por la propia ciudadanía con materiales modestos y austeros. El mencionado autor identifica varios oficios presentes en varios fueros de villas situadas al sur del sistema central como Cuenca, Plasencia, Baeza, Alcaraz y otras: el de "maestro de obras" (391) como experto en construcción de tor res, puentes, molinos, bodegas, iglesias y casas; el oficio de carpintero (393), que hace referencia a la construcción de armaduras de cubierta o a otros elementos estructurales; la figura de "tapiador, cimentador o maestro de las paredes" (394) aparece definida como "especialistas que trabajan la tierra aglutinada y pisada en encofrados". Es posible que existiera una figura análoga en la zona norte del sistema central, que no solo trabajara la tapia de tierra apisonada sino que conociera la técnica de la mampostería encofrada. Indica igualmente que I os materiales principales de construcción son locales: "la madera, las arenas y las arcillas, con pocas referencias a otros materiales más nobles como la piedra" (395).

La relación de ofi cios que ex trae Alberto Garín está muy estructurada y hace referencia en muchos casos a los contratos vinculantes entre trabajador y demandante, con la consiguiente responsabilidad de ambos en su cumplimiento. Es difícil conocer en qué condiciones se realizarian estos oficios en las villas estudiadas, al inicio de su repoblación, con la llegada de pobladores de distintos orígenes y costumbres. Por otra parte, en el caso de la muralla la figura del demandante es diferente de la que aparece en obras de particulares.

\subsection{Cronología de las murallas estudiadas}

Conocer en qué fecha se construyeron estas murallas es uno de los aspectos que más interés suscita. El estudio de la técnica constructiva empleada puede permitir avanzar en esta dirección. Como es sabido, la tapia no es una técnica exclusivamente medieval sino que ha sido utilizada muy profusamente a lo largo de los siglos en varios territorios y por distintas civilizaciones. Los textos clásicos a los que se ha hecho referencia en capítulos anteriores sitúan este sistema constructivo ya en I a época romana.

Por otra parte, también existen restos físicos de este sistema que se observan en construcciones que datan de la época romana. A modo de ejemplo, el uso de tapial de cal y canto en el anfiteatro romano de Purpan-Ancely, en Toulouse, es un ejemplo de uso de e sta técnica por los romanos (Fig. 6.52, Fig. 6.53). Aparece en I os muros radiales del anfiteatro, muros estructurales, y se hace con cantos rodados. Es posible identificar unidades constructivas, tapias, en los muros existentes. Por esta razón no es factible atribuir una fecha de construcción por el simple hecho de identificar la tapia como técnica constructiva. No obstante, las características que rodean esta técnica, como son los materiales empleados, si se ha producido apisonado o vertido, las dimensiones empleadas y las características del tapial utilizado pueden permitir identificar una tapia con características propias de este periodo. 


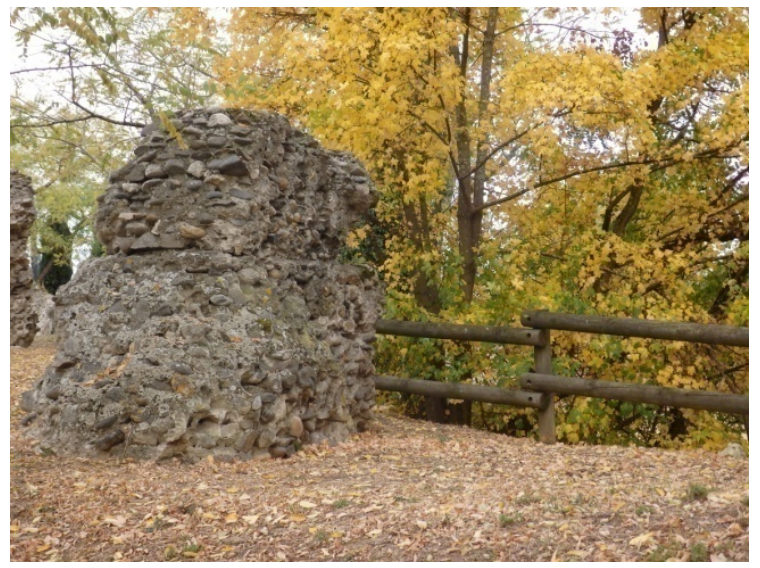

Fig. 6.52. Restos del anfiteatro romano de PurpanAncely, en Toulouse, donde es visible el uso de encofrados en uno de los muros radiales [A.S.E. 24/10/2015]

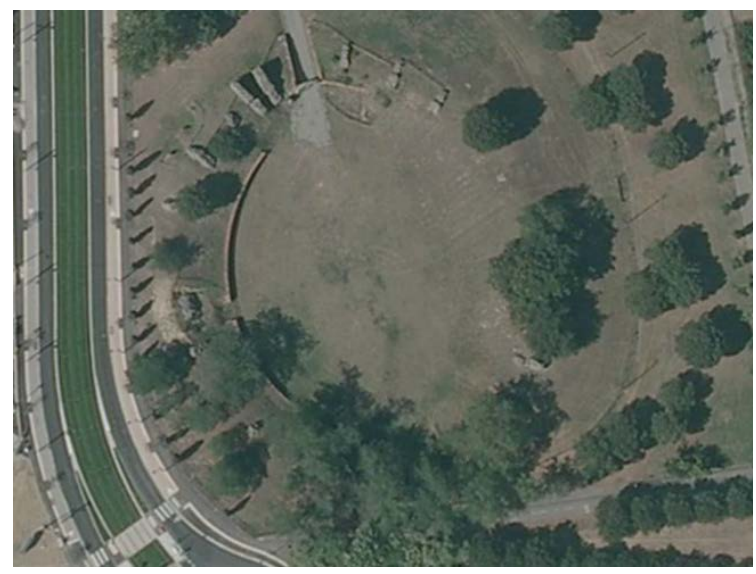

Fig. 6.53. Vista aérea del anfiteatro romano de Purpan-Ancely, en Toulouse. Fuente: Géoportail http://tab.geoportail.fr/ [Consultado el 11/02/2016]

De acuerdo con lo expuesto en el Capítulo 3, donde s e habla de la formación y evolución de las Comunidades de Villa y Tierra, ya se plantea el marco en el que estas murallas fueron construidas, desde el siglo XI al siglo XIII, aunque fuera aprovechando las bases de tramos y elementos de murallas existentes. Dentro de esta franja, se ha tratado de encontrar un periodo más corto que permita situar la construcción de estas murallas, teniendo en cuenta las aportaciones de otros investigadores.

Como dificultad añadida para llevar a cabo una datación, se sitúan las reparaciones llevadas a cabo en las murallas a lo largo de los siglos. Son estos arreglos los que suelen aparecen en documentos históricos, en forma de partidas presupuestarias para la reparaciones de $\mathrm{m}$ uros. En los casos de Coca, Cuéllar o $\mathrm{S}$ epúlveda, se han reflejado menciones de este tipo, procedentes habitualmente de archivos municipales. Por otra parte, se ha señalado la tendencia a reparar y reconstruir los elementos entendidos como más representativos de las murallas, como las puertas y las torres, y en menor medida, las almenas. En cuanto a los lienzos, en algunos casos, como Sepúlveda, se observan discontinuidades importantes en las bases, que muestran varias fases de construcción. Esto es también visible en otras murallas, como en Coca o en $\mathrm{C}$ uéllar, pero ya de forma muy puntual. Aun así, es sorprendente la relativa homogeneidad que se observa en muchos de los lienzos, cuando emplean la tapia de mampostería. La reparación que se producía en estos lienzos es difícil de evaluar, o queda muy enmascarada por el paso del tiempo. En casos como el de Fuentidueña, no se han detectado fases o evidentes zonas de reparación en los lienzos analizados, propias de siglos pasados.

En el caso de Sepúlveda, M. Dolores Martín Aymerich y su equipo (1990, 137-138) define un tipo de apar ejo (C-3) que engloba aquel que presenta marcas de cajas o cajeados, por lo que se ha entendido que se refiere a las tapias estudiadas en esta investigación. Para tratar de es tablecer la fecha de es te aparejo toman como referencia otro tipo de parejo que consideran anterior (C-2), situado sobre las bases de los torreones de la plaza del Mercado. Para datar este otro aparejo establecen como fecha de partida 1076, fecha en la que creen que datan las bases de los mencionados 
torreones, y establecen como límite el año 1504, fecha en la que las torres están ya construidas, conocida a partir de un documento histórico. A continuación, se preguntan en qué momento de esa franja de tiempo se hizo necesario recrecer las defensas de la villa. Consideran que es en el siglo XV cuando se emplea este tipo de aparejo, razonando que en fec has anteriores solo se encuentran menciones de obr as de reparación. A partir de esta datación, plantean que el aparejo C-3 es entonces posterior al siglo XV.

En respuesta a es te planteamiento, hay razones que apoy arían la ausencia de necesidad de recrecer murallas en el siglo XV y más adelante. En primer lugar, el contexto bélico existente durante los siglos IX a XIII ha desaparecido en el siglo XV, por lo que no s e encuentran razones por las que sea necesario, en esa fecha, no solo recrecer algunas torres sino construir el tramo de varias centenas de metros de longitud situado al oeste de la puerta de Duruelo. Otro argumento es que, dados los avances producidos en la artillería, las murallas, tal y como son visibles hoy en día en Sepúlveda, habrían perdido su capacidad defensiva en el siglo XV. Construir murallas o recrecerlas con las mismas características no sería eficaz en esas fechas, dada su vulnerabilidad frente a las nuevas armas de ataque. E I castillo de Coca (Fig. 5.1.7, pág. 106) es un ej emplo del tipo de arquitectura que se construía en el siglo XV y presenta avances de la poliorcética que no se encuentran en la muralla de Sepúlveda. Finalmente, en el siglo XV ya se estaban empleando otras formas de construir tapia, incluyendo la presencia de machones de ladrillo o añadiendo verdugadas también de ladrillo. Es posible que, en caso de realizar recrecidos de muralla en esa época, se hubieran incorporado nuevas soluciones en lugar de uti lizar tapias monolíticas, con elementos de ladrillo como machones o varias verdugadas.

En esta investigación se ha considerado que la construcción de las murallas construidas con tapia de mampostería tendría que haberse producido en una fr anja más corta, anterior al siglo XV. La fecha de gestación de la repoblación de este territorio se sitúa en 1072 (Monsalvo 2003,53), que pod ría consistir en la fecha de partida. Para establecer una fecha límite se ha tenido en cuenta la situación fronteriza del territorio estudiado, que a principios del siglo XII se situaba a $200 \mathrm{~km}$ de la frontera con el territorio almorávide. En relación con el proceso repoblador en el que se construyen estas murallas de tapia, es difícil establecer en qué momento se construyen las murallas. ¿Es acaso la primera actividad al poblar la nueva villa? ¿Se espera hasta el auge económico del siglo XIII cuando las villas ya forman parte de la retaguardia? Parece lógico pensar que en una s ituación de peligro, cuanto antes se construyeran las defensas, mejor. La reutilización de antiguas murallas y la prisa con la que par ecen haberse construido algunos lienzos como el caso de Fuentidueña, podrían apoyar esta hipótesis. La construcción de murallas por recintos también podría explicar la gran extensión de algunas de ellas. Primeramente, se habría construido una muralla que abarcara menor superficie y que se ampliaría posteriormente. Sólo en el caso de Cuéllar la existencia de dos recintos es evidente. En otras villas, los recintos podrían diferenciarse por las distintas configuraciones de sus tapias; en el caso de Fuentidueña parece existir algunas diferencias entre el lienzo T6-T7 y el P3-T10, como la integración de las torres con el lienzo, su sección en planta, o el tapial empleado en cada caso. 
Los investigadores I. Hernández y Raimundo Moreno (2007) tratan el empleo de la mampostería encofrada en el ámbito religioso y muestran ejemplos con técnicas similares a las empleadas en I as fortificaciones analizadas $(515,517)$. Muchos de estos casos se sitúan en villas analizadas en este estudio como Pedraza o Sepúlveda y también se mencionan ejemplos como la iglesia de San Martín de Fuentidueña, la de Santa María del Casuar en Montejo de la Vega de la Serrezuela, o la de Santiago en Ayllón. En los ejemplos religiosos aportados se observan algunas diferencias con las tapias de las murallas estudiadas. El espesor de los muros parece inferior, los huecos vacíos de los mechinales indican que las agujas fueron reutilizadas, las dimensiones de los mechinales parecen mayores en proporción con la altura de las tapias y los límites verticales de las tapias muestran una ligera inclinación. El tipo de a guja empleado parece constante, con los mismos mechinales en los muros. Las tapias visibles en las murallas muestran un as pecto más desordenado y menos calculado que las visibles en los muros de las iglesias, donde los paramentos son rectos y se producen encuentros en ángulos rectos entre los muros. En las murallas, no se encuentran ángulos rectos entre muros y muchos lienzos presentan hiladas irregulares y desordenadas de tapi a. Esta diferencia puede deberse a un a menor prisa en la construcción de la iglesia frente a la muralla, a la intervención de menos trabajadores que coordinar o también a un mayor control de la técnica en el caso de la iglesia. Por otra parte, la diferencia entre construir un muro de tapia de mampostería en una iglesia de estas características frente a un lienzo de muralla es importante. La longitud de los muros no es equiparable y tampoco su altura. El asentamiento en un terreno con desniveles también dificulta la tarea.

Los autores señalan que determinar la cronología de es tas construcciones es una tarea difícil, pero consideran que su construcción no se extendería más allá de los siglos XII y XIII. En las conclusiones de su estudio, establecen un margen cronológico desde 1100 a 1247 (518). De acuerdo con estos datos, la construcción de las murallas en el contexto de la repoblación de las Comunidades de Villa y Tierra podría situarse en fechas cercanas a estas. ¿Se construirían las iglesias antes, después o de for ma simultánea a I a construcción del as murallas? Esta pregunta es muy difícil de responder, ya que existen varios tipos de iglesia, con posiciones diferentes con respecto al recito amurallado. Por una parte, se podría pensar en una iglesia principal de la villa, en torno a la cual se creen las primeras casas. Esta iglesia se construiría antes o simultáneamente a la muralla medieval. Si se reaprovechara una iglesia ya existente, esta se repararía o reconstruiría antes o simultáneamente a la construcción de la muralla medieval. Otro tipo de iglesia es aquella que se construye extramuros de un primer recinto, que se observa incluida en segundos recintos amurallados. Necesariamente, se ha c onstruido después del primer recinto, pero antes 0 simultáneamente al segundo. La última opción es la de la iglesia ermita, que se sitúa ex profeso alejada del núcleo y que puede verse fagocitada por la villa cuando crece o estar lo suficientemente alejada como para no ser alcanzada aunque la villa crezca. En este caso, es difícil averiguar qué relación tiene su construcción con la de la muralla.

José María Monsalvo (2003, 70, nota 78 ) indica que para la ciudad de Salamanca, un artículo del fuero permite fechar en 1147 el momento en el que el concejo empezó a reconstruir las murallas viejas, el "muro de I a ciudat". El autor plantea que podría 
tratarse de una reconstrucción de las murallas romanas. En el fuero, parece hacerse un llamamiento a los habitantes del arrabal para que participen en la construcción del muro de la villa, con la promesa de que una v ez hecho, serán los habitantes de la ciudad los que participen en la construcción de la muralla del arrabal. De acuerdo con el autor, el "muro del arrabal" comprendería las ampliaciones medievales y según señala todavía estaría construyéndose en el siglo XIII y tardaría en terminarse.

Parece lógico pensar que las murallas de este estudio, al igual que las iglesias mencionadas, también deberían estar construidas en 1247, teniendo en cuenta que en esta fecha, estas villas se encuentran en la retaguardia, alejadas del peligro más inmediato e iniciando un nuevo modelo social, político y económico que se aleja del contexto bélico. Sin embargo, las menciones a la muralla de Salamanca y el hecho de que pudiera seguir construyéndose en el siglo XIII, hace difícil plantear que podrían haber iniciado su construcción a principios del siglo XII. La relativa velocidad de construcción de las murallas de tapia de mampostería, tal y como se ha planteado anteriormente, choca con el hecho de que pudieran tardar en construirse 100 años. Otros factores como el económico, de abastecimiento de material o de mano de obra tendrían que frenar el proceso de construcción. Tal y como se ha mencionado anteriormente, las sucesivas reparaciones de las que son objeto estas murallas hasta los siglos XIV y XV, dificultan esta tarea de datación.

Para conocer fechas más precisas, se podría profundizar en esta dirección a través de la aplicación del a dendrocronología. En los restos encontrados, se observan numerosos mechinales donde todavía se alojan agujas de madera. A través de esta técnica se podría tratar de fechar el año en el que se abatió el árbol empleado en la fabricación de las agujas del tapial. El análisis de esas muestras podría arrojar luz sobre su edad y permitir una datación más exacta.

\subsection{Restauración de las murallas}

Aunque esta investigación no se ha enfocado en la restauración arquitectónica, sí que ha sido posible observar prácticas restauradoras inadecuadas para los conjuntos amurallados. Principalmente se observa una es casa atención a la tapia de mampostería como elemento constructivo, olvidando que está muy presente en los lienzos de estas construcciones. Se confunde habitualmente con un aparejo de mampostería y algunas reparaciones ocultan la existencia de $\mathrm{m}$ echinales y las divisiones entre tapias de forma indiscriminada. Se ha detectado la necesidad de prestar mayor atención a las tapias en la restauración de los lienzos, ya que s us marcas son fácilmente borrables, causando una pér dida importante en el entendimiento de es tas construcciones. Se han enc ontrado reparaciones con la adición de mampuestos y morteros realizadas sin planificación ni estrategia y que por lo tanto deber ían evitarse. La reparación de murallas no puede c onsistir en la aplicación de nuevos morteros de cemento o de $\mathrm{c}$ al y la adición de mampuestos creando parches de mampostería. Tampoco en la homogeneización de paramentos con revocos o r ejuntados que de stacan la forma de los mampuestos, como si se tratara de sillares. Es necesario aproximarse a los lienzos de forma más cuidadosa y 
aplicarle productos que no deterioren su aspecto original sino que lo mantengan con la menor alteración posible. También es necesario entender la muralla como un conjunto de partes, alguna de ellas realizadas en diferentes épocas y con distintos sistemas que han de poder diferenciarse tras una restauración.

Hace ya veintiséis años, los arqueólogos que estudiaban Sepúlveda (Aymerich et. al. $1990,133)$ indicaron que "la verdadera restauración no ha l legado aún al tratamiento de los restos arquitectónicos, en la inmensa mayoría del as obras, aunque se amparen, teóricamente, bajo ese nombre. Se trata de simples lavados de cara, que provocan además en muchos casos irreparables pérdidas para la integridad del monumento o, en el mejor de los casos, cambios de imagen tan discutibles como gratuitos". La administración, la sociedad y los profesionales hemos de seguir buscando soluciones para restaurar estas edificaciones, ayudándonos de las soluciones que hayan tenido éxito en otros lugares y tambien siendo críticos con los resultados.

Por otra parte, la restauración a nivel global del total del recinto amurallado, parece tender a la reconstrucción de las murallas con nuevos tramos construidos desde cero o con recrecidos nuevos sobre los tramos medievales. La construcción de adarves modernos que permitan el recorrido sobre las murallas es habitual. En los casos analizados, el caso de Cuéllar presenta una restauración de estas características y el Plan Director de Maderuelo propone una solución similar, al menos de reconstrucción de torres. Una parte de la sociedad pide este tipo de restauraciones tal vez porque permiten ver una opción de muralla completa o porque se interpretan como reclamo turistico más eficaz que un trozo de lienzo aislado. Por otra parte, la reconstrucción tiene el riesgo de que inventa nuevas formas, elige soluciones que se imponen sobre el conjunto de la sociedad y resta importancia a las partes originales.

La muralla es una construcción muy particular en la ciudad, que no se puede equiparar con otras fácilmente, ya que de forma habitual no tiene espacios interiores a los que se pueda dar un nuevo uso, a excepción de algunas puertas o torres de especial entidad. No ocurre con los lienzos, que son simplemente muros que no engloban espacios interiores y cuya función original se ha per dido. En otros ejemplos de patrimonio arquitectónico no oc urre así y es posible ver castillos o i glesias restaurados y reconstruidos para su utilización con nuevos usos, lo que implica nuevas instalaciones, cumplimiento de normativas actuales. En muchos casos, se ha mostrado que dar un nuevo uso a un edificio histórico es una garantía de su conservación. En el caso de los lienzos de la muralla un nuevo uso así entendido no es tan sencillo. Explotar la dimensión urbana de la muralla es una opción que permite enfatizar la presencia de la construcción defensiva y mejorar el espacio urbano a través de la integración de la muralla en sus recorridos. Sería posible fomentar la visita de la muralla a través de recorridos peatonales a sus pies, a tr avés de paseos urbanos que recorran el perímetro o que una $\mathrm{n}$ la ubicación de cada uno de los restos. Del mismo modo, se puede impulsar la contemplación del recinto desde puntos concretos de la villa, que permitan mirar a l a muralla y no tanto des de la muralla. Para experimentar la sensación de contemplar el paisaje desde el adarve, es posible realizar una construcción auxiliar puntual, ligera, discreta, que pueda ser eliminada con relativa 
facilidad, que no se apoye en la muralla, de carácter aislado junto a ella, que sea accesible para todos. La $\mathrm{m}$ uralla ha de entenderse en I a actualidad como un monumento, un doc umento arquitectónico muy valioso que no ha de romperse, alterarse o ampliarse. 



\section{Conclusiones}

A continuación, se exponen las conclusiones a las que se ha llegado a lo largo de esta investigación. Se ha dirigido de forma más intensa al estudio constructivo de los lienzos de muralla y las conclusiones principales son las relativas al ámbito constructivo. Aun así, se han extraído conclusiones en otros aspectos tratados en la investigación como son la metodología empleada, el conjunto del recinto amurallado y los resultados del análisis histórico. Finalmente, se dedica un apartado a las futuras líneas de investigación que se pueden plantear en continuidad con esta investigación o vinculadas a alguno de los aspectos tratados en ella.

\subsection{Conclusiones relativas a la metodología}

El trabajo de campo ha sido un método necesario para la recolección de datos y la realización de esta investigación ha dependido de forma mayoritaria en la toma de esos datos. Aun así, se han detectado limitaciones que existen en las visitas in situ como el acceso a determinados puntos de los asentamientos, por existir grandes desniveles, por encontrarse en lugares ocultos por la vegetación o por situarse en propiedades privadas. Se ha echado en falta la disposición de más herramientas, una coordinación más intensa con otras disciplinas familiarizadas con recursos topográficos para conseguir acceder a todos los puntos. Esta limitación ha condicionado los resultados de uno de los casos, Pedraza, donde se ha podido extraer menor cantidad de información de restos existentes.

La consulta de fuentes históricas o estudios acerca de estas fuentes han aportado datos escasos sobre las murallas físicamente y muy poco sobre la forma de construirse o quienes participaban en la construcción. Se han encontrado escasas menciones o ninguna referencia en las fuentes consultadas. Sorprende no encontrar ninguna mención a la muralla en documentos como el catastro del Marqués de la Ensenada. Desde un $p$ unto de v ista constructivo, solo se ha enc ontrado alguna mención en los datos extraídos de Sepúlveda (Martín Aymerich et. al. 1990, 106). De nuevo la coordinación con otras disciplinas familiarizadas con documentación histórica podría aportar más resultados.

Los métodos empleados para representar los lienzos de muralla han sido muy útiles. La herramienta informática Agisoft PhotoScan ha permitido construir de forma exitosa modelos $3 \mathrm{~d}$ de lienzos de muralla, y extraer alzados de fotografías rectificadas sobre los que se ha podido identificar elementos constructivos con facilidad y realizar mediciones de cada uno de ellos. Otros elementos de la muralla pueden ofrecer mayor dificultad en este tipo de representación arquitectónica, por la existencia de partes 
Las murallas en las Comunidades de Villa y Tierra de la Diócesis de Segovia en los siglos XI a XIII.

Técnica y sistemas constructivos de la arquitectura defensiva medieval.

curvas que tienen un comportamiento más complejo y un resultado de menor calidad en el uso de este programa informático. Este método ha sido muy sencillo y accesible, con resultados muy positivos.

El dibujo sobre los alzados de fotografía rectificada ha permitido extraer cada uno de los elementos constructivos visibles y ha hecho posible su identificación, numeración, toma de medidas y recogida de las características de sus mechinales, como la posición, la separación entre ellos o su configuración. Este sistema de representación de las tapias podría aplicarse a todo el recinto amurallado y no solo a los tramos estudiados en esta investigación, para poder conocer en $p$ rofundidad las características constructivas de todo el recinto.

El empleo de datos geolocalizados de instituciones como el Catastro, el IDECyL o el IGN han sido de utilidad para la construcción de un SIG de trabajo que ha permitido analizar el asentamiento de los núcleos a una escala general y producir planos de síntesis de aquellos aspectos relacionados con la construcción de la muralla como es el territorio y el terreno de asentamiento, así como la configuración de la ciudad medieval visible a través del parcelario.

La utilización de herramientas estadísticas ha resultado de gran utilidad. Por una parte, la representación de los datos extraídos de un lienzo a través de los diagramas de caja ha permitido ilustrar los márgenes dimensionales de las tapias de forma más eficaz que a través de una tabla con valores numéricos. También ha funcionado a la hora de extraer una medida representativa de las dimensiones de cada elemento constructivo de un lienzo. Por otra parte, de cara a la comparación de resultados, los gráficos en formato biplot realizados por Componentes Principales han pe rmitido realizar una comparación objetiva de los parámetros analizados para cada caso. Aun así, esta comparación se ha utilizado como refuerzo de la comparación convencional de parámetros, uno a uno. Se ha sido consciente de la limitación de datos disponibles para la utilización de este método cuya eficacia es más evidente cuando se manejan datos muy superiores a los aportados por esta investigación.

\subsection{Conclusiones en el conjunto del recinto amurallado}

No se observa una planificación en el trazado del recinto, más allá de la de aprovechar las ventajas que ofrece el territorio, acercándose habitualmente a la confluencia de dos ríos y situando sus defensas en el borde dela roca. Se ha podido comprobar la reutilización delas bases de defensas anteriores, construyéndose con tapia sobre aparejos de piedra o ubicando el trazado de la muralla en la posición de murallas muy anteriores como en el caso de Coca, donde al menos un tramo coincide con el trazado de la muralla vaccea.

En el breve análisis de parcelario realizado en cada caso, con objeto de situar la muralla en el núcleo, se ha podi do comprobar que un estudio del parcelario en profundidad podría arrojar resultados de gran interés acerca de los recintos amurallados estudiados. En el caso de Sepúlveda, se produce por un lado una 
configuración particular de las calles que rodean el cerro de Somosierra y confluyen en el actual castillo y por otra parte, la plaza del mercado que se extiende ante el castillo en una disposición que es habitual frente a la puerta de un muralla; un ejemplo de esta disposición se puede ver en la plaza de $S$ an Pablo de Valladolid donde antes se ubicaba un puerta o en la plaza de Zorrilla donde se situaba la puerta del Campo. Son pistas que han permitido plantear en el capítulo de este caso la posibilidad de que el actual castillo funcionara en un or igen como puerta del recinto amurallado. La ubicación tan baja del castillo cuando habitualmente se sitúan en las zonas más altas del asentamiento también apoyaría este planteamiento.

Aunque el enfoque de este trabajo no ha sido el estudio de las tipologías de torres del recinto amurallado, la aproximación que se ha llevado a cabo muestra ejemplos de distintas configuraciones en cada uno de los recintos. Las formas en planta son de tipo rectangular y semicircular. En todos los recintos excepto en Coca se observa un uso mayoritario de torres rectangulares. Las torres semicirculares más sorprendentes son las de Fuentidueña, que se diferencian del resto por su gran diámetro, solo igualado en la torre T1 de C uéllar. Las plantas poligonales identificadas en C uéllar o C oca parecen vinculadas a la reutilización de bases preexistentes.

La gran mayoría de las torres de estos recintos, tanto las de planta rectangular como las de planta semicircular son macizas. Este hecho es especialmente sorprendente en el caso de Fuentidueña, cuyas torres semicirculares de gran diámetro son macizas y por tanto han necesitado una cantidad ingente de material para construirse. En el resto de casos, las dimensiones son menores y su masividad parece más controlada.

Se ha obs ervado la ausencia de torres durante largas distancias en los lienzos analizados. En los casos de Cuéllar o S epulveda se encuentran tramos muy largos donde no se conservan torres ni marcas de su existencia, sino que se ven lienzos continuos. En Fuentidueña se observan lienzos con torres adosadas con posterioridad, que muestran al menos que el lienzo fue construido de forma continua, sin torres, que luego se añadieron tal vez de forma inmediata o tiempo más tarde. La inclusión de la torre en el lienzo podría suponer una dificultad en I a construcción del mismo. La integración de torre en un lienzo construido con tapia podría ser más complejo que continuar con el lienzo. La ausencia de torres puede indicar una falta de conocimiento constructivo para integrarlas en los lienzos. La construcción de torres significaría una evolución, un avance frente a los lienzos continuos.

Las torres que se conservan son escasas por lo que el análisis de la separación que hay entre ellas no ha mostrado una tendencia clara. Por otra parte, la existencia de largos tramos que se ha comentado en el párrafo anterior tampoco aporta información en este sentido. De acuerdo con los datos disponibles, la separación más habitual entre torres se sitúa en el margen de los 25-30m. 
Las murallas en las Comunidades de Villa y Tierra de la Diócesis de Segovia en los siglos XI a XIII. Técnica y sistemas constructivos de la arquitectura defensiva medieval.

\subsection{Conclusiones en el ámbito constructivo}

La identificación de los sistemas constructivos empleados en las muralla ha permitido detectar el empleo de la tapia de mampostería o mampostería encofrada como técnica protagonista en los lienzos de las murallas. Se observa la utilización de esta técnica de forma mayoritaria en los lienzos de muralla, se podría decir que se trata de la base constructiva en los lienzos de e stas construcciones. Las técnicas alternativas encontradas se ubican en I as bases de I os lienzos y no s e utilizan de forma generalizada sino que son puntuales y muestran diferencias en cada una de las villas analizadas.

El uso de esta técnica en estas murallas puede parecer evidente; en otras zonas de la península ibérica se han documentado y analizado otros ejemplos de murallas que se construyen con tapia de tierra con distintas variantes. La e scasa investigación realizada sobre las murallas que se estudian aquí no ha per mitido establecer hasta ahora el empleo de esta técnica.

En otros elementos de la muralla, como puertas y torres, el empleo de mampostería encofrada no está generalizado. En la puertas de Coca y en algunas de las de Sepúlveda se utiliza esta técnica. En las torres, se emplea de forma generalizada en Fuentidueña, en algunas torres de Sepúlveda (en las zonas superiores), pero no es posible indicar que se emplee también de forma mayoritaria en torres y puertas de todos los recintos.

En esta investigación también se ha querido mostrar la importancia que tienen los lienzos de muralla frente a otros elementos como las torres o puertas. Estas últimas suelen llamar la atención por sus formas singulares, decoración o por encontrarse en lugares de $p$ aso. Los distintos líderes o au toridades al cargo de la villa, que se suceden a lo largo del tiempo, tienden a querer dejar un símbolo de su poder en este tipo de el ementos, allí donde son visibles por todos los habitantes y por todos los viajeros, por lo que las puertas pueden incluir todo tipo de alteraciones. En este sentido, los lienzos se sitúan en el extremo opuesto; tienen un carácter menos representativo y por esta razón acumulan menos modificaciones con el paso del tiempo. En su lugar, son absorbidos por nuevas edificaciones, quedan ocultos o simplemente nadie los mira. Desde un punto de vista constructivo, los lienzos ganan importancia frente a puertas y torres, por ese menor grado de alteración.

La presencia de esta técnica en todos los casos analizados permite considerarla como un sistema que podría emplearse de forma generalizada en las murallas medievales cristianas. Se trata de un sistema relativamente fácil de ejecutar, que tiene un procedimiento repetitivo donde las primeras hiladas pueden realizarse de forma más lenta, pero que a base de reproducir centenas de v eces puede "automatizarse" ganando en velocidad y eficacia. Por otra parte, los materiales necesarios para el llenado del tapial están disponibles en el entorno y no requieren de la talla de piedra. De acuerdo con el cálculo aproximado en el apartado de análisis de resultados es posible que las murallas de tapias se realizaran con relativa rapidez, aunque dependiendo siempre de varios factores, como la mano de obra disponible ol a recolección de materiales necesarios. Además, el proceso está condicionado por el 
lento proceso de fraguado de la tapia que debería de tenerse en cuenta para alternar periodos de construcción de tapia con otras tareas de la obra durante el fraguado, o tal vez para realizar la construcción de varios tramos a la vez que permitiera trabajar en unos cuando otros están fraguando.

El uso de la tapia de mampostería es visible en los lienzos principalmente, en algunas torres e incluso en la construcción de almenado, con moldes de menores dimensiones. Este empleo generalizado hace pensar que debía de tratarse de un sistema muy conocido, o muy fácil de acometer. Por otra parte, las variantes encontradas en los ejemplos analizados, muchas de ellas en los mismos tramos de muralla, lleva a pensar que se trataba de una técnica muy extendida, con distintas manías y gustos en función del grupo de trabajadores que construyera cada tramo. La variedad de mechinales en un mismo tramo como ocurre en Fuentidueña o en Coca muestra que no había un consenso propio de expertos.

La tapia parece accesible para todos, no requiere de maestros canteros, solo es necesario disponer de varios tapiales y tener acceso a la fabricación de agujas para la producción en serie de las tapias. Se ha hablado en varias ocasiones de la irregularidad que presentan las hiladas de tapia en varios de los tramos analizados. Es el tramo T5-T6 de Fuentidueña el que muestra el mayor desorden por construirse, tal vez, en una zona de desnivel. La irregularidad de Fuentidueña apoya que se construía con escasa planificación y sin una visión general del lienzo. Se observa desorden en las hiladas de tapia y encuentros entre ellas desafortunados, que obligan al empleo de tapias de forma triangular o trapezoidal para resolver los encuentros entre hiladas. Frente a es te desorden, se observa en C oca una construcción por tramos. Este sistema representa un avance frente al desordenado y caótico encuentro de Fuentidueña, un s igno de pl anificación. Aun así estos tramos tienen longitudes dispares y no parecen responder a una lógica concreta.

Aparte de la tapia de mampostería se han identificado otras técnicas en los recintos estudiados que se acumulan principalmente en puertas y torres. Entre estas técnicas, se hace necesario señalar el escaso de empleo del ladrillo en los lienzos de muralla, a través de verdugadas o machones. La presencia de ladrillo es nula en los lienzos de todos los casos y escasa en puertas y torres, a excepción de Cuéllar donde aparece en varias puertas y en alguna torre. En Pedraza se utiliza ladrillo en la puerta de la Villa, y en Coca se observa ladrillo en la única puerta que se conserva. El ejemplo de la puerta de Coca tiene especial interés puesto que las dos torres de flanqueo del acceso no utilizan ladrillo en su construcción. El ladrillo solo aparece en el frente y en remate de la puerta lo que permite deducir que se trata de una añadido y que no forma parte del sistema original de construcción, que sería similar al visible en las torres de flanqueo. En los lienzos esta conclusión es más evidente, puesto que no se observa el uso de este material en ninguno de los lienzos analizados.

\subsubsection{Tipología de tapia}

De acuerdo con la tipología de tapia planteada por Amparo Graciani y Miguel A. Tabales $(2008,139)$ el tipo de tapia de cada uno de los casos coincide en todos ellos 
Las murallas en las Comunidades de Villa y Tierra de la Diócesis de Segovia en los siglos XI a XIII. Técnica y sistemas constructivos de la arquitectura defensiva medieval.

por tratarse de tapia monolítica. Todos los casos muestran mechinales rematados por mampuestos. Los casos de Coca y Pedraza presentan una verdugada de piedra visible en la base de las tapias. El caso de Sepúlveda presenta tapia con machones de piedra en dos de sus puertas.

En relación con la clasificación de Ignacio J. Gil Crespo (2013, 554-557), la tipología de las tapias es coincidente en I os parámetros de "Material de c onstrucción", "Compactación del material", "Función constructiva", "Acabado superficial", "Combinación de materiales", "Situación de mechinales" y "Formación de mechinales". Las tapias analizadas se diferencian en los parámetros de "Encofrado" y "Sección de mechinales". La comparación entre todos los casos no es posible aplicarla con el parámetro "Profundidad de mechinales" por no contar con los valores de este parámetro en todos ellos. En el $70 \%$ de los parámetros se produce una coincidencia de todos los casos, frente a un $20 \%$ de l os parámetros que muestran resultados diferentes en I os casos analizados. Los casos de $C$ uéllar y Coca muestran una coincidencia del $90 \%$ y de un $80 \%$ con Fuentidueña y Sepúlveda.

Los parámetros propios son similares a los planteados por los citados investigadores y añaden nuevos parámetros como las dimensiones de la tapia, la existencia de verdugadas, de marcas de tablas de encofrado o de tramos constructivos. Las dimensiones en al tura y anchura son relativamente similares en todos los casos excepto en el de Pedraza donde se reduce de forma importante tanto en altura como en anchura. En el resto de casos, los valores de altura de tapia oscilan entre 103,50 y $127 \mathrm{~cm}$. En este margen habría tres tendencias, la primera con una al tura cercana a $105 \mathrm{~cm}$, la segunda con una altura de $116 \mathrm{~cm}$ y la tercera con una altura de $127 \mathrm{~cm}$. En cuanto a la anchura, se sitúa en el margen entre 260 y $288 \mathrm{~cm}$. En este margen no se observan tendencias. Las diferencias en altura no superan los $25 \mathrm{~cm}$ (que supone una variación de un $20 \%$ del total) y en anchura no supera los $30 \mathrm{~cm}$ (que supone una variación de un $10 \%$ sobre el total). Entre los casos cuyas dimensiones se aproximan, todos excepto el caso de Pedraza, el valor de la anchura es más variable frente al de la altura, pero teniendo en cuenta el porcentaje de variación en relación con el total, la variación en anchura es menor.

No se ha encontrado razón por la cual en los tramos analizados de Sepúlveda y de Fuentidueña (P3-T10), existen hiladas de tapia con una altura bastante mayor que el resto de hiladas. De nuevo podría pensarse en la existencia de grupos de trabajadores diferentes, cuadrillas con distintas técnicas. No se observan diferencias suficientes en el lienzo como para plantear que pueda tratarse de una hilada de tapia construida con anterioridad y que luego se ha reaprovechado construyendo nuevas hiladas de distinta dimensión, como ocurre en Sepúlveda donde la hilada de diferente altura se encuentra en la base del lienzo. En el caso de Fuentidueña sería al revés, puesto que la hilada con diferente altura se sitúa en la parte superior del lienzo.

La diferencia más notable entre los casos analizados es el tipo de tapial empleado, identificado de forma evidente en los casos de Coca, Cuéllar y Fuentidueña a partir de la posición de los mechinales y de forma más deficiente en el resto de casos donde las marcas del tapial son menos evidentes. De acuerdo con este parámetro, Coca y Cuéllar se diferencian del resto por emplear un tapial diferente. El segundo parámetro 
que diferencia los tramos analizados es la sección de las agujas empleadas, que no es homogénea en ninguno de los casos, a excepción de Pedraza, de nuevo condicionada por la escasez de tapias analizadas. El empleo de agujas unitarias se observa en todos los casos, aunque se observe el uso simultáneo de varillas pareadas en Sepúlveda y Fuentidueña. Otro parámetro de diferenciación es el uso de tramos constructivos en los casos de Coca y Cuéllar, que no son visibles en el resto de casos. La existencia de v erdugadas de pi edra se identifica en solo dos casos, Coca y Pedraza. Finalmente el parámetro de espesor aísla a Fuentidueña del resto de casos con un es pesor que se reduce a la mitad en comparación con el resto de tramos analizados.

La comparación realizada a través del sistema de Componentes Principales permite comprobar que el caso de Pedraza se aleja de todos los demás de forma muy clara. Ahora bien, este resultado no es del todo convincente, teniendo en cuenta que en Pedraza se ha analizado un número muy reducido de tapias y no se han podido incluir los datos de los escasos restos disponibles por las ya mencionadas dificultades de accesibilidad. Por otra parte, este sistema parece agrupar por un lado los casos de Coca y Cuéllar y por otro los casos de Fuentidueña, Maderuelo y Sepúlveda, aunque este último se debate entre los dos grupos condicionado por el tipo de tapial que lo aleja de los casos de Coca y Cuéllar, y por la ausencia de verdugada de piedra en sus tapias que lo acerca al segundo grupo.

\subsection{Conclusiones en el ámbito histórico}

En las hipótesis planteadas al principio de es te documento, se comenta que está aceptada desde un punto de vista histórico la existencia de la Extremadura Castellana como una zona geográfica donde se produjo una repoblación basada en la creación de villas nuevas o reconstrucción de villas existentes, protegidas con una muralla. El estudio constructivo de estas murallas ha permitido identificar una técnica constructiva empleada en todas ellas. Se han podido identificar otras técnicas utilizadas con anterioridad, situadas en las bases de lienzos y torres, y también técnicas que han llegado con posterioridad, como el empleo del ladrillo en la tapia mixta.

No es posible atribuir un periodo histórico a un muro por el simple hecho de que esté realizado con tapia. No obstante, la técnica con tapia puede realizarse de diversas maneras, en tierra, apisonada, con calicostrados, con cantos rodados, incluyendo ladrillo o tapia de mampostería como en los casos analizados. Parece posible atribuir a un mismo periodo histórico el uso de la tapia de mampostería estudiada en es ta investigación, que tiene en común los parámetros significativos reflejados en el análisis de resultados. Sin embargo, los parámetros que diferencian algunos casos de otros, no dejan de tener importancia en la ejecución de la muralla. Es el caso del espesor tan diferente en el ejemplo de Fuentidueña o del empleo de tapiales unitarios en I os tramos analizados de Cuéllar y Coca.

Tal y como se discute en el análisis de resultados, es difícil determinar un periodo concreto en el que se construyeron estas murallas. Aun así se podrían plantear que estas murallas comenzaran a construirse en el siglo XII y se encontraban construidas a 
Las murallas en las Comunidades de Villa y Tierra de la Diócesis de Segovia en los siglos XI a XIII.

Técnica y sistemas constructivos de la arquitectura defensiva medieval.

mediados del siglo XIII. Durante este periodo, es posible que se produzca una evolución entre ellas, y que unos recintos presenten mejoras defensivas frente a otros que puedan incorporarlas con posterioridad. Es el caso de las torres de flanqueo en los lienzos o de la construcción por tramos visible en los casos de Coca y Cuéllar. En Fuentidueña las torres semicirculares del tramo T5-T7 se adosan con posterioridad, frente a la zona P3-T11 que ya incorpora torres de flanqueo separadas entre sí una distancia estratégica. Otro factor es la construcción por tramos, que podría considerarse una mejora en el método de construcción de murallas, frente al lienzo continuo, donde al menos se observa una voluntad de planificación.

En contraposición de la construcción por tramos o la incorporación de torres, hay otros factores que indican una falta de planificación o de conocimiento constructivo. Esto puede observarse en I a irregularidad de I as tapias en muchos de los lienzos analizados y en el empleo de agujas con secciones y configuraciones variadas dentro de un mismo tramo.

El protagonismo del ciudadano en la sociedad de los concejos podría tener un reflejo en la construcción de las defensas de s us villas. No se trata de construcciones realizadas por la iglesia o por el rey, ni tampoco por señores. En las construcciones de este tipo se observa un gran esfuerzo de representación, mientras que en las murallas estudiadas no hay apenas sillería y la decoración es casi inexistente. Cuando existe, es probable que haya sido añadida con posterioridad, como ocurre con algunos escudos visibles en las puertas. La muralla tiene un c arácter funcional, ha s ido construida como defensa y la imagen que ofrece es intimidatoria, de fortaleza, de villa protegida, pero solo a través de la altura y longitud de sus lienzos o con la volumetría de sus torres; imagen que es todavía perceptible por ejemplo al acercarse a Fuentidueña, aunque el recinto esté fragmentado y deteriorado. Esta ausencia de decoración y de imagen proyectada apoya el hecho que la construcción no estaba supervisada por figuras de autoridad que pidiesen la incorporación de símbolos o de señas distintivas, o que buscasen ocultar con sillería zonas construidas con otras calidades.

Tal vez existían facilidades para la creación de estas villas por parte de la monarquía, que impulsaba estos asentamientos a través de ventajas para la población, pero sus defensas no parecen construidas por una población experta. El uso intenso de la tapia de mampostería en estas murallas permite plantear que se adopta este sistema por su sencillez, su aparente rapidez, su esquema repetitivo que permite mantener un control sobre el muro, en definitiva, un sistema al alcance de cualquier villano.

En la descripción de la estructura de los concejos, se hacen varias menciones a la fiscalización de la muralla, cualquier impuesto parece gravado con un porcentaje para la muralla y si no, a través de trabajo en su mantenimiento. Es posible que la construcción de la misma funcionara de la misma manera y la solución para no pagar fuera participar. En cualquier caso, el análisis constructivo de los tramos de muralla estudiados, así como el estudio del conjunto de los recintos amurallados parece apuntar que la construcción de I a muralla se realizaba por los propios villanos, liderados tal vez por los caballeros villanos, con una planificación escasa que podría haber mejorado al incorporarse las torres de flanqueo o la construcción por tramos. 


\subsection{Futuras líneas de investigación}

Se ha mostrado, en la acotación histórica y geográfica de este estudio, la gran amplitud del territorio que engloba las Comunidades de Villa y Tierra, y por lo tanto la existencia de numerosos ejemplos de ciudades amuralladas que forman parte de este proceso repoblador. El estudio de las murallas de otras villas pertenecientes a este proceso repoblador podría permitir comparar los mismos parámetros extraídos en esta investigación u otros nuevos que aparezcan en otros recintos o que sean propuestos por otros investigadores.

Esta investigación se ha centrado en el estudio constructivo de lienzos de muralla, haciendo algunas referencias a otros elementos como las torres o las puertas. Cada uno de los ejemplos de esta investigación es susceptible de ser analizado bajo otras ópticas como la urbanística o la tipológica. El estudio tipológico de torres y puertas de los recintos analizados puede extraer información de la evolución de estos elementos, detallando las modificaciones que se han producido; puede asimismo extraer datos acerca de las mejoras añadidas desde un punto de vista defensivo.

Se ha adelantado en las páginas precedentes que los análisis urbanos realizados en las villas estudiadas permiten extraer marcas y trazados para deducir que rumbo siguió la formación urbana medieval de estas villas. El estudio del tejido urbano dentro de los recintos amurallados de estas y otras villas pertenecientes a este proceso repoblador es otra línea de investigación que puede aportar datos acerca de aquellos tramos de muralla hoy desaparecidos, y también acerca de la formación de las agrupaciones de parcelas visibles en algunas de las villas analizadas.

De cara a otras disciplinas, los ayuntamientos de algunas de I as villas estudiadas poseen archivos con documentación histórica que se encuentra sin analizar y sin clasificar, que podrían ser estudiados desde la óptica de la arquitectura defensiva. Esta documentación podría proporcionar información acerca del recorrido de partes de la muralla desaparecidos o de antiguos recintos de menor superficie. La investigación en esta dirección aportaría datos valiosos sobre estas construcciones que se podrían combinar con los resultados de otros estudios sobre esas villas.

Aunque escasos, existen algunos escudos en las murallas de estas villas. El estudio de estos elementos, su identificación con el periodo histórico correspondiente y su comparación con los de otras villas podría también constituir una línea de investigación que permita ahondar en el carácter de estas construcciones defensivas.

El estado de conservación de algunas de estas murallas, así como las reparaciones y restauraciones observadas ponen de manifiesto que la restauración de murallas es un aspecto que requiere la atención de la sociedad y de los profesionales dedicados a este tipo de intervenciones. Sistemas constructivos como la tapia de mampostería necesitan de un estudio que determine la idoneidad de las técnicas restauradoras a aplicar. No es posible aplicar los mismos procedimientos que con un aparejo de mampostería convencional o un muro de sillería. La investigación en la restauración de este tipo de tapias podría suponer una valiosa aportación a este campo, facilitando la intervención en este tipo de construcciones. Este estudio podría aportar nuevos 
enfoques al debate existente acerca de los distintos tipos de restauración arquitectónica.

Desde un punto de vista urbano, la restauración urbana de murallas es otro aspecto a investigar. La integración de una construcción cuya función ha quedado obsoleta en el funcionamiento de una ciudad moderna es otra línea de investigación que puede abordarse para núcleos como los estudiados en esta investigación, donde el número de habitantes es reducido o también en grandes ciudades. La muralla tiene gran potencial como recurso urbano por tratarse de un elemento que recorre o rodea la ciudad y que cuando es posible se puede convertir en e je que estructure usos o actividades en determinadas áreas de la ciudad. La vinculación de parques, áreas de ocio o paseos a áreas colindantes con tramos de muralla puede potenciar la visibilidad de esta y a la vez conectar estos usos con la ciudad. El estudio de otras soluciones o propuestas para integrar la muralla en la ciudad es una línea de investigación necesaria en el campo de la arquitectura defensiva.

Tal y como se ha adelantado en la discusión, el estudio de las agujas de madera embebidas en las tapias empleado la dendrocronología puede tal vez aportar más información sobre la cronología de es tas construcciones. La investigación en es ta dirección es otro enfoque más para el estudio de la arquitectura defensiva. La extracción de muestras de algunas de las agujas existentes en los lienzos de muralla y su posterior análisis podría datar lienzos del mismo recinto amurallado y establecer diferencias entre sí o entre murallas de diferentes villas. En una línea similar a esta, de análisis en laboratorio, la recogida de muestras de tapias de una o de varias murallas y una posterior comparación de su composición permitiría establecer relaciones o diferencias en función de la tierra empleada o la proporción de cal y arcillas añadida. 


\section{Conclusions}

Cette recherche a été dirigée d'une façon plus intense à l'analyse constructive des pans de murailles et les conclusions principales sont celles reliés au domaine constructif. Tout de même, des conclusions ont été extraites dans d'autres aspects traités dans la recherche comme la méthodologie utilisée, l'ensemble de la muraille et les résultats de l'analyse historique. À la fin, un paragraphe décrit les futurs sujets de recherche qui se proposent en continuité avec cette recherche.

\subsection{Conclusions relatives à la méthodologie}

Le travail de terrain a été une méthode nécessaire pour la récolte de données, la réalisation de cette recherche a dépendu de façon majoritaire de la prise de ces données. Tout de même, des limitations ont été détectées dans les visites in situ comme l'accès difficile à quelques lieux par l'existence de dénivellations importantes, ou parce qu'ils se trouvaient dans des points cachés para la végétation ou dans des propriétés privées. II y a eu un manque d'outils, d'une coordination plus intense avec d'autres disciplines familiarisées avec des ressources topographiques pour pouvoir accéder à tous les points. Cette limitation a conditionné les résultats d'un des cas, Pedraza, où l'information extraite des restes architectoniques a été inférieure par rapport à d'autres cas.

La consulte de sources historiques ou d'études sur ces sources n'a pas apporté de données importantes sur les murailles physiquement et très peu d'information sur la forme de les construire ou sur quelles personnes participaient à s a construction. Aucune ou très rares mentions ont étés trouvées dans les sources consultées. II est surprenant de ne pas avoir trouvé aucune allusion à la muraille dans des documents comme le Cadastre du Marquis Ensenada. D'un point de vue constructif, des allusions aux matériaux utilisés ont été trouvées dans les données extraites à Sepúlveda (Martín Aymerich et. al. 1990, 106). À nouveau, la coordination avec d'autres disciplines familiarisées avec la documentation historique aurait pu peut-être apporter plus de résultats.

Les méthodes utilisées pour représenter les pans de murailles ont été très utiles. Le programme informatique Agisoft PhotoScan a permis de construire avec succès des modèles $3 \mathrm{D}$ des pans de $\mathrm{m}$ uraille. Sur les relevés photogrammétriques extraits, l'identification des éléments constructifs a été facilement réalisée et mesuré chacun des éléments. Quelques éléments de la muraille différents des pans peuvent être plus difficiles à relever avec ce système de représentation en raison des parties en courbe, qui ont un comportement plus complexe dans ce programme informatique; les 
Les murailles dans les "Comunidades de Villa y Tierra" dans la Diocèse de Ségovie du XI ${ }^{\text {ème }}$ au XIII" siècle. Technique et systèmes constructifs de l'architecture défensive médiévale.

résultats ont été d'inférieure qualité. En général, cette méthode a été très simple à utiliser, avec des résultats très positifs.

Le dessin sur les relevés photométriques a permis d'extraire les éléments constructifs visibles et a fait possible leur identification, numération, prise de mesures et la récolte des caractéristiques des boulins, leur position, la séparation entre eux ou leur configuration. Ce système de représentation des blocs pourrait être appliqué à toute la muraille et pas seulement aux tronçons étudiés dans cette recherche, pour pouvoir connaître en profondeur les caractéristiques constructives de l'ensemble des murs.

L'emploi de données géolocalisées d'institutions comme le Cadastre, IDECyL ou IGN ont été très utiles pour la construction d'un SIG de travail. Ceci a permis d'analyser les villes à une échelle générale et produire des plans de synthèse des aspects reliés avec la construction de la muraille : le territoire et le terrain d'établissement, ainsi que la configuration de la ville médiévale présente dans le plan parcellaire.

L'utilisation d'outils statistiques a ét é très utile. D'une part, la représentation des données extraites d'un pan de muraille à travers les diagrammes en boîte a permis d'illustrer les marges dimensionnelles des blocs d'une façon plus efficace qu'à travers une table avec les valeurs numériques. De plus, ce système a été utile pour extraire une mesure représentative des dimensions de chaque élément constructif d'un pan. D'autre part, face à la comparaison des résultats, les graphiques avec le format biplot réalisées en composantes principales ont permis de faire une comparaison objective des paramètres analysées pour chaque cas. Tout de même, cette comparaison a été réalisée comme renfort sur la comparaison conventionnelle des paramètres, un à un. II est prudent de penser que dans cette recherche il y a une petite quantité de données disponibles pour l'utilisation de cette méthode. En effet, son efficacité est plus évidente quand une plus grande quantité de données est gérée.

\subsection{Conclusions dans l'ensemble de la muraille}

La planification dans la construction de l'enceinte de ces villes n'est pas observée, il est remarquable seulement l'utilisation des avantages qu'offre le territoire, les villes se rapprochent à la confluence de deux rivières et situent les murailles sur le bord du rocher, pour profiter de la dénivellation. La réutilisation de bases de défenses antérieures a été confirmée, en construisant avec maçonnerie coffrée sur des appareils en pierre existants ou en plaçant le tracé de la muraille sur la position de murailles antérieures comme dans le cas de Coca, où a u moins une partie de la muraille se place sur une muraille vaccée.

La brève analyse parcellaire réalisée dans chaque cas, afin de situer la muraille dans la ville, montre une relation entre la muraille et le tissu urbain. Une analyse en profondeur pourrait éclaircir cette relation pour obtenir des résultats plus importants sur l'empreinte de la muraille dans la configuration urbaine. Dans le cas de Sepúlveda, il y a d'une part une configuration particulière de rues qui entourent la colline de Somosierra et confluent dans le château, d'autre part la place du marché s'étend 
devant le château avec une disposition habituelle en face d'une porte de muraille. Un exemple de cette disposition peut se trouver dans la place de San Pablo de Valladolid où il y avait une porte de muraille, ou bien à la place de Zorrilla où se situait la porte « de Campo ». Ces pistes qui ont permis de poser que le château aurait pu fonctionner avant comme porte de l'enceinte urbaine. La localisation si baisse du château qui habituellement s'établit dans les zones les plus hautes de la ville soutient cette proposition.

Bien que le point de vue de cette recherche n'a pas été l'étude des typologies des tours de la muraille, l'approche qui a é té réalisée montre des exemples avec une configuration différente dans chacune des villes. Le plan des tours est principalement rectangulaire et semi-circulaire. Dans toutes les murailles à I 'exception de C oca, l'utilisation majoritaire de tours rectangulaires est observée. Les tours semi-circulaires plus surprenantes sont celles de Fuentidueña qui sont différentes du reste en raison de leur grand diamètre, seulement comparable dans la tour T1 de Cuéllar. Les plans polygonaux identifiés à Cuéllar ou à Coca semblent reliés à la réutilisation de bases préexistantes.

La plupart des tours de ces enceintes, celles de plan rectangulaire et celles de plan semi-circulaire, sont massives. Ce fait est spécialement surprenant dans le cas de Fuentidueña, dont les tours semi-circulaires de grand diamètre sont massives et pourtant ont eu besoin d'une quantité immense de matériel pour se construire. Dans le reste de cas, les dimensions sont inférieures et la massivité semble plus contrôlée.

L'absence de tours a été observée dans de longues distances des pans analysées. Dans les cas de Cuéllar ou Sepúlveda il y a des tronçons très longs où il n'y a pas de tours ni aucune trace de leur existence, les pans son continus. À Fuentidueña, les pans de muraille ont des tours qui ont été adossées après, le pan a été construit sans tours. L'inclusion de la tour dans le pan pou vait supposer une di fficulté dans la construction de l'ensemble. L'intégration de la tour dans un pan construit avec de la maçonnerie coffrée pouvait être plus complexe que construire la muraille sans tours. L'absence de tours peut indiquer un manque de connaissance constructive pour les intégrer dans les pans. La construction de tours pouvait signifier une évolution, une avance face aux pans continus.

Les tours qui se conservent sont peu nombreuses, l'analyse de la séparation entre elles n'a pas montré une tendance claire. L'existence de longs tronçons sans tours mentionné dans le paragraphe antérieur n'apporte pas d'information à ce sujet. D'après les donnés disponibles, la séparation plus habituelle entre les tours est dans la marge de $25-30 \mathrm{~m}$.

\subsection{Conclusions dans le cadre constructif}

L'identification des systhèmes construtifs employés dans les murailles a per mis de détecter l'emploi de la maçonnerie coffrée comme une technique protagoniste dans les pans des murailles. Cette technique est présente d'une façon majoritaire dans les pans, elle est la base constructive de cette partie de la muraille. Les techniques 
Les murailles dans les "Comunidades de Villa y Tierra" dans la Diocèse de Ségovie du XI ${ }^{\text {ème }}$ au XIII" siècle. Technique et systèmes constructifs de l'architecture défensive médiévale.

alternatives trouvées se situent dans les bases des pans et ne s'utilisent pas d'une manière généralisée mais plutôt rare et montrent des différences entre les villes analysées.

L'utilisation de c ette technique dans ces murailles peut paraître évidente. Dans d'autres parties de la péninsule ibérique, des exemples de murailles qui se construisent avec plusieurs versions du pisé ont été documentés. La recherche dans le domaine traité ici a été très réduite, jusqu'aujourd'hui ce fait n'a pas permis d'établir l'emploi de cette technique dans ces cas.

Dans d'autres éléments de la muraille, comme les portes el les tours, l'emploi de la maçonnerie coffrée n'est pas généralisé. Seulement dans la porte de Coca et dans quelques portes de Sepúlveda cette technique est utilisée. Dans les tours, elle est employée d'une façon généralisée à Fuentidueña et dans les parties supérieures de quelques tours de Sepúlveda, mais il est impossible de signaler un emploi majoritaire dans les portes et les tours de toutes les villes.

Cette recherche a voulu aussi montrer l'importance qu'ont les pans des murailles face à d'autres éléments comme les portes et les tours. Ces dernières ont habituellement des formes singulières, de la décoration, ou bien se trouvent dans des positions fréquentées de la ville, ce qui contribue à a ttirer l'attention sur elles par rapport à d'autres éléments. Les chefs ou autorités en charge de la ville qui se sont succédé durant des siècles ont tendance à vouloir laisser des symboles de leur pouvoir dans ce type d'élément, là où ils sont plus visibles par tous les habitants et les voyageurs, pour cette raison les portes peuvent réunir plusieurs altérations. Dans ce sens, les pans se situent à l'extrémité opposée, ils ont un caractère moins représentatif et pour ce motif ils accumulent moins de modifications avec le passage du temps. Au contraire, ils sont absorbés par des nouvelles édifications, restent cachés ou simplement personne ne les regarde. D'un point de vue constructif, les pans gagnent importance face aux portes et aux tours, par ce degré plus petit d'altération.

La présence de cette technique en tous les cas analysés permet de la considérer comme un système qui pourrait s'employer d'une façon généralisée dans les murailles médiévales chrétiennes. Ce système est relativement facile d'exécuter, il a un procédé répétitif où les premières rangées peuvent se réaliser d'une façon plus lente, mais qu'à force de le reproduire centaines de fois peut «s'automatiser», améliorant la vitesse et l'efficacité. D'autre part, les matériaux nécéssaires pour le remplisement du coffrage sont disponibles dans l'environnement et n'ont pas besoin de la taille de la pierre. D'accord avec le calcul approximatif du chapitre d'analyse des résultats, il est possible que les murailles puissent se construire avec une certaine vitesse, en dépendant toujours de plusieurs facteurs comme la main-d'œuvre disponible ou la récolte des matériaux nécéssaires. De plus, le processus est conditionné par le lent durcissement des blocs qui devrait d'être tenu en compte pour alterner de périodes de construction des blocs avec d'autres activités, ou peut être pour réaliser la construction de plusieurs tronçons à la fois qui permettrait de travailler dans une partie pendant le durcissement des autres. 
L'utilisation de la maçonnerie coffrée est remarquable dans les pans principalement, dans quelques tours, et même dans la construction des créneaux, avec des moules plus petits. L'utilisation généralisée fait penser que ce système devait être très connu, ou facile à réaliser. D'autre part, les variantes trouvées dans les exemples analysés, dans les mêmes tronçons de muraille ou dans de trançons différents, fait penser que c'était une technique connue avec des différentes solutions ou manies en fonction du groupe d'ouvriers assigné à chaque tronçon. La varieté de boulins dans un $m$ ême tronçon comme il est remarquable à Fuentidueña ou à Coca montre qu'il n'y avait pas un consensus caractéristique des experts.

La maçonnerie coffrée semble accesible à tous, n'exige pas la présence de carriers experts, il est seulement nécéssaire d'avoir plusieurs banches de bois et avoir accès à la fabrication des clefs en bois. L'irregularité que présentent les rangées de blocs dans quelques tronçons analysés a été signalée dans plusieurs cas. Le tronçon T5-T6 de Fuentidueña est celui qui montre un gran désordre dans sa construction, peut-être à cause du terrain en pente où il se trouve. L'irrégularité de Fuentidueña soutient que la construction se faisait sans planification et sans une vision générale du pan. II y a un désorde dans les rangées des blocs de la muraille puis des recontres malheureuses entre eux, qui obligent à l'emploi de blocs de forme triangulaire ou trapezoïdale pour réssoudre les rencontres des rangées. Face à ce désordre, une construction faite en portions est remarquable à Coca. Ce système représente un progrès, un signe de planification face au désordonné et chaotique pan de Fuentidueña. Tout de même, ces portions ont des longueurs variées et ne répondent pás a un patron concret.

D'autres techniques ont été identifiées dans les murailles analysées en plus de la maçonnerie coffrée, qui s'accumulent principalement dans les portes el les tours. Parmi ces techniques se trouve l'utilisation de la brique ; la rare utilisation de la brique dans les pans de muraille en rangées isolées ou dans des piliers entre les blocs de maçonnerie coffrée est significative. La présence de brique est nulle dans les pans de tous les cas analysés et est rare dans les portes et les tours, à l'exception de Cuéllar où la brique est visible dans plusieurs portes et quelques tours. À Pedraza la brique s'utilise dans la porte de "la Villa" et à Coca la brique s'emploi dans l'unique porte qui se conserve. L'exemple de la porte de Coca a un interêt spécial car les deux tours qui flanquent l'accès n'utilisent pas la brique à sa construction. La brique aparaît seulement dans le front et dans la partie supérieure, ce qui a permis de déduire que cela a été ajouté après, il ne fait pas partie du système originale de construction. Cette conclusion est plus évidente dans les pans, où l'emploi de la brique n'est pas présent du tout.

\subsubsection{Typologie du bloc}

D'accord avec la typologie proposée par Amparo Graciani y Miguel A. Tabales (2008, 139), la typologie des blocs de maçonnerie coffrée de chaque cas coïncide, il s'agit dans tous les cas un bloc monolitique. Tous les cas montrent des boulins qui ont un couronnement avec des pierres irrégulieres. Les cas de Coca et Pedraza présentent une rangée de pierre dans la base de ses blocs. Le cas de Sepúlveda présente un bloc avec des piliers en pierre de taille dans deux de ses portes. 
Les murailles dans les "Comunidades de Villa y Tierra" dans la Diocèse de Ségovie du XI ${ }^{\text {ème }}$ au XIII siècle. Technique et systèmes constructifs de l'architecture défensive médiévale.

Dans la classification de J. Gil Crespo (2013, 554-557), la typologie des blocs coïncide dans les paramètres de "Matériel de construction ", "Compactage du matériel », "Fonction constructive », "Finitions de s urface », "Combinaison de matériaux ", "Situations des boulins » et «Formation des boulins ». Les blocs analysés ont des résultats différents dans les paramètres "Coffrage » et "Sections des clefs». Le paramètre "Profondeur des boulins » n'a pas une valeur dans tous les cas, alors ce n'est pas possible de réaliser une comparaison. Dans le $70 \%$ des paramètres il y a une coïncidence des valeurs de tous les cas, face à un $20 \%$ des paramètres qui montrent des résultats différents. Les cas de Cuéllar et Coca montrent une coïncidence du $90 \%$ des paramètres et de $80 \%$ avec Fuentidueña et Sepúlveda.

Les paramètres de cette recherche sont similaires à c eux proposées para les chercheurs cités, avec quelques-uns nouveaux comme les dimensions des blocs, l'existence de rangées de pierres ou brique dans les bases de blocs, l'existence de traces des planchers utilisés dans le coffrage ou de portions constructives. Les dimensions de hauteur et largeur sont relativement similaires dans tous les cas à l'exception de Pedraza où ces dimensions sont beaucoup plus petites. Dans le reste de cas, les valeurs de la hauteur du bloc se trouvent entre $103,50 \mathrm{~cm}$ et $127 \mathrm{~cm}$. Dans cette marge il a trois groupes, le premier avec une hauteur de $105 \mathrm{~cm}$, le deuxième avec $116 \mathrm{~cm}$ et le troisième avec $127 \mathrm{~cm}$. Quant à la largeur, elle se trouve entre $260 \mathrm{~cm}$ et $288 \mathrm{~cm}$. Dans cette marge il n'a pas des groupes ou des tendances. Les différences en hauteur ne dépassent pas les $25 \mathrm{~cm}$ (cela est une variation de $20 \%$ du total) et en largeur ne dépassent pas les $30 \mathrm{~cm}$ (une variation de $10 \%$ du total). Parmi les cas où les dimensions sont proches, tous à l'exception de Pedraza, la valeur de la largeur est plus variable que celle de la hauteur, les différences entre les blocs sont plus grandes, mais tenant en compte le pourcentage de variation par rapport au total de la largeur, la variation est mineure.

La raison par laquelle dans les cas de Sepúlveda et de Fuentidueña (P3-T10), il y a des rangées de blocs avec une hauteur considerablement supérieure que le reste des rangées, n'a pas été trouvée. À nouveau, la raison pourraît être l'existence de groupes d'ouvriers différents, avec des différentes técniques et outils. II n'y a pas des différences suffissantes dans les pans pour proposer que ces rangées ont été construites avant puis ont été reutilisées après en construisant dessus des blocs avec des nouvelles dimensions. Ceci se produit à Sepúlveda (P11-oeste200), où cette rangée de différente hauteur se situe dans la base du pan. Dans le cas de Fuentidueña (P3-T10), ce serait a l'envers, car la rangée de différente hauteur se situe dans la partie supérieure du pan.

La différence plus importante entre les cas analisés est le type de banche de bois utilisé, identifié clairement à C uéllar, Coca et Fuentidueña d'accord avec la position des boulins et d'une façon insuffisante dans le reste de cas, où les traces des banches ne sont pas si visibles. D'après ce paramètre, Cuéllar et Coca se différence du reste car ils emploient une banche différente. Le second paramètre qui différence les tronçons analysées est la section des pieces en bois transversales de la banche, qui n'est pas homogène dans aucun cas, à l'exception de Pedraza, à nouveau conditionné par le manque de de blocs analysés. L'emploi de clefs unitaires est observé dans tous 
les cas, même si l'emploi de ces pièces en couple est utilisé de façon simultanée dans les cas de $S$ epúlveda y Fuentidueña. Un autre paramètre différent est celui des portions constructives dans les cas de Coca et Cuéllar, qui ne sont pas remarquables dans le reste de cas. L'existence de rangées de pierres irrégulières est identifié en seulement deux cas, Coca et Pedraza. Finalement, le paramètre d'epaiseur isole le cas de Fuentidueña du reste de cas, avec la moitié d'épaiseur para rapport au reste de tronçons analysés.

La comparaison realisée en Composantes Principales permet de vérifier que le cas de Pedraza s'éloigne de tous les autres d'une façon très claire. Néanmoins, ce résultat n'est pás convaincant, tenant en compte qu'à Pedraza un petit nombre de blocs a été analysé et il y a eu des difficultés d'accésibilité qui ont empêché d'inclure tous les restes existants. D'autre part, ce système semble regrouper d'un côté les cas de Coca et Cuéllar et d'un autre côté les cas de Fuentidueña, Maderuelo et Sepúlveda, même si ce dernier se trouve entre les deux groupes, conditionné para le type de banche qui l'éloigne de Coca et Cuéllar, puis par l'absence de rangées de pierre qui lui rapproche du deuxième groupe.

\subsection{Conclusions dans le domaine historique}

Dans les hypothèses proposées au début de ce document, il y a une m ention sur l'acceptation, du point de vie historique, de que l'Estrémadure de Castille est une zone géographique où s'est produit un repeuplement. Ce repeupleument s'est produit avec la création de villes nouvelles ou bien avec la reconstruction de villes existentes, dans tous les cas protégées par une muraille. L'étude constructif des ces murailles a permis d'identifier d'autres techiques utilisées antérieurement, situées dans les bases des pans et des tours, et aussi des techniques qui ont arrivé posterieurement, comme par exemple la brique dans les blocs mixtes.

Ce n'est pas possible d'attribuer une période historique à un mur seulement parce qu'il est construit avec des blocs. Cependant, la technique des blocs peut être réalisé de plusieurs manières différentes, avec de la terre, le pisé, avec de la chaux entre les couches de terre, avec des galets, en ajoutant de la brique ou avec la maçonnerie coffrée comme dans les cas analysés ici. II semble possible d'attribuer à une même période historique l'utilisation de la maçonnerie coffrée étudiée dans cette recherche, qui a en c ommun plusieurs paramètres significatifs revelés dans l'analyse des résultats. Toutefois, les paramètres qui différencent quelques cas par rapport à d'autres sont aussi importants dans l'exécution de la muraille, comme par exemple l'epaisseur si différente dans le cas de Fuentidueña ou l'emploi de banches unitaires dans les troçons de Cuéllar et de Coca.

D'accord avec ce qui est décrit dans l'analyse de resultats, il est difficile de déterminer une période précise de construction des murailles. Tout de même, il est possible de proposer que ces murailles ont comencé leur constrution dans le XII ${ }^{\text {ème }}$ siècle et se trouvaient déjà construites au milieu du XIII ${ }^{\text {ème }}$ siècle. Durant cette période, une évolution dans la construction s'est possiblement produite entre elles; quelques enceintes présentent des améliorations défensives face à d'autres qui les ont peut être 
Les murailles dans les "Comunidades de Villa y Tierra" dans la Diocèse de Ségovie du XI ${ }^{\text {ème }}$ au XIII siècle. Technique et systèmes constructifs de l'architecture défensive médiévale.

incorporées après. Par exemple, les tours flanquantes des pans ou la construction en tronçons remarquable à Coca et Cuéllar. À Fuentidueña, les tours semi-circulaires du tronçon T5-T6 ont été adossées après, par opposition au tronçon P3-T11 qui incorpore des tours flanquantes séparées une distance stratégique. Un autre facteur est la construction en tronçons qui pourrait être considerée comme une amélioration dans la construction des murailles, face au pan continu, où au moins une volonté de planification est observée.

Par opposition à la construction en portions ou l'incorporation de tours, il y a d'autres facteurs qu'indiquent un manque de planification ou de connaissances constructives. Ceci peut être observé dans l'irrégularité des blocs dans plusieurs des pans analysés et dans l'emploi des clefs des banches avec des sections et configurations variées dans un même tronçon.

Le protagonisme du citoyen dans la société des ces territoires pourrait avoir un reflet dans la construction des défenses de villes. Ce ne sont pas des constructions réalisées par l'église ou par le roi, en non plus par de seigneurs. Dans ces constructions il est remarquable un grand éffort de représentation, tandis que dans les murailles étudiées ici il n'y a presque pas de la pierre de taille ni décoration. Quand il y a une décoration, elle a été probablement ajoutée après comme arrive avec quelques emblèmes situés sur les portes. Les murailles possèdent un caractère fonctionel, elles ont été construites comme défense et l'image qu'elles offrent intimide, elles ont une image de forteresse, de ville protégée mais seulement avec la hauteur et longueur de ses pans ou avec la volumétrie de ses tours ; cette image est encore perceptible, par exemple, à Fuentidueña même si l'enceinte est détériorée et fragmentée. L'absence de décoration et d'image projetée soutien le fait de que ces constructions n'était pas supervisées par des personalités puissantes qui demandaient l'incorporation de $s$ ymboles de $s$ on pouvoir ou qui cherchaient à cacher avec des pierres de taille les parties construites avec des qualités inférieures.

II existaient peut-être des facilités pour la création de ces villes de la part de la monarchie, qui encourageait ces noyaux avec des primes pour la population, mais ses défenses ne semblent pas construites par une population experte. L'emploi intense de la maçonnerie coffrée permet de proposer que ce système a été adopté par sa simplicité, la vitesse apparente a laquelle il se construit, le schéma répétitif qu'il suit, en somme, un système à la portée de n'importe quel paysan ou habitant des villes.

Dans la description de la structure de ce territoire, organisée en communes, il y a plusieurs mentions au contrôle fiscal relié à la muraille, n'importe quel impôt semble grevée avec un pourcentage destiné à la muraille. La construction de la muraille a peut-être fonctionné d'une façon similaire et la solution pour ne pas payer serait de participer à la construction. Dans tout cas, analyse constructive des tronçons de muraille ainsi que l'étude de l'ensemble des enceintes semble indiquer que la construction de la muraille était réalisée par les habitants des villes eux-mêmes, dirigés peut-être par les chevaliers des villes, sans une planification importante qui a pu améliorer en ajoutant les tours flanquantes ou la construction en portions. 


\subsection{Futurs sujets de recherche}

Le cadre historique et géographique décrit dans cette recherche a montré la grande étendue du territoire qui englobe les "Comunidades de V illa y Tierra ", et pourtant l'existence de nombreux exemples de villes fortifiées qui font partie de ce processus de repeuplement. L'étude des murailles d'autres villes appartenant à ce processus pourrait permettre la comparaison des mêmes paramètres extraits dans cette recherche ou de nouveaux paramètres qui apparaissent dans les autres enceintes ou qui soient proposées par d'autres chercheurs.

Cette recherche a étudié principalement les aspects constructifs des pans de muraille, en faisant des références à d'autres éléments comme les tours ou les portes. Chaque exemple est susceptible d'être analysé d'accord avec d'autres points de vue comme l'urbanistique ou le typologique. L'étude typologique des tours et des portes des murailles analysées peut extraire information de l'évolution de ces éléments, en détaillant les modifications qui se sont produites, et peut extraire des données sur les améliorations ajoutées d'un point de vue défensif.

Dans les pages précédentes, l'importance les analyses urbaines a été soulignée, puisqu'elles permettent d'extraire les marques et traces pour déduire quelle direction suivait la formation urbaine médiévale de ces villes. L'étude du tissu urbain à l'intérieur des murailles de ces villes et d'autres appartenant à ce processus de repeuplement est un autre sujet de recherche qui peut apporter des données sur les tronçons de muraille disparus et aussi sur la formation des ensembles de parcelles visibles dans quelquesunes des villes analysées.

Face à d'autres disciplines, les mairies de quelques villes étudiées possèdent des archives avec documentation historique qui se trouve sans analyser et sans classifier, qui pourrait être étudié dans l'optique de l'architecture défensive. Cette documentation peut fournir information sur le tracé de la muraille disparue ou bien sur des enceintes antérieures avec une surface inférieure. La recherche suivant cette direction pourrait apporter des précieuses données sur ces constructions que peuvent être combinées avec les résultats d'autres études sur les villes.

Même s'ils sont rares, il y a des emblèmes en plusieurs murailles des ces villes. L'étude de ces éléments, son identification avec la période historique correspondante et sa comparaison avec ceux d'autres villes pourrait aussi constituer un sujet de recherche qui permettrait d'approfondir dans le caractère de ces constructions défensives.

L'état de conservation de ces murailles, ainsi que les réparations et restaurations observées mettent en évidence que la restauration des murailles est un aspect qui requiert l'attention de la société et des professionnels qui travaillent dans ce type d'intervention. Les systèmes constructifs comme la maçonnerie coffrée ont besoin d'une étude qui détermine l'aptitude des techniques de restauration à appliquer. Ce n'est pas possible d'appliquer les mêmes procédés qu'avec un appareil de maçonnerie 
conventionnel ou un mur de pierre de taille. La recherche sur la restauration de ce type de bloc pourrait supposer une précieuse contribution dans ce domaine, et rendre plus facile l'intervention dans ce type de construction. Cette étude pourrait apporter des nouvelles approches au débat sur les différents types de restauration architectonique.

D'un point de $v$ ue urbain, la restauration des murailles est un au tre aspect à rechercher. L'intégration d'une construction dont la fonction est restée obsolète dans le fonctionnement d'une ville moderne est un autre sujet de recherche que peut être abordé pour les noyaux analysés ici, où le nombre d'habitants est petit, ou aussi dans des grandes villes. La muraille possède un énorme potentiel comme ressource urbaine car il s'agit d'un élément qui parcours et fait le tour de la ville et qui peut être transformée en un axe qui structure les usages oles activités dans des zones spécifiques de la ville. Le lien entre parcs, zones de loisirs ou promenades avec des zones adjacentes à la muraille peut renforcer sa visibilité et connecter ces usages dans la ville. L'étude d'autres solutions ou propositions pour intégrer la muraille dans la ville est un sujet de recherche nécessaire dans le domaine de l'architecture défensive.

Dans le chapitre d'analyse de résultats, l'intérêt des clefs en bois abandonnés à l'intérieur des murs a été accentué car l'analyse des ces pièces avec la méthode de la dendrochronologie peut apporter plus d'information sur la chronologie de ces constructions. Travailler dans cette direction entraîne une nouv elle approche pour l'étude de l'architecture défensive. L'extraction d'échantillons des clefs en bois qui se trouvent encore dans les pans des murailles et leur analyse pourrait aider à dater les pans d'une ou de plusieurs murailles, et comparer les résultats de chaque cas. Un autre sujet similaire au précédent, qui implique aussi du travail au laboratoire, serait la récolte d'échantillons de la terre des blocs d'une ou plusieurs murailles pour réaliser une comparaison de la composition de matériaux des différents cas et détecter les différences d'après la terre employée ou la proportion de chaux et argile ajoutée. 


\section{Bibliografía}

Adán Álvarez, Gema. 1996. "La muralla de Oviedo: construcción, arreglos y desarreglos". En Actas del Primer Congreso Nacional de Historia de la Construcción, editado por A. de las Casas, S. Huerta, E. Rabasa, 5-12. Madrid: Instituto Juan de Herrera, CEHOPU.

http://www.sedhc.es/biblioteca/actas/CNHC1_002\%20.pdf [Consultado el 7/12/2016]

Afanador García, Nelson, Mayerly Carrascal Delgado y Marvin J. Bayona Chinchilla. 2013. "Experimentación, comportamiento y modelación de la tierra pisada". Revista Facultad de Ingeniería UPTC 22 (35): 47-59.

https://dialnet.unirioja.es/descarga/articulo/5029430.pdf [Consultado el 28/10/2016]

Albardonedo Freire, Antonio. 2000. "Fuentes legales sobre construcción: las Ordenanças de Sevilla (1527)". En Actas del Tercer Congreso Nacional de Historia de la Construcción, vol.1, 1-12, editado por A. Graciani, S. Huerta, E. Rabasa. M. Tabales. Madrid: Instituto Juan de Herrera. http://www.sedhc.es/biblioteca/actas/CNHC3_001_Albardonedo\%20A.pdf [Consultado el $7 / 12 / 2016]$

2002. "Fuentes escritas para el conocimiento de la construcción medieval". En La técnica de la arquitectura medieval, editado por Amparo Graciani, 1534. Sevilla: Universidad de Sevilla.

y Fernando Betancourt. 2005. "Régimen jurídico de la construcción en las partidas de Alfonso X el Sabio". En Actas del Cuarto Congreso Nacional de Historia de la Construcción, vol. 1, 11-22, editado por S. Huerta. Madrid: Instituto Juan de Herrera.

http://www.sedhc.es/biblioteca/actas/CNHC4_002.pdf [Consultado el 7/12/2016]

Algorri García, Eloy y Mariano Vázquez Espí. 1996. "Enmienda a dos de los errores más comunes sobre el tapial". En Actas del Primer Congreso Nacional de Historia de la Construcción, editado por A. de las Casas, S. Huerta, E. Rabasa, 19-23. Madrid: Instituto Juan de Herrera, CEHOPU. http://www.sedhc.es/biblioteca/actas/CNHC1_004\%20.pdf [Consultado el 21/11/2016]

Alía Alía, Martín et. al. 1998. "La muralla de Hice, enclave y tipología de la construcción". En Actas del Segundo Congreso Nacional de Historia de la Construcción, editado por F. Bores, J. Fernández, S. Huerta y E. Rabasa, 812. Madrid: Instituto Juan de Herrera.

http://www.sedhc.es/biblioteca/actas/CNHC2_002.pdf [Consultado el 7/12/2016]

Anselmo, Marcello d'. 1998. "Las estructuras y los materiales de los cercos de murallas". En Actas del Segundo Congreso Nacional de Historia de la Construcción, editado por F. Bores, J. Fernández, S. Huerta y E. Rabasa, 111-117. Madrid: Instituto Juan de Herrera.

http://www.sedhc.es/biblioteca/actas/CNHC2_016.pdf [Consultado el 7/12/2016] 
Las murallas en las Comunidades de Villa y Tierra de la Diócesis de Segovia en los siglos XI a XIII.

Técnica y sistemas constructivos de la arquitectura defensiva medieval.

Arieta Verdasco, Valentín. 2016. "Iglesias fortificadas de Castilla y León. Simbiosis arquitectónica entre el uso defensivo y el religioso". Tesis doctoral, Universidad de Valladolid.

http://uvadoc.uva.es/handle/10324/16377 [Consultado el 3/3/2016]

Asenjo, María y José M. Monsalvo. 2006. "Dos visiones de las villas de la Extremadura: sectores occidental y oriental de la cuenta meridional del Duero (siglos XI- final XV)". En Las Villas Nuevas Medievales del suroeste europeo. De la fundación medieval al siglo XXI. Análisis histórico y lectura contemporánea, editado por Pascual Martínez y Mertxe Urteaga, 239-266. Irún: Arkeolan.

Arizaga Bolumburu, Beatriz. 1990. Urbanística medieval (Guipúzcoa). San Sebastián: Kriselu.

Arroyo-Bishop, Daniel. 1991. "El sistema ArchéoDATA. Hacia la creación de un sistema de información Arqueológica (SIA)". Complutum 1:167-174. http://revistas.ucm.es/index.php/CMPL/article/viewFile/CMPL9191120167A/30110 [Consultado el 8/9/2015]

Azuar Ruiz, Rafael. 1995. "Las técnicas constructivas en Al-Ándalus. El origen de la sillería y del hormigón de tapial". En Actas de V Semana de Estudios Medievales. Nájera, 1 al 15 de agosto de 1994. Logroño: Instituto de Estudios Riojanos.

http://dialnet.unirioja.es/descarga/articulo/554266.pdf [Consultado el 24/11/2015]

2005. "Las técnicas constructivas en la formación de al-Ándalus". Arqueología de la arquitectura 4:149-160.

http://arqarqt.revistas.csic.es/index.php/arqarqt/article/viewFile/80/77 [Consultado el 8/5/2015]

Balado, Arturo y Consuelo Escribano. 2012. Castillos de las fronteras. Valladolid: Junta de Castilla y León. Consejería de Cultura y Turismo.

http://www.patrimoniocultural.jcyl.es/web/jcyl/PatrimonioCultural/es/Plantilla100DetalleFeed/128 4180255460/Publicacion/1284220429995/Redaccion [Consultado el 27/10/2014]

Barrio Barrio, Juan A. y José V. Cabezuelo Pliego, eds. 1998. "La fortaleza medieval". En Actas XV Asamblea General de la Sociedad de Estudios Medievales. Alicante: Sociedad Española de Estudios Medievales.

Barrios García, Ángel y Alberto Martín Expósito. 1983. "Demografía medieval: modelos de poblamiento en la Extremadura castellana a mediados del siglo XIII". Studia historica. Historia medieval 1: 113-148.

http://dialnet.unirioja.es/servlet/articulo?codigo=3106921 [Consultado el 1/1/2016]

1987. "Repoblación de la zona meridional del Duero. Fases de ocupación, procedencias y distribución espacial de los grupos pobladores". Studia Historia. Historia medieval 5: 33-82.

http://revistas.usal.es/index.php/Studia_H_Historia_Medieval/article/viewFile/4324/4337 [Consultado el 1/12/2015]

Basterra Otero, Luis Alfonso. 1998. "Las estructuras arquitectónicas de Félix Candela: una revisión actual”. Tesis doctoral, Universidad de Valladolid.

2012. Construcción de estructuras de madera. Valladolid: Secretariado de Publicaciones e Intercambio Editorial. 
Baudreu, Dominique. 2003. "Habitats et fortifications en terre crue d'époque médiévale dans le Midi de la France". En Échanges transdisciplinaires sur les constructions en terre crue, 1 - Terre modelée, découpée ou coffrée. Matériaux et modes de mise en œuvre, actes de la table ronde de Montpellier, 17-18 novembre 2001, dirigido por Claire Anne de Chazelles y Alain Klein, 359-375. Montpellier: Editions de l’Espérou.

Bazzana, André, ed. 1988. Castrum 3: Guerre, fortification et habitat dans le monde méditerranéen au Moyen Âge. Madrid: Casa de Velázquez.

2003. "Les remparts de Taroudannt (Maroc du sud): un conservatoire des modes de construction en terre crue ( $\mathrm{XI}^{\mathrm{e}}-\mathrm{XVI}{ }^{\mathrm{e}}$ siècles)". En Échanges transdisciplinaires sur les constructions en terre crue, 1 - Terre modelée, découpée ou coffrée. Matériaux et modes de mise en œuvre, dirigido por Claire Anne de Chazelles y Alain Klein, 343-357. Montpellier: Editions de l'Espérou.

Becerra García, Juan M. 1999. "La legislación española sobre patrimonio histórico. Origen y antecedentes. La ley del patrimonio histórico andaluz". En Actas de las $V$ Jornadas sobre Historia de Marchena. El Patrimonio y su conservación. Celebradas del 6 al 9 de octubre de 1999, 9-30. Marchena: Biblioteca Pública Municipal.

http://www.bibliotecaspublicas.es/marchena/imagenes/V_1_Becerra_legislacion.pdf [Consultado el 23/11/2015]

Bellido, Tania. 2008. "Análisis estratigráfico en la muralla medieval de Marchena (Sevilla)". Arqueología de la Arquitectura 5: 159-185.

http://arqarqt.revistas.csic.es/index.php/arqarqt/article/download/94/91 [Consultado el 9/9/2015]

Bessac, Jean C., Joëlle Burnouf y Florence Journot. 1999. La construction. La pierre. Paris: Errance.

Bessac, Jean C. et al. 1999. La construction. Les matériaux durs: pierre et terre cuite. Paris: Errance.

Benito, Félix. 1996. "Las murallas castellanas, su influencia en la evolución histórica y morfológica de la ciudad. Zamora y Segovia como ejemplos". En La ciudad y sus murallas, editado por Francisco J. Gallego, 117-141. Granada: Universidad de Granada.

2000. La formación de la ciudad medieval. Valladolid: Secretariado de publicaciones e intercambio editorial, Universidad de Valladolid.

2005. "El sistema de medieval de asentamientos en Castilla y León". Arqueología y territorio medieval 12 (2): 57-74.

Bevan, Bernard. 2012. Historia de la arquitectura española: del Imperio Romano a la Ilustración. Barcelona: Reverté.

Blanco, J. Francisco. 1991. "El circuito amurallado de Coca". En Actas del III Congreso de Arqueología Medieval Española. Vol. 2, Comunicaciones, 433-439. Oviedo: Universidad de Oviedo. https://books.google.es/books?id=2diqpqpbMeMC\&lpg=PP1\&hl=es\&pg=PA433 [Consultado el 22/8/2016] 
Las murallas en las Comunidades de Villa y Tierra de la Diócesis de Segovia en los siglos XI a XIII. Técnica y sistemas constructivos de la arquitectura defensiva medieval.

2011. "Coca en los inicios de su historia". En Historia de Coca. Estudios sobre Historia y Arte en Coca. XXXII Curso de Historia de Segovia (Segovia, abril-mayo de 2011) coordinado por Víctor M. Cabañero, 71-98. Segovia: Real Academia de Historia y Arte de San Quirce.

2014. "Descubierta la muralla vaccea de Cauca". Vaccea Anuario 2013 7: 7879.

Blieck, Gilles, Philippe Contamine, Nicolas Faucherre et Jean Mesqui, eds. 1999. Les enceintes urbaines (XIII $-X V I^{e}$ siècle). Paris: Éditions du CTHS.

Borrero Fernández, Mercedes. 2002. "Los medios humanos y la sociología de la construcción medieval". En La técnica de la arquitectura medieval, editado por Amparo Graciani, 97-122. Sevilla: Universidad de Sevilla.

Caballero Zoreda, Luis. 1995. "Método para el análisis estratigráfico de construcciones históricas o 'lectura de paramentos'". Informes de la construcción 435: 37-46. http://informesdelaconstruccion.revistas.csic.es/index.php/informesdelaconstruccion/article/view File/1096/1180 [Consultado el 23/6/2016]

Cadiñanos Bardeci, Inocencio. 1987. Arquitectura fortificada en la provincia de Burgos. Burgos: Diputación Provincial de Burgos.

Canivell, Jacinto. 2010. "Análisis comparativo de las intervenciones en fábrica de tapial. El caso de las fortificaciones". En La arquitectura construida en tierra. Tradición e innovación. Congresos de arquitectura de tierra en Cuenca de Campos 2004/2009, coordinado por José L. Sainz Guerra y Félix Jové Sandoval, 141-154. Valladolid: Cátedra Juan de Villanueva.

http://www5.uva.es/grupotierra/publicaciones/digital/libro2010/2010_9788469345542_p141154_canivell.pdf [Consultado el 8/5/2015]

2011. "Metodología de diagnóstico y caracterización de fábricas históricas de tapia". Tesis doctoral, Universidad de Sevilla.

Cámara Muñoz, Alicia y Javier Gutiérrez Marcos, coords. 1993. Castillos, fortificaciones y recintos amurallados de la Comunidad de Madrid. Madrid: Consejería de Educación y Cultura de la Comunidad de Madrid.

Camino, M. Soledad. 2000. Construcción y ornamentación de las fachadas de ladrillo prensado, al descubierto, en la ciudad de Valladolid. Alicante: Biblioteca Virtual Miguel de Cervantes.

http://www.cervantesvirtual.com/nd/ark:/59851/bmcr78b9 [Consultado el 8/11/2015]

, Félix Jové Sandoval y Alfredo Llorente 2010. "Las paredes de tapial con machones de ladrillo o piedra y verdugadas de ladrillo, en la arquitectura religiosa de Valladolid". En La arquitectura construida en tierra. Tradición e innovación. Congresos de arquitectura de tierra en Cuenca de Campos 2004/2009, coordinado por José L. Sainz Guerra y Félix Jové Sandoval, 4754. Valladolid: Cátedra Juan de Villanueva.

http://www5.uva.es/grupotierra/publicaciones/digital/libro2010/2010_9788469345542_p047-

054_camino.pdf [Consultado el 8/11/2015] 
, Alexandra Labrador y María Vega. 2011. "La fábrica mixta de tapia y ladrillo, un invariante de la arquitectura monacal de Valladolid, España, hasta el siglo XX". En Construcción con tierra. Tecnología y arquitectura. Congresos de arquitectura de tierra en Cuenca de Campos 2010/2011, coordinado por Félix Jové Sandoval y José L. Sainz Guerra, 47-56. Valladolid: Cátedra Juan de Villanueva.

http://www5.uva.es/grupotierra/publicaciones/digital/libro2011/2011_9788469481073_p047-

056_camino.pdf [Consultado el 4/11/2015]

Campomanes Alvaredo, Emilio. 2001. "Introducción al estudio estratigráfico de la muralla de León”. En La fortificación medieval en la península ibérica, actas del IV curso de Cultura Medieval 21-26 de septiembre de 1992, coordinado por Pedro L. Huerta, 351-360. Aguilar de Campoo: Fundación Santa María la Real.

Cardells Martí, Francisco A. 2009. "Las bases del territorio en la frontera. El caso de la comarca de Valencia en el siglo XIII". En Hacedores de Frontera. Estudios sobre el contexto social de la Frontera en la España Medieval, dirigido por Manuel A. Rodríguez, 265-279. Madrid: CEU Ediciones.

Carrascal Antón, Federico. 1976. Castillos y murallas de Valladolid. Valladolid: Institución Cultural Simancas.

Casa Martínez, Carlos de la. 1990. Castillos de Soria: aproximación a la arquitectura militar medieval. Soria: Universidad Internacional Alfonso VIII.

Castro Fernández, Javier de et al. 2001. Guía de las Fortificaciones de frontera: Salamanca. Valladolid: Fundación del Patrimonio Histórico de Castilla y León.

Cátedra Tomás, María. 2007. Para entender las murallas de Ávila: una mirada desde la historia y la antropología. Valladolid: Ámbito.

Caucanas, Sylvie y Nelly Pousthomis-Dalle. 2013. L'abbaye de Lagrasse. Art, Archéologie et Histoire. Actes des journées d'études des 14 et 15 septembre 2012. Carcassonne.

Cervera Vera, Luis. 1980. Puerta de la muralla medieval de Lerma. Burgos: Institución Fernán González.

1989. La villa murada de Urueña (Valladolid). Valladolid: Editora provincial, Diputación Provincial de Valladolid.

1993. El auténtico contorno de la muralla de Madrigal de las Altas Torres (Ávila). Madrid: Editorial Alpuerto.

Chazelles, Claire-Anne de y Emilie Leal . 2003. "Les murs en terre crue d'un faubourg médiéval de Narbonne". En Échanges transdisciplinaires sur les constructions en terre crue, 1 - Terre modelée, découpée ou coffrée. Matériaux et modes de mise en œuvre, actes de la table ronde de Montpellier, 17-18 novembre 2001, dirigido por Claire Anne de Chazelles y Alain Klein, 247-261. Montpellier:

Editions de l'Espérou. 
Las murallas en las Comunidades de Villa y Tierra de la Diócesis de Segovia en los siglos XI a XIII. Técnica y sistemas constructivos de la arquitectura defensiva medieval.

Choisy, Auguste. 1899. Histoire de l'Architecture. 2 vols. Paris: Gauthier-Villars. http://gallica.bnf.fr/ark:/12148/bpt6k6417116t http://gallica.bnf.fr/ark:/12148/bpt6k6584016q [Consultado el 22/2/2016]

Chueca Goitia, Fernando. 2001. Historia de la Arquitectura Española. Tomo I. Edad Antigua y Edad Media. Ávila: Fundación Cultural Santa Teresa.

Claramunt Rodríguez, Salvador. 1992. "La mujer en el fuero de Cuenca”. España Medieval 2: 297-313.

http://revistas.ucm.es/index.php/ELEM/article/view/ELEM8282120297A/25337 [Consultado el $10 / 2 / 2016]$

Climent Simón, José M., Enrique Gandía Álvarez y Mª Isabel Giner García. 2011. "Torres y murallas de la segunda albacara del castillo de Cullera". En Actas del Séptimo Congreso Nacional de Historia de la Construcción, 263-272, editado por S. Huerta, I. Gil, S. García, M. Taín. Madrid: Instituto Juan de Herrera.

http://www.sedhc.es/biblioteca/actas/CNHC_7\%20(27).pdf [Consultado el 7/12/2016]

Cobos, Fernando y José J. de Castro. 1998. Castillos y Fortalezas. León: Edilesa.

y José J. de Castro. 2007. "Murallas medievales, castillos y torreones". En Patrimonio arquitectónico de Castilla y León. 2, Arquitectura militar, editado por José R. Nieto González, 57-276. Valladolid: Junta de Castilla y León.

2011. "Los castillos de la Mota de Medina del Campo". En Conocer Valladolid 2010. IV Curso de patrimonio cultural. Valladolid: Ayuntamiento de Valladolid.

y Manuel Retuerce. 2011. Metodología, valoración y criterios de intervención en la arquitectura fortificada de Castilla y León. Catálogo de las provincias de León, Salamanca, Valladolid y Zamora. Valladolid: Junta de Castilla y León, Consejería de Cultura y Turismo.

http://eprints.ucm.es/23418/1/Cobos\%26Retuerce_Arquit_fortificada.pdf [Consultado el 29/1/2014]

, José J. de Castro y Rodrigo Canal. 2012. Castros y recintos de la frontera de León en los siglos XII y XIII. Fortificaciones de tapial de cal y canto o mampostería encofrada. Valladolid: Junta de Castilla y León, Consejería de Cultura y Turismo.

http://www.patrimoniocultural.jcyl.es/web/jcyl/PatrimonioCultural/es/Plantilla100Detalle/1284217 324650/_/1284228008981/Redaccion/[Consultado el 17/9/2014.]

y João Campos. 2013. Almeida, Ciudad Rodrigo: la fortificación de la Raya Central/a fortificação da Raia Central. Ciudad Rodrigo: Consorcio Transfronterizo de Ciudades Amuralladas.

2014. "Fuentes de estudio y valoración de la arquitectura defensiva". Patrimonio Cultural de España. Arquitectura Defensiva 9: 81-92.

http://ipce.mcu.es/difusion/publicaciones/revistas-patr.html [Consultado el 23/11/2015]

Cointeraux, François. 1793. Ecole d'architecture rurale. Paris: chez le citoyen Cointeraux, ou chez le citoyen Fuchs.

http://cnum.cnam.fr/PDF/cnum_8LA18_2.pdf http://cnum.cnam.fr/PDF/cnum_8LA18_4.pdf http://cnum.cnam.fr/PDF/cnum_8LA18_5.pdf [Consultado el 22/9/2014] 
Cómez, Rafael. 2009. Los constructores de la España medieval. Sevilla: Universidad de Sevilla.

Cooper, Edward. 1981. Castillos señoriales de los siglos xV y XVI. 2 vols. Madrid: Fundación Universitaria Española.

1991. Castillos señoriales en la corona de Castilla. 3 vols. Valladolid: Junta de Castilla y León, Consejería de Cultura y Turismo.

2014. La fortificación de España en los siglos XIII y XIV. 2 vols. Madrid: Marcial Pons.

Coca, Verónica y Guillermo Quiroga. 2014. "Construcción en tierra y calicanto en Madrigal de las Altas Torres, Ávila: Estado de conservación de la arquitectura vernácula y monumental". En La arquitectura construida en tierra. Patrimonio y vivienda. X CIATTI 2013. Congresos de arquitectura de tierra en Cuenca de Campos, coordinado por José L. Sainz Guerra Guerra y Félix Jové Sandoval, 79-86. Valladolid: Cátedra Juan de Villanueva.

http://www5.uva.es/grupotierra/publicaciones/digital/libro2014/079-086-coca.pdf [Consultado el 8/5/2015]

Cuchí i Burgos, Albert. 1996. "La técnica tradicional del tapial”. En Actas del Primer Congreso Nacional de Historia de la Construcción, editado por A. de las Casas, S. Huerta, E. Rabasa, 19-23. Madrid: Instituto Juan de Herrera, CEHOPU.

http://www.sedhc.es/biblioteca/actas/CNHC1_023.pdf [Consultado el 21/11/2016]

Cuéllar Lázaro, Juan. 2007. Fuentidueña: Comunidad de Villa y Tierra (Segovia). Madrid: Gramadosa S.L.

2012. "Fuentidueña: Comunidad de Villa y Tierra, Segovia, (Siglos XIII-XVIII)". Tesis doctoral, Universidad Complutense de Madrid.

http://eprints.ucm.es/17412/1/T34074.pdf [Consultado el 13/8/2014]

Curiel Esparza, Jorge, Julián Cantó Perelló y M. Asunción Calvo. 1998. “Las ordenanzas municipales en la Edad Media". En Actas del Segundo Congreso Nacional de Historia de la Construcción, 107-109, editado por F. Bores, J. Fernández, S. Huerta, E. Rabasa. Madrid: Instituto Juan de Herrera. http://www.sedhc.es/biblioteca/actas/CNHC2_015.pdf [Consultado el 7/12/2016]

Cressier, Patrice, ed. 2008. Castrum 8: Le château et la ville. Espaces et réseaux (VI ${ }^{e}$ XIII ${ }^{e}$ siècle). Madrid: Casa de Velázquez.

Cristini, Valentina y José R. Ruiz Checa. 2011. "Caracterización constructiva de las fábricas medievales en el ámbito del fuero de Cuenca (s. XII-XIII)". Arché 6:8794.

http://www.irp.webs.upv.es/documents/arche_article_183.pdf [Consultado el 17/11/2015]

Cueto Ruiz, Ronald. 1995. La comunidad de villa y tierra de Maderuelo. Segovia: Academia de Historia y Arte de San Quirce. 
Las murallas en las Comunidades de Villa y Tierra de la Diócesis de Segovia en los siglos XI a XIII. Técnica y sistemas constructivos de la arquitectura defensiva medieval.

Darles, Christian. 2007a. "État des recherches concernant les fortifications de SaintLézer, un 'castrum' de l'Antiquité tardive en Novempopulonie, province d' Aquitaine". En Murallas de ciudades romanas en el occidente del Imperio, Lucus Augusti como paradigma: actas del Congreso Internacional celebrado en Lugo, 185-200, coordinado por Antonio Rodríguez Colmenero e Isabel Rodá de Llanza. Lugo: Diputación Provincial de Lugo.

2007b. "Généralités sur le rempart tibérien de Toulouse et résultats des dernières recherches". En Murallas de ciudades romanas en el occidente del Imperio, Lucus Augusti como paradigma: actas del Congreso Internacional celebrado en Lugo, 201-216, coordinado por Antonio Rodríguez Colmenero y Isabel Rodà de Llanza. Lugo: Diputación Provincial de Lugo.

Diago Hernando, Máximo. 2011. "Los aprovechamientos de las tierras de titularidad pública en las Comunidades de Villa y Tierra de la Extremadura castellanoleonesa entre los siglos XIII y XVII". En Las Comunidades de Villa y Tierra. Dinámicas históricas y problemáticas actuales, editado por Víctor Muñoz Gómez, 85-113. Murcia: edit.um.

Divorne, Françoise, Bernard Gendre, Bruno Lavergne y Philippe Panerai. 1985. Essai sur la régularité. Les Bastides d'Aquitaine, du Bas-Languedoc et du Béarn. Bruxelles: AAM Éditions.

Domingo Marazuela, David y Begoña Sevillano. 2012. La muralla de Segovia. Segovia: Ayuntamiento de Segovia, Concejalía de Patrimonio Histórico y Turismo.

Duarte Sánchez, Antonio D., Jorge Mambrilla y Alfonso Rodríguez, trads. 2004. Flavio Vegecio Renato. Recopilación sobre las instituciones militares. Murcia. http://deim.urv.cat/ blas.herrera/reimilitarisesp.pdf [Consultado el 23/2/2016]

Eco, Umberto. 1985. Cómo se hace una tesis. Técnicas y procedimientos de investigación, estudio y escritura. Barcelona: Gedisa.

Escobar González, Ana. 2013. "Dos torres. Dos modelos constructivos diferentes para la casa Eraso. Segovia". En Actas del Octavo Congreso Nacional de Historia de la Construcción, 253-261, editado por Santiago Huerta y Fabián López Ulloa. Madrid: Instituto Juan de Herrera.

http://www.sedhc.es/biblioteca/actas/Aju\%20027\%20Escobar.pdf [Consultado el 7/12/2016]

2014. "Carácter defensivo de las casas torre en la ciudad de Segovia". En Historia, arquitectura y construcción fortificada. Ensayos sobre investigaciones recientes, editado por Ignacio J. Gil Crespo, 181-208. Madrid: Instituto Juan de Herrera.

Eslava Galán, Juan. 1984. "Materiales y técnicas constructivas en la fortificación bajomedieval". Cuadernos de Estudios Medievales XII-XIII: 271-278. http://digibug.ugr.es/bitstream/10481/30267/1/CEM-012-013.001-Art\%C3\%ADculo-018.pdf [Consultado el 16/3/2016]

Esquieu, Yves y Jean M. Pesez, eds. 1998. Cent maisons médiévales en France (du $X I^{e}$ au milieu $d u X V I^{e}$ siècle). Un corpus et une esquisse. Paris: CNRS Éditions. 
Escribano Velasco, Consuelo y Arturo Balado Pachón. 2001. "El Pico del Calvario, Portillo (Valladolid). Un asentamiento altomedieval fortificado al sur del Duero". En La fortificación medieval en la península ibérica, actas del IV curso de Cultura Medieval 21-26 de septiembre de 1992, coordinado por Pedro L. Huerta, 271-276. Aguilar de Campoo: Fundación Santa María la Real.

y Mónica Hernansanz. 2001. "Las fortificaciones medievales de Íscar, Valladolid". En La fortificación medieval en la península ibérica, actas del IV curso de Cultura Medieval 21-26 de septiembre de 1992, coordinado por Pedro L. Huerta, 277-288. Aguilar de Campoo: Fundación Santa María la Real.

y Luis C. San Miguel. 2001. "La Cerca Vieja de Valladolid". En La fortificación medieval en la península ibérica, actas del IV curso de Cultura Medieval 2126 de septiembre de 1992, coordinado por Pedro L. Huerta, 285-294. Palencia: Fundación Santa María la Real.

Escudero Nieto, Félix. 2003. "Madrigal de las Altas Torres, sus murallas y el enigma histórico de su pastelero". Castillos de España 131: 43-48.

2004. "La ciudad de Daroca, su castillo y murallas y otras singularidades". Castillos de España 133: 48-51.

Espinosa de los Monteros, Juan y Luis Martín-Artajo Saracho. 1974. Corpus de castillos medievales de Castilla. Bilbao: Editorial Clave.

Estepa Díez, Carlos. 2011. "El poder real y los concejos en la Extremadura castellana”. En Las Comunidades de Villa y Tierra. Dinámicas históricas y problemáticas actuales, editado por Víctor Muñoz Gómez, 37-53. Murcia: edit.um.

Faucherre, Nicolas. 2008. Places fortes, bastion du pouvoir. Paris: Rempart.

Fernández, Juan J., José I. Sánchez Rivera y Jesús San José. 2004. Las ruinas de Dios: arquitectura religiosa olvidada en la provincia de Valladolid: partidos judiciales de Mota del Marqués, Peñafiel, Tordesillas y Valoria la Buena. Valladolid: Universidad de Valladolid.

, Jesús I. San José y José I. Sánchez Rivera. 2014. "Torres de tierra en Castilla y León: Evolución desde la torre maciza al recubrimiento cerámico". En La arquitectura construida en tierra. Patrimonio y vivienda. X CIATTI 2013, coordinado por José L. Sainz Guerra y Félix Jové Sandoval, 135-146. Valladolid: Cátedra Juan de Villanueva.

http://www5.uva.es/grupotierra/publicaciones/digital/libro2014/135-146-fernandez.pdf [Consultado el 8/5/2015]

Fernandez Ugalde, Antonio. 1998. Las murallas de Madrid: Arqueología medieval urbana. Madrid: Comunidad de Madrid, Dirección General de Patrimonio Cultural. 
Las murallas en las Comunidades de Villa y Tierra de la Diócesis de Segovia en los siglos XI a XIII. Técnica y sistemas constructivos de la arquitectura defensiva medieval.

Ferreras Fincias, Fco. Javier. 1996. "Castrotorafe (Zamora): conservación y ruina de la fortaleza santiaguista, 1494-1736". En Actas del Primer Congreso Nacional de Historia de la Construcción, editado por A. de las Casas, S. Huerta, E. Rabasa, 203-209. Madrid: Instituto Juan de Herrera, CEHOPU. http://www.sedhc.es/biblioteca/actas/CNHC1_028.pdf [Consultado el 7/12/2016]

Font, Fermín. 2011. "Una intervención reciente: consolidación de muros de tapia del tercer recinto del Castell de Vell de Castellón". En Construcción con tierra. Tecnología y arquitectura, coordinado por Félix Jové Sandoval y José L. Sainz Guerra, 101-112. Valladolid: Cátedra Juan de Villanueva. http://www5.uva.es/grupotierra/publicaciones/digital/libro2011/2011_9788469481073_p101112_font.pdf [Consultado el 8/5/2015]

2014. "Diversas intervenciones en una torre de tapia en el castillo de Oropesa del Mar, Castellón". En La arquitectura construida en tierra. Patrimonio y vivienda. X CIATTI 2013, coordinado por José L. Sainz Guerra y Félix Jové Sandoval, 209-216. Valladolid: Cátedra Juan de Villanueva. http://www5.uva.es/grupotierra/publicaciones/digital/libro2014/209-216-font.pdf [Consultado el $8 / 5 / 2015]$

Freire Tellado, Manuel J. 2003. "Typological study of the late medieval galician towers: Application to the restoration of the tower 'Torre de Vilanova dos Infantes"'. En The Proceedings of the First International Congress on Construction History, 923-934, editado por S. Huerta. Madrid: Instituto Juan de Herrera, SEHC, COAC, CAATC.

http://www.sedhc.es/biblioteca/actas/CIHC1_091_Freire\%20M.pdf [Consultado el 7/12/2016]

Fraile Delgado, Miguel. 2005. "Materiales de construcción de los castillos de Castilla y León". Tesis Doctoral, Universidad Politécnica de Madrid. http://oa.upm.es/487/1/MIGUEL_FRAILE_DELGADO.pdf [Consultado el 29/4/ 2014]

Franco Aliaga, Tomás.1997. Geografía física de España. Madrid: Universidad Nacional de Educación a Distancia.

Franco Silva, Alfonso. 1991. "Pedraza de la Sierra: el proceso de formación de unas ordenanzas de villa y tierra en los siglo XIV y XV". Historia. Instituciones. Documentos 18: 97-142.

http://institucional.us.es/revistas/historia/18/05\%20franco\%20silva.pdf [Consultado el 16/02/2016]

Fuente, María J. 1998. "Los inicios de la contabilidad municipal en Castilla. Paredes de Nava (1386-1396)". Espacio, Tiempo y Forma, Vol. 3. Historia Medieval 11: 61-83. http://revistas.uned.es/index.php/ETFIII/article/download/3627/3484 [Consultado el 30/11/2015]

Gacto Fernández, M. Trinidad. 1977. Estructura de la población de la Extremadura Leonesa en los siglos XII y XIII. Salamanca: Centro de Estudios Salmantinos. 
Gago Vaquero, José L. 1988. La arquitectura y los arquitectos del ensanche de Zamora 1920-1950. Zamora: Instituto de Estudios Zamoranos Florián de Ocampo, Diputación de Zamora.

Galarza, Manuel. 1996. "La tapia valenciana: una técnica constructiva poco conocida". En Actas del Primer Congreso Nacional de Historia de la Construcción, editado por A. de las Casas, S. Huerta, E. Rabasa, 211-215. Madrid: Instituto Juan de Herrera, CEHOPU.

http://www.sedhc.es/biblioteca/actas/CNHC1_029.pdf [Consultado el 5/5/2014]

Galindo García, Jorge. 1996. "La construcción de murallas: un aspecto del saber constructivo presente en los tratados de arquitectura militar (siglos XVI a XVIII)". En Actas del Primer Congreso Nacional de Historia de la Construcción, 217-222, editado por A. de las Casas, S. Huerta, E. Rabasa. Madrid: Instituto Juan de Herrera.

http://www.sedhc.es/biblioteca/actas/CNHC1_030.pdf [Consultado el 7/12/2016]

Gallego Roca, Francisco J. 1996. La ciudad y sus murallas. Granada: Universidad de Granada.

Gamazo, Germán. 1958. Castillos en Castilla: estampas comentadas. Madrid: Hauser y Menet.

Gamero, Víctor, Pablo Rodríguez Navarro y Teresa Gil. 2014. "Las murallas de Mascarell, Castellón". En La arquitectura construida en tierra. Patrimonio y vivienda. X CIATTI 2013. Congresos de arquitectura de tierra en Cuenca de Campos, coordinado por José L. Sainz Guerra y Félix Jové Sandoval, 109116. Valladolid: Cátedra Juan de Villanueva.

http://www5.uva.es/grupotierra/publicaciones/digital/libro2014/109-116-gamero.pdf [Consultado el 8/5/2015]

García Antón, José. 1993. Las murallas medievales de Murcia. Murcia: Universidad de Murcia.

García de Cortázar, José A. et al. 1985. Organización social del espacio en la España medieval. La Corona de Castilla en los siglos VIII a XV. Barcelona: Editorial Ariel S.A.

1990. La sociedad rural en la España medieval. Madrid: Siglo XXI de España Editores S.A.

García-Pulido, J. Luis y Manuel M. Alonso. 2013. "Fábricas de tierra encofradas asociadas a la muralla sureste de Arcos de la Frontera, Cádiz". En Construcción con tierra. Pasado, presente y futuro. Congreso de arquitectura de tierra en Cuenca de Campos 2012, coordinado por Félix Jové Sandoval y José L. Sainz Guerra, 37-52. Valladolid: Cátedra Juan de Villanueva. http://www5.uva.es/grupotierra/publicaciones/digital/libro2013/03tr-garcia-pulido.pdf [Consultado el 8/5/2015]

Garín, Alberto. 1996. "Los oficios de la construcción en los fueros castellano-leoneses medievales". Boletín de la Real Academia de Bellas Artes de San Fernando 82: 381-400. 
Las murallas en las Comunidades de Villa y Tierra de la Diócesis de Segovia en los siglos XI a XIII.

Técnica y sistemas constructivos de la arquitectura defensiva medieval.

Garmy, Pierre y Louis Maurin. 1996. Enceintes romaines d'Aquitaine. Bordeaux, Dax, Périgueux, Bazas. Paris: Éditions de la maison des sciences de l'homme.

Gautier Dalché, Jean. 1979. Historia urbana de León y Castilla en la Edad Media (siglos IX-XIII). Madrid: Siglo XXI de España Editores S.A.

Gea, Isabel y José M. Castellanos. 2008. Las murallas medievales de Madrid. Madrid: Ediciones La Librería.

Genís Vinyals, Mariona y Jordi Planelles Salvans. 2011. "La realidad construida del castillo de Cubelles según las trazas y el contrato del trazista fray Josep de la Concepció en relación a los tratados constructivos del siglo XVII: puntos de encuentro y desencuentro". En Actas del Séptimo Congreso Nacional de Historia de la Construcción, 539-548, editado por S. Huerta, I. Gil, S. García, M. Taín. Madrid: Instituto Juan de Herrera.

http://www.sedhc.es/biblioteca/actas/CNHC_7\%20(55).pdf [Consultado el 7/12/2016]

Ger y Lóbez, Florencio. 1898. Tratado de construcción civil. Badajoz: La Minerva Extremeña.

http://www.sedhc.es/bibliotecaD/1898_Fl_Ger_y_Lobez_Construccion_civil_Texto.pdf http://www.sedhc.es/bibliotecaD/1898_FI_Ger_y_Lobez_Construccion_civil_Laminas.pdf [Consultado el 16/3/2016]

Gil Crespo, Ignacio J. 2011. "Fundamentos constructivos de las fortificaciones bajomedievales en la provincia de Soria: fábrica de mampostería con verdugadas de ladrillo en el castillo de Arcos de Jalón". En Actas del Séptimo Congreso Nacional de Historia de la Construcción, 549-562, editado por S. Huerta, I. Gil, S. García, M. Taín. Madrid: Instituto Juan de Herrera. http://www.sedhc.es/biblioteca/actas/CNHC_7\%20(56).pdf [Consultado el 712/2016]

2013. "Fundamentos constructivos de las fortificaciones fronterizas entre las coronas de Castilla y Aragón de los siglos XII al XV en la actual provincia de Soria". Tesis doctoral, Universidad Politécnica de Madrid. http://oa.upm.es/22399/1/IGNACIO_JAVIER_GIL_CRESPO_a.pdf

2014a. "El interés por el estudio de la historia, arquitectura y construcción fortificada. Introducción a los ensayos sobre investigaciones recientes". En Historia, arquitectura y construcción fortificada. Ensayos sobre investigaciones recientes, editado por Ignacio J. Gil Crespo, 17-22. Madrid: Instituto Juan de Herrera.

2014b. "Historiografía de la historia de la construcción fortificada medieval". En Historia, arquitectura y construcción fortificada. Ensayos sobre investigaciones recientes, editado por Ignacio J. Gil Crespo, 23-65. Madrid: Instituto Juan de Herrera.

2014c. "Técnicas medievales de construcción en tapia de tierra y de cal y canto: los castillos de Soria". En La arquitectura construida en tierra.

Patrimonio y vivienda. X CIATTI 2013. Congresos de arquitectura de tierra en Cuenca de Campos, coordinado por José L. Sainz Guerra y Félix Jové Sandoval, 125-134. Valladolid: Cátedra Juan de Villanueva. 
2016. "Wooden reinforcing chains in the spanish medieval fortification". En The Proceedings of the Third Annual Conference of the Construction History Society, coordinado por James W.P. Campbell, 129-140.

Giuliato, Gérard. 1993. Châteaux et villes fortes du Comté de Vaudémont en Lorraine médiévale. Nancy: Presses Universitaires de Nancy.

Gonçalves Díez, María y Carlos Miranda Barroso. 2011. "El Torreón de los Guzmanes de Caleruega: del conocimiento constructivo a la lógica funcional". En Actas del Séptimo Congreso Nacional de Historia de la Construcción, 573-582, editado por S. Huerta, I. Gil, S. García, M. Taín. Madrid: Instituto Juan de Herrera.

http://www.sedhc.es/biblioteca/actas/CNHC_7\%20(58).pdf [Consultado el 7/12/2016]

González, Julio. 1960. El reino de Castilla en la época de Alfonso VIII. Tomo II. Madrid: Consejo Superior de Investigaciones Científicas (CSIC), Escuela de Estudios Medievales.

1975. La Extremadura Castellana al mediar el siglo XIII. Madrid: Hispania.

González Cristóbal, Margarita, Guillermo Herrero Gómez y José A. Linage Conde, coords. 2011. Sepúlveda en la Historia. Sepúlveda: Ayuntamiento de Sepúlveda.

González de la Granja, María E. 2010. "Construcción y evolución temporal de la muralla de Ávila: Últimas aportaciones historiográficas". Norba Arte XXX: 924.

González García, Juan L. 2004. Alberto Durero. Tratado de arquitectura y urbanismo militar. Madrid: Akal Ediciones.

González Herrero, Manuel.1998. Las Comunidades de Villa y Tierra en Segovia. Segovia: Academia de Historia y Arte de San Quirce.

Guillot, Florence. 2013. Fortifications médiévales dans les Pyrénées. Toulouse: Éditions In Extenso.

Gutiérrez, Ramón y Cristina Esteras. 1991. Territorio y fortificación: Vauban, Fernández de Medrano, Ignacio Sala y Félix Prosperi: influencia en España y América. Madrid: Ediciones Tuero.

Gutiérrez González, José A. 1995. Fortificaciones y feudalismo en el origen y formación del Reino Leonés (siglos IX-XIII). Valladolid: Universidad de Valladolid.

1998. "Arquitectura militar y sistemas de fortificaciones en el Reino de León". En Castillos medievales del Reino de León. León: S.A. Hullera VascoLeonesa.

2003. "La formación del dominio político y territorial: del Realengo al Señorío de Léon”. Arqueología y Territorio Medieval 10 (2): 9-43. 
Las murallas en las Comunidades de Villa y Tierra de la Diócesis de Segovia en los siglos XI a XIII. Técnica y sistemas constructivos de la arquitectura defensiva medieval.

y Magdalena Valor, eds. 2014. The archeology of Medieval Spain 1100-1500. Sheffield, UK; Bristol, CT: Equinox.

Gutiérrez Robledo, José L. 2007. "Las murallas: el caso de Ávila”. En Actas del congreso internacional Ciudades Amuralladas de Pamplona, 117-150. Pamplona: Gobierno de Navarra.

2009. Las murallas de Ávila: arquitectura e historia. Ávila: Institución Gran Duque de Alba.

Guilleux, Joseph. 2000. L'enceinte romaine du Mans. Saint Jean d’Angely: Éditions Jean-Michel Bordessoules.

Graciani, Amparo. 2002. "Los equipos de obra y los medios auxiliares de la Edad Media". En La técnica de la arquitectura medieval, editado por Amparo Graciani, 175-206. Sevilla: Universidad de Sevilla.

y Miguel A. Tabales 2003. "Typological observations on tapia walls in the area of Seville. 11th-19th centuries". En The Proceedings of the First International Congress on Construction History, 1096-1106, editado por S. Huerta. Madrid: Instituto Juan de Herrera, SEHC, COAC, CAATC.

http://www.sedhc.es/biblioteca/actas/CIHC1_106_Graciani\%20A.pdf [Consultado el 7/12/2016]

y Miguel A. Tabales. 2008. "El tapial en el área sevillana. Avance cronotipológico estructural”. Arqueología de la arquitectura 5: 135-158. http://arqarqt.revistas.csic.es/index.php/arqarqt/article/download/93/90 [Consultado el 26/1/2016]

2009. "Fábricas islámicas del mirador almohade de la muralla de Marchena (Sevilla). Tramos de la Alcazaba y El Parque”. Laboratorio del Arte 21: 13-35. http://institucional.us.es/revistas/arte/21/01\%20graciani.pdf [Consultado el 24/11/2015]

Hernández, I. y Raimundo Moreno. 2007. "Tipologías y variantes de la construcción con mampostería en época medieval: aproximación al caso segoviano". En Actas del Quinto Congreso Nacional de Historia de la Construcción, Burgos, 7-9 de junio 2007, editado por M. Arenillas, C. Segura, F. Bueno, S. Huerta, 513-518. Madrid: Instituto Juan de Herrera.

http://www.sedhc.es/biblioteca/actas/CNHC5_049-I.Hern_ndez.pdf [Consultado el 18/9/2014]

Herrera Casado, Antonio. 1989. Castillos y fortalezas de Castilla-La Mancha. Toledo: Junta de Comunidades de Castilla-La Mancha.

Herrero García, Estefanía. 2014. "Sistema defensivo de la ciudad de Segovia. Técnicas constructivas y cambio de uso". En Historia, arquitectura y construcción fortificada. Ensayos sobre investigaciones recientes, editado por Ignacio J. Gil, 105-144. Madrid: Instituto Juan de Herrera. 
y Miguel A. Martín Blanco. 2015. "Hipótesis del sistema constructivo de la muralla de la repoblación cristiana de la ciudad de Segovia". En Actas del Noveno Congreso Nacional y Primer Congreso Internacional Hispanoamericano de Historia de la Construcción, vol. 2, editado por Santiago Huerta y Paula Fuentes, 801-810. Madrid: Instituto Juan de Herrera, ETS de Arquitectura de Madrid.

Herrero Prieto, César. 1990. "Factores explicativos del desarrollo municipal mediante el análisis en componentes principales". En Actas del $2^{\circ}$ Congreso de Economía Regional de Castilla y León, 648-663. León: Junta de Castilla y León.

http://www.jcyl.es/jcyl/cee/dgeae/congresos_ecoreg/CERCL/23648.PDF [Consultado el 01/12/2016]

Hernández Díaz, Ángel. 1996. "Conservación de las murallas de Ávila”. En La ciudady sus murallas, editado por Francisco J. Gallego, 161-179. Granada: Universidad de Granada.

Hernansanz Navas, Justo. 1985. Fuentidueña y su alfoz: Notas históricoarqueológicas. Madrid: Graymo.

Hoz, Jaime de, Luis Maldonado y Fernando Vela Cossío. 2003. Tierra: Diccionario de construcción tradicional. San Sebastián: Nerea.

Jiménez Esteban, Jorge. 1993. Murallas de España. Madrid: Rueda. 1995. Castillos de España. Madrid: Rueda.

Jové, Félix. 2002. "Las casas-cueva de Aguilar de Campos. Origen y razón constructiva". Tesis Doctoral, Universidad de Valladolid.

, David Muñoz y Luis Pahíno. 2010b. "Análisis tipológico y constructivo de muros curvos de tapial. Molinos de viendo en Tierra de Campos". En La arquitectura construida en tierra. Tradición e innovación. Congresos de arquitectura de tierra en Cuenca de Campos 2004/2009, coordinado por José L. Sainz Guerra y Félix Jové Sandoval, 187-196. Valladolid: Cátedra Juan de Villanueva.

http://www5.uva.es/grupotierra/publicaciones/digital/libro2010/2010_9788469345542_p187196_jove.pdf [Consultado el 8/5/2015]

, José L. Sainz Guerra, Pedro J. Olmos et al. 2011."Caracterización de suelos para la restauración de las murallas de tapia de la alcazaba de Badajoz". En Construcción con tierra. Tecnología y arquitectura. Congresos de arquitectura de tierra en Cuenca de Campos 2010/2011, coordinado por Félix Jové Sandoval y José L. Sainz Guerra, 267-276. Valladolid: Cátedra Juan de Villanueva.

http://www5.uva.es/grupotierra/publicaciones/digital/libro2011/2011_9788469481073_p267-

276_jove.pdf [Consultado el 7/5/ 2015] 
Las murallas en las Comunidades de Villa y Tierra de la Diócesis de Segovia en los siglos XI a XIII.

Técnica y sistemas constructivos de la arquitectura defensiva medieval.

Kagan, Richard L. 2000. Urban Images of the Hispanic World, 1493-1793. London: Yale University Press.

https://books.google.es/books?id=EDMBMPc863oC\&printsec=frontcover\&hl=es [Consultado el $4 / 7 / 2016]$

Ladero Quesada, Miguel A. 1990. Castillos medievales del Reino de León. Madrid Spainfo.

Lampérez y Romea, Vicente. 1993. Arquitectura civil española de los siglos I al XVIII. 2 vols. Madrid: Giner.

Lavedan, Pierre et Jeanne Hugueney. 1974. L'urbanisme au Moyen Âge. Droz, Genève: Bibliothèque de la Société Française d'Archéologie.

Leblanc, Gratien. 1984. Toulouse, les remparts du Faubourg Saint-Cyprien. Toulouse: E. Privat.

Linage Conde, Antonio. 1972. Hacia una biografía de la villa de Sepúlveda. Segovia: Caja de Ahorros y Monte de Piedad de Segovia. 1991. Sepúlveda y el cañón del Duratón. León: Ediciones Lancia.

2011. "Sepúlveda en la aventura humana”. En Sepúlveda en la historia, coordinado por Margarita González Cristóbal et al., 9-33. Sepúlveda: Ayuntamiento de Sepúlveda.

Litoux, Emmanuel y Gaël Carré. 2008. Manoirs médiévaux. Maisons habitées, maisons fortifiées. Paris: Rempart.

Littré, Émile, trad. 1877. Histoire naturelle de Pline: avec la traduction en français. Tome 2. Paris: Firmin-Didot et Cie.

http://gallica.bnf.fr/ark:/12148/bpt6k282082c [Consultado el 24/2/2016]

Llorente Mínguez, Juan C., Fernando Nieto Criado y Jesús Nieto Criado. 2012. "Urbanismo y patrimonio en una villa de la Extremadura castellano-leonesa. El casco urbano de Cuéllar y sus murallas". En Las Comunidades de Villa y Tierra. Dinámicas históricas y problemáticas actuales, editado por Víctor Muñoz Gómez, 221-249. Murcia: edit.um.

López, Cecilia, Luis Gonzalo Sequeda-Castañeda y Crispín Celis. 2010.

"Determinación del fraguado de morteros de cal mediante fenolftaleína". En Actas del III Congresso de arquitetura e construção com terra no Brasil, 1-11 . Campo Grande: Terra Brasil.

https://www.researchgate.net/profile/Luis_Sequeda-

Castaneda/publication/233907299_Determinacion_del_fraguado_de_morteros_de_cal_mediant e_fenolftaleina/links/09e4150cbca801dcc4000000.pdf?origin=publication_detail [Consultado el 29/10/2016] 
López, Vicente, Teresa Pellicer, Pablo Rodríguez et al. 2014. "Estudios previos para la restauración de la torre muza de Benifaio (Valencia): Un planteamiento multidisciplinar en el ámbito universitario". En La arquitectura construida en tierra. Patrimonio y vivienda. X CIATTI 2013. Congresos de arquitectura de tierra en Cuenca de Campos, coordinado por José L. Sainz Guerra y Félix Jové Sandoval, 177-186. Valladolid: Cátedra Juan de Villanueva.

http://www5.uva.es/grupotierra/publicaciones/digital/libro2014/177-186-lopez.pdf [Consultado el $8 / 5 / 2015]$

López Bragado, Daniel. 2016. "Zamora Forma Urbis. Análisis gráfico del origen y evolución del recinto amurallado de Zamora". Tesis doctoral, Universidad de Valladolid.

López Ramón, Ma Inmaculada. 1996. “Cambios (materiales, técnicas y estructuras) en las fortificaciones nazaríes tras la conquista castellana”. En Actas del Primer Congreso Nacional de Historia de la Construcción, editado por A. de las Casas, S. Huerta, E. Rabasa, 323-329. Madrid: Instituto Juan de Herrera, CEHOPU.

http://www.sedhc.es/biblioteca/actas/CNHC1_045.pdf [Consultado el 7/12/2016]

López Vázquez, Luis B. y M. José Torres Montealegre. 1998. "Estudio de las murallas de Talavera de la Reina: Deterioro y restauración”. En Actas del Segundo Congreso Nacional de Historia de la Construcción, editado por F. Bores, J. Fernández, S. Huerta y E. Rabasa, 475-482. Madrid: Instituto Juan de Herrera.

http://www.sedhc.es/biblioteca/actas/CNHC2_060.pdf [Consultado el 7/12/2016]

Loppe, Frédéric. 2010. Construire en terre pendant la guerre de cent ans: Les fortifications de Castelnaudary (Aude) vers 1355-1450. Carcassonne: Centre d'Archéologie Médiévale du Languedoc.

Lozoya, Juan de Contreras y López de Ayala, Marqués de. 2013. "La matriz del sello concejil de Cuéllar". Boletín de la Real Academia de la Historia. Tomo 113, Año 1943. Alicante: Biblioteca Virtual Miguel de Cervantes. http://www.cervantesvirtual.com/nd/ark:/59851/bmc4x706 [Consultado el 8/6/2016]

Madoz, Pascual. 1847. Diccionario Geográfico-Estadístico-Histórico de España y sus posesiones de ultramar. Tomos I-XVI. Madrid: D. José Rojas. http://www.bibliotecavirtualdeandalucia.es/catalogo/consulta/registro.cmd?id=6353 [Consultado el 19/5/2015]

Malalana, Antonio. 2009a. "La evolución de los recintos urbanos amurallados castellano-leoneses a lo largo del siglo XII". Arqueología y territorio medieval 16: $75-136$.

2009b. "El contexto de los recintos amurallados románicos en los enclaves de frontera, en los siglos XII y XIII". En Hacedores de Frontera. Estudios sobre el contexto social de la Frontera en la España Medieval, dirigido por Manuel A. Rodríguez, 205-264. Madrid: CEU Ediciones. 
Las murallas en las Comunidades de Villa y Tierra de la Diócesis de Segovia en los siglos XI a XIII. Técnica y sistemas constructivos de la arquitectura defensiva medieval.

Maldonado, Luis, Francisco J. Castilla y Fernando Vela Cossío. 1997. "La técnica del tapial en la comunidad autónoma de Madrid. Aplicación de nuevos materiales para la consolidación de muros de tapia". Informes de la construcción 452 (49): 27-37.

http://informesdelaconstruccion.revistas.csic.es/index.php/informesdelaconstruccion/article/view File/925/1008 [Consultado el 5/11/2015]

Malpica Cuello, Antonio. 1996. Poblamiento y castillos en Granada. Barcelona: Lunwerg.

https://books.google.es/books?id=XsvMJa8YvHcC\&lpg=PP1 [Consultado el 8/3/2016]

2003. Los castillos en al-Andalus y la organización del territorio. Cáceres: Universidad de Extremadura.

Mañanes, Tomás y Felipe Valbuena. 1977. "Torres y fortalezas medievales al sur del Duero en la provincia de Valladolid". Boletín del Seminario de Estudios de Arte y Arqueología 43: 111-126.

http://dialnet.unirioja.es/descarga/articulo/2691443.pdf [Consultado el 6/5/2014]

, Felipe Valbuena y José L. Alonso. 1980. "La arquitectura militar del reino de León con el de Castilla, en los siglos XII y XIII". Tierras de León: Revista de la Diputación Provincial 41(20): 59-88.

http://www.saber.es/web/biblioteca/libros/tierras-de-leon/html/41/6arquitectura.pdf [Consultado el 6/5/2014]

Marcos, Ricardo. 1879. Manual del Albañil. Madrid: Biblioteca Enciclopédica Popular llustrada.

http://www.cehopu.cedex.es/img/bibliotecaD/1879_Ricardo_Marcos_y_Bausa_Manual_del_alb anil [Consultado el 16/2/2016]

Márquez Bueno, Samuel y Pedro Gurriarán Daza. 2003. "La muralla almohade de Cáceres: aspectos constructivos, formales y funcionales". Arqueología y Territorio Medieval 10 (1): 57- 118.

http://www.ujaen.es/revista/arqytm/PDF/R10_1/R101_3_Marquez.pdf [Consultado el 6/5/2014]

y Pedro Gurriarán Daza. 2008. "Recursos formales y constructivos en la arquitectura militar almohade de al-Andalus". Arqueología de la Arquitectura 5: 115-134.

http://arqarqt.revistas.csic.es/index.php/arqarqt/article/view/92/89 [Consultado el 31/10/2014]

Martín Aymerich, M. Dolores; Teresa Tardío y Alonso Zamora. 1990. Las murallas de Sepúlveda (Segovia). Un ensayo de aproximación con métodos arqueológicos a un ejemplo de pervivencia arquitectónica. Segovia: Diputación de Segovia.

Martín García, Mariano. 2005. "La construcción del tapial en época nazarí: el caso de la muralla exterior del Albaicín de Granada". En Actas del Cuarto Congreso Nacional de Historia de la Construcción en Cádiz, 27-29 de enero de 2005, Vol. 2, coordinado por Santiago Huerta, 741-749. Madrid: Instituto Juan de Herrera.

http://www.sedhc.es/biblioteca/actas/CNHC4_071.pdf [Consultado el 8/5/2015]

y José $M^{a}$ Martín Civantos. 2009. "Técnicas y tipologías constructivas de las fortificaciones medievales de la axarquía almeriense". En Actas del Sexto Congreso Nacional de Historia de la Construcción, 815-924, editadas por S. Huerta, R. Marín, R. Soler, A. Zaragozá. Madrid: Instituto Juan de Herrera. http://www.sedhc.es/biblioteca/actas/CNHC6_\%20(76).pdf [Consultado el 7/12/2016] 
Martín Blanco, Miguel A. 2013. "Las torres de las murallas de Segovia". Arte y Ciudad 3 (1): 679-696.

http://dialnet.unirioja.es/descarga/articulo/4704621.pdf [Consultado el 18/10/2014]

2014. "Discontinuidades y pervivencias en la muralla de Segovia". En Historia, arquitectura y construcción fortificada. Ensayos sobre investigaciones recientes, editado por Ignacio J. Gil, 145-180. Madrid: Instituto Juan de Herrera.

Martín Jiménez, Carlos M. 2003. Rutas para descubrir los castillos y fortalezas de Castilla y León. Valladolid: Ámbito.

Martín Montes, Miguel A. 2001. "Valladolid: lugar fortificado durante los siglos XII y XIII". En La fortificación medieval en la península ibérica, actas del IV curso de Cultura Medieval 21-26 de septiembre de 1992, coordinado por Pedro L. Huerta, 285-294. Aguilar de Campoo: Fundación Santa María la Real.

Martín Rodríguez, José L. 1993. Manual de Historia de España. La España Medieval. Vol. 2. Madrid: Historia 16.

Martínez de Aguirre, Javier. 2007. "Villas fortificadas y defensa del Reino de Navarra (siglos XI-XV)". En Actas del congreso internacional Ciudades Amuralladas de Pamplona, 89-115. Pamplona: Gobierno de Navarra.

Martínez Llorente, Félix J.1990. Régimen jurídico de la Extremadura Castellana Medieval: las comunidades de villa y tierra: (s. X-XIV). Valladolid: Secretariado de publicaciones de la Universidad de Valladolid.

Martínez Díez, Gonzalo. 1983. Las Comunidades de Villa y Tierra en la Extremadura Castellana. Madrid: Editora Nacional.

2011. "La repoblación de la Extremadura castellana y las Comunidades de Villa y Tierra". En Las Comunidades de Villa y Tierra. Dinámicas históricas y problemáticas actuales, editado por Víctor Muñoz Gómez, 19-36. Murcia: edit.um.

Martínez Sopena, Pascual. 1985. La Tierra de Campos Occidental. Poblamiento, poder y comunidad del siglo $x$ al XIII. Valladolid: Institución Cultural Simancas de la Diputación Provincial de Valladolid.

, Vidal Aguado Seisdedos y Rafael González Rodríguez. 1996. Privilegios reales de la Villa de Benavente (siglos XII - XIV). Benavente: Centro de Estudios Benaventanos 'Ledo del Pozo'.

y Mertxe Urteaga, eds. 2006a. Las Villas Nuevas Medievales del Suroeste Europeo. Boletín Arkeolan 14. Irún: Centro de Estudios e Investigaciones Histórico-arqueológicas.

, José L. Sainz Guerra, Carlos M. Reglero, Victor Muñoz y Andrea Martín. 2006b. "Las 'villas nuevas' al norte del Duero: de la Rioja al Bierzo (siglos XIIXIII)". En Las Villas Nuevas Medievales del Suroeste Europeo, editado por Pascual Martínez Sopena y Mertxe Urteaga, 217- 237. Irún: Centro de Estudios e Investigaciones Histórico-arqueológicas. 
Las murallas en las Comunidades de Villa y Tierra de la Diócesis de Segovia en los siglos XI a XIII. Técnica y sistemas constructivos de la arquitectura defensiva medieval.

2010a. "Las villas del rey y las fronteras del reino (ca. 1158-1230)". En Construir la identidad en la Edad Media, editado por José A. Jara, y Georges Martín e Isabel Alfonso, Colección Humanidades 112: 105-143. Cuenca: Ediciones Universidad de Castilla La Mancha.

2010b. "Los espacios de las villas nuevas medievales en Castilla (siglos XII y XIII). Geometrías y Centralidades". Studium Medievale. Percepció $i$ experiència de l'espai a l'Edat Mitjana 3: 179-199.

2011. "Ideología y práctica en las políticas pobladoras de los reyes hispanos (ca. 1180-1230)". En Actas de XXXVII semana de Estudios Medievales. 1212 1214: el trienio que hizo a Europa, 155-182. Pamplona: Gobierno de Navarra.

2015. "Entre Islam et Chrétienté. La territorialisation des frontières, $\mathrm{XI}^{\mathrm{e}}$ et $\mathrm{XVI} \mathrm{I}^{\mathrm{e}}$ siècle". Histoire, 193-215. Rennes: Presses Universitaires de Rennes.

Mazzoli-Guintard, Christine. 2000. Ciudades de al-Andalus. España y Portugal en la época musulmana (siglos VIII a XV). Granada: Almed.

Merino Gómez, Elena. 2011. "Torres medievales en la baja Moraña (Ávila): Análisis constructivo, histórico y artístico a partir de su documentación gráfica". Tesis Doctoral, Universidad de Valladolid.

http://uvadoc.uva.es/handle/10324/963 [Consultado el 16/9/2014]

Miguel Ojeda, Gonzalo. 1961. "Torres y castillos burgaleses”. Boletín de la Institución Fernán González 156: 679-686.

http://hdl.handle.net/10259.4/1459 [Consultado el 1/3/2016]

1961. "Torres y castillos burgaleses [2]". Boletín de la Institución Fernán González 157: 717-727.

http://hdl.handle.net/10259.4/1462 [Consultado el 1/3/2016]

1962. "Torres y castillos burgaleses [3]". Boletín de la Institución Fernán González 158: 41-52.

http://hdl.handle.net/10259.4/1609 [Consultado el 1/3/2016]

Mileto, Camila y Fernando Vegas. 2010. "El análisis estratigráfico: una herramienta de conocimiento y conservación de la arquitectura". En Arqueología aplicada al estudio e interpretación de edificios históricos. Últimas tendencias metodológicas, coordinado por Concepción Martín y Esther de Vega, 145157. Madrid: Ministerio de Cultura.

Miquel, Jacques. 1981. L'architecture militaire dans le Rouergue au Moyen Âge et l'organisation de la défense. 2 vols. Rodez: Editions Française d'Arts Graphiques.

Monjó Carrió, Juan. 1999. "Evolución histórica de la arquitectura de tierra en España". En Arquitectura de tierra: Encuentros Internacionales Centro de Investigación Navapalos, 31-44. Madrid: Ministerio de Fomento. 
Monsalvo, José M. 2003. "Frontera pionera, monarquía en expansión y formación de los concejos de villa y tierra. Relaciones de poder en el realengo concejil entre el Duero y el Tajo (c.1072-c.1222)". Arqueología y territorio medieval 10 (2):45-126.

http://www.ujaen.es/revista/arqytm/PDF/R10_2/R102_2_Monsalvo.pdf [Consultado el $13 / 01 / 2015]$

2010. Atlas histórico de la España Medieval. Madrid: Editorial Síntesis.

Mora-Figueroa, Luis de. 1996. Glosario de arquitectura defensiva medieval. Cádiz: Universidad de Cádiz.

Morales Martínez, Alfredo J. 2007. "Las murallas de Sevilla”. En Actas del congreso internacional Ciudades Amuralladas de Pamplona, 151-166. Pamplona: Gobierno de Navarra.

Moxó, Salvador de. 1979. Repoblación y sociedad en la España cristiana medieval. Madrid: Ediciones Rialp S.A.

Muñoz Gómez, Víctor, ed. 2012. Las Comunidades de Villa y Tierra. Dinámicas históricas y problemáticas actuales. Murcia: edit.um.

Muñoz Ruano, Juan. 2000. "Construcciones histórico-militares en la línea estratégica del Tajo". Tesis Doctoral, Universidad Complutense de Madrid. http://biblioteca.ucm.es/tesis/19972000/H/0/H0047601.pdf [Consultado el 30/11/2015]

Nacente, Francisco. 1890. El constructor moderno, Tratado Teórico y Práctico de Arquitectura y Albañilería. Barcelona: Ignacio Monrós y Compañía.

Noguera Giménez, Juan F. 2006. "Cartas de restauración del patrimonio arquitectónico. Historia y estudio comparativo”. Arché 1: 283-296.

http://www.irp.webs.upv.es/documents/arche_article_36.pdf [Consultado el 17/11/2015]

Ontiveros, Esther, Eduardo M. Sebastián, Ignacio Valverde, et al. 2008. "Estudio de los materiales de construcción de las murallas del Albaycín (Granada)". Boletín de Instituto Andaluz de Patrimonio Histórico 66:(32-47).

http://www.iaph.es/revistaph/index.php/revistaph/article/download/2527/2527 [Consultado el 30/4/2014]

Oliver Domingo, José L., trad. 1997. De Architectura. Opus in Libris Decem. Madrid: Alianza Editorial.

http://aparejadoresacc.com/wp-content/uploads/Vitruvio_Polion_Marco.pdf [Consultado el $18 / 2 / 2016]$

Olmos, Emilio. 2000. La Comunidad de Villa y Tierra de Cuéllar a fines de la Edad Media. Poder político concejil, ordenanzas municipales y regulación de la actividad económica. Colección Historia y Sociedad 68. Valladolid: Universidad de Valladolid.

Pablo, Roberto de y Cristina Santos, eds. 2014. El castillo de Berlanga. Siglos de historia en torno a sus murallas. Berlanga de Duero: Asociación de Amigos del Castillo de Berlanga. 
Las murallas en las Comunidades de Villa y Tierra de la Diócesis de Segovia en los siglos XI a XIII.

Técnica y sistemas constructivos de la arquitectura defensiva medieval.

Palacios, J. Santiago. 2006. "Castillos contra castillos. Padrastros y fortalezas de asedio en la España Medieval". Arqueología y territorio medieval 13 (2): 3356.

2008. Fortaleza y poder político. Guadalajara: Aache Ediciones.

2009. "De hisn a castrum. Los castillos fronterizos del reino de Toledo en el umbral de un nuevo tiempo". En Hacedores de Frontera. Estudios sobre el contexto social de la Frontera en la España Medieval, dirigido por Manuel A. Rodríguez, 281-321. Madrid: CEU Ediciones.

Parron-Kontis, Isabelle y Nicolas Reveyron, eds. 2005. Archéologie du bâti: pour une harmonisation des méthodes. Actes de la table ronde 9 et 10 novembre 2001. Paris: Éditions Errance.

Pastor, Reyna. 1975. Del Islam al cristianismo. En las fronteras de dos formaciones económico-sociales: Toledo siglos XI a XIII. Barcelona: Península.

Passini, Jean. 1993. "El medio urbano como informador arqueológico medieval". En Actas de la III Semana de Estudios Medievales: Nájera, 3 al 7 de agosto de 1992, coordinado por José I. de la Iglesia, 89-102. Logroño: Instituto de Estudios Riojanos.

http://dialnet.unirioja.es/descarga/articulo/554243.pdf [Consultado el 16/11/2015]

Pavón Maldonado, Basilio. 1977. "Contribución al estudio del arabismo de los castillos de la Península Ibérica (región levantina). El castillo de Olocau de Valencia". Al-Andalus XLII(1): 207-225.

http://search.proquest.com/docview/1304057553?accountid=14778 [Consultado el 12/1/2016]

1993. Ciudades y fortalezas lusomusulmanas: Crónicas de viajes por el sur de Portugal. Madrid: Agencia española de Cooperación Internacional, Instituto de Cooperación con el Mundo Árabe.

1999. Tratado de arquitectura hispano-musulmana. II. Ciudades y Fortalezas. Madrid: Consejo Superior de Investigaciones Científicas (CSIC).

Pérez deTudela, M. Isabel. 1991. Arquitectura militar castellano-leonesa. Significado histórico y glosario. Colección Castillos y Vida Histórica. Madrid: Castellum.

Pérez de Villareal, Vidal. 1989. "Kisulabeak. Hornos de cal”. Cuadernos de etnología y etnografía de Navarra 21 (54): 377-406.

https://dialnet.unirioja.es/descarga/articulo/144782.pdf [Consultado el 27/9/2016]

Periago Lorente, Miguel. 2003. "Procopio de Cesarea: Los Edificios”. Estudios

Orientales 7: 9-136. http://www.um.es/cepoat/estudiosorientales/?page_id=291

[Consultado el 23/2/2016]

Portela, Ermelindo. 1985. "Del Duero al Tajo”. En Organización social del espacio en la España medieval. La Corona de Castilla en los siglos VIII a XV, coordinado por José A. García de Cortázar, 85-106. Barcelona: Ediciones Ariel S. L. 
Quesada, Santiago y L. José García-Pulido. 2013. "Las torres medievales del valle del Segura de la Sierra o la construcción del paisaje. Análisis de las tapias de tierra y cal empleadas en sus fábricas, propuestas de conservación". En Construcción con tierra. Pasado, presente y futuro. Congreso de arquitectura de tierra en Cuenca de Campos 2012, coordinado por Félix Jové Sandoval y José L. Sainz Guerra, 109-122. Valladolid: Cátedra Juan de Villanueva. http://www5.uva.es/grupotierra/publicaciones/digital/libro2013/10tr-quesada.pdf [Consultado el 8/5/2015]

Quesada Quesada, Tomás. 1998. "Poblamiento y fortificación del territorio en los siglos XII-XIII. El caso de las sierras meridionales de Jaén". En Castillos y territorio en Al-Andalus, editado por Antonio Malpica, 141-163. Granada: Athos-Pérgamos S.L.

Quevedo Rojas, Carlos. 2015. "Análisis constructivo y criterios de intervención en el castillo medieval de Matrera (Villamartín, Cádiz)". En Actas del Noveno Congreso Nacional y Primer Congreso Internacional Hispanoamericano de Historia de la Construcción, vol. 3, editado por Santiago Huerta y Paula Fuentes, 1387-1398. Madrid: Instituto Juan de Herrera, ETS de Arquitectura de Madrid.

Quirós Castillo, J. Antonio. 2002. "Arqueología de la arquitectura en España". Arqueología de la arquitectura 1: 27-38.

http://arqarqt.revistas.csic.es/index.php/arqarqt/article/viewFile/4/4 [Consultado el 9/9/2015]

Quitério, Paulo. 2010. "Castelo de Paderne, Portugal. Intervenção na sua muralha almôada". En La arquitectura construida en tierra. Tradición e innovación. Congresos de arquitectura de tierra en Cuenca de Campos 2004/2009, coordinado por José L. Sainz Guerra y Félix Jové Sandoval, 67-74. Valladolid: Cátedra Juan de Villanueva.

http://www5.uva.es/grupotierra/publicaciones/digital/libro2010/2010_9788469345542_p067074_quiterio.pdf [Consultado el 8/5/2015]

Ramírez, Alicia. "Las construcciones medievales de la sierra de Almenara (Lorca, Murcia)". Alberca 9: 111-133.

http://www.amigosdelmuseoarqueologicodelorca.com/alberca/pdf/alberca9/ALBERCA9_CAP_0 4.pdf [Consultado el 30/4/2014]

Ramos de Castro, Guadalupe. 1978. Las murallas de Zamora. Zamora: Ministerio de Cultura, Delegación Provincial de Zamora.

Reveyron, Nicolas. 2002. "L'apport de l'archéologie du bâti dans la monographie d'architecture". In-Situ 2: 1-12.

http://dx.doi.org/10.4000/insitu.1200 [Consultado el 8/9/2015]

Rodríguez Martínez, Felipe. 1998. Historia de Coca: Estudios y documentos. Coca: Ayuntamiento de Coca.

2007. Coca: Ciudad de Cauca. Madrid: Mediterráneo-Meral. 
Las murallas en las Comunidades de Villa y Tierra de la Diócesis de Segovia en los siglos XI a XIII. Técnica y sistemas constructivos de la arquitectura defensiva medieval.

2011. "Aproximación histórica a la Edad Media en Coca". En Historia de Coca. Estudios sobre Historia y Arte en Coca. XXXII Curso de Historia de Segovia (Segovia, abril-mayo de 2011) coordinado por Víctor M. Cabañero, 133-179. Segovia: Real Academia de Historia y Arte de San Quirce.

Rodríguez Navarro, Pablo. 2008. "La torre árabe observatorio en tierras valencianas. Tipología arquitectónica”. Tesis doctoral, Universidad Politécnica de Valencia. http://dx.doi.org/10.4995/Thesis/10251/3542 [Consultado el 12/7/2015]

y Ferrán Vilaplana. 2015. "La tapia árabe de la torre de Almudaina (Alicante). Lectura formal, material y constructiva". En Construcción con tierra. Investigación y documentación. XI CIATTI 2014. Congresos de arquitectura de tierra en Cuenca de Campos, coordinado por Félix Jové Sandoval y José L. Sainz Guerra, 65-72. Valladolid: Cátedra Juan de Villanueva.

http://www5.uva.es/grupotierra/publicaciones/digital/libro2015/006vilaplana.pdf [Consultado el $15 / 12 / 2015]$

Rodríguez de la Peña, Manuel A. (dir.). 2009. Hacedores de frontera. Estudios sobre el contexto social de la Frontera en la España medieval. Madrid: CEU Ediciones.

Rojas, Cristóbal de. 1598. Teoría y práctica de la fortificación. Madrid: Luis Sánchez. http://www.sedhc.es/bibliotecaD/1598_Cristobal_Rojas_Teorica_practica_fortificacion.pdf [Consultado el 16/3/2016]

Romero Bejarano, Manuel. 2005. "De informes, ruinas y corrupción. El estado de la muralla de Jerez de la Frontera en 1510". En Actas del Cuarto Congreso Nacional de Historia de la Construcción, 988-992, editado por S. Huerta. Madrid: Instituto Juan de Herrera, SEHC, COAC, CAATC. http://www.sedhc.es/biblioteca/actas/CNHC4_095.pdf [Consultado el 7/12/2016]

Rosenthal, Franz, trad. 1967. The Muqaddimah, de Abd Ar Rahman bin Muhammed ibn Khaldun. Publicado online en The Personal Blog of Asadullah Ali AlAndalusi. The Andalusian Project.

https://asadullahali.files.wordpress.com/2012/10/ibn_khaldun-al_muqaddimah.pdf [Consultado el $9 / 3 / 2016]$

Rossier Limiñana, Pablo. 1990. Origen y evolución de las murallas de Alicante. Alicante: Patronato Municipal de V Centenario de la ciudad de Alicante.

Rivas, Juan L. de las e Inés Cieza, coords. 2009. Atlas de Conjuntos Históricos de Castilla y León. Valladolid: Junta de Castilla y León.

Río Muñoz, Mónica del, Jesús San José y Félix Jové Sandoval. 2015. "Análisis de la repercusión de los tratados y manuales históricos en España y Europa en el estudio de la técnica de la tapia". En Construcción con tierra. Investigación y documentación. XI CIATTI 2014. Congresos de arquitectura de tierra en Cuenca de Campos, coordinado por Félix Jové Sandoval y José L. Sainz Guerra, 35-44. Valladolid: Cátedra Juan de Villanueva.

http://www5.uva.es/grupotierra/publicaciones/digital/libro2015/003delrio.pdf [Consultado el 07/01/2015]

2016. "Fábricas históricas de tapia mixta en el área central de Castilla y León". Tesis doctoral, Universidad de Valladolid. 
Sáez, Emilio et al. 1953. Los fueros de Sepúlveda. Segovia: Diputación Provincial de Segovia.

Sánchez Albornoz, Claudio. 1966. Despoblación y repoblación del valle del Duero. Buenos Aires: Universidad de Buenos Aires. Instituto de Historia de España. 1984. Una ciudad de la España cristiana hace mil años. Estampas de la vida en León. Madrid: Ediciones Rialp S.A.

Sánchez Real, José. 1986. La muralla de Tarragona. Tarragona: Ayuntamiento de Tarragona.

San José, Jesús I. 1994. Arquitectura religiosa en Sanabria: sus espacios, organizaciones y tipologías. Zamora: Instituto de Estudios Zamoranos Florián de Ocampo.

Santamaría, Juan M. 1971. Las Iglesias románicas de la Comunidad de Villa y Tierra de Pedraza. Segovia: Caja de Ahorros y Monte de Piedad.

Sainz Esteban, Alicia, José L. Sainz Guerra, Félix Jové Sandoval, José Martínez et al. 2013. "La arquitectura en tierra en las Villas Nuevas Medievales castellanas. Relación entre arquitectura y urbanismo. Análisis de los núcleos de Peñaflor y Tordehumos, Valladolid". En Construcción con tierra. Pasado, presente y futuro. Congreso de arquitectura de tierra en Cuenca de Campos 2012, coordinado por Félix Jové Sandoval y José L. Sainz Guerra, 61-72. Valladolid: Cátedra Juan de Villanueva.

http://www5.uva.es/grupotierra/publicaciones/digital/libro2013/05tr-sainz.pdf [Consultado el 8/5/2015]

2014a. "Entrevista con el profesor José Avelino Gutiérrez González sobre los patrones de medida y sistemas de construcción en el territorio leonés en la Edad Media. ETS Arquitectura de Valladolid, 21 de mayo de 2012". En Las Villas Nuevas Medievales de Castilla y León, coordinado por José L. Sainz Guerra, 223-243. Valladolid: Universidad de Valladolid, ETS Arquitectura. http://www5.uva.es/grupotierra/publicaciones/digital/librovnm/20150109-Libro-VNM.pdf [Consultado el 8/5/2015]

, José L. Sainz Guerra y Félix Jové Sandoval. 2014b."The walls of the Medieval new town of Vertavillo, Palencia (Spain)". En Vernacular Architecture. Towards a sustainable Future, editado por Camila Mileto, Fernando Vegas, L. García y Valentina Cristini, 661-666. Londres: CRC Press. 
Las murallas en las Comunidades de Villa y Tierra de la Diócesis de Segovia en los siglos XI a XIII. Técnica y sistemas constructivos de la arquitectura defensiva medieval.

y Félix Jové Sandoval. 2015a. "Aproximación al sistema constructivo de la muralla medieval de Fuentidueña, Segovia”. En Construcción con tierra. Investigación y documentación. XI CIATTI 2014. Congresos de arquitectura de tierra en Cuenca de Campos, coordinado por Félix Jové Sandoval y José L. Sainz Guerra, 55-64. Valladolid: Cátedra Juan de Villanueva.

http://www5.uva.es/grupotierra/publicaciones/digital/libro2015/005sainzesteban.pdf [Consultado el 15/12/2015]

2015b. "Sistema constructivo de las murallas en las comunidades de Villa y Tierra. Los casos de Coca, Cuéllar y Montejo (Segovia)". En Actas del Noveno Congreso Nacional y Primer Congreso Internacional Hispanoamericano de Historia de la Construcción, vol. 3, editado por Santiago Huerta y Paula Fuentes, 1541-1550. Madrid: Instituto Juan de Herrera, ETS de Arquitectura de Madrid.

2016. "Constructive similarities and differences in the walls in 'Comunidades de Villa y Tierra' in the Diocese of Segovia, Spain". En The Proceedings of the Third Annual Conference of the Construction History Society, coordinado por James W.P. Campbell, 140-152. Cambridge: Construction History Society.

Sainz Guerra, José L. 1990. La génesis de la plaza en Castilla durante la Edad Media. Valladolid: Colegio Oficial de Arquitectos de Castilla y León Este.

, Félix Jové Sandoval, Alicia Sainz Esteban et al. 2011. "La arquitectura en tierra en las villas nuevas medievales castellanas. Análisis de la relación entre arquitectura y urbanismo". En Construcción con tierra. Tecnología y arquitectura. Congresos de arquitectura de tierra en Cuenca de Campos 2010/2011, coordinado por Félix Jové Sandoval y J. Luis Sainz, 431-440. Valladolid: Cátedra Juan de Villanueva.

http://www5.uva.es/grupotierra/publicaciones/digital/libro2011/2011_9788469481073_p431440_sainz.pdf [Consultado el 4/2/2015]

y Alicia Sainz Esteban. 2014. "Las VNM castellanas. Análisis de las huellas de sus trazados en la cartografía actual. Aguilar de Campos, Peñaflor de Hornija, Vertavillo y Herrera de Pisuerga". En Las Villas Nuevas Medievales de Castilla y León, coordinado por José L. Sainz Guerra, 153-188. Valladolid: Universidad de Valladolid, ETS Arquitectura.

http://www5.uva.es/grupotierra/publicaciones/digital/librovnm/20150109-Libro-VNM.pdf [Consultado el 8/5/2015]

Sainz de Robles, Federico C. 1952. Castillos en España. Madrid: Aguilar.

Sanz del Olmo, Beatriz y Gustavo Pedrosillo Herrera. 2005. "Calero, un oficio perdido". Técnica Industrial 258: 62-65.

http://www.tecnicaindustrial.es/tiadmin/numeros/18/40/a40.pdf [Consultado el 27/9/2016]

Sarthou Carreres, Carlos. 1983. Castillos de España. Madrid: Espasa-Calpe S.A. 
Scellès, Maurice. 1999. Cahors. Ville et architecture civile au Moyen Âge (XII ${ }^{e}-X V^{e}$ siècles). Cahiers du patrimoine 54. Paris: Éditions du Patrimoine.

Schnell Quiertant, Pablo. 2014. "El inventario de arquitectura defensiva de la AEAC, un ejemplo de ciencia ciudadana de España". Patrimonio Cultural de España. Arquitectura Defensiva 9: 81-92.

http://ipce.mcu.es/difusion/publicaciones/revistas-patr.html [Consultado el 23/11/2015]

Séraphin, Gilles. 2014. Donjons \& Châteaux du Moyen Âge dans le Lot. Cahors: Éditions midi-pyrénéennes.

Suárez Bilbao, coord. 2008. Los fueros de Sepúlveda y las sociedades de frontera. II Symposium Internacional de Estudios Históricos de Sepúlveda. Madrid: Dykinson.

Suárez Japón, Juan M. 1999. El derribo de las murallas de Cádiz. Crónica de una transformación urbana. Cádiz: Universidad de Cádiz.

Tabales Rodríguez, Miguel A. 2002. "Aportaciones de la arqueología medieval al conocimiento de las técnicas constructivas". En La técnica de la arquitectura medieval, editado por Amparo Graciani, 35-74. Sevilla: Universidad de Sevilla.

Terrase, Michel. 1969. "Buitrago". Mélanges de la Casa de Velázquez 5:189-205. http://dx.doi.org/10.3406/casa.1969.996 [Consultado el 11/5/2015]

Torres Balbás, Leopoldo. 1922. "Las murallas que caen". Arquitectura IV: 77-84. http://oa.upm.es/34065/1/1922_murallas_torresb_opt.pdf [Consultado el 5/11/2015] 1949. Arte almohade. Arte nazarí. Arte mudéjar. Colección Ars Hipaniae, vol. IV. Madrid: Plus Ultra.

1985. Ciudades hispanomusulmanas. 2 vols. Madrid: Instituto Hispano-Árabe de Cultura.

Valdeón Baruque, Julio. 1991. "Reflexiones sobre las murallas urbanas de la Castilla medieval". En La ciudad y las murallas, editado por Cesare de Seta y Jacques Le Goff, 67-87. Madrid: Cátedra.

Valdés, Nicolás. 1859. Manual del ingeniero: resumen de la mayor parte de los conocimientos elementales y de aplicación en las profesiones del ingeniero y arquitecto. Paris: J. Dumaine.

http://bvpb. mcu.es/es/consulta/registro.cmd?id=449660 [Consultado el 16/02/2016]

Vauban, Sébastien le Prestre de. 1692. Nouvelle manière de fortifier de Mr. de Vauban. Paris: chez Sebastien Mabre Cramois.

http://dx.doi.org/10.3931/e-rara-29531 [Consultado el 4/7/2016]

Vela Tejada, José y Francisco Martín García, trads. 1991. Poliorcética de Eneas el Táctico y Estratagemas de Polieno. Madrid: Gredos. 
Las murallas en las Comunidades de Villa y Tierra de la Diócesis de Segovia en los siglos XI a XIII. Técnica y sistemas constructivos de la arquitectura defensiva medieval.

Velasco Bayón, Balbino. 2012. "La Comunidad de Villa y Tierra de Cuéllar. Evolución histórica”. En Las Comunidades de Villa y Tierra. Dinámicas históricas y problemáticas actuales, editado por Víctor Muñoz Gómez, 205-220. Murcia: edit.um.

2013. Historia de Cuéllar. Segovia: Diputación Provincial.

Veyssiere, Frédéric. 2003. "Un exemple de bâti villageois en pisé aux XI ${ }^{\mathrm{e}}$ et $\mathrm{XII}$ siècles: les maisons et le rempart du site de la Gravette à l'Isle-Jourdan (Gers)". En Échanges transdisciplinaires sur les constructions en terre crue, 1 - Terre modelée, découpée ou coffrée. Matériaux et modes de mise en œuvre, actes de la table ronde de Montpellier, 17-18 novembre 2001, dirigido por Claire Anne de Chazelles y Alain Klein, 359-375. Montpellier: Editions de l'Espérou.

Villafruela Arranz, Esther, Miguel A. García y Fernando Vela Cossío. 2005. Las murallas de Miranda del Castañar (Salamanca). Estudio arqueológico de la construcción histórica. Valladolid: Junta de Castilla y León.

Villanueva, Juan de. 1827. Arte de albañilería. Madrid: Oficina Don Francisco Martínez Dávila.

http://www.bma.arch.unige.it/pdf/CD4-

Varios_parte2de2/1827\%20Villanueva.\%20Arte\%20de\%20albanileria.pdf [Consultado el 20/4/2015]

Villanueva Domínguez, Luis de. 1998. "Análisis espacial y constructivo del castillo de Chinchón por el método comparado". En Actas del Segundo Congreso Nacional de Historia de la Construcción, editado por F. Bores, J. Fernández, S. Huerta y E. Rabasa, 515-524. Madrid: Instituto Juan de Herrera. http://www.sedhc.es/biblioteca/actas/CNHC2_065.pdf [Consultado el 7/12/2016]

Susana Mora y David Sanz. 2005. "La construcción medieval y renacentista en las puertas del conjunto amurallado de Moya (Cuenca). Materiales históricos y técnicas constructivas". En Actas del Cuarto Congreso Nacional de la Historia de Construcción, editado por Santiago Huerta, 1116-1121. Madrid: Instituto Juan de Herrera.

http://www.sedhc.es/biblioteca/actas/CNHC4_107.pdf [Consultado el 7/12/2016]

Villar García, Luis M. 1986. La Extremadura Castellano-Leonesa, guerreros, clérigos y campesinos (711-1252). Valladolid: Junta de Castilla y León.

Villena, Leonardo. 1965. "Bibliografía clásica de poliorcética y fortificación”. Boletín de la Asociación Española de Amigos de los Castillos 49: 153-190.

2006. "Las primera torres rectangulares en oriente y en iberia". Discurso de recepción. Asamblea amistosa literaria. Asociación Española de Amigos de los Castillos.

http://aeac.e.telefonica.net/biblioteca\%20virtual/torresrectangulares.htm [Consultado el 15/3/2016]

Viollet-le-Duc, Eugène E. 1854. Essai sur l'architecture militaire au Moyen-Âge. Paris: Bance. http://gallica.bnf.fr/ark:/12148/bpt6k165547k [Consultado el 22/2/2016] 
1879. Le siège de La Roche-Pont. Paris: J. Hertzel.

http://gallica.bnf.fr/ark:/12148/bpt6k6566945m [Consultado el 22/2/2016]

1888. La cité de Carcassonne (Aude). Paris: Librairie des imprimeries

réunies. http://gallica.bnf.fr/ark:/12148/bpt6k204053b [Consultado el 22/2/2016]

Yzquierdo Perrín, Javier. 2009. Murallas y puertas de Burgos. Bilbao: Beta III Milenio.

Zamora, Alonso y Fernando Vela Cossío. 2005. "Paramentos de fortificaciones en la Segovia Prerrománica (siglos VII al XI)". En Actas del Cuarto Congreso Nacional de la Historia de Construcción en Cádiz, 27-29 de enero de 2005, Vol. 2, coordinado por Santiago Huerta, 1137-1154. Madrid: Instituto Juan de Herrera.

http:// www.sedhc.es/biblioteca/actas/CNHC4_109.pdf [Consultado el 31/10/2014]

2011. "Los Muros de Sepúlveda". En Sepúlveda en la historia, coordinado por Margarita González Cristóbal et al., 149-190. Sepúlveda: Ayuntamiento de Sepúlveda.

University of Chicago. 2010. The Chicago manual of style. 16th ed. Chicago: Chicago University Press.

VVAA. 2004. Simposio Internacional Arquitectura Fortificada: conservación, restauración y uso de los castillos. Segovia: Fundación del Patrimonio Histórico de Castilla y León.

Fuentes:

ca. 1516. Título del otorgamiento del Fuero de Sepúlveda. Biblioteca Nacional de España. http://bdh.bne.es/bnesearch/detalle/bdh0000116686 [Consultado el 18/2/2016]

2008. Las siete partidas del Rey Don Alfonso el Sabio: cotejadas con varios códices antiguos por la Real Academia de la Historia. Alicante: Biblioteca Virtual Miguel de Cervantes.

http://www.cervantesvirtual.com/nd/ark:/59851/bmcsb449

http://www.cervantesvirtual.com/nd/ark:/59851/bmcf1903

http://www.cervantesvirtual.com/nd/ark:/59851/bmc0k2b9 [Consultado el 10/2/2016]

1202. Cavanilles, Antonio. Memoria sobre el fuero de Madrid del año 1202. Sevilla:

Edición digital, reproducción fotográfica facsimilar del original de la Universidad de Sevilla.

http://fama2.us.es/fde/memoriaSobreEIFueroDeMadrid.pdf [Consultado el 19/1/2016]

1112. Fuero de Molina. Transcripción de la Asociación Cultural Hortezano de Ablanque, Guadalajara. http://www.ablanque.com/pdf/FUEROS_MOLINA.pdf [Consultado el 19/1/2016]

1787. Los diez libros de architectura de M. Vitruvio Polion traducidos del latin, y comentados por don Joseph Ortíz y Sanz. Madrid: Imprenta Real.

http://bdh.bne.es/bnesearch/detalle/bdh0000012956 [Consultado el 18/2/2016] 
Las murallas en las Comunidades de Villa y Tierra de la Diócesis de Segovia en los siglos XI a XIII.

Técnica y sistemas constructivos de la arquitectura defensiva medieval.

1764. Instituciones militares de Fl. Vegecio Renato; traducidas del latín al castellano por D. Jaime de Viana. Madrid: impreso en casa de Joaquin Ibarra. http://bdh.bne.es/bnesearch/detalle/bdh0000080768 [Consultado el 18/2/2016]

Maltret, Claude, trad. 1662. Obra de Procopio de Cesarea. Operum Procopii Caesariensis tomi duo. Accesserunt Nicephori Bryennii commentarii, 2 vols, editado por Niccoló Alamani. Paris: e. Typ regia.

http://gallica.bnf.fr/ark:/12148/bpt6k5774214k [Consultado el 23/2/2016]

Hergueta, Narciso. 2006. Fueros inéditos de Viguera y de Val de Funes, otorgados por D. Alfonso el Batallador. Alicante: Biblioteca Virtual Miguel de Cervantes. http://www.cervantesvirtual.com/nd/ark:/59851/bmccj8r7 [Consultado el 11/2/2016]

Gayangos, Pascual de. 1858. La gran conquista de Ultramar que mandó escribir el rey don Alfonso el Sabio ilustrada con notas críticas y un glosario por Pascual de Gayangos. Madrid: Madrid M. Rivadeneyra.

http://bdh.bne.es/bnesearch/detalle/bdh0000012558 [Consultado el 23/2/2016] 
Anexos 

Anexo 1: Fichas de selección 

FICHA DE TOMA DE DATOS

Ubicación: Coca, Segovia.

Diócesis de Segovia.

Fecha: 2/11/2014

Redactora: Alicia Sainz Esteban

\section{DATOS GENERALES}

Figura de

planeamiento general

- Normas Subsidiarias Municipales (NNSS). Fecha de aprobación: 30/03/2001; Fecha de

publicación: 21/06/2001.

- Plan Especial de Protección, Reforma Interior y Catálogo del Conjunto Histórico. Fecha de aprobación: 30/04/2003; Fecha de publicación: 06/06/2003.

Arquitectura defensiva BIC

- Recinto murado de la villa (Categoría: Conjunto Histórico). Fecha de declaración: 04/06/1931.

- Castillo de Coca (Categoría: Monumento). Fecha de declaración: 04/06/1931.

- Torre de San Nicolás (Monumento).Fecha de declaración: 04/06/1931.

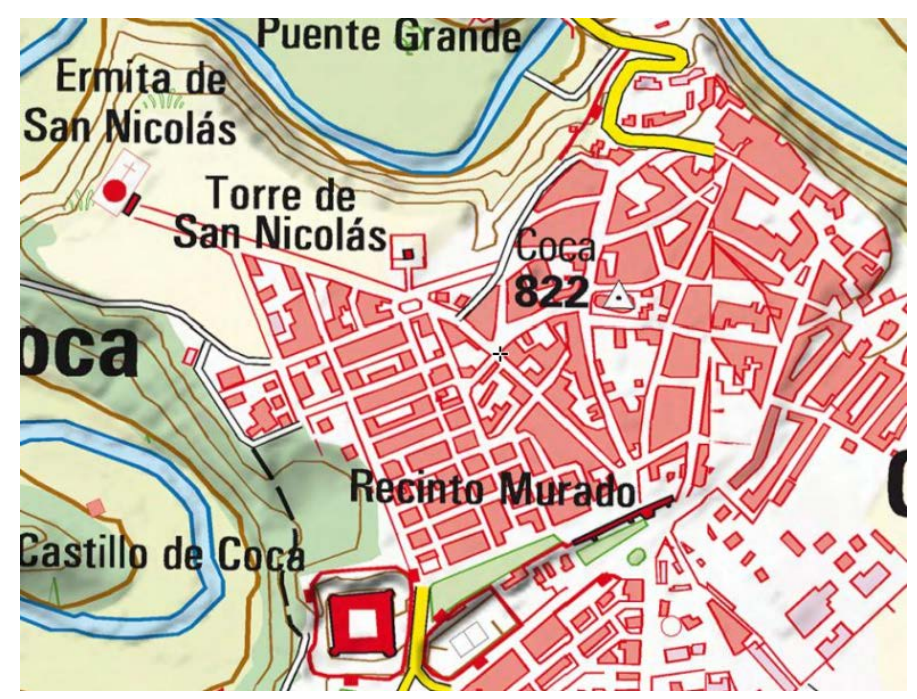

Fragmento de Mapa Topográfico Nacional. 1:25.000 Fuente:

Visor Iberpix IGN

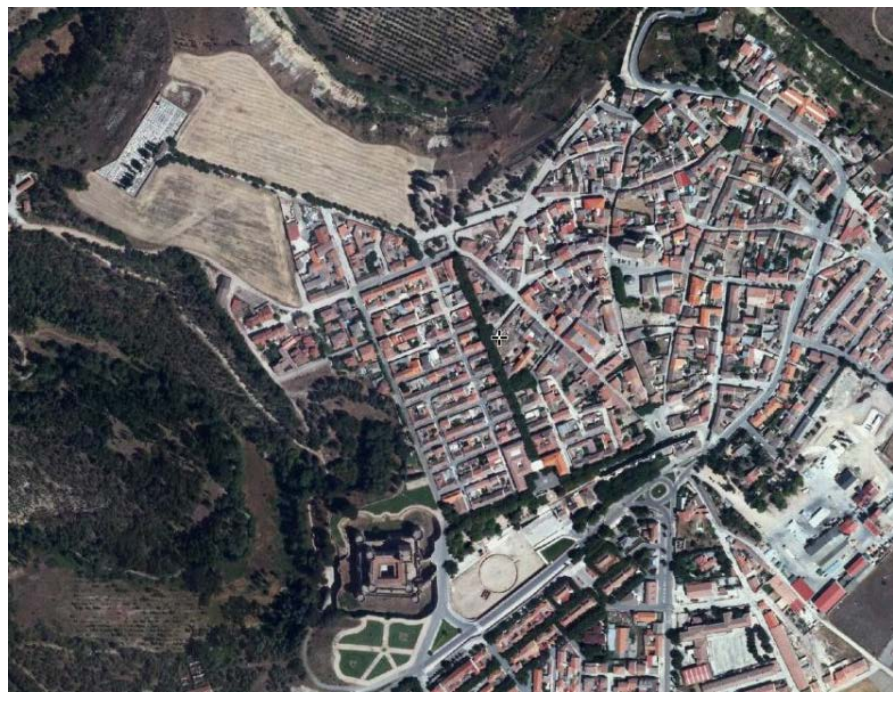

Fotografía aérea del núcleo. Fuente: PNOA IGN.

\begin{tabular}{|c|c|c|c|}
\hline \multicolumn{4}{|c|}{ DATOS TIPOLÓGICOS } \\
\hline $\begin{array}{l}\text { Restos } \\
\text { identificados }\end{array}$ & Elementos identificados & Localización UTM & $\begin{array}{l}\text { Estado de } \\
\text { conservación }\end{array}$ \\
\hline Castillo & Castillo completo & E 372106, N 4563777, Huso 30T & Buen estado. \\
\hline Muralla & $\begin{array}{l}\text { Lienzo } 200 \mathrm{~m} \\
\text { Puerta de la Villa } \\
\text { Lienzo junto a castillo } \\
\text { Restos intermitentes }\end{array}$ & $\begin{array}{l}\text { E 372387, N 4563871, Huso 30T } \\
\text { E 372436, N 4563891, Huso 30T } \\
\text { E 372165, N 4563746, Huso 30T } \\
\text { E 372010, N 4563945, Huso 30T }\end{array}$ & $\begin{array}{l}\text { Buen estado. } \\
\text { Buen estado. } \\
\text { Consolidado } \\
\text { Ruina. }\end{array}$ \\
\hline $\begin{array}{l}\text { Iglesia } \\
\text { fortificada }\end{array}$ & Torre & E 372168, N 4564177, Huso 30T & Buen estado. \\
\hline
\end{tabular}

\section{DATOS CONSTRUCTIVOS}

\begin{tabular}{|l|c|c|c|c|c|c|c|c|c|}
\hline $\begin{array}{l}\text { Materiales } \\
\text { constructivos }\end{array}$ & \multicolumn{2}{|l|}{ Ladrillo } & \multicolumn{9}{l|}{ Piedra } & Tierra \\
\hline $\begin{array}{l}\text { Sistemas } \\
\text { constructivos }\end{array}$ & Aparejo & Otros & $\begin{array}{c}\text { Tapia } \\
\text { mixta }\end{array}$ & $\begin{array}{c}\text { Mampostería } \\
\text { de piedra }\end{array}$ & Sillarejo & Sillería & $\begin{array}{c}\text { Tapia de } \\
\text { mampostería }\end{array}$ & $\begin{array}{c}\text { Tapia de } \\
\text { cal y } \\
\text { canto }\end{array}$ & $\begin{array}{c}\text { Tapia } \\
\text { de } \\
\text { tierra }\end{array}$ \\
\hline Muralla & $\mathrm{x}$ & & $\mathrm{x}$ & & & & $\mathrm{x}$ & $\mathrm{x}$ & \\
\hline Castillo & $\mathrm{x}$ & $\mathrm{x}$ & & & & & & & \\
\hline Iglesia de S & & & & & & & & $\mathrm{x}$ & $\mathrm{x}$ \\
\hline
\end{tabular}


FICHA DE TOMA DE DATOS

Ubicación: Coca, Segovia.

Diócesis de Segovia.

Fecha: 2/11/2014

Redactora: Alicia Sainz Esteban

01

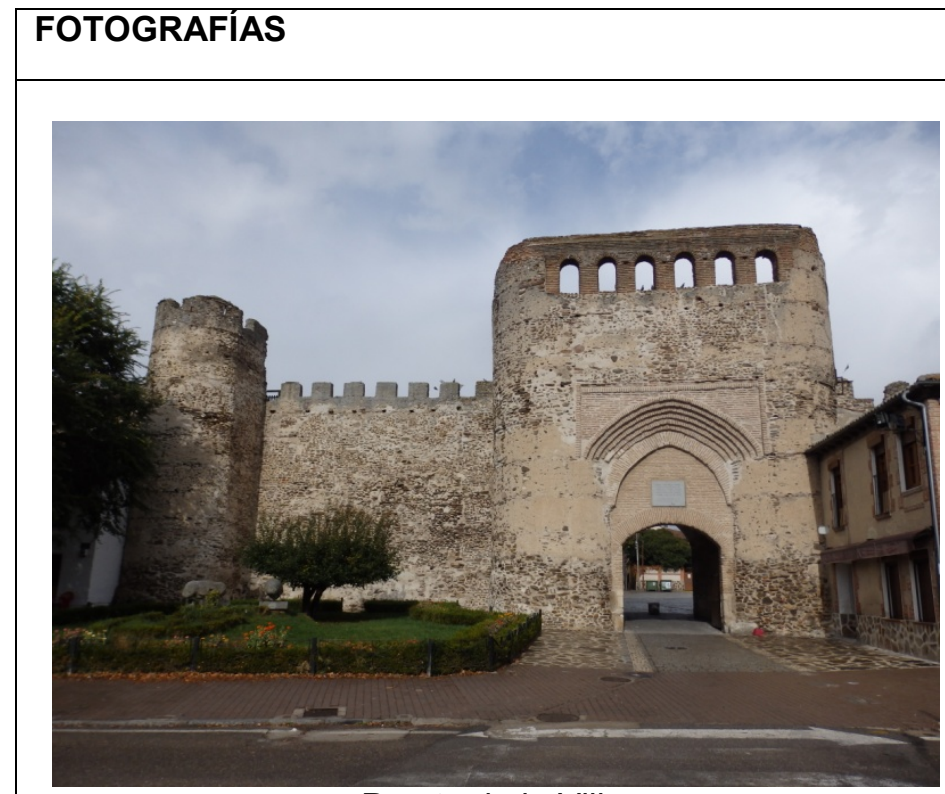

Puerta de la Villa

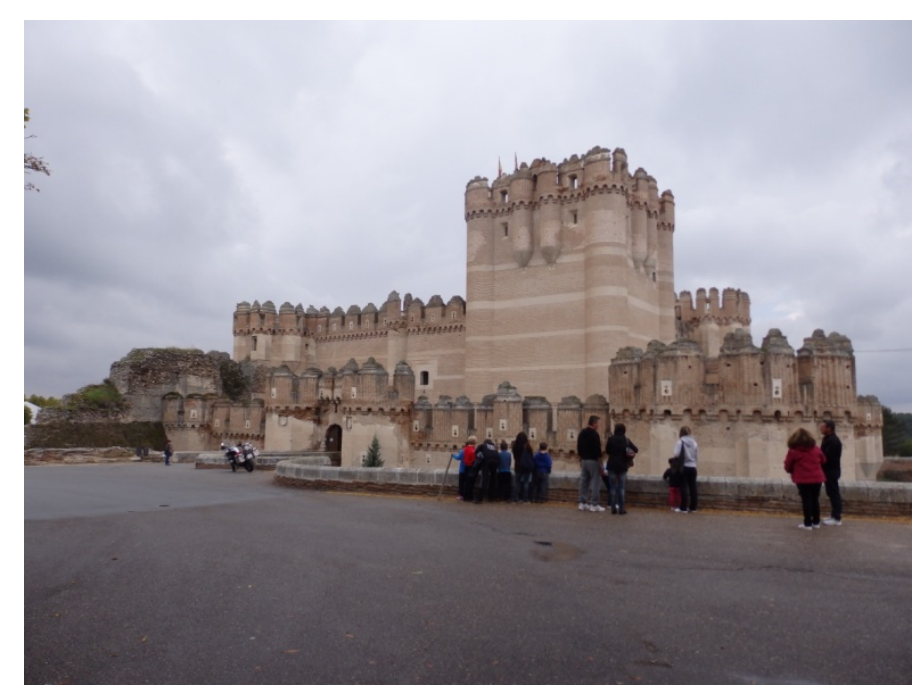

Castillo de Coca

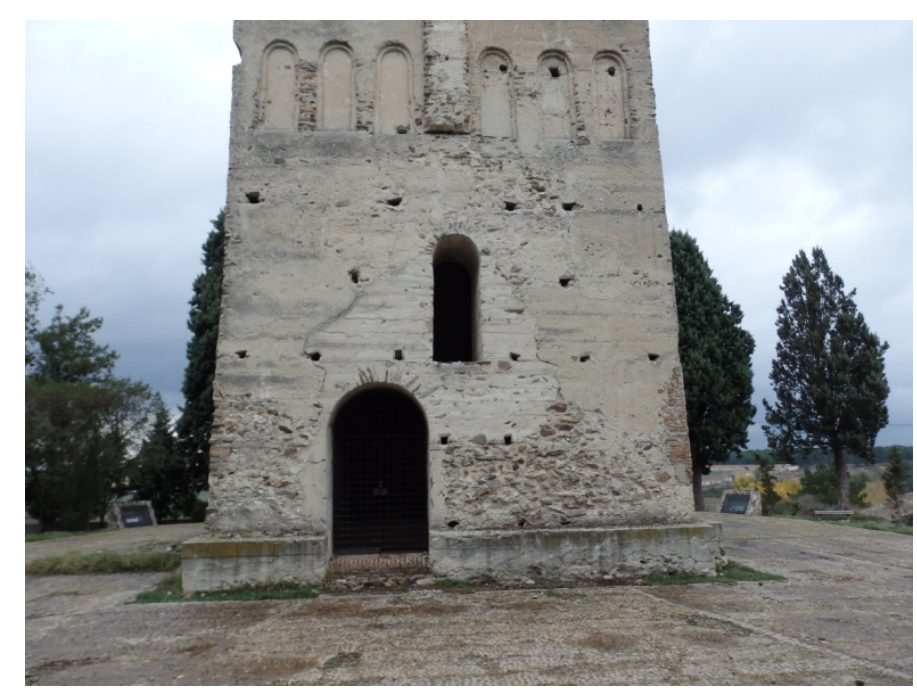

Base de la torre de San Nicolás

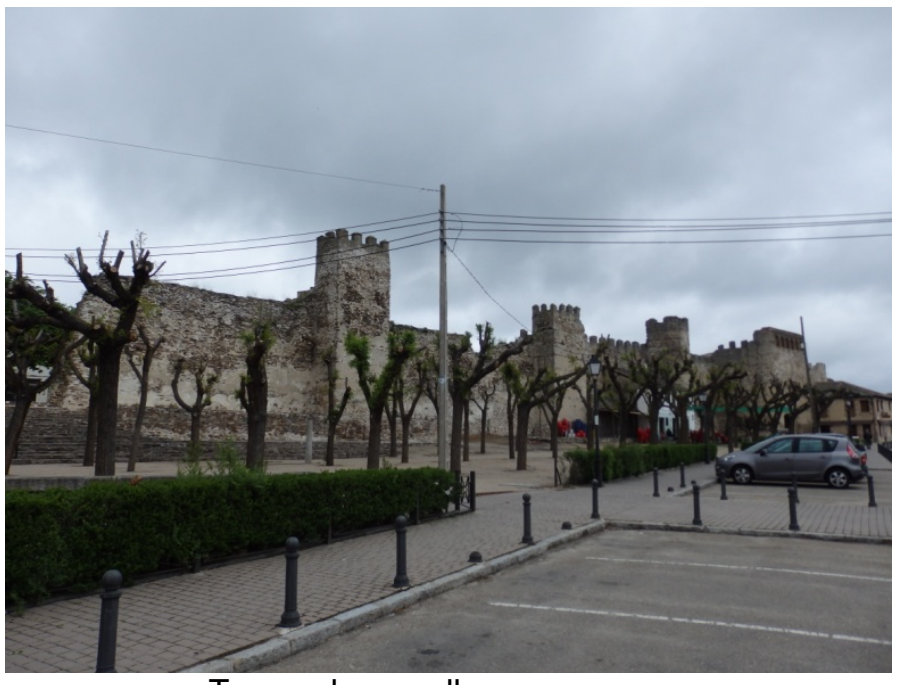

Tramo de muralla en zona sur.

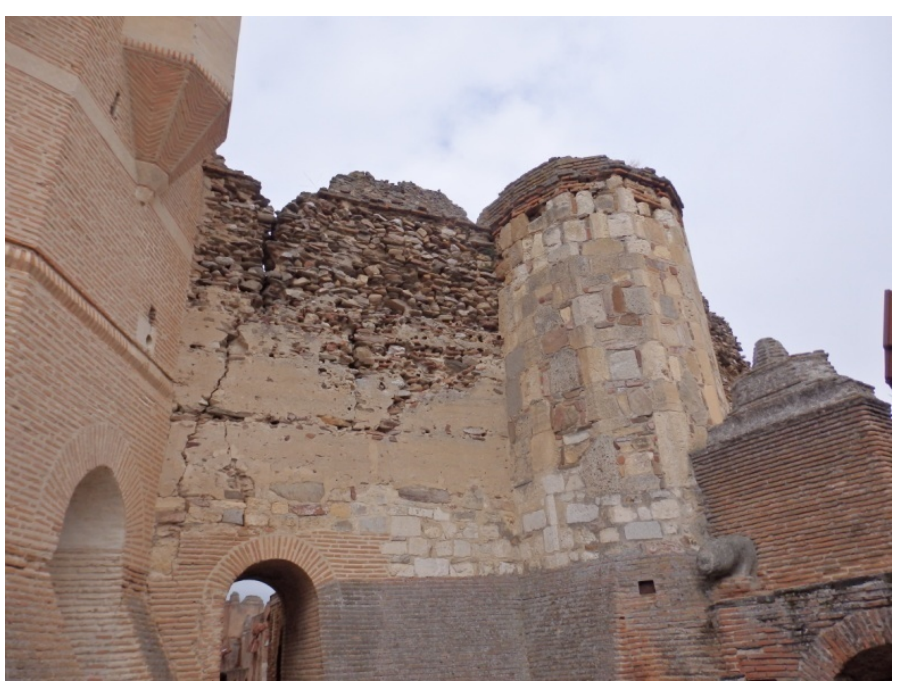

Muralla adosada al castillo

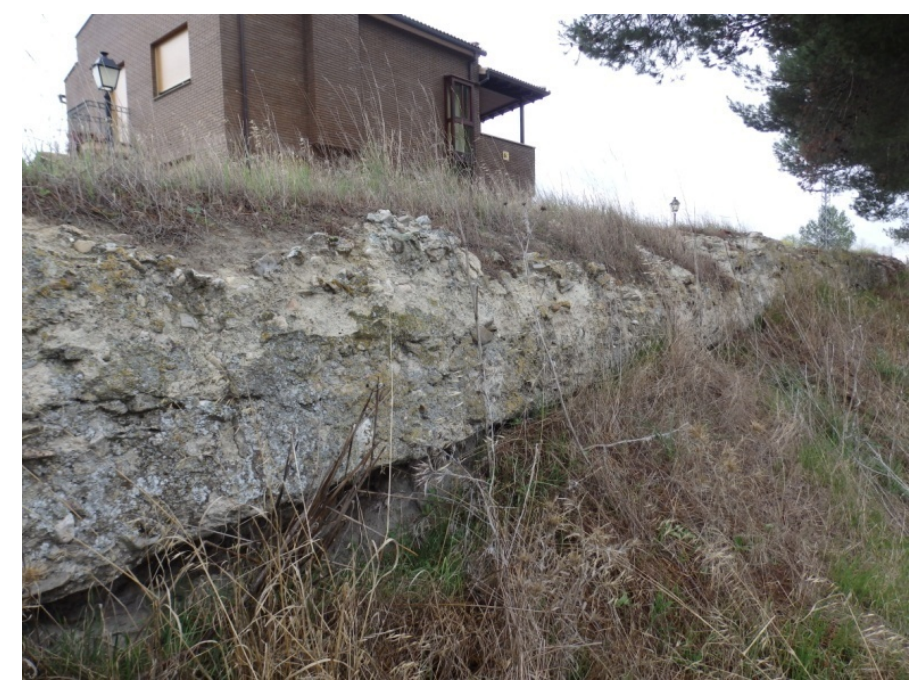

Restos en la zona este 
FICHA DE TOMA DE DATOS

Ubicación: Coca, Segovia.

Diócesis de Segovia.

Fecha: 2/11/2014

Redactora: Alicia Sainz Esteban

\section{ESTUDIOS REALIZADOS}

Martínez Díez, Gonzalo. 1983. Las Comunidades de Villa y Tierra en la Extremadura Castellana. Madrid: Editora Nacional.

Citado en páginas:

408-413,

443-449.

Benito, Félix. 1996. "Las murallas castellanas, su influencia en la evolución histórica y morfológica de la ciudad. Zamora y Segovia como ejemplos" en La ciudad y sus murallas, editado por Francisco J. Gallego, 117-141. Granada: Universidad de Granada.

Citado en páginas: 140.

Blanco, J. Francisco. 1991. "El circuito amurallado de Coca". En Actas del III Congreso de Arqueología Medieval Española. Vol. 2, Comunicaciones, 433-439. Oviedo: Universidad de Oviedo.

2011. "Coca en los inicios de su historia". En Historia de Coca. Estudios sobre Historia y Arte en Coca. XXXII Curso de Historia de Segovia (Segovia, abril-mayo de 2011) coordinado por Víctor M. Cabañero, 71-98. Segovia: Real Academia de Historia y Arte de San Quirce.

2014. "Descubierta la muralla vaccea de Cauca". Vaccea Anuario 2013 7: 78-79.

Rivas, Juan L. de las. 2009. Atlas de Conjuntos Históricos de Castilla y León. Valladolid: Junta de Castilla y León.

\section{CASOS DE LA INVESTIGACIÓN}

Incluido como caso de estudio de la investigación

Razones
SI

Existencia de lienzo de muralla medieval 



\section{FICHA RESUMEN}

Ubicación: Cuéllar, Segovia.

Diócesis de Segovia.

Fecha: 20/8/2014

Redactora: Alicia Sainz Esteban

\section{DATOS GENERALES}

Planeamiento $\quad$ Normas Urbanísticas Municipales (NUM). Fecha de aprobación: 05/05/2011; fecha de publicación: general 29/06/2011.

PEP, PERI, mejor urbana y Catálogo del Conjunto Histórico (PECH). Fecha de aprobación: 29/07/1999; fecha de publicación: 04/10/1999.

Arquitectura $\quad$ Recinto murado y castillo de Beltrán de la C. Fecha declaración: 04/06/1931.

defensiva Iglesia de San Esteban. Fecha declaración: 04/06/1931.

BIC Iglesia de San Martín. Fecha declaración: 04/06/1931.

La villa. Fecha declaración: 17/06/1995.

Palacio de Pedro El Cruel. Fecha declaración: 26/08/1974.
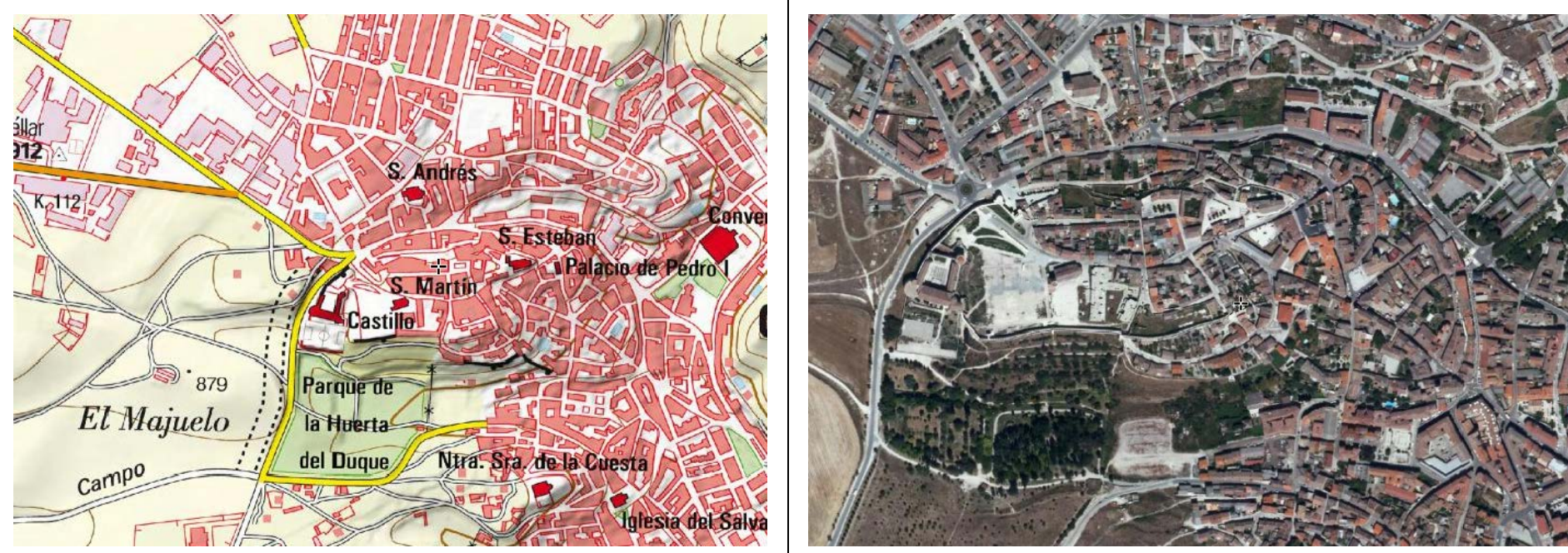

Fragmento de Mapa Topográfico Nacional. 1:25.000. Fuente Visor Iberpix IGN.

Fotografía aérea del núcleo. Fuente: Visor Iberpix IGN.

\section{DATOS TIPOLÓGICOS}

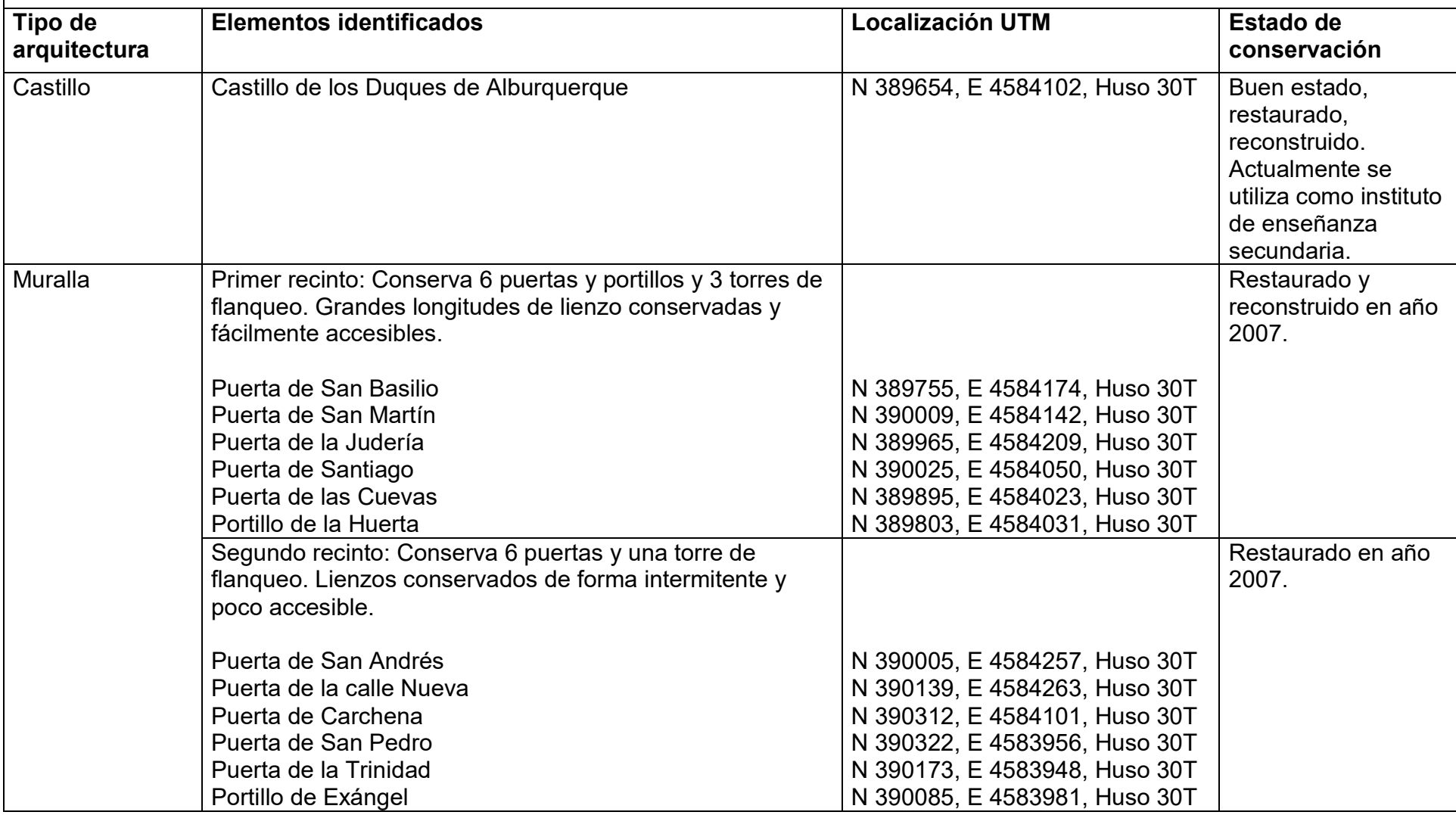


Ubicación: Cuéllar, Segovia.

Diócesis de Segovia.

Fecha: 20/8/2014

Redactora: Alicia Sainz Esteban

02

\begin{tabular}{|l|l|l|l|}
\hline \multirow{2}{*}{ Torre } & Torre de San Martín & N 389805, E 4584089, Huso 30T & Buen estado. \\
\cline { 2 - 3 } & Torre de San Esteban & N 390080, E 4584193, Huso 30T & Buen estado. \\
\hline Iglesia fortificada & Iglesia de San Esteban & & \\
\hline
\end{tabular}

\section{DATOS CONSTRUCTIVOS}

\begin{tabular}{l|c|c|c|c|c|c|c|c|c|}
\hline $\begin{array}{l}\text { Materiales } \\
\text { constructivos }\end{array}$ & \multicolumn{2}{|l|}{ Ladrillo } & \multicolumn{9}{l|}{ Piedra } & \multicolumn{2}{l|}{ Tierra } \\
\hline $\begin{array}{l}\text { Sistemas } \\
\text { constructivos }\end{array}$ & Aparejo & Otros & $\begin{array}{c}\text { Tapia } \\
\text { mixta }\end{array}$ & $\begin{array}{c}\text { Mampostería } \\
\text { de piedra }\end{array}$ & Sillarejo & Sillería & $\begin{array}{c}\text { Tapia de } \\
\text { mampostería }\end{array}$ & $\begin{array}{c}\text { Tapia de } \\
\text { cal y } \\
\text { canto }\end{array}$ & $\begin{array}{c}\text { Tapia } \\
\text { de } \\
\text { tierra }\end{array}$ \\
\hline Muralla & $\mathrm{x}$ & & $\mathrm{x}$ & $\mathrm{x}$ & $\mathrm{x}$ & $\mathrm{x}$ & $\mathrm{x}$ & & \\
\hline Castillo & & & & & & $\mathrm{x}$ & $\mathrm{x}$ & & \\
\hline $\begin{array}{l}\text { Torre de San } \\
\text { Martín }\end{array}$ & & $\mathrm{x}$ & & & & $\mathrm{x}$ & & & \\
\hline $\begin{array}{l}\text { Torre de San } \\
\text { Esteban }\end{array}$ & & $\mathrm{x}$ & & & & & & & $\mathrm{x}$ \\
\hline $\begin{array}{l}\text { Iglesia de San } \\
\text { Esteban }\end{array}$ & $\mathrm{x}$ & & & $\mathrm{x}$ & & $\mathrm{x}$ & & & \\
\hline
\end{tabular}

\section{FOTOGRAFÍAS}

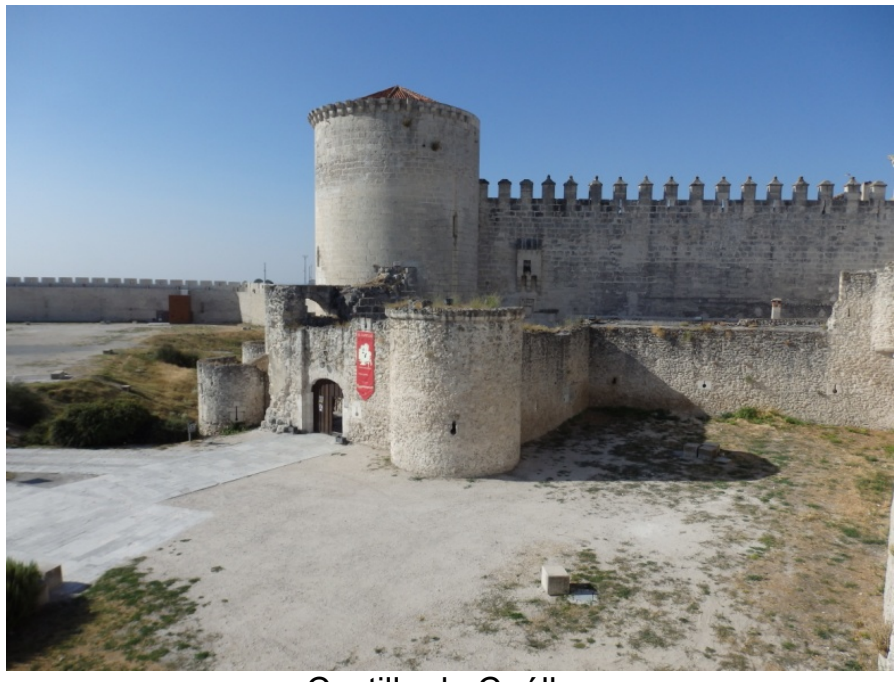

Castillo de Cuéllar

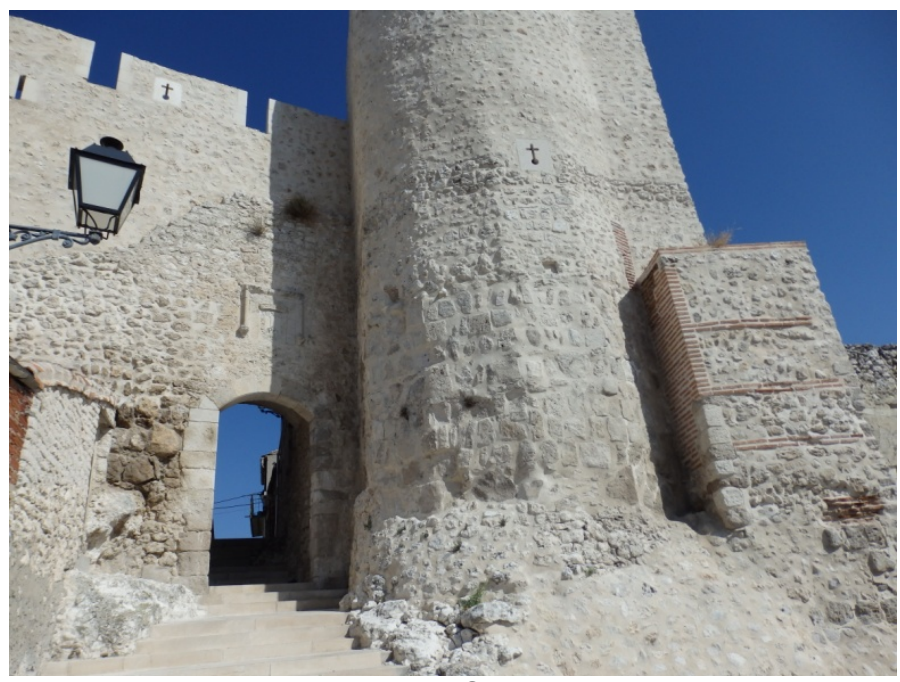

Puerta de Santiago

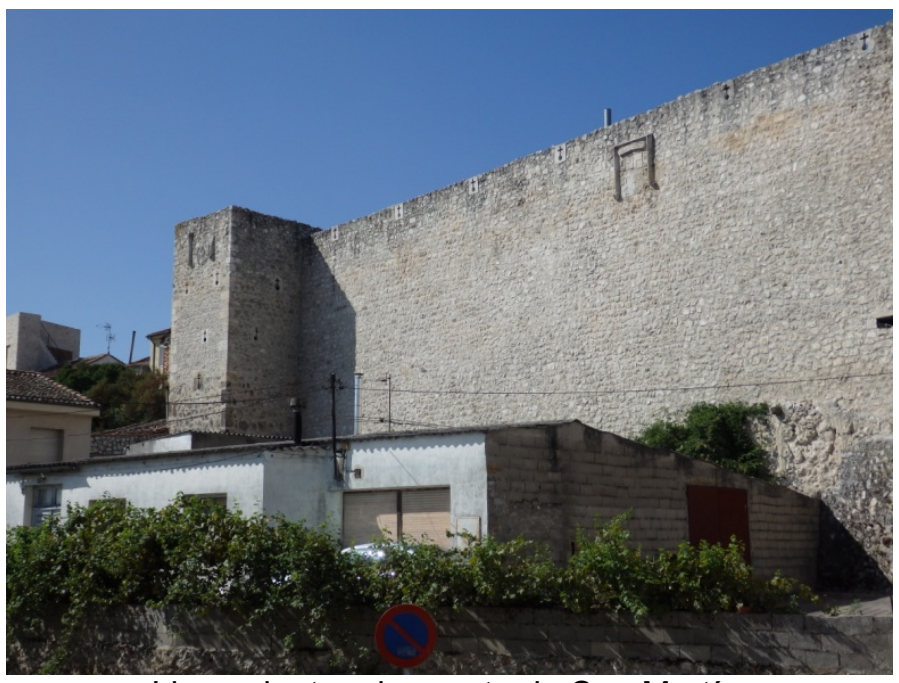

Lienzo junto a la puerta de San Martín

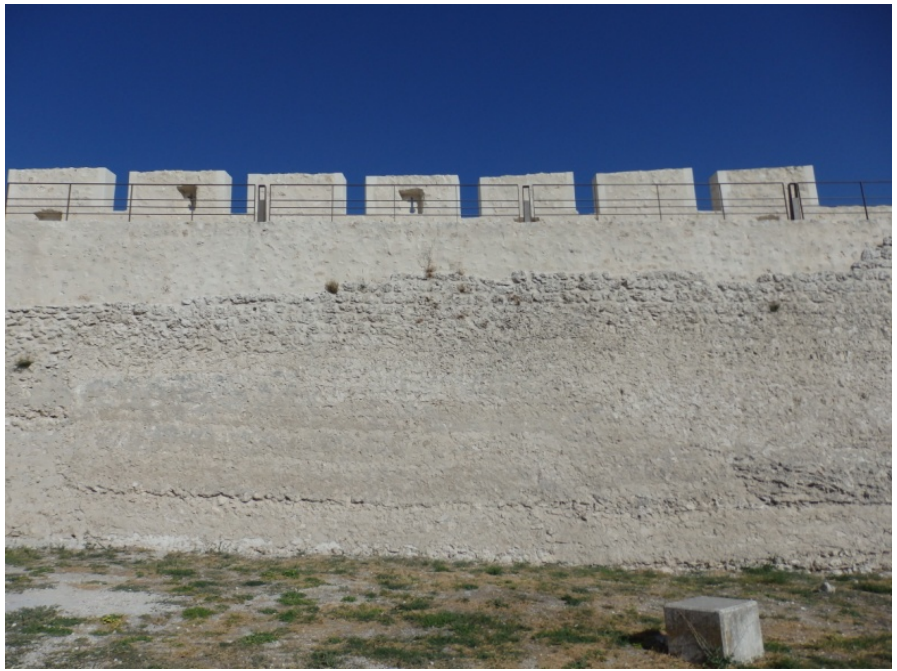

Lienzo junto al castillo 
Ubicación: Cuéllar, Segovia.

Diócesis de Segovia.

\section{Fecha: 20/8/2014}

Redactora: Alicia Sainz Esteban

02

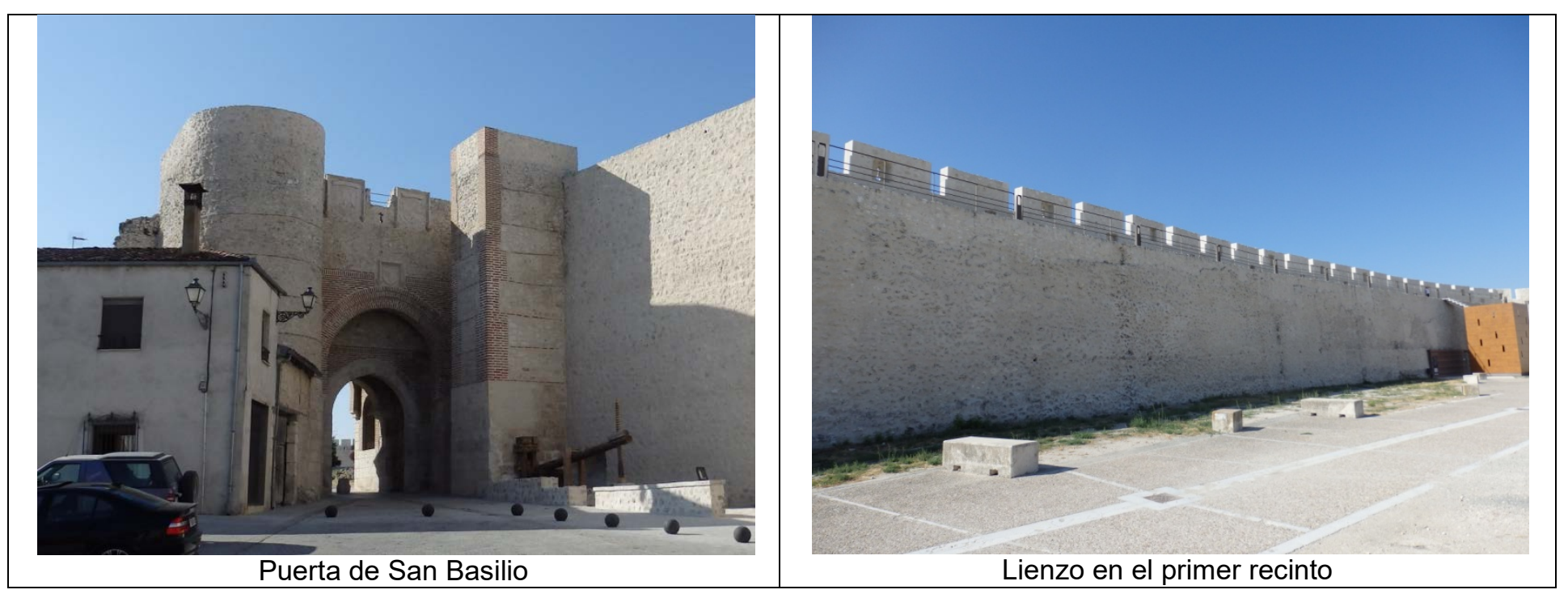

\section{ESTUDIOS REALIZADOS}

Martínez Díez, Gonzalo. 1983. Las Comunidades de Villa y Tierra en la Extremadura Castellana. Madrid: Editora Nacional.

Citado en páginas: 407-425.

Velasco Bayón, Balbino. 2013. Historia de Cuéllar. Segovia: Diputación Provincial.

Olmos, Emilio. 2000. La Comunidad de Villa y Tierra de Cuéllar a fines de la Edad Media. Poder político concejil, ordenanzas municipales y regulación de la actividad económica. Colección Historia y Sociedad 68. Valladolid: Universidad de Valladolid.

Rivas, Juan L. de las. 2009. Atlas de Conjuntos Históricos de Castilla y León. Valladolid: Junta de Castilla y León.

Citado en páginas: 469-472

\section{CASOS DE LA INVESTIGACIÓN}

Incluido como caso de estudio de la investigación Razones
SI

Existencia de restos de muralla, con varias puertas y grandes longitudes de lienzo. 



\section{FICHA RESUMEN}

\section{Ubicación:}

Fuentidueña, Segovia.

Diócesis de Segovia.

Fecha: 17/6/2014

Redactora: Alicia Sainz Esteban

\section{DATOS GENERALES}

Planeamiento Sin planeamiento general. Actualmente se están tramitando las primeras NUM+PECH.

general

Arquitectura $\quad$ Ruinas del castillo. Fecha declaración: 12/04/1996.

defensiva El pueblo. Fecha declaración: 24/04/2007.

BIC Iglesia de San Martín. Fecha declaración: 04/06/1931.

Ruinas Hospital de la Magdalena. Fecha declaración: 16/06/1995.

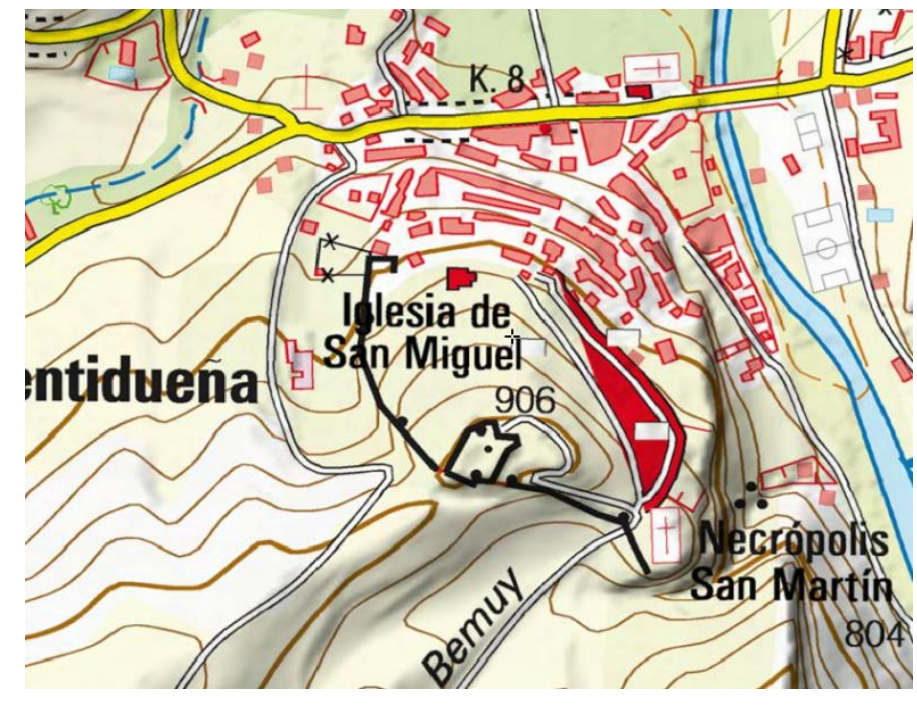

Fragmento de Mapa Topográfico Nacional. 1:25.000. Fuente: Visor Iberpix IGN.

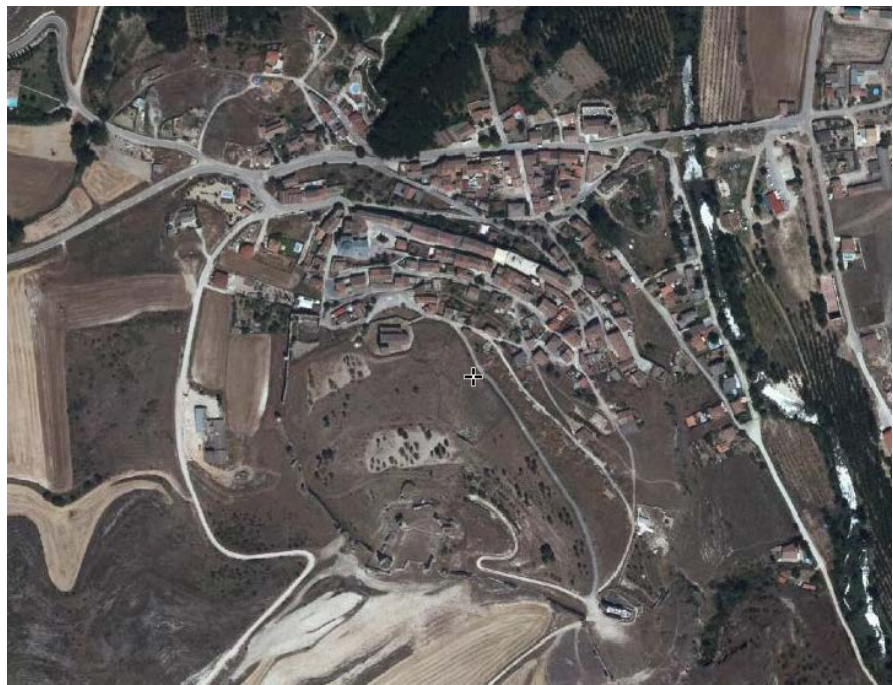

Fotografía aérea del núcleo. Fuente: Visor Iberpix IGN.

\begin{tabular}{|c|c|c|c|}
\hline \multicolumn{4}{|c|}{ DATOS TIPOLÓGICOS } \\
\hline \multirow[t]{2}{*}{ Muralla } & $\begin{array}{l}\text { Parte urbana } \\
\text { Puerta de Palacio } \\
\text { Puerta de la Calzada }\end{array}$ & $\begin{array}{l}\text { N 418058, E 4588366, Huso 30T } \\
\text { N 418281, E 4588303, Huso 30T }\end{array}$ & $\begin{array}{l}\text { Restaurada y reconstruida. } \\
\text { Restaurada } \\
\text { Restaurada }\end{array}$ \\
\hline & $\begin{array}{l}\text { Parte en campo } \\
\text { Puerta de Alfonso VIII }\end{array}$ & N 418297, E 4587965, Huso 30T & $\begin{array}{l}\text { Lienzos en mal estado, reparados puntualmente. } \\
\text { Restaurada. }\end{array}$ \\
\hline Iglesia fortificada & Iglesia de San Martín & N 418325, E 4587976, Huso 30T & $\begin{array}{l}\text { Ruina. Ábside cedido en } 1957 \text { a los Estados } \\
\text { Unidos de América. Se encuentra en el Museo } \\
\text { Metropolitano de Nueva York. }\end{array}$ \\
\hline
\end{tabular}

\section{DATOS CONSTRUCTIVOS}

\begin{tabular}{|c|c|c|c|c|c|c|c|c|c|}
\hline Materiales & Ladrillo & & & \multicolumn{4}{|c|}{ Piedra } & & Tierra \\
\hline $\begin{array}{l}\text { Sistemas } \\
\text { constructivos }\end{array}$ & Aparejo & Otros & $\begin{array}{l}\text { Tapia } \\
\text { mixta }\end{array}$ & $\begin{array}{c}\text { Mampostería } \\
\text { de piedra }\end{array}$ & Sillarejo & Sillería & $\begin{array}{c}\text { Tapia de } \\
\text { mampostería }\end{array}$ & $\begin{array}{c}\text { Tapia de } \\
\text { cal y } \\
\text { canto } \\
\end{array}$ & $\begin{array}{c}\text { Tapia } \\
\text { de } \\
\text { tierra }\end{array}$ \\
\hline Muralla & & $\mathrm{X}^{*}$ & & $x$ & & $x$ & $x$ & & \\
\hline Castillo & & & & $x$ & $x$ & $x$ & $\mathrm{x}$ & & \\
\hline
\end{tabular}

\footnotetext{
* Mampostería encintada.
} 


\section{FICHA RESUMEN}

\section{Ubicación:}

Fuentidueña, Segovia.

Diócesis de Segovia.

Fecha: 17/6/2014

Redactora: Alicia Sainz Esteban

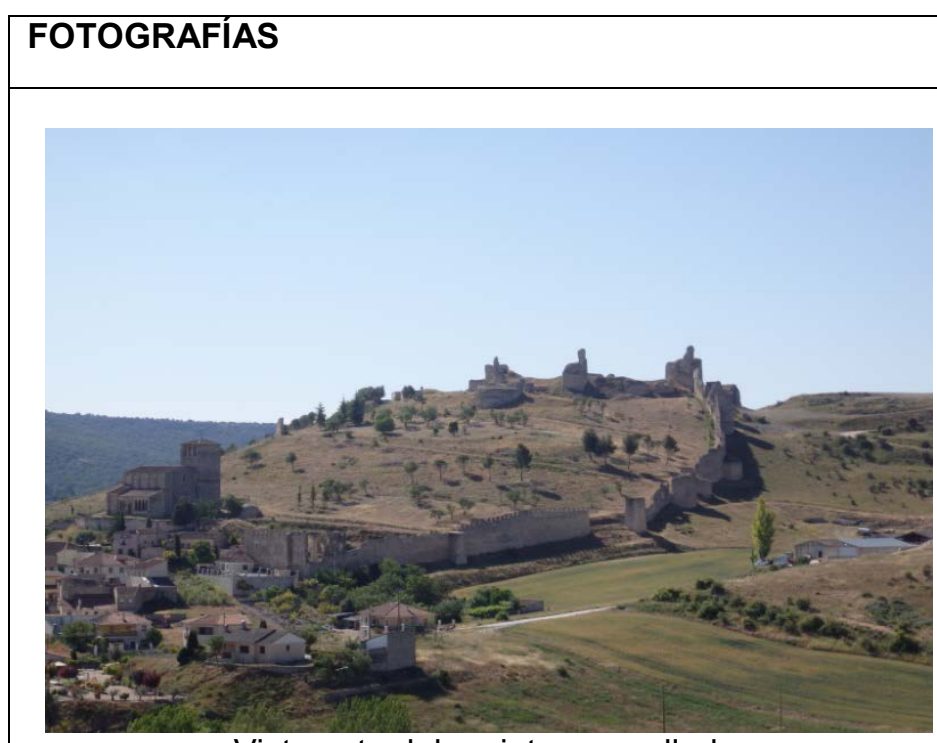

Vista este del recinto amurallado

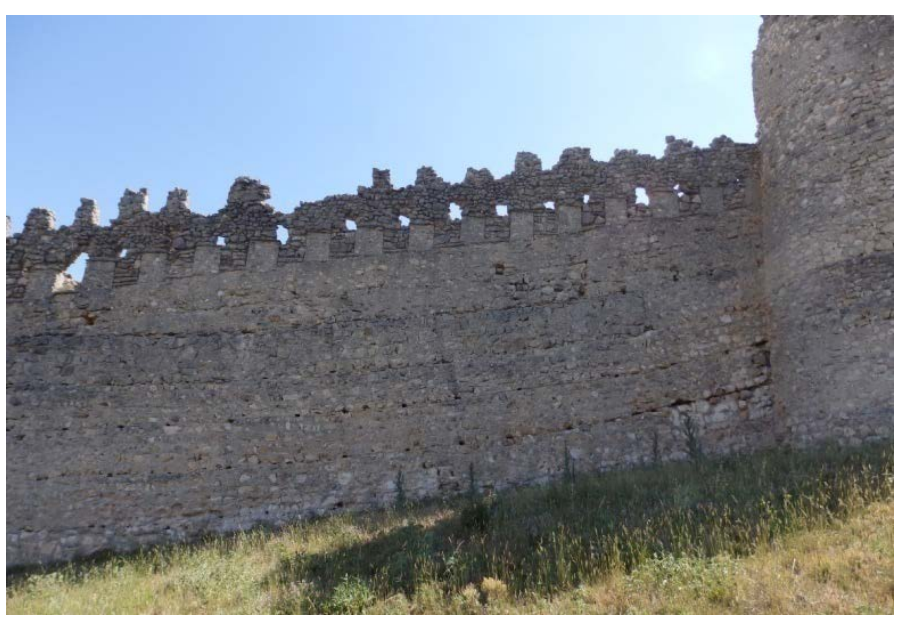

Tramo junto a torre T6 en zona este del recinto

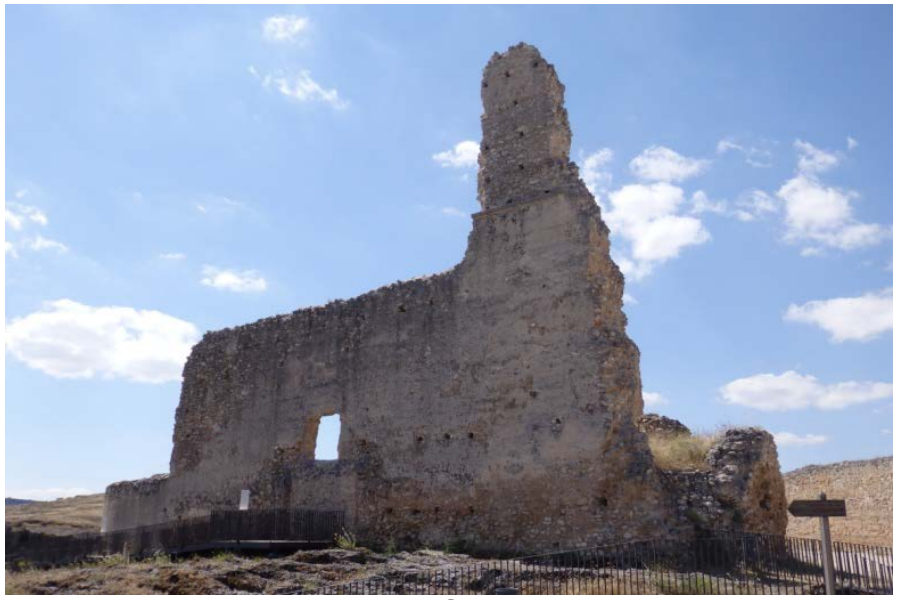

Iglesia de San Martín

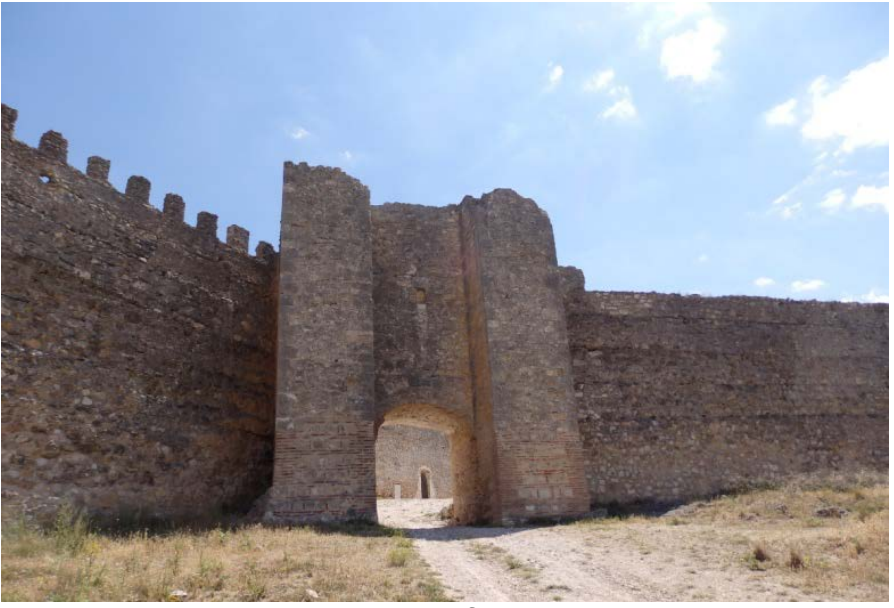

Puerta de Alfonso VIII

\section{ESTUDIOS REALIZADOS}

Martínez Díez, Gonzalo. 1983. Las Comunidades de Villa y Tierra en la Extremadura Castellana. Madrid: Editora Nacional.

Citado en páginas: 397405, 352

Hernansanz, Justo. 1985. Fuentidueña y su alfoz. Notas histórico-arqueológicas. Madrid: Graymo.

Jiménez Esteban, Jorge. 1993. Murallas de España. Madrid: Rueda.

Citado en:

171-177

Zamora, Alonso y Fernando Vela Cossío. 2005. "Paramentos de fortificaciones en la Segovia Prerrománica (siglos VII al XI)". En Actas del Cuarto Congreso Nacional de la Historia de Construcción en Cádiz, 27-29 de enero de 2005, Vol. 2, coordinado por Santiago Huerta, 1137-1154. Madrid: Instituto Juan de Herrera.

Rivas, Juan L. de las. 2009. Atlas de Conjuntos Históricos de Castilla y León. Valladolid: Junta de Castilla y León.

Citado en páginas: 1137 , 1139.

Citado en páginas: 473476

\section{CASOS DE LA INVESTIGACIÓN}

Incluido como caso de estudio de la investigación Razones

S Existencia de muralla, tanto puertas como longitudes de lienzo significativas. 


\section{DATOS GENERALES}

\begin{tabular}{l|l}
\hline $\begin{array}{l}\text { Figura de } \\
\text { planeamiento general }\end{array}$ & $\begin{array}{l}\text { Revisión de Normas Subsidiarias. Fecha de aprobación: 14/11/1997; fecha de publicación: } \\
08 / 01 / 1998 .\end{array}$ \\
\hline Elementos BIC & Ningún bien BIC recogido en el catálogo de BICs de Castilla y León. \\
\hline
\end{tabular}

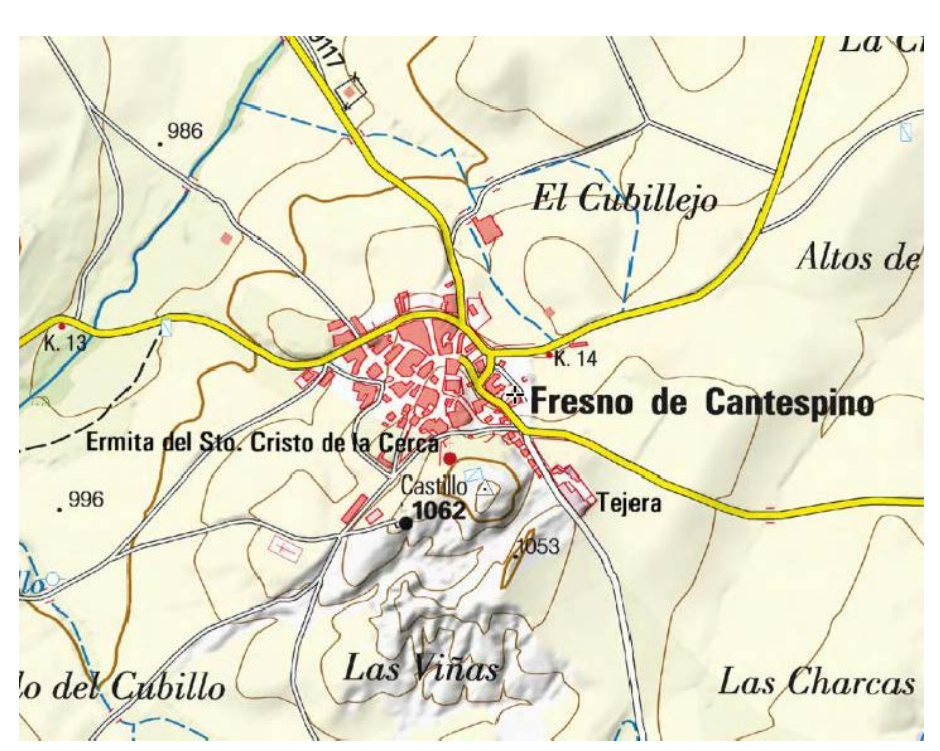

Fragmento de Mapa Topográfico Nacional. 1:25.000 Fuente: Visor Iberpix IGN.

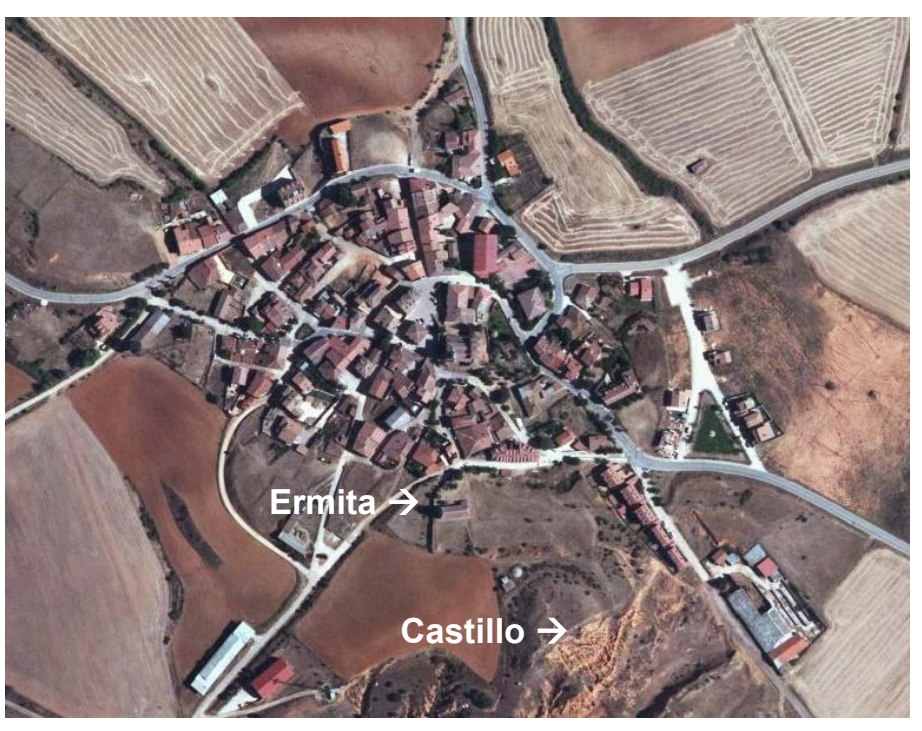

Fotografía aérea del núcleo. Fuente: PNOA IGN.

\begin{tabular}{|l|l|l|l|}
\hline \multicolumn{2}{|l|}{ DATOS TIPOLÓGICOS } & Localización UTM & $\begin{array}{l}\text { Estado de } \\
\text { conservación }\end{array}$ \\
\hline $\begin{array}{l}\text { Restos } \\
\text { identificados }\end{array}$ & Elementos identificados & E 458360, N 4579537, Huso 30T & Ruina \\
\hline Castillo & Resto de torre de directriz circular & E 458365, N 4579545, Huso 30T & Ruina \\
\cline { 2 - 4 } & Resto de muro & E 458270, N 4579634, Huso 30T & Buen estado \\
\hline $\begin{array}{l}\text { Iglesia } \\
\text { fortificada }\end{array}$ & Ermita del Santo Cristo de la Cerca & & \\
\hline
\end{tabular}

\section{DATOS CONSTRUCTIVOS}

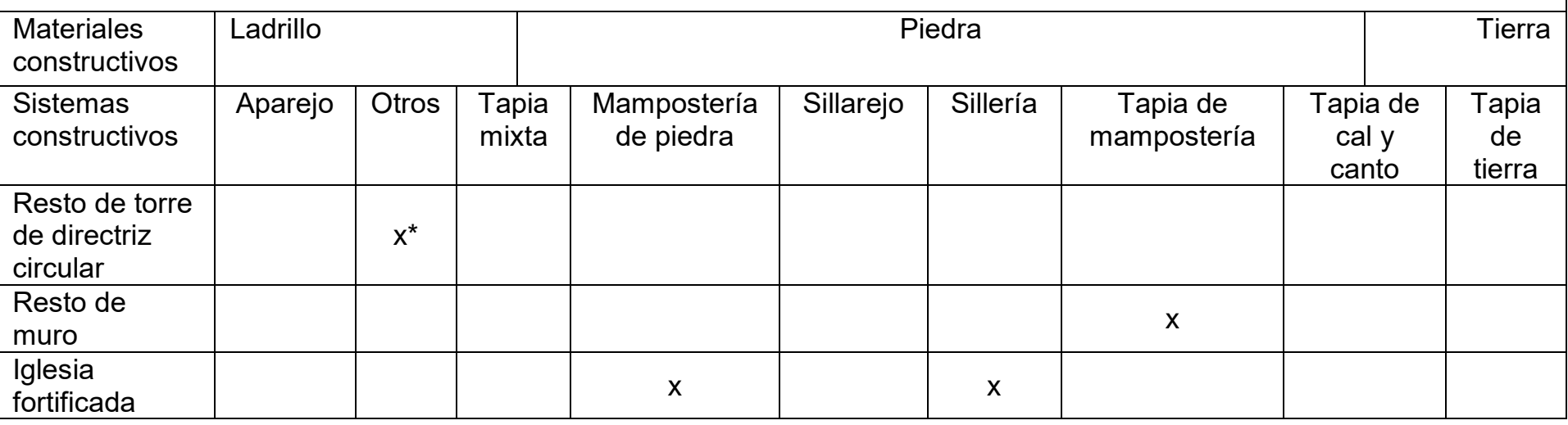

* Mampostería encintada. 
Ubicación: Fresno de Cantespino, Segovia.

Diócesis de Segovia.

Fecha: 3/9/2014

Redactora: Alicia Sainz Esteban

04

\section{FOTOGRAFÍAS}

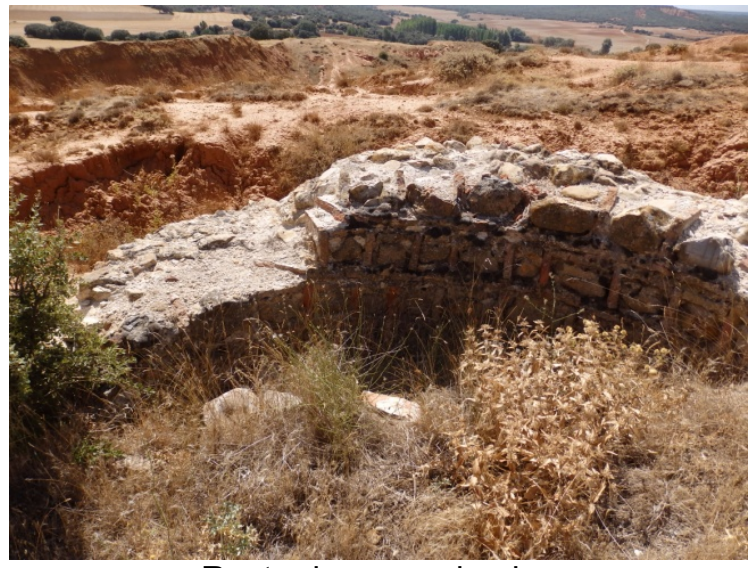

Resto de muro circular

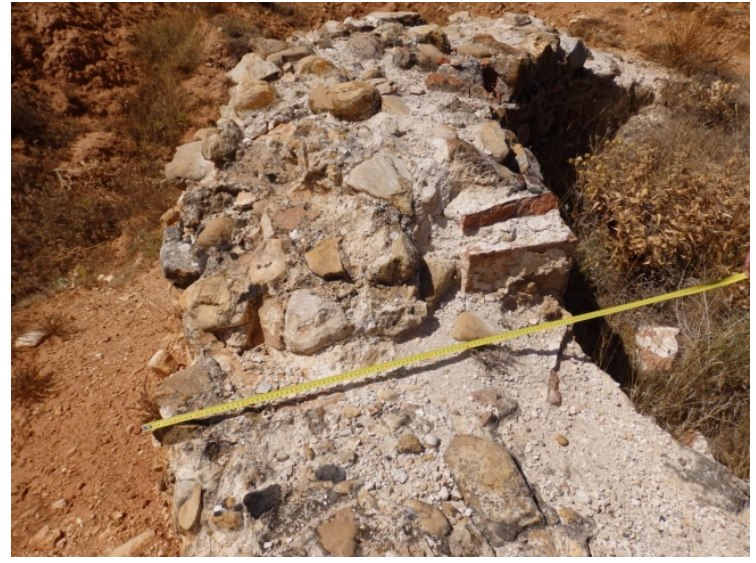

Resto de muro circular

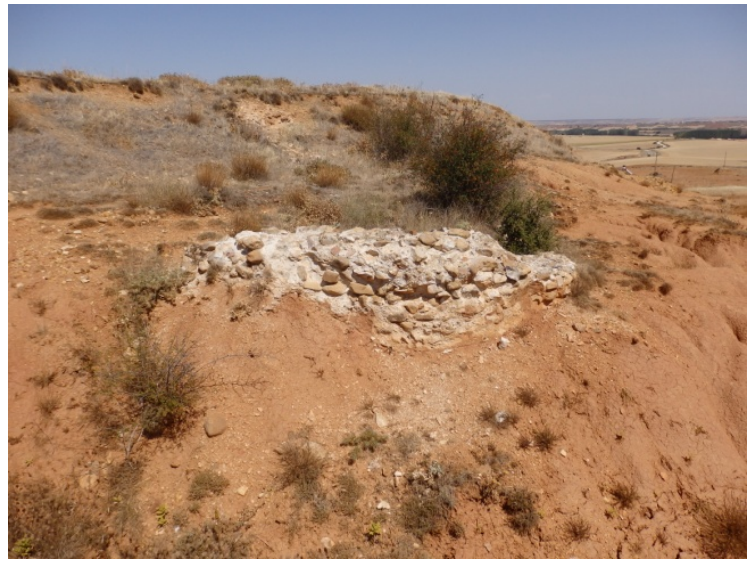

Resto de muro

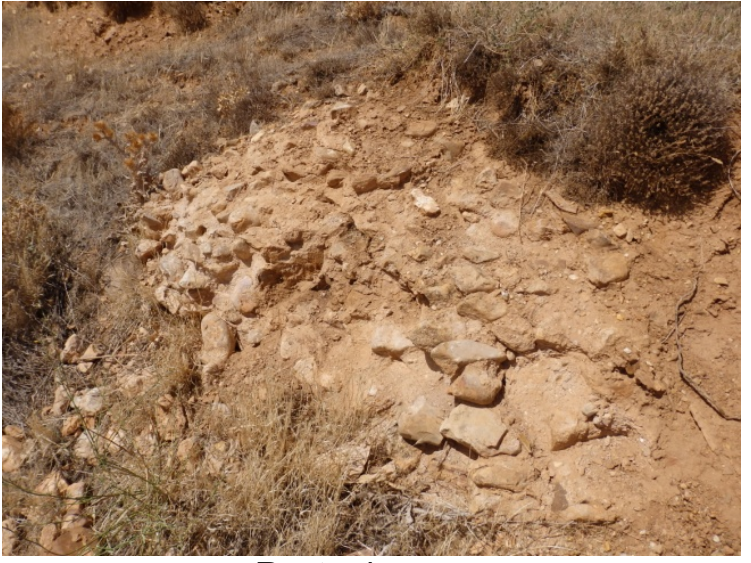

Resto de muro

\section{ESTUDIOS REALIZADOS}

Martínez Díez, Gonzalo. 1983. Las Comunidades de Villa y Tierra en la Extremadura Castellana. Madrid: Editora Nacional.

Citado en páginas:

351-357

Martín Aymerich, M. Dolores; Teresa Tardío y Alonso Zamora. 1990. Las murallas de Sepúlveda (Segovia). Un ensayo de aproximación con métodos arqueológicos a un ejemplo de pervivencia arquitectónica. Segovia: Diputación de Segovia.

Citado en páginas: 134

Zamora, Alonso y Fernando Vela Cossío. 2005. "Paramentos de fortificaciones en la Segovia Prerrománica (siglos VII al XI)". En Actas del Cuarto Congreso Nacional de la Historia de Construcción en Cádiz, 27-29 de enero de 2005, Vol. 2, coordinado por Santiago Huerta, 1137-1154. Madrid: Citado en páginas: Instituto Juan de Herrera.

\section{CASOS DE LA INVESTIGACIÓN}

Incluido como caso de estudio de la investigación Razones

NO

Escasos restos defensivos, ausencia de muralla. 


\section{FICHA DE TOMA DE DATOS}

\section{Ubicación:}

Íscar, Valladolid.

Diócesis de Segovia

Fecha: 23/10/2014

Redactora: Alicia Sainz Esteban

\section{DATOS GENERALES}

\begin{tabular}{l|l}
\hline Figura de & Normas Urbanísticas Municipales (NUM). Fecha de aprobación: 02/04/2003; Fecha de
\end{tabular} planeamiento general publicación: 03/07/2003.

Arquitectura defensiva Castillo de Íscar. Fecha de declaración: 05/05/1949.

BIC

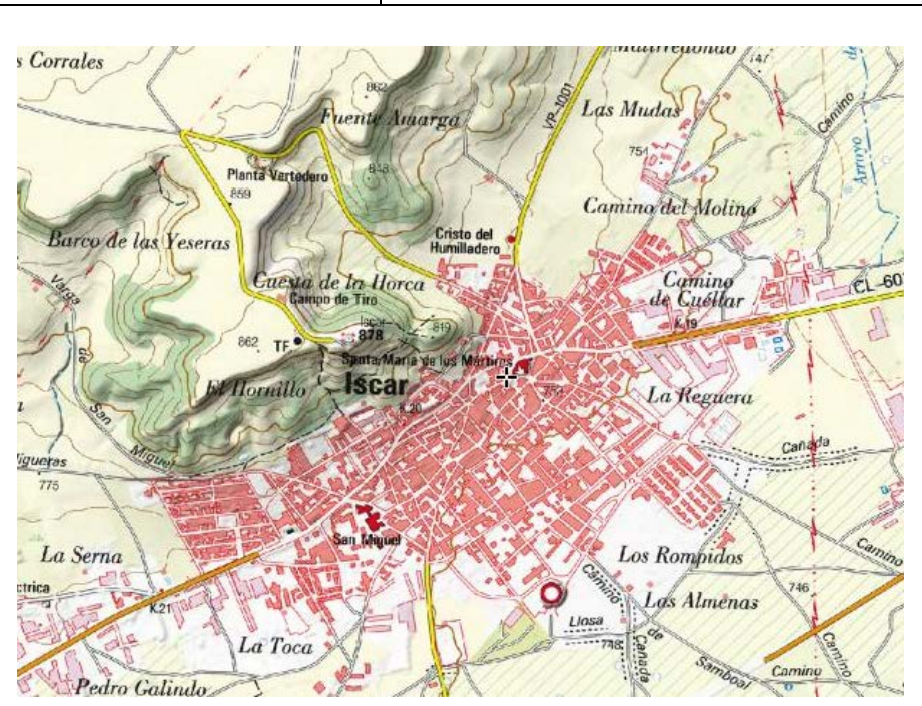

Fragmento de Mapa Topográfico Nacional. 1:25.000 Fuente: Visor Iberpix IGN.

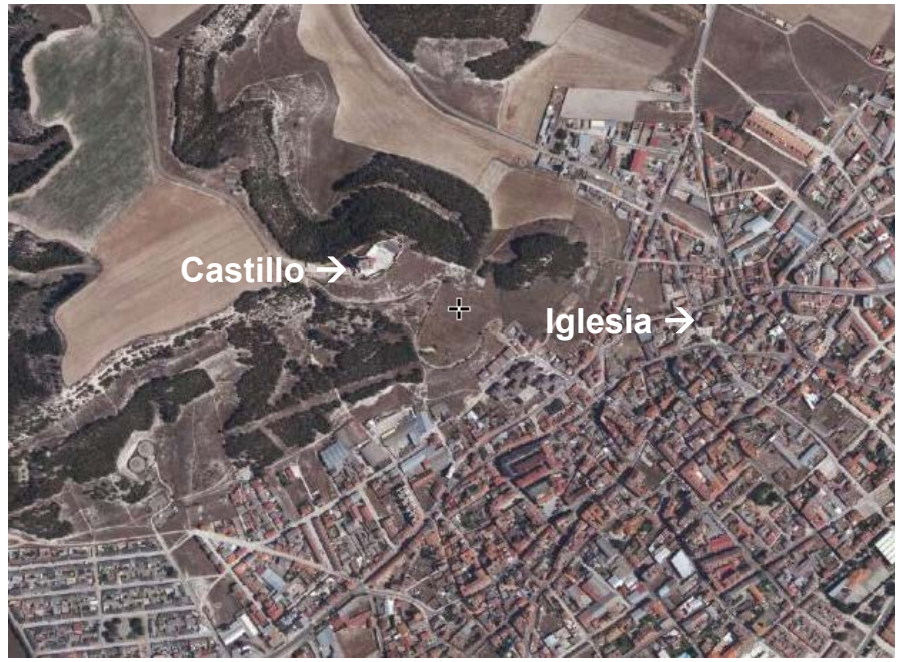

Fotografía aérea del núcleo. Fuente: PNOA IGN.

\begin{tabular}{|l|l|l|l|}
\hline \multicolumn{2}{|l|}{ DATOS TIPOLÓGICOS } \\
\hline $\begin{array}{l}\text { Restos } \\
\text { identificados }\end{array}$ & Elementos identificados & Localización UTM & Estado de conservación \\
\hline Castillo & $\begin{array}{l}\text { Torre del homenaje, muralla del } \\
\text { castillo. }\end{array}$ & E 371391, N 4580422, Huso 30T & $\begin{array}{l}\text { Buen estado, restaurado. } \\
\text { Actualmente se elabora en su } \\
\text { interior cerveza artesanal. }\end{array}$ \\
\hline $\begin{array}{l}\text { Iglesia } \\
\text { fortificada }\end{array}$ & $\begin{array}{l}\text { Muro con contrafuertes que rodea } \\
\text { la iglesia. }\end{array}$ & E 371984, N 4580322, Huso 30T & Buen estado, reparado. \\
\hline
\end{tabular}

\section{DATOS CONSTRUCTIVOS}

\begin{tabular}{|l|c|c|c|c|c|c|c|c|c|}
\hline $\begin{array}{l}\text { Materiales } \\
\text { constructivos }\end{array}$ & \multicolumn{2}{|l|}{ Ladrillo } & \multicolumn{9}{l|}{ Piedra } & \multicolumn{2}{l|}{ Tierra } \\
\hline $\begin{array}{l}\text { Sistemas } \\
\text { constructivos }\end{array}$ & Aparejo & Otros & $\begin{array}{c}\text { Tapia } \\
\text { mixta }\end{array}$ & $\begin{array}{c}\text { Mampostería } \\
\text { de piedra }\end{array}$ & Sillarejo & Sillería & $\begin{array}{c}\text { Tapia de } \\
\text { mampost } \\
\text { ería }\end{array}$ & $\begin{array}{c}\text { Tapia de cal } \\
\mathrm{y} \text { canto }\end{array}$ & $\begin{array}{c}\text { Tapia de } \\
\text { tierra }\end{array}$ \\
\hline Castillo & & & & & & $\mathrm{x}$ & & & \\
\hline $\begin{array}{l}\text { Iglesia de } \\
\text { Santa María }\end{array}$ & $\mathrm{x}$ & & & $\mathrm{x}$ & & $\mathrm{x}$ & & & \\
\hline
\end{tabular}




\section{FICHA DE TOMA DE DATOS}

\section{Ubicación:}

Íscar, Valladolid.

Diócesis de Segovia

Fecha: 23/10/2014

Redactora: Alicia Sainz Esteban

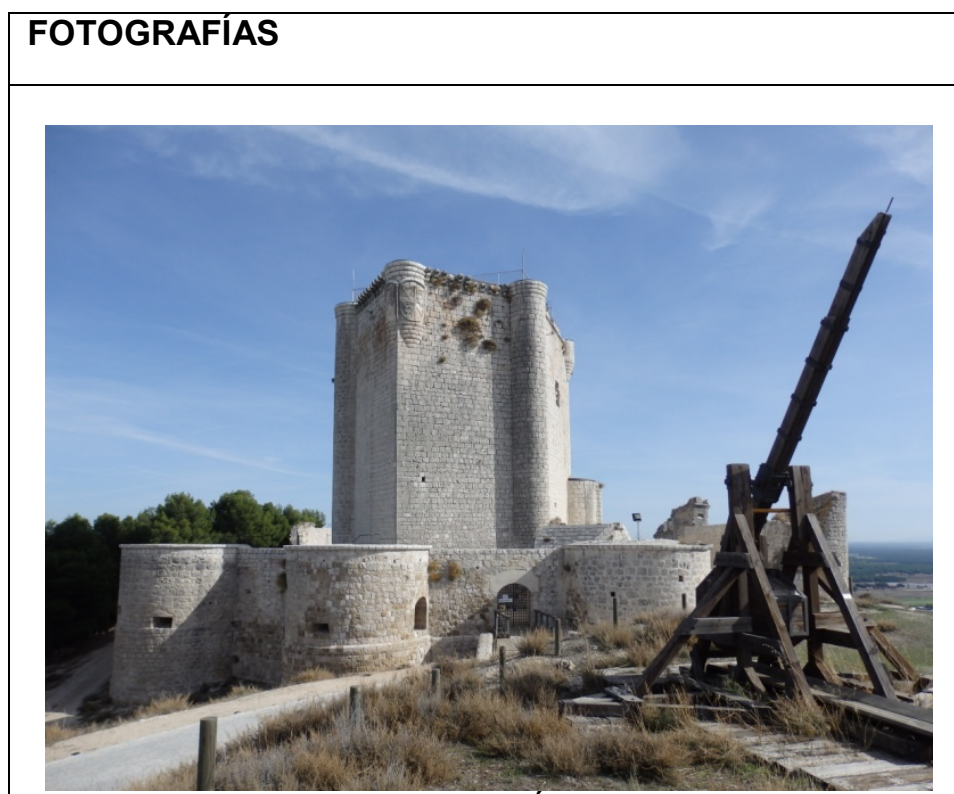

Castillo de Íscar

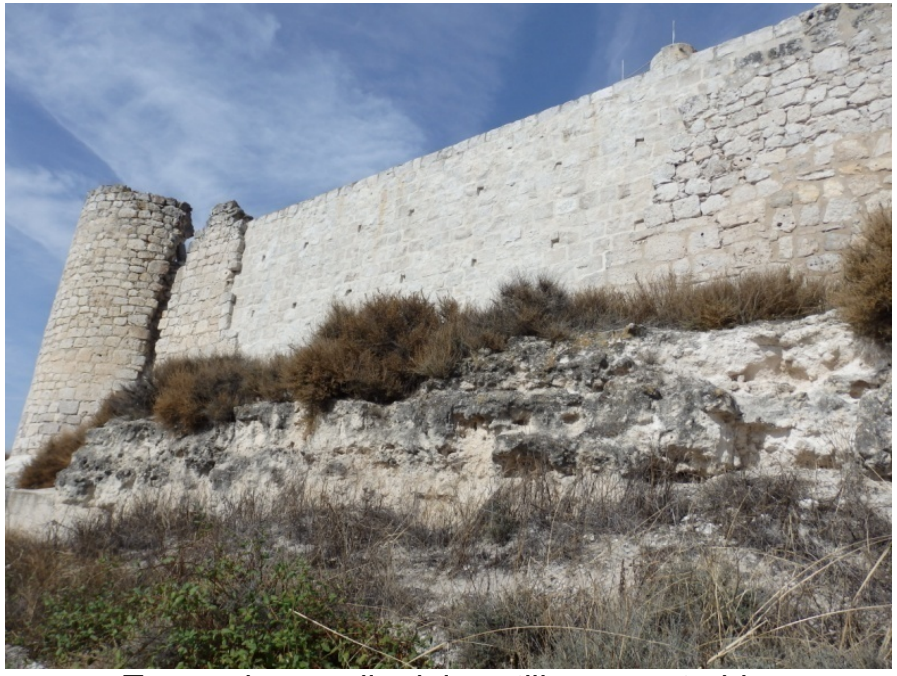

Tramo de muralla del castillo reconstruida

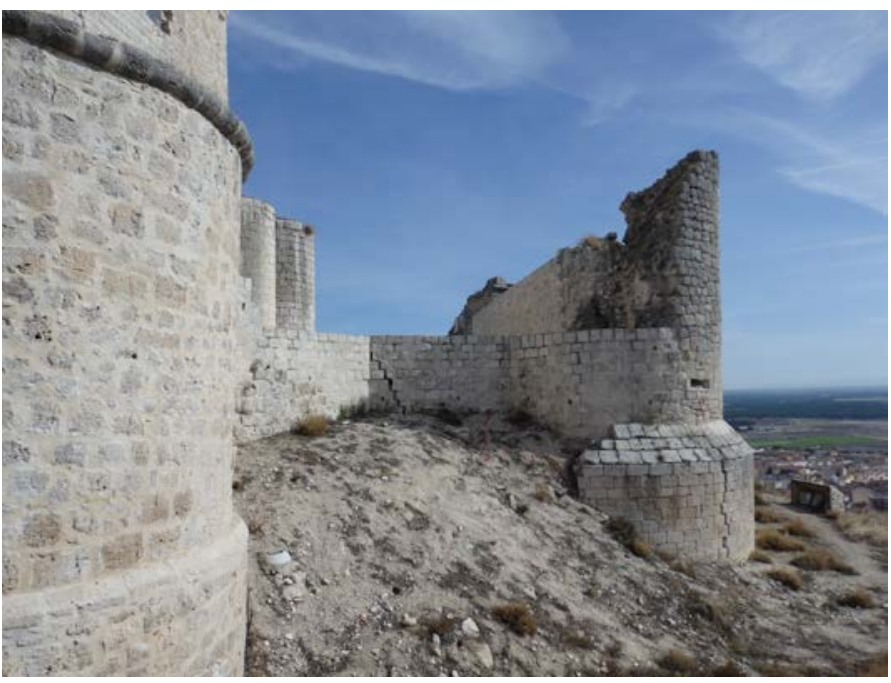

Torreones de la muralla del castillo

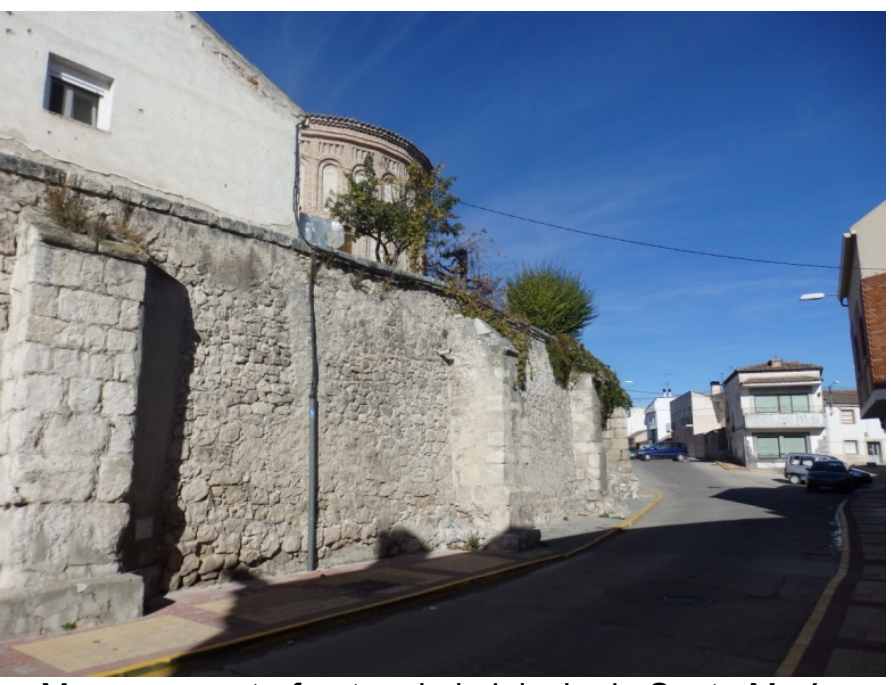

Muro con contrafuertes de la iglesia de Santa María

\section{ESTUDIOS REALIZADOS}

Martínez Díez, Gonzalo. 1983. Las Comunidades de Villa y Tierra en la Extremadura Castellana. Madrid: Editora Nacional.

Citado en

páginas:

437-442

Escribano Velasco, Consuelo y Mónica Hernansanz. 2001. "Las fortificaciones medievales de Íscar,

Valladolid" en La fortificación medieval en la península ibérica, actas del IV curso de Cultura

Medieval 21-26 de septiembre de 1992, coordinado por Pedro L. Huerta, 277-288. Aguilar de

Campoo, Palencia: Fundación Santa María la Real.

\section{CASOS DE LA INVESTIGACIÓN}

Incluido como caso de estudio de la investigación Razones
$\mathrm{NO}$

Ausencia de muralla. Es llamativa la planicie en cuyo borde se asienta el castillo, ya que recuerda a otros

asentamientos como Coca o Sepúlveda. 


\section{FICHA DE TOMA DE DATOS}

\section{Ubicación:}

Maderuelo, Segovia.

Diócesis de Segovia.

Fecha: 3/9/2014

Redactora: Alicia Sainz Esteban

\section{DATOS GENERALES}

Figura de $\quad$ - Normas Urbanísticas Municipales (NUM). Fecha de aprobación: 28/06/2004; Fecha de planeamiento general publicación: 28/04/2005.

- Plan Especial de Protección, Reforma Interior, mejora urbana y Catálogo del Conjunto Histórico. Fecha de aprobación: 22/12/2010; Fecha de publicación: 19/04/2011.

- Plan Director de restauración de las Murallas de Maderuelo (2007).

\begin{tabular}{|l|l|}
\hline Elementos BIC & - La villa (Categoría: Conjunto Histórico). Fecha de declaración: 21/12/1993. \\
& - Castillo de la Villa (Categoría: Castillos). Fecha de declaración: 05/05/1949.
\end{tabular}

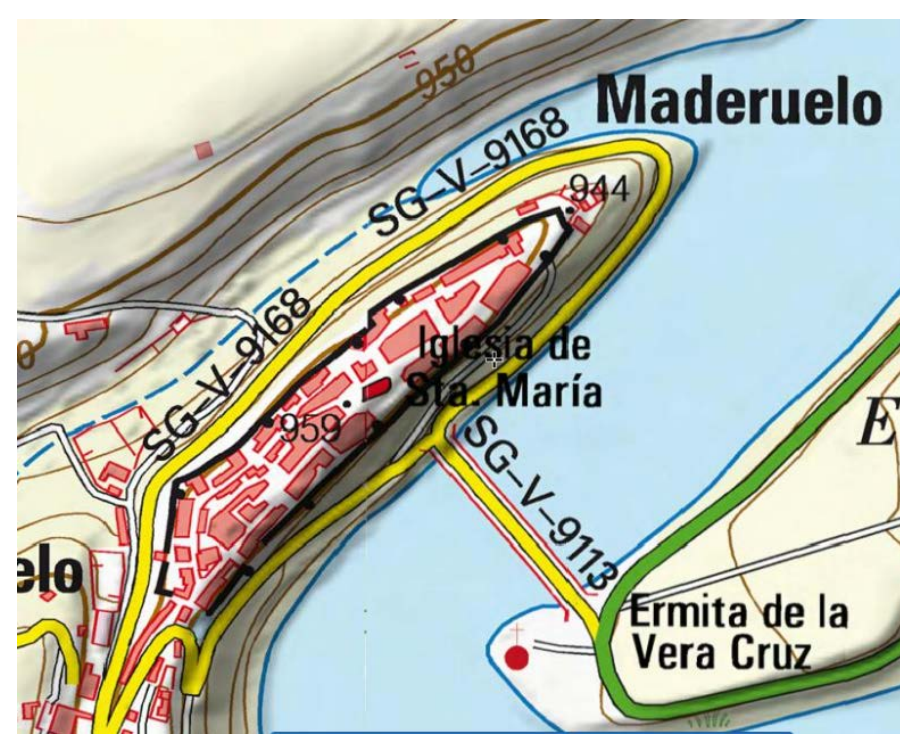

Fragmento de Mapa Topográfico Nacional. 1:25.000 Fuente: Visor Iberpix IGN.

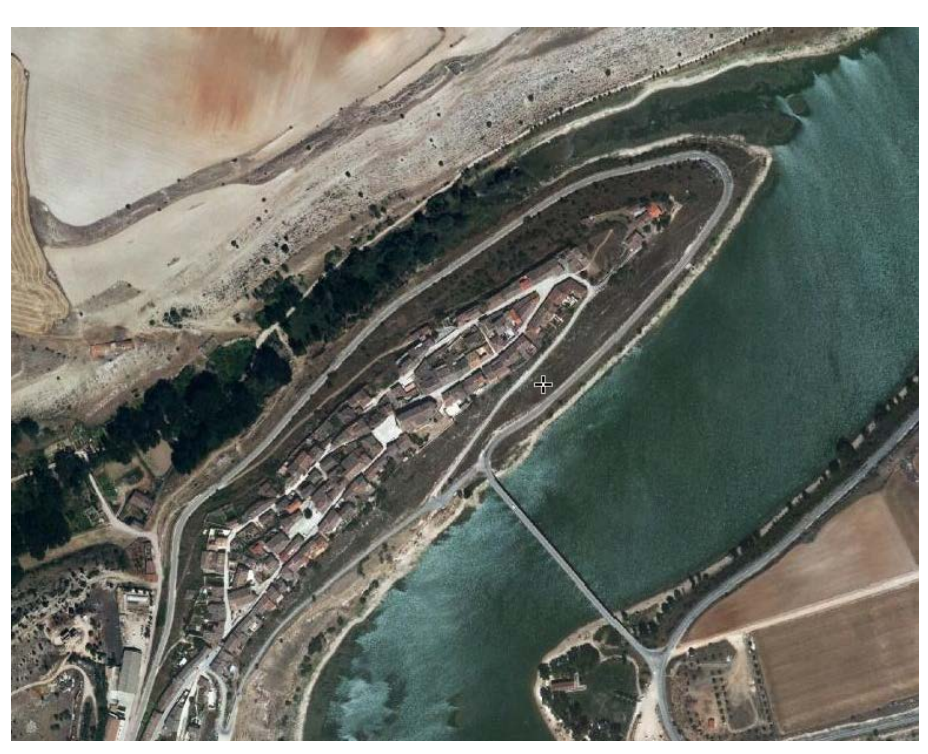

Fotografía aérea del núcleo. Fuente: PNOA IGN.

\begin{tabular}{|l|l|l|l|}
\hline \multicolumn{2}{|l|}{ DATOS TIPOLÓGICOS } \\
\begin{tabular}{|l|l|l|} 
Restos \\
identificados
\end{tabular} & Elementos identificados & $\begin{array}{l}\text { Estado de } \\
\text { conservación }\end{array}$ & Localización UTM \\
\hline Castillo & Resto de torre de planta cuadrada & Ruina & E 458360, N 4579537, Huso 30T \\
\hline Muralla & $\begin{array}{l}\text { Puerta de la Villa } \\
\text { Puerta del Barrio } \\
\text { Torre del Oeste } \\
\text { Lienzos intermitentes } \\
\text { Lienzos restaurados y reconstruidos. }\end{array}$ & $\begin{array}{l}\text { Conjunto restaurado, } \\
\text { reparado. }\end{array}$ & $\begin{array}{l}\text { E 456331, N 4592776, Huso 30T } \\
\text { E 456536, N 4593086, Huso 30T } \\
\text { E 456294, N 4592784, Huso 30T }\end{array}$ \\
\hline $\begin{array}{l}\text { Iglesia } \\
\text { fortificada }\end{array}$ & Iglesia de Santa María del Castillo. & Buen estado. & E 456536, N 4593013, Huso 30T \\
\hline
\end{tabular}

\section{DATOS CONSTRUCTIVOS}

\begin{tabular}{|c|c|c|c|c|c|c|c|c|c|}
\hline Materiales & \multicolumn{3}{|l|}{ Ladrillo } & \multicolumn{4}{|c|}{ Piedra } & \multicolumn{2}{|c|}{ Tierra } \\
\hline $\begin{array}{l}\text { Sistemas } \\
\text { constructivos }\end{array}$ & Aparejo & Otros & $\begin{array}{l}\text { Tapia } \\
\text { mixta }\end{array}$ & $\begin{array}{c}\text { Mampostería } \\
\text { de piedra }\end{array}$ & Sillarejo & Sillería & $\begin{array}{c}\text { Tapia de } \\
\text { mampostería }\end{array}$ & $\begin{array}{c}\text { Tapia } \\
\text { de cal y } \\
\text { canto }\end{array}$ & $\begin{array}{c}\text { Tapia de } \\
\text { tierra }\end{array}$ \\
\hline Muralla & & & & $x$ & $x$ & $x$ & $x$ & & \\
\hline Castillo & & & & & & & $x$ & & \\
\hline Iglesia & $x$ & $\mathrm{X}^{*}$ & $x$ & & $x$ & $x$ & & & \\
\hline
\end{tabular}

* verdugada doble 


\section{FICHA DE TOMA DE DATOS}

\section{Ubicación:}

Maderuelo, Segovia.

Diócesis de Segovia.

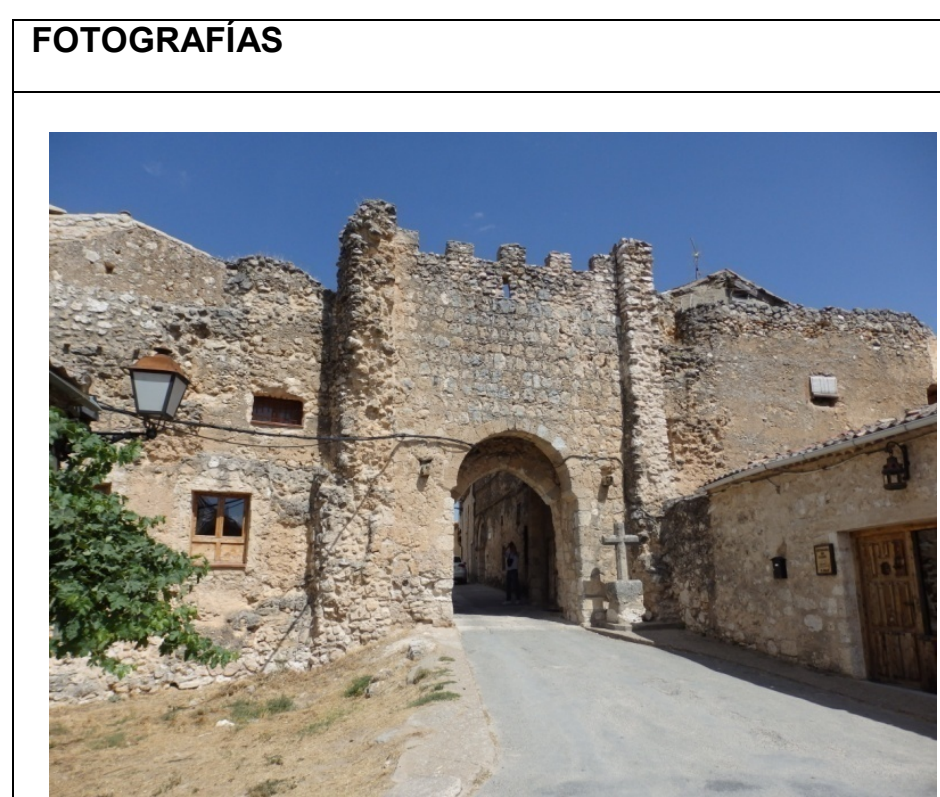

Puerta de la Villa

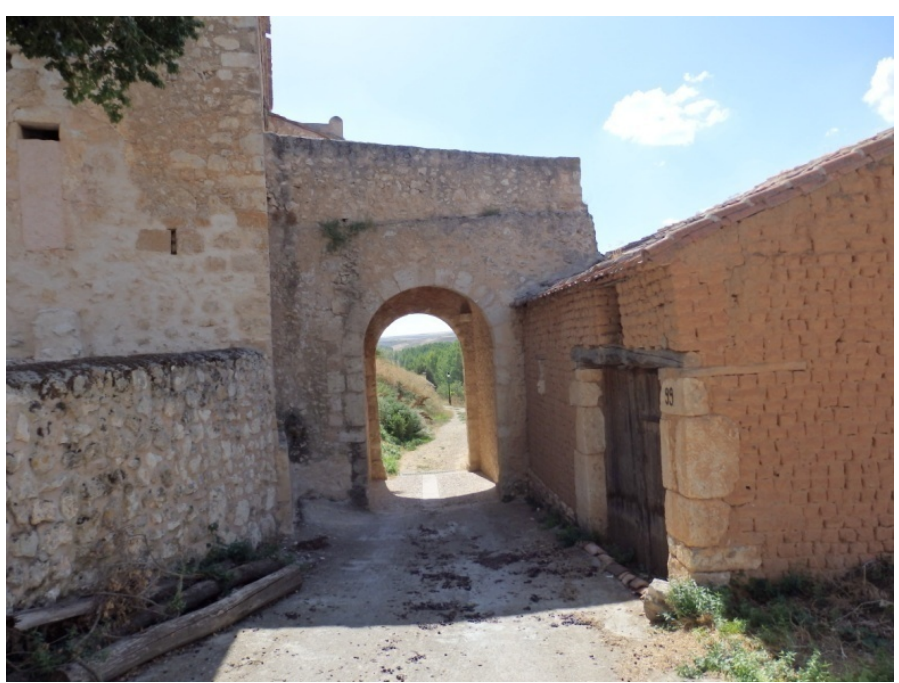

Puerta del Barrio desde el interior.

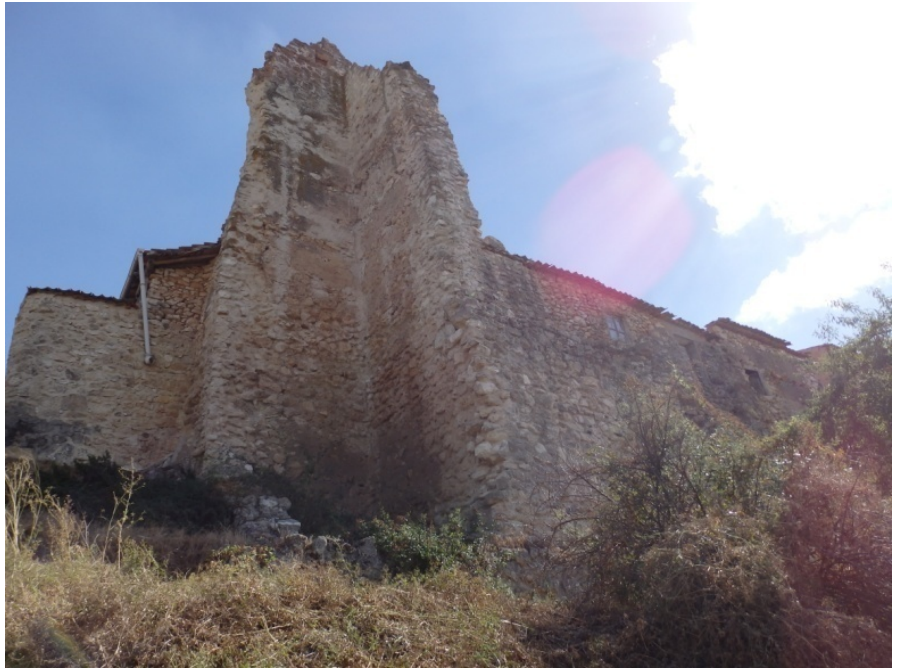

Restos de la torre del castillo

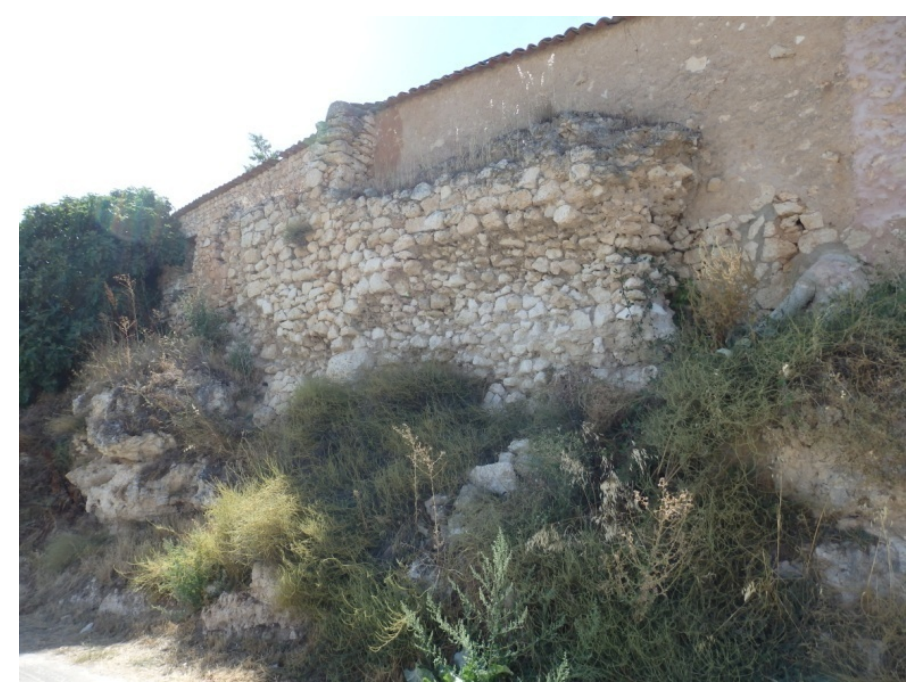

Restos en zona noroeste.

\section{ESTUDIOS REALIZADOS}

Martínez Díez, Gonzalo. 1983. Las Comunidades de Villa y Tierra en la Extremadura Castellana. Madrid: Editora Nacional.

Citado en

páginas:

326,352 ,

307-310.

Cueto Ruiz, Ronald. 1995. La comunidad de villa y tierra de Maderuelo. Segovia: Academia de Historia y

Arte de San Quirce.

Rivas, Juan L. de las. 2009. Atlas de Conjuntos Históricos de Castilla y León. Valladolid: Junta de Castilla y León.

Citado en

páginas: 477-479

\section{CASOS DE LA INVESTIGACIÓN}

Incluido como caso de estudio de la investigación Razones
Existencia de muralla, con restos suficientes para análisis constructivo. 
Ubicación: Montejo de la Vega de la Serrezuela, Segovia.

Diócesis de Segovia.

Fecha: 10/12/2014

Redactora: Alicia Sainz Esteban

\section{DATOS GENERALES}

Figura de $\quad$ Delimitación de Suelo Urbano (DSU). Fecha de aprobación: 03/04/1998; fecha de publicación: planeamiento general 29/04/1998.

Arquitectura defensiva Restos convento e iglesia de San Martín de Casuar. Fecha de declaración: 20/08/1997.

BIC

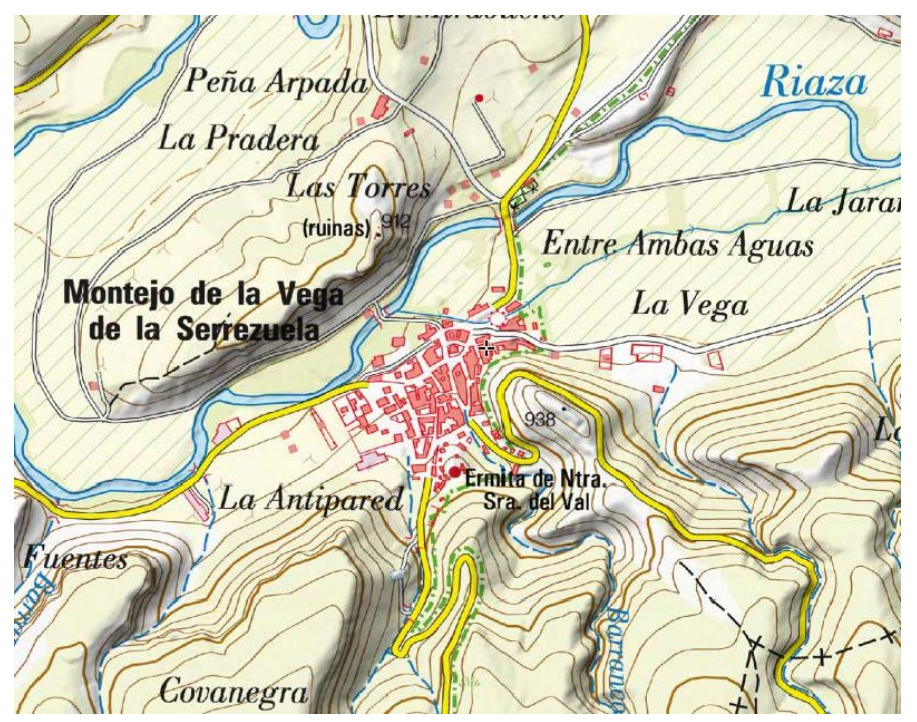

Fragmento de Mapa Topográfico Nacional. 1:25.000 Fuente: Visor Iberpix IGN.

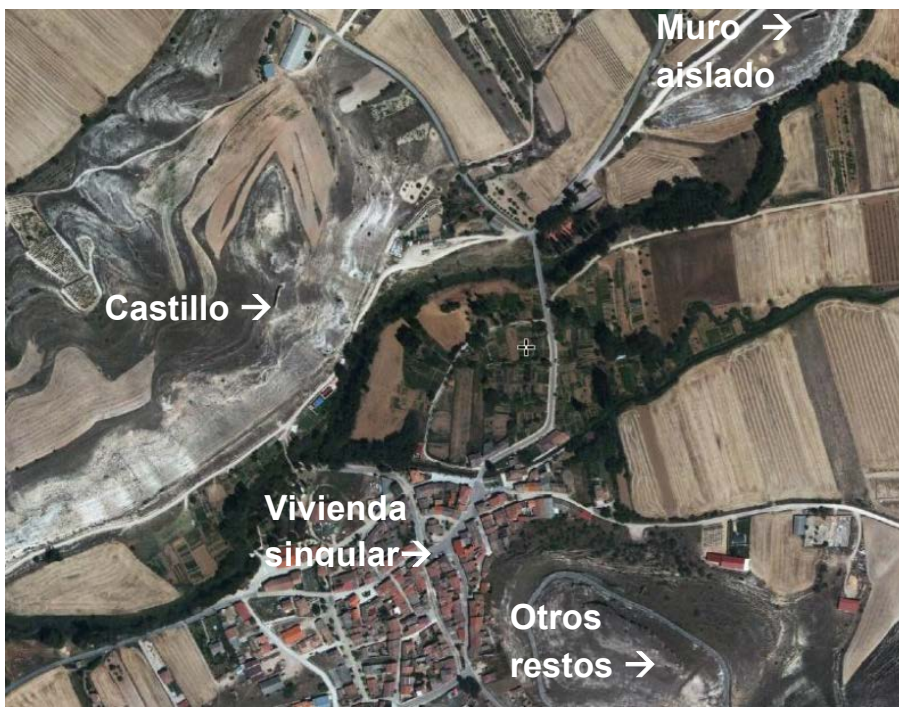

Fotografía aérea del núcleo. Fuente: PNOA IGN.

\section{DATOS TIPOLÓGICOS}

\begin{tabular}{|l|l|l|l|}
\hline $\begin{array}{l}\text { Restos } \\
\text { identificados }\end{array}$ & Elementos identificados & Localización UTM & $\begin{array}{l}\text { Estado de } \\
\text { conservación }\end{array}$ \\
\hline Castillo & Resto de torre & N 445411, E 4600154, Huso 30T & Ruina \\
\cline { 2 - 4 } & Resto de muro & N 445406, E 4600140, Huso 30T & Ruina \\
\hline $\begin{array}{l}\text { Vivienda } \\
\text { singular }\end{array}$ & $\begin{array}{l}\text { Vivienda singular, de muros sin apenas } \\
\text { ventanas, aspecto defensivo. }\end{array}$ & N 445576, E 4599856, Huso 30T & Buen estado \\
\hline Casa fuerte & $\begin{array}{l}\text { Muro aislado que puede ser integrante de } \\
\text { casa fuerte, según el inventario de } \\
\text { arquitectura defensiva de la Asociación } \\
\text { Amigos de los Castillos }\end{array}$ & N 445978, E 3600439, Huso 30T & Ruina \\
\hline Otros restos & Resto de muro & E 445810, N 4599761, Huso 30T & Ruina \\
\hline
\end{tabular}

\section{DATOS CONSTRUCTIVOS}

\begin{tabular}{|c|c|c|c|c|c|c|c|c|c|}
\hline Materiales & Ladrillo & & \multicolumn{6}{|c|}{ Piedra } & \multirow{2}{*}{$\begin{array}{c}\text { Tierra } \\
\begin{array}{c}\text { Tapia } \\
\text { de } \\
\text { tierra }\end{array}\end{array}$} \\
\hline $\begin{array}{l}\text { Sistemas } \\
\text { constructivos }\end{array}$ & Aparejo & Otros & $\begin{array}{l}\text { Tapia } \\
\text { mixta }\end{array}$ & $\begin{array}{l}\text { Mampostería } \\
\text { de piedra }\end{array}$ & Sillarejo & Sillería & $\begin{array}{c}\text { Tapia de } \\
\text { mampostería }\end{array}$ & $\begin{array}{c}\text { Tapia de } \\
\text { cal y } \\
\text { canto }\end{array}$ & \\
\hline Castillo & & & & & & & $x$ & & \\
\hline Casa fuerte & & & & & & & $x$ & & \\
\hline $\begin{array}{l}\text { Vivienda } \\
\text { singular }\end{array}$ & & & & $x$ & & $x$ & & & \\
\hline Otros restos & & & & & & & $x$ & & \\
\hline
\end{tabular}


Ubicación: Montejo de la Vega de la Serrezuela, Segovia.

Diócesis de Segovia.

Fecha: 10/12/2014

Redactora: Alicia Sainz Esteban

07

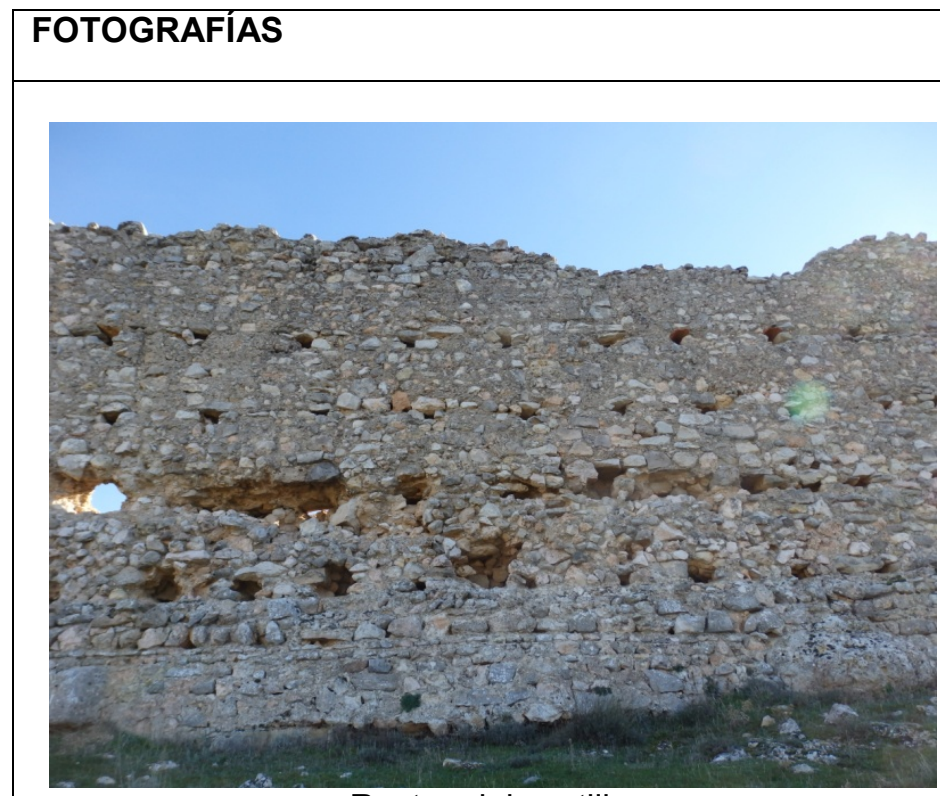

Restos del castillo

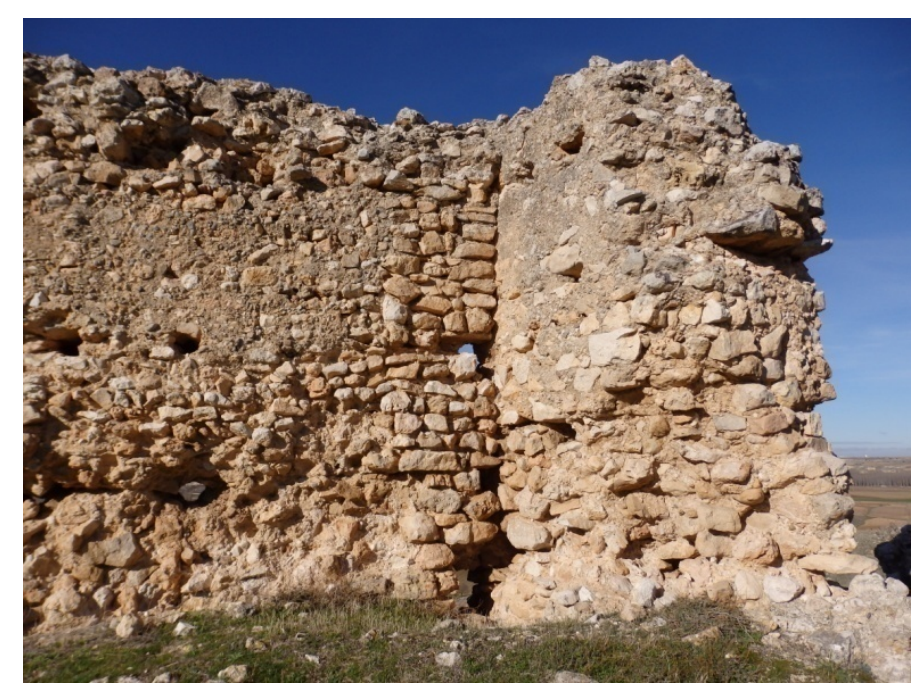

Parte de la torre arruinada

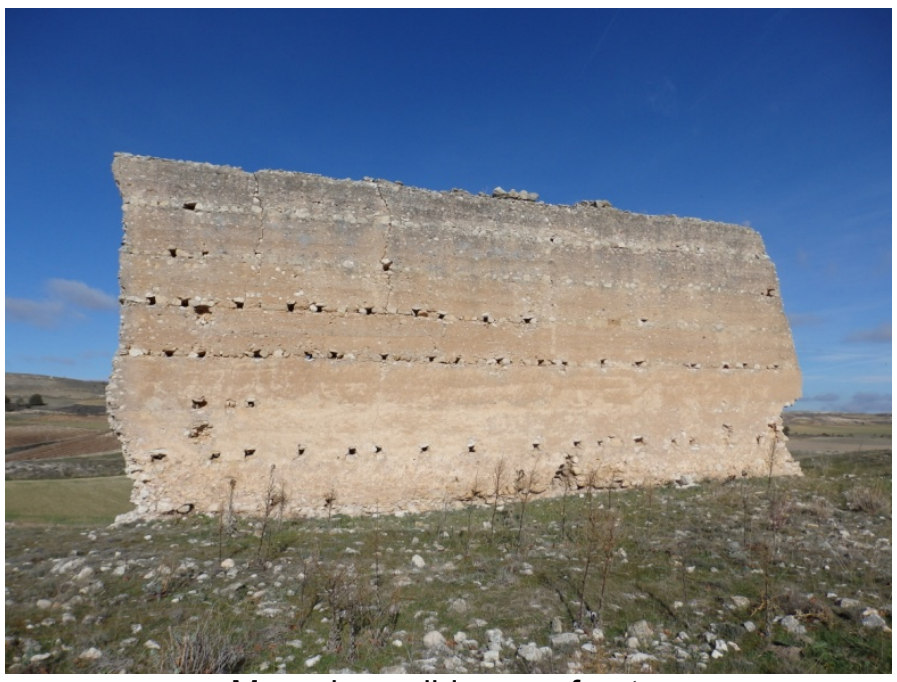

Muro de posible casa fuerte

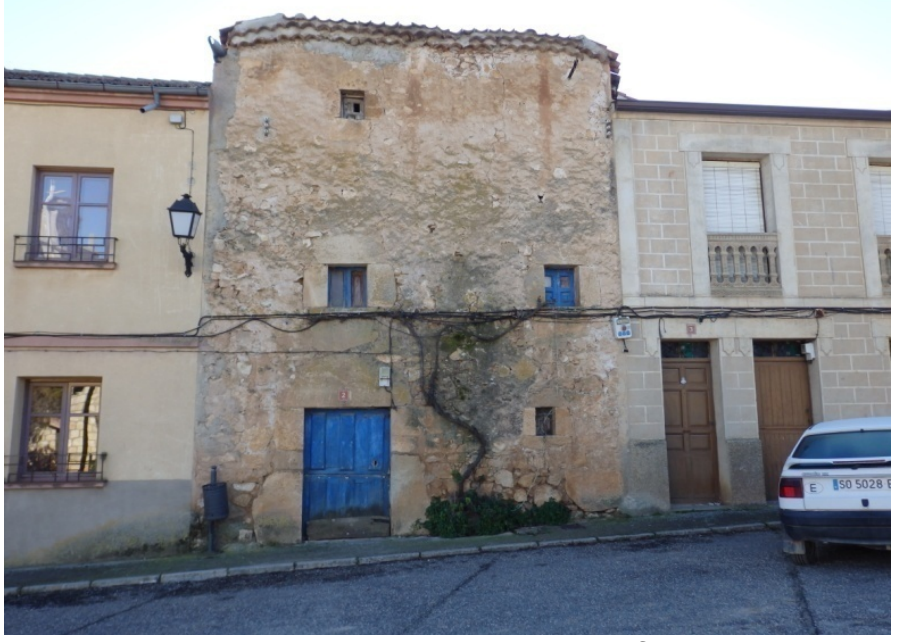

Vivienda singular de aspecto defensivo

\section{ESTUDIOS REALIZADOS}

Martínez Díez, Gonzalo. 1983. Las Comunidades de Villa y Tierra en la Extremadura Castellana. Madrid: Editora Nacional.

\section{CASOS DE LA INVESTIGACIÓN}

Incluido como caso de estudio de la investigación

NO

Razones

Existencia de restos defensivos, pero ausencia de muralla. 
FICHA RESUMEN

Ubicación: Pedraza, Segovia

Diócesis de Segovia.

Fecha: 07/05/2014

Redactora: Alicia Sainz Esteban

\section{DATOS GENERALES}

\begin{tabular}{|c|c|}
\hline $\begin{array}{l}\text { Planeamiento } \\
\text { general }\end{array}$ & $\begin{array}{l}\text { - Normas Urbanísticas Municipales (NUM). Fecha de aprobación: 30/07/2013; Fecha de publicación: } \\
\text { 21/11/2013. } \\
\text { - Plan Especial del Casco Histórico (PECH). Fecha de aprobación: 30/06/2013; Fecha de publicación: } \\
\text { 21/11/2013. }\end{array}$ \\
\hline $\begin{array}{l}\text { Arquitectura } \\
\text { defensiva } \mathrm{BIC}\end{array}$ & $\begin{array}{l}\text { - La Villa (Categoría: Conjunto Histórico). Fecha de declaración: 12/4/1951. } \\
\text { - Castillo de Zuloaga (Categoría: Castillos). Fecha de declaración: 05/05/1949. }\end{array}$ \\
\hline
\end{tabular}

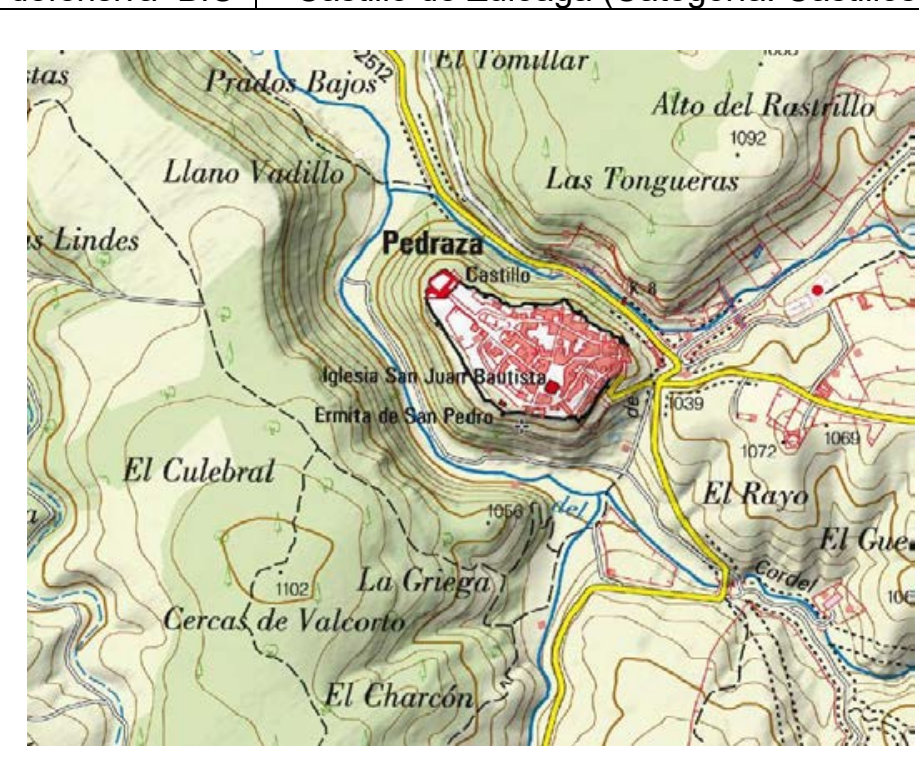

Fragmento de Mapa Topográfico Nacional. 1:25.000. Fuente:

Visor Iberpix IGN.

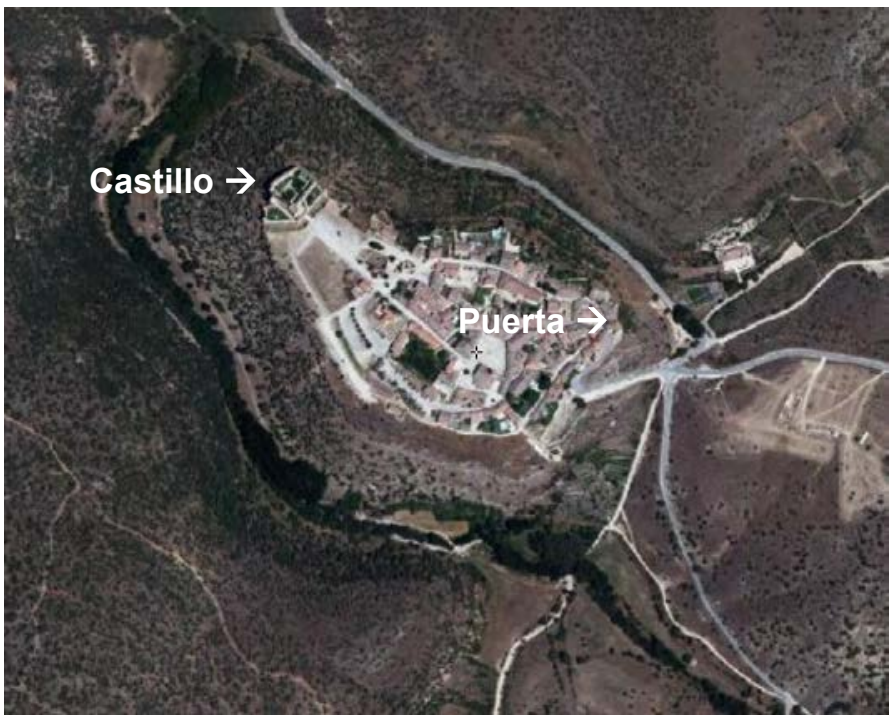

Fotografía aérea del núcleo. Fuente: Visor Iberpix IGN.

\section{DATOS TIPOLÓGICOS}

\begin{tabular}{|l|l|l|l|}
\hline $\begin{array}{l}\text { Tipo de } \\
\text { arquitectura }\end{array}$ & Elementos identificados & Localización UTM & Estado de conservación \\
\hline Castillo & Torre del homenaje, muralla del castillo. & E 431634, N 4553803, Huso 30T & Restaurado. \\
\hline Muralla & $\begin{array}{l}\text { Puerta de la Villa } \\
\text { Torre de Hontanillas }\end{array}$ & $\begin{array}{l}\text { E 432066, N 4553625, Huso 30T } \\
\text { E 431973, N 4553477, Huso 30T }\end{array}$ & $\begin{array}{l}\text { Restaurado. } \\
\text { Restaurado-reconstruido. }\end{array}$ \\
\hline
\end{tabular}

\section{DATOS CONSTRUCTIVOS}

\begin{tabular}{|c|c|c|c|c|c|c|c|c|c|}
\hline Materiales & Ladrillo & & & & & & Tierra & & \\
\hline $\begin{array}{l}\text { Sistemas } \\
\text { constructivos }\end{array}$ & Aparejo & Otros & $\begin{array}{l}\text { Tapia } \\
\text { mixta }\end{array}$ & $\begin{array}{c}\text { Mampostería } \\
\text { de piedra }\end{array}$ & Sillarejo & Sillería & $\begin{array}{c}\text { Tapia de } \\
\text { mampostería }\end{array}$ & $\begin{array}{c}\text { Tapia de } \\
\text { cal y } \\
\text { canto }\end{array}$ & $\begin{array}{c}\text { Tapia } \\
\text { de } \\
\text { tierra }\end{array}$ \\
\hline Muralla & & & & $x$ & $x$ & & $x$ & & \\
\hline Castillo & & & & & & $x$ & & & \\
\hline
\end{tabular}




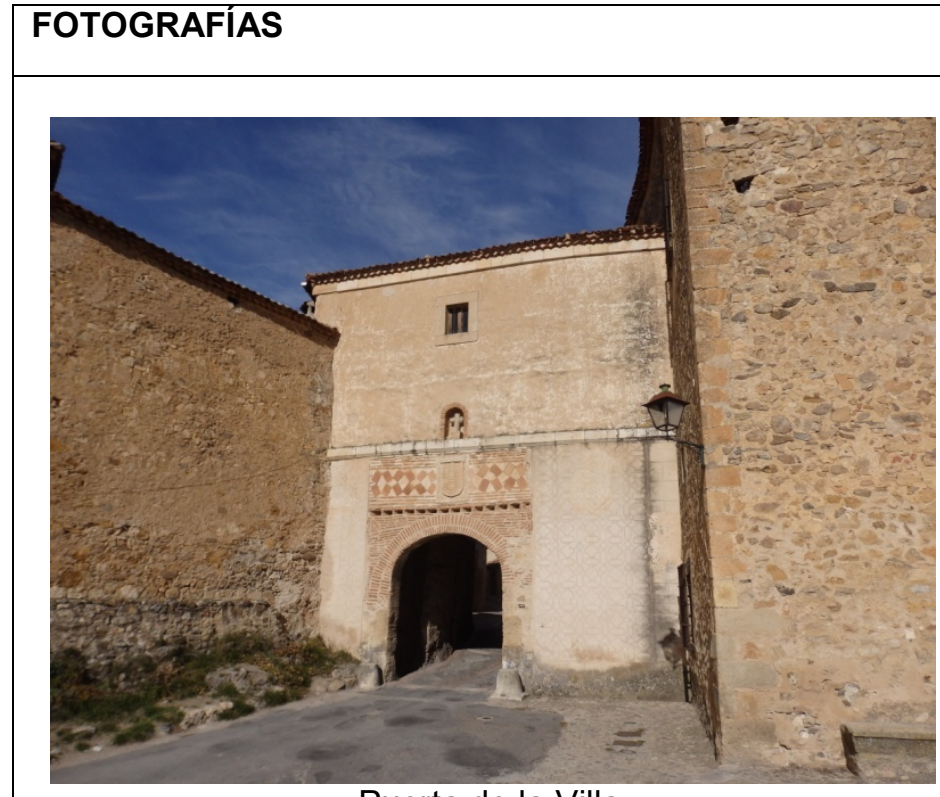

Puerta de la Villa

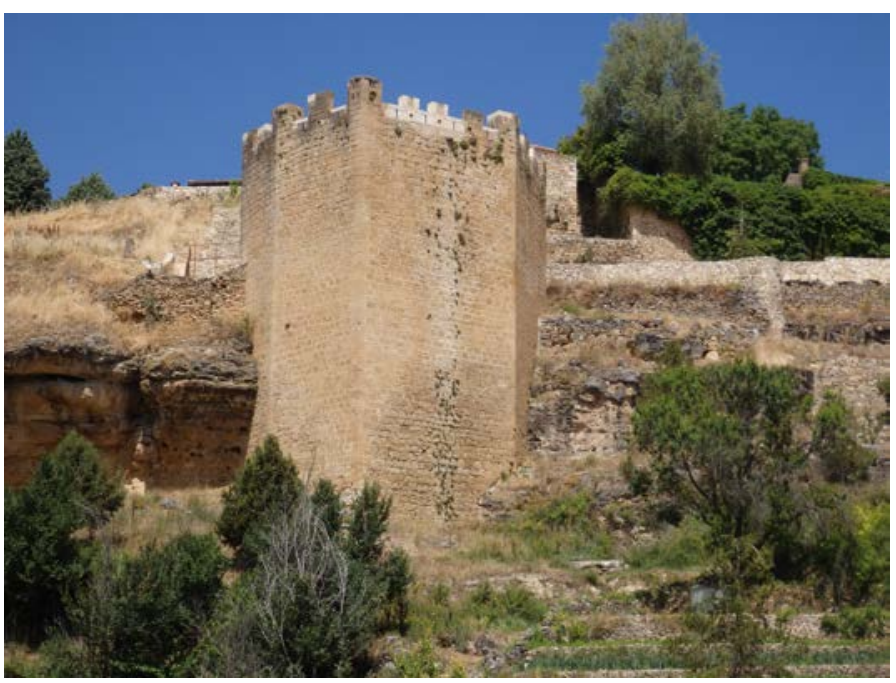

Torre de Hontanillas

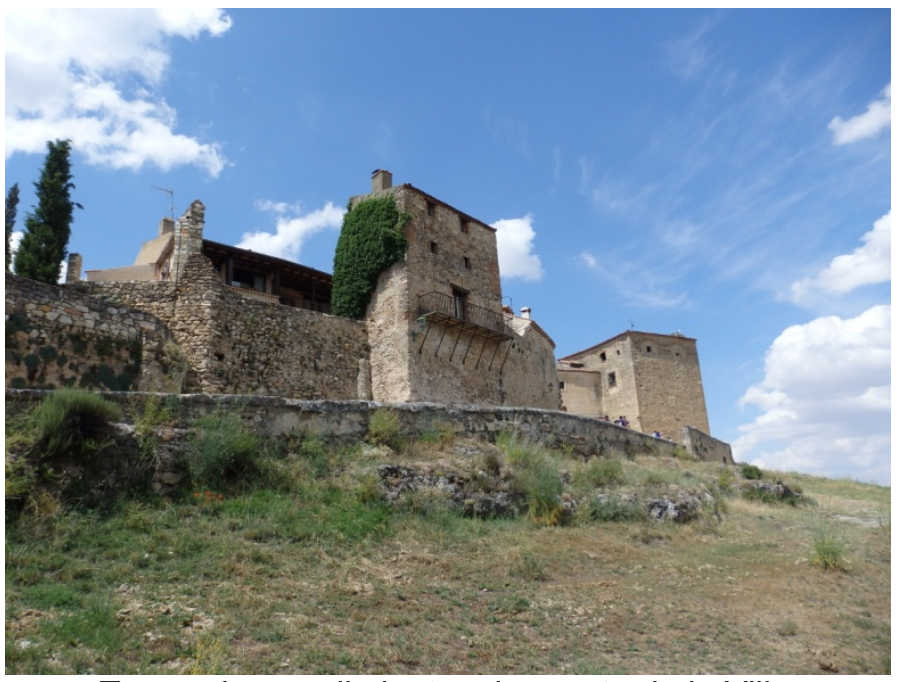

Tramo de muralla junto a la puerta de la Villa

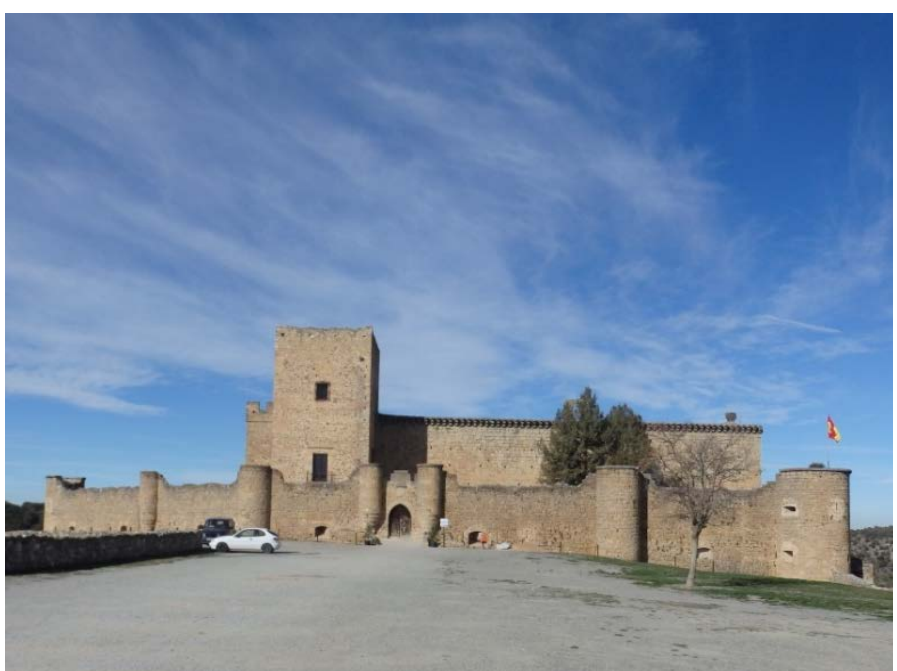

Castillo de Zuloaga

\section{ESTUDIOS REALIZADOS}

Martínez Díez, Gonzalo. 1983. Las Comunidades de Villa y Tierra en la Extremadura Castellana. Madrid: Editora Nacional.

Citado en páginas: 359-384.

Rivas, Juan L. de las. 2009. Atlas de Conjuntos Históricos de Castilla y León. Valladolid: Junta de Castilla y León.

Citado en páginas: $481-484$

\section{CASOS DE LA INVESTIGACIÓN}

Incluido como caso de estudio de la investigación SI Razones Existencia de muralla, con restos para análisis constructivo. 


\section{FICHA RESUMEN}

\section{Ubicación:}

Sepúlveda, Segovia.

Diócesis de Segovia.

Fecha: 5/7/2014

Redactora: Alicia Sainz Esteban

\section{DATOS GENERALES}

\begin{tabular}{l|l}
\hline $\begin{array}{l}\text { Planeamiento } \\
\text { general }\end{array}$ & $\begin{array}{l}\text { Normas Subsidiarias Municipales (NNSS). Fecha de aprobación: 16/12/1997; fecha de publicación: } \\
12 / 01 / 1998 .\end{array}$ \\
& $\begin{array}{l}\text { Modificación Puntual 1/2004 de las NNSS. Cambios de delimitación de Conjunto Histórico, zona } \\
\text { protección muralla, zona camino del cementerio, Catálogo y Protección Arqueológica. Fecha de } \\
\text { aprobación: 12/04/2016; fecha de publicación: 26/04/2016. } \\
\text { Plan Especial de Conjunto Histórico. Fecha de aprobación: 12/04/2016; fecha de publicación: } \\
\text { 29/04/2016. }\end{array}$ \\
\hline $\begin{array}{l}\text { Arquitectura } \\
\text { defensiva BIC }\end{array}$ & $\begin{array}{l}\text { Castillo. Fecha declaración: 05/05/1949. } \\
\text { La villa. Fecha declaración: 7/03/1951. }\end{array}$
\end{tabular}

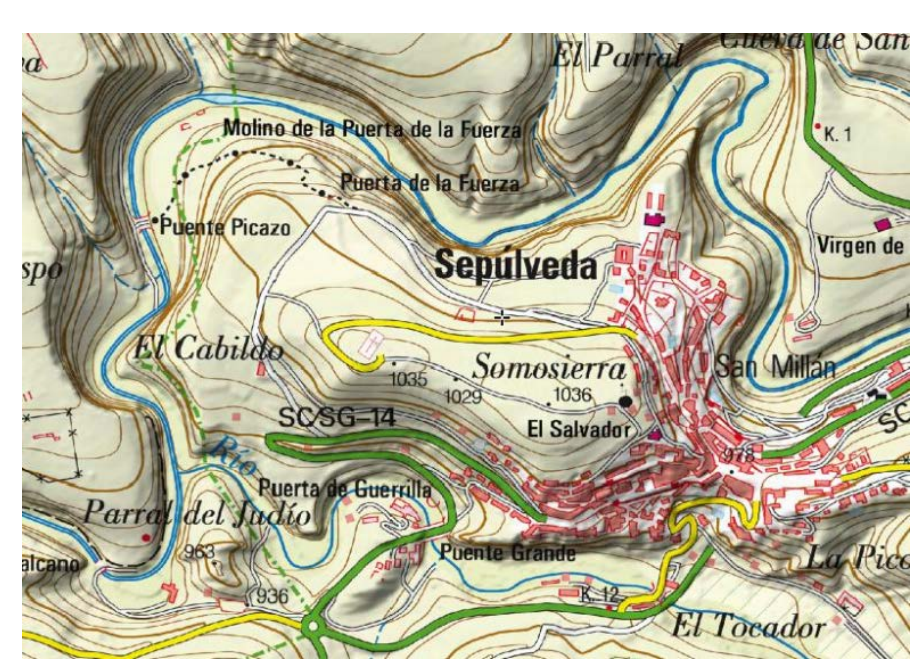

Fragmento de Mapa Topográfico Nacional. 1:25.000. Fuente: Visor Iberpix IGN.

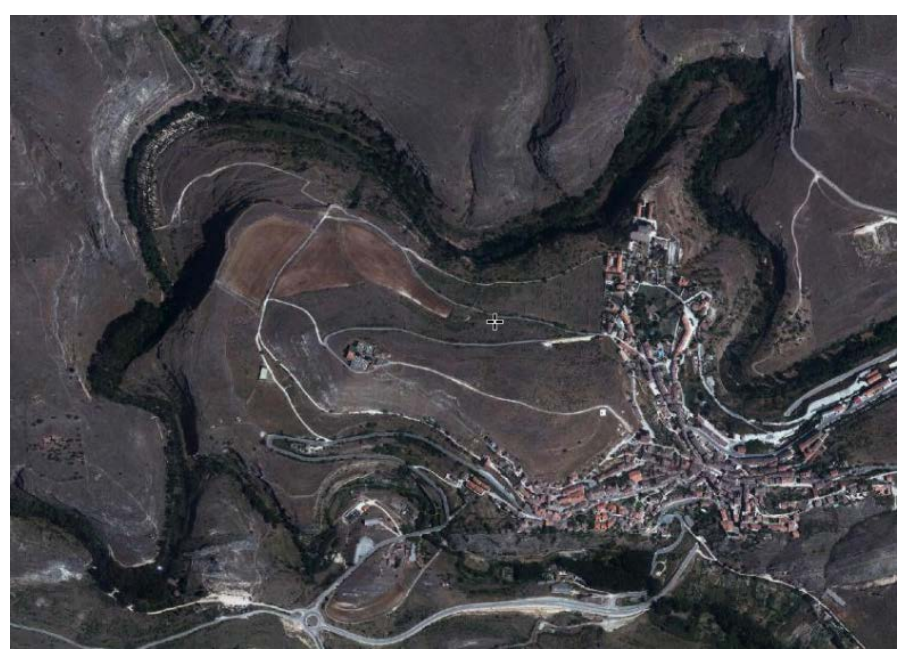

Fotografía aérea del núcleo. Fuente: Visor Iberpix IGN.

\section{DATOS TIPOLÓGICOS}

\begin{tabular}{|l|l|l|l|}
\hline $\begin{array}{l}\text { Tipo de } \\
\text { arquitectura }\end{array}$ & Elementos identificados & Localización UTM & Estado de conservación \\
\hline Castillo & Castillo de Fernán González & N 437296, E 4572032, Huso 30T & $\begin{array}{l}\text { Restos reutilizados, con } \\
\text { construcciones adosadas. }\end{array}$ \\
\hline Muralla & Parte urbana & $\begin{array}{l}\text { Zona urbana restaurada y } \\
\text { reconstruida de forma } \\
\text { general. }\end{array}$ \\
& $\begin{array}{l}\text { Puerta del Río } \\
\text { Puerta del Azogue } \\
\text { El Postiguillo }\end{array}$ & $\begin{array}{l}\text { N 437171, E 4571900, Huso 30T } \\
\text { N 437251, E 4572119, Huso 30T } \\
\text { N 437295, E 4572227, Huso 30T }\end{array}$ & \\
\cline { 2 - 5 } & $\begin{array}{l}\text { Parte en campo. Conserva 3 puertas y un postigo. } \\
\text { Grandes longitudes de lienzo conservado en zona }\end{array}$ & & \\
& $\begin{array}{l}\text { este. } \\
\text { Puerta de la Fuerza } \\
\text { Puerta de Duruelo }\end{array}$ & N 436472, E 4572613, Huso 30T \\
& N 436709, E 4571933, Huso 30T & $\begin{array}{l}\text { Reparada. } \\
\text { Reparada, pérdida de } \\
\text { elementos. } \\
\text { Ruina consolidada. } \\
\text { Ruina consolidada. } \\
\text { Puerta de Castro } \\
\text { Postigo del Vado } \\
\text { Lienzo Duruelo-este }\end{array}$ & $\begin{array}{l}\text { N 436316, E 4572006, Huso 30T estado. } \\
\text { N 437371, E 4572522, Huso 30T }\end{array}$ \\
\hline
\end{tabular}

\section{DATOS CONSTRUCTIVOS}

\begin{tabular}{|c|c|c|c|c|c|c|c|c|c|}
\hline Materiales & \multicolumn{3}{|l|}{ Ladrillo } & \multicolumn{3}{|c|}{ Piedra } & \multicolumn{3}{|l|}{ Tierra } \\
\hline $\begin{array}{l}\text { Sistemas } \\
\text { constructivos }\end{array}$ & Aparejo & Otros & $\begin{array}{l}\text { Tapia } \\
\text { mixta }\end{array}$ & $\begin{array}{c}\text { Mampostería } \\
\text { de piedra }\end{array}$ & Sillarejo & Sillería & $\begin{array}{c}\text { Tapia de } \\
\text { mampostería }\end{array}$ & $\begin{array}{c}\text { Tapia de } \\
\text { cal y } \\
\text { canto }\end{array}$ & $\begin{array}{c}\text { Tapia } \\
\text { de } \\
\text { tierra }\end{array}$ \\
\hline Muralla & & & & $x$ & & $x$ & $x$ & & \\
\hline Castillo & & & & $x$ & & & $x$ & & \\
\hline
\end{tabular}




\section{FICHA RESUMEN}

\section{Ubicación:}

Sepúlveda, Segovia.

Diócesis de Segovia.

Fecha: 5/7/2014

Redactora: Alicia Sainz Esteban

09

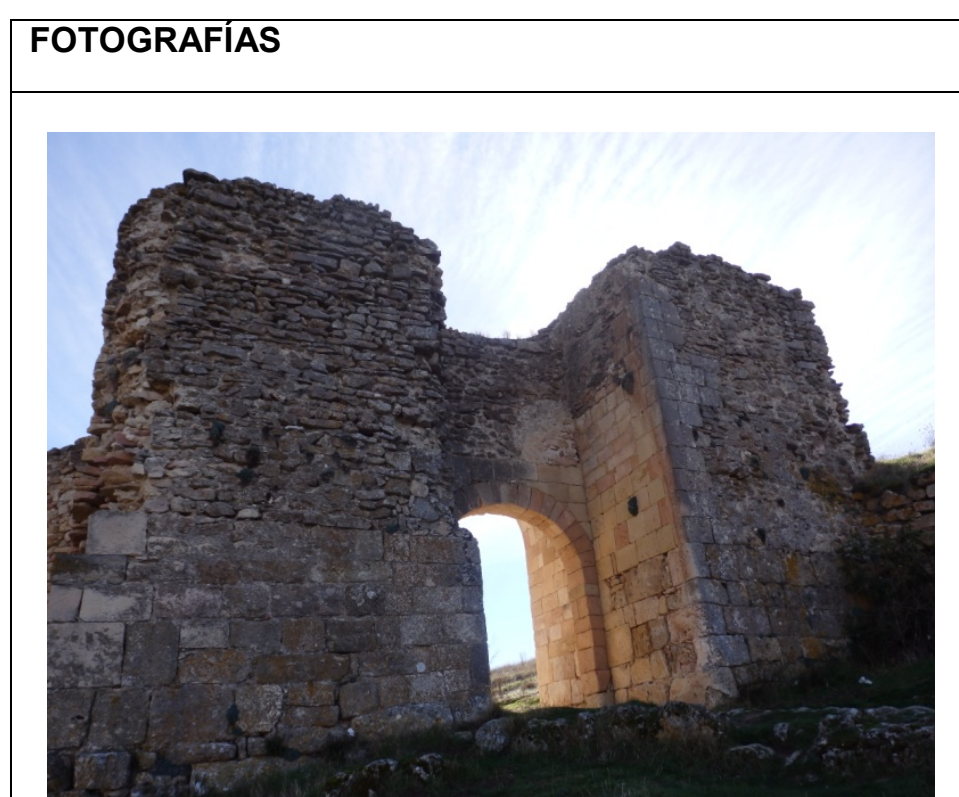

Puerta de la Fuerza

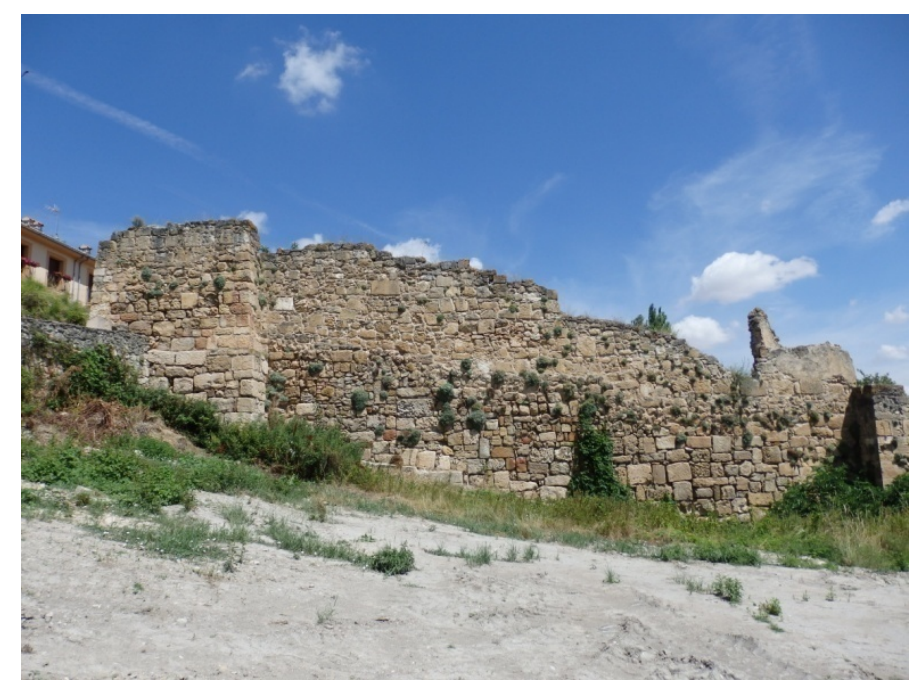

Tramo en zona del Postiguillo
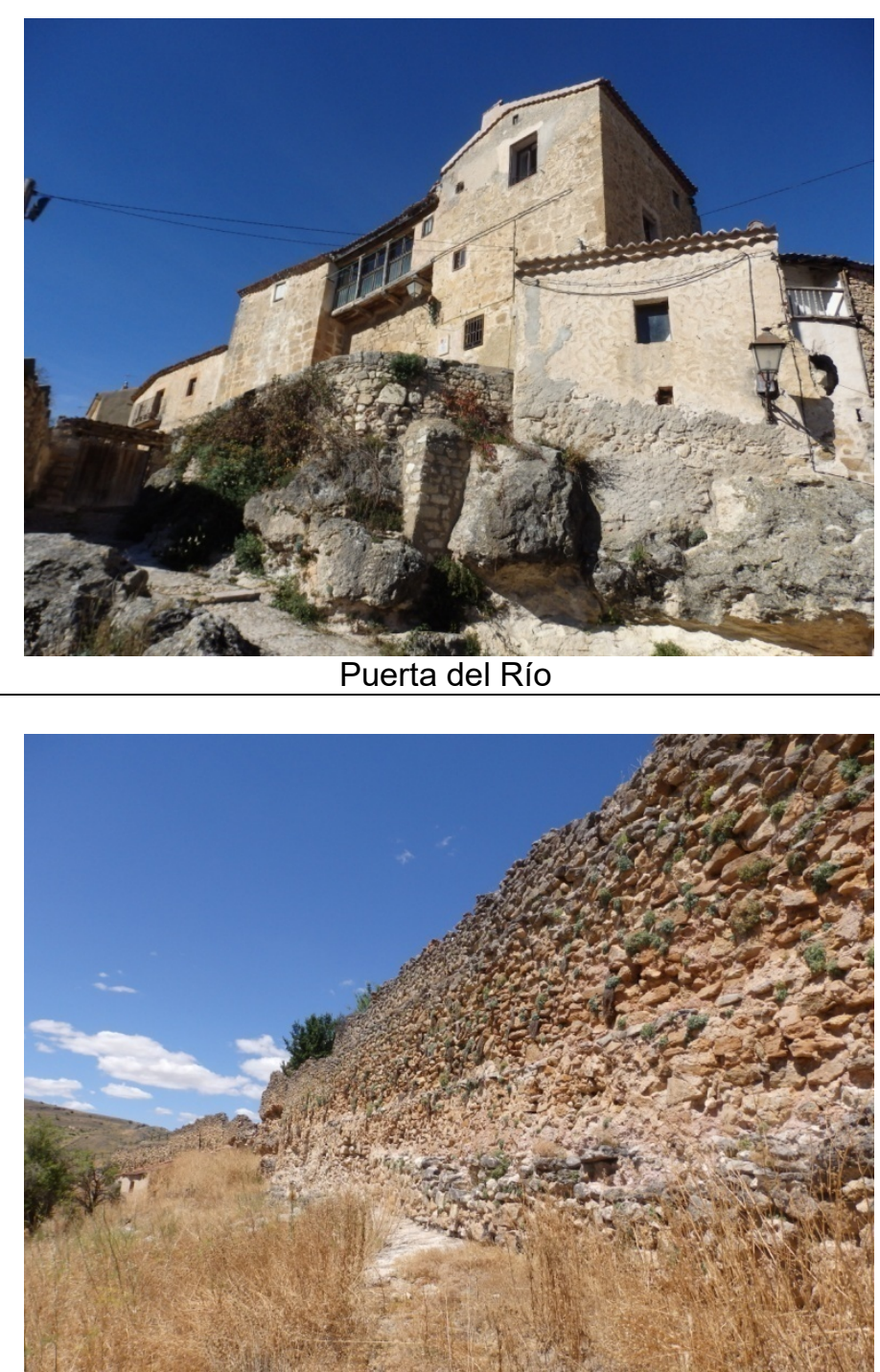

Tramo en zona al este de la puerta de Duruelo

\section{ESTUDIOS REALIZADOS}

Martínez Díez, Gonzalo. 1983. Las Comunidades de Villa y Tierra en la Extremadura Castellana. Madrid: Editora Nacional.

Citado en páginas:

Martín Aymerich, M. Dolores; Teresa Tardío y Alonso Zamora. 1990. Las murallas de Sepúlveda

(Segovia). Un ensayo de aproximación con métodos arqueológicos a un ejemplo de pervivencia arquitectónica. Segovia: Diputación de Segovia.

Rivas, Juan L. de las. 2009. Atlas de Conjuntos Históricos de Castilla y León. Valladolid: Junta de Castilla y León.

Citado en páginas: 493-495

\section{CASOS DE LA INVESTIGACIÓN}

Incluido como caso de estudio de la investigación Razones
Existencia de muralla, con restos suficientes para análisis constructivo. 


\section{DATOS GENERALES}

\begin{tabular}{l|l}
\hline $\begin{array}{l}\text { Planeamiento } \\
\text { general }\end{array}$ & $\begin{array}{l}\text { Revisión del Plan General de Ordenación Urbana. Fecha } \\
\text { publicación: 03/01/2008. }\end{array}$ \\
\hline Arquitectura & Alcázar de la ciudad. Fecha de declaración: 04/06/1931. \\
defensiva & $\begin{array}{l}\text { Torre de Hércules. Fecha de declaración: 04/06/1931. } \\
\text { BIC }\end{array}$ \\
$\begin{array}{l}\text { Puerta de San Andrés. Fecha de declaración: 04/06/1931. } \\
\text { Casa de las Cadenas. Fecha de declaración: 14/01/1983. }\end{array}$
\end{tabular}
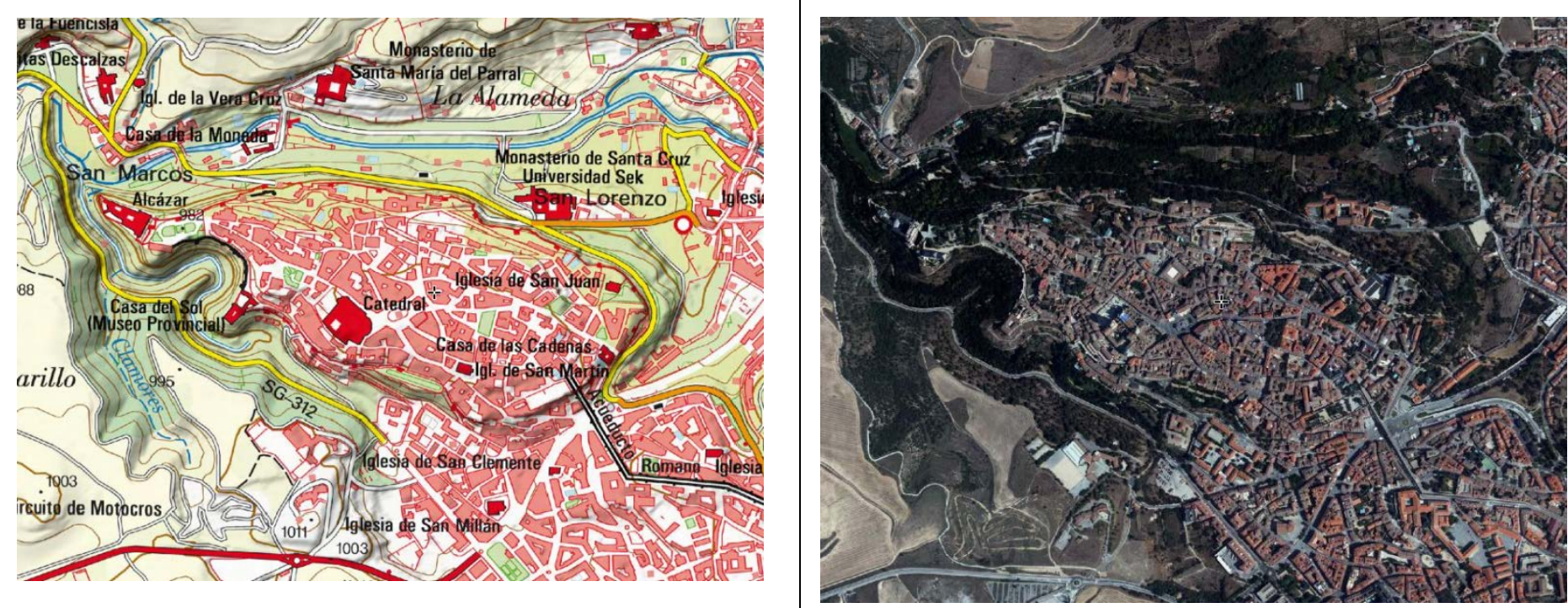

Fragmento de Mapa Topográfico Nacional. 1:25.000. Fuente: Visor lberpix IGN.

\section{ESTUDIOS REALIZADOS}

Martínez Díez, Gonzalo. 1983. Las Comunidades de Villa y Tierra en la Extremadura Castellana. Madrid: Editora Nacional.

Escobar González, Ana. 2014. "Carácter defensivo de las casas torre en la ciudad de Segovia" en Historia, arquitectura y construcción fortificada. Ensayos sobre investigaciones recientes, editado por Ignacio J. Gil Crespo, 181-208. Madrid: Instituto Juan de Herrera.

Herrero García, Estefanía. 2014. "Sistema defensivo de la ciudad de Segovia. Técnicas constructivas y cambio de uso" en Historia, arquitectura y construcción fortificada. Ensayos sobre investigaciones recientes, editado por Ignacio J. Gil, 105-144. Madrid: Instituto Juan de Herrera.

y Miguel A. Martín Blanco. 2015. "Hipótesis del sistema constructivo de la muralla de la repoblación cristiana de la ciudad de Segovia" en Actas del Noveno Congreso Nacional y Primer Congreso Internacional Hispanoamericano de Historia de la Construcción, vol. 2, editado por Santiago Huerta y Paula Fuentes, 801-810. Madrid: Instituto Juan de Herrera, ETS de Arquitectura de Madrid.

Martín Blanco, Miguel A. 2013. "Las torres de las murallas de Segovia". En Arte y Ciudad 3 (1): 679-696. http://dialnet.unirioja.es/descarga/articulo/4704621.pdf [Consultado el 18/10/2014]

2014a. "Discontinuidades y pervivencias en la muralla de Segovia" en Historia, arquitectura y construcción fortificada. Ensayos sobre investigaciones recientes, editado por Ignacio J. Gil, 145180. Madrid: Instituto Juan de Herrera.

Rivas, Juan L. de las. 2009. Atlas de Conjuntos Históricos de Castilla y León. Valladolid: Junta de Castilla y León. 
FICHA RESUMEN

Ubicación: Segovia, Segovia.

Diócesis de Segovia

Fecha: 30/12/2014

Redactora: Alicia Sainz Esteban

10

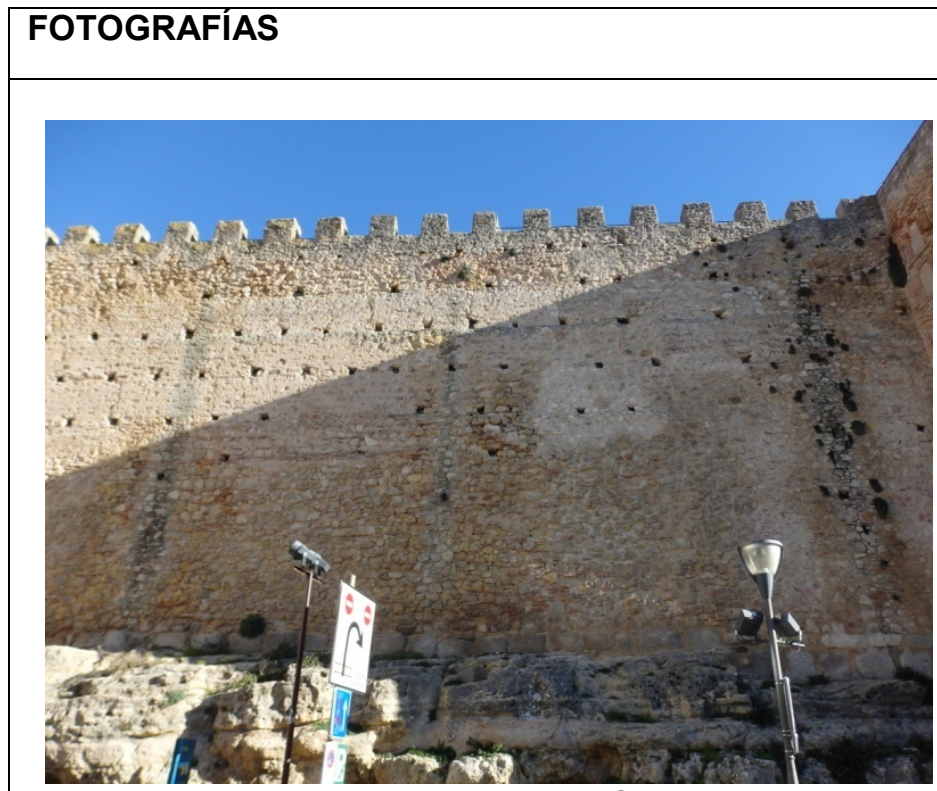

Muralla junto a la puerta de San Andrés

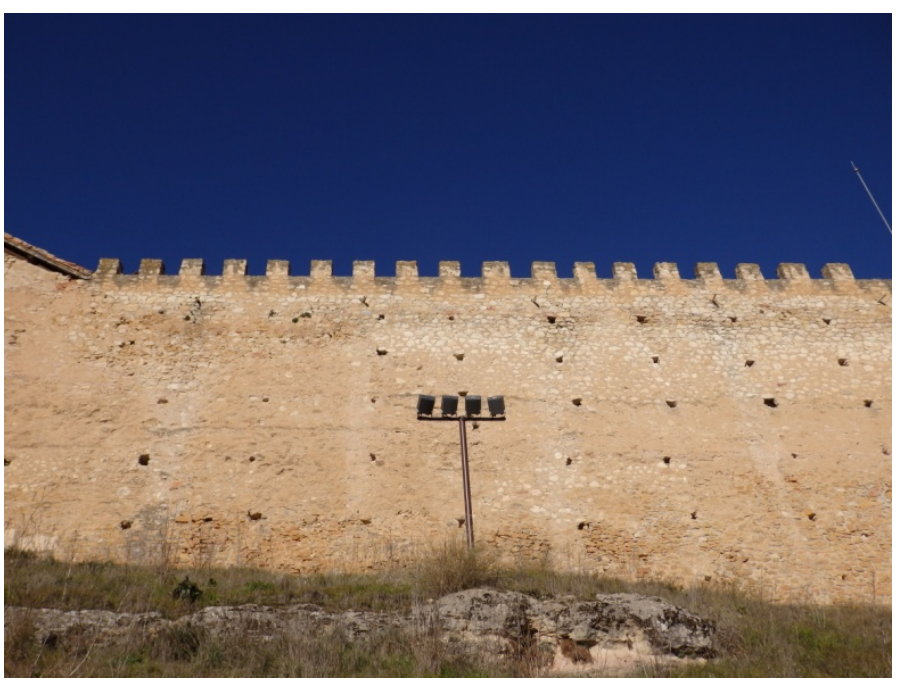

Tramo de muralla

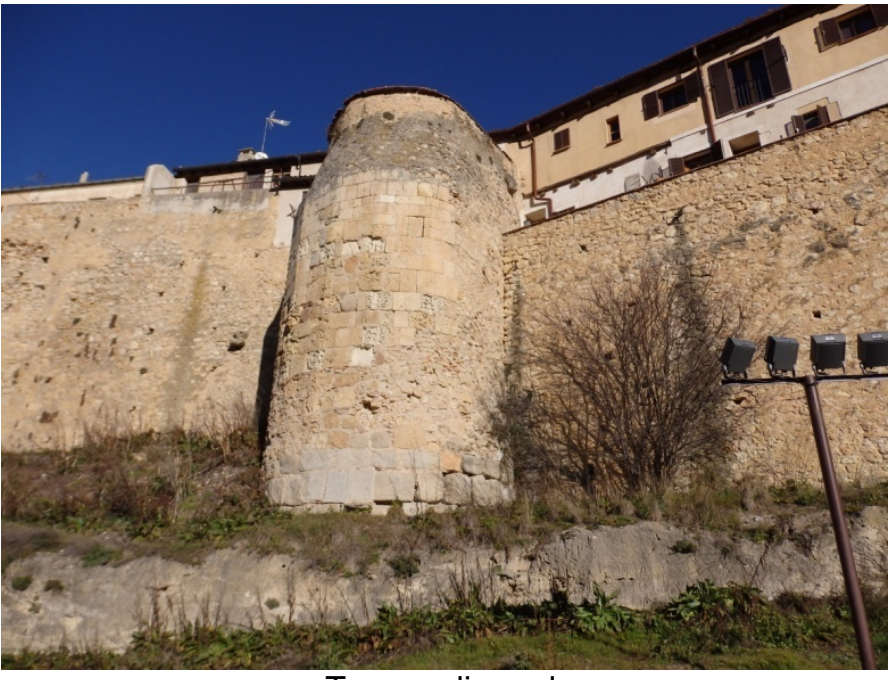

Torre poligonal

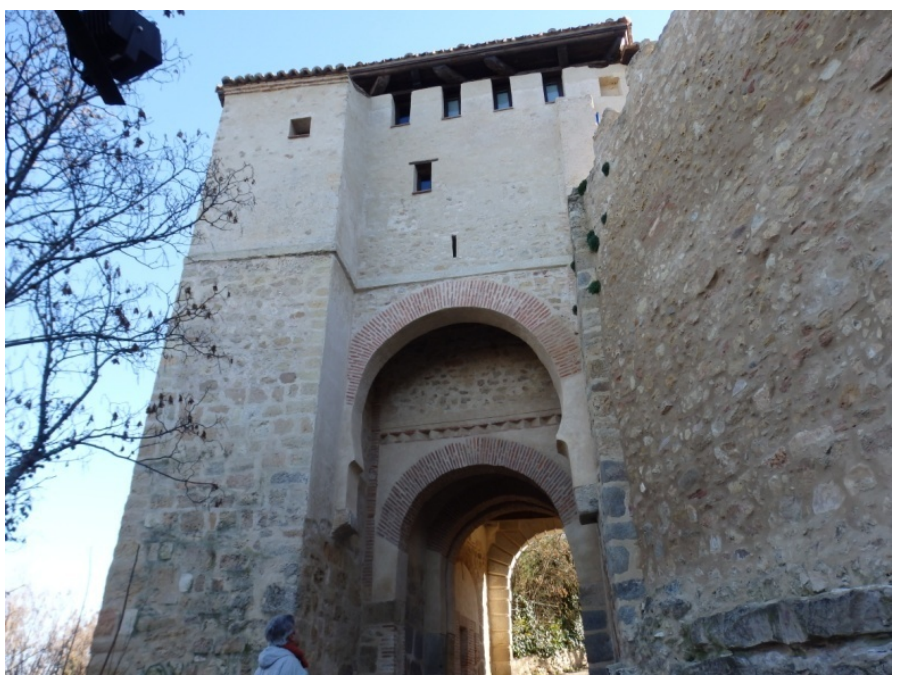

Puerta de Santiago

\section{CASOS DE LA INVESTIGACIÓN}

Incluido como caso de estudio de la investigación Razones
NO

Muralla en estudio por parte de otros investigadores.

Recinto complejo que requeriría de un estudio individual. 


\section{FICHA DE SELECCIÓN}

Ubicación: Turégano, Segovia.

Diócesis de Segovia.

Fecha: 14/8/2016

Redactora: Alicia Sainz Esteban

\section{DATOS GENERALES}

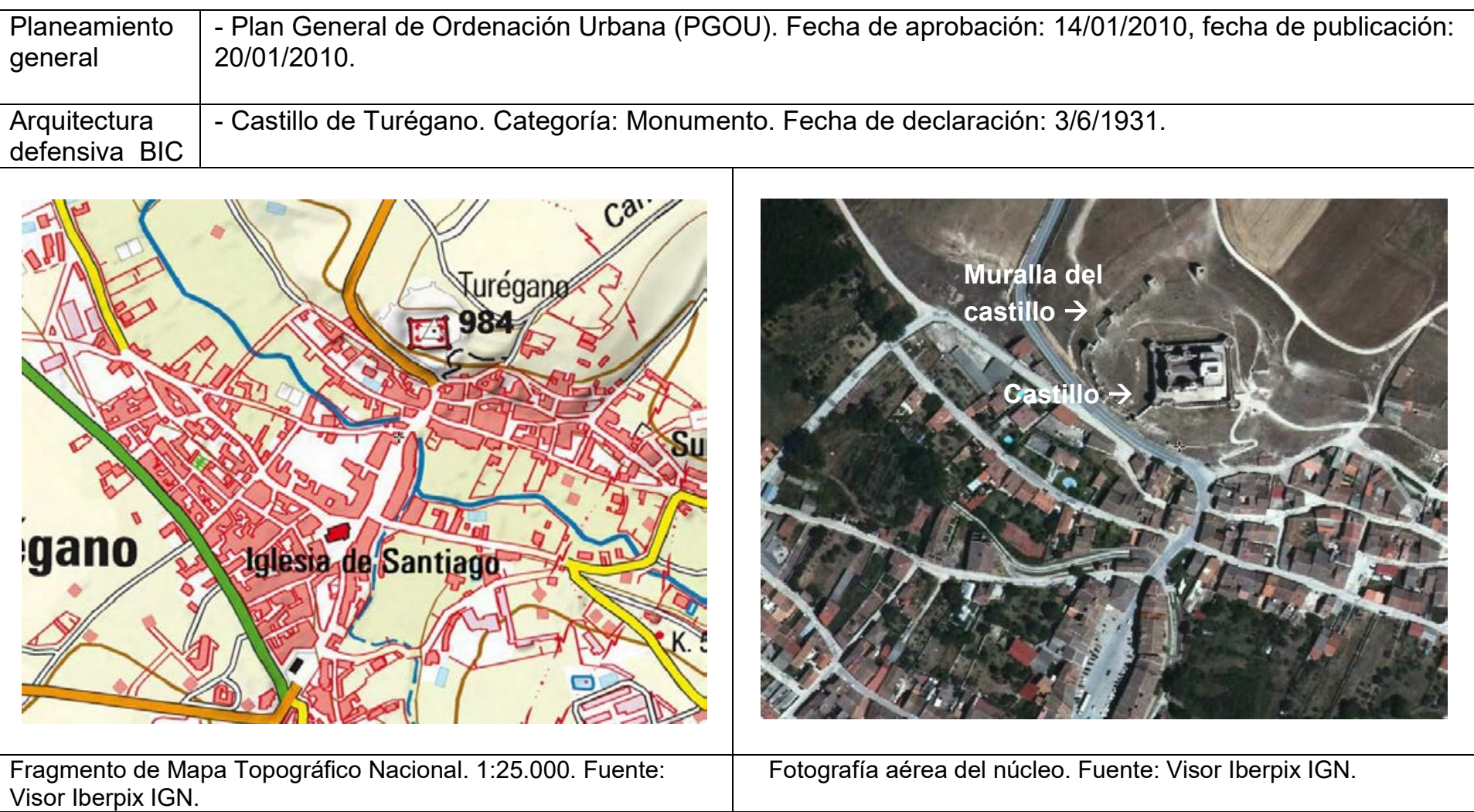

Visor Iberpix IGN.

\section{DATOS TIPOLÓGICOS}

\begin{tabular}{|l|l|l|l|}
\hline $\begin{array}{l}\text { Tipo de } \\
\text { arquitectura }\end{array}$ & Elementos identificados & Localización UTM & Estado de conservación \\
\hline Castillo & Castillo y su muralla. & E 415662, N 4556796, Huso 30 T & Restaurado, reparado. \\
\hline $\begin{array}{l}\text { Muralla en torno } \\
\text { al castillo }\end{array}$ & $\begin{array}{l}\text { Cinco torres cuadradas. } \\
\text { Una torre circular } \\
\text { Tramos de lienzo }\end{array}$ & $\begin{array}{l}\text { E 415662, N 4556867, Huso 30T } \\
\text { E 415615, N 4556763, Huso 30T } \\
\text { E 415586, N 4556788, Huso 30T }\end{array}$ & $\begin{array}{l}\text { Reparado } \\
\text { Ruina }\end{array}$ \\
\hline
\end{tabular}

\section{DATOS CONSTRUCTIVOS}

\begin{tabular}{|c|c|c|c|c|c|c|c|c|c|}
\hline $\begin{array}{l}\text { Materiales } \\
\text { constructivos }\end{array}$ & \multicolumn{3}{|l|}{ Ladrillo } & \multicolumn{3}{|c|}{ Piedra } & & & Tierra \\
\hline $\begin{array}{l}\text { Sistemas } \\
\text { constructivos }\end{array}$ & Aparejo & Otros & $\begin{array}{l}\text { Tapia } \\
\text { mixta }\end{array}$ & $\begin{array}{c}\text { Mampostería } \\
\text { de piedra }\end{array}$ & Sillarejo & Sillería & $\begin{array}{c}\text { Tapia de } \\
\text { mampostería }\end{array}$ & $\begin{array}{c}\text { Tapia de } \\
\text { cal y } \\
\text { canto }\end{array}$ & $\begin{array}{c}\text { Tapia } \\
\text { de } \\
\text { tierra }\end{array}$ \\
\hline Castillo & & & & & $x$ & $x$ & & & \\
\hline $\begin{array}{l}\text { Muralla en } \\
\text { torno al } \\
\text { castillo }\end{array}$ & & & & & $x$ & & $x$ & $x$ & $x$ \\
\hline
\end{tabular}




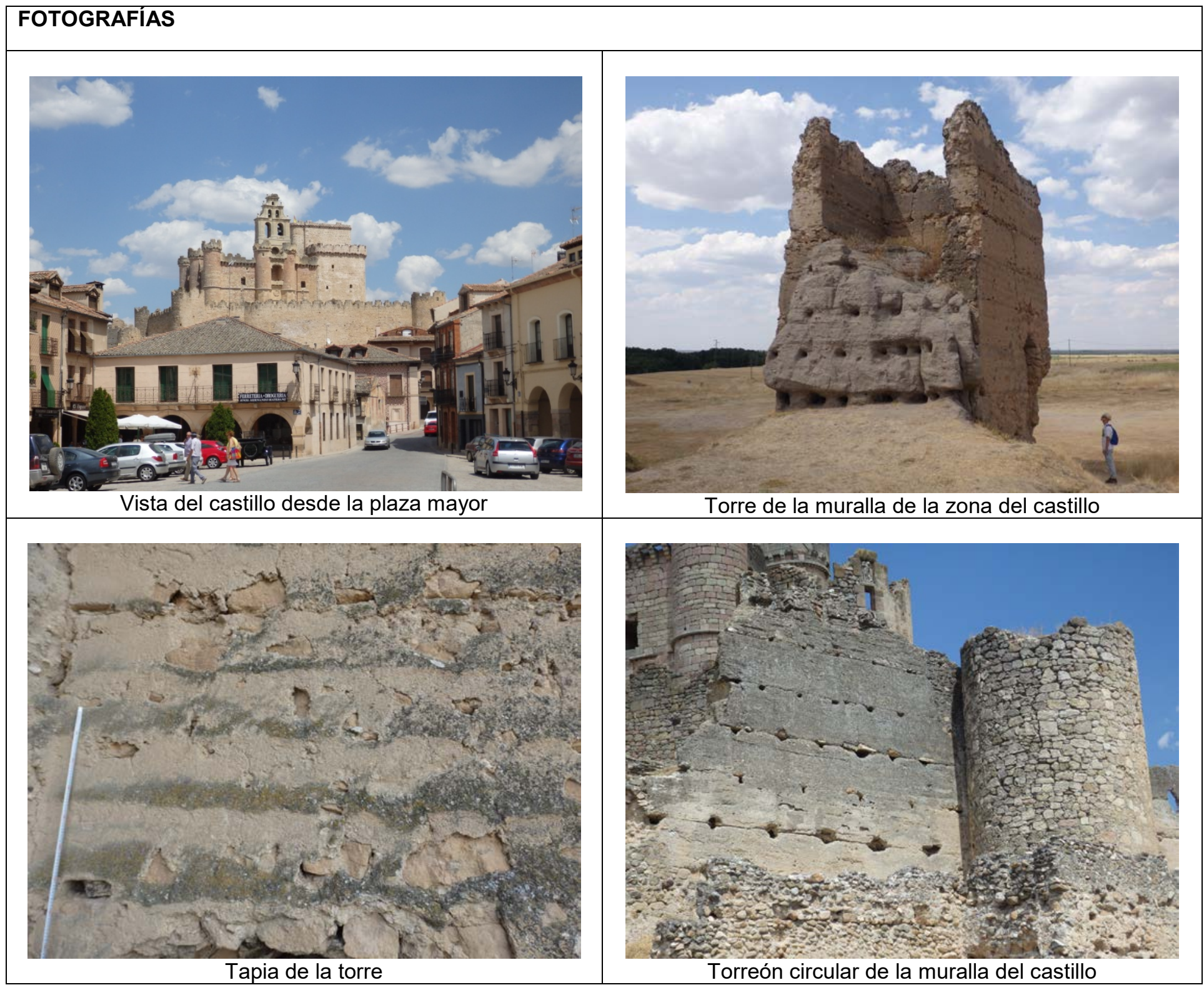

\section{CASOS DE LA INVESTIGACIÓN}

Incluido como caso de estudio de la investigación Razones de exclusión
$\mathrm{NO}$

Restos defensivos vinculados con el castillo. Villa no considerada como cabecera de comunidad de Villa y Tierra. 


\section{FICHA DE SELECCIÓN}

Ubicación: Ayllón, Segovia.

Colindante con Diócesis de Segovia.

Fecha: 3/9/2014

Redactora: Alicia Sainz Esteban

\section{DATOS GENERALES}

Planeamiento $\quad$ - Revisión de Normas Subsidiarias Municipales (NNSS). Fecha de aprobación: 16/06/2000, fecha de general publicación: 21/07/2000.

- Plan Especial de Casco Histórico (PECH). Fecha de aprobación: 27/12/1999, fecha de publicación: 24/01/2000.

Arquitectura $\quad$ - La villa (Categoría: Conjunto Histórico). Fecha de declaración: 12/06/1973.

defensiva BIC - Recinto fortificado de Ayllón (Categoría: ). Fecha de declaración: 05/05/1949.

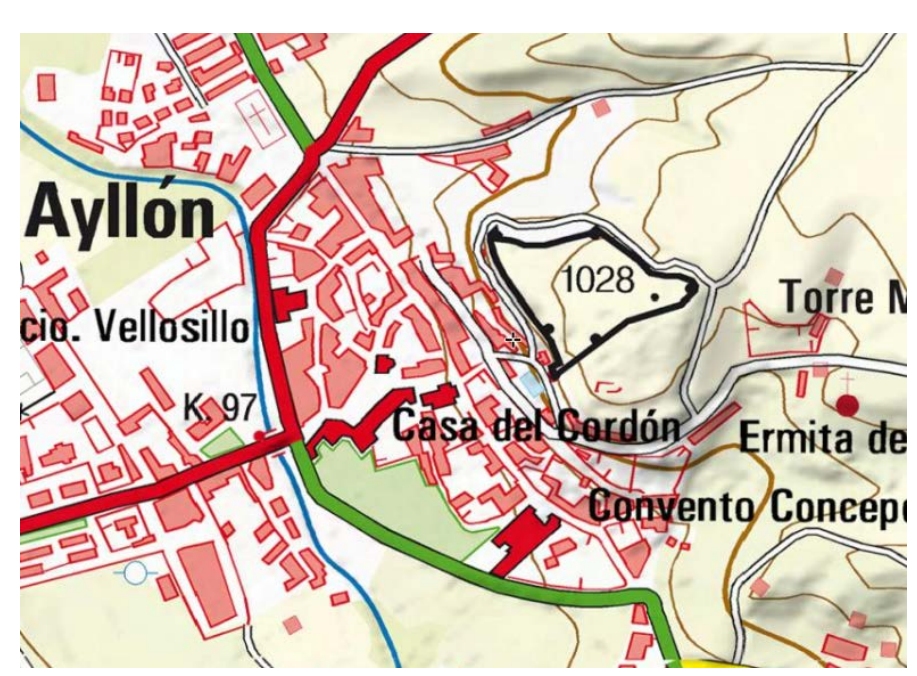

Fragmento de Mapa Topográfico Nacional. 1:25.000. Fuente: Visor Iberpix IGN.

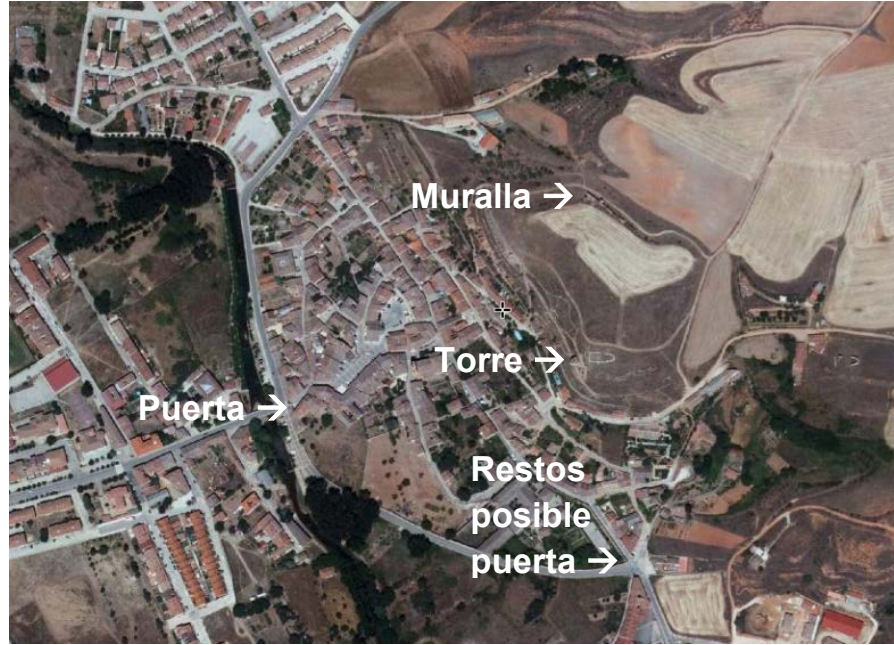

Fotografía aérea del núcleo. Fuente: Visor Iberpix IGN.

\section{DATOS TIPOLÓGICOS}

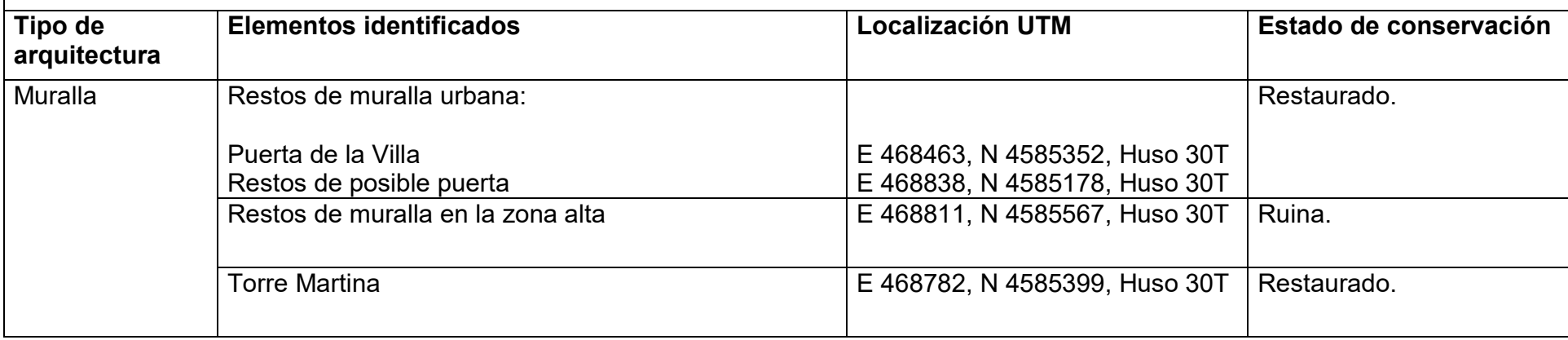

\section{DATOS CONSTRUCTIVOS}

\begin{tabular}{|c|c|c|c|c|c|c|c|c|c|}
\hline $\begin{array}{l}\text { Materiales } \\
\text { constructivos }\end{array}$ & Ladrillo & & & & Piedra & & & & Tierra \\
\hline $\begin{array}{l}\text { Sistemas } \\
\text { constructivos }\end{array}$ & Aparejo & Otros & $\begin{array}{l}\text { Tapia } \\
\text { mixta }\end{array}$ & $\begin{array}{c}\text { Mampostería } \\
\text { de piedra }\end{array}$ & Sillarejo & Sillería & $\begin{array}{c}\text { Tapia de } \\
\text { mampostería }\end{array}$ & $\begin{array}{c}\text { Tapia de } \\
\text { cal y } \\
\text { canto }\end{array}$ & $\begin{array}{l}\text { Tapia } \\
\text { de } \\
\text { tierra }\end{array}$ \\
\hline $\begin{array}{l}\text { Muralla zona } \\
\text { alta }\end{array}$ & & & & & & $x$ & $x$ & & $x$ \\
\hline
\end{tabular}




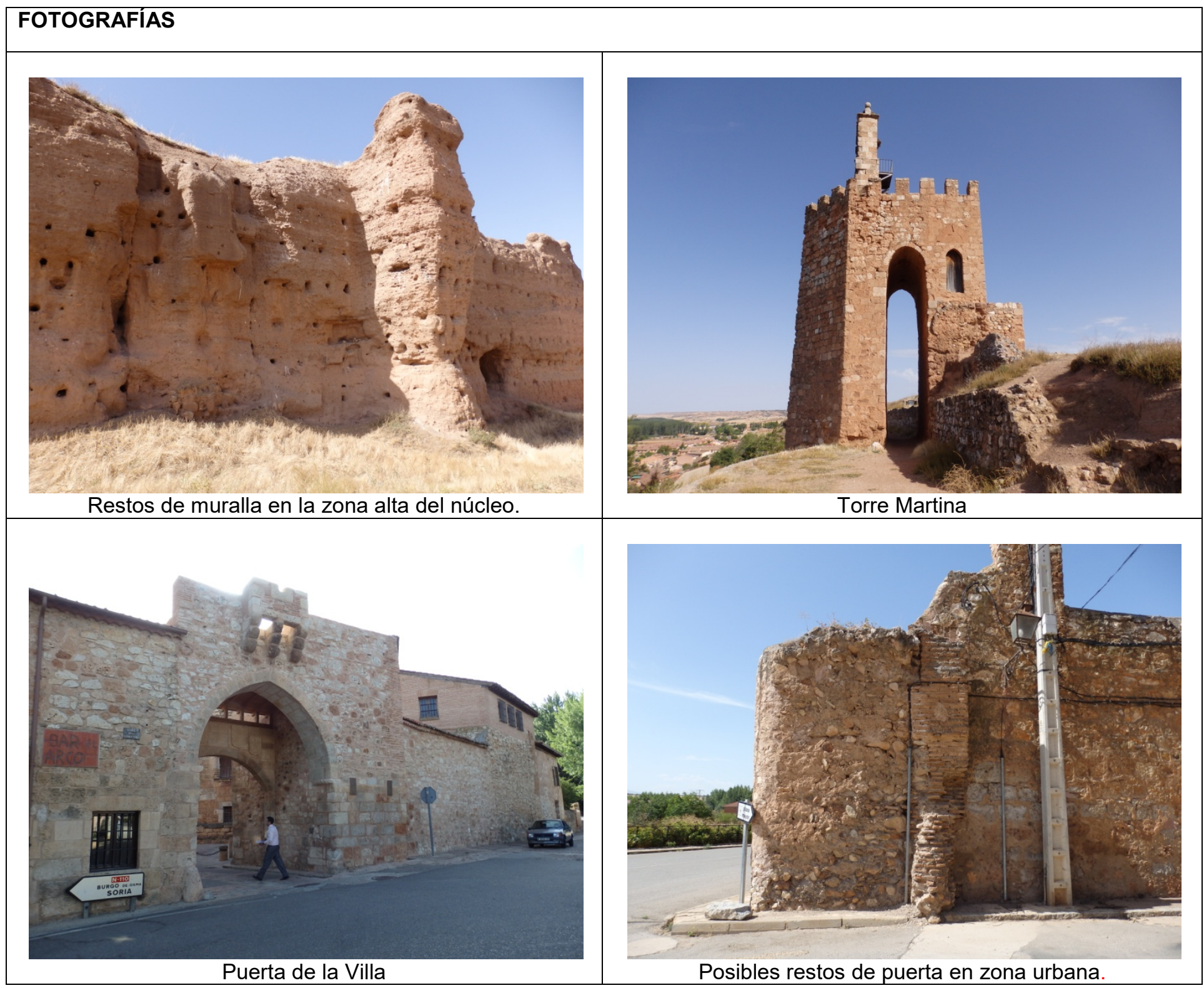

\section{ESTUDIOS REALIZADOS}

Martínez Díez, Gonzalo. 1983. Las Comunidades de Villa y Tierra en la Extremadura Castellana. Madrid: Editora Nacional.

Citado en páginas: 311-323.

Rivas, Juan L. de las. 2009. Atlas de Conjuntos Históricos de Castilla y León. Valladolid: Junta de Castilla y León.

Citado en páginas: 461-161

\section{CASOS DE LA INVESTIGACIÓN}

Incluido como caso de estudio de la investigación Razones de exclusión

NO

Restos defensivos con menor relación constructiva con otros casos. 
FICHA RESUMEN

Ubicación: Haza, Burgos

Colinda con la Diócesis de Segovia.

Fecha: 29/10/2014

Redactora: Alicia Sainz Esteban

\section{DATOS GENERALES}

\begin{tabular}{|l|l|}
\hline $\begin{array}{l}\text { Planeamiento } \\
\text { general }\end{array}$ & Sin planeamiento general. \\
\hline $\begin{array}{l}\text { Arquitectura } \\
\text { defensiva BIC }\end{array}$ & - Conjunto fortificado de Haza (Categoría: Conjunto Histórico). Fecha de declaración: 15/12/2010. \\
\hline
\end{tabular}

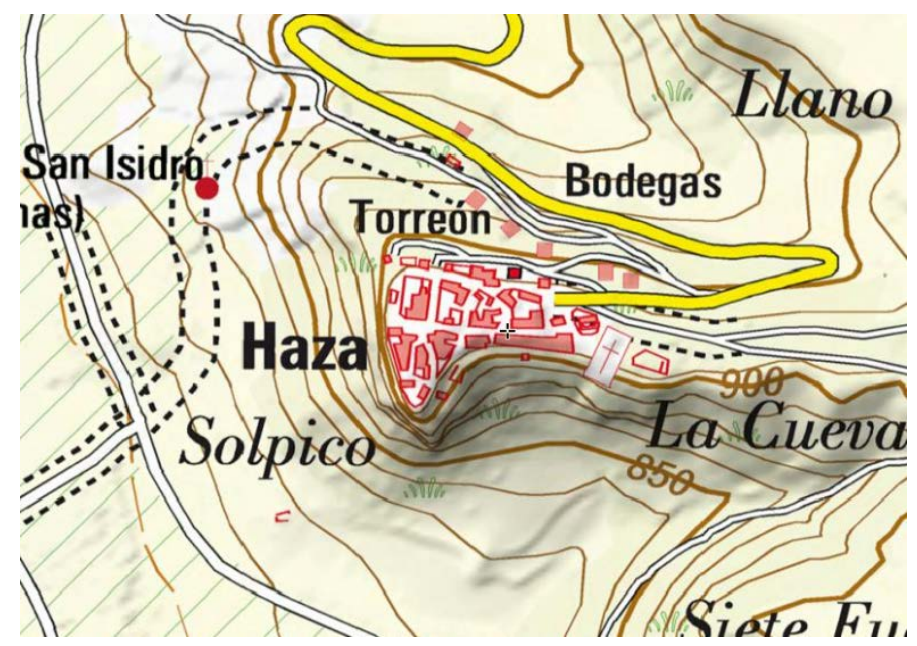

Fragmento de Mapa Topográfico Nacional. 1:25.000. Fuente: Visor Iberpix IGN.

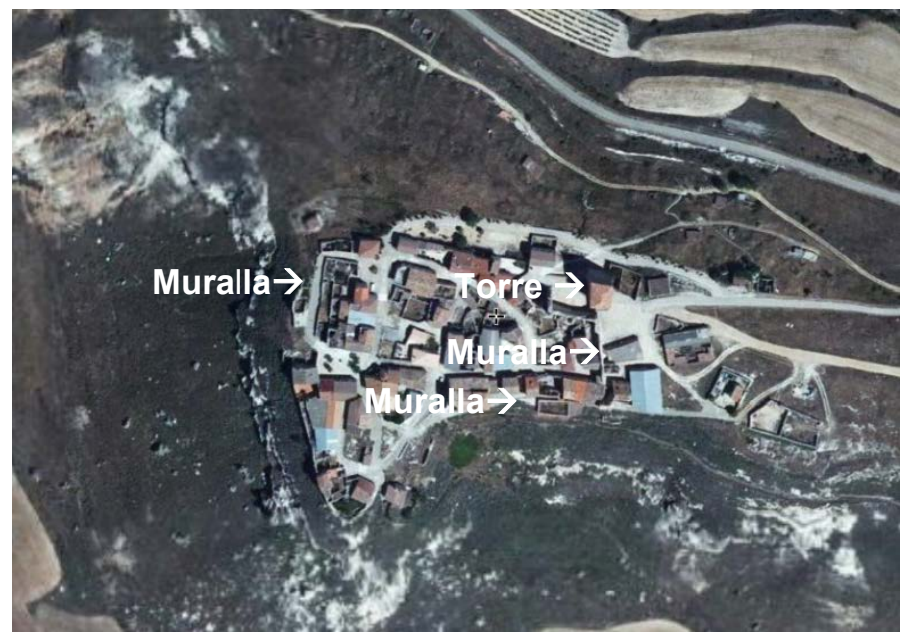

Fotografía aérea del núcleo. Fuente: Visor Iberpix IGN.

\begin{tabular}{l}
\hline \begin{tabular}{l|l|l|l|}
\hline DATOS TIPOLÓGICOS & Localización UTM & Estado de conservación \\
\hline $\begin{array}{l}\text { Tipo de } \\
\text { arquitectura }\end{array}$ & Elementos identificados & E 430882, N 4608089, Huso 30T & $\begin{array}{l}\text { Restaurado, partes } \\
\text { reconstruidas. }\end{array}$ \\
\hline Castillo & Torre del homenaje & $\begin{array}{l}\text { E 430719, N 4608095, Huso 30T } \\
\text { E 430860, N 4608030, Huso 30T } \\
\text { E 430884, N 4608051, Huso 30T }\end{array}$ & $\begin{array}{l}\text { Muen estado. } \\
\text { Buen estado. Nuevas } \\
\text { construcciones } \\
\text { demasiado próximas. }\end{array}$ \\
\hline $\begin{array}{l}\text { Muralla } \\
\text { Zona oeste } \\
\text { Zona este }\end{array}$ & & & \\
\hline
\end{tabular}
\end{tabular}

\section{DATOS CONSTRUCTIVOS}

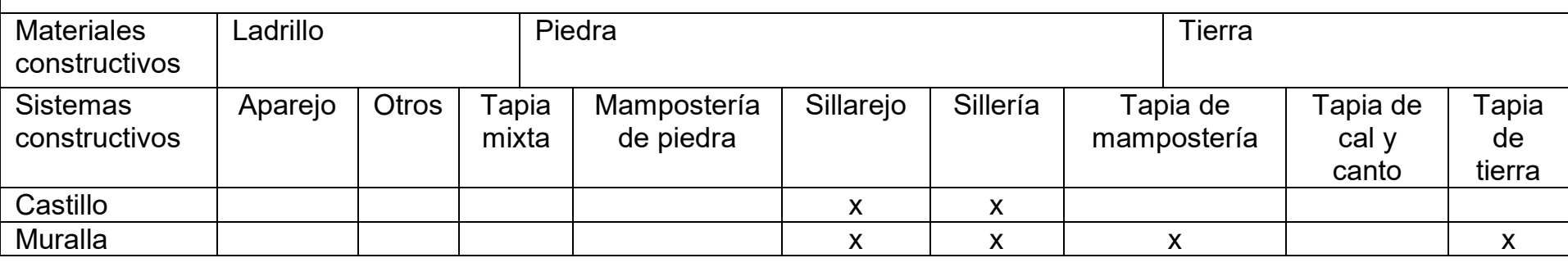




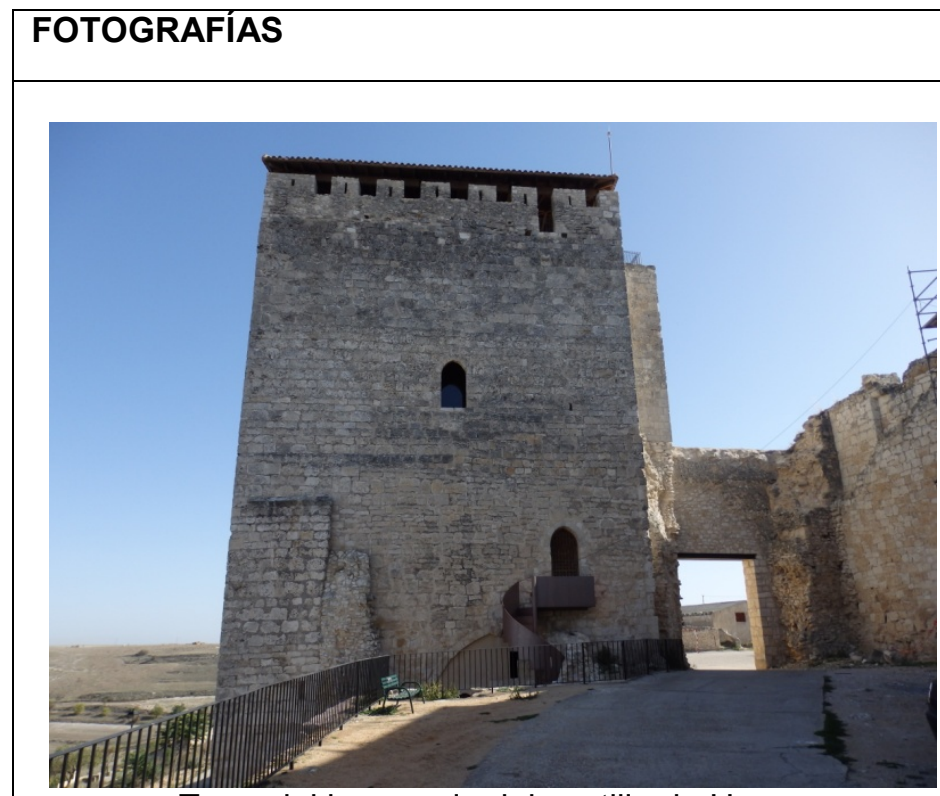

Torre del homenaje del castillo de Haza.

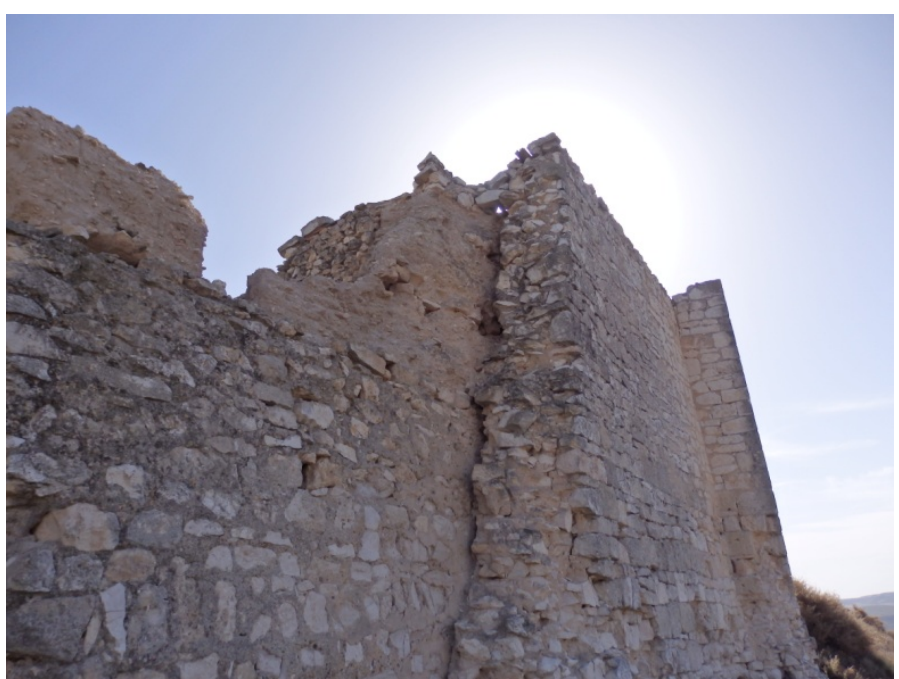

Muro adosado a un muro anterior en zona oeste.
Fecha: 29/10/2014

Redactora: Alicia Sainz Esteban

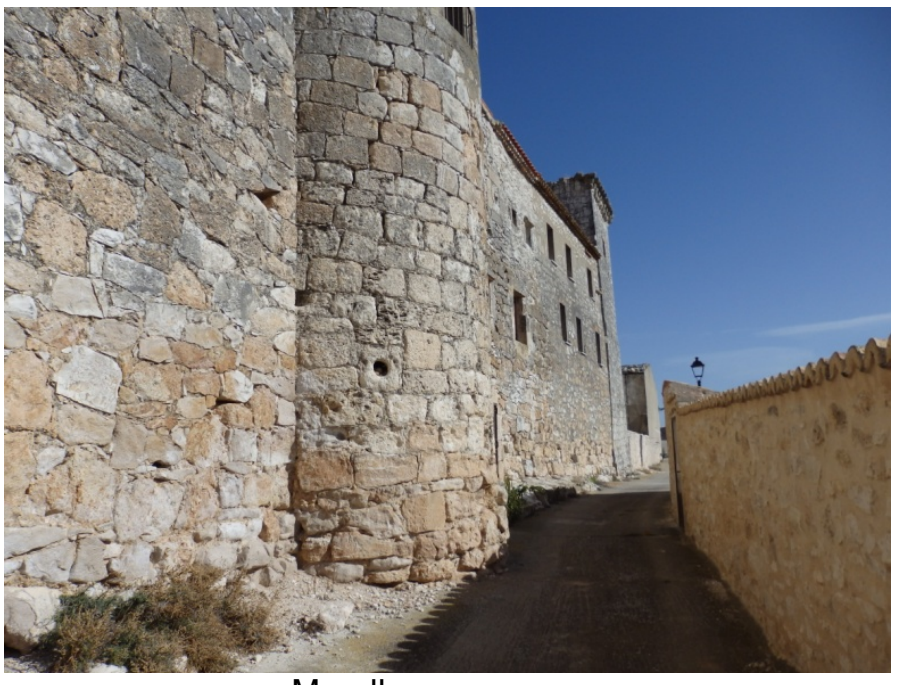

Muralla en zona sur

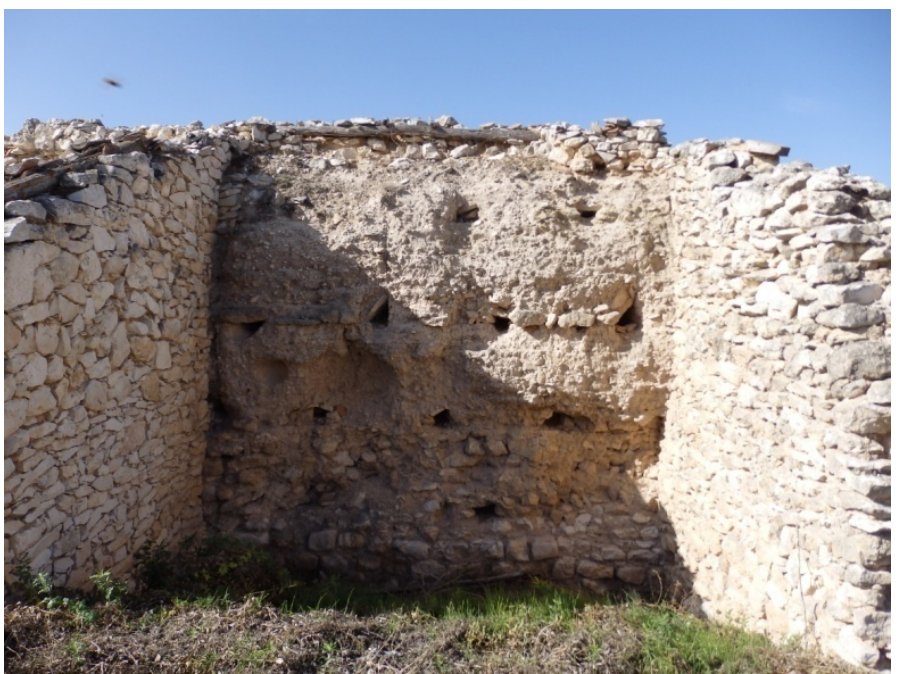

Parte interior de muralla en zona oeste.

\section{ESTUDIOS REALIZADOS}

Martínez Díez, Gonzalo. 1983. Las Comunidades de Villa y Tierra en la Extremadura Castellana. Madrid: Editora Nacional.

Citado en

páginas:

295-300.

\section{CASOS DE LA INVESTIGACIÓN}

Incluido como caso de estudio de la investigación NO

Razones de la exclusión

Restos de muralla escasos. 


\section{DATOS GENERALES}

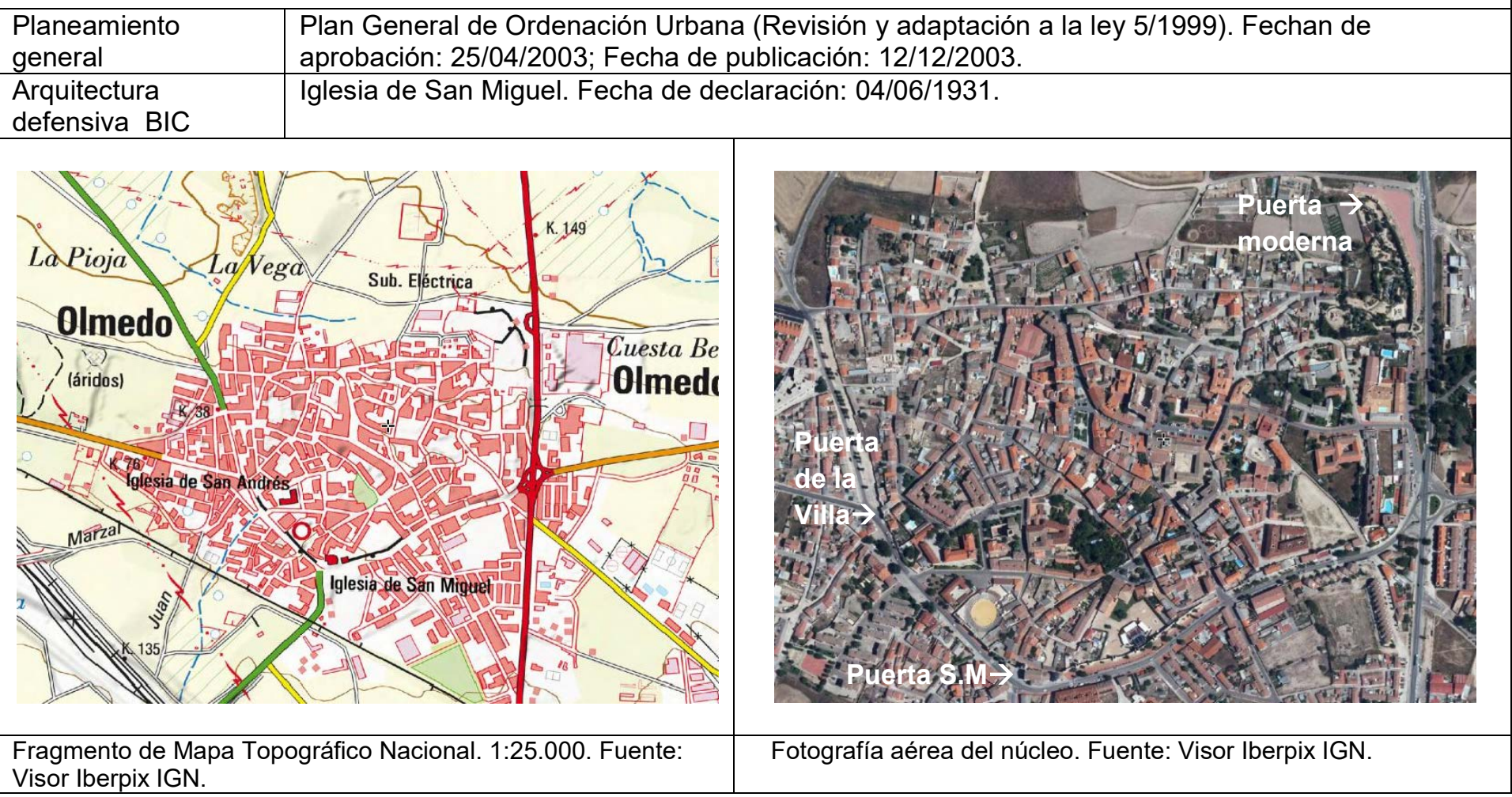

\section{DATOS TIPOLÓGICOS}

\begin{tabular}{|l|l|l|l|}
\hline $\begin{array}{l}\text { Tipo de } \\
\text { arquitectura }\end{array}$ & Elementos identificados & Localización UTM & Estado de conservación \\
\hline Muralla & Varios tramos de muralla y dos puertas. & & $\begin{array}{l}\text { Restaurada } \\
\text { mayoritariamente, aunque } \\
\text { con zonas arruinadas. }\end{array}$ \\
& $\begin{array}{l}\text { Puerta de San Miguel } \\
\text { Puerta de la Villa } \\
\text { Puerta de aspecto moderno }\end{array}$ & $\begin{array}{l}\text { E 358668, N 4571836, Huso 30T } \\
\text { E 358477, N 4572040, Huso 30T } \\
\text { E 359154, N 4572478, Huso 30T }\end{array}$ & Restaurada. Buen estado. \\
\hline $\begin{array}{l}\text { Iglesia de San } \\
\text { Miguel }\end{array}$ & $\begin{array}{l}\text { Iglesia adosada a muralla. Aprovecha sus lienzos. } \\
\text { E 358687, N 4571818, Huso 30T }\end{array}$ & Rusiad & \\
\hline
\end{tabular}

\section{DATOS CONSTRUCTIVOS}

\begin{tabular}{|l|c|c|c|c|c|c|c|c|c|}
\hline $\begin{array}{l}\text { Materiales } \\
\text { constructivos }\end{array}$ & \multicolumn{2}{|l|}{ Ladrillo } & \multicolumn{2}{l|}{ Piedra } & \multicolumn{2}{l|}{ Tierra } \\
\hline $\begin{array}{l}\text { Sistemas } \\
\text { constructivos }\end{array}$ & Aparejo & Otros & $\begin{array}{c}\text { Tapia } \\
\text { mixta }\end{array}$ & $\begin{array}{c}\text { Mampostería } \\
\text { de piedra }\end{array}$ & $\begin{array}{c}\text { Sillarejo } \\
\text { Sillería }\end{array}$ & $\begin{array}{c}\text { Tapia de } \\
\text { mampostería }\end{array}$ & $\begin{array}{c}\text { Tapia de } \\
\text { cal y } \\
\text { canto }\end{array}$ & $\begin{array}{c}\text { Tapia } \\
\text { de } \\
\text { tierra }\end{array}$ \\
\hline Muralla & $\mathrm{x}$ & $\mathrm{x}^{*}$ & & & & & $\mathrm{x}$ & $\mathrm{x}$ \\
\hline $\begin{array}{l}\text { Iglesia de San } \\
\text { Miguel }\end{array}$ & $\mathrm{x}$ & $\mathrm{x}^{*}$ & $\mathrm{x}$ & & $\mathrm{x}$ & $\mathrm{x}$ & $\mathrm{x}$ & \\
\hline
\end{tabular}

${ }^{*}$ Verdugadas aisladas. 
FICHA RESUMEN

Ubicación: Olmedo, Valladolid

Colinda con la Diócesis de Segovia.

Fecha: 1/9/2014

Redactora: Alicia Sainz Esteban

14

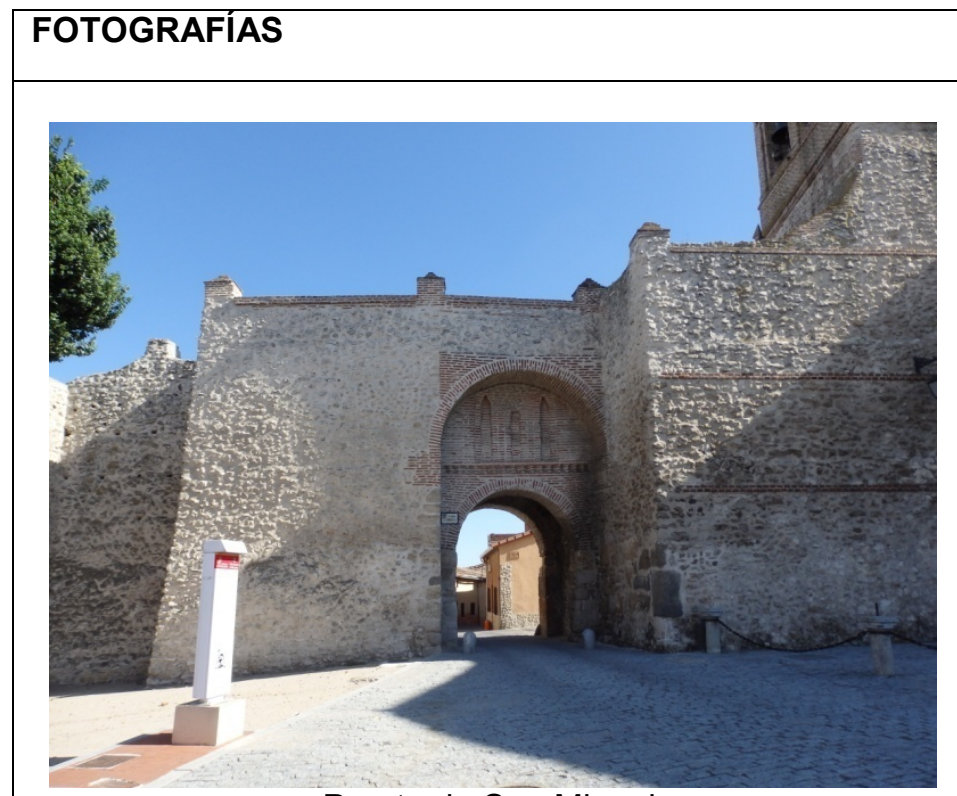

Puerta de San Miguel

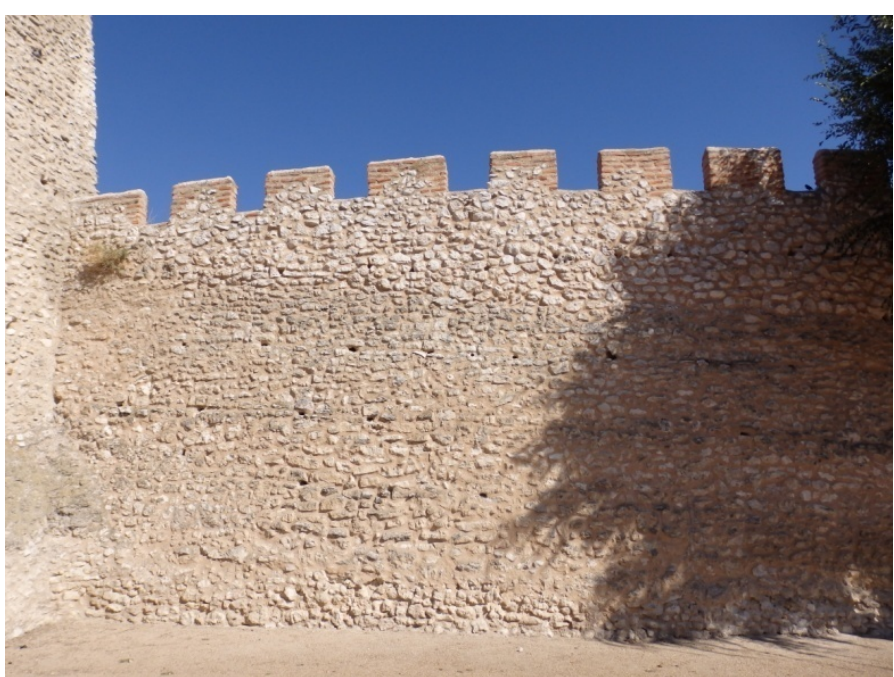

Lienzo en zona sur

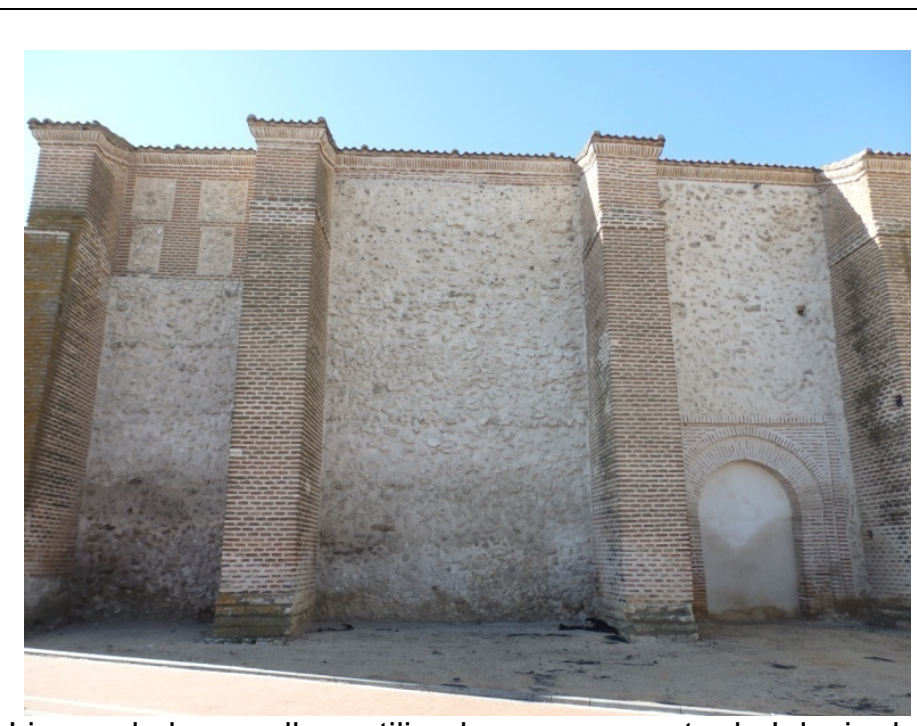

Lienzo de la muralla reutilizado en muro norte de Iglesia de San Miguel.

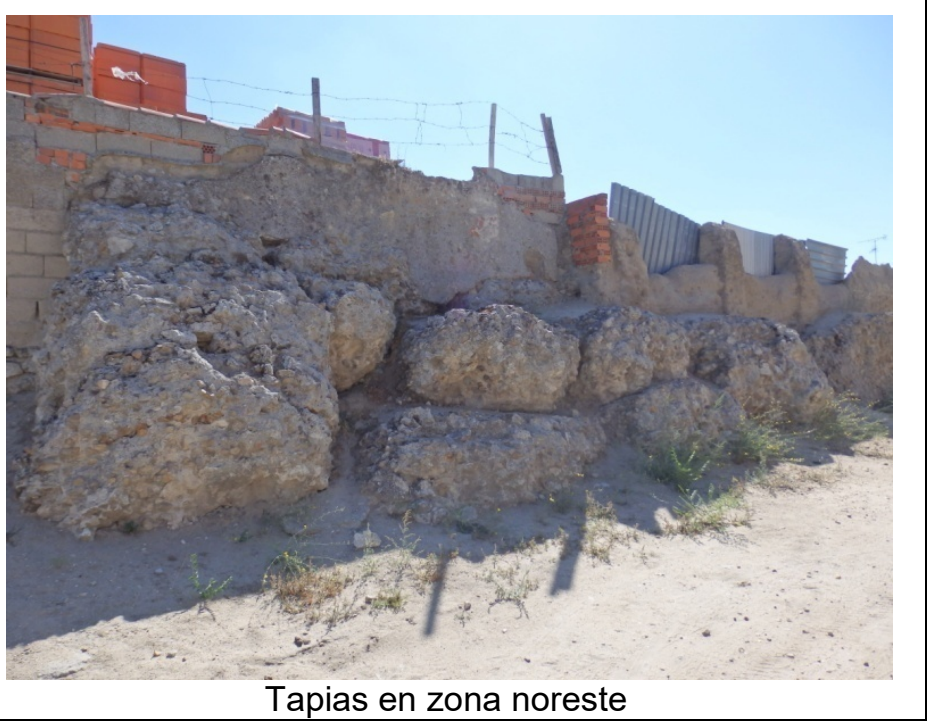

\section{ESTUDIOS REALIZADOS}

Martínez Díez, Gonzalo. 1983. Las Comunidades de Villa y Tierra en la Extremadura Castellana. Madrid: Editora Nacional.

\section{CASOS DE LA INVESTIGACIÓN}

Incluido como caso de estudio de la investigación $\mathrm{NO}$

Razones

Muralla de gran interés que no se incluirá como caso, pero cuyas soluciones constructivas se compararán con los casos de estudio. 
Ubicación: Peñafiel, Valladolid

Colinda con Diócesis de Segovia.

Fecha: 29/10/2014

Redactora: Alicia Sainz Esteban

\section{DATOS GENERALES}

\begin{tabular}{l|l}
$\begin{array}{l}\text { Planeamiento } \\
\text { general }\end{array}$ & - Plan General de Ordenación Urbana. Fecha de aprobación: 25/09/2012; fecha de publicación: \\
\hline $\begin{array}{l}\text { Arquitectura } \\
\text { defensiva BIC }\end{array}$ & $\begin{array}{l}\text { - El castillo (Categoría: Monumento). Fecha de declaración: 08/06/1917. } \\
\text { - La villa (Categoría: Conjunto Histórico). Fecha de declaración: 24/02/1999. } \\
\text { - Torre del reloj (Categoría: Monumento). Fecha de declaración: 21/01/1982. }\end{array}$ \\
\hline
\end{tabular}

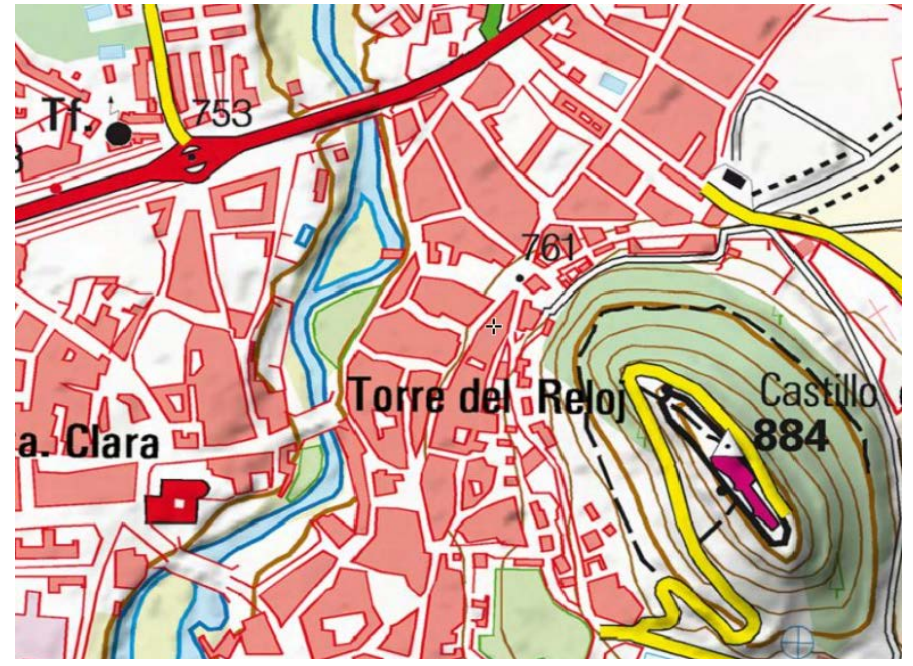

Fragmento de Mapa Topográfico Nacional. 1:25.000. Fuente:

Visor Iberpix IGN.

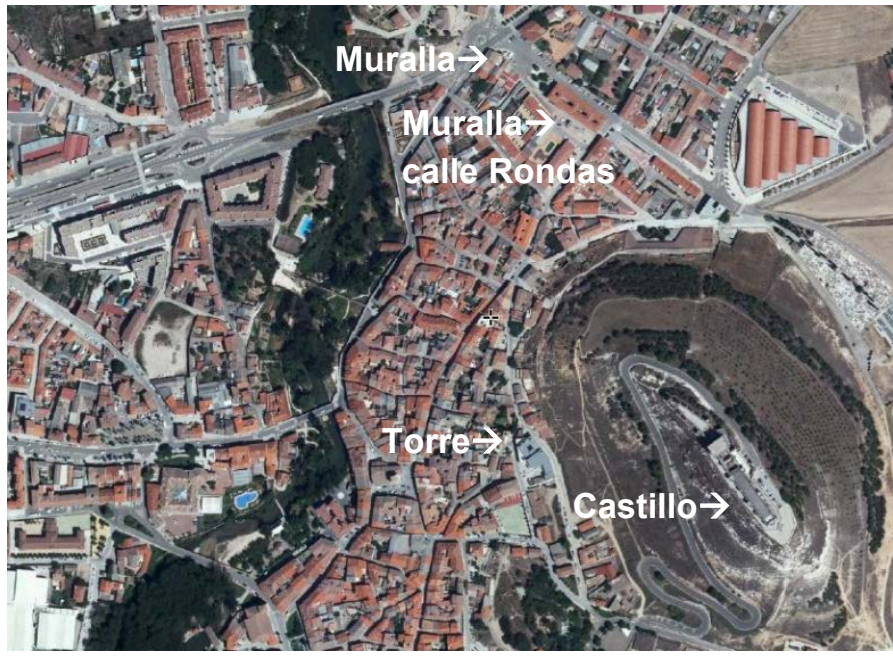

Fotografía aérea del núcleo. Fuente: Visor Iberpix IGN.

\begin{tabular}{|l|l|l|l|}
\hline DATOS TIPOLÓGICOS & Localización UTM & Estado de conservación \\
\hline $\begin{array}{l}\text { Tipo de } \\
\text { arquitectura }\end{array}$ & Elementos identificados & E 407118, N 4605616, Huso 30T & $\begin{array}{l}\text { Restaurado, partes } \\
\text { reconstruidas. Uso actual } \\
\text { como Museo del Vino. }\end{array}$ \\
\hline Castillo & Torre del homenaje y muralla del castillo. & $\begin{array}{l}\text { E 406890, N 4606045, Huso 30T } \\
\text { E 4069arado, reconstruido. } \\
\text { Ruina. }\end{array}$ \\
\hline Muralla & $\begin{array}{l}\text { Tramo junto a carretera Valladolid-Soria } \\
\text { Tramo en calle Rondas. }\end{array}$ & E 406885, N 4605581, Huso 30T & Buen estado. \\
\hline Torre & Torre del reloj, aislada. & & \\
\hline
\end{tabular}

\section{DATOS CONSTRUCTIVOS}

\begin{tabular}{|c|c|c|c|c|c|c|c|c|c|}
\hline $\begin{array}{l}\text { Materiales } \\
\text { constructivos }\end{array}$ & \multicolumn{3}{|l|}{ Ladrillo } & \multicolumn{3}{|c|}{ Piedra } & \multicolumn{2}{|l|}{ Tierra } & \\
\hline $\begin{array}{l}\text { Sistemas } \\
\text { constructivos }\end{array}$ & Aparejo & Otros & $\begin{array}{l}\text { Tapia } \\
\text { mixta }\end{array}$ & $\begin{array}{c}\text { Mampostería } \\
\text { de piedra }\end{array}$ & Sillarejo & Sillería & $\begin{array}{c}\text { Tapia de } \\
\text { mampostería }\end{array}$ & $\begin{array}{c}\text { Tapia de } \\
\text { cal y } \\
\text { canto }\end{array}$ & $\begin{array}{c}\text { Tapia } \\
\text { de } \\
\text { tierra }\end{array}$ \\
\hline Muralla & & & & & $x$ & $x$ & & & $x$ \\
\hline Castillo & & & & & $x$ & $x$ & & & \\
\hline Torre del reloj & & & & & & $x$ & $x$ & & \\
\hline
\end{tabular}


FICHA RESUMEN

Ubicación: Peñafiel, Valladolid

Colinda con Diócesis de Segovia.

Fecha: 29/10/2014

Redactora: Alicia Sainz Esteban

15

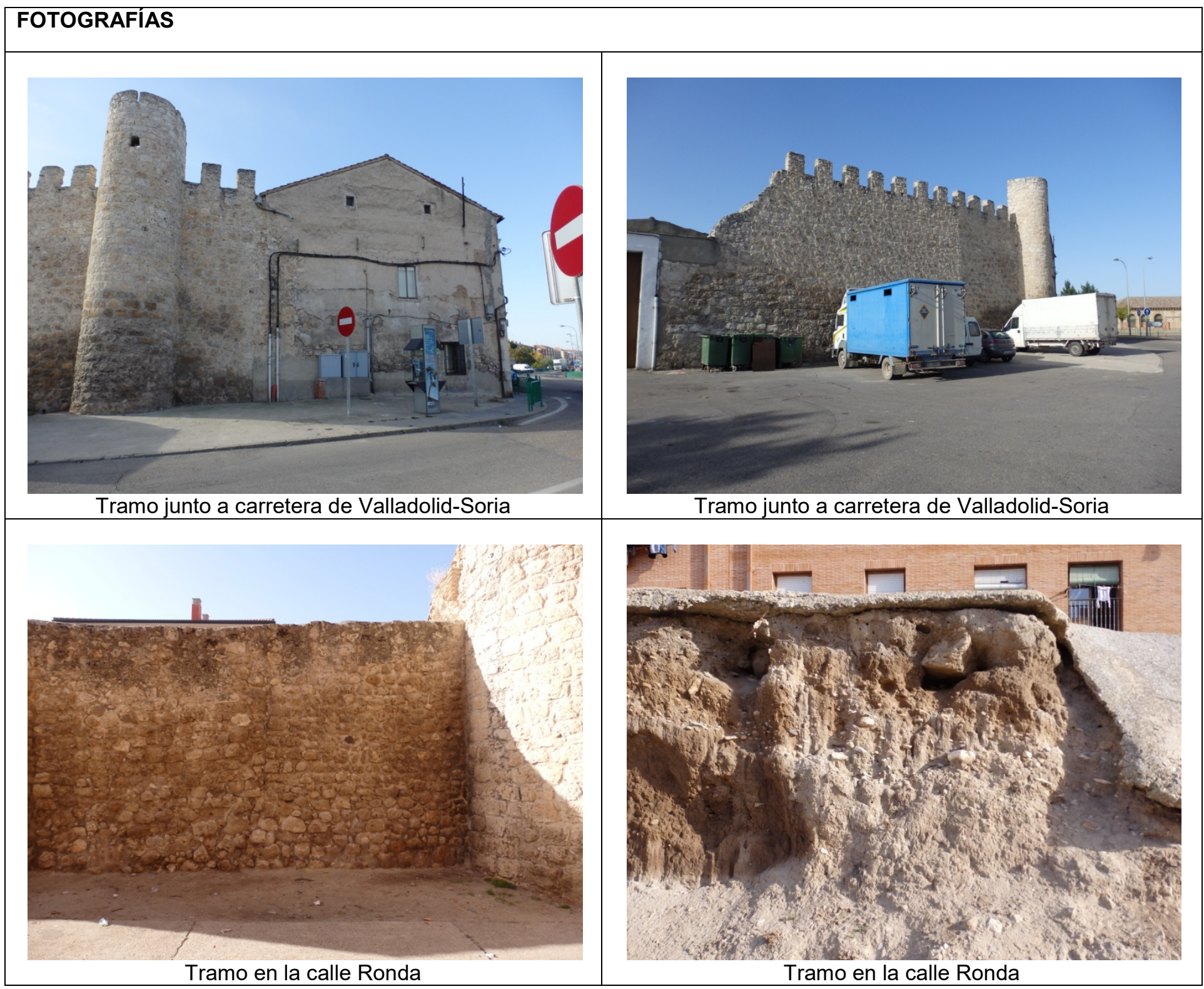

\section{ESTUDIOS REALIZADOS}

Martínez Díez, Gonzalo. 1983. Las Comunidades de Villa y Tierra en la Extremadura Castellana. Madrid: Editora Nacional.

Citado en páginas: 326 , 385-396, 407,516

Rivas, Juan L. de las. 2009. Atlas de Conjuntos Históricos de Castilla y León. Valladolid: Junta de Castilla y León.

Citado en páginas: 573-576

\section{CASOS DE LA INVESTIGACIÓN}

Incluido como caso de estudio de la investigación Razones
NO

Existencia de muralla, con restos de escasa entidad para análisis constructivo. 
FICHA RESUMEN

Ubicación: Portillo,Valladolid.

Colinda con Diócesis de Segovia.

Fecha: 23/10/2014

Redactora: Alicia Sainz Esteban

16

\section{DATOS GENERALES}

Planeamiento $\quad$ - Plan General de Ordenación Urbana (PGOU). Fecha de aprobación: 24/10/2005. Fecha de general

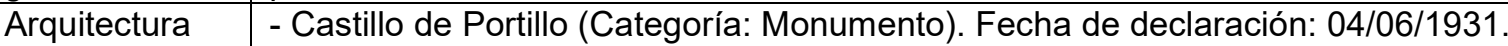

defensiva BIC

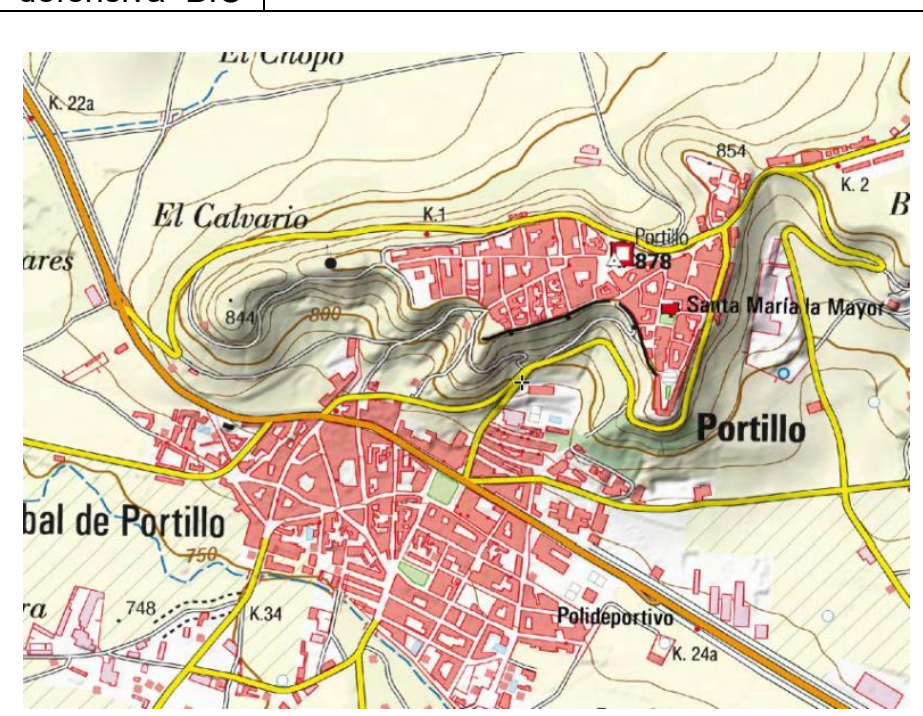

Fragmento de Mapa Topográfico Nacional. 1:25.000. Fuente: Visor Iberpix IGN.

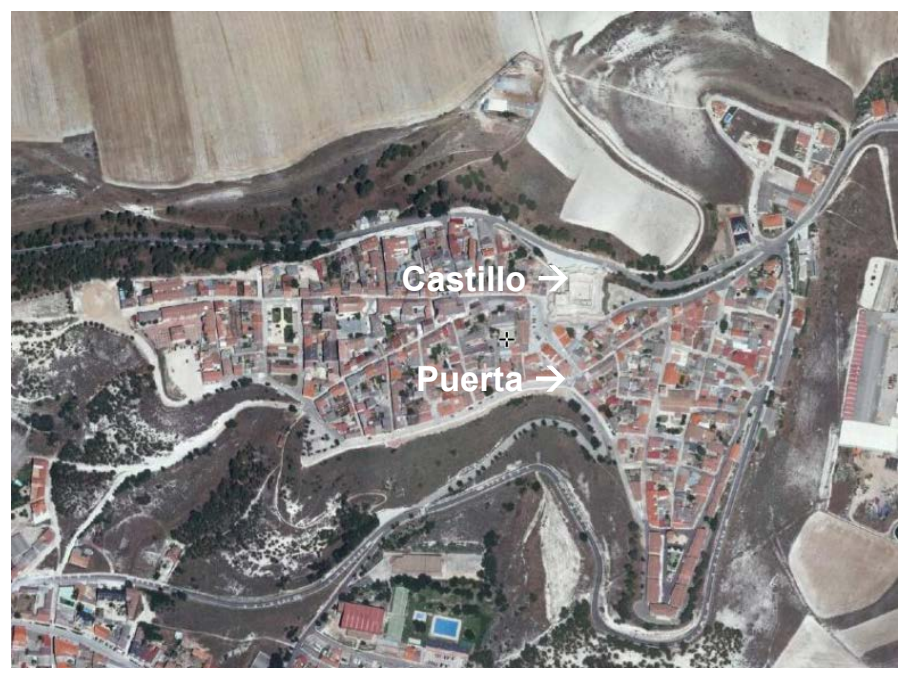

Fotografía aérea del núcleo. Fuente: Visor Iberpix IGN.

\section{DATOS TIPOLÓGICOS}

\begin{tabular}{|l|l|l|l|}
\hline $\begin{array}{l}\text { Tipo de } \\
\text { arquitectura }\end{array}$ & Elementos identificados & Localización UTM & Estado de conservación \\
\hline Castillo & Torre del homenaje, muralla del castillo. & E 367428, N 4593176, Huso 30T & Consolidado. \\
\hline Muralla & $\begin{array}{l}\text { Puerta } \\
\text { Tramo junto a puerta } \\
\text { Tramo junto a castillo }\end{array}$ & $\begin{array}{l}\text { E 367417, N 4593069, Huso 30T } \\
\text { E 367405, N 4593070, Huso 30T } \\
\text { E 367389, N 4593210, Huso 30T }\end{array}$ & Bueno. \\
\hline
\end{tabular}

\section{DATOS CONSTRUCTIVOS}

\begin{tabular}{|l|l|l|l|l|c|c|c|c|c|c|}
\hline $\begin{array}{l}\text { Materiales } \\
\text { constructivos }\end{array}$ & Ladrillo & Otros & $\begin{array}{c}\text { Tapia } \\
\text { mixta }\end{array}$ & $\begin{array}{c}\text { Mampostería } \\
\text { de piedra } \\
\text { constructivos }\end{array}$ & Aparejo & Sillarejo & Sillería & $\begin{array}{c}\text { Tapia de } \\
\text { mampostería }\end{array}$ & $\begin{array}{c}\text { Tapia de } \\
\text { cal y } \\
\text { canto }\end{array}$ & $\begin{array}{c}\text { Tapia } \\
\text { de } \\
\text { tierra }\end{array}$ \\
\hline Muralla & & & & $\mathrm{x}$ & $\mathrm{x}$ & $\mathrm{x}$ & & \\
\hline Castillo & & & & & & $\mathrm{x}$ & & \\
\hline
\end{tabular}



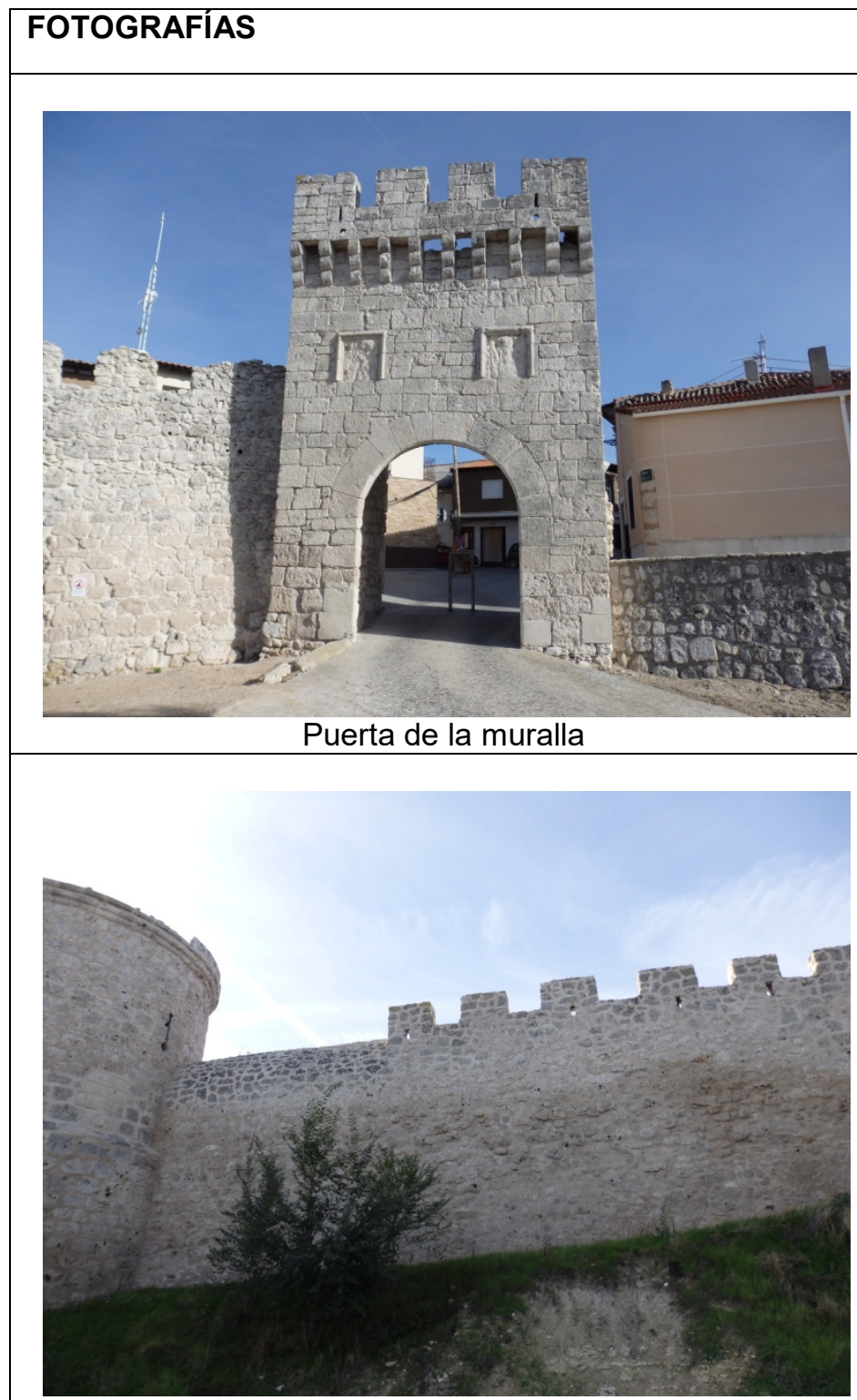

Tramo de muralla al noroeste del castillo

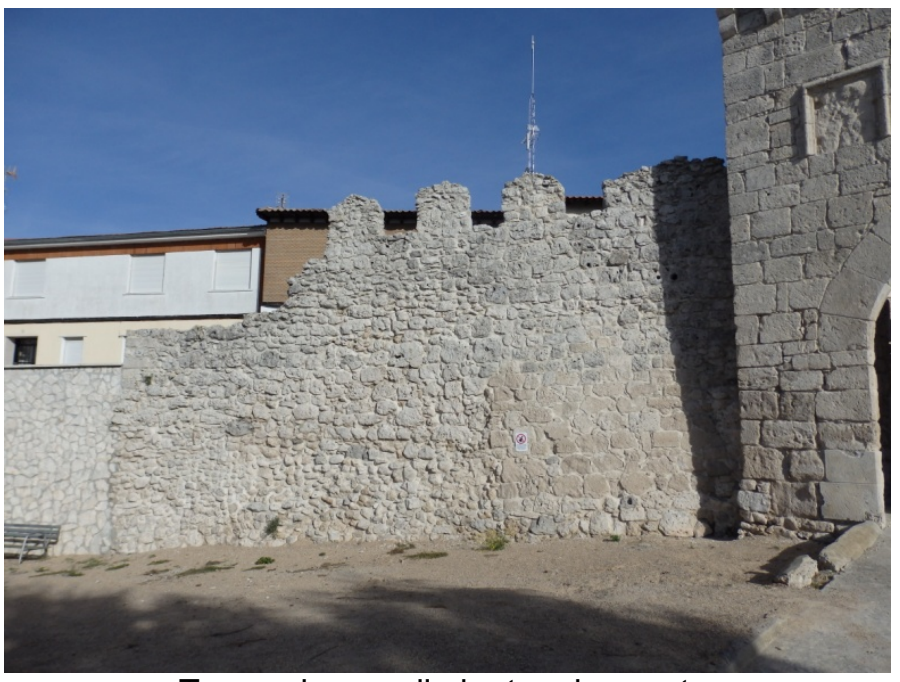

Tramo de muralla junto a la puerta

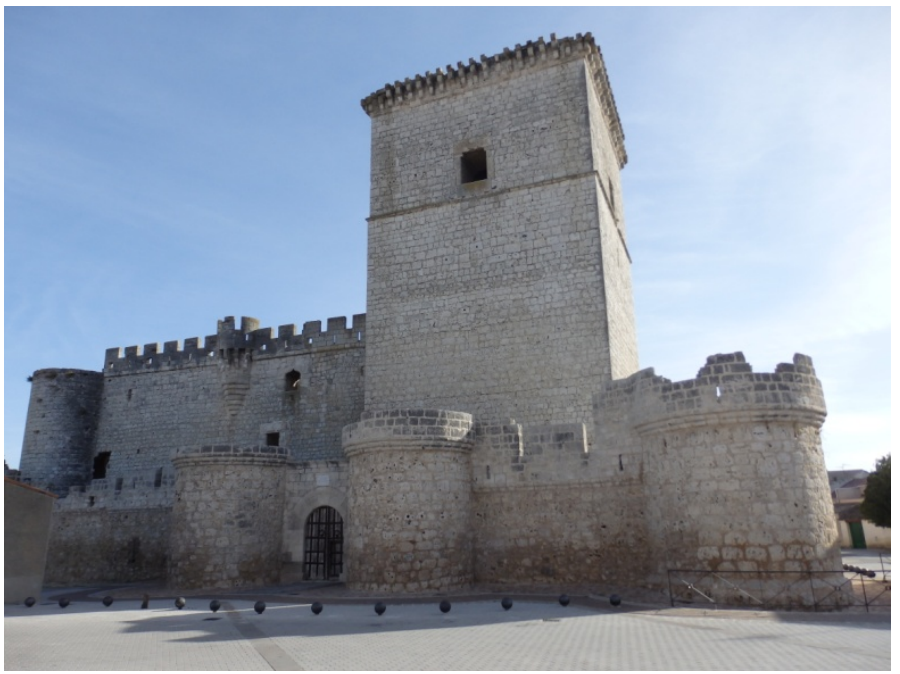

Castillo de Portillo

\section{ESTUDIOS REALIZADOS}

Martínez Díez, Gonzalo. 1983. Las Comunidades de Villa y Tierra en la Extremadura Castellana. Madrid: Editora Nacional.

Citado en páginas: 312 , 427-435.

\section{CASOS DE LA INVESTIGACIÓN}

Incluido como caso de estudio de la investigación Razones
$\mathrm{NO}$

Escasos restos de la muralla medieval 
Anexo 2: Líneas de comando empleadas en las gráficas del programa $R$ 

Gráfica Fig. 4.6

$>$ datos <- read.csv2(file="C:/Tesis/R/montej01.csv", header=T)

$>$ datos

\begin{tabular}{|c|c|c|}
\hline alttapia & 13 & 1.16 \\
\hline 1.12 & 14 & 1.17 \\
\hline 1.14 & 15 & 1.16 \\
\hline 1.14 & 16 & 1.14 \\
\hline 1.13 & 17 & 1.21 \\
\hline 1.17 & 18 & 1.17 \\
\hline 1.16 & 19 & 1.18 \\
\hline 1.13 & 20 & 1.25 \\
\hline 1.19 & 21 & 1.24 \\
\hline 1.18 & 22 & 1.21 \\
\hline 1.15 & 23 & 1.19 \\
\hline 1.18 & 24 & 1.15 \\
\hline 115 & 25 & 1.17 \\
\hline
\end{tabular}

> boxplot (datos\$alttapia, main="Altura de tapia", ylab="(m)", col=131, las $=2$, cex . axis $=0.95$, cex . main=0.95)

\section{Gráfica Fig. 4.7}

$>$ datos $2<-$ read.csv2(file=" C:/Tesis/R/montejo2.csv", header $=T$ )

$>$ datos 2

\begin{tabular}{llllll}
\multicolumn{2}{l}{ mechdist } & 23 & 1.28 & 46 & 1.26 \\
1 & 1.31 & 24 & 1.28 & 47 & 1.29 \\
2 & 1.26 & 25 & 1.32 & 48 & 1.25 \\
3 & 1.28 & 26 & 1.24 & 49 & 1.23 \\
4 & 1.22 & 27 & 1.29 & 50 & 1.26 \\
5 & 1.30 & 28 & 1.27 & 51 & 1.29 \\
6 & 1.25 & 29 & 1.26 & 52 & 1.25 \\
7 & 1.25 & 30 & 1.28 & 53 & 1.31 \\
8 & 1.30 & 31 & 1.33 & 54 & 1.22 \\
9 & 1.26 & 32 & 1.24 & 55 & 1.33 \\
10 & 1.22 & 33 & 1.32 & 56 & 1.22 \\
11 & 1.16 & 34 & 1.26 & 57 & 1.35 \\
12 & 1.28 & 35 & 1.22 & 58 & 1.22 \\
13 & 1.27 & 36 & 1.29 & 59 & 1.31 \\
14 & 1.27 & 37 & 1.23 & 60 & 1.30 \\
15 & 1.26 & 38 & 1.23 & 62 & 1.28 \\
16 & 1.26 & 39 & 1.25 & 63 & 1.31 \\
17 & 1.27 & 40 & 1.27 & 64 & 1.17 \\
18 & 1.26 & 41 & 1.27 & 65 & 1.27 \\
19 & 1.29 & 42 & 1.33 & 66 & 1.30 \\
20 & 1.24 & 43 & 1.25 & & \\
21 & 1.26 & 44 & 1.32 & & 61
\end{tabular}

$>$ boxplot (datos $2 \$ m e c h d i s t$, main="Separación mechinales en tapia", ylab="(m)", col=131, las $=2$, cex axis $=0.95$, cex main=0.95) 
Gráfica Fig. 5.1.66

$>$ cocaancho<- read.csv2(file=" C:/Tesis/R/coca-anchoprob-vis.csv", header=T)

$>$ cocaancho

$\begin{array}{rrrrrrrr}\text { anchoprob anchovis } & 19 & 2.56 & \text { NA } & 38 & 2.44 & \text { NA } \\ 2.44 & 2.44 & 20 & 0.90 & \text { NA } & 39 & 2.47 & \text { NA } \\ 1.78 & 1.78 & 21 & 2.76 & \text { NA } & 40 & 2.91 & \text { NA } \\ 2.79 & 2.81 & 22 & 2.97 & \text { NA } & 41 & 3.00 & \text { NA } \\ 2.81 & 2.37 & 23 & 3.01 & \text { NA } & 42 & 2.87 & \text { NA } \\ 2.81 & 0.90 & 24 & 2.95 & \text { NA } & 43 & 2.65 & \text { NA } \\ 2.89 & 2.76 & 25 & 2.87 & \text { NA } & 44 & 3.09 & \text { NA } \\ 2.71 & 2.66 & 26 & 2.92 & \text { NA } & 45 & 2.56 & \text { NA } \\ 2.87 & 2.18 & 27 & 2.94 & \text { NA } & 46 & 2.87 & \text { NA } \\ 3.03 & 2.44 & 28 & 2.78 & \text { NA } & 47 & 2.87 & \text { NA } \\ 2.87 & 2.47 & 29 & 2.55 & \text { NA } & 48 & 2.64 & \text { NA } \\ 2.50 & 2.87 & 30 & 2.99 & \text { NA } & 49 & 2.08 & \text { NA } \\ 2.47 & 2.64 & 31 & 2.89 & \text { NA } & 50 & 2.69 & \text { NA } \\ 2.18 & 2.08 & 32 & 2.50 & \text { NA } & 51 & 2.77 & \text { NA } \\ 2.92 & 2.69 & 33 & 3.00 & \text { NA } & 52 & 2.69 & \text { NA } \\ 2.99 & 2.77 & 34 & 2.66 & \text { NA } & 53 & 2.68 & \text { NA } \\ 2.37 & 2.80 & 35 & 2.18 & \text { NA } & 54 & 2.90 & \text { NA } \\ 2.45 & \text { NA } & 36 & 2.81 & \text { NA } & 55 & 2.88 & \text { NA } \\ 2.42 & \text { NA } & 37 & 2.44 & \text { NA } & 56 & 2.80 & \text { NA }\end{array}$

$>$ boxplot (cocaancho\$anchoprob, cocaancho\$anchovis, main="Anchura de tapia visible y probable", ylab="(m)", col=131, las=2, cex.axis=1, cex.main=1)

\section{Gráfica Fig. 5.1.67}

$>$ cocaalto<- read.csv2(file=" C:/Tesis/R/coca-altoprob-vis.csv", header=T)

\begin{tabular}{|c|c|c|c|c|c|c|c|c|}
\hline & alto & & 19 & 1.23 & 1.23 & 39 & 1.27 & 1.17 \\
\hline & oprob & altovis & 20 & 1.32 & 1.32 & 40 & 1.26 & 1.21 \\
\hline 1 & 1.40 & 1.40 & 21 & 1.28 & 1.28 & 41 & 1.30 & 1.50 \\
\hline 2 & 1.40 & 1.40 & 22 & 1.31 & 1.31 & 42 & 1.23 & 1.54 \\
\hline 3 & 1.36 & 1.36 & 23 & 1.26 & 1.26 & 43 & 1.38 & 1.32 \\
\hline 4 & 1.33 & 1.33 & 24 & 1.31 & 1.31 & 44 & 1.41 & 1.52 \\
\hline 5 & 1.08 & 1.08 & 25 & 1.30 & 1.30 & 45 & 1.41 & 1.31 \\
\hline 6 & 1.14 & 1.14 & 26 & 1.25 & 1.25 & 46 & 1.35 & NA \\
\hline 7 & 1.21 & 1.21 & 27 & 1.13 & 1.13 & 47 & 1.29 & NA \\
\hline 8 & 1.27 & 1.27 & 28 & 1.12 & 1.12 & 48 & 1.00 & NA \\
\hline 9 & 1.19 & 1.19 & 29 & 1.33 & 1.22 & 49 & 1.11 & NA \\
\hline 10 & 1.11 & 1.11 & 30 & 1.33 & 1.33 & 50 & 1.17 & NA \\
\hline 11 & 1.21 & 1.21 & 31 & 1.20 & 1.25 & 51 & 1.21 & NA \\
\hline 12 & 1.16 & 1.16 & 32 & 1.32 & 1.23 & 52 & 1.50 & NA \\
\hline 13 & 1.16 & 1.16 & 33 & 1.22 & 1.23 & 53 & 1.54 & NA \\
\hline 14 & 1.32 & 1.32 & 34 & 1.33 & 1.27 & 54 & 1.32 & NA \\
\hline 15 & 1.24 & 1.24 & 35 & 1.25 & 1.27 & 55 & 1.52 & NA \\
\hline 16 & 1.16 & 1.16 & 36 & 1.23 & 1.29 & 56 & 1.31 & NA \\
\hline 17 & 1.25 & 1.25 & 37 & 1.23 & 1.00 & & & \\
\hline 18 & 1.27 & 1.27 & 38 & 1.27 & 1.11 & & & \\
\hline
\end{tabular}

$>$ boxplot (cocaalto\$altoprob, cocaalto\$altovis, main="Altura de tapia visible y probable", ylab="(m)", col=131, las=2, cex.axis=1, cex.main=1) 


\section{Gráfica Fig. 5.1.68}

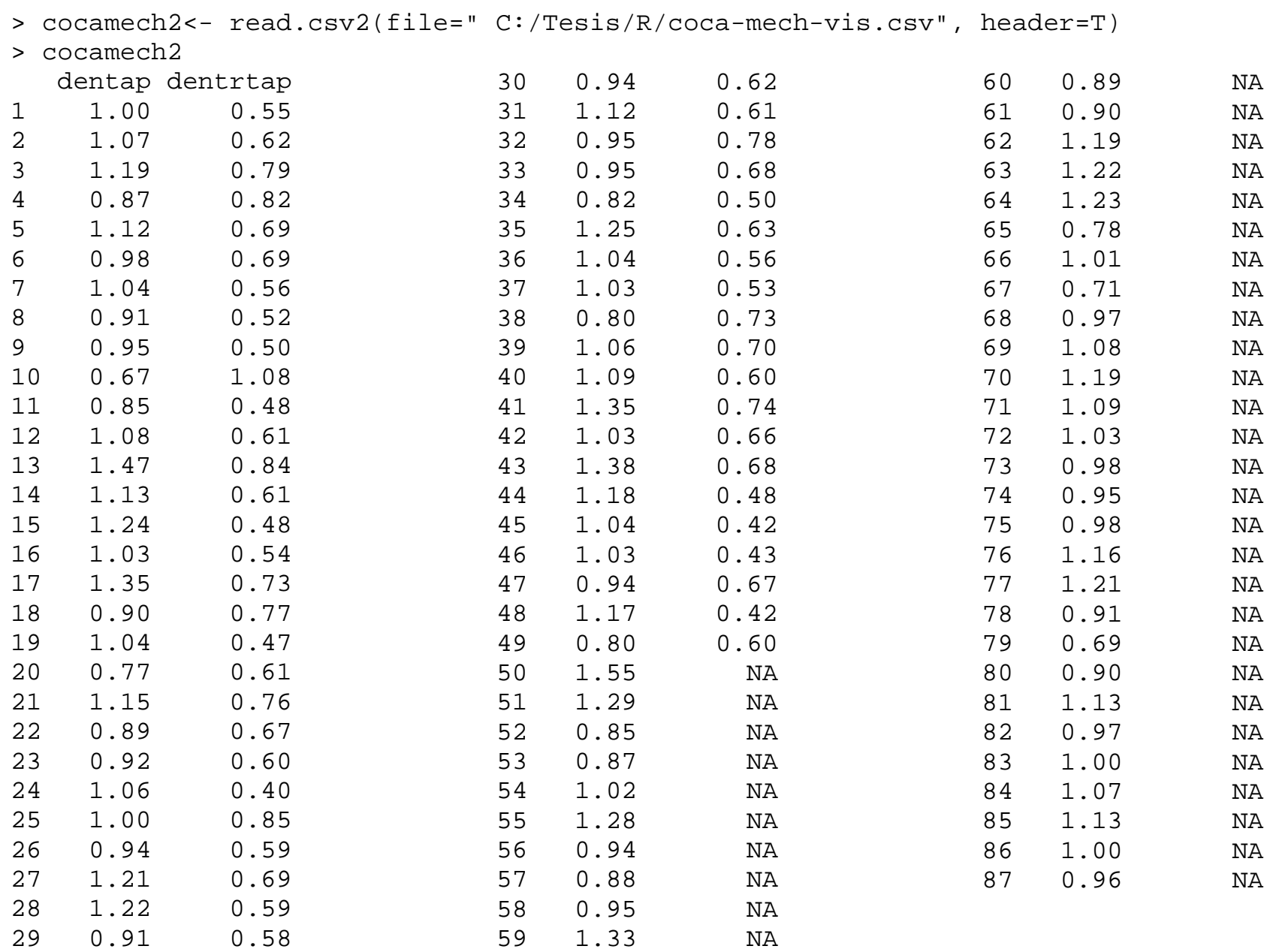

$>$ boxplot (cocamech2\$dentap, cocamech2\$dentrtap, main="Distancia entre mechinales visibles", ylab="(m)", col=131, las=2, cex.axis=1, cex.main=1)

\section{Gráfica Fig. 5.1.69}

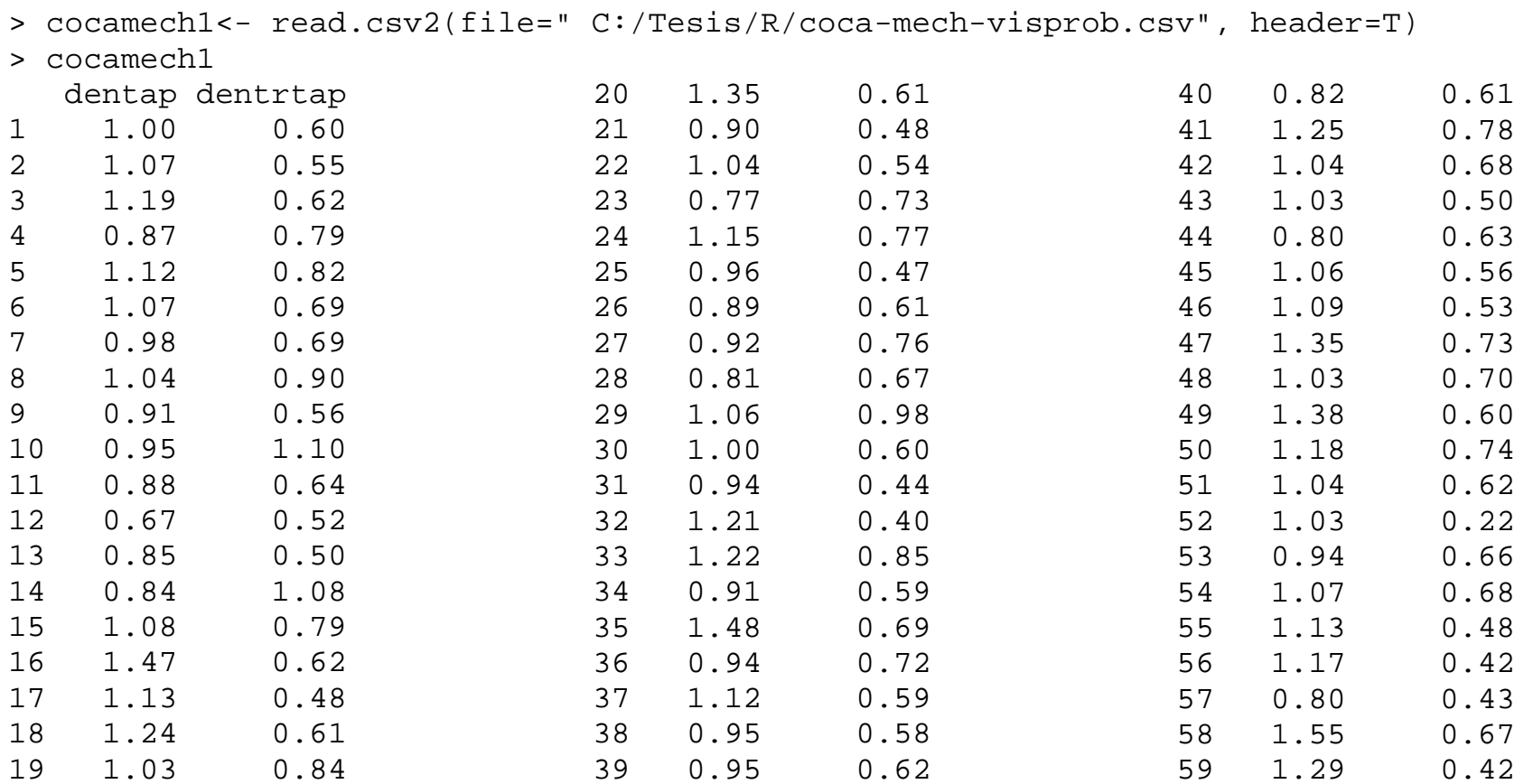




$\begin{array}{lllllllll}60 & 0.88 & 0.60 & 73 & 1.23 & \text { NA } & 86 & 1.16 & \text { NA } \\ 61 & 0.85 & \text { NA } & 74 & 0.96 & \text { NA } & 87 & 1.21 & \text { NA } \\ 62 & 0.87 & \text { NA } & 75 & 0.78 & \text { NA } & 88 & 0.91 & \text { NA } \\ 63 & 1.02 & \text { NA } & 76 & 1.01 & \text { NA } & 89 & 0.69 & \text { NA } \\ 64 & 1.28 & \text { NA } & 77 & 0.71 & \text { NA } & 90 & 0.90 & \text { NA } \\ 65 & 0.94 & \text { NA } & 78 & 0.97 & \text { NA } & 91 & 1.13 & \text { NA } \\ 66 & 0.88 & \text { NA } & 79 & 1.08 & \text { NA } & 92 & 0.97 & \text { NA } \\ 67 & 0.95 & \text { NA } & 80 & 1.19 & \text { NA } & 93 & 1.00 & \text { NA } \\ 68 & 1.33 & \text { NA } & 81 & 1.09 & \text { NA } & 94 & 1.07 & \text { NA } \\ 69 & 0.89 & \text { NA } & 82 & 1.03 & \text { NA } & 95 & 1.13 & \text { NA } \\ 70 & 0.90 & \text { NA } & 83 & 0.98 & \text { NA } & 96 & 1.00 & \text { NA } \\ 71 & 1.19 & \text { NA } & 84 & 0.95 & \text { NA } & 97 & 0.96 & \text { NA } \\ 72 & 1.22 & \text { NA } & 85 & 0.98 & \text { NA } & & 9\end{array}$

$>$ boxplot (cocamech1\$dentap, cocamech1\$dentrtap, main="Distancia entre mechinales visibles y probables", ylab="(m)", col=131, las=2, cex.axis=1, cex.main=1)

\section{Gráficas Fig. 5.2.105 y Fig. 5.2.106}

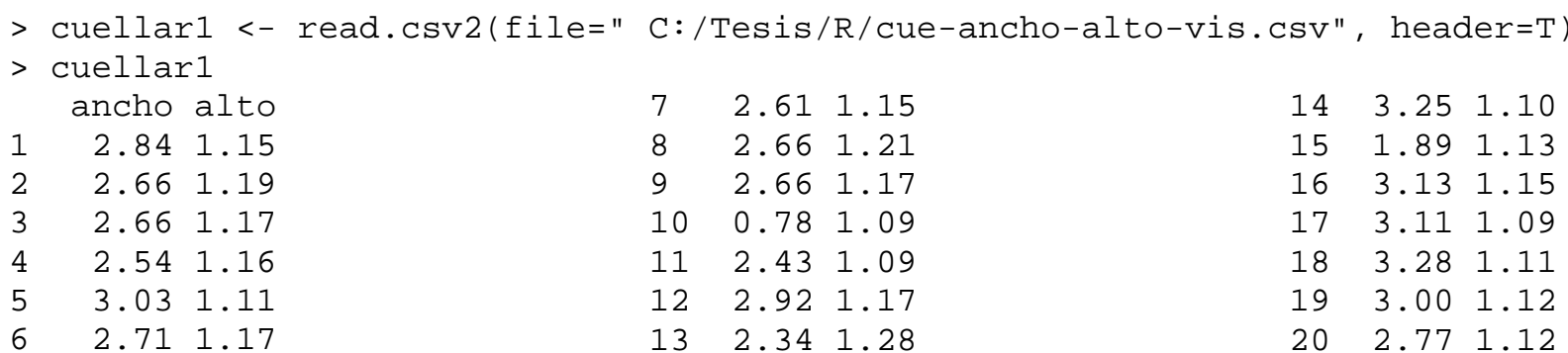

> boxplot (cuellar1\$alto, main="Altura de tapia visible", ylab="(m)", col=131, las $=2$, cex . axis $=1$, cex $\cdot \operatorname{main}=1$ )

> boxplot (cuellar1\$ancho, main="Anchura de tapia visible", ylab="(m)", col=131, las $=2$, cex . axis=1, cex . main=1)

\section{Gráficas Fig. 5.2.107 y Fig. 5.2.108}

$>$ cuellar2 <- read.csv2(file=" C:/Tesis/R/cue-ancho-alto-prob.csv", header=T)

$>$ cuellar 2

\begin{tabular}{|c|c|c|c|c|c|c|c|}
\hline anchop & altop & 11 & 2.61 & 1.15 & 22 & 2.81 & 1.14 \\
\hline 2.64 & 1.07 & 12 & 2.66 & 1.21 & 23 & 2.79 & 1.13 \\
\hline 2.84 & 1.15 & 13 & 2.66 & 1.17 & 24 & 2.78 & $\odot$ \\
\hline 2.66 & 1.19 & 14 & 0.78 & 1.09 & 25 & 2.77 & \\
\hline 2.66 & 1.17 & 15 & 2.43 & 1.09 & 26 & 3.13 & 1. \\
\hline 2.54 & 1.16 & 16 & 2.92 & 1.17 & 27 & 3.11 & 1. \\
\hline 2.19 & 1.23 & 17 & 2.34 & 1.28 & 28 & 3.28 & 1. \\
\hline 2.73 & 1.21 & 18 & 3.25 & 1.10 & 29 & 3.00 & \\
\hline 2.87 & 1.27 & 19 & 1.89 & 1.13 & 30 & 2.77 & \\
\hline
\end{tabular}

$\begin{array}{llllll}9 & 3.03 & 1.11 & 20 & 2.82 & 1.14\end{array}$

$\begin{array}{llllll}10 & 2.71 & 1.17 & 21 & 2.64 & 1.17\end{array}$

$>$ boxplot (cuellar2\$altop, main="Altura de tapia (incluye datos probables)", $\mathrm{ylab}="(\mathrm{~m}) ", \mathrm{col}=131, \mathrm{las}=2$, cex . axis=1, cex. main=1)

> boxplot (cuellar2\$anchop, main="Anchura de tapia (incluye datos probables)", $\mathrm{ylab}="(\mathrm{~m}) ", \mathrm{col}=131, \mathrm{las}=2$, cex. axis=1, cex. main=1)

$>$ 


\section{Gráfica Fig. 5.3.89}

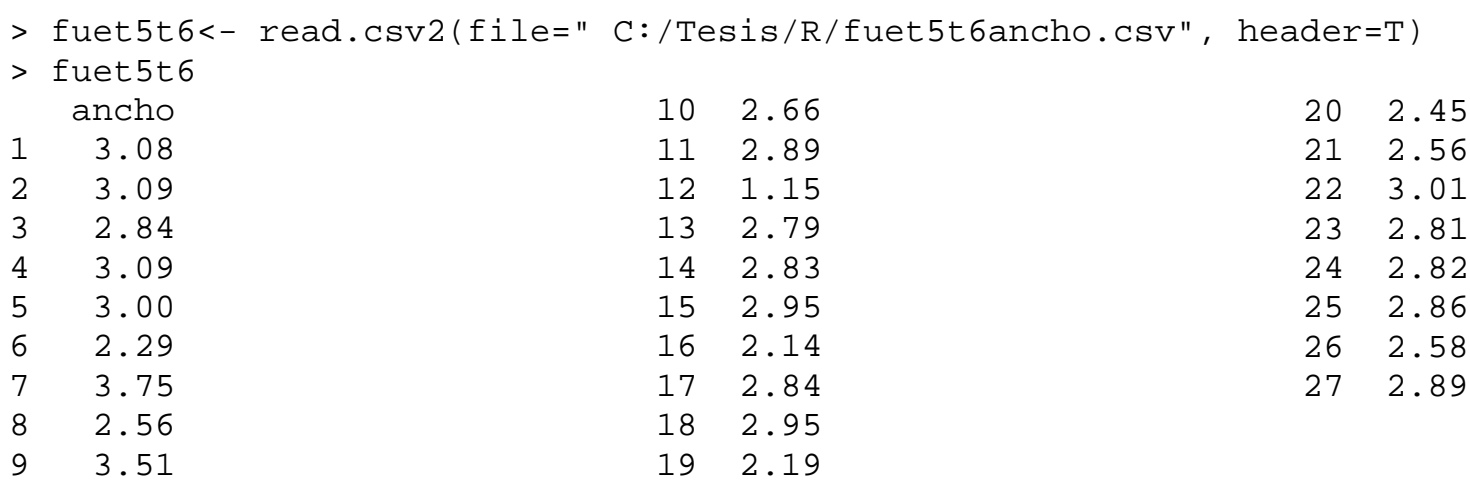

$>$ boxplot (fuet5t6\$ancho, main="Anchura de tapia visible", ylab="(m)", col=131, las $=2$, cex . axis $=1$, cex $\cdot$ main=1)

\section{Gráfica Fig. 5.3.90}

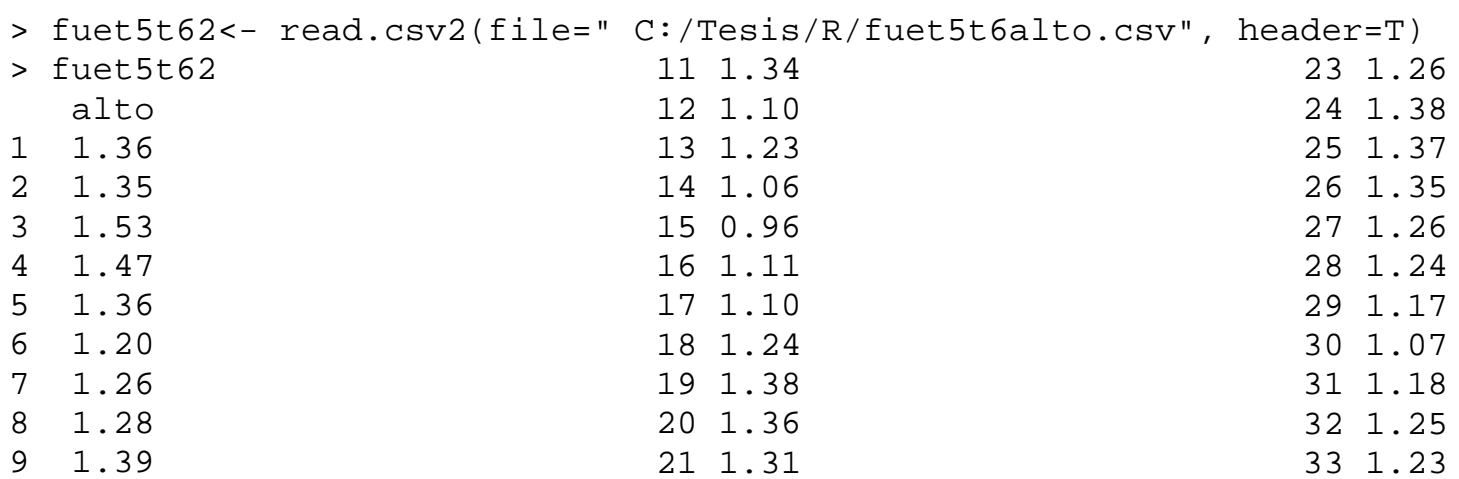

101.41

220.95

$>$ boxplot (fuet5t62\$alto, main="Altura de tapia visible", ylab="(m)", col=131, las $=2$, cex. axis $=1$, cex. $\operatorname{main}=1$ )

\section{Gráfica Fig. 5.3.98}

$>$ fuet5t6mech<- read.csv2(file=" $c: /$ Tesis/R/fue-t5-t6-d2mech.csv", header=T)

$>$ fuet5t6mech

$$
\mathrm{H} 2 \mathrm{H} 3 \quad \mathrm{H} 4 \quad \mathrm{H} 5
$$

1.131 .211 .441 .38

1.631 .671 .411 .15

1.741 .521 .231 .46

$1.321 .48 \quad 1.631 .45$

1.171 .521 .721 .11

$1.911 .47 \quad 1.281 .78$

NA 1.641 .591 .55

NA 1.471 .411 .44

NA 1.261 .691 .62

10 NA 1.68 NA NA

$>$ boxplot (fuet5t6mech $\$ \mathrm{H} 2$, fuet5t6mech $\$ H 3$, fuet 5 t $6 \mathrm{mech} \$ \mathrm{H} 4$, fuet $5 \mathrm{t} 6 \mathrm{mech} \$ \mathrm{H} 5$, main="Separación mechinales $D 2 ", y l a b="(m) ", c o l=131$, las=2, cex. axis=1, cex.main=1) 


\section{Gráfica Fig. 5.3.107}

$>$ fuep3t10ancho<- read.csv2(file=" c:/Tesis/R/fp3t10ancho.csv", header=T)

$>$ fuep3t10ancho

$\begin{array}{rrrrrrrrr} & \text { anchoprob } & \text { anchovis } & 11 & 2.96 & 3.00 & 22 & 2.92 & 3.29 \\ 1 & 2.75 & 2.98 & 12 & 3.06 & 2.83 & 23 & 2.64 & 3.09 \\ 2 & 2.83 & 3.07 & 13 & 3.00 & 2.94 & 24 & 2.76 & 3.07 \\ 3 & 2.98 & 2.84 & 14 & 2.83 & 2.83 & 25 & 2.89 & 2.82 \\ 4 & 3.07 & 2.94 & 15 & 2.94 & 2.80 & 26 & 2.82 & \text { NA } \\ 5 & 2.84 & 3.03 & 16 & 2.83 & 3.12 & 27 & 2.87 & \text { NA } \\ 6 & 2.94 & 2.85 & 17 & 2.80 & 2.91 & 28 & 2.60 & \text { NA } \\ 7 & 3.03 & 2.66 & 18 & 3.12 & 3.09 & 29 & 3.29 & \text { NA } \\ 8 & 2.85 & 2.20 & 19 & 2.91 & 2.02 & 30 & 3.09 & \text { NA } \\ 9 & 2.66 & 2.96 & 20 & 3.09 & 2.92 & 31 & 3.07 & \text { NA } \\ 10 & 2.20 & 3.06 & 21 & 2.02 & 2.64 & 32 & 2.82 & \text { NA }\end{array}$

$>$ boxplot (fuep3t10ancho\$anchoprob, fuep3t10ancho\$anchovis, main="Anchura de tapia visible y probable", ylab="(m)", col=131, las=2, cex.axis=1, cex.main=1)

\section{Gráfica Fig. 5.3.108}

$>$ fuep3t10alto<- read.csv2(file=" C:/Tesis/R/fp3t10alto.csv", header=T)

$>$ fuep3t10alto

H3 H4 H5

$1 \quad 1.221 .081 .36$

21.191 .211 .26

$3 \quad 1.141 .21 \quad 1.34$

$4 \quad 1.24 \quad 1.16 \quad 1.25$

$\begin{array}{llll}5 & 1.19 & 1.15 & 1.31\end{array}$

$\begin{array}{llll}6 & 1.14 & 1.15 & 1.28\end{array}$

$\begin{array}{llll}7 & 1.24 & 1.10 & 1.32\end{array}$

$\begin{array}{llll}8 & 1.17 & 1.26 & 1.35\end{array}$

$9 \quad 1.08 \quad 1.11 \quad 1.38$

$101.11 \quad 1.281 .26$

$\begin{array}{llll}11 & 1.07 & 1.28 & 1.34\end{array}$

$121.231 .07 \quad \mathrm{NA}$

$>$ boxplot (fuep3t10alto\$H3, fuep3t10alto\$H4, fuep3t10alto\$H5, main="Altura de tapia visible por hiladas", ylab="(m)", col=131, las=2, cex. axis=1, cex.main=1)

\section{Gráfica Fig. 5.6.68}

$>$ sepumechh2h5<- read.csv2(file="I:/Tesis/Tablas/Programa R/sepumech-h2-h5.csv", header $=\mathrm{T}$ )

$>$ sepumechh2h5

$$
\text { alto }
$$

11.03

21.11

31.03

$4 \quad 0.98$

51.08

$6 \quad 1.12$
$7 \quad 1.02$

80.81

91.09

101.05

111.10

121.00

131.17
141.03

151.09

$16 \quad 0.97$

171.04

$18 \quad 0.96$ 
$>$ boxplot (sepumechh2h5\$alto, main="Altura de hiladas H2 a H5", ylab="(m)", col=131, las $=2$, cex . axis=1, cex $\cdot$ main=1)

\section{Gráfica Fig. 5.6.69}

$>$ sepumech<- read.csv2(file=" C:/Tesis/R/sepumech.csv", header $=T$ )

$>$ sepumech

$\begin{array}{lllll}\mathrm{H} 5 & \mathrm{H} 4 & \mathrm{H} 3 & \mathrm{H} 2 & \mathrm{H} 1\end{array}$

$\begin{array}{lllll}1 & 1.03 & 1.11 & 0.81 \quad \mathrm{NA} \quad \mathrm{NA}\end{array}$

$2 \quad N A \quad 1.03 \quad 1.09 \quad 1.03 \quad N A$

$3 \quad N A \quad 0.98 \quad 1.051 .09 \quad N A$

$4 \quad \mathrm{NA} \quad 1.08 \quad 1.10 \quad 0.97 \quad \mathrm{NA}$

$5 \quad N A \quad 1.12 \quad 1.00 \quad 1.04 \quad 1.20$

$6 \quad$ NA $1.02 \quad 1.17 \quad 0.96 \quad 1.19$

$>$ boxplot ( $\operatorname{sepumech} \$ H 5$, sepumech $\$ H 4$, sepumech $\$ H 3$, sepumech $\$ H 2$, sepumech $\$ H 1$, main="Altura de hilada", ylab="(m)", col=131, las=2, cex.axis=1, cex.main=1)

$>$

\section{Gráfica Fig. 5.7.50}

tapiag1 <- read.csv2(file="C:/Tesis/R/nar-tapiag1.csv", header=T) tapiag1

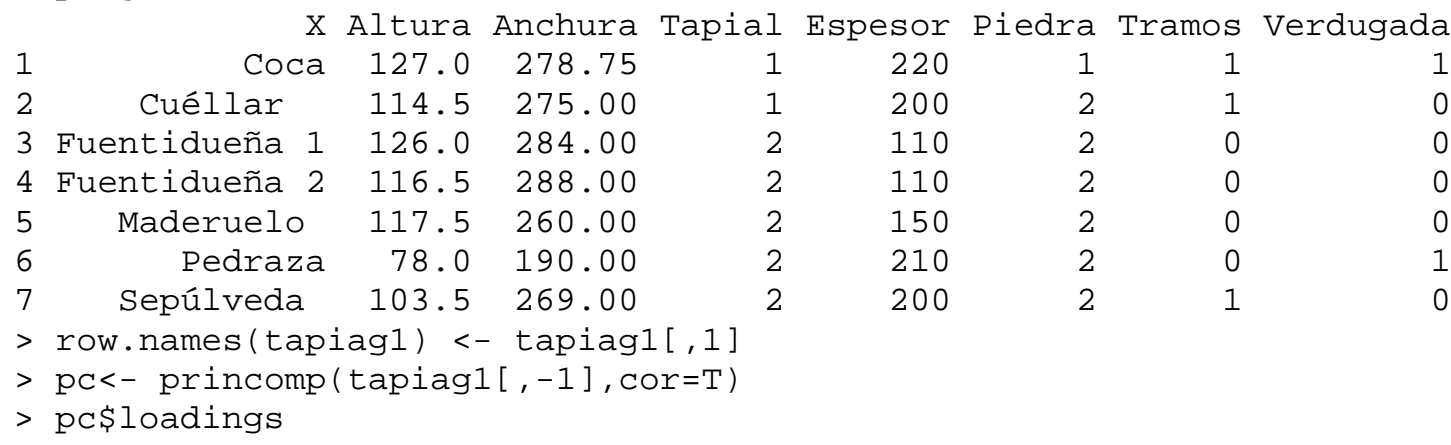

Loadings:

$\begin{array}{lrrrrrrr} & \text { Comp.1 Comp.2 } & \text { Comp.3 } & \text { Comp.4 } & \text { Comp.5 } & \text { Comp.6 } & \text { Comp.7 } \\ \text { Altura } & & -0.585 & -0.274 & & 0.596 & 0.458 & -0.115 \\ \text { Anchura } & & -0.607 & & -0.227 & -0.464 & -0.257 & -0.545 \\ \text { Tapial } & 0.474 & 0.217 & -0.103 & -0.817 & 0.163 & 0.128 & \\ \text { Espesor } & -0.478 & 0.259 & 0.315 & -0.138 & 0.489 & -0.263 & -0.528 \\ \text { Piedra } & 0.462 & 0.145 & 0.514 & 0.343 & & 0.454 & -0.415 \\ \text { Tramos } & -0.440 & -0.182 & 0.539 & -0.373 & -0.196 & 0.447 & 0.324 \\ \text { Verdugada } & -0.371 & 0.347 & -0.510 & & -0.350 & 0.482 & -0.357\end{array}$

Comp.1 Comp. 2 Comp. 3 Comp. 4 Comp. 5 Comp. 6 Comp. 7

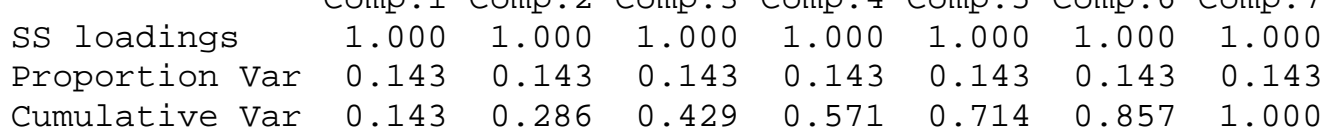

$>$ pc\$scores

Comp.1 Comp. $2 \quad$ Comp. $3 \quad$ Comp. 4

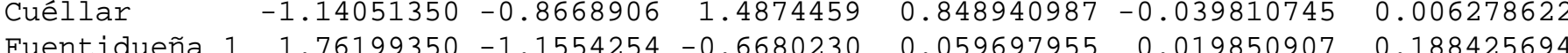

$\begin{array}{lllllllll}\text { Fuentidueña } 2 & 1.78434831 & -0.8768951 & -0.4975422 & -0.008028422 & -0.401970757 & -0.123145887\end{array}$

Maderuelo

$1.32341064-0.1345883-0.2559107$

$\odot .073413453$

$\odot .497578886-0.102447094$ 


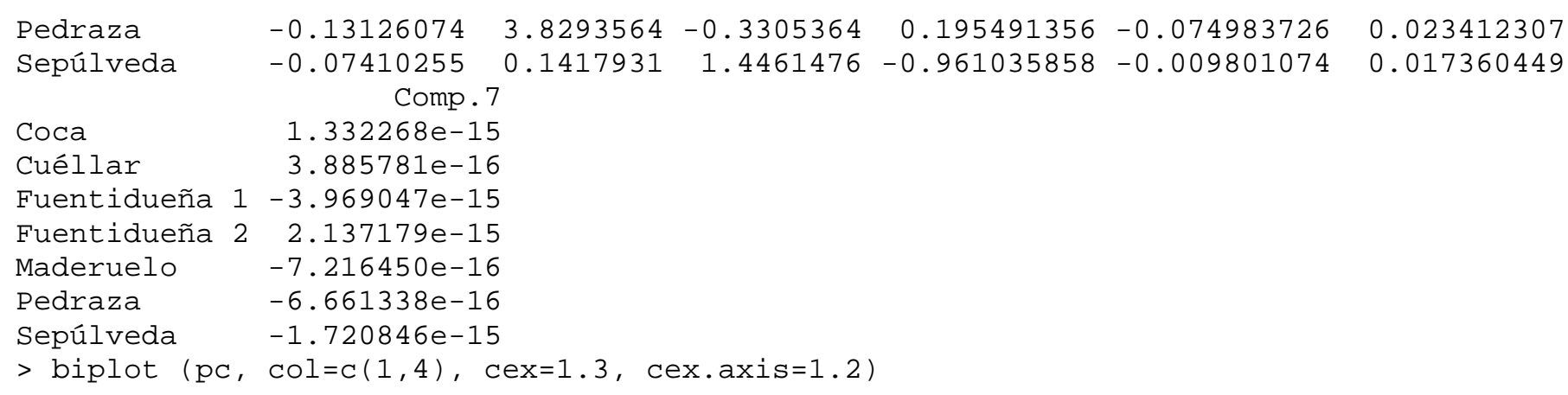

\section{Gráfica Fig. 5.7.51}

$>$ tapiag5 <- read.csv2(file=" C:/Tesis/R/nar-tapiag5NV.csv", header=T)

$>\operatorname{tapiag} 5$

\begin{tabular}{|c|c|c|c|}
\hline X & ira & ura & Es \\
\hline Coca & 127.0 & 278.75 & \\
\hline Cuéllar & 114.5 & 275.00 & \\
\hline Fuentidueña 1 & 126.0 & 284.00 & \\
\hline Fuentidueña 2 & 116.5 & 288.00 & \\
\hline Maderuelo & 117.5 & 260.00 & \\
\hline Pedraza & 78.0 & 190.00 & \\
\hline Sepúlveda & 103.5 & 269.00 & \\
\hline Aledua.Llombai & 82.5 & 221.00 & \\
\hline Bofilla. Bétera & 87.0 & 200.00 & \\
\hline Ermita. Serra & 72.5 & 210.00 & \\
\hline Espioca. Picassent & 83.0 & 212.00 & \\
\hline Gestalgar & 82.5 & 165.00 & \\
\hline Montroi & 82.5 & 244.00 & \\
\hline Muza. Benifaió & 82.5 & 212.00 & \\
\hline Olla. Olocau & 80.0 & 203.00 & \\
\hline Ría. Serra & 82.5 & 204.00 & \\
\hline Sot de Chera & 82.5 & 205.00 & \\
\hline
\end{tabular}

$>$

$>$

$>$ row.names (tapiag5) <- tapiag5 $[, 1]$

pc<- princomp (tapiag5 $[,-1]$, cor $=\mathrm{T}$ )

$>$ pc\$scores

$\begin{array}{lrrr} & \text { Comp.1 } & \text { Comp.2 } & \text { Comp.3 } \\ \text { Coca } & -2.45777809 & 0.8729882 & 0.46386786 \\ \text { Cuéllar } & -1.88299008 & 0.8901037 & 0.04154013 \\ \text { Fuentidueña 1 } & -1.92476693 & -1.8005570 & 0.08329624 \\ \text { Fuentidueña 2 } & -1.64096749 & -1.6974970 & -0.36004088 \\ \text { Maderuelo } & -1.40060633 & -0.5152417 & 0.31949269 \\ \text { Pedraza } & 1.03893130 & 1.8142567 & 0.29768098 \\ \text { Sepúlveda } & -1.44757940 & 1.4575623 & -0.22889439 \\ \text { Aledua. Llombai } & 0.56522620 & 0.4186016 & -0.24029720 \\ \text { Bofilla. Bétera } & 0.97900021 & -0.4271773 & 0.26181244 \\ \text { Ermita. Serra } & 1.36994597 & -0.4201133 & -0.50258927 \\ \text { Espioca. Picassent } & 0.93509893 & -0.5498152 & -0.13632112 \\ \text { Gestalgar } & 1.99734837 & -1.1315649 & 0.68672816 \\ \text { Montroi } & 0.09990779 & 0.5026892 & -0.67083936 \\ \text { Muza. Benifaió } & 0.92273148 & -0.4032144 & -0.14292148 \\ \text { Olla. Olocau } & 0.99945930 & 0.4925848 & 0.01018632 \\ \text { Ría. Serra } & 0.97987082 & 0.0384388 & 0.04927024 \\ \text { Sot de Chera } & 0.86716794 & 0.4579554 & 0.06802866\end{array}$

$>$ pc\$loadings

Loadings:

Comp. 1 Comp. 2 Comp. 3

Altura $-0.684-0.215 \quad 0.697$

$\begin{array}{ll}\text { Anchura }-0.697 & -0.712\end{array}$ 
Espesor $-0.216 \quad 0.972$

$\begin{array}{llll}\text { SS loadings } \quad 1.000 & 1.000 & 1.000\end{array}$

$\begin{array}{llll}\text { Proportion Var } & 0.333 & 0.333 & 0.333\end{array}$

Cumulative $\operatorname{Var} 0.333 \quad 0.667 \quad 1.000$

$>$ biplot $(p c, \operatorname{col}=c(1,4), \operatorname{cex}=1.3, \operatorname{cex} . \operatorname{axis}=1.2)$

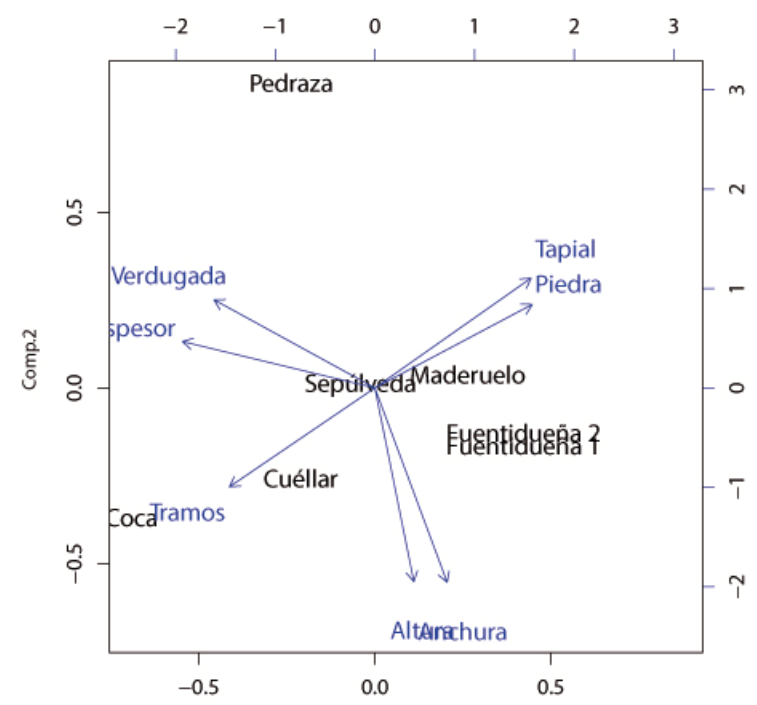

Gráfica Fig. 5.7.50

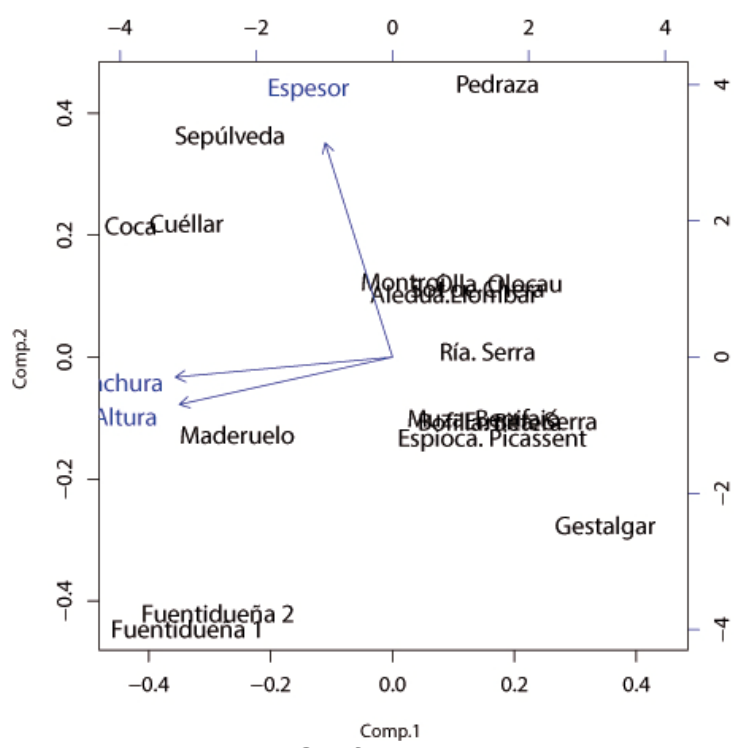

Gráfica Fig. 5.7.51 

Anexo 3: Fichas de características de las herramientas empleadas 

- Cámara fotográfica Olympus SZ-16 DZ-105

Características principales

Zoom óptico súper angular 24x (25-

$600 \mathrm{~mm}$ )

48x con el Zoom Súper Resolución

Tecnología iHS

CMOS de 16 megapíxeles

Procesador de imagen TruePic $\mathrm{V}$

LCD en color de 3" y 460.000 puntos

Macro Telefoto

Estabilización de Imagen Dual

Estabilizador para Vídeo Multi-motion

Grabación de vídeo Full HD de 108 0p y

Control HDMI

Foto en vídeo

Vídeos de alta velocidad

Filtro Mágico para fotos y/o vídeos

Modo Estabilización Escena Nocturna

Ajuste de retroiluminación HDR

iAuto avanzado y AF por seguimiento

Detección de Rostros y Tecnología de

Ajuste de Sombras

Modo Maquillaje

Modo Mascotas

Panorama Inteligente

Modos de escena

Compatibilidad con tarjetas Eye-Fi

Compatibilidad con tarjetas FlashAir

Olympus Image Share (OI.Share)

Carga de batería USB

Cuerpo metálico

\section{Especificaciones}

Sensor de imagen

Píxeles efectivos: 16 megapíxeles

Tipo: 1/2.3" CMOS

Objetivo: Zoom óptico, 24x (angular)

Distancia focal equivalente en una cámara de

$35 \mathrm{~mm}: 25-600 \mathrm{~mm}$

Apertura máxima: 3.0 - 6.9

Monitor

Resolución: 460000 Píxeles

Tamaño de pantalla: $7.6 \mathrm{~cm} / 3.0 "$

Tipo Monitor: LCD

Sistema de grabación de vídeo

Formato de grabación: QuickTime Motion JPEG $尺$

Calidad de vídeo HD: 1080P / 30 fps Tiempo

de grabación: 29 min.

Calidad de vídeo: VGA Tiempo de grabación:

Hasta la capacidad de la tarjeta

Tamaño

Dimensiones $(\mathrm{A} \times \mathrm{A} \times \mathrm{P}): 107.9 \times 69.7 \times 39.9$

$\mathrm{mm}$

Peso: $227 \mathrm{~g}$ 
- Medidor láser BOSCH PRL 25. Características técnicas:

Identificador de producto del fabricante 0603016200

Peso del producto $181 \mathrm{~g}$

Dimensiones del producto

Pilas:

Número de modelo del producto

$31 \times 18,5 \times 7 \mathrm{~cm}$

Color

4 AAA necesaria(s), incluida(s)

Estilo

Fuente de alimentación

0603016200

Negro, Verde

Diámetro del área de trabajo

Voltaje

Pilas

Número de productos

Sistema

1.5 voltios

1

Métrica

Exactitud

Color del láser

Componentes incluidos

$2 \mathrm{~mm}$

Pilas incluidas

Rojo

4 pilas de 1,5 V LR03 (AAA), Bolsa de protección

Pilas necesarias

Sí

Battery Cell Type

Carga eléctrica de la batería

Peso

Alcalino

1.5

180 gramos 


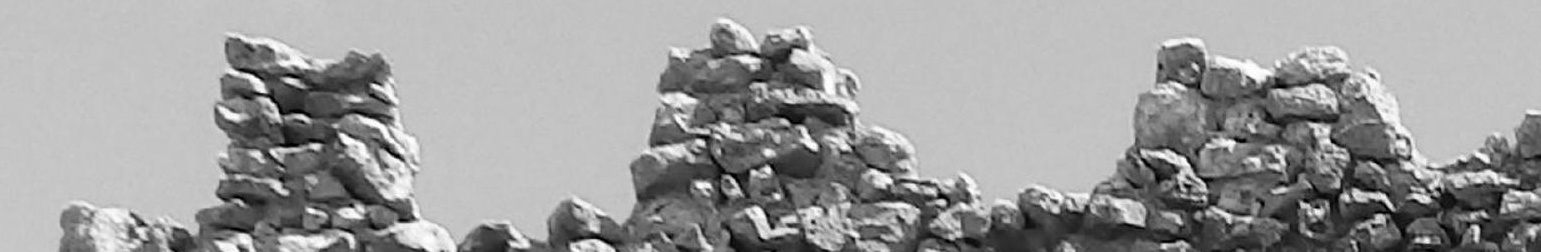

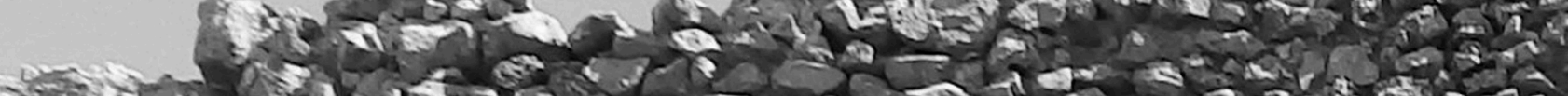

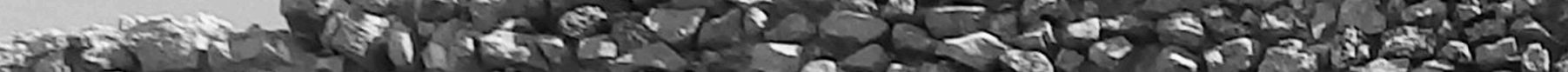

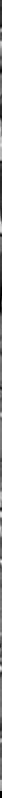

